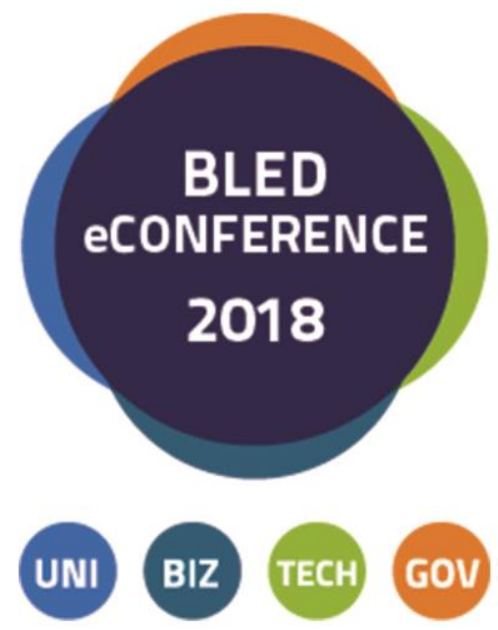

\title{
$31^{\text {ST }}$ BLED ECONFERENCE
}

DIGITAL TRANSFORMATION MEETING THE CHALLENGES JUNE 17 - 20, 2018, BLED, SLOVENIA

CONFERENCE Proceedings

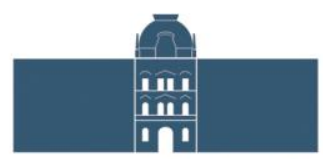

University of Maribor Press 



\title{
$31^{\mathrm{ST}}$ Bled eConference Digital Transformation: Meeting the Challenges
}

\author{
June 17 - 20, 2018, Bled, Slovenia
}

Conference Proceedings

Editors:

dr. Andreja Pucihar

dr. Mirjana Kljajić Borštnar

dr. Pascal Ravesteijn

dr. Juergen Seitz

dr. Roger Bons

June 2018 
Title: $\quad 31^{\mathrm{ST}}$ Bled eConference Digital Transformation: Meeting the Challenges

Subtitle: June $17-20,2018$, Bled, Slovenia, Conference Proceedings

Editors: Andreja Pucihar, (University of Maribor, Faculty of Organizational Sciences, Slovenia), Mirjana Kljajić Borštnar, (University of Maribor, Faculty of Organizational Sciences, Slovenia), Pascal Ravesteijn (HU University of Applied Sciences Utrecht, The Netherlands), Juergen Seitz (Baden-Wuerttemberg Cooperative State University, Germany) Roger Bons (FOM Hochschule, Germany)

Review: Albrecht Fritzsche, (Friedrich-Alexander University Erlangen-Nuremburg, Germany), Alenka Baggia, (University of Maribor, Slovenia), Ana Meštrović, (University of Rijeka, Croatia), Anand Sheombar, (HU University of Applied Sciences Utrecht, Netherlands), Andrej Škraba, (University of Maribor, Slovenia), Andreja Pucihar, (University of Maribor, Slovenia), Anna Sell, (Åbo Akademi University, Finland), Arjen Maris, (HU University of Applied Sciences Utrecht, Netherlands), Arthur Tatnall, (Victoria University, Australia), Benny De Waal, (HU University of Applied Sciences Utrecht, Netherlands), Casandra Grundstrom, (University of Oulu, Finland), Catherine Han Lin, (Deakin University, Australia), Christer Carlsson (Åbo Akademi University, Finland), Christian Bremser, (University of Applied Sciences Mainz, Germany), Christian Kittl, (evolaris next level Research Centre, Austria), David Murungi, (Bentley University, United States), David Phillips, (Deakin University, Australia), Davorin Kofjač, (University of Maribor, Slovenia), Doug Vogel, (Harbin Institute of Technology, China), Edvard Tijan, (University of Rijeka, Croatia), Eeva Kettunen. (University of Jyvaskyla, Finland), Florian Maurer, (Vorarlberg University of Applied Sciences, Austria), Francesco Pisani, (Frankfurt School of Finance \& Management, Germany), Friedrich Holotiuk, (Frankfurt School of Finance \& Management, Germany), Gregor Lenart, (University of Maribor, Slovenia), Guido Ongena, (HU University of Applied Sciences Utrecht, Netherlands), Hans Allmér, (Linnaeus University, Sweden), Hans-Dieter Zimmermann, (FHS St. Gallen, Switzerland), Harald Vranken, (Radboud University, Netherlands), Harry Bouwman, (Delft University of Technology, Netherlands), Helen Cripps, (Edith cowan University, Australia), Indrit Troshani, (University of Adelaide, Australia), Jakobus Smit, (HU University of Applied Sciences Utrecht, Netherlands), Jeroen Van Grondelle, (HU University of Applied Sciences Utrecht, Netherlands), Johan Versendaal, (HU University of Applied Sciences Utrecht, Netherlands), Jonna Järveläinen, (University of Turku, Finland), Juergen Moormann, (Frankfurt School of Finance \& Management, Germany), Juergen Seitz, (Baden-Wuerttemberg Cooperative State University, Germany), Julian Szymanski, (Gdansk University of Technology, Poland), Katri Kerem, (Estonian Business School, Estonia), Kirsten LiereNetheler, (University of Osnabrück, Germany), Kristin Vogelsang, (University of Osnabrück, Germany), Lauri Frank, (University of Jyvaskyla, Finland), Leif Marcusson, (Linnaeus University, Sweden), Liam D. Turner, (Cardiff University, Wales), Luuk Simons, (Delft University, Netherlands), Marijn G. A. Plomp, (VU University Amsterdam, Netherlands), Marja Exalto, (HU University of Applied Sciences Utrecht, Netherlands), Marjeta Marolt, (University of Maribor, Slovenia), Mark de Reuver, (Delft University of Technology, Netherlands), Marko Urh, (University of Maribor, Slovenia), Marta Aranyossy, (Corvinus University of Budapest, Hungary), Matt Glowatz, (University College Dublin, Ireland), Matthijs Smakman, (HU University of Applied Sciences Utrecht, Netherlands), Michael Meyer, (Braunschweig University of Technology, Germany), Milan Frederik Klus, (University of Münster, Germany), Mirjana Kljajić Borštnar, (University of Maribor, Slovenia), Mladen Jardas, (University of Rijeka, Croatia), Nilmini Wickramasinghe, (Epworth HealthCare and Deakin University, Australia), Pascal Ravensteijn, (HU University of Applied Sciences Utrecht, Netherlands), Patrick Helmholz, (Braunschweig University of Technology, Germany), Robertas Damasevicius, (Kaunas University od Technology, Lithuania), Roger Bons, (FOM University of Applied Sciences for Economics and Management, Germany), Rok Piltaver, (Jožef Stefan Institute, Slovenia), Ronald Spanjers, (Roessingh, Centrum voor Revalidatie, Netherlands), Sanda Martinčić Ipšić, (University of Rijeka, Croatia), Siw Lundqvist, (Linnaeus University, Sweden), Slobodan Beliga, (University of Rijeka, Croatia), Stefan Stieglitz, (University of Duisburg-Essen, Germany), Tiina Kemppainen, (University of Jyväskylä, Finland), Todor Stefan Lohwasser, (University of Münster, Germany), Tuomas Kari, (University of Jyvaskyla, Finland)

Committee: Andreja Pucihar, (University of Maribor, Slovenia), Mirjana Kljajić Borštnar, (University of Maribor, Slovenia), Iztok Podbregar, (University of Maribor, Slovenia), Christian Kittl, (evolaris next level Research Centre, Austria), Pascal Ravesteijn, (University of Applied Sciences Utrecht, Netherlands), Hans-Dieter Zimmermann, (FHS St. Gallen, Switzerland), Helen Cripps, (Edith Cowan University, Australia), Nilmini Wickramasinghe, (Epworth HealthCare and Deakin University, Australia), Juergen Seitz, (Baden-Wuerttemberg Cooperative State University, Germany), Christer Carlsson, (Åbo Akademi University, Finland), Pirkko Walden, (Åbo Akademi University, Finland), Christian Kittl, (evolaris next level Research Centre, Austria), Matt Glowatz, (University College Dublin, Ireland), Roger Clarke, (Xamax Consultancy Pty Ltd \& The Australian National University, Australia), Roger Bons, (Professor, FOM Hochschule, Germany), Doug Vogel, (Harbin Institute of Technology, China), Johan Versendaal, (HU University of Applied Sciences Utrecht and Open University of the Netherlands, Netherlands), Marijn Plomp, (Vrije Universiteit Amsterdam, The Netherlands) 
Technical Borut Slabe (Unversity of Maribor, Faculty of Organizational Sciences) and Jan Perša (University of editors: Maribor Press)

Cover Jan Perša (University of Maribor Press)

design:

Conference: $\quad 31^{\mathrm{ST}}$ Bled eConference: Digital Transformation: Meeting the Challenges

Conference June $17-20,2018$

date:

\section{Co-publisher/Izdajateljica:}

University of Maribor, Faculty of Organizational Sciences

Kidričeva cesta 55a, $4000 \mathrm{Kranj}$, Slovenia

http://www.fov.um.si, dekanat@fov.uni-mb.si

\section{Publisher/Založnik}

University of Maribor Press

Slomškov trg 15, 2000 Maribor, Slovenia

http://press.um.si, zalozba@um.si

Edition: $\quad 1^{\mathrm{ST}}$

Available at: http://press.um.si/index.php/ump/catalog/book/343

Published: $\quad$ Maribor, June 2018

\section{(c) University of Maribor Press}

All rights reserved. No part of this book may be reprinted or reproduced or utilized in any form or by any electronic, mechanical, or other means, now known or hereafter invented, including photocopying and recording, or in any information storage or retrieval system, without permission in writing from the publisher.

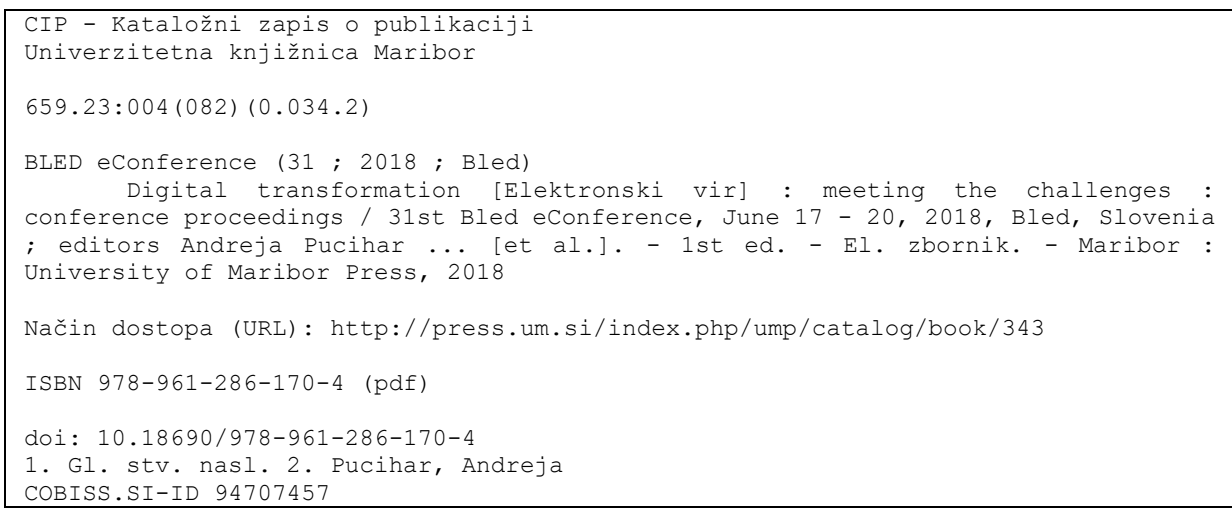

ISBN 978-961-286-170-4

DOI: https://doi.org/10.18690/978-961-286-170-4

Price: Free copy

For publisher: full. prof. Žan Jan Oplotnik, Ph.D., Vicerector (University of Maribor) 



\title{
Digital Transformation: Meeting the Challenges
}

\author{
ANDREJA PuCIHAR, MirJana KLJAJIĆ BorŠTnAR, PASCAL \\ RAVESTEIJN, JUERGEN SEITZ \& ROGER BONS
}

\begin{abstract}
Bled eConference, organized by University of Maribor, Faculty of Organizational Sciences, has been shaping electronic interactions since 1988. Bled eConference is the oldest, most traditional and well renowned conference in the field with more than 30 years of tradition. The theme of this year's conference is dedicated to "Digital Transformation - Meeting the Challenges".

The evolution of digital technologies and solutions has significantly impacted the way in which business is conducted and have big implications on our lives. Nowadays digital economy calls for transformation of businesses, governments, education and societies as whole. It also calls for enabling policies and politics for cross border and global digital business.
\end{abstract}

In this year's conference, we address various aspects of digital transformation and provide directions and guidelines for organizations to meet and overcome these challenges on their way towards successful digital transformation. Themes covered in the papers of these proceedings are focused on: digital transformation; business model innovation; blockchain and social media; big data, data science, and decision support systems; ehealth, digital wellness and wellbeing; new applications and organizational models; and novel approaches and cases in education in digital economy.

Keywords: digital transformation $\cdot$ business model innovation $\bullet$ digital technology $\bullet$ innovation $\bullet$ digitalization $\bullet$

Correspondence Address: Andreja Pucihar, Ph.D. Program Committee Chair, 31st Bled eConference, Associate Professor, University of Maribor, Faculty of Organizational Sciences, Kidričeva cesta 55a, 4000 Kranj, Slovenia e-mail: andreja.pucihar@fov.uni-mb.si. Mirjana Kljajič Borštnar, Ph.D., Associate Professor, University of Maribor, Faculty of Organizational Sciences, Kidričeva cesta 55a, $4000 \mathrm{Kranj}$, Slovenia e-mail: mirjana.kljajic@fov.uni-mb.si. Pascal Ravesteijn, Professor, HU University of Applied Sciences Utrecht, Bolognalaan 101, 3584 CJ Utrecht, The Netherlands, e-mail: pascal.ravesteijn@hu.nl. Juergen Seitz, Professor, BadenWuerttemberg Cooperative State University, Marienstraße 20, 89518 Heidenheim an der Brenz, Germany, e-mail: seitz@dhbw-heidenheim.de. Roger Bons, Professor, FOM Hochschule, Herkulesstraße 32, 45127 Essen, Germany, e-mail: roger.bons@ fom.de 


\section{Table of Contents}

\section{Conference Proceedings}

Integrating Maritime National Single Window with

Port Community System - Case Study Croatia

Edvard Tijan, Mladen Jardas, Saša Aksentijević \& Ana Perić Hadžić

How to start with big data - a multiple case study

Christian Bremser, Gunther Piller \& Franz Rothlauf

Citizen adoption of e-government services - Evidence from Hungary

Marta Aranyossy

Studying Complex IT Challenges? Discuss Real Cases

Janis L. Gogan \& David M. Murungi

Business Model Innovation and Firm Performance: The Role of

Mediation and Moderation Factors

Mohammad-Ali Latifi \& Harry Bouwman

Towards Responsible Data Analytics: A Process Approach

Roger Clarke \& Kerry Taylor

Examining the PoC System Implementation and Adoption: A FVM

Perspective

Imran Muhammad \& Nilmini Wickramasinghe

Influence of Digital Coaching on Physical Activity: Motivation and

Behaviour of Physically Inactive Individuals

Tuomas Kari \& Petriina Rinne

Perceived Intrusiveness of Personalized Marketing

Katri Kerem \& Monika Ulla

Digital Wellness Services' Servicescape for Young Elderly

Hans Allmér

Developing an E-learning Course on Serious Games: A

Multidisciplinary Approach

Tanja Korhonen, Teija Ravelin \& Raija Halonen

An Explorative Study Into Situational Artefact Construction in Business 
Digital Transformation in Healthcare - the case of a Chinese Medicine

Catherine Han Lin, David Phillips \& Nilmini Wickramasinghe

eHealth WhatsApp Group for Social Support: Preliminary Results

Luuk P.A. Simons, Wouter A.C. Van Den Heuvel \& Catholijn M. Jonker

Critical success factors in the design of suitable oncology platforms

Muhammad Nadeem Shuakat \& Nilmini Wickramasinghe

Digital Wellness Services: Key to Better Quality of Life for Young

Elderly

Christer Carlsson \& Pirkko Walden

Improving Smart City Design: A Conceptual Model for Governing

Complex Smart City Ecosystems

Mervi Hämäläinen \& Pasi Tyrväinen

Transforming operating rooms: factors for successful implementations of new medical equipment

Navin Sewberath Misser, Joris Jaspers, Bas van Zaane, Hein Gooszen \& Johan Versendaal

Digital Transformation in Retail: Can Customer Value Services enhance the Experience?

Michael Meyer, Patrick Helmholz \& Susanne Robra-Bissantz

Motives to Form Alliances for Digital Innovation: The Case of Banks and Fintechs

Friedrich Holotiuk, Milan Frederik Klus, Todor Stefan Lohwasser \& Jürgen Moormann

Evaluation of Push Notifications for Social Media Applications

Emma Fahlman, Thomas Mejtoft \& Helen Cripps

Learning Success: A Comparative Analysis of a Digital Game-Based

Approach and a Face-to-Face Approach

Linda Eckardt \& Susanne Robra-Bissantz

Blockchain-based Smart Contracts in Waste Management: A Silver Bullet?

Guido Ongena, Koen Smit, Jarno Boksebeld, Gerben Adams, Yorin Roelofs

\& Pascal Ravesteijn

Boosting Innovation for the Development of Smart-Service Factories of the Future: The Cases of the Federal State of Vorarlberg and its

Neighbouring Regions

Florian Maurer \& Albrecht Fritzsche 
Business Customer eXperience Alignment Framework: Improving Customer Satisfaction

Felix Gras, Pascal Ravesteijn, Marlies van Steenbergen \& Roland Bijvank

Adaptation of enterprise architecture efforts to an agile environment

Robin Duijs, Pascal Ravesteijn \& Marlies van Steenbergen

Willingness to Use Smartphone Application Assistant to Support

Migraine Treatment

Hanna-Leena Huttunen \& Raija Halonen

ICT supporting healthcare for elderly in China: A systematic mapping study

Zihao Liu \& Raija Halonen

A case for participatory practices in the digital transformation of insurance

Michael Persson, Casandra Grundstrom \& Karin Väyrynen

How a flexible collaboration infrastructure impacts healthcare

information exchange

Rogier van de Wetering \& Johan Versendaal

Uncovering the digital " $x$ " phenomena in the IS field:

A text analysis approach

Joaquin Rodriguez \& Gabriele Piccoli

Can Sport and Wellness Technology be My Personal Trainer? -

Teenagers and Digital Coaching

Eeva Kettunen \& Tuomas Kari

Designing business model tooling for business model exploration: An experimental design for evaluation

Alexia Athanasopoulou \& Mark de Reuver

Identifying the Sales Patterns of Online Stores with Time Series

Clustering

Markus Makkonen \& Lauri Frank

The Role of Competition in the Adoption of Mobile Payment among

Merchants

Francesco Pisani \& Jürgen Moormann

Co-creation Model to Design Wearables for Emotional Wellness of

Elderly

Muhammad Usman Warraich, Irum Rauf \& Anna Sell

Determining the Required Capacity of Business Information

Management: Towards a Concise Instrument

Frank Van Outvorst, Mart Meijnen, Pascal Timens, Sjoerd Walenbergh, Benny De Waal 
Business Model Innovation in European SMEs - Descriptive analysis of quantitative survey and case survey data

Marikka Heikkilä \& Harry Bouwman

Means to Survive Disruption: Business Model Innovation and Strategic

Continuity Management?

Jukka Heikkilä, Marikka Heikkilä, Marko Niemimaa \& Jonna Järveläinen

SMEs Perspective on Business Model Innovation

Marjeta Marolt, Gregor Lenart, Mirjana Kljajić Borštnar, Doroteja Vidmar \&

Andreja Pucihar

Comparative Study of Sharing Economy Business Models in

Accommodation Sector

Rimantas Gatautis $\dagger$, Eglè Vaičiukynaitė \& Elena Vitkauskaite

\section{Doctoral Consortium}

What do we Know about Personality Traits, Technology Use, Intention, Reputation and Brand Credibility? Cross Cultural Issues in the Aviation Industry's User-Generated Content (UGC)

Ukamaka Onyenucheya

A model for smart technology adaptation in the case of urban infrastructure development with the purpose of improving the quality of citizens' well-being

Vasja Roblek

Managing Complexity of Digital Transformation with Enterprise

Fabian Gampfer

Energy security as an indicator of the efficiency of strategic energy management in the European Union

Bojana Vasić

Obtaining and Evaluating Digital Competences of Slovenian General

Gymnasium Students

Srečko Zakrajšek

Technology Enabled Sustainable Business Model Innovation

Doroteja Vidmar

Literature Review on Root Cause Analysis

Jaka Toman

Designing an Adaptive and Sustainable ITG model for SMEs 


\title{
Integrating Maritime National Single Window with Port Community System - Case Study Croatia
}

\author{
EdVARd TuJan, MLaden JaRdas, SAŠA AKSEnTIJEVIĆ \& \\ ANA PERIĆ HADŽIĆ
}

\begin{abstract}
A single point of data entry for documentary requirements and procedures in maritime transport - Maritime National Single Window (MNSW) includes process integration of all stakeholders in the entire seaport system. The primary goal of the MNSW is to eliminate data redundancy in a way that the entered data is instantly visible in other systems, according to the set level of authorization and authentication. In many seaports, the administrative MNSW is connected to the commercial Port Community System (PCS), an information system for the exchange of cargo related commercial data. The linking of the MNSW and the PCS connects the administrative with the commercial business aspect, making seaport business processes more efficient and more effective. Both interfaces can only be developed by using process reengineering and presume significant investments in underlying information technologies. Such implementation requires in-depth analysis of all stakeholders' processes in the seaport system, in order for both systems to complement each other.
\end{abstract}

Keywords: • Maritime National Single Window • Port Community System

- business integration $\cdot$ reengineering $\bullet$

Correspondence Address: Edvard Tijan, Ph.D., Associate Professor, University of Rijeka, Faculty of Maritime Studies, Studentska 2, Rijeka, Croatia, e-mail: etijan@pfri.hr. 2nd Author Mladen Jardas, MSc., assistant, University of Rijeka, Faculty of Maritime Studies, Studentska 2, Rijeka, Croatia ,e-mail: mjardas@pfri.hr. 3rd Author Saša Aksentijević, Ph.D., Assistant Professor, Aksentijević Forensics and Consulting, Gornji Sroki 125a, Viškovo, Croatia, e-mail: sasa.aksentijevic@gmail.com. 4th Author Ana Perić Hadžić, Associate Professor, University of Rijeka, Faculty of Maritime Studies, Studentska 2, Rijeka, Croatia, e-mail: ana@pfri.hr

DOI https://doi.org/10.18690/978-961-286-170-4.1

ISBN 978-961-286-170-4

(C) 2018 University of Maribor Press

Available at: http://press.um.si. 
According to the Directive 2010/65/EU of the European Parliament and of the Council (Directive 2010/65EU, 2010) each Member State should implement the Maritime National Single Window (MNSW) in order to optimize and facilitate the process of announcement and registration of ships which arrive to ports and/or depart from ports of the Member States. Single Window is defined as a facility that allows parties involved in trade and transport to lodge standardized information and documents using a single entry point to fulfil all import, export, and transit-related regulatory requirements (Moïsé, E. et al., 2011). MNSW is the place where according to the Directive, all information is entered only once, and becomes available to various competent authorities and the Member States. The aim of the Directive is to simplify and harmonize the administrative procedures applicable to maritime transport by electronic data exchange prescribed by standards and rationalization of formal reporting (European Commission, 2015).

According to the new directive, which should be published mid-2018, a better cooperation is required between national authorities in the development of the MNSW and the implementation of the eManifest. The main objective of the eManifest is to demonstrate the way in which cargo-related information required by both maritime and customs authorities can be submitted together with other reporting formalities required by Directive 2010/65/EU in a harmonised manner, and using a European Maritime Single Windows environment (EMSA, 2015). The Republic of Croatia, as an EU member, is obligated to invest in the development of information technologies and thus in the development of the MNSW (EMSA, 2015). The development of MNSW should accelerate business processes, which also means increasing competitiveness in relation to neighboring ports. Croatia is currently using an integrated maritime information system (CIMIS) (Čičovački, 2013) for electronic delivery and exchange of data about ships, cargo and passengers in the official processing of announcement, arrival and departure of the ships, their stay in ports, as well as the related official procedures.

The problems occur in subsequent official procedures due to multiple entries of the same data in several diverse applications where errors often occur during repeated data input. Data is still duplicated using paper and electronic means (inputting the same data in different systems). It is therefore necessary to develop a Port Community System (PCS) which represents a neutral platform for electronic data exchange between all stakeholders of the port process (Bezić et. al., 2011). By harmonizing MNSW and PCS, the ultimate goal would have been achieved, which is the elimination of data duplication in a way that once entered data is visible to all stakeholders of the seaport system, resulting in more efficient and more effective business processes.

\section{Maritime National Single Window and Port Community System}

One of the most acute problems of seaport processes is the lack of automatic data exchange between existing systems. Processes are being slowed down due to the administrative load, which refers to the entry of data related to the announcement and 
registration of the arrival of ships into the port. Processes are being slowed down even further in the commercial part of the port activities (cargo-related data) because of the similar reasons. Stakeholders involved in seaport processes are still burdened with the manual inputting of data into paper documents, documents that contain almost the same information as already electronically submitted data. Therefore, data and/or document distribution to the competent authorities creates confusion caused by data redundancy. These administrative tasks significantly increase shipping costs by utilizing excessive waiting time for cargo processing, also causing delays in the next port of call. This archaic method of doing business reduces the competitiveness of maritime transport. Therefore, the EU has adopted a Directive 2010/65/EU about reporting formal reports, whose goal is to harmonize administrative procedures applicable to maritime transport. To achieve this, it is necessary to develop the MNSW that would be connected with the SafeSeaNet, eCustoms and other regional and supranational electronic data exchange systems. Safeseanet, a system of EU for the exchange of maritime information to promote efficient maritime transport (SafeSeaNet, 2016) provides almost real-time information for about 17 thousand ships that operate on a daily basis throughout the EU (EMSA, 2018). The data that are exchanged in SafeSeaNet are identity of the ship, position and condition of the ship, time of departure and arrival, incident reports, details of dangerous cargo, waste and ship safety. eCustoms is defined as an application of IT technologies in public administration. It is connected with the organizational changes and new abilities of public services, which aim to improve quality of provided services by the government (Granqvist et al., 2012.)

MNSW are systems that combine data from all ports of a state and have B2G features (Single Window Directive for formalities in maritime traffic, 2015). Usually a smaller set of data is shared through these systems because this data is important on the national level. For the past several years, the EU has been working on the development of the European Maritime Single Window (EMSW) with the aim to fully harmonize interfaces available to operators of ships in order to provide required information all across the EU. The purpose of EMSW is to standardize information needed for port management so that the submitted data can be publicly available to all relevant stakeholders. (EMSA, 2018) To improve business processes, EMSW and MNSW should be synchronized and fully integrated with the PCS. The PCS combines and exchanges data among all the stakeholders involved in the operation of a particular port cluster (van Oosterhout et al., 2008). Many countries do not have a developed MNSW, but they have very diverse and well developed PCS systems instead. There is no global and standardized PCS model applicable to all ports as it may be the case with the MNSW. Each PCS is specific, each country has specific legal regulations and therefore each port community develops its own PCS according to its needs. Each PCS should communicate through the interface of MNSW so that the data would not be duplicated and in order to speed up business processes (Kapidani et. al., 2015).

PCS helps stakeholders of the port processes to reduce logistics costs through faster information flow, deliver the cargo faster, enable the flow of goods, and finally, boost economic growth. As a secondary result it helps in reduction of externalities such as 
pollution and harmful emissions (IPCSA, 2018). Therefore, conclusion can be derived that there is no unique way to define MNSW. Each Member State will have its own requirements and conditions, for example, should the MNSW be associated with other systems of the authorities or will the authorities only collect information from the MNSW's user interface; should the national maritime transport system (in Croatia CIMIS) be part of the holistic MNSW solution or will it be a separate system; which legal regulations will be included in the development of the MNSW environment.

\section{Current State of MNSW Development in the Republic of Croatia}

Beginning with 2013, an integrated maritime information system (CIMIS) has been in development in the Republic of Croatia for electronic delivery and data exchange about ships, cargo and passengers in the official proceedings of announcement and registration of arrival and departure, as well as related official procedures except in one segment customs supervision of ship's cargo. Using announcement of the ship's arrival, the agent receives the documents that are entered into the CIMIS system (The regulation on forms, documents and data in maritime traffic, their collection and exchange, and the issuing of Free Pratique, 2017). In the relevant documents, some fields are redundant, but in the CIMIS system they are entered only once, and the entered data is automatically propagated into the fields of other documents, where applicable.

Documents entered into CIMIS are Notification of arrival, Ballast Water Reporting Form, Notification of Ship-Generated Waste, ISPS Code Arrival Notification, Dangerous Goods Manifest, PortPlus Announcement - PSC MEI, IMO FAL forms (Tijan et al., 2017). By entering data related to the announcement of the ship's arrival, the data becomes visible to all users of the process and they can use them for planning and implementation of their own activities. During the announcement of ship's arrival, the data about the ship, the voyage, passengers, crew, cargo and documents that are submitted during the procedure of the ship's arrival are entered into the system (Tijan et al., 2017). At the time when the foreseen operations are completed during stay of the ship in the port, be it commercial activities related to loading or unloading of cargo, the ship's agent (or ship's captain) submits required documents through the CIMIS system that are then used by all stakeholders involved in the administrative reception of the ship such as the Harbor Master Office, Port Authority, Ministry of Health, Ministry of Internal Affairs and Customs. Data provided through the CIMIS system are the crew and passengers list, stability calculations of the ship, the permit to complete all customs procedures, ETD, actual quantity of the cargo and exact number of passengers on board. The port authority defines location of the mooring or berthing through CIMIS and confirms the ETA. 


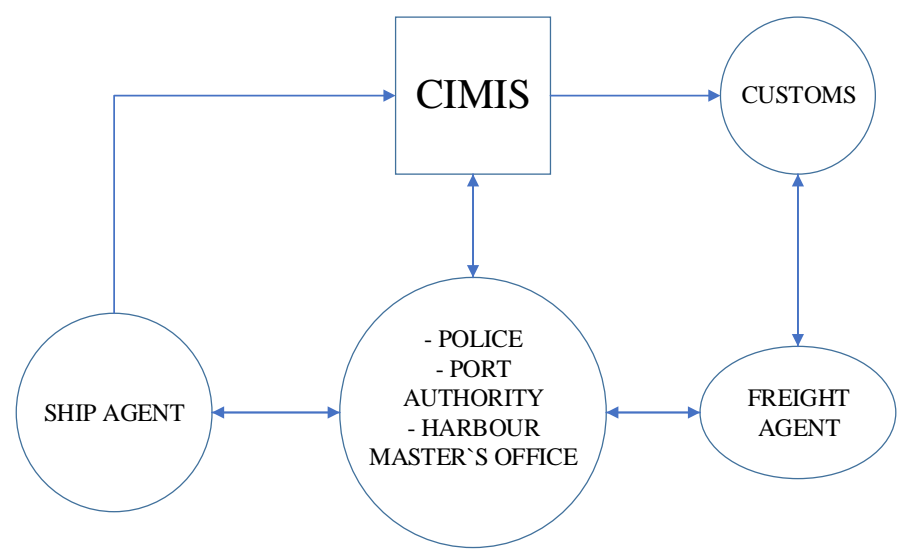

Scheme 1: Current procedures in Croatian ports

The problem occurs after the ship's arrival in the port at the cargo registration through Cargo Declaration - IMO FAL 2 form, (IMO, 2018) which in the current system does not have the possibility of uploading so the data must be manually entered which requires quite a lot of time. Often, multiple errors occur when entering the data.

At this point, it is important to distinguish the ship's agent (usually one) from the freight agent (possibly multiple). Several freight agents can sometimes handle the cargo formalities for different cargo aboard the same ship. The freight agent takes the cargo list from CIMIS and must enter the cargo data in detail in the IMO FAL 2 form, which is after completion sent to the Customs administration. It should be emphasized that the Customs interface is functioning independently of the CIMIS system and that is the reason why it is necessary to constantly retype the data manually (Čičovački, 2018). The Customs administration communicates directly with the freight forwarder and the freight agent during cargo processing (Tijan et al., 2017).

The same procedure is applicable when the ship leaves the port. The freight agent manually fills out the data (Export manifest) and only then the ship can leave the port. This problem occurs also because the whole procedure does not use electronic signature resulting in processes being performed both in electronic and in paper form (Port of Rijeka Authority, 2018).

The procedure is even more complicated in the case when the ship is moored outside the customs gate (Tijan et. al., 2017). Then the ship agent needs to submit the request to the Ministry of Internal Affairs and to the Customs Administration that approves the request. The Harbor Master's Office gives the consent to such request which is previously approved by the Ministry of Internal Affairs and the Customs administration.

In terms of delivering real and accurate data of the ship, the ship's agent announces the ETA via CIMIS (Čičovački 2018). This data can be used by the Harbor Master Office, 
pilot service, tug service, and the number of available tugs can be checked if they are necessary for the ship's entry process. The Harbor Master's Office then issues the formal permit which enables the start of port operations that are not directly under the jurisdiction of the Port Authority. This permit may only be issued after the following services have ascertained that there are no obstacles in their domain of jurisdiction: consent must be given by the Sanitary Inspection, the Border Phytosanitary Inspection, the Ministry of the Internal Affairs - Maritime Police and the Customs Administration. The port authority shall provide (in the CIMIS system) a certificate of the quantity of the ship's really delivered (unloaded) waste to the Harbor Master's Office for inspection so that the ships can receive the permit to navigate to the next port without the delivery of the waste and/or cargo residues (Tijan et. al., 2017).

If a ship is travelling in an international voyage from the mooring or berthing that is outside of the customs gate, the agent must submit a request. Upon receipt of the request, the Ministry of Internal Affairs can make the necessary checks and issue a decision that is available to the Customs, or to the Harbor Master Office through the CIMIS. On the basis of the received data, documents related to the international voyages departing from the last Croatian port, the port authority issues the permission to the ship to leave the port when all conditions for departure are met in accordance with special regulations.

\section{Development of MNSW and PCS with EMSW in Croatia}

At the beginning of 2017, the EU ministers agreed on a declaration that would harmonize the data between ports of the Member States (European Commission, 2018). The European Maritime Single Windows (EMSW) is a place where all information (except eManifest) is registered and accessible to all various competent authorities (EMSA, 2018). The data would be available to all providers of the ship-related data (agents, ship masters, ship owners), relevant public authorities associated with the seaport and other Member States of the SafeSeaNet. The data that is entered in the EMSW are port arrival and departure, ship particulars, cargo and dangerous goods, ship`s stores, crew and passengers, crew`s effects, security, waste and health data. The ship agent registers the described information in previously described CIMIS system, which in Croatia currently serves as the MNSW.

In the development of the single interface, MNSW would represent an information bus established between the CIMIS and the EMSW. By linking these systems, administrative procedure of the ship's arrival and departure would be significantly accelerated, which would also accelerate other administrative and commercial procedures between the stakeholders of the seaport system. Data redundancy would also be avoided. In a real life scenario, the ship agent inputs the ship identification data, crew list and other relevant data in the CIMIS system, which could be avoided because of established connection to the EMSW through the MNSW bus. For example, if the ship is leaving the port of Trieste for the port of Rijeka, all data related to the ship would be visible through the EMSW in the next phase(s) of the voyage. 


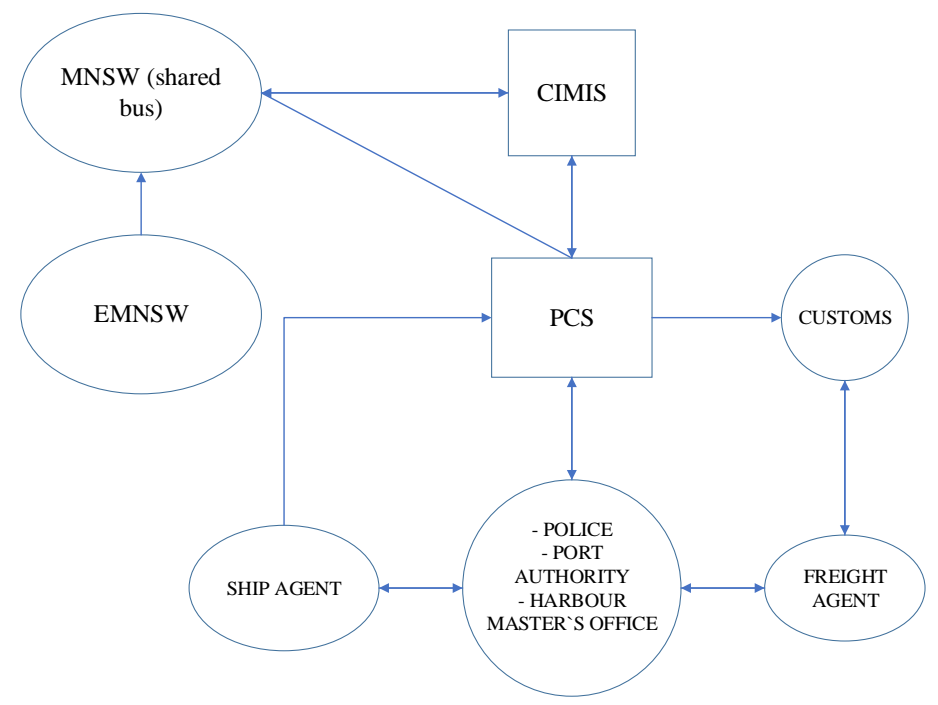

Scheme 2: System orchestration in Croatian Maritime National Single Window

Further problems that slow down the seaport processes are caused by an underdeveloped or non-existent PCS system (current exception is the port of Ploče, where PCS is partially introduced and still in development), thus making the customs procedures and the work of freight agents more difficult. By introducing the eManifest into the EMSW, the work of the freight agent and customs would be considerably simplified.

The eManifest project started in February 2017 and will encompass the Arrival Manifest, using the existing Maritime Single Window prototype which was developed by the European Maritime Safety Agency (EMSA) in compliance with the Directive 2010/65/EU on reporting formalities (EMSA, 2016). The eManifest, or electronic cargo list, contains information about the status of transported goods and is considered to be a practical solution by which this could be achieved. The eManifest would assume the form of a harmonized electronic cargo list and as such would represent an instrument for further facilitation of the maritime transport which is done by ships that operate in seaports of the EU and third countries. The eManifest must be available in electronic form to the customs authorities at the next port of call where the cargo will be unloaded, whereby quick transit would be enabled to cargo from the EU (European Commission, 2018). By referring to the information about the cargo that is collected in the previous port in the eManifest, an additional factor of compliance with the fiscal and safety requirements of the EU would be provided. By introducing the electronic signature within the PCS system, administration procedures would be additionally validated and secured. 
E. Tijan, M. Jardas, S. Aksentijević \& A. Perić Hadžić: Integrating Maritime National Single

Window with Port Community System - Case Study Croatia

The integration of MNSW and PCS would greatly contribute to the development of seaport processes, while at the same time the cost to the ship owners or shippers would be reduced. Therefore, it is of a common interest to speed up and facilitate the procedures required for the arrival, stay and departure of the ship, throughout the business processes. For example, when a ship departs from one port, the ship's port of entry would convey the EMSW data regarding the arrival of the ship to the next port. The data entered in the EMSW would be synchronized to national platforms or the NMSW. The next step is establishing the connection of the NMSW with the PCS. The data entered in NMSW (synchronized data from EMSW) would be visible in the PCS (an integration of the entire port community is required as shown in Scheme 3.).
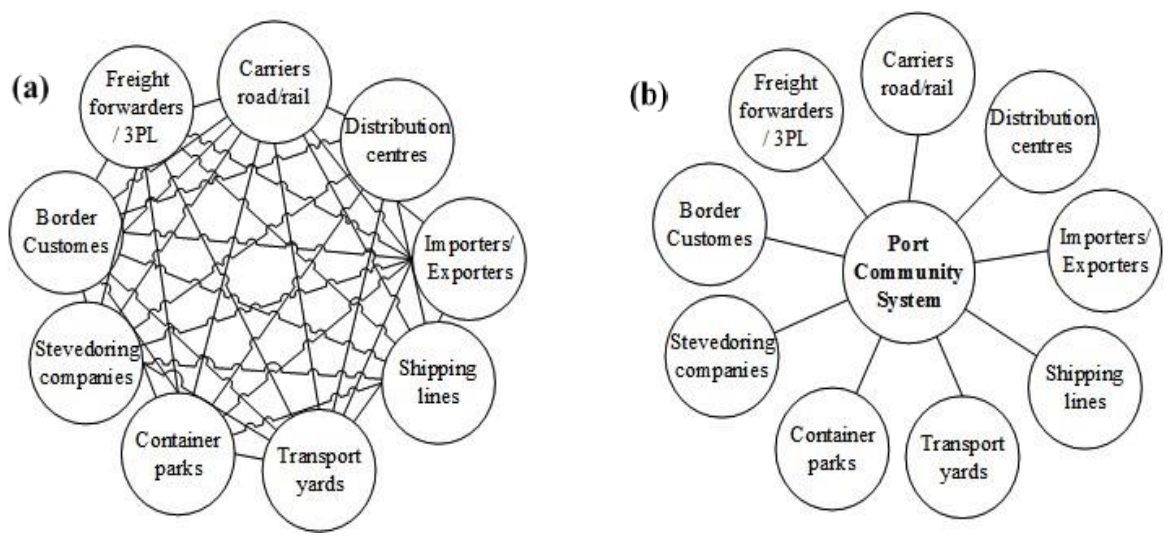

Scheme 3. Communication between individual seaport stakeholders (a) without the PCS and (b) with the PCS (Irrannezhad et. al., 2017)

Using the data related to the type and size of the ship, the port authority could plan in advance or define the place of mooring or berthing, so all stakeholders of the port process could be optimally organized such as pilots, Harbor Master Office, customs, etc. (scheme 4). The described communication would greatly accelerate and facilitate the ship's agent work through the announcement and registration procedures of the ship, as well as other operational activities during the ship's stay in the port. 


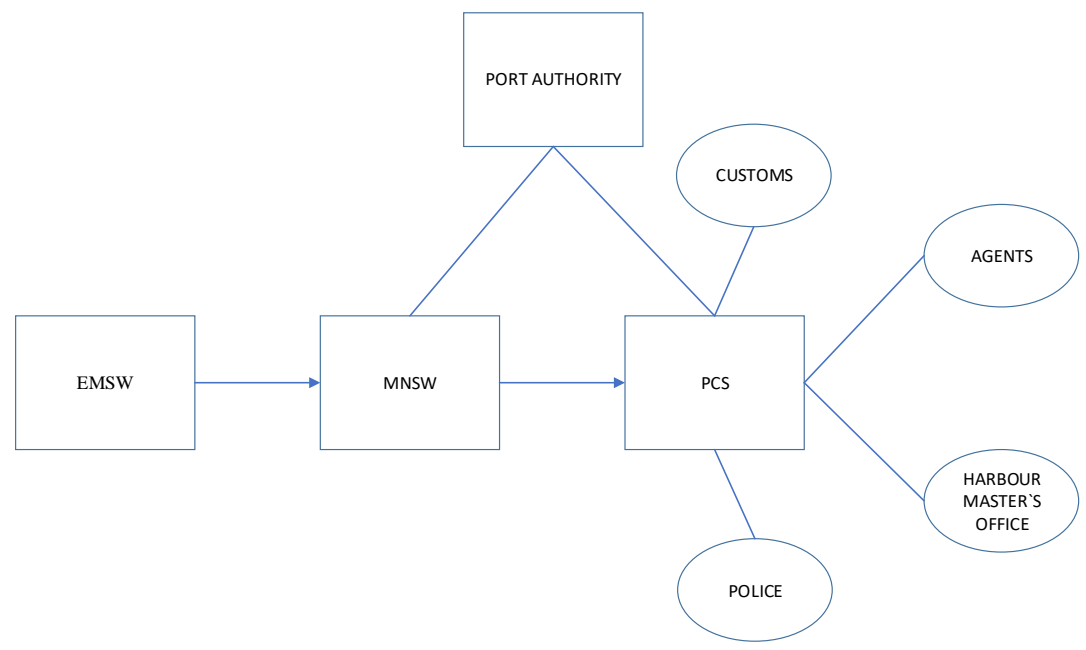

Scheme 4: Integration between MNSW and PCS

\section{6}

\section{Conclusion}

According to the presented research, Croatia will have to develop the MNSW to comply with the present EU recommendations. For the development of the MNSW, it is necessary to analyze the existing systems that will participate in the exchange of data, their ability to communicate through exchange of the messages, receiving, storing and exchanging the documents and information. It is important to emphasize that there is no unified or universally applicable method of establishing the MNSW. It is necessary to establish a broader integration infrastructure of seaport stakeholders. In Croatia, the MNSW should be integrated with the CIMIS system, which proved to be successful and well accepted by stakeholders. Therefore, the MNSW should represent a "government service bus" that will be used for the exchange of data, ensure the compliance with business processes and conversion of the various data formats entered by stakeholders. This means that the MNSW system should not be used for the active entry of documents and data in the sense of a single data entry point. The relevant data exchange will be achieved through the existing or future systems (the new PCS systems of Croatian seaports). The construction of the PCS system is essential for the stakeholders of the port processes to whom business operations would considerably be facilitated through faster information flow and the reduction of errors that occur through multiple data entry. In order to achieve this, it is primarily necessary to invest in information and communication technologies that represent the basis for the described development. This should substantially accelerate business and port operations, both in the seaport itself, and among stakeholders. In addition to the acceleration of the processes, it would also simplify data entry procedures, resources would be used more efficiently, redundant data would be eliminated, cargo would be processed faster (which especially applies to the Customs part) and security, integrity and transparency of the process would be greatly increased. 
E. Tijan, M. Jardas, S. Aksentijević \& A. Perić Hadžić: Integrating Maritime National Single

Window with Port Community System - Case Study Croatia

\section{Acknowledgement}

This work has been financially supported by University of Rijeka under the Faculty of Maritime Studies projects.

\section{References}

Bezić H., Tijan E., Aksentijević S. (2011). Port Community Systems - Economic Feasibility Evaluation. Review of Contemporary Entrepreneurship, Business, and Economic Issues. J.J. Strossmayer University of Osijek, Faculty of Economics in Osijek. 2/2011 247-256 - 2011.

Čičovački, L. (2018). Maritime National Single Window - today and tomorrow, MNSW and maritime traffic digitalization conference. Ministry of Sea, Transport and Infrastructure of Croatia, Maritime Safety Directorate

Čičovački L. (2013). Electronic announcement of vessel departure in domestic voyage via Croatian Integrated Maritime Information System - CIMIS, Ministry of Sea, Transport and Infrastructure of Croatia, Maritime Safety Directorate

Directive 2010/65 EU of the European Parliament and of the Council, Official Journal of the European Union, 2010

EMSA (2015). National Single Window Prototype - An electronic solution for simplifying administrative procedures

EMSA (2016). eManifest Pilot Project, Version 0.8.

EMSA (2018.) European Maritime Single Window (EMSW), http://emsa.europa.eu/infographics/item/2832-european-maritime-single-window-emsw.html, (05.03.2018.)

EMSA (2018). European Maritime Single Window Environment, http://www.emsa.europa.eu/related-projects/emsw.html 05.03.2018.)

EMSA (2018). Vessel traffic monitoring in EU waters, http://www.emsa.europa.eu/ssnmain.html (05.03.2018.)

European Commission (2015). National Single Window Guidelines

European Commission, Mobility and Transport, https://ec.europa.eu/transport/modes/maritime/digital-services/e-maritime_nl, 05.03.2018)

Granqvist, M., Hintsa, J., Mannisto, T. (2012). Future Development of e-Customs: A Survey Study with Swiss Companies, International Journal of Electronic Government Research, Vol. 8, No. 4, pp. 49-59.

IMO, FAL forms and Certificates, http://www.imo.org/en/OurWork/Facilitation/FormsCertificates/Pages/Default.aspx, 05.03.2018.

International Port Community System Association (IPCSA), Port Community Systems, http://www.epcsa.eu/pcs, 05.03.2018.

Irannezhad E., Hickman M., Prato C. Modelling the Efficiency of a Port Community System as an Agent - based Process (2017). The 6th International Workshop on Agent-based Mobility, Traffic and Transportation Models, Methodologies and Applications

Kapidani N., Kočan E. (2015). Implementation of National Maritime Single Window in Montenegro. Telecommunications Forum Telfor (TELFOR), 201523.

Moïsé, E., Orliac, T., Minor P. (2011), Trade Facilitation Indicators: The Impact on Trade Costs, OECD Trade Policy Working Papers, No. 118, OECD Publishing, http://dx.doi.org/10.1787/5kg6nk654hmr-en

Port of Rijeka Authority (2018), Maritime National Single Window and maritime traffic digitalization conference 
The regulation on forms, documents and data in maritime traffic, their collection and exchange, and the issuing of Free Pratique (Croatian Official Gazette 70/2013, 55/2015 and 103/2017) SafeSeaNet, (2016) Interface and Functionalities Control Document, Version 1.1.2.

Srour, van Oosterhout, van Baalen, Zuidwijk (2008). Port Community System Implementation:

Lessons Learned from International Scan, Conference: Conference: Transportation Research Board 87th Annual Meeting, Volume: 08-2041

Tijan E., Zec D., Jugović A., Aksentijević S., Jardas M., (2017), The development of the Single Window for maritime traffic formalities (NSW). University of Rijeka, Faculty of Maritime Studies.

Single Window Directive for formalities in maritime traffic (Croatian Official Gazette 119/2015). 
12 3 $31^{\text {ST }}$ Bled eConference: Digital Transformation: MeEting the Challenges June 17 - 20, 2018, BLED, SLOVENIA, CONFERENCE PROCEEDINGS 
$31^{\text {ST }}$ Bled eConference: Digital Transformation: MeEting the Challenges JunE 17 - 20, 2018, Bled, SLOVENIA, CONFERENCE PROCEEDINGS

A. Pucihar, M. Kljajić Borštnar, C. Kittl, P. Ravesteijn, R. Clarke \& R. Bons

\title{
How to start with big data - a multiple case study
}

\section{Christian Bremser, GunTHER Piller \& Franz RothlauF}

\begin{abstract}
As part of an advancing digitalization, many enterprises feel the need to explore the possibilities big data may provide for their business. However, only a few companies use big data applications productively, despite its high expected potential. How companies examine the possibilities of big data, is therefore a highly interesting and relevant question. Based on a multiple case study we identify three different approaches: Companies either initially focus entirely on business aspects, or on a systematic build-up of a big data technology and data platform. Innovation adoption research is used as a theoretical basis.
\end{abstract}

Keywords: • big data $\bullet$ digitalization $\bullet$ innovation adoption $\bullet$,

CoRrespondence AdDRess: Christian Bremser, University of Applied Sciences Mainz, LucyHillebrand-Straße 2, 55128 Mainz, Germany, e-mail: christian.bremser@hs-mainz.de. Gunther Piller, University of Applied Sciences Mainz, Lucy-Hillebrand-Straße 2, 55128 Mainz, Germany, e-mail: gunther.piller@hs-mainz.de. Franz Rothlauf, Gutenberg University Mainz, Saarstraße 21, 55122 Mainz, e-mail: rothlauf@uni-mainz.de.

DOI https://doi.org/10.18690/978-961-286-170-4.2

ISBN 978-961-286-170-4

(C) 2018 University of Maribor Press

Available at: http://press.um.si. 
The potential benefits and challenges associated with big data are an important topic for companies in all industries - in particular in the current era of an increasing digitalization. Big data promises new data-driven services to improve processes and enable innovative products and business models (Sivarajah et al., 2017). Against this backdrop, a growing number of companies are investing in big data, combined with the hopes of competitive advantages (Constantiou \& Kallinikos, 2015). Nevertheless, companies seem to have difficulties with the productive implementation of big data applications. According to a Gartner study, only $14 \%$ of enterprises have put big data projects into production (Kart, 2015). Therefore research on the adoption of big data applications are important and of scientific and practical interest.

The introduction of innovations is described by adoption theories. The process of innovation adoption typically involves two phases (Rogers, 2003): initiation and implementation. Within these phases, new technologies have to overcome several hurdles before being used productively. For technology-driven innovations, like big data (Nam, Kang, \& Kim, 2015), the initiation phase, where companies search for valuable use cases for different big data technologies, poses a first serious obstacle. This initial step towards the exploration of big data potentials is the focus of our study. In particular we address the following research question:

Which generic approaches can be identified when companies explore the potentials of big data in the initiation phase of innovation adoption?

Despite the high relevance, there are no specific studies on the initiation phase of big data adoption. Current research mainly investigates general influencing factors and hurdles during the implementation of big data technologies. In contrast, this paper analyses current approaches for the exploration of new big data potentials in the initiation phase. For this purpose, a multiple case study with ten companies from different industries was conducted. The organizational adoption process of Rogers (2003) has been used as a theoretical starting point.

This report is organized as follows: The current research on big data adoption is summarized in the next section. Section 3 presents our conceptual framework. Section 4 introduces the research design. Section 5 presents the findings from our cases. A discussion of the results in section 6 and a summary of the main points in section 7 complete this work.

\section{Current research}

Big data is defined by the TechAmerica Foundation (2012) as "a term that describes large volumes of high velocity, complex and variable data that require advanced techniques and technologies to enable the capture, storage, distribution, management, and analysis of the information." Obviously, big data is a bundle of new technological and methodological possibilities that allow to process and analyse large, complex and rapidly 


$$
\begin{aligned}
& 31^{\text {ST }} \text { Bled eCONFEREnCE: Digital Transformation: MeEting the Challenges } \\
& \text { June } 17 \text { - 20, 2018, BLED, SLOVENIA, CONFERENCE PROCEEDINGS } \\
& \text { C. Bremser, G. Piller \& F. Rothlauf: How to start with big data - a multiple case study }
\end{aligned}
$$

growing data sets (e.g. stream analytics, in-memory data processing, NoSQL databases). Enterprises want to take advantage of these opportunities and promise a wide range of benefits through the introduction of big data applications (see, for example, (Brown, Chui, \& Manyika, 2011; Davenport, Barth, \& Bean, 2012; Kiron, Prentice, \& Ferguson, 2014)). One approach to describe the introduction of technology-driven innovations is the adoption theory. On the one hand, this theory covers the identification of factors that influence the decision-making process of innovation adoption (Rogers, 2003). On the other hand, it describes the process which innovations have to go through, ranging from an initial awareness in companies to its productive use (Fichman, 2000). Previous work in the context of big data adoption mainly focuses on the investigation of general influencing factors through the Technology-Organization-Environment Framework (TOE) (see, for example, (Agrawal, 2015; Malaka \& Brown, 2015; Sun et al., 2016)). The TOE describes the impact of technological, organizational and environmental aspects on organizational decision making with respect to technology innovations (Tornatzky, L. G., Fleischer, M. \& Chakrabarti, 1990). As a result, it has been shown (Agrawal, 2015; Malaka \& Brown, 2015; Sun et al., 2016) that the protection and integration of data are considered as important technological challenges. Organizational aspects, such as, unclear processes, lack of analytical skills and indistinct prioritization of use cases are further obstacles to the successful adoption of big data. However, the adoption is positively influenced by company size and competition intensity.

Nam et al. (2015) have investigated the change of influencing factors during the adoption process. As a result, Nam et al. (2015) prove that existing information systems (IS) competence has a positive impact in the beginning of the adoption process, while competitive intensity and financial readiness significantly support the successful implementation of use cases.

Bremser et al. (2017) have used the TOE to identify factors that influence the approaches companies use to explore big data potentials. IS competence, perceived complexity of the big data technologies, as well as the financial and strategic readiness of companies were identified as major influencing factors.

So far an investigation of the big data adoption process has been carried out only by Chen et al. (2015). They use a multiple case study to describe the implementation phase and corresponding influencing factors. TOE (Tornatzky, L. G., Fleischer, M. \& Chakrabarti, 1990), diffusion of innovation (Rogers, 2003) and the IT fashion theory (Wang, 2010) were used as sources for influence factors. The diffusion theory describes the spreading of an innovation among members of a social system (Rogers, 2003). The IT fashion theory highlight the social settings of emerging IT trends, e.g. the influence of consultants and technology analysts (Wang, 2010). According to Chen et al. (2015) the implementation phase involves far-reaching organizational changes that are necessary for the productive implementation of big data applications. As a result, they present a "limbo stage", where companies continuously experiment with big data technologies for a long time and do not proceed to deployment, despite their intent to adopt. 
This overview of current research shows that influence factors on the adoption process for big data have already been extensively discussed. An investigation of the adoption process was conducted by Chen et al. (2015), but only with focus on the implementation phase. Despite its high relevance, no scientific investigation exists for the initiation phase when companies start to approach the potentials of big data.

\section{Conceptual Framework}

In order to address this research gap by investigating the initial exploration of big data applications, Rogers' adoption process (2003) is used as a theoretical starting point which is illustrated in figure 1. According to Rogers (2003), the process of innovation adoption is described by two major phases: initiation and implementation, with both phases being separated by an adoption decision. The initiation phase consists of two stages:

The first stage agenda-setting is triggered by an organizational problem or by the perception of an innovation. The organizational problem manifests itself through a perceived performance gap, which is the result of internal inefficiency or altered environmental conditions (Damanpour \& Schneider, 2006). The observation of an innovation is achieved by continuously scanning the business environment (for example, monitoring competitors or technological developments). Both triggers force enterprises to consider the potentials of innovations. Within the agenda-setting stage the entrepreneurial range of possible reactions with respect to innovations is weighed. For example, a company decides how to react on the availability of a new technology.

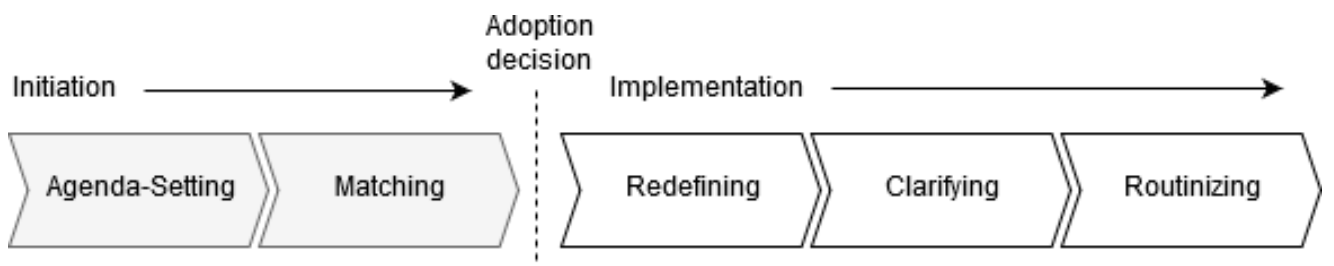

Research focus

Figure 1: Innovation adoption process by Rogers (2003)

The second stage matching includes all activities that proof whether an identified innovation is suitable for fulfilling the organizational needs in context of the current situation of a company. Typically, some members of an organizational unit explore the capabilities of the innovation to make a prediction on its potential for specific use cases. If this forecast is positive, the implementation phase is triggered in the adoption process. This phase consists of the stages redefining, clarifying and routinizing, and includes all the activities and decisions that are necessary to put the innovation into production. The present research focuses on the initiation phase of the adoption process. The implementation phase is not the subject of this work. It has been investigated already by Chen et al. (2015). 


$$
\begin{aligned}
& 31^{\text {ST }} \text { Bled eCONFEREnCE: Digital Transformation: MeEting the Challenges } \\
& \text { June } 17 \text { - 20, 2018, BLED, SLOVENIA, CONFERENCE PROCEEDINGS } \\
& \text { C. Bremser, G. Piller \& F. Rothlauf: How to start with big data - a multiple case study }
\end{aligned}
$$

\section{Research Design}

Phenomena around big data adoption are complex and certainly not well understood so far. For this reason, a case study approach is suitable (Dubé \& Paré, 2003; Yin, 2003). Our main information sources are in-depth expert interviews with key-informants. Interviewees were heads of business and IT divisions, chief architects and chief strategist. In the sense of a strict implementation of the research design, four established quality criteria were used (Yin, 2003): external validity, internal validity, construct validity and reliability.

The external validity focusses on the generalizability of the results. This is ensured by replicating the case studies. In the context of big data adoption, it was decided to conduct a multiple case study. The case studies were selected according to the "literal replication logic" (Dubé \& Paré, 2003). In order to ensure a comparable organizational and technological context pure internet companies were excluded in the selection phase of the case studies. In addition, the reference to big data has been validated by scientific big data taxonomies (see, e.g. (Kune et al., 2016)). Big data taxonomies represent a classification scheme and show which technologies, methods and data are typically used in the context of big data.

In order to ensure internal validity, the interview guide was developed on the basis of the conceptual framework described in chapter 3. The expert interviews were semi-structured and we kept our questions open to allow interviewees freely to speak. The first part contains general questions about the role and responsibility of the interviewee, the current strategic and tactical challenges of the company and their influence upon dealing with new possibilities of big data. The second part of our questions concentrates on the current use of data, methods and technologies for data-driven decision making as well as corresponding organizational structures and processes. For example, we asked about the relevance of data and data-driven decision making in different organizations and inquired which kind of analytical applications were currently in use. The third and most extensive set of questions was directed upon "why" and "how" organizations explore the potentials of big data. These questions concerned the trigger of big data initiatives, their focus and their organizational setup. Also we inquired the process for the evaluation of big data potentials and the criteria applied therein.

Yin (2003) suggests triangulation to ensure construct validity. Within the case studies, different data sources were therefore used. In addition to the key-informant interviews, public and - if available - internal documents of big data initiatives and strategies of the investigated companies were used. Furthermore, interviews with other organizational members, consultants and software vendors specialized on big data adoption were conducted to triangulate the data.

In order to minimize errors and biases, the reliability of the case studies was ensured by establishing a case study database. There, we stored all information about the data collection process, the data itself and the case study results. According to Yin (2003), this helps to provide the same results in repeated trials. 
The data collection started in June 2016 and stretched over a period of seven months. Each interview lasted approximately 90 minutes and was conducted on site or by telephone conference. The conversations were recorded and transcribed. Shortly after each interview, the main points and key findings were recapitulated in a contact summary sheet (Miles, Huberman, \& Saldana, 2013). The interviews were then analysed and coded. We used first-level coding (Miles et al., 2013) to identify in particular all statements related to company's procedures for the initiation phase of big data adoption.

Table 1 presents an overview of the participants of the case study. In the case selection, we focused on companies that have more than 10,000 employees and their headquarters in Germany. The investigated companies operate business-to-consumer as well as in business-to-business segments. The interviewees had roles in business and IT and were responsible for big data activities within their organizations.

Table 1: Participating companies

\begin{tabular}{|c|c|c|c|c|}
\hline & Industry & $\begin{array}{l}\text { Number of } \\
\text { employees }\end{array}$ & $\begin{array}{l}\text { business } \\
\text { segment }\end{array}$ & Role of Interviewee \\
\hline 1 & Transport & $>50,000$ & $\mathrm{~B} 2 \mathrm{C}, \mathrm{B} 2 \mathrm{~B}$ & Head Domain Architecture \\
\hline 2 & Banking & $>50,000$ & $\mathrm{~B} 2 \mathrm{C}, \mathrm{B} 2 \mathrm{~B}$ & Head IT Architecture \\
\hline 3 & Insurance & $>10,000$ & $\mathrm{~B} 2 \mathrm{C}, \mathrm{B} 2 \mathrm{~B}$ & Head Group Strategy \\
\hline 4 & Manufacturing Vehicle & $>50,000$ & B2B & IS Chief-Architect \\
\hline 5 & Retail Trade & $>50,000$ & $\mathrm{~B} 2 \mathrm{C}$ & Head Business Intelligence \\
\hline 6 & Utilities & $>50,000$ & $\mathrm{~B} 2 \mathrm{C}, \mathrm{B} 2 \mathrm{~B}$ & Chief Digital IT Strategist \\
\hline 7 & Manufacturing Vehicle & $>50,000$ & B2B & Head Analytics Lab \\
\hline 8 & Manufacturing Apparel & $>50,000$ & $\mathrm{~B} 2 \mathrm{C}$ & Head Data Analytics Lab \\
\hline 9 & Manufacturing CPG & $>10,000$ & $\mathrm{~B} 2 \mathrm{C}$ & $\begin{array}{l}\text { Head Marketing \& } \\
\text { Analytics }\end{array}$ \\
\hline 10 & $\begin{array}{l}\text { Manufacturing } \\
\text { Chemicals }\end{array}$ & $>10,000$ & B2B & Head BI Architecture \\
\hline
\end{tabular}

The analysis of these cases was carried out in a twofold way. First, we have used a withincase analysis (Yin, 2003) to extract all characteristic content related to the agenda-setting and matching stages of individual cases. The corresponding results are shown in chapter 5. For data presentation we apply the process definition of Hammer and Champy (1993) , showing in particular input, activities and results. In the second step, a cross-case analysis (Yin, 2003) was conducted and the cases were compared to each other. The result of this comparison is discussed in chapter 6 .

\section{$5 \quad$ Results from cases}

The trigger for a company to deal with the possibilities of a technological innovation is, according to Rogers, a performance gap of the company or the perception of new possibilities (Rogers, 2003). In the case of a technology-driven innovation, a company 


\section{$31^{\text {ST }}$ Bled ECONFEREnCE: Digital Transformation: MeEting the Challenges June 17 - 20, 2018, BLED, SLOVENIA, CONFERENCE PROCEEDINGS \\ C. Bremser, G. Piller \& F. Rothlauf: How to start with big data - a multiple case study}

examines in the subsequently launched agenda-setting phase, how it shall react upon the availability of a new technology (Rogers, 2003). The result is a so-called agenda, which defines the goals of the next steps in the adoption process.

The following matching phase examines the extent to which an innovation could be used to address entrepreneurial needs. If a promising forecast can be given for a specific application scenario, the innovation will be proposed for implementation (Rogers, 2003). Table 2 shows an overview of the agenda-setting and matching phase.

Table 2: Agenda Setting and Matching by Rogers (Rogers, 2003)

\begin{tabular}{|c|c|}
\hline \multicolumn{2}{|c|}{ Agenda-Setting } \\
\hline Input & Performance gap or perception of an innovation \\
\hline Activity & Consideration of possible organizational reactions \\
\hline Result & $\begin{array}{l}\text { Agenda, containing company-specific goals for the next activities } \\
\text { in the adoption process }\end{array}$ \\
\hline \multicolumn{2}{|c|}{ Matching } \\
\hline Input & Agenda \\
\hline Activity & $\begin{array}{l}\text { Exploration whether organizational needs can be addressed } \\
\text { with the innovation }\end{array}$ \\
\hline Result & $\begin{array}{l}\text { Decision-making document for the possible implementation of an } \\
\text { use case }\end{array}$ \\
\hline
\end{tabular}

In all observed cases, the big data adoption process was initiated by senior management. Always the perception of the hype surrounding big data was decisive, not a search for ways to solve existing requirements. This is described by an interviewee from case 8 as follows: "It was our former CIO [...], who said that big data is a megatrend, which I will definitely not miss ...".

The long-term expectations companies relate to big data span from possible improvements of existing processes to entirely new business services or business models. A quote from case 5 confirms this: "... [we hope to use big data] either for rationalization or for other value-creation opportunities, which are not necessarily connected to rationalization, but where really new fields are opened up."

In order to determine the direction of the next big data activities, the topic was discussed at senior management level in all companies. As a result, first objectives and corresponding steps have been defined. Personnel responsible for big data initiatives and resources for project teams were named. Table 3 shows the short-term goals, i.e. the agenda, for the different big data initiatives. 
C. Bremser, G. Piller \& F. Rothlauf: How to start with big data - a multiple case study

Table 3: Agenda of the interview participants

\begin{tabular}{|l|l|}
\hline $\mathbf{1}$ & Portfolio for innovative data-driven products, services, business models \\
\hline $\mathbf{2}$ & $\begin{array}{l}\text { Possibilities for the cost-neutral minimization of technological hurdles for future } \\
\text { big data applications }\end{array}$ \\
\hline $\mathbf{3}$ & $\begin{array}{l}\text { Roadmap for a systematic development of internal capabilities to use big data } \\
\text { technologies and to provide data appropriately }\end{array}$ \\
\hline $\mathbf{4}$ & $\begin{array}{l}\text { Consistent data basis for company-wide analyses, initially for the identification of } \\
\text { potential efficiency enhancements within the existing value chain }\end{array}$ \\
\hline $\mathbf{5}$ & $\begin{array}{l}\text { Opportunities for a future-oriented development of a data and technology platform } \\
\text { for analytical applications }\end{array}$ \\
\hline $\mathbf{6}$ & $\begin{array}{l}\text { Portfolio of innovative digital products for public, commercial and private } \\
\text { customers }\end{array}$ \\
\hline $\mathbf{7}$ & $\begin{array}{l}\text { List of necessary requirements with respect to technologies and organizations for } \\
\text { future data-driven product innovations as well as a consistent data base }\end{array}$ \\
\hline $\mathbf{8}$ & $\begin{array}{l}\text { Potentials for innovative products and process optimizations along existing value } \\
\text { chains }\end{array}$ \\
\hline $\mathbf{9}$ & $\begin{array}{l}\text { Possibilities of data analyses to increase the efficiency of existing processes with } \\
\text { focus on marketing and sales }\end{array}$ \\
\hline $\mathbf{1 0}$ & Data basis out of existing and new data for future data-driven services \\
\hline
\end{tabular}

As Table 3 shows, the aim of companies in cases 1, 6, 8, 9 was directed towards application use cases. For the remaining enterprises (cases 2, 3, 4, 5, 7, 10), the creation of a good technological starting point and a solid basis of data was at the forefront.

Following their agenda, the examined companies have carried out different activities in the matching phase. The main activities of the investigated cases are shown in Table 4 . 


\section{$31^{\text {ST }}$ Bled ECONFEREnCE: Digital Transformation: MeEting the Challenges June 17 - 20, 2018, BLED, SLOVENIA, CONFERENCE PROCEEDINGS \\ C. Bremser, G. Piller \& F. Rothlauf: How to start with big data - a multiple case study}

\section{Table 4: Main activities of the matching phase}

\begin{tabular}{|c|c|}
\hline 1 & $\begin{array}{l}\text { - Search for new, data-driven products and customer services carried out by business departments } \\
\text { - } \quad \text { Evaluation of use cases in terms of their economic value } \\
\text { Implementation of prototypes in cross-functional project teams partly with external support by } \\
\text { consultancies } \\
\text { - Validation of prototypes in selected market segments }\end{array}$ \\
\hline 2 & $\begin{array}{l}\text { - Analysis of existing requirements conducted by the IT architecture organization to identify } \\
\text { opportunities for implementing big data technologies } \\
\text { - Search for opportunities to replace existing IT components cost-neutrally with big data } \\
\text { technologies (for example Hadoop file system instead of Oracle cluster) }\end{array}$ \\
\hline 3 & $\begin{array}{l}\text { - Gap analysis for big data capabilities and corresponding pre-requisites through industry-specific } \\
\text { big data use cases } \\
\text { - Roadmap definition for the development of missing capabilities focussing on big data technologies } \\
\text { and data management through a work group guided by middle management }\end{array}$ \\
\hline 4 & $\begin{array}{l}\text { - } \quad \text { Definition of performance key performance indicators (KPI) through top management for cross } \\
\text { functional business processes } \\
\text { - } \quad \text { Validation of KPIs and identification of weaknesses in the data architecture via data lab } \\
\text { - }\end{array}$ \\
\hline 5 & $\begin{array}{l}\text { - Continuous evaluation of technology innovations for the evolution of the central data platform } \\
\text { through employees of the internal IT department } \\
\text { - Identification and integration of new data sources for future big data use cases }\end{array}$ \\
\hline 6 & $\begin{array}{l}\text { - Search for new data driven customer services in the B2C and B2B segment by cross-functional } \\
\text { teams staffed with employees from business and IT departments } \\
\text { - Development of potential services as prototypes using agile project methodologies } \\
\text { - Evaluation of the big data use cases from an economic perspective as a proof of concept (PoC) } \\
\text { within a time-limited test phase in selected market segments }\end{array}$ \\
\hline 7 & $\begin{array}{l}\text { - } \quad \text { Reduction of data silos and creation of a central data basis } \\
\text { - Exploratory implementation of industry-specific big data uses cases in a laboratory environment } \\
\text { - Evaluation of typical big data requirements and their impact on the technology landscape and } \\
\text { organization }\end{array}$ \\
\hline 8 & $\begin{array}{l}\text { - Search for use cases in business divisions with focus on potential growth fields and customer } \\
\text { benefits } \\
\text { - Establishing a laboratory within the IT department for exploratory data analysis; recruitment of } \\
\text { data scientists and data engineers } \\
\text { - Identification of lighthouse use cases and implementation as PoC in a laboratory environment }\end{array}$ \\
\hline 9 & $\begin{array}{l}\text { - Identification of new opportunities for data driven personalized customer services in marketing } \\
\text { and sales departments } \\
\text { - Use case driven extension of the enterprise-wide data platform through external IT providers } \\
\text { focussing on the integration of external data, e.g. media data from external agencies }\end{array}$ \\
\hline 10 & $\begin{array}{l}\text { - Development of a cloud data lake and integration of enterprise data by the business intelligence } \\
\text { and advanced analytics departments } \\
\text { - } \\
\text { - } \\
\text { Design and implementation of data governance processes } \\
\text { Recruitment of Data Scientist to investigate future big data use cases }\end{array}$ \\
\hline
\end{tabular}

The matching phase aims at the provisioning of appropriate information to decide upon the adoption of specific big data use cases. As Table 4 shows, some enterprises (cases 2, 
$3,4,5,7,10)$ develop a data platform and capabilities to deal with big data technologies, in line with their agenda. Investigations of company-specific big data use cases were planned by these companies after these activities. Companies (cases 1, 6, 8,9) which implement and evaluate prototypes for specific use cases, take these into a project or innovation portfolio in case of a positive adoption decision. There, the use cases compete with other enterprise projects for the resources required for a productive implementation.

\section{Discussion}

A comparison of the case studies shows that three different approaches can be identified. Figure 2 illustrates this in a schematic way.

The first approach (Business First) focuses entirely on a business perspective. Companies in this category search for use cases with high expected business value. These use cases span from possible improvements of existing processes to entirely new business services or business models. A quote from case 1 emphasizes this: "... on the one hand you have to adapt the existing business to the current market [...], i.e. to improve existing processes [...] On the other hand you have to invent new processes or tackle new business models". A technical evaluation of the use cases with regard to their possible integration into existing IT landscapes is not carried out during the initiation phase. This is shown by a quotation from case 6: "At the beginning, the integration is actually subordinated [...] If a product that has been developed in a sandbox is successful on the market, of course, we want to integrate it." Typically, big data use cases are developed as stand-alone IT systems with necessary big data technologies and data in a laboratory environment. Developed prototypes are then tested with selected market participants. If this phase is successful, the use cases are suggested for productive implementation. For example, case 6 states: "[the goal is to] test use cases in 6-12 months with several thousands, maybe even ten thousands of customers in real use. And then there's the decision: go or no-go." In case of a positive decision, applications will initially operate as independent IT systems, being then integrated step by step into existing IT landscapes. Companies with this approach can be found in cases 1, 6, 8 and 9 . 

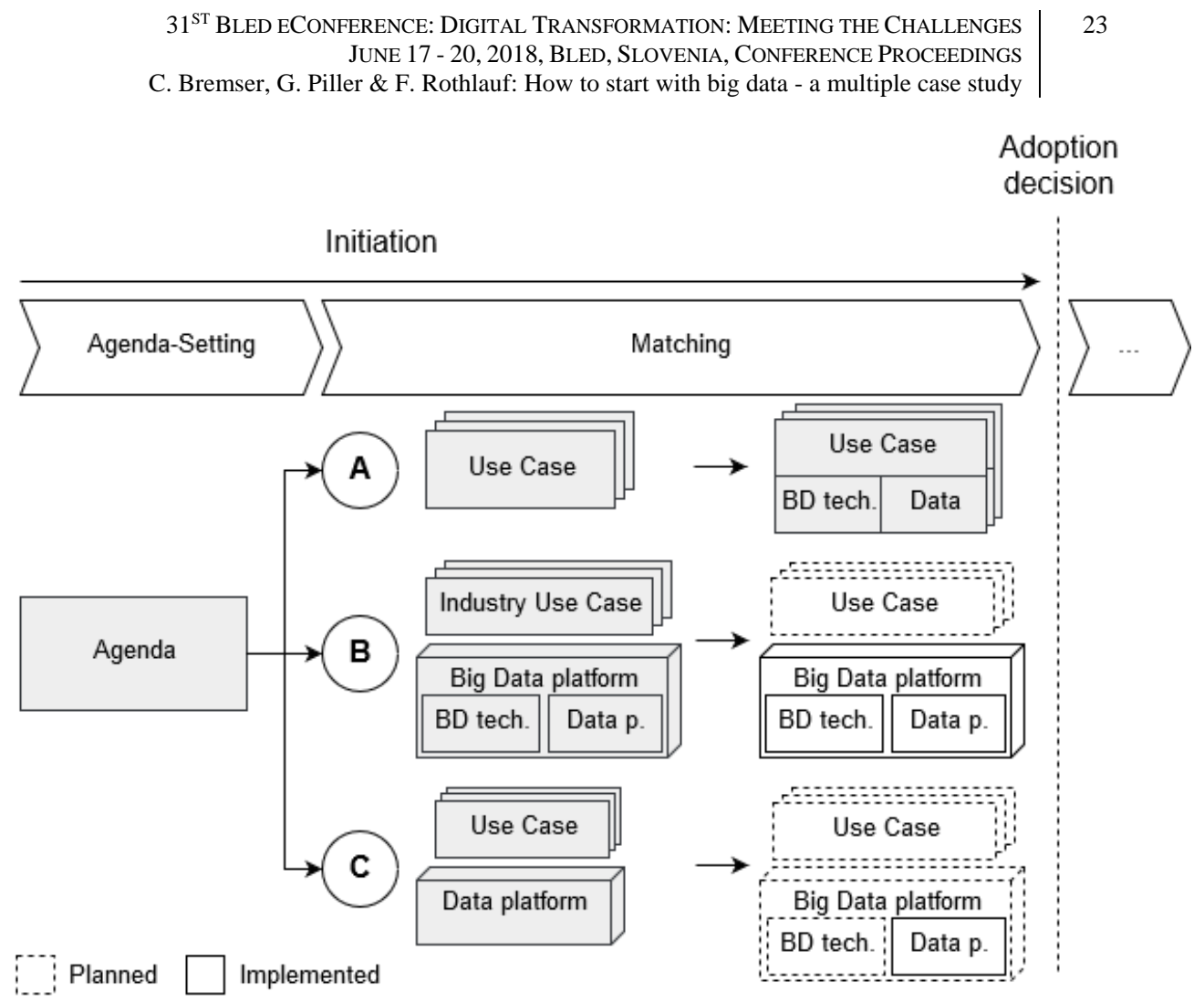

Notes: BD tech.: Big Data technology, Data p.: Data platform

Figure 2: Approaches to the analysis of big data potentials: A) Business First, B) Platform Building, C) Data Integration

The second approach (Platform Building) aims upon the development of a technology and data platform for big data. For this purpose requirements derived from industryspecific use cases are analyzed for orientation. In addition, existing business demands were used to introduce new technologies, for example in case 2: "... it is the strategy [...] to use new technologies for existing demands that we are obliged to do, in order to [...] reduce the hurdle for hardly-calculable [big data] use cases.". Companies with this approach want to keep the monetary expenses for future use cases as low as possible mostly due to financial restrictions. Therefore, e.g. in case 2, existing data management technologies are successively substituted by big data technologies (e.g. hadoop for archiving bank account movements). To keep pace with current developments - although business departments have not identified convincing big data use cases yet - is another observed motivation for platform building, e.g. in case 5: "In memory technology, [...] in the next 10 years, this will be used in all areas. Then I can already invest now, without a concrete use case in mind". The big data platform resulting from this approach forms the basis for the subsequent identification and evaluation of big data use cases. This approach can be found in case 2, 3,5 and 7 . 
The primary objective of the third approach (Data Integration) is to provide a consistent basis of data for future analyses. Consistent and integrated data are considered as a fundamental basis for all further developments in the area of big data. For instance, case 10 emphasizes: "... this is our approach [...], we want to build up an enterprise data repository, [...] step by step, to integrate and organize all data there, to build a semantic network". In the cases following this approach, the created data platform is first used for traditional analyses. If they proof successful, companies plan to deal with big data use cases and technologies. Case 4 and 10 follow this approach.

A comparison of the three approaches shows that Business First focuses on the realization of business potentials and initially neglects the integration of new technologies and data sources. This is in contrast to the approaches Platform Building and Data Integration. There, the integration of technologies and data is of primary interest and seen as a necessary step towards the successful adoption of big data. In Business First, investigations of the required efforts for implementing use cases into the productive IT landscape are postponed to a later stage. Also investigations of constraints from a technical or data management perspective are ignored here during the initiation phase. If a lack of necessary technological or methodical competences arises, organizations procure external resources to bridge these gaps, e.g. through external IT service provider or consultancies with specialist knowledge. For instance, case 9 states: "Our IT is a profit center. They do not expose employees to innovative topics; they only want to put employees into projects. But that's a problem. People are not trained and further educated [..] Therefore, I have to hire Accenture or any other consultancy, I pay the double day rate, but it can realize my use cases in half of the time."

Differences can also be found in the organizational set ups of the three approaches. In Business First, the identification of possible use cases is carried out by business departments, while the evaluation and implementation of prototypes is mainly conducted within cross-functional teams staffed with employees from business and IT. In Platform Building and Data Integration, traditional IT projects are carried out in IT departments introducing and integrating new technologies and data sources. IT-driven laboratory environments are often used to identify requirements for a future big data infrastructure. This is emphasized by a statement from case 7: "We [the data lab] do not necessarily need to solve the Autonomous Driving. We [the company] have enough engineers for that. Our goal is to provide the technical possibilities that this can work."

\section{$7 \quad$ Summary and outlook}

In this paper we have investigated how companies start exploring big data potentials and how companies proceed to an adoption decision. The theoretical framework was the adoption process of Rogers (2003), whose first stages of the agenda setting and matching phases were examined in detail based on a multiple case study. As a result, three different approaches could be identified. Companies either initially focus on business aspects, or on a systematic build-up of a big data technology and data platform. 


$$
\begin{aligned}
& 31^{\text {ST }} \text { Bled ECONFEREnCE: Digital Transformation: MeEting the Challenges } \\
& \text { June } 17 \text { - 20, 2018, Bled, Slovenia, CONFERENCE ProceEdings } \\
& \text { C. Bremser, G. Piller \& F. Rothlauf: How to start with big data - a multiple case study }
\end{aligned}
$$

The next step is to examine in detail the influence factors that are responsible for these different strategies and the advantages and disadvantages associated with them. The insights gained from current and upcoming studies will be then used to construct a method kit for the identification and evaluation of potential big data use cases, catering to the specific needs of individual enterprises.

\section{References}

Agrawal, K. P. (2015). Investigating the Determinants of Big Data Analytics ( BDA ) Adoption in Asian Emerging Economies. Academy of Management Proceedings, 2015(1), 11290. https://doi.org/10.5465/AMBPP.2015.11290abstract

Bremser, C., Piller, G., \& Rothlauf, F. (2017). Strategies and Influencing Factors for Big Data Exploration. In Proceedings of the American Conference on Information Systems. Boston, USA: AIS Electronic Library.

Brown, B., Chui, M., \& Manyika, J. (2011). Are You Ready for the Era of "Big Data"? McKinsey Quarterly, 4(1), 24-35.

Chen, H.-M., Kazman, R., \& Matthes, F. (2015). Demystifying big data adoption: Beyond IT fashion and relative advantage. In DIGIT 2015 Proceedings. Fort Worth, USA: AIS Electronic Library.

Constantiou, I. D., \& Kallinikos, J. (2015). New Games, New Rules: Big Data and the Changing Context of Strategy. Journal of Information Technology, 30(1), 44-57. https://doi.org/10.1057/jit.2014.17

Damanpour, F., \& Schneider, M. (2006). Phases of the adoption of innovation in organizations: Effects of environment, organization and top managers. British Journal of Management, 17(3), 215-236. https://doi.org/10.1111/j.1467-8551.2006.00498.x

Davenport, T. H., Barth, P., \& Bean, R. (2012). How "Big Data" is Different. MIT Sloan Management Review, 54(1), 22-24.

Dubé, L., \& Paré, G. (2003). Rigor in Information Systems Positivist Case Research: Current Practices, Trends, and Recommendations. MIS Quarterly, 27(4), 597-636. https://doi.org/10.2307/30036550

Fichman, R. G. (2000). The Diffusion and Assimilation of Information Technology Innovations. Framing the Domains of IT Management, 105-127. https://doi.org/10.1.1.24.4539

Hammer, M., \& Champy, J. (1993). Reengineering the corporation. A manifesto for business revolution. Business Horizon, 36(5), 90-91.

Kart, L. (2015). Big Data Industry Insights 2015. Retrieved March 30, 2017, from http://public.brighttalk.com/resource/core/80421/september_29_industry_insights_lkart_1184 53.pdf

Kiron, D., Prentice, P. K., \& Ferguson, R. B. (2014). The Analytics Mandate. MIT Sloan Management Review, 55(4), 1.

Kune, R., Konugurthi, P. K., Agarwal, A., Chillarige, R. R., \& Buyya, R. (2016). The Anatomy of Big Data Computing. Software - Practice and Experience, 46(1), 79-105. https://doi.org/10.1002/spe.2374

Malaka, I., \& Brown, I. (2015). Challenges to the Organisational Adoption of Big Data Analytics : A Case Study in the South African Teleco. Industry. In Proceedings of the South African Institute of Computer Scientists and Information Technologists Conference (p. 27). Stellenbosch, South Africa: ACM Digital Library.

Miles, M. B., Huberman, A. M., \& Saldana, J. (2013). Qualitative Data Analysis: A Methods Sourcebook (3rd ed.). Los Angeles: SAGE Publications.

Nam, D. W., Kang, D., \& Kim, S. H. (2015). Process of Big Data Analysis Adoption: Defining Big 
Data as a New IS Innovation and Examining Factors Affecting the Process. In Proceedings of the Hawaii International Conference on System Sciences (pp. 4792-4801). Kauai, HI, USA: IEEE.

Rogers, E. M. (2003). Diffusion of Innovations (5th ed.). New York: Free Press.

Sivarajah, U., Kamal, M. M., Irani, Z., \& Weerakkody, V. (2017). Critical Analysis of Big Data Challenges and Analytical Methods. Journal of Business Research, 70, 263-286. https://doi.org/10.1016/j.jbusres.2016.08.001

Sun, S., Cegielski, C. G., Jia, L., \& Hall, D. J. (2016). Understanding the Factors Affecting the Organizational Adoption of Big Data. Journal of Computer Information Systems, 1-11. https://doi.org/10.1080/08874417.2016.1222891

TechAmerica Foundation. (2012). Demystifying Big Data: A Practical Guide to Transforming the Business of Government. Retrieved March 30, 2017, from https://bigdatawg.nist.gov/_uploadfiles/M0068_v1_3903747095.pdf

Tornatzky, L. G., Fleischer, M. \& Chakrabarti, A. K. (1990). Technological Innovation as a Process. In Processes of Technological Innovation. Lexington: Lexington Books.

Wang, P. (2010). Chasing The Hottest IT: Effects of Information Technology Fashion on Organizations. MIS Quarterly, 34(1), 63-85.

Yin, R. K. (2003). Case Study Research: Design and Methods. Case Study Research: Design and Methods (3rd ed.). New York: SAGE Publications. 


\title{
Citizen adoption of e-government services - Evidence from Hungary
}

\section{MARTA ARANYOSSY}

\begin{abstract}
In a citizen centric approach - which became increasingly popular in the last decade - e-government success begins with citizens starting to use e-government systems, solutions, services. In line with this our paper investigates the factors - presented by the technology acceptance literature - influencing e-government service usage, on a large representative Hungarian sample concerning a wide range of $\mathrm{B} 2 \mathrm{C}$ public administration services. Our results imply that the Hungarian government can further increase the usage of e-government services by influencing effort expectancy, trust of internet, facilitating conditions, user experience or habits.
\end{abstract}

Keywords: • e-government • technology adoption • UTAUT • egovernment adoption •

CORRESPOndence AdDREss: Marta Aranyossy, Ph.D., Assistant Professor, Corvinus University of Budapest, Corvinus Business School, Budapest, Fővám tér 8., Hungary, marta.aranyossy@unicorvinus.hu 
Some current streams of e-government research focus on customer centric service development and performance assessment (see Scott et al. 2009; Alomari 2012; Barbosa 2013; Nica 2015; Carter et al., 2016). This perspective acknowledges the key role of citizens as end users of e-government services (Clarke-Pucihar 2013). One of the main questions of citizen centric e-government research - and also e-government research in general - is: why do or do not citizens use e-government services, what motivates technology acceptance on the field (Bannister - Connolly, 2012; Rana et al., 2013). In order to develop citizen-centred electronic services that create value for citizens and society alike, government agencies must explore and understand the factors that drive adoption and usage of these digital innovations first (Carter-Belanger 2005).

The theories of technology acceptance are relatively often used in e-government literature: amongst the most cited 15 e-government articles 5 used TAM (Technology Acceptance Model) or DOI (Diffusion of Innovation) (Belanger-Carter 2012, 371). Rana et al. (2013) identified 54 articles using TAM, 20 using DOI and 13 based on UTAUT (United Theory of Acceptance and Use of Technology) in the e-government literature. So technology adoption by individuals has been the subject of several studies, as we will show in a literature review in the next section. Although this field is not underresearched most of the studies fall into the following categories:

- analysing technology adoption of e-government services under hypothetical circumstances (e.g. Alomari et a. 2014; Nemeslaki et al. 2016 );

- analysing only intent to use not actual usage of an e-government service (e.g. Carter - Belanger 2005, Lin et al. 2011);

- analysing actual usage of only one system or service (e.g. Hung et al. 2006, AlAwadhi - Morris 2008).

In this paper we aim to present a more comprehensive research on e-government adoption: we explore adoption factors of 12 different Hungarian e-government services, focusing on actual usage, using a large and representative sample. These 12 service areas represent the whole palette of currently available e-government services in Hungary. Also, our research is broad from a theoretical point of view: we examined many of the possible factors of technology acceptance suggested by the literature, this way presenting results independent of the different models. We believe that this rich evidence will give researchers and practitioners a more detailed view of factors driving citizen adoption of e-government services. 
In the end, the success of e-government initiatives depends significantly on whether users - public employees or citizens - are willing to accept and use the innovation, the new tool, system or service. One of the most utilised models for the exploration of information technology innovation acceptance is the TAM (Technology Acceptance Model - see Davis 1989; Venkatesh-Davis 2000). The essence of the model is rather simple: attitudes regarding use, intention to use, and actual use are defined by two variables: perceived usefulness of the system and its perceived ease of use. In the IT literature, more than 100 empirical studies tested these simple relationships of the TAM model. The effect of perceived usefulness was supported in $74 \%$ of these studies, while ease of use often proved to be a necessary, but not sufficient condition (Lee et al. 2003).

Regarding e-government innovation adoption, a considerable number of empirical research papers utilised the TAM model, or its expanded versions. Carter and Belanger (2005) also performed their research using a modified version of TAM, finding that regarding e-government services, three primary factors define citizens' intention to use: perceived ease of use, compatibility (congruency with and similarity to citizens' normal way of communication or transactions) and reliability (whether users judge the service to be reliable and safe, and trust it). Many also used the TAM model regarding the acceptance of other e-government innovation, for example, e-voting technology (Schaupp - Carter 2005; Chiang 2009; Choi - Kim 2012, Nemeslaki et al. 2016), and found its explanatory power to be strong.

The original TAM model was extended by many, and the UTAUT model (United Theory of Acceptance and Use of Technology, Venkatesh et al. 2003; see Figure 1) attempted to unify these improvements into a single model. In the last decade, the use of the UTAUT model gained acceptance in the e-government literature as well (e.g. Gupta et al. 2008; Powel et al. 2012). Here, along with the original two TAM variables, the moderating effects of social environmental influence, other workplace driving factors, and individual characteristics (users' age, gender, experience, and voluntary nature of use) are also present in the model's context. Hung et al. (2006) used an expanded TAM and UTAUT model to research factors influencing willingness to use a Taiwanese online tax system, and found the following significant factors that effected attitudes regarding use: perceived usefulness, perceived ease of use, perceived risk, trust, compatibility, as well as external influence, interpersonal influence, self-efficacy (one's mental image of one's own efficiency) and facilitating conditions. Along with external factors, factors such as media influence should be mentioned, while interpersonal influence may take the form of colleagues and friends' positive opinions on e-government services, and their encouragement to use it. Finally, the easy accessibility and availability of the necessary devices, hardware, and software is a must among the facilitating conditions. 


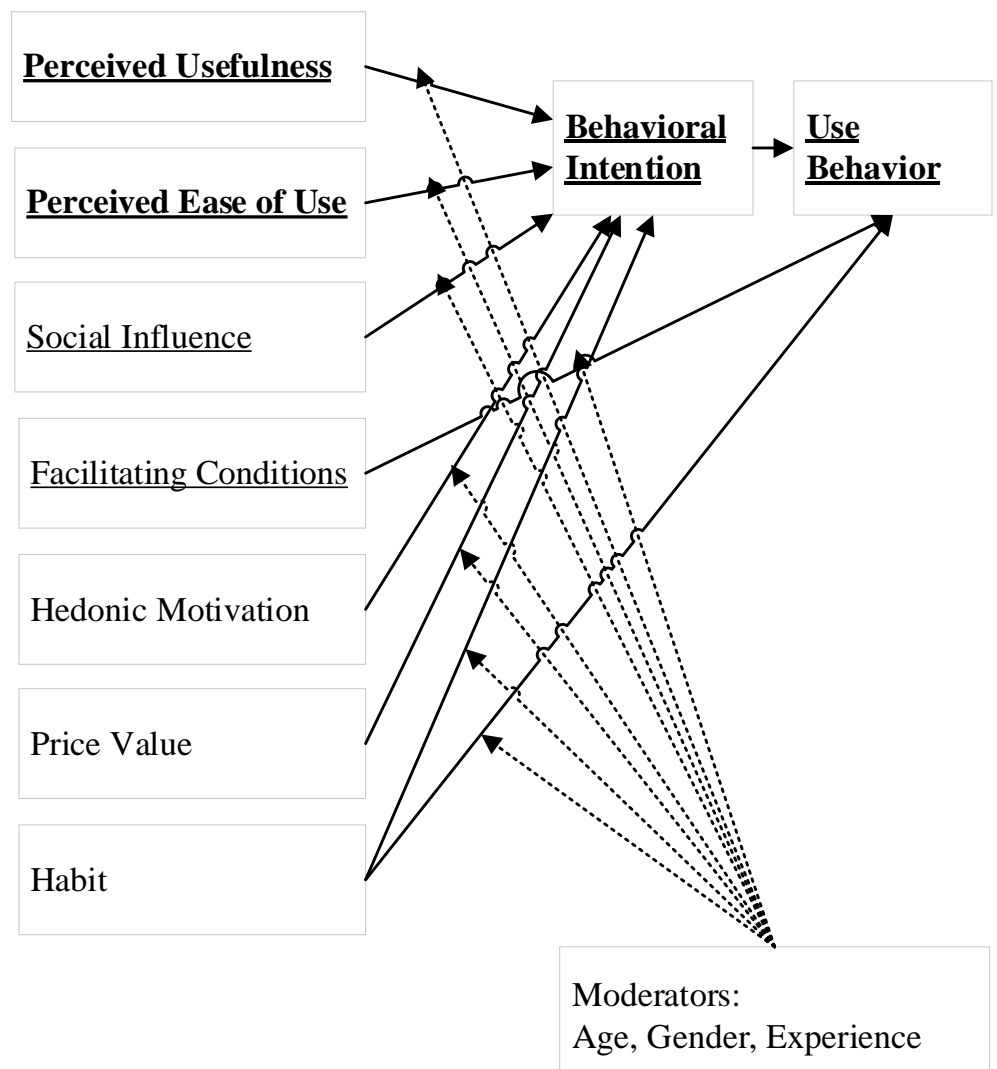

Figure 1: The TAM (elements in bold; Davis 1989) and the expanded UTAUT model (elements underlined, Venkatesh et al. 2003) and UTAUT 2 (the entire figure; Venkatesh et al. 2012)

While UTAUT is a popular model, Venkatesh et al. (2012) proposed a further extended version, UTAUT2. With three new constructs - hedonic motivation, price value, and habit - the predictive power of their model increased significantly.

Diffusion of Innovation (DOI, Rogers 2003) is also a widely used model in IT adoption research, but e-government researchers claim that its core constructs are similar to and substitutable by TAM factors: relative advantage with perceived usefulness and complexity with perceived ease of use (Carter - Bélanger 2005; Colesca - Dobrica 2008). Rana et al. (2013) compared the explanatory power of the five most used IT adoption models in a meta-analysis based on 87 studies of citizen centric e-government services. Based on their results, all of the basic relationships of TAM could be confirmed. This was the most widely used model in research focused on e-government adoption, and this also seemed the most appropriate one for studies that focus on citizens. Although DOI was the second most common research framework, only a small number of its relationships were validated, and empirical research only concentrated on three of its explanatory variables 
(compatibility, complexity, relative benefits). The most important of the new variables of the UTAUT model is the social effect, while the effect of facilitating conditions was under-researched. This meta-analysis also highlighted that factors - that all central models lack - such as trust, safety, privacy, and risk - appear rather often in empirical studies on e-government adoption and seem to have significant effects.

Naturally, along with using the theories of the scientific mainstream, independent egovernment acceptance theories have also been constructed. Ziemba and co-authors (2013, 2015), for example, examine factors of a successful e-government in one such model. In their model of e-government adoption at the local and state levels, they attempt to explain the three factors of e-government adoption (ICT availability, ICT competence and awareness, ICT use) with economic, socio-cultural, technological, and organisational factors. In Table 1 we summarise a number of further e-government technology adoption models, to demonstrate the diversity of theoretical approaches. 
Table 1: Special e-government technology adoption models (partially based on Panda - Sahu 2013)

\begin{tabular}{|l|l|l|}
\hline Authors & Model focus & Studied factors \\
\hline $\begin{array}{l}\text { TAS - GENIS- } \\
\text { GRUBER }\end{array}$ & $\begin{array}{l}\text { Cultural Factors Affect on } \\
\text { Adoption, partially based on } \\
\text { Hofstede (with a focus on e- } \\
\text { procurement) }\end{array}$ & $\begin{array}{l}\text { Power Distance Index; } \\
\text { Individualism Index; } \\
\text { Uncertainty Avoidance Index; } \\
\text { Trust; } \\
\text { Technology Acceptance Ratio }\end{array}$ \\
\hline $\begin{array}{l}\text { GUHA } \\
\text { CHAKRABARTI } \\
(2014)\end{array}$ & $\begin{array}{l}\text { Analysis of adoption factors } \\
\text { from a network theory viewpoint }\end{array}$ & $\begin{array}{l}\text { Partner selection } \\
\text { Network goal } \\
\text { Institutionalisation } \\
\text { Network structuring } \\
\text { Incentive design }\end{array}$ \\
\hline TEICH (2010) & $\begin{array}{l}\text { Technology adoption based on } \\
\text { the DOI and TOE (Technology, } \\
\text { Organization, } \\
\text { Environment) models and } \\
\text { motivation theories (with a focus } \\
\text { on e-procurement) }\end{array}$ & $\begin{array}{l}\text { Technological factors: perceived benefits, } \\
\text { relative benefits, compatibility, complexity; } \\
\text { Organisational factors: } \\
\text { competence, technical skills, financial skills, } \\
\text { cultural and organisational skills; } \\
\text { Partner factors: partner competence, strength, } \\
\text { other partner factors } \\
\text { Network factors: network size, internal } \\
\text { relationships, technology infrastructure, other } \\
\text { network factors }\end{array}$ \\
& &
\end{tabular}

The model of Ziemba et al. (2015) is one of the few e-government adoption researches in Central and Eastern European context. While the usage of TAM is not without exception in Hungarian technology adoption research as well (e.g. Keszey - Zsukk 2017), Hungarian e-government adoption research is still rare (e.g. Nemeslaki et al. 2016; Molnár et al., 2017).

\section{$3 \quad$ Research model and methodology}

The empirical basis of or research was the Good State Public Administration Opinion Survey (henceforward referred to as Survey; Kaiser 2017) carried out in Hungary 2017. The data collection was planned, tested and carried out by Szociometrum Social Science Research. The survey questions were tested on a representative sample for the adult (age $18+)$ Hungarian population. The sampling method was multistage, proportionally stratified probability sampling, while the database was also corrected ex post with matrix weighting procedure concerning age, gender, region, settlement type and education. (See descriptive statistics in Table 2.) 
Table 2: Descriptive statistics of the Good State Public Administration Opinion Survey sample

\begin{tabular}{|lll|lll}
\hline Gender & Frequency & Percent & Age & \\
Female & 1352 & $54 \%$ & Mean & & 46.51 \\
Male & 1154 & $46 \%$ & Median & & 45 \\
\cline { 1 - 2 } Total & 2506 & $100 \%$ & Range & & $19-89$ \\
\cline { 1 - 2 } Education & Frequency & Percent & St. Dev & & 16.334 \\
Maximum primary & 796 & $32 \%$ & Type of settlement & Frequency & Percent \\
school & & & & & \\
Secondary school & 1211 & $48 \%$ & Capital (Budapest) & 460 & $18 \%$ \\
Bachelor degree & 399 & $16 \%$ & County centres & 539 & $22 \%$ \\
Master degree & 99 & $4 \%$ & Town & 635 & $25 \%$ \\
Postgradual degree & 2 & $0 \%$ & Village & 872 & $35 \%$ \\
\cline { 1 - 1 } Total & 2506 & $100 \%$ & Total & 2506 & $100 \%$ \\
\hline
\end{tabular}

The Survey contained 70 questions, some with many sub-questions, of which we are only using some (see Appendix 1) to explore the influencing factors of e-government service usage. The Survey provided the opportunity to use a large $(n=2506)$ representative database, with data about citizens' usage and experience of 12 different areas of egovernment services (see list in Table 3 ) and the citizens general background as well.

For these 12 administrative areas citizens were asked whether they had to use these public services in the past 3 years, if yes, whether they did that themselves, and finally if yes, in what way did they gather information (in person, via phone, via e-mail, via website) or handled the necessary transaction (in person, via phone, online or via app, via post). This data gave us the opportunity to compare citizens using online and traditional channels in the information or the transaction phase of public administration on different fields. 
Table 3: List of government service areas and frequency of online usage (11. Administration of construction affairs was omitted from further analysis due to the low subsample size)

\begin{tabular}{|l|r|c|c|}
\hline \multicolumn{1}{|c|}{ Government service areas } & N & \multicolumn{2}{c|}{ Frequency } \\
\hline 1. Income tax administration & & $\begin{array}{c}\text { Information } \\
\text { online }\end{array}$ & $\begin{array}{c}\text { Transaction } \\
\text { online }\end{array}$ \\
\hline 2. Tax administration at municipalities & 399 & $71(19 \%)$ & $101(27 \%)$ \\
\hline $\begin{array}{l}\text { 3. Other tax administration at the national tax and } \\
\text { customs administration agency }\end{array}$ & 238 & $18(8 \%)$ & $17(7 \%)$ \\
\hline 4. Administration of government issued documents & 129 & $25(21 \%)$ & $22(18 \%)$ \\
\hline 5. Family support administration & 1041 & $150(16 \%)$ & $59(6 \%)$ \\
\hline 6. Health insurance administration & 222 & $25(12 \%)$ & $15(7 \%)$ \\
\hline 7. Unemployment administration & 126 & $19(16 \%)$ & $13(11 \%)$ \\
\hline 8. Social benefits administration & 159 & $8(5 \%)$ & $6(4 \%)$ \\
\hline 9. Pension insurance administration & 239 & $13(6 \%)$ & $5(2 \%)$ \\
\hline 10. Land registry administration & 97 & $11(12 \%)$ & $7(7 \%)$ \\
\hline 11. Administration of construction affairs & 147 & $19(14 \%)$ & $13(9 \%)$ \\
\hline 12. Motor vehicle administration & 41 & $7(18 \%)$ & $9(25 \%)$ \\
\hline & 395 & $73(20 \%)$ & $44(11 \%)$ \\
\hline
\end{tabular}

To test the different factors of e-government adoption we used as many variables from the literature (summarized in the previous section) for which we had the corresponding relevant data in the Survey. This gave us the opportunity to test the effect of the following factors:

- Effort expectancy (Perceived ease of use)

- Trust of internet

- Trust of government

- Facilitating conditions

- Experience

- Habit

- Age

- Gender

The basis of this factor selection was Venkatesh et al. (2012). We analysed most of the factors and moderators included in UTAUT2 (presented in Figure 1). Notice that we did not use one of the key variables of TAM, perceived usefulness, as the survey question concerning this was too distant and biased. We also did not include price value and hedonic motivation, as by definition these concepts are less relevant in e-government settings and also did not have a real history in e-government adoption research. 
Our list of factors under examination is also similar to e-government adoption research carried out by Carter - Belanger (2005) in two respects: we tested many potential factors from different theoretic models, and we included the factor of trust. Trust related concepts are amongst the most common extensions of TAM in e-government research and their significance is shown in many studies (e.g. Schaupp - Carter 2005, Powell et al. 2012). Just like these previous studies we included both trust in the internet and trust in the government in our research.

For measurement of the factors we used direct survey variables in case of age and gender, and factor analysis in case of the other six. The original questions, their measurement, factor component matrices and KMO statistics can be found in Appendix 1. Although answers to the key construct questions were measured on a Likert scale, if a Likert scale is equidistant it behaves more like an interval-level measurement and therefore, can be viewed as an interval scale and used for factor analysis (see Carifio - Perla 2007).

The operationalization methods of the Good State data collection did not allow us to build regression or structural equation model - common in the TAM literature - for the analysis. So to test the relationships between the potential influential factors and actual usage we used traditional association metrics and statistical tests to identify significant differences between online and offline e-government service users. Being aware of the limits of the measurement scales used in the data collection not only ANOVA-based mean tests, but also nonparametric Mann Whitney $U$ test and median tests where employed to identify significant differences of distributions and medians. The limitations of the database is also the reason behind our decision that age, gender and experience were also be tested as potential influential factors and not as modifiers.

Although the database served as a source of many limitations, but it was also advantageous from another point of view: it allowed us not only to test adoption factors of actual usage, but we could distinguish between informational and transaction level of e-government usage as well. In summary, the guiding research question of our study was: Which factors - presented in the technology acceptance literature - are associated with informational or transactional e-government service use in comparison to traditional forms of public service use concerning a wide range of $B 2 C$ public administration services in Hungary? The research model is represented in Figure 2.

4

Results

A summary of our results is presented in Table 4 and Figure 2. We indicated all the connections, where we found statistically significant differences between mean or median values of online and offline users of administrative government services.

The sample for construction affairs administration (11.) was too low to carry out in depth statistical analysis or find significant results - so in the further discussion we focus on the other eleven service areas. 
Table 4: Results by government service areas where factor values for online users are significantly higher than factor values for offline users

$(*: p<0.05, * *: p<0.01$, bold: difference in factor is larger than $25 \%$ of the range of its value)

\begin{tabular}{|c|c|c|}
\hline \multirow[t]{2}{*}{ Government service areas } & \multicolumn{2}{|c|}{ Adoption factors found significant } \\
\hline & Information online & Transaction online \\
\hline 1. Income tax administration & $\begin{array}{c}\text { Effort expectancy*, Trust of } \\
\text { internet**, Facilitating } \\
\text { conditions } * * \text {, Experience } \\
\text { Habit } \\
\text { Ha* }\end{array}$ & $\begin{array}{c}\text { Effort expectancy**, Trust of } \\
\text { internet**, Trust of } \\
\text { government*, Facilitating } \\
\text { conditions**, Experience }{ }^{* *}, \\
\text { Habit** }\end{array}$ \\
\hline 2. Tax administration at municipalities & Facilitating conditions**, Habit* & $\begin{array}{c}\text { Trust of internet } * * \text {, Facilitating } \\
\text { conditions**, Habit** }\end{array}$ \\
\hline $\begin{array}{l}\text { 3. Other tax administration at the national tax and } \\
\text { customs administration agency }\end{array}$ & $\begin{array}{l}\text { Effort expectancy*, Trust of } \\
\text { government } * *, \text { Facilitating } \\
\text { conditions**, Habit** }\end{array}$ & $\begin{array}{l}\text { Effort expectancy**, } \\
\text { Experience*, Habit** }\end{array}$ \\
\hline 4. Administration of government issued documents & $\begin{array}{c}\text { Effort expectancy*, Trust of } \\
\text { internet**, Trust of } \\
\text { government**, Facilitating } \\
\text { conditions }{ }^{* *} \text {, Experience }{ }^{* *}, \\
\text { Habit**, Age* }\end{array}$ & $\begin{array}{c}\text { Effort expectancy**, Trust of } \\
\text { internet**, Facilitating } \\
\text { conditions**, Experience**, } \\
\text { Habit** }\end{array}$ \\
\hline 5. Family support administration & $\begin{array}{l}\text { Trust of internet**, Facilitating } \\
\text { conditions**, Habit**, }\end{array}$ & $\begin{array}{c}\text { Trust of internet**, Facilitating } \\
\text { conditions } * * \text {, Experience**, } \\
\text { Habit } * *\end{array}$ \\
\hline 6. Health insurance administration & $\begin{array}{c}\text { Trust of internet } * * \text {, Facilitating } \\
\text { conditions**, Experience**, } \\
\text { Habit* }\end{array}$ & $\begin{array}{c}\text { Trust of internet*, Facilitating } \\
\text { conditions*, Experience*, } \\
\text { Habit** }\end{array}$ \\
\hline 7. Unemployment administration & Trust of internet ${ }^{* *}$, Habit* & Experience* $^{*}$, Habit** \\
\hline 8. Social benefits administration & $\begin{array}{c}\text { Trust of internet } * * \text {, Facilitating } \\
\text { conditions**, Habit } * *\end{array}$ & $\begin{array}{l}\text { Facilitating conditions } * * \\
\text { Experience }^{* *}, \text { Habit }^{* *}\end{array}$ \\
\hline 9. Pension insurance administration & $\begin{array}{c}\text { Trust of internet**, Facilitating } \\
\text { conditions**, Experience**, } \\
\text { Habit*, Gender* }\end{array}$ & $\begin{array}{c}\text { Trust of internet*, Trust of } \\
\text { government } * \text {, Facilitating } \\
\text { conditions**, Experience*, } \\
\text { Habit } * *\end{array}$ \\
\hline 10. Land registry administration & $\begin{array}{c}\text { Trust of internet*, Facilitating } \\
\text { conditions**, Experience*, } \\
\text { Habit*** }\end{array}$ & $\begin{array}{l}\text { Facilitating conditions**, } \\
\text { Habit* }\end{array}$ \\
\hline 11. Administration of construction affairs & - & - \\
\hline 12. Motor vehicle administration & $\begin{array}{c}\text { Effort expectancy*, Trust of } \\
\text { internet }^{* *} \text {, Experience**, } \\
\text { Habit* }\end{array}$ & $\begin{array}{l}\text { Effort expectancy*, Trust of } \\
\text { internet**, Facilitating } \\
\text { conditions**, Experience**, } \\
\text { Habit** }\end{array}$ \\
\hline
\end{tabular}



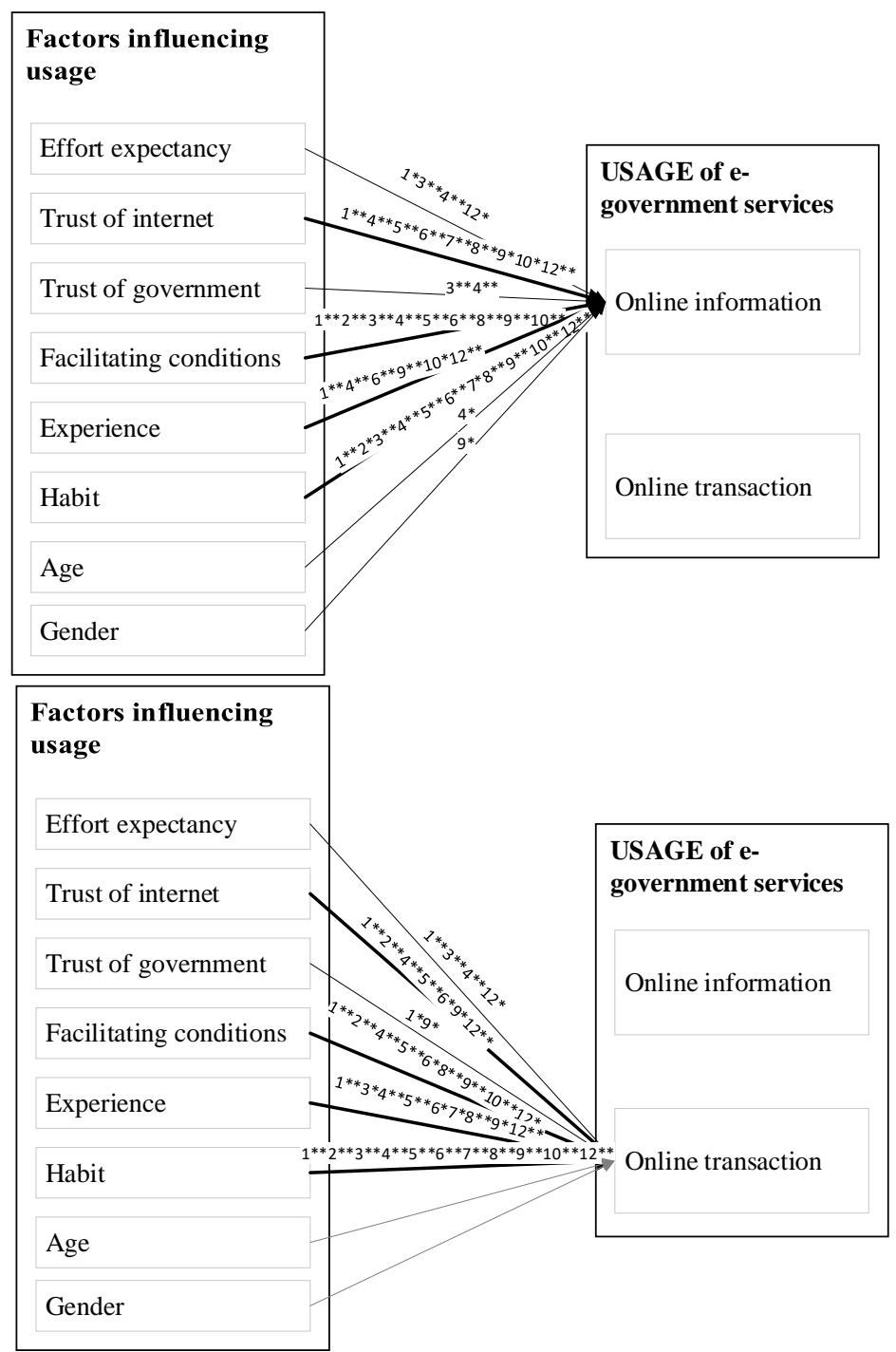

Figure 2: Model Results

(the identification number of the government service area - see numbered list in Table 3 is indicated above the arrows where factor values for online users are significantly higher than factor values for offline users, $*$ : $p<0.05, * *: p<0.01$ )

We see that the most common relationships related to informational e-government usage are with habit, facilitating conditions and internet trust: the level of these factors was significantly higher for online users than for offline ones in at least nine of the eleven observed service areas. These factors are similarly important in case of e-government transactions as well, although here the level of experience is also significantly higher for online users. On the other hand, trust in the government, age or gender does not seem to 
differentiate between citizens using e-government services and citizens that are choosing offline administrative options (only in some rare, specific service areas).

5

Discussion

Concerning the original factors of TAM our results seem to be less decisive. The effect of performance expectancy was not measurable based on our database and effort expectancy seems to be an important determinant in only four out of the eleven Hungarian e-government service areas. These areas are: income and other tax administration, government issued document and motor vehicle administration - most of these being the larger subsamples and still showing significant relationships only at $p<0.05$ levels. So effort expectancy seems not to be the main factor behind Hungarian citizens' decision of using online or offline e-government platforms. One of the reasons behind this result could be that we tested effects on actual e-government usage only, and not on behavioural intention - while according to the original TAM, effort expectancy has a direct effect on intent to use and not on actual usage.

If we look at the extended UTAUT2 factors we see more significant results. Habit seems to be the most important differentiator between offline and online usage in all egovernment service areas. The relationship with habit is significant in all 22 cases (all 11 analysed service areas, regarding both online information and transaction), and in 17 instances the level of habit for online users is more than $25 \%$ higher than others (as a percentage of the range of this variable). We conceptualized habit as prior behaviour (Kim - Malhotra 2005), so our results suggest that prior general administrative behaviour and platform choices influence electronic government adoption of Hungarian citizens the most. Habit has been one of the two factors in UTAUT2 with assumed direct effect on actual usage - this direct effect has been found significant originally by Venkatesh et al (2012) and in case of e-government usage here as well.

The other factor of UTAUT2 (and UTAUT) with hypothesised direct effect on usage is the factor of facilitating conditions. Facilitating conditions - measured by the accessibility of devices and internet connection - was the second most important factor in our study of Hungarian e-government adoption as well: found significant in 18 out of 22 cases. According to a study of the Hungarian Central Statistical Office (2015) $76 \%$ of adult Hungarian citizens are using computers and the internet - only 1-2\% less than the European average (although some differences between rural areas might still exist; Csótó - Herdon, 2008). This means that the significant effect of facilitating conditions for some citizens is not caused by a nationwide lagging of ICT penetration. The generally high level of connectivity might also be a reason why there is a significant but never above $25 \%$ difference in the value of the facilitating conditions factor when comparing online and offline government service users.

We mentioned that internet and government trust are frequent extensions of the TAM/UTAUT in e-government literature. The phenomenon that only internet trust has a significant effect on e-government adoption is also not uncommon. Trust in the government seemed not to be a significant influencer of adoption in international studies 
(e.g. Powell et al. 2012) or in other Hungarian studies (NEMESLAKI et al. 2016) - and that is what we see in our case as well. Examining a broad spectrum of e-government areas we found a statistically significant relationship between citizens' trust in the government and e-government adoption only in four cases. Interestingly enough three of these cases are tax and pension related transactions, which have serious financial components - these seem to be the cases where higher level of government trust leads to more online transactions.

Conversely, trust in the internet seems to have a significant effect in a wide range of Hungarian e-government areas (in 16 analysed cases). In 8 instances the trust level of online government service users is above $25 \%$ higher than the offline ones. This is not entirely surprising in Hungarian context, as the low level of internet trust among Hungarians was one of the factors why Hungary lagged behind in terms of e-commerce and especially e-payment market developments (e.g. Aranyossy - Juhász 2013; FehérVarga 2017). Concerning Hungarians' e-voting attitude Nemeslaki et al. (2016) found that internet trust is the second most important factor, and the statistical data collection of HCSO (2015) also stated that $11 \%$ of Hungarian citizens are not using e-government transactions because they do not trust the systems enough to give their personal data. Our results also confirm this important role of trust in the internet in Hungarian e-government adoption.

Although we handled the variables of age, gender and experience differently than the original UTAUT2 by analysing them as factors and not moderators, our results here are also noteworthy. While based on our analysis the age and gender of the citizens are not differentiating factors in terms of administrative channel choice (offline vs. online) experience is. Citizens choosing six of the informational and nine of the transactional egovernment services have significantly higher level of experience in other, nongovernmental online transactions than offline citizens. This also suggests, that experience is more important when citizens have to choose a transactional channel, and less for collecting information online - so to administer online people rely more on prior experiences of e-transactions.

\section{Conclusions, limitations and implications for theory and practice}

In this paper we tested six factors of the UTAUT2 model extended with trust to analyse e-government adoption on a large Hungarian sample. One of the novelties of our research was that we examined factors of actual e-government usage and not only the behavioural intent. Also the robustness of our findings is increased by the fact that not only one but eleven, a near total spectrum of Hungarian G2C administration service areas were examined. We found that the key factors differentiating e-government users are habit, trust in the internet and facilitating conditions, while in case of online transactions prior e-commerce experience is also important.

Practitioners might also be interested in some of the detailed results of analysis on the level of the eleven individual government service areas. The service with the highest proportion of online users ( $27 \%$ vs. the average $9,6 \%$ ) was income tax administration. 
This is not surprising knowing that the Hungarian tax authority informs about the possibilities of the online income tax administration option every citizen yearly, strongly arguing for the usage of the online platform. Also, at the beginning of 2017 a new income tax administration service was launched making the tax declaration process faster and easier and the usage of the platform more user friendly. While the Hungarian online income tax administration platform seems to be a success it is still true that all of the examined factors except for age and gender show a significant effect on adoption (see Appendix 2), so there are still possibilities to increase the number of online users by influencing citizens' internet trust or facilitating conditions for example.

On the other hand, the most frequently used administrative service seems to be the administration of government issued documents: more than $41 \%$ of the citizens had to deal with this process. While many people search for information online regarding this process only $6 \%$ of them chose online transactional options. This gives the government an opportunity to have a significant impact on e-government penetration based - partly on our results as well: by influencing effort expectancy, trust of internet, facilitating conditions, experience or even habit if possible.

Methodological limitations of our study could also guide future research. A more modelspecific data collection method - including direct questions regarding performance expectancy and more detailed Likert-scales to measure - would have supported more complex analysis, potentially even with PLS method. On the other hand our data and analysis could be used to draw more in depth conclusions regarding the individual egovernment areas - the length of this paper did not allow the publication of these details.

\section{Acknowledgments}

This paper has been written with the support and within the framework of: KÖFOP 2.1.2 - VEKOP - 15-2016-00001 Public Service Development for Establishing Good Governance: Digital Governance and Digital Government Research Program.

\section{References}

AlAwadhi, S. \& Morris, A. (2008): The Use of the UTAUT Model in the Adoption of Egovernment Services in Kuwait. Proceedings of the 41st Hawaii International Conference on System Sciences. 1530-1605/08 IEEE https://doi.org/10.1109/HICSS.2008.452

Alomari, M. K., Sandhu, K., \& Woods, P. (2014): Exploring citizen perceptions of barriers to egovernment adoption in a developing country. Transforming Government: People, Process and Policy, 8(1), 131-150. https://doi.org/10.1108/TG-05-2013-0013

Aranyossy, M., \& Juhász, P. (2013): Értékteremtés e-kereskedelemmel-kitörési lehetőség a recesszió sújtotta magyar kiskereskedelemben?/Value creation of e-commerce-Chance to break out for the recession-hit Hungarian retail sector?. Vezetéstudomány/Budapest Management Review, 44(11), 16-33.

Azadegan, A. - Teich, J. (2010): Effective Benchmarking of Innovation Adoptions: A Theoretical Framework for e-Procurement Technologies. Benchmarking: An International Journal, 17(4), 472-490. https://doi.org/10.1108/14635771011060558 
Barbosa, A. F., Pozzebon, M., \& Diniz, E. H. (2013): Rethinking E-Government Performance Assessment From A Citizen Perspective. Public Administration, 91(3), 744-762. https://doi.org/10.1111/j.1467-9299.2012.02095.x

Bannister, F., \& Connolly, R. (2012): Forward to the past: Lessons for the future of e-government from the story so far. Information Polity, 17(3, 4), 211-226.

Bélanger, F. - Carter, L. (2012): Digitizing government interactions with constituents: an historical review of e-government research in information systems. Journal of the Association for information Systems, 13(5), 363. https://doi.org/10.17705/1jais.00295

Carifio, J., \& Perla, R. (2007): Ten common misunderstandings, misconceptions, persistent myths and urban legends about Likert scales and Likert response formats and their antidotes. Journal of Social Sciences, 3(3), 106-116. https://doi.org/10.3844/jssp.2007.106.116

Carter, L. - Bélanger, F. (2005): The utilization of e-government services: citizen trust, innovation and acceptance factors. Information Systems Journal, 15(1), 5-25. https://doi.org/10.1111/j.1365-2575.2005.00183.x

Carter, L., Weerakkody, V., Phillips, B., \& Dwivedi, Y. K. (2016): Citizen adoption of egovernment Services: Exploring citizen perceptions of online services in the United States and United Kingdom. Information Systems Management, 33(2), 124-140. https://doi.org/10.1080/10580530.2016.1155948

Chiang, L. (2009): Trust and security in the e-voting system. Electronic Government, an International Journal, 6(4), 343-360. https://doi.org/10.1504/EG.2009.027782

Choi, S. O. - Kim, B. C. (2012): Voter intention to use e-voting technologies: security, technology acceptance, election type, and political ideology. Journal of Information Technology and Politics, 9(4), 433-452. https://doi.org/10.1080/19331681.2012.710042

Clarke, R., \& Pucihar, A. (2013): Electronic interaction research 1988-2012 through the lens of the Bled eConference. Electronic Markets, 23(4), 271-283. https://doi.org/10.1007/s12525-0130144-4

Colesca, S. E., \& Dobrica, L. (2008): Adoption and use of e-government services: The case of Romania. Journal of applied research and technology, 6(3), 204-217.

Csótó, M., \& Herdon, M. (2008). Information technology in rural Hungary: plans and reality. in: Rural Futures: Dreams, Dilemmas, Dangers. University of Plymouth, UK

Davis, F. D. (1989): Perceived usefulness, perceived ease of use, and user acceptance of information technology. MIS Ouarterly, 13(3), 319-339. https://doi.org/10.2307/249008

DeLone, W. H., \& McLean, E. R. (1992): Information systems success: The quest for the dependent variable. Information systems research, 3(1), 60-95. https://doi.org/10.1287/isre.3.1.60

Fehér, P. \& Varga, K. (2017): Using Design Thinking to Identify Banking Digitization Opportunities-Snapshot of the Hungarian Banking System. BLED 2017 Proceedings. 39. http://aisel.aisnet.org/bled2017/39 (24.01.2018)

Guha, J. - Chakrabarti, B. (2014): Making e-government work: Adopting the network approach. Government Information Quarterly, 31(2), 327-336. https://doi.org/10.1016/j.giq.2013.11.008

Gupta, B. - Dasgupta, S. - Gupta, A. (2008): Adoption of ICT in a government organization in a developing country: An empirical study. The Journal of Strategic Information Systems, 17(2), 140-154. https://doi.org/10.1016/j.jsis.2007.12.004

HCSO (2015): Infokommunikációs (IKT-) eszközök és használatuk a háztartásokban és a vállalkozásokban, 2014 / ICT devices and their usage in households and enterprises, 2014. Hungarian Central Statistical Office, http://www.ksh.hu/docs/hun/xftp/idoszaki/ikt/ikt14.pdf (23.01.2018)

Hung, S. Y., Chang, C. M., \& Yu, T. J. (2006): Determinants of user acceptance of the eGovernment services: The case of online tax filing and payment system. Government Information Quarterly, 23(1), 97-122. https://doi.org/10.1016/j.giq.2005.11.005

Kaiser, T. (2017): A Jó Állam kutatások bemutatása: koncepciók és perspektívák. Summary of the Good State research at National University of Public Service on 18.10.2017, Budapest, 
$31^{\text {ST }}$ Bled eConference: Digital Transformation: MeEting the Challenges JunE 17 - 20, 2018, BLED, SLOVENIA, CONFERENCE PROCEEDINGS

M. Aranyossy: Citizen adoption of e-government services - Evidence from Hungary

http://akfi-dl.uni-

nke.hu/jo_allam_jelentes_2017/prezentaciok/plenaris/KaiserTamas_JoAllamJelentesBemutata s.pdf (18.01.2018)

Keszey, T., \& Zsukk, J. (2017): Az új technológiák fogyasztói elfogadása. A magyar és nemzetközi szakirodalom áttekintése és kritikai értékelése. Vezetéstudomány/Budapest Management Review, 48(10), 38-47.

Kim, S. S., \& Malhotra, N. K. (2005): A Longitudinal Model of Continued IS Use: An Integrative View of Four Mechanisms Underlying Post-Adoption Phenomena, Management Science, 51(5), 741-755. https://doi.org/10.1287/mnsc.1040.0326

Lee, Y. - Kozar, K. A. - Larsen, K. (2003): The technology acceptance model: Past, present, and future. Communications of the Association for Information Systems, 12(50), 752-780.

Lin, F., Fofanah, S. S., \& Liang, D. (2011): Assessing citizen adoption of e-Government initiatives in Gambia: A validation of the technology acceptance model in information systems success. Government Information Quarterly, 28(2), 271-279. https://doi.org/10.1016/j.giq.2010.09.004

Molnár, T., Kö, A., \& Mátyus, B. (2017): Exploring Usability and Acceptance Factors of mGovernment Systems for Elderly. In International Conference on Electronic Government and the Information Systems Perspective, Springer, 175-188. https://doi.org/10.1007/978-3-31964248-2 13

Nemeslaki, A., Aranyossy, M., \& Sasvári, P. (2016): Could on-line voting boost desire to vote?Technology acceptance perceptions of young Hungarian citizens. Government Information Quarterly, 33(4), 705-714. https://doi.org/10.1016/i.giq.2016.11.003

Nica, E. (2015): Sustainable Development and citizen-Centric E-government Services, Economics, Management, and Financial Markets, 10, 69-74.

Panda, P. - Sahu, G. P. (2013): Critical success factors for e-Gov project: A unified model. IUP Journal of Supply Chain Management, 10(2),19-32.

Powell, A. - Williams, C. K. - Bock, D. B., Doellman, T. - Allen, J. (2012): e-Voting intent: A comparison of young and elderly voters. Government Information Quarterly, 29(3), 361-372. https://doi.org/10.1016/j.giq.2012.01.003

Rana, N. P., Dwivedi, Y. K., \& Williams, M. D. (2013): Evaluating alternative theoretical models for examining citizen centric adoption of e-government. Transforming Government: People, Process and Policy, 7(1), 27-49. https://doi.org/10.1108/17506161311308151

Rogers, E. M.(2003): Diffusion of Innovations. 5th Edition. New York, NY: Free Press

Schaupp, C. L. - Carter, L. (2005): E-voting: from apathy to adoption. Journal of Enterprise Information Management, 18(5), 586-601. https://doi.org/10.1108/17410390510624025

Scott, M. - DeLone, W. H. - Golden, W. (2009): Understanding net benefits: A citizen-based perspective on e-government success. ICIS 2009 Proceedings, Paper 86.

Tas, B. K. O. - Genis-Gruber, A. (2008): E-Procurement Savings and the Competition Effect: Analysis of Cultural Differences Through a Unified Model. TOBB University of Economics and Technology, Department of Economics Working Paper, 8-15.

Venkatesh, V. - Davis, F. D. (2000): A theoretical extension of the technology acceptance model: Four longitudinal field studies. Management Science, 45(2), 186-204. https://doi.org/10.1287/mnsc.46.2.186.11926

Venkatesh, V. - Morris, M. G. - Davis, G. B. - Davis, F. D. (2003): User acceptance of information technology: Toward a unified view. MIS Quarterly, 27(3), 425-478. https://doi.org/10.2307/30036540

Venkatesh, V., Thong, J. Y. L., \& Xu, X. (2012): Consumer acceptance and use of information: extending the unified theory of acceptance and use of technology. MIS Quarterly 36(1), 157178.

Ziemba, E. - Papaj, T. - Żelazny, R. (2013): A model of success factors for e-government adoptionthe case of Poland. Issues in Information Systems, 14(2), 87-100. 
M. Aranyossy: Citizen adoption of e-government services - Evidence from Hungary

Ziemba, E. - Papaj, T. - Jadamus-Hacura, M. (2015): Critical success factors for adopting state and local egovernment-Polish insights. Proceedings of the 13th International Conference on eSociety 2015, International Association for Development of the Information Society, 95-102. 


\section{Appendix}

\section{Good State Public Administration Opinion Survey - selected questions, measurements} and results of the factor analyses

\begin{tabular}{|c|c|c|c|}
\hline Code & Question & Measurement & \begin{tabular}{c|} 
Factor \\
Component \\
Matrix \\
\end{tabular} \\
\hline & USAGE & & \\
\hline K25. & $\begin{array}{l}\text { During the last three years - 2014-15-16 - did you have to deal } \\
\text { with any of the following public administration matters? }\end{array}$ & binary variables: $\mathrm{YES}-\mathrm{NO}$ & \\
\hline K25-26-27-28.1. & Income tax administration & & \\
\hline K25-26-27-28.2. & Tax administration at municipalities & & \\
\hline K25-26-27-28.3. & $\begin{array}{l}\text { Other tax administration at the national tax and customs } \\
\text { administration agency }\end{array}$ & & \\
\hline K25-26-27-28.4. & Administration of government issued documents & & \\
\hline K25-26-27-28.5. & Family support administration & & \\
\hline K25-26-27-28.6. & Health insurance administration & & \\
\hline K25-26-27-28.7. & Unemployment administration & & \\
\hline K25-26-27-28.8. & Social benefits administration & & \\
\hline K25-26-27-28.9. & Pension insurance administration & & \\
\hline K25-26-27-28.10 & Land registry administration & & \\
\hline K25-26-27-28.11 & Administration of construction affairs & & \\
\hline K25-26-27-28.12 & Motor vehicle administration & & \\
\hline K26. & If yes: Did you administer it yourself? & binary variables: $\mathrm{YES}-\mathrm{NO}$ & \\
\hline K27. & $\begin{array}{l}\text { If yes: What channels of information did you use before starting } \\
\text { the administrative process? } 1 \text {. personal customer service } 2 \text {. } \\
\text { telephone 3. e-mail 4. website 5. none }\end{array}$ & binary variables: $\mathrm{YES}-\mathrm{NO}$ & \\
\hline K28. & $\begin{array}{l}\text { Did you use the following channels as part of the administrative } \\
\text { process? 1. personal customer service 2. telephone customer } \\
\text { service 3. online service or application 4. postal service } 5 \text {. } \\
\text { other }\end{array}$ & binary variables: YES - NO & \\
\hline & EFFORT EXPECTANCY & Factor analysis of the following variable (KMO: 0.740 ) & \\
\hline K6.1 & $\begin{array}{l}\text { It is characteristic of me that I start an online administration } \\
\text { process, but I get stuck and I quit. }\end{array}$ & Likert scale: 1 -perfectly true .... 4-not true at all & 0.948 \\
\hline K6.2 & $\begin{array}{l}\text { It is characteristic of me that I start an online administration } \\
\text { process, but I do not finish in time and I quit. }\end{array}$ & Likert scale: 1 -perfectly true .... 4-not true at all & 0.947 \\
\hline K6.3 & $\begin{array}{l}\text { It is characteristic of me that in an online administration process I } \\
\text { can only partially arrange what I want to. }\end{array}$ & Likert scale: 1 -perfectly true .... 4-not true at all & 0.903 \\
\hline K6.8 & $\begin{array}{l}\text { I find it easy to orient myself on the websites where I have to } \\
\text { administer. }\end{array}$ & Likert scale: 4 -perfectly true .... 1-not true at all & 0.138 \\
\hline & TRUST OF INTERNET & Factor analysis of the following variable (KMO: 0.806) & \\
\hline K6.4 & I never give my bank account data while shopping online. & Likert scale: 1-perfectly true .... 4-not true at all & 0.807 \\
\hline K6.5 & I do not register on online platforms till I have to. & Likert scale: 1 -perfectly true .... 4-not true at all & 0.843 \\
\hline K6.6 & I am averse from giving my personal information on the internet. & Likert scale: 1 -perfectly true .... 4-not true at all & 0.891 \\
\hline K6.7 & $\begin{array}{l}\text { There are some personal data of mine which I would not give even } \\
\text { while registering on state organisations' websites. }\end{array}$ & Likert scale: 1 -perfectly true .... 4-not true at all & 0.789 \\
\hline & TRUST OF GOVERNMENT & Factor analysis of the following variable (KMO: 0.769 ) & \\
\hline K9.1 & $\begin{array}{l}\text { If the state registers our real estates, motor vehicles, their } \\
\text { property rights are insured. }\end{array}$ & Likert scale: 4-perfectly true .... 1-not true at all & 0.660 \\
\hline K9.3 & $\begin{array}{l}\text { Without official documents we would not be able to enter into } \\
\text { contracts, sign on for jobs. }\end{array}$ & Likert scale: 4 -perfectly true .... 1-not true at all & 0.449 \\
\hline K9.8 & $\begin{array}{l}\text { Public administration is necessary to care for pensioners and the } \\
\text { ones in need. }\end{array}$ & Likert scale: 4-perfectly true .... 1-not true at all & 0.678 \\
\hline K9.9 & State care actually comes to those who are entitled to it. & Likert scale: 4-perfectly true .... 1-not true at all & 0.633 \\
\hline K9.10 & $\begin{array}{l}\text { A country can be efficient only if it has an efficient public } \\
\text { administration. }\end{array}$ & Likert scale: 4-perfectly true .... 1-not true at all & 0.566 \\
\hline K9.11 & The Hungarian public administration works efficiently. & Likert scale: 4 -perfectly true .... 1-not true at all & 0.717 \\
\hline $\mathrm{K} 23.2$ & State organisations protect are personal information properly. & Likert scale: 4 -perfectly true .... 1-not true at all & 0.609 \\
\hline
\end{tabular}


$31^{\text {ST }}$ Bled eConference: Digital Transformation: MeEting the Challenges

M. Aranyossy: Citizen adoption of e-government services - Evidence from Hungary

\begin{tabular}{|c|c|c|c|}
\hline Code & Question & Measurement & $\begin{array}{c}\text { Factor } \\
\text { Component } \\
\text { Matrix } \\
\end{array}$ \\
\hline & FACILITATING CONDITIONS & Factor analysis of the following variable (KMO: 0.675 ) & \\
\hline K17.1 & $\overline{\text { How many personal computers are there in your household? }}$ & Integer & 0.520 \\
\hline K17.2 & How many notebook/laptop/netbook are there in your household? & Integer & 0.688 \\
\hline K17.3 & How many tablet are there in your household? & Integer & 0.632 \\
\hline K17.5 & How many smart phone are there in your household? & Integer & 0.831 \\
\hline \multirow[t]{2}{*}{ K1. } & How many internet connections are there in your household? & Integer & 0.792 \\
\hline & EXPERIENCE & Factor analysis of the following variable (KMO: 0.810 ) & \\
\hline K5 & How often do you do the following activities? & Likert scale: 1 - never $\ldots . .4$-almost every day & \\
\hline K5.1 & searching online & & 0.599 \\
\hline K5.2 & reading news online & & 0.551 \\
\hline K5.3 & e-mail & & 0.676 \\
\hline K5.4 & online messaging & & 0.571 \\
\hline K5.5 & using social media platforms & & 0.432 \\
\hline K5.6 & making online phone calls & & 0.626 \\
\hline K5.7 & e-learning & & 0.598 \\
\hline K5.8 & working online & & 0.580 \\
\hline K5.9 & shopping online & & 0.675 \\
\hline K5.10 & selling online & & 0.565 \\
\hline \multirow[t]{2}{*}{ K5.11 } & online banking & & 0.630 \\
\hline & HABIT & Factor analysis of the following variable (KMO: 0.701) & \\
\hline K15.13 & If possible I avoid dealing with administration online. & Likert scale: 1 -perfectly true .... 4-not true at all & 0.860 \\
\hline K15.14 & I prefer dealing with administration in person than online. & Likert scale: 1 -perfectly true .... 4-not true at all & 0.839 \\
\hline \multirow[t]{2}{*}{ K15.15 } & I prefer dealing with administration online than on the phone. & Likert scale: 4 -perfectly true .... 1-not true at all & 0.818 \\
\hline & $\underline{\mathrm{AGE}}$ & & \\
\hline \multirow[t]{2}{*}{ D6. } & Please give the year of your birth & From this transformed: Age in years - String & \\
\hline & GENDER & & \\
\hline D5. & Responder's gender & binary variable: male - female & \\
\hline
\end{tabular}




\section{Appendix 2}

\section{PERSONAL INCOME TAX ADMINISTRATION}

(ANOVA, significant mean differences, $* \mathrm{p}<0.05 ; * * \mathrm{p}<0.01$ )

\begin{tabular}{|c|c|c|c|c|}
\hline $\begin{array}{c}\text { FACTORS } \\
\text { INFLUENCING USAGE }\end{array}$ & \multicolumn{2}{|c|}{ online information } & \multicolumn{2}{|c|}{ online transaction } \\
\hline & no & yes & no & yes \\
\hline n & $296(81 \%)$ & $71(19 \%)$ & $267(73 \%)$ & $101(27 \%)$ \\
\hline Effort expectancy & $-0.025^{*}$ & $0.245^{*}$ & $-0.026^{* *}$ & $0.324^{* *}$ \\
\hline Trust of internet & $-0.037^{* *}$ & $0.452^{* *}$ & $-0.125^{* *}$ & $0.495^{* *}$ \\
\hline Trust of government & -0.094 & 0.043 & $-0.080^{*}$ & $0.188^{*}$ \\
\hline Facilitating conditions & $0.278^{* *}$ & $0.702^{* *}$ & $0.184^{* *}$ & $0.766^{* *}$ \\
\hline Experience & $0.143^{* *}$ & $0.797^{* *}$ & $-0.005^{* *}$ & $0.941^{* *}$ \\
\hline Habit & $-0.095^{* *}$ & $0.809^{* *}$ & $-0.263^{* *}$ & $1.015^{* *}$ \\
\hline Age & \multicolumn{3}{|c}{ no significant relationships } \\
\hline Gender & \multicolumn{3}{|c}{ no significant relationships } \\
\hline
\end{tabular}

\section{ADMINISTRATION OF GOVERNMENT ISSUED DOCUMENTS}

(ANOVA, significant mean differences, * $\mathrm{p}<0.05 ; * * \mathrm{p}<0.01$

Nonparametric Mann Whitney U test $(\mathrm{p}<0.05)$, significant distribution differences with bold)

\begin{tabular}{|c|c|c|c|c|}
\hline \multirow{2}{*}{ FACTORS } & \multicolumn{2}{|c|}{ online information } & \multicolumn{2}{c|}{ online transaction } \\
\hline INFLUENCING USAGE & no & yes & no & yes \\
\hline n & $815(84 \%)$ & $150(16 \%)$ & $972(94 \%)$ & $59(6 \%)$ \\
\hline Effort expectancy & $-0.026^{* *}$ & $0.307^{* *}$ & $-0.002^{* *}$ & $0.366^{* *}$ \\
\hline Trust of internet & $-0.052^{* *}$ & $0.571^{* *}$ & $0.039^{* *}$ & $0.572^{* *}$ \\
\hline Trust of government & $-0.121^{* *}$ & $0.192^{* *}$ & -0.098 & 0.114 \\
\hline Facilitating conditions & $0.141^{* *}$ & $0.786^{* *}$ & $0.183^{* *}$ & $0.816^{* *}$ \\
\hline Experience & $-0.016^{* *}$ & $0.650^{* *}$ & $0.048^{* *}$ & $0.873^{* *}$ \\
\hline Habit & $-0.179^{* *}$ & $1.001^{* *}$ & $-0.017^{* *}$ & $1.108^{* *}$ \\
\hline Age & $\mathbf{4 4}$ years & $\mathbf{4 2}$ years & no significant \\
& & & relationships \\
\hline Gender & & no significant relationships \\
\hline
\end{tabular}




\title{
Studying Complex IT Challenges? Discuss Real Cases
}

\author{
JANIS L. GOGAN \& DAVID M. MURUNGI
}

\begin{abstract}
Field-based case studies are uniquely suited to exploring the complex challenges of digital transformation. We propose that real discussion cases (developed from rigorously-researched field-based case studies) can trigger useful discourse that helps scholars improve theories addressing complex digital transformation challenges. To advance this argument we undertook an extreme-case study to examine the practices and theoretical contributions of an exceptionally impactful researcher in a nonIT domain (Sumantra Ghoshal, an international management scholar who conducted many field- base case studies and produced many real discussion cases). Based on our extreme-case study findings we consider implications for research on digital transformation.
\end{abstract}

Keywords: $\bullet$ case research $\bullet$ case study $\bullet$ discourse $\bullet$ teaching cases $\bullet$

CoRrespondence AdDRESS: Janis L. Gogan, DBA, Professor, Bentley University, Information \& Process Management, 75 Forest Street, Waltham MA 02452-4705 USA, jgogan@ bentley.edu.

David M. Murungi, Ph.D., Assistant Professor, Bentley University, Information \& Process Management, 75 Forest Street, Waltham MA 02452-4705, USA, dmurungi@ bentley.edu. 


\section{Introduction}

Field-based case studies are uniquely suited to exploring complex challenges organizations face in adopting and implementing emerging technologies (Eisenhardt 1989). We propose that real discussion cases, developed from rigorously-researched field- based case studies, can trigger useful scholarly discourse. Because case discussants can interpret real cases richly, holistically, and freely, discussions can help the researcher appreciate new perspectives on study findings, particularly if disscussants vary in their backgrounds, experience, and other dimensions. New perspectives, in turn, may help the researcher identify useful new questions for further study. Thus, when real cases are critiqued through discussions among scholars and with practitioners, scholars should develop ideas that lead to stronger theories.

To advance this argument, we present an extreme-case study which examined the work and research practices of an exceptionally impactful scholar in a non-IT domain: Sumantra Ghoshal. As explained in Yin (2018) and Mills et al. (2010) an extreme-case study is an appropriate research method if the objective is to learn from a rare or unusually positive or negative example. In a 20-year academic career (1985-2004) Ghoshal published more than 70 papers, 12 books, and 36 (or more) discussion cases ${ }^{1}$ before his death at age 55 in 2004. One of the most influential management scholars of the $20^{\text {th }}$ century (Rugman 2002), Ghoshal is best known for conceptualizing the multinational corporation (MNC) as an inter-organizational network confronting the dual challenges of integration and differentiation (first articulated by Lawrence and Lorsch, 1967 as intraorganizational challenges). Later, Ghoshal's papers considered why human resources management practices were not keeping pace with socio-economic and technical forces. $\mathrm{He}$ also published much-cited critiques of rational-actor management theories which, he asserted, harm both business education and management practice (Ghoshal 2005).

In 2010 the Sumantra Ghoshal Conference was established at London Business School (LBS) in his honor; its annual Ghoshal Award for Research Relevance and Rigour has gone to Kathleen Eisenhardt, Michael Tushman, Ranjay Gulati, David Teece, Robert Sutton, Ron Adner, Laurence Capron, and Amy Edmondson.

Thus, the extreme case of Sumantra Ghoshal is that of a scholar who made an exceptionally strong impact on the field of international management, as well as more generally on theories of management, leadership, and organization design and business education. His documented enthusiasm for translating field-based case studies into both scholarly publications and practitioner publications - including real discussion cases -provides an opportunity for us to consider whether and how case research and discussion cases influence research outputs and practices. In this paper we show that Ghoshal's case research was complemented by vigorous case discussions with co-authors, business leaders, and students. Consistent with ideas advanced by Vermeulen (2007), we contend that case discussions were important to a virtuous cycle of communication that improved both the relevance and rigor of his research. The extreme-case study evidence presented here supports our proposition that real discussion cases can trigger a process of mutuallyinforming collaboration among scholars and practitioners. 
In this paper, we first define and discuss foundation concepts: discourse, case research, complex IT challenges. Next, we report on our extreme-case study (of Ghoshal as an extreme case of exemplary double-impact research). After discussing how cases informed Ghoshal's work, we consider implications for research on digital transformation. We conclude with a broader consideration of how rigorously researched real discussion cases contribute to theories addressing complex IT challenges.

\section{Foundation Concepts: Discourse, Complex IT Challenges, and Discussion Cases}

\subsection{Discourse}

Ideas are socially constructed in discourse among an "invisible college" of scholars (Paisley 1972), within and across disciplinary and geographic boundaries. Impactful research may contribute to the invisible college, to practice, or to both, and scholarly research and teaching can be synergistic: "Theory surely leads to practice, but practice also leads to theory. Teaching, at its best, shapes both research and practice. ..." (Boyer 1990, p. 16). Vermuelen (2007) proposes that two communication loops help a scholar produce rigorous and relevant work (Figure 1). Consistent with this view, Tushman and O'Reilly (2007) report that doing case interviews and discussing real cases in executive programs are mutually-reinforcing activities.

Thus, a real discussion case can trigger virtuous cycles of reflection and feedback. While Figure 1 emphasizes executive education discussions, we propose a broader view of the Relevance communication loop: case discussion with undergraduate or MBA students, $\mathrm{PhD}$ students, colleagues, and/or people in various jobs at various levels in various industries may give a researcher new ideas that trigger new studies in the Rigor communication loop.

Loop 1: Rigor

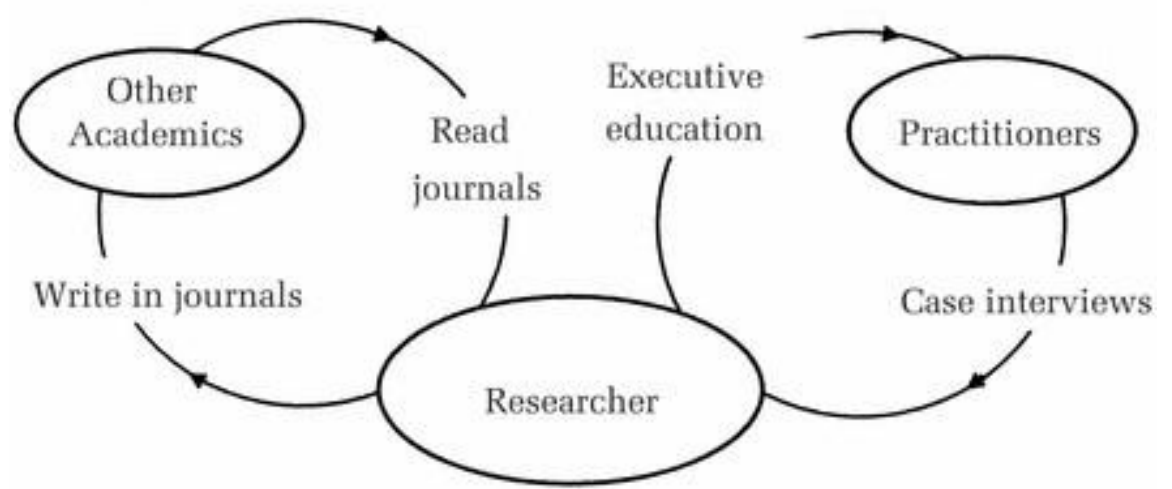

Figure 1: Loops of Communication (Vermeulen 2007, p. 757) 
Vermeulen's rigor-relevance communication loops are supported by discourse theory, which explains how arguments are translated from one domain to another. "Argumentation" -- broadly construed as a way to justify knowledge claims (Habermas 1984; Toulmin 2003) - is categorized in two complementary types: Dialectical and Rhetorical (Hohman 2000; Leff 2002). Dialectical argumentation, corresponding to Vermeulen's Rigor communication loop, is an abstract and structured form of propositional logic that tests arguments by applying formal rules (Rowland 1987). Rhetorical argumentation, corresponding to Vermeulen's Relevance loop, tests the plausibility of a proposition relative to a particular audience, rather than in relation to alternative propositions (Jacobs 2000). Some theorists view the two forms of argument as antagonistic, since the tendency of dialectical argument is to transcend, while the tendency of rhetorical argument is to situate (Leff 2002). Aristotle saw the two forms of argument as complementary. He argued that rhetoric is the necessary counterpart of dialectic, since rhetoric is needed to defend decisions (you may be right, but you still need to convince others (in Krabbe 2000). Leff (2002) also sees rhetoric and dialectic as complementary, in that dialectic depends on rhetoric to "close and define the situations in which it can operate." In this view, rhetoric can provide provisional, local closure when conclusive agreements are not reached through inference. However, the addition of dialectical rationality to an argument helps achieve the goal of effective persuasion.

In the IS subfield of systems design and development, Peter Checkland's engaged scholarship (action research) resonates in ways similar to Vermeulen's Loops of Communication, particularly in the Inquiring Learning Cycle of SSM (Checkland 1999, p. A9). He states optimistically that "as long as the interaction between the rhetoric and the experienced 'reality' is the subject of conscious and continual reflection, there is a good chance of recognizing and pinning down the learning which has occurred." Yet, he cautions, "The process of learning by relating experiences to ideas is always both rich and confusing." (Checkland 1999, p. A7). The field of IS is grateful that Checkland and colleagues did not give up; their ability to rethink classic systems engineering methodology led to the important "distinction between 'hard' and 'soft' systems thinking": the world may be 'hard' but the essential 'process of inquiry' is the 'soft' and all-important 'learning system' (Checkland, 1999, p A7)

\subsection{Complexity and Case Research}

Complex problems (and especially-complex "wicked" problems) arise in many contexts, including government policymaking (Nickerson and Sanders 2014), corporate strategy (Camillus (2008 and 2016), software development (DeGrace and Stahl 1990), and other domains (e.g., Conklin 2005; Ritchey 2011). A wicked problem is "a social or cultural problem... that is difficult or impossible to solve for as many as four reasons:

1) incomplete or contradictory knowledge,

2) the number of people and opinions involved,

3) the large economic burden, and

4) [being] interconnected ... with other problems." (Kolko 2012) 


\section{$31^{\text {ST }}$ Bled ECONFEREnCE: Digital Transformation: MeEting the Challenges June 17 - 20, 2018, BLED, SLOVENIA, CONFERENCE ProceEDINGS \\ J. L. Gogan \& D. M. Murungi: Studying Complex IT Challenges? Discuss Real Cases}

Methods of engaged scholarship, including action research (Checkland 1999) and case research (the topic of this paper) are well suited to the study of complex problems, including emerging-IT challenges. Several recent case studies show the benefit of using case research to study complex emerging-IT challenges:

- A recent multiple-case study aimed to understand how "big old" companies achieve digital transformation. That study homed in on two key capabilities: building and continuously improving an organization's "operational backbone" for highly reliable systems and data, and building and refining a flexible and responsive "digital services platform" (Sebastian et al., 2017).

- Another multiple-case study (Ma and McGroarty 2017) considered how three disruptive technologies - high- frequency trading, social network analytics and smart mobile applications - change financial markets and introduce important societal implications. Their case findings demonstrate that while innovations led to improvements (e.g., harnessing crowd wisdom, leading traders to produce more accurate price estimates) the increased transaction velocity gave rise to new or exacerbated challenges (e.g., misinformation due to complex information networks, speculative trading behavior, increased market volatility).

- An ethnographic case study (Niemimaa and Niemimaa 2017) investigated how universal best-practice prescriptions for information systems security are translated into actual organizational practices. While the literature had shown that best practices should be contextualized, little was known about how organizations actually translate these into situated practice. This case study both illuminates important translational mechanisms and reveals hurdles which an organization faced during this translation process.

Case researchers disseminate their findings via three routes: scholarly journals (e.g. EJIS, $M I S Q$ ), practitioner outlets (e.g., MISQe, Harvard Business Review), and discussion cases (distributed by CaseCentre, HBS Publishing and others). We argue that these varied publication outlets make it possible for case researchers to produce stronger and more useful theories about complex IT challenges, by triggering discourse among scholars, practitioners and future leaders (e.g., MBA students). Real discussion cases are particularly well suited to this process, as we discuss next.

\subsection{Discussion Cases}

An ideal high-quality real discussion case (per Naumes and Naumes 2012) is based on primary data gathered in the field (via interviews and observation, data from an organization's web site, annual reports, internal memoranda, etc.). The case provides truthful evidence about multiple facets of a focal situation (that is, it is real). It takes the point of view of a particular protagonist at a point in time and (if written well) it has a story-like tone that helps readers empathize with the protagonist. Skilled case discussion facilitators encourage discussants to "stand in the shoes" of this manager at this organization, facing this particular challenge. The problem the manager faces "has not yet been solved, and may even remain to be identified" (Naumes and Naumes, 2012 p. 33). As is true of most complex problems, there is no single "right" answer, and the 
discussion case does not explicitly state the author's interpretation (thus freeing discussants to offer their interpretations). In discussion, participants usually come to appreciate facets they did not consider during individual case preparation (Andersen and Schiano 2014).

These characteristics make the preparation of a real discussion case a useful (maybe optimal) early step in a program of research on a complex emerging-IT problem. Emerging IT challenges involve equivocal technologies: IT appplications for which "information is incomplete, hyperbolic, or highly ambiguous" (Berente et al. 2011). Most emerging IT challenges are equivocal because of the essential flexibility of software; its potential is limited primarily by the imagination and skill of its developers. Similarly, the potential of a flexible IT-enabled platform is limited primarily by the imagination and skills of its end users. Consider the many emergent forms that an Excel spreadsheet or Word document (examples of end-user platforms) can take through use. ERP and other enterprise and inter-enterprise software may be tightly restrictive, but other IT platforms offer great flexibility -- so much so that Cash et al. (2008) observe that every IT organization faces a continual challenge of effectively managing known technologies and applications (with low or manageable equivocality), while exploring a continuous stream of new equivocal technologies (via separate processes, structures and controls that are conducive to experimentation).

Relevant individual and collective sensemaking about equivocal technologies is supported by collective discourse, in which varied interpretations of use and value are aired. Reporting on a case study of sensemaking in a virtual world (Second Life), Berente et al. (2011, p. 705) concluded: "From rational argumentation around conceptual capabilities to the metaphorical association with earlier waves of innovation, individuals draw upon a rich tapestry of sensemaking strategies to confront the equivocality that they encounter."

Having laid out our arguments for the importance of discourse for making sense of equivocal technologies in general, and for how real discussion cases support flexible sensemaking that may improve theory, we next report on the extreme case of an exemplary double-impact researcher: Sumantra Ghoshal. Our findings will reveal how real discussion cases support the dual communication loops of rigor and relevance (or of dialectic and rhetoric).

\section{The Extreme Case of Sumantra Ghoshal}

\subsection{Case Study Overview}

This study is part of a broader investigation of how exemplary double-impact scholars in several management disciplines use case studies to investigate complex problems. Our investigation began with an exploratory single-case study, in which we examined the extreme case of an influential international management scholar (Sumantra Ghoshal's home discipline was management, not IS management). We drew primarily on archival sources (his papers, discussion cases, and books, as well as presentations, articles and 


$$
\begin{aligned}
& 31^{\text {ST }} \text { Bled ECONFERENCE: Digital Transformation: MEETING THE CHALlengeS } \\
& \text { JunE } 17 \text { - 20, 2018, BLED, SLOVENIA, CONFERENCE PROCEEDINGS } \\
& \text { J. L. Gogan \& D. M. Murungi: Studying Complex IT Challenges? Discuss Real Cases }
\end{aligned}
$$

books about him). We also conducted a one-hour telephone interview with his main collaborator, Christopher Bartlett, who co-authored four books and ten Financial Times (FT)50 journal publications with Ghoshal.

Born in 1948 in Calcutta, Ghoshal studied physics at Delhi University, and worked for Indian Oil for about a decade, before moving to the United States to pursue graduate studies. His MIT Master's thesis (1983) asked 32 US managers in Fortune 500 multinational corporations (MNCs) about their external information needs. Similar to Aguilar (1967) Ghoshal reported that competitive and market information were important to these managers; however, respondents' rankings of other factors differed from prior studies. Ghoshal built on this initial work while earning two doctorates: a PhD from MIT in 1985 and a DBA from Harvard in 1986. His rise was meteoric. His scholarly career began at INSEAD in 1985 and he also was founding dean of IBS- Hyderabad. He joined the LBS faculty in 1994 and remained at LBS until his death in 2004. Our case study time period covers his doctoral studies until his death. Exhibit 1 summarizes Ghoshal's work over his two-decade scholarly career. His Top Ten most highly-cited journal publications for his career (four with Bartlett) yielded more than 38,800 citations.

\subsection{Sumantra Ghoshal's Two-Decade Scholarly Career, 1985-1995}

Our purpose is to elucidate how Ghoshal successfully blended rigorous case research, story-like discussion cases, and practitioner articles and books, leading to strong and useful new theories of international management. However, this section should not be approached as a literature review, since our purpose is to illustrate the value of conducting rigorous case research, producing discussion cases, and discussing them -- not to fully inform the reader about international managementresearch.

Ghoshal's MIT PhD dissertation reference list shows Ghoshal (1985) was influenced by many scholars in the "invisible college" (175 works cited). This was a multi-method study (surveys, cases, non-case interviews) of environmental scanning at both individual and organizational levels of analysis. It aimed to answer two questions: RQ1) What environmental, organizational, and individual attributes affect the way managers scan their business environments? RQ2) How might a firm organize the environmental scanning function? Ghoshal saw organizations as complex systems and noted that organizational complexity is second only to a "transcendent" level of complexity in general systems theory (Boulding, 1956), similar to a wicked problem (Rittell and Webber 1973). To learn how managers allocated time to various informational tasks, Ghoshal surveyed 55 managers at six Korean global trading companies and 56 managers at 10 Korean manufacturers (similar to Mintzberg, 1978 and 1990). To learn why, he interviewed 36 managers in three Korean firms, and visited environmental scanning departments at two firms which each used a scanning methodology that was pioneered by a former Samsung employee. Ghoshal also reported in detail on a Samsung case study that, he stated, led him to believe that organizational capabilities are heavily affected by individual competencies/behaviors. This theme pervades much of his later work. 
For his Harvard DBA Ghoshal worked under the supervision of Christopher Bartlett, who had already launched what would be a nine-case study in three industries and three countries (US, Europe, Japan):

\begin{tabular}{|c|c|c|}
\hline Electronics & Telecom & Packaged Goods \\
\hline GE & ITT & Unilever \\
\hline Philips & Ericsson & P\&G \\
\hline Matsushita & NEC & Kao \\
\hline
\end{tabular}

Bartlett's project aimed to create teaching cases and a book for a new course, Managing International Business (MIB). "Everything we worked on showed up in that MIB course," Bartlett told us. The nine cases (of which, the Matsushita case was led by Ghoshal) are the "core" of Managing Across Borders (Bartlett and Ghoshal 1989). Before being made available via HBS Publishing ${ }^{2}$, they were taught in a short executive education course and the MIB course, and described in three early practitioner publications (Ghoshal \& Bartlett 1986; Bartlett \& Ghoshal 1987a and 1987b). By 1991, four discussion cases from their work were in the HBSP system: GE (391-144), Komatsu (390-037), Matsushita (388144), and $P \& G$ (384-139).

Ghoshal's DBA thesis (Ghoshal 1986) asked: "How can relations between the headquarters and subsidiaries of a large multinational corporation be organized so as to facilitate innovations in the company?" His study was conducted in three stages:

1) 100 interviews on 38 innovation cases at Ericsson (Sweden), Matsushita (Japan), NEC (US), Philips (Netherlands).

2) Surveys of $300+$ managers at Matsushita, NEC, and Philips.

3) Survey sent to $500 \mathrm{~N}$ American and European multinationals, with 65 responses.

The case studies revealed four innovation processes (center-for-global, local-for-local, local-for-global, global-for-global) and three MNC subsidiary types: Innovator, Contributor, Implementer. Ghoshal (1986) stated: "The organizational factors that facilitate each process are not only different but mutually contradictory. Herein lies a key challenge for MNC managers: designing an organization that can facilitate all three innovation processes simultaneously. ... Based on both case and survey research, a framework is developed to suggest a basis for differentiation in allocation of subsidiary roles and structuring of headquarters-subsidiary relations...."

In the Acknowledgements section of his 1986 DBA thesis, Ghoshal's praise for his supervisor points to how their discussions helped him form and reform ideas. He stated: "Professor Christopher Bartlett, the chairman of my thesis committee, must share both credit and discredit for this thesis, not only because of his personal involvement with the research ... but also because of his overall influence on the ways in which I have come to think about the task of business administration in general, and about management of multinationals, in particular. ... Many of the ideas and concepts presented in this report arose in the course of many, many hours of discussions with him in the lobbies of strange hotels in three continents, in deserted class rooms of Aldrich and Cotting, and in overcrowded airplanes. ..." 


\section{$31^{\text {ST }}$ Bled ECONFEREnCE: Digital Transformation: MeEting the Challenges June 17 - 20, 2018, BLED, SLOVENIA, CONFERENCE ProceEDINGS \\ J. L. Gogan \& D. M. Murungi: Studying Complex IT Challenges? Discuss Real Cases}

The thesis, centered on the 38 cases in four companies (an embedded-cases study design), launched both his career and Bartlett's. Together, they published 16 case-infused journal publications by 1995. Meanwhile, Ghoshal authored seven other case-infused FT-50 publications and 14 discussion cases (alone or with other co-authors) by 1995 . In the second decade of his career Ghoshal produced another five scholarly FT50 papers (none with Bartlett), 11 practitioner papers (seven with Bartlett), 20 real discussion cases (none with Bartlett, who produced 36 other cases during the same time ${ }^{3}$ ), and nine books with six sets of co-authors (some with Bartlett, including new editions of books).

Ghoshal's view of organizations as complex social systems was strongly linked to his belief in the value of case research, both in terms of the data gathered in each case study and discussions about them with students and colleagues. In a paper published the year after he died, Ghoshal urged business schools to embrace Boyer's recommendations for pluralistic scholarship": "We need to ... reengage with the scholarship of integration, application and pedagogy to build management theories that are broader and richer than the reductionist and partial theories we have been developing over the last 30 years." (Ghoshal, 2005, p. 87). In this paper he cites Friedrich von Hayek's 1989 Nobel Memorial Lecture, in which Hayek asserted that a dangerous "pretense of knowledge" is often produced when positivist "scientific" methods are applied to complex social phenomena (such as institutional change). Physical systems, Hayek explained, operate independent of research; the earth is round and gravity exerts its pull regardless of what or how we think about these phenomena. Thus, Hayek asserted, positivist research on a physical phenomenon can change our understanding but does not change the phenomenon. In contrast, when positivist research is applied to a social phenomenon, people who believe the resulting theory may change their actions based on it - in turn, changing the phenomenon. Ghoshal urged management scholars to "temper the pretense of knowledge" through engaged scholarship, including through conducting and discussing rigorous field-based case studies (Ghoshal 2005, p. 87).

\subsection{Christopher Bartlett Reflecting on his Research Collaboration with Sumantra Ghoshal}

A conference presentation or journal publication can trigger a useful discussion about a complex phenomenon, and, we suggest, another valuable way to trigger useful scholarly discussion is to prepare real discussion cases as part of one's program of case research. Our extreme-case study of Ghoshal, an extraordinarily impactful scholar in the field of international management, reveals that case discussion among scholars and with leaders, managers, and business students can yield useful insights about a complex problem, which in turn can improve theory or generate new theory.

Christopher Bartlett, who has produced 74 real discussion cases in his career so far (most recently in 2017) also believes cases trigger fruitful conversations that improve theory. In 2007 Bartlett gave a talk at the inaugural Sumantra Ghoshal Conference at London Business School. A summary and commentary about this talk (Rynes 2007) restated Bartlett's view that Ghoshal exemplified several characteristics important to engaged scholarship, including "1) A commitment to field research, built on a profound respect for 
practitioners. 2) Engagement and ongoing dialog with practitioners ... 3) Teaching and research as interdependent activities, with teaching cases being the first output of field research."

We conducted a telephone interview with Bartlett, in fall 2017. Asked to reflect on his collaboration with Ghoshal, he stated: "Case research, teaching, and publications are tightly bound and closely intertwined. I've always thought of a three-legged stool: academically engaging plus managerially engaging plus pedagogically engaging. All three are always an explicit part of the case research engagement." Bartlett's first publications with Ghoshal were "driven by both our three-industry research design and the ability to come into the MBA and executive classrooms with cases. Also, we were doing a lot of outside consulting activity. ...We were not, at first, led by a strong conceptual model in this research..."

Bartlett described their collaboration: "We beat each other up in discussions; pushing ideas back and forth. Out of these cases came a belief that a very different managerial model was developing at companies." Discussions with students and with each other led Bartlett and Ghoshal to ideas discussed in their books and many of their journal publications. Bartlett stated, "I learned a huge amount from my MBA students. Discussing a case was a way to test ideas; students would push back. Executive Education participants would push back especially hard; they were quite a reality check on the ideas. ... Sumantra and I could really push each other to go far deeper.... It was intense ... yet we had such an easy rapport." Their work practice was punctuated by energetic conversations: "I would take the lead on managerial articles; Sumantra would take the lead on the academic papers. Once a first draft was written, we would switch; I'd work on his, he'd work on mine. We beat each other up in the process, butting heads until we agreed we had a compelling story to tell. ... It was a pretty constant ongoing collaboration.”

All 20 papers that Bartlett published in the FT50 during his career were co-authored with Ghoshal (in addition, Ghoshal produced 16 other FT50 papers, alone or with others).

\section{Discussion and Implications for Research on Complex IT Challenges}

\subsection{Main Findings from the Extreme Case of Sumantra Ghoshal}

Our extreme-case study of one scholar's work practices and influence illustrates how rigorous case research - and, importantly, real discussion cases produced from this research-- contribute to understanding complex challenges and to helping researchers identify plausible solutions and build better theories. Ghoshal and Bartlett produced many cases about international management, and discussing them was essential to developing their influential theories. We also observe that Ghoshal's extensive reference lists point to his respect for the "invisible college" (a form of asynchronous scholarly discourse). Cases were central to his work, but not the only tool in his kit. His respect for other research methods is evident in his other qualitative studies (questioning managers in similar jobs in many organizations) and quantitative studies (surveys). 


\section{$31^{\text {ST }}$ Bled ECONFEREnCE: Digital Transformation: MeEting the Challenges JunE 17 - 20, 2018, BLED, SLOVENIA, CONFERENCE PROCEEDINGS \\ J. L. Gogan \& D. M. Murungi: Studying Complex IT Challenges? Discuss Real Cases}

Ghoshal's engaged scholarship helped him deeply understand the messy complexity of organizational life and to avoid Hayek's "pretense of knowledge." Both his papers and discussion cases triggered important conversations about management and (later) management education (in his later years Ghoshal criticized managerial theories and teaching approaches that, he felt, over- emphasize analytic techniques and a rational-actor perspective, while underemphasizing behavioral and social aspects of organizational life). Evidence of his impact on theories that address complex challenges of global management is incontrovertible (nearly 40,000 citations to his Top Ten FT50 papers; see Appendix 1), as is the evidence (presented here) of how case research contributed to his (and Bartlett's) thinking.

Ghoshal's body of work, combined with Bartlett's description of their work practices, point to the potential that real discussion cases offer for helping managers and scholars avoid faddish discourse -in any managerial domain, including IS management. Based on the extreme case of impactful research described here, we propose that a program of research on a complex IT phenomenon should include some field-based case studies, from which it is helpful to produce some real discussioncases.

\subsection{Case Studies, Case Discussions and Discourse}

Case research demands cognitive flexibility. When evidence pointed in new directions, and/or when other scholars and practitioners offered alternative interpretations, Ghoshal looked in those directions. For example, an early paper (Ghoshal 1987) explained that strategic competencies and organizational structures for international operations vary, yielding three enterprise archetypes: multinational, global, international. Later, Ghoshal proposed that effective leaders of transnational enterprises master multinational, global, and international strategic competencies and structures (all of these, not just one). Importantly, this insight arose from discussing cases with his students and his main collaborator. Bartlett and Ghoshal had many vigorous and productive conversations, with each other and with MBA and executive students and other scholars.

Case discussions often reveal new facets of a phenomenon. Discussants are encouraged to identify with the case protagonist and to recognize that there are usually several right answers (and also many wrong answers) to a complex situation. To some extent, discussants are free to focus on aspects that interest them and to argue why these matter. Conventional scholarly discussions (such as those triggered at conferences) can also produce helpful insights, but if these discussions are confined to small circles of interested scholars, diverse voices may not be mixed into the stew of ideas they stir. Discussing a case with students or practitioners can help a scholar see other facets. Thus, real discussion cases can play a useful role in triggering conversations that scholars have with other scholars and with business or public leaders, managers, and students.

Addressing the problem of IT fads (unreasonable expectations and irrationally skewed perceptions of IT innovations), Hirschheim et al. (2012) argue that while scholarly analysis can validate reasonable claims about an innovation, the analysis can also help prevent detrimental "flighty" claims from taking off. However, lengthy peer review 
processes delay publications, which in turn can delay the emergence of scholarly discussions about new IT phenomena. How to get scholars involved sufficiently early to influence the trajectory of a management fad? Hirscheim et al.'s answer: don't wait for the final journal publication; improve discourse by making fine-grained scholarly analysis available at an earlier stage in a program of research. That argument assumes that ideas flow from one scholar to another as we read each other's works. However, we caution that an important earlier study based on discourse analysis reported that only about $5 \%$ of papers that cited "Power, Politics and MIS Implementation (Markus 1984) had engaged with that study's central tenets. In its Conclusion section this paper glumly asked: "Does the IS discipline support a true and active dialogue around concrete research questions about phenomena of interest? Or are we just ships passing in the night, using selected referential spotlights to see the shape and direction of other vessels?" (Hansen et al. 2006, p. 419). We argue that real discussion cases might more quickly help scholars and practitioners jointly evaluate complex IT phenomena -- such as cognitive computing initiatives, digital transformation tactics, or rapidly changing cyber-attack practices and related incident response practices. For fast-moving topics like these, scholarly theorizing can greatly benefit when scholars and practitioners talk with each other about practices in the field.

To study complex IT phenomena, curious scholars with complementary expertise and interests, who are skilled in various methods and theories, may produce very helpful case studies. Subsequently, when smart people from multiple theoretical and methodological perspectives argue vigorously about the cases, good ideas should emerge. Sumantra Ghoshal greatly valued his collaboration with Chris Bartlett, and Bartlett greatly appreciated how "butting heads" together produced great ideas.

\subsection{Study Limitations and Suggestions for Further Research}

Ghoshal's scholarly journey leads us to believe that, for a program of research about a complex IT challenge, an optimal starting point is to conduct one or more rigorous fieldbased case studies and to produce a few real discussion cases from these. However, our research has limitations. We conducted a single extreme-case study, whereas a more comprehensive embedded- cases study could use content analysis to trace specific Ghoshal ideas through his discussion cases, practitioner articles and scholarly papers (each stream of Ghoshal research would be treated as an embedded case).

We have not yet deeply considered rival explanations. For example, could Ghoshal's strong impact be a function of his superior intelligence or superior ability to persuade, independent of his choice to conduct case research and his enthusiasm for discussion cases? Other rival explanations may emerge from further studies of how other exemplary scholars' ideas propagate and develop - such as by considering Kathleen Eisenhardt (first recipient of the Ghoshal Award), other recipients of that award, and various influential IS case researchers. Thus far, no IS researcher has received the Ghoshal award, so to identify exemplary dobule- impact scholars to study, it will be necessary to apply similar criteria as those which are used by the Ghoshal Award committee to identify influential researchers in other domains who exemplify both rigor and relevance. By studying other 


\section{$31^{\text {ST }}$ Bled ECONFEREnCE: Digital Transformation: MEETING THE CHALlengeS JunE 17 - 20, 2018, BLED, SLOVENIA, CONFERENCE PROCEEDINGS \\ J. L. Gogan \& D. M. Murungi: Studying Complex IT Challenges? Discuss Real Cases}

influential scholars we will have an opportunity to learn to what extent conversations about real discussion cases help shape theory, compared with other forms of individual and collaborative sensemaking.

One could also choose to study the contrasting case: research practices of influential management and IS scholars who never conduct case research. By examining how these scholars engage in individual and collaborative sensemaking, compared with case researchers, we might be able to home in on the unique contribution played by real discussion cases and also identify alternative mechanisms that support discourse which improves theory. We acknowledge that many influential scholars (and many goodenough scholars) in the field of IS are neither case teachers nor case researchers. Surely other forms of discourse contribute to how scholarly ideas are aired and shaped and considered in terms of their potential to extend or build management theory or IT management theory.

Another limitation arises from our choice to focus on an extreme case, from which we cannot easily generalize -- Ghoshal set a nearly-unattainable standard of research productivity and excellence, whereas most scholars produce far fewer papers and books, and with modest impacts. We also recognize that case research skill is honed with practice and tempered by the researcher's deep knowledge of his/her field and related business fields. Discussion leadership skill is also honed through practice and tempered by broad knowledge. So, a scholar who seeks to emulate Ghoshal's approach to research first needs to read deeply and widely, and to develop expertise in carrying out high quality field case research, and to become skilled at writing real discussion cases, and become skilled at facilitating case discussions. It may be useful to study the scholarly journeys of good (not great) case researchers, to learn whether and how good-enough case research produces ideas that benefit theory and practice, and whether extensive discussion involving participants from multiple occupations and representing mulitple perspectives is fruitful in this context.

Prior studies that employed discourse analysis in social media and other IT-enabled contexts suggest opportunities for future research that would explore whether and how case discussions trigger theoretically-important ideas. For example, a three-case Wikipedia study of editing and written discussion on three topics -- Armenian Genocide, Ethanol Fuel, Intellectual Property - analyzed the findings in light of the Theory of Rational Discourse (Habermas 1984) and concluded that it is possible to design an information system that supports "the emancipatory objectives of critical social theory ... [by circumventing] much of the influence of relations of power and domination." (Hansen et al. 2009). Examining how "software development team members achieve a level of understanding that allows them to work in parallel yet create interdependent components or modules that work together seamlessly" another study (Hansen and Rennecker 2010) sought to understand how hermeneutic interpretation takes shape through collaboration. Further building on prior work by Weick (1995) and Weick et al. (2005), a third study proposed that "individuals make sense of new information technologies through discourse." It concluded: "In making sense of innovations, individuals present, negotiate and argue for a range of perspectives on the value of the emergent techology ... in a 
sensemaking process ... ultimately influencing the adoption and evolution of a technology.” (Berente et al. 2011, p.686).

Just as the three studies described above captured peoples' arguments about new IT or IS work, an important next step in our program of research could be to conduct a study which analyzes transcripts of one or more recorded discussions (by MBA and/or executive participants) of real cases that address complex IT challenges. That study could examine the arguments advanced in discussions, in light of each argument's potential for extending or building relevant theory. Once this first step is taken (to verify that theoreticallyimportant ideas are aired and shaped in case discussions), a next step would be to conduct further studies to investigate whether, how, and to what extent ideas aired in case discussions actually do inform theorizing, and whether, how and to what extent the theorizing actually informs influential research on complex IT challenges.

Based on one extreme-case study of an extraordinary scholar in the field of international management, we have argued for how discussion of rigorously-researched real cases may help IS scholars propose and improve theories addressing complex digital transformation challenges. We hope we have identified a way for the field of IS to avoid the fate of "ships passing in the night."

\section{Acknowledgments}

We gratefully acknowledge Chris Bartlett, for sharing his thoughts about case research, discussion cases, and Sumantra Ghoshal.

\section{References}

This list includes those Ghoshal papers and books that are cited in the text of this paper, whereas Appendix 1 lists all of his papers and books.

Allen, T.J. (1966). Managing the Flow of Scientific and Technological Information. MIT PhD Dissertation.

Andersen, E., Schiano, B. (2014). Teaching with Cases: A Practical Guide. Harvard Business School Press, 1495-ENG.

Bartlett, C.A. (1979). Multinational Structural Evolution: The Changing Decision Environment in International Divisions. Doctoral thesis, Harvard University Graduate School of Business Administration.

Bartlett, C.A., Ghoshal, S. (1987a). Managing Across Borders: New Strategic Requirements. MIT Sloan Management Review 28, no. 4 (summer): 7-17

Bartlett, C.A., Ghoshal, S..(1987b). Managing Across Borders: New Organizational Responses. MIT Sloan Management Review 29, no. 1 (Fall): 43-54.

Bartlett, C.A., Ghoshal, S. (1989). Managing Across Borders. Harvard Business School Press.

Berente N., Hansen S., Pike J.C., Bateman P.J. (2011). Arguing the Value of Virtual Worlds: Patterns of Discursive Sensemaking of an Innovative Technology. MIS Quarterly 35(3): 685709, September.

Boulding, K.E. (1956). General Systems Theory: The Skeleton of Science. Management Science 2(3): 197-208, April. 


$$
\begin{array}{r}
31^{\text {ST }} \text { Bled eConference: Digital Transformation: MeEting the Challenges } \\
\text { June } 17 \text { - 20, 2018, Bled, Slovenia, Conference ProceEdings } \\
\text { J. L. Gogan \& D. M. Murungi: Studying Complex IT Challenges? Discuss Real Cases }
\end{array}
$$

Boyer, E.L. (1990). Scholarship Reconsidered: Priorities of the Professoriate. The Carnegie Foundation for the Advancement of Teaching. Burt, R.S. (2004). Structural Holes and Good Ideas. American Journal of Sociology 110(2): Sept.

Camillus, J.C. (2008). Strategy as a Wicked Problem. Harvard Business Review 86: 98-101.

Camillus, J.C. (2016). Wicked Strategies: How Companies Conquer Complexity and Confound Competitors. U of Toronto Press.

Cash, J.I., Earl, M.J., Morison R. (2008). Teaming Up to Crack Innovation and Enterprise Integration Harvard Business Review November. Checkland , P. (1999). Systems Thinking, Systems Practice: A 30-Year Retrospective. Wiley.

Churchman, C.W. (1967). Wicked Problems. Management Science 14(4): Dec. doi:10.1287/mnsc.14.4.B141

Conklin, J. (2005). Dialogue Mapping: Building Shared Understanding of Wicked Problems. Wiley, November, ISBN 978-0-470-01768-5. Daft, R.L., Weick, K.E. (1984). Toward a Model of Organizations as Interpretation Systems. Academy of Management Review 9.

DeGrace, P., Stahl, H.L. (1990)/ Wicked Problems, Righteous Solutions: A Catalog of Modern Engineering Paradigms. Yourdon Press. Eisenhardt, K.M. (1989). Building theories from case study research. Academy of Management Review 14(4): 532-550.

Ghoshal, S. (1985). Environmental Scanning: An Individual and Organizational Level of Analysis. $\mathrm{PhD}$ Dissertation, MIT.

Ghoshal, S. (1986). The Innovative Multinational: A differentiated Network of Organizational Roles and Management Processes. DBA Thesis, Harvard Graduate School of Administration.

Ghoshal, S. (1987). Global Strategy: An Organizing Framework. Strategic Management Journal 8(5): 425-440, Sep-Oct. Ghoshal, S. et al. (1999). A New Manifesto for Management. MIT Sloan Management Review 40(3): 9-20, Spring.

Ghoshal, S. (2005). Bad Management Theories are Destroying Good Management Practices. AoM Learning \& Education 4(1): 75-91. Ghoshal, S., Bartlett, C.A. (1986). Tap your Subsidiaries for Global Reach. Harvard Business Review, Nov-Dec.

Habermas, J., Habermas, J. (1984). The Theory of Communicative Action. Beacon Press.

Hansen S, Berente N, Lyytinen K (2009). Wikipedia, Critical Social Theory and the Possibility of Rational Discourse. The Information Society 25(1): 38-59.

Hansen, S., Lyytinen, K., Markus, M.L. (2006). The Legacy of 'Power and Politics' in Disciplinary Discourse: A Citation Analysis. ICIS 2006 Proceedings: 407-424. Association for Information Systems.

Hansen S., Rennecker J. (2010). Getting on the Same Page: Collective Hermenutics in a Systems Development Team. Information and Organization 20: 44-63.

Hirschheim, R., Murungi, D. M., and Peña, S. (2012). Witty Invention or Dubious Fad? Using Argument Mapping to Examine the Contours of Management Fashion, Information and Organization 22(1): 60-84.

Hohmann, H. (2000). Rhetoric and Dialectic: Some Historical and Legal Perspectives, Argumentation 14(3): 223-234. Jacobs, S. (2000). Rhetoric and Dialectic from the Standpoint of Normative Pragmatics, Argumentation 14(3): 261-286. Krabbe, E.C. (2000). Meeting in the House of Callias: Rhetoric and Dialectic, Argumentation 14(3): 205-217.

Kolko, J. (2012) Wicked Problems: Problems Worth Solving, Stanford Social Innovation Review, Mar. Lawrence P.R, Lorsch J.W. (1967). Organization and Environment. Harvard University Press.

Leff, M. (2002). Relation between Dialectic and Rhetoric in Classical and Modern Perspective, in Dialectic and Rhetoric. Springer, 53-63. Ma, T., McGroarty, F. (2017). Social Machines: How Recent Technological Advances Have Aided Financialisation, Journal of Information 
Technology 32(3): 234-250.

Markus, M.L. (1983). Power, Politics and MIS Implementation. Communications of the ACM 26(6): 430-444, June. Mills A.J., Durepos G., Wiebe E. (2010) Encyclopedia of Case Research.Sage

Mintzberg, H. (1978). Patterns in Strategy Formulation, Management Science 24.

Mintzberg, H. (1990). The Manager's job: Folklore and fact. Harvard Business Review March-April. Naumes W., Naumes M.J. (2012). The Art and Craft of Case Writing (3rd Edition). ME Sharpe.

Nickerson J., Sanders R. (2014). Tackling Wicked Government Problems. Brookings Institution Press, Oct. ISBN13: 978-0815725077 Niemimaa, E., Niemimaa, M. (2017). Information Systems Security Policy Implementation in Practice: From Best Practices to Situated

Practices. European Journal of Information Systems 26(1): 1-20.

Paisley, W. (1972). The Role of Invisible Colleges in Scientific Information Transfer, Educational Researcher 1(4): 5ff, April. Ritchey, T. (2011). Wicked Problems - Social Messes: Decision Support Modelling with Morphological Analysis. Springer.

Rittel, H.W.J., Webber, M. (1973). Dilemmas in a General Theory of Planning, Policy Sciences. 4, 155-169. Rowland, R.C. (1987). On Defining Argument, Philosophy \& Rhetoric, pp. 140-159.

Rugman, A.M. (2002). The Influence of Managing Across Borders on the Field of International Management, Advances in Comparative International Management 14: 37-56, 2002.

Rynes, S. (2007). Editor's Foreword: Carrying Sumantra Ghoshal's Torch: Creating More Positive, Relevant, and Ecologically Valid Research, Academy of Management Journal 50(4): 745-747.

Sebastian, I.M., Ross, J.W., Beath, C., Mocker, M., Moloney, K.G., Fonstad, N.O. (2017). How Big Old Companies Navigate Digital Transformation. MIS Quarterly Executive 16(3), September.

Toulmin, S. (2003). The Uses of Argument (Updated Edition; first publication 1958). Cambridge: Cambridge University Press.

Tushman, M., O'Reilly, C. (2007). Research and Relevance: Implications of Pasteur's Quadrant for Doctoral Programs and Faculty Development. Academy of Management Journal 50(4): 769774.

Vermeulen, F. (2007). I Shall not Remain Insignificant: Adding a Second Loop to Matter More. Academy of Management Journal 50(4): 754-761.

Weick, K. (1995). Sensemaking in Organizations. Thousand Oaks, CA: Sage Publications.

Weick, K., Sutcliffe, K.M., Obstfeld, D. (2005). Organizing and the Process of Sensemaking. Organization Science 16(4): 409-421. Yin, R.K. (2018). Case Study Research and Applications: Design and Methods. Sage. 


\section{Appendix 1: Sumantra Ghoshal}

\section{Books (later editions noted)}

\begin{tabular}{|l|l|}
\hline 2006 & A Bias for Action (Bruch \& Ghoshal) \\
\hline 2005 & Organization Theory and the Multinational Corporation (Westney and Ghoshal) \\
\hline 2004 & The Future of the Multinational Company (Birkenshaw, Ghoshal, Markides, Stopford, Yip) \\
\hline 2002 & Managing Radical Change: What Indian Companies Must Do ... (Ghoshal, Piramal, Bartlett) \\
\hline 2002 & World Class in India: A Casebook of Companies in Transformation (Ghoshal, Piramal, Budhiraja) \\
\hline 2000 & Transnational Management: Text, Cases and Readings (co-author with CA Bartlett on first 5 editions) \\
\hline 1999 & Managing Across Borders: The Transnational Solution (2 editions, co-authored with CA Bartlett) \\
\hline 1997 & The Individualized Corporation (Ghoshal and Bartlettl) \\
\hline 1987 & The Strategy Process: Concepts, Contexts, Cases (Mintzberg, Lampel, Quinn, Ghoshal). \\
\hline 1997 & The Differentiated Network (Nohria, Ghoshal) \\
\hline
\end{tabular}

Career Top Ten Journal Publications, per Google Scholar (last two considered a tie for 10th)

\begin{tabular}{|c|c|c|c|}
\hline 16,862 & 1998 & $\begin{array}{l}\text { AoM } \\
\text { Review }\end{array}$ & $\begin{array}{l}\text { Nahapiet, Ghoshal. Social capital, intellectual capital, and organizational } \\
\text { advantage. }\end{array}$ \\
\hline 6,347 & 1998 & $\begin{array}{l}\text { AoM } \\
\text { Journal }\end{array}$ & $\begin{array}{l}\text { Tsai, Ghoshal. Social capital and value creation: The role of intrafirm } \\
\text { networks }\end{array}$ \\
\hline 3,562 & 2005 & $\begin{array}{l}\text { AoM } \\
\text { L\&E }\end{array}$ & $\begin{array}{l}\text { Ghoshal. Bad management theories are destroying good management } \\
\text { practices }\end{array}$ \\
\hline 2,970 & 1996 & $\begin{array}{l}\text { AoM } \\
\text { Review }\end{array}$ & Ghoshal, Moran. Bad for practice: A critique of the transaction cost theory \\
\hline 2,474 & $\begin{array}{l}1990 \\
*\end{array}$ & $\begin{array}{l}\text { AoM } \\
\text { Review }\end{array}$ & $\begin{array}{l}\text { Ghoshal, Bartlett. The multinational corporation as an interorganizational } \\
\text { network }\end{array}$ \\
\hline 1,745 & 1987 & SMJ & Ghoshal. Global strategy: An organizing framework \\
\hline 1,100 & $\begin{array}{l}1986 \\
*\end{array}$ & HBR & Ghoshal, Bartlett. Tap your subsidiaries for global reach \\
\hline 1,127 & 1989 & SMJ & Ghoshal, Nohria. Internal differentiation within multinational corporations \\
\hline 971 & $\begin{array}{l}1988 \\
*\end{array}$ & JIBS & $\begin{array}{l}\text { Ghoshal, Bartlett. Creation, adoption and diffusion of innovations by } \\
\text { subsidiaries }\end{array}$ \\
\hline 838 & 1994 & SMJ & $\begin{array}{l}\text { Nohria, Ghoshal. Differentiated fit and shared values: Alternatives for } \\
\text { mananging HQ-subsidiary relations }\end{array}$ \\
\hline 826 & $\begin{array}{l}1993 \\
*\end{array}$ & SMJ & $\begin{array}{l}\text { Bartlett, Ghoshal. Beyond the M-form: Toward a managerial theory of the } \\
\text { firm }\end{array}$ \\
\hline
\end{tabular}

38,802 citations

1 AoM Journal, 3 AoM Review, 1 JIBS, 1 HBR, 2 SMJ 4 coauthored w CA Bartlett 
37 Papers in the FT 50 journals (20 papers co-authored with C Bartlett indicated with *)

\author{
Academy of Management Review \\ California Management Review \\ Harvard Business Review \\ Journal \\ of \\ Internat \\ ional \\ Busine \\ ss \\ Studies \\ 1998 \\ $1988^{*}$ \\ Journal \\ of \\ Operati \\ ons \\ Manag \\ ement \\ Strategic Management Journal \\ MIT Sloan Management Review
}

199919961990

1998* 1997* 19921988

$20042003^{*} 2000^{*} 1995^{*} 1995^{*} 1994^{*} 1992^{*} 1990^{*} 1986^{*}$

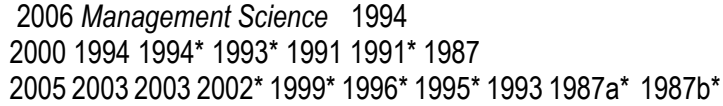

36 Discussion Cases (in CaseCentre and HBS Publishing Collections, Feb 2017)

\begin{tabular}{|l|l|l|l|}
\hline $\begin{array}{l}396- \\
142\end{array}$ & Lufthansa: The challenge of globalization. & $902-020$ & $\begin{array}{l}\text { Ogilvyone: Integrating } \\
\text { enterprise. }\end{array}$ \\
\hline $\begin{array}{l}389- \\
025\end{array}$ & $\begin{array}{l}\text { Scandinavian Airlines Systems (SAS) in } \\
1988 .\end{array}$ & $390-037$ & $\begin{array}{l}\text { Electrolux: Acquisition } \\
\text { integration of Zanussi. }\end{array}$ \\
\hline $\begin{array}{l}389- \\
021\end{array}$ & The Dunlop-Pirelli Union & $393-007$ & Cartier: A legend of luxury \\
\hline $\begin{array}{l}394- \\
140\end{array}$ & The transformation of AT\&T. & $396-028$ & Felix Constructions SA. \\
\hline $\begin{array}{l}392- \\
031\end{array}$ & Canon: Competing on capabilities. & $396-050$ & SA Chupa Chups \\
\hline $\begin{array}{l}396- \\
138\end{array}$ & $\begin{array}{l}\text { Philips Semiconductors: Breaking with the } \\
\text { past. }\end{array}$ & $396-154$ & $\begin{array}{l}\text { The LG Group: Leaping to the } \\
\text { Future. }\end{array}$ \\
\hline $\begin{array}{l}392- \\
055\end{array}$ & $\begin{array}{l}\text { Andersen Consulting (Europe): ...PRIZE } \\
\text { WINNER }\end{array}$ & $302-124$ & The transformation of Bajaj Auto. \\
\hline $\begin{array}{l}394- \\
396-\end{array}$ & ISS - International Service System A/S. & $399-088$ & $\begin{array}{l}\text { Housing Development } \\
\text { Corp. (HDFC) }\end{array}$ \\
\hline $\begin{array}{l}\text { Indian Oxygen Ltd: Transformation in India. } \\
394- \\
051\end{array}$ & General Electric synopsis. & $302-035$ & $\begin{array}{l}\text { Nicholas Piramal LTD: Integrating } \\
\text { diversity. }\end{array}$ \\
\hline $\begin{array}{l}388- \\
144\end{array}$ & $\begin{array}{l}* \text { Matsushita Electric Industrial (MEI) in } \\
\text { 1987. }\end{array}$ & $396-048$ & $\begin{array}{l}\text { WIPRO Corporation: Balancing the } \\
\text { future. }\end{array}$ \\
\hline $\begin{array}{l}392- \\
049\end{array}$ & $\begin{array}{l}\text { Lufthansa 2000: Maintaining the change } \\
\text { momentum. }\end{array}$ & $302-034$ & $\begin{array}{l}\text { Sun } \\
\text { innovation ... }\end{array}$ \\
\hline
\end{tabular}




$$
\begin{array}{r}
31^{\text {ST }} \text { Bled eConference: Digital Transformation: MeEting The Challenges } \\
\text { June } 17 \text { - 20, 2018, Bled, Slovenia, Conference ProceEdings }
\end{array}
$$

J. L. Gogan \& D. M. Murungi: Studying Complex IT Challenges? Discuss Real Cases

\begin{tabular}{|l|l|l|l|}
\hline $\begin{array}{l}302- \\
199\end{array}$ & $\begin{array}{l}\text { Hindustan Lever Limited: Levers for } \\
\text { change. }\end{array}$ & $399-054$ & $\begin{array}{l}\text { VIP Luggage: “It takes a lot to be a } \\
\text { VIP” }\end{array}$ \\
\hline $\begin{array}{l}396- \\
141\end{array}$ & British Telecommunications PLC ... & $305-149$ & Emirates Airline: Hub of the world. \\
\hline $\begin{array}{l}396- \\
139\end{array}$ & Standard Chartered Bank. & $302-090$ & $\begin{array}{l}\text { Natura: The magic behind Brazil's } \\
\ldots .\end{array}$ \\
\hline $\begin{array}{l}399- \\
053\end{array}$ & Siemens Nixdorf IS. & & \\
\hline $\begin{array}{l}392- \\
033\end{array}$ & The transformation of BP & & \\
& & & \\
\hline
\end{tabular}




\title{
Business Model Innovation and Firm Performance: The Role of Mediation and Moderation Factors
}

\author{
MOHAMMAD-ALI LATIFI \& HARRY BOUWMAN
}

\begin{abstract}
Business model (BM) innovation is vital for today's businesses. However, BM innovations can be irreversible, and therefore, in comparison to product, service or process innovation, entail bigger risk and ambiguity. Understanding the way in which BM innovation exerts influences over firm's performance would help business-owners to be more effective. Based on a systematic literature review, a model to examine how BMI impacts firm performance through mediating and moderating factors was developed. Based on in-depth analysis of 37 articles, we identified twenty moderating factors classified in four groups, i.e., FirmCharacteristics, Industry-Characteristics, BM Implementation, and BM Practices, and ten mediating factors, categorized in three sub-groups, i.e., Revenue Growth, Efficiency Growth, and Enhancing the Organizational Capabilities. This paper offers the grounding for empirical research as well contribute to the development of tools to assess the effectiveness of the BMI.
\end{abstract}

Keywords: • Business Model Innovation - Performance • Mediation • Moderation •

Correspondence AdDress: Mohammad-Ali Latifi, Ph.D. Candidate, Delft University of Technology, Technology, Policy and Mangement Faculty, Jaffalaan 5, Delft, The Netherlands, email: s.m.a.latifirostami@tudelft.nl. Harry Bouwman, Professor, Delft University of Technology, Technology, Policy and Mangement Faculty, Jaffalaan 5, Delft, The Netherlands, e-mail: W.A.G.A.Bouwman@tudelft.nl 
M. Latifi \& H. Bouwman: Business Model Innovation and Firm Performance: The Role of

Mediation and Moderation Factors

Business is subject to rapid change in technology, regulation, and customers and competitors behaviors. To sustain continued growth, to become more profitable or simply to survive, firms have to adapt their business logic. Since the advent of the Internet, the notion of Business Model (BM) and Business Model Innovation (BMI) gained a lot of attention in industry and academia. BMs describe the logic of how a company creates, delivers and captures value (Teece, 2010). As a means of renewal and adaptation to a changing market (Hartmann, Oriani, \& Bateman, 2013), Business Model innovation has the potential to create competitive advantage (Magretta, 2002), can enhance value creation (Teece, 2010) and opportunity recognition (Guo, Tang, Su, \& Katz, 2017) to exploit a market niche not addressed by competitors (C. Zott \& Amit, 2007). Since performance improvement is at the heart of any firms, the contribution of BMI on performance has attracted more and more attention (Hartmann et al., 2013; Lambert \& Davidson, 2013; Karimi \& Walter, 2016). Although these studies have enriched knowledge on the link between BMI and performance, this line of research is still at an infant stage (Zott and Amit, 2013).

Unlike innovation in product, service, and process, BMI requires fundamental changes in core components of the organization's BM (Nair, Paulose, Palacios, \& Tafur, 2013). BM Innovation (BMI) is therefore associated with high risk and uncertainty also due to the possible turmoil and resistance in the organization (Yannopoulos, 2013). The bestformulated BM may fail to lead to improved performance if not handled properly (Chesbrough, 2010; Knab \& Rohrbeck, 2014). For instance, Christensen, Bartman, and Van Bever (2016) identified that more than $60 \%$ of BMI efforts did not deliver the expected improved performance.

BMI does not automatically trigger impressive performance gains. So far, most academic studies looked primarily at types and components of BMs and proposed a large number of distinct explanations of BM performance (Haggège, Gauthier, \& Rüling, 2017). To date, we have no understanding of cause-effect relationships and mutual dependencies in the linkage between the BMI and firm performance (Methlie \& Pedersen, 2008). BMI scholars, recently, have called for causal analyses of antecedences and effects of BM, for large-scale investigations and application of advanced methodologies (Zott et al., 2011; Spieth et al., 2014; Clauss, 2016; Methlie \& Pedersen, 2008). With the exception of some qualitative studies, there is little empirical research examining factors which influence the success of BMI initiatives in firms (Patrick Spieth et al., 2016). In the literature, the causal relation between BMI activities and firm higher performance remains unclear (Sebastian Knab, René Rohrbeck, 2014).

In this study, we are not focused on the question of whether BMI has performance implications. This study attempts to address deeper questions about (1) 'WHY' and 'HOW' BMI affects performance, i.e. researchers simply directly relate BMI to performance without understanding what is in between, and (2), 'WHEN' and under which conditions, the relationship between BMI and firm performance can be 
strengthened. The first question leads to the need to understand mediators, and the second to understand moderators factors.

Therefore, our objective is:

to develop a conceptual framework that explains the complex mechanisms through which BMI influences firm performance.

We contribute to existing Business Model literature in two ways. First, the proposed model considers mediating and moderating effects elucidate how managers can ensure that BMI brings more benefits for the firms in terms of performance, and provides a conceptual foundation for practice and future research. Second, it helps practitioners to align their BMI efforts with firm's strategy and daily operational activities by providing a big more concrete picture of what is going on in the firm.

This paper is structured as follows: First, the literature on mediating factors between BMI and performance of the firm is shortly presented, followed by a discussion of our empirical constructs. Our research method is then described. Next, the conceptual model is presented. Finally, we draw conclusions, discuss limitations and come up with some suggestion for future research.

\section{Literature Review}

Business Model Innovation. A business model, which serves as a tool to analyze and communicate strategic choices (Lambert \& Davidson, 2013; Shafer, Smith, \& Linder, 2005), is seen as a realized expression of strategy (Casadesus-Masanell \& Ricart, 2010; Dahan, Doh, Oetzel, \& Yaziji, 2010) and articulates how available resources can be used effectively, how costs can be reduced, and how new sources of revenues can be leveraged (Chesbrough, 2007). According to Bock, Opsahl, George, and Gann, (2012), firms striving for a long-term performance need to innovate their BM. Moreover, the potential of technologies can often only be realized by using a new BM (Chesbrough \& Rosenbloom, 2002). At a fundamental level, scholars and practitioners agree that the BM is vital to growth (Teece, 2010; Terrenghi, Schwarz, Legner, \& Eisert, 2017), gain competitive advantage (Mitchell, 2003; Afuah, 2000), enhance long-term performance (Bock et al., 2012), and enable further innovation (Zott, 2011).

Through BMI, a firm may be able to exploit a new market which is not addressed by its competitors and open up a niche market (Hartmann et al., 2013). However, BMI is a highly complicated and risky process with an uncertain outcome (Waldner, Poetz, Grimpe, \& Eurich, 2015; Marc, Sosna; Rosa Nelly, Trevinyo-Rodriguez; Ramakrishna, 2010; Chesbrough, 2010), because it necessitates experimentation (McGrath, 2010), managing conflicts, interaction with people on different level of expertise and modifying the ongoing process of BM (Latifi \& Bouwman, 2017) and asks for specific leadership style (Smith, Binns, and Tushman, 2010). Hence, knowing how and when to innovate a $\mathrm{BM}$ is a serious challenge (Hartmann et al., 2013). 
Firm Performance. Performance has been at the core of management thinking (Haggège et al., 2017), as performance directly affects the continuation of the firm, it became an essential concept in management research (Rauter, Jonker, \& Baumgartner, 2017). Venkatraman and Ramanujam (1986) have pointed out that firm performance is a multidimensional construct. They proposed three general levels of firm performance, i.e. financial performance, business performance and organisational effectiveness, each which their own indicators like for example return on assets (ROA) (Parker, 2000), growth, market share, diversification, and product development (Gray, 1997), and employees satisfaction, quality, and social responsibility (Rauter et al., 2017).

Initial research model. Building on the short review and following Foss and Saebi (2016), we consider performance, innovativeness, as outcomes. Moderators can be studied on a macro, or on a micro/firm level as depicted in figure 1. This model is elaborated upon based on a systematic literature review.

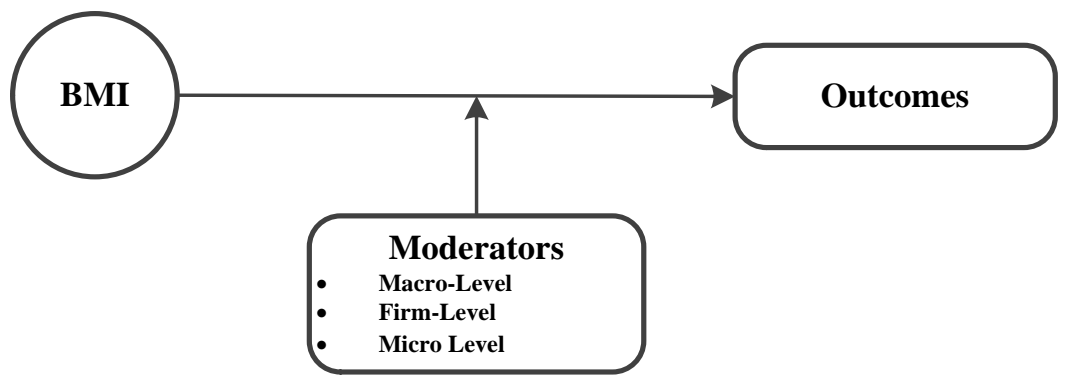

Figure 1: Initial Research Model adapted from Foss \& Saebi (2016).

A systematic literature review is based on replicable, scientific, and transparent process (Cook et al.,1997). Using such an approach researcher's potential bias will become explicit, effects of chance decrease, and the validity of data analysis will enhance (Reim, Panda, \& Ortqvista, 2015). As mentioned, we were looking for finding out under which moderating and mediating mechanism BMIs has an effect on performance. Next, we made use of academic databases such as Web of Science, ABI/INFORMS, Science Direct, and Wiley Online Library. 'Business model,' 'mediating,' 'moderating,' and 'performance' were used as keywords in search of databases. We did not set any limitations on papers' publication date or types of documents. So we included journal papers, conference articles, working papers as well as book chapters. This search yielded 115 publications considered to be relevant based on titles, abstract and keywords. Omitting duplications, these produced 97 unique citations. 
In the third step, based on the abstracts, collected publications were screened for their match and correspondence with our research objective. We include papers based on the following criteria:

- Are explicitly and empirically tested hypotheses about the relation between BMI and Business Performance by using a quantitative, empirical, analytical approach being proposed.

- Is reference made to BMI as a way to change main components of the BM by introducing a new system of value creation, value proposition and value capture?

- Refers to Business Performance, as discussed before

- Refers to the firm as a unit of analysis.

Based on criteria mentioned above, thirty-five papers found to be irrelevant at this stage. Only reviews reporting relevant outcomes (remaining fifty-two publications) were reviewed to find out that articles met the above-specified inclusion criteria. Through indepth review, twenty-seven papers were identified as relevant. Furthermore, references of identified articles were used as a secondary source of literature analysis. This resulted in identifying ten additional papers. These papers were included in our sample. As a result, our systematic literature review was built on thirty-seven articles.

As said before, many research has recently revealed that there is a lack of knowledge in the causal relationship between BMI and firm performance and asked to consider mediation and moderation effects between these two. Therefore, we expected to find few numbers of studies, hence did not set any limitation on publication years and paper types. Figure 2 has been shown that the topic has received attention in recent years, and approximately $76 \%$ of our 37 selected articles were published between 2012 and 2017 . Moreover, 33 out of them were journaled papers (89\%), three conference papers $(8 \%)$, and one working paper (3\%).

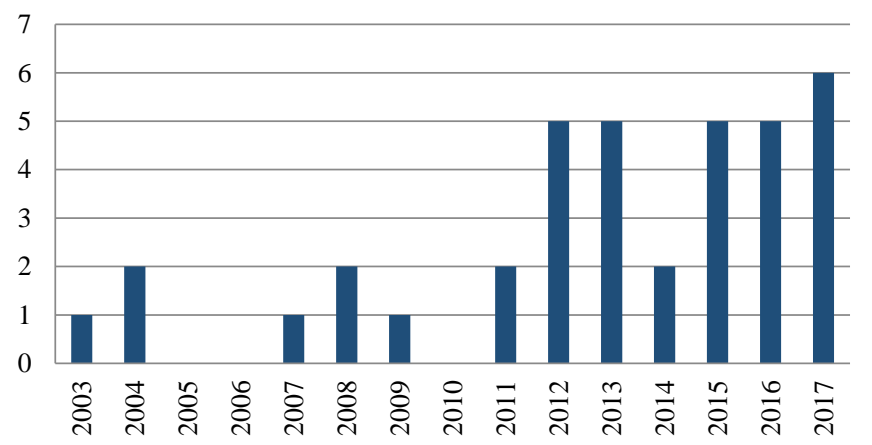

Figure 2: Number of selected papers in the final analysis (Yearly)

In describing, classifying and analyzing the selected papers, we employed a coding approach classifying mediator, moderator, and control variables. All key points were 
listed on a coding sheet (Dey, 1993) and classified into new categories (Burnard, 1991). After this open coding, the categorized list was jointed under higher level classifications. To limit the number of categories, data were grouped (Dey, 1993).

\section{$4 \quad$ Results}

\subsection{Moderation Effects}

Different factors introduced in the literature as contingency and moderating variables which can effects relationship between BMI and fir performance. Some factors were not linked directly to the firm but are related to its environment such as industry sectors. Other factors were associated with firm's attributes, for instance, its size and age. We could find a great amount of identified factors were related to how the BMI was implemented within the firm, for example, the employees' skills and commitment can strengthen the relationship between BMI and performance. There was another group of factors were mostly related to BMI practices, such as the speed, scope, and novelty of BMI which can influence the relationship. Therefore based on abovementioned criteria, we categorized identified moderating factors into four groups; BMI-Implementation, BMI-Practices, Firm-Characteristics, and Industry-Characteristics.

BMI-Implementation. In our previous study on why BMI fail to deliver expected outcomes (Latifi \& Bouwman, 2017), we revealed that about $60 \%$ of identified barriers to accomplish BMI objectives and attain expected performance lies in the implementation stage of BM. Although managers mostly concentrate and spend a lot of time and energy on (re-)designing a viable BM, the major challenges can be found in the implementation of a BM, as BMI implies fundamental (Nair et al., 2013). Various studies mentioned "poor implementation" as one of the main reasons of BM failure (Osterwalder, 2012; Batocchio, Ghezzi, \& Rangone, 2016; Chesbrough, 2010; Yannopoulos, 2013). Therefore the more skilfully and knowledgeably firm implement their BMI, the more performance enhancement will occur. Many studies revealed that key source of BM failure is connected to its management (Batocchio et al., 2016; Zott, Amit, \& Massa, 2010; Chesbrough, 2010). Moreover, Martins, Gerasymenko, De Clercq, and Saprienza (2014) affirmed a positive relationship between BM change experience of a firm's CEO and performance.

People in a company are key to success or failure of a BM innovation program (Hittmár, Varmus, \& Lendel, 2014). Depending on the degree of changes in the BM, not only some employees' training is required to develop relevant capabilities (Batocchio et al., 2016; Hittmár, Varmus, \& Lendel, 2014), but hiring new personnel with special qualification also might be needed (Knab \& Rohrbeck, 2014).

$\mathrm{BM}$ is often used as an approach to make clear what the core logic of a company is; it is also important to share and to communicate the BM within the organization. Serrano, Serrano, and Al-Debei (2010) stated that lack of communication is an important issue of successful implementation of BMI. Lack of communication also leads to distrust between 


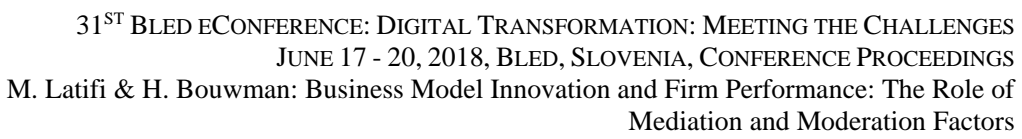

employees, departments, and management (Hittmár et al., 2014), therefore can influence the effective implementation of BMI.

BMI-Practices. Foss and Saebi (2017) reported that different organizational capabilities and practices are required to support BMI such as experimentation and learning through trial-and-error (Marc Sosna; Rosa Nelly, Trevinyo-Rodriguez; Ramakrishna, 2010), and tools to support practitioners in managing the BMI process were presented.

Moreover, as one of the management practices in BM innovation, Bocken, Weissbrod, and Tennant, (2016) stated that business experimentation not only can lead to creating more BMI but also is viewed as a process to achieve greater levels of innovation in the BM. According to Brunswicker, Wrigley, and Bucolo (2013), the BM 'experimentation', helps firms to test assumptions and hypothesized outcome through empirical observations such as usage data and market share. Yli-huumo, Rissanen, Maglyas, and Smolander (2015) argued that most of their research participant acknowledge that even though using experimentations might require investing more time to create and release the features to the end-user, it is still a better approach when expanding business and introducing highquality products.

Although there are some commonly used tools and frameworks such as Canvas, STOF, CSOFT, and VISOR and tools (see businessmakeover.eu) to support the process of BMI, Terrenghi et al. (2017) expressed the necessity for developing of software and tools that support the entire process of BM management. There is however hardly empirically studies on whether BM tooling contributes to the process of BMI or not (de Reuver et al., 2018, forthcoming). Karimi and Walter (2016) argued that companies mostly use the BM concept for analysis and design, but have not yet fully embraced it as management instrument in the implementation and control phases. Moreover, according to Gerasymenko et al. (2015) and Nicholls-Nixon and Cooper (2000); the scope of innovation in $\mathrm{BM}$, for instance, to change in one or two components or to change entire the BM, i.e., an architectural change, can impact the outcome of BMI. Apart from the scope, the speed of change and the path followed to reach the new BM plays a critical role (Foss \& Saebi, 2016).

The degree of novelty of BM also can be important. There is a different level of performance expected for new to the firm than for new to the industry or even new to the world BMs (Dahlin \& Behrens, 2005; Zott \& Amit, 2007).

Firm-characteristics. Prior research revealed that firms do not attain equally from innovativeness because their capability to capture the value of innovativeness depends on different characteristics of firm and industry (Sorescu and Spanjol 2008; Tellis, Prabhu, and Chandy 2009). Therefore, some specific characteristics of organizations can strengthen the relationship between BMI on performance. Based on our literature review, firm-characteristics consists of firm size, firm experience, firm age, advertising intensity, expenditures on R\&D, the intensity of change, and scope of change in BM. 
Hartmann et al. (2013), found the size of the firm and experience of the firm to be positively related to performance (Zott \& Amit, 2007; Klepper \& Simons, 2000) and revealed the moderating role of firm size and firm experience. The size of the firm has been associated with firm innovation in a variety of research (Gronum, Steen, \& Verreynne, 2016; Heij, Volberda, \& Van den Bosch, 2014; Rubera \& Kirca, 2012; Damanpour, 1991). Rubera and Kirca (2012) argued that larger the firms, the more likely to benefit from innovativeness in terms of market and financial positions. They can utilize more resources and reach consumers more quickly because they have better access to distribution channels, enjoy economies of scale, benefit from brand reputation.

Gronum et al. (2016) consider firm age, measured by the number of years since its founding, as moderating variables on the relationship between BMI and performance. In their research, Heij et al. (2014) also took into account firm age as a moderator variable. Rubera and Kirca (2012) and Zott and Amit (2007) considered the advertising intensity as a moderating effect in their research. Furthermore, expenditures on $R \& D$ has been seen as an important factor which influences the relationship between BMI and firm performance (Zott \& Amit, 2007). Gerasymenko et al. (2015) revealed that the intensity of change in BM innovation, incremental or radical change, has a moderating effect on the relationship between BMI and firm performance. They also consider the scope of change, innovation in the core or peripheral aspects of the firm BM as a moderator.

Industry-characteristics. Industry-characteristics impact has theoretical foundations in the Industrial Organisation theory discussing environmental factors in relation to the industry in which a firm acts and having a significant influence on firm's performance (Rauter et al., 2017). We considered industry sector, industry life cycle, industry competition, environmental conditions (dynamism, complexity, and turbulence), hightechnology versus low-technology industries as relevant industry-characteristics factors. Gronum et al. (2015), Heij et al. (2014), and Brettel, Strese, and Flatten (2012) considered industry sector as a moderating factor between BMI and firm performance. Moreover, industry life cycle has an important role to play in affecting BMs (Wei, Song, \& Wang, 2017). Waldner et al. (2015) expressed that most BMI to occur in the emergent life cycle stage of the industry, but not in mature or in decline stages.

Rules of the game in the business world are not only determined by the firm's actions but also by competitors and environmental causes (Carayannis, Sindakis, \& Walter, 2015). When a potential competitor decides to enter the industry, the firm may have to modify its plan of action based on competitor's BM (Casadesus-Masanell \& Ricart, 2010). Waldner et al. (2015) in their empirical research on a sample of 1,242 Austrian firms, argued that industry competition negatively influences the degree of BMI.

In different studies, dynamic environments were considered as moderating variable. Dynamic environments can be seen as a source of opportunities (Schneider and Spieth, 2013). Thus, in more dynamic environments, developing and running a new BM can be expected to have a stronger effect on firm performance than in less dynamic environments (Heij et al., 2014). On the other hand, regulation changes occurring within and outside 
the industry can influence the performance of an ongoing BM innovation (Bohnsack, Pinkse, \& Kolk, 2014; De Reuver et al., 2009). Zott and Amit (2007) in their research on 190 entrepreneurial firms, found a little support to moderating effect of environmental conditions on the relationship between BM design and the performance of a firm.

Rubera and Kirca (2012) argued that since innovation has a different impact on hightechnology and low-technology industry, the technology level of industry can be taken into account as a moderator. Innovation is crucial for competition in high-tech industries, in which firms are forced to constantly introduce new products to meet rapidly changing consumer needs.

\subsection{Mediation Variables}

We found ten mediating effects and categorized them into four groups which are associated with Efficiency Growth, Revenue Growth, and Enhancing the Organizational Capabilities.

Efficiency Growth. Zott and Amit (2007) stressed that one of the key influences of BMI on firm performance occurs when it focuses on efficiency. BMI can take the ICT ventures to complete its transactions more efficient, by reducing transaction costs within the firm and with outsiders (Ben Romdhane Ladib \& Lakhal, 2015). According to Chesbrough (2007), BMI leverage performance through utilizing available resources more effectively, as well as reduction in production costs. For instance, by adopting new partnering models such as outsourcing, organizations are able to more effectively scale down operations.

Efficiency-centered BM design theme, according to Gronum et al. (2015) can enhance the firm performance through reduction in inventory costs and decrease in marketing, sales, and other communication expenditures for all participants in company supply chain. Furthermore, increasing scale leads to reducing operating costs. Therefore, by focusing on lowering operating cost, benefits can be passed on to customers.

Revenue Growth. BMI can provide opportunities both during periods of rapid economic growth and at times of economic downturn via exploiting ongoing industry transformation. Plenty of scholars stated that BMI through creating values (Teece, 2010) and opportunity recognition (Guo et al., 2017) leads to exploit a market niche not addressed by its competitors (Zott \& Amit, 2007) and in such a way, increase firm's revenue growth. To illustrate, by adopting new partnering models, organizations are able to create additional access to additional resources to scale up quickly or complementary resources as new opportunities for service bundling arise.

BMI using new ways for economic exchanges and focusing on novelty can create value for stakeholders (Ladib \& Lakhal, 2015). Introducing a new BM with new components also can provide opportunities for new complementary effects among existing components of services and products (Heij et al., 2014) an in this way it can increase 
revenues. Vermeer (2016) shows that new revenue model, as one of the components of $\mathrm{BM}$, has the strongest effect on firm performance (Vermeer, 2016).

Gronum et al. (2015) confirmed the mediatory effect of the novelty design theme between innovation breadth and firm performance. They stated the BM novelty could improve the performance through the following mechanism; firm can offers new combinations of products, services, and information to customers (bundling), links customers to products/services in novel ways (new experience) (Bouwman et al, 2008), design new transaction mechanism (Zott \& Amit, 2007), and finally, innovating in one component needs to be complemented by changes in other components.

Enhancing the Organizational Capabilities. Organizational capabilities are required to make BMI efforts. Firms to be enabled to renew their BM, need to possess a certain level of capabilities such as detecting new technology and market needs, open-mindedness and innovativeness. Once firm starts to explore, design, test and implement their BMI, this process of BMI, enhance its organizational capabilities. For example, being opportunity seeker is required for developing a BMI, on the other hand, conducting a BMI after a while, improve opportunity seeking capability of the firm. In other words, with BMI firms are expected to improve their organizational capabilities.

The capacity to innovate is one of the most significant factors that improve business performance (Burns \& Stalker, 1961; Porter, 1990). Culture, defined as expressed norms, values, and beliefs, boost behavior ultimately related to business performance (Hult et al., 2004). When specific attitudes are accommodated in the organizational culture, the consequences of behavior are expanded across circumstances, groups, and individuals within the firm. As Barney (1986) stated a culture that supports the implementation of a strategic attempt, like in our research BMI, is not easy to imitate and then can lead to a sustainable competitive advantage.

Another organizational capabilities might mediate the relationship between BMI and performance is the capability of opportunity-seeking. The role of BMI in opportunityseeking behavior has been emphasized in several studies (Chesbrough, 2010; Dewald and Bowen, 2010; Doz and Kosonen, 2010). Exploiting opportunities were proved as a mean to impact firm performance by BM (Bock et al., 2012).

BMI is a result of performing innovation in the firm BM. As a consequence, BMI can increase the innovativeness of people within the firm in various ways such as sharing the business idea entire organization, developing the opportunity seeking capabilities and creating real value propositions .

Moreover, organizational learning is one of the critical organizational processes through which information and knowledge can be processed, and it can change the attributes, behaviors, capabilities, and performance of an organization. Hu (2014) in his research conducted on 163 companies confirmed that BMs affect technological innovation performance through organizational learning indirectly. 
Mahmood and Hanafi (2013) affirmed that entrepreneurial orientation is a capability that provides a competitive advantage and impressive performance to the firm. In addition, research conducted by Ladib et al. (2015) also expressed that by learning how gathering the unique know-how and utilizing of rare resources, BMI creates a benefit of a hard to imitate innovation.

Building on the literature review, we developed an exhaustive and reference model (Figure 3) to explore the relationship between BMI and firm performance.

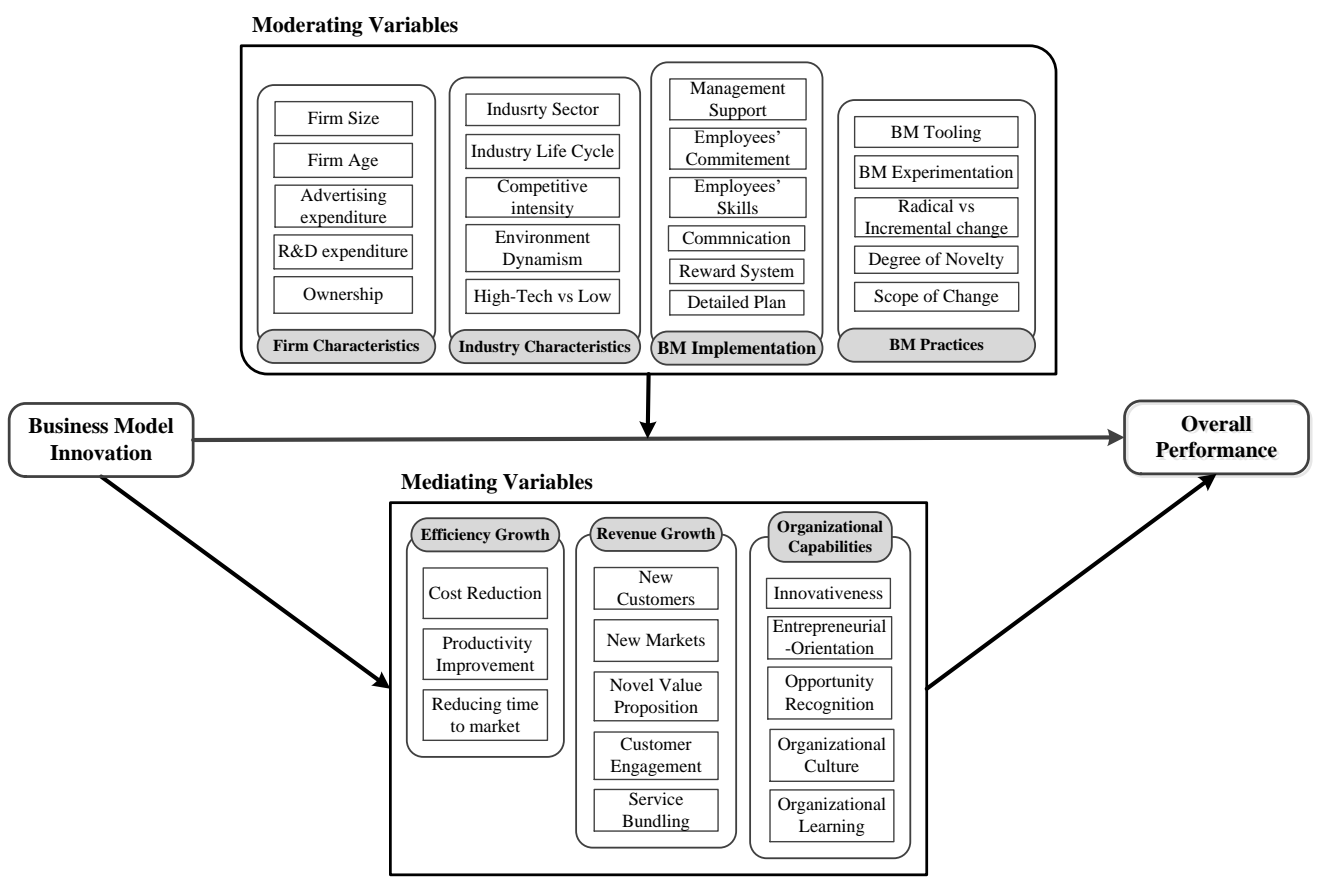

Figure 3: Research outcome: BMI mechanism to boost firm performance

\section{$5 \quad$ Discussion and Conclusion}

These days the only thing that is constant is change itself. Adapting to change is crucial for businesses. Being aware of this complex and dynamic environment, companies have to introduce a new way of earning money and improve their performance by innovating their BM. Although in the last two decades researchers conceptualized, defined and provided different frameworks and tools to support practitioners and company-owners to develop their BMI, there is still ambiguity about how BMI leads to firm performance. We found empirical research with contradictory outcomes; some revealed that there is a positive, some negative and in some cases they could not find significant relations. Understanding the mechanism under which BMI impact performance is not an easy task 
due to many variables at play, the long assumed causal chain of events, while in practices BMI processes are far from linear and can be considered to be a kind of tinkering process (Heikkilä et al., 2018). As stated by Foss and Saebi (2016), it is not a linear mechanism for creating value starting from suppliers moving to the firm and the customers. Value creation comprises a more complicated, interconnected set of interactions and activities among different actors.

To fully understand the effect of BMI on performance, it requires clear identification of the causal structure in the relationship between BMI and performance (Fry \& Smith, 1987) and in-depth know-how what actually happens in BMI projects, with paths are followed and with what outcomes, as is shown by extensive case study research (Heikkilä et al., 2018). In this paper, based on systematic literature review of empirical studies, we develop a model that presents potential moderating, and mediating effects are playing a role when researching BMI and firm performance (see figure 3).

To identify under which conditions, the relationship between BMI and firm performance can be affected, we could identify twenty moderating factors and classify them in four sub-groups; Firm-Characteristics includes firm size, age, advertising and R\&D expenditures, and type of ownership; Industry-Characteristics consists of industry sector and life cycle, competition intensity, environment dynamism and level of technology; BM Implementation comprise of top management support, employees' commitment and skills, communications among different stakeholders and, having detailed plan of action, and the last one, BM Practices; includes BM tooling, BM experimentation, Scope of change, Speed of Change, and Degree of Novelty.

While looking at this different moderating subgroups, the moderating factors which are related to firm-characteristics and industry-characteristics are mostly non-variant, and firms cannot manage them to improve the performance of BMI effort. For instance, although firm size, firm age, and industry sector can influence the relationship between BMI and performance, firm owners and managers are not probably able to change them. On the other hand, moderating factors which associated with BM-Implementation and BM-Practices are mostly actionable. For example, practitioners can use BM tooling, BM experimentation or increase their employees' motivation or not; they can make the decision for taking some specific action. BM-Implementation and BM-Practices related factors are more manageable. Therefore, there is a lot of room for firm owners, managers and even researchers to work in these two specific subgroups to reach a higher firm performance.

To answer under which casual mechanism the BMI indirectly influence the firm performance, in next step, we found 10 mediating factors and classify them into three sub-groups; Efficiency \& Cost Reduction, e.g. focus on productivity, reducing time to market, and cost reduction due to partnership; New Customers \& Revenue Growth, e.g. Focus on new value propositions, customer engagement, service bundling and creating lock-in effect, and the next mediator sub-group, Enhancing the Organizational 
Capabilities consists of innovativeness, organizational learning, organizational culture, developing opportunity recognition and fostering entrepreneurial orientation.

Although our findings revealed that the research to find the mediation and moderation factors between BMI and firm performance are limited, we found 23 studies proposing moderating effect and 19 research considered specific factors as control variables (which means that they can affect the relationship). However, only eleven studies tested the causal relationship and mediation effects between BMI and firm performance. Because of the significant role of mediation factors in understanding how BMI improve the outcomes of the company, more research in this field is required. Developing a testable casual model of how BMI impact on firm performance, we argue that we fill the gap in the literature and the model can pave the way for future researchers. Authors, at a next step, aim to examine the model by using empirical data gathered from SMEs throughout of Europe in 2017 and 2018.

This paper also has some limitations. We were able to identify 37 articles in the selected academic database which hypothesized and empirically tested the mediation and moderation effects on relationships between BMI and firm performance for in-depth analysis; However, by focussing on journal papers only, we might have missed recent research, as well as research in other languages than English. Limitations related to selection bias may also play a role.

\section{Acknowledgment}

The work leading to these results has received funding from the European Community's Horizon 2020 Program (2014-2020) under grant agreement 645791. The content herein reflects only the authors' view. The European Commission is not responsible for any use that may be made of the information it contains.

\section{References}

Afuah, A. and Tucci, C. (2000) Internet Business Models and Strategies: Text and Cases. McGrawHill, New York.

Baden-Fuller C, Haefliger S. (2013). Business Models and Technological Innovation. Long Range Planning.

Batocchio, A., Ghezzi, A., \& Rangone, A. (2016). A method for evaluating business models implementation process. Business Process Management Journal, 22(4), 712-735. https://doi.org/10.1108/BPMJ-08-2015-0117

Ben Romdhane Ladib, N., \& Lakhal, L. (2015). Alignment between business model and business strategy and contribution to the performance: Empirical evidence from ICT Tunisian venture. Journal of High Technology Management Research, 26(2), 168-176.

Barney, J., (1986). Strategic factor markets: expectations, luck, and business strategy. Manag. Sd. 32 (10), 1231-1241.

Bock, A. J., Opsahl, T., George, G., \& Gann, D. M. (2012). The Effects of Culture and Structure on Strategic Flexibility during Business Model Innovation. Journal of Management Studies, 49(2), 279-305. https://doi.org/10.1111/j.1467-6486.2011.01030.x

Bohnsack, R., Pinkse, J., \& Kolk, A. (2014). Business models for sustainable technologies: 
$31^{\text {ST }}$ Bled eConference: Digital TRANSFormation: MeEting THe Challenges

June 17 - 20, 2018, BLED, SLOVENIA, CONFERENCE PROCEEDINGS

M. Latifi \& H. Bouwman: Business Model Innovation and Firm Performance: The Role of

Mediation and Moderation Factors

Exploring business model evolution in the case of electric vehicles. Research Policy, 43(2), 284-300.

Brettel, M., Strese, S., \& Flatten, T. C. (2012). Improving the performance of business models with relationship marketing efforts - An entrepreneurial perspective. European Management Journal, 30(2), 85-98. https://doi.org/10.1016/j.emj.2011.11.003

Brunswicker, S., Wrigley, C., \& Bucolo, S. (2013). The Experimental Nature of New Venture Creation, 139-151. https://doi.org/10.1007/978-3-319-00179-1

Burnard, P. (1991). A method of analysing interview transcripts in qualitative research. Nurse Education Today, 11(6), 461-466. https://doi.org/10.1016/0260-6917(91)90009-Y

Burns, T. and Stalker, G.M. (1966) The Management of Innovation. London: Tavistock.

Carayannis, E. G., Sindakis, S., \& Walter, C. (2015). Business Model Innovation as Lever of Organizational Sustainability. Journal of Technology Transfer, 40(1), 85-104.

Casadesus-Masanell, R., \& Ricart, J. (2010). From strategy to business models and onto tactics. Long Range Planning, 45. https://doi.org/10.1016/j.lrp.2010.01.004

Chesbrough, H. (2007). Business model innovation: it's not just about technology anymore. Strategy \& Leadership, 35(6), 12-17. https://doi.org/10.1108/10878570710833714

Chesbrough, H. (2010). Business model innovation: Opportunities and barriers. Long Range Planning, 43(2-3), 354-363. https://doi.org/10.1016/j.lrp.2009.07.010

Chesbrough, H., \& Rosenbloom, R. S. (2002). The role of the business model in capturing value from innovation: evidence from Xerox Corporation' $\mathrm{s}$ technology spin-off companies. Industrial and Corporate Change, 11(3), 529-555. https://doi.org/10.1093/icc/11.3.529

Christensen, C. M., Bartman, T., \& Van Bever, D. (2016). The hard truth about business model innovation. MIT Sloan Management Review, 58(1).

Clauss, T. (2016). Measuring Business Model Innovation: Conceptualization, Scale Development and Proof of Performance.pdf. $R \& D$ Management, (1), 1-19. https://doi.org/10.1111/radm.12186

Cook, Deborah ; Randolph, Adrienne; Kernerman, Phillip; Cupido, Cynthia; King, Derek; Soukup, Clara; Brun-Buisson, Christian. ,(1997). "Central venous catheter replacement strategies: A systematic review of the literature", Critical Care Medicine, August 1997 - Volume 25 - Issue 8 - pp 1417-1424

Dahan, N., Doh, J., Oetzel, J., Yaziji, M., (2010). Corporate NGO Collaboration: Co-Creating New Business Models for Developing Markets. Long Range Planning 43 (2-3), 326e342.

Damanpour, Fariborz (1991), "Organizational Innovations: A Meta-Analysis of Effects of Determinants and Moderators," Academy of Management Journal, 34 (3), 555-91.

Dewald, J. and Bowen, F.E. (2010) 'Storm clouds and silver linings: responding to disruptive innovations through cognitive resilience', Entrepreneurship Theory and Practice, Vol. 34, No. 1, pp.197-218.

Dey I. (1993) “Qualitative Data Analysis. A User-Friendly Guide for Social Scientists”. Routledge, London.

Doz, Y.L. and Kosonen, M. (2010) 'Embedding Strategic Agility - A Leadership Agenda for Accelerating Business Model Renewal.' Long Range Planning, vol. 43, no. 2-3, pp. 370-382.

Foss, N. J., \& Saebi, T. (2016). Fifteen Years of Research on Business Model Innovation: How Far Have We Come, and Where Should We Go? Journal of Management, $X X(\mathrm{X}), 1-28$. https://doi.org/10.1177/0149206316675927

Fry, L. W., \& Smith, D. A. (1987). Congruence, contingency, and theory building. Academy of Management Review, 12: 117-132.

George, G., Bock, A.J. (2011). The Business Model in Practice and its Implications for Entrepreneurship Research. Entrep. Theory Pract. 35, 83-11. 
Gerasymenko, V. De Clercq, D. Sapienza, H. J. (2015). Changing the Business Model: Effects of Venture Capital Firms and Outside CEOs on Portfolio Company Performance. Strategic Entrepreneurship Journal, 9:1, 79-98.

Gronum, S., Steen, J., \& Verreynne, M.-L. (2016). Business model design and innovation: Unlocking the performance benefits of innovation. Australian Journal of Management, 41(3), 585-605.

Guo, H., Tang, J., Su, Z., \& Katz, J. A. (2017). Opportunity recognition and SME performance: the mediating effect of business model innovation. $R \& D$ Management, 47(3), 431-442.

Haggège, M., Gauthier, C., \& Rüling, C.-C. (2017). Business model performance: five key drivers. Journal of Business Strategy, 38(2), 6-15. https://doi.org/10.1108/JBS-09-2016-0093

Hartmann, M., Oriani, R., \& Bateman, H. (2013). The Performance Effect of Business Model Innovation: An Empirical Analysis of Pension Funds. 35th DRUID Celebration Conference 2013, 1-34. https://doi.org/10.5465/AMBPP.2013.10986abstract

Heij, C. V., Volberda, H., \& Van den Boasch, F. (2014). How Does Business Model Innovation Influence Firm Performance : the Moderating Effect of Environmental Dynamism.

Heikkilä, M., H. Bouwman, \& J. Heikkilä (2017,). From Strategic Goals to Business Model Innovation Paths: an exploratory study. Journal of Small Business and Enterprise Development.

Hittmár, Š., Varmus, M., \& Lendel, V. (2014). Proposal of Model for Effective Implementation of Innovation Strategy to Business. Procedia - Social and Behavioral Sciences, 109, 1194-1198. https://doi.org/10.1016/j.sbspro.2013.12.611

$\mathrm{Hu}$, B. (2014). Linking business models with technological innovation performance through organizational learning. European Management Journal, 32(4), 587-595. https://doi.org/10.1016/j.emj.2013.10.009

Karimi, J., \& Walter, Z. (2016). Corporate Entrepreneurship, Disruptive Business Model Innovation Adoption, and Its Performance: The Case of the Newspaper Industry. Long Range Planning, 49(3), 342-360. https://doi.org/10.1016/j.lrp.2015.09.004

Klepper, S., Simons, K.L., (2000). Dominance by birthright: entry of prior radio pro- ducers and competitive ramifications in the U.S. television receiver industry. Strategic Management Journal, 21, 997-1016.

Knab, S., \& Rohrbeck, R. (2014). Why intended business model innovation fails to deliver: Insights from a longitudinal study in the German smart energy market, 527-538. Retrieved from http://papers.ssrn.com/sol3/Delivery.cfm?abstractid=2447651

Lambert, S. C., \& Davidson, R. A. (2013). Applications of the business model in studies of enterprise success, innovation and classification: An analysis of empirical research from 1996 to 2010. European Management Journal, 31(6), 668-681. https://doi.org/10.1016/j.emj.2012.07.007

Latifi, S. M., \& Bouwman, H. (2017). Why does Business Model Innovation fail to deliver expected outcomes? Proceedings of ISPIM Conferences, (March), 1-16. Retrieved from http://search.ebscohost.com/login.aspx?direct=true \&db=bth\&AN=122622746\&site=ehostlive

Magretta, J. (2002). Why Business Models Matter, HBR.pdf, 86-92.

Marc, Sosna; Rosa Nelly, Trevinyo-Rodriguez; Ramakrishna, V. (2010). Business Model Innovation Through Try and Error Learning_Sosna_2010.pdf, 43(383), 407.

Martins, L., Gerasymenko, V., De Clercq, D., \& Saprienza, J. H. (2014). Changing the business model: effects of venture capital firms and outside CEOs on portfolio company performance. Strategic Entrepreneurship Journal, 1(1), 27-47. https://doi.org/10.1002/sej

McGrath, R. G. (2010). Business models: A discovery driven approach. Long Range Planning, 43(2-3), 247-261. https://doi.org/10.1016/j.lrp.2009.07.005

Methlie, L. B., \& Pedersen, P. E. (2008). Business model performance: Reflections from three studies of mobile data services. Nordic and Baltic Journal of Information and Communications 
$31^{\text {ST }}$ Bled eConference: Digital Transformation: MeEting the Challenges

JunE 17 - 20, 2018, BLED, SLOVENIA, CONFERENCE PROCEEDINGS

M. Latifi \& H. Bouwman: Business Model Innovation and Firm Performance: The Role of

Mediation and Moderation Factors

Technologies, 2(1), 23-38.

Mitchell D, Coles C. (2003). The Ultimate Competitive Advantage of Continuing Business Model Innovation. Journal of Business Strategy 24(5): 15-21.

Murphy GB, Trailer JW, Hill RC (1996). Measuring performance in entrepreneurship research. J. Bus. Res., 36: 15-23.

Nair, S., Paulose, H., Palacios, M., \& Tafur, J. (2013). Service orientation: effectuating business model innovation. The Service Industries Journal, 33(9-10), 958-975. https://doi.org/10.1080/02642069.2013.746670

Nancy M.P. Bocken, I. W. and M. T. (2016). Business Model Experimentation for Sustainability. Smart Innovation, Systems and Technologies, 52. https://doi.org/10.1007/978-3-319-32098-4

Osterwalder, A. (2012), "Why business models fail?", Business Model Alchemist, available at: http://businessmodelalchemist.com/blog/2012/05/why-business-models-fail.html (accessed Jan. 22, 2018).

Porter, M.E., (1990). The Competitive Advantage of Nations. The Free Press, New York.

Rauter, R., Jonker, J., \& Baumgartner, R. J. (2017). Going one â $€^{\mathrm{TM}} \mathrm{s}$ own way: drivers in developing business models for sustainability. Journal of Cleaner Production, 140, 144-154.

Reim, W., Panda, V., \& Ortqvista, D. (2015). Product - Service System s ( PSS ) business m odels and tactics - a system atic literature review. Journal O F Cleaner Production, 97, 61-75.

Rubera, G., \& Kirca, A. H. (2012). Firm Innovativeness and Its Performance Outcomes: A MetaAnalytic Review and Theoretical Integration. Journal of Marketing, 76(3), 130-147. 4

Schneider S, Spieth P. (2013). Business Model Innovation: Towards an Integrated Future Research Agenda. International Journal of Innovation Management 17(1)

Serrano, A. E., Serrano, A., \& Al-Debei, M. (2010). Implementing an e-business model for a dotcom SME: Lessons learned. 16th Americas Conference on Information Systems 2010, AMCIS 2010, 6, 4566-4574.

Shafer, S.M., Smith, H.J., Linder, J.C., (2005). The power of business models. Bus. Horiz. 48 (3), 199-207.

Smith WK, Binns A, Tushman ML. (2010). Complex Business Models: Managing Strategic Paradoxes Simultaneously. Long Range Planning 43(2-3): 448-461.

Sorescu, Alina B., Jelena Spanjol (2008), “Innovation's Effect on Firm Value and Risk: Insights from Consumer Packaged Goods," Journal of Marketing, 72 (March), 114-32.

Sorescu, Alina B., Rajesh Chandy, and Jaideep C. Prabhu (2003), "Sources and Financial Consequences of Radical Innovation: Insights from Pharmaceuticals," Journal of Marketing, 67 (October), 82-102.

Spieth, P. Schneckenberg, D. Ricart, J. E. (2014). Business model innovation - state of the art and future challenges for the field. $R \& D$ Management $44: 3,237-247$.

Teece, D. J. (2010). Business models, business strategy and innovation. Long Range Planning, 43(2-3), 172-194. https://doi.org/10.1016/j.lrp.2009.07.003

Tellis, Gerard J. Jaideep C. Prabhu, and Rajesh K. Chandy (2009), "Radical Innovation Across Nations: The Preeminence of Corporate Culture," Journal of Marketing, 73 (January), 3-23.

Terrenghi, N., Schwarz, J., Legner, C., \& Eisert, U. (2017). Business Model Management: Current Practices, Required Activities and IT Support. 13th International Conference on Wirtschaftsinformatik, 972-986.

Venkatraman; Ramanujam, V. (1986). Measurement of Business Performance in Strategy Research: A Comparison of Approaches Massachusetts Institute of Technology. Academy of Management Review, 11(4), 801-814.

Vermeer, T. (2016). The relationship between business models and firm performance as measured through business model components. 7th IBA Barchelor Thesis Conference.

Waldner, F., Poetz, M. K., Grimpe, C., \& Eurich, M. (2015). Industry Structure and Business Model Innovation Antecedents and consequences of business model innovation: The role of industry 
structure, 33(33).

Wei, Z., Song, X., \& Wang, D. (2017). Manufacturing flexibility, business model design, and firm performance. International Journal of Production Economics, 193(28), 87-97.

Yannopoulos, P. (2013). Business Model Innovation: Literature Review and Propositions Proceedings of International Business and Social Sciences and Research Conference. Proceedings of International Business and Social Sciences and Research Conference, Hotel Mariiott Casamagna, Cancun, Mexico, (December), 1-13.

Yli-huumo, J., Rissanen, T., Maglyas, A., \& Smolander, K. (2015). The Relationship Between Business Model Experimentation and Technical Debt, 210, 17-29.

Zott, C., \& Amit, R. (2007). Business model design and the performance of entrepreneurial firms. Organization Science, 18(2). https://doi.org/10.1287/orsc.1060.0232

Zott, C., Amit, R., \& Massa, L. (2010). The business model: Theoretical roots, recent developments, and future research. IESE Research Papers, 3(September), 45.

Zott, C., Amit, R., \& Massa, L. (2011). The business model: recent developments and future research. Journal of Management, 37(4), 1019-1042. 


\title{
Towards Responsible Data Analytics: A Process Approach
}

\section{ROGER CLARKE \& KERRY TAYLOR}

\begin{abstract}
The big data movement has been characterised by highly enthusiastic promotion, and caution has been in short supply. New data analytic techniques are beginning to be applied to the operational activities of government agencies and corporations. If projects are conducted in much the same carefree manner as research experiments, they will inevitably have negative impacts on the organisations conducting them, and on their employees, other organisations and other individuals. The limited literature on process management for data analytics has not yet got to grips with the risks involved. This paper presents an adapted business process model that embeds quality assurance, and enables organisations to filter out irresponsible applications.
\end{abstract}

Keywords: • Big Data • Data Science - Life Cycle • Business Process • Quality•

CoRRESPONDENCE AdDREss: Roger Clarke, Xamax Consultancy Pty Ltd, Canberra, Australia, ANU Research School of Social Science, and UNSW Law, e-mail: Roger.Clarke@xamax.com.au. Kerry Taylor, Associate Professor, Research School of Social Science, Australian National University, Canberra, Australia, e-mail: Kerry.Taylor@anu.edu.au.

DOI https://doi.org/10.18690/978-961-286-170-4.6

ISBN 978-961-286-170-4

(C) 2018 University of Maribor Press

Available at: http://press.um.si. 
R. Clarke \& K. Taylor: Towards Responsible Data Analytics: A Process Approach

Big Data and Data Analytics have attracted a great deal of attention. However, the techniques are now escaping from the laboratory with only a limited degree of maturity having been achieved. Unless businesslike approaches are adopted, the intentional looseness of academic experiments may become engrained in practice. The objective of the work reported here is to specify a business process whereby organisations can ensure that applications of data analytics satisfy both strategic and policy purposes and legal and ethical constraints.

A design science research approach was adopted (Brown et al. 1978, Hevner et al. 2004, Hevner 2007). Although primarily applied to the development of information technology artefacts, the approach is also relevant to socio-technical artefacts, including methods for applying technology (Gregor \& Hevner 2013, p.337). As Peffers et al. (2007) acknowledges, "for design in practice, the Design Science Research Methodology (DSRM) may contain unnecessary elements for some contexts" (p.72). DSRM has accordingly been applied as a guide rather than as a specification.

The research commenced with problem identification and motivation, followed by definition of the objectives. This laid the foundation for design and development of the artefact. The approach adopted in the later phases was to consider a real-world case and demonstrate that the use of the method would have been likely to identify in advance the problems that arose in the case, and hence would have avoided harm and protected investment.

The paper commences with a brief review of the fields of big data and data analytics, sufficient to provide a basis for the analysis that follows. Representations of the data analytics business process are identified in text-books and the academic literature. The risks arising from data analytics activities are then considered, and techniques for identifying and addressing those risks are identified. Refinements to the conventional business process are proposed that enable data analytics to be conducted in a responsible manner. An initial evaluation of the proposed process is performed, by applying it to a case study.

\section{$2 \quad$ Big Data and Data Analytics}

Stripped of marketing prose, the term 'big data' merely means any relatively large data collection. The key characteristics were originally postulated as volume, velocity and variety (Laney 2001). Further factors were added later, including value and veracity (Schroeck et al. 2012). Such vague formulations as 'data that's too big, too fast or too hard for existing tools to process' pervade the definitions catalogued in OT (2013), Ward \& Barker (2013), and De Mauro et al. (2015).

The term 'data analytics' has been used in technical disciplines for many years. It refers to the techniques whereby a data collection is used to draw inferences. Previous 
decades of work in statistical sciences, operations research, management science and data mining have delivered a very substantial array of analytical tools, and more are being developed. Chen et al. (2012) uses the term Business Intelligence and Analytics (BI\&A), and distinguishes two phases to date. Those authors see BI\&A 1.0 as being characterised by "data management and warehousing, reporting, dashboards, ad hoc query, search-based BI, [online analytical processing (OLAP)], interactive visualization, scorecards, predictive modeling, and data mining" (p. 1166). BIA 2.0, on the other hand, which has been evident since the early 2000s, is associated with web and social media analytics, including sentiment analysis, and associated-rule and graph mining, much of which is dependent on semantic web notions and text analysis tools (pp. 1167-68). The authors anticipated 'BIA 3.0', to cope with mobile and sensor-generated data. The term 'fast data' has since emerged, to refer to near-realtime analysis of data-streams (e.g. Pathirage \& Plale 2015).

When considering how to manage data analytics activities, it is useful to distinguish categories of purpose to which big data analytics may be applied. See Table 1. Hypothesis testing involves quite different approaches from the drawing of inferences about populations, and from the construction of profiles. Further, whereas those three categories relate to populations, several other functions to which data analytics can be applied relate to individuals.

On the basis of this brief overview, the following section presents a description of the conventional business processes for data analytics. 


\section{Table 1: Purposes of Big Data Analytics After Clarke (2017), Table 1}

\section{$\underline{\text { Population Focus }}$}

\section{Hypothesis Testing}

This approach evaluates whether a proposition is supported by the available data. The proposition may be a prediction from theory, an existing heuristic, or a hunch

\section{Population Inferencing}

This approach draws inferences about a population of entities, or about sub-populations. In particular, correlations may be drawn among particular attributes

\section{Construction of Profiles}

This approach identifies key characteristics of some category of entities. For example, attributes and behaviours of a target group, such as 'drug mules', sufferers from particular diseases, or children with particular aptitudes, may exhibit statistical consistencies

\section{$\underline{\text { Individual Focus }}$}

\section{Application of Profiles}

A search can be conducted for individual entities that exhibit patterns associated with a particular, previously asserted or computed profile, thereby generating a set of entities of interest. Similarly, individual entities may be classified according to previously asserted or computed profiles so that inferences about individuals may be drawn by referring to the behaviours of the class

\section{Discovery of Anomalies}

This approach draws inferences about individual entities within the population. For example, a person may be inferred to have provided inconsistent information to two organisations, or to exhibit behaviour in one context inconsistent with behaviour in another

\section{Discovery of Outliers}

Statistical outliers are often disregarded, but this approach regards them instead as valuable needles in large haystacks, because they may represent exceptional cases, or may herald a 'flex-point' or 'quantum shift' 
$31^{\text {ST }}$ Bled eConference: Digital Transformation: MeEting the Challenges

R. Clarke \& K. Taylor: Towards Responsible Data Analytics: A Process Approach

The Conventional Data Analytics Process

A remarkably small proportion of the multitude of papers on big data has as its focus the business process or life-cycle of data analytics. There is little evidence of a cumulative literature or a dominant authority referred back to by subsequent authors.

Chen et al. (2014) suggests four phases of "the value chain of big data", but from a process perspective the authors offer little more than four phase-names and a threestep breakdown of the second phase. Their phases are: data generation, data acquisition (comprising collection, transportation and pre-processing), data storage and data analysis. Jagadish et al. (2014) uses instead a five-step process, comprising: acquisition; extraction and cleaning; integration, aggregation, and representation; modeling and analysis; and interpretation. The framework of Pääkkönen \& Pakkala (2015) involves seven process phases of source acquisition (implied), extraction, loading and preprocessing, processing, analysis, loading and transformation, and interfacing and visualisation.

Huang et al. (2015) has six steps, commencing with question formulation and proceeding to data collection, data storage and transferral, data analysis, report / visualisation, and evaluation. Phillips-Wren et al. (2015) uses the five phases of sources, preparation, storage, analysis, and access and usage. Elragal \& Klischewski (2017) offer 'pre-stage', acquisition, preprocessing, analytics and interpretation. The Wikipedia entry for Predictive Analytics is somewhat more comprehensive, with Project Definition, Data Collection and Data Analysis, followed by Statistics, Modelling and Deployment, and culminating in a Model Monitoring phase. Textbook approaches include Provost \& Fawcett (2013), which proposes the phases Business Understanding, Data Understanding, Data Preparation, Modeling, Evaluation and Deployment.

In Figure 1, a process model is presented that is a composite of the elements found in the above sources.

However, it embodies a key refinement. The majority of the examples that have been identified omit any preliminary phase. It would arguably be too constraining to impose a 'requirements elicitation' phase on those data analytics activities that are oriented towards opportunity discovery and creation. On the other hand, some degree of framing is needed, even for creative work. The expression 'Terms of Reference' has accordingly been used for the first phase, to encourage pre-thinking about the project's context, but also to encompass degrees of formalisation ranging from 'question formulation' to 'requirements analysis'.

The subsequent phases will vary in their content depending on the nature and purpose of the particular project. The second, Data Source Discovery phase, covers such activities as search, evaluation, and negotiation of access. The third phase, Data Acquisition, deals with the collection or extraction of data from the identified source(s) and may include primary data collection from source through surveys, 
polls, or on-line instrumentation. In the fourth, Data Pre-Processing phase, data from various sources may be integrated and may be scrubbed, re-formatted, interpolated and/or modified. These lay the foundations for the fifth and sixth Data Analysis and Data Exploitation phases, including such activities as inferencing, visualisation, interpretation, and application.

\section{Terms of} Reference

\section{Data \\ Source \\ Discovery}

3. Data

Acquisition

\section{Data Pre-}

Processing

5. Data

Analysis

\section{Data}

Exploitation

Figure 1: A Conventional Process Model for Data Analytics Projects 


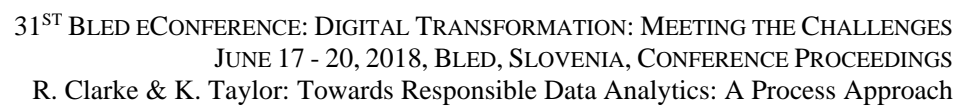

The following section discusses risks that arise from the conduct of data analytics and conventional approaches to the discovery and management of risks.

\section{$4 \quad$ Risks and Responsibilities}

Most of the literature on big data and data analytics is concerned with the identification of opportunities, and much of it is highly upbeat and excited about the prospects. Some articles do, however, urge caution, e.g. "well-designed and highly functional [business intelligence] systems that include inaccurate and unreliable data will have only limited value, and can even adversely impact business performance" (Park et al. 2012). Elragal \& Klischewski (2017) also express concern about completeness, correctness, and consistency. The following paragraphs briefly summarise the results of prior research by the first-named author on quality factors in big data and data analytics, reported in Wigan \& Clarke (2013), and Clarke (2015, 2016a, 2016b, 2017).

Data quality factors comprise those characteristics that can be assessed at the time that the data is originally created. They include syntactical validity, appropriate association, appropriate signification, accuracy, precision and temporal applicability. Information quality factors, on the other hand, are those that can only be assessed at the time of use, and in the context of use. These include theoretical and practical relevance, currency, completeness, controls and auditability. Blithe claims are made about data quality not mattering when very large quantities of data are available. e.g. "the need to find a scrupulously accurate sample (the world of small data) has been overtaken by the availability of all of the data-much of it messy but in such volumes that new correlations can be found. In other words quantity trumps quality" (Turnbull 2014). Executives know not to take such claims at face value, because there are only limited and fairly specific circumstances in which they can be justified. Many of the purposes to which data analytics is put may be seriously undermined by low-quality data.

Claims are also rife in the data mining literature that data can be 'cleaned' or 'cleansed' (Rahm \& Do 2000, Müller \& Freytag 2003). Such processes are better described as 'wrangling' (Kandel et al. 2011), and are most honestly referred to as 'data scrubbing'. By whatever name, these techniques seek to address such problems as missing values, syntactical errors in data content, syntactical differences among apparently comparable data-items, low quality at time of capture, degraded quality during storage and missing metadata. Energetic as the endeavour may be, however, it seldom achieves a state reasonably described as 'clean'. Few of the processes described in the literature and applied in practice involve comparisons against an authoritative external reference, most of the processes are merely manipulations based on statistical analyses of the data-set itself, and the changes made as a result of such activities introduce errors.

Decision quality factors must also be carefully considered, because otherwise the value of data analytics work will be undermined, and harm will arise if the results are 
relied upon for real-world decision-making. The meaning of individual data-items is frequently opaque, and may be assumed rather than being understood in sufficient depth, with the result that misunderstandings and mistaken assumptions readily occur. The many and varied analytical techniques all make assumptions about data and about context, and some of those assumptions are implicit rather than clearly stated. The preconditions for use of each technique may or may not be taught in parallel with the mechanics of the technique, and the significance of that information may or may not be grasped, and may or may not be remembered.

The rationale underlying the inferences that each data analytics technique gives rise to may be clear to the analyst, and may be successfully communicated to the decisionmaker who relies on it. However, the transparency of rationale varies a great deal, and in many of the new techniques that have emerged during the last decade, is seriously lacking. Neural networks are largely empirical. They are not based on any formal model of a solution, of a problem, or even of a problem-domain (Clarke 1991, Knight 2017). Further, their behaviour may vary greatly depending on the trainingset used and the detail of the implementation and parameter-setting of the method used against the training-set. Similarly, the various forms of AI and machine learning (ML) that are being applied in this field provide outputs, but seldom make available humanly-understandable explanations of how those outputs were achieved and what assumptions underlie them. Another approach that may suffer from the problem is 'predictive analytics', which is sometimes used in the very narrow sense of extrapolations of patterns derived from time-series rather than of the time-series themselves.

The plethora of quality factors that can undermine data analytics efforts give rise to considerable risks.

Many are borne by the organisation that exploits the outputs of data analytics techniques. These include negative impacts on the quality of organisational decisions and actions, and hence on return on investment and policy outcomes. There may also be opportunity costs, if resources are diverted to big data projects that, with hindsight, could have been better invested in alternative activities with higher return.

Some risks are borne by other parties, however, because organisational decisions and actions affect other organisations and individuals. Decisions and actions that are unreasonable or even wrong can inflict harm ranging from inconvenience, via onerousness and inversion of the onus of proof, to serious economic, financial, psychological and/or societalharm. Such problems may return to haunt the organisation whose actions gave rise to them, in such forms as reputational damage, lawsuits and additional regulatory imposts.

Wild enthusiasts such as Anderson (2008), McAfee \& Brynjolfsson (2012) and Mayer-Schonberger \& Cukier (2013) publish claims that science is obsolete and that the need is now to know, not to know why. Hard-headed directors, auditors and executives, on the other hand, seek assurance that authors of that ilk are unable to 
provide. Professionals and consultants support executives in managing risk, by means of a variety of tools. Quality assurance and formal risk assessment are well-known techniques and are the subject of copious documentation in both formal Standards (ISO 31000 and 31010, and the 27005 series) and commercial processes (ISACA COBIT, ITIL, PRINCE2, etc.). Risk assessment processes of these kinds are conducted from the organisation's own perspective. Where risks fall on other organisations and individuals, other techniques are needed. Relevant techniques include Technology Assessment (TA - Guston \& Sarewitz 2002), Privacy Impact Assessment (PIA - Clarke 2009, Wright \& De Hert 2012) and Surveillance Impact Assessment (Wright \& Raab 2012).

The following section considers how the conventional process model identified in section 3 can be adapted in order to manage the risks identified in this section.

\section{$5 \quad$ An Adapted Business Process}

Previous research established a set of Guidelines for the conduct of data analytics in a manner that is responsible in terms of protecting the interests both of the organisation on whose behalf the activity is being performed and of other stakeholders (Clarke 2018). Those Guidelines provide a basis on which a business process can be established that addresses the weaknesses in existing approaches. The following sub- sections identify further process elements that need to be added to the conventional process depicted in Figure 1, present an adapted form of business process, and discuss alternative ways in which the proposed generic business model can be applied.

\subsection{Additional Process Elements}

The purpose of the new artefact is to provide a basis whereby an organisation can ensure that problems arising during the data analytics process can be detected, and detected early. This enables appropriate measures to be put in place in order to address those problems. Two categories of process element need to be added to the conventional model described earlier: evaluation steps, and selection constructs that, under appropriate circumstances, loop the flow back to an earlier phase.

Awareness of risks is a crucial pre-condition for effective risk management, and hence there is a need for evaluation of both data and decision processes against quality standards. Cai \& Zhu (2015) and Hastie \& O'Donnell (2017), for example, each includes an outline of a data quality assessment process. A few authors, such as Koronios et al. (2014), expressly include one or more evaluation elements, and feedback or feedforward from those elements. In the Knowledge Discovery in Databases (KDD) community, a 'knowledge discovery process' has been proposed that recognises the need for loops back to earlier phases where data or processes fall short of reasonable standards (Fayyad et al. 1996, Han et al. 2011). Elragal \& Klischewski (2017) discuss epistemological challenges in data analytics, the importance of understanding model assumptions, and the need for results to be assessed. 
Various tests need to be performed, and appropriate locations need to be identified at which each test can be applied. Established techniques of quality assurance (QA) and risk assessment (RA) can be brought to bear, including requirements elicitation, interviews with executive, managerial, supervisory and operational staff, and review of the data. Similarly, the conventional classification of risk management (RM) strategies can be applied, distinguishing proactive strategies (avoidance, deterrence, prevention, redundancy), reactive strategies (detection, reduction/mitigation, recovery, insurance) and non-reactive strategies (self-insurance, graceful degradation, graceless degradation).

Where significant impacts may arise outside the organisation, the additional techniques of impact assessment (IA) and impact management (IM) are needed. These activities develop an appreciation of the contexts, needs and values of external stakeholders. Many external stakeholders are users of, or at least participants in, the system in question. However, it is important not to overlook 'usees', by which is meant organisations, but more commonly individuals, who are affected by the system without directly participating in it (Clarke 1992, Fischer-Hübner \& Lindskog 2001, Baumer 2015). Developing the necessary appreciation generally depends on consultation with representatives or and/or advocates for the various external stakeholder groups.

\subsection{A Generic Business Process}

In this sub-section, the conventional model that was presented in Figure 1 is adapted, by building in evaluation steps and conditionally redirected flows. A general framework is provided by professional standards in the areas of QA, RA and IA, and RM and IM. More specifically, the adapted model reflects the specific risk factors identified in the Guidelines for the responsible conduct of data analytics (Clarke 2018). A copy of the Guidelines is provided as an Appendix to the present paper.

The adapted business process is presented in Figure 2. The discussion in this section intentionally uses general and even vague expressions, in order to accommodate the considerable diversity of purposes to which data analytics is put, as discussed earlier, in section 2 and Table 1.

During Phase 1 - Terms of Reference, it is advantageous to not only clarify the problem or opportunity that is the project's focus, but also the governance framework that applies, the expertise required within the team, and the legal compliance and public expectations that are relevant to the activity (paras. 1.1-1.3 of the Guidelines). These provide reference-points that support subsequent evaluation steps.

After Phase 2 - Data Source Discovery, the Evaluation step needs to reconsider section 1 of the Guidelines (G1.1-1.3). Of particular significance is the legality of the intended acquisition and use of the data. This step also needs to examine the extent to which the team has understood the problem-domain (G2.1) and the nature of the data sources, including the data's provenance (Clarke 2015), purposes of creation, 
definitions, and quality (G2.2). Depending on the conclusions reached in the evaluation step, it may be necessary to return to Phase 1 and re-cast the Terms of Reference, or even to abort the project.

After Phase 3 - Data Acquisition, the theoretical evaluation of data quality that was undertaken after Phase 2 needs to be complemented by practical assessment against the full suite of data quality and information quality factors discussed in section 4, including the incidence and impact of missing data and non- conformant data (G2.2). The effects of any merger, scrubbing, identity protection or data security measures undertaken prior to the data coming under the control of the project team must also be assessed (G2.3-2.8).

After Phase 4 - Data Pre-Processing, the effects of all merger, scrubbing, identity protection and data security measures undertaken by or for the project team must be assessed (G2.3-2.8). In addition to data and information quality factors, a look-ahead to the Data Analysis phase is advisable, in order to anticipate any further issues with data characteristics that may arise, such as incompleteness, inconsistency, and format and measurement scale incompatibilities. It may transpire that the project flow needs to depart from the mainstream. For example, it may be that the project should be held in Phase 4 until further work relevant to data quality is performed. Alternatively, it may be necessary to loop back to the 3rd phase, e.g. by re-acquiring the data using different parameter-settings or procedures, or to the 2 nd phase, to acquire data from alternative sources, or even to the 1 st phase, in order to re-conceive the project.

After Phase 5 - Data Analysis, the evaluation step needs to consider all of Guidelines 3.1-3.6. These relate to the adequacy of the expertise applied to the analytics, the nature of, and the intrinsic assumptions underlying, the relevant analytical techniques, the nature of the data, the compatibility of the data and the technique, the statistical confidence or error rate supporting the inferences drawn, and the transparency of the rationale for inferences drawn. Where the data or the inferences drawn involve sensitivity and/or the actions taken as a result are likely to be particularly impactful, a look-ahead may be advisable, in particular by performing some preliminary reality testing (G4.3). 
96 3 $31^{\text {ST }}$ BLED eConference: Digital TRANSFormation: MEETING THE ChallengeS June 17 - 20, 2018, BLED, SLOVENIA, CONFERENCE PROCEEDINGS

R. Clarke \& K. Taylor: Towards Responsible Data Analytics: A Process Approach

\section{Terms of Reference}
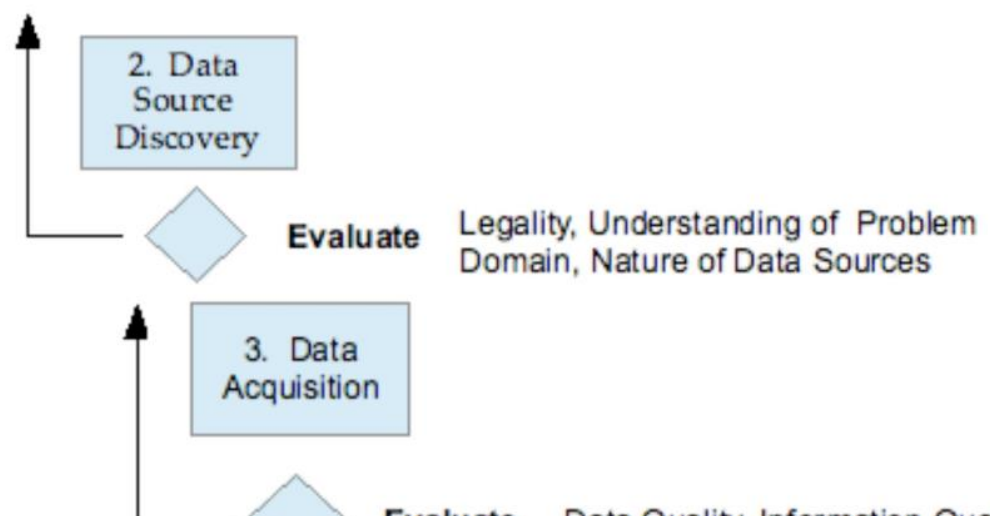

3. Data Acquisition

Evaluate Data Quality, Information Quality

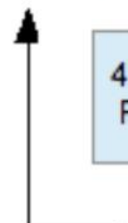

4. Data PreProcessing

Evaluate Data Quality, Information Quality

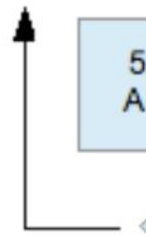

5. Data

Analysis

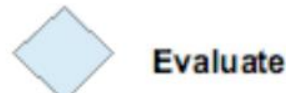

Expertise, Techniques, Compatibility of Data and Techniques, Transparency of Rationale

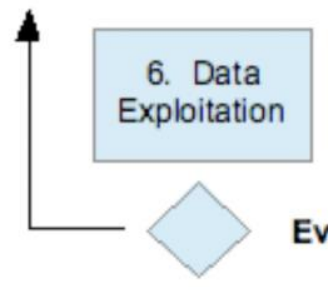

Evaluate Impact, Proportionality, Reality Tests, Safeguards, Understandability, Review, Recourse

Figure 2: A Business Process Model for Responsible Data Analytics Projects 
After Phase 6 - Data Exploitation, it is important to apply all of Guidelines 4.1-4.11. These involve appreciation of the impacts (e.g. by workshopping with staff and others with familiarity with the relevant parts of the real world), internal cost/benefit and risk assessment, where relevant external impact assessment, reality testing, the design, implementation and testing of safeguards (such as metricated pilots, interviews, feedback processes, feedback evaluation), proportionality checking, contestability, testing of the understandability of the decision-rationale, and review and recourse. Depending on the nature and potential impact of the actions that are being considered, it may be advisable to commence the evaluation process at an early stage in this phase, rather than at the end of it.

The adapted business process features the same phases as the conventional model. Evaluation steps have been specified after each phase, together with guidance in relation to circumstances in which looping back to prior phases is desirable and even essential. The adapted model enables the identification of problems at an early stage, and hence the implementation of measures to address them. It therefore fulfils the declared objective of the research, which was to specify a business process whereby organisations can ensure that applications of data analytics satisfy both strategic and policy purposes and legal and ethical constraints.

\subsection{Instantiations}

The business process model in Figure 2, and the Guidelines on which it was to a considerable extent based, were expressed in somewhat abstract terms. That was necessary in order to achieve sufficient generality to enable application in a range of circumstances.

One dimension of diversity among projects is the category of purpose, as discussed in section 2 and Table 1 . Another way in which projects differ is their degree of embeddedness within a corporate framework. In the case of a standalone project, each phase and each evaluation step may need to be planned and performed as a new activity. At the other extremity, every phase and every step may be tightly constrained by existing corporate policies and practices, perhaps in the form of an industry standard or a proprietary process management framework imposed by or on the organisation.

Another factor to consider in applying the model to a project is the extent to which the project is ground- breaking or novel. A less painstaking approach can reasonably be adopted where the project falls into a well-known category, and is being conducted by a team with both expertise and experience in relation to the problem-domain, the data-sets, the data analytic techniques, the pitfalls, the stakeholders and their interests, and the project's potential impacts.

The following section makes an initial contribution to the evaluation of the proposed business process. 
R. Clarke \& K. Taylor: Towards Responsible Data Analytics: A Process Approach

\section{$6 \quad$ Application and Evaluation}

In Peffers et al. (2007), two related phases are defined towards the end of the design research approach. These distinguish 'demonstration' of the use of the artifact to solve one or more instances of the problem (by means of experimentation, simulation, case study, proof, or other appropriate activity), from 'evaluation', which involves more formal observation and measurement of the new artefact's effectiveness in addressing the stated objectives. The research reported in this paper includes a demonstration step, based on a case study.

Centrelink is the Australian government agency responsible for distributing welfare payments. During the second half of 2016, Centrelink launched a new system that was intended to improve the efficiency of the agency's processes whereby control is exercised over overpayments. The new Online Compliance Intervention (OCI) system featured simple data analytics that were used to draw inferences about likely overpayments of welfare payments, combined with automated decision-making. The implementation resulted in a large proportion, and very large numbers, of unjustified and harmful actions by the agency, which gave rise to serious public concern and two external investigations, which in turn forced the agency to make multiple changes to the scheme.

This represents a suitable test-case for the artefact developed in this research project. The data analytics used were trivially simple, but the big data collections that were matched were not. The project was real - and, indeed, for many of the people affected by it, all too real. It involved all steps of the life-cycle. In addition, unlike most private sector data analytics projects, it was subject to the glare of publicity, and is documented by two substantial and independent reports. A 3,000-word case study was prepared by the first-named author, based on the two reports and about 20 substantive media articles. It is provided as Supplementary Material in support of the present paper.

The major problems arising in the case appear to have resulted from a small number of factors. The most critical issue was that the new system implicitly assumed that the annual income declared by welfare recipients to the taxation agency could be divided by 26 in order to establish a reliable estimate of the income that each of them earned in each fortnight of that year. Many welfare recipients, on the other hand, earn some and even all of their small incomes from short-term, casual and/or seasonal employment, and hence they work variable numbers of hours per fortnight. This has the inevitable result that their income is unevenly distributed across the year, and an assumption of even distribution is seriously problematical. Centrelink failed to appreciate how significant that issue was, and remained in denial 12 months after implementation.

The generic business process proposed in Figure 2 includes within Phase 1 - Terms of Reference the establishment of a governance process, identification of the expertise required within the team, and consideration of the legal compliance and 
public expectations that are relevant to the activity. If the team had included people with strong familiarity with both the real world of benefit recipients and the relevant data models, together with experienced data analysts, then the unreasonableness of the assumption of income being evenly distributed over a period would have been obvious. Similarly, if the agency's legal obligations, and the vulnerability of many of its clients, had been clear in the minds of the team-members, they would have taken greater care in considering the potential impacts of the design. Even if these framing elements had been overlooked, any and all of the five evaluation steps across the recommended life-cycle would have been very likely to identify this major problem well in advance of implementation. In particular, it would have become clear that the design process needed to include consultation with the operational staff, the taxation agency, and advocates for welfare recipients' interests.

A second major problem was the abandonment of checks with employers, which Centrelink had identified as an avoidable cost. The agency sought to transfer these costs to the recipients; but this proved to be unreasonable, partly because of many recipients' cognitive and performative limitations, and partly for systemic reasons. Had the proposed business process model been used, the unreality of this key assumption might also have been uncovered during one of the early-phase evaluation steps; but at the very least it would have become apparent during Phase 6 - Data Exploitation.

A third problem was the automation of both debt-raising and the commencement of debt collection. The triggers were nothing more than non-response by the targeted welfare recipient, or their failure to deliver satisfactory evidence to prosecute their innocence of the accusation. The previous system had involved considerable computer-based support, but also a number of manual steps. Under the new, naive system of suspicion-generation, the case-load leapt more than 30-fold, from 20,000 p.a. to 10-20,000 per week. This overwhelmed the support services, resulting in a complete log-jam of enquiries and complaints, and escalating numbers of autogenerated debts and debt-collection activities. Several of the elements making up this compounding problem could have been intercepted early in the process, and all of them would have become apparent at latest during the Phase 6 evaluation steps, if the business process in Figure 2 had been applied.

The Centrelink case demonstrates the benefits of inserting QA elements between the successive phases, and the insertion of loops where problems are found. It also provides the valuable insight that a conventional requirements analysis that incorporated interviews with operational staff, followed by internal risk assessment, may well have been sufficient to prevent much of the harm, but that these alone would have very likely missed some key factors. Because the system directly affected 'usees', external impact assessment was necessary, including consultation with advocacy organisations. 


\section{$7 \quad$ Implications and Conclusions}

Conventional business processes for data analytics lack three important features: a preliminary, planning phase; evaluation steps; and criteria for deciding whether a project needs to be looped back to an earlier phase. On the basis of established theories and prior research into risk assessment of data analytics projects, an adapted business process model was proposed, which makes good those deficiencies. A recent case was considered in the light of the adapted model.

The implications for practice are clear. Data analytics embodies many risks. Organisations that conduct or commission data analytics projects are subject to legal obligations. In some contexts, such as highly- regulated industry sectors, these may be fairly specific; but in any case company directors are subject to broad responsibilities in relation to the management of risk. The concerns of consumers and citizens are increasing, the media is eager to snowball cases of large organisations treating people badly, and social media has provided means for the public to escalate issues themselves. Investors, board rooms and executives will demand that a balance is struck between data exploitation and due care. QA, RA and RM, and IA and IM, need to be applied. The adapted business process shows how.

The research reported here can be strengthened in a number of ways. It is built primarily on academic work, because reliable reports of active data analytics projects are difficult to acquire. A much stronger empirical base is needed, such that actual business processes can be better understood, and the adapted model's efficacy can be evaluated. The model is, for the reasons explained above, generic in nature. It requires tailoring to the various specific contexts identified above, and further articulation.

A number of implications can be drawn for research in the area. Observation of practice, and publications arising from it, are likely to encounter nervousness on the part of project teams and the organisations for whom the project is undertaken. Some concerns will relate to competitive, commercial and strategic factors, and others to ethical, legal and political considerations. Academic projects to apply data analytics tools need to incorporate controls at a much earlier stage than is currently the case, to ensure that the transitions from research to industrial R\&D, and on to live use, are not undermined by the late discovery of quality issues. The work reported here accordingly provides a substantial contribution to both practice and research.

\section{References}

Anderson C. (2008) 'The End of Theory: The Data Deluge Makes the Scientific Method Obsolete' Wired Magazine 16:07, 23 June 2008, at ://archive.wired.com/science/discoveries/magazine/16-07/pb_theory

Baumer E.P.S. (2015) 'Usees' Proc. 33rd Annual ACM Conference on Human Factors in Computing Systems (CHI'15), April 2015

Brown H., Cook R. \& Gabel M. (1978) 'Environmental Design Science Primer' Advocate Press, 1978 
Cai L. \& Zhu Y. (2015) 'The Challenges of Data Quality and Data Quality Assessment in the Big Data Era' Data Science Journal 14 (2015) 2, at http://doi.org/10.5334/dsj-2015-002

Cao L. (2016) 'Data science: nature and pitfalls' IEEE Intelligent Systems 31, 5 (September/October 2016) 66-75, at http://ieeexplore.ieee.org/stamp/stamp.jsp?arnumber=7579413

Cao L. (2017) 'Data science: a comprehensive overview' ACM Computing Surveys 50, 3 (October 2017), at http://dl.acm.org/ft_gateway.cfm?id=3076253\&type=pdf

Chen H., Chiang R.H.L. \& Storey V.C. (2012) 'Business Intelligence and Analytics: From Big Data to Big Impact' MIS Quarterly 36, 4 (December 2012) 1165-1188, at http://ai.arizona.edu/mis510/other/MISQ\%2520BI\%2520Special\%2520Issue\%2520Introducti on\%2520Che n-Chiang-Storey\%2520December\%25202012.pdf

Chen M., Mao S. \& Liu Y. (2014) 'Big Data: A Survey' Mobile Network Applications 19 (2014) 171?209, at http://www.ece.ubc.ca/ minchen/min_paper/BigDataSurvey2014.pdf

Clarke R. (1991) 'A Contingency Approach to the Application Software Generations' Database 22, 3 (Summer 1991) $23 \quad-\quad 34, \quad$ PrePrint at http://www.rogerclarke.com/SOS/SwareGenns.html

Clarke R. (1992) 'Extra-Organisational Systems: A Challenge to the Software Engineering Paradigm' Proc. IFIP World Congress, Madrid, September 1992, PrePrint at http://www.rogerclarke.com/SOS/PaperExtraOrgSys.html

Clarke R. (2009) 'Privacy Impact Assessment: Its Origins and Development' Computer Law \& Security Review 25, 2 (April 2009) 123-135, athttp://www.rogerclarke.com/DV/PIAHist08.html

Clarke R. (2015) 'Quasi-Empirical Scenario Analysis and Its Application to Big Data Quality' Proc. 28th Bled eConference, Slovenia, 7-10 June 2015, PrePrint at http://www.rogerclarke.com/EC/BDSA.html

Clarke R. (2016a) 'Big Data, Big Risks' Information Systems Journal 26, 1 (January 2016) 7790, PrePrint at http://www.rogerclarke.com/EC/BDBR.html

Clarke R. (2016b) 'Quality Assurance for Security Applications of Big Data' Proc. European Intelligence and Security Informatics Conference (EISIC), Uppsala, 17-19 August 2016, PrePrint at http://www.rogerclarke.com/EC/BDQAS.html

Clarke R. (2017) 'Big Data Prophylactics' Chapter 1 in Lehmann A., Whitehouse D., FischerHübner S., Fritsch L. \& Raab C. (eds.) 'Privacy and Identity Management. Facing up to Next Steps' Springer, 2017, pp. 3-14, at http://www.rogerclarke.com/DV/BDP.html

Clarke R. (2018) 'Guidelines for the Responsible Application of Data Analytics' Forthcoming, Computer Law \& Security Review 34, 3 (Jul-Aug 2018), PrePrint at http://www.rogerclarke.com/EC/GDA.html

De Mauro A., Greco M. \& Grimaldi M. (2015) 'What is big data? A consensual definition and a review of key research topics ' Proc. AIP 1644 (2015) 97 (2015), at http://big-datafr.com/wp- content/uploads/2015/02/aip-scitation-what-is-bigdata.pdf

Elragal A. \& Klischewski R. (2017) 'Theory-driven or process-driven prediction? Epistemological challenges of big data analytics' Journal of Big Data 4.19 (2017), at https://journalofbigdata.springeropen.com/articles/10.1186/s40537-017-0079-2

Fayyad U., Piatetsky-Shapiro G. \& Smyth P. (1996) 'The KDD Process for Extracting Useful Knowledge from Volumes of Data' Commun. ACM 39, 11 (November 1996) 27-34

Fischer-Hübner S. \& Lindskog H. (2001) ' Teaching Privacy-Enhancing Technologies' Proc IFIP WG 11.8 2nd World Conference on Information Security Education, Perth, Australia (2001)

Gregor S. \& Hevner A. (2013) 'Positioning Design Science Research for Maximum Impact' MIS Quarterly 37, 2 (June $2013 \quad$ ) 337-355, at https://ai.arizona.edu/sites/ai/files/MIS611D/gregor-2013-positioning- presenting-designscience-research.pdf 
Guston D.H. \& Sarewitz D. (2001) 'Real-time technology assessment' Technology in Society 24 (2002) 93- 109, athttp://archive.cspo.org/documents/realtimeTA.pdf

Han J., Kamber M. \& Pei J. (2011) 'Data mining: concepts and techniques' Morgan Kaufmannn, 3rd Edition, 2011

Hastie R. \& O’Donnell A. (2017) 'Training Pack: Responsible Data Management' Oxfam, August 2017, at https://protection.interaction.org/2004-2/

Hevner A.R. (2007) 'A three cycle view of design science research' Scandinavian Journal of Information Systems 19, 2 (2007) 4

Hevner A.R., March S.T., Park J. \& Ram S. (2004) 'Design science in information systems research' MIS Quarterly 28, 1 (2004) 75-105

Huang T., Lan L., Fang X., Min J. \& Wang F. (2015) 'Promises and Challenges of Big Data Computing in Health Sciences' Big Data Research 2, 1 (March 2015) 2-11

Jagadish H.V., Gehrke J., Labrinidis A., Papakonstantinou Y., Patel J.M., Ramakrishnan R. \& Shahabi C. (2014) 'Big data and its technical challenges' Communications of the ACM 57, 7 (July 2014) 86-94

Kandel, S., Heer, J., C. Plaisant, C., Kennedy, J., van Ham, F., Henry-Riche, N., Weaver, C., Lee, B., Brodbeck, D. \& Buono, P. (2011) 'Research directions for data wrangling: visualizations and transformations for usable and credible data' Information Visualization 10. 4 (October 2011) 271-288, at https://idl.cs.washington.edu/files/2011-DataWranglingIVJ.pdf

Knight W. (2017) 'The Dark Secret at the Heart of AI' 11 April 2017, MIT Technology Review https://www.technologyreview.com/s/604087/the-dark-secret-at-the-heart-of-ai/

Koronios A., Gao J. \& Selle S. (2014) 'Big Data Project Success ? A Meta Analysis' Proc. PACIS 2014, p.376, at http://aisel.aisnet.org/pacis2014/376

Laney D. (2001) '3D Data Management: Controlling Data Volume, Velocity and Variety' MetaGroup, February 2001, at http://blogs.gartner.com/doug-laney/files/2012/01/ad949-3DData-Management- Controlling-Data-Volume-Velocity-and-Variety.pdf

McAfee A. \& Brynjolfsson E. (2012) 'Big Data: The Management Revolution' Harvard Business Review (October 2012) 61-68

Marchand D.A. \& Peppard J. (2013) 'Why IT Fumbles Analytics' Harv. Bus. Rev. (Jan-Feb 2013) 2-9

Mayer-Schonberger V. \& Cukier K. (2013) 'Big Data: A Revolution That Will Transform How We Live, Work and Think' John Murray, 2013

Müller H. \& Freytag J.-C. (2003) 'Problems, Methods and Challenges in Comprehensive Data Cleansing' Technical Report HUB-IB-164, Humboldt-Universität zu Berlin, Institut für Informatik, 2003, at http://www.informatik.unijena.de/dbis/lehre/ss2005/sem_dwh/lit/MuFr03.pdf

OT (2013) 'Definitions of Big Data' OpenTracker.com, apparently of April 2013, at http://www.opentracker.net/article/definitions-big-data

Pääkkönen P. \& Pakkala D. (2015) 'Reference Architecture and Classification of Technologies, Products and Services for Big Data Systems' Big Data Research 2, 4 (2015) 166-186, at https://www.sciencedirect.com/science/article/pii/S2214579615000027/pdfft?md5=5af64200 1f750f63eaeb 3fbe35f5ccdc\&pid=1-s2.0-S2214579615000027-main.pdf

Park S.-H., Huh S.-Y., Oh W. \& Han A.P. (2012) 'A Social Network-Based Inference Model for Validating Customer Profile Data' MIS Quarterly 36, 4 (December 2012) 1217-1237, at http://www.is.cityu.edu.hk/staff/sangphan/mobility/papers/BI_MISQ_\%5BHAN,\%2520Sang $\% 2520$ Pi1\%5 D.pdf

Pathirage M. \& Plale B. (2015) 'Fast Data Management with Distributed Streaming SQL' arXiv preprint arXiv:1511.03935, at http://arxiv.org/abs/1511.03935

Peffers K., Tuunanen T., Rothenberger M. \& Chatterjee S. (2007) 'A design science research methodology for information systems research' Journal of Management Information 
Systems, $\quad 24, \quad 3 \quad$ (2007) $\quad 35-77, \quad$ at http://www.sirel.fi/ttt/Downloads/Design\%20Science\%20Research\%20Methodology\%20 2008.pdf

Phillips-Wren G., Iyer L.S., Kulkarni U. \& Ariyachandra T. (2015) 'Business Analytics in the Context of Big Data: A Roadmap for Research' Commun. AIS 37, 23

Provost F. \& Fawcett T. (2013) 'Data Science for Business' O'Reilly, 2013

Rahm E. \& Do H.H. (2000) 'Data cleaning: Problems and current approaches' IEEE Data Eng. Bull., 2000, at http://dc-pubs.dbs.unileipzig.de/files/Rahm2000DataCleaningProblemsand.pdf

Schroeck M., Shockley R., Smart J., Romero-Morales D. \& Tufano P. (2012) `Analytics : The real world use of big data' IBM Institute for Business Value / Saïd Business School at the University of Oxford, October 2012, at http://www.ibm.com/smarterplanet/global/files/se sv_se intelligence_Analytics_-

_The_real-world_use_of_big_data.pdf

Turnbull M. (2014) 'Benefiting from big data the government's approach' Address by the Minister for Communications (and soon afterwards, the Prime Minister) to the Australian Information Industry Association, April 2014, at https://www.malcolmturnbull.com.au/media/benefiting-from-big-data-the- governmentsapproach

Ward J.S. \& Barker A. (2013) 'Undefined By Data: A Survey of Big Data Definitions' arXiv, 2013, at https://arxiv.org/pdf/1309.5821

Wigan M.R. \& Clarke R. (2013) 'Big Data's Big Unintended Consequences' IEEE Computer 46, 6 (June 2013) 46 - 53, PrePrint at http://www.rogerclarke.com/DV/BigData-1303.html

Wright D. \& De Hert P. (eds) (2012) 'Privacy Impact Assessments' Springer, 2012

Wright D. \& Raab C.D. (2012) 'Constructing a surveillance impact assessment' Computer Law \& Security Review 28, 6 (December 2012) 613-626 


\section{Appendix: Guidelines for Responsible Application of Data Analytics}

\section{GENERAL}

$\underline{\text { DO's }}$

\section{1 - Governance}

Ensure that a comprehensive governance framework is in place prior to, during, and for the relevant period after data acquisition, analysis and use activities, that it is commensurate with the activities' potential impacts, and that it encompasses:

a) risk assessment and risk management from the perspectives of all affected parties

b) express assignments of accountability, at an appropriate level of granularity

\section{2 - Expertise}

Ensure that all individuals participating in the activities have education, training, and experience in relation to the real-world systems about which inferences are to be drawn, appropriate to the roles that they play

\section{3 - Compliance}

Ensure that all activities are compliant with all relevant laws and established public policy positions within relevant jurisdictions, and with public standards of behaviour

\section{DATA ACQUISITION}

\section{DO's}

\section{1 - The Problem Domain}

Understand the real-world systems about which inferences are to be drawn and to which data analytics are to be applied

\section{2 - The Data Sources}

Understand each source of data, including:

a) the data's provenance

b) the purposes for which the data was created

c) the meaning of each data-item at the time of creation

d) the data quality at the time of creation

e) the data quality and information quality at the time of use

\section{3 - Data Merger}

If data is to be merged from multiple sources, assess the compatibility of the various collections, records and items of data, taking into account the data's provenance, purposes, meaning and quality, and the potential impact of mis-matching and mistaken assumptions 


\section{4 - Data Scrubbing}

If data is to be scrubbed, cleaned or cleansed, assess the reliability of the processes for the intended purpose and the potential impacts of mistaken assumptions and erroneous changes

\section{5 - Identity Protection}

If the association of data with an entity is sensitive, apply techniques to the data whose effectiveness is commensurate with the risks to those entities, in order to ensure pseudonymisation (if the purpose is to draw inferences about individual entities), or deidentification (if the purpose is other than to draw inferences about individual entities)

\section{6 - Data Security}

Minimise the risks arising from data acquisition, storage, access, distribution and retention, and manage the unavoidable risks

\section{DON'Ts}

\section{7 - Identifier Compatibility}

Don't merge data-sets unless the identifiers in each data-set are compatible with one another at a level of reliability commensurate with the potential impact of the inferences drawn

\section{8 - Content Compatibility}

Don't merge data-sets unless the reliability of comparisons among the data-items in the sources reaches a threshold commensurate with the potential impact of the inferences drawn

\section{DATA ANALYSIS}

\section{DO's}

\section{1 - Expertise}

Ensure that all staff and contractors involved in the analysis have:

a) appropriate professional qualifications

b) training in the specific tools and processes

c) sufficient familiarity with the real-world system to which the data relates and with the manner in which the data purports to represent that real-world system

d) accountability for their analyses

\section{2 - The Nature of the Tools}

Understand the origins, nature and limitations of data analytic tools that are considered for use 


\section{3 - The Nature of the Data Processed by the Tools}

Understand the assumptions that data analytic tools make about the data that they process, and the extent to which the data to be processed is consistent with those assumptions. Important areas in which assumptions may exist include:

a) the presence of values in relevant data-items

b) the presence of only specific, pre-defined values in relevant data-items

c) the scales against which relevant data-items have been measured

d) the precision with which relevant data-items have been expressed

\section{4 - The Suitability of the Tool and the Data}

Demonstrate the applicability of each particular data analytic tool to the particular data that it is proposed be processed using it

\section{DON'Ts}

\section{5 - Inappropriate Data}

Don't apply data analytics unless the data satisfies threshold tests commensurate with the potential impact of the inferences drawn, in relation to data quality, internal consistency, and reliable correspondence with the real-world systems about which inferences are to be drawn

\section{6 - Humanly-Understandable Rationale}

Don't apply an analytical tool that lacks transparency, by which is meant that the rationale for inferences that it draws is expressible in humanly-understandable terms

\section{USE OF THE INFERENCES}

\section{$\underline{\text { DO's }}$}

\section{1 - The Impacts}

Understand the potential negative impacts on stakeholders of reliance on the inferences drawn, taking into account the quality of the data and the data analysis process

\section{2 - Evaluation}

Where decisions based on inferences from data analytics may have material negative impacts, evaluate the advantages and disadvantages of proceeding, by conducting costbenefit analysis and risk assessment from an organisational perspective, and impact assessments from the perspectives of other internal and external stakeholders

\section{3 - Reality Testing}

Test a sufficient sample of the results of the analysis against the real world, in order to gain insight into the reliability of the data as a representation of relevant real-world entities and their attributes 


\section{4 - Safeguards}

Design, implement and maintain safeguards and mitigation measures, together with controls that ensure the safeguards and mitigation measures are functioning as intended, commensurate with the potential impacts of the inferences drawn

\section{5 - Proportionality}

Where specific decisions based on inferences from data analytics may have material negative impacts on individuals, consider the reasonableness of the decisions prior to committing to them

\section{6 - Contestability}

Where actions are taken based on inferences drawn from data analytics, ensure that the rationale for the decisions is transparent to people affected by them, and that mechanisms exist whereby stakeholders can access information about, and if appropriate complain about and dispute interpretations, inferences, decisions and actions

\section{7 - Breathing Space}

Provide stakeholders who perceive that they will be negatively impacted by the action with the opportunity to understand and to contest the proposed action

\section{8 - Post-Implementation Review}

Ensure that actions and their outcomes are audited, and that adjustments are made to reflect the findings

\section{DON'Ts}

\section{9 - Humanly-Understandable Rationale}

Don't take actions based on inferences drawn from an analytical tool in any context that may have a material negative impact on any stakeholder unless the rationale for each inference is readily available to those stakeholders in humanly-understandable terms

\subsection{0 - Precipitate Actions}

Don't take actions based on inferences drawn from data analytics until stakeholders who perceive that they may be materially negatively impacted by the action have had a reasonable opportunity to understand and to contest the proposed action. Denial of a reasonable opportunity is only justifiable on the basis of emergency, as distinct from urgency or mere expediency or efficiency. Where a reasonable opportunity is not provided, ensure that stringent safeguards, mitigation measures and controls are designed, implemented and maintained in relation to justification, reporting, review, and recourse in the case of unjustified or disproportionate actions

\subsection{1 - Automated Decision-Making}

Don't delegate to a device any decision that has potentially harmful effects without ensuring that it is subject to specific human approval prior to implementation, by a person who is acting as an agent for the accountable organisation 
108 3 $31^{\text {ST }}$ Bled eConference: Digital Transformation: MeEting the Challenges June 17 - 20, 2018, BLED, SLOVENIA, CONFERENCE PROCEEDINGS 


\title{
Examining the PoC System Implementation and Adoption: A FVM Perspective
}

\author{
IMRAN MUHAMMAD \& NILMINI WICKRAMASINGHE
}

\begin{abstract}
HIS implementation is complex and involves people issues as well as technological issues. The effect of sociotechnical issues such as macro level or external factors including political, social, economic, environmental infrastructure and technology, laws and regulations; meso level or organizational factors such as leadership, management style, policies, structure; and micro level or tactical factors such as information sharing, training and learning, technical staff or user behaviour, have been less widely studied. Yet, it is precisely these issues that separately or in combination derail numerous HIS implementations. To examine this dilemma, we proffer a unique application of the fit viability model (FVM) to facilitate a better understanding of key issues pertaining the implementation and adoption of a Point of Care (PoC) System at one of the not for profit private hospitals in Australia. This will help the decision makers in hospital to understand how the new system fits within the different departments and also is it a viable option to install such a new system. This study focuses on just two departments of the hospital; namely, food services and environment services. An exploratory single case qualitative study methodology is adopted. From such an analysis, it is possible to identify optimal aspects with the PoC solution and opportunities to add value.
\end{abstract}

Keywords: • Point of Care Systems • Fit-Viability Model • PoC • FVM •

CORRESPONDENCE AdDRESS: Imran Muhammad, Ph.D., Lecturer,Deakin University, Faculty of Health, L4, BC Building, 221 Burwood Highway, Burwood, Victoria 3125 Australia, e-mail: imran.muhammad@deakin.edu.au. Prof. Nilmini Wickramasinghe, Ph.D., Professor Health Informatics Management, Deakin University, Faculty of Health, L4, BC Building, 221 Burwood Highway, Burwood, Victoria 3125 Australia, e-mail: imran.muhammad@deakin.edu.au.

DOI https://doi.org/10.18690/978-961-286-170-4.7

ISBN 978-961-286-170-4

(C) 2018 University of Maribor Press

Available at: http://press.um.si. 
I. Muhammad \& N. Wickramasinghe: Examining the PoC System Implementation and Adoption:

A FVM Perspective

Information technology is an important part of almost every industry in the developed world. Businesses are expanding their boundaries by using integrated and collaborative IT solutions. Due to an ever-increasing need for effective and efficient healthcare services and delivery, healthcare organisations are now trying to find integrated solutions for their business needs to automate their processes to gain a strategic advantage (Ives and Jarvenpaa 1991). In addition, the complex nature of healthcare services is compelling and forcing healthcare organizations to adopt best available technologies, but the problem here organizations are facing is that they need to adopt technologies according to their requirements and best fit having considered their environment, infrastructure, government regulations, and scope of their business, availability of funds and local culture and norms (Ignatiadis and Nandhakumar 2007). Healthcare organisations are inclusive organisations, involving different stakeholders, partners, customers and suppliers from different cultures and different systems; they need more sophisticated means of communication and interaction (Harris, Moran, \& Moran, 2004). Since the last decade of the last century, we have witnessed a significant growth in the adoption rate of information technology and a big shift towards the deployment of Health Information Systems (HIS) (Muhammad et al 2014). Most countries have responded positively to the changing global market place and are reaping the strategic benefits by implementing HIS (Mukesh and Betsy 2009).

HIS implementation is a difficult and complex decision and system implementation is not limited to just installing software; ie, it is much more than a technology adoption. Rather, it involves people issues more than technological issues (Cresswell, Worth, \& Sheikh, 2011). Research indicates that people issues are more to blame for the unsuccessful efforts of eHealth implementations (Mukesh and Betsy 2009). The effect of sociotechnical issues such as macro level or external factors including political, social, economic, environmental infrastructure and technology, laws and regulations; meso level or organizational factors such as leadership, management style, policies, structure; and micro level or tactical factors such as information sharing, training and learning, technical staff or user behavior have been less widely studied (Nguyen et al., 2015). Yet, it is precisely these issues that separately or in combination derail numerous HIS implementations (Nguyen et al., 2015). To examine this dilemma, we proffer a unique application of the fit viability model (FVM) (Liang, Huang, Yeh, \& Lin, 2007) to facilitate a better understanding of key issues pertaining the implementation and adoption of a Point of Care ( $\mathrm{PoC})$ System at one of the not for profit private hospitals in Australia. In so doing, we answer the research question: "How can a FVM assist in unpacking the varied sociotechnical issues in the adoption and implementation of PoC system?". This will help the decision makers in hospital to understand how the new system fits within the different departments and also is it a viable option to install such a new system. This study deals with just two departments of the hospitals namely, food services and environment services. An exploratory single case study methodology is adopted. From such an analysis, we believe it will be possible to identify optimal PoC solutions and opportunities to add value. 


\section{Literature Review}

Many healthcare information systems have been implemented around the globe with mixed results, despite the claims that HIS can play a significant role in efficiency and effectiveness of healthcare service delivery (Muhammad et al 2014) The literature provides evidence of failed clinical systems and lack of adoption by users (DesRoches et al., 2008; Protti et al., 2009). Challenges and barriers to implementation and adoption of bedside PoC systems in hospital wards have been extensively debated (Brailer, 2005; Choi et al., 2004; Yao, Schmitz, \& Warren, 2005; Nguyen et al., 2015). Researchers have divided these barriers into different categories ranging from environmental, social, technical and Organisational (André et al., 2008). These factors can play a very crucial role in the decision-making process of technology adoption (Huang \& Palvia, 2001). In a healthcare service context, where organisations are now required to work as a networked framework, health information technology implementation and adoption would be a more complex and challenging endeavor because of the different business processes, the available infrastructure, compatibility issues, decision centres, authorization mechanisms and hierarchies, enterprise systems and data semantics (Avgerou, 2008; Liu et al., 2011; Trudel, 2010). IT implementations can cause serious disruptions in service deliveries and in result, at productivity and healthcare services are one of the very critical areas of services that cannot afford disruptions (Kralewski et al., 2010; Scott et al., 2005).

There are many organisational barriers to the implementation and the adoption of eHealth technologies, for example, poor governance, organisational culture and proper management of the change process that could harm the flow of transformation (Greenhalgh \& Stones, 2010; Kennedy, 2011). These issues can aggravate the resistance to the change process and complicate the dissemination of the eHealth technology. Technological issues can also exacerbate the resistance to the adoption of health information technology (Muhammad et al 2014). The lack of infrastructure, and standards results in a fragmentation of healthcare information systems and this contributes to creating a very complex situation for coordination (Kennedy, 2011; Trudel, 2010). Preimplementation and post-implementation vendor support is another key concern for organisations (Kennedy 2011; Liu et al. 2011). Lack of technical resources and experience with information technology implementation within healthcare settings are other problems faced by many (Trudel 2010; Liu et al. 2011; Kennedy 2011).

People issues, ranging from user acceptance (Trudel, 2010), perceived ease of use (AlAzmi et al., 2009), lack of knowledge about the system (André et al., 2008; Liu et al., 2011), lack of training, lack of stakeholder consultation (Showell, 2011), lack of willingness to assimilate the technology in to daily routines and processes (Greenhalgh \& Stones, 2010), conflict between system and user embedded values (Greenhalgh \& Stones, 2010), complex and complicated user interfaces (Yusof et al. 2007), conflict between physician activities and training schedules (André et al. 2008; Yusof et al. 2007;) and complications in patient-provider communications are some of the major concerns. Further, it is paramount that the systems are user centric and have a good fit with user values as well as existing healthcare systems (Liang, Huang, Yeh, \& Lin, 2007). 
I. Muhammad \& N. Wickramasinghe: Examining the PoC System Implementation and Adoption:

A FVM Perspective

\subsection{Fit-Viability Model}

As Tjan (2001) proposed fit viability dimensions for evaluating Internet initiative projects. Liang and Wei (2004), by taking these two dimensions and adding Task Technology Fit (TTF) theory, proposed a fit-viability model to study m-commerce applications. In their framework, viability measures the readiness of the organization for the technology adoption and implementation, and fit measures capabilities of the systems to optimally perform the required tasks. These two dimensions make a simple matrix with fit on horizontal and viability on vertical axis. By using the four corners of the matrix, organizations can make an informed decision for technology adoption and implementation.

\subsection{Task-Technology Fit}

The theoretical basis of the fit construct is derived from the Task-Technology Fit model which according to Goodhue $(1995 ; 1998)$ argues that a fit between task characteristics and system features need to be high for the better performance and success and this will have effect on the decision-making process of an organization. Research (Madapusi 2008; Soh et al. 2000) has indicated that if a system is more aligned with the requirements of the users there are greater chances of system success which leads to better performance. It means that if the features offered by the system fit with the task requirements the users will be more incline to use it.

\subsection{Viability}

Viability refers to the degree of impact of environment and organizational factors on a system adoption and implementation decision. These factors at the macro level include political and social, economic, environmental as well as infrastructure/technology factors. At the organizational level literature has proposed many factors at the strategic and tactical levels (Umble et al., 2003). These factors include leadership, management style, polices, information sharing, training and learning, technical staff, and user behaviour. Taking the example of PoC, economic and technological factors are crucial factors in HIS system implementations; and ignoring these factors could lead to unsuccessful projects. Management support, physical and IT infrastructure create stronger desire of system implementation and innovation adoption, that positively impact viability of the system.

\section{$3 \quad$ Research Framwork}

The research framework shown in figure 1 illustrates is used to identify the key constructs and factors affecting $\mathrm{PoC}$ system implementations. The $\mathrm{PoC}$ is a patient bedside solution that can be accessed across the hospital by clinicians and also has a patient portal component. It is not an EMR (electronic medical record) but has many features and capabilities similar to an EMR. It also has a patient entertainment component. The PoC system was implemented into the not-for private tertiary hospital system (the chosen case 
study) gradually starting in late 2015. Primary objectives for its implementation included to enhance the patient experience and provide value-based patient-centred care. The system has many modules of which this paper focuses on catering/food services and environmental services. Fit is measured by matching the requirements of the organization with the functionalities offered by the PoC system e.g. data format, operating procedures, and output format while viability is measured by assessing the impact of national and organizational factors on the adoption decision of the organization and individual user adoption.

Considering that the PoC has many similar factors to other e-health solutions such as political and sociotechnical factor identified by (Muhammad et al 2016) in evaluation of MyHealth record in Australia (the Australian national e-health solution) and smart card solution in Germany (the German national e-health solution), thus it is logical to use these factors as the basis of the model. This conceptual model serves to capture the important aspects of the barriers and facilitators for the prediction of the successful adoption and implementation of the PoC. The proposed model identifies a network of different actors interconnected to each other. It further illustrates that a central issue with the evaluation of IT based healthcare is influenced by the complexity of the evaluation objects and includes both social and technical considerations (Greenhalgh \& Stones, 2010). For instance, the nature of the integration of healthcare information systems with the culture and business processes of healthcare organisations puts more emphasis on the evaluation methods and goes beyond the technology aspects of hardware and software, furthermore, external and internal environmental factors as well as an understanding of the diverse nature of system effects in the healthcare settings is required (Greenhalgh \& Stones, 2010). This emphasis is on creating a better fit between human, contextual and technological factors for the successful implementation and adoption of health information systems (Yusof et al., 2008). 
I. Muhammad \& N. Wickramasinghe: Examining the PoC System Implementation and Adoption:

A FVM Perspective

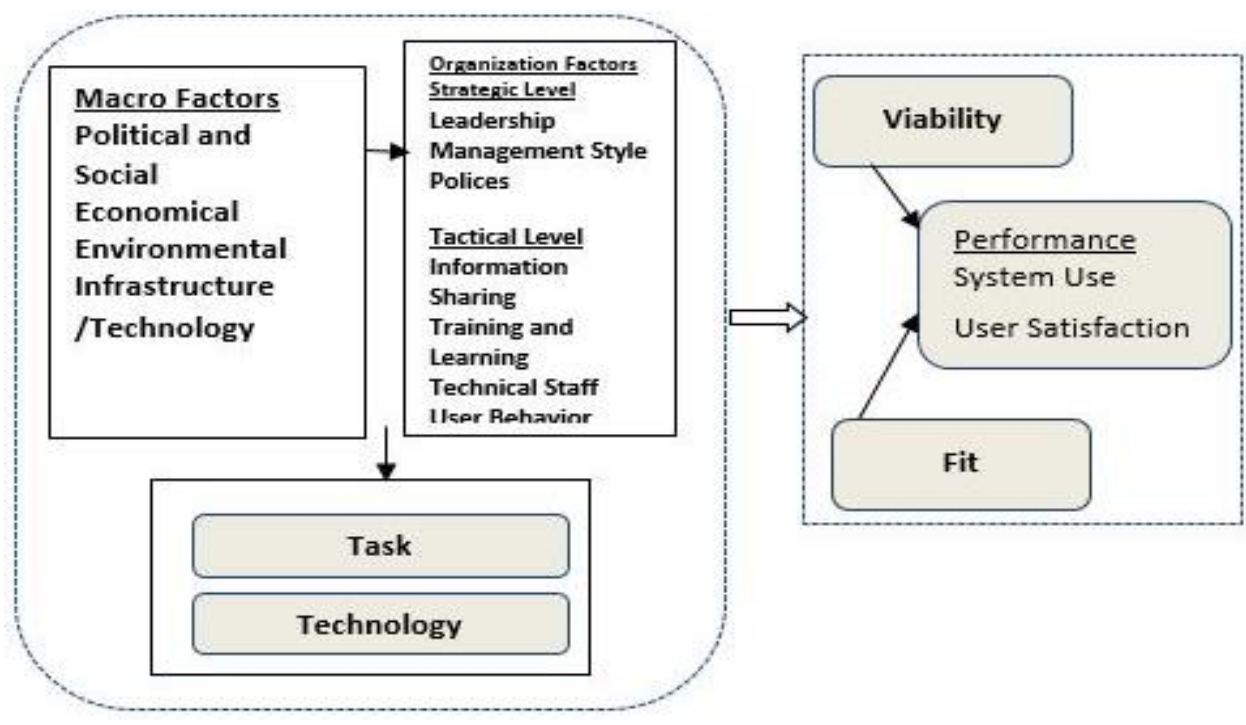

Figure 1: FVM

4

Methodology

Based on the criteria given by Yin (2010); the appropriate choice of methodology to test the use and usability of the proposed framework (figure 1) is a qualitative case study research because this is an exploratory study of a new phenomenon of bedside PoC information system's implementation. Further, we wish to explore how the PoC solution at different sites of the hospital can be implemented successfully and what are the factors that impact on the implementation and adoption of this HIS based intervention. Qualitative research is holistic, humanistic, and interactive, it can provide more support to focus on the study of a complex phenomenon of human and system interaction and relationship; as in our case multisite bedside PoC system implementations. Qualitative research can provide deeper understanding of the phenomenon as compared to quantitative study because of the exploratory nature of the study and focus which would not be on quantitative measures (Yin, 2010). For this study, several archival records and documents relating to the health information and communication technologies implementation and adoption in healthcare service delivery settings along with hospital and OneView reports and evaluations were critically analysed. These documents were of great value in developing an understanding of the need for a PoC system and factors important for the implementation and adoption of this system. This analysis assisted in developing the theoretical re-search framework and in planning the primary data collection strategies for the larger study. A priori themes were developed through a pilot study and then literature was analysed using thematic analysis and hermeneutic analysis (Boyatziz, 1998; Kvale, 1996), then we performed a gap analysis. The analysis led us towards the development of FVM for this study. 
Data for this piolet study was collected using unstructured interview and analysis of archival material. As far as possible, the multiple stakeholder views (i.e.; Service providers, regulator, payer, Food and environment services, and hospital and patient perspectives) in healthcare were captured. Data analysis included standard qualitative techniques such as thematic analysis where a priori themes were derived from the components in the conceptual model. The case studies all exemplify various aspects of the proffered conceptual model in this way serving to validate the model and demonstrate its usefulness in unpacking critical aspects with HIS implementation.

\subsection{The context before and after OneView PoC system}

This section presents a process map for two departments of the hospital before and after the implementation of the OneView PoC system. It must be noted here that prior to the PoC system, there was another system known as Infotainment. This system had many problems concerning mainly to poor technical support, frequent hardware and software failures, smaller screens, and usability issues especially with the user interface and the biometrics registries. That systems really did not fit with in the hospital quality services environment thus the change was impending. This section will explain the process before and after OneView PoC system within two departments; namely Food Services and Environmental Services. These departments are chosen as they are fully transitioned to the new PoC system now.

\subsubsection{The Context of Food Services}

Prior to the current PoC system, the processes in the Food Services were facilitated using an application called Delegate. This application had been in use since the opening of Epworth Eastern and has been replaced by OneView PoC system. Hence, the old PoC system was not used by the staff from Food Services.

\subsubsection{The Context of Food Services Prior to OneView PoC system}

Managing patients' meal orders was handled by the Department of Food Services. The contact point was the Menu Monitors, who take the meal orders 24 hours prior to the actual delivery of meal. A computerized system called Delegate Prior to OneView PoC system was used for the order and delivery services. Delegate system was installed on a number of computers on wheels (mainly laptops). Taking orders and delivery meals to the patient includes discussing the options and personal preferences for the breakfast, lunch, and dinner for the next day. This process would usually consume nearly $70 \%$ of the Menu Monitor's work time with a rate of 14 patients per hour. That is 3-4 minute per patient. Patients can choose three full courses for the next day from a menu that changes every three years hospital wide. The gathered information about the meal preferences was then entered by the Menu Monitors into Delegate, and then spread sheets were printed off this system to circulate to kitchens. These sheets were then assigned to different chefs as 
I. Muhammad \& N. Wickramasinghe: Examining the PoC System Implementation and Adoption:

A FVM Perspective

'Production Lists'. Throughout the day, three production lists were prepared, one in the morning $(7: 00 \mathrm{am})$, the second is after breakfast $(10: 00 \mathrm{am})$, and the third is at 3:30 PM for the evening as Figure 2 below illustrates.

Two main issues were found in this way of handling patients' meals. The first relates to the information collection, and the second issue about Delegate performance and functionality.

Although preparing the production lists was time consuming and required loads of time for the interaction between patients and menu monitors, still four types of information were not possible to capture using Delegate and the process around it. Those are:

I. Late orders: Meal orders for patients admitted after 8 pm during week days and after $7 \mathrm{pm}$ during weekends were not attended. This group of patients did not had a choice of food for the first day of their admission because they could not see the menu monitors. Rather, they would have the default meal for the day.

II. Food allergy for visited patients: Delegate did not had any capability to record any food allergy patients may have. This piece of information normally comes from iPM. In many cases this information was then not passed on to the chefs, so they make meals without taking that into consideration.

III. Discharged people: Depending on the time patients are discharged, many cases reportedly happened where meal orders were made, but patients had been discharged. Again, this piece is coming from iPM, and not passed on to the Food Services staff at the right time.

IV. People with changed diet codes: As treatment plans progress, patients may change their diet codes, such as changing from 'not eating' to 'eating' and from 'soft' to 'hard' food. These changes were also managed by nurses using iPM, however, the co-operation between nurses and Food Services was not maintained at all times, which resulted in many cases meals were not made according to these changes. 


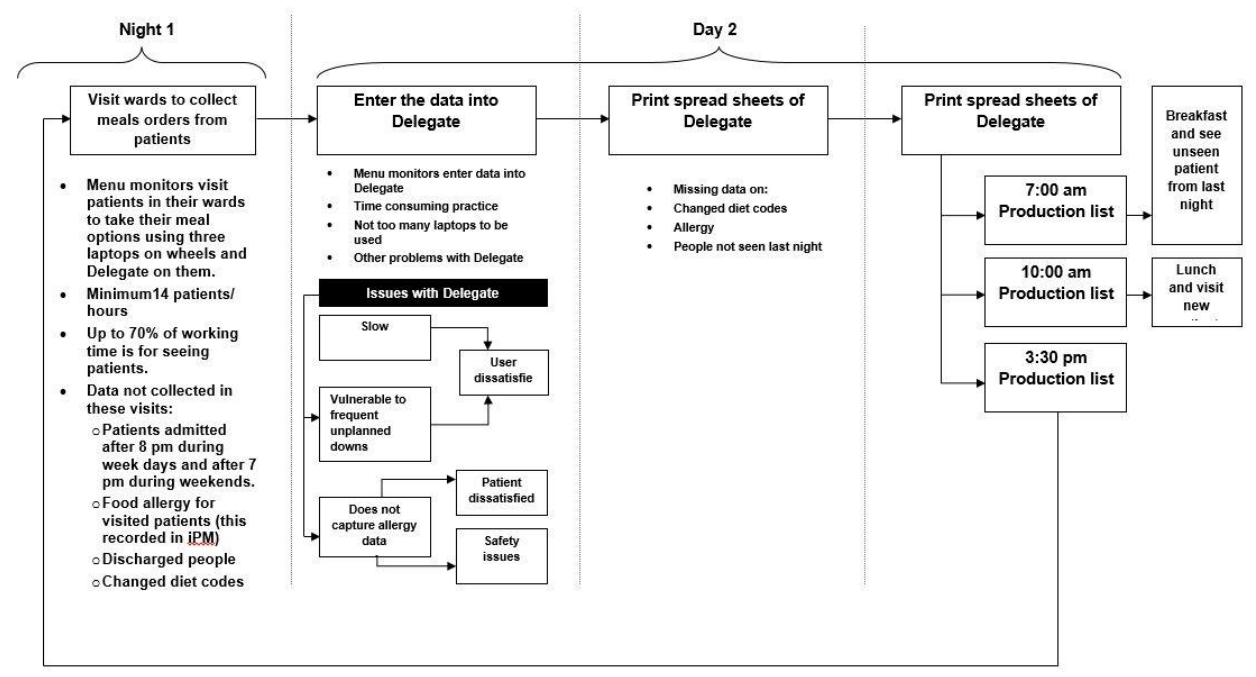

Figure 2: A Flow chart for ordering meals before PoC

These issues had direct and indirect impacts on the cost and quality of provided services as Table 1 below summarizes.

Table 1: Issues resulting from the conventional way to handle meal orders prior to OneView PoC system

\begin{tabular}{|l|l|l|}
\hline Issue & Impact on Cost & Impact on quality \\
\hline Late orders & $\begin{array}{l}\text { None, as patients receive } \\
\text { the default meal for the } \\
\text { next day }\end{array}$ & $\begin{array}{l}\text { Negative impact on patient } \\
\text { satisfaction }\end{array}$ \\
\hline $\begin{array}{l}\text { Food allergy for visited } \\
\text { patients }\end{array}$ & $\begin{array}{l}\text { Wasted food, unplanned } \\
\text { care for the resulting } \\
\text { allergy which may result in } \\
\text { implications on patients' } \\
\text { insurance cover }\end{array}$ & $\begin{array}{l}\text { Negative impact on patient } \\
\text { satisfaction and safety as } \\
\text { well as trust in the hospital }\end{array}$ \\
\hline Discharged patient & Wasted food & More pressure on chefs \\
\hline $\begin{array}{l}\text { Patients with changed } \\
\text { diet codes }\end{array}$ & Wasted food & $\begin{array}{l}\text { Negative impact on patient } \\
\text { satisfaction }\end{array}$ \\
\hline
\end{tabular}

Delegate has a number of issues as the interviewees from the Food Services agreed. These issues include:

I. It was perceived to be a slow system.

II. System was not really fit for the task.

III. Long term viability of the system was really doubtful even though infrastructure and management support were available. 
I. Muhammad \& N. Wickramasinghe: Examining the PoC System Implementation and Adoption:

A FVM Perspective

IV. The system had many technical problems and fixing these problems took long times as described by this interviewee: "If there is some technical problems with Delegate this would take long time to fix. I mean when the system goes down it really goes down and takes a while to fix".

V. As mentioned before, Delegate did not have the capability to capture food allergy data, which forced the staff at the Food Services to look up these data from iPM. This was not possible all the time, which resulted in a number of cases where patients had food that they were allergic to, consequence this had negative impact on patient satisfaction and healthcare services and delivery of the hospital.

While some issues with Delegate had negative impacts on the users, thus they became dissatisfied about the system; but few problems were really serious problem with real consequences on patient's health and safety. Not only did it negatively affect patient satisfaction and experience, but it also represented a real risk factor and caused safety issues to the patients and the hospital at the same time.

\subsubsection{The Context of Food Services After OneView PoC system}

Using OneView PoC system, patients can place their orders of meals through their user interface. The arrival of this function to the PoC system has partially solved the issues faced by the conventional system; namely late patients (after 8 pm weekdays and after 7:00 pm weekends), allergy data, and patients with changed diet coeds. Late patients can order their favorite meals for the next day if they want to, they can state their allergy status through the admission form, and nurses can change patients' diet codes right from OneView PoC system.

Currently, no more than $10 \%$ of the patients are using the PoC system to order their meals. On asking on the reasons behind that, two main reasons were identified. The first is some issues with the user interface, especially with elderly patients, as patients need to scroll down to the bottom of the screen to reach the meal ordering function. During the scrolling down, a number of pop-ups will appear and may disrupt their endeavor: "We go up and introduce the system to them. When you go into the system at the minute, the way they implemented it, it is hard to use. You've got to scroll down to find the ordering". 


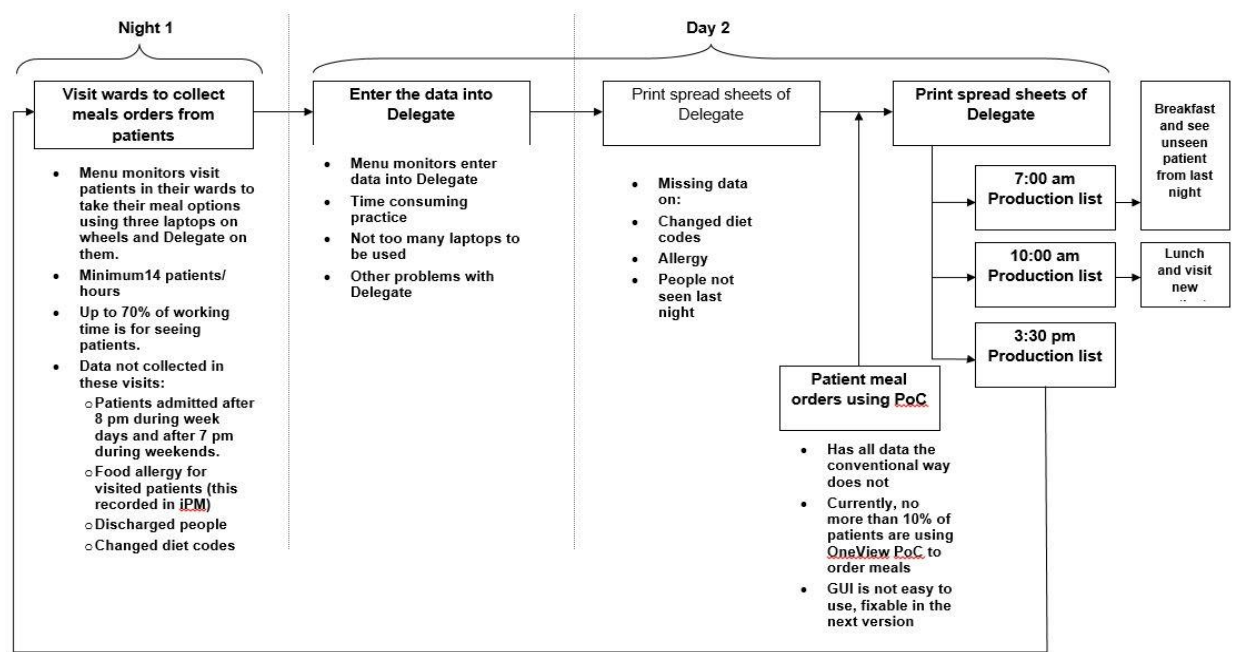

Figure 3: A Flow chart for ordering meals after PoC

The other reason relates to the conceptual resistance by some patients to rely on a 'machine' to order their meals, preferring human-human interaction more than humanmachine interaction. This was agreed upon by both interviewees from the Food Services. As a result of being in a hybrid environment, i.e. a minority of patients are using the PoC system to order their meals, and the majority are still using conventional way to order their meals, Delegate now has colored dots to indicate the patients who used the PoC system to order their meals. Hence, the menu monitors do not need to visit them to organize their meals.

With the expected increase of the uptake of this function in the PoC system, more patients will adopt this function, and more time required to see patients by their menu monitors will be freed-up. This is expected to have positive impacts on the hospital and its patients. In addition, it is expected that there will be a significant saving regarding food wastage.

\subsection{The Context of Environmental Services}

The Environmental Services is a dedicated team whose two main responsibilities are 1) providing all types of cleaning (steam cleaning, buffer cleaning, advanced cleaning, curtains cleaning, etc.), and 2) patient transportation. In terms on human resources, the Environmental Services team comprises about 60 staff. Of this figure, about 40 works in cleaning, and the reminder work in patient transportation.

Unlike the Food Services, which had Delegate as a computerized system to facilitate food-related processes prior to the OneView PoC system, the operations of the Environmental Services at the hospital were mainly based on phone to phone and face to face communications. Introducing the OneView PoC system and integrating the Room Ready Module into it has made considerable change in the processes of this vital 
I. Muhammad \& N. Wickramasinghe: Examining the PoC System Implementation and Adoption:

A FVM Perspective

department. The following is a summary of the process map of the Environmental Services at the hospital before and after OneView PoC system.

\subsubsection{The Context of Environmental Services before OneView PoC system}

The process of performing jobs by the Environmental Services before the PoC had three main steps. 1) Initiating the job by nurses and specific cleaners; 2) receiving job orders by the supervisors within the Environmental Services; and 3) assigning tasks to cleaners as Figure 4 depicts.

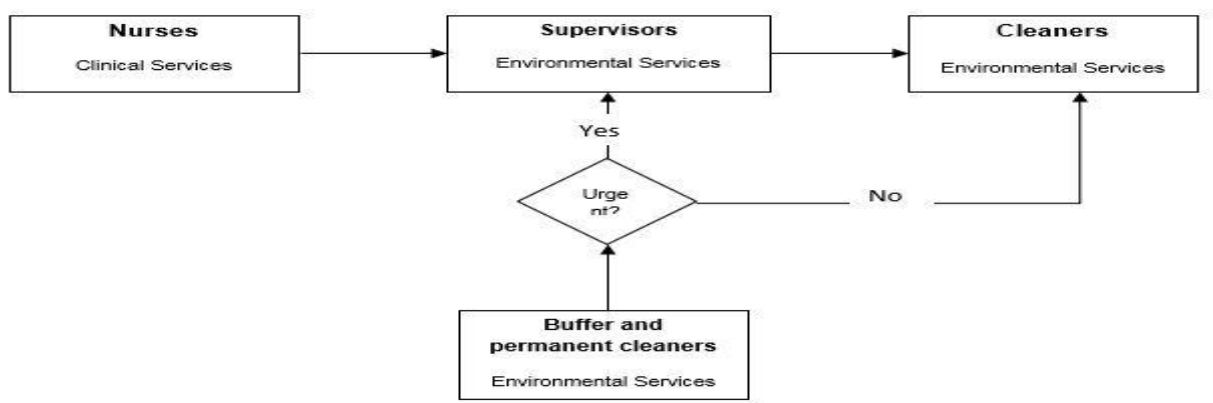

Figure 4: A map for the Environmental Services before OneView PoC

Nurses normally initiate job orders when needed. This includes preparing rooms before admitting new patients to these rooms, cleaning rooms after patients have been discharged, and as needed if a patient had an incident such as bleeding or vomiting. These job orders go to the supervisors from the Environmental Services using face to face or phone to phone communications tools. The supervisors in turn convey these orders to the cleaners across the hospitals using same communication means, i.e. phone and face to face. Apart from nurses, buffer cleaners and permanent cleaners can initiate job orders if need be. This normally happens when one of these cleaners realizes, while doing their jobs, there exist some curtains or carpet need to be cleaned, and they do not have the required equipment to do so. Once the need of a cleaner has been established, the path of this order in dependent upon its urgency. If the job was of a higher urgency, then these cleaners inform their supervisors either by phone calls or by hand-written notes. Then the supervisors assign the tasks to different cleaners on floor accordingly. If the job was not considered urgent by these cleaners, then they will wait till the next shift of cleaners has come to do the job based on hand written notes, which caused extended times to do specific jobs. The level of urgency was left to the cleaners to decide.

This system had caused many problems, which can be summarized as follows:

1. Over relaying on human factors: As can be seen, the whole processes of the Environmental Services team are centered on human communications and judgment. This resulted in many cases where jobs were not done or took longer time to be addressed. This is particularly acute in the cases where patients had 
to wait outside their rooms while cleaning the room, which resulted in unsatisfied patients and nurses.

2. Lack of co-ordination in the multi levels of communications: Given that nurses, supervisors, and permanent and buffer cleaners could initiate job orders, cleaners in many cases were confused about their tasks and what tasks had higher priorities. This lack of coordination was due to adopting phone calls, handwritten notes, and face to face means.

3. Inability to address language barriers: Given that a considerable portion of the cleaners had language barriers, their understanding of their assigned tasks over the phone or hand-written notes was reportedly limited in many cases, which caused many jobs not done properly.

4. More effort by cleaners: As the job orders did not have enough information about their jobs (locations, level of urgency, and required equipment), the cleaners had to go to the site to manually collect all of this information and come back to their workplace to collect the right equipment for that specific job. This caused them to walk back and forth many times, which reduced their productivity and the quality of their jobs, and increased their fatigue.

5. Lack of accountability: As the majority of the needed jobs were verbally conveyed from one stakeholder to another, the possibility of creating accountability and tracking the performance of different units and individuals were almost impossible. This is especially acute in the case of cleaners with limited literacy, as well as the communications between nurses (Clinical Services) and the cleaners and their supervisors as Figure 4 depicts.

These issues had direct and indirect impacts on the cost and quality of provided services as Table 2 below summarizes 
I. Muhammad \& N. Wickramasinghe: Examining the PoC System Implementation and Adoption:

A FVM Perspective

Table 1: Issues resulting from the conventional way to handle environmental services prior to PoC system

\begin{tabular}{|l|l|l|}
\hline Problems & Impact on Cost & Impact on Quality \\
\hline $\begin{array}{l}\text { Over relaying on Human } \\
\text { Factors }\end{array}$ & $\begin{array}{l}\text { Double work resulted in many cases, which implied } \\
\text { extra cost and less quality }\end{array}$ \\
\hline $\begin{array}{l}\text { Lack of Co-ordination: } \\
\text { Multi levels of } \\
\text { communications }\end{array}$ & $\begin{array}{l}\text { As many jobs needed to be repeated, double works } \\
\text { resulted in many cases, which implied extra cost and } \\
\text { less quality }\end{array}$ \\
\hline Language barriers & $\begin{array}{l}\text { Given the missing } \\
\text { information on the nature } \\
\text { of their tasks, cleaners had } \\
\text { to survey the location of } \\
\text { their jobs in person, which } \\
\text { resulted in them walking } \\
\text { for extended times/ } / \\
\text { distances. }\end{array}$ & $\begin{array}{l}\text { Due to the unneeded } \\
\text { increased workload, the } \\
\text { quality of cleaning } \\
\text { services was negatively } \\
\text { affected }\end{array}$ \\
\hline Lack of accountability & $\begin{array}{l}\text { Tracking the performance of individuals and different } \\
\text { unit was almost impossible }\end{array}$ \\
\hline
\end{tabular}

\subsubsection{The Context of Environmental Services after OneView PoC system}

Introducing the OneView PoC system, particularly the Room Ready Module, has notably streamlined the cleaning related processes of the Environmental Services, while the other vital role of the Environmental Services; namely patient transportation, is still conducted using the conventional way, with a vision to integrate this function into the OneView PoC in later enhancements.

The Room Ready Module enables nurses, permanent cleaners, and buffer cleaners to log into the system and place cleaning orders with enough details about the job, its location, requirements and level of urgency. This information is then conveyed to the cleaners on floor as short text messages on their PoC phones. Based on the nature of the jobs, cleaners can choose the jobs of higher urgency, closer to their geographic location, and/ or achievable using their current equipment. This has resulted in saving cleaners' times and efforts, which in turn has shown faster responses to the cleaning needs initiated by different wards, units, and individuals. Not only has the Room Ready module enhanced quality and productively of cleaners, but it has also resulted in a simpler map of cleaning processes performed by the Environmental Services as Figure 5 depicts. 


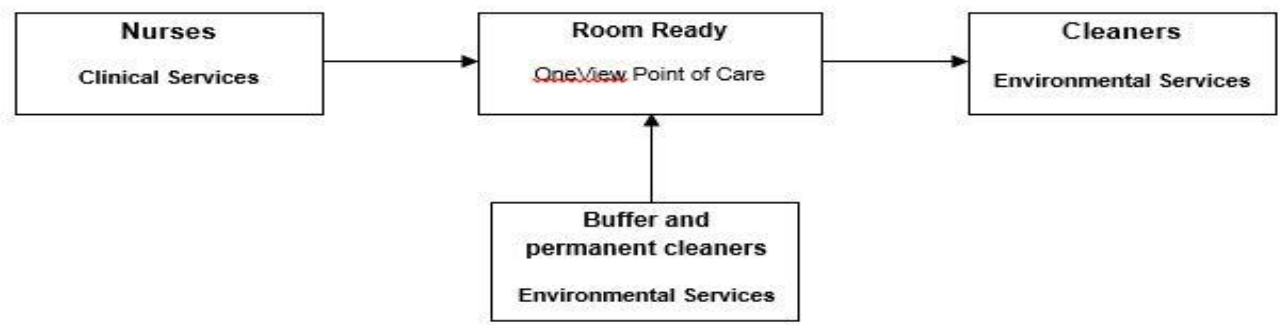

Figure 5: A map for the Environmental Services after OneView PoC

The initial findings from the interviews show that the use of OneView PoC system to support the cleaning processes at Epworth Eastern has addressed most of the problems faced by the conventional way to manage the cleaning needs for the hospital. Table 2 summarized these findings:

Table 2: The impact of Room Ready Module from the OneView PoC system

\begin{tabular}{|c|c|c|c|}
\hline \multirow[t]{2}{*}{ Problems } & \multirow[t]{2}{*}{$\begin{array}{l}\text { How has OneView PoC addressed } \\
\text { the problems }\end{array}$} & \multicolumn{2}{|c|}{$\begin{array}{c}\text { Impact of OneView } \\
\text { PoC on }\end{array}$} \\
\hline & & Quality & Cost \\
\hline $\begin{array}{l}\text { Over relaying on } \\
\text { Human Factors }\end{array}$ & $\begin{array}{l}\text { This problem has been partially } \\
\text { solved, as human still need to log in } \\
\text { and place job orders. The existence of } \\
\text { Room Ready though has increased } \\
\text { the ability to place jobs and track } \\
\text { them. }\end{array}$ & $\begin{array}{c}\text { Positive } \\
\mathrm{M}\end{array}$ & $\begin{array}{c}\text { Positive } \\
\text { M }\end{array}$ \\
\hline $\begin{array}{l}\text { Lack of } \mathrm{Co}- \\
\text { ordination: }\end{array}$ & \multirow{2}{*}{$\begin{array}{l}\text { The introduction on Room Ready } \\
\text { Module has eliminated one layer of } \\
\text { communications in the process map } \\
\text { of cleaning services. That is the } \\
\text { supervisors, which has freed up their } \\
\text { time, and has rebuilt their roles } \\
\text { around coordinating different tasks } \\
\text { and following up with different } \\
\text { stakeholders. }\end{array}$} & \multirow[t]{2}{*}{$\begin{array}{c}\text { Positive } \\
\mathrm{H}\end{array}$} & \multirow[t]{2}{*}{$\begin{array}{c}\text { Positive } \\
\text { M }\end{array}$} \\
\hline $\begin{array}{l}\text { Multi levels of } \\
\text { communications }\end{array}$ & & & \\
\hline Language barriers & $\begin{array}{l}\text { As job orders come to cleaners in a } \\
\text { form of short text messages on their } \\
\text { PoC phones, this problem has been } \\
\text { partially solved. }\end{array}$ & $\begin{array}{l}\text { Positive } \\
\text { L }\end{array}$ & $\begin{array}{l}\text { Positive } \\
\text { L }\end{array}$ \\
\hline $\begin{array}{l}\text { More effort } \\
\text { cleaners }\end{array}$ & $\begin{array}{l}\text { As the jobs orders come with a } \\
\text { relatively comprehensive set of } \\
\text { information, cleaners don't need to } \\
\text { go and assess the job before actually } \\
\text { doing the job, which resulted less }\end{array}$ & $\begin{array}{c}\text { Positive } \\
\mathrm{H}\end{array}$ & $\begin{array}{c}\text { Positive } \\
\mathrm{M}\end{array}$ \\
\hline
\end{tabular}


I. Muhammad \& N. Wickramasinghe: Examining the PoC System Implementation and Adoption:

A FVM Perspective

\begin{tabular}{|l|l|c|c|}
\hline & $\begin{array}{l}\text { effort from them, and more tasks } \\
\text { performed every day than before }\end{array}$ & & \\
\hline Lack & $\begin{array}{l}\text { All jobs' orders are now documented } \\
\text { and stored in the system. Hence, } \\
\text { accountability }\end{array} \quad \begin{array}{l}\text { Positive } \\
\text { progress and the responses from } \\
\text { different stakeholders is always } \\
\text { possible. }\end{array}$ & Positive & $\mathrm{H}$ \\
\hline
\end{tabular}

Legends: L: Low, M: Medium, H: High

The initial results suggested that the PoC system for food and environment services is fit for task and very much viable to implement. Almost all sites of hospital were ready for implementation. IT Infrastructure was fit for the purpose while physical infrastructure needs changes for one site. Environment was favorable, and project have full support from top management. Appropriate budget was allocated for the project. Our initial analysis suggest that the use of system will be depended on the fitness of the system for the tasks. Users were very positive in its very early stages of deployment. We contend that a large-scale study is prudent to further understand the capacities of implementation and use of this system for clinical services.

\section{Conclusion}

The purpose of this research paper is to conceptualize a framework to investigate the implementation and use viability of a bedside PoC health information and entertainment system for food and environment services for patients in private hospital wards, since we recognize that with e-innovations not only the technology solution is necessary but it is also critical to look at organizational and societal aspects concurrently especially in today's global business environment. ehealth system implementations comprise of technology as well as human involvement. In view of this, it is important to investigate the impact of political and social, economic, environmental and infrastructure/technology factors on the organizational decision making. We underscore the importance of studying the system viability and fit before making any decision about system adoption and deployment. Technology needs to have a good fit to perform the required tasks, only then can system viability and fit have positive effects on the organization's performance and that can be measured by system use and user satisfaction and thus ensure the full potential of a solution is realised.

The theoretical contribution of the paper is the use of Fit-viability model for the evaluation of health information technology (HIT) implementation in private hospital settings. This model has never been used of HIT implementations, thus we believe the model will present more informed lens for decision makers to understand HIT implementation. The practical implication of the Fit-Viability model presented in this paper can be realised by using the developed model to measure the fitness and viability of implementing health information technology in hospital settings. This should be able to envisage the possibility of success. 


\section{Muhammad \& N. Wickramasinghe: Examining the PoC System Implementation and Adoption:}

There are also limitations of this study First, the theoretical generalizability of the FVM needs critical testing in future studies. Second, the findings of this paper are based on just two segments of the hospital namely food services and environmental services, thus more extensive studies including more segments of hospital may be necessary.

\section{References}

Al-Azmi, S. F., Al-Enezi, N., \& Chowdhury, R. I. (2009). Users' attitudes to an electronic medical record system and its correlates: A multivariate analysis. HIM J, 38(2), 33-40.

André, B., Ringdal, G. I., Loge, J. H., Rannestad, T., Laerum, H., \& Kaasa, S. (2008). Experiences with the implementation of computerized tools in health care units: a review article. Intl. Journal of Human-Computer Interaction, 24(8), 753-775.

Avgerou, C. (2008). Information systems in developing countries: a critical research review. Journal of Information Technology, 23, 133-146. doi:10.1057/palgrave.jit.2000136

Boyatzis, R. E. (1998). Transforming Qualitative Information: Thematic Analysis and Code Development (1st ed.). Sage Publications, Inc.

Brailer, D. J. (2005). Interoperability: the key to the future health care system. Health Affairs, 24, W5.

Cresswell, K., Worth, A., \& Sheikh, A. (2011). Implementing and adopting electronic health record systems: How actor-network theory can support evaluation. Clinical Governance: An International Journal, 16(4), 320-336. https://doi.org/10.1108/14777271111175369

Choi, J., Chun, J., Lee, K., Lee, S., Shin, D., Hyun, S., ... Kim, D. (2004). MobileNurse: hand-held information system for point of nursing care. Computer Methods and Programs in Biomedicine, 74(3), 245-254.

DesRoches, C. M., Campbell, E. G., Rao, S. R., Donelan, K., Ferris, T. G., Jha, A., ... Blumenthal, D. (2008). Electronic Health Records in Ambulatory Care -- A National Survey of Physicians. New England Journal of Medicine, 359, $50-60$.

Greenhalgh, T., \& Stones, R. (2010). Theorising big IT programmes in healthcare: strong structuration theory meets actor-network theory. Social Science \& Medicine (1982), 70(9), 1285-1294. doi:10.1016/j.socscimed.2009.12.034

Huang, Z., \& Palvia, P. (2001). ERP implementation issues in advanced and developing countries. Business Process Management Journal, 7(3), 276-284. doi:10.1108/14637150110392773

Ignatiadis, I., and Nandhakumar, j. (2007). "The impact of enterprise systems on organizational resilience", Journal of Information Technology, 22: 36-43.

Ives, B. and Jarvenpaa, S.L. (1991). "Applications of Global Information Technology: Key Issues for Management”, MIS Quarterly 15 vol 1, pp. 33-49

Kvale, S. (1996). InterViews: An Introduction to Qualitative Research Interviewing (1st ed.). Sage Publications, Inc.

Kralewski, J., Dowd, B. E., Zink, T., \& Gans, D. N. (2010). Preparing your practice for the adoption and implementation of electronic health records. Physician Executive, 36(2), 30-33.

Kennedy, B. L. (2011). Exploring the Sustainment of Health Information Technology: Successful Practices for Addressing Human Factors. NORTHCENTRAL UNIVERSITY. pp. 7-17.

Liang, T.-P., Huang, C.-W., Yeh, Y.-H., \& Lin, B. (2007). Adoption of mobile technology in business: a fit-viability model. Industrial Management \& Data Systems, 107(8), 1154-1169. https://doi.org/10.1108/02635570710822796

Liang, T.P. and Wei, C.P. (2004), "Introduction to the special issue: a framework for mobile commerce applications", International Journal of Electronic Commerce, Vol. 8 No. 3 ,

Liu, L. S., Shih, P. C., \& Hayes, G. R. (2011). Barriers to the adoption and use of personal health record systems. In Proceedings of the 2011 iConference (pp. 363-370). 
I. Muhammad \& N. Wickramasinghe: Examining the PoC System Implementation and Adoption:

A FVM Perspective

Muhammad, I., \& Wickramasinghe, N. (2014). How an Actor Network Theory (ANT) Analysis Can Help Us to Understand the Personally Controlled Electronic Health Record (PCEHR) in Australia. Technological Advancements and the Impact of Actor-Network Theory, 15-34.

Mukesh S., Betsy J. G. (2009) “Chinese Cultural Implications for ERP Implementation” Journal of Technology Management \& Innovation Volume 4, Issue 1

Nguyen, L., Bakewell, L., Wickramasinghe, N., Haddad, P., Muhammad, I., Moghimi, H., ... Botti, M. (2015). Transition from Paper to Electronic Nursing Documentation in Residential Aged Care: an Actor Network Theory Analysis. Electronic Journal of Health Informatics, 9(1), 4.

Protti, D., Johansen, I., \& Perez-Torres, F. (2009). Comparing the application of Health Information Technology in primary care in Denmark and Andalucía, Spain. International Journal of Medical Informatics, 78(4), 270-283. doi:10.1016/j.ijmedinf.2008.08.002

Scott, J. T., Rundall, T. G., Vogt, T. M., \& Hsu, J. (2005). Kaiser Permanente's experience of implementing an electronic medical record: a qualitative study. BMJ (Clinical Research Ed.), 331(7528), 1313-6.

Showell, C. M. (2011). Citizens, patients and policy: a challenge for Australia's national electronic health record. Health Information Management Journal, 40(2), 39-43.

Soh, C., Kien, S. S., and Tay-Yap, J. (2000) "Enterprise Resource Planning: Cultural Fits and Misfits: Is ERP a Universal Solution?" Communications of the ACM, 43 Vol. 4, pp. 47-51.

Tjan, A.K. (2001), "Finally, a way to put your internet portfolio in order", Harvard Business Review, Vol. 79 No. 2, pp. 76-85.

Trudel, M. C. (2010). Challenges to personal information sharing in interorganizational settings: Learning from the Quebec Health Smart Card project. THE UNIVERSITY OF WESTERN ONTARIO.

Umble, E., Haft, R., and Umble, M. (2003). "Enterprise Resource Planning: Implementation Procedures and Critical Success Factors," European Journal of Operational Research, 146, Vol. 2 pp. 241-257

Yao, J., Schmitz, R., \& Warren, S. (2005). A wearable point-of-care system for home use that incorporates plug-and-play and wireless standards. IEEE Transactions on Information Technology in Biomedicine, 9(3), 363-371.

Yusof, M. M., Papazafeiropoulou, A., Paul, R. J., \& Stergioulas, L. K. (2008). Investigating evaluation frameworks for health information systems. International Journal of Medical Informatics, 77(6), 377-385. doi:10.1016/j.ijmedinf.2007.08.004 


\title{
Influence of Digital Coaching on Physical Activity: Motivation and Behaviour of Physically Inactive Individuals
}

\author{
TUOMAS KARI \& PETRIINA RINNE
}

\begin{abstract}
Digital wellness solutions and their use have become increasingly common. Respectively, the need to understand their users and usage has increased. A general problem with wellness technologies is that they typically provide feedback through numbers and graphs instead of providing actual guidance. One potential and novel solution for this is digital coaching. This study is one of the first to examine digital coaching features and their influence. We define digital coaching in the context of sports and wellness technology and investigate its influence on physical activity motivation and behaviour of physically inactive individuals. The study is based on thematic analysis of 20 semi-structured interviews conducted for 10 participants who used a novel digital coaching solution for one month. The digital coaching solution was found to be beneficial for physical activity and exercise motivation and behaviour. It assisted the users in many ways through different elements and mechanisms. Further, the benefits also spurred to other aspect of physical wellness. The results are discussed and implications provided.
\end{abstract}

Keywords: - Digital Coaching - Digital Coach - eWellbeing - Digital Wellness $\bullet$ Physical Activity $\bullet$ Wellness Technology $\bullet$ Sports Technology $\bullet$ Motivation • Behaviour • IS use •

CORRESPONDENCE AdDRESS: Tuomas Kari, D.Sc., Postdoctoral researcher, University of Jyvaskyla, Faculty of Information Technology, P.O. Box 3540014 Jyvaskylan yliopisto, Finland, e-mail: tuomas.t.kari@jyu.fi. Petriina Rinne, MSc, University of Jyvaskyla, Faculty of Information Technology, P.O. Box 3540014 Jyvaskylan yliopisto, Finland, e-mail: petriina.r.rinne@student.jyu.fi 
T. Kari \& P. Rinne: Influence of Digital Coaching on Physical Activity: Motivation and Behaviour of Physically Inactive Individuals

Technological development has promoted the emergence of various new technologies that allow their user to track, measure, and evaluate a multitude of personal activities and biosignals. During the past years, both individual consumers as well as the healthcare sector have become more and more interested to measure and promote health, wellness, and physical performance by using such technologies. Indeed, the number of such technologies in the market has exploded, as their popularity and significance in both individual level and in healthcare has gradually risen.

Wellness technologies often include features for some form of self-tracking. The use of different self-tracking technologies has become a part of daily life for an increasing number of people (McFedries, 2013), and they are commonly used, for example, as tools to promote personal health and wellness (Swan, 2013). There once was a time when these kinds of technologies were designed purely for athletes, but nowadays there is a huge amount of different digital wellness technologies, such as devices, services, and applications aimed for regular users with all levels of physical activity. Indeed, the users of these technologies are a very varying group of users (Kettunen et al., 2017). Wellness technologies are still typically designed and developed for working age or younger population, but their increasing need and potential also among older users has been presented (Carlsson \& Walden, 2017).

Whilst technology in general has developed, physical inactivity has become a major global health issue. According to WHO (2017), in a global scale, around 25\% of adults and more than $80 \%$ of the world's adolescent population are not sufficiently physically active. Insufficient physical activity is the fourth leading risk factor for noncommunicable diseases and death worldwide, while physical activity has significant health benefits across all age groups and contributes to the prevention of diseases (WHO, 2017). Researchers in various fields have begun a serious research effort to find solutions to combat the problems of sedentary lifestyle, which are becoming increasingly widespread in our society. One stream of research concerning this has been the investigation of could different wellness technologies be used to promote the physical activity of their users.

Studies on wellness technology use have found that feedback from wellness technologies can heighten the user's awareness of personal physical activity and motivate towards it (e.g., Chan, Ryan \& Tudor-Locke, 2004; Faghri et al., 2008; Kang et al., 2009; Kari et al., 2016b; Kari et al., 2017; Wang et al., 2016). However, while tracking wellness related data may result in better awareness of daily activity, it may not be sufficient to maintain the use of wellness technologies (Miyamoto et al., 2016), which can also affect maintaining wellness routines (Warraich, 2016). Thus, providing guidance and goals for using these technologies would probably increase the adherence to using them and subsequently, adherence to wellness related routines, such as physical activity. 


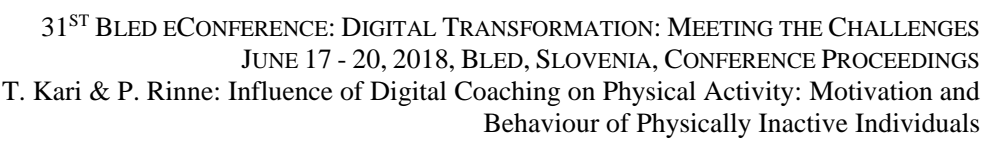

A general problem with sports and wellness technologies has been that they are more focused on providing feedback through numbers and graphs instead of providing actual manageable solutions. Research has shown that the users of wellness technologies want clear, relevant, and easy-to-understand feedback from their activities as well as information on how they should go about with their physical activity and exercise. This would likely lead to the use being more goal-oriented (e.g., Kari et al. 2016a; Kari et al. 2017b), which is generally seen beneficial (Locke \& Latham, 2002; Shilts, Horowitz, \& Townsend, 2004). Thus, providing the users with actual manageable steps, for example, in the form of a personalized workout plans, would increase the possibility of making both the use of the wellness technologies and the behaviour of the users more goaloriented. One potential solution for this is digital coaching. Schmidt et al. (2015) present a demand for a goal-driven support of fitness goal achievement to be addressed by digital coaching.

We define digital coaching in the context of sports and wellness technology: Digital coaching refers to information technology mediated sports and wellness related coaching activities that are generated by a software without human intervention. Coaching activities can be any kind of activities that guide, direct, train, or instruct the person being coached.

The interest towards different solutions to fall under the digital coaching definition has increased among users, industry, and healthcare as well as in academia. However, as these digital coaching solutions are quite novel, the number of studies concerning their effects or the experiences that people have with them is still rather limited. Therefore, it is important to kick-start the research on the topic. This kind of research can offer numerous valuable implications for the development and use of technologies with digital coaching features, and further, aid in promoting physical activity.

This study investigates the influence of digital coaching features on the physical activity motivation and behaviour of physically inactive individuals. This will provide new, relevant, and valuable information on digital coaching and technologies with digital coaching features. The main research questions of the study are:

1) How is the influence of digital coaching to physical activity motivation and behaviour of physically inactive individuals?

2) What are the central aspects of digital coaching that respond to users' needs? The focus of the study is on the users' subjective experiences. The study is explorative in nature and follows a qualitative approach. The study is based on thematic analysis of 20 semi-structured interviews conducted to ten individual participants. The participants were using a wellness technology with novel digital coaching features for a period of one month.

Our study is one of the first ones to examine digital coaching solutions and their influence. The study presents some highly valuable first insights to digital coaching research and increases the understanding of digital coaching solutions and their use and influence. Our findings will provide the industry and parties working with physical activity promotion 
T. Kari \& P. Rinne: Influence of Digital Coaching on Physical Activity: Motivation and Behaviour of Physically Inactive Individuals

new science-based knowledge and implications, which will assist in designing and developing digital coaching features for wellness, health, and sports, and in planning new kinds of novel interventions to promote physical activity. In addition, our findings can be valuable to the healthcare sector when deploying technologies with digital coaching features to the patients.

\section{$2 \quad$ Background}

\subsection{The Digital Coaching Feature Used in this Study}

The digital coaching feature used in our study was the Next Workout Recommendation feature by Firstbeat Technologies (Firstbeat Technologies Oy, 2018a). It is designed to work as a digital coach. A knowledge base with scientifically validated facts behind the feature can be found from Firstbeat's White Papers and Publications website (Firstbeat Technologies Oy, 2018d). The Next Workout Recommendation feature can be varied to a certain extent depending on the requirements of the (corporate) customer. In our study, the functionality of the feature was as described below.

In the beginning of the use, the user conducts a test with the feature and it provides an estimation of the person's $\mathrm{VO} 2$ max fitness level using "a proprietary method shown to be $95 \%$ accurate compared to laboratory measurements". The test can be conducted during any freely performed walk, run, or ride (Firstbeat Technologies Oy, 2017; 2018b). The VO2max fitness level estimation (presented as the fitness level in the feature) gets more accurate the more the user uses the feature. After the base-level test, the user determines whether s/he is aiming to maintain the current fitness level or to improve it. If the user sets a goal to improve the fitness level, s/he will also get to choose the degree between improve and improve fast. The feature will then create an adaptive target goal for the user. The chosen approach will influence the degree of physiological impact targeted for the given workouts. Based on the background and the goal of the user, the chosen approach, and the estimated base-level of fitness, the feature creates a personalised and adaptive continuous seven-day workout plan that automatically adapts after each workout based on the activities of the user. The feature provides a specific workout or a rest day for each day. If the user misses a session or does the training longer or harder than suggested, the feature takes this into account and adapts the training plan accordingly. Moreover, when the fitness level changes, the feature will adapt the program accordingly: if the fitness level increases, the planned workouts will require more effort to be completed and if it decreases, the planned workouts will become easier (Firstbeat Technologies Oy, 2018c). Thus, the feature is suitable for people with different fitness levels and different physical activity levels, including physically inactive people.

The feature is designed and best suited for aerobic training but places no restrictions regarding the specific sport conducted. If the user chooses so, the feature can also provide real-time guidance during the workout. The real-time guidance communicates to the user to maintain, increase, or decrease the current exertion level, and shows how much of the current workout has been conducted. It also shows when the goal of the workout has been 


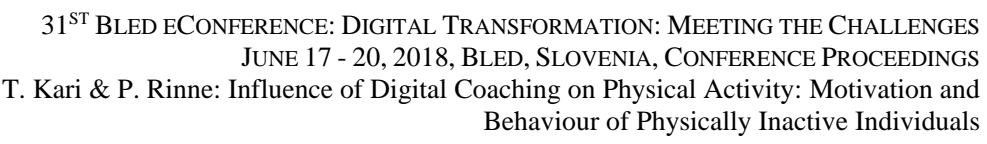

reached, but the training continues until the user decides to end it. The feature also provides different views that display, for example, the user's progress and various other information. Some of the views contain elements aiming to wake the experience of gamification (Kari et al., 2016b) in the user to further increase the motivation. Such elements include, for example, progress bars, comparison, and levels. An example view is presented in the appendix.

VO2max - the used metric to present the fitness level in the feature - is a metric that defines one's personal aerobic/cardiorespiratory fitness level. It describes the body's capability to bring oxygen into the body through the lungs, transport it through the circulatory system to the muscles, and use it as part of body's energy production method. Higher VO2max scores are strongly related to not just aerobic performance but also health and longevity in general (Firstbeat Technologies Oy, 2018b). For more detailed description of VO2max, see (Firstbeat Technologies Oy, 2017).

\subsection{Goal Setting}

Goal setting can be an important facilitator for behaviour change (Locke \& Latham, 2002; Shilts et al., 2004) and it provides a potential strategy for transforming physical activity information into practical actions (Shilts et al., 2004). To be effective, goal setting requires some form of self-tracking to better support the realisation of goals and the increase in self-efficacy (Fukuoka et al., 2010; Locke \& Latham, 2002; Shilts et al., 2004). Goal setting can be viewed through three central dimensions: 1) self-set goals - assigned goals - participatory goals; 2 ) personalised goals - non-personalised goals; 3 ) fixed goals - adaptive goals (Zhou et al., 2018). Despite self-set goals typically being of highest personal importance, a literature review (Shilts et al., 2004) on goal setting shows that assigned goals are more effective in comparison to self-set goals (Zhou et al., 2018). Studies have also shown that interventions utilising wellness technology with fixed and non-personalised physical activity goals are often significantly less effective than interventions with adaptive goals (Adams et al., 2017; Adams et al. 2013; Jakicic et al., 2016; Zhou et al., 2018) or with personalised goals (Chan et al., 2004; Jakicic et al., 2016; Tudor-Locke, 2002; Zhou et al., 2018) in increasing physical activity levels. The weakness in providing fixed and non-personalized goals to all users is that in many cases it irresistibly leads to either goals that are too high or even unrealistic or too low and unchallenging. This obviously decreases the effectiveness of the goal setting (TudorLocke, 2002; Zhou et al., 2018) and leads to non-optimal behaviour. Studies have also shown that in the case of sports and wellness technology, the utilitarian goals are one of the important drivers behind use intention (Makkonen et al., 2012a; Makkonen et al., $2012 \mathrm{~b}$ ). Thus, the adaptive and personalized goals and training plans provided by the Next Workout Recommendation feature pose much potential regarding physical activity and fitness. 
T. Kari \& P. Rinne: Influence of Digital Coaching on Physical Activity: Motivation and Behaviour of Physically Inactive Individuals

The basic setting of our study included participants who implemented the Next Workout Recommendation digital coaching feature into use for a period of one month. Due to its novelty, at the time of the use period (September-October 2017), the Next Workout Recommendation feature was not yet implemented on any commercial physical devices, though the first products implemented with it were released not long after (early 2018). Therefore, the participants used a mobile application version (provided by Firstbeat) that was installed to their smart phones before the use period started. For clarity, we refer to the used Next Workout Recommendation feature as application in the remaining of the paper. All the participants were also given a heart rate belt and personally instructed on how to use the application and how to interpret the received information. As physically inactive individuals seldom want to maintain their current fitness level but rather to increase it, all the participants were set with a goal of improving fitness level in the application (improve approach). The application then created and provided each one with a personalised target goal to be aimed for in one month and started providing the users with adaptive continuous seven-day workout plan to reach that target goal. As the aim of the study was not in increasing the physical fitness levels of the participants per se but to investigate the application's influence on motivation and behaviour, we did not require the participants to conduct every workout the application suggested, but rather wanted the use to be as natural as possible. Thus, it was a voluntary choice to do or not to do the suggested workouts. This kind of autonomy is also central in the self-determination theory (Ryan \& Deci, 2000).

To conduct our study, we chose a qualitative approach. Qualitative research aims to understand people, their sayings and behaviour, as well as the cultural and social context they are living in. The goal is to find new knowledge and understand real life phenomena. One of the central benefits of qualitative research is enabling the researcher to see and understand the underlying contexts in which decisions are made and actions take place (Myers, 2013).

To collect the data, we chose interviews as the data collection method. According to Myers \& Newman (2007, p. 3) qualitative interview is the "most common and one of the most important data gathering tools in qualitative research". More precisely, we chose a semi-structured interview, which is the most used type of interview in IS research. In a semi-structured interview, there is an incomplete script, but it is typical that some preformed structure is prepared that the interviewer follows (Myers \& Newman, 2007). This was also the case in our interviews. In planning and conducting the interviews, we followed relevant guidelines (e.g., Guest, Bunce \& Johnson, 2006; Myers, 2013; Myers $\&$ Newman, 2007) regarding semi-structured interviews. The goal was to gain maximal benefit from using the method and to avoid the potential problems and pitfalls.

We conducted two interviews for each interviewee, one before and one after the use period. The first one mainly focused on the expectations towards the application and its influence, whereas the second one focused mainly on the experiences and perceived 
influence of using the application on physical activity and exercise motivation and behaviour. Therefore, two distinct interview scripts were created. One for the interviews before (Script 1) and one for the interviews after (Script 2) the use period. It is to be noted that the interviews also included themes for a purpose of another study. However, this cannot be seen to affect the results of this study. However, it affected the development of the scripts so that they also included themes and questions deriving from theories less connected to this particular paper. The themes for Script 1 were mainly developed based on the research questions, previous literature, and the theoretical background, while some themes also derived from the UTAUT2 (Venkatesh, Thong \& Xu, 2012) and innovationdecision process (Rogers, 2003). Script 2 included the same aspects but focusing more on the experiences from the use period plus questions deriving from self-determination theory (Ryan \& Deci, 2000). The themes of both interviews are presented in the appendices. But as mentioned, not all themes were used in this particular paper. Following Myers and Newman (2007), the interviews included the opening, the introduction, key questions related to certain themes, and the closing.

To recruit the participants, we used a snowball sampling approach (Patton, 2002). First, we searched persons that met the criterion and then suggested them with the possibility to participate in the study. Then, the selected participants were asked for and provided information on additional potential participants and these again were contacted. Following McCracken (1988), in selecting the interviewees we aimed for a fairly homogenous sample that share critical similarities concerning the research question, this way aiming to maximise the richness and depth of the data. In addition, certain criteria were used: 1) the person was physically inactive at the moment, 2) the person had the possibility and interest to implement the application into use, and 3) the person was motivated to take part in the research.

In the end, the study was conducted with ten participants. We conducted 12 interviews before the use period, but had two dropouts during the use period due to sickness affecting not being able to exercise. Thus, we conducted 10 interviews after the use period. We did not include the interviews from the two dropouts in our analysis. The first round of interviews was held early September 2017 before the use period began, and the second interviews during November 2017 by one of the authors. The interviews were held faceto-face with the interviewee, with the exception of one interview that was conducted via mobile phone. On average, the interviews lasted 25 and 49 minutes. The interviews were recorded and transcribed (in the interviewees native language). Based on the transcriptions and notes made during the interviews, the analysis began.

For the purposes of this particular paper, our analysis mainly focused on the data collected with the second-round interviews. To analyse the data, we used thematic analysis, which is the most widely used method of analysis in qualitative research (Guest, MacQueen \& Namey, 2012). Thematic analysis is a method for "identifying, analyzing and reporting patterns (themes) within data" (Braun \& Clarke, 2006, p. 79). Using thematic analysis, a researcher can organise and describe the data set in rich detail, and typically go even deeper by interpreting various aspects of the research subject (Braun \& Clarke, 2006). In 
T. Kari \& P. Rinne: Influence of Digital Coaching on Physical Activity: Motivation and Behaviour of Physically Inactive Individuals

addition to identifying, analysing, and reporting the themes in our data, we also aimed to interpret various specific related aspects and exceptions. In conducting the analysis, we applied guidelines from Braun and Clarke (2006) and Patton (2002). As they suggest, these guidelines were applied flexibly to fit the research questions and the collected data. Further, as suggested, the analysis process was not a linear phase-to-phase process but a recursive one, in which we moved back and forth between the different phases of the analysis.

\section{$4 \quad$ Results}

The ten participants consisted of five females and five males with the mean age of 31,6 years. The description of each participant can be found in Table 1. In general, the participants had rather little previous experience on using sports or wellness technology. Only two owned some such device at the moment, but neither of them was using it actively. The physical activity background of the participants varied a lot. Some had a more active history through some hobby and some had even competed earlier in their life, whereas others had been more or less physically inactive their whole life and regarded themselves as beginners in terms of exercise. However, it is to be noted that even though some participants had been more physically active in the past, at the moment when the use period started, they all considered themselves to be physically inactive, and at most, taking part in exercise activities was occasional. Everyone also perceived their current aerobic fitness level as low or fair at best.

Table 1: Description of the Sample

\begin{tabular}{|c|c|c|c|c|}
\hline Participant & Gender & Age & $\begin{array}{c}\text { Physical Activity } \\
\text { Background }\end{array}$ & $\begin{array}{c}\text { Previous Experience on } \\
\text { Sports Technology }\end{array}$ \\
\hline 1 & Female & 34 & Competition history & Heart rate monitor \\
\hline 2 & Female & 28 & Beginner & - \\
\hline 3 & Male & 28 & Competition history & - \\
\hline 4 & Female & 21 & Beginner & Mobile applications \\
\hline 5 & Male & 33 & Competition history & Heart rate monitor \\
\hline 6 & Male & 41 & Competition history & Heart rate monitor, app \\
\hline 7 & Male & 30 & Hobby history & Mobile applications \\
\hline 8 & Female & 25 & Competition history & - \\
\hline 9 & Female & 51 & Competition history & Pedometer (in a phone) \\
\hline 10 & Male & 25 & Hobby history & . \\
\hline
\end{tabular}


$31^{\text {ST }}$ Bled eConference: Digital TRANSFormation: MEETING THE CHALLENGES JunE 17 - 20, 2018, BLED, SLOVENIA, CONFERENCE PRoCEEDINGS

T. Kari \& P. Rinne: Influence of Digital Coaching on Physical Activity: Motivation and Behaviour of Physically Inactive Individuals

\subsection{Influence of Digital Coaching to Physical Activity Motivation and Behaviour}

The digital coaching application was found to beneficial for physical activity and exercise motivation. Each of the participants reported that their motivation towards physical activity had increased during the use period. The element that most affected the motivation was reported to be that some outsider told what to do and how to do it. Also, being able to follow own progress was perceived highly motivational. Another aspect that influenced the motivation was that the digital coach had a role in changing the person's whole mentality regarding physical activity. Many reported that they had previously had different kinds of challenges that inhibited being physically active, for example, related to false assumptions regarding how they should exercise. The application was also perceived to be a better motivator than most of the previous things that the users had tried, as the application was more capable in solving those challenges that the users had previously experienced.

The application was also able to make the physical activity more goal-oriented. The users wanted to accomplish the goals of individual workouts, and achieving those was perceived as steps in achieving the overall goal of improving fitness. Workout specific goals were reported to be sufficiently short-term, and thus, easier to achieve and good in maintaining motivation. Further, the users reported that if they only had a much larger goal to achieve at once, it would likely feel unachievable and subsequently lower the motivation. Achieving these smaller workout specific goals was perceived to increase personal capability towards exercise and additionally make one proud of him or herself, further increasing the motivation.

Seeing the upcoming workouts from the application was perceived as very interesting, and many reported to be waiting for the moments when they received updates to their adaptive workout plan. The length or the exertion level of the upcoming workout did not affect whether the users planned to go perform it or not. In addition, being able to see the workout plan beforehand helped in organising the day's schedule and the daily life in general, which for some was a big but positive change. This aided in fitting physical activity into the daily routines and transforming the increased motivation to actual physical activity behaviours.

The digital coaching application also influenced the users' actual behaviours in many ways. First of all, it increased their level of physical activity. Whereas many had felt exercising challenging for one reasons or another before implementing the application, the application lowered the level of starting a workout by providing a ready-made plan and guidance to individual workouts. Further, it helped to realise that being physically active and doing workouts is not actually that demanding as they had thought. Everyone reported that the application had developed their habits and ways of being physically active. 
T. Kari \& P. Rinne: Influence of Digital Coaching on Physical Activity: Motivation and Behaviour of Physically Inactive Individuals

The application also changed the way they conducted their individual workouts. Many reported that when they had previously tried exercising for a while, they had done so with a much higher exertion level, because they had thought that for a workout to be beneficial, one has to go all out. Thus, they usually had exercised too hard and subsequently been exhausted after each workout, which had made them feel negative towards exercising and stop it altogether. Instead, now they felt that the exercise intensity during the workouts had been much lower and more pleasing, which subsequently had made them experience better feeling during the workout and also after it. The real-time guidance had a major role in keeping the right heart rate and exertion level during the workouts, and also in teaching the users how certain kinds of workouts should feel physically. It also motivated to keep going until the goal of the workout had been reached, especially when they didn't otherwise feel so keen on exercising. Indeed, even though the application had made the feeling during and after the workouts more pleasing, it did not magically make everyone enjoy every aspect of exercising all at once, and the sofa was still seen as an intriguing option, yet one that was chosen much less frequently than before.

Reaching the workout specific goals was perceived important and trust towards the application was strong. Therefore, the real-time guidance was generally followed quite accurately. However, this also had its turnside. If one wanted to follow the real-time guidance accurately, it made social exercising more difficult. The need to follow a certain exertion level for a certain time was sometimes seen as difficult to do together with someone else. Though some also reported that the application and especially its real-time guidance made them feel like they had a companion when exercising alone.

Receiving a plan also affected other aspects of life than just physical activity. The users reported that they had started to pay more attention to nutrition and proper breakfast or skipped drinking alcohol if they had a workout planned for the next day. In other words, the application did not just influence those moments of exercise but also the time between them. Almost everyone reported that their appreciation towards physical wellness had changed during the use period. As they had been physically more active, they had noticed it influencing their sleep positively and made them pay more attention to their nutrition and eating rhythm. Everyone planned to continue being more physically active also in the future.

\subsection{Central Aspects of Digital Coaching Regarding Users' Needs and Challenges}

Digital coaching can answer to various kinds of needs and bring solutions to various challenges. However, we also found certain aspects that should be paid more attention to in the design process. The most notable need that the application answered to was providing the users personalized workouts suited for their personal fitness level, doing of which had previously been challenging to many. This led the user to exercise with right exertion level and frequency. The ready-made workout plans also decreased the perceived stress regarding physical activity, as the planning and tracking was done by the application. The users also reported that despite not necessarily having a particularly good 
overall knowledge on physiology, it didn't matter, as the application in a way took care of that part. The perceived advantage over optional wellness technologies without digital coaching features was evident, and everyone would have been willing to pay for such digital coaching features alone.

The three most central features regarding matching own previous needs and challenges were reported to be personalised workout plans, real-time guidance, and the ability to follow own progress. Personalisation was especially highlighted and appreciated. It was also highly regarded that the application was able to adapt the workout plan based on the user's activity, for example, if one had overachieved or in contrast skipped a workout. An additional need that the application answered to was the ability to start a guided workout straight from one's own door, without the need to separately go for a group workout session in a gym, which could be challenging due to requiring more time and having a higher starting step.

One interesting finding was that the application was perceived to be as any coach or personal trainer in a sense that the users would have wanted to communicate with it more. For example, if a user knew beforehand that $\mathrm{s} / \mathrm{he}$ was unable to conduct the upcoming workout due to work, travel, not feeling well, or another obstacle, s/he would have wanted to tell the digital coach this, so that the coach could have moved the workout for the day before or otherwise adapt the plan. Some also had specific weekdays when they were never able to conduct workouts due to other hobbies. It also seemed to us that among some users, the application had roused a sense of obligation towards the digital coach, and they would have wanted to explain why they were unable to conduct certain workouts. Thus, it can be said that for some, the interaction with the digital coach application had some human characteristics in it.

Even though the users mostly perceived following the development of their fitness in a general level as clear, for some, presenting the actual values and fitness level through VO2max was difficult to comprehend. They had difficulties in understanding the scale and what kind of changes in VO2max would be realistic in the first place. It was also wished that the application would have notified about increased fitness level with more clarity and accompanied rewarding.

Some elements of the real-time guidance were also reported to have waken the experience of gamification, for example regarding reaching own goals. Those elements were liked and some expressed they would have liked to see more of such elements in the application. On the other hand, even though it was generally wished that the application would have provided further (digital) rewards, the users would not have wanted it to exaggerate accomplishing goals of individual workouts, as the most important feeling of success came from within.

The application did not provide separate reminder notifications for the users about individual workouts. Whether it should have divided opinions. Whereas some would have 
T. Kari \& P. Rinne: Influence of Digital Coaching on Physical Activity: Motivation and Behaviour of Physically Inactive Individuals

valued daily notifications of the next workout, some reported that it might have felt pressuring.

The users reported that they had learned much from using the digital coach, for example, about heart rate levels and how to exercise according to them, how a certain exertion level should feel, and scheduling the workouts into the daily life. Finding the solutions to these needs and challenges would influence the ways of exercising in the future.

\section{$5 \quad$ Conclusions}

The purpose of this study was to increase the understanding of novel digital coaching solutions and their use. More precisely, we investigated the influence of digital coaching features on the physical activity motivation and behaviour of physically inactive individuals. The focus was also on central aspects of digital coaching that respond to users' needs. In our qualitative study based on interviews and thematic analysis, the participants used the Next Workout Recommendation digital coaching feature by Firstbeat Technologies for one month. We also provide a definition of digital coaching in the context of sports and wellness technology: Digital coaching refers to information technology mediated sports and wellness related coaching activities that are generated by a software without human intervention. Coaching activities can be any kind of activities that guide, direct, train, or instruct the person being coached.

The application with the digital coaching feature was found to beneficial for physical activity and exercise motivation. The element that most affected the motivation was some outsider, in this case the digital coach, instructing the what, when, and how regarding exercise. Further, knowing that these instructions were targeted specifically to them as individuals and based on their personal fitness level and actions was much appreciated and perceived important. Also, being able to follow personal progress was perceived highly motivational. The application was also able to make the whole physical activity regime more goal-oriented, which had a further motivating effect.

The application also aided in fitting physical activity into the daily routines and transforming the increased motivation to actual physical activity behaviours. The digital coaching application influenced the users' actual behaviours in many ways. First and foremost, it was able to increase the level of physical activity for these previously physically inactive individuals. It also guided and taught them to conduct their workouts with appropriate frequency and exertion level, which subsequently led them to enjoy exercising more and get more positive feelings after the workouts. Thus, the application was able to shift their whole mentality regarding physical activity and fitness to more positive direction.

The digital coaching feature influenced also other aspects of life than just physical activity. The users had started paying more attention to, for example, nutrition, diet, sleep, and alcohol consumption. In other words, the application did not just influence those 


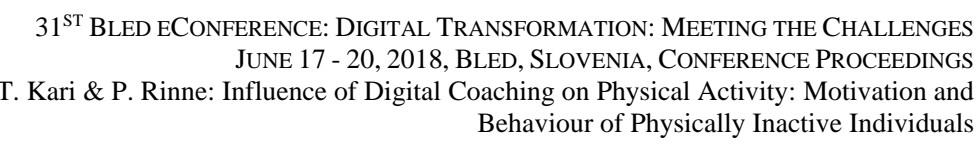

moments of exercise but also the behaviours in between them. Subsequently, it increased the general appreciation towards physical wellness in a positive way.

The application was able to meet several kinds of needs and give solutions to various previously felt challenges. Thus, it seems that a digital coaching feature like the one used in our study can really be beneficial. At least among physically inactive individuals and on a short-term. As the use period lasted only one month, it is difficult to draw longerterm conclusions. Also, the needs and challenges of, for example athletes, can be very different. Thus, the particular digital coach used in our study might not be so influential and successful among other user groups, and more research is needed in that regard. The digital coaches should indeed be designed with the target group in mind, first investigating the target group.

One interesting finding was that the digital coach was perceived as any coach or personal trainer in a sense that the users would have wanted to communicate with it more, for example, regarding upcoming or missed workouts. This is something for the designers to acknowledge. They should provide communication and interaction possibilities between the user and the digital coach. The users clearly want to explain if they are not or have not been able to follow the plan and want the digital coach to adapt the workout plan accordingly. Also, as the users clearly perceived the interaction with digital coach to have human characteristics, the digital coaches could have some human like avatars or similar. As for further practical implications, it would probably be valued if the digital coach could better be able to adapt individual workouts so that it would better support social exercising, should the user want to exercise with a friend for example. In the beginning of the use, the metrics used to display fitness level should be thoroughly explained. The users could also be provided with different options regarding the metrics, so they could choose between different metrics based on their own will and background knowledge. The designers should also undertake the process of gamification (Kari et al., 2016b) and implement digital coaches with gamified features. But needing to be careful not to overemphasise individual elements or overgamify the use. Special attention should also be paid to conducting the base-level tests as accurately as possible. If the digital coach would estimate the user's base-level incorrectly and with relatively high error, it would probably lead to wrong kinds of plans and individual workouts and to presenting the progress in physical fitness falsely. Nevertheless, even with the need for great accuracy, conducting the base-level test should still be easy and effortless enough also for physically inactive users, who do not necessarily possess much knowledge on physical activity. This is one of the main challenges for the designers to overcome.

To conclude, this study is one of the first ones to examine novel digital coaching solutions and their influence. Increasing the understanding of digital coaching solutions and their use and influence, the study provides highly valuable first insights both for the researchers and for the wellness and sports technology providers. The industry as well as the actors working with physical activity promotion can utilise our findings and implications in designing and developing digital coaching features for wellness, health, and sports, and 
T. Kari \& P. Rinne: Influence of Digital Coaching on Physical Activity: Motivation and Behaviour of Physically Inactive Individuals

in planning new kinds of novel interventions to promote physical activity. The study also lays foundation for future research on digital coaching.

There are few notable limitations in the study. First, although the interviews provided a very valuable set of information, the number of participants in the study could have been higher. The study had to consist of physically inactive people willing to implement a sports technology application with digital coaching features into use, which is not the most typical of target groups, though a highly important one. However, all interviewees had interest towards the solution, and thus, the implementation was based on own interest. We also followed previous guidelines (McCracken, 1988) in selecting the interviewees. We also believe that an adequate number of interviews were conducted, as we recognised that their marginal benefit was notably reduced. Second limitation concern the relatively short usage period of one month, which reduces the ability to make long-term interpretations. However, from a physical point of view, a month is considered long enough to be able to see changes in fitness level, especially among people with below average fitness level (Jürimäe et al., 1985).

Third limitation relates to the general limitations of qualitative interview. To overcome these, we followed well-established guidelines for semi-structured interviews in planning and conducting the interviews (e.g., Braun \& Clarke, 2006; Guest et al., 2006; Myers, 2013; Myers \& Newman, 2007). This, we believe, enabled us to avoid the possible problems and pitfalls and helped us to gain maximal benefit from using a semi-structured interview. As Guest et al. (2012) point out, the identified themes in the thematic analysis are always based on the interpretations of the researchers. Therefore, we also applied relevant guidelines in doing the analysis. As is typical to qualitative research, it is difficult to make generalizations from the sample to a larger population (Myers, 2013) and one should be cautious if doing so.

Despite these limitations, the research offers some highly valuable first insights and a good overview on the subject. The findings of the study also provide potential paths for future research. Being one of the first studies to examine these kinds of digital coaching solutions and their influence, it can serve as a starting point and a reference to future studies. Future research would benefit if to be conducted with larger samples and longer use periods. The target group could naturally also be other than physically inactive people, as digital coaching has the potential to be beneficial for people with all levels of physical activity and fitness as well as for people of different ages. Future studies could also specifically focus to certain types of users who share similar goals, for example, regarding a certain sport, certain competition, physical ability, weight loss, or other specific area. We would also encourage researchers to conduct more research in regards to digital coaching and the different aspects of it, not just from the IS perspective but from other perspectives as well, for example, health and exercise science and psychology. Thus, we make a call for cross-disciplinary research on digital coaching and their effects on human behaviour and wellbeing. 


\section{$31^{\text {ST }}$ Bled ECONFEREnCE: Digital Transformation: MeEting the Challenges June 17 - 20, 2018, BLED, Slovenia, CONFERENCE ProceEdings \\ T. Kari \& P. Rinne: Influence of Digital Coaching on Physical Activity: Motivation and Behaviour of Physically Inactive Individuals}

\section{References}

Adams, M. A., Hurley, J. C., Todd, M., Bhuiyan, N., Jarrett, C. L., Tucker, W. J., ... \& Angadi, S. S. (2017). Adaptive goal setting and financial incentives: a $2 \times 2$ factorial randomized controlled trial to increase adults' physical activity. BMC Public Health, 17(1), 286.

Adams, M. A., Sallis, J. F., Norman, G. J., Hovell, M. F., Hekler, E. B., \& Perata, E. (2013). An adaptive physical activity intervention for overweight adults: a randomized controlled trial. PloS One, 8(12), e82901.

Braun, V., \& Clarke, V. (2006). Using thematic analysis in psychology. Qualitative Research in Psychology, 3(2), 77-101.

Carlsson, C., \& Walden, P. (2017). Digital Coaching to Build Sustainable Wellness Routines for Young Elderly. In The 30th Bled eConference "Digital Transformation - From Connecting Things to Transforming Our Lives” Research Volume, 18.-21.6.2017 (pp. 57-70). Bled, Slovenia: University of Maribor.

Chan, C. B., Ryan, D. A., \& Tudor-Locke, C. (2004). Health benefits of a pedometer-based physical activity intervention in sedentary workers. Preventive Medicine, 39(6), 1215-1222.

Faghri, P. D., Omokaro, C., Parker, C., Nichols, E., Gustavesen, S., \& Blozie, E. (2008). Etechnology and pedometer walking program to increase physical activity at work. The Journal of Primary Prevention, 29(1), 73-91.

Firstbeat Technologies Oy. (2017). Automated Fitness Level (VO2max) Estimation with Heart Rate and Speed Data. White Paper.

Firstbeat Technologies Oy. (2018a). Retrieved 6.2.2018 from https://www.firstbeat.com/

Firstbeat Technologies Oy. (2018b). VO2max Fitness Level. Retrieved 6.2.2018 from https://www.firstbeat.com/en/consumer-feature/vo2max-fitness-level/

Firstbeat Technologies Oy. (2018c). Personalized Training Plans: Cardio. Retrieved 6.2.2018 from https://www.firstbeat.com/en/consumer-feature/personalized-training-plans-cardio/

Firstbeat Technologies Oy. (2018d). White Papers and Publications. Retrieved 19.4.2018 from https://www.firstbeat.com/en/science-and-physiology/white-papers-and-publications/

Fukuoka, Y., Vittinghoff, E., Jong, S. S., \& Haskell, W. (2010). Innovation to motivation - Pilot study of a mobile phone intervention to increase physical activity among sedentary women. Preventive Medicine, 51(3-4), 287-289.

Guest, G., Bunce, A., \& Johnson, L. (2006). How many interviews are enough? an experiment with data saturation and variability. Field Methods, 18(1), 59-82.

Guest, G., MacQueen, K. M., \& Namey, E. E. (2012). Applied thematic analysis. Los Angeles, CA: SAGE.

Jakicic, J. M., Davis, K. K., Rogers, R. J., King, W. C., Marcus, M. D., Helsel, D., ... \& Belle, S. H. (2016). Effect of wearable technology combined with a lifestyle intervention on long-term weight loss: the IDEA randomized clinical trial. JAMA, 316(11), 1161-1171.

Jürimäe, T., Viru, A., Pedaste, J., \& Toode, K. (1985). Changes in physical capacity and serum lipids and lipo-proteins during running training program in female university students. Biology of Sport, 2(4), 243-253.

Kang, M., Marshall, S. J., Barreira, T. V., \& Lee, J. O. (2009). Effect of pedometer-based physical activity interventions: a meta-analysis. Research Quarterly for Exercise and sport, 80(3), 648-655.

Kari, T., Kettunen, E., Moilanen, P., \& Frank, L. (2017a). Wellness Technology Use in Everyday Life: A Diary Study. In The 30th Bled eConference "Digital Transformation - From Connecting Things to Transforming Our Lives" Research Volume, 18.-21.6.2017 (pp. 279294). Bled, Slovenia: University of Maribor.

Kari, T., Koivunen, S., Frank, L., Makkonen, M., \& Moilanen, P. (2016a). Critical Experiences During the Implementation of a Self-Tracking Technology. In The 20th Pacific Asia 
$31^{\text {ST }}$ Bled eConference: Digital Transformation: MeEting the Challenges JunE 17 - 20, 2018, BLED, SLOVENIA, CONFERENCE PROCEEDINGS

T. Kari \& P. Rinne: Influence of Digital Coaching on Physical Activity: Motivation and Behaviour of Physically Inactive Individuals

Conference on Information Systems (PACIS), 27.6.-1.7.2016 (16 pages). Chiayi, Taiwan: AIS.

Kari, T., Koivunen, S., Frank, L., Makkonen, M., \& Moilanen, P. (2017b). The expected and perceived well-being effects of short-term self-tracking technology use. International Journal of Networking and Virtual Organisations, 17(4), 354-370.

Kari, T., Piippo, J., Frank, L., Makkonen, M., \& Moilanen, P. (2016b). To gamify or not to gamify?: gamification in exercise applications and its role in impacting exercise motivation. In The 29th Bled eConference "Digital economy" Research Volume, 19.-22.6.2016 (pp. 393 405). Bled, Slovenia: University of Maribor.

Kettunen, E., Kari, T., Moilanen, P., Vehmas, H. M., \& Frank, L. (2017). Ideal Types of Sport and Wellness Technology Users. In The 11th Mediterranean Conference on Information Systems (MCIS), 4.-5.9.2017 (12 pages). Genoa, Italy: AIS.

Locke, E. A., \& Latham, G. P. (2002). Building a practically useful theory of goal setting and task motivation: A 35-year odyssey. American Psychologist, 57(9), 705-717.

Makkonen, M., Frank, L., Kari, T., \& Moilanen, P. (2012a). Explaining the usage intentions of exercise monitoring devices: The usage of heart rate monitors in Finland. In the 18th Americas Conference on Information Systems (AMCIS) 2012, 9.-11.8.2012 (Paper 13). Seattle, USA: AIS.

Makkonen, M., Frank, L., Kari, T., \& Moilanen, P. (2012b). Examining the usage intentions of exercise monitoring devices: The usage of pedometers and route trackers in Finland. In The 25th Bled eConference "eDependability: Reliable and Trustworthy eStructures, eProcesses, eOperations and eServices for the Future" Research Volume, 17.-20.6.2012 (pp. 439-453). Bled, Slovenia: University of Maribor.

McCracken, G. (1988). The long interview. Newbury Park, CA: SAGE.

Mcfedries, P. (2013). Tracking the quantified self. IEEE Spectrum, 8(50). 24.

Miyamoto, S. W., Henderson, S., Young, H. M., Pande, A., \& Han, J. J. (2016). Tracking health data is not enough: a qualitative exploration of the role of healthcare partnerships and mhealth technology to promote physical activity and to sustain behavior change. JMIR mHealth and uHealth, 4(1), e5.

Myers, M. D. (2013). Qualitative research in business and management (2nd edition). Los Angeles, CA: SAGE.

Myers, M. D., \& Newman, M. (2007). The qualitative interview in IS research: examining the craft. Information and Organization, 17(1), 2-26.

Patton, M. Q. (2002). Qualitative research \& evaluation methods (3rd edition). Thousand Oaks, CA: SAGE.

Rogers, E. M. (2003). Diffusion of innovations (5th edition). New York, NY: Free Press.

Ryan, R. M., \& Deci, E. L. (2000). Self-determination theory and the facilitation of intrinsic motivation, social development, and well-being. American Psychologist, 55(1), 68-78.

Shilts, M. K., Horowitz, M., \& Townsend, M. S. (2004). Goal setting as a strategy for dietary and physical activity behavior change: a review of the literature. American Journal of Health Promotion, 19(2), 81-93.

Schmidt, B., Benchea, S., Eichin, R., \& Meurisch, C. (2015). Fitness tracker or digital personal coach: how to personalize training. In The 2015 ACM International Joint Conference on Pervasive and Ubiquitous Computing and ACM International Symposium on Wearable Computers, 7.-11.9.2017 (pp. 1063-1067). Osaka, Japan: ACM.

Swan, M. (2013). The quantified self: Fundamental disruption in big data science and biological discovery. Big Data, 1(2), 85-99.

Tudor-Locke, C. (2002). Taking steps toward increased physical activity: Using pedometers to measure and motivate. President's Council on Physical Fitness and Sports Research Digest, 3(17), 3-10. 
Venkatesh, V., Thong, J. Y., \& Xu, X. (2012). Consumer acceptance and use of information technology: extending the unified theory of acceptance and use of technology. MIS Quarterly, 36(1), 157-178.

Wang, J. B., Cataldo, J. K., Ayala, G. X., Natarajan, L., Cadmus-Bertram, L. A., White, M. M., ... \& Pierce, J. P. (2016). Mobile and wearable device features that matter in promoting physical activity. Journal of Mobile Technology in Medicine, 5(2), 2-11.

Warraich, M. U. (2016). Wellness Routines with Wearable Activity Trackers: A Systematic Review. In The 10th Mediterranean Conference on Information Systems (MCIS), 4.-6.9.2016 (13 pages). Paphos, Cyprus: AIS.

World Health Organization (WHO). (2017). Physical activity. Retrieved 1.2.2018 from http://www.who.int/mediacentre/factsheets/fs385/en/

Zhou, M., Fukuoka, Y., Mintz, Y., Goldberg, K., Kaminsky, P., Flowers, E., \& Aswani, A. (2018). Evaluating Machine Learning-Based Automated Personalized Daily Step Goals Delivered Through a Mobile Phone App: Randomized Controlled Trial. JMIR mHealth and uHealth, 6(1), e28. 
T. Kari \& P. Rinne: Influence of Digital Coaching on Physical Activity: Motivation and Behaviour of Physically Inactive Individuals

\section{Appendices}

Appendix A: Themes of the 1st round interviews

\begin{tabular}{|c|c|c|}
\hline 1. Background & 1.1 Demographics & $\begin{array}{l}1.2 \text { Socioeconomic } \\
\text { characteristics }\end{array}$ \\
\hline 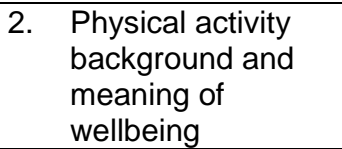 & 3. Previous experience & $\begin{array}{l}\text { 4. Innovativeness, } \\
\text { personality variables }\end{array}$ \\
\hline $\begin{array}{l}\text { 5. Challenges and } \\
\text { needs with physical } \\
\text { activity }\end{array}$ & $\begin{array}{ll}\text { 6. } & \text { Performance } \\
\text { expectancy and } \\
\text { personal goal setting }\end{array}$ & $\begin{array}{l}\text { 7. Effort expectancy } \\
\text { and facilitating } \\
\text { conditions }\end{array}$ \\
\hline 8. Hedonic motivation & 9. Habit & $\begin{array}{l}\text { 10. Physical activity and } \\
\text { exercise motivation }\end{array}$ \\
\hline 11. Social aspects & & \\
\hline
\end{tabular}

More detailed descriptions with key questions are available from the authors by request.

Appendix B: Themes of the 2nd round interviews

\begin{tabular}{|c|c|c|}
\hline 1. Meaning of wellbeing & 2. Use experiences & 3. Social aspects \\
\hline $\begin{array}{l}\text { 4. Challenges and } \\
\text { needs with physical } \\
\text { activity }\end{array}$ & $\begin{array}{ll}\text { 5. } & \text { Performance } \\
& \text { experience and } \\
& \text { personal goal setting }\end{array}$ & $\begin{array}{ll}\text { 6. } & \text { Effort experience } \\
\text { and facilitating } \\
\text { conditions }\end{array}$ \\
\hline 7. Hedonic motivation & $\begin{array}{l}\text { 8. Elements of the } \\
\text { solution and physical } \\
\text { activity motivation }\end{array}$ & 9. Habit \\
\hline 10. Relative advantage & 11. Adaptability & 12. Price value \\
\hline $\begin{array}{l}\text { 13. Physical activity and } \\
\text { exercise motivation }\end{array}$ & 14. Other aspects & \\
\hline
\end{tabular}

More detailed descriptions with key questions are available from the authors by request. 
T. Kari \& P. Rinne: Influence of Digital Coaching on Physical Activity: Motivation and Behaviour of Physically Inactive Individuals

Appendix C: An example view of the Next Workout Recommendation Feature

다웅 …

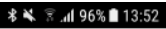

$\leftarrow \quad$ Next Workout Recommendation

\begin{tabular}{l}
\hline Today's advice \\
$\begin{array}{l}\text { You have done your recommended amount of } \\
\text { exercise for today. This will benefit your fitness! }\end{array}$ \\
\hline VO2max Fitness Level \\
\hline $\begin{array}{l}\text { Good } \\
46.2 \mathrm{~m} / \mathrm{kg} / \mathrm{min}\end{array}$ \\
$\begin{array}{c}\text { Potential to reach in a month with } \\
\text { recommended workouts }\end{array}$ \\
\hline Training Load \\
\hline Low \\
$\begin{array}{l}54 \text { EPOC in } \\
\text { last } 7 \text { days }\end{array}$ \\
\hline
\end{tabular}

- Alm for optimal area to benefit fitness

Recovery Time Advisor

Short

20 to full

20 to full
recovery

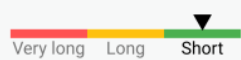

Ready for improving training 
146 31 $31^{\text {ST }}$ Bled eConference: Digital Transformation: MeEting the Challenges JUNE 17 - 20, 2018, BLED, SLOVENIA, CONFERENCE PROCEEDINGS 


\title{
Perceived Intrusiveness of Personalized Marketing
}

\author{
KATRI KEREM \& MONIKA ULLA
}

\begin{abstract}
Businesses collect vast amounts of customer data via forms that consumers fill in themselves and with automatic data collection tools. Advances of data collecting methods outpace consumers' understanding of how their personal data is used. This paper investigates how the consumers perceive the pros and cons of marketers using their personal data for customized marketing messages and product offers. A qualitative study was conducted among Estonian consumers. In depth interviews with 18 consumers revealed surprisingly positive attitudes but also highlighted how consumers do the privacy calculus. Data based personalization is welcomed if the consumers perceive to receive benefits for disclosing their data. The results demonstrate that women are more willing to share their personal data for business purposes.
\end{abstract}

Keywords: • Personalized marketing $\bullet$ Privacy concerns $\bullet$ Personalizationprivacy paradox $\bullet$

CoRresPondence AdDREss: Katri Kerem, Ph.D., Professor, Estonian Business School, Department of Marketing and Communication, Lauteri 3, Tallinn 10114, Estonia, e-mail: katri.kerem@ebs.ee. Monika Ulla, MA, Estonian Business School, Department of Marketing and Communication, Lauteri 3, Tallinn 10114, Estonia, e-mail: monika.ulla@hotmail.com

DOI https://doi.org/10.18690/978-961-286-170-4.9

ISBN 978-961-286-170-4

(C) 2018 University of Maribor Press

Available at: http://press.um.si. 


\section{Introduction}

Personalization is by no means a new idea or concept in the world of marketing. Consumers are increasingly seeking customized solutions and businesses are trying to meet these needs without compromising the economies of scale.

Advances in data collection methods allow companies to gather vast amount of non-selfdisclosed information about consumers, to automate the monitoring of consumers' purchasing behaviour and to use the accumulated data for targeted marketing communication and customizing their offers. Personalized marketing enabled by data management platforms is integral to consumers receiving relevant, timely, engaging, and personalized messaging and advertisements that resonate with their unique needs and preferences. Although personalization, customization, and exact targeting is appreciated by the consumers while saving time and money, such personalized services demanding detailed customer information may cause privacy related problems. To avoid negative attitudes and loss of goodwill, businesses must be sensitive to consumer expectations associated with data collection and usage.

The aim of this research paper is to map the attitudes of Estonian consumers and study the link between personalized marketing and perceived intrusiveness among Estonian consumers. The authors will analyse the consumers' attitude towards personalization, their willingness to disclose personal data and the perceived usefulness of personalized marketing communication.

\section{$2 \quad$ Literature Review}

\subsection{Personalization in Marketing}

The aim of personalization is to speed up customers' decision and purchase process via tailoring marketing messages and product offers. By definition, personalization is the ability and skill to proactively tailor products and customer experience to the preferences of individual consumers based on their personal information (Chellappa \& Sin, 2005). As Vesanen (2007, pp. 409-410) points out, "the concept of personalization is currently used to cover a very fragmented set of ideas, and a clear theoretical framework is lacking". Both consumer acceptance of personalization and the tools and techniques of personalization are in constant flux as the technologies change at a rapid pace. Tactics that worked well in their early phases may become counterproductive as customers get fed up by certain type of communication.

Personalization seems to promise savings in time and money both for the seller and the buyer but nevertheless there is a thin line between appropriate personalization and perceived intrusiveness (Truong \& Simmons, 2010). Personalization can both strengthen or weaken the relationship customer has with a brand (Aguirre et al., 2016) and the reactions to personalized messages can be either positive or negative (White et al., 2008). Thus the question of personalization poses significant strategic challenges to marketers. 
The benefits of personalization include increasing the efficiency of the client's purchase process and specifically narrowing down alternative solutions/actions to the most relevant ones. Time savings are an important bonus (Aguirre et al., 2016). At the same time it may feel unpleasant to realize that someone is following and recording your activities and data and this can lead to lower adoption rates, increased sense of vulnerability (Aguirre et al., 2016) or avoiding doing business with specific companies at all (McDonald \& Cranor, 2010).

Successful personalization can only be based on having relevant and sufficient information about the consumers, including, but not limited to, the information that consumers have shared about themselves on informed consent and information that has been collected with the help of digital technologies. The quality of personalization and ability to meet individual needs is vital for successful personalization (Jahng, Jain \& Ramamurthy, 2002) and it is possible to improve the usefulness of personalization for both the company and the consumer only via a very thorough customer data collection and analysis. Collecting, storing and utilizing customer data will inevitably lead customers to question the value of allowing businesses to work with the data and ponder about the ethical limits of tracking customers. Therefore it is important to understand consumers' perception of privacy and their willingness to trade privacy for personalization.

\subsection{Privacy Conceptualizations and Concerns}

Various authors have defined privacy and there is no single definition that would encompass all the aspects of the concept. Westin (1997) has defined privacy as a right of an individual to decide how, when and to what extent to disclose personal information to others. Clarke (1999) has added that privacy also includes a person's will to sustain a personal space that would be free from interference by others (including also businesses in the context of marketing). From consumers' point of view privacy is highly subjective and depends on one's ability to understand privacy related issues and take decisions regarding that.

Past research has identified a privacy concern as a two-component construct. If a customer has good knowledge and (perceived) control over collecting, storing and using data about her/him, the privacy concern tends to be low, and vice versa (Milne 2000, Sheehan \& Hoy 2000). Alt, Hartwig and Reinhold (2016) have included the dimension of privacy awareness into the discussion, claiming that without awareness consumers are unable to make decisions and give educated permission to use their personal data for business purposes. Awareness, in turn, does not necessarily lead to rational decisions. Knowledge-behaviour gap is well documented in various fields, and it applies for privacy decisions as well (Bakos, Marotta-Wurgler \& Trotten, 2009; Murumaa-Mengel, et.al., 2014). Most of the privacy laws and regulations postulate that people should be given complete and thorough information about data collection, storage and usage but in reality people hardly pay attention. The key reasons for not paying attention to privacy conditions and agreements are information overload and lengthy material (Helberger, 2013), easiness of just ticking the box and agreement as a default option (Murumaa- 
Mengel, et.al., 2014), or unclear wording of the text (Lurger 2013; Murumaa-Mengel, et.al., 2014).

Dinev and Hart (2006) have described e-commerce customers as rational actors who conduct cost-benefit analysis comparing gains and losses of giving away data. But frequently data disclosure is not under the control of the consumer, or at least consumer cannot avoid giving delivery address, credit card data, etc, for a vendor for fulfilling the order (Smith \& Shao, 2007) and this creates a personalization-privacy paradox, a situation where consumers are willing to share data for some purposes and reluctant to do so for some other reasons (Aquirre et al., 2016).

The questions and decisions regarding privacy and data disclosure are not easy ones for consumers. The concept itself is multifaceted and difficult to comprehend for the consumers, as are contemporary data collection methods. It is difficult for consumers to take control over their privacy because most of the data based marketing activities happen in a "black box" for them and they can only guess what will happen if their data is analysed.

\section{$3 \quad$ Methods}

The aim of the current study was to map the attitudes and perception towards privacy and study the link between personalization and intrusiveness. The study adopted qualitative approach as privacy related issues are perceived and addressed very differently by consumers. A quantified research instrument would not have been adequate to capture the meaning of the phenomenon in the minds of consumers. In-depth interviews are considered appropriate when the goal is to collect information on emerging issues (Marshall \& Rossman, 2006).

The semi structured interview plan was composed to include the main themes arising from past research and structured around the key research questions. The questions in the interview plan were constructed by the authors of the current study.

The first section of questions was designed to understand how consumers understand personalization and to seek insights about their experiences and beliefs. Previous studies pointed out both positive and negative aspects regarding personalization and the authors aimed to clarify the balance among Estonian consumers.

The second section of interview plan included guiding questions to see how consumers understand privacy and how they rationalize giving access to their data. The authors further wanted to explore if the consumers undertake some sort of privacy calculus expecting value in return to access to their data.

The third section of interview questions addressed personalized marketing communication and aimed to identify the balance between losing privacy and enjoying benefits from precisely targeted communications. 
A non-probability convenience sampling method was used to recruit voluntary participants for this study. The call for participation was posted to 5 different social media groups in Estonia (heritage society, gardening group, marketplace, neighbourhood group and baby products group). These groups were selected to achieve variety in the sample and all of them were known to the researchers to have an active membership. Further, the researchers recruited an equal number of male and female participants and observed that the interviewees would be of different backgrounds. The initial plan was to conduct a total of 20 interviews but data saturation (Miles \& Huberman, 1994) was achieved with 18 interviews. Such size of the final sample is considered suitable (Baker \& Edwards, 2012). The interviews lasted between 45 minutes and 2.5 hours and were conducted in locations preferred by the interviewees. The age range of the interviewees was between 28 and 74.

All the interviews were recorded with the permission of the participants, and transcribed in verbatim. Coding was conducted manually. The initial codes were developed deductively from the previous studies and additional inductive codes emerged from the material. Content analysis was used to interpret the textual data through classification that involves coding and identifying common themes (Hsieh \& Shannon, 2005). Structural coding and categorization were conducted following the principles and guidelines presented by Saldaña (2009). Specific information on coding does not fit the length limits of the current paper and is available from the authors.

\section{$4 \quad$ Results and Discussion}

\subsection{Consumer experiences and attitudes regarding personalization}

The initial analysis of the research material made it clear that marketers and researchers have a tendency to overestimate the knowledge of consumers regarding various marketing techniques and concepts related to digital business. Only one participant among the 18 associated personalization with mapping customer needs on individual level and making offers based on that.

The typical reasoning was as follows:

Personalization.... is that marketing according to someones' needs? You pick a target group and make offers to them? $\left(P 4, M 28^{11}\right)$

Because of the widespread practice of phone marketing this topic was also frequently linked to the perception of personalization.

When the researchers explained personalization with guiding questions the respondents started to recall their own experiences with individualized offers. The prevalent opinion about personalized marketing was positive, participants pointed out time saving and narrowing down choice options. The study confirmed that the consumers actually

${ }^{11} \mathrm{P}$ denotes the number of participant, $\mathrm{M} / \mathrm{F}$ denotes gender, and the number shows age of the study participant. 
appreciate offers that are based on their purchase history and current needs. A few consumers were critical towards the idea of personalization claiming that there is a lot of very shallow personalization. One of the more critical participants commented:

Personalization seems to come to an end with using my name, everything that follows is mostly generic. They do not pay enough attention. The first stage shows me that it is personalized but contentwise it is empty $(P 4, M 28)$

Additionally, the interviewees highlighted that personalization helps them to feel special, even if they recognize someone's business interests behind that. Still, such approach gives customers a feeling that someone cares about them and addresses their problems. This in turn is vital for successful long term customer relationships

I feel myself special, someone has taken trouble to deal with my problem. Makes me feel important.... (P3, F38)

Nearly all of the interviewees extended to the topic of privacy quite early into the interview. The main concerns were that "being followed" generates an uneasy feeling and narrowing down selection was perceived as limiting ones' freedom of choice, that can even lead to resistance or avoiding certain brands or businesses. In general, the reasoning was in line with what has been suggested previously, e.g. by Aguierre et al. (2016), but also a few new ideas were added. One of the participants used the word "intensity" referring to the situation where the personalization becomes disturbingly overwhelming: I have the loyalty card of the Rimi supermarket and if they put together a shopping list for me there is a very thin line when it becomes annoying. This becomes too intense, they overdo it... (P10, M40).

The consumers argued also that acceptability of personalization and data use has category differences. The word "discreet" was used by one of the male interviewees. Frequently marketers fail to understand that there are very private and personal products and services that consumers want to keep secret even from their closest ones.

Several participants commented on the fact that personalization tends to overly rely on past data and behaviour. While in many categories past behaviour is a good proxy for future needs, it may not be so in all the categories, especially if to look beyond first necessity.

Speaking of AirBnB, it should propose me new destinations, not only these where I have already been.... If they would really understand that I like to travel, and they would look where I have been and they could propose me new destinations based on my preferences, that would be cool.... (P5, F32)

So to conclude, in general the Estonian customers' understanding and attitude towards personalization is in line what has been pointed out in past studies. The positive gains included time saving, making choice process easier and communicating relevant content. The negatives were related to the feeling of being followed and concern about privacy. Also, narrowing down choice or limiting options can be perceived as negative. The more unique aspects highlighted in the study emphasized the need to be discreet, think in terms of product/service category specifics and not to fall in the trap of recommending solutions that the customer has happily purchased before. 


\subsection{Consumer attitudes regarding disclosing personal data}

The main aim of the following section was to find out how the consumers think about disclosing personal data and what motivates them to share data with businesses. The secondary aim was to map the customers' awareness of various digital data collection methods.

The results reveal that customers are willing to disclose data in case the related product or service is important to them and there are perceived benefits in data disclosure. Consumers do a quick privacy calculus in their minds. One of the contributions of the current study is the tendency that women are a lot more likely to share their data with businesses.

The privacy calculus also included considering whether the required data is really relevant and necessary for the company. There seem to be clear "layers" of data:

I am ready to share all the obvious data: my age, gender, city-level location, number of kids, and their ages.

Going beyond the basic data sharing is dependent on the client history:

If I have been a client for a while and developed a trustworthy relationship, I can share my address.

And high-risk information is shared only for specific purposes when there is a very clear benefit for that:

Uber and Taxify have got my credit card details so that I can pay automatically (all three quotes P3, F38)

Analysing the opinions of the male participants it was more than obvious that they'd like to share as little data as possible. They do not welcome marketing offers and if something is communicated to them personally it needs to be very precisely targeted to their individual profile. Otherwise the companies have no reason to believe that men will pay attention to their messages and offers. Some of the male interviewees claimed to regularly insert fake data to registration forms to avoid any future communication.

Men seem to be clearly disturbed by the marketing messages:

If I register for a loyalty card and I need to give my e-mail address I will do that. Although I know that it really disturbs me when I get something like this /refers to marketing offers/. I want to take my own decisions (P11, M37)

They are careful to make sure that they do not get additional messages and may decide not to join a loyalty program if they fear to receive communication in the future I really pay attention to disclosing data. I can share my ID code if it is really justified, but I will definitely not tick the box to say I am interested in further offers. Frequently I just do not join loyalty programs because there is so much clutter (P9, M46) 
Although all of the participants expressed their concern about the privacy intrusion and giving away (too much) data they also saw this as unavoidable reality that one has to agree with general terms and conditions.

As pointed out earlier the secondary aim of this subsection of the study was also to find out how much knowledge consumers have about contemporary data collection methods. Several participants indicated that they have a feeling that the recent developments in the digital world are difficult to comprehend:

I have a feeling that I do not get it and I am not able to handle it. It seems that sometimes I have shared my data without even noticing it (P6, F40).

Although the interviewees had noticed information about cookies and also clicked to accept cookies, only a few really understood what cookies do and why they are needed. Consumers give permission to track their activities on the Internet without actually understanding what they have agreed to. Furthermore they consciously decide not to delve into the complicated lingo of the internet small print.

I tell you honestly, I do not understand it. I see this 'cookie-talk' popping up but I never pay attention. If I am interested in the website I just click "I agree" (P1, F40)

The interviewees commented that if the company clearly asks for data and also informs that data will be used for marketing purposes, it actually increases trust and improves consumers' attitude towards the brand. Informing about the clear purpose why data is used is vital for fruitful marketing. If consumers have given their data for a specific purpose they dislike when it is cross-used for something different. Consumers have had previous negative experience with receiving offers and communication in areas that they have not indicated as a preference themselves and that is not related to their past activities. If I disclose data I need to choose the types of communication I am ready to receive. E.g. if I have indicated that I am into cooking they should no way send me e-mails about garden tools or clothing. It is vital that I indicate and edit my preferences, not someone else (P17, M40).

To sum up, the attitudes towards data sharing were varied. It emerged as a clear tendency that women are more willing to disclose data and see more benefits to it. Men, on the contrary, are mostly reluctant to share data and try to find ways to avoid it as much as possible. Different strategies are employed for that - from disclosing fake information to just not doing business with a brand or a website.

\subsection{Consumer attitudes regarding personalized marketing communication}

In general the interviewees had noticed that in depth personalization is still at its infancy. Dominant reasoning was that personalization pays off only with a wealthy clientele and because of the size and economic power of the local market personalized marketing communication is not too widespread in Estonia.

Those study participants who had made purchases with global retailers and service providers had a more substantial experience and they were also aware that the ads they see are based on their previous behaviour and purchases. Some of the respondents though 
had not been thinking why specific ads are served to them even if these match their preferences quite closely.

The key expectations to personalization were precisely selected messages/offers and a clear understanding that the messages really are personalized beyond adding person's name to otherwise generic newsletter.

One of the negative aspects participants had experienced was the overly familiar tone of the messages that was not perceived appropriate for a business relationship. Traditional norms of Estonian language prescribe using you (plural) when addressing someone who is not your personal friend and you (singular) is reserved to closer relationships. This distinction is also indicating degree of social distance (Keevallik, 1999) and although younger generations do not always stick to this rule, consumers find it intruding if businesses fail to use the formal you.

Positive tone of voice and good humour are warmly welcomed by customers, especially if the business manages to be consistent in its messages.

In case consumers realize that something has been personalized based on their profile but they have not clearly given a permission for data use, it makes them really annoyed:

I do understand that there is a lot of such data collection that I am not aware, and I will not get to know about, and let it be like that. But if it becomes visible that someone has really been stalking me and ads appear in totally 'wrong' places for me, it is deplorable $(P 6, F 40)$

The analysis of the data shows that consumers dislike most cross-usage of data, i.e. when consumers have given their data for one purpose but the company uses it for other purposes. Some consumers are just surprised when they see that activities they have conducted in one channel or website reflect to what they see in other locations, but a lot of consumers feel really annoyed and disturbed.

Participants criticized retargeting quite unanimously as nearly all of them had no idea how to stop the ads 'following' them long after they had lost interest or need for the product or just had already made the purchase. Retargeting seems to be a favourite tool for marketers and has indeed shown some good business results, but it becomes annoying really quickly. Consumers also realized that retargeting is based on data that is collected without their explicit permission and this realization made them feel uncomfortable and disturbed. In comparison, e-mail marketing and marketing in social media were better received due to the "unsubscribe" options or possibility to "un-like" a page that shares info that is no longer relevant.

Although there were polarized opinions on personalized e-mail messages it was generally regarded as the most acceptable channel for sending marketing related information. Minority of participants, all of them male, were strictly opposed to e-mail communication from brands and were annoyed if they had given e-mail address for specific purposes, e.g. informing about the order status, or sharing info regarding specific flight, and later the same businesses had added them to the address base of the newsletter recipients. The 
majority of participants commented on the low intrusiveness of e-mail marketing: it is easy to delete or unsubscribe and it gives the recipient freedom to decide if they want to interact with the communication or not.

Banner ads were regarded as something that you have to withstand. Some of the personalized web advertising was regarded as valuable, especially on social media where targeting is based on user's hobbies and lifestyle. Interviewees who had experienced precise high quality personalization had also more positive attitudes towards it. They were of opinion that good personalization compensates for giving access to data and losing some privacy.

Only one of the participants reported an experience with personalized advertising that violated privacy to extreme:

After the Berlin Marathon I opened the website of Postimees /major daily newspaper/and I was shown a banner with my photo and name advertising the option of ordering the photos. This was extremely unpleasant and scary. How did the photo get there? Will everyone see it? (P3, F38)

Some of the interviewees had also experienced personalized messages that were not framed to their personal preferences and induced them to decide not to buy.

I had been looking at Jura coffee machines and I have thought to buy it for a really long time. And then they offered that if I make the purchase I get cappuccino cups as a gift. But I do not drink cappuccino and I don 't have anything to do with the cups. I did not buy the machine either (P13, F41)

So if companies want to go into personalization, it must be done tactfully, with certain moderation and real knowledge about customers' needs and preferences.

\section{$5 \quad$ Conclusion}

Personalization of marketing messages and product/service offerings poses specific strategic challenges. This research provides a qualitative analysis of consumers' attitudes towards privacy and personalized marketing communication. While part of the results were in line with previous studies, there were quite a few outcomes that add value both theoretically and empirically.

Stereotypically (and also scientifically) we may know the differences between males and females as customers, but the current study provided proof that men have a lot more negative attitudes towards personalized communication, do their privacy calculus more rigidly and go to great lengths to avoid giving away their data. Using fake contact details and e-mail addresses are extreme examples of this.

The evidence from current research strongly suggests that consumers' awareness and understanding of the options of data gathering, usage and personalization is low and marketers should not assume that when a client agrees to give access to data, accepts cookies or switches on location tracking, he or she really is able to evaluate the costs and 
benefits of these activities. Even when consumers have given permission to use data for marketing purposes the outcome may be dissatisfaction and distrust.

The assumption that retargeting is an efficient means of advertising as it is based on consumers' previous activities is strongly challenged by the current research as most of the consumers reported retargeting to be "stalking" and intrusive.

It is very difficult to draw a "red line" of privacy violations as consumer tolerance and acceptance of personalization varies to a great extent. It is however obvious, that technological skilfulness of the marketers needs to be well balanced with understanding the consumer sentiment - occasions of very precise and personal communication in unexpected situations was perceived extremely negatively.

The current research supports the view that well-crafted personalized marketing messages and advertisements are generally well received. However it would be necessary to pursue further research to understand better the exact situations when a well personalized message will start to appear as intrusive.

\section{References}

Alt, R., Hartwig, M., \& Reinhold, O. (2016). Privacy Awareness in Mobile Business: How Mobile OS and Apps Support Transparency in the Use of Personal Data. In Bled eConference, June 19-22, 2016 (pp. 28-43). Maribor: University of Maribor Press.

Aguirre, E, Roggeveen, A. L; Grewal, D; \& Wetzels, M. (2016). The Personalization-Privacy Paradox: Implications for New Media. The Journal of Consumer Marketing, 33(2), 98-110. doi: 10.1108/JCM-06-2015-1458.

Baker, S. E., \& Edwards, R. (2012). How many qualitative interviews is enough? Expert voices and early career reflections on sampling and cases in qualitative research. Southampton: ESRC National Centre for Research Methods, University of Southampton.

Bakos, Y., Marotta-Wurgler, F., \& Trotten, R. R. (2009). Does anyone read the fine print? Testing a Law and Economics Approach to Standard Form Contracts. In CELS $20094^{\text {th }}$ Annual Conference on Empirical Legal Studies Paper, 6.10.2009, NYU Law and Economic Research Paper No. 09-40.

Chellappa, R. K., \& Sin, R. G. (2005). Personalization versus Privacy: An Empirical Examination of the Online Consumer's Dilemma. Information Technology Management, 6, 181-202. doi:10.1007/s10799-005-5879-y.

Clarke R. (1999). Internet Privacy Concerns Confirm the Case for Intervention, Communications of the ACM 42(2), 60-68.

Dinev, T., \& Hart, P. (2006). An extended privacy calculus model for e-commerce transactions. Information Systems Research, 17(1), 61-80. doi:10.1287/isre.1060.0080.

Helberger, N. (2013). Forms matter: Informing consumers effectively. Study commissioned by BEUC. Amsterdam, 2013.

Hsieh, H.-F. \& Shannon, S. E. (2005). Three approaches to qualitative content analysis. Qualitative Health Research, 15, 1277-1288. doi:10.1177/1049732305276687.

Jahng, J. J., Jain, H., \& Ramamurthy, K. (2002). Personality traits and effectiveness of presentation of product information in e-business systems. European Journal of Information Systems, 11(3), 181-195 
Keevallik, L. (1999). The use and abuse of singular and plural address forms in Estonian. International Journal of the Sociology of Language, 139(1), 125-144. doi:10.1515/ijsl.1999.139.125.

Lurger, E., Moran, S., \& Rodden, T. (2013). Consent for All: Revealing the Hidden Complexity of Terms and Conditions. Proceedings of ACM CHI 2013: Human Factors in Computing Systems. New York, 2687-2696.

McDonald, A. M., \& Cranor, L. F. (2010). Beliefs and behaviors: Internet users' understanding of behavioral advertising. Tech. Rep. Carnegie Mellon University, Pittsburgh.

Miles, M. B., \& Huberman, A. M. (1994). Qualitative data analysis: An expanded sourcebook (2nd ed.). Thousand Oaks, CA: Sage.

Milne, G. R. (2000). Privacy and ethical issues in database/interactive marketing and public policy: A research framework and overview of the special issue. Journal of Public Policy and Marketing, 19(1), 1-6.

Murumaa-Mengel, M., Pruulmann-Vengerfeld, P., \& Laas-Mikko, K. (2014). Privaatsus inimõigusena ja igapäevatehnoloogiad. Tallinn: Inimõiguste Instituut.

Saldaña, J. (2009). The Coding Manual for Qualitative Researchers. Thousand Oaks, CA: Sage.

Sheehan, K. B. \& Hoy, M. G. (2000). Dimensions of privacy concern among online consumers. Journal of Public Policy \& Marketing, 19(1), 62-73.

Smith, R. \& Shao, J. (2007). Privacy and e-commerce: A consumer-centric perspective. Electronic Commerce Research, 7 (2), 89-116. doi:10.1007/s10660-007-9002-9.

Truong, Y. and Simmons, G. (2010). Perceived intrusiveness in digital advertising: strategic marketing implications. Journal of Strategic Marketing, 18 (3), 239-256. doi: 10.1080/09652540903511308.

Westin, A. F. (1997). Legal safeguards to insure privacy in a computer society. Communications of the ACM, 10, 533-537.

White, T. B., Zahay, D. L., Thorbjornsen, H. \& Shavitt, S. (2008). Getting too personal: reactance to highly personalized email solicitations. Marketing Letters, 19(1), 39-50. doi:10.1007/s11002-007-9027-9. 


\title{
Digital Wellness Services' Servicescape for Young Elderly
}

\section{HANS ALLMÉR}

\begin{abstract}
Digital devices reshape the servicescape of wellness, helping people, e.g. young elderly, to benefit from digital wellness services (henceforth DWSs) provided in a digital servicescape. This paper builds on five prior studies and explores: (i) what requirements young elderly have, in order to benefit from DWSs, and (ii) what service providers should consider, and pay regard to, when they develop and offer DWSs to young elderly. Hence, this paper argues for DWSs to be subsets of a digital servicescape. This research developed a model for how different parties, e.g. young elderly, their friends and relatives, developers, providers, but also the society per se, could gain from the DWSs. The DWSs create opportunities for a win-win-win situation. Important for the young elderly are motivation, trust, and credibility. Important for developers and providers are to motivate the users, to create trustworthiness, to provide user guidance, and to develop through co-creation.
\end{abstract}

Keywords: • Personalized marketing $\bullet$ Privacy concerns $\bullet$ Personalizationprivacy paradox $\bullet$

CORRESPONDENCE AdDRESS: Hans Allmér, Åbo Akademi, 20500 Åbo, Finland / Linnaeus University, School of Business and Economics, 39182 Kalmar, Sweden, hans.allmer@lnu.se

DOI https://doi.org/10.18690/978-961-286-170-4.10

ISBN 978-961-286-170-4

(C) 2018 University of Maribor Press

Available at: http://press.um.si. 


\section{Introduction}

Wellness is a conception that combines many aspects on several levels and dimensions. "Wellness is a multidimensional state of being describing the existence of positive health in an individual as exemplified by quality of life and a sense of well-being" (Corbin \& Pangrazi, 2001, p. 3). As people grow older, they often want to use new technology even if there could be problems that originate from the fact that young people often design for young people. Still, there are quite a lot of technical devices and applications available for young elderly $(60-75$ years), and seniors $(76+)$, that they would gain wellness from using. Campbell (2015) highlights that even though people age in their own manner, with different health issues to cope with; there are some features about aging applicable to most people. Vision and hearing are reduced, motor skills are declining, and cognition and memory might vary a lot. Further, they have often grown deep relationships over time that they want to keep and maintain, but they are more geographically restricted than younger people generally are. Hence, virtual contacts would be a great opportunity if they would find the technical solutions useful. It is important to keep in mind that elderly people could be used to technology, but could still need some guidance and support. Campbell (2015) describes an older man, who wanted to read further from various links but did not understand how to open them, because he was not used to the interface. He proposes some reminders for those who develop technical solutions for elderly

e.g. "avoid small-screen devices", provide sizing opportunities, "reduce the distance between interface elements that are likely to be used in sequence", "enable connection with a smaller, more important group of people", "during longer tasks, give clear feedback on progress and reminders of goals" (ibid.).

Wellness is an ongoing process in which different dimensions interact with each other and shape a holistic picture of individuals. Along the years, many have dealt with wellness e.g.:

- Dunn (1959, p. 447) proposing that "High-level of wellness for the individual is defined as an integrated method of functioning which is oriented toward maximizing the potential of which the individual is capable, within the environment where he is functioning".

- León et al. (2016, p. 1) stating that wellness is about "dynamic balance of physical, emotional, social, spiritual, and intellectual health".

- Smith Maguire (2007) proposing wellness to aim at offering and achieving abetter life in balance.

- Hattie, Myers, and Sweeney (2004) adding environmental as a seventh dimension, to the six dimensional model of wellness by Hettler (1976), which originally contained social, intellectual, spiritual, physical, emotional, and occupational aspects.

For young elderly, digital wellness services (henceforth DWSs), i.e. apps and devices, could be an appropriate instrument for achieving wellness adapted to individual needs and requirements. Services exist together, and alongside, with physical products and 
constitute the core of the offer to customers "customers consume and use goods, services or any resource as service to achieve something" (Grönroos, 2015, p. vii). "Service is a simple, yet powerful and multifaceted construct and that it is the correct designation, not only to characterize emerging and converging marketing thought, but also to accurately inform and motivate the associated research, practice, and public policy" (Vargo \& Lusch, 2008a, p. 36). Service as a phenomenon is complicated to define as the term has many meanings (Grönroos, 2015). The foundation of a service lies in that it is intangible and therefore the customer cannot see, touch or smell services (Solomon, Marshall, Stuart, Mitchell, \& Barnes, 2013). The latter becomes particularly interesting seen in the light of digitalization, and how these potential shortcomings could be dealt with online. Studying wellness and services in connection to social, cultural, psychological, cognitive, and biological aspects of aging would be a start for example by putting forward the importance of assistive technology, where devices and applications can decrease elderly or ill people's need for help and assistance (Bagwell, 2016). Further, DWSs for young elderly can make a positive impact on their health that will reduce the probability of getting serious illness, and there is a need for developing DWSs (Carlsson \& Walden, 2015). Marklund (2016) argues for the importance of a holistic view on wellness, since it is not only one single factor affecting peoples' wellness, rather a combination of different factors. Exercising both body and brain is crucial and must be done properly; otherwise, there is a serious and increasing risk for illness and premature death. Hence, the research questions are:

What demands and needs are required from young elderly as customers of DWSs? What should providers consider when offering DWSs to young elderly?

\section{$2 \quad$ Related work}

Harris and Goode (2010, p. 231) define e-servicescape as "online environment factors that exist during service delivery". Hopkins, Grove, Raymond, and LaForge (2009) state that the e- servicescape is a site on the Internet where customers and service providers interact. The digital services can be provided by using various devices e.g. computers, tablets, smartphones, and activity bracelets. A digital servicescape, for enabling physical wellness apps, can be developed and designed for training, sleeping, and measuring various body functions. Apps provide information to the user and can encourage physical training by sending a reminder to the user, or by showing how the users' fitness develops over time. Intellectual wellness can be strengthened by providing the apps that encourage training of the brain. Emotional wellness are apps providing e.g. possibilities for the user to show emotions like happiness, sadness, loneliness, and participation in other people's feelings. Chiu and $\mathrm{Hu}$ (2015) argue that well designed app technologies can be beneficial to what they describe as older adults as it can strengthen physical and psychological well-being in a cost-effective way. Platt, Outlay, Sarkar, and Karnes (2015) propose the wellness app technology to be an important and promising tool to help people maintain good health, to decrease human suffering and in parallel decrease costs for healthcare. Harris and Goode (2010, p. 231) define e-servicescape "as the online environment factors that exist during service delivery". Hopkins et al. (2009) argue that the e- servicescape is an Internet site where customers interact with a company. The interaction includes the companies' design and features. Harris and Goode (2010, p. 239) discuss different terms regarding offers 
provided on internet, e.g. e-servicescape, online servicescape, and online environment, and state "Nevertheless, we are favourably biased toward the term 'e- servicescape', since the label emphasizes the context of online exchange and highlights that purchasing online involves element of self-service, even when products are purchased".

In an e-servicescape, the physical-to-virtual transfer of activity requires providers to rethink the traditional rules for building trust and loyalty in order to meet the needs and demands of prospects and customers (Rivard, 2012). It is important to strive towards message credibility that is comparable with the sender's credibility, since trust is necessary in an e-servicescape. Otherwise, the customers will probably reject the offered services. Papadopoulou, Andreou, Kanellis, and Martakos (2001) highlight trust, and state that trust are closely connected to both relationship marketing and servicescape. Doney and Cannon (1997) identified five trust- building processes: Intentionality, capability, prediction, transference, calculative; Papadopoulou et al. (2001) added credibility to the list. The trust building processes are: (i) to make a promise, (ii) to enable a promise, and (iii) to keep a promise (Papadopoulou et al., 2001).

To create trustfully electronic servicescapes, Papadopoulou et al. (2001) propose that Websites should be transformed to customer-centric e-servicescapes that offer digital experience as a way to develop indelible relationships between business and customers. Trust can be transformed through customer networks by recommendations from others, and lead to customers who are willing to try digital services. Trust will develop over time with increased customer loyalty when customers are repeatedly satisfied with their servicescape interactions. "Each time a promise is made, enabled and kept, it is evaluated with the intentionality, the capability and the credibility process confirming the customer's trusting beliefs in the business benevolence, competence and credibility. The level of trust is also related to the experience that the customer gains within the e-servicescape" (Papadopoulou et al., 2001, p. 327).

The design of user interfaces plays a central role on digital devices (Al-Showarah, AlJawad, \& Sellahewa, 2014). The interfaces must be designed so that elderly people can benefit from their offerings. The demands and requirements on the digital devices, e.g. smartphones could vary depending on user preferences such as age according to Tsai, Tseng, and Chang (2017). Elderly compared with children and adults, often respond more slowly when using smartphones, which providers need to take into account when developing interfaces. Smith and Chaparro (2015) claim that there are differences between elderly and other groups that must be remembered during development of digital devices for elderly, i.e. elderly use smartphones less than others due to touchscreens' shortcomings. The size, spacing and location of the target influences the performance and the performance is greater with audiotactile feedback in comparison with tactile and auditory (Hwangbo, Yoon, Jin, Han, \& Ji, 2012).

Proactive feedback can be seen as guidance if common problems that users experience are taken into consideration, so feedback could be given to provide help in advance. Electronic feedback could increase or decrease the gain of the amplifiers (Black, 1934). "When there are only two parts joined so that each affects the other, the properties of the 
feedback give important and useful information about the properties of the whole" (Ashby $\&$ Pierce, 1957, p. 54) the proactive feedback is built in with the user interface. "The user interface is constantly making progress and ubiquitous nowadays, however its design currently is still lack of concern towards usability and accessibility of the elderly" (Hsiao, Lee, Yang, \& Chen, 2017, p. 158).

Motivation occurs when an individual directs behaviour towards a goal (Nationalencyklopedin, 2015). Further, it is about forces that initiate, give energy, guide, and maintain behaviour (Vroom, 1964); goal setting is important for task performance whether an individual gives up or completes a task (Locke, 1968). Two behavioural elements deal with motivation; the individual's choice of path among alternatives and amplitude / vigour of the action, for its tendency to persist over time in the chosen path (Atkinson, 1957). There are three types of motivation: Internal motivation, external motivation, and amotivation. The psychological needs mediate between the first and the third element, and are of three types: Autonomy, competence, and relatedness. The outcomes are of three types: Affective, cognitive, and behavioural. Motivation can be divided into three main groups: Internal motivation, instrumental motivation, and motivation as an interaction between the individual and the environment (Alvesson, 2013). Internal motivation emphasizes the individual's internal needs and forces; instrumental motivation stresses a perspective of individuals trying to achieve rewards and avoiding punishments, and an interactive motivation approach involving norms, reciprocity, and identity. In the human mentality three levels occur: Human nature, culture, and personality. Human nature is universal and inherited, culture is for a specific group / category and is learned, and lastly personality is specific to the individual and is inherited and learned (Hofstede, 1994).

\section{$3 \quad$ Method}

This research carried out five studies, in which three methods were applied; the first study, one survey and a focus group; the second study, two surveys and two focus groups, the third study, a survey, the fourth study, a literature review, and the fifth study, a focus group. The first three respondent groups consisted of different network members. There were 32 respondents in the first group, 15 in the second, and 16 in the third group, in total 63. The first group was mostly retired people, who bowled together weekly. The second and third groups contained two different groups of retired people, who played boule together. Three surveys and focus groups conducted in 2012 and in 2013, collected data about the respondents and about their IT use and preferences. A literature review was conducted with the purpose of finding patterns about what is put forward regarding servicescape, e-servicescape, and information system. A complementary survey, and yet another focus group (D), based on the above studies, were carried out. 
The four surveys concerned Internet services, i.e. whether or not the respondents were interested in making use of others' knowledge, and of sharing their own knowledge with others. Generally, the respondents were not particularly interested in sharing their knowledge online, except as regarded knowledge connected to their professional skills (49\%) and travelling (56 \%) (Allmér \& Råberg, 2013).

The results from the interview with focus group A, showed that the group mainly used the Internet for searching for information, and that very few shared information, knowledge and/or opinions. They commented that in some cases they were forced into using services on the Internet (e.g. bank services, healthcare services, and communication with organizations and authorities). All of the respondents mentioned bank services, since many banks are closing their physical offices, decreasing opening hours and personal services, increasing the costs for services in bank offices and more, all of which are forcing customers to use Internet services whether they want to or not (Allmér \& Råberg, 2013).

Group B focused on why they do not utilize services available through the Internet today. The results showed that they were extremely concerned about having a personal connection with the people taking an active part in services on the Internet (e.g. when discussing health issues they want to see, and have direct communication with the expert/doctor, and preferably, a history with that person). They needed to feel confident in whom they interact with, what kind of knowledge that person has, what kind of previous record of accomplishment that person has, and what will happen with the information they are willing to share and discuss? They also felt worried about entering new services, as a whole, even if it was just for trial reasons (Råberg \& Allmér, 2013).

Group $\mathrm{C}$ felt anxiety towards trying digital services and sharing information, but also worried about knowledge and opinions on digital service applications and social media. Primarily three things concerned the young elderly in relation to previous results. Firstly, they needed to feel secure about their data, identity, username, password, credit card number, comments and knowledge in that it would not be abused and/or hijacked in any way. They also needed to be secure about that they are communicating with the right person, and about that person's good intentions. Secondly, they needed a personal touch and guidance about digital services. Personal touch means recommendations from acquaintances, who they could contact before using the service, or could ask for help to find the right kind of service. Thirdly, they thought some service applications were so general and offered too many options, which only complicated things. Hence, they wanted to have the ability to decrease the number of options to solely those alternatives that they really wanted. They wanted to customize the service options through interaction with the service provider (Råberg \& Allmér, 2013).

For group D the top-three reasons for using were help and support with technology, professional knowledge, planning, scheduling, and being reminded. The top-three reasons for sharing were professional knowledge, memory training, and health advice. The three 
of least interest for using were (not / no answer) health advice, technology help and support, and planning, scheduling, and being reminded. The three of least interest for sharing were intermediation of work, technology help and support, and training coaches. Some conclusions could be made (Allmér \& Marcusson, 2018):

- They have skills, such as knowledge and experience, as well as time to help other people. They do so in clubs and societies or with friends and acquaintances. When the parties know each other, the offers can be clear, transparent, and distinct. When offers are addressed to people outside these zones different problems can occur. The young elderly are keen to feel secure in a support situation and with a beneficiary.

- It was shown that clarity in how the offer is disseminated is of importance for the young elderly.

- There are two types of support that may be offered; time and skills. Time can for example be used for a walk in the park, a wheelchair walk, reading aloud from a magazine or a book, and as company to a museum, theatre, or concert. Skills can be knowledge and experience that are professional (e.g. tax returns) or that originate from hobbies and interests (e.g. fruit tree pruning and fixing the car).

- The young elderly need to feel secure in a support situation. They also argue that the person who receives support must bring about the type of security they need, which depends on several factors, e.g. are the persons known to each other, are there only the two persons in the situation, is it in one party's home, or is the beneficiary disabled? To strengthen this feeling of security an intermediary can play a role.

The literature review resulted in the supposition that a digital servicescape is possible. However, in some cases a detour is necessary since it is not possible to apply the senses smell, touch, and taste digitally (Allmér, 2014).

\section{Discussion}

This section discusses young elderly's views on DWSs (5.1) and presents a model of digital wellness services' servicescape (henceforth DiWeSS) (5.2).

\subsection{Young elderly's views on DWSs}

The findings have clearly shown that the young elderly commonly use IT, have Internet access, and are worried about the risks and threats that lie in wait for them online. They showed scarce interest to utilize others' knowledge and to share their own knowledge with others, with few exceptions. Hence, from this starting point it is obvious that the actual use of DWS solutions comes from some kind of motivation (Alvesson, 2013; Atkinson, 1957; Hofstede, 1994; Locke, 1968; Vroom, 1964) and it is just as obvious that usage depends on trust (Doney \& Cannon, 1997; Papadopoulou et al., 2001; Rivard, 2012) for the provider, who are expected to create a safe and secure environment. It is utterly important that the young elderly feel that it is both secure and safe to use DWSs. Young elderly use digital equipment in their daily life and have access to Internet, which means 
that the technology is no obstacle per se; it is rather their feelings towards the consequences that might come from the usage.

The worries connected to sharing online, and to using for example apps, must be overcome in order to make use of the possibilities that actually are available, and that can come in handy for a lot of purposes and reasons. Obstacles like anxiety about trusting others, including the technical facilities and apps online, must be handled from the providers' side for the young elderly to overcome their resistance and hesitation. What a proposition conveys must be obvious to the customer, i.e. to the young elderly, which is crucial for the provider to understand and to act on. To offer reliable and thoughtful guidance (Ashby \& Pierce, 1957; Black, 1934; Hsiao et al., 2017), as well as a good usability (Al-Showarah et al., 2014; Hwangbo et al., 2012; Smith \& Chaparro, 2015; Tsai et al., 2017) would make this possible, according to the research findings. One way of achieving this is to co-create trust and motivation with the young elderly, to invite them to participate.

Group D stresses the necessity of guidance / support with technological issues as something that really has to be carefully handled. A provider should meet these demands, and by that also create trust (Doney \& Cannon, 1997; Papadopoulou et al., 2001; Rivard, 2012). Digital servicescape designed to provide good usability (Al-Showarah et al., 2014; Hwangbo et al., 2012; Smith \& Chaparro, 2015; Tsai et al., 2017) and guidance (Ashby \& Pierce, 1957; Black, 1934; Hsiao et al., 2017) are likely to create security, trust (Doney \& Cannon, 1997; Papadopoulou et al., 2001; Rivard, 2012), and motivation (Alvesson, 2013; Atkinson, 1957; Hofstede, 1994; Locke, 1968; Vroom, 1964) to use. It should be very clear that the responsibility to fulfil these demands is in the hands of the provider, who should meet these demands to the fullest.

\subsection{DiWeSS' context model}

The purpose was to put together findings from five previous studies (four papers / articles) regarding young elderly's DWSs into a model. Four research papers' key findings end up in a focusing on digital servicescape that is further developed into a focus on providing DWSs (apps and devices). In a digital servicescape, the provider and the customer / user meet in a moment of truth and a context of trust, and this is crucially important. It is in the digital servicescape the clash occurs, and therefore where the services offered will be accepted or rejected. The interface of the digital servicescape should emulate a place between the provider and the customer / user that works almost like a Velcro in order to build a sustainable relation between the different parts involved. On this basis, it can be argued for a need for a DiWeSS that emerges and appears as a subset of the e-servicescape. A digital servicescape has in comparison with a physical servicescape some limitations when it comes to what is possible to present (e.g. the sense of smell, touch and taste) on for instance a computer, tablet, or a smartphone. However, it could be argued that it is plausible to provide the feeling of a smell, touch, and taste even if it is not possible to the full extent. This in turn, affects the possibilities to provide DWSs, as it is hard to show people what the service actually can bring them. 
The DiWeSS' context model (figure 1) puts forward three perspectives: on the one hand the developer and provider, and on the other hand, the young elderly. These three parts interact where the provider offers the DWSs with DiWeSS to the young elderly.

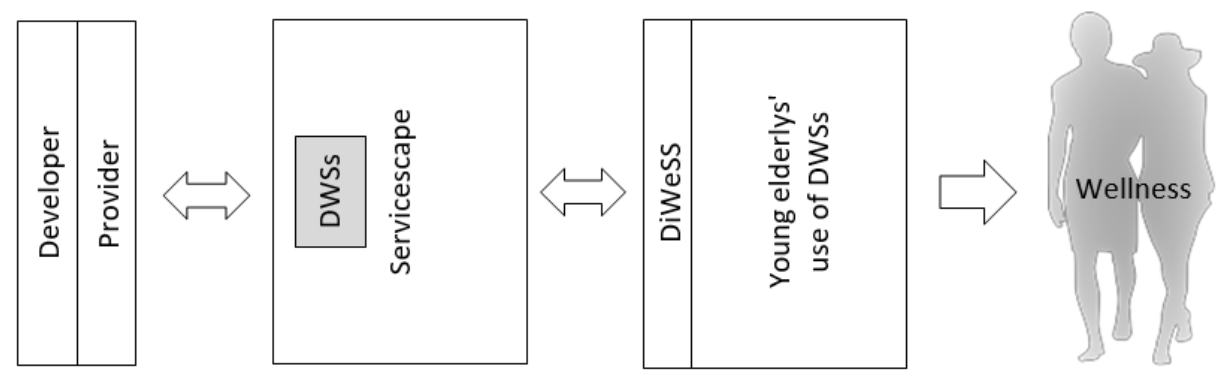

Figure 1: DiWeSS' context model

DWS with DiWeSS points towards a win-win-win-situation. On one side are the developers and providers, and on the other side are the young elderly with their needs in everyday life. Further, the part about how these needs are met with DWSs should be included in the model. To some extent, e.g. family, friends, and society among others, can also be considered as stakeholders. Companies and organizations that provide digital services, which meet the demands of customers, have the opportunity to make a profit, which means a win situation for them. Well working DWSs with DiWeSS will help people to have a more eventful, healthier and longer life, which certainly can be seen as a win for them. People that are healthier and satisfied with their life can have a positive influence on other people and therefore demand less service from society, which will be a win for the society per se.

\section{Conclusions, limitations and further research}

The first research question is about needs and requirements of the target group and the second research question is about demands on providers, both in the context of DWSs for young elderly. A short answer to these questions is presented in a program (figure 2). With the purpose to underline the keys to DiWeSS for young elderly, the most important issues are brought together in a program. 


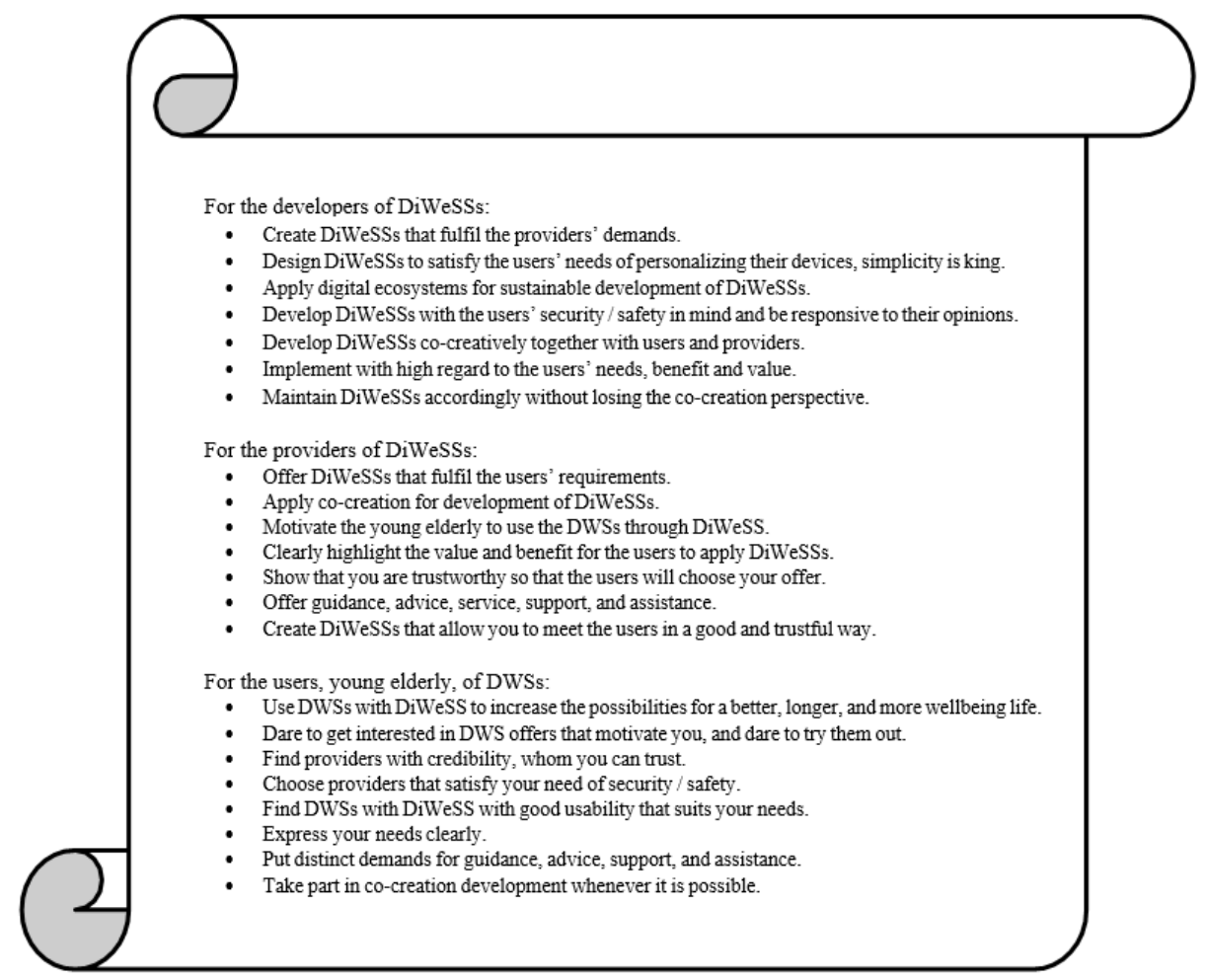

Figure 2: DiWeSS' program

If DiWeSS works for young elderly, it probably will work for other age groups as well. There are some implications for practise, and for further research, to highlight and discuss.

- Firstly, there is a need for deeper understanding of the benefits that a welldesigned DiWeSS can bring to people in general, and to the group of young elderly in particular, as most people eventually will be among the group of young elderly.

- Secondly, there is a need to put research effort into the group of seniors, as it can be beneficiary to them too.

- Thirdly, there is an implication for putting effort into research on if it could lead to a win - win - win situation if young elderly are provided with DWSs through DiWeSS. If so, how should it be constructed?

For everybody it is nicer to get old if you are in good shape; to get a few more good years. A well-designed servicescape would be most helpful in order to support the use of DWSs. Therefore, use DWSs with DiWeSS! 


\section{$31^{\text {ST }}$ Bled eConference: Digital Transformation: MeEting the Challenges June 17 - 20, 2018, BLED, SLOVENIA, CONFERENCE PROCEEDINGS H. Allmér: Digital Wellness Services' Servicescape for Young Elderly}

\section{Acknowledgement}

I am grateful to the reviewers for their comments.

\section{References}

Al-Showarah, S., Al-Jawad, N., \& Sellahewa, H. (2014). Effects of user age on smartphone and tablet use, measured with an eye-tracker via fixation duration, scanpath duration, and saccades proportion8514, 3-14. Retrieved from doi:10.1007/9783-319-07440-5_1

Allmér, H. (2014). E-servicescape is plausible. IRIS Selected Papers(5).

Allmér, H., \& Marcusson, L. (2018). The five-key element model for altruistic young elderly.

(In review).

Allmér, H., \& Råberg, M. (2013). Young-elderly and digital use. Paper presented the IRIS 2013 Conference, Oslo, Norway.

Alvesson, M. (2013). Organisation och ledning: ett något skeptiskt perspektiv. Lund: Studentlitteratur.

Ashby, W. R., \& Pierce, J. R. (1957). An Introduction to Cybernetics. Physics Today, 10(7), 34-36. doi:10.1063/1.3060436

Atkinson, J. W. (1957). Motivational determinants of risk-taking behavior. Psychological Review, 64(6p1), 359.

Bagwell, D. K. B. S. (2016). Geriatrics and Gerontology. In. Ipswich, USA: Salem Press. Black, H. S. (1934). Stabilized feed-back amplifiers. Electrical Engineering, 53(4), 590-590.

doi:10.1109/EE.1934.6539889

Campbell, O. (2015). Designing For The Elderly: Ways Older People Use Digital Technology Differently. Smashing Magazine. Retrieved from 02-20) https://www.smashingmagazine.com/2015/02/designing-digitaltechnology-for-the- elderly/

Carlsson, C., \& Walden, P. (2015). Digital Wellness Services For "Young Elderly" A Missed Opportunity For Mobile Services. AIS Electronic Library (AISeL).

Chiu, C., \& Hu, Y. (2015). Promoting Older Adults' Well-Being Through Apps-based Technology Training Services: A Mixed Method Approach. The Gerontologist, 55(Suppl2), 758-758. doi:10.1093/geront/gnv395.04

Corbin, C. B., \& Pangrazi, R. P. (2001). Toward a Uniform Definition of Wellness: A Commentary. Washington D. C.: President's Council on Physical Fitness and Sports Research Digest.

Doney, P. M., \& Cannon, J. P. (1997). An Examination of the Nature of Trust in Buyer-Seller Relationships. Journal of Marketing, 61(2), 35-51. doi:10.2307/1251829

Dunn, H. L. (1959). What high-level wellness means. Canadian journal of public health $=$ Revue canadienne de santé publique, 50, 447.

Grönroos, C. (2015). Service management and marketing: managing the service profit logic (4 ed.). Chichester: John Wiley \& Sons.

Harris, L. C., \& Goode, M. M. H. (2010). Online servicescapes, trust, and purchase intentions. Journal of Services Marketing, 24(3), 230-243. doi:DOI: 10.1108/08876041011040631.

Hattie, J., Myers, J., \& Sweeney, T. (2004). A Factor Structure of Wellness: Theory, Assessment, Analysis, and Practice. Journal of Counseling and Development : JCD, 82(3), 354-364. doi:10.1002/j.1556-6678.2004.tb00321.x

Hettler, B. (1976). The six dimensions of wellness. Retrieved from (2017-03-05) http://www.hettler.com/Origins.htm

Hofstede, G. (1994). Cultures and organizations: software of the mind: intercultural cooperation and its importance for survival. London: Harper/Collins. 
Hopkins, C. D., Grove, S. J., Raymond, M. A., \& LaForge, M. C. (2009). Designing the eServicescape: Implications for Online Retailers. Journal of Internet Commerce, 8(1/2), 23-43. doi:10.1080/15332860903182487

Hsiao, S.-W., Lee, C.-H., Yang, M.-H., \& Chen, R.-Q. (2017). User interface based on natural interaction design for seniors. Computers in Human Behavior, 75, 147-159. doi:10.1016/j.chb.2017.05.011

Hwangbo, H., Yoon, S. H., Jin, B. S., Han, Y. S., \& Ji, Y. G. (2012). A Study of Pointing Performance of Elderly Users on Smartphones. International Journal of Human-Computer Interaction. doi:10.1080/10447318.2012.729996

León, M., Nieto-Hipólito, J., Garibaldi-Beltrán, J., Amaya-Parra, G., Luque-Morales, P., MagañaEspinoza, P., \& Aguilar-Velazco, J. (2016). Designing a Model of a Digital Ecosystem for Healthcare and Wellness Using the Business Model Canvas. J Med Syst, 40(6), 1-9. doi:10.1007/s10916-016-0488-3

Locke, E. A. (1968). Toward a theory of task motivation and incentives. Organizational behavior and human performance, 3(2), 157-189.

Marklund, B. (2016). [Conversation over health-related issues 2016-10-27]. Nationalencyklopedin. (2015). Different Dictionary Words In.

Papadopoulou, P., Andreou, A., Kanellis, P., \& Martakos, D. (2001). Trust and Relationship Building in Electronic Commerce. Internet Research, 11(4), 322-332. doi:10.1108/10662240110402777

Platt, A., Outlay, C., Sarkar, P., \& Karnes, S. (2015). Evaluating User Needs in Wellness Apps. International Journal of Human-Computer Interaction. doi:10.1080/10447318.2015.1099803

Rivard, S. (2012). Information technology implementers\&\#039; responses to user resistance nature and effects. Management information systems : mis quarterly, 36(3), 897-920.

Råberg, M., \& Allmér, H. (2013). Young-elderly and digital services. Paper presented at the IRIS 2013 conference, Oslo, Norway.

Smith, A. L., \& Chaparro, B. S. (2015). Smartphone Text Input Method Performance, Usability, and Preference With Younger and Older Adults. Human Factors: The Journal of Human Factors and Ergonomics Society, 57(6), 1015-1028. doi:10.1177/0018720815575644

Smith Maguire, J. (2007). Fit for consumption: sociology and the business of fitness. Milton Park, Abingdon, Oxon; New York: Routledge.

Solomon, M. R., Marshall, G. W., Stuart, E. W., Mitchell, V., \& Barnes, B. (2013). Marketing: real people, real decisions. Harlow: Pearson.

Tsai, T.-H., Tseng, K. C., \& Chang, Y.-S. (2017). Testing the usability of smartphone surface gestures on different sizes of smartphones by different age groups of users. Computers in Human Behavior, 75, 103-116. doi:10.1016/j.chb.2017.05.013

Vargo, S. L., \& Lusch, R. F. (2008a). Why "service"? Journal of the Academy of Marketing Science, 36(1), 25-38.

Vroom, V. H. (1964). Work and motivation. NY: John Wiley \& Sons. 


\title{
Developing an E-learning Course on Serious Games: A Multidisciplinary Approach
}

\author{
TANJA KoRHONEN, TEIJA RAVELIN \& RAIJA HALONEN
}

\begin{abstract}
The use of serious games (SGs) for different purposes is increasing. The development of successful and effective SGs requires a team with professional knowledge from different areas and a joint understanding of the SG development process. The research goal was to find a way to educate multidisciplinary students via an e-learning course about SGs. An action research study was initiated, and social constructivism theory-based e-learning courses on SGs were developed. The Carpe Diem Learning design method was used in the planning phase, followed by three iterations on course development and implementation. The feedback and observations were analysed in each iteration, and changes to the courses were made according to them. This iterative development and incremental improvement of an online course according to feedback was found to be a good approach.
\end{abstract}

Keywords: • Serious Games • E-learning • Education •

CoRrespondence AdDress: Korhonen, Ph.D. student, Senior Lecturer, Kajaani University of Applied Sciences, School of Information Systems, Ketunpolku 187101 Kajaani, Finland, e-mail: tanja.korhonen@kamk.fi , Ravelin, Ph.D., Senior Lecturer, Kajaani University of Applied Sciences, School of Health, Ketunpolku 187101 Kajaani, Finland, e-mail: Teija.ravelin@kamk.fi, Halonen, Ph.D., Adjunct professor, University of Oulu, Faculty of Information Technology and Electrical Engineering, 90014 Oulu, Finland, raija.halonen@oulu.fi 
T. Korhonen, T. Ravelin \& R. Halonen: Developing an E-learning Course on Serious Games: A Multidisciplinary Approach

1

\section{Introduction}

The primary objective of a serious game (SG) is more than simply entertainment (Djaouti, Alvarez, Jessel \& Rampnoux, 2011; Susi, Johannesson \& Backlund, 2007; Zyda, 2005). These games, also called applied games, can be used to either change a player's behaviour or motivate them in a particular way (Baranowski et al., 2013; Ryan, Rigby \& Przybylski, 2006). Due to the many different potential applications of SGs (see, e.g. Zyda, 2005; Kemppainen, Korhonen \& Ravelin, 2014; Ricciardi \& Paolis, 2014), their development requires the involvement of experts from a variety of disciplines. To develop effective SGs, meaning they effectively achieve their serious purpose, more education is needed (De Troyer, 2017). In this study, our research goal was to find a solution to educate a multidisciplinary audience about SGs.

The Internet and rapidly developed information and communication technology (ICT) have built new methods of education and learning (Gomez, Wu \& Passerini, 2010). Especially, the role of e-learning has grown as part of the acquisition of new skills and knowledge. Despite its technical requirements, the pedagogical aspects should be noted, as well. To evaluate the effectiveness of e-learning, Yunus and Salim (2008) proposed a framework consisting of five dimensions (individual, knowledge, learning, content, and relationship between the instruction and the learner) to enable e-learning.

The main research question in this study was: How to develop an e-learning course on SGs for multidisciplinary students? To answer this question, the following sub-questions were asked:

- How to design an e-learning course with social constructivism theory as an approach?

- What kind of content is needed regarding SGs when designing a course for multidisciplinary students?

- How to utilise gamification to motivate students?

This research followed action research techniques. An action research study aims to solve current practical problems while expanding on scientific knowledge, typically using an iterative research process where researchers are part of the study (Baskerville \& Myers, 2004; Baskerville, 1999; Coghlan \& Brannic, 2014).

This paper describes an action research study of the development and implementation of e-learning courses on SGs, and it is organised into five major sections. The next section reviews related works. Section three presents the research methodology, and the results are presented after that. The paper ends with a discussion and conclusions. 


\section{$2 \quad$ Related Work}

\subsection{Pedagogical Background}

ICT-based communication increases learning by activating students, and team-based methods in online environments improve the effectiveness of learning (Gomez et al., 2010). Third-generation distance education, meaning that student support is integrated with teaching, giving students possibility to create learning content instead of adopting ready-made content, is a radical change for pedagogy. Also educational institutions are challenged to adopt technology that develops at a rapid pace. (Tait, 2014.)

The concept of learning related to this development work is based on social constructivism theory. In social constructivism theory, social interaction between people is seen as the primary source of cognitive development in a learning context. (Durairaj \& Umar, 2015.) Knowledge is constructed by exchanging dialogue in a social setting and co-constructed in the environment with others (Shaikh et al., 2017).

Students acquire knowledge by interacting and collaborating with a knowledgeable individual. Involvement and interaction in group discussions provide students with the opportunity to generalise and transfer their knowledge. Social constructivism theory highlights the importance of feedback to help students construct their knowledge. (Durairaj \& Umar, 2015.) Although learning happens through collaboration, it is an internal mechanism within the individual. Individual learning is a product of knowledge creation, and it happens when collaboration takes place and when knowledge itself is cocreated in the environment. (Shaikh et al., 2017.)

The social constructivism approach has been applied in online courses (Shaikh et al., 2017). Online learning and self-study are seen possible in the social constructivism context because the learner has inherited evolved cultural tools deliberately devised for intentional learning (Marsh \& Ketterer, 2005).

The tension between the synchronous and asynchronous delivery of online courses is recognised. Shared deadlines result in improved motivation, and in contrast, asynchronous delivery gives students more freedom. (Shaikh et al., 2017.) Considering the dropout rate, Onah, Sinclair and Boyatt (2014) note that in most MOOC (Massive Open Online Course) courses, less than 13\% of students finished the course.

In online courses, it is challenging to provide individual help to students, and to guarantee that the course outcomes have been achieved. Crowdsourcing has been seen to have the potential to answer these questions. Crowd formation in an online setting related to specific knowledge domains can connect students and make interacting and collaborating with knowledgeable individuals possible. (Shaikh et al., 2017.) 
T. Korhonen, T. Ravelin \& R. Halonen: Developing an E-learning Course on Serious Games: A Multidisciplinary Approach

\subsection{Design Method}

Kali, Levin-Peled and Dori (2009) reported about the challenges to design courses that promote collaborative learning in higher education. According to them, teachers willing to adopt socio-constructivist pedagogies often face challenges related to fulfilling their objectives without the thorough application of carefully planned design methods. They also encouraged teachers to formulate and refine guidelines to fit with the objectives and to find sensible methods in the design.

Carpe Diem Learning design method describes a team-based, collaborative online learning design process, that typically comprises two or three academics (Salmon et al., 2014; Salmon \& Wright, 2014). This method is suitable for designing new courses. Carpe Diem focuses on learning design needs for specific units of study. The basic process is delivered in a two-day workshop, and the basic idea is that people are designing something that could be put into immediate use with participants. By the end of the workshop, there will be a unit or module partly built in the online environment and an action plan to support it. (Salmon \& Wright, 2014.)

\subsection{Serious Games as a Topic}

The concept of a SG involves a digital game whose main purpose is something other than pure entertainment, and it is designed to be used in training, education, and healthcare (Loh, Sheng \& Ifenthaler, 2015).

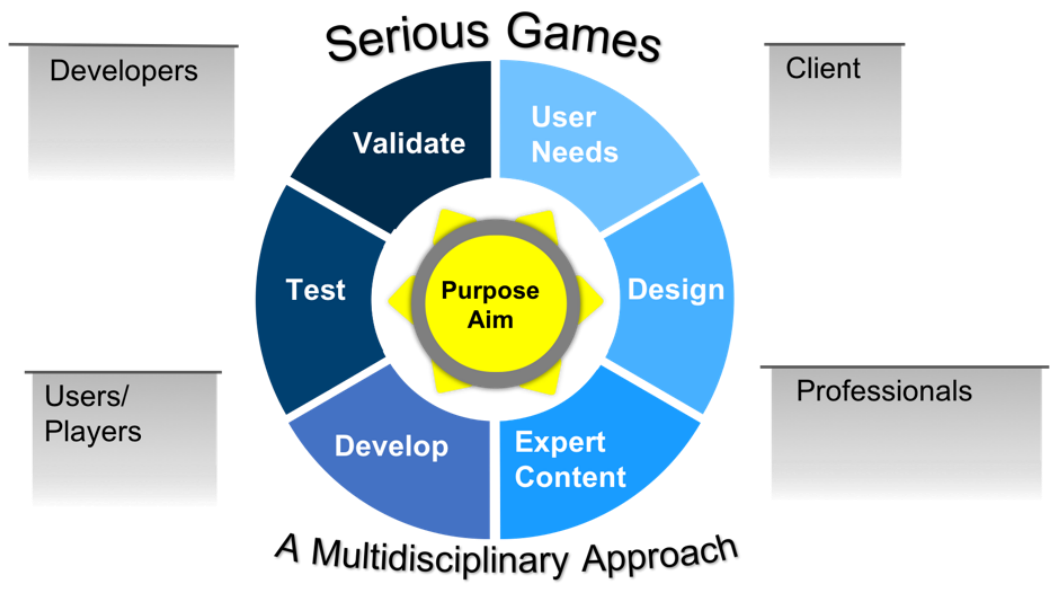

Figure 1: Phases and actors in SGs development.

Developing a SG requires not only game development skills and an understanding of good game design, but also the ability "to solve an organizational need or to be of utility in some other aspect beyond entertainment" (Backlund et al., 2017, p. 15). SG development is seen as an interdisciplinary scene (see Fig. 1.), where input is needed from 
many domains (Backlund et al., 2017). Client procurement skills are seen as a challenge: they have significantly high or low expectations, and they lack knowledge of possible solutions regarding gamification and SGs (Backlund et al., 2017). The education and consultancy of customers could be considered a solution for this challenge. De Troyer (2017) also presents the need for multidisciplinary tools to assist during the development of SGs, guidelines for developing SGs, and knowledge of SGs.

Several disciplines should be involved when designing and implementing SGs. Professionals participating in the development process should acquire knowledge and an understanding of the SG development process. (Korhonen et al., 2017.)

The term multidisciplinary expertise refers to the gathering of professionals from multiple academic disciplines to solve collaboratively a defined problem (Nancarrow et al., 2013). Furthermore, game development requires a team of experts with different backgrounds, and the development of SGs requires the participation of professionals in the target content area (Kemppainen et al., 2014; Korhonen \& Halonen, 2017a). Figure 1 illustrates the aspects of SG design: SGs are designed using basic game design techniques, but for the defined purpose (Loh et al., 2015) and users.

\section{$3 \quad$ Research Methodology}

Action research aims to solve current practical problems while expanding scientific knowledge, typically using an iterative research process where researchers are part of the study (Baskerville \& Myers, 2004; Baskerville, 1999). As a concept, action research was introduced by Lewin (1946), who studied workers' intergroup relations and actions, as well as the barriers the workers met at work.

Specifically, action research is an effective research method in cases that include active participation in organisations that are in the process of changing and that raise research interest among researchers. In practice, the change can be carried out by professional researchers who want to develop their work processes and practices in their environment. Action research appears in a cyclical process, and it is collaborative in nature. (Coghlan \& Brannic, 2014.) 
T. Korhonen, T. Ravelin \& R. Halonen: Developing an E-learning Course on Serious Games: A Multidisciplinary Approach

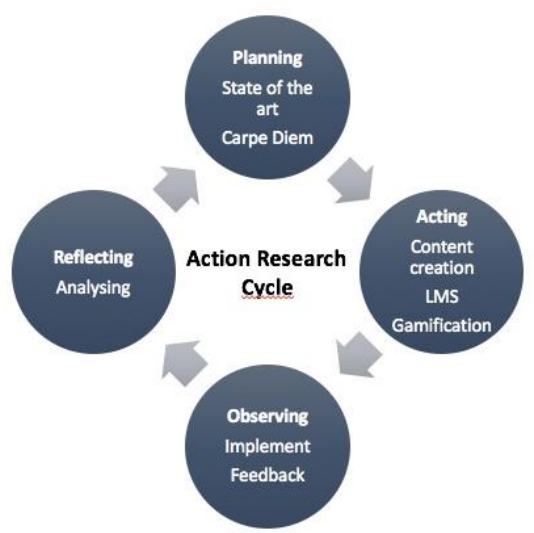

Figure 2: Action research cycle in developing an e-learning course on serious games.

In the current study (see Fig. 2), two of the authors were involved in developing the course as part of the organisation and its practitioners: one from information systems with technical background in gaming and one from healthcare expertise area. They observed the overall process of developing the course, and they participated in practical work as developers (see Coghlan \& Brannic, 2014).

\section{Development of the Course on Serious Games}

This section presents the phases in the development of the course on SGs that apply the cycle of action research (see Fig. 2). Planning started with research on the-state-of-the art in SG courses, and it continued by applying the Carpe Diem Learning design methodology. This was followed by content selection and creation in a learning management system (LMS), including the use of gamification techniques. Observation took place during three implementation phases, and all feedback was analysed and used in the iterative development of the course.

\subsection{The State-of-the-Art in Serious Game Education}

At the time of this study, year 2016, there were few online SG courses and education available in English, and the quality and content of the courses varied greatly. There were no courses in Finnish. After searching using Google, we listed courses that were found in English and offered as online courses. Then the search was narrowed down to courses that suited also to experts outside game development (see Table 1). 
T. Korhonen, T. Ravelin \& R. Halonen: Developing an E-learning Course on Serious Games: A Multidisciplinary Approach

Table 1: Available SG Online Courses

\begin{tabular}{|c|c|c|c|}
\hline \multirow{2}{*}{ Course name } & \multicolumn{3}{|c|}{ Table of available online SG courses - top3 } \\
\hline & Link & Syllabus & Remarks \\
\hline $\begin{array}{l}\text { Serious } \\
\text { Gaming }\end{array}$ & $\begin{array}{l}\text { https://www.coursera. } \\
\text { org/learn/serious- } \\
\text { gaming }\end{array}$ & $\begin{array}{l}\text { "You will learn the ins } \\
\text { and outs of games that } \\
\text { are designed with exactly } \\
\text { those purposes in mind: } \\
\text { serious games." }\end{array}$ & $\begin{array}{l}\text { Most suitable } \\
\text { for a } \\
\text { multidiscipli- } \\
\text { nary audience. }\end{array}$ \\
\hline $\begin{array}{l}\text { Serious Game } \\
\text { Design and } \\
\text { Development }\end{array}$ & $\begin{array}{l}\text { https://iversity.org/en } \\
\text { courses/serious- } \\
\text { game-design }\end{array}$ & $\begin{array}{l}\text { "Students will go } \\
\text { through all the steps of } \\
\text { the development of a } \\
\text { Serious Educational } \\
\text { Game." }\end{array}$ & Ended 2015. \\
\hline $\begin{array}{l}\text { Design and } \\
\text { Development } \\
\text { of Games for } \\
\text { Learning }\end{array}$ & $\begin{array}{l}\underline{\text { https://www.edx.org/ }} \\
\underline{\text { course/design- }} \\
\underline{\text { development-games- }} \\
\underline{\text { learning-mitx-11- }} \\
\underline{127 x-0}\end{array}$ & $\begin{array}{l}\text { "We will hear from } \\
\text { experts working on many } \\
\text { aspects of learning } \\
\text { games from design to } \\
\text { development to } \\
\text { implementation." }\end{array}$ & $\begin{array}{l}\text { No verified } \\
\text { certificate } \\
\text { available. }\end{array}$ \\
\hline
\end{tabular}

Table 1 describes the three courses that were offered as online courses on SGs and considered to suite for non-game development audiences.

\subsection{Planning the Course}

In planning the online course in higher education (HE) level on SGs, a Carpe Diem Learning design method (see Salmon et al., 2014) was applied. This method was chosen because it is effective, creative, student-centred, and multidisciplinary teamwork was needed in planning the brand-new course. The process started with the guidance of the facilitator. There were six steps in the process (see Salmon et al., 2014):

1. Write the blueprint - envision the future.

2. Make a storyboard - become a designer.

3. Build your prototype online.

4. Check reality.

5. Review and adjust.

6. Plan your next step.

First, HE healthcare and sports bachelor's students were selected as the pilot course's primary target group. While writing the blueprint, the mission for the online course from the students' viewpoint was defined. The mission was set (see Table 2), and the look and feel of the course was described as creative, playful, professional, and engaging. After that, it was time to define what was supposed to be achieved after the course: "By the end of the course, I will be able to generate ideas concerning SGs, and I will know how to go further with them." Then, it was explored how to assess these outcomes and how to fulfil 
T. Korhonen, T. Ravelin \& R. Halonen: Developing an E-learning Course on Serious Games: A Multidisciplinary Approach

the promises made. For example, to be engaging, course methods included peerreviewing and rapid feedback. For assessing knowledge, there were online tests and a game evaluation assignment. The learning objectives of the course are described in Table 2 .

Table 2: The SGs course plan.

\begin{tabular}{|l|l|}
\hline Target group & $\begin{array}{l}\text { Online course on SGs } \\
\text { Primary: Higher Education healthcare and sports students } \\
\text { (Bachelor's level). } \\
\text { Secondary: All interested students and professionals }\end{array}$ \\
\hline The mission & $\begin{array}{l}\text { "I have courage to generate SG ideas and go further with my } \\
\text { ideas." }\end{array}$ \\
\hline Learning objectives & $\begin{array}{l}\text { Student will.. } \\
\text { get familiar with the concept and the development } \\
\text { process of serious games and gamification. } \\
\text { find out about the owner's role in a serious games } \\
\text { development project and learn a variety of innovation } \\
\text { methods for developing your game ideas. } \\
\text { learn to understand the technological perspective behind } \\
\text { gamified solutions. }\end{array}$ \\
\hline The methods & Gamification, peer discussions, peer-reviewing, online tests. \\
\hline
\end{tabular}

During the storyboard phase, the progression of the course was planned. The ways how gamification (defined as "using game design elements in non-game contexts" (see Deterding et al., 2011)) can be used to motivate students. One gamified element was proceeding in LMS from level to level (see Fig. 3). Each level included a certain assignment to complete before proceeding to the next level. Social interaction was emphasised during the course via peer discussions included in the assignments. The delivery of the course was both synchronous and asynchronous. At first, the timetable for proceeding from level to level was set, but it was considered to limit the students. Thus it was possible to proceed at one's own pace but via the level structure of the course, the social interaction was ensured.

\subsection{Content of the Course}

The course content was selected so that students with a limited background in and knowledge of games could participate. The learning material covered videos, PowerPoint presentations with audio, web pages, and scientific and popular articles. The course could be studied independently, online, within the assigned timeframe, and the tasks required collaboration with peer students. The assignments consisted of group discussions, playing games, a competence test, a game evaluation, and an assignment where students 
brainstormed their own SGs. A literature research task was added to the final implementation. The basic course structure with levels is illustrated in Figure 3.

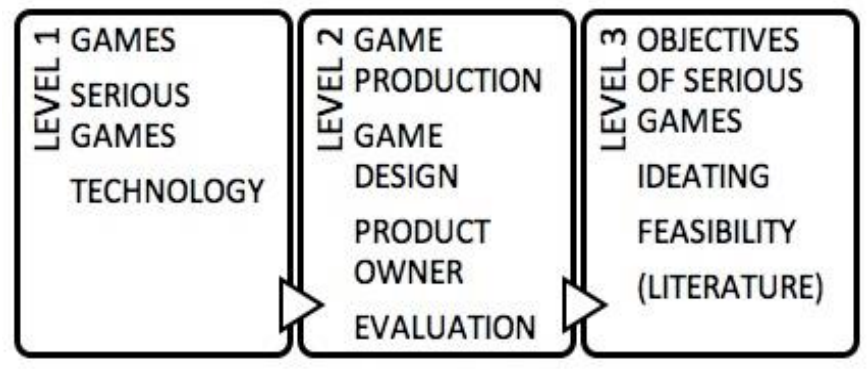

Figure 3: Basic Structure of the Planned E-learning Course on SGs.

Level 1 started with the definition of general terms related to games, gamification, and SGs. After the completion of an assignment at level 1, level 2 opened automatically. This part of the course consisted of deeper information about games, such as genres, different types of SGs, and game design and production, as well as how to act as a product owner or client in a SG project. In level 3, the content was more oriented toward SGs, especially regarding attitudes and motivation.

\subsection{Iterative Course Development: Implementation, Observation, and Reflection}

The course was built to the Moodle LMS and it proceeded from level to level according our storyboard. Some parts, like visual layout, were not possible to realise in the Moodle. The total study period was planned to be 2.5 months for 3 ECTS (European Credit Transfer and Accumulation System), which equates 81 hours of HE students' work. The teachers' role was active at the beginning, in the middle, and at the end of the course. Before releasing the course, feedback was given by colleagues, and some changes were made.

The course had three implementations with observation and reflection phases. The first implementation of the course in Finnish was realised as open online studies during summer 2016. A part of the material was delivered in English. The professional backgrounds of 21 enrolled students varied greatly. Among participants, there were, for example, nursing, healthcare and sports students, librarians, IT specialists, teachers, and physiotherapists. Eight of the students completed the course on time (38\%, see Fig. 5), and 15 of them gave feedback, which is described in Table 3.

The second implementation of the course was realised between autumn 2016 and winter 2017 on a new learning platform, a Moodle-based LMS, especially designed to serve open education and cross-institutional studies. This course was targeted to a multidisciplinary audience. In total, 28 participants signed up, and 25 of them completed the course $(89 \%$, see Fig. 5). 
T. Korhonen, T. Ravelin \& R. Halonen: Developing an E-learning Course on Serious Games: A Multidisciplinary Approach

Table 3: SGs course implementations during 2016-2017.

\begin{tabular}{|c|c|c|c|c|}
\hline $\begin{array}{l}\text { Implemen- } \\
\text { tation of the } \\
\text { open online } \\
\text { course on } \\
\text { SGs (ECTS) }\end{array}$ & $\begin{array}{l}\text { Parti- } \\
\text { cipants } \\
\text { enrol- } \\
\text { led (no.) }\end{array}$ & $\begin{array}{l}\text { Participants } \\
\text { that finished } \\
\text { the course/ } \\
\text { passed }(\%)\end{array}$ & Positive feedback & $\begin{array}{l}\text { Critical feedback and } \\
\text { suggestions }\end{array}$ \\
\hline $\begin{array}{l}\text { Summer } \\
2016,(3 \\
\text { ECTS })\end{array}$ & 21 & $38 \%$ & $\begin{array}{l}\text { Peer discussions } \\
\text { Positive attitude towards } \\
\text { gaming } \\
\text { Finding new interesting } \\
\text { games to play } \\
\text { Clear and beneficial } \\
\text { assignments }\end{array}$ & $\begin{array}{l}\text { Communication } \\
\text { Outlook of the course } \\
\text { Need for more teacher } \\
\text { support } \\
\text { Activating interventions } \\
\text { Clearer and } \\
\text { approachable materials }\end{array}$ \\
\hline $\begin{array}{l}\text { Autumn } 2016 \\
\text { - Winter } 2017 \\
\text { (3 ECTS) }\end{array}$ & 28 & $89 \%$ & Course content & $\begin{array}{l}\text { More material in } \\
\text { Finnish. } \\
\text { Better timetabling of } \\
\text { assignments } \\
\text { A chat channel for real- } \\
\text { time peer } \\
\text { communication } \\
\text { The removal of } \\
\text { technical problems }\end{array}$ \\
\hline $\begin{array}{l}\text { Summer } 2017 \\
\text { (local } \\
\text { language) } \\
\text { (5 ECTS) }\end{array}$ & 156 & $29.5 \%$ & $\begin{array}{l}\text { Suitable for studying SGs } \\
\text { The assignments were } \\
\text { considered useful and } \\
\text { helpful } \\
\text { Peer work }\end{array}$ & $\begin{array}{l}\text { Guided tutorial } \\
\text { More feedback from the } \\
\text { teachers } \\
\text { Peer work } \\
\text { Gamified tools } \\
\text { (collecting coins) }\end{array}$ \\
\hline $\begin{array}{l}\text { Summer } 2017 \\
\text { (English) } \\
\text { (5 ECTS) } \\
\end{array}$ & 102 & $11.8 \%$ & Suitable for studying SGs & $\begin{array}{l}\text { Clearer information } \\
\text { about assignments } \\
\text { Help in technical issues }\end{array}$ \\
\hline
\end{tabular}

Table 3 sums up the main feedback from the course. The course was stated to be suitable for studying SGs and the positive attitude related to gaming was mentioned as one positive remark. Students needed more clearer instructions in some assignments, better or free timetable of assignments, and reported technical problems specially at the beginning of the course. Teacher's presence was wished (activating interventions, feedback, support) even when it had been stated that the course was independently studied on-line course. Peer discussions were seen both as positive and negative issue.

A few game companies were interviewed and their viewpoint regarding the content required to educate adequate $\mathrm{SG}$ experts were asked. Certain main categories emerged from companies' responses: game technology; business-related topics, such as budgeting, sales, and marketing; service design; and understanding the entire nature of game development, which involves multidisciplinary teamwork. The course was refined to bring closer subject area and game development experts. 
The third implementation (see Fig. 4) took place during summer 2017, one course in Finnish and one in English. The course was designed as a self-learning, online course, and it was upgraded to 5 ECTS. It was refined based on the feedback given by former course students, especially related to timetabling and technical problems. A chat for peer communication was also created. Besides the existing level structure, new tools for gamification were added: a progress bar that showed the activity completion, a top active student list and a stash that meant collectable coins (six) hidden in the course area.

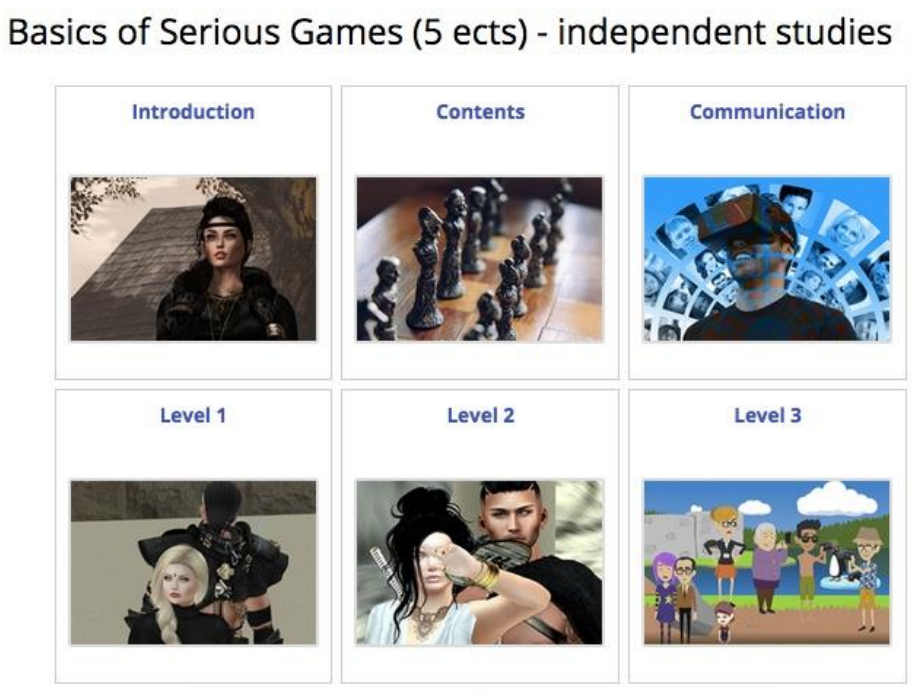

Figure 4: Final course on new LMS (part of the user interface).

In total, 156 participants signed up to participate in the course in Finnish, and 46 (29.5\%) of them completed the course (see Fig. 5). As well, 102 students joined the English course, and $12(11.8 \%)$ of them finished with an accepted grade. Some of the students signed up to take both of courses and completed only one of them. Because courses were offered freely in national level for HE or professionals without any fee as summer studies, the interruption rate was quite high. Table 3 describes the main feedback. 
T. Korhonen, T. Ravelin \& R. Halonen: Developing an E-learning Course on Serious Games: A Multidisciplinary Approach

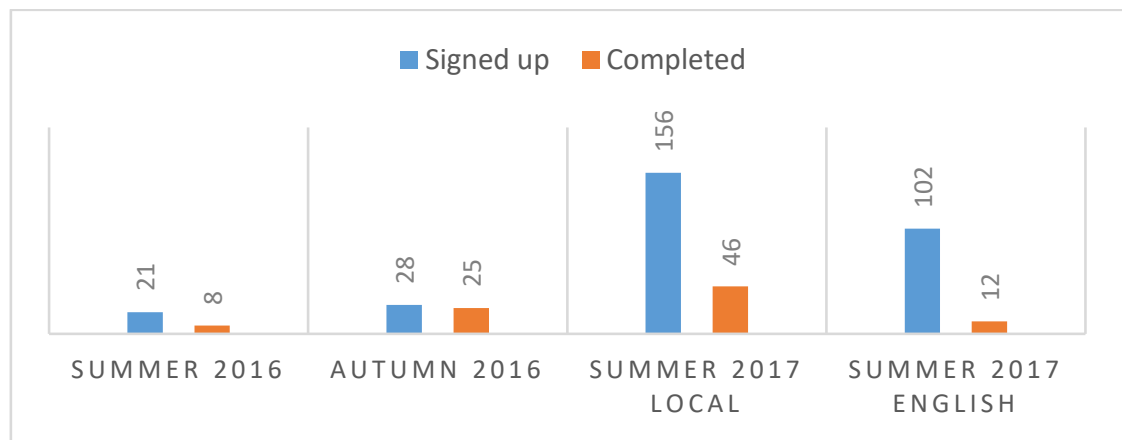

Figure 5: Participants, that signed up and completed SGs courses in 2016-17.

\section{$5 \quad$ Discussion and Conclusions}

The purpose of the study was to identify how to build an e-learning course on SGs for multidisciplinary students. Earlier knowledge revealed the need for experience in several disciplines, including understanding behavioural (Baranowski et al., 2013), pedagogical (Durairaj \& Umar, 2015; Shaikh et al., 2017), and expertise (Kemppainen et al., 2014) related aspects. Additional challenges were related to the online environment (see Gomez et al., 2010) and using two languages.

To answer the main research question related to developing an e-learning course and to identify a way to educate multidisciplinary audiences about SGs, an action research project was initiated. The solution was sought by first analysing state-of-the-art knowledge and then planning the course. After that, content for the course was defined, and finally, an iterative approach was applied in the development of the three implementations.

Social constructivism theory was used as a pedagogical approach in designing an elearning course on SGs. The social interactions and dialogue between students were based on peer discussions and chats. Knowledge construction in a social setting was one of the main ideas of the course, and crowdsourcing was used by taking advantage of the multidisciplinary knowledge of the students. Social constructivism theory emphasises the importance of feedback, and in this course, the feedback method was peer feedback. The idea of intentional learning was the basis in planning the independent conduct of the course (Durairaj \& Umar, 2015; Shaikh et al., 2017).

The heterogeneous student group online brought up new challenges for the content: different backgrounds and starting levels on the topic of SGs had to be considered. This gap was covered by maintaining joint interest and goals in learning (see Shaikh et al., 2017).

The feedback from students revealed that the discussions were considered fruitful, though some activating interventions were proposed. Positive attitude changes toward gaming 
were reported. Assignments and material received mixed feedback: some of the students felt they were clear and beneficial, while some needed more structured content and help with assignments. A teacher's presence, such as for support, communication, and feedback, was expected, even though the courses were noted to be studied independently. These findings support the suggestions of Yunus and Salim (2008).

As a summary, the study revealed nine attention points:

1. Carpe Diem method (Salmon et al., 2014) supports multidisciplinary work in planning an online course.

2. The schedule in online course must be set but not too tight. An asynchronous model for online courses gives students more freedom (see also Duraij \& Umar, 2015).

3. Assignments and timetables have to be as clear as possible.

4. Peer discussions are an important part of e-learning, and they support social constructivism theory (Durairaj \& Umar, 2015; Shaikh et al., 2017; Marsh \& Ketterer, 2005). Enabling chat supports discussions.

5. Peer evaluation does not replace the feedback and presence of a teacher. Using too much peer work can be seen as forced.

6. Students who are more advanced in the topic can utilise their expertise in discussions and propose new ideas and materials to their peers.

7. Gamification integrated into course structure, such as levels and a progress bar, can be considered motivating, if they work well. Gamification without connection to course structure (e.g. collecting coins) can be seen as irritating.

8. Even in an independent online course, a teacher is needed: to help with technical issues, to clarify assignments if needed, and to activate discussions (see Tait, 2014).

9. The iterative development and incremental improvement of an online course according to feedback is a good approach (see Fig. 6).

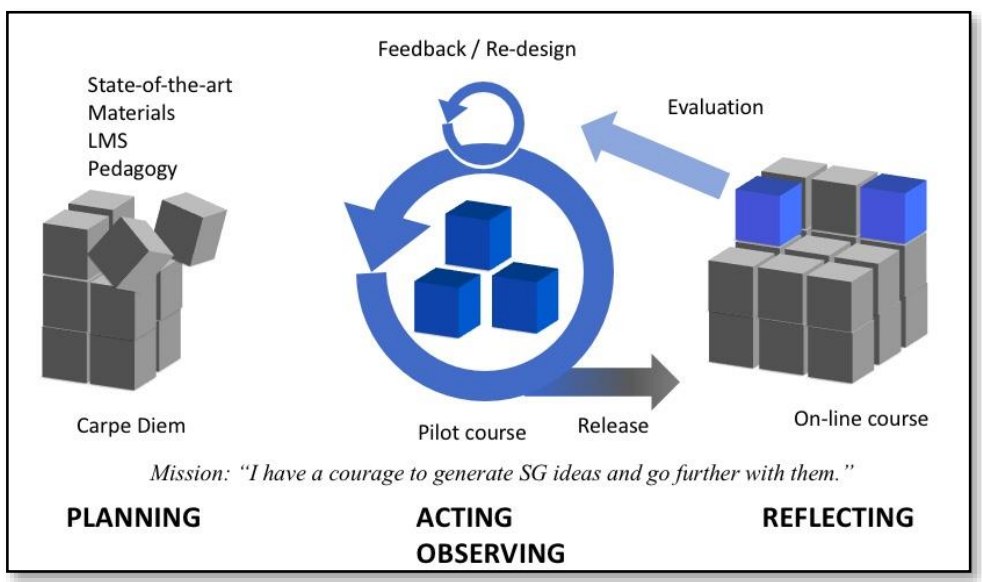

Figure 6: Phases in action research study on developing an e-learning course on SGs. 
T. Korhonen, T. Ravelin \& R. Halonen: Developing an E-learning Course on Serious Games: A Multidisciplinary Approach

The current work continues within the multidisciplinary education on SGs. One expansion will be courses targeted to specific professional areas, such as nursing and healthcare. In these holistic courses on SGs, the developed online course will work as a background material, and it will be completed with hands-on SG prototyping workshops.

\section{Acknowledgments}

The research for this paper was financially supported by the European Social Fund (ESF) and Niilo Helander Foundation. The developed courses can be found from www.segabu.fi

\section{References}

Backlund P., Engström H., Berg Marklund B. \& M. Toftedahl. (2017). Developing games for nonleisure contexts: Identification of challenges and research gaps. In 2017 9th International Conference on Virtual Worlds and Games for Serious Applications (VS-Games), Athens, 2017, pp. 15-22. doi: 10.1109/VS-GAMES.2017.8055806

Baranowski T., Buday R., Thompson D., Lyons E.J., Shirong Lu A. \& Baranowski J. (2013). Developing Games for Health Behavior Change: Getting Started. Games for Health Journal: Research, Development, and Clinical Applications 2(4), 183-190.

Baskerville R. (1999). Investigating Information Systems with Action Research. Communications of the Association for Information Systems: Vol. 2, Article 19. Available at: http://aisel.aisnet.org/cais/vol2/iss1/19

Baskerville R. \& Myers M. (2004). Special issue on action research in information systems: Making research relevant to practice. Foreword. MIS Quarterly 28(3), 329-335.

Coghlan D. \& Brannic T. (2014). Doing action research in your own organization. 4th edition, Sage Publishing.

Deterding S., Dixon D., Khaled R., \& Nacke L. (2011). From game design elements to gamefulness: defining "gamification". In Proceedings of the 15th International Academic MindTrek Conference: Envisioning Future Media Environments (MindTrek '11). ACM, New York, NY, USA, 9-15. doi: https://doi.org/10.1145/2181037.2181040

De Troyer O. (2017). Towards effective serious games. In 9th International Conference on Virtual Worlds and Games for Serious Applications (VS-Games). Athens, pp. 284-289. doi: 10.1109/VS-GAMES.2017.8056615

Djaouti D., Alvarez J., Jessel J.-P. \& Rampnoux O. (2011). Origins of Serious Games. Serious Games and Edutainment Applications. Springer-Verlag London Limited.

Durairaj K. and Umar I.N. (2015). A proposed conceptual framework in measuring social interaction and knowledge construction level in asynchronous forum among university students. Procedia - Social and Behavioral Sciences, Volume 176, pp. 451-457. https://doi.org/10.1016/j.sbspro.2015.01.496

Gomez E.A., Wu D., \& K. Passerini K. (2010). Computer-supported team-based learning: The impact of motivation, enjoyment and team contributions on learning outcomes. Computers \& Education 55(1), 379-390. https://doi.org/10.1016/j.compedu.2010.02.003

Kali Y., Levin-Peled R. \& Dori Y.J. (2009). The role of design-principles in designing courses that promote collaborative learning in higher-education. Computers in Human Behavior 25(5), 1067-1078. https://doi.org/10.1016/j.chb.2009.01.006

Kemppainen J., T. Korhonen T. \& T. Ravelin T. (2014). Developing Health Games Requires Multidisciplinary Expertise. Finnish Journal of eHealth and eWelfare 6(4), 200-205. Available at: https://journal.fi/finjehew/article/view/48213 


\section{T. Korhonen, T. Ravelin \& R. Halonen: Developing an E-learning Course on Serious Games: A} Multidisciplinary Approach

Korhonen T. \& Halonen R. (2017a). On the development of serious games in the health sector - A case study of a serious game tool to improve life management skills in the young. In Proceedings of the 19th International Conference on Enterprise Information Systems (ICEIS 2017), Volume 3, pp. 135-142. doi: 10.5220/0006331001350142

Korhonen T. \& Halonen R. (2017b). Serious games in healthcare: A systematic mapping study. In Proceedings of the 30th Bled eConference, Bled, Slovenia, pp. 349-368. https://doi.org/10.18690/978-961-286-043-1.25

Korhonen T., Halonen R., Ravelin T., J. Kemppainen J. \& Koskela K. (2017). A multidisciplinary approach to serious games development in the health sector. In Proceedings of the 11th Mediterranean Conference on Information Systems, Genoa, Italy. MCIS 2017 Proceedings. 30. Available at: http://aisel.aisnet.org/mcis2017/30

Lewin K. (1946). Action research and minority problems. Journal of Social Issues 2(4), 34-46. 10.1111/j.1540-4560.1946.tb02295.x

Loh C.S., Sheng Y., \& Ifenthaler D. (2015). Serious games analytics: Theoretical framework. In Serious games analytics: Methodologies for Performance Measurement, Assessment, and Improvement, 3-29. New York, NY: Springer International Publishing. 10.1007/978-3-31905834-4_1

Marsh G.E. \& Ketterer J.J. (2005). Situating the Zone of Proximal Development. Online Journal of Distance Learning Administration, VIII(II).

Nancarrow S.A., Booth A., Ariss S., Smith T., Enderby P., \& Roots A. (2013). Ten principles of good interdisciplinary team work. Human Resources for Health, 11:19. http://doi.org/10.1186/1478-4491-11-19

Onah D.F.O., Sinclair J. \& Boyatt R. (2014). Dropout rates of massive open online courses : behavioural patterns. In 6th International Conference on Education and New Learning Technologies, Barcelona, Spain. Published in: EDULEARN14 Proceedings pp. 5825-5834.

Ricciardi F. \& De Paolis L.T.D. (2014). A comprehensive review of serious games in health professions. International Journal of Computer Games Technology Vol. 2014, Article ID 787968, 11 pages. http://dx.doi.org/10.1155/2014/787968

Ryan R.M., Rigby S. \& Przybylski A. (2006). The Motivational Pull of Video Games: A SelfDetermination Theory Approach. Motivation and Emotion 30(4), 344-360. http://dx.doi.org/10.1007/s11031-006-9051-8

Salmon G., Gregory J., Dona K.L. \& Ross B. (2014). Experiental online development for education: The example of the Carpe Diem MOOC. British Journal of Educational Technology 46(3), 542556. http://dx.doi.org/10.1111/bjet.12256

Salmon G. \& Wright P. (2014). Transforming Future Teaching through Carpe Diem, Learning Design. Education Sciences 4(1), 52-63. doi:10.3390/educsci4010052.

Shaikh U.U., Umari U., Karim S. \& Asif Z. (2017). Re-Thinking Vygotsky: Applying Social Constructivism to Asynchronous Online Courses utilizing the Power of Crowdsourcing. In Proceedings of the 21st Pacific Asia Conference on Information Systems, Langkawi, Malaysia. PACIS 2017 Proceedings, 233. Available at: http://aisel.aisnet.org/pacis2017/233

Susi T., Johannesson M. \& Backlund P. (2007). Serious Games: An Overview. Technical Report HS-IKI-TR-07-001. Available at: http://his.divaportal.org/smash/get/diva2:2416/FULLTEXT01.pdf

Tait A. (2014). From place to virtual space: Reconfiguring student support for distance and elearning in the digital age. Open Praxis 6(1), 5-16. http://dx.doi.org/10.5944/openpraxis.6.1.102

Yunus Y. \& Salim J. (2008). Framework for the evaluation of e-learning in Malaysian Public Sector from the pedagogical perspective. In Proceedings of the International Symposium on Information Technology (ITSim), Vol. 3, 8 pages. IEEE. 
186 | $31^{\text {ST }}$ Bled eConference: Digital Transformation: MEeting the ChallengeS

JunE 17 - 20, 2018, BLED, SLOVENIA, CONFERENCE PROCEEDINGS

T. Korhonen, T. Ravelin \& R. Halonen: Developing an E-learning Course on Serious Games: A Multidisciplinary Approach

Zyda M. (2005). From visual simulation to virtual reality to games. IEEE Computer 38(9), 25-32. https://doi.org/10.1109/MC.2005.297 


\title{
An Explorative Study Into Situational Artefact Construction in Business Rules Management
}

\author{
SAM LEEWIS, KoEN SMIT \& MARTIJN ZOET
}

\begin{abstract}
The implementation of software products is a time-consuming activity and requires specific expertise to be completed successfully. This is especially the case in research fields where there is no or little tool support available, such as Business Rules Management (BRM) and Business Rules Management Solutions (BRMS). Tool support is essential to successfully guide the organizational implementation of a BRMS. Motivated by the diversity of organizational structures and their BRMS implementation contexts, we design a situational-aware framework for the organizational implementation of BRMS. The framework is based on the theory of situational artefact construction. Using situational artefact construction, we study 13 BRMS implementation cases distributed over the financial and public sectors in the Netherlands. Based on the results of the cases analysed we present a framework with three main artefacts that are a stepping-stone towards further research on situational implementation methodology in the BRM field.
\end{abstract}

Keywords: • Business Rules Management • Business Rules Management Solution • Situational Artefact Construction •

CorRespondence AdDress: Sam Leewis, Digital Smart Services, HU University of Applied Sciences Utrecht, Nijenoord 1, 3552 AS Utrecht, The Netherlands, e-mail: sam.leewis@hu.nl. Koen Smit, Digital Smart Services, HU University of Applied Sciences Utrecht, Nijenoord 1, 3552 AS Utrecht, The Netherlands, e-mail: koen.smit@hu.nl. Martijn Zoet, Optimizing KnowledgeIntensive Business Processes, Zuyd University of Applied Sciencess, Ligne 1, 6131 MT Sittard, The Netherlands, e-mail: martijn.zoet@zuyd.nl 
S. Leewis, K. Smit \& M. Zoet: An Explorative Study Into Situational Artefact Construction in

Business Rules Management

An increasing amount of laws and regulations and the demand for IT automation raises the need for handling business rules in a proper way (Boyer \& Mili, 2011; Graham, 2007). This occurs since the introduction of the separation of concerns principle (van der Aalst, 1998) and Business Rules Management (BRM) (Boyer \& Mili, 2011; Morgan, 2002; Ross, 2013). The fact that organizations increasingly consider business rules as a separate 'concern' to manage in combination with the growing amount of business rules results in organizations seeking a solution to manage their business rules. We refer to such a solution as a Business Rules Management Solution (BRMS). A BRMS can be implemented to manage the elicitated, designed, specified, and deployed business rules (Nelson, Rariden, Sen, \& Texas, 2008; Smit \& Zoet, 2016; Taylor, 2011; Zoet \& Versendaal, 2013)

In the field of information systems, the domain of Business Rules Management (BRM) is a relatively young subject of study and gained the interest from researchers the past several years (Zoet, 2014). This is especially the case for the organizational implementation of a BRMS (Nelson, Peterson, Rariden, \& Sen, 2010).

This study focuses on the latest one motivated by the significant difference in scientific contributions for organizational implementations support of BRMS compared to technical implementations support (Nelson et al., 2010; Zoet, 2014). Therefore, the researchers intend to answer the following research question: "How to develop a framework that supports the organisational implementation of a business rules management solution?"

In this research, we adopt the situational artefact construction technique (Hevner, March, Park, \& Ram, 2004; Winter, 2011a, 2011b) to answer this research question and design a framework. The framework involves three main artefacts 1) the BRMS analysis tool to extract the building blocks of a BRMS; 2) the BRMS construction process, which analyses the identified design problems and problem classes in order to elicit design situations and design factors; and 3) the BRMS metamodel to facilitate the instantiation of the elicited data from the BRMS analysis tool and BRMS construction process.

Situational artefact construction is applied in other research fields such as software product management (Bekkers, van de Weerd, Brinkkemper, \& Mahieu, 2008; van de Weerd, 2009), and business process management (Bucher \& Winter, 2010; Ravesteyn \& Jansen, 2009). The BRM research field lacks this type of research and therefore this research is of an explorative nature. In this study, the developed BRMS framework is validated with 13 BRMS implementation cases from the financial and the public industries in the Netherlands. Additional validation of framework feasibility is conducted by analysing the elicited data, specifying design situations and design factors, and instantiating the BRMS metamodel. Therefore, the main contribution of this paper is of twofold; 1) the BRMS implementation framework is described, and 2) the BRMS implementation framework is applied to the 13 BRMS implementation cases. 
The remainder of the paper is structured as follows: First, the BRMS in the context of the related work is discussed. Second, this is followed by the research methods utilized for this study. Next, the BRMS implementation framework is proposed as a proof of concept together with its major elements. Subsequently, the BRMS implementation framework is validated through expert interviews. Lastly, the conclusions are provided that can be drawn from the results, together with a critical view of the results of this study followed by possible future research.

\section{$2 \quad$ Related Work}

Business rules describe the state of affairs of what the business demands (Business Rules Group, 2003; Morgan, 2002). For this research, we adopt the definition of a business rule by Morgan (2002): ' 'a statement that defines or constrains some aspect of the business. It is intended to assert business structure or to control or influence the behaviour of the business.",

To improve the grip on business rules, organizations search for a controlled approach to support the management of business rules, this approach is called BRM (Boyer \& Mili, 2011; Ross, 2003). BRM is defined as: ' 'a systematic and controlled approach to get a grip on business decisions and business logic to support the elicitation, design specification, verification, validation, deployment, execution, governance, and monitoring of both business decisions and business logic" (Smit, Zoet, \& Berkhout, 2017). The BRM capabilities are part of an approach or method with the goal to translate sources like law and regulations or internal policies into products or services. Smit and Zoet (2016) explains in their work, in detail, the specifics of the BRM capabilities. Earlier mentioned capabilities of BRM need to be supported by some sort of IT solution. A specific IT solution in the context of BRM is a BRMS (Graham, 2007).

A BRMS is ''a configuration of capabilities which supports the Elicitation, Design, Specification, Verification, Validation, Deployment, Execution, Monitoring, and Governance of business rules" (Leewis, Smit, \& Zoet, 2018). Each implementation of a BRMS is one capability or a combination of the nine Capabilities (as shown in Figure 1) which an organization can configure for their own purposes to create, implement, and manage business rules (Smit \& Zoet, 2016; Zoet, 2014; Zoet \& Versendaal, 2013). The technical implementation of a BRMS is covered extensively in researchArnott \& Pervan, 2014; Rosca \& Wild, 2002; Zoet, 2014). Analysis of the literature on organizational implementation of a BRMS results in no relevant related work (Nelson et al., 2008; Zoet, 2014). Previously conducted research has shown that different BRMSs have a common Design Problem (Aier, Riege, \& Winter, 2008; Baumöl, 2005; Bucher \& Winter, 2010; Klesse \& Winter, 2007). A common Design Problem is the difference between the goal state and the current state of a system, a BRMS, and is an indication that common Problem Classes, for which Design Solution can be created, exists (Winter, 2011b). Winter, (2011b) depicts a Problem Class as a set of comparable Design Problems. A Problem Space is a collection of multiple Problem Classes. An instantiation of a Problem Class in a specific organization is defined as a Design Solution. Specific for the BRMS Problem 
S. Leewis, K. Smit \& M. Zoet: An Explorative Study Into Situational Artefact Construction in Business Rules Management

Space, the Design Solution is a specific configuration of the earlier mentioned nine BRMS Capabilities (Smit \& Zoet, 2016; Zoet \& Versendaal, 2013). Every configuration of BRMS Capabilities is influenced by certain factors, so-called Situational Factors. Situational Factors describe the context in which an information system artefact or organization has to operate in a way that the deployed artefact fits the context of the environment.

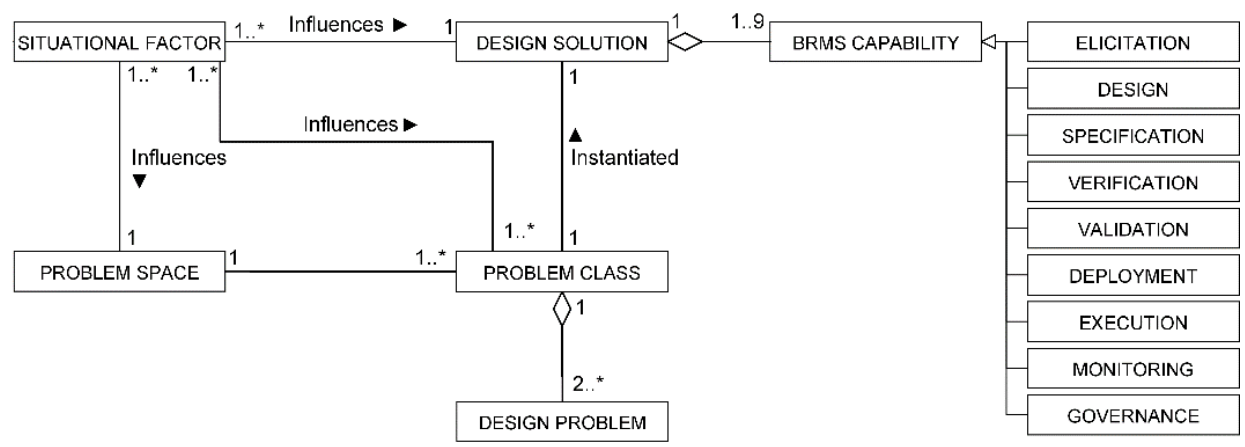

Figure 1: BRMS problem space

Research identifying situational factors is conducted in the situational method engineering research field (Brinkkemper, 1996; Karlsson, Ågerfalk, \& Hjalmarsson, 2001; Rolland \& Prakash, 1996; van Slooten \& Hodes, 1996), with specific applications in software product management (Bekkers et al., 2008; van de Weerd, 2009), and business process management (Bucher \& Winter, 2010; Ravesteyn \& Jansen, 2009).

The BRMS implementation framework can be constructed as a situational artefact, which ensures that the framework could be adapted to solve different design problems within a problem class (Winter, 2011b). Winter (2011b) proposed in his work a technique to create situational artefacts, which is used as a guideline in this study.

\section{$3 \quad$ Research Method}

The Situational artefact construction technique from Winter (2011a, 2011b) is used as a research method to create a situational artefact (the BRMS implementation framework) to support BRMS implementations. To structure and ground the research activities, Hevner's Design Science Research is used (Hevner et al., 2004). The situational artefact construction technique exists of eleven steps and is adapted specifically on situational artefact construction in the BRMS domain, adaptation is needed because the focus of the initial situational artefact construction is on a generic level in the context of software development. In the BRM research field, a more qualitative approach is needed because the field lacks standards as a base to perform quantitative analysis on. The original process is focused on creating a situational artefact for any given research field. This technique embodies the following steps: 1) Initial demarcation of the design problem class, 2) 
Identification of potential contingency factors, 3) Field study analysis of design problems in practice, 4) Refining specifications of the design problem class, 5) Calculation of ultrametric distances, 6) Determination of a useful level of generality, 7) Specification of design situations, 8) Identifying characterizing design factors, 9) Linking design factors to related design problems, 10) Deriving elementary problem-solving actions, and 11) Deriving method configuration rules (Winter, 2011a, 2011b). The eleven situational artefact construction steps are elaborated further in the paper with data used from a running experiment (Leewis, Smit, \& Zoet, 2018; Leewis, Smit, Zoet, \& Berkhout, 2018). The 13 gathered BRMS implementation cases were used as input for creating the BRMS implementation framework and are explained in detail in the work of Leewis, Smit, Zoet, et al. (2018).

\section{$4 \quad$ BRMS Implementation Framework}

This section describes the elements of the developed BRMS implementation framework, which are all focussed on supporting organizational implementations of a BRMS. The first element of the BRMS implementation framework is the BRMS analysis tool. This tool is mainly focussed to gather BRMS implementation cases and is explained in detail in the work of Leewis, Smit, \& Zoet (2018). The second element of the BRMS implementation framework is the BRMS construction process. This process aims at analysing data from the BRMS analysis tool and to use this data for the design of the BRMS metamodel. Hence, the third element of the BRMS implementation framework is the BRMS metamodel where all the elements important for a BRMS implementation are specified. The situational artefact construction method from Winter (Winter, 2011a, 2011b) is used as a guideline to create a situational artefact in the BRM domain.

\subsection{Initial demarcation of the design problem class}

Discovery of the BRM problem space is needed to identify the existing knowledge on creating a situational artefact in the field of BRM. The goal of this step is to discover concepts in the field of BRM to support the creation of a situational artefact. A literature review is conducted to create an overview of the existing body of knowledge. This step is covered extensively in the work of Leewis, Smit, \& Zoet (2018).

\subsection{Identification of potential contingency factors}

The literature review is also used for the identification of potential contingency factors. This literature review resulted in the creation of the BRMS analysis tool which purpose is to gather and analyse BRMS implementation cases (Leewis, Smit, \& Zoet, 2018). Additional interviews are conducted with members of the BRM community to validate the discovered problem classes, and the contingency factors included in BRMS analysis tool. The BRMS analysis tool is constructed by combining knowledge derived from literature and knowledge derived from interviews with BRM experts. 
$31^{\text {ST }}$ Bled eConference: Digital TRANSFormation: MeEting THE Challenges June 17 - 20, 2018, BLED, SLOVENIA, CONFERENCE PROCEEDINGS

S. Leewis, K. Smit \& M. Zoet: An Explorative Study Into Situational Artefact Construction in Business Rules Management

\subsection{Field study analysis of design problems in practice}

The goal of this field study is to collect data on different BRMS implementations. The set of implementations used in the work of Leewis, Smit, Zoet, et al. (2018) are used in this study to create the BRMS implementation framework. These collections of different implementations can create an overview of clusters of situational factors that influence the different problem classes in the business rules management solution problem space. Thereby, creating a situational artefact for each situation. To reduce a large number of contingency factors into a relevant set of design factors, a qualitative approach of a Principal Component Analysis (PCA) was performed. The main goal of a PCA is reducing a list of potential contingency factors to relevant design factors (Abdi \& Williams, 2010; Jolliffe, 2002).

\subsection{Refining specifications of the design problem class}

The previous three steps focus on creating a relevant list of design factors. This step focusses on specifying and refining the design factors into more specific and refined design problem classes. The design problem classes identified in earlier steps should be refined more to ensure define the degree of homogeneity of the solutions. This will result in the excluding of "outlier" design solutions and thereby ensuring the degree of homogeneity. The problem classes identified are: 1) Elicitation, 2) Design, 3) Specification, 4) Verification, 5) Validation, 6) Deployment, 7) Execution, 8) Monitoring, and 9) Governance. The problem classes are identical with the BRM capabilities (Smit \& Zoet, 2016). The next step will cluster the solutions into relevant clusters which are representative towards all the gathered BRMS implementation cases.

\subsection{Calculation of ultra-metric distances}

Problem classes can be divided into a number of generic design situations depending on the degree of generality. The generic design situations are the specified solutions depending on the number of clusters selected in the problem class. Based on the Euclidian distance, the similarity (or dissimilarity) of two design solutions within a problem class can be represented by an ultrametric-distance (Deza \& Deza, 2016). The cases and their distances are visualized using a tree-like graph. Ultrametric-distances can be visualized by a graph whose $\mathrm{Y}$-axis represents generality and whose $\mathrm{X}$-axis represents the set of observed cases. The similarity or dissimilarity of two design solutions (or more) corresponds to the generality level of their relation. If the similarity is high, their relation is represented on a lower level of generality (Winter, 2011a). Figure 2 shows the ultrametric distance of the elicitation problem class (because of space constraints only the elicitation capability is included in this paper). 


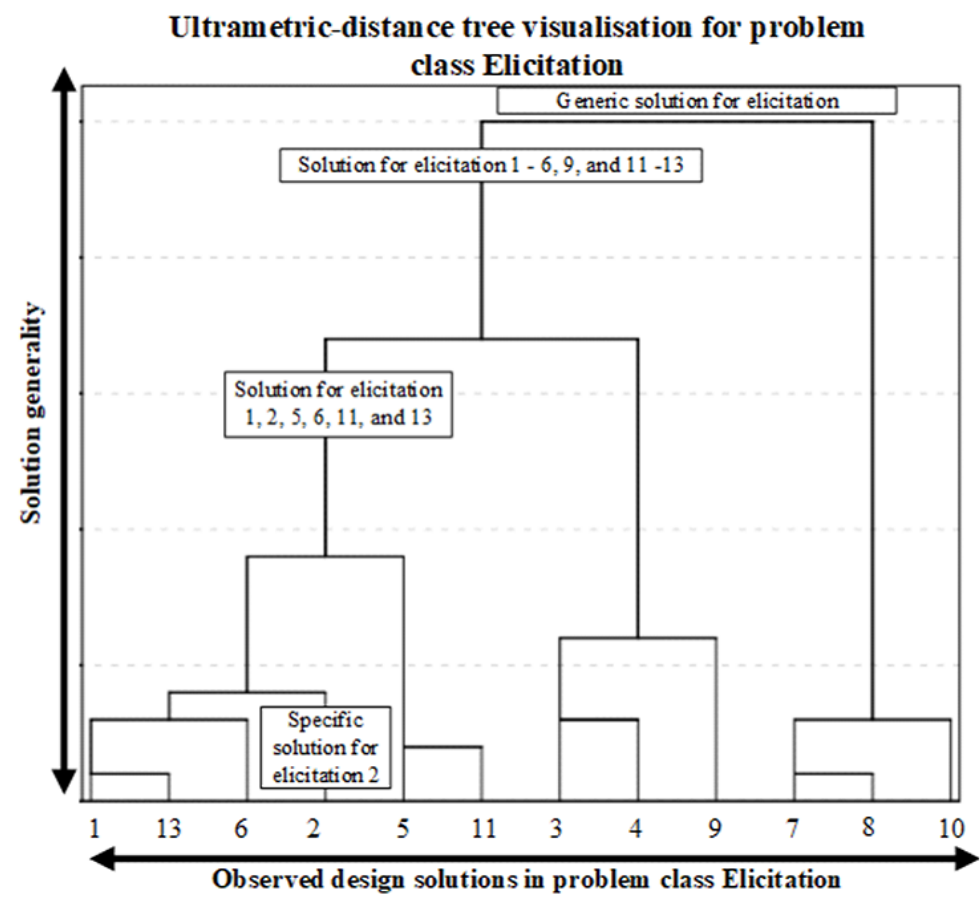

Figure 2: Ultrametric-distance visualization

This graph contains 12 solutions (elicitation 1-11, and 13) for the elicitation problem class. Important to mention is that the sample includes 13 implementations, only case 12 didn't implement the elicitation problems class. Therefore, case 12 is not included in the analysis of the problem class. Observed case 2 is represented by its own specific solution, Elicitation solution 2. This level of generality is the same for the other observed cases on this level which are represented by their own specific solution. Observed case 1, 2, 5, 6, 11 and, 13 are represented by a more generic solution, Elicitation solution 1, 2, 5, 6, 11 and, 13. The observed cases $1-6,9$, and 11, 13 are represented by an even more generic solution, Elicitation solution $1-6,9$, and 11, 13. At the top level, the generic solution contains all the observed cases and is the most generic representation towards all the observed cases.

\subsection{Determination of level of generality}

This step will focus on what level of generality is needed to have optimal cluster consistency in a design solution. In order to not only visualize the generic solutions (as shown in Figure 2), but also specify the generic solutions (as shown in Figure 3), k-means cluster analyses are applied to the BRMS implementation cases. Thereby, determining the optimal number of clusters for the design solution. An optimal number of clusters is 
31 $1^{\text {ST }}$ Bled EConference: Digital Transformation: MeEting the Challenges June 17 - 20, 2018, BLED, SLOVENIA, CONFERENCE PROCEEDINGS

S. Leewis, K. Smit \& M. Zoet: An Explorative Study Into Situational Artefact Construction in Business Rules Management

where the number of clusters has the lowest error sum, as shown in Figure 3. The k-mean cluster analyses were conducted with the minimum amount of cluster and the maximum amount of cluster possible in the problem class. These cluster analyses were conducted for each problem class because the possibility exists that a solution contains only one capability (problem class). For each solution the error total which is calculated from the distances of all implementation cases to the centre of their clusters. Based on this total, the so-called elbow criterion is used (Everitt, Landau, Leese, \& Stahl, 2011; Hardle \& Simar, 2007; Winter, 2011b). The elbow criterion indicates which increased number of clusters leads to an above-average improvement in the error sum. The error sum is plotted on the $y$-axis, and the number of clusters is plotted on the y-axis, an elbow arises for the 4-cluster, 7-cluster and 10-cluster solution as shown in Figure 3. The 4-cluster solution is selected due to the lowest error sum compared to the 7- and 10-cluster solutions.

\section{Elicitation}

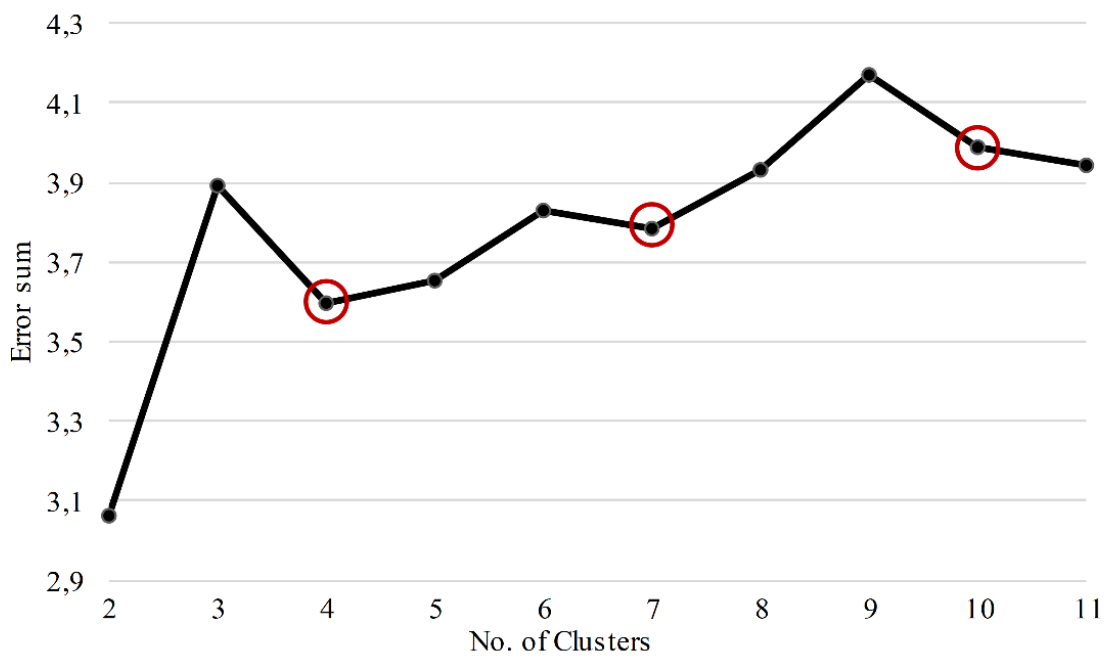

Figure 3: Elicitation problem class elbow criterion

\subsection{Specification of design situations}

The design situations need more than only a formal definition (which is done by the ultrametric-distance calculation) but also need semantic interpretation (i.e. by specifying the design problem types). The ultrametric-distances are used, for semantically specifying the design situations. The problem classes are specified into their preferred cluster consistency. The Elicitation problem class is specified into a 4-cluster solution, and these four different clusters are specified using a mean comparison analysis. This analysis aims at specifying the design situations. The goal of this is to create different design situations, as shown, for example, in Table 1. Thereby, aiming at what is the exact reason why these design solutions are created into a cluster. Elements of all the design situations in a 
problem class which were identical were excluded from the design situation specification. Specifying design situations aims at showing factors which differentiate a design situation from another design situation, this will not help when identical elements do not differentiate a design situation from another design situation. These factors need to be characterized further.

Table 1: Elicitation design situations

\begin{tabular}{|c|c|}
\hline Design Situation 1: & Design Situation 2: \\
\hline Public sector focussed & Public sector focussed \\
\hline Organisations with $2001-5000$ employees & Organisations with more than 5000 employees \\
\hline Organisation implementation focussed & Line of business implementation focussed \\
\hline Fully manual elicitation focussed (autonomy level 1) & $\begin{array}{l}\text { Capability is supported with a complete set of action } \\
\text { alternatives (autonomy level 2) }\end{array}$ \\
\hline Database data is used for elicitating business rules & $\begin{array}{l}\text { No database data is used for elicitating business } \\
\text { rules }\end{array}$ \\
\hline $\begin{array}{l}\text { Outcome of the capability is not a relevant set of selected } \\
\text { sources }\end{array}$ & $\begin{array}{l}\text { Outcome of the capability is a relevant set of } \\
\text { selected sources }\end{array}$ \\
\hline Scenario analysis is conducted & No scenario analys is is conducted \\
\hline Design Situation 3: & Design Situation 4: \\
\hline Financial sector focus sed & Financial sector focussed \\
\hline Organis ations with more than 5000 employees & Organisations with $251-500$ employees \\
\hline Line of business implementation focussed & Line of business implementation focussed \\
\hline $\begin{array}{l}\text { Capability is supported with a narrowed down set of action } \\
\text { alternatives (autonomy level 3) }\end{array}$ & Fully manual elicitation focussed (autonomy level 1) \\
\hline No database data is used for elicitating business rules & $\begin{array}{l}\text { No database data is used for elicitating business } \\
\text { rules }\end{array}$ \\
\hline $\begin{array}{l}\text { Outcome of the capability is not a relevant set of selected } \\
\text { sources }\end{array}$ & $\begin{array}{l}\text { Outcome of the capability is a relevant set of } \\
\text { selected sources }\end{array}$ \\
\hline No scenario analysis is conducted & Scenario analysis is conducted \\
\hline
\end{tabular}

\subsection{Identifying characterizing design factors}

Each design situation consists of characterizing design factors and needs to be specified further. Every design factor has different values, these values influence the characterization of the design factor and thereby the design situation. An example of a design factor: Capability leader, which characterizes the department that is in the lead regarding the specific capability, shown in Table 2 . The value of this capability could be one of the following departments: IT, the business, or a central IT/business group. Characterizing design factors are defined together with their values and related problem classes. Characterizing design factors define the design situations, but there are also design factors which do not characterize design situations but are still important for solving design problems. Non-characterizing design factors (ID\# 42 and 43 in Table 2) are not specifically solving design problems but are directly related to the problem classes, which in their turn solve certain design problems. The reason that these design factors are non-characterizing is that for all the design situations in a problem class these design factors have the same value. 
S. Leewis, K. Smit \& M. Zoet: An Explorative Study Into Situational Artefact Construction in Business Rules Management

Table 2: Examples (non)-characterizing design factors

\begin{tabular}{|c|c|c|c|c|}
\hline ID: & Problem class: & Design factor: & Value: & Description: \\
\hline 4 & \begin{tabular}{|l|} 
Design, Specification, \\
Deployment, Execution, \\
Monitoring, and \\
Governance
\end{tabular} & $\begin{array}{l}\text { Capability } \\
\text { leader }\end{array}$ & $\begin{array}{l}\text { IT, Business, or } \\
\text { Central } \\
\text { IT/Business } \\
\text { group }\end{array}$ & $\begin{array}{l}\text { The Capability leader design } \\
\text { factor characterizes which } \\
\text { department is in the lead of the } \\
\text { specific capability }\end{array}$ \\
\hline 5 & All & $\begin{array}{l}\text { Capability } \\
\text { autonomy }\end{array}$ & $\begin{array}{l}\text { Autonomy level } \\
1-10\end{array}$ & $\begin{array}{l}\text { The capability autonomy } \\
\text { characterises the level of } \\
\text { autonomy on which the } \\
\text { capability in the BRMS } \\
\text { operates }\end{array}$ \\
\hline 6 & Elicitation & \begin{tabular}{|l|} 
Elicitation \\
source (Data) \\
\end{tabular} & Yes/No & $\begin{array}{l}\text { Database data is used as a } \\
\text { source for elicitation. }\end{array}$ \\
\hline 7 & Elicitation & $\begin{array}{l}\text { Relevant set of } \\
\text { selected } \\
\text { sources }\end{array}$ & Yes/No & $\begin{array}{l}\text { The output of elicitation is a } \\
\text { relevant set of selected } \\
\text { sources. }\end{array}$ \\
\hline 8 & Elicitation & $\begin{array}{l}\text { Scenario } \\
\text { analysis }\end{array}$ & Yes/No & $\begin{array}{l}\text { Scenario analysis is used } \\
\text { during elicitation. }\end{array}$ \\
\hline 42 & Elicitation & \begin{tabular}{|l|} 
Elicitation \\
source \\
(People) \\
\end{tabular} & Yes & $\begin{array}{l}\text { People are used as a source } \\
\text { for elicitation. }\end{array}$ \\
\hline 43 & Elicitation & \begin{tabular}{|l} 
Elicitation \\
source \\
(Documents)
\end{tabular} & Yes & $\begin{array}{l}\text { Documents are used as a } \\
\text { source for elicitation. }\end{array}$ \\
\hline
\end{tabular}

\subsection{Linking design factors to related design problems}

The characterized design factors described in the earlier sections need to be linked to the 24 proposed design problems which are discovered in the work of (Leewis, Smit, Zoet, et al., 2018) and adopted for this study. All earlier conducted steps analyse the existing design solutions. These design solutions are cases of successful BRMS implementations. These design solutions were created with a certain purpose, solving an existing problem, and therefore the design factors can be qualitatively interpreted and linked to the known design problems, as shown in Table 3. The 24 known design problems were mapped against the identified and characterized design factors. An example of this is the design problem 'Increase Elicitation productivity', which could be positively impacted by letting the system take over some tasks. The design factors solving this design problem are: (capability autonomy), using data as a source when eliciting, the output of elicitation is a relevant set of selected sources (which could be reused), performing a scenario analysis which is based on business scenarios. In short, a certain combination of characterized design factors could solve a certain design problem. 
Table 3: Examples Design factors linked to Design Problems

\begin{tabular}{|l|l|l|l|l|l|l|l|l|l|l|l|l|l|l|l|l|l|l|l|l|l|l|l|l|l|}
\hline $\begin{array}{l}\text { Design } \\
\text { problems: }\end{array}$ & $\mathbf{5}$ & $\mathbf{6}$ & $\mathbf{7}$ & $\mathbf{8}$ & $\mathbf{9}$ & $\mathbf{1 0}$ & $\mathbf{1 4}$ & $\mathbf{1 6}$ & $\mathbf{2 1}$ & $\mathbf{2 6}$ & $\mathbf{2 7}$ & $\mathbf{2 8}$ & $\mathbf{2 9}$ & $\mathbf{3 0}$ & $\mathbf{3 1}$ & $\mathbf{3 2}$ & $\mathbf{3 3}$ & $\mathbf{3 4}$ & $\mathbf{3 5}$ & $\mathbf{3 6}$ & $\mathbf{3 7}$ & $\mathbf{3 8}$ & $\mathbf{3 9}$ & $\mathbf{4 0}$ & $\mathbf{4 1}$ \\
\hline $\begin{array}{l}\text { Increase } \\
\text { Elicitation } \\
\text { productivity }\end{array}$ & $\mathrm{X}$ & $\mathrm{X}$ & $\mathrm{X}$ & $\mathrm{X}$ & & $\mathrm{X}$ & & & & & & & & & & & & & & & & & \\
\hline $\begin{array}{l}\text { Construct } \\
\text { library of } \\
\text { decisions }\end{array}$
\end{tabular}

\subsection{Deriving elementary problem-solving actions}

The possible next step would be deriving elementary problem-solving actions by comparing design solutions with design problems. Out of these elementary problemsolving actions, method fragments are created. In this research, we make a distinction between two phases. An organization utilizes no BRMS or does utilize a BRMS. This is the same for each observed case, and the road to implementing a BRMS is different for each case. When implementing a BRMS in a specific organization, there is no wrong selection of design factors, only the best fit for a specific organizations situation. Nonetheless, it is still possible to create method fragments to support solving design problems when implementing a BRMS. An example of this is as followed: design problem \#1 low productivity of elicitation, is proposed to be solved with a certain configuration of characterizing design factors. Design problem \#1 could be solved with a combination of the following design factors: \#5 Capability autonomy (and the specific level of autonomy), \#6 Elicitation source (Data), \#7 Relevant set of selected sources, \#8 Scenario analysis, and \#14 Role: Input. Design factor \#5, \#6, \#7, \#8 and \#14 result into method fragment \#2, \#3, \#4, \#5, and \#12. The combination of these design factors and their created method fragments will evolve into a method which could solve design problem \#1 as shown in Figure 4. 
S. Leewis, K. Smit \& M. Zoet: An Explorative Study Into Situational Artefact Construction in Business Rules Management

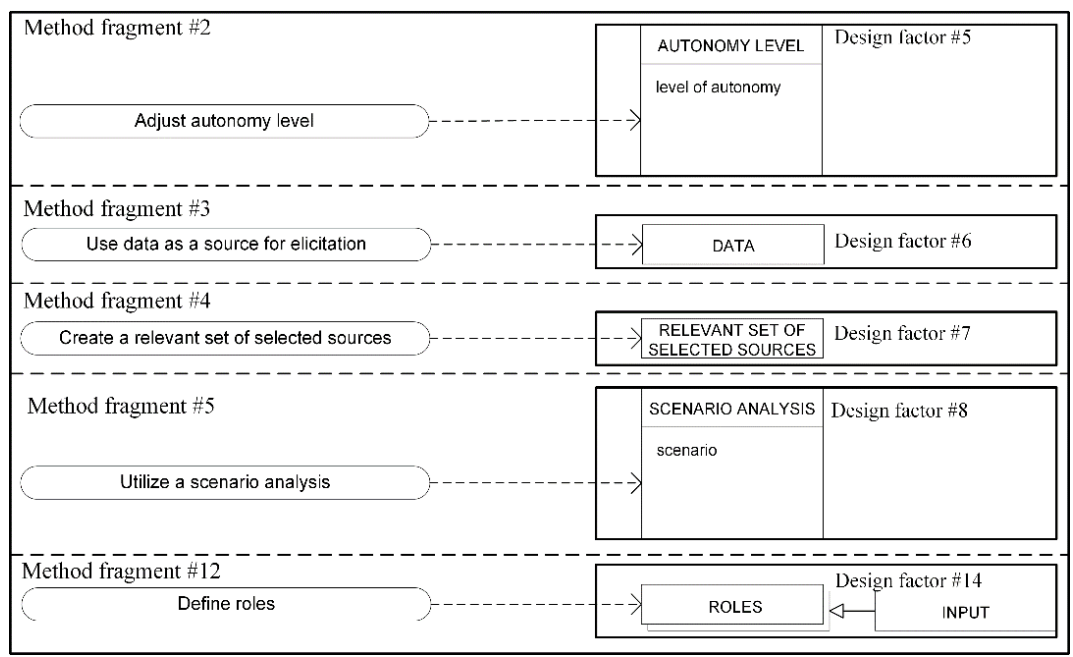

Figure 4: Problem-solving actions

\subsection{Deriving method configuration rules}

Based on the set of identified design problems and specified method fragments, method configuration rules need to be derived. Basically, the (reusable) method fragments identified in the previous section need to be related to their respective design situations. Configuration rules need to be designed which guides the configuration of solutions to solve specific design problems, as shown in Table 4. Merging the method fragments into one super method is not sufficient for solving the design problems. A certain combination of design problems and design factors requires additional information and attention. Therefore, characterizing design factors related to a certain problem class automatically means that a whole problem class (capability) is implemented. It is not possible to only implement certain parts of a problem class, this is because of the dependencies of the solutions. Therefore, the whole problem class is implemented together with the related non-characterizing design factors and the related characterizing design factors. Certain design situations indicate that BRMS implementation cases exist which deliberately did not have a design factor implemented even if this design factor should solve a specific design problem. The configuration of a design situation depends on design factors which identify the type of implementation. The design factors identifying the types of implementations are focused on the sector in which the organization operates, the number of employees working at this organization, and the focus of the implementation. A specific value of these three design factors gives an indication which design situation fits the organization needs. 
Table 4: Method configuration rules

\begin{tabular}{|l|l|}
\hline Design problem: & Implement a method consisting of method fragment: \\
\hline Increase Elicitation productivity & $\mathrm{N} 1, \mathrm{~N} 2$, and \#1 - \#13 \\
\hline Construct library of decisions & $\mathrm{N} 1, \mathrm{~N} 2, \mathrm{~N} 4, \mathrm{~N} 5, \# 1$ - \#13,\#17 - \#21, and \#22 - \#37 \\
\hline Ensure artifact relationship insight & $\mathrm{N} 2, \mathrm{~N} 6, \# 1, \# 2, \# 6-\# 13, \# 24$ - \#36, and \#38 \\
\hline
\end{tabular}

\subsection{BRMS metamodel}

The BRMS metamodel is the result of the BRMS analysis tool and the BRMS construction process. It contains all the identified elements in the BRMS construction process together with their specific values and the relations between these elements. Previous sections resulted in the identification of important elements of a BRMS together with their specific values and are included in the BRMS metamodel, as shown in Figure 5. This metamodel shows the relations between the identified elements with each their specific number present in a BRMS implementation. The BRMS metamodel consists of the identified SITUATIONAL FACTORS: EMPLOYEE RANGE, SECTOR, and IMPLEMENTATION FOCUS, the identified PROBLEM CLASSES: ELICITATION, DESIGN, SPECIFICATION, VERIFICATION, VALIDATION, DEPLOYMENT, EXECUTION, MONITORING, and GOVERNANCE, the number of DESIGN PROBLEMS, METHOD FRAGMENTS, DESIGN FACTORS, and DESIGN SITUATIONS, and together with their relationships. In the future, the BRMS metamodel could be used as a reference model for tools focussed on supporting the implementation of a BRMS.

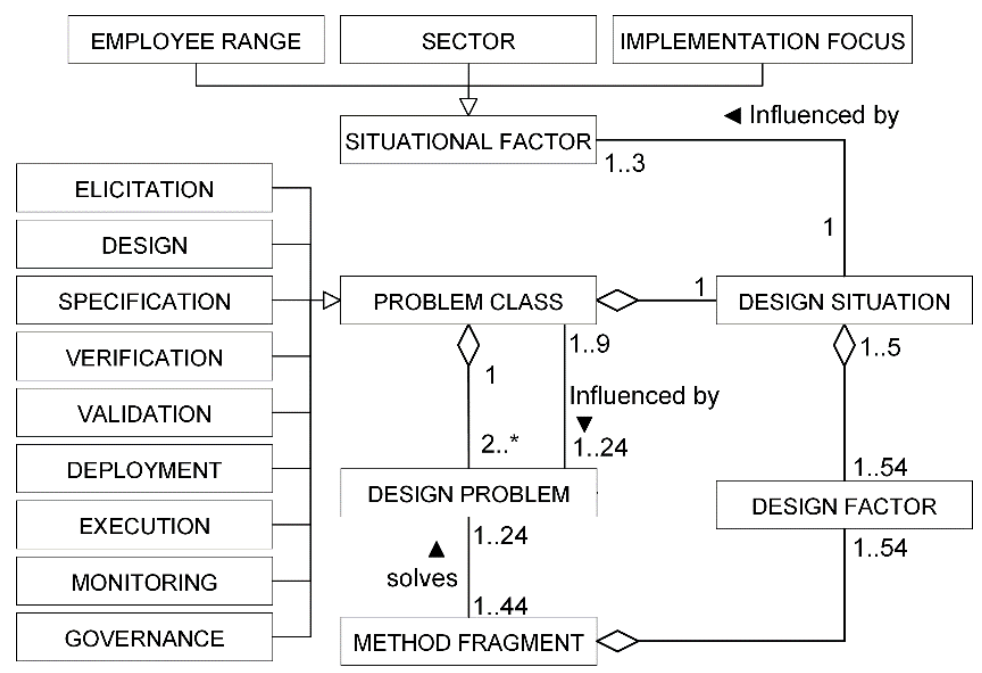

Figure 5: BRMS metamodel 
$31^{\text {ST }}$ Bled eConference: Digital Transformation: MeEting the Challenges June 17 - 20, 2018, Bled, SLOvenia, CONFERENCE PROCEEDINGS

S. Leewis, K. Smit \& M. Zoet: An Explorative Study Into Situational Artefact Construction in

Business Rules Management

5

Validation

When following the initial situational artefact construction technique, one of the first additions made was regarding the validation part of the results, specific with people from practice. The research fields of BRM and BRMS are lacking standardization and therefore comparison, and validation is needed from practice (Nelson et al., 2008; Zoet, 2014). Semi-structured interviews were conducted with the focus on validating the correctness of the BRMS implementation framework and it's containing elements. The same selection is made as with the validation of the BRMS analysis tool (Leewis, Smit, \& Zoet, 2018), which focussed on experts with experience in the BRM and BRMS research field. In total, three experts were interviewed. The first expert is a professor lecturing and performing research in the field of BRM and BRMS. The second expert is a lecturer and $\mathrm{PhD}$ candidate with 6 years of practical and research experience in the field of BRM and BRMS. The third expert is a lecturer with 3 years of practical and research experience on BRMS capabilities. An interview protocol was created for the expert interviews to ensure a structured and consistent line of questioning. The major elements (BRMS analysis tool, BRMS construction process, and BRMS metamodel) of the BRMS framework and the sub-elements (Problem Classes, Design Situations, Method Fragments, and Method Configuration Rules) were proposed to the experts. The experts indicated which possible changes should be made and which elements should be included or excluded. Besides stating whether elements are correct or not correct, examples from practice were asked from the experts to support the validity of the BRMS implementation framework.

6

Conclusions

The goal of this research was to develop a framework to support the implementation of a business rules management solution from an organizational perspective. In order to achieve this goal, we explored the business rules management problem space and its neighbouring fields on techniques to create a framework. We selected the situational artefact construction technique of Winter (Winter, 2011a, 2011b) as a guideline for creating our framework. To be able to create a situational artefact, the state of the art of the BRM and BRMS research field needed to be explored. The state of the art literature review results with regards to the BRMS analysis tool (Leewis, Smit, \& Zoet, 2018) was used as a reference for this study. The 13 BRMS implementations gathered using the BRMS analysis tool (Leewis, Smit, \& Zoet, 2018) were used as input for the BRMS construction process. Analysis of the BRMS implementation data using the BRMS construction process resulted in elements to support the creation of the BRMS implementation framework. The elements identified in the BRMS analysis tool and the BRMS construction process resulted in the BRMS metamodel, as presented in Figure 5. Because of the explorative nature of this study the composition of the BRMS metamodel could change as the maturity of the research field improves.

We believe that creating this framework to support BRMS implementations from an organizational perspective will contribute to the maturity of the BRM and BRMS field, creating a foundation towards other situational artefact research in general and in the 
BRM and BRMS field. However, we believe certain aspects of this research are susceptible for discussion. One of the main limitations of this research is that situational artefact construction relies on large samples $(60+$ BRMS implementation cases at minimum) as input for the data analysis. Our sample consists of only 13 BRMS implementation cases. The initial quantitative PCA was replaced with a qualitative approach due to the fact of the small sample $(n=13)$. Furthermore, the small sample size had an influence on the instantiation of design factors. The number of experts $(n=3)$ used for validation of the BRMS analysis tool and the BRMS implementation framework are identified as a limitation and as a threat to the construct validity, and reliability. Being that the BRMS analysis tool is an important element of creating the BRMS implementation framework. The possibility exists that the experts, if biased, have a higher impact on the validity of the BRMS analysis tool and the BRMS implementation framework when low in numbers.

The BRMS implementation framework is validated by experts in an expert interview. However, to support a real-world BRMS implementation, real-world proof is needed that the framework is valid and correct. Lastly, the exploratory nature of this research concerning the use of situational artefact construction in an immature field. It is still not proven adequately that using this technique is possible in immature fields which could pose threats to validity as well. Based on these points of discussion we argue that future research is needed in the field of situational artefact construction with a focus on immature fields.

\section{References}

Abdi, H., \& Williams, L. J. (2010). Principal component analysis. Wiley Interdisciplinary Reviews: Computational Statistics, 2(4), 433-459. http://doi.org/10.1002/wics.101

Aier, S., Riege, C., \& Winter, R. (2008). Classification of enterprise architecture scenarios - an exploratory analysis. Enterprise Modelling and Information Systems Architectures, 3(1), 1423. http://doi.org/10.18417/emisa.3.1.2

Arnott, D., \& Pervan, G. (2014). A critical analysis of decision support systems research revisited: The rise of design science. Journal of Information Technology, 29(4), 269-293. http://doi.org/10.1057/jit.2014.16

Baumöl, U. (2005). Strategic agility through situational method construction. In Proceedings of EURAM 2005 (European Academy of Management). Munchen.

Bekkers, W., van de Weerd, I., Brinkkemper, S., \& Mahieu, A. (2008). The Influence of Situational Factors in Software Product Management: An Empirical Study. In 2008 Second International Workshop on Software Product Management (pp. 43-50).

Boyer, J., \& Mili, H. (2011). Agile business rule development. Agile Business Rule Development. Berlin, Heidelberg: Springer. http://doi.org/10.1007/978-3-642-19041-4

Brinkkemper, S. (1996). Method engineering: Engineering of information systems development methods and tools. Information and Software Technology, 38(4), 275-280. http://doi.org/10.1016/0950-5849(95)01059-9

Bucher, T., \& Winter, R. (2010). Taxonomy of business process management approaches. In Handbook on Business Process Management (pp. 93-114). New York, NY: Springer.

Business Rules Group. (2003). The Business Rules Manifesto. Retrieved from http://www.businessrulesgroup.org/brmanifesto/BRManifesto.pdf 
$31^{\text {ST }}$ Bled eConference: Digital TRANSFormation: MeEting the Challenges June 17 - 20, 2018, BLED, SLOVENIA, CONFERENCE PROCEEDINGS

S. Leewis, K. Smit \& M. Zoet: An Explorative Study Into Situational Artefact Construction in Business Rules Management

Deza, M. M., \& Deza, E. (2016). Encyclopedia of Distances (4th ed.). Berlin: Springer Berlin Heidelberg. Retrieved from http://www.springer.com/us/book/9783642002342

Everitt, B. S., Landau, S., Leese, M., \& Stahl, D. (2011). Cluster Analysis (5th ed.). London: Wiley. http://doi.org/10.1007/BF00154794

Graham, I. (2007). Business rules management and service oriented architecture a pattern language (1st ed.). Hoboken, NJ: John Wiley \& Sons.

Hardle, W., \& Simar, L. (2007). Applied multivariate statistical analysis (2nd ed.). Berlin: Springer-Verlag. http://doi.org/10.1007/978-3-540-72244-1

Hevner, A. R., March, S. T., Park, J., \& Ram, S. (2004). Design Science in Information Systems Research. MIS Quarterly, 1(28), 75-105.

Jolliffe, I. T. (2002). Principal Component Analysis, Second Edition. Springer Series in Statistics (Vol. 98). New York, NY: Springer Berlin Heidelberg. http://doi.org/10.1007/b98835

Karlsson, F., Ågerfalk, P. J., \& Hjalmarsson, A. (2001). Method configuration with development tracks and generic project types.

Klesse, M., \& Winter, R. (2007). Organizational forms of data warehousing: An explorative analysis. In Proceedings of the 40th Annual Hawaii International Conference on System Sciences (p. 11). http://doi.org/10.1109/HICSS.2007.417

Leewis, S., Smit, K., \& Zoet, M. (2018). A Tool for Analyzing Business Rules Management Solution Implementations. In eKNOW 2018: The Tenth International Conference on Information, Process, and Knowledge Management Performance (pp. 95-100). Rome.

Leewis, S., Smit, K., Zoet, M., \& Berkhout, M. (2018). Solving Problems by Implementing a Business Rules Management System. In eKNOW 2018: The Tenth International Conference on Information, Process, and Knowledge Management Performance (pp. 89-94). Rome.

Morgan, T. (2002). Business Rules and Information Systems: Aligning IT with Business Goals. Boston, MA: Addison-Wesley.

Nelson, M. L., Peterson, J., Rariden, R. L., \& Sen, R. (2010). Transitioning to a business rule management service model: Case studies from the property and casualty insurance industry. Information and Management, 47(1), 30-41. http://doi.org/10.1016/j.im.2009.09.007

Nelson, M. L., Rariden, R. L., Sen, R., \& Texas, A. (2008). A Lifecycle Approach towards Business Rules Management. In 41st Hawaii International Conference on System Sciences (pp. 1-10).

Ravesteyn, P., \& Jansen, S. (2009). A Situational Implementation Method for Business Process Management Systems. In Proceedings of the Fifteenth Americas Conference on Information Systems (AMCIS) (pp. 1-9). San Francisco, CA.

Rolland, C., \& Prakash, N. (1996). A proposal for context-specific method engineering. In Method Engineering (pp. 191-208). Springer.

Rosca, D., \& Wild, C. (2002). Towards a flexible deployment of business rules. Expert Systems with Applications, 23(4), 385-394.

Ross, R. G. (2003). Principles of the business rule approach (1st ed.). Boston, MA: AddisonWesley Professional.

Ross, R. G. (2013). What You Need to Know About Business Rules. Business Rule Concepts, 2331.

Smit, K., \& Zoet, M. (2016). Management control system for business rules management. International Journal on Advances in Systems and Measurements (IARIA), 9(3), 210-219.

Smit, K., Zoet, M., \& Berkhout, M. (2017). Functional Requirements for Business Rules Management Systems. Twenty-Third Americas Conference on Information Systems, 1-10.

Taylor, J. (2011). Decision Management Systems: A Practical Guide to Using Business Rules and Predictive Analytics (1st ed.). Indianapolis, IN: IBM press.

van de Weerd, I. (2009). Advancing in software product management: An incremental method engineering approach. Utrecht: Utrecht University.

van der Aalst, W. M. P. (1998). Three Good reasons for Using a Petri-net-based Workflow 
Management System. In Information and Process Integration in Enterprises: Rethinking Documents (pp. 161-182).

van Slooten, K., \& Hodes, B. (1996). Characterizing IS Development Projects. Proceedings of the IFIP TC8, WG8.1/8.2 Working Conference on Method Engineering, 26-28 August 1996, Atlanta, USA, (1992), 29-44. http://doi.org/10.1007/978-0-387-35080-6_3

Winter, R. (2011a). Design Solution Analysis for the Construction of Situational Design Methods. In Engineering Methods in the Service-Oriented Context (pp. 19-33). Berlin: Springer.

Winter, R. (2011b). Problem analysis for situational artefact construction in information systems. In Emerging themes in information systems and organization studies (pp. 97-113). Berlin: Springer.

Zoet, M. (2014). Methods and Concepts for Business Rules Management. Utrecht: Hogeschool Utrecht.

Zoet, M., \& Versendaal, J. (2013). Business Rules Management Solutions Problem Space: Situational Factors. In Pacific Asia Conference on Information Systems 2013 (PACIS) (p. 247). 


\title{
Digital Transformation in Healthcare - the case of a Chinese Medicine Inquiring System
}

\author{
CATHERINE HAN LIN, DAVID PHILliPS \& \\ NILMINI WICKRAMASINGHE
}

\begin{abstract}
The unique philosophy, diagnosis, and treatment methods of Chinese Medicine (CM) suggest that Health Informatics developments in this domain could benefit by adopting a more suitable synthesis, specifically, incorporating Hegelian and Kantian inquiring systems with the support from Singerian, Lockean, and Leibnizian inquiring systems, and key concepts of Knowledge Management.

Directed by qualitative methodology with Case Study and Design Science methods, the specific CM inquiring system, a Patient Management System (PMS) prototype, was constructed. It is anticipated that this experiment provides suggestions and reference to Health Informatics implementations in CM. This paper focuses on the design and building of the PMS.
\end{abstract}

Keywords: • Health Informatics $\bullet$ Chinese Medicine $\bullet$ Patient Management System • Inquiring System •

CORRESPONDENCE ADDRESS: Catherine Han Lin, Deakin University, Faculty of Health, Burwood Campus, Australia, e-mail: lcatheri@deakin.edu.au. David Phillips, Ph.D., Professor, Deakin University, Faculty of Health, Burwood Campus, Australia, e-mail: david.phillips@deakin.edu.au. Nilmini Wickramasinghe, Ph.D., Professor, Deakin University, Faculty of Health, Burwood Campus, Australia, e-mail: n.wickramasinghe@ deakin.edu.au. 
S. Leewis, K. Smit \& M. Zoet: An Explorative Study Into Situational Artefact Construction in Business Rules Management

Managing hospital and clinical information in the 21 st century has moved away from using paper-based systems to incorporating Health Informatics (Lin et al., 2015b; Wickramasinghe \& Schaffer, 2010). Many system applications, solutions and research projects have been developed, and brought great benefits to the healthcare sector (Buntin et al., 2011; Groves et al., 2016; Wager et al., 2017). For example, Electronic Health Record (EHR) implementations are widespread and used in many hospitals globally (Alharthi et al., 2014; King et al., 2014; Nguyen et al., 2014). Jha et al. (2008) reported that like the United Kingdom, nearly 90\% of General Practitioners (GP) in Australia and New Zealand use EHR (Jha et al., 2008). Hence, it is more important than ever that patient medical information is kept up-to-date and made available for all healthcare workers and providers. This understanding is also supported by the Chinese Medicine Board of Australia (CMBA), who has stated that patient health records are expected to be accurate, legible, clear, and contain sufficient detail so that another practitioner can take over the care of the patient if necessary. Moreover, the Guidelines of Patient Health Records have also stated that patient records must be kept in accordance with the requirements of Australian laws relating to health records information management (CMBA, 2016b). Therefore, Chinese medicine $(\mathrm{CM})$ patient records must support the HealthConnect ${ }^{1}$ Personally Controlled EHR requirements, if required (CMBA, 2016b).

Besides EHR, clinical management systems such as Clinical Knowledge Management (CKM) and Clinical Decision Support (CDS) are also utilised in hospitals and clinics (Berner \& La Lande, 2016; Büchner et al., 2016; Lin et al., 2015b; Varghese et al., 2016; Wager et al., 2017). This is because CKM and CDS, with compiled comprehensive medical knowledge, can provide assistance to various aspects of decision making. However, it has been shown that current Health Informatics developments in CM have limitations (Chan et al., 2015; Lin et al., 2016). There is a lack of a more suitable synthesis support due to CM's unique philosophy, diagnosis, and treatment methods (Chan et al., 2015; Lin et al., 2015b; Yang et al., 2009). Based on Churchman's Inquiring System, Lin et al. proposed that the CM Inquiring System suggests that CM Health Informatics are more Hegelian and Kantian inquiring systems with support from Singerian, Lockean, and Leibnizian inquiring systems, combining with key concepts of Knowledge Management (KM) (Lin et al., 2015a; Lin et al., 2015b).

How can Information Systems/Information Technology (IS/IT) be used to support the delivery of CM? This research examined the potential of using IS/IT tools and techniques in CM clinics, therefore enhancing the delivery of CM practices. Analysing Churchman's Inquiring Systems and KM concepts has led to the proposal of the CM Inquiring system. Constructing the Patient Management System (PMS) became the vehicle for utilising IS/IT and supporting the delivery of CM clinical practices. 


\section{Methodology and Processes}

This research adopted a qualitative methodology with Case Study and Design Science methods. Through a typical Case Study, in-depth insights and understanding of why people do things the way they do can be captured (Harding, 2013; Yin, 2013). In the current research, data were collected via various sources (including visiting case clinics and from interviewees, participants, field notes, government and organizational documentations), which helped analysing and addressing the research question (Barratt et al., 2011). Well known Case Study tools and techniques, such as interview, observation and analysis of documents, were used in assisting data collection and analysis (Barratt et al., 2011). This provided increased reliability of data and a stronger evidence base (Barratt et al., 2011; Silverman, 2016).

In selecting the case clinics, this research used a range of selection criteria which included clinic size, number of patients, number of clinic staff, types of medicine and usage, diagnosis, treatments and dispensing patterns, clinical administration, and government compliance and adherence to standards. Six clinics in Melbourne, Australia were chosen for this study. Collected data were used for studying common themes and assisted in forming the core and foundation of the PMS prototype, which was proposed to answer the research question using a practical approach and providing a tangible solution.

The process of building this prototype was guided by Design Science guidelines and principles (Hevner \& Chatterjee, 2010). Design Science is regarded as an important and legitimate IS research paradigm, and has its roots in the field of engineering and science artefacts (Gregor \& Hevner, 2013; Hevner \& Chatterjee, 2010). Further, March \& Smith outlined four Design Science outputs, specifically constructs, models, methods, and instantiations (March \& Smith, 1995). The construction is related to a problem/solution, which typically involves problem awareness and specification as well as solution proposal (Peffers et al., 2007; Vaishnavi \& Kuechler, 2015; Wieringa, 2014). Models as problem and solution statements express the relationships between construction processes such as problem awareness (this can include the research question, synthesis and/or solution proposal) (Peffers et al., 2007; Vaishnavi \& Kuechler, 2015). Methods are sets of algorithms or guidelines used to direct the developments of the proposed solution (Peffers et al., 2007; Vaishnavi \& Kuechler, 2015). Instantiation is the operationalisation of constructs, models, and methods (Vaishnavi \& Kuechler, 2015). Following these principles, Vaishnavi and Kuechler (2015) provide a general model describing a cycle of process steps, as: 1) awareness of the problem (construction), an initial proposal depicting the existence of a problem that needs to be solved; 2) suggestion and/or solution statements (models and methods), a phase where the formulated proposal is tested if it can be transferred into a tentative design (Vaishnavi \& Kuechler, 2015); 3) development (instantiation), or the building process of the artefact; 4 ) evaluation, where once the artefact is developed, it is evaluated accordingly to the criteria; and 5) conclusion, where the research final results are consolidated and summarised. These processes are repetitive in the sense that each step can lead to refinement and improvement of prior steps through the knowledge flows (Gregor \& Hevner, 2013; Vaishnavi \& Kuechler, 2015; Wieringa, 
S. Leewis, K. Smit \& M. Zoet: An Explorative Study Into Situational Artefact Construction in Business Rules Management

2014). It is through this cycle of evaluations, refinement, and better understanding that new knowledge is produced (Gregor \& Hevner, 2013; Vaishnavi \& Kuechler, 2015; Wieringa, 2014). Based on these processes, PMS development is elaborated in the following sub sections.

\subsection{Problem Awareness and Verification}

The awareness and verification of the problem in this research came from a literature review and case study. First, the traditional, manual form of clinical management is increasingly out-dated, where new computerised systems can facilitate superior practice (Lin et al., 2014; Yang et al., 2009). Second, incorporating new and/or updated international and national CM practice standards, regulations, and registrations (AHPRA, 2014; CMBA, 2012a, 2012b, 2016b; WHO, 2013) can be better achieved through IS/IT (Hu et al., 2013; Lin et al., 2016). Third, because most of the current IS/IT system solutions utilised in CM have been created in China or Asia, there is limited employment and research in this domain in western countries such as Australia (Lin et al., 2014; Lin et al., 2016; Lukman et al., 2007). The case clinics then verified the existence of these problems.

\subsection{Solution Design and Development}

In this process, a solution framework and structure were designed for the research problem tailored to the current CM clinic practices. It is important to "identify and conceptualize current (as-is) business processes and future (to-be) processes" (Rosemann \& vom Brocke, 2015) in any Business Process Management design and modelling. Therefore, in this research analysis was performed at two major phases. First, the existing clinical situation (as-is) was modelled, described, and analysed. Second, areas of improvements were identified for the proposed PMS system structure. The new (to-be) system was also analysed, explained, and modelled. A range of IT tools and techniques were used in designing the system solution. For example, a $\mathrm{UML}^{2}$ Activity Diagram was used to illustrate the CM clinic's daily operations and processes (Rosemann \& vom Brocke, 2015), hence giving important information about functionalities, boundaries, and guidelines for the construction. $\mathrm{ERD}^{3}$ was created presenting the interconnection and management of the PMS system data (Murphy et al., 2016). WAMP ${ }^{4}$, a Window based, open-source web development tool containing a web server with Apache, PHP, and MYSQL were installed, and a sitemap (See Appendix 2 - PMS Website Map) was designed to guide the navigation within the PMS.

\subsection{Evaluation}

The evaluation phase ensures rigour (Rosemann \& vom Brocke, 2015), where the modules of the proposed system are evaluated, and refined by research participants with specification, expectation, and precise scope. For example, a Patient Entry Form (a feature/function of PMS) was tested by entering and retrieving testing data. Changes were made after the testing with participants' feedback. The research went through at least one 
Design Science evaluation cycle and validated the research prototype in terms of functionality, usability, and completeness.

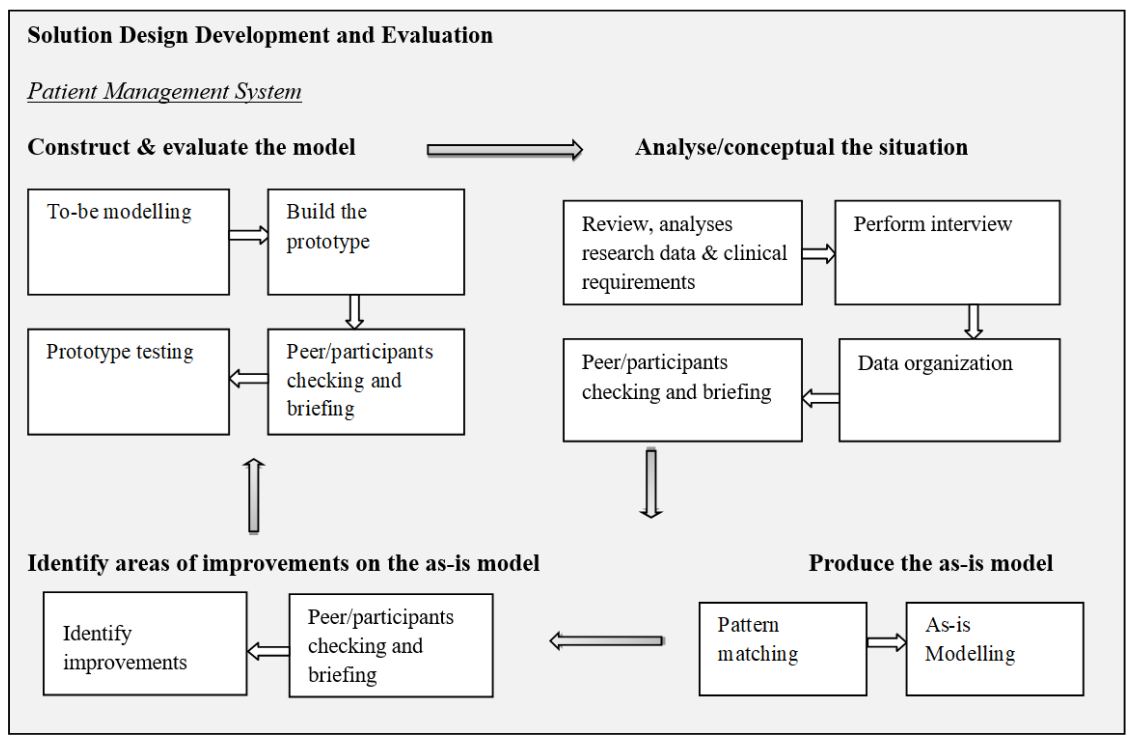

Figure 1: Solution design, development, and evaluation for the PMS.

At the completion of the above processes, research findings and results are summarised. Research contributions, limitations and future studies/approaches are identified and have been documented in a research thesis and publications.

\section{$4 \quad$ PMS Design and Development}

The PMS prototype had the purpose of assisting CM clinics patient management via various system methods, tool, and techniques. Hence, it was necessary to identify and analyse the major activities/processes. Figure 2 illustrates these activities (Appendix 3 lists and explains the symbols that were used in the activity diagrams).

To achieve the idea of user flexibility, multi devices, real-time and fast access of patients' information, the PMS is a web application which allows multi device access (including Desktop or laptop computer, tablet, and mobile phones). 
S. Leewis, K. Smit \& M. Zoet: An Explorative Study Into Situational Artefact Construction in Business Rules Management

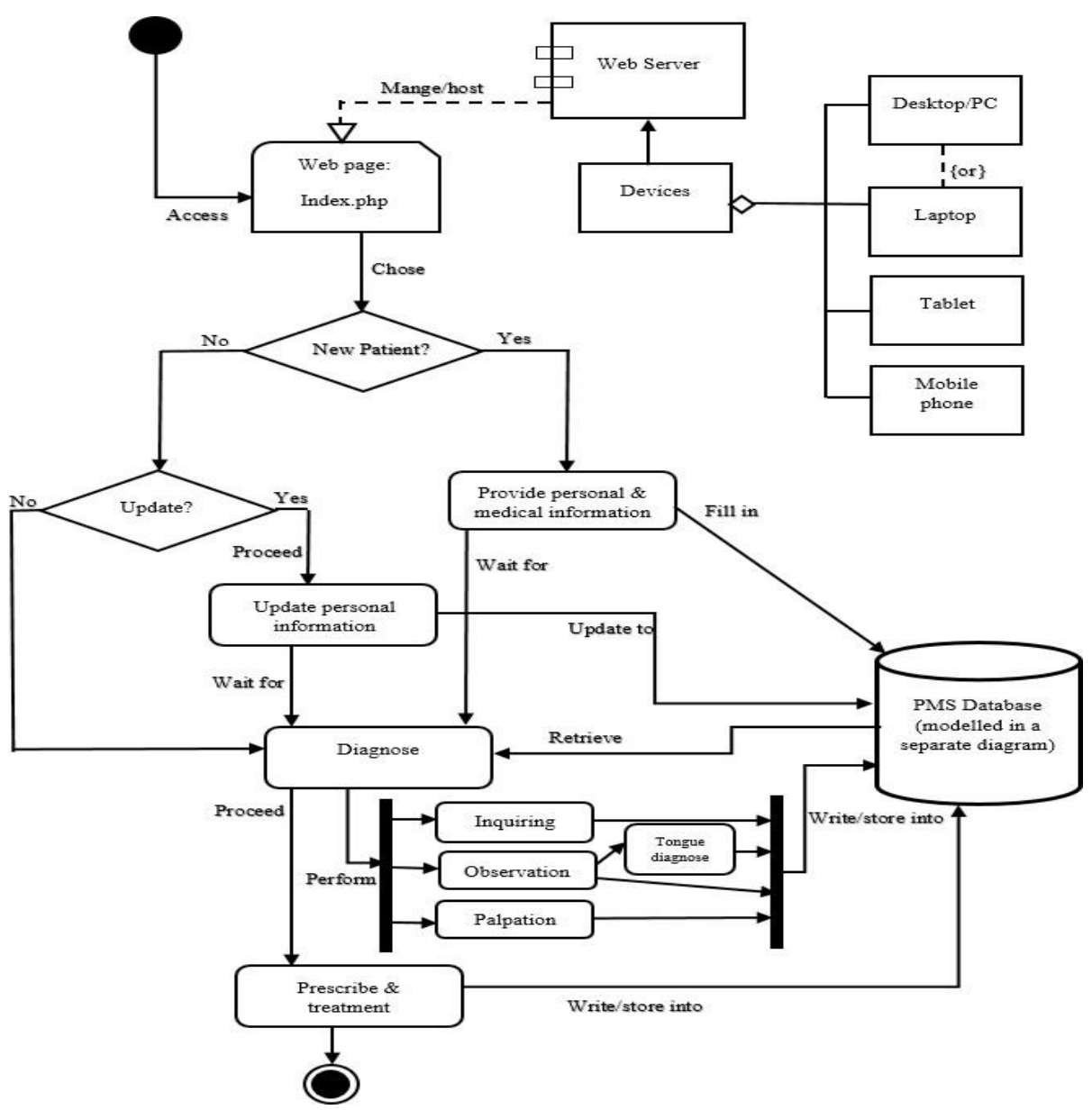

Figure 2: Activity diagram of the proposed PMS design with computerised components.

\subsection{PMS Database}

Tracing through the PMS functions and activities design, information required for each activity was identified. As a result, twelve tables were created (via running $\mathrm{SQL}^{5}$ statements). For example, the User table contains physician and administrator details; therefore, it includes table fields of: UserId, Title, UserFirstName, UserLastName, Sex, DateOfBirth, Password, UserLevel, UserPosition, MaritialStatus, Address, Suburb, PostCode, Mobile, HomePhone, WorkPhone, and Email. UserId was created as the Primary $\mathrm{Key}^{6}$ to ensure that every physician and/or administrator has a unique identification number to avoid duplicate records (for example, one patient's record is saved more than once in the same table), confusing and incorrect information (such as a 
different person with the same name). This Primary Key was used as the Foreign Key ${ }^{7}$ to link/relate the other tables of doctor_patient (UserId was renamed as doctorId in this table), doctor_note (UserId was renamed as doctorId in this table), drag_drop_info, tongue_diagnosis (UserId was renamed as doctorId in this table), and treatment. This linkage/relationship is an essential requirement and concept in Relational Database Design (Coronel \& Morris, 2016), which enables the actions of selecting (for example, search for a particular patient with key words), inserting (for instance, add new physician or patient into the User or Patient table), updating (such as update patient's new mobile phone number) and queries that had been identified in the activity diagrams (for example, update and storing existing patient's personal information in the PMS database).

The tongue_diagnosis table stores the patient's tongue image, with a test image incorporated in the PMS prototype. A real patient's tongue image, however, can be uploaded and used in the future. Further, a portion (left tip of the tongue) of the test image was used to test the PMS tongue diagnosis. This portion image, as a canvas, was subdivided into many mini-parts to obtain accurate and exact location and symptoms of the patient's disorder conditions represented on the tongue image. Each tongue diagnosis on the tongue image is saved into this table for records and retrievals.

The drag_drop_info table stores the symbol combination of the patient's tongue diagnosis. For example, a patient may have a red spot (represented by the symbol $\mathrm{X}$ ) or all $(\mathrm{O}, \mid$, and ) symptoms at the same tongue location (see Appendix 4 for description of each symbol).

The medication table contains the CM herbs provided by the CMBA recommended CM medication list (CMBA, 2016a). This table supports the search function at the prescription generation stage. The comments_table stores CM physician's diagnosis notes of each patient's visit. Finally, the PMS database contains twelve tables, which are: user, patient, doctor_patient, patient_history, tongue_diagnosis, drag_drop_info, doctor_note, medication, clinic, patient_clinic, treatment, and comments_table (see Appendix 1-ERD of PMS Database Tables and Relationships).

\subsection{PMS Diagnose, Prescription and Treatment}

In the PMS, diagnosis is conducted by the CM physicians, as they have the knowledge, expertise, and responsibility. Therefore, this process/activity should be restricted to CM physicians only; hence, authorisation must be implemented. Figure 3 shows that at the login webpage, CM physicians can login with a username and password which were created by the system administrator in advance and stored in the PMS database User table. Then they were retrieved for verification to eliminate false logins. Upon a successful login, the patient details can be searched. The CM physician can update the patient's details if necessary, view the patient's medical histories, start the diagnosis and prescribe treatments. All diagnosis information is then added to the PMS database tables (e.g. doctor_note, tongue_diagnosis, and drag_drop_info) which is hosted by the web server. 
S. Leewis, K. Smit \& M. Zoet: An Explorative Study Into Situational Artefact Construction in Business Rules Management
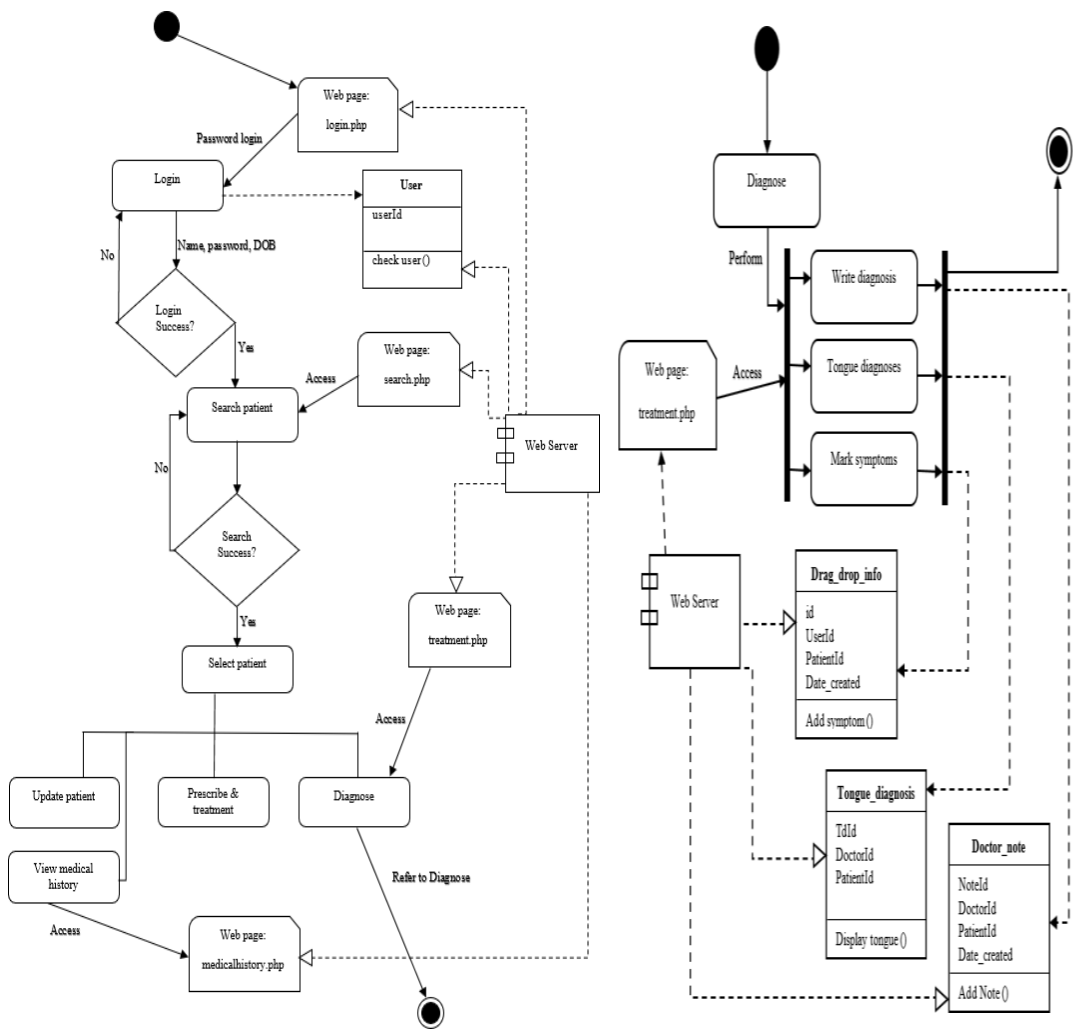

Figure 3: Activity diagram of the PMS physician login and diagnosis functions.

The PMS system diagnosis processes/activities include write diagnosis notes, tongue diagnoses, and mark symptoms. The treatment webpage provides menu links for the CM physicians to write diagnosis notes, diagnose and mark tongue symptoms directly on the graphic interface on the webpage (see Appendix 4 - PMS Tongue Diagnosis). This information and symptoms are then saved into the PMS database tables. When performing tongue diagnosis, the patient's tongue image is displayed on the screen, allowing the physician to mark the symptoms on the exact location on the image using the tool of drag-and-drop with built-in symbols (for example, $\mathrm{X}$ indicate red dots, $\mathrm{O}$ indicate purple dots, | indicate cracks, and indicate teeth mark). This graphic and/or image user interaction design offers the following advantages comparing to the traditional writing (on paper or electronic notes) method: 1) Visual aid. A picture/image can contain many visual $r$ and it can suddenly give the viewer (whoever has the authority to access the image) a clear, whole, focused, visual, and vivid memories of the patient's health problem. 2) Accurate indication. The image is a visual confirmation of the patient's condition that complements the recorded notes. The problem/illness is indicated and located at the exact and accurate location supported with colour, texture, shape, and size. 3) Supporting 
efficiency. This saves time for the physicians and avoids having to write lengthy descriptions of the patient's illness and diagnosis. It is easier for other health workers and the patient to understand their health problem. 4) Provide selection of methods, tools, and techniques for diagnosis, hence supporting the CM Inquiring System that CM Health Informatics is more a Hegelian and Kantian inquiring system (Lin et al., 2015a). This proposal suggests that duality (tacit and explicit, Yin and Yang) and multiplicity (on perspectives, models and techniques, interpretations and explanations) are key components.

In addition to the graphic/image tongue diagnosis, the PMS offers different devices and input methods (keyboard and/or touch screen).

CM prescription and treatments commonly contain herbal medications (Kaptchuk, 2014; Maciocia, 2015). In the PMS herbal medicine prescription and treatments design (Appendix 5 - PMS CM Prescription and Treatment), experienced CM physicians who have mastered the medicine names can write/input the herbal medicine name (in both English and Chinese) in the prescription notes (stored in the comments_table) without assistance. Otherwise, a search of a specific CM herb name can be achieved via the search option with a letter or key word as the parameter to search the CM medication table. According to CMBA's guideline, it is compulsory that all prescriptive CM medicine names are recorded in English (CMBA, 2016b), with Chinese names (either PinYin ${ }^{8}$ or character) being optional and to be added after the English name (CMBA, 2016a). Based on this, the PMS was designed primarily in English. Once the right herb is selected, then it can be written into the prescription notes. It is also common that many herbs are listed and put together as a compound in a single prescription.

The medication table in the PMS database was created with guidance from CMBA's recommended CM medication list (CMBA, 2016a). The PDF list file was downloaded from the official CMBA website, converted to a text file, and imported into the PMS database.

The 'Medical Treatment' link opens the 'Patient Treatment Notes' screen (see Appendix 5 ), where prescription and treatments can be entered directly via keyboard-entry. Both English (mandatory) and Chinese (optional) names can be used here. A physician can search for a CM herb by clicking the 'Search Medicine details' button. This opens the lower panel screen for medicine search. A list of herb names will appear after a letter is typed in the 'Search' box and the 'Go" button clicked. An herb can be selected at the left side under the 'Matched Medicine Details' list table. The 'Details' link at the right side of the table leads to the displaying of the herb details including: English Name, Scientific Name, Pharmaceutical Name, Authorised PinYin Name, Simplified Chinese Characters, Simplified Character Keystrokes, Traditional Chinese Characters, and Chinese Species Name. The patient's herbal prescription is saved once the 'Submit' button is clicked. To view a patient's prescription history, physicians can select the 'Treatment History' link, then select the date under the 'Medical Notes Visit Dates'. 
S. Leewis, K. Smit \& M. Zoet: An Explorative Study Into Situational Artefact Construction in Business Rules Management

\subsection{Other Key PMS Modules}

In addition to the Diagnosis, Prescription, and Treatment models, the PMS contains the following extra modules.

- New Patient Personal and Medical Information Management. In this implementation, a patient is encouraged to answer if they are a new patient to the clinic, and a new patient must provide their personal information and medical history to the clinic. In PMS this can be done while the patient is waiting for a consultation via different devices through the clinic's web address. Some information is important and required by both the clinics and CMBA standards, therefore these fields (such as patient names, date-of-birth, and gender) must be filled before the webpage is processed. Here security checks are performed at the webpage and web server, if any required fields are not filled, the patient is asked to re-enter the missing fields. A new patient is also asked to provide medical history information, by proceeding to the next webpage (reason webpage) and filling in all additional required fields. The same type of security check is performed on required fields for medical history before all the input data are added/written into the PMS database. The patient and patient_history tables then store the new patient's personal and medical history.

- Updating Existing Patient Personal Information. Existing patient information is stored and managed by the PMS database. At the times when this information must be updated/changed due to various reasons (such as change of phone number or address), a patient can do this update via devices accessing the clinic web address. By giving the correct patient's first and last names as well as the date-of-birth, existing patient's information can be searched and retrieved from the PMS database. On the details webpage, update links to each specific patient information (such as update mobile phone number) can be selected, then new/changed information is updated into the PMS database patient table. This process can also be done by the clinical physician and administrator on behalf of the patient, so this feature provides additional efficiency and flexibility to the system.

- Clinic patients and physicians online list. A link is provided to display the list of all patients and/or physicians in the PMS database. This function is available for both the clinic administrator and physician.

- A physician can update their own personal details. The logic behind this activity is identical to the patient's personal information update. However, the only difference is that changed information is updated to different tables.

- Adding a patient link is available for both the administrator and/or physician. This is because at times, new patients may not be able to add themselves to the clinic system for various reasons, such as a disability and/or difficulty in reading and writing. This function/activity is very similar to managing a patient's personal and medical history information.

- Clinic administrators are not permitted to perform diagnosis, prescription, and treatments; therefore, they do not see/access these links and menu options in the PMS. They can, however, add a new physician/doctor into the PMS database. 


\subsection{PMS Evaluation}

The PMS was carefully designed to meet all the requirements after comprehensive analysis of the research domain, scope, and proposed theory. Using different analytical tools and methods, the final designs of the PMS were very thorough, clear, modular, and instructional. Hence, they were easier to build. Despite this, the PMS went through the Design Science evaluation cycle as explained below.

At the design stage, the 'Diagnose' module took several attempts, and the conclusion was that it needed to be broken into further sub-segments to fully embrace all necessary components. This analysis resulted in the modular workflows as shown in Figure 3.

It was decided that a generic tongue image would be useful for documenting tongue diagnosis. During development, it was realised that taking a portion of the tongue image as a smaller sample to work on would be much easier and quicker to implement all the identified functions and features. As from the system performance point of view, the tongue image is a canvas on the webpage, once a portion of a tongue diagnosis is working as desired without any problem, then the concept and technique can be extended and applied to all areas of a tongue. However, targeting and working on a smaller tongue image reduces PMS database capacity, especially tables (such as tongue_diagnosis, drag_drop_info). This in return promotes faster process time at the run time, reduce coding complexity, and downgrade system errors. As a proof-of-concept, it was decided to use the right tip of a tongue image for the tongue diagnosis module in the PMS prototype.

Initial development was made on a local computer with the agreed development tools. After many tests (for each individual module and all combinations), the developed PMS was ready to be released to the research clinic participants and other researchers for further testing. This meant that the PMS had to be hosted on a remote web server where all participants could gain access. For this reason, a webhost service was purchased. Following the same format, all PMS files, modules, and structure were recreated and transferred to the new web server (http://catherinehanlin.net/pms/index.php). During this process, various configuration problems and incompatibilities occurred. For example, database location, connections, and queries were modified with the new web server details and rules. After a number of further testing and development, all problems were rectified, and the prototype were tested again. Furthermore, the researcher created a unique account with user names and password for each participant. Operation instructions and a user menu were sent to all the participants.

After several weeks of participant testing, feedback was received and gathered. Most of the comments and suggestions were very positive. For example, all participants agreed that the design of using real- time, flexible multi-device on entering patient's personal and medical history was very good, as it saved clinic physicians and/or administrators time. The built-in security control (with user login requirements) on PMS was well designed and developed. All participants liked the graphic tongue diagnose module and suggested that it can be used as an excellent resource in teaching trainee CM practitioners. 
S. Leewis, K. Smit \& M. Zoet: An Explorative Study Into Situational Artefact Construction in Business Rules Management

The participants suggested that testing was hampered by just following the written instructions. On that basis, three YouTube videos for assistance to new users were developed:

1. New patient module (to enter a new patient personal and medical history on PMS): https://www.youtube.com/watch?v=kbzwGOQx3uA

2. Existing patient checking and updating personal information (this can be done by the patient themselves after user name and date-of-birth verification and confirmation): https://www.youtube.com/watch?v=tdWrZ8awq8I. These two modules above can be operated via any devices - mobile, tablet, laptop, and desktop.

3. The tongue diagnosis module: https://www.youtube.com/watch?v=4GTDDA0JfmM

\section{Conclusions and Future Development}

This paper has presented the rational for embracing a CM inquiring system grounded in the incorporation of Hegelian and Kantian as well as support from Singerian, Lockean and Leibnizian perspectives. To illustrate, the presented PMS prototype was designed drawing from a Design Science methodology. The PMS prototype is an endeavour created by following the proposed CM Inquiring System theory which extends Churchman's Inquiring System concept to the CM clinical system domain. The PMS was built to incorporate and accommodate multiple methods, tools, technologies, viewpoints and interpretations, knowledge and language duality, and contributions to the research domain. As an initial step, the PMS has its limitations and can be further developed as suggested below.

- The limitation of typical Australian CM case clinics can be extended by studying more case clinics nationally and internationally to accommodate new requirements and updates.

- This research is limited to the development of a patient management solution, with other areas such as Acupuncture Information Management, Finance management, Material/medicine Order and Management to be considered in future iterations.

- The PMS can be further refined with a more sophisticated visual/graphical interface, and security configurations which are tailored to individual healthcare institutes.

This research has many contributions to theory with the development of the inquiring system and practice with the potential of the PMS to digitally transform practice patterns and workflows in the context of Chinese medicine clinics. Future developments will include more specific tailoring of the solution to particular clinics' needs as well as expanding the functionality of the various aspects within the solution. In closing, we note that the paper highlights an opportunity for digital transformation in what has been historically a very traditional domain grounded in ancient practices. 
S. Leewis, K. Smit \& M. Zoet: An Explorative Study Into Situational Artefact Construction in Business Rules Management

\section{References}

AHPRA, C. (2014). Chinese medicine regulation at work in Australia, 2013/14. https://www.ahpra.gov.au/Publications/Corporate-publications/Annual-reports.aspx:

AHPRA Retrieved from http://www.ahpra.gov.au/Publications/Corporatepublications/Annual- reports/Annual-report-archive.aspx.

Alharthi, H., Youssef, A., Radwan, S., Al-Muallim, S., \& Zainab, A.-T. (2014). Physician satisfaction with electronic medical records in a major Saudi Government hospital. Journal of Taibah University Medical Sciences, 9(3), 213-218.

Barratt, M., Choi, T. Y., \& Li, M. (2011). Qualitative case studies in operations management: Trends, research outcomes, and future research implications. Journal of Operations Management, 29(4), 329-342.

Berner, E. S., \& La Lande, T. J. (2016). Overview of clinical decision support systems Clinical decision support systems (pp. 1-17): Springer.

Büchner, V. A., Hinz, V., \& Schreyögg, J. (2016). Health systems: changes in hospital efficiency and profitability. Health care management science, 19(2), 130-143.

Buntin, M. B., Burke, M. F., Hoaglin, M. C., \& Blumenthal, D. (2011). The benefits of health information technology: a review of the recent literature shows predominantly positive results. Health Affairs, 30(3), 464-471.

Chan, K., Hu, X.-Y., Razmovski-Naumovski, V., \& Robinson, N. (2015). Challenges and opportunities of integrating traditional Chinese medicine into mainstream medicine: a review of the current situation. European Journal of Integrative Medicine, 7(1), 67-75.

CMBA. (2012a). Continuing Professional Development. http://www.chinesemedicineboard.gov.au/CodesGuidelines/FAQ/CPD.aspx:

CMBA Retrieved from http://www.chinesemedicineboard.gov.au/Codes-Guidelines/FAQ/CPD.aspx.

CMBA. (2012b). Infection prevention and control guidelines for acupuncture practice. http://www.chinesemedicineboard.gov.au/Codes-Guidelines/FAQ/Infection-

prevention.aspx: CMBA Retrieved from

http://www.chinesemedicineboard.gov.au/Codes-

Guidelines/FAQ/Infection-prevention.aspx.

CMBA. (2016a). CMBA Codes and Guidelines. Retrieved 19/10/2016, from http://www.chinesemedicineboard.gov.au/Codes-Guidelines.aspx

CMBA. (2016b). Guidelines for Patient Health Records. Chinese Medicine Board of Australia: $\begin{array}{llll}\text { Chinese } & \begin{array}{l}\text { Medicine } \\ \text { Retrieved }\end{array} & \begin{array}{l}\text { Board } \\ \text { from }\end{array} & \text { of Australia }\end{array}$

http://www.chinesemedicineboard.gov.au/Codes-Guidelines/FAQ/Patient-records.aspx.

Coronel, C., \& Morris, S. (2016). Database systems: design, implementation, \& management: Cengage Learning.

Friedenthal, S., Moore, A., \& Steiner, R. (2014). A practical guide to SysML: the systems modeling language: Morgan Kaufmann.

Gregor, S., \& Hevner, A. R. (2013). Positioning and presenting design science research for maximum impact. MIS quarterly, 37(2), 337-355.

Groves, P., Kayyali, B., Knott, D., \& Kuiken, S. V. (2016). The'big data'revolution in healthcare: Accelerating value and innovation.

Harding, J. (2013). Qualitative data analysis from start to finish: Sage.

Hevner, A., \& Chatterjee, S. (2010). Design science research in information systems: Springer.

Hu, N.-Z., Lee, C.-Y., Hou, M. C., \& Chen, Y.-L. (2013). A cloud system for mobile medical services of traditional Chinese medicine. Journal of medical systems, 37(6), 9978. 
S. Leewis, K. Smit \& M. Zoet: An Explorative Study Into Situational Artefact Construction in Business Rules Management

Jha, A. K., Doolan, D., Grandt, D., Scott, T., \& Bates, D. W. (2008). The use of health information technology in seven nations. International journal of medical informatics, 77(12), 848-854.

Jia, Z., \& Zhao, H. (2014). A Joint Graph Model for Pinyin-to-Chinese Conversion with Typo Correction. In ACL (1) (1512-1523).

Kaptchuk, T. (2014). The web that has no weaver: understanding Chinese medicine: BookBaby.

King, J., Patel, V., Jamoom, E. W., \& Furukawa, M. F. (2014). Clinical benefits of electronic health record use: national findings. Health services research, 49(1pt2), 392-404.

Lin, C. H., Pittayachawan, S., Yang, A. W. H., \& Wickramasinghe, N. (2014). Using IS/IT to support the delivery of Chinese medicine: a Chinese medicine clinic management system. International Journal of Biomedical Engineering and Technology, 16(3), 223-243.

Lin, C. H., Wei, A., Yang, H., Pittayachawan, S., Vogel, D., \& Wickramasinghe, N. (2015a). Inquiring Knowledge Management Systems--A Chinese Medicine Perspective. In System Sciences (HICSS), 2015 48th Hawaii International Conference on (3682-3690).

Lin, C. H., Yang, A. W. H., Pittayachawan, S., \& Wickramasinghe, N. (2015b). An Analysis on the Utilisation of Health Information Technology to Support Clinical Operation of Chinese Medicine. United States of America: IGI Global.

Lin, C. H., Yang, A. W. H., Pittayachawan, S., \& Wickramasinghe, N. (2016). Health information technology to support the delivery of Chinese medicine: The design of a Chinese medicine clinic system Contemporary Consumer Health Informatics (pp. 219-233): Springer.

Lukman, S., He, Y., \& Hui, S. C. (2007). Computational methods for Traditional Chinese Medicine: a survey. Comput Methods Programs Biomed, 88(3), 283-294. doi: 10.1016/j.cmpb.2007.09.008

Maciocia, G. (2015). The foundations of Chinese medicine: a comprehensive text: Elsevier Health Sciences.

March, S. T., \& Smith, G. F. (1995). Design and natural science research on information technology.

Decision Support Systems, 15(4), 251-266.

Murphy, S. N., Klann, J. G., \& Meeks-Johnson, J. (2016). Information Technology Systems Clinical Informatics Study Guide (pp. 189-218): Springer.

Nguyen, L., Bellucci, E., \& Nguyen, L. T. (2014). Electronic health records implementation: an evaluation of information system impact and contingency factors. International journal of medical informatics, 83(11), 779-796.

Peffers, K., Tuunanen, T., Rothenberger, M. A., \& Chatterjee, S. (2007). A design science research methodology for information systems research. Journal of management information systems, 24(3), 45-77.

Rosemann, M., \& vom Brocke, J. (2015). The six core elements of business process management

Handbook on Business Process Management 1 (pp. 105-122): Springer.

Silverman, D. (2016). Qualitative research: Sage.

Thalheim, B. (2013). Entity-relationship modeling: foundations of database technology: Springer Science \& Business Media.

Unni, M., \& Baskaran, K. (2012). Semantic Information Retrieval Using WAMP Server. International Journal of Advanced Research in Computer Science and Software Engineering, 2(11).

Vaishnavi, V. K., \& Kuechler, W. (2015). Design science research methods and patterns: innovating information and communication technology: Crc Press.

Varghese, P., Wright, A., Andersen, J. M., Yoshida, E. I., \& Bates, D. W. (2016). Clinical Decision Support: The Experience at Brigham and Women's Hospital/Partners HealthCare Clinical decision support systems (pp. 227-244): Springer.

Wager, K. A., Lee, F. W., \& Glaser, J. P. (2017). Health care information systems: a practical approach for health care management: John Wiley \& Sons. 
WHO. (2013). WHO traditional medicine strategy: 2014-2023: World Health Organization. Wickramasinghe, N., \& Schaffer, J. (2010). Realizing value driven e-health solutions. Washington DC:

Report for IBM.

Wieringa, R. J. (2014). Design science methodology for information systems and software engineering: Springer.

Wikipedia. (2017a). PinYin.PinYin. https://en.wikipedia.org/wiki/Pinyin: Wikipedia. Retrieved from https://en.wikipedia.org/wiki/Pinyin

Wikipedia. (2017b). WampServer. In Wikipedia (Ed.).WampServer. Wikipedia: Wikipedia. Retrieved from https://en.wikipedia.org/wiki/WampServer

Yang, A. W., Allan, G., Li, C. G., \& Xue, C. C. (2009). Effective Application of Knowledge Management in Evidence-based Chinese Medicine: A Case Study. Evid Based Complement Alternat Med, 6(3), 393-398. doi: 10.1093/ecam/nem124

Yin, R. K. (2013). Case study research: Design and methods: Sage publications. 
S. Leewis, K. Smit \& M. Zoet: An Explorative Study Into Situational Artefact Construction in Business Rules Management

Appendix 1: Entity Relational Diagram of PMS Database Tables and Relationships $十_{1} \in$ One to many (n) relationship

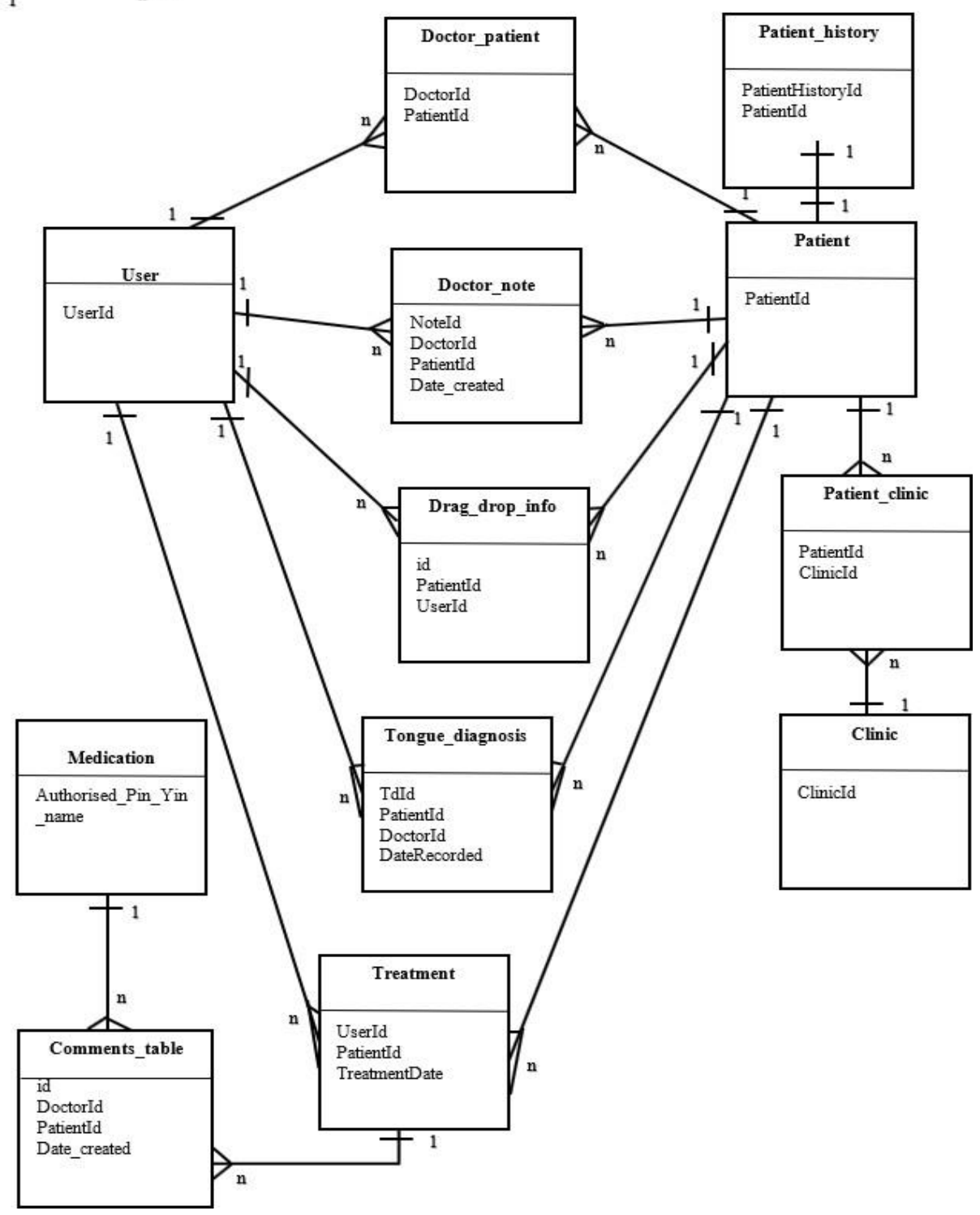


Appendix 2: PMS Website Map

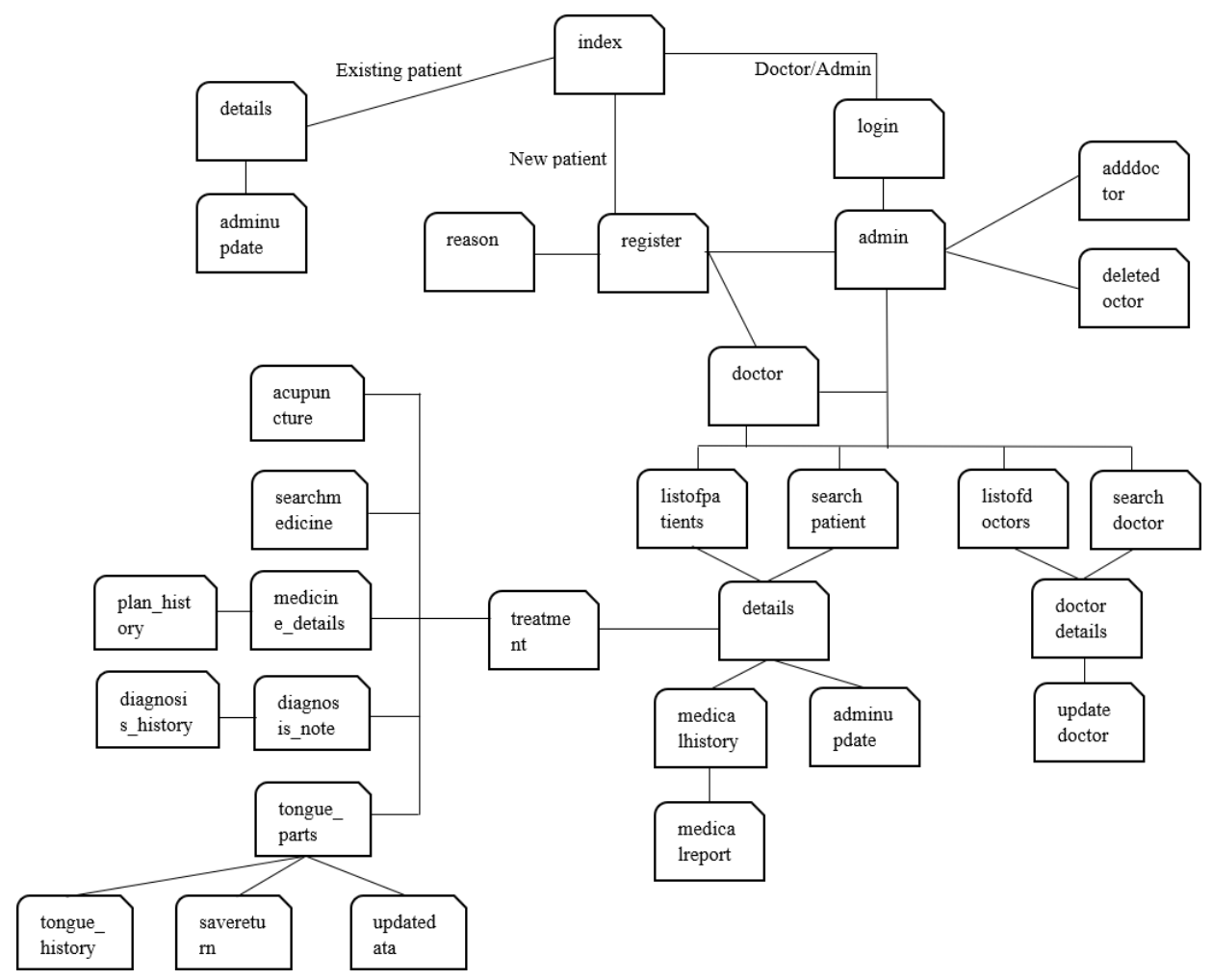

At the first (index) webpage, an existing patient can view and update his/her personal details with correct first and last Names and date-of-birth. If the patient is new, these personal details as well as the patient's medical history are collected via the register and 'reason' pages. Physicians and clinic administrators must provide a valid login to enter the PMS system to access functions/features that are have restricted access. An administrator can add a new physician into the PMS database as well as deleting a physician who no longer works at the clinic, these two functions are restricted to administrators who have the correct login details. Like physicians, the administrators can also search a patient and/or physician, see the list of patients and/or physicians, view and update their details. An administrator cannot perform diagnosis, prescription, and treatment. These core PMS functions belong to physicians only, where tongue diagnosis with graphical image of patient's tongue is analysed and examined. Diagnosis note and prescription details are recorded into the PMS database tables. 
222 31 $1^{\text {ST }}$ Bled eConference: Digital Transformation: MeEting THE Challenges

June 17 - 20, 2018, BLED, SLOVENIA, CONFERENCE PROCEEDINGS

S. Leewis, K. Smit \& M. Zoet: An Explorative Study Into Situational Artefact Construction in Business Rules Management

\section{Appendix 3: Symbols Used in the Activity Diagrams}

\begin{tabular}{|c|c|}
\hline Symbols & Description \\
\hline & Solid circle represents the start. \\
\hline & Bull's eye indicates the endpoint. \\
\hline & Solid line with a solid arrowhead is a symbol for a transition. \\
\hline & Round-corner rectangle represents an activity. \\
\hline & A diamond indicates a selection or decision. \\
\hline & $\begin{array}{l}\text { Solid bold lines show the separate transitions/activities into concurrent paths (first solid bold line } \\
\text { indicates the beginning of the split; the second solid bold line signifies the merge). }\end{array}$ \\
\hline$\Rightarrow$ & Transition occurs from an activity is presented by a broken line with solid arrowhead. \\
\hline & A broken line with empty arrowhead represents transitions outside of activities. \\
\hline & An empty small diamond with links indicates instances of the same object. \\
\hline & A sharp corner rectangle indicates hardware such as electronic devices. \\
\hline & A rectangle with left top round corner and snipped right top corner represents a webpage. \\
\hline 串 & A sharp corner rectangle with two mini sharp corner rectangles at left indicates a server. \\
\hline & $\begin{array}{l}\text { A sharp corner rectangle with two separation lines represents a database table/ entity. Table name } \\
\text { is written at the top, table columns/attribute names are listed next, and the activities/functions are } \\
\text { stated at the bottom separation. }\end{array}$ \\
\hline & A cylinder represents a database. \\
\hline
\end{tabular}




\section{Appendix 4: PMS Tongue Diagnosis.}

Tongue observation is an important part of CM diagnosis. CM physicians often indicate the colours of the tongue body and tongue coating, for example, tongue body: red, pale, purple; tongue coating: thin or thick, dry or moisture, or simply no coating. Hence, the PMS provides the option of entering tongue diagnosis note, where these notes can then be reviewed through the 'Tongue History' link (circled in red below). To be consistent, a list of symbols was used to signify different conditions. It is important to point out that these conditions can appear at multiple tongue areas (e.g. left, right, centre), so that one symbol can be used (drag and place) multiple times.

\begin{tabular}{|l|l|}
\hline Symbol & \\
\hline$x$ & Indicate red dots on the tongue \\
\hline 0 & Indicate purple dots on the tongue \\
\hline $\mathrm{I}$ & Indicate the cracks on the tongue \\
\hline$\sim$ & Indicate teeth marks at the sides of the tongue \\
\hline
\end{tabular}

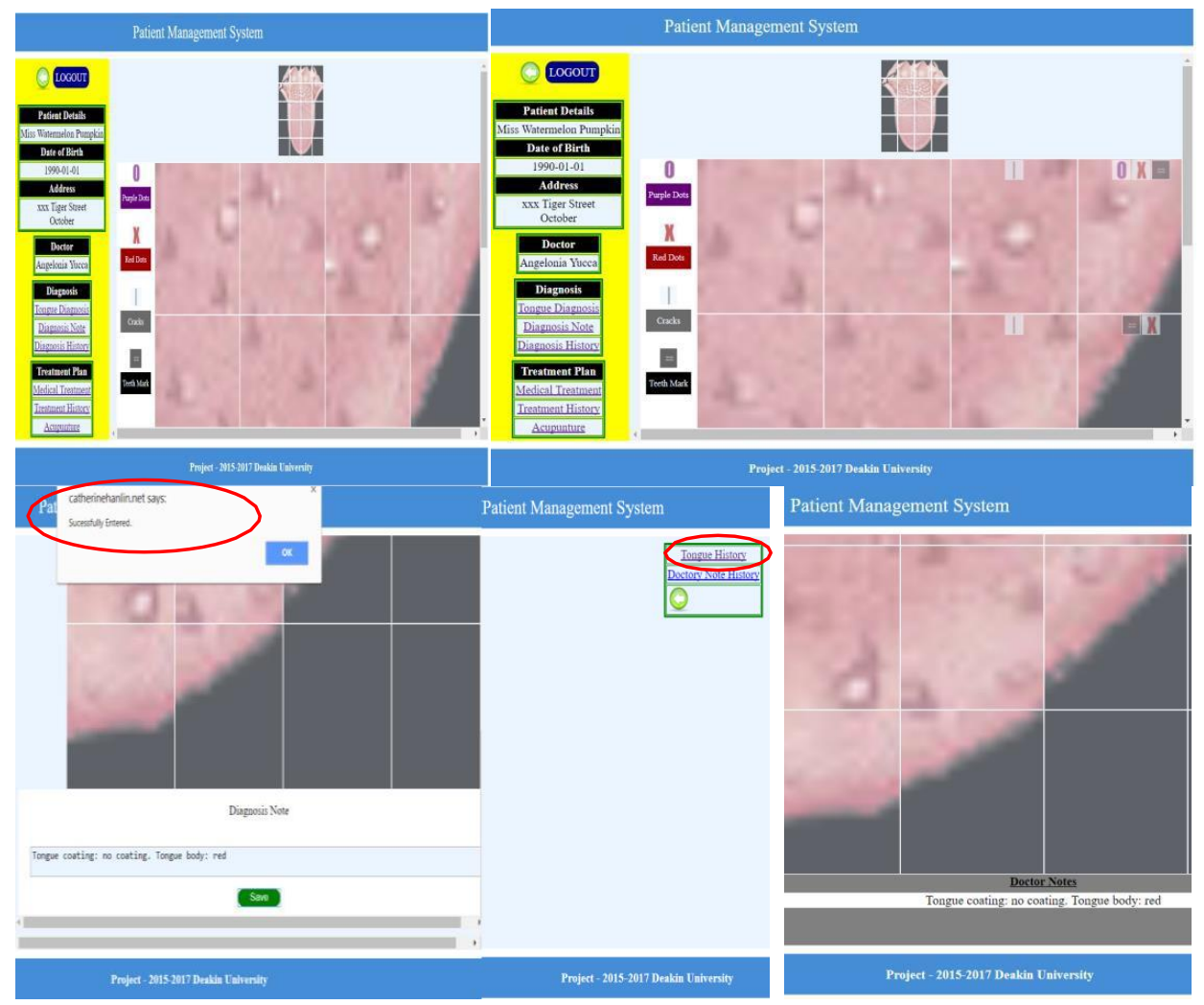


224 3 $31^{\text {ST }}$ BLED eConference: Digital TRANSFormation: MeEting the ChallengeS June 17 - 20, 2018, BLED, SLOVENIA, CONFERENCE PROCEEDINGS

S. Leewis, K. Smit \& M. Zoet: An Explorative Study Into Situational Artefact Construction in Business Rules Management

Appendix 5: PMS Prescription and Treatment

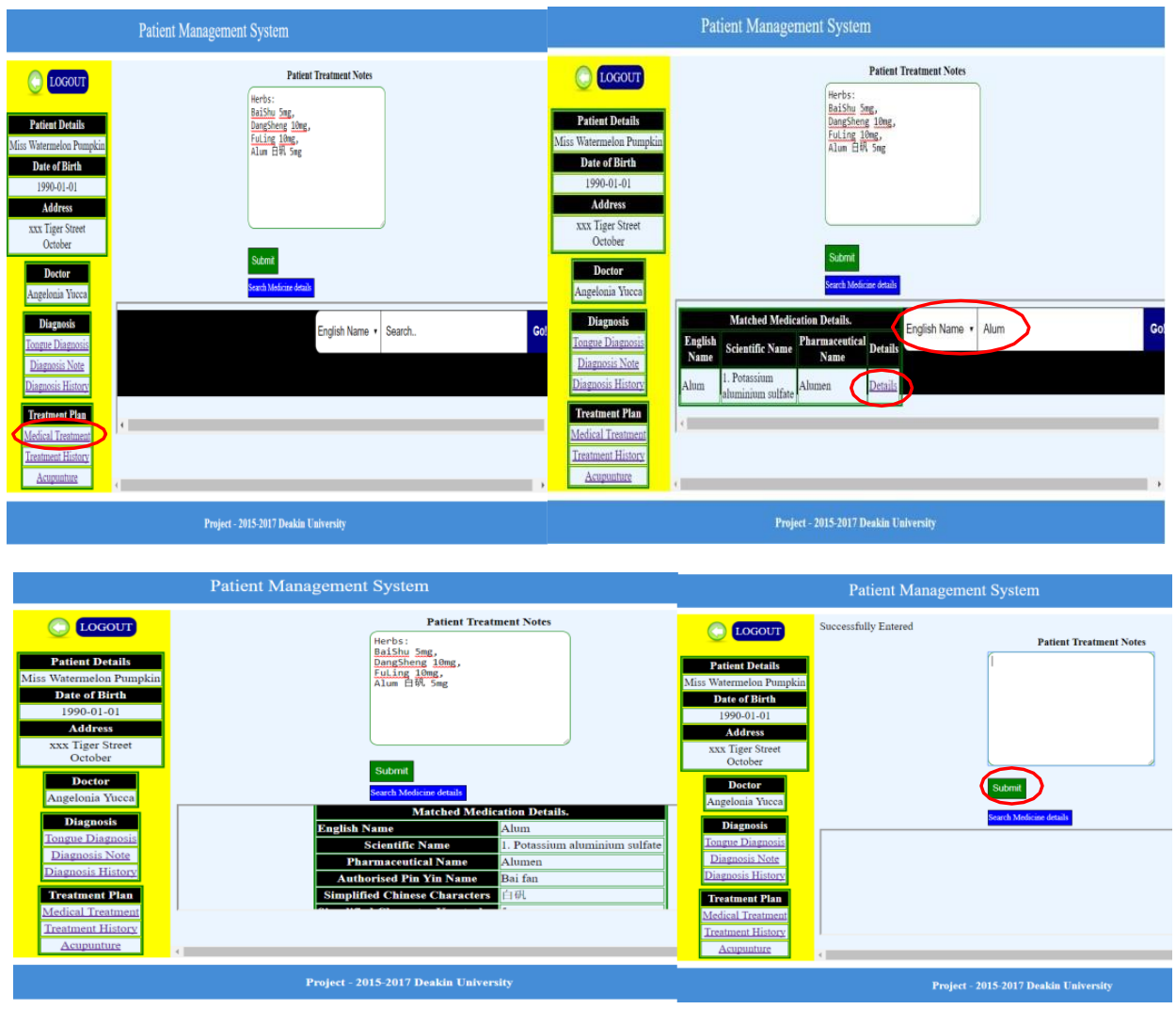

To view patient's prescription history, select the 'Treatment History' link (circled in red), select the date under the 'Medical Notes Visit Dates' (circled in red).

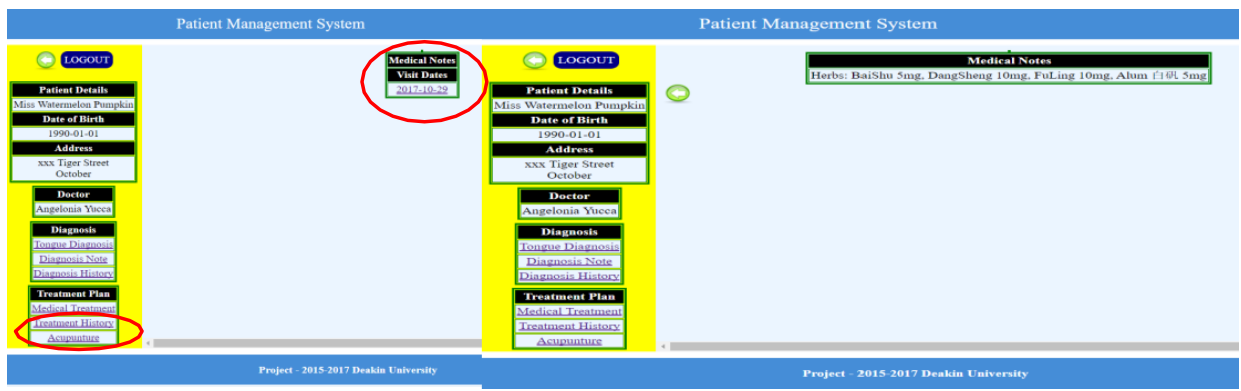




\title{
eHealth WhatsApp Group for Social Support: Preliminary Results
}

\author{
LuUK P.A. Simons, Wouter A.C. VAN Den Heuvel \& \\ CATHOLIJN M. JONKER
}

\begin{abstract}
Within groups that are starting a healthy lifestyle intervention together, there is potential for social e-support, as an addition to individual coaching. However, the support technology should be low-tech, lowthreshold and preferably already omnipresent. A WhatsApp group was chosen as support tool, given the large variety of groups normally coached: from elderly, IT-phobic diabetics to highly educated young professionals. In this explorative pilot study, 11 young professionals volunteered. Despite their time-constrained schedules, 81 user inputs were generated in the first weeks, and the users valued the WhatsApp group as an attractive social support addition to the existing eTools and personal coaching which have a more functional focus on individual progress. Based on preliminary results: a) the WhatsApp group generated higher participation than most other social media, b) deploying social media use motives, c) possibly due to the relatively high 'presence' and 'engagement' attributes of WhatsApp, and d) contributing to healthy behaviours and health advocacy.
\end{abstract}

Keywords: • eHealth $\bullet$ WhatsApp Group $•$ Peer Coaching $\bullet$ Service Design

Correspondence Address: Luuk P.A. Simons, Ph.D., Sr Fellow, Delft University of Technology, Computer Science (room 6.760), Van Mourik Broekmanweg 6, 2628 XE Delft, Netherlands, email: L.P.A.Simons@TUDelft.nl. Wouter A.C. van den Heuvel, Health Coach Program (room 5.05), Stevinweg 1, Delft, Netherlands, e-mail: Wouter.vandenHeuvel@HealthCoachProgram.nl. Catholijn M. Jonker Ph.D., Professor, Delft University of Technology, Computer Science, Van Mourik Broekmanweg 6, 2628 XE Delft, Netherlands, e-mail: C.M.Jonker@TUDelft.nl

DOI https://doi.org/10.18690/978-961-286-170-4.14

ISBN 978-961-286-170-4

(C) 2018 University of Maribor Press

Available at: http://press.um.si. 
L. P.A. Simons, W. A.C. van den Heuvel \& C. A. M. Jonker: eHealth WhatsApp Group for Social Support: Preliminary Results

In academic thinking, like the HAPA (Health Action Process Approach) model (Schwarzer 2008, Lippke 2009, Wiedeman 2011) and i-change model (De Vries 1998), as well as in the design of eHealth solutions (Simons 2010), the initial focus often tended to be largely aimed at the functional level. For example, three health behaviour improvement phases that are often mentioned in this line of thinking are: firstly raising health awareness, secondly developing intentions and making plans, plus thirdly implementing health behaviours (including coping, experimenting, improving, sustaining). Thus, health behaviour improvement appear to revolve around setting goals and achieving them.

However, in working with type 2 Diabetes Mellitus (DM2) patient groups over the past years, we observed multiple user needs and behaviours regarding affective social group support. For example, in the short term of making the first twelve weeks of healthy lifestyle improvements, patients saw each other three times per week for physical training, but they also used that time for sharing experiences, exchanging ideas, showing how well they were doing (or not), celebrating successes and making fun of each other (Simons 2016). And in the longer run (50 weeks), even though the collective training was over, the group spontaneously organized to continue seeing each other once every month (Simons 2017). This triggered us to think how we could provide a more continuous, omnipresent support on the emotional- and group level?

However, regarding technology use, several patient groups tend to be relatively ICTilliterate and/or even have an ICT-aversion. Still, smartphones are ubiquitous now in the Netherlands, as are messaging and the sharing of photos and videos. Thus, a WhatsApp group was chosen as support tool for an explorative pilot study, being low-tech, lowthreshold and omnipresent. In order to test robustness across user groups, this study focusses on preliminary results from a healthy lifestyle group of young professionals.

The WhatsApp group is offered as a voluntary addition to an existing eSupported Health Coach Program, comprising of a personal coach plus multiple eHealth tools described elsewhere (Simons 2010b, 2014, 2016). The pre-existing eSupport has a rather functional focus: aimed at diagnosis (health behaviours, levels of physical and mental health), health awareness and -literacy, experimenting with new health behaviours, plus fitting them to personal preferences and agendas. Also, the focus is largely on the individual and his/her family. The question in this explorative pilot study is whether the WhatsApp group offers emotional- and group level support.

A special challenge is the degree of participation; in other social media over $90 \%$ of users only consume, but do not participate in the sense of providing responses or inputs (Nonnecke 1999). 


\section{Research Question:}

- Does the WhatsApp group have added value by harnessing social motivators (like connecting with each other, sharing experiences or showing your best) and affective motivators (like pride, having fun, encouragement or compliments)?

\section{2}

\section{Theory}

As explained in the introduction, we focus on in this paper on the social and affective support that the WhatsApp group may add to the functional health support existing in the eSupported health program. While using a persuasive technology approach (Fogg 2002, 2009, Hamari 2014) to stimulate healthy behaviours, there were three types of service design goals present in this pilot study, which we describe below, see also Table 1 .

First, the overall purpose of the eSupported health program is promoting long term ( $>12$ months) healthy patterns. Thus the focus in not on short term dieting or exercise activities, but on developing a health identity (including health perceptions and habits) which supports long term health behaviours (see also Simons 2015 for a more detailed explanation of the health competencies that almost 'automatically' contribute to long term health). One of those long term fundaments is developing a positive health identity (including self-norms, health literacy and -beliefs). One type of digital behaviour that can often be seen in social media like in Strava or Runkeeper Apps (Simons 2013, 2014), as well as Facebook, WhatsApp or YouTube (Khan 2017) is 'Showing my best' and encouraging/supporting each other in that behaviour. In social media the underlying motive for posting contributions is often called 'Self-Status Seeking' (Park 2009 , Khan 2017), but it is also similar to health-related feeling good about yourself (Fuhrman 2005), becoming a better person (Paffenbarger 1996) and developing friendship and pride (Reiss 2004). The next type of health identity behaviour has to do with 'becoming your own version of a health person'. In the first experimentation weeks of the program, it is important to explore which health behaviours fit your personal preferences, as well as your social- and agenda-contexts (Simons 2017b). In this 'learning to understand how health behaviours work for me' phase, see Table 1, it helps to exchange ideas and share examples with others.

Second, the WhatsApp group pilot had the service design goal of fostering peer coaching via advocacy for three domains of health behaviours: healthy diet, physical activity and mental energy, see Table 1. These are also the health domains the focus of the eSupported health program. A mechanism making this peer coaching goal especially interesting for us, is something we observed in previous groups (Simons 2016, 2017) as well as in 'supersurvivor' roles in resilience literature (Southwick 2012). In this resilience literature, three levels of competence are distinguished, with thus two possibilities to step up. First, people can move from low levels of [health] competence and self-efficacy (on occasion 'falling victim' to the effects of ineffective behaviours and coping styles) to the middle level of 'survivor' where competence and coping levels are quite adequate. But the most interesting step is when previous 'victims' become 'super-survivors' (Southwick 2012), teaching others how to grow. In this process they use their own victim pitfalls/experiences 
L. P.A. Simons, W. A.C. van den Heuvel \& C. A. M. Jonker: eHealth WhatsApp Group for Social Support: Preliminary Results

as assets to better understand, empathize and coach others. When certain people in a health group become 'super-survivors' this is a win-win: it further stimulates their own health identity and it provides additional support and inspiration for the other groups members. Conceptually, super-survivors can be seen as a strong form of advocates, role models, or peer coaches (Prochaska 1997, Southwick 2013, Thom 2013).

Table 1: Service Design Goals of WhatsApp Group, Added to eSupported Health Program

\begin{tabular}{|l|l|l|}
\hline 1. Health Identity/Literacy & $\begin{array}{l}\text { 2. Peer } \\
\text { Coaching/Advocacy }\end{array}$ & 3. Social Support Motives \\
\hline $\begin{array}{l}\text { A. Showing my best and } \\
\text { celebrating progress. }\end{array}$ & A. Healthy diet. & $\begin{array}{l}\text { A. Asking/giving practical } \\
\text { support. }\end{array}$ \\
$\begin{array}{l}\text { B. Learning to understand } \\
\text { how health behaviours } \\
\text { work for me. }\end{array}$ & $\begin{array}{l}\text { B. Physical activity. } \\
\text { C. Mental energy. }\end{array}$ & $\begin{array}{l}\text { B. Asking/giving affective } \\
\text { support. } \\
\text { C. Fun and humour. }\end{array}$ \\
\hline
\end{tabular}

The third design goal of the pilot is to support social interaction motives and use them to stimulate a healthy lifestyle. When looking at the user motives from the Uses and Gratifications Theory (UGT) of social media research (McQuail 2010, Khan 2017), the 'Self-Status Seeking' motive was already addressed with motive 1A, showing my best. Next, there are two rather functional UGT motives: 'giving information' and 'seeking information.' In the context of a health intervention, this generally means asking and giving practical information, see motive $3 \mathrm{~A}$ in Table 1 . Next, there is the 'social interaction' motive, in this context of health support, taking the form of asking and giving affective support and feedback, see motive 3B. Finally, there is the 'entertainment' motive, see 3C 'Fun and humour' inputs listed in Table 1.

In the next section we explain how we use the design research approach in this pilot study.

\section{Methods, Study Design, Intervention}

In this section we discuss our design research approach and explorative pilot study. Regarding our design research approach, we follow the design cycle of Vaishnavi \& Kuechler (2004): from problem awareness and solution suggestion to development, evaluation and conclusion.

At the end of January 2018, a group of 15 employees from academia started with an eSupported healthy lifestyle program. On their start day, 11 of them volunteered to participate in the WhatsApp group support pilot, after reading the pilot study information and signing consent forms. They were a highly international group of scientists (China, Italy, Latin America, Netherlands, South-Africa, Ukraine, Greece, Iran, India) from different disciplines at the Delft University of Technology: Postdocs, tenure trackers, assistant professors and the majority were $\mathrm{PhD}$ candidates. A first important characteristic of this group is that they are very time-constrained. They experience a high work load (as confirmed with intake surveys) and only want to spend time on (health- or other) activities if they are deemed useful for their performance as professionals. Secondly, the majority 
of them are young professionals, in their first or second job, and relatively unexperienced in managing work-life balance or ensuring healthy choices. It is not uncommon in this group to observe unhealthy belief/behaviour patterns like: 'I am not productive enough > I will skip my breaks -> I lack energy -> I need more sugar.' Or sacrificing sleep, or exercise, or socializing, for the sake of working longer hours. Or other unhealthy 'corporate athlete' (Loehr 2001) patterns. Thirdly, 80\% of participants had a Mental Health score (RAND-SF8, Ware 1998) below the overall Dutch average (for all age groups combined), even though their average age was below 35 years old. Thus a $20 \%$ Mental Health score below average would have been more appropriate instead of $80 \%$. During the pilot of nine weeks, all WhatsApp user inputs are anonymized, counted and clustered based on their contributions to the design goals. Two of the authors conducted the clustering independently and then discussed results in order to reach unanimous scores. Besides the user inputs analysis, subjective user evaluations are collected. We asked them to evaluate WhatsApp group contributions to the design goals (5-point Likert scale, plus explanations, extracted during telephone interviews). This paper reports on the preliminary results in February, based on the first two weeks of the pilot.

Our research method follows three steps: a) As 'awareness' and 'suggestion' steps: Formulate possible social and affective WhatsApp user contribution motives that suit the design goals of the WhatsApp pilot (this step follows solution suggestions in the abduction step of Vaishnavi and Kuechler; this study does not test the underlying assumptions, but takes them as a stepping stone: section 2). b) As 'development' and 'evaluation' steps: Adding the WhatsApp group support pilot to existing eSupported health program, plus evaluation: quantitatively based on numbers of user inputs per design goal, plus qualitatively, based on user feedback (deduction step of Vaishnavi and Kuechler: section 4). c) As 'conclusion' step several design lessons are drawn, for practice as well as theory, see section 5 . 
L. P.A. Simons, W. A.C. van den Heuvel \& C. A. M. Jonker: eHealth WhatsApp Group for Social Support: Preliminary Results

Knowledge

Flows
Process

Steps
Logical

Formalism

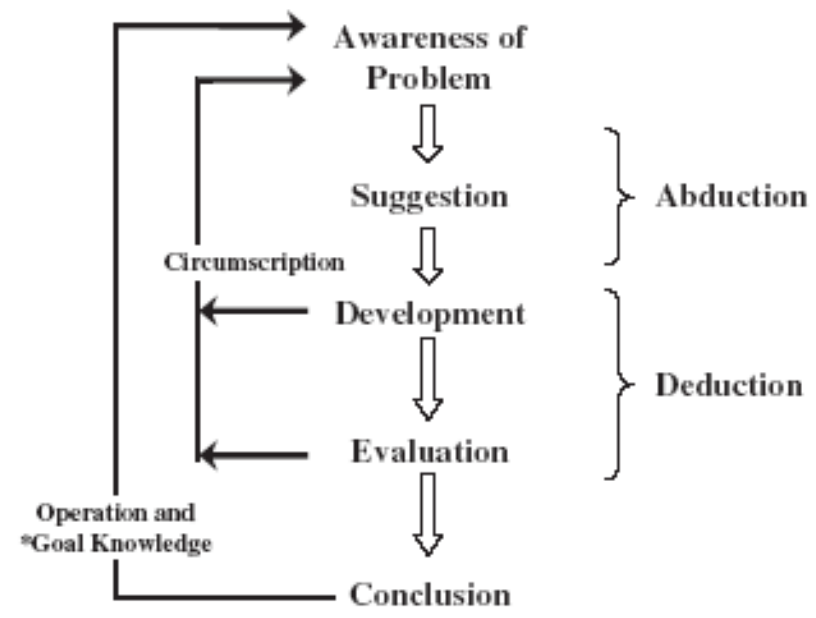

Figure 1: Design Cycle Knowledge via Design Iterations and Evaluations (Vaishnavi 2004)

\section{The WhatsApp group is an add-on to an existing eSupported health program}

The WhatsApp group support pilot is an add-on to an existing eSupported health program, which combines coach sessions with electronic dashboarding and self-management, plus electronic health tips and a digital health quiz game. Key functionalities are (Simons 2010, 2014, 2015):

- A personal online health dashboard with graphs of progress towards adherence targets on the various health behaviours;

- Automated feedback on lifestyle aspects where positive scores have been achieved (nutrition, physical activity, stress management or an overall score);

- (Tele)coaching by a health coach, generating online coach reports on progress towards adherence targets in the personal dashboard;

- Options to ask questions to the coach: via messaging within the dashboard or via email;

- Online schedule indicating upcoming events: group sessions, individual coach sessions (when and where), physical measurements, surveys;

- A micro-learning Health Quiz accessible via smartphone, mail and/or web;

- $\quad$ Reading materials in the mail; 
- Weekly tips via email on health, motivation and self-management;

- Besides individual coaching, group sessions are also used in order to stimulate group support, mutual inspiration and encouragement, plus peer education.

\section{$4 \quad$ Results}

In this section we discuss the preliminary results of the first two weeks of the pilot in Feb 2018. Besides the WhatsApp group activity, participant activities in the rest of the eSupported health program were: a full day workshop at the start, intake interview and questionnaire, using the Health Quiz and other eTools, and an individual health coach session in the first week after the start workshop. These participant activities were conducted alongside their busy jobs.

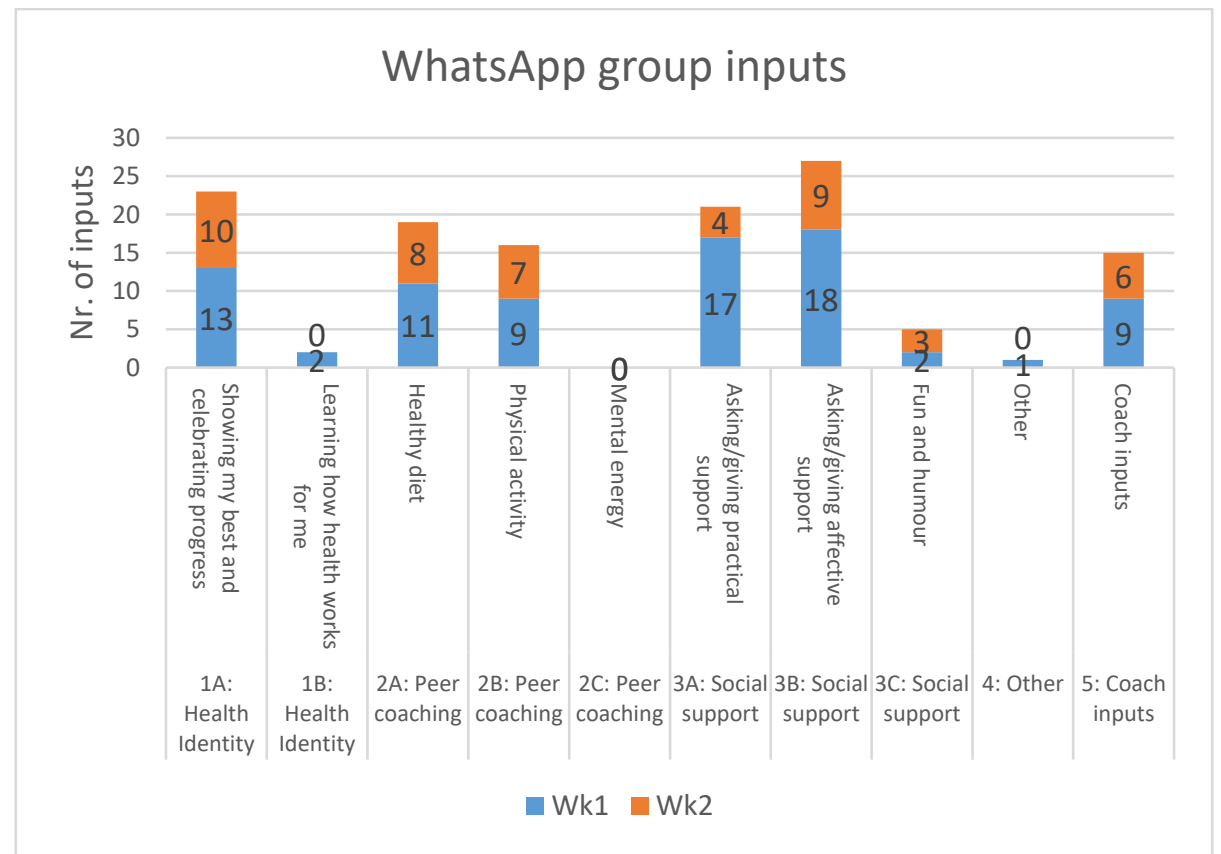

Figure 2: WhatsApp user \& coach inputs in weeks 1 and 2, on the service design goals.

With this group of $n=11$ participants, 81 inputs in total were collected in the first two weeks, of which 15 coach inputs (who were part of the WhatsApp group to help the group along) and 66 participant inputs, see Figure 2. Some inputs qualified for more than one goal, hence the sum of scores are higher. The first cluster, 'Showing my best and celebrating', of the first design goal (fostering health identity and literacy) received relatively many $(n=23)$ inputs. Regarding the second design goal (peer coaching and advocacy), the first two clusters ('Healthy diet' and 'Physical activity') received $n=19$ and $n=16$ inputs respectively, whereas 'Mental energy' received none, which is a paradox in comparison with their mental energy challenges (see section 3) and which we address 
L. P.A. Simons, W. A.C. van den Heuvel \& C. A. M. Jonker: eHealth WhatsApp Group for Social Support: Preliminary Results

in the discussion section. The third design goal of social support received respectively: $\mathrm{n}=21$ practical support inputs, $\mathrm{n}=27$ affective support inputs, plus $\mathrm{n}=5$ fun inputs. This suggests a tentative 'yes' on the social and affective support goals of the research question.

Figure 3 displays the distribution of inputs across participants. As often with social media inputs, the distribution is highly skewed (Nonnecke 1999) with one participant generating $\mathrm{n}=29$ inputs and three participants inputting less than two. These three participants were the only Chinese participants in the group, see also the Discussion section.

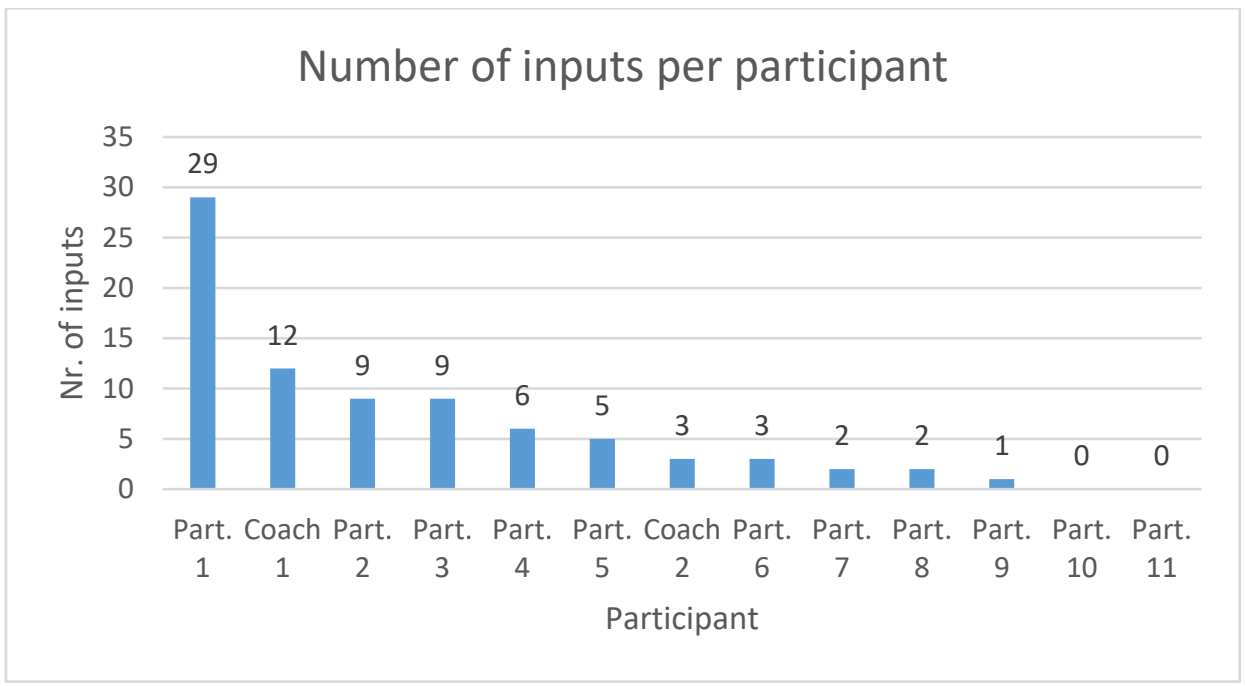

Figure 3: WhatsApp input distribution across participants.

The final study results stem from the user evaluations, see also Table 2. The first design goal of developing a health identity is least recognized: in their opinion this is already covered (possibly due to the start workshop and eSupported coaching, which has that focus at its core?) The second goal of developing peer coaching by having participants share their examples, is recognized to some extent. However, question 4 on happiness with the degree of peer support received, illustrates the uneven roles and inputs: the two most-contributing participants are the ones least satisfied with the degree of peer support they received. The third design goal regarding advice and encouragement from the group, was highly recognized. As well as the overall added value of the WhatsApp group on top of the other eSupport tools, see evaluation question 5. On the one hand WhatsApp as a medium is ignored less than mails, Apps or Internet dashboard. And on the other hand, the WhatsApp group support gives more continuous encouragement, plus visual inspiration. It is perceived as more open and less hierarchical. 
Table 2: User evaluations (5-pnt Likert: strongly disagree (1) - strongly agree (5). >4 = Bold)

\begin{tabular}{|l|c|}
\hline User evaluation questions, plus explanations (n=7) & $\begin{array}{c}\text { Average } \\
(3= \\
\text { neutral) }\end{array}$ \\
\hline $\begin{array}{l}\text { 1. 'Helped me develop my health identity?' } \\
\text { - Two disagree, because already developing health identity. } \\
\text { - Three agree, because of continuous reminders it provides. }\end{array}$ & 3.3 \\
\hline $\begin{array}{l}\text { 2. 'Helped me by sharing our examples?' } \\
\text { - Mostly agree, due to inspiration from the diversity of inputs. The photos } \\
\text { help. }\end{array}$ & 3.9 \\
\hline $\begin{array}{l}\text { 3. 'Helped me with group advice plus encouragements?' } \\
\text { - (Strongly) agree, due to constant reminders, awareness, } \\
\text { encouragements. }\end{array}$ & 4.4 \\
\hline $\begin{array}{l}\text { 4. 'I am glad with the peer support?' } \\
\text { - Two disagree, the two advocates giving most inputs: 'more giving than } \\
\text { getting'. } \\
\text { - Others agree. }\end{array}$ & 3.7 \\
\hline $\begin{array}{l}\text { 5. 'The WhatsApp group adds value?' } \\
\text { - Agree: 'Really different from the eSupported coaching: it gives more } \\
\text { continuous encouragement, plus visual inspiration. More open, less } \\
\text { hierarchical.' } \\
\text { - 'WhatsApp is ignored less than mails, Apps or Internet dashboard.' } \\
\text { - 'Potential could be used more: with more start day group interactions } \\
\text { and some more coach contributions in the WhatsApp.' }\end{array}$ & \\
\hline
\end{tabular}

\section{Discussion; Implications for Practice and Theory}

Firstly, it is nice to conclude that this WhatsApp group pilot generated higher degrees of participation than many other social media settings (often more large-scale and 'feeling' more anonymous like on Youtube) with their $90 \%$ passive viewers (Nonnecke 1999, Sun 2014, Khan 2017). This is possibly due to the relatively high 'presence' and 'engagement' attributes of WhatsApp, as reported back by our participants. The three Chinese participants did not contribute much, as also explained regarding Figure 3. We learned that WhatsApp is not available in China, thus it is not a usual (much less an omnipresent) communication channel for them, even when living abroad.

Secondly, combining the quantitative and subjective results from the previous section, we tentatively summarize in Table 3 the WhatsApp group contributions to the three service design goals of the pilot. And given our research question regarding possible affective contributions (in addition to the more utilitarian eSupported coaching), we made this distinction explicit in columns 2 and 3. 
For the first design goal of promoting health identity and literacy we found an interesting paradox: even though 1A, 'Showing my best and celebrating', received $n=23$ inputs, our pilot participants did not perceive clear contributions to developing their health identity. Given their own explanations (see previous section), we conclude that the perceived added value on top of the eSupported coaching was limited for this goal. Maybe the 'showing my best' inputs do hardly contribute to developing a health identity? Plus, we cannot conclude at this point what the subconscious effects are of the positive behaviour reinforcements from these $\mathrm{n}=23$ 'celebrations'? Hence the 'Yes?' for $1 \mathrm{~A}$ in column 2: it is an affective form of group support, but maybe hardly contributing for its service design goal.

For the second service design goal of supporting peer coaching and advocacy, we found that most remarks on healthy diet (2A) and physical activity (2B) had a practical/utility focus. Still some of the inputs were more affective encouragements, hence the '(Some)' in column 2. Unfortunately, regarding $2 \mathrm{~A}$ and $2 \mathrm{~B}$, there is uneven reciprocity: the two most-contributing participants are the ones least satisfied with the degree of peer support they received: they gave more than they got. The other group members were more satisfied with the peer coaching they received. Finally, no mental energy (2C) inputs were shared. This is likely due to at least two reasons: firstly, diet and exercise are 'safer' topics. And secondly, mental energy becomes a more prominent topic in the second month, so the results from those weeks will be interesting to see.

With regard to the third design goal of social support and interactions, both the practical and the affect support examples were amply present, as well as a few examples of humorous inputs. This coincides well with the user evaluations of the attractiveness and added value of the WhatsApp group support.

Table 3: Summary of WhatsApp group support for Service Design Goals (author opinions)

\begin{tabular}{|l|c|c|}
\hline Service Design Goals & Support, Affective? & Support, Utilitarian? \\
\hline 1. Health Identity/Literacy & & \\
\hline A. Showing my best and celebrating progress. & Yes? & No \\
\hline $\begin{array}{l}\text { B. Learning to understand how health } \\
\text { behaviours work for me. }\end{array}$ & & \\
\hline 2. Peer Coaching/Advocacy & & Yes \\
\hline A. Healthy diet. & (Some) & Yes \\
\hline B. Physical activity. & (Some) & No \\
\hline C. Mental energy. & & Yes \\
\hline 3. Social Support Motives & & \\
\hline A. Asking/giving practical support. & Yes & \\
\hline B. Asking/giving affective support. & Yes, some & \\
\hline C. Fun and humour. & & \\
\hline
\end{tabular}


Limitations of this study are the small scale $(n=11)$, plus the preliminary nature of the results (week 1 and 2). Usage and contribution patterns can be expected to evolve in the weeks to follow, which we will be keep to analyse in the near future. Given the small scale, we are also not able to correct for cultural differences in the group. Also, theory testing is out of the scope of this explorative study. Finally, the added value that participants perceive, is an added value relative to the existing eSupported health coaching, which makes users' added value perceptions harder to objectify.

A main lesson for practice may be that a WhatsApp group is a low-cost, low-tech, lowthreshold way for peer group support, on top of more functional forms of care or coaching. Still, even though the number of coach inputs are modest, it is vital that an expert coach is present in the group, to a) ensure the quality of advice and discussions, b) catalyze group interactions, c) ask certain users for help as health advocates in the group, based on their affinity, and d) ensure that help is always given to participants when they need it.

A lesson for theory might be that the motives we observed for participation were similar to the motives from the Uses and Gratifications framework of social media research (McQuail 2010, Khan 2017), but that the relatively high 'presence' and 'engagement' attributes of WhatsApp, plus the fact that a relatively small scale group setting is used, creates higher degrees of participation and contribution than seen in most social media settings. In terms of the three drivers from persuasive technology (Fogg 2009): firstly, the WhatsApp group provides regular triggers that participants are unlikely to ignore. Secondly, in terms of simplicity: it is very easy to contribute. Sometimes it is even more difficult not to respond (being socially deviant) than to respond, given the social reciprocity in the group. And thirdly, regarding motivators: most uses and gratifications from social media are present (social interaction, giving information, seeking information, self-status seeking and entertainment), as well as affective encouragements and receiving practical suggestions even when not explicitly asking for or seeking information.

Finally, regarding the 'super-survivor' or advocate roles, preliminary results are promising, but more research is needed.

\section{Acknowledgments}

The authors are very thankful to the participants, as well as Saar van der Graaff as primary coach of this group, for their contributions to this study.

\section{References}

De Vries, H., et al. (2008). The effectiveness of tailored feedback and action plans in an intervention addressing multiple health behaviors. Am J Health Promot. 22(6): p. 417-25.

Fogg, B.J. (2002). Persuasive technology: using computers to change what we think and do." Ubiquity, December (2002): 5.

Fogg, B. J. (2009). A behavior model for persuasive design. Proceedings of the 4th international conference on persuasive technology. ACM, 2009. 
$31^{\text {ST }}$ Bled eConference: Digital Transformation: MeEting the Challenges June 17 - 20, 2018, BLED, SLOVENIA, CONFERENCE PROCEEDINGS

L. P.A. Simons, W. A.C. van den Heuvel \& C. A. M. Jonker: eHealth WhatsApp Group for Social Support: Preliminary Results

Fuhrman, J. (2005). Eat to live: the revolutionary formula for fast and sustained weight loss. New York: Little, Brown and Company.

Hamari, J., Koivisto, J., \& Pakkanen, T. (2014, May). Do persuasive technologies persuade?-a review of empirical studies. In International conference on persuasive technology, Springer, Cham., pp. 118-136.

Khan, M. L. (2017). Social media engagement: What motivates user participation and consumption on YouTube?. Computers in Human Behavior, 66, pp. 236-247.

Lippke, S., Wiedemann, A. U., Ziegelmann, J. P., Reuter, T. and Schwarzer, R. (2009). Selfefficacy moderates the mediation of intentions into behavior via plans. American Journal of Health Behavior, 33(5), 521-529.

Loehr, J., \& Schwartz, T. (2001). The making of a corporate athlete. Harvard business review, 79(1), pp. 120-129.

McQuail, D. (2010). McQuail's mass communication theory. Sage, London.

Nonnecke, B., \& Preece, J. (1999). Shedding light on lurkers in online communities. Ethnographic Studies in Real and Virtual Environments: Inhabited Information Spaces and Connected Communities, Edinburgh, pp. 123-128.

Paffenbarger, R. S., \& Olsen, E. (1996). Lifefit: An Effective exercise program for optimal health and a longer life. Champaign, IL: Human Kinectics.

Park, N., Kee, K. F., \& Valenzuela, S. (2009). Being immersed in social networking environment: Facebook groups, uses and gratifications, and social outcomes. CyberPsychology \& Behavior, 12(6), pp. 729-733.

Prochaska, J. O., \& Velicer, W. F. (1997). The transtheoretical model of health behavior change. American journal of health promotion, 12(1), pp. 38-48.

Reiss, S. (2004). Multifaceted nature of intrinsic motivation: The theory of 16 basic desires. Review of General Psychology, 8(3), pp. 179-193.

Schwarzer, R., et al. (2010). Translating intentions into nutrition behaviors via planning requires self-efficacy: evidence from Thailand and Germany. Int J Psychol. 45(4): p. 260-8.

Simons LPA, Foerster F., Bruck PA, Motiwalla L \& Jonker CM. (2014b). Microlearning mApp to Improve Long Term Health Behaviours: Design and Test of Multi-Channel Service Mix. Paper presented at the 27th Bled eConference. Bled, Slovenia, Proceedings. Retrieval from www.bledconference.org and http://aisel.aisnet.org/bled2014/4

Simons LPA, Foerster F., Bruck PA, Motiwalla L \& Jonker CM. (2015). Microlearning mApp Raises Health Competence: Hybrid Service Design. Health and Technology, 5 pp 35-43. DOI 10.1007/s12553-015-0095-1

Simons LPA, Hafkamp MPJ, Bodegom D, Dumaij A, Jonker CM. (2017b). Improving Employee Health; Lessons from an RCT. Int. J. Networking and Virtual Organisations, Vol. 17, No. 4, pp.341-353.

Simons, LPA and Hampe, JF. (2010). Exploring e/mHealth Potential for Health Improvement; A Design Analysis for Future e/mHealth Impact. Paper presented at the 23rd Bled eConference. Bled, Slovenia, from www.bledconference.org.

Simons, LPA, and Hampe, JF. (2010b). Service Experience Design for Healthy Living Support; Comparing an In-House with an eHealth Solution. Paper presented at the 23rd Bled eConference. Bled, Slovenia, from www.bledconference.org.

Simons, LPA, Hampe JF, and Guldemond NA. (2012). Designing Healthy Consumption Support: Mobile application use added to (e)Coach Solution. Paper presented at the 25th Bled eConference. Bled, Slovenia, from www.bledconference.org.

Simons LPA, Hampe JF, Guldemond NA. (2013). Designing Healthy Living Support: Mobile applications added to hybrid (e)Coach Solution, Health and Technology, 3 (1), pp.1-11.

Simons LPA, Hampe JF, Guldemond NA. (2014). ICT supported healthy lifestyle interventions: Design Lessons. Electronic Markets. 24 pp. 179-192. DOI 10.1007/s12525-014-0157-7. 
Simons, LPA, Pijl M, Verhoef J, Lamb HJ, van Ommen B, Gerritsen B, Bizino MB, Snel M, Feenstra R, Jonker CM. (2016). Intensive Lifestyle (e)Support to Reverse Diabetes-2. Paper presented at the 29th Bled eConference. Bled, Slovenia, from www.bledconference.org. en http://aisel.aisnet.org/cgi/viewcontent.cgi?article=1023\&context=bled2016

Simons, LPA, Pijl M, Verhoef J, Lamb HJ, van Ommen B, Gerritsen B, Bizino MB, Snel M, Feenstra R, Jonker CM. (2017). Diabetes Lifestyle (e)Coaching 50 Weeks Follow Up; Technology Acceptance \& e-Relationships, pp. 545-560, presented at the 30th Bled eConference. Bled, Slovenia, Proceedings retrieval from www.bledconference.org. ISBN 978961-286-043-1, DOI: https://doi.org/10.18690/978-961-286-043-1

Southwick, S. M., \& Charney, D. S. (2012). Resilience: The science of mastering life's greatest challenges. Cambridge University Press.

Sun, N., Rau, P. P. L., \& Ma, L. (2014). Understanding lurkers in online communities: A literature review. Computers in Human Behavior, 38, pp. 110-117.

Thom, D. H., Ghorob, A., Hessler, D., De Vore, D., Chen, E., \& Bodenheimer, T. A. (2013). Impact of peer health coaching on glycemic control in low-income patients with diabetes: a randomized controlled trial. The Annals of Family Medicine, 11(2), pp. 137-144.

Vaishnavi, V., \& Kuechler, W. (2004, last updated August 16, 2009). Design Research in Information Systems. from http://desrist.org/design-research-in-information-systems

Ware Jr, J.E. and Gandek, B. (1998). "Overview of the SF-36 health survey and the international quality of life assessment (IQOLA) project." Journal of clinical epidemiology 51.11 (1998): 903-912.

Wiedemann, A. U., Lippke, S., Reuter, T., Ziegelmann, J. P. and Schwarzer, R. (2011). How planning facilitates behaviour change: Additive and interactive effects of a randomized controlled trial. European Journal of Social Psychology, 41, 42-51. 
238 3 $31^{\text {ST }}$ Bled eConference: Digital Transformation: MeEting the Challenges JUNE 17 - 20, 2018, BLED, SLOVENIA, CONFERENCE PROCEEDINGS 


\title{
Critical success factors in the design of suitable oncology platforms
}

\author{
MUHAMMAD NADEEM SHUAKAT \& NILMINI \\ WICKRAMASINGHE
}

\begin{abstract}
Cancer, a chronic disease has become one of the primary causes of death in advanced countries. The diagnosis, medication and treatment for cancer is very expensive. Healthcare providers, especially in cancer care, need to automate and accelerate access to patient data and evidence based decision making along with greater quality control and safety. Oncology information systems (OIS) provide a simple solution for this. This study compared 3 different leading international oncology information systems capable of delivering high-value, patient centred care to cancer patients in the Australian context. This work analysed functionality, usability and interoperability of these systems for the Australian healthcare environment and their integration with existing systems and assets. Critical success factors in the design of platforms to make them perform better from clinicians' and patients' points of view have also been discussed.

Keywords: - Healthcare - Oncology Information Systems $・$ Critical Success Factors $\bullet$ Clinicians $\bullet$
\end{abstract}

CORRESPONDENCE AdDRESS: Muhammad Nadeem Shuakat, Ph.D., Epworth HealthCare and Deakin University, Australia, e-mail: nadeem_ntu@yahoo.com. Nilmini Wickramasinghe, Epworth HealthCare and Deakin University, Australia, e-mail: nilmini.work@gmail.com

DOI https://doi.org/10.18690/978-961-286-170-4.15

ISBN 978-961-286-170-4

(C) 2018 University of Maribor Press

Available at: http://press.um.si. 
M. N. Shuakat \& N. Wickramasinghe: Critical success factors in the design of suitable oncology platforms

1

\section{Introduction}

Along with other chronic diseases, cancer has become one of the leading causes of death ("Cancer in Australia," 2017; Torre, Siegel, Ward, \& Jemal, 2016; Yach, Hawkes, Gould, $\&$ Hofman, 2004). By the age of 85, one in two Australians will be diagnosed with cancer and 1 in 5 will die from cancer ("Twitter graphic cancer in Aust 2017,"). Males (around $54 \%$ ) are more likely to suffer from cancer than females (around 46\%). 1 in 3 males whereas 1 in 4 females will be identified with cancer by the age of 75 ("Cancer in Australia 2017," 2017). As shown in Table 1, it was estimated that in 2017 around 134,174 people will be identified as cancer sufferers and that the number of cancer cases is expected to rise further to 150,000 till 2020. Cancer related treatments and medicines are extremely expensive; in Australia, the health care system bears most of the burden which is more than $\$ 4.5$ billion (6.9\%) ("Cancer in Australia," 2017). Typical, treatment protocols of cancer patients involve surgery, radiation therapies and chemotherapy (Crawford, 2013). These procedures involve critical control over surgery, the amount of radiation and cytotoxic doses for chemotherapy (Wickramasinghe, Haddad, Vaughan, Han-Lin, \& Moghimi, 2015).

Table 1: Estimated incidence of all cancers combined, by sex, 2017 ("Cancer in Australia 2017," 2017)

\begin{tabular}{|l|l|l|l|}
\hline & Males & Females & Persons \\
\hline Number of cases & 72,169 & 62,005 & 134,174 \\
\hline Age-standardised rate & 525.9 & 422.9 & 469.6 \\
\hline $\begin{array}{l}\text { Per cent of all cancer } \\
\text { cases }\end{array}$ & 53.8 & 46.2 & 100.0 \\
\hline Risk to age 75 & 1 in 3 & 1 in 4 & 1 in 3 \\
\hline Risk to age 85 & 1 in 2 & 1 in 2 & 1 in 2 \\
\hline
\end{tabular}

In general, people living in Australia have a better chance of survival than people living in other parts of the world ("Cancer in Australia 2017," 2017; "Cancer in Australia in breif 2017," 2018; "Twitter graphic cancer in Aust 2017,"). This is attributed to better awareness and improved clinical care (Crawford, 2013). The overall reduction in cancer incidences, in Australia is primarily due to decreased number of cases in prostate cancer in men ("Prostate cancer in Australia," 2013). This decline in cancer trends could be associated to increased awareness and prostate specific antigen (PSA) testing in males ("Cancer in Australia in breif 2017," 2018).

\section{$2 \quad$ Need for OIS (oncology information system)}

Owing to new advancements in diagnostic and treatment therapies, today we are in a better position to identify early and understand more fully diseases and their management, resulting in longer and healthier life outcomes ("Cancer in Australia 2017," 2017). This 
era of knowledge and easy access to information through the Internet, print and electronic media has made us more demanding of every aspect of health and wellbeing (Duckett \& Willcox, 2015). It is a well-established fact that improved health literacy leads to better health outcomes (Nutbeam, 2008). Overall, it has put an enormous burden over global healthcare systems due to an ageing population (Prince et al., 2015; Yach et al., 2004). In such a challenging situation, even a small error in treatment, documentation or missing a scheduled appointment can be fatal and can cost a huge amount to the healthcare system (Berwick, 2003). To cope with these errors and get up to date information about patient history, medication and treatments, electronic health records and data systems have been introduced in many advanced countries (Sulaiman \& Wickramasinghe, 2014; Wickramasinghe \& Schaffer, 2010). These electronic healthcare records (EHR) can help in managing a single record instead of multiple records for same patient, and thus also reducing multiple testing/treatment or medication (Duncan et al., 2010; Hillestad et al., 2005).

Especially, when it comes to treating of cancer patients, the need to avoid every possible error becomes even more crucial due to the toxicity and cost of drugs and radiation therapies (Evans, Ashbury, Hogue, Smith, \& Pun, 2014; Fasola et al., 2008). Therefore, the need to synchronize all treatments, provide instant access to updated records and information on the latest state of tumour/disease and informed decision making through a cancer registry becomes very crucial (Duncan et al., 2010). No two cancer patients are the same, even though there might be two persons having similar conditions and symptoms of cancer, their treatment plan and recovery will vary depending upon a variety of different factors (Štambuk, Šundov, Kuret, Beljan, \& Anđelinović, 2010; "Understanding Cancer," 2018). Therefore, their treatment needs to be very personal and entirely customised to help them recover better and faster ("No two breast cancer patients are the same and treatment should be tailored ", 2018). Thus, arising a necessity for incorporating a variety of treatment plans and multidisciplinary departments within or across the hospitals into one single system (Crawford, 2013; Herre \& Heller, 2004).

The utilization of an oncology information system (OIS) helps in integration of radiation oncology, particle therapy and medical oncology patient data into a single database with multi-user and multiple site access (Janssen et al., 2017). The OIS seamlessly connects to any linear accelerator and treatment planning system. It also helps in the evaluation and comparison of patients under treatment to existing data in cancer registries, using artificial intelligence (A.I.) to speed up process and minimize errors. Development of disease specific clinical protocols are made easy by OIS and it helps in generating standard and consistent care (Krayenbuehl, Norton, Studer, \& Guckenberger, 2015). By utilizing OIS, clinicians can monitor the amount of dose and review treatment images in one single system to determine if they need to change the dosing plan (Cheng, Wu, Liu, \& Kwong, 2011). 
$31^{\text {ST }}$ Bled eConference: Digital TRANSFormation: MeEting the Challenges

June 17 - 20, 2018, BLED, SLOVENIA, CONFERENCE PROCEEDINGS

M. N. Shuakat \& N. Wickramasinghe: Critical success factors in the design of suitable oncology platforms

Methodology

The objective of this exploratory qualitative study was to assess the critical aspects of leading OIS when implemented into the Australian healthcare context. To do this, we adopted a mixed methodology; first we compared 3 leading solutions that were developed either in US or Europe. Comparisons were made by performing a hermeneutic analysis on all publically available data. In addition, site visits (public and private healthcare sector) took place. We then conducted focus group discussion respectively with patients and clinicians (in both the public and private sectors) to further ascertain their perspectives of features they would like in such systems and how these might be beneficial. The initial findings are presented below.

\subsection{Comparison and discussion of different OIS:}

Three different leading international oncology information systems were analysed. Specifically, their main features as relevant and beneficial in the Australian health care system for cancer care were examined. The summary of the comparison is presented in Table 2. After completing the comparison for these systems, a focus group discussion with oncology clinicians \& patients was conducted to further gain important insights.

From Clinician and healthcare provider's point of view it was noted that most of the providers (public hospitals and private) have had different systems of patient data recording and maintaining. This makes it challenging for clinicians who must work with multiple systems. Different hospitals are now collaborating, or amalgamating to become a big single healthcare provider through acquisitions. This then means that they need to integrate their previously separate systems within and across the different sites. This is challenging however, due to the differences of existing infrastructure and their versions; hence, more often than not poor integration, disrupted work flow and different user interfaces result. After discussions with oncology clinicians and managers at different healthcare organisations, critical factors were identified to improve the overall performance of OIS including:

- Adherence to agreed international and Australian standards

- Interoperability and leverage of existing assets and capabilities

- Need to fit Australian/Victorian healthcare system e.g., VMOs (visiting medical officers)

- Inclusion of billing and concession through PBS and MBS systems

- Need for real time data exploring, updating and communication of change in plan

- Special attention to encryption, privacy and cyber security issues

- Need for auto triggering and notification of change in plan for medication or radiation

- Need to distribute and calculate share for specialists and nurses

- Licensing issues within and among different health care providers

- Transferring and accessing data within and from different sites 
- Access for organizations not having OIS e.g., Medicare or other agencies

- Consistency around treatments protocols, timelines and costing forecasting

- Web based with login access from anywhere

- Value for money, the selected digital technology must be cost effective and productive

- OIS must be capable for keeping track of safety and quality control in medication, treatment, scheduling of appointments.

From patient, family members and care provider's points of view, it was found that the person who suffers the most is the cancer patient and family members. The patient and family members' needs and desires tend to be the most ignored during the treatment and recovery phases and hence the patient experience is less than satisfactory. For many clinicians, nurses and healthcare providers the patient is just another subject and one more case study for different treatments. The patients were desirous of more empowerment and access to information and data through psychological surveys, awareness / training, visual treatment, booking/cancelling/ rescheduling their appointments. Further, having the capacity to participate in patient reported outcomes and self-reporting pain and progress of recovery on a daily and hourly basis was key for them to improve their patient experience. Many patients also wanted the ability to log their medication e.g., missing and on-time or ordering for repeats. To summarise, the key factors from Australian patient point of view:

- $\quad$ Pain grading and registering

- User friendly interface and ease of interpretation

- Psychological, emotional and social support or stories

- Up to date knowledge on new treatments and ongoing research

- Training and visual experiences for treatments and therapies

- Automatic concession and payments through PBS and MBS

- Keeping privacy and confidentiality of patients, the data should be available anonymously for research and matching with similar case studies, their implications, complications and recoveries. 
M. N. Shuakat \& N. Wickramasinghe: Critical success factors in the design of suitable oncology platforms

Table 3: Comparison of different leading international oncology inforamtion systems (OIS) in Australian context

\begin{tabular}{|c|c|c|c|}
\hline & System A & System B & System C \\
\hline $\begin{array}{l}\text { Multiple } \\
\text { therapies } \\
\text { (medical \& } \\
\text { radiation } \\
\text { oncology) }\end{array}$ & - $\quad$ Yes & - $\quad$ Yes & Yes \\
\hline Billing & $\begin{array}{ll} & \text { Billing \& cancer registry } \\
\text { - } & \text { Missed-procedure billing } \\
\text { advisories }\end{array}$ & $\begin{array}{l}\text { Billing and } \\
\text { other third-party } \\
\text { systems }\end{array}$ & $\begin{array}{l}\text { Claims and } \\
\text { billing data } \\
\text { from } \\
\text { financial } \\
\text { systems }\end{array}$ \\
\hline $\begin{array}{l}\text { Image } \\
\text { management }\end{array}$ & 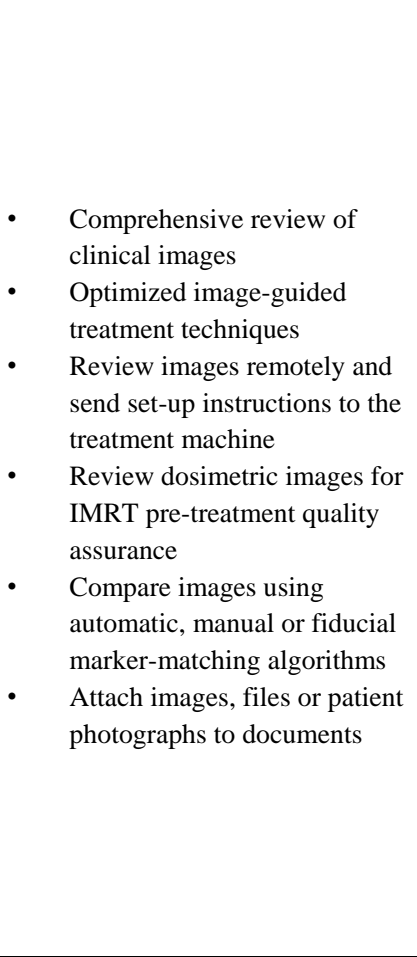 & $\begin{array}{ll}\text { - } & \text { Sophisticated } \\
\text { image } \\
\text { visualization \& } \\
\text { distribution } \\
\text { - } 3 \text { D viewers: } \\
\text { RTP, XVI, \& } \\
\text { iView GT }{ }^{\mathrm{T} M} \\
\text { integration, } \\
\text { adding and } \\
\text { synchronizing } \\
\text { tools, 2D image } \\
\text { registration, } \\
\text { volume image } \\
\text { viewing } \\
\text { External image } \\
\text { registration } \\
\text { Stereoscopic \& } \\
\text { volume image } \\
\text { registration } \\
\text { Setup details, } \\
\text { immobilization } \\
\text { devices and } \\
\text { reference } \\
\text { images entered } \\
\text { into treatment } \\
\text { chart }\end{array}$ & $\begin{array}{l}\text { Present } \\
\text { complex, } \\
\text { personalized } \\
\text { analytics on } \\
\text { individual } \\
\text { patients } \\
\text { based on } \\
\text { clinical, } \\
\text { molecular, } \\
\text { and other } \\
\text { relevant data } \\
\text { in a clinically } \\
\text { actionable } \\
\text { format }\end{array}$ \\
\hline $\begin{array}{l}\text { Clinician led and } \\
\text { patient-centric }\end{array}$ & $\begin{array}{l}\text { Appointment scheduling, review } \\
\text { images remotely, customisable data } \\
\text { collection forms and questionnaires }\end{array}$ & $\begin{array}{l}\text { Electronic patient } \\
\text { management allows } \\
\text { users to achieve a } \\
\text { paperless, filmless } \\
\text { working } \\
\text { environment; } \\
\text { treatment setup }\end{array}$ & $\begin{array}{l}\text { Configure CARE } \\
\text { reports to contain } \\
\text { personalized } \\
\text { analytic content } \\
\text { and historical } \\
\text { patient content } \\
\text { formatted to your }\end{array}$ \\
\hline
\end{tabular}


M. N. Shuakat \& N. Wickramasinghe: Critical success factors in the design of suitable oncology platforms

\begin{tabular}{|c|c|c|c|}
\hline & & $\begin{array}{l}\text { workflow } \\
\text { management }\end{array}$ & $\begin{array}{l}\text { institution's \& } \\
\text { clinician's specific } \\
\text { needs }\end{array}$ \\
\hline $\begin{array}{l}\text { Information and } \\
\text { analytics }\end{array}$ & Pain scoring to identify trends & Trend analysis & $\begin{array}{l}\text { Integration, } \\
\text { aggregation \& } \\
\text { personalized } \\
\text { analytics on highly } \\
\text { complex, } \\
\text { disparate, multi- } \\
\text { institutional data } \\
\text { sources }\end{array}$ \\
\hline $\begin{array}{l}\text { Adherence to } \\
\text { agreed standards } \\
\text { and } \\
\text { interoperability } \\
\text { \& leveraging } \\
\text { existing assets } \\
\text { and capabilities }\end{array}$ & $\begin{array}{l}\text { Automates patient-data transfer } \\
\text { with external hospital systems using } \\
\text { standard communication protocols }\end{array}$ & $\begin{array}{l}\text { Seamless } \\
\text { connectivity to } \\
\text { virtually any linear } \\
\text { accelerator \& } \\
\text { treatment planning } \\
\text { system from any } \\
\text { vendor, providing } \\
\text { unmatched } \\
\text { integration, freedom } \\
\text { and flexibility }\end{array}$ & $\begin{array}{l}\text { IT team, data and } \\
\text { network security } \\
\text { resulting in very } \\
\text { fast time-to-value. }\end{array}$ \\
\hline PBS / MBS & - & - & - \\
\hline $\begin{array}{l}\text { Robust privacy, } \\
\text { security and data } \\
\text { protection }\end{array}$ & $\begin{array}{l}\text { Built-in EDI (electronic data } \\
\text { interchange) for } \\
\text { secure online claim submissions } \\
\text { High Availability and Rapid } \\
\text { Recovery Protection (HARRP) } \\
\text { continuous data protection and } \\
\text { ensures minimal data loss and } \\
\text { immediate recovery }\end{array}$ & $\begin{array}{l}\text { Eliminate error-prone } \\
\text { work through tight } \\
\text { integration that } \\
\text { enables the seamless } \\
\text { transition of data } \\
\text { between tools }\end{array}$ & - \\
\hline $\begin{array}{l}\text { Safety and } \\
\text { Quality }\end{array}$ & $\begin{array}{l}\text { Facilitates compliance with the } \\
\text { Work Health and Safety (WHS) } \\
\text { Act }\end{array}$ & $\begin{array}{l}\text { Manual, barcode and } \\
\text { biometric patient } \\
\text { identification and } \\
\text { verification options } \\
\text { provide multilevel } \\
\text { safety checkpoints }\end{array}$ & $\begin{array}{l}\text { Quality and safety } \\
\text { reporting. }\end{array}$ \\
\hline $\begin{array}{l}\text { Comparison of } \\
\text { cost, } \\
\text { complications, } \\
\text { toxicity and } \\
\text { practice }\end{array}$ & - & - & $\begin{array}{l}\text { System C gives } \\
\text { comparison of } \\
\text { cost, } \\
\text { complications, } \\
\text { toxicity and even } \\
\text { between different } \\
\text { practice centres or } \\
\text { clinics. }\end{array}$ \\
\hline
\end{tabular}


M. N. Shuakat \& N. Wickramasinghe: Critical success factors in the design of suitable oncology platforms

\section{Conclusion}

This study is a first step in a longer research stream to identify key needs and critical success factors for OISs. We conducted a comparison of 3 leading international OISs and followed this up by focus group discussions with clinicians and patients (both public and private healthcare sectors) respectively. Our initial findings have been summarized above. Cancer is becoming a leading cause of death globally and has stretched healthcare budgets due to expensive medicine and radiation therapies. Oncology information systems can help in integrating patient history, imaging data, medication, radiation, recovery \& progress and change in plan from multiple users and multiple sites. Unfortunately, most of the leading international OIS available are not designed and customized for the Australian context. Communication and interoperability among existing systems and assets along with access to medical specialists and government agencies for up to date data monitoring and subsidized treatments need to be included into these systems. From patient's prospective, ease and access of using systems for appointment scheduling, rescheduling and cancelling, learning regarding treatment protocols and pathways available, survivor stories, peer and family support, pain grading \& registering and finally medication missing or overdosing logging were main concerns. Inclusion of these key factors into any oncology information systems will make such system more likely to gain strong clinician and patient user satisfaction and thereby provide a successful and superior transformation of care in this context.

\section{References}

Berwick, D. M. (2003). Disseminating innovations in health care. Jama, 289(15), 1969-1975. doi: 10.1001/jama.289.15.1969

Cancer in Australia. (2017). Retrieved 19/02/2018, from https://www.cancer.org.au/aboutcancer/what-is-cancer/facts-and-figures.html

Cancer in Australia 2017. (2017). Canberra: Australian Institute of Health and Welfare.

Cancer in Australia in breif 2017. (2018). Retrieved 19/02/2018, from https://www.aihw.gov.au/getmedia/a7ef1bb6-c61a-4046-97f3-8dea2fd315c0/cancer-inaustralia-in-brief-2017-slideshow.pptx.aspx

Cheng, H. C., Wu, V. W., Liu, E. S., \& Kwong, D. L. (2011). Evaluation of radiation dose and image quality for the Varian cone beam computed tomography system. International Journal of Radiation Oncology• Biology• Physics, 80(1), 291-300.

Crawford, S. (2013). Is it time for a new paradigm for systemic cancer treatment? Lessons from a century of cancer chemotherapy. Frontiers in pharmacology, 4, 68.

Duckett, S., \& Willcox, S. (2015). The Australian health care system: Oxford University Press.

Duncan, L. D., Gray, K., Lewis, J. M., Bell, J. L., Bigge, J., \& McKinney, J. M. (2010). Clinical integration of picture archiving and communication systems with pathology and hospital information system in oncology. The American Surgeon, 76(9), 982-986.

Evans, W., Ashbury, F. D., Hogue, G., Smith, A., \& Pun, J. (2014). Implementing a regional oncology information system: approach and lessons learned. Current Oncology, 21(5), 224.

Fasola, G., Aita, M., Marini, L., Follador, A., Tosolini, M., Mattioni, L. Aprile, G. (2008). Drug waste minimisation and cost-containment in medical oncology: two-year results of a feasibility study. BMC health services research, 8(1), 70. 
M. N. Shuakat \& N. Wickramasinghe: Critical success factors in the design of suitable oncology platforms

Herre, H., \& Heller, B. (2004). Ontological foundations of medical information systems. Paper presented at the New Trends in Software Methodologies, Tools and Techniques: Proceedings of the Third SoMeT_W04, volume 111 of Frontiers in Artificial Intelligence and Applications.

Hillestad, R., Bigelow, J., Bower, A., Girosi, F., Meili, R., Scoville, R., \& Taylor, R. (2005). Can electronic medical record systems transform health care? Potential health benefits, savings, and costs. Health affairs, 24(5), 1103-1117.

Janssen, A., Brunner, M., Keep, M., Hines, M., Nagarajan, S. V., Kielly-Carroll, C. Shaw, T. (2017). Interdisciplinary eHealth Practice in Cancer Care: A Review of the Literature. International journal of environmental research and public health, 14(11), 1289.

Krayenbuehl, J., Norton, I., Studer, G., \& Guckenberger, M. (2015). Evaluation of an automated knowledge based treatment planning system for head and neck. Radiation Oncology, 10(1), 226.

No two breast cancer patients are the same and treatment should be tailored (2018). Retrieved 05/03/2018, 2018, from http://www.totalhealth.co.uk/blog/no-two-breast-cancer-patients-aresame-and-treatment-should-be-tailored

Nutbeam, D. (2008). The evolving concept of health literacy. Social science \& medicine, 67(12), 2072-2078.

Prince, M. J., Wu, F., Guo, Y., Robledo, L. M. G., O'Donnell, M., Sullivan, R., \& Yusuf, S. (2015). The burden of disease in older people and implications for health policy and practice. The Lancet, 385(9967), 549-562.

Prostate cancer in Australia. (2013): Australian Institute of Health and Welfare 2013.

Štambuk, S., Šundov, D., Kuret, S., Beljan, R., \& Anđelinović, S̆. (2010). Future perspectives of personalized oncology. Collegium antropologicum, 34(2), 763-769.

Sulaiman, H., \& Wickramasinghe, N. (2014). Assimilating Healthcare Information Systems in a Malaysian Hospital. CAIS, 34, 77.

Torre, L. A., Siegel, R. L., Ward, E. M., \& Jemal, A. (2016). Global cancer incidence and mortality rates and trends - an update. Cancer Epidemiology and Prevention Biomarkers, 25(1), 16-27.

Twitter graphic cancer in Aust 2017. Retrieved 19/02/2018, 2018, from https://www.aihw.gov.au/getmedia/96aa3854-ceb0-40c5-8d25-27d4b1098490/twittergraphic-cancer-in-aust-2017.pdf.aspx

Understanding Cancer. (2018). Retrieved 5/03/2018, 2018, from https://www.mesotheliomagroup.com/our-mission/resources/understanding-cancer/

Wickramasinghe, N., Haddad, P., Vaughan, S., Han-Lin, C., \& Moghimi, H. (2015). Identifying key success factors for the adoption and implementation of a chemotherapy ordering system: A case study from the Australian private healthcare sector. Paper presented at the $21 \mathrm{st}$ Americas Conference on Information Systems, AMCIS 2015.

Wickramasinghe, N., \& Schaffer, J. (2010). Realizing value driven e-health solutions. Washington DC: Report for IBM.

Yach, D., Hawkes, C., Gould, C. L., \& Hofman, K. J. (2004). The global burden of chronic diseases: overcoming impediments to prevention and control. Jama, 291(21), 2616-2622. 
248 31 $31^{\text {ST }}$ Bled eConference: Digital Transformation: MeEting the Challenges JunE 17 - 20, 2018, BLED, SLOVENIA, CONFERENCE PROCEEDINGS 


\title{
Digital Wellness Services: Key to Better Quality of Life for Young Elderly
}

\section{CHRISTER CARLSSON \& PIRKKO WALDEN}

\begin{abstract}
Digital wellness services for the "young elderly" (the 60-75 years old age group) will be interventions in their daily routines and if/when they are accepted and adopted they will help keep the young elderly in better shape for their senior years (75+). This will contribute to significant reductions in the estimated costs for health and social care for the ageing population. On an individual level, digital wellness services contribute to a better quality of life if designed to fit the needs of the young elderly. Platform tech- nology for digital services offers possible tools for intervention if the tools and services fit the requirements of the young elderly. We summarize several of our studies as a syn- thesis and work out a conceptual framework to facilitate the design and implementation of digital wellness services.
\end{abstract}

Keywords: • Young Elderly • Wellness • Digital Services • Conceptual Frame- work •

CoRrespondence AdDress: Christer Carlsson, Dr, Professor, Institute for Advanced Management Systems Research, Auriga Business Center, 20100 Turku, Finland, e-mail: christer.carlsson@abo.fi. Pirkko Walden, Dr, Professor, Institute for Advanced Management Systems Research, Auriga Business Center, 20100 Turku, Finland e-mail: pirkko.walden@abo.fi 
The socioeconomic impact of ageing citizens is already high in most EU countries as their proportion of the population is growing and there is growing political pressure to find long- term strategies for the ageing population (UN (2014)). The strategic thinking focuses more on handling the health and social care costs of ailing senior citizens than on preventive programs to keep ageing citizens in better health all the way to advanced years. It would make more sense to find out if some proactive, preventive program could help reduce the annual cost in- creases expected for the ageing population (UN (2014)).

The logic we worked out is quite simple: get the young elderly [the 60-75 years old age group] to change their daily routines in ways, which will improve their probability to have a healthy life into advanced age [described as 90+].

There are some basic facts to build on. The young elderly represents $18-23 \%$ of the population in most EU countries; this is a large segment, recent statistical estimates show that it will be about 97 million EU citizens by 2020 (EC (2014)). In the Nordic countries, there were close to 4 million citizens in the young elderly age group in 2016 (Nordic (2017)).

Rough estimates (worked out from Statistics Finland (2016)) show that the annual benchmark cost for health and social care for the ageing population could be around 320$350 \mathrm{~B} €$ in the EU countries. We can probably reduce this cost by $10-15 \%$ if we get young elderly physically more active. In a 5-year program with an enrolment of $15-20 \%$ of the age group we could get about 20 million young elderly to stay healthy which will save costs of at least 20-25 B€ annually. Staying healthy should be a long-term program which means that the effects move on to the senior $[75+]$ age group where the annual costs and the potential savings are much higher.

A proactive program to build digital wellness services for the young elderly is interesting for the digital services industry as the young elderly represent very large and growing markets (given income levels and accumulated wealth).

The focus on the young elderly is a new approach for digital services, a market for which there has been no interest to develop mobile value services (Bouwman et al (2014), Carlsson and Walden (2012)). There is another, more important reason - society needs to have a strategy for the young elderly different from the health and social care strategy for the senior age group. A majority of the young elderly are reasonably healthy, active and socially interactive and do not require much intervention or support from the public health and social care systems. Conse- quently, the various programs for the ageing population (EC (2014)) miss the young elderly and the possibilities to build proactive and preventive programs.

We collected first-hand knowledge and experience of the young elderly market in Finland through the Data to Intelligence (D2I) SHOK program (Tekes 340/12) and we have 
continued work on the themes opened up in the program in several studies (Carlsson and Walden (2016, 2017a, 2017b)).

A first result we found was that wellness services are needed and useful - and wanted for individual young elderly; a second result was that wellness services need to be digital to make them accessible efficiently and cost-effectively - the preferred way of distribution is through smartphones. A third result emphasized the need for an ecosystem of designers, developers, builders, maintainers and distributors of the digital services to have enough resources available to service 100-200 000 users (first in Finland). This again, as a fourth result, requires an indus- try and university collaboration network. A fifth result, is that there is potential for building a young elderly EU market, which may both grow very fast and be very large.

The aim with digital wellness services - as we could summarize it - is to find methods and tools to form and support interventions to introduce and sustain wellness routines. These rou- tines will improve the probability for better health in senior years and better quality of life for an ageing population.

The rest of the paper follows this storyline. In section 2, we will work out approaches to well- ness and some requirements on digital wellness services to contribute to and sustain wellness. In section 3, we summarize material from several empirical studies in order to get early verifi- cation of how the proposed storyline could work. In section 4, we work out a conceptual frame- work to serve as a basis for the design of digital wellness services. Section 5 is a summary with some conclusions.

\section{$2 \quad$ Wellness and Digital Wellness Services for Young Elderly}

The WHO defines wellness as "the complete mental, physical as well as social well-being of a person or groups of persons in achieving the best satisfying or fulfilling life and not merely the absence of disease or any form of infirmity (WHO (2014)). "Well-being" is imprecise as it builds on anything from systematic action to random events. We decided on wellness as it fit our requirements for the design of digital wellness services. Wellness gets meanings from dif- ferent angles (Adams (2003), Rachele et al (2013)) in various contexts, and is an active research area (UCR (2013)). For work with young elderly user groups, we adopted a practical definition: wellness - to be in sufficiently good shape of mind and body to be successful with all everyday requirements.

The understanding of wellness follows insights we got from the young elderly themselves: "it is nicer to get old if you are in good shape" or a more serious version: "to get good remaining years".

Our early work built on an ad hoc assumption that wellness mostly comes from physical activ- ity. Literature studies show that there are many more aspects to wellness (Rachele et al (2013), UCR (2013)). 
Physical wellness (to be in good shape) is easy to understand and to work out. Studies show (Jonasson (2017), Wallén et al (2014)) that physical exercise is a corner stone for sustaining a good quality of life in senior years. The young elderly themselves report (Carlsson and Walden (2016)) that as they turned 60 they noticed that their bodies start to impose functional limita- tions on them and realized that some active measures will be required to improve on things. Karolinska Institutet (Wallén et al (2014)) shows in a synthesis of several studies of physical wellness routines over several years for 2500 elderly Swedes (the age group 65-84), some in- teresting results. The findings are that $12 \% / 14 \%$ female/male show no activity to improve their physical wellness. There are $69 \%$ / 64\% female/male, who show regular physical wellness activity at low or medium intensity (recommendation: at least 150 minutes at medium intensity every week). The remaining about $20 \%$ show regular physical wellness activity at medium or high intensity. Only regular physical activity at high intensity will have long-term health ef- fects.

For young elderly the questions are what exercises and how to get health effects (and some- times at what cost and even why). There are good answers to the why - research shows that work on physical wellness will have positive effects also on intellectual, emotional and social wellness and will reduce the probability to get serious (often agerelated) illnesses (Wallén et al (2014)). The what, how and at what cost is the arena for digital wellness services.

Intellectual wellness is more difficult, it is more demanding to work on building and sustaining intellectual wellness. Among the young elderly, we have registered concern for deteriorating cognitive capability and capacity, for memory loss and for the onset of Alzheimer disease. Work on physical wellness will reduce the probability for Alzheimer (Jonasson (2017)) and serious game theory, methods and technology (Birkenbush and Christ (2013)) will contribute to building and sustaining cognitive capability. Digital wellness services with serious games could contribute to cognitive capabilityand to sustaining memory functions.

Social wellness combines with both physical and intellectual wellness. Social media with many variations (Hanna et al (2011) offer viable platforms for connecting with other people. Physical exercise gets more effective in peer groups through challenges and cooperation (Walden et al (2017)). Group members can share insight and experience on effective wellness routines, social media links to innovative and good exercises and experience with health effects. Much in the same way, peer groups form around and with serious games (Birkenbush and Christ (2013)). Young elderly we worked with in focus groups (Sell et al (2017)) described that some ailments will prevent them from getting active on physical wellness, which then will close them out of the corresponding peer groups. Unless they find stimulation in intellectual wellness activities, which include cultural programs of various kinds, and the peer groups in these activities, they will be lonely. Loneliness is an often-reported malady in the ageing population (Walden et al (2017)) and will have a negative impact on emotional wellness. On the other hand, young el- derly of our focus groups (Sell et al (2017)) quite often stressed, "being alone by choice is not being lonely". 


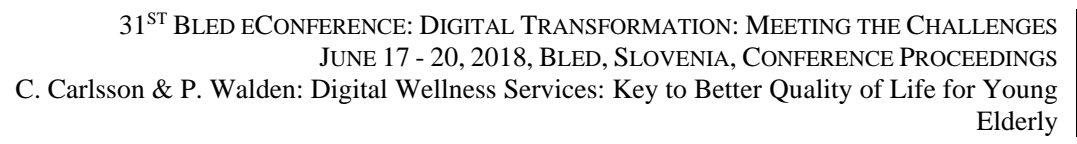

253

Emotional wellness is now the arena for studies with mindfulness tools, of which there are more than 200 apps for Android smartphones (van Emmerick et al (2018)). Mindfulness-based interventions induce improvements of positive affect and depression (van Emmerick et al (2018)).

We have focused the development of digital wellness services on physical, intellectual, social and emotional wellness and on sustaining this support for the time needed to gain and sustain positive health effects for the young elderly into advanced years (the age group $90+)($ Carlsson and Walden (2017a)).

A first observation is that we are going to need and use digital wellness services for 1520 years. In the digital service market, where applications typically need to be improved and re- launched every 6-12 months, this means dozens of generations of digital services. A second observation follows; an ecosystem of about 100 SMEs should develop, sustain and innovate the generations of digital services the young elderly will adopt, pay for and use for 15-20 years. A third observation is that the young elderly is a demanding user group; digital wellness ser- vices need to be intuitive, easy to use (probably voice activated), user and context adaptive (probably omnivore), i.e. the services apply advanced and innovative technology. A fourth observation is that even with reasonable success the digital wellness services will have hun- dreds of thousands of users (even 11.5 million) in the Nordic countries only (the estimates upgraded in 2018). Distribution of the services need to build on cloud service platforms. The user interfaces are (families of) applications on smartphones that collect data and support wear- ables. Software should be advanced enough and adaptable to the users to fit the requirements of young elderly.

Statistics show that smartphones are becoming affordable general purpose instruments and will be even more so by the year 2020 (the mobile connection subscriptions are more than $100 \%$ of the population in most EU countries; the proportion of smart phones is closing on 70\% in several EU countries (Ericsson (2017)). Statistics Finland (2017) shows that close to $80 \%$ of the age group 55-64 own and use smartphones. Thus, counting on smartphones as the platform is viable.

\section{$3 \quad$ Early Empirical Findings}

We have carried out a number of empirical studies with groups of young elderly in order to get first tests of the wellness concepts we are working with and to find out if the visions we have on digital wellness services make sense. We will briefly summarize the key findings from these studies; details in (Carlsson and Carlsson (2016), Carlsson and Walden $(2016,2017 \mathrm{a}, 2017 \mathrm{~b}))$. We carried out a survey of the young elderly in the Åland Islands and collected 101 usable answers with a $26.6 \%$ response rate. There was a female majority among the respondents, and most of them belonged to the young elderly group (a few were seniors). A minority had only basic education (21\%), the majority had second level technical/commercial degrees. In the sample, about $75 \%$ were retired (fully retired as some of them stated) but $25 \%$ were working full- or part-time or with voluntary work (in order to stay active). The most typical annual incomes before tax were $<30000 €$ (about 
$50 \%$ of the sample), but the other half reported 30-50 $000 €$, which is on the higher end of annual income for Finnish retirees (Staistics Finland (2016)). These profiles are typical and representative for the Åland group of young elderly.

We found that $73 \%$ of the respondents used smartphones; we also found that $73 \%$ of the re- spondents used mobile apps for navigation, weather forecasting, Internet search, etc. (which require smartphones).

We collected experience with and attitudes to mobile apps with a series of questions (Venkatesh et al. (2012)), in order to get some idea on how to build digital wellness services. The adoption of mobile apps scored high on a 5-grade Likert scale on several items; the following items scored between [4.32] and [3.75] for 70 respondents and show elements, we need to be aware of,

- mobile apps are useful in my daily life; I will continue to use mobile apps; mobile apps help me to carry out my tasks faster; using mobile apps helps me to carry out important tasks; I can use mobile apps without assistance; I have the necessary knowledge to use mobile apps; it is easy for me to learn to use mobile apps; I can use the mobile apps I need with the phone I have.

The results gave us some insight to build on: (i) daily routines is a good choice for focus; (ii) wellness routines should be important part of daily routines; (iii) digital wellness services should be usable without assistance; (iv) smartphone users have sufficient skills to learn digital services.

Then we moved on to get an understanding of what perceptions the young elderly have of physical and intellectual wellness. A number of proposals scored high on a 6-grade forced scale (101 respondents); the following items scored between [4.91] and [3.94]:

- intellectual challenges are important for my wellbeing; I get sufficient intellectual stimulation from my everyday life; my physical health has been good compared to people around me; my resistance to illness is good; the amount of information I have to process in my daily life is suitable for me (not too much, not too little); I expect my physical health to remain good; I expect my physical health to deteriorate with increasing age.

The results show that young elderly have a good understanding of what forms wellness (cf. Carlsson and Walden (2016, 2017a, 2017b) for details), which is encouraging for work on the design of digital wellness services. There is also understanding of interaction between physical and intellectual wellness.

Then we tested the idea that relations between socio-economic characteristics, attitudes toward the use of mobile applications and perceptions about wellness could help identify potential users (see details in Carlsson and Carlsson (2016), Carlsson and Walden (2016)).

After discussion and feedback on the earlier papers, we realized that this proposal could be tested with potential user groups. These could include early users of wellness services 
(early movers, in the Rogers theory) who could trigger a growing demand for digital wellness services (Rogers (1962)). We will give a brief summary of the methods we used (Carlsson and Carlsson (2016), Carlsson and Walden (2017 a,b) for details).

The starting point was a factor analysis with 19 statements on mobile applications and 11 state- ments on wellness to find possible groupings. The results gave an indication for possible sum variables (cf. Table 1, first column) which we tested for reliability by calculating Cronbach's alpha coefficients; we reached the target value $(\alpha>0.7)$ for the constructed sum variables (cf. Table 1, the names show the groupings we found, for instance mobile_apps_positive is a grouping of respondents that are positive to the use of mobile apps).

Table 1: Mann-Whitney U-test on sum-variables.

\begin{tabular}{|c|c|c|c|c|c|c|c|c|c|c|c|c|c|c|}
\hline \multicolumn{15}{|l|}{ Mann-Whitney U-test, $\square=0.05$} \\
\hline \multirow[b]{2}{*}{ SUM VARIABLES } & \multicolumn{2}{|c|}{ Age } & \multicolumn{2}{|c|}{ Gender } & \multicolumn{2}{|c|}{ Highest level of education } & \multicolumn{2}{|c|}{ Marital status } & \multicolumn{2}{|c|}{ Current work status } & \multicolumn{2}{|c|}{$\begin{array}{c}\text { Annual income before tax } \\
€\end{array}$} & \multicolumn{2}{|c|}{$\begin{array}{l}\text { Level of experience using } \\
\text { mobile apps }\end{array}$} \\
\hline & $-69 \mathrm{yrs}$ & $70-y r s$ & male & female & - institute & $\begin{array}{l}\text { higher } \\
\text { vocational } \\
\text { school - }\end{array}$ & single & $\begin{array}{l}\text { in a } \\
\text { relation- } \\
\text { ship }\end{array}$ & $\begin{array}{l}\text { in working } \\
\text { life a/o } \\
\text { volunteer }\end{array}$ & retired & -30000 & $30001-$ & routine & advanced \\
\hline \multicolumn{15}{|l|}{ Mobile_apps_positive } \\
\hline Asymp. Sig (2-tailed) & \multicolumn{2}{|c|}{0.001} & \multicolumn{2}{|c|}{0.622} & \multicolumn{2}{|c|}{0.068} & \multicolumn{2}{|c|}{0.977} & \multicolumn{2}{|c|}{0.002} & \multicolumn{2}{|c|}{0.725} & \multicolumn{2}{|c|}{0.036} \\
\hline $\begin{array}{l}\text { Mobile_apps_experienced } \\
\qquad \text { Mean rank }\end{array}$ & 35.10 & 32.37 & 34.71 & 33.31 & 27.87 & 38.14 & 34.57 & 33.74 & 39.13 & 31.22 & 29.20 & 37.80 & 20.75 & 36.42 \\
\hline Asymp. Sig (2-tailed) & \multicolumn{2}{|c|}{0.572} & \multicolumn{2}{|c|}{0.767} & \multicolumn{2}{|c|}{0.034} & \multicolumn{2}{|c|}{0.871} & \multicolumn{2}{|c|}{0.128} & \multicolumn{2}{|c|}{0.067} & \multicolumn{2}{|c|}{0.003} \\
\hline $\begin{array}{l}\text { Mobile_apps_social } \\
\text { Mean rank }\end{array}$ & 34.69 & 31.67 & 30.79 & 36.38 & 31.35 & 34.90 & 35.36 & 32.57 & 32.58 & 33.17 & 35.00 & 32.00 & 27.84 & 33.41 \\
\hline Asymp. Sig (2-tailed) & \multicolumn{2}{|c|}{0.531} & \multicolumn{2}{|c|}{0.236} & \multicolumn{2}{|c|}{0.461} & \multicolumn{2}{|c|}{0.575} & \multicolumn{2}{|c|}{0.908} & \multicolumn{2}{|c|}{0.524} & \multicolumn{2}{|c|}{0.292} \\
\hline $\begin{array}{l}\text { Mobile apps value } \\
\qquad \text { Mean rank }\end{array}$ & 36.59 & 28.75 & 36.87 & 29.69 & 26.83 & 37.84 & 30.81 & 34.76 & 38.71 & 30.98 & 29.12 & 37.26 & 27.16 & 33.65 \\
\hline Asymp. Sig (2-tailed) & \multicolumn{2}{|c|}{0.096} & 0.1 & & 0. & D & 0.4 & & 0.1 & & 0.0 & & 0.2 & \\
\hline $\begin{array}{l}\text { Physical_wellness_positive } \\
\text { Mean rank }\end{array}$ & 48.88 & 45.79 & 57.27 & 40.00 & 44.48 & 50.16 & 48.41 & 47.78 & 54.16 & 45.47 & 40.84 & 54.45 & 40.13 & 33.45 \\
\hline Asymp. Sig (2-tailed) & & & 0.0 & D & & & 0.9 & & 0.1 & & $C$ & ) & 0.2 & \\
\hline $\begin{array}{l}\text { Intellectual_wellness_positive } \\
\text { Mean rank }\end{array}$ & 49.62 & 42.45 & 46.79 & 47.16 & 41.28 & 51.08 & 52.92 & 43.74 & 61.11 & 42.63 & 42.84 & 51.64 & 37.75 & 34.72 \\
\hline Asymp. Sig (2-tailed) & & & 0.9 & & & & 0.1 & & 0.0 & & 0.1 & & 0.5 & \\
\hline $\begin{array}{l}\text { Mobile_app_users } \\
\text { Mean rank }\end{array}$ & 36.01 & 26.29 & 32.25 & 31.74 & 26.38 & 35.46 & 31.63 & 32.17 & 38.69 & 28.56 & 29.58 & 33.30 & 16.50 & 34.93 \\
\hline Asymp. Sig (2-tailed) & 0 & $37)$ & 0.9 & & 0. & & 0.9 & & 0.0 & & 0.4 & & 0.0 & 8 \\
\hline Wellness_positive & 48.23 & 42.09 & 50.09 & 42.65 & 42.30 & 48.30 & 46.66 & 45.64 & 51.93 & 43.54 & 41.22 & 50.17 & 39.84 & 32.86 \\
\hline Asymp. Sig (2-tailed) & & & 0.1 & & & & 0.8 & & 0.1 & & 0.1 & & 0.2 & \\
\hline & $N=$ & 3-95 & $N=6$ & & $N=6$ & & $N=6$ & & $N=63$ & & $N=6$ & & $N=6$ & $3-95$ \\
\hline
\end{tabular}

We next run a non-parametric Mann-Whitney U-test to explore possible differences of the sum variables between gender, age, the highest level of education, marital status, current work sta- tus, annual income and level of experience of using mobile applications; the red "ovals" in Table 1 show significant differences.

In summary: we found significant differences in the positive attitudes to using mobile apps between the two age groups; the younger age group was more positive. The more educated group was experienced in using mobile apps. The more educated group was socially active in using mobile apps. The group with higher income gave more value to 
mobile apps. Males with higher income had a positive perception of (their) physical wellness. The group with a more active work status had a positive perception of their intellectual wellness.

Now we have some insight of how to introduce digital wellness services for young elderly. We should start with young elderly, who are,

- Active in full time/part time/volunteer work \& advanced users of mobile apps \& $<70$ years

- $\quad$ Experienced users of mobile apps \& more educated

- Males with good physical health \& income $>30 \mathrm{k} €$ per year

- More educated \& find mobile apps good value for the price

This insight needs, of course, testing with more groups of young elderly, but it is a starting point. It also makes sense - active people will be early movers (Rogers (1962)) and more edu- cated people younger than 70 are experienced users of smartphones and mobile apps. Males, who are more educated and have good income, find mobile apps good value for the price (and would be willing to pay for digital wellness services).

A survey of wellness literature (Walden et al (2017)) found that younger age, better health, higher education and not living alone is associated with higher likeliness to adopt and use technology among the elderly (the factors in italics are the same as those found with the Mann- Whitney). In addition, a positive and optimistic disposition gives a higher likeliness to adopt technology.

In (Walden et al (2017)) a market segmentation of the young elderly was done; $k$-means clus- tering of the Åland data identified two clusters labelled secure and insecure wellness. The young elderly in the secure cluster (i) were in good health, (ii) have an optimistic attitude to their future health, (iii) find intellectual activities important, and (iv) want to partake in intel- lectually demanding pastimes. These features add to those found with the Mann-Whitney and give a more complete view of what factors to focus on for intellectual wellness. Interestingly enough, the young elderly in the insecure cluster were (i) in worse health than people around them, (ii) pessimistic to their future health, (iii) negative to the importance of intellectual ac- tivities but (iv) willing to partake in them.

In semi-structured interviews with 34 young elderly, (Sell et al (2017), more potentially im- portant features were identified. There were attitudes of - what will others think of me - when the possibility to get active in physical wellness exercises was discussed. Another aspect - what would I do there - showed that the social context of wellness activities is new and somewhat problematic. Problems with - how to act in social situations - brought up aspects we had not thought about.

Separately we tested what would be a reasonable monthly cost for digital wellness services; we found that $19.95 € /$ month would be possible (cf. mobile apps good value for the price); the core issue is the value young elderly find with wellness interventions in their daily routines. The series of studies shows that it is meaningful to work out programs 
for digital wellness services for young elderly. Given that, there are technology challenges to build services that will be effective wellness interventions in daily routines, that will be meaningful and sustain- able, that will be cost-effective and that can be tailored (over time) for individual user require- ments.

\section{Conceptual Framework for Digital Wellness Services for Young Elderly}

Work on digital wellness services started off as an ad hoc exercise on activities that we regarded as needed and wanted. We assumed that we could develop activities for the intended users with wearables and smartphone platforms, activities that we could design, develop and implement as simple and self-evident constructs and that the intended users would rush to get, to start using and would be willing to pay for. Work with groups of young elderly, both in semi-struc- tured interviews and with a survey, quickly showed the context and the task to be more com- plex.

Besides the technology platforms we will also need a conceptual framework for key constructs of the various types of digital wellness services.

The concept of wellness is a fundamental starting point; we should be able to show if paying users of digital wellness services are better off at $t+1$ than they were at $t$ after having used the services. This is rather simple for individuals, but more demanding if the individual wants comparisons with peer, age, gender and health groups or against some accepted standard for wellness. Wellness is (for instance) graded in (Belohlavek et al (2017)) poor, marginal, me-dium, acceptable, good, excellent-for age, gender and health; maybe also for activity, income, intellectual activity, socio-economic status and attitude to life; factors that we found to have meaningful contributions to wellness.

We will use a standard approach and formulate wellness $(\mathrm{W})$ with a 4-tuple,

$$
\mathrm{W}=\langle\mathrm{P}, \mathrm{I}, \mathrm{S}, \mathrm{E}\rangle
$$

where P, I, S and E are numerical or linguistic sets (Belohlavek et al (2017)) that represent physical, intellectual, social and emotional wellness. Physical wellness gets grades in several different ways as wearables and smartphone apps try to support changes and improvements through physical exercises; we have selected the following elements,

$$
\mathrm{W}_{\mathrm{P}}=\left\langle\mathrm{P}_{\mathrm{STEPS}}, \mathrm{P}_{\mathrm{StReNGTH}}, \mathrm{P}_{\mathrm{GROUP}}, \mathrm{P}_{\mathrm{HR}}, \mathrm{P}_{\mathrm{KCAL}}, \mathrm{P}_{\mathrm{SLEEP}}, \mathrm{P}_{\mathrm{MISC}}>\right.
$$

where,

- $\quad$ PSTEPs covers walking, running \& variations; 10000 steps/day recommended

- P $_{\text {StRenGth }}$ covers gym programs; varied targets; $60 \mathrm{~min} /$ program recommended

- $\quad P_{\text {GROUP }}$ covers exercise programs done in group; varied targets

- $\quad P_{\text {HR }}$ covers heart rate; intensity; combines with the three previous measures

- $\mathrm{P}_{\mathrm{KCAL}}$ covers burn of calories; combines with the four previous measures

- $\quad$ PLEEP $_{\text {Sovers duration, quality of sleep }}$

- $\mathrm{P}_{\mathrm{MISC}}$ covers physical activities not planned as exercise (e.g. gardening) 
Physical wellness, $\mathrm{W}_{\mathrm{P}}$, will be an index that combines the six elements measured in different dimensions and registered on wearables and smartphones; we notice that there is a data fusion problem ( $\mathrm{Wu}$ and Crestani (2015)) as we need mappings between the various dimensions. Apps for physical exercises typically allow a user to set some targets and then report daily activity relative to target levels; there is typically no mapping the activities and no connection to any optimal target for the individual.

There are more challenges to follow and measure intellectual wellness, $\mathrm{W}_{\mathrm{I}}$,

$$
\mathrm{W}_{\mathrm{I}}=\left\langle\mathrm{I}_{\mathrm{GAMES}}, \mathrm{I}_{\mathrm{LITT}}, \mathrm{I}_{\text {MUSIC }}>\right.
$$

where,

- $\mathrm{I}_{\mathrm{GAMES}}$ covers serious games, memory games, cross-words, Sudoku

- I LITT $_{\text {covers literature, theatre }}$

- $\mathrm{I}_{\mathrm{MUSIC}}$ covers concerts, opera, choirs, classic ensembles, jazz bands

The extent and intensity of the intellectual activities will require some innovations on how to register and measure them.

On the other hand, social wellness, $\mathrm{W}_{\mathrm{S}}$, does not offer that many challenges, $\mathrm{W}_{\mathrm{S}}=\left\langle\mathrm{S}_{\mathrm{FAM}}, \mathrm{S}_{\mathrm{VA}}, \mathrm{S}_{\mathrm{SM}}, \mathrm{S}_{\mathrm{P} 2 \mathrm{P}}, \mathrm{S}_{\mathrm{ASSOC}}\right\rangle$

where,

- $\mathrm{S}_{\mathrm{FAM}}$ covers interactions with family, friends, colleagues, peers, hobby groups

- $\mathrm{S}_{\mathrm{VA}}$ covers volunteer activities to help others

- $\mathrm{S}_{\mathrm{SM}}$ covers interactions through social media

- $\mathrm{S}_{\mathrm{P} 2 \mathrm{P}}$ are person-to-person projects, joint activities

- $\mathrm{S}_{\mathrm{ASSOC}}$ are (active) membership in associations with interesting activities

Typically, $\mathrm{W}_{\mathrm{S}}$ activities are registered and measured in terms of frequency, duration and inten- sity for which it is possible to define target levels, objectives and goals.

Finally, emotional wellness, $\mathrm{W}_{\mathrm{E}}$, offers quite some challenges, as the substance is personal, individual and difficult to follow with digital devices. Here we have tried to capture some ele- ments,

$\mathrm{W}_{\mathrm{E}}=\left\langle\mathrm{E}_{\mathrm{MF}}, \mathrm{E}_{\mathrm{E}-\mathrm{APP}}\right\rangle$

where,

- $\mathrm{E}_{\mathrm{MF}}$ covers work with mindfulness tools

- E E-APP is a collection of emotional well-being apps

It appears possible to register $\mathrm{W}_{\mathrm{E}}$ and to measure the number and intensity of activities in the two entities based on personal reporting; there is a large number of mindfulness apps for smartphones and they may offer some measurement system, but there are challenges to find measures for adequate representation of emotional wellness. 


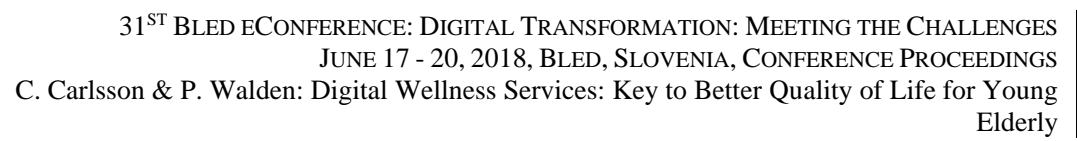

259

The sets defined in (2)-(5) are numerical and linguistic, i.e. defined as fuzzy sets (Belohlavek et al (2017)). We can work out fusion functions (Wu and Crestani (2015)) so that the wellness measures $\mathrm{W}_{\mathrm{P}}, \mathrm{W}_{\mathrm{I}}, \mathrm{W}_{\mathrm{S}}$, and $\mathrm{W}_{\mathrm{E}}$ are scalable as $[0,100]$ or as $[0,1]$, or as percentages of some ideal value vectors $\mathbf{W}_{\mathbf{P}}, \mathbf{W}_{\mathbf{I}}, \mathbf{W}_{\mathbf{S}}$, and $\mathbf{W}_{\mathbf{E}}$. The ideal values can first be some research-based targets (or even standards) but should become personalized and individual over time as well- ness is personal and individual. Then we can introduce context sensitive individual weight vectors that can be numerical or linguistic, to determine personal wellness status on a daily, weekly or monthly base:

$\mathrm{W}=\mathrm{w}_{1} \times \mathrm{W}_{\mathrm{P}} \Delta \mathrm{W}_{2} \times \mathrm{W}_{\mathrm{I}} \Delta \mathrm{W}_{3} \times \mathrm{W}_{\mathrm{S}} \Delta \mathrm{W}_{4} \times \mathrm{W}_{\mathrm{E}}$

In (6) the $\Delta$-operator can be additive or compensatory (Belohlavek et al (2017)) to allow for "lower status on physical wellness to compensate for higher status on intellectual wellness". Then a user can find daily or weekly (or monthly) satisfaction with her/his quality of life as reported on the smartphone.

\section{$5 \quad$ Summary and Conclusions}

We attempted a synthesis of several of our previous studies combined with supporting literature to get an improved knowledge base for building and implementing digital wellness services. We build on a simple logic: get the young elderly to change their daily routines in ways, which will improve their probability to have a healthy life into advanced age $[90+]$.

We have argued that wellness is a viable approach to achieve this change by using digital well- ness services as interventions in daily routines. We worked this out with physical, intellectual, social and emotional wellness constructs that we have fitted into a conceptual framework. The framework is proposed to serve the development of numerical, digital technology platforms, that combine fuzzy linguistic representations of wellness with fuzzy logic operators to form digital wellness services.

\section{References}

Adams, T. B. (2003), The Power of Perceptions: Measuring Wellness in a Globally Acceptable, Philosophically Con- sistent Way, Wellness Management. www.hedir.org

Belohlavek, R., Dauben, J.W. \& Klir, G.J. (2017). Fuzzy Logic and Mathematics. Oxford University Press

Birkenbush, J. \& Christ, O. (2013). Concepts behind Serious Games and Computer Based Trainings in Health Care: Immersion, Presence, Flow, doi: 10.4018/978-1-4666-3673-6.ch001, Information Science Reference (an imprint of IGI Global), March 2013

Bouwman, H., Carlsson, C., de Reuver, M., Hampe, F. and Walden, P. (2014). Mobile R\&D Prototypes - What is Hampering Market Implementation, International Journal of Innovation and Technology Management, Vol.11, No.1, 18 pages

Carlsson, C. and Walden, P. (2017). Digital Wellness Services and Sustainable Wellness Routines, in Marinos The- mistocleous and Vincenzo Morabito (eds.): Information Systems, 14th Euoropean, Mediterranean and Middle Eastern Conference (EMCIS 2017), Springer-Verlag, Heidelberg 2017, pp 337-352 
$31^{\text {ST }}$ Bled eConference: Digital Transformation: MeEting the Challenges JunE 17 - 20, 2018, BLED, SLOVEnia, CONFERENCE PROCEEDINGS

C. Carlsson \& P. Walden: Digital Wellness Services: Key to Better Quality of Life for Young Elderly

Carlsson, C. and Walden, P. (2017). Digital Coaching to Build Sustainable Wellness Routines for Young Elderly, Proceedings of the 30th eBled Conference, Bled 2017, pp 57-70

Carlsson, C. and Walden, P. (2016). Digital Wellness Services for the Young Elderly A Missed Opportunity for Mobile Services, JTAECR, Vol. 11, 2016

Carlsson, C. and Carlsson, J. (2016). Interventions to Form Wellness Routines Among Young Elderly, Proceedings of the 29th eBled Conference, Digital Wellness Track, pp 406-418

Carlsson, C. and Walden, P. (2012). From MCOM Visions to Mobile Value Services; Roger Clarke, Andreja Puchar and Joze Gricar (eds.), The First 25 Years of the Bled eConference, University of Maribor, Bled, pp 69-91

European Commission (2014), Population Ageing in Europe: facts, implications and policies, doi: $10.2777 / 60452$

Hanna, R., Rohm, A. \& Crittenden, V.L. (2011).We're all connected: The power of the social media Ecosystem, Busi- ness Horizons (2011) 54, 265-273

https://www.ericsson.com/assets/local/mobility-report/documents/2017/ericssonmobility-report-november-2017.pdf https://www.stat.fi/til/sutivi/2017/13/sutivi_2017_13_2017-1122_kat_002_fi.html

Jonasson, L. (2017). Aerobic Fitness and Healthy Brain Aging. Cognition, Brain Structure, and Dopamine, Doctoral Dissertation, Umeå University

Nordic countries (http://91.208.143.100/pxweb/norden/pxweb/en/Nordic\%20Statistics/Nordic\%20S tatistics Popu- lation_Population\%20projections/POPU06.px/?rxid=fff-33fb5-841d4c27-8e-7f-8b85c23036af 2017-05-29

Rachele, J. N., Washington, T. L., Cuddihy, T. F., Barwais, F. A. \& McPhail, S. M. (2013), Valid and Reliable As- sessment of Wellness Among Adolescents: Do You Know What You Are Measuring? International Journal of Well- being, 3(2), 162172

Rogers, E. (1962). Diffusion of Innovations, Free Press of Glencoc

Walden, C., Sell, A. and Walden, P. (2017). My Wellness as a Mobile App. Identifying Wellness Types among the Young Elderly. Proceedings of the 50th Hawaii International Conference on System Sciences, IEEE, pp 1473-1483

Statistics Finland 2014, 2016, http://www.stat.fi

UCR report on wellness dimensions, https://wellness.ucr.edu/seven_dimensions.html

United Nations Department of Economic and Social Affairs (2014), Population ageing and sustainable development, No. 2014/4; available at: http://www.un.org./en/development/desa/population/publications/pdf/popfacts/Popfacts_2014-4, retrieved March 21, 2015.

Sell, A., Walden, C. and Walden, P. (2017). Wearables and Wellness for the Young Elderly - Transforming Everyday Lives?, Proceedings of the 30th eBled Conference, Digital Wellness Track, Bled 2017, pp 637-650

Wallén, M. B., Ståhle, A., Hagströmer, M., Franzén, E. \& Roaldsen, K. S. (2014), Motionsvanor och erfarenheter av motion hos äldre vuxna, Karolinska Institutet, Stockholm, March 2014

Van Emmerik, A.A.P., Berings, F \& Lancee, J. (2018). Efficacy of a Mindfulness-Based Mobile Application: a Ran- domized Waiting-List Controlled Trial, Mindfulness 9: 187-198 

$31^{\text {ST }}$ Bled eConference: Digital Transformation: MeEting the Challenges JunE 17 - 20, 2018, BLED, SLOVENIA, CONFERENCE PROCEEDINGS
C. Carlsson \& P. Walden: Digital Wellness Services: Key to Better Quality of Life for Young 261

Venkatesh, V., Thong, J. Y. L. \& Xu, X. (2012), Consumer Acceptance and Use of Information Technology: Extending the Unified Theory of Acceptance and Use of Technology, MIS Quarterly, 36(1), 157-178.

World Health Organization (2014), Preamble to the Constitution, www.who.int, retrieved March $28,2015$.

Wu, S. \& Crestani, F. (2015), A geometric framework for data fusion in information retrieval, Information Systems, Vol. 50, June 2015, 20-35 
262 31 $31^{\text {ST }}$ Bled eConference: Digital TRANSFormation: MEeting the ChallengeS JUNE 17 - 20, 2018, BLED, SLOVENIA, CONFERENCE PROCEEDINGS 


\title{
Improving Smart City Design: A Conceptual Model for Governing Complex Smart City Ecosystems
}

\author{
MERVI HÄMÄLÄINEN \& PASI TYRVÄINEN
}

\begin{abstract}
Smart city concept is a viable nominee to solve the dilemmas urbanization creates globally. By means of digital technologies like Internet-of-Things, artificial intelligence and data analytics cities aim to optimize city performances like mobility, environment, security, health care and social services. Furthermore, cities actively endorse usage of digital technologies to foster digitalization and new business innovation to nurture local economy and social well-being. Smart city market is growing, but simultaneously fragmented smart city markets and initiatives face challenges with governance, ecosystem orchestration and continuity. Transformation to smart city is a complex long-term process, which requires collaboration with heterogeneous stakeholder groups and capabilities to evaluate wide spectrum of new digital technologies and their fitness to diverse city functions and processes. This sets high demands for the smart city governance and management. A smart city conceptual model (SCCM) presented in this paper aims to assist cities with this endeavor. SCCM observes complex smart cities from organizational and technical perspectives providing practical instrument for smart city stakeholders to lead city towards data and digital technology assisted smart city. SCCM considers four primary dimensions, strategy, technology, governance and stakeholders. Each primary dimension is complemented with sub-elements, which all together form meaningful interrelations and provides comprehensive and systematic approach for the smart city design, development and implementation.
\end{abstract}

Keywords: - Smart city - Strategy - Governance - Stakeholders • Technology $\bullet$ Ecosystem $\bullet$ Digital technologies $\bullet$

CORRESPONDENCE ADDRESS: Mervi Hämäläinen, Ph.D. researcher, University of Jyvaskyla, Faculty of Information Technology, P.O.Box 35, FI-40014 University of Jyvaskyla Finland, e-mail: mervi.a.hamalainen@jyu.fi. Pasi Tyrväinen, Professor, University of Jyvaskyla, Faculty of Information Technology, P.O.Box 35, FI-40014 University of Jyvaskyla Finland, Finland, e-mail: pasi.tyrvainen@jyu.fi. 
The smart city concept attracts city governments, industries and academia globally. In the area of EU alone, over 1300 smart city related proposals, commitment and project exist. European cities invest on information and digital technologies to renew power grids, buildings, public transportation and waste management systems. (European innovation partnership on smart cities and communities.) By investing on modern smart city technologies cities aim to enhance city security, optimize city processes and usage of scarce resources and improve data driven city governance. Cities aim also by means of digital technologies to foster new knowledge creation and innovation and stimulate local businesses and collaboration. (Baccarne, Mechant \& Schuurman, 2014; Batty et al., 2012; Caragliu, Del Bo \& Nijkamp, 2011; Gabrys, 2014; Li, Nucciarelli, Roden \& Graham, 2016; Zanella et al., 2014.)

Even though smart city has been a trendy phenomenon and smart city markets are growing it is worth bearing in mind that each city should focus on developing the smart city from its own particular needs and perspectives. As cities are constantly evolving systems and vulnerable to external uncertainties (Jabareen, 2013) smart city initiatives should be considered as long-term development process, which impacts for instance city strategy, resources, capabilities and stakeholder relations. Creating a specific smart city strategy is proposed to consider and analyze city's macro environment, but also evaluate feasibility of the new digital technologies in diverse city domains and recognize resources and capabilities needed for the smart city transformation. The specific smart city strategy also addresses risks and funding needs for smart city initiatives.

Objective of this paper is to present smart city conceptual model (SCCM) that assists cities and their stakeholders to carry out robust smart city initiatives and enhance sustainable smart city ecosystem design and development. Foundation for SCCM is derived from the systematic literature review of the smart city ecosystems and value networks. SCCM originates from a perception that design and management of the complex smart city is not a trivial task and many smart city initiatives have failed due to weak smart city governance, ecosystem orchestration and insufficient digital technology knowledge and capabilities. SCCM aims thus to clarify complex smart city governance, ownership, orchestration and decision making procedures and advance technological compatibility and correct skills and resource allocation in cities Furthermore, SCCM aims to provide tools to accelerate competitiveness, transparency and economic growth in cities.

This paper first discusses the methodological principles and secondly presents the conceptual foundations for the smart city conceptual model. Conclusion section summarizes and finalizes the paper. 


\section{Methodology}

Smart city is a complex phenomenon, which interest diverse research disciplines like social and environmental sciences, information systems, computer and engineering, urban development and business \& economics. Purpose of this paper is to build a smart city conceptual model, which derives its foundations from the literature of the smart city ecosystems and value networks in diverse research fields. Jabareen (2009) suggests that qualitative methods are adequate and useful for building conceptual frameworks from the multidisciplinary literature. Grounded theory as a research method offers a procedure for conceptual framework analysis and building conceptual frameworks (Jabareen, 2009). As an inductive theory the grounded theory allows the salient concepts to emerge from the literature (Wolfswinkel, Furtmueller \& Wilderom, 2013) and identify the major concepts relevant for the study phenomenon (Jabareen, 2009). Due to the multidisciplinary nature of the smart city phenomenon, the principles from the "Grounded-Theory LiteratureReview Method" by Wolfswinkel et al. (2013) and the conceptual framework analysis by Jabareen (2009) were utilized when conducting the literature review. The literature review addressed the search terms "smart city", "intelligent city" or "digital city" ecosystems and "smart city", "intelligent city" or "digital city" value networks. The search terms were applied to Scopus, Web-of-Science, SAGE Journal Online and AISeL databases. (Table 1.)

Table 4: Search terms and databases

\begin{tabular}{|l|c|c|c|c|c|}
\hline Search terms & Scopus Elsevier API & Web-of-Science (WoS) & SAGE Journals Online & AISeL & Total \\
\hline "smart city" + ecosystem & 41 & 21 & 29 & 8 & 99 \\
\hline "digital city" + ecosystem & 0 & 1 & 6 & 0 & 7 \\
\hline "intelligent city" + ecosystem & 4 & 3 & 3 & 0 & 10 \\
\hline "smart city" + value network & 25 & 12 & 2 & 11 & 50 \\
\hline "intelligent city" + value network & 1 & 0 & 0 & 0 & 1 \\
\hline "digital city" + value network & 3 & 3 & 0 & 2 & 8 \\
\hline Total & $\mathbf{7 4}$ & 40 & 40 & 21 & 175 \\
\hline
\end{tabular}

Search terms covered articles from social and environmental sciences, information systems, computer and engineering, urban development and business \& economics disciplines. Alltogether 175 articles were found, but after removing dublicates 126 journal articles were left. Document titles and abstracts were reviewed and 44 papers were selected for closer review. Based on the key terms that emerged from the literature concepts of strategy, technology, governance and stakeholders formed the parent dimensions for the smart city conceptual model. The sub-concepts were derived from the literature review complemented with the relevant articles from the literature of strategy and organization management, software ecosystems and from the literature of the smart city technology test and experimentation platforms. 


\section{Conceptual Foundations}

Objectives of the robust smart city is to accelerate and reduce costs of the city services and enhance the return on investments (Vilajosana et al., 2013), accelerate economic growth and competitiveness and transparency (Perez, Poncela, Moreno-Roldan \& Memon, 2015; Yovanof \& Hazapis, 2009). An explicit smart city design clarifies complex smart city governance, stakeholder relationships, orchestration and decision making procedures (Scuotto et al., 2016; Vilajosana et al., 2013) and advances technological compatibility and correct resource allocation in cities (Carvalho, 2015; Scuotto et al., 2016; Vilajosana et al., 2013; Veeckman \& van der Graaf, 2015), but above all smart city initiatives should aim to improve the quality of citizens lives. The following chapters present the conceptual foundations for the SCCM, which consists of strategy, technology, governance, and stakeholder dimensions (Fig 1). Strategy dimension considers aspects of smart city vision and strategy, capabilities and digital strategy. Technology dimension discusses about digital technologies, architecture design, technology experimentation and security and privacy issues in smart city. Vertical and horizontal scopes conclude technology dimension. Governance section describes orchestration of the smart city stakeholders and ecosystems and considers funding and risk management elements. Final, the fourth stakeholder dimension elaborates quadruple helix and stakeholder value.

\subsection{Strategy}

Strategy is defined as an analytical process of intentional action plans and stream of decisions (Minzberg, 1978) to achieve the long-term goals under certain conditions (Mintzberg \& Waters, 1985). Strategy is also considered as a cohesive response to diagnosed challenges (Rumelt, 2009) identified in the operational environment. Strategy is a deliberate and inclusive plan of action to commit and dedicate the whole organization to common goals. Strategy identifies the use of resources, predicts and evaluates the risks and indicates willingness of action to accomplish the goals. (Henderson, 1989.) Strategy dimension clarifies smart city vision and strategy, digital strategy and enhance to figure out required capabilities. 


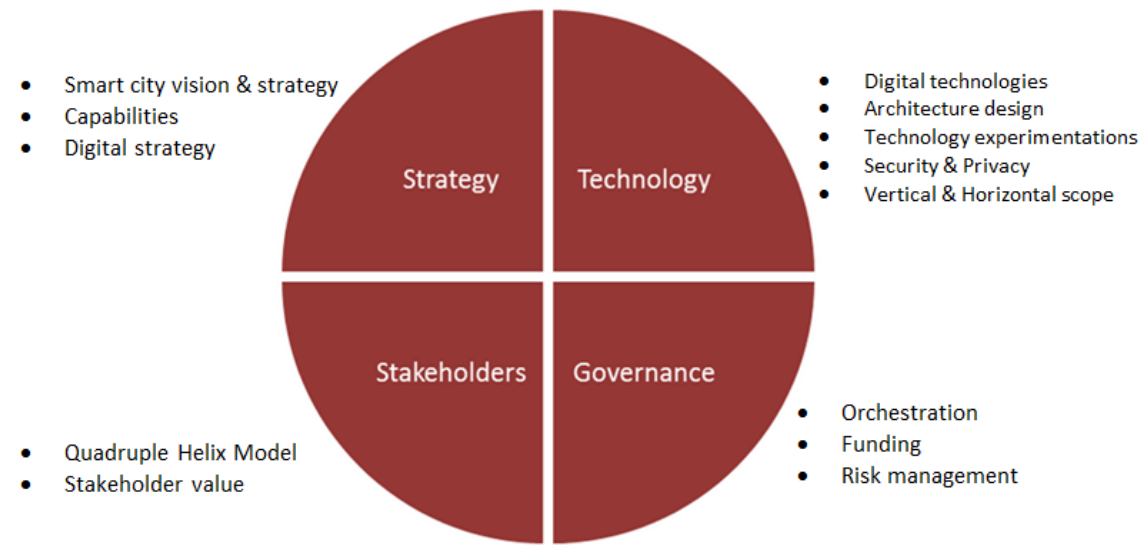

Figure 6: A conceptual model for the smart city design

\subsubsection{Smart city vision, strategy, capabilities and digital strategy}

Smart city vision's aim is to express the idea or image of a desirable future (Nanus, 1992) the city is seeking from the smart city initiatives. Vision is characterized as consistent, vivid and dynamic narrative that creates shared meaning of the future clarifying organization's ambitions and ideology (Collins \& Porras; 2005; Levin, 2000). Smart city vision thus acts as a means of communications and is a catalyst for inspiration during the turbulent times and change (Levin, 2000; Nanus, 1992).

Transforming city towards smart city is a long-term journey that requires changes in the city strategy and resources allocation. A specific smart city strategy recognizes the changes in political and social conditions, but further identifies the changes that occur in technologies, legislation and economy. The smart city strategy sets goals and considers resources and capabilities required for successful smart city implementation. Smart city capabilities refer to city's ability to create technical, management and governance skills and knowledge to design and orchestrate innovative and sustainable smart city initiatives that creates value for its stakeholders (Baccarne et al., 2014; Komninos, 2011; Scuotto et al., 2016; Tillie \& van der Heijden, 2016). In broader perspective the smart city strategy also considers the impacts of climate change and global political situations on cities' circumstances.

Ongoing decade has been the rise of new digital technologies. Digital technologies are perceived as a combination of heterogeneous information, cloud computing, communication and connected devices (Bharadwaj, El Sawy, Pavlou \& Venkatraman; 2013) complemented with technologies like social media, mobile, big data and data analytics (Ross et al., 2016), artificial intelligence and blockchain technologies. Digital technologies are applied in diverse parts of organization infrastructures. Business units, capabilities, processes and services are interconnected with digital technology solutions 
(Bharadwaj et al., 2013). IS literature discuss about combining the strategy and business strategy and calls the fusion as a digital business strategy (Bharadwaj et al., 2013; Mithas, Tafti \& Mitchell, 2013; Ross et al., 2016). The digital business strategy is defined as organizational or business strategy (Bharadwaj et al., 2013; Ross et al., 2016), which consists of complex and interrelated elements (Mithas et al., 2013) like digital resources and capabilities that create and deliver differential value for the organization operating under constantly changing environment (Bharadwaj et al., 2013; Ross et al., 2016). The digital business strategy thus considers how IS and business strategies jointly not separately reacts to changes in operational environment and create value for the organization and its stakeholders.

In the smart city context digital strategy should support and be aligned with smart city strategy. Smart city strategy envisions the future state of the city by means of digital technologies and considers how complex digital technologies are integrated to the city's infrastructure to enhance the city processes and functions, service design and capability creation. The smart city strategy acknowledges the common goals and value creation possibilities to citizens and stakeholders in public and private sectors by means of digital technologies.

\subsection{Technology}

Technology is information, skills and processes to accomplish tasks or artifacts. From sociotechnical perspective technology covers all the elements needed for the output; people, machines, systems and methods, processes, and economical and physical environments. (Kline, 1985; Banta, 2009.) Technology dimension discusses about digital technologies, architecture design, technology experimentations, security and privacy element and vertical and horizontal scope.

\subsubsection{Digital technologies and architecture design}

Digital technologies like Internet-of-Things (IoT), artificial intelligence (AI), blockchain, big data and data analytics are rapidly escalating and influencing multiple industries and cities. Heterogeneous IoT technologies are widely used in diverse smart city domains to monitor city activities like traffic, parking places and air quality. The data generated and analyzed from IoT network enable more precise data of the city status providing fuel for more accurate decision making. (Sanchez et al., 2014.) AI and blockchain are technologies that are entering into smart city initiatives. AI mimics natural intelligence and cognitive abilities and utilizes technologies like face recognition, machine learning and natural language analysis. AI is utilized e.g. in analyzing health data to optimize public healthcare services and activities (Jiang et al., 2017). Blockchain in turn is a decentralized network, where data is transparent, immutable and transactions are verified. Blockchain technologies are experimented in the areas where control over the personal data and privacy are critical. (Pazaitis, Filippi \& Kostakis, 2017; Zyskind \& Nathan, 2015.) Digital identities are example of entities, which contain sensitive information like social security numbers, passwords and usernames. In smart city context blockchain 
$31^{\text {ST }}$ Bled eConference: Digital Transformation: MeEting the Challenges

based digital identities improves data transparency and individual's rights for his/her personal data and reduce risks for data breaches. Smart cities globally are discovering use cases to test and experiment new technologies in diverse city domains.

Foundation for enterprise architecture concept originates from the need to combine complex business and information systems (IS) (Zachman, 1987). Enterprise architecture is used as a blueprint (Simon, Fischbach \& Schoder, 2013) to describe the components, relationships and interactions of the business processes and information systems (Aier, Kurpjuweit, Saat \& Winter, 2009; Ross, Weill \& Robertson, 2006; Buckl et al., 2010) and to support orchestration and alignment of the business and IS in the organization (Aier et al., 2009; Müller \& Reinert, 2014). Enterprise architecture is like a shared language that clarifies and enhances the communication between organization's internal and external stakeholders (Aier et al., 2009; Buckl et al., 2010).

In the smart city context architecture design is an instrument to categorize complex city organization into simple, descriptive and well-defined parts (Müller \& Reinert, 2014; Zachman International). Smart city architecture design enhances interoperability and integration of the complex technical components to smart city infrastructure and supports communication and requirements management among stakeholders. Smart city architecture design provides long-term views on city's systems, processes, capabilities and digital technologies and increases smart city implementation success, communication and value creation among the stakeholders. (Aier et al., 2009; Buckl et al., 2010; Ross et al., 2006).

\subsubsection{Technology experimentations in smart cities}

Technology test and experimentation platforms (TEP) like testbeds, living labs and prototyping platforms provide facilities to test and experiment new ICT and digital solutions with real users before final release (Ballon, Pierson \& Delaere; 2005). For an experimenting organization technology tests and experiments provide facilities to develop technology solutions iteratively and evaluate solution's feasibility and usability in real-world with real users. Additionally TEPs provide more accurate test results and reduces costs of an evaluation cycle and improves technology innovation and user adoption. (Hämäläinen \& Tyrväinen, 2016; Sanchez et al., 2014.)

Cities provide multidimensional environment for developing and testing diverse combination of digital technologies. In the smart city settings living labs have been popular environments to test new technologies and solutions. Elements like involvement of the city and citizens, heterogeneous digital technologies, openness, real-world experiments and scalability are fundamental to technology experimentations' success in the smart cities. Opening smart city TEPs to external stakeholders' use the city enhance heterogeneous digital technologies' reliability and interoperability in the real-world city domains. Simultaneously access to the smart city assets like TEP facilities, information, application development interfaces, technologies and user communities are available to 
the smart city stakeholders. (Hämäläinen \& Tyrväinen, 2016; Olivares, Royo \& Ortiz, 2013; Sanchez et al., 2014; Schaffers et al., 2011; Yokoyama, 2015.)

Real-world smart city use cases benefit all the stakeholders in the smart city ecosystem. There for real-world smart city technology experimentations are emphasized when implementing new technologies in the cities.

\subsubsection{Security and privacy}

Term cyber security is defined as "the protection of cyberspace itself, the electronic information, the ICTs that support cyberspace, and the users of cyberspace in their personal, societal and national capacity, including any of their interests, either tangible or intangible, that are vulnerable to attacks originating in cyberspace" (Von Solms \& Van Niekerk, 2013). Along with the protection of the ICT infrastructure and information, the cyber security concerns the protection of the individuals and the infrastructure of the society and the whole nation (Von Solms \& Van Niekerk, 2013). Privacy refers to individual's rights to his/her personal data. Oliveira \& Zaïane (2004) determines the privacy as "users' rights to conceal their personal information and have some degree of control over the user of any personal information disclosed to others".

Digital technologies are integral part of the smart city initiatives and new digital technologies are widely applied in multiple city domains. However, the more digital technologies are applied in the smart city infrastructure, the greater the potential for vulnerabilities and data breaches. Actualized cyber-attacks may in the worst cases paralyze city's power grids and water supplies or disable the critical telecommunication connections. Unprotected digital smart city solutions may also lead to misuse of private data or data breaches. Smart cities are forced to consider carefully cyber security and issues like ownership and access to the city's digital services, platforms and data (Carvalho, 2015; Merlino et al., 2015; Mital, Pani, Damodaran \& Ramesh; 2015; Lengyel et al., 2015) to guarantee the safety and security of the smart city.

\subsubsection{Vertical and horizontal scope}

Many smart-city initiatives have been created around a certain vertical industry or an industry emphasizing the goals of a single vertical theme, such as energy efficiency, traffic or health care. The vertical approach in smart city initiatives influences the choice of employed technologies and standards that will best support the needs and requirements of a chosen industry. (Hämäläinen \& Tyrväinen, 2016.) Focusing only on particular vertical restricted data silos may emerge. This may prevent more extensive technology and data adoption and exploitation in smart cities. Horizontality in smart city context describes a wider set of IoT devices and other wireless sensors, applications and services combining data from multiple city domains and industries to service developers. The horizontal approach contributes broader set of data and expands the possibilities to create new services based on integrated vertical data. 


\subsection{Governance}

Governance is defined as "the sum of the many ways individuals and institutions, public and private, manage their common affairs. It is the continuing process through which conflicting or diverse interests may be accommodated and co-operative action may be taken". (Commission on Global Governance, 1995.) Governance dimension consists of ecosystem orchestration, funding and risk management.

\subsubsection{Smart city ecosystems and orchestration}

Ecosystem management and orchestration enhances the evolution and sustainability of the ecosystem and increases the value for ecosystem actors (Korpela, Ritala, Vilko \& Hallikas, 2013; Manikas, Wnuk \& Shollo, 2015). The orchestrator's role is to form common vision for the ecosystem and facilitate ecosystem emergence (Korpela et al., 2013) and sustainability. The orchestrator manages and leads the actors to desired common direction (Korpela et al., 2013) and ensures ecosystem decision making process (Manikas, 2016). Furthermore, the orchestrator co-ordinates the critical resources required for the ecosystem evolvement and enhance the creation of trust and value among the ecosystem actors (Autio \& Thomas, 2014).

Smart city is determined as an organic, collective and collaborative ecosystem (Baccarne et al., 2014; Komninos, 2011), which co-create sustainable innovations and engender innovative entrepreneurial, social and innovation ecosystems to improve the economy, human capital and quality of life in a city (Baccarne et al., 2014; Komninos, 2011; Roth, Kaivo-Oja \& Hirschmann, 2014; Schaffers, Ratti \& Komninos, 2012). In the smart cities multiple ecosystems and numerous stakeholder relationships exist. Smart city ecosystem orchestration and clear role management improve communication and value creation among stakeholders and thus enhance the success of smart city initiatives.

\subsubsection{Funding and risk management}

Funding and financial resources are critical for the smart city initiatives. Both public and private investment organizations fund the smart city projects of various scales. Funding programs are available for infrastructure development, capacity building, and research and innovation activities. Little is known about the smart cities' return-on-investments (ROI) or smart city investments' impacts on socio-economic issues like employment and new business model innovations. Standards and metrics to evaluate the success of the smart city strategy and investments are thus emphasized.

Smart cities generate opportunities, but simultaneously also risks. In complex and decentralized organizations like cities demand for coordinated risk management policy exist (Oulasvirta \& Anttiroiko, 2017). Risk management should have a strategic focus (Duckert, 2010) and be aligned with organization strategy. In the smart cities risks concern not only technology and network infrastructures, but also smart city organization and government. (Nam \& Pardo, 2011.) There for smart city should evaluate internal and 
external risks and reflect them to strategy and consider impacts to organization, financing, legislative issues and stakeholder relations. (COSO, 2016; Oulasvirta \& Anttiroiko, 2017).

\subsection{Stakeholder}

The stakeholder theory observes stakeholder relations and describes how organization operates through stakeholder relations and how stakeholder interests and value expectations are considered and met. The stakeholder theory emphasizes to create value for its stakeholders in an effective way as it enhances the stakeholders' commitment and responsibility. (Freeman et al., 2010; Jensen, 2001.) Freeman (1984) describes stakeholder "as any group or individual who can affect or is affected by the achievement of an organization's purpose". The components of the quadruple helix and stakeholder value are covered in the stakeholder dimension.

\subsubsection{Quadruple helix and stakeholder value}

Triple-helix, university-industry-government, partnership has been the dominant collaboration model in the smart cities. Aim of the trilateral triple helix networks is to benefit the knowledge created in each organization and engender new innovations and innovation ecosystems (Etzkowitz, 2003). Industries' interest in the smart cities is to experiment and employ new technologies in the real-life environment and discover new value creation and business opportunities. For public organizations like city and academia the smart city concept provides environment for developing and testing technologies, but also potential for new knowledge creation, service design and possibility to stimulate local economy and interdisciplinary research activities. In the smart city context it is emphasized to extend triple helix model to include people and civil society as the forth helix and form quadruple helix partnerships. In the smart cities the citizens are seen as co-creators and social innovators (Carayannis \& Campbell, 2011; Komninos, Pallot \& Schaffers; 2013; Petersen, Concilio \& Oliveira, 2015) who may own such a social capital and knowledge from their livelihood (Lea, Blackstock, Giang \& Vogt; 2015) that is valuable for improving the community's living conditions and environment. By integrating local community and citizens to urban development the city strengthens bottom-up smart city development and improves technology acceptance among the citizens (Ballon et al., 2005; Lea et al., 2015; Schaffers et al., 2011).

Value proposition is associated with the stakeholder relations and business model design. Value is linked to benefits (Rescher, 1969) each stakeholder is seeking from the value networks and stakeholder relations. Received value may occur in the form of goods, services, financial profits, cost savings, knowledge or in improved quality (Allee, 2008; Sainio, Saarenketo, Nummela \& Eriksson, 2011), but received value may further emerge in-directly in the value networks (Allee, 2008; Ojala \& Helander, 2014; Ojala \& Tyrväinen, 2011). Access to a new market or resources that otherwise are unreachable are examples of the in-direct value in the value networks (Ojala \& Helander, 2014). 
Smart cities are growing markets attracting multiple organizations and stakeholders. Despite of tremendous possibilities the smart city phenomenon creates, leading smart city from pilot stage to more mature level takes time and results may be realized with extended period of time. Smart city strategy, quadruple helix collaboration and ecosystem orchestration and management improve communication and trust among stakeholders and enhance to evaluate value propositions and business potential in the smart city projects.

\section{Conclusion}

This paper elaborated and presented smart city conceptual model (SCCM), which aim is to strengthen smart city design and ecosystem governance. The rationale for elaborating SCCM emerge from the perception that cities' have inadequate capabilities to govern complex smart city ecosystems and manage rapidly changing digital technologies in city setting. Due to these reasons many nascent smart city projects perish after the project funding is used. Aim of the SCCM is to assist smart city practitioners to form long-term smart city vision and strategy, facilitate the governance of the heterogeneous stakeholder relations and digital technologies and to assist evaluate risks and funding needs. SCCM aims further to enhance the smart city stakeholders to outline and evaluate smart city projects and assist to unlock the barriers for business model innovation and value creation in the smart city ecosystems. SCCM consists of four main dimensions, strategy, technology, governance and stakeholder and their sub-components. SCCM dimensions and sub-components form meaningful interrelations and provide comprehensive approach to design smart city initiatives and ecosystems.

It is highlighted to integrate social, economic and ecological perspectives to enhance social sustainability in society (Eizenberg \& Jabareen, 2017). One of the emphazised goals for smart city initiatives is to improve the quality of citizens' lives. Including social and political aspects in the SCCM would extend perspectives for more resilient and sustainable smart city design. Further, indicators to measure and analyze smart city initiatives are emphasized to support the management and success of the smart city projects.

\section{Acknowledgments}

Funding: This work was conducted under the $5 \mathrm{~K}$ project funded by the TEKES foundation, Finland and EU/European Regional Development Fund.

\section{References}

Aier, S., Kurpjuweit, S., Saat, J., \& Winter, R. (2009). Enterprise architecture design as an engineering discipline. AIS Transactions on Enterprise Systems, 1(1), 36-43.

Allee, V. (2008). Value network analysis and value conversion of tangible and intangible assets. Journal of intellectual capital, 9(1), 5-24.

Autio, E., \& Thomas, L. (2014). Innovation ecosystems. The Oxford handbook of innovation management, 204-288. 
Baccarne, B., Mechant, P., \& Schuurman, D. (2014). Empowered cities? An analysis of the structure and generated value of the smart city Ghent. InSmart City (pp. 157-182). Springer International Publishing.

Ballon, P., Pierson, J., \& Delaere, S. (2005). Test and experimentation platforms for

broadband innovation: Examining european practice. Available at SSRN 1331557.

Banta, D. (2009). What is technology assessment?. International Journal of Technology Assessment in Health Care, 25(S1), 7-9.

Batty, M., Axhausen, K. W., Giannotti, F., Pozdnoukhov, A., Bazzani, A., Wachowicz, M., ... \& Portugali, Y. (2012). Smart cities of the future. The European Physical Journal Special Topics, 214(1), 481-518.

Bharadwaj, A., El Sawy, O. A., Pavlou, P. A., \& Venkatraman, N. V. (2013). Digital business strategy: toward a next generation of insights. MIS Quarterly: Management Information Systems, 37 (2), pp. 471-482.

Buckl, S., Matthes, F., Roth, S., Schulz, C., \& Schweda, C. M. (2010, November). A conceptual framework for enterprise architecture design. In International Workshop on Trends in Enterprise Architecture Research (pp. 44-56). Springer Berlin Heidelberg.

Caragliu, A., Del Bo, C., \& Nijkamp, P. (2011). Smart cities in Europe. Journal of urban technology, 18(2), 65-82.

Carvalho, L. (2015). Smart cities from scratch? A socio-technical perspective. Cambridge Journal of Regions, Economy and Society, 8(1), 43-60. doi: 10.1093/cjres/rsu010

Collins, J. C., \& Porras, J. I. (2005). Built to last: Successful habits of visionary companies. Random House.

Commission on Global Governance. (1995). Our Global Neighborhood, Oxford: Oxford University Press. Ref 26.4.2017. http://www.gdrc.org/u-gov/global-neighbourhood/chap1.htm

COSO. 2016. Enterprise risk management. Aligning risks with strategy and performance. Executive summary.

Duckert, G. H. (2010). Practical Enterprise Risk Management. Hoboken: Wiley. Retrieved from http://ebookcentral.proquest.com/lib/jyvaskyla-ebooks/detail.action?docID=624515. 21.3.2017.

Eizenberg, E., \& Jabareen, Y. (2017). Social sustainability: A new conceptual framework. Sustainability, 9(1), 68.

Etzkowitz, H. (2003). Innovation in innovation: The triple helix of university-industrygovernment relations. Social science information, 42(3), 293-337.

European innovation partnership on smart cities and communities. Ref. 28.2.2017. https://eusmartcities.eu/about.

Freeman, R.E. (1984). Strategic Management: A Stakeholder Approach. London: Pitman Publishing Inc.

Freeman, R.E., Harrison, J.S., Wicks, A.C., Parmar, B.L. \& De Colle, S. (2010). Stakeholder Theory: The state of the art. United Kingdom: Campbridge Universtiy Press.

Gabrys, J. Programming environments: Environmentality and citizen sensing in the smart city (2014) Environment and Planning D: Society and Space, 32 (1), pp. 30-48.

Hamalainen, M., \& Tyrvainen, P. (2016, September). A framework for IoT service experiment platforms in smart-city environments. In Smart Cities Conference (ISC2), 2016 IEEE International (pp. 1-8). IEEE.

Henderson, B. D. (1989). The origin of strategy. Harvard business review, 67(6), 139-143.

Jabareen, Y. (2009). Building a conceptual framework: philosophy, definitions, and procedure. International Journal of Qualitative Methods, 8(4), 49-62.

Jabareen, Y. (2013). Planning the resilient city: Concepts and strategies for coping with climate change and environmental risk. Cities, 31, 220-229. 
Jensen, M.C. (2001). Value Maximization, Stakeholder Theory, and the Corporate Objective Function. Journal of Applied Corporate Finance, 14(3), 8-21.

Jiang, F., Jiang, Y., Zhi, H., Dong, Y., Li, H., Ma, S., ... \& Wang, Y. (2017). Artificial intelligence in healthcare: past, present and future. Stroke and Vascular Neurology, svn-2017.

Kline, S. J. (1985). What is technology?. Bulletin of Science, Technology \& Society, 5(3), 215-218.

Komninos, N. (2011). Intelligent cities: variable geometries of spatial intelligence. Intelligent Buildings International, 3(3), 172-188.

Komninos, N., Pallot, M., \& Schaffers, H. (2013). Special issue on smart cities and the future internet in Europe. Journal of the Knowledge Economy, 4(2), 119-134

Korpela, K., Ritala, P., Vilko, J., \& Hallikas, J. (2013). A management and orchestration model for integrating Digital Business Ecosystems. International Journal of Integrated Supply Management, 8(1/2/3), 24-51.

Lea, R., Blackstock, M., Giang, N., \& Vogt, D. (2015). Smart cities: Engaging users and developers to foster innovation ecosystems. Proceedings of the 2015 ACM

International Joint Conference on Pervasive and Ubiquitous Computing and Proceedings of the 2015 ACM International Symposium on Wearable Computers, 1535-1542.

Lengyel, L., Ekler, P., Ujj, T., Balogh, T., \& Charaf, H. (2015). SensorHUB: an IoT driver framework for supporting sensor networks and data analysis. International Journal of Distributed Sensor Networks, 2015, 109.

Levin, I. M. (2000). Vision revisited telling the story of the future. The Journal of Applied Behavioral Science, 36(1), 91-107.

Li, F., Nucciarelli, A., Roden, S., \& Graham, G. (2016). How smart cities transform operations models: a new research agenda for operations management in the digital economy. Production Planning \& Control, 27(6), 514-528.

Manikas, K. (2016). Revisiting software ecosystems research: A longitudinal literature study. Journal of Systems and Software, 117, 84-103.

Manikas, K., Wnuk, K., \& Shollo, A. (2015). Defining decision making strategies in software ecosystem governance. Department of Computer Science, University of Copenhagen.

Merlino, G., Bruneo, D., Distefano, S., Longo, F., Puliafito, A., \& Al-Anbuky, A. (2015). A smart city lighting case study on an openstack-powered infrastructure. Sensors, 15(7), 16314-16335.

Mintzberg, H. (1978). Patterns in Strategy Formation. Management Science, 24(9), 934-948.

Mintzberg, H., \& Waters, J. A. (1985). Of strategies, deliberate and emergent. Strategic management journal, 6(3), 257-272.

Mital, M., Pani, A. K., Damodaran, S., \& Ramesh, R. (2015). Cloud based management and control system for smart communities: A practical case study. Computers in Industry, 74, 162-172.

Mithas, S., Tafti, A., \& Mitchell, W. (2013). How a Firm's Competitive Environment and Digital Strategic Posture Influence Digital Business Strategy. Mis Quarterly, 37(2), 511-536.

Müller, W., \& Reinert, F. (2014, January). A methodology for development of enterprise architecture of PPDR organisations. In Proceedings of the International Conference on Software Engineering Research and Practice (SERP) (p. 1). The Steering Committee of The World Congress in Computer Science, Computer Engineering and Applied Computing (WorldComp).

Nam, T., \& Pardo, T. A. (2011, September). Smart city as urban innovation: Focusing on management, policy, and context. In Proceedings of the 5th international conference on theory and practice of electronic governance (pp. 185-194). ACM.

Nanus, B. (1992). Visionary Leadership: Creating a Compelling Sense of Direction for Your Organization. Jossey-Bass Inc., 350 Sansome Street, San Francisco, CA 94104-1310.

Ojala, A. \& Tyrväinen, P. (2011). Value Networks in cloud computing. Journal

of Business Strategy, 32(6), 40-49. 
Ojala, A. \& Helander, N. (2014). Value creation and evolution of a value net

work: A longitudinal case study on Platform-as-a-Service provider. In Proceedings of $47^{\text {th }}$ Hawaii International Conference on System Science (HICSS 2014) (975-984).

Olivares, T., Royo, F., \& Ortiz, A. M. (2013, November). An experimental testbed for smart cities applications. In Proceedings of the 11th ACM international symposium on Mobility management and wireless access (pp. 115-118). ACM.

Oliveira, S. R., \& Zaïane, O. R. (2004, August). Toward standardization in privacy-preserving data mining. In ACM SIGKDD 3rd Workshop on Data Mining Standards (pp. 7-17).

Oulasvirta, L., \& Anttiroiko, A. V. (2017). Adoption of comprehensive risk management in local government. Local Government Studies, 1-24.

Pazaitis, A., De Filippi, P., \& Kostakis, V. (2017). Blockchain and value systems in the sharing economy: The illustrative case of Backfeed. Technological Forecasting and Social Change, 125, 105-115.

Perez, I., Poncela, J., Moreno-Roldan, J. M., \& Memon, M. S. (2015). IntelCity, Multiplatform Development of Information Access Platform for Smart Cities. Wireless Personal Communications, 85(2), 463-481.

Petersen, S. A., Grazia Concilio, \& Oliveira, M. (2015). Smart Neighbourhood Learning-the case of MyNeighbourhood. IxD\&A, 27, 66-78

Rescher, N. (1969). Introduction to value thoery. New Jersey: Prentice-Hall, Inc., Englewood Cliffs.

Ross, J. W., Sebastian, I., Beath, C., Mocker, M., Moloney, K., \& Fonstad, N. (2016). Designing and Executing Digital Strategies.

Ross, J. W., Weill, P., \& Robertson, D. C. (2006). Enterprise architecture as strategy: Creating a foundation for business execution. Harvard Business Press.

Roth, S., Kaivo-Oja, J., \& Hirschmann, T. (2013). Smart regions: Two cases of crowdsourcing for regional development. International Journal of Entrepreneurship and Small Business, 20(3), 272-285.

Rumelt, R. P. (2009). Strategy in a 'structural break'. McKinsey Quarterly, 1, 35-42.

Sainio, L-M., Saarenketo, S., Nummela, N. \& Eriksson, T. (2011). Value creation

of an internationalizing entrepreneurial firm. The business model perspective. Journal of Small Business and Enterprise Development, 18(3), 556-570.

Sanchez, L., Muñoz, L., Galache, J. A., Sotres, P., Santana, J. R., Gutierrez, V., ... \& Pfisterer, D. (2014). SmartSantander: IoT experimentation over a smart city testbed. Computer Networks, 61, 217-238.

Schaffers, H., Sällström, A., Pallot, M., Hernández-Muñoz, J. M., Santoro, R., \& Trousse, B. (2011). Integrating living labs with future internet experimental platforms for co-creating services within smart cities. Concurrent Enterprising (ICE), 2011 17th International Conference on, 1-11.

Schaffers, H., Komninos, N., Pallot, M., Trousse, B., Nilsson, M., \& Oliveira, A. (2011, May). Smart cities and the future internet: Towards cooperation frameworks for open innovation. In The Future Internet Assembly (pp. 431-446). Springer Berlin Heidelberg.

Schaffers, H., Ratti, C., \& Komninos, N. (2012). Special Issue on Smart Applications for Smart Cities-New Approaches to Innovation: Guest Editors' Introduction. Journal of theoretical and applied electronic commerce research, 7(3), ii-v.

Scuotto, V., Ferraris, A., \& Bresciani, S. (2016). Internet of Things: Applications and challenges in smart cities: a case study of IBM smart city projects. Business Process Management Journal, 22(2), 357-367.

Simon, D., Fischbach, K., \& Schoder, D. (2013). An exploration of enterprise architecture research. Communications of the Association for Information Systems, 32(1), 1-72. 
Tillie, N., \& van der Heijden, R. (2016). Advancing urban ecosystem governance in Rotterdam: From experimenting and evidence gathering to new ways for integrated planning. Environmental Science \& Policy, 62, 139-144.

Veeckman, C., \& van der Graaf, S. (2015). The City as Living Laboratory: Empowering Citizens with the Citadel Toolkit. Technology Innovation Management Review, 5(3).

Vilajosana, I., Llosa, J., Martinez, B., Domingo-Prieto, M., Angles, A., \& Vilajosana, X. (2013). Bootstrapping smart cities through a self-sustainable model based on big data flows. IEEE Communications Magazine, 51(6), 128-134.

Von Solms, R., \& Van Niekerk, J. (2013). From information security to cyber security. Computers \& Security, 38, 97-102.

Wolfswinkel, J. F., Furtmueller, E., \& Wilderom, C. P. (2013). Using grounded theory as a method for rigorously reviewing literature. European Journal of Information Systems, 22(1), 45-55.

Yokoyama, T., Akiyama, T., Kashihara, S., Kawamoto, Y., \& Gurgen, L. (2015). Considerations towards the construction of smart city testbed based on use case and testbed analysis. Proceedings of the 2015 ACM International Joint Conference on Pervasive and Ubiquitous Computing and Proceedings of the 2015 ACM International Symposium on Wearable Computers, 1623-1630.

Yovanof, G. S., \& Hazapis, G. N. (2009). An architectural framework and enabling wireless technologies for digital cities \& intelligent urban environments. Wireless personal communications, 49(3), 445-463.

Zachman, J. A. (1987). A framework for information systems architecture. IBM systems journal, 26(3), 276-292.

Zachman International. Ref. 27.3.2017. https://www.zachman.com/

Zanella, A., Bui, N., Castellani, A., Vangelista, L., \& Zorzi, M. (2014). Internet of things for smart cities. IEEE Internet of Things Journal, 1(1), 22-32.

Zyskind, G., \& Nathan, O. (2015, May). Decentralizing privacy: Using blockchain to protect personal data. In Security and Privacy Workshops (SPW), 2015 IEEE (pp. 180-184). IEEE. 
278 3 $31^{\text {ST }}$ Bled eConference: Digital Transformation: MeEting the ChallengeS June 17 - 20, 2018, BLED, SLOVENIA, CONFERENCE PROCEEDINGS 


\title{
Transforming operating rooms: factors for successful implementations of new medical equipment
}

\author{
NAVIn SEWBERATH Misser, JoRis JASPERS, BAS VAN ZAANE, \\ HEIN GOOSZEN \& JOHAN VERSENDAAL
}

\begin{abstract}
Operating Rooms (OR's) are complex, high tech environments with extensive use of medical equipment and information technology. The implementation of new medical equipment with the aim to increase safety, improve patient outcomes or to improve efficiency may initially cause disruptions in the OR, which influence its success. Between and within hospitals the implementation of medical equipment varies and a generic implementation model omits. The aim of this study is to identify factors for successful implementations according to surgical supportive staff. Results are compared with findings from other published studies. In total 90 out of 235 surveys were returned (38\%). Respondents, scrub nurses and circulating nurses, indicate that implementation and integration of new medical equipment in current activities and ICT systems remain a challenge. In this study we identified the following factors: a coherent and holistic implementation approach; integration of medical equipment in processes, systems and organization; knowledge and skill development and effective communication during the implementation process.
\end{abstract}

Keywords: - Implementation • Operating Room • Operating Theatre • Medical Technology • Medical Equipment • Training • Healthcare transformation $\bullet$ Technological innovation $\bullet$ Scrub nurse $\bullet$ Circulating nurse - Process integration •

CoRrespondence AdDREss: Navin Sewberath Misser Bsc. Msc., Ph.D.-candidate and Programme coordinator Industrial Engineering and Management programme, HU University of applied sciences, Institute for Engineering and Design, Padualaan 99, 3584CH Utrecht, The Netherlands, email: Navin.SewberathMisser@hu.nl. Joris Jaspers Ph.D., Associate Professor Labour Saving Devices, University Medical Center Utrecht, Heidelberglaan 100, 3584CX Utrecht, The Netherlands, email: J.Jaspers@umcutrecht.nl. B. van Zaane MD Ph.D., Anesthesiologist, University Medical Center Utrecht, Heidelberglaan 100, 3584CX Utrecht, The Netherlands, email: B.vanZaane@umcutrecht.nl. Prof. Dr. Hein Gooszen, emeritus Professor of surgery, Radboud University Medical Center Nijmegen, Geert Grooteplein Zuid 10, 6525 GA Nijmegen, The Netherlands, email: Hein.Gooszen67@gmail.com. Prof. Dr. Johan Versendaal, Professor Digital Smart Services, HU University of applied sciences, 3584CH Utrecht, The Netherlands, email: Johan.Versendaal@hu.nl. 
Operating Rooms (OR's) are one of the most complex, high tech and high reliability environments to implement radical transformations. In OR's surgeries are performed by surgeons, supported by anesthetic (supportive) staff and surgical supporting staff (scrub and circulating nurses) (Frasier et al., 2017; Kang, Massey, \& Gillespie, 2015; Sheikhzadeh, Gore, Zuckerman, \& Nordin, 2009). To enable these surgeries additional stakeholders are involved, such as the sterilization department, logistical employees and in some instances operators, or manufacturers of medical equipment. The implementation of new medical equipment or new information technology requires a systemic approach, since many stakeholders and resources in the OR are affected and involved. The Dutch Hospital Association (NZA) agreed upon a set of rules regarding the implementation of new medical devices in hospitals: Covenant Medical Technology (CMT). This agreement provides policy guidelines throughout the life cycle of medical equipment to ensure patient safety. These policies address acquiring, implementing, using, and disposing medical devices (Dutch Hospital Association, 2016). In the CMT medical devices are defined as devices that have direct impact on the patient and the outcome of the treatment. These devices entail technical devices varying from mechanical equipment to electronic, and information processing devices (i.e. hardware and software). For the purpose of this study medical devices and (medical) information technology (i.e. hardware and software) are referred to as medical equipment. Hospitals in the Netherlands have implemented the CMT and these hospitals defined and implemented local policies throughout the life cycle of medical devices. The Dutch Health and Youth Care Inspectorate regularly audits the associated local policies regarding this CMT. Implemented local policies related to the CMT result in a variety of ways to implement medical equipment, resulting in a variety of implementation activities, implementation outcomes, and unexpected implementation lead times. In our opinion generic implementation guidelines for medical equipment in OR's should be available to contribute to patient safety, as patient safety is one of the main pillars in hospitals to ensure safe surgical and treatment interventions. Therefore, the aim of our study is to search for factors of importance regarding the implementation of new medical equipment in the OR among various stakeholders. In this study we focus on surgical supporting staff, as stakeholders in the implementation process, and as members of the surgical team (Stefanidis, Fanelli, Price, \& Richardson, 2014). When new medical equipment is introduced in the OR, surgical supporting staff should be able to complete their tasks related to this new equipment. Surgical supporting staff is involved in preparatory activities prior to surgeries such as logistics, assembly, setup and disassembly of medical equipment, and ensures compliance to other protocols such as safety, hygiene and sterility.

For this explorative study the following research question is defined:

Which factors for successful implementation can be identified from a surgical supporting staff's perspective, when introducing new medical equipment in the OR? Medical equipment also includes information systems. 
The purpose of this study is to explore relevant factors for implementations of new medical equipment according to surgical supporting staff. In addition we performed a literature review to compare our findings. To this end we searched for papers in the database PubMed using the following words: implementation of medical equipment, information systems, equipment in OR's.

\subsection{Study population}

The data gathering process took place at an annual two-day congress for surgical supporting staff (scrub nurses and circulating nurses) in The Netherlands. Surgical supporting staff from various hospitals visited this congress and this survey was included in the information package which was handed out during registration.

\section{$2.2 \quad$ Survey}

As many attendees were expected to attend the congress, we used a questionnaire or survey to gather data. Based on available literature, the following variables were identified for our study (Dutch Hospital Association, 2016; Stefanidis et al., 2014):

1. Implementation: needed steps for an implementation process; aspects for successful implementation; best practises and possibilities for improvement;

2. Training and governance: needed elements of and responsibility for the training process;

3. Readiness: readiness assessments.

Aside these themes we explored other factors regarding the implementation process of technology:

4. Other: use of an implementation protocol; use of the Covenant for Medical Technology (CMT).

A survey was set up by the first author (NSM) and this survey was reviewed by members in the research team. The final survey consisted of two sections with 28 open ended and closed questions in Dutch language (Bryman \& Bell, 2007). The first section is used to gather data about the respondent, their role within the OR, their working environment (hospital) and their specialisms. In the second section respondents provide information regarding implementations in their working environment. In table 1 the relation between variables and questions is explained, as well as the type of response. 
N. S. Misser, J. Jaspers, B. van Zaane, H. Gooszen \& J. Versendaal: Transforming operating rooms: factors for successful implementations of new medical equipment

Table 1: Variables related to questions in survey

\begin{tabular}{|c|c|c|}
\hline Variable & Question & Type of response \\
\hline \multirow[t]{5}{*}{ 1. Implementation } & $\begin{array}{l}\text { Q14: Which steps are currently undertaken in the } \\
\text { implementation process for new medical equipment? }\end{array}$ & Multiple responses \\
\hline & $\begin{array}{l}\text { Q16: Which aspects are important when implementing new } \\
\text { medical equipment successfully? }\end{array}$ & Open question \\
\hline & $\begin{array}{l}\text { Q20a: Which aspects of the implementation process } \\
\text { are currently going well? }\end{array}$ & Open question \\
\hline & $\begin{array}{l}\text { Q20b: Which aspects of the implementation process } \\
\text { provide room for improvement? }\end{array}$ & Open question \\
\hline & $\begin{array}{l}\text { Q22: It is clear how new medical equipment are being } \\
\text { implemented. }\end{array}$ & Likert scale (1-5) \\
\hline Variable & Question & Type of response \\
\hline \multirow[t]{3}{*}{$\begin{array}{l}\text { 2. Training and } \\
\text { governance }\end{array}$} & $\begin{array}{l}\text { Q15: Which elements should be part of training prior to } \\
\text { the implementation of new medical equipment? }\end{array}$ & Multiple responses \\
\hline & $\begin{array}{l}\text { Q17: Who should be responsible for organizing and } \\
\text { facilitating necessary training regarding the new medical } \\
\text { equipment? }\end{array}$ & Multiple responses \\
\hline & $\begin{array}{l}\text { Q19: Who should assess if a scrub nurse is ready for using } \\
\text { the new medical equipment? }\end{array}$ & Multiple responses \\
\hline Readiness & $\begin{array}{l}\text { Q18: How should the readiness for the use of the new } \\
\text { medical equipment be assessed? }\end{array}$ & Multiple responses \\
\hline \multirow[t]{2}{*}{ 4. Other } & $\begin{array}{l}\text { Q23: Currently an implementation protocol is in place for } \\
\text { the implementation of new medical equipment }\end{array}$ & Likert scale (1-5) \\
\hline & $\begin{array}{l}\text { Q23 The covenant medical technology is currently in } \\
\text { use in our hospital }\end{array}$ & Likert scale (1-5) \\
\hline
\end{tabular}

In the last part of the survey, respondents reflected on statements regarding implementation processes and activities in the respondents' working environment.

\subsection{Data gathering and processing}

Completed surveys were handed in by the respondents at the information desk of the congress. These surveys were processed in IBM SPSS Statistics version 23 and Microsoft Excel 2013. We mainly used descriptive statistics to analyze and evaluate the responses due to the explorative nature of this study. Responses to open ended questions were categorized traceably in Microsoft Excel.

\section{$3 \quad$ Results}

There were 235 surgical supporting staff visitors at the congress and surveys were handed out to these visitors. The number of completed surveys was 92 (response 39\%). Two records were deleted (response $=38 \%$ ), since these records contained mainly missing 
values $(n=90)$. The literature review resulted in 24 articles and relevant articles were used to analyze survey results.

\subsection{Respondent information}

Out of the 90 respondents, 8 were male and 84 female. Four of the respondents were scrub nurses in training, 18 had less than 5 years of experience and 58 had more than 5 years of experience. The respondents represented 43 Dutch hospitals; one respondent was a visitor from Luxembourg and two respondents worked in Belgium. The respondents had one or more medical specialties or focus areas, shown in table 2 .

Table 2: Focus areas of the respondents (Results)

\begin{tabular}{lcc}
\hline Focus area & Frequency & Percentage of total \\
\hline All-round & 27 & $19 \%$ \\
General surgery & 20 & $14 \%$ \\
Orthopedics & 18 & $12 \%$ \\
Ear Nose Throat & 18 & $12 \%$ \\
Gynecology & 11 & $8 \%$ \\
Plastic surgery & 11 & $8 \%$ \\
Ophthalmology & 10 & $7 \%$ \\
Vascular surgery & 8 & $6 \%$ \\
Neurosurgery & 7 & $5 \%$ \\
Traumatology & 4 & $3 \%$ \\
Urology & 4 & $3 \%$ \\
Bariatrics & 3 & $2 \%$ \\
Cardiology & 2 & $1 \%$ \\
Oral surgery & 1 & $1 \%$ \\
Oncologic surgery & 1 & $1 \%$ \\
\hline
\end{tabular}

Table 2 shows the frequency distribution of focus areas of respondents and the focus areas all- round, general surgery, orthopedics and ear, nose and throat (ENT) were mentioned often. The majority of the respondents $(99 \%)$ stated that medical equipment was implemented up to two years prior to completing the survey. In table 2 the impact of implementations is presented. 
Table 2: Impact of implementations (Results)

\begin{tabular}{|c|c|c|c|c|c|c|c|c|c|}
\hline \multirow{2}{*}{$\begin{array}{l}\text { Topic } \\
\text { Response }\end{array}$} & \multicolumn{3}{|c|}{$\begin{array}{c}\text { Process changes } \\
n=89\end{array}$} & \multicolumn{3}{|c|}{$\begin{array}{c}\text { CT Changes } \\
n=86\end{array}$} & \multicolumn{3}{|c|}{$\begin{array}{c}\text { Training } \\
\mathrm{n}=86\end{array}$} \\
\hline & Yes & No & $\begin{array}{l}\text { Don't } \\
\text { know }\end{array}$ & Yes & No & $\begin{array}{l}\text { Don't } \\
\text { know }\end{array}$ & Yes & No & $\begin{array}{l}\text { Don't } \\
\text { know }\end{array}$ \\
\hline $\begin{array}{l}\text { Percentage of } \\
\text { responses }\end{array}$ & $80 \%$ & $16 \%$ & $4 \%$ & $62 \%$ & $15 \%$ & $13 \%$ & $91 \%$ & $9 \%$ & $0 \%$ \\
\hline
\end{tabular}

The respondents indicate that the implementation of medical equipment impacts the working activities (processes), resulting in alteration of processes and protocols (80\%). In protocols for surgical supporting staff, instructions for work are described. In $62 \%$ of the cases medical equipment resulted in changes within information systems and $91 \%$ of the respondents indicated that they received some kind of training related to the implementation of medical equipment.

\subsection{Implementation}

Implementation of new medical equipment in OR's can be complex task, as many stakeholders are involved. Respondents provided an overview of undertaken activities to implement medical equipment, see table 3 .

Table 3: Needed steps in an implementation process (Results)

\begin{tabular}{lcc}
\hline Undertaken Steps & $\begin{array}{c}\text { Frequency } \\
\mathbf{N}=90\end{array}$ & Percentage \\
\cline { 2 - 2 } Introducing device & 82 & $91 \%$ \\
Simulations & 70 & $78 \%$ \\
Inform stakeholders & 60 & $67 \%$ \\
Theoretical training & 54 & $60 \%$ \\
Supervision by coworker & 48 & $53 \%$ \\
Evaluating experiences & 23 & $26 \%$ \\
Skills assessment & 18 & $20 \%$ \\
Modifying Protocols & 3 & $3 \%$ \\
Other & 3 & $3 \%$ \\
\hline
\end{tabular}

Respondents were able to choose which steps were taken when implementing medical equipment; they were able to add activities to the set of responses. Based on their experience, respondents recognized 5 relevant steps during implementation: introduction of the device, simulations, informing stakeholders, theoretical training and instructions, and supervisions by coworkers while practicing. Skills assessments, evaluation of experiences, and modification of working protocols were recognized less frequent as part of undertaken steps for implementation. Activities of importance during implementation 

rooms: factors for successful implementations of new medical equipment

were: receiving information and instructions regarding the device, practicing with the device, and the need of clear procedures regarding the use of the device (question 16). Respondents defined the following activities that went well during implementation: practicing, with the device, collaboration with the manufacturer of the device and receiving assistance, information and instructions related to the use of the device. However, 35 respondents $(38 \%)$ identified aspects needing improvement. These aspects were: introduction time, meaning that the implementation process was rushed and that more time was needed $(n=9)$; a lack of information regarding the device, limited instructions $(n=9)$, and limited assessment regarding the use of the device $(n=9)$. Based on the statement regarding the clarity of the implementation process, $15 \%$ of the respondents (fully) agreed and $38 \%$ indicated that more clarity in the implementation process is needed.

\subsection{Training and governance}

Training of users of new medical equipment is part of the implementation process, as training contributes to the safe use of medical equipment in the OR. Scrub nurses were able to select necessary features for training prior to the implementation of medical equipment. These features are shown in table 4 .

Table 4: Training features (Results)

\begin{tabular}{lcc}
\hline Training feature & $\begin{array}{l}\text { Frequency } \\
\mathrm{N}=90\end{array}$ & Percentage \\
\hline Introduction to the device & 83 & $92 \%$ \\
Simulate & 77 & $86 \%$ \\
Knowledge sharing from an expert & 76 & $84 \%$ \\
Video of device use & 58 & $64 \%$ \\
Specific courses & 48 & $53 \%$ \\
Online course & 39 & $43 \%$ \\
Training changing ICT & 37 & $41 \%$ \\
Training in changing protocols & 32 & $36 \%$ \\
Congress visits & 27 & $30 \%$ \\
Simulate on animate models & 19 & $21 \%$ \\
Assessing previous research & 15 & $17 \%$ \\
Other & 7 & $8 \%$ \\
\hline
\end{tabular}

Respondents indicated that instructions of and introductions to the new device are vital to the implementation process. Simulations, practicing with the device and expert knowledge should be parts of training as well. Furthermore, videos and courses regarding the device are marked as important. Respondents $(n=68)$ indicated that the manager of the $\mathrm{OR}$ is responsible for organizing and facilitating trainings regarding the introduction 
of a new medical equipment. Senior scrub nurse $(n=24)$, surgeons $(n=21)$ and the technical department $(\mathrm{n}=17)$ are indicated as responsible stakeholders for organizing and facilitating trainings.

\subsection{Readiness for use}

During training the question arises how the readiness for use of the new device should be assessed. Respondents preferred a self-assessment $(n=43)$ and a demonstration to colleagues $(n=31)$ as preferred options for readiness assessments, followed by an exam with demonstration and an exam at an external institute. Assessments performed by manufacturers or supervisors are other preferred ways to assess the readiness for use.

\subsection{Implementation protocols}

In the last part of the survey respondents were able to reflect on statements regarding an the presence of an implementation protocol and the implemented Covenant Medical Technology (CMT). The results to these statements are shown in table 4 .

Table 4: Results on presence implementation protocol and implementation of the CMT

\begin{tabular}{lcccccc}
\hline & $\begin{array}{c}\text { Completely } \\
\text { disagree }\end{array}$ & Disagree & Neutral & Agree & $\begin{array}{c}\text { Fully } \\
\text { agree }\end{array}$ & $\begin{array}{c}\text { Don't } \\
\text { know }\end{array}$ \\
\hline $\begin{array}{l}\text { Protocol present } \\
(n=85)\end{array}$ & $5 \%$ & $22 \%$ & $16 \%$ & $20 \%$ & $8 \%$ & $31 \%$ \\
$\begin{array}{l}\text { CMT implemented } \\
(n=81)\end{array}$ & $1 \%$ & $12 \%$ & $11 \%$ & $32 \%$ & $12 \%$ & $33 \%$ \\
\hline
\end{tabular}

Almost $28 \%$ of the respondents agreed with the statement that an implementation protocol was present for the implementation of new medical equipment. In paragraph 3.1 the majority of the respondents $(99 \%)$ indicated that medical equipment was implemented and a large percentage indicated that either a protocol omits $(27 \%)$ or that respondents were not aware of the existence of an implementation protocol (30\%). Regarding the implementation of the Covenant Medical Technology (CMT), 41\% of the respondents agreed with the statement that the CMT was implemented in their hospital and $31 \%$ of the respondents was not aware of the implementation of the CMT. Only $12 \%$ of the respondents disagreed with this statement, meaning that the CMT was not yet implemented in their hospital.

\section{$4 \quad$ Discussion}

In this study we explored factors for successful implementations of new medical equipment according to surgical supporting staff, with a focus on scrub nurses and circulating nurses. Ongoing activities for surgeons and surgical supporting staff are disrupted by the implementation of innovations, which can be either updated or new equipment or procedures (Stefanidis et al., 2014). New medical equipment to be used during surgeries, require skill and experience regarding the use of the device. Skill and experience vary as many stakeholders are involved in preparation, during and after 
surgeries. The need for the perspective of surgical supporting staff is supported by Stefanidis' study (2014), as they are part of the surgical team. A notable finding is that respondents feel that the manager of the OR should be responsible for the organization and facilitation of training regarding new medical equipment, whereas surgeons indicate that surgeons themselves are responsible for the monitoring of the introduction of new equipment (Stefanidis et al., 2014). An explanation may be that needed skills and experience regarding the new device differs: surgeons monitor the functionality and use of the new device during surgery and surgical supporting staff is involved in supporting activities prior, during and after surgery. In literature there are many cases regarding new operative techniques and new medical equipment with varying success of the functionality of the device, but the number of studies and holistic methods for implementation of new medical devices in OR's is limited. Respondents indicate that the success of implementations of new medical equipment varies and that implementations are perceived to be rushed through.

A large group indicates that an implementation protocol omits and that awareness of the implementation of the CMT is limited. Although policies regarding the CMT should be in place, respondents indicate that more time is needed for implementation activities and communication needs to be improved. Stakeholders in the OR perform tasks according to protocols and respondents indicate that the integration of new medical equipment requires changes in protocols and ICT systems. Surprisingly, only a minority of respondents confirms that relevant protocols are actually updated due to the implementation of new medical equipment. Based on literature and experience we argue that implementation of new medical equipment should be approached in a holistic matter, taking multiple perspectives of stakeholders into account. We argue that implementation activities should result in integration in processes (protocols), systems and organization, knowledge and skill development, and increased experience. Therefore, respondents confirm the need for effective communication, training, time for and clarity of the implementation process. We propose that these are factors for successful implementation of medical devices. Careful preparation and planning is needed to identify the team members and to identify steps for implementation. Integration in (ICT) systems and regular activities by updating protocols is needed during the implementation (Frasier et al., 2017; Meyfroidt, 2009).

Respondents confirm, in accordance with literature, that introductions to the device, simulations and training are necessary to work effectively and safely with the new device. They indicate that simulation and training is needed and they value expert instructions and videos (Carrino et al., 1998; Guédon et al., 2014; Marvik, Lango, \& Yavuz, 2004; Pennington \& DeRienzo, 2010; Pluyter, Rutkowski, \& Jakimowicz, 2014). Regarding readiness assessments surgical supporting staff prefers self-assessments and demonstration to colleagues, whereas surgeons suggest extensive training for use of the new device (Stefanidis et al., 2014). This distinguishes the roles, as supportive surgical staff is responsible for setup and disassembly of equipment and surgeons are responsible for the safe use of the medical device and the patient outcome (Collar et al., 2012). During the implementation process involvement of the operating team and other stakeholders is needed facilitated by effective communication throughout the implementation process 
(Bhatt, Carlson, \& Deckers, 2014; Frasier et al., 2017; Marvik, Lango, \& Yavuz, 2004; Pennington \& DeRienzo, 2010; Saleem et al., 2015).

\section{$5 \quad$ Limitations}

This study results in factors for successful implementations of medical technology in OR's based on a survey from the perspective of surgical supporting staff (scrub nurses and circulating nurses). Other members of surgical supporting staff such as anesthetic (supporting) staff, operators of medical equipment and other departments are not included in this study. The identified factors for implementation still need validation based on empirical data.

\section{Conclusion}

Disruptions in OR's and enhancements of medical care are also influenced by introducing new medical equipment. In this study we focused on the research question "Which factors for successful implementation can be identified from a surgical supporting staff's perspective, when introducing new medical equipment in the OR?" Based on the survey results and literature we identified the following factors relevant for an implementation of medical equipment in the OR: a coherent and holistic implementation approach; integration in processes, systems and organization; knowledge and skill development and effective communication during the implementation process.

\section{Acknowledgment}

The authors express their gratitude to the Dutch Operating Room Nurses Association (LVO) for the opportunity to distribute surveys at their annual congress (www.lvo.nl).

\section{References}

Bhatt, A. S., Carlson, G. W., \& Deckers, P. J. (2014). Improving operating room turnover time: a systems based approach. Journal of Medical Systems, 38(12), 148. https://doi.org/10.1007/s10916-014-0148-4

Bryman, A., \& Bell, E. (2007). Business Research Methods. New York, USA: Oxford University Press.

Carrino, J. A., Unkel, P. J., Miller, I. D., Bowser, C. L., Freckleton, M. W., \& Johnson,

T. G. (1998). Large-scale PACS implementation. Journal of Digital Imaging, 11(3 Suppl 1), 3-7.

Collar, R. M., Shuman, A. G., Feiner, S., McGonegal, A. K., Heidel, N., Duck, M., ... Bradford, C. R. (2012). Lean Management in Academic Surgery. Journal of the American College

$$
\text { of Surgeons, 214(6), 928-936. }
$$

https://doi.org/http://dx.doi.org/10.1016/j.jamcollsurg.2012.03.002

Dutch Hospital Association. (2016). Convenant Veilige toepassing van medische technologie in de medisch specialistische zorg. Bilthoven: Barnyard Creative Powerhouse.

Frasier, L. L., Pavuluri Quamme, S. R., Becker, A., Booth, S., Gutt, A., Wiegmann, D., \& Greenberg, C. C. (2017). Investigating Teamwork in the Operating Room. JAMA Surgery, 152(1), 109. https://doi.org/10.1001/jamasurg.2016.3110 

rooms: factors for successful implementations of new medical equipment

Guédon, A. C. P., Wauben, L. S. G. L., de Korne, D. F., Overvelde, M., Dankelman, J., \& van den Dobbelsteen, J. J. (2014). A RFID Specific Participatory Design Approach to Support Design and Implementation of Real-Time Location Systems in the Operating Room. Journal of Medical Systems, 39(1). https://doi.org/10.1007/s10916-014-0168-0

Kang, E., Massey, D., \& Gillespie, B. M. (2015). Factors that influence the non- technical skills performance of scrub nurses: a prospective study. Journal of Advanced Nursing, 71(12), 28462857. https://doi.org/10.1111/jan.12743

Marvik, R., Lango, T., \& Yavuz, Y. (2004). An experimental operating room project for advanced laparoscopic surgery. Seminars in Laparoscopic Surgery, 11(3), 211-216.

Meyfroidt, G. (2009). How to implement information technology in the operating room and the intensive care unit. Best Practice \& Research Clinical Anaesthesiology, 23(1), 1-14. https://doi.org/10.1016/j.bpa.2008.07.004

Pennington, C., \& DeRienzo, N. R. (2010). An Effective Process for Making Decisions About Major Operating Room Purchases. \{AORN\} Journal, 91(3), 341-349. https://doi.org/http://dx.doi.org/10.1016/j.aorn.2009.10.021

Pluyter, J. R., Rutkowski, A. F., \& Jakimowicz, J. J. (2014). Immersive training: Breaking the bubble and measuring the heat. Surgical Endoscopy and Other Interventional Techniques, 28(5), 1545-1554. https://doi.org/10.1007/s00464-

013-3350-4

Saleem, J. J., Plew, W. R., Speir, R. C., Herout, J., Wilck, N. R., Ryan, D. M., .. Phillips, T. (2015). Understanding barriers and facilitators to the use of Clinical Information Systems for intensive care units and Anesthesia Record Keeping: A rapid ethnography. International Journal of Medical Informatics, 84(7), 500-

511. https://doi.org/http://dx.doi.org/10.1016/j.ijmedinf.2015.03.006

Sheikhzadeh, A., Gore, C., Zuckerman, J. D., \& Nordin, M. (2009). Perioperating nurses and technicians' perceptions of ergonomic risk factors in the surgical environment. Applied Ergonomics, 40(5), 833-839.

https://doi.org/http://dx.doi.org/10.1016/j.apergo.2008.09.012

Stefanidis, D., Fanelli, R. D., Price, R., \& Richardson, W. (2014). SAGES guidelines for the introduction of new technology and techniques. Surgical Endoscopy, 28(8), 2257-71. https://doi.org/10.1007/s00464-014-3587-6 
290 31 $31^{\text {ST }}$ Bled eConference: Digital Transformation: MeEting the Challenges JunE 17 - 20, 2018, BLED, SLOVEnIA, CONFERENCE PROCEEDINGS 


\title{
Digital Transformation in Retail:
} Can Customer Value Services enhance the Experience?

\author{
Michael MeYer, PATRICK HeLMHOLZ \\ $\&$ SUSANNE ROBRA-BISSANTZ
}

\begin{abstract}
The brick-and-mortar retail is struggling with the digital transformation and the shift to e-commerce. Likewise, technological developments in retail service delivery raise new questions concerning the nature of relationships between retailers and customers. To secure a strong customer relationship and support satisfaction, retailers have to transform their real-world advantages into digital goods and offer new value services to the customer. With an iterative process based on design science research (DSR), we want to explore the impact of different combinations of technology-mediated value services in customer-retail-relationships. Therefore, we want to evaluate, compare and classify a combination of emotional and context-aware approaches as well as services which link online and offline advantages. This research is aimed to identify services to support and lead the brick-and-mortar retailers through the digital transformation.
\end{abstract}

Keywords: $\bullet$ retail $\bullet$ context $\bullet$ emotion $\bullet$ digital transformation $\bullet$ customer value service •

CoRRESPONDENCE AdDRESS: Michael Meyer, University of Braunschweig, Chair of Information Management, Mühlenpfordtstr. 23, Braunschweig, Germany, e-mail: m.meyer@tubraunschweig.de. Patrick Helmholz, University of Braunschweig, Chair of Information Management, Mühlenpfordtstr. 23, Braunschweig, Germany, e-mail: p.helmholz@tubraunschweig.de. Susanne Robra-Bissantz, University of Braunschweig, Chair of Information Management, Mühlenpfordtstr. 23, Braunschweig, Germany, e-mail: s.robra-bissantz@tubraunschweig.de. 
$31^{\text {ST }}$ Bled ECONFERENCE: Digital TRANSFormation: MeEting the Challenges

JunE 17 - 20, 2018, BLED, SLOVEnIA, CONFERENCE PROCEEDINGS

M. Meyer, P. Helmholz \& S. Robra-Bissantz: Digital Transformation in Retail: Can Customer

Value Services enhance the Experience?

The significant and continuous growth of e-commerce as well as the digital transformation itself are responsible for a necessary transformation process of the brick and mortar retail sector (Dennis, Jayawardhena, \& Papamatthaiou, 2010; Doherty \& EllisChadwick, 2010; Hagberg, Sundstrom, \& Egels-Zandén, 2016; Sands, Ferraro, \& Luxton, 2010). The current phenomenon of digitalization in retail space is subject of different research projects with particular importance (Hagberg et al., 2016; Keeling, Keeling, \& McGoldrick, 2013). At the same time mobile devices - especially smartphones and recently smartwatches - enable this digital transformation and trend to change the customer behavior (Blázquez, 2014). Mobile devices offer more specific and situationrelated information to the customer (Rohm \& Sultan, 2006). Adopting to this mobile and smart technology, nowadays customers are able to access the internet anytime and anywhere. Thus, they are also able to get product-specific information like price ranges, pictures and customer reviews faster and easier (Spaid \& Flint, 2014). Furthermore, not only the customers' behavior changes, their expectations do as well. While integrating mobile devices into their everyday life, customers expect enhanced accessibility of retailers in online and offline channels (Fulgoni, 2014). This new digital retail situation offers many threads but also numerous opportunities for brick-and-mortar retail (Härtfelder \& Winkelmann, 2016). The brick and mortar sector has already recognised the problems, but so far hardly reacted. New approaches and technologies should therefore be carried primarily through research into the retail sector.

To serve the customer better and offer a good customer-experience, it seems necessary to combine the positive parts of online and offline channels to an omni-channel strategy. Based on the current situation of brick-and-mortar retail, we want to examine if it is possible to digitalize the retailer's advantage of personal advice, supported by emotional data, to achieve a closer and more personal digital relationship between customer and retailer.

The broad definition of digitalization is the "integration of digital technologies into everyday life by the digitalization of everything that can be digitized" (Brave \& Nass, 2002). Furthermore, it is firstly linked to create new value (Amit \& Zott, 2001) and secondly to enhance the relationship between customer and retailer (Hagberg et al., 2016). As said, this relationship has changed fundamentally within the last years, due to the increased use of internet technologies. At the same time and due to the spreading of mobile devices, using contextual information may lead to a personalized digital advisory (Härtfelder \& Winkelmann, 2016). Especially inner states like emotions can provide insights into the customers' specific situations and thus their needs (Brave \& Nass, 2002). Understanding and solving the customers' problems in a digital enhanced way can increase the perceived equality in the relationship between customer and retailer (Scoble \& Israel, 2014). 


\section{Research Agenda}

Based on the current situation of brick-and-mortar retail, we intend to examine if there is a possibility to digitalize the retailers' advantage of personal advice, supported by contextual data, to achieve a closer and more personal digital relationship. Keeling et al. (2013), which classified different human-to-human and human-to-technology relationships (see chapter 4 and Figure 1), already observed that some artefacts like plain websites or nowadays avatars are less co-operative and socio-emotional than relationships to real people (Keeling et al., 2013). Based on their work we plan to examine new digital value services, which perform better in terms of cooperation and socio-emotionality. Additionally, we intend to combine retailers' online and offline advantages to increase the customer experience and satisfaction. In our approach, we suggest a contextual respectively emotional customer situation analysis to digitalize and extend the retailers' advantage of personal advisory.

Our research follows the design science research methodology (DSRM) of Peffers et al. (2007) in order to test and evaluate appropriate information system artefacts for the brick and mortar retail business. Accordingly, we are planning an iterative process consisting of surveys, experiments with existing applications or prototypes and finally prototypical development (see Figure 3).

Correspondingly, this research-in-progress paper is structured as follows. In the next chapter, we'll explain the importance of context-aware value services for retail, especially emotions as a highly important context factor (see chapter 3.1). In chapter 3.2, we propose emotional-awareness as an approach to enhance customer-centric value services in order to describe, understand and use the situation of the customer. In chapter 3.3, we introduce cooperation and co-operative information systems and the added values they offer to the customer. Chapter 4 demonstrates our approach to test and classify different modern information systems. The classification will follow and enhance the basic research of Keeling et al. (2013), who were able to categorize different technologies for customerretailer relationships in 2013. In a similar way we plan to compare different modern information systems in order to understand why and how various elements will affect the customer-retailer relationship. Chapter 5 sums up the approach of this research and presents future work.

\section{Context-aware Value Services}

To enable a better and more personalized user experience for retail shopping, it is important to describe a customer's situation. The elements of a situation are defined by context. "Context is any information that can be used to characterize the situation of an entity" (Dey \& Abowd, 1999). An entity is deemed as a person, place, or an object. Therefore, any kind of information which helps to characterize the situation of a customer can be considered as context (Dey, 2001). Minsky (2007) expanded the term context to a multidimensional parameter involving time, location and subjectivity in perceptions and emotions. Accordingly, context-awareness means the ability of a software to adapt to a 
current situation. Software or applications of this kind are able to change their behavior in a certain situation in order to create a context-based value to the user (Baldauf, 2007). Due to the advances in technology, the decrease of cost and size of devices and to the onward development of sensors, context-aware computing is pushed forward (Yurur et al., 2016). Especially in combination with mobile devices, the use of context information and context-aware applications seems reasonable (Baldauf, 2007). Using a mobile device, the changing situation and therefore the context of the customer can be tracked. Related to retail, context-awareness could be a way to improve the shopping experience and intensify the personal relationship by better understanding what the customers want and how they would like to be advised (Frijda, 1993). For our research, we intend to focus on a very specific context factor which has a great influence on shopping behavior: the human emotion.

\subsection{The Power of Emotions}

In the following, we discuss the importance of emotions and how they are able to influence our daily life. Furthermore, we illustrate the role emotions can play in relation to information systems, especially as an enabler for designing more personalized services for the customer. An emotion is a reaction of the human body to an occurring stimulus like an event of a certain importance to the customer. At the same time, they lead to high mental activity and can contain high degrees of pleasure or displeasure (Brave \& Nass, 2002; Cabanac, 2002). Since emotions manifest in different ways, many researchers try to pinpoint what kind of emotions exist and how they can be categorized (Lövheim, 2012; Plutchik, 2001; Russell, 1980). In addition, some researchers tried to define basic emotions like anger, disgust, fear, happiness, sadness and surprise (Ekman, 1992). Emotions are a typical human characteristic and have an impact on many aspects of our life like perception, rational thinking und decision making (Brave \& Nass, 2002; Hussain, Peter, \& Bieber, 2009; Picard, 1995; Reeves, Deeks, Higgins, \& Wells, 2008).

Therefore, they can be responsible for one being productive or staying in bed as well as buying a new product or cancelling a shopping process. Since humans tend to treat computers like other humans, emotions are also a field of interest of information systems research, especially human-computer interactions (Brave \& Nass, 2002; Picard, Vyzas, $\&$ Healey, 2001). The research field of affective computing is dedicated to enable information systems to properly react to human emotions and therefore to be able to simulate emotional intelligence (see chapter 3.2; Picard, 1995). An emotion-aware information system may be capable of enhancing the communication between human und information system (Peter \& Urban, 2012). This in turn can lead to a better und more fitting adaptation to the customer's situation and to an increased customer experience. For example, an information system that uses the customer's emotional state as an information to understand his or her situation may enhance the pleasure of the purchasing process (Hussain et al., 2009). 


\subsection{Emotional Intelligence and Measurement}

Humans are able to observe and understand emotional states of another person by recognizing facial expressions, gestures, posture and other information concerning the current situation (Hussain et al., 2009). So how can an information system be enabled to measure und interpret human emotions? There are various methods to deduce emotional states. On the one hand the evaluation of facial expressions and variances of the voice can be consulted to gain knowledge about the customer's emotions (Brave \& Nass, 2002; Essa \& Pentland, 1994; Essa \& Pentland, 1995; Peter \& Russel, 2008). On the other hand, biofeedback like heart rate and skin conductance can provide vital information for uncovering emotional states (Picard \& Klein, 2002; Picard et al., 2001). To measure emotions in a mobile environment, smartphones and smartwatches, equipped with different biometric sensors, provide an unobtrusive possibility of measurement (Bachmann et al., 2015; LiKamWa et al., 2013; Muaremi, Arnrich, \& Tröster, 2013). Finally, self-assessment can be a method to determine the current emotional state of an individual. This kind of self-report measure uses questionnaires to gain insight and exists in different forms. Some questionnaires present words like adjectives to describe emotions (Izard, 1972). Others use a two-dimensional approach and distinguish between arousal as a degree of activation and valence to define whether an emotion is either pleasant or unpleasant (Barrett \& Russell, 1999). In addition, some researcher use pictures, pictograms or even emoticons to provide an emotional scale (Bradley \& Lang, 1994; Meschtscherjakov, Weiss, \& Scherndl, 2009). The ability to recognize and understand emotions - both of oneself and of others - is known as emotional intelligence. Part of this is integrating this emotional information in order to enhance and support one's problem-solving. Another important component of emotional intelligence is the appraisal and expression of emotions, which can also be described with the term empathy (Mayer $\&$ Geher, 1996; Salovey \& Mayer, 1990). In our research approach, we intend to unlock and increase the possibilities of information systems to work with emotional information in order to obtain emotional intelligence.

\subsection{Co-operative Services}

In the following, we derive co-operative services and show their characteristics. People cooperate with each other because of emotional relationships or moral obligation. For a cooperation, at least two partners agree on the contribution and the outcome of the cooperation. A common strategy to reach a goal is not needed for a cooperation (Gerosa et al., 2006). A behavior is cooperative if it provides a benefit to another individual and if it has evolved at least partially because of this benefit (West, Griffin, \& Gardner, 2007). Information systems can actively support cooperation between provider and customer, or even act as cooperation partners themselves. Co-operative information systems support the customer proactively and context-aware. They provide the customer with help and recommendations without actively asking for it, like context-aware recommender systems or digital assistants. A digital assistant should feel like a good friend with whom the users like to communicate (Siemon et al., 2017; West et al., 2007). 


\section{$4 \quad$ Emotional and Co-operative Digital Value Services}

New technological developments and information systems in retail service delivery raise new questions concerning the nature of relationships between retailers and customers. Keeling et al. (2013) categorized retail and social relationships in four different dimensions. Guided by their classification, Figure 1 visualizes different human-to-human and human-to-technology relationships according to the two dimensions cooperative/friendly - competitive/hostile and socio-emotional/informal - taskoriented/formal. The classification shows that the human-to-technology relationships like plain websites or avatars are situated in the lower left quadrant and thus are more competitive and task-oriented than classic social relationships to team mates, neighbors or close friends. It is also indicated that human-to-human retail relationships are classified quite differently. While a phone salesman is classified as more competitive and taskoriented, the relationship with a farmer's market sales person feels more emotional, friendly and co-operative.

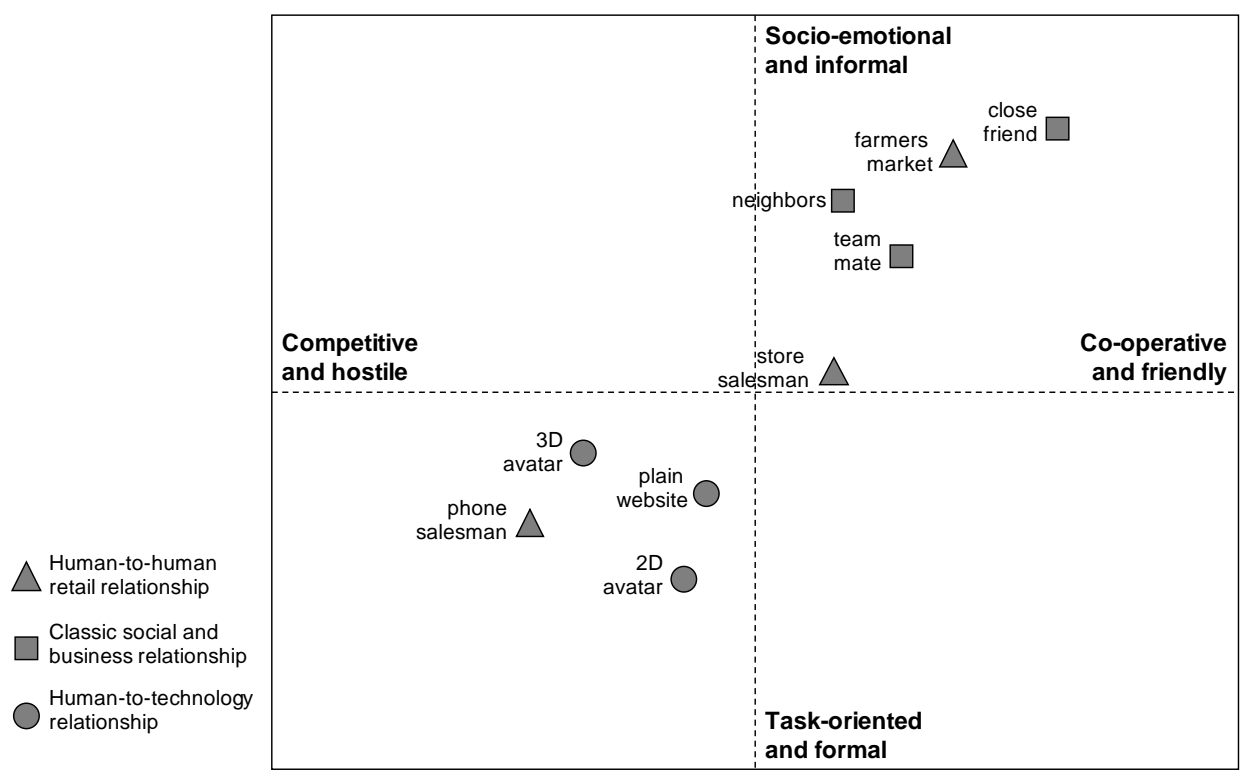

Figure 1: Relationships in digital age based on Keeling et al. (2013)

In our research approach, we intend to close the identified gap between human-totechnology relationships and human-to-human retail relationships by enhancing the customer's perception of the co-operation and friendliness as well as socio-emotionality and informality of a digital value service. With these, we aim for a solution to ultimately improve the customer-retailer relationship and customer experience. In order to understand why and how various elements affect the customer-retailer relationship, we plan to compare and classify different customer value services. Since the study of Keeling 
M. Meyer, P. Helmholz \& S. Robra-Bissantz: Digital Transformation in Retail: Can Customer Value Services enhance the Experience?

et al. in 2013, technological advances and new sensor technologies have created new services which may close the described gap (see Figure 2; Yurur et al., 2016).

Human-to-technology

relationship

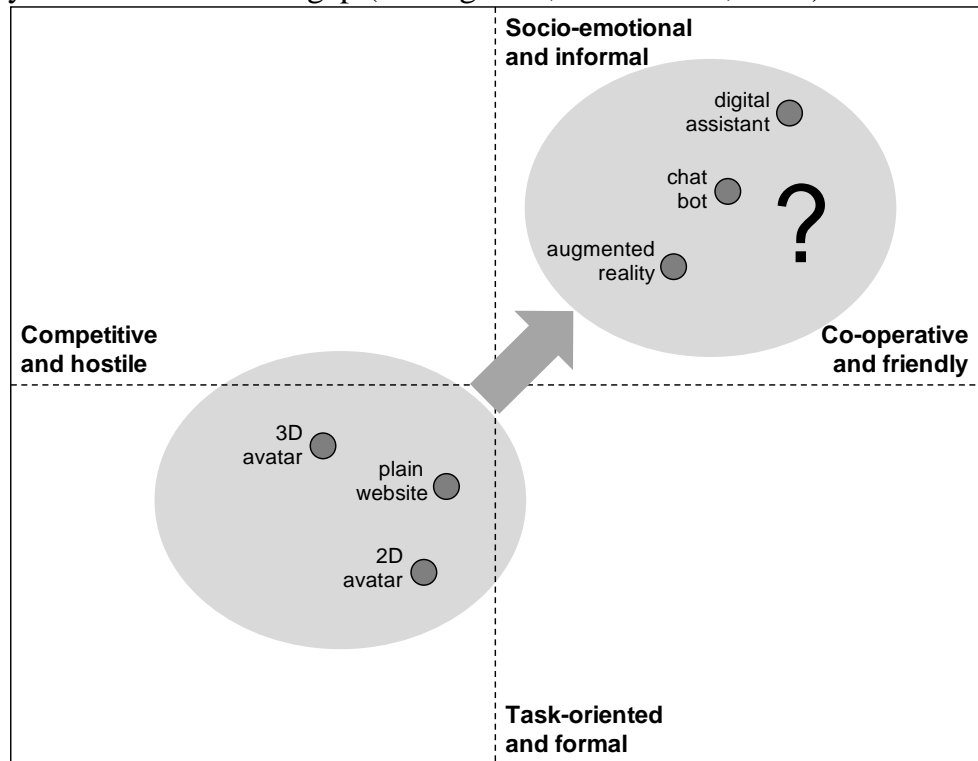

Figure 2: Classic human-to-technology relationships and modern relationships based on

Keeling et al. (2013)

For example, emotion-aware digital assistants are able to support the customer in the shopping process, augmented reality can enhance the feeling of advice and product testing or location-aware chat bots can pop up when the customer needs help or an opinion. After a literature review, the exact digital value services we plan to compare will be determined. Based on the customer surveys and interviews we will examine these services in order to identify strengths and weaknesses while enhancing the classification of Keeling et al. (2013). Furthermore, we plan to develop an own prototype, which will be evaluated continuously (see Figure 3).

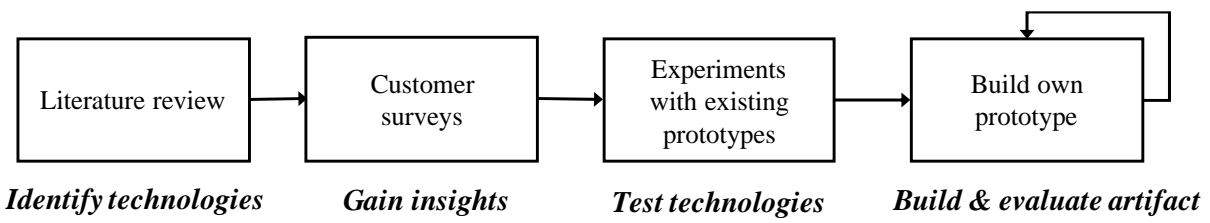

Identify and classify technologies to build customer value services

Figure 3: Research process on customer value services for retail 
As pointed out, the brick-and-mortar retail is struggling with the digital transformation and the shift to e-commerce. Hence, to manage this shift and to secure a strong customer relationship, retailers must transform their real-world advantages like personal advisory and the personal contact to the customer into a digital value (support) service. Based on the research on relationships in digital age - especially human-to-computer-relationships - by Keeling et al. (2013), we intend to continue the investigation with modern digital services. Therefore, we will explore the impact of different combinations of technologymediated value services on customer-retail-relationships. After completing the preliminary investigations by literature and surveys (see chapter 4), laboratory experiments will be carried out. These experiments will be evaluated and continued by field experiments in the local retail business. Followed by the development of an own prototype. In addition, new ways of mobile emotional measurement and analysis provided by unobtrusive wearables like smartwatches will be investigated. The purpose of our research is to understand how a technology-mediated relationship feels. The long-term goal is to pinpoint specific elements in order to create more co-operative and socioemotional information systems that fit to the users' expectations.

\section{References}

Amit, R., \& Zott, C. (2001). Value creation in e-business. Strategic Management Journal, 22(6-7), 493-520. https://doi.org/10.1002/smj.187

Bachmann, A., Klebsattel, C., Schankin, A., Riedel, T., Beigl, M., Reichert, M., ... Ebner-Priemer, U. (2015). Leveraging smartwatches for unobtrusive mobile ambulatory mood assessment. In UbiComp/ISWC'15 Adjunct (pp. 1057-1062). https://doi.org/10.1145/2800835.2800960

Baldauf, M. (2007). A survey on context-aware systems. Information Systems, 2(4), 263-277.

Barrett, L. F., \& Russell, J. A. (1999). The Structure of Current Affect: Controversies and Emerging Consensus. Current Directions in Psychological Science, 8(1), 10-14. https://doi.org/10.1111/1467-8721.00003

Blázquez, M. (2014). Fashion Shopping in Multichannel Retail: The Role of Technology in Enhancing the Customer Experience. International Journal of Electronic Commerce, 18(4), 97-116. https://doi.org/10.2753/JEC1086-4415180404

Bradley, M., \& Lang, P. J. (1994). Measuring emotion: The self-assessment manikin and the semantic differential. Journal of Behavior Therapy and Experimental Psychiatry, 25(I), 49-59. https://doi.org/10.1016/0005-7916(94)90063-9

Brave, S., \& Nass, C. (2002). Emotion in human-computer interaction. In J. A. Jacko \& A. Sears (Eds.), The human-computer interaction handbook (pp. 81-96). Hillsdale, NJ, USA: L. Erlbaum Associates Inc.

Cabanac, M. (2002). What is emotion? Behavioural Processes, 60(2), 69-83. https://doi.org/10.1016/S0376-6357(02)00078-5

Dennis, C., Jayawardhena, C., \& Papamatthaiou, E. K. (2010). Antecedents of internet shopping intentions and the moderating effects of substitutability. International Review of Retail, Distribution and Consumer Research, 20(4), 411-430. https://doi.org/10.1080/09593969.2010.504008

Dey, A. K. (2001). Understanding and Using Context. Journal of Personal Ubiquitous Computing, 5(1), 4-7. https://doi.org/http://dx.doi.org/10.1007/s007790170019

Dey, A. K., \& Abowd, G. D. (1999). Towards a Better Understanding of Context and Context- 
M. Meyer, P. Helmholz \& S. Robra-Bissantz: Digital Transformation in Retail: Can Customer Value Services enhance the Experience?

Awareness. International Symposium on Handheld and Ubiquitous Computing, 40(3), 304307. https://doi.org/10.1007/3-540-48157-5_29

Doherty, N. F., \& Ellis-Chadwick, F. (2010). Evaluating the role of electronic commerce in transforming the retail sector. The International Review of Retail, Distribution and Consumer Research. https://doi.org/10.1080/09593969.2010.504001

Ekman, P. (1992). Are there basic emotions? Psychological Review, 99(3), 550-553. https://doi.org/10.1037/0033-295X.99.3.550.

Essa, I. A., \& Pentland, A. (1994). A Vision System for Observing and Extracting Facial Action Parameters. In Proceedings of IEEE Computer Society Conference on Computer Vision and Pattern Recognition (pp. 76-83). https://doi.org/10.1109/CVPR.1994.323813

Essa, I. a., \& Pentland, A. P. (1995). Facial expression recognition using a dynamic model and motion energy. In Proceedings of IEEE International Conference on Computer Vision (pp. 360-367). https://doi.org/10.1109/ICCV.1995.466916

Frijda, N. H. (1993). Moods, emotion episodes, and emotions. In Handbook of emotions (pp. 381403). https://doi.org/http://dx.doi.org/10.1016/S0065-2601(08)60214-2

Fulgoni, G. M. (2014). “Omni-Channel” Retail Insights and The Consumer's Path-to-Purchase How Digital Has Transformed the Way People Make Purchasing Decisions. Journal of Advertising Research, 54(4). https://doi.org/12.2501/JAR-4-377-380

Gerosa, M. A., Pimentel, M., Fuks, H., \& de Lucena, C. J. P. (2006). Development of Groupware Based on the 3C Collaboration Model and Component Technology, 302-309. https://doi.org/10.1007/11853862_24

Hagberg, J., Sundstrom, M., \& Egels-Zandén, N. (2016). The digitalization of retailing: an exploratory framework. International Journal of Retail \& Distribution Management, 44(6), 336-368. https://doi.org/10.1108/IJRDM-09-2015-0140

Härtfelder, J., \& Winkelmann, A. (2016). Opportunities and Challenges for Local Retailing in an Environment Dominated by Mobile Internet Devices - Literature Review and Gap Analysis. Multikonferenz Wirtschaftsinformatik, MKWI, 1(August), 33-44.

Hussain, S. S., Peter, C., \& Bieber, G. (2009). Emotion Recognition on the Go: Providing Personalized Services Based on Emotional States. In MobileHCI (Vol. 1).

Izard, C. E. (1972). Patterns of Emotions: A New Analysis of Anxiety and Depression. Patterns of Emotions. https://doi.org/10.1016/B978-0-12-377750-8.50015-5

Keeling, K., Keeling, D., \& McGoldrick, P. (2013). Retail relationships in a digital age. Journal of Business Research, 66(7), 847-855. https://doi.org/10.1016/j.jbusres.2011.06.010

LiKamWa, R., Liu, Y., Lane, N. D., \& Zhong, L. (2013). MoodScope: Building a Mood Sensor from Smartphone Usage Patterns. In Proceeding of the 11th annual international conference on Mobile systems, applications, and services - MobiSys '13 (p. 465). https://doi.org/10.1145/2462456.2483967

Lövheim, H. (2012). A new three-dimensional model for emotions and monoamine $\begin{array}{llll}\text { neurotransmitters. } & \text { Medical 341-348. }\end{array}$ https://doi.org/10.1016/j.mehy.2011.11.016

Mayer, J. D., \& Geher, G. (1996). Emotional intelligence and the identification of emotion. Intelligence, 22(2), 89-113. https://doi.org/10.1016/S0160-2896(96)90011-2

Meschtscherjakov, A., Weiss, A., \& Scherndl, T. (2009). Utilizing Emoticons on Mobile Devices within ESM studies to Measure Emotions in the Field. Technology (Vol. 9).

Minsky, M. (2007). The Emotion Machine: Commonsense Thinking, Artificial Intelligence, and the Future of the Human Mind. Simon \& Schuster.

Muaremi, A., Arnrich, B., \& Tröster, G. (2013). Towards Measuring Stress with Smartphones and Wearable Devices During Workday and Sleep. BioNanoScience, 3(2), 172-183. https://doi.org/10.1007/s12668-013-0089-2

Peffers, K., Tuunanen, T., Rothenberger, M. A., \& Chatterjee, S. (2007). A Design Science 
$31^{\text {ST }}$ BLED ECONFERENCE: Digital TRANSFormation: MeEting the Challenges JunE 17 - 20, 2018, BLED, SLOVEnIA, CONFERENCE PROCEEDINGS

M. Meyer, P. Helmholz \& S. Robra-Bissantz: Digital Transformation in Retail: Can Customer Value Services enhance the Experience?

Research Methodology for Information Systems Research. Journal of Management Information Systems, 24(3), 45-77. https://doi.org/10.2753/MIS0742-1222240302

Peter, C., \& Russel, B. (2008). Affect and Emotion in Human-Computer Interaction: From Theory to Applications. Affect and Emotion in HCI, LNC (1st ed.). Springer Publishing Company, Incorporated. https://doi.org/10.1007/978-3-540-85099-1_10

Peter, C., \& Urban, B. (2012). Emotion in Human-Computer Interaction. Expanding the Frontiers of Visual Analytics and Visualization, 81-109. https://doi.org/10.1007/978-1-4471-2804-5

Picard, R., \& Klein, J. (2002). Computers that Recognise and Respond to User Emotion: Theoretical and Practical Implications. Interacting with Computers, 14(2), 141-169.

Picard, R. W. (1995). Affective Computing. MIT Press. https://doi.org/10.1007/BF01238028

Picard, R. W., Vyzas, E., \& Healey, J. (2001). Toward machine emotional intelligence: analysis of affective physiological state. IEEE Transactions on Pattern Analysis and Machine Intelligence, 23(10), 1175-1191. https://doi.org/10.1109/34.954607

Plutchik, R. (2001). The Nature of Emotions: Human emotions have deep evolutionary roots, a fact that may explain their complexity and provide tools for clinical practice. American Scientist, 89(4), 344-350. https://doi.org/10.1511/2001.4.344

Reeves, B. C., Deeks, J. J., Higgins, J. P. T., \& Wells, G. a. (2008). PART 3 : Special topics 13 Including non-randomized studies.

Rohm, A., \& Sultan, F. (2006). An exploratory cross-market study of mobile marketing acceptance. International Journal of Mobile Marketing, 1, 4-12.

Russell, J. A. (1980). A circumplex model of affect. Journal of Personality and Social Psychology, 39(6), 1161-1178. https://doi.org/10.1037/h0077714

Salovey, P., \& Mayer, J. D. (1990). Emotional Intelligence. Imagination, Cognition and Personality, 9(3), 185-211. https://doi.org/10.2190/DUGG-P24E-52WK-6CDG

Sands, S., Ferraro, C., \& Luxton, S. (2010). Does the online channel pay? A comparison of online versus offline information search on physical store spend. International Review of Retail, Distribution and Consumer Research, 20(4), 397-410. https://doi.org/10.1080/09593969.2010.504006

Scoble, R., \& Israel, S. (2014). Age of Context: Mobile, Sensors, Data and the Future of Privacy.

Siemon, D., Becker, F., Eckardt, L., \& Robra-Bissantz, S. (2017). One for all and all for one towards a framework for collaboration support systems. Education and Information Technologies, 1-25. https://doi.org/10.1007/s10639-017-9651-9

Spaid, B. I., \& Flint, D. J. (2014). The Meaning of Shopping Experiences Augmented By Mobile Internet Devices. The Journal of Marketing Theory and Practice, 22(1), 73-90. https://doi.org/10.2753/MTP1069-6679220105

West, S. A., Griffin, A. S., \& Gardner, A. (2007). Social semantics: Altruism, cooperation, mutualism, strong reciprocity and group selection. Journal of Evolutionary Biology, 20(2), 415-432. https://doi.org/10.1111/j.1420-9101.2006.01258.x

Yurur, O., Liu, C. H., Sheng, Z., Leung, V. C. M., Moreno, W., \& Leung, K. K. (2016). Contextawareness for mobile sensing: A survey and future directions. IEEE Communications Surveys and Tutorials, 18(1), 68-93. https://doi.org/10.1109/COMST.2014.2381246 


\title{
Motives to Form Alliances for Digital Innovation: The Case of Banks and Fintechs
}

\author{
FrIEDRICH HOLOTIUK, MILAN FREDERIK KLUS, TODOR \\ STEFAN LOHWASSER \& JÜRGEN MOORMANN
}

\begin{abstract}
In times of digitalization, the need for alliances among firms increases due to higher com- plexity and greater dynamics. Digital innovation leads to challenges for incumbent firms in adapting to changing rules set by new competitors and higher customer expectations. However, young firms providing technical solutions for the financial services industry (fintechs) also face difficulties; for instance, in meeting high regulatory requirements. Increasing alliances in the financial services industry can be observed due to shortcom- ings on the side of banks and fintechs. We conducted interviews to examine the motives of these alliance partners. The resulting motives are categorized as matching, comple- mentary, and neutral. We derive practical implications in the form of recommendations for alliances, and deliver theoretical insights regarding criteria for digitalinnovation- based alliances.
\end{abstract}

Keywords: • Digitalization • Digital Innovation • Fintechs • Motives •

CORRESPONDENCE ADDRESS: Friedrich Holotiuk, Frankfurt School of Finance \& Management, Germany, e-mail: f.holotiuk@fs.de. Milan Frederik Klus, University of Münster, Germany, e- mail: milan.klus@wiwi.uni-muenster.de. Todor Stefan Lohwasser, University of Münster, Ger- many, email: todor.lohwasser@wiwi.uni-muenster.de. Jürgen Moormann, Frankfurt School of Finance \& Management, Germany, e-mail: j.moormann@fs.de. 
F. Holotiuk, M. F. Klus, T. S. Lohwasser \& J. Moormann: Motives to Form Alliances for Digital Innovation: The Case of Banks and Fintechs

The rise of fintechs has drawn significant attention to the financial services industry. Once believed to be a disruptor, this rise has developed towards co-existence and bank-fintech alli- ances. The advantages offered by fintechs have been identified in the area of customer experi- ence, whereas those of banks are mainly in the area of back-office processing and meeting regulatory standards (Jenkins, 2016). Consequently, fintechs have established an image repre- senting innovation and exploration, whereas banks represent continuity and seniority (Bussmann, 2017).

These aspects have been believed to be mutually exclusive and leading to fierce competition (Nienaber, 2016). However, the co-existence of incumbents and start-ups can be beneficial. For example, in the beer industry, the increasing number of microbreweries has broadened the beer market and created new markets and customer groups. Thus, many big players have re- considered their product portfolio or actively approached microbreweries.

Similar developments are unfolding in the financial services industry, where ongoing digitali- zation requires extensive innovation (Brandl \& Hornuf, 2017). Digital innovation incorporates processes, services/products, and business models enabled by digital technologies (Fichman, Dos Santos, \& Zheng, 2014).

The rise of fintechs has gained speed in light of these developments (Puschmann, 2017). Typ- ically, fintechs are small, nimble start-ups that use digital technologies to deliver certain forms of financial services. The emergence of digital technologies has provided new opportunities for services that are being exploited by fintechs. Fintechs have partly taken over functions previously reserved for incumbents; e.g., in payments, lending, and investing (Eickhoff, Muntermann, \& Weinrich, 2017).

While this development has previously been seen as a disruption to the traditional financial service industry, it is now increasingly leading to the formation of alliances (Bocks, 2017). Now, fintechs may target their digitally augmented services/products toward the large cus- tomer base of banks (Puschmann, 2017). Banks can help fintechs address regulatory require- ments and gain access to new customer groups. Consequently, alliances between banks and fintechs are emerging, though the phenomenon remains novel and the motivation for such part- nerships is not yet well understood.

Extant literature has treated the "selection of partners [...] as exogenous" (Li, Eden, Hitt, $\&$ Ireland, 2008, p. 315) and thus has not focused on this area. Hence, the topic of partner selec- tion has received little attention, despite longstanding research emphasizing its crucial role during alliance formation (Hitt, Tyler, Hardee, \& Park, 1995). Moreover, motivations to part- ner, and the subsequent selection of partners for alliances to develop digital innovation has received even less attention. Hence, we must first understand this motivation before analyzing the selection of partners and the nature of alliances (Bresnen $\&$ Marshall, 2000). We formulate the following research question: 


\section{What are the motives of banks and fintechs to form alliances for digital innovation?}

This paper explores motivations for bank-fintech alliances and categorizes these in a frame- work. The paper is structured as follows: Section two outlines the recent development of banks and fintechs, existing research on digital innovation, and motivation to partner. Section three explains our methodology. The identified motives are presented in section four. Section five discusses the motives and their systemization, and concludes the paper.

\section{$2 \quad$ Background}

\subsection{Digital Innovation}

In order compete in a business environment strongly disrupted by digitalization, digital inno- vation is becoming increasingly important (Nambisan, Lyytinen, Majchrzak, \& Song, 2017). Yoo et al. (2010, p. 725) define digital innovation as "the carrying out of new combinations of digital and physical components to produce novel products." Digital innovation augments tra- ditional physical products with digital components (Yoo, Boland, Lyytinen, \& Majchrzak, 2012) and enhances the usage and customer experience (Porter \& Heppelmann, 2015). Thus, new processes, products, services, and business models are designed using digital technologies (Fichman et al., 2014).

Digital innovation impacts the formation of business model innovation and firm performance due to the often-missing internal knowledge on digital technologies and, hence, the need to acquire and integrate complementary external knowledge (Hildebrandt, Hanelt, Firk, \& Kolbe, 2015). In the financial services industry, the integration of external knowledge led to digital innovations around new processes (e.g., account opening process based on 'video-ident'), ser- vices (e.g., online social investment strategies and remote consulting services), and business models (e.g., online banks and peer-to-peer transfers). Although innovations always "require successful integration of heterogeneous knowledge, $[\ldots]$ the convergence of pervasive digital technology intensifies the degree of heterogeneity and the need for dynamic balancing and integration of knowledge resources. For example, convergent products may derive from com- pletely different industries and unrelated bodies of knowledge" (Yoo et al., 2012, p. 1401). Consequently, the quest for new knowledge to develop digital innovation triggers various mo- tives for partners to form alliances and seek access to external knowledge.

\subsection{Motivations of Alliance Partners}

Alongside digital innovation, other factors trigger motivations to form alliances. The increase of international interorganizational collaboration has been attributed to disrupting changes in the market and ongoing globalization (Robson, 2002). In the management literature, several theoretical perspectives, including transaction costs, resource dependency, organizational learning, strategic positioning, and institutional theory, have been applied to explain alliance formation (Nielsen, 2003). 
Thus, it is widely assumed that motivation to form alliances is based on a rationale that the perceived value or benefit from the alliance outweighs the costs (Geringer, 1991). Benefits one alliance partner can offer the other include "skills, competencies, capabilities, and knowledge" (Nielsen, 2003, p. 302), but these can only be fully captured when partners are carefully se- lected and both sides motives' are understood.

Based on these insights, the motives of partners have been identified. For instance, Glaister (1996) identifies 16 motives in a sample of UK joint ventures with Western European partners: Gain presences in a new market, obtain faster entry to market, facilitate internal expansion, compete against common competitor, obtain economies of scale, maintain market position, exchange complementary technology, diversify products, concentrate on higher-margin busi- ness, obtain faster payback on investment, spread risk of large projects, share $R \& D$ costs, re- duce competition, produce at lowest cost location, exchange patents/territories, and conform to foreign government policy. The wide spectrum of motives shows that alliances "are becom- ing an essential feature of companies' overall organizational structure, and competitive ad- vantage increasingly depends not only on a company's internal capabilities but also on the types of alliances and the scope of its relationships with other companies" (Parkhe, 1991, pp. 579-580). Ever since these first findings on alliances the importance of alliances has increased. Consequently, there is ongoing interest in academia in alliances and their underlying motives.

\subsection{Alliances in the Financial Services Industry}

The growing importance of alliances is also influencing the financial services industry. One contributing factor therein is digital innovation leading to increased customer expectations. Customers are demanding financial services 24/7, and at the greatest convenience. Moreover, digital technologies enable the provision of financial services at any given location. Further- more, digital technologies create huge cost savings potential for banks by reducing the tradi- tional brick-and-mortar infrastructure and streamlining the workforce. New technologies also facilitate the creation of new services and accessing new sources of revenue (Brynjolfsson \& McAfee, 2014). However, banks often lack the necessary knowledge for digital innovation, while fintechs are tapping into these new opportunities.

Consequently, due to differences in skills and knowledge (which have been identified as "in- gredients" for alliances (Hagedoorn \& Schakenraad, 1994)), banks and fintechs appear to be interesting alliance partners for each other. Prior to forming such alliances is some motivation to do so, yet the specific motives for each side have not been studied to date and can currently only be inferred. Due to high regulation, very specific service offerings, and the novelty of digital innovation, general assumptions and findings regarding joint ventures (Glaister, 1996) or classical R\&D alliances (Bai \& O'Brien, 2008) are not applicable. Our research explores the motivation for digital-innovationbased bank-fintech alliances. 


\section{$3 \quad$ Methodology}

We collected data in 15 cases, based on identification of digital innovations emerging from alliances between banks and fintechs as well as industry reports on alliances, within the finan- cial services industry in Germany. We conducted 18 interviews to understand what motivates the individual partners of bank-fintech alliances. Currently, such alliances are a multi-layered phenomenon; hence, we took an explorative case study approach (Eisenhardt, 1989).

The case alliances in our research were identified by analyzing press releases and searching online for news sources and databases, such as Crunchbase. Within each case, the interviewees from the respective sides were selected according to set criteria: First, they had to be actively involved in the alliance (in either its formation or managing the modus operandi). Second, they had to be in touch with the alliance partner on a regular basis, to substantiate their active par- ticipation in the alliance. Third, they had to hold a managerial position at the bank or a high position in the fintech (typically, we interviewed founders). Lastly, they had to have a profound understanding of the innovation developed within, or the innovation that initiated, the alliance. Additionally, we identified two independent consultants who were not involved in any alliance of our set but have been involved in bank-fintech alliances before - either on the bank's or the fintech's side. In total, we conducted nine interviews with banks, seven with fintechs, and two with the independent consultants (Table 1). We aimed for equal representation of fintechs and banks, while the consultants were used to triangulate the findings. 
F. Holotiuk, M. F. Klus, T. S. Lohwasser \& J. Moormann: Motives to Form Alliances for Digital Innovation: The Case of Banks and Fintechs

Table 1: List of interviewees and their position

\begin{tabular}{|c|l|l|c|}
\hline ID & Group & Position & Length in mins \\
\hline 1 & Bank & Director Venture Vehicle/ Incubator & 62 \\
\hline 2 & Bank & Director B2B and Innovation & 51 \\
\hline 3 & Fintech & Founder & 58 \\
\hline 4 & Fintech & Head of Partnerships & 67 \\
\hline 5 & Consultant & Fintech Mentor; Venture Partner & 78 \\
\hline 6 & Fintech & Head of Sales & 54 \\
\hline 7 & Bank & Director Investing & 61 \\
\hline 8 & Fintech & Founder and Chief Executive Officer & 63 \\
\hline 9 & Fintech & Chief Customer Officer & 72 \\
\hline 10 & Fintech & Founder & 61 \\
\hline 11 & Bank & Director Trading and Investing & 73 \\
\hline 12 & Bank & Director Business Development & 71 \\
\hline 13 & Bank & Director Business Development & 69 \\
\hline 14 & Bank & Director Business Development & 66 \\
\hline 15 & Consultant & Partner Consulting for Fintechs & 70 \\
\hline 16 & Bank & Director Partner \& Innovation (Private Clients) & 72 \\
\hline 17 & Bank & Board Member and Director B2B & 39 \\
\hline 18 & Fintech & Founder & 63 \\
\hline
\end{tabular}

To capture the multi-layered phenomenon of bank-fintech alliances, we ensured the examina- tion in various research directions by following Eisenhardt (1989) and Yin (2009) and design- ing semi-structured interview guidelines with open-ended questions. This guaranteed we could analyze all perspectives and assessments expressed by the interviewees. All interviews were audio-recorded and transcribed for further analysis. The interviews took place in Q3 and Q4 of 2017. Transcript coding was performed using MaxQDA v.12.2.

Data analysis started with descriptive codes based on motives mentioned by the interviewees. This led to the identification of 266 coded segments across the 18 interviews. Here, our focus was to "organize and make sense of the qualitative data" (Basit, 2003, p. 152) and understand how the motives were perceived and understood by the interviewees. Subsequently, the mo- tives were analyzed for duplicates and similar content. We assigned categories to each coded segment based on the motivation encapsulated in the segment following an open coding ap- proach (Strauss \& Corbin, 2008). This process was highly iterative and involved studying each interview 
individually, and in contrast to interviews from the other (bank or fintech) group. Each category represents one motivation of either banks or fintechs. Finally, we condensed similar categories (describing similar motives) to a common category. This nuanced analysis of the motives enabled us to derive nine categories of motives from our interviews.

\section{$4 \quad$ Findings}

This section presents the five motives for banks and the four for fintechs, and outlines a sys- tematization thereof. The motives are backed by quotations from our interviewees (in italic with interviewee ID given in brackets).

\subsection{Motives of Banks}

\section{(Rapid) Innovation}

In all nine cases analyzed, banks were keen to partner with fintechs to speed up innovation processes that would otherwise consume too much time and financial and managerial resources. Since this applied to the whole sample, it reveals that banks are not only interested in advanced ideas but also value well-thought-out turnkey solutions for their business. Our inter- viewees stated that banks could innovate by themselves, but have become "too large and too ponderous to promote internal change processes" (I12). The interviewees were aware that this is the result of old, traditional structures and "the IT implementation of an idea would take 10 times longer, as these changes are tested more extensively until everything, e.g. all regulatory requirements, fits" (I13). Since regulators demand the implementation or alteration of various processes multiple times per year, companies outside banks are able to screen these new de- mands and become "better and more efficient or safer in these topics" (I7). Thus, from the viewpoint of banks, fintechs are specialists who mainly focus on problems that impact most banks. Furthermore, implementation for fintechs is easy, as they have a "smaller set-up and are faster" (I16). Banks "only have to dock [the innovations] on [their] structure and then [they] can work with them" (II6).

\section{Competitive Advantage}

As a second motivation, in five of the nine cases banks were motivated to partner with fintechs to achieve competitive advantage and increase customer value. Interestingly, banks acknowl- edged that fintechs might provide "something different, better, higher, more advanced, or [something that] just goes down well with a customer" (I11). As, for instance, the German financial services industry becomes increasingly competitive between traditional banks, every bank's revenues based on the classic interest-bearing business model decreases. "Every bank searches for additional potential for revenuecreation. We can perhaps also offer real added value to meet our customers' demands by using the data we have anyway" (I7). However, fintechs usually offer their services to a variety of banks, which diminishes the unique selling proposition as banks prefer exclusive partnerships (I7). 


\section{Outsourcing}

Third, banks try to avoid using their own resources on new and risky innovations with unknown results, and attempt to save costs as "smaller firms with only a few employees can simply pro- duce considerably cheaper and achieve [...] more attractive prices for the market" (I11). Banks use fintechs to reduce their own workload, so that their employees can focus on core activities. Thus, banks "do not need to tie [up] additional manpower as we already have enough other issues" (I7). As the development of new business areas uses up already scarce internal resources, one bank interviewee mentioned that "we do not need to set up these inter- nal resources anyway. We can acquire them [from] the market just as well" (II2) as "fintechs are, even with the API [Application Programming Interface] development, faster and better than when we would use our own internal resources we currently have in stock" (I12). Banks also consider the extent to which, and for what purpose, they outsource certain activities. Some banks consider outsourcing a huge part of their value chain, such as digital payment services, while others aim to establish a wholly new business field (I13). In banking, services of fintechs often remain unrecognized for customers in the background as so-called "white labels" that are "easier and faster to implement [...] and use [...] than to build the whole system up by our- selves" (I14). Further, these partnerships allow banks to "broadly diversify their $R \& D$ activi- ties as there is a very active fintech scene" (I13).

In conclusion, banks prefer to focus on their core activities, as they are "no[t a] techcompany nor an IT-firm. We are a bank-we are good [at] financial consulting, we are good [at] ad- dressing behavioral finance topics [...] We are not good at writing computer programs" (I12).

\section{Learning}

The banks' motivations to partner with fintechs not only relate to outsourcing of non-core ac- tivities; it is also important to them to learn from the fintechs' way of thinking and to "break up and adjust existing processes, which becomes harder the longer the process exists. It is, of course, easier for other companies which can start from scratch and build up a blueprint of how to newly arrange a whole process" (I7). Their "different approach causes pinpricks to reconsider our traditional thinking" (II). Thus, fintechs are seen as sparring partners that allow "in-depth discussions from a different point of view [...] and start processes in our bank which we probably would never have seen nor pursued" (I11). Hence, fintechs "use a very stringent approach in the processing of information" (I7) and provide an "impulse which is a very, very exciting driver [...] and always leads to crossfertilization" (I11).

\section{Business Model Evolution}

As information about banks becomes increasingly ubiquitous and barriers to switching finan- cial institutions fall, banks fear the increasing speed of change (II1). They are also afraid that "fintechs [will advance] to a point of digital transformation, where they are able to replace current business models by providing scalable, digital, and intelligent solutions"(I13). Hence, banks are "searching for new business" (I13) as they are feeling "very high pressure - on the one side high regulatory pressure and on the other side lowinterest margins" (I13). The in- terviews stated that banks see opportunities within digital 
financial services as an "extremely interesting and exciting business area, but we know that our technical possibilities are by far not as advanced as the fintechs'. That's why we entered this strategic partnership" (I2). These partnerships help to "identify and launch new business models and consider all the different possible approaches" (I13). However, the interviewees mentioned that some banks do not fol- low any clear strategy (I14). It can also be assumed that banks fear missing opportunities to establish sustainable business models for the future, as "it is incredibly difficult to know what happens where and since we also want to follow a digital strategy, everyone in the management is anxious to follow this opportunity" (I1). They also try to "convince the workforce to catch up speed and acknowledge the urgency for an organizational change-or, even more-to truly achieve a mindset change" (II1). Hence, banks see investments in fintechs as M\&A activities (II7).

\subsection{Motives of Fintechs}

\section{Trust and Credibility}

Surprisingly, the motivations of the interviewed fintechs to partner with banks are less diverse. Six out of seven respondents considered alliances as valuable assets for obtaining trust and credibility (I9). On the one hand, gaining trust and credibility through alliances with established banks is central to attract end customers, as "trust is very, very important and helps the inves- tors to gain confidence in the product" (I4). Particularly in the "payment sector, the brand, or better said the trust, is very, very important-especially in Germany" (I3). On the other hand, fintechs wish to partner with more banks and get access to their customer base. Since failures in alliances with fintechs might harm banks' reputations, banks become cautious as they "are always a bit afraid of how long the fintech will still exist or if the processes are [as] reliable as they are in old traditional institutions" (I3). To overcome this burden, fintechs wish to win partners for their product or service in order to establish a "trust element" (I3) and run a "flag- ship project to overcome reputational risk issues" (I3). Furthermore, they use feedback dis- cussions to ask the banks to "assess out of their own experience how the acceptance of the product or service among customers will be" (I9). Thus, fintechs use banks for "entrance to the market" (I9).

\section{Resources and Synergies}

Four out of seven fintechs mentioned that they see their partner as a "customer that also has the financial endowment to break new ground, which in turn helps us" (I3). Fintechs further benefit from the higher marketing budgets of banks, and from other synergies in marketing (I3). Besides a product-related partnership, "there are banks which also invest in start-ups-which means that in some partnerships the bank only wants to get to know [the fintech] and vice versa to investigate [whether] the partnership might be expanded to an investment" (IPW3). As soon as fintechs provide services, where there is any type of payment involved they need deep knowledge, as well as assets, to ensure proper handling, alongside a license to con- form to regulations $(I 4, I 8)$. As these requirements can be a financial burden for fintechs, or sometimes "impossible" according to European policies (I3), three out of eight fintechs men- tioned sharing costs of conforming to regulation as 
an alliance motivation. However, alongside superior financial endowment, fintechs often wish to access banks' data and infrastructure to apply and test their product or service in realistic cases (I8).

\section{Customer Acquisition}

As incumbent banks can provide large customer bases, which might be an even more interest- ing asset for fintechs than financial support, three interviewees from fintechs described "higher prominence [...] which means more customers and transactions" (I3) as a key motivation for alliances, as a database of "around one million existing customers is incredibly tempting" (I18).

\section{Learning}

Two fintechs mentioned intending to acquire knowledge about the market and the industry (I3), as banks "already have a long tradition" (I8). Alongside learning how banks think in terms of partnership and investment, fintechs want to "understand more and more how the customer thinks and how industry structures work" (I3) or how banks provide "services for independent financial service providers" (I8).

\subsection{Systematization of the Motives}

Most motives within the bank and fintech group are unique and distinct with only one overlap between both groups. However, the picture becomes more complex when looking at the sides' different motives. Figure 1 compares the motives of banks and fintechs. The circles represent the motives, while their size indicates comparatively, how frequently they were mentioned. The horizontal categories show whether the motives can be seen as matching, complementary, or neutral. This categorization reflects the manifestation of the motives' relationships in our cases.

Firstly, neutral motives are predominantly beneficial to only one side of an alliance. To im- prove their own competitive advantage, some banks use fintechs for innovative (often also highly customized) application programming or specialized tasks. Other banks use alliances with fintechs as an opportunity to evolve their own business model. Some fintechs pursue the formation of an alliance primarily to promote their products based on the banks' trust and cred- ibility.

Secondly, complementary motives are considered as beneficial for both sides of an alliance and supportive for furthering digital innovation. For example, the motive of banks to rapid innovation through fintechs can well harmonize with providing them with needed resources (e.g., banking licenses). Banks aim to outsource certain activities such as developing digital standard applications (e.g., peer-to-peer money transfer apps), implementation of new regula- tory rules, and servicing niche customer groups. These activities can be covered by fintechs and, at the same time, fintechs can acquire more customers for themselves with the bank's help. This may lead to 'coopetition' as banks and fintechs cooperate and compete simultaneously (Bengtsson \& Kock, 2000). 
Lastly, matching motives are identical among the alliance partners and offer a good fit to form new alliances. Learning can improve both partner's positioning through making up for certain shortcomings, such as missing knowledge about digital technologies on the banks' side or missing knowledge on regulatory and legal specifications on the fintechs' side. However, learning requires time and trust to create deep business knowledge (I3).

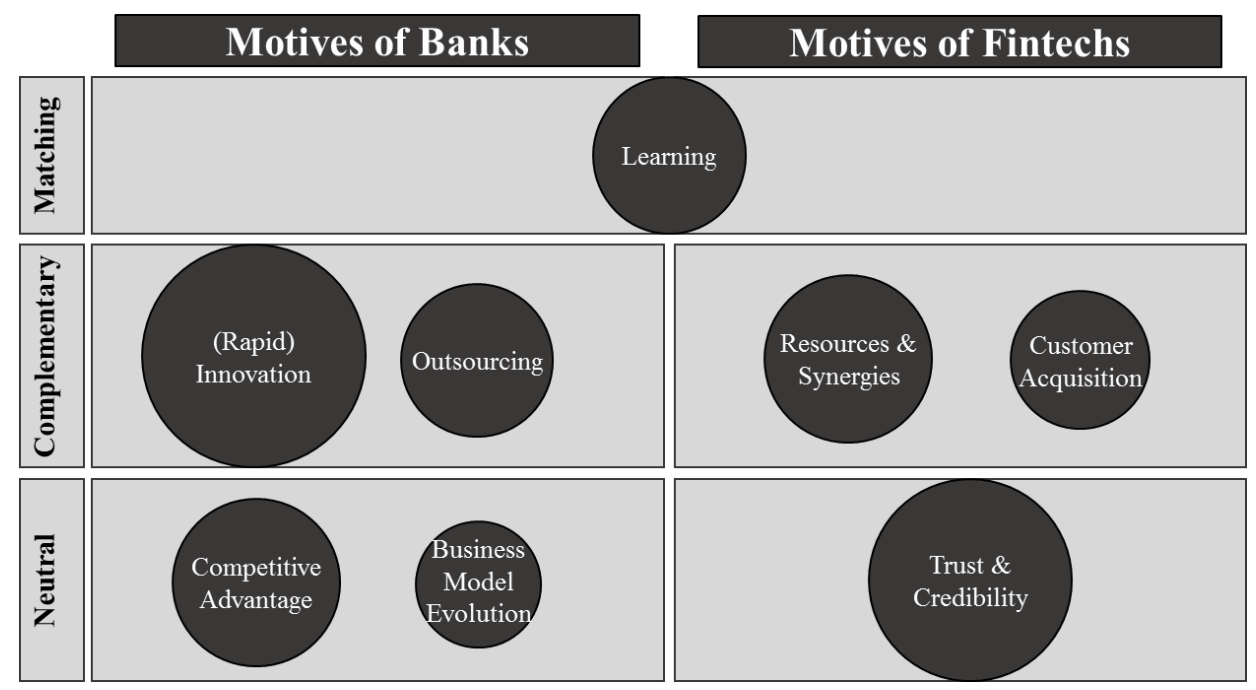

Figure 1: Overview of the motives to form alliances

\section{$5 \quad$ Discussion and Concluding Remarks}

As the financial services industry is considered relatively conservative and alliances with start- ups are a relatively new phenomenon in this field, the topic of bank-fintech alliances is highly relevant for both practice and academic research. Recent studies have examined fintechs as such (Puschmann, 2017) and the emergence of a global fintech market (Haddad \& Hornuf, 2016); however, the motivations of banks and fintechs to partner has not been analyzed in depth. Building on the literature of fintechs, digital innovation, and alliance-partner selection, this paper identifies several motives of partners to form bankfintech alliances.

The results show a variety of motives, which are often heterogeneous both within the two groups and across the comparison. The clustering proposed in Figure 1 is a first approach to systemizing motivation in this field. The categories within the framework are based on the frequency with which similar motives were mentioned, which we take to indicate their rele- vance.

The findings show that banks tend to pursue rapid innovation and competitive advantage, while fintechs seek to benefit from the banks' reputation and expand their customer base. Trust seems to be key for fintechs, as finance is a sensitive issue for customers who do 
F. Holotiuk, M. F. Klus, T. S. Lohwasser \& J. Moormann: Motives to Form Alliances for Digital Innovation: The Case of Banks and Fintechs

not want to entrust their money to unknown providers and regulatory authorities. However, trust also plays a role for banks as potential partners. Thus, established banks have to protect their own reputation, which could be damaged by alliance partners' misconduct.

The heterogeneity of motives is not necessarily negative, as the motives are not contradictory in all cases and thus not mutually exclusive. For example, banks' strategic motivation to be- come more digital aligns with fintechs' motivation to expand their customer base. For example, the alliance partner's expanded customer base increases visibility of the bank's new orienta- tion, yielding a common benefit.

A comparison of the motives shows that only learning applies to both. Fintechs are especially interested in building functioning and stable companies, while banks want to learn more about the dynamics and agility of fintechs. Organizational learning, or, more precisely, interorgani- zational learning, is an often-discussed topic in both academia and practice, which is also rel- evant for bank-fintech alliances. Banks can either develop innovative products themselves or outsource to fintechs for more rapid outcomes; if they want to become more innovative them- selves, fintechs can serve as a companion throughout the learning process. Theoretically, banks can then develop "fintech products" in-house and no longer depend on alliances. Fintechs could also benefit from temporary alliances by developing stable organizational structures, expand-ing their customer base, and building their reputation. They may also be able to eventually break away from the partnership to establish themselves as competitors.

However, if banks do not strive for learning, but rather want to save costs and resources through outsourcing, they become increasingly dependent on their partners. Consequently, fintechs' bargaining power may increase over time and the conditions for further collaboration could be renegotiated. Our findings show that banks value achieving competitive advantage slightly more than learning. This poses a question regarding the actual design of the alliances and the associated objectives of banks and fintechs.

Knight (2000) states that trust, teamwork, and commitment are prerequisites for learning in interorganizational relationships. Corresponding factors require time and interfaces in daily collaboration. Furthermore, Sobrero and Roberts (2001, p. 493) identify "the type of problem- solving activities being partitioned and their level of interdependency with the rest of the pro- ject" as relevant regarding performance outcomes of a partnership. This stimulates a trade-off between a short-term efficiency increase and a long-term learning process (Sobrero \& Roberts, 2001). If a well-functioning learning process is of interest, which seems to be the case for both banks and fintechs, a customer-service-provider relationship, which is limited to sharing the fintech product, is insufficient. A closer form of alliance with tight collaboration, efficient knowledge management, well-coordinated interfaces, and appropriate organization is also re- quired. Since knowledge is a fundamental resource for gaining competitive advantage (Cegarra-Navarro, 2005), and learning promotes process and product co-innovation (Westerlund \& Rajala, 2010), we suggest that future research investigate interorganizational learning in the context of bank- 
fintech alliances. In this setting, special attention should be paid to existing forms of interaction to identify opportunities for interorganizational learning.

This paper focuses on the motivation to partner, but not the design of the alliance itself. Our study is also limited by the small number of companies interviewed, which restricts the validity of the results. Additionally, only the German market was considered; thus, larger studies are necessary to confirm the robustness of the results. Furthermore, the assessment of whether certain motives are contradictory or complementary depends on context, making general state- ments difficult.

Despite these limitations, the study outlines an approach to systematizing the various motives for bank-fintech alliances. We believe that our results are generalizable due to no country- specific arguments in our reasoning and transferable to other contexts (e.g., countries or mar- kets with similar characteristics). Still this should be tested by further research. In addition to the abovementioned implications for future research, practical implications include the sug- gestion that both banks and fintechs clearly identify their respective motivations before form- ing alliances. Their own motives should be compared with those of the potential partner to identify synergies, as well as potential conflicts of interest, at an early stage.

\section{References}

Bai, Y., \& O'Brien, G. C. (2008). The Strategic Motives behind Firm's Engagement in Cooperative Research and Development. Journal of Modelling in Management, 3(2), 162181.

Basit, T. (2003). Manual or Electronic? The Role of Coding in Qualitative Data Analysis.

Educational Research, 45(2), 143-154.

Bengtsson, M., \& Kock, S. (2000). "Coopetition” in Business Networks - to Cooperate and Compete Simultaneously. Industrial Marketing Management, 29(5), 411-426.

Bocks, B. (2017). Die jungen Wilden werden erwachsen. Retrieved February 14, 2018, from https://www.springerprofessional.de/en/fintechs/bank-it/die-jungen-wilden-werden-solangsam-reifer-fintechs-wachsen-lang/15144350

Brandl, B., \& Hornuf, L. (2017). Where Did Fintechs Come from, and Where Do They Go? The Transformation of the Financial Industry in Germany after Digitalization. SSRN Working Paper.

Bresnen, M., \& Marshall, N. (2000). Motivation, commitment and the use of incentives in partnerships and alliances. Construction Management and Economics, 18(5), 587-598.

Brynjolfsson, E., \& McAfee, A. (2014). The Second Machine Age: Work, Progress, and Prosperity in a Time of Brilliant Technologies. New York: W. W. Norton \& Company.

Bussmann, O. (2017). The Future of Finance: FinTech, Tech Disruption, and Orchestrating Innovation. In R. Francioni \& R. A. Schwartz (Eds.), Equity Markets in Transition (pp. 473486). Zurich: Springer International Publishing.

Cegarra-Navarro, J. G. (2005). An empirical investigation of organizational learning through strategic alliances between smes. Journal of Strategic Marketing, 13(3), 316. 
Eickhoff, M., Muntermann, J., \& Weinrich, T. (2017). What do FinTechs actually do? A Taxonomy of FinTech Business Models. In Proceedings of the International Conference on Information Systems (pp. 1-19). Seoul.

Eisenhardt, K. M. (1989). Building Theories from Case Study Research. Academy of Management Review, 14(4), 532-550.

Fichman, R. G., Dos Santos, B. L., \& Zheng, Z. (Eric). (2014). Digital Innovation As a Fundamental and Powerful Concept in the Information Systems Curriculum. MIS Quarterly, 38(2), 329-A15.

Geringer, M. J. (1991). Strategic Determinants of Partner Selection Criteria in International Joint Ventures. Journal of International Business Studies, 22(1), 41-62.

Glaister, K. W. (1996). UK-Western European Strategic Alliances: Motives and Selection Criteria. Journal of Euromarketing, 5(4), 5-35.

Haddad, C., \& Hornuf, L. (2016). The Emergence of the Global Fintech Market: Economic and Technological Determinants. CESifo Working Paper Series.

Hagedoorn, J., \& Schakenraad, J. (1994). The Effect of Strategic Technology Alliances on Company Performance. Strategic Management Journal, 15(4), 291-309.

Hildebrandt, B., Hanelt, A., Firk, S., \& Kolbe, L. M. (2015). Entering the Digital Era - The Impact of Digital Technology - related M \& As on Business Model Innovations of Automobile OEMs Chair of Information Management. In Proceedings of the International Conference on Information Systems (pp. 1-21). Fort Worth.

Hitt, M. A., Tyler, B. B., Hardee, C., \& Park, D. (1995). Understanding Strategic Intent in the Global Marketplace. Academy of Management Executive, 9(2), 12-19.

Jenkins, I. (2016). Collaboration not Competition: Banks Find New Partners. Retrieved February 23, 2018, from http://pwc.blogs.com/fintech/2016/08/banks-collaboratewith- fintechs-rather-than-viewing-them-as-competition.html

Knight, L. A. (2000). Learning to collaborate: a study of individual and organizational learning, and interorganizational relationships. Journal of Strategic Marketing, 8(2), 121-138.

Li, D., Eden, L., Hitt, M., \& Ireland, D. (2008). Friends, Acquaintances, or Strangers? Partner Selection in R\&D Alliances. Academy of Management Journal, 51(2), 315334.

Nambisan, S., Lyytinen, K., Majchrzak, A., \& Song, M. (2017). Digital Innovation Management: Reinventing Innovation Management Research in a Digital Wolrd. MIS Quarterly, 41(1), 223-238.

Nielsen, B. B. (2003). An empirical investigation of the drivers of international strategic alliance formation. European Management Journal, 21(3), 301-322.

Nienaber, R. (2016). Banks Need to Think Collaboration Rather Than Competition. In S. Chishti \& J. Barberis (Eds.), The FinTech Book (pp. 20-21). West Sussex: John Wiley \& Sons, Ltd.

Parkhe, A. (1991). Interfirm Diversity, Organizational Learning, and Longevity in Global Strategic Alliances. Journal of International Business Studies, 22(4), 579601.

Porter, M. E., \& Heppelmann, J. E. (2015). How Smart, Connected Products Are Transforming Companies. Harvard Business Review, 92(11), 96-114.

Puschmann, T. (2017). Fintech. Business \& Information Systems Engineering, 59(1), 69-76.

Robson, M. J. (2002). Partner selection in successful international strategic alliances: The role of co-operation. Journal of General Management, 28(1), 1-15. 
F. Holotiuk, M. F. Klus, T. S. Lohwasser \& J. Moormann: Motives to Form Alliances for Digital Innovation: The Case of Banks and Fintechs

Sobrero, M., \& Roberts, E. B. (2001). The trade-off between-efficiency and learning in interorganizational relationships for product development. Management Science, 47(4), 493511.

Strauss, A., \& Corbin, J. (2008). Basics of Qualitative Research: Techniques and Procedures for Developing Grounded Theory. Basics of Qualitative Research Grounded Theory Procedures and Techniques (Vol. 3). Thousand Oaks: Sage Publishing.

Westerlund, M., \& Rajala, R. (2010). Learning and innovation in inter-organizational network collaboration. Journal of Business \& Industrial Marketing, 25(6), 435-442.

Yin, R. K. (2009). Case Study Research: Design and Methods. New York: Sage Publications.

Yoo, Y., Boland, R. J., Lyytinen, K., \& Majchrzak, A. (2012). Organizing for Innovation in the Digitized World. Organization Science, 23(5), 1398-1408.

Yoo, Y., Henfridsson, O., \& Lyytinen, K. (2010). The New Organizing Logic of Digital Innovation: An Agenda for Information Systems Research. Information Systems Research, 21(4), 724-735. 
316 |31 $31^{\text {ST }}$ Bled eConference: Digital Transformation: MeEting the Challenges JunE 17 - 20, 2018, BLED, SLOVEnIA, CONFERENCE PROCEEDINGS 


\title{
Evaluation of Push Notifications for Social Media Applications
}

\author{
EMma FAHLMAN, ThOMAS MEJTOFT \& HELEN CRIPPS
}

\begin{abstract}
The growth of social media has impacted on people's everyday life, precipitating the development of a new set of guidelines for designing applications (apps), creating heightened user engagement without crossing the line to frustration. This study focuses on how push notifications from social media apps should be designed in order to keep the user intrigued and returning to the app, without annoying the user to the point where they turn the push notifications off. The exponential growth in the usage of social media has emphasised the importance of designing apps with a usercentred functionality. The study used a combination of a survey questionnaire and a qualitative perception study, with the results collected as both data and extracts from interviews. This study identified that a high frequency of notifications from social media apps has led to resentment by users against pushes notifications in general. The app-user relationship is cemented from the beginning of the experience and the action the user takes in relation to notifications depends on their perception of the senders' intentions. Younger users' actions are also predominately driven by the phenomena Fear of Missing Out.
\end{abstract}

Keywords: • Social media • Push notification • Users perceptions •

CORRESPONDENCE AdDRESS: Emma Fahlman, Umea University, Digital Media Lab, Department of Applied Physics and Electronics, Umeå University, Sweden, e-mail mailto:emmaafahlman@hotmail.com. Thomas Mejtoft, Ph.D., Associate Professor, Umea University, Digital Media Lab, Department of Applied Physics and Electronics, Umeå University, Sweden, e-mail: thomas.mejtoft@umu.se. Helen Cripps, Ph.D., Senior Lecturer, Edith Cowan University, Business and Law, Perth, Australia, e-mail: h.cripps@ecu.edu.au. 
E. Fahlman, T. Mejtoft \& H. Cripps: Evaluation of Push Notifications for Social Media Applications

Nowadays a majority of applications (apps) for smartphones use push notifications as a way to communicate to the user and create greater engagement (Kim and Baek, 2018). For app developers, notifications are an effective way to interact with the users in different ways depending on the nature of your notification. However, when a notification is sent out to a user, it is delivered directly with without considering the users situation or psychological state (Okoshi et. al., 2016). The notification could be perceived as a distraction or interruption, potentially causing inattention and frustration for the recipient, even if the content of the notification is not demanding at all (Kushlev, Proulx and Dunn, 2016). Despite the frustration, a user might respond subconscious to an interruption due to sound or vibrations in association with the notification, and leading them into their smartphone to explore which application that sent the notification (Turner, Allen and Whitaker, 2015). If the main goal of the notification were to get the users attention, it would be beneficial to create an interrupting notification that uses audio, vibration and an urgent formulation of the text. Where the aim of engaging the user fails is when the user decides to turn off the notification (which can be made in most application settings) in their smartphone, and the application loses the ability to communicate with the user (Pielot and Rello, 2017).

There are many factors to take into account when dealing with users' actions in relation to notifications in real life situations. The app designer must keep the user intrigued and drawn back into the application, without crossing the line where interest turns into frustration. As Buttrick, Linehan and Kirman (2014) suggest the interaction between people and contemporary technology could be perceived as a submissive (user)-dominant (technology) relationship. They also state that technology is ostensibly developed to support people in their daily lives, but in recent years technology could be viewed as more demanding, rather than supportive (Buttrick, Linehan and Kirman, 2014; Kushlev, Proulx and Dunn, 2017). Turner, Allen and Whitaker (2017) suggest with the ubiquity of notifications comes increased cognitive load for the user. Notifications have been used extensively in marketing particular in retail with the rise of geo-location technology (Faulds et al., 2018; Kim and Baek, 2018) however rather that guiding the user the notifications are seen as intrusive (Karapanos, Teixeira and Gouveia, 2016). If designers start out from the assumption that contemporary technology is a demanding force in the human-computer relationship, then they could implement the philosophy when designing a notification (Saltan, 2014; Turner, Allen and Whitaker, 2015).

This study will explore how the app-user interaction can be structured to benefit both the developer and the user. The research seeks to identify how to optimise the notification without annoying the user to the point where they turn off the push functions. The study will identify the most suitable way of using push notification for social media apps so the user cannot resist opening them. 


\section{$2 \quad$ Background}

How the human-computer relationship works when dealing with push notifications has been investigated in prior studies conducted in the field (e.g. An, Woo, Lee and Yeom, 2016; Elslander and Tanaka, 2013; Turner, Allen and Whitaker, 2015). The usage patterns on social media today are also an important factor to take into account for this study when dealing with the users' behaviour and interaction with smartphones (Fox and Mooreland, 2015).

\subsection{Daily notifications}

An extensive study done by Elslander and Tanaka (2013) at Kyoto University, Japan, provided some interesting results about the use and perception of mobile notifications. They handed out a survey containing various questions about notifications and received 9900 answers. From the data analysis some parameters distinguished themselves. According to their study, roughly half of smartphone users receive less than 10 notifications per day. The difference is that younger smartphone users (aged below 25) and female respondents tend to get notified on more occasions than older users and male respondents. Furthermore, there is a visible difference depending to which operating system (OS) the users smartphone has, 69\% of Android users gets more than 10 notification per day while only $45 \%$ of iOS users do.

\subsection{Interaction with notifications}

Besides looking into the amount of notifications users receive, it is important to analyse how the users interacts with them to get a better insight of their behaviour. Fox and Mooreland (2015) found that notification such as automated Birthday updates from Facebook made users fell obligated and pressured to post on their friend's timeline. This sense of and cognitive loaded in response to notifications has been identified in previous research (e.g. Okoshi, et al. 2015; Westermann, Möller and Wechsung, 2015).

Another parameter for measuring notification was suggested in Elslander and Tanakas' (2013) that study showed that nearly all respondents admit to activating their phones' screen regularly in order to check for missed notifications. An et al., (2015) found that multiple notification in quick succession lead users to "lose" and disconnect from notifications. More importantly, the frequency of interaction differed between gender and age in their study. The respondents aged under 25 claimed to check their phone at least once an hour, while respondents aged over 25 stated to only do so sporadically. Furthermore, almost half of the female users check at least once an hour compared to only one in three male users. Android users also check their phone more frequently for notifications they missed out on than iOS users. Half of all Android users checked their phone at least hourly, compared to only 16\% of iOS users (Elslander and Tanakas, 2013). 


\subsection{Difference between operating systems}

The difference in the users' behaviour between operating systems (OS) can be explained by looking into how the different OS handles and displays the notifications to the user. The two most common systems are Android that uses the notification drawer and iOS that uses the notification centre ( $\mathrm{Li}, 2017)$. Both systems have an associated workflow that differs between the two platforms. What can be seen is that notifications are much more prominent on the Android as they are repeatedly appearing on the locked screen and sticky icons are placed on the home screen, giving the user a frequent reminder to open them. Android also allows third party applications to submit a customized view object in the notification view (Xu and $\mathrm{Zhu}, 2012$ ). With iOS, being less able to be customized, it only allows submitting text content. Also, the iOS user is only reminded of new notifications once and after they have appeared on the screen the notifications hides in the notification centre $(\mathrm{Li}, 2017)$. The pull-down notification centre that holds an overview of the current notifications on the phone was initially released on the Android OS. In 2011, Apple introduced a very similar looking feature with iOS 5 (Li, 2017). Both notification centres have been evolving since by adding new functionality like custom icons, images and action buttons with the aim of drawing the user back into the apps.

\subsection{Use of Social Media}

Social media platforms have in the last couple of years become a central part of people's everyday life and studies have shown that nearly two-thirds of American adults used social network sites according to Perrin (2015). The rise of social media has affected areas divers areas of peoples' lives including as work, politics and political deliberation. Social media has even changed the way people get and share information and their communication patterns around the globe about civic life, health, dating and well-being (Perrin, 2015). The study found a prominent correlation between age and the level of social media use. Since the introduction of social media young adults in the ages 18 to 29 have always been the most likely users. In 2015, 90\% of young adults in America used social media compared to $12 \%$ in 2005 (Perrin, 2015). Also, among the users aged 30-49 there has been a 69-percentage point increase in use during the same time period.

During $2017,81 \%$ of the Swedish population, with access to the Internet, visited some kind of social media network site (Davidsson and Thoresson, 2017). This number has been steadily increasing ever since the concept of social media was established (Davidsson and Thoresson, 2017; Findahl, 2011). Especially interesting is it to see how fast the average ages of the regular social media user has dropped during the past years in. Currently, there are no signs on an overall decrease in the use of social media platforms, which highlights the importance of designing apps with user centred functionality (e.g. Nielsen, 2012). 


\subsection{Fear of Missing Out}

The growing impact of social media on people's everyday life has promoted a development of a new set of rules and guidelines when designing mobile applications. The pace of life online and offline is becoming increasingly intertwined and has led to an up rise of the phenomenon termed Fear of Missing Out (FoMO) (Kushlev, Proulx and Dunn, 2016). In a study done by Przybylski et al. (2013, p. 1841), the phenomena is defined as a "pervasive apprehension that others might be having rewarding experiences from which one is absent"

". People with FoMO tend to be present online more, especially on social media, and this can lead to people experiencing low levels of overall life satisfaction and a greater sense of isolation (Kushlev, Proulx and Dunn, 2017). Previous research found a correlation between FoMO and young adults who tended to use Facebook more often immediately after waking up, before going to sleep, and were more likely to give into the temptation of composing and checking text messages and emails while operating motor vehicles (Przybylski et al. 2013). This phenomena can also be connected to the study by Elslander and Tanaka (2013), that showed nearly all respondents admit to activating their phones' screen regularly in order to check for missed notifications.

With the rise in social media usage and increase in notifications received by users this research seeks to identify the design parameters for application notifications that would engage users without frustrating or alienating them.

\section{3}

\section{Method}

This study is based on a combination of a survey-based questionnaire and a qualitative perception study, which were undertaken during late 2017. The survey used was based by prior studies in the field of push notifications and social media that gather quantitative data about the users' preferences, while the test is to study people's actions and thoughts about push notifications (Elslander and Tanaka, 2013; Perrin, 2015). The survey was limited to people who has a smartphone since that is a requirement for being able to receive push notifications from social media applications.

\subsection{Survey}

The first phase in data collection uses an Internet based survey that was distributed, via Google Forms, to a sample of young adults due to their significant use of social media (Perrin, 2015). The survey included demographic questions focusing on age and gender, and technical questions, such as operating system (OS) of their smartphone. These three factors can be useful in the analysis of the received data. The structural questions of the survey investigated the app-user relationship and their personal preferences towards intriguing push notifications. 
E. Fahlman, T. Mejtoft \& H. Cripps: Evaluation of Push Notifications for Social Media Applications

Besides the three important factors of age, gender and OS, further categories of questions are included in the survey according to the users' notification preferences. The six defined parameters are based on Elslander and Tanaka's (2013) survey aimed to distinguish the most significant questions to receive valid responses. The parameters for this survey are presented in Table 1.

Table 1: Notification Parameters

\begin{tabular}{|l|l|}
\hline $\begin{array}{l}\text { Notification } \\
\text { Characteristic }\end{array}$ & Measure \\
\hline Amount & For how many social media apps have you enabled push notifications? \\
\hline Frequency & How often do you (in general) receive notifications from social media? \\
\hline Importance & How important are social media notifications to you? \\
\hline Action & $\begin{array}{l}\text { What action do you generally take upon receiving a notification from } \\
\text { social media? }\end{array}$ \\
\hline Behaviour & Which notification would you open? \\
\hline Preferences & Give an example of a push notification that makes you happy/annoyed. \\
\hline
\end{tabular}

\subsection{Perception study}

In addition to the survey, a high fidelity (hi-fi) prototype that simulates push notifications was created and displayed to the test persons who agreed to participate. The prototype is very basic, only focusing on the notifications and present two options, "open" or "cancel". The simulated push notification contained a text message written in a different character or tone. Either the text had a demanding and forcing tone, or it was mainly of an informative and polite tone this is designed to see how the user perceive and interacts with the different characteristic of the notification. The notifications were designed to be as trustworthy as possible and recognized as typical notifications generated from an existing social media application. Based on Nielsen's (2000) research on how many users needed to cover usability issues, the perception study was performed on six people, which makes it possible to draw initial conclusions (Nielsen, 2000). This test was supplemented with a follow up question after each decision to improve the level of knowledge about the users perception of the characteristics. Through this method the test for this study induced the user into a familiar feeling of a real-life situation and act naturally according to their normal behaviour, in addition to providing more information to the results.

\section{$4 \quad$ Results}

The results of this study collected as both data and extracts from interviews are presented and discussed in the following tables and lists. The study population mainly focusing on young adults with an equal division between gender and operating system used.

\subsection{Results from survey}

The survey was made available for one week and during that time generated 85 responses. The majority of the respondents belonged to the age group 18-29 and the distribution of 
gender was almost equivalent between females and males. The responses to the six parameters stated in the method are listed in Table 2 according to the most picked option.

Table 2: Survey Responses

\begin{tabular}{|c|c|}
\hline $\begin{array}{l}\text { Notification } \\
\text { Characteristic }\end{array}$ & Survey Responses \\
\hline Amount & $\begin{array}{l}72.6 \% \text { of the users stated that they only have enabled push notifications } \\
\text { for a few important social media apps. }\end{array}$ \\
\hline Frequency & $40 \%$ of the respondents receive more than 15 notifications per day \\
\hline Importance & $\begin{array}{l}31.8 \% \text { evaluated the importance of social media notifications as number } \\
3 \text { on a } 1-5 \text { scale. }\end{array}$ \\
\hline Action & $54.8 \%$ stated that they open a received notification later on. \\
\hline Behaviour & $\begin{array}{l}\text { Option between two characteristics } \\
\circ \quad \text { The push notification with a more demanding character was } \\
\text { selected by } 53 \% \text { of the respondents. } \\
\text { The push notification with a subtle and solely informative } \\
\text { character was selected by } 79.8 \% \text { of the respondents. }\end{array}$ \\
\hline Preferences & $\begin{array}{l}\text { Examples of emotions towards notifications (based on the survey). } \\
\circ \text { Happy: Snapchat, comments/likes on their own posts and } \\
\text { friend requests on Facebook. } \\
\text { Annoyed: Suggestions in general, spam (advertisement) and } \\
\text { comments on Facebook post they do not care about. }\end{array}$ \\
\hline
\end{tabular}

The demographic results from the survey of total 85 respondents are presented in Table 3. 
E. Fahlman, T. Mejtoft \& H. Cripps: Evaluation of Push Notifications for Social Media Applications

Table 3: Demographic Results

\begin{tabular}{|c|c|}
\hline & Percent \\
\hline $0-18$ & $3.5 \%$ \\
\hline $18-29$ & $90.6 \%$ \\
\hline $30-49$ & $2.4 \%$ \\
\hline $50+$ & $3.5 \%$ \\
\hline Gender & Percent \\
\hline Female & $57.6 \%$ \\
\hline Male & $42.4 \%$ \\
\hline Operating system & Percent \\
\hline iOS & $51.8 \%$ \\
\hline Android & $48.2 \%$ \\
\hline Amount notifications enabled for social media apps & Percent \\
\hline Only for a few important apps & $72.6 \%$ \\
\hline All of them & $25.0 \%$ \\
\hline None of them & $2.4 \%$ \\
\hline Frequency of receiving notifications & Percent \\
\hline More than 15 per day & $40.0 \%$ \\
\hline 5-10 per day & $24.7 \%$ \\
\hline $10-15$ per day & $20.0 \%$ \\
\hline 1-5 per day & $10.6 \%$ \\
\hline None & $4.7 \%$ \\
\hline Importance of social media notifications & Percent \\
\hline 5 (very important) & $3.5 \%$ \\
\hline 4 & $27.1 \%$ \\
\hline 3 & $31.8 \%$ \\
\hline 2 & $23.5 \%$ \\
\hline 1 (not at all) & $14.1 \%$ \\
\hline Action upon received notification & Percent \\
\hline Open later on & $54.8 \%$ \\
\hline Open immediately & $41.7 \%$ \\
\hline Ignore & $28.6 \%$ \\
\hline Other action & $4.8 \%$ \\
\hline Behaviour to characteristic of notification & Percent \\
\hline "10 people wants to be your friend, respond now or they will never return" & $53.0 \%$ \\
\hline "You have 10 new possible friends" & $47.0 \%$ \\
\hline "You have a new comment on your post" & $79.8 \%$ \\
\hline "Someone has written a comment you better read right away, or be ashamed" & $20.2 \%$ \\
\hline
\end{tabular}




\subsection{Results from perception study}

The qualitative test resulted in six interviews and the average age of the test participant was 24.2 years old, across the group of young adults. Gender and OS was evenly distributed in the test group between females versus males and Android versus iOS. During the test they were presented with twelve push notifications. The topics of the notifications came in pairs with the same meaning, but with either of a demanding or informative character and were displayed in a randomized order. As stated in the methodology, the participants got the choice of either open or cancel the push. The statistics of their choices are presented in table 4 below, where the option with the most votes is highlighted in bolder font. Some participants stated that they would just lock the screen without taking any action upon the notifications, those are displayed with a line.

Table 4: Data from perception study

\begin{tabular}{|l|l|l|}
\hline Type & Cancel & Open \\
\hline Demanding & 1 & $\mathbf{5}$ \\
Informative & 3 & 3 \\
Demanding & 1 & $\mathbf{4}$ \\
Informative & 3 & 3 \\
Demanding & - & $\mathbf{5}$ \\
Informative & 2 & 2 \\
Demanding & $\mathbf{4}$ & 2 \\
Informative & $\mathbf{5}$ & 1 \\
Demanding & 3 & 3 \\
Informative & 2 & $\mathbf{4}$ \\
Demanding & $\mathbf{5}$ & - \\
Informative & $\mathbf{5}$ & 1 \\
\hline
\end{tabular}

The option between the pairs of different notification characteristics that got the most votes to be opened is displayed as the list down below. 
E. Fahlman, T. Mejtoft \& H. Cripps: Evaluation of Push Notifications for Social Media Applications

Table 5: Notifications most likely to be opened

\begin{tabular}{|l|l|}
\hline Notification & Responses \\
\hline $\begin{array}{l}\text { Happy } \\
\text { Birthday }\end{array}$ & $\begin{array}{l}5 / 6 \text { chose to open the demanding push "Check it out!! 143 friends has wished } \\
\text { you a happy birthday!". }\end{array}$ \\
\hline New post & $3 / 6$ chose to open the informative push "Your friend has written a post". \\
\hline $\begin{array}{l}\text { Friend } \\
\text { request }\end{array}$ & $\begin{array}{l}\text { This topic did not get a winner (equal). Both the demanding and informative } \\
\text { push was opened by } 4 / 6 \text { people. }\end{array}$ \\
\hline New message & $5 / 6$ chose to open the demanding push "You have just got 1 new message". \\
\hline New update & $\begin{array}{l}\text { This topic did not get a winner (equal). Both the demanding and informative } \\
\text { push was opened only by } 1 / 6 \text { people. }\end{array}$ \\
\hline New push & $3 / 6$ chose to open the demanding push "1 new push, push them back now!". \\
\hline
\end{tabular}

In total, the test participants chose to open a push of a demanding character 19 times and cancel 14 times. Of the informative character, the test persons chose to open them 14 times and cancel 20 times.

\section{$5 \quad$ Discussion}

When looking into the results of the survey and the perception study, some data can be discussed in the terms of participants' behaviour. From the results it seems that most of the people involved in this study cared more about the identity of the sender of the notification, than the character of the push notification itself. From the survey, $72.6 \%$ of the 85 respondents only had activated push notifications for a few important social media apps and only $40 \%$ of the respondents usually received more than 15 notifications per day. The frequency of notifications did not differ between the genders of the respondents for this study. This differs from the previous research by Elslander and Tanaka (2013), which may be due to the smaller sample size in this study. That study found that the high frequency of notifications from social media apps has led to resentment against push notifications in general among young adults (Okoshi et al. 2015). This finding is something designers must take into account when developing this kind of functionality.

From the perception study, the notifications of a demanding character were predominant opened in comparison with the informative ones. Two of the topics got the same amount of the choice between open or cancel, those were "A new friend request" and "New update available". Of the respondents five out of the six chose to open both the demanding and informative notification about a new friend request. Their reasoning behind this was that getting a friend request is always something that makes them happy and interested. It can also be argued that this is an extension of the phenomena of the Fear of Missing Out (FoMO) as stated in the study done by Przybylski et. al. (2013). This test shows that the user might care more about notifications if it has to do with their social life, since a missed friend request can give a pervasive apprehension that a rewarding experience has been missed.

The notification about a new update was cancel by five out of the six participants for both the positive and negative formats with the argument by the participant is that updates are 


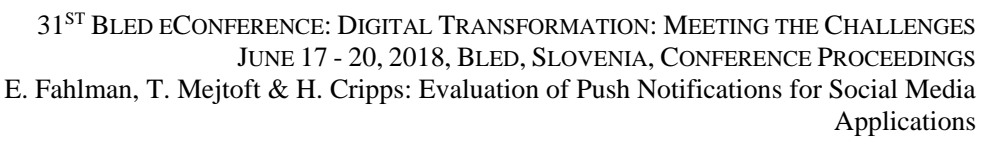

always boring. In comparison with a new friend request, an update does not usually give the user any rewards in the social context. These results speak to the significant factor of the users emotions towards the content of the notification. The notification could be made more irresistible for the user to open by taking advantage of the FoMO phenomena and by writing them in a way that is presenting the content of the notification as something that will be rewarding to the user (Przybylski et. al, 2013).

The follow-up questions provided additional clarification of and insights into the motivations behind the choices. Almost all of the participants stated that the most crucial factor when deciding what action to take upon receiving a notification is based on which app the push has been sent from. This factor can be difficult to change for the application designer as they only have control over the different characteristic of the content of the push notification not the app itself. However this finding is important for the developer to keep in mind from the beginning when creating the app. Today users apparently have a very strong relationship to their apps and know what to expect from them (Fox and Moreland, 2015). This relationship may have effected of the majority of the respondents for this study being young adults who have been active on social media since the beginning (Perrin, 2015). Therefore they know what to expect from different types of apps as the state of the relationship and the nature of the future interaction between app and user is setup in the very beginning from the first notification.

\section{6}

\section{Conclusions}

The results of the study show that people are used to receive a large number of notifications from social media applications everyday, even though they do not find them very important or interesting. The data from the survey also showed that people had really strong feelings towards some apps in particular. When they got to state their personal preferences, almost all of them felt resentment towards notification from Facebook, while notifications from Snapchat made nearly all of them feel happy.

The results from the perception study illustrate that notifications of a more demanding character were predominantly opened more often than the purely informative pushes, which is consistent with Turner, Allen and Whitaker (2017) who found that context is an influence on the decision to open. However, according to the test participants' feedback the most crucial factor in the choice to open a notification is base on which app sent it to them. The conclusion of this study is that the app-user relationship is set from the very beginning of the use of the app. This study identifies that the most suitable way of using push notifications for social media apps is to build up a trustworthy relationship with the user from the start by using a vocabulary that fits the common language of the user and avoid sending out notifications without content. The user will be drawn back into the app if they feel like the sender has good intentions and is given the user something in return on a fundamental emotional basis by opening the nonfiction. Opening notifications could be made more irresistible to the user by taking advantage of the FoMO phenomena, by writing them in a way that is presenting the content of the notification as something that will be rewarding to the user. There are several ethical issues that are raised when 
discussing the use of notification because of the interruption of the user. Recent research is focusing on the impact of consumers' attention and overall wellbeing when being continually interrupted by notifications (Kushlev, Proulx and Dunn, 2016; Kushlev, Proulx and Dunn, 2017; Pielot and Rello, 2017). However, if the goal is to generate revisits, the results suggest that a demanding character of the notification is a good choice of direction and will generate a higher frequency of revisits. There are reservations to giving this recommendation to developers due to the potential stress this might put upon the user (cf. Karapanos, Teixeira and Gouveia, 2016; Kushlev, Proulx and Dunn, 2016) and the possible negative long-term consequences of the app-user relationship. With the proliferation of applications all demanding attention from the smart phone user, the design of apps and psychological impact of notifications will be a growing area of research (cf. Turner, Allen and Whitaker, 2017).

\section{$7 \quad$ Limitations and Further Research}

The study was undertaken with Swedish participants focusing on social media platforms. The research could be extended by carrying out cross country research to evaluate if the results hold true for young people from different cultural backgrounds that may have different usage patterns and use different social media applications. Though not within the scope of this study, further longitudinal testing of the users response it suggested to investigate if the users perceptions towards the notification changed over time or as result of their changing attitudes towards and use of the various social media platforms. While this research focused on social media applications uses are now bombarded by a variety of notifications from other applications such as calendar updates and instant messaging. Additional research could compare the impact of notifications from a wider variety of applications including those designed to have health or behavioural benefits (Hosch et al., 2017).

\section{References}

An, D., Woo, H., Lee, C., \& Yeom, I. (2016). Quality Measurement of Push Services for Smart Devices. Wireless Personal Communications 88(2), 319-36.

Buttrick, L., Linehan, C., \& Kirman, B. (2014). Fifty shades of CHI: the perverse and humiliating human-computer relationship. In CHI '14 Extended Abstracts on Human Factors in Computing Systems (CHI EA '14). ACM, New York, NY, USA, 825-834.

Davidsson, P., \& Thoresson, A. (2017). Svenskarna och Internet 2017: Undersökning om svenskarnas internetvanor. Internetstiftelsen i Sverige.

Elslander, J., \& Tanaka, K. (2013). A Notification-Centric Mobile Interaction Survey and Framework. In Jatowt A. et al. (Eds.), Social Informatics. SocInfo 2013. Lecture Notes in Computer Science, vol. 8238. Springer.

Faulds, D., Mangold, W., Raju, P., \& Valsalan, S. (2018). The mobile shopping revolution: Redefining the consumer decision process. Business Horizons, 61(2), 323-338.

Findahl, O. (2011). Svenskarna och Internet 2011. Stiftelsen .SE.

Fox, J., \& Moreland, J. (2015). The dark side of social networking sites: An exploration of the relational and psychological stressors associated with Facebook use and affordances. Computers in Human Behavior, 45, 168-176. 
E. Fahlman, T. Mejtoft \& H. Cripps: Evaluation of Push Notifications for Social Media Applications

Horsch, C. et al. (2017). Reminders Make People Adhere Better to a Self-Help Sleep Intervention. Health and Technology 7(2), 173-88.

Karapanos, E., Teixeira, P., \& Gouveia, R. (2016). Need fulfillment and experiences on social media: A case on Facebook and WhatsApp. Computers in Human Behavior, 55, 888-897.

Kim, S., \& Baek, T. (2018). Examining the antecedents and consequences of mobile app engagement. Telematics and Informatics, 35(1), 148-158.

Kushlev, K., Proulx, J., \& Dunn, E. W. (2016). Silence your phones: Smartphone notifications increase inattention and hyperactivity symptoms. In Proceedings of the 2016 CHI Conference on Human Factors in Computing Systems (CHI'16) (pp. 1011-1020). ACM.

Kushlev, K., Proulx, J. D. E. \& Dunn, E. W. (2017). Digitally Connected, Socially Disconnected: The Effects of Relying on Technology Rather Than Other People, Computers in Human Behavior, 76, 68-74.

Li, P. (2017). Why do Android users open more notifications than iOS users. Retrieved March 13, 2018, from https://www.plotprojects.com/blog/why-do-android-users-open-morenotifications-than-ios-users/

Nielsen, J. (2012). Usability 101: Introduction to Usability. Retrieved May 10, 2018, from https://www.nngroup.com/articles/usability-101-introduction-to-usability/

Nielsen, J. (2000). Why You Only Need to Test with 5 Users. Retrieved March 13, 2018, from https://www.nngroup.com/articles/why-you-only-need-to-test-with-5-users/

Okoshi, T., Nozaki, H., Nakazawa, J., Tokuda, H., Ramos, J., \& Dey, A. (2016). Towards attention-aware adaptive notification on smart phones. Pervasive and Mobile Computing, 26, 17-34.

Pielot, M. and Rello, L. (2017). Productive, Anxious, Lonely - 24 Hours Without Push Notifications. In Proceedings of the 19th International Conference on Human-Computer Interaction with Mobile Devices and Services (MobileHCI '17). ACM.

Perrin, A., (2015). Social Networking Usage: 2005-2015. Pew Research Center. October 2015. Retrieved March 13, 2018, from http://www.pewinternet.org/2015/10/08/2015/SocialNetworking-Usage-2005-2015

Przybylski, A. K., Murayama, K., DeHaan, C. R., \& Gladwell, V. (2013). Motivational, emotional, and behavioral correlates of fear of missing out. Computers in Human Behavior, 29, 1841-1848.

Sultan, A. (2014). Addiction to mobile text messaging applications is nothing to "lol" about. Social Science Journal, 51(1), 57-57.

Turner L. D., Allen S. M., \& Whitaker R. M. (2015). Push or Delay? Decomposing Smartphone Notification Response Behaviour. In Salah A., Kröse B., Cook D. (Eds), Human Behavior Understanding. Lecture Notes in Computer Science, vol 9277. Springer.

Turner, L. D., Allen, S. M., \& Whitaker, R. M. (2017). Reachable but not receptive: Enhancing smartphone interruptibility prediction by modelling the extent of user engagement with notifications. Pervasive and Mobile Computing, 40, 480-494.

Westermann, T., Möller, S. and Wechsung, I. (2015) Assessing the Relationship between Technical Affinity, Stress and Notifications on Smartphones, In the Proceedings of the 17th International Conference / Human-Computer Interaction with Mobile Devices and Services Adjunct (MobileHCI '15), (pp. 652-659).

$\mathrm{Xu}, \mathrm{Z}$., \& Zhu, S. (2012). Abusing notification services on smartphones for phishing and spamming. Proceedings of the 6th USENIX Conference on Offensive Technologies, 1-11. 
$330 \quad 31^{\text {ST }}$ Bled eConference: Digital TRANSFormation: MEeting the ChallengeS June 17 - 20, 2018, Bled, SLOVEnia, ConfERENCE PROCEEDINGS 


\title{
Learning Success: A Comparative Analysis of a Digital Game-Based Approach and a Face-to-Face Approach
}

\author{
LINDA ECKARDT \& SUSANNE ROBRA-BISSANTZ
}

\begin{abstract}
This study compares traditional face-to-face learning with digital game-based learning. A student group has to learn aspects of internet search in a face-to-face learning environment that combines lecture and tutorial and a further group has to learn the same aspects within a serious game. The comparison focuses on learning success. Measuring learning success is difficult and therefore the study includes questions to assess knowledge, motivation, fun and satisfaction in a pre- and post-tests. The results of the study show that the students evaluate game-based learning better in all surveyed categories.
\end{abstract}

Keywords: - Game-based Learning - Serious Game • Face-to-Face Learning • Learning Success • Information Literacy •

CORRESPONDENCE ADDRESS: Linda Eckardt, Technische Universität Braunschweig, chair of information management, Muehlenpfordtstr. 23, Braunschweig, Germany, e-mail: linda.eckardt@tu-bs.de. Susanne Robra-Bissantz, Technische Universität Braunschweig, chair of information management, Muehlenpfordtstr. 23, Braunschweig, Germany, e-mail: s.robrabissantz@tu-bs.de 
L. Eckardt \& S. Robra-Bissantz: Learning Success: A Comparative Analysis of a Digital Game-

Based Approach and a Face-to-Face Approach

\section{$1 \quad$ Introduction and Motivation}

Gamification describes the integration of game elements in a non-gaming context, for example education (Deterding et al. 2011). In contrast to gamification, a serious game refers to the development of a full-fledge game with fixed rules and objectives, including aspects of design (Deterding et al. 2011). The integration of game elements in a learning context is not new. There are many examples using gamification (e.g. "Bibliobouts" (Markey et al. 2008)) or serious games (e.g. "Planet in Peril" (Sittler et al. 2011)) in education. Although the boundaries between gamification and serious games are not clearly defined, the two game-based learning (GBL) approaches have one thing in common: both use game elements as motivational affordance. Thereby learners engage more and deal with additional topics that they would otherwise learn less about (Kapp 2012). On the one hand, the integration of game elements offers an effective and active knowledge acquirement through the promotion of students' participation and interaction (Branston 2006). On the other hand, students' motivation, fun and engagement can be enhanced, so that learning success could be positively influenced (Branston 2006).

Kerres (2011) defines learning success as the result of all didactic activities, which does not only mean the retention of facts, events or processes. For example, learning success includes emotional reactions (e.g. motivation, interest, fun), experienced quality of learning (e.g. content quality, quality of care and communication), satisfaction with learning behavior and result, learning behavior (e.g. duration and intensity) and objective knowledge gain at different intervals (Kerres 2001). Consequently, learning success consists of more than one dimension and is difficult to measure (Mager 1972).

Although, there are only a few papers dealing with the learning success of GBL applications. For example, LaRose et al. (1998) examined the impact of learning success based on two student groups. One group attended a traditional face-to-face (F2F) lecture and the other group attended an e-learning supported lecture. The study did not show any significant differences in the achieved grade, the students' attitude towards the learning method or the immediacy of the instructors with the learners (LaRose et al. 1998). In addition, Krause et al. (2015) examined a systematic analysis of the effects of gamification on the binding of students and their success in learning. The participants were divided into non-gamification and gamification groups. The groups were analyzed with respect to three criteria (retention period, quiz-correctness and test result). One of their research questions was whether gamification supports the students' learning success in the offered online course. The results of their study showed significant differences in performance between the different groups. The gamification group achieved a 25\% higher result in retention rate and a $12.5 \%$ better result in the quiz test (Krause et al. 2015). Furthermore, Jong et al. (2006) performed a comparative study with 158 participants and 4 teachers between traditional web-based learning and situated game-based learning (SGBL). The comparative study showed that the SGBL was preferred by the participants and the course was more interesting and demanding. Additionally, the students could retain the learning content better. However, the study did not provide any evidence that SGBL could better convey the learning content (Jong et al. 2006). 
Previous studies defined learning success in GBL applications predominantly in connection with the grade, the retention rate or the subjectively perceived knowledge gain. The aim of this study is therefore to measure learning success with such an application over several dimensions. This is examined by a comparative analysis between a traditional F2F lecture and a serious game. Thereby, the objective and subjective knowledge gain are determined at different intervals as well as the satisfaction, fun and motivation with both learning methods.

\section{Serious Game »Lost in Antarctica}

The digital GBL application used for this study is a serious game. The serious game is „Lost in Antarctica”. In this browser game, which is designed as a point-and-click adventure, students travel as a group of scientists to the South Pole and crash due to a snowstorm. In addition to their scientific research, the defective airplane must be repaired (Eckardt \& Robra-Bissantz 2016). Figure 1 shows six screenshots of the serious game. Students learn information literacy through playing. Information literacy describes the ability of a person "to recognize when information is needed and [...] to locate, evaluate, and use effectively the needed information" (American Library Association 1989). In this serious game, the students learn aspects of internet search, database search, research strategies in general, recognizing scientific literature, scientific writing, citing, literature management, copyright, time management and how to publish a scientific work. 
L. Eckardt \& S. Robra-Bissantz: Learning Success: A Comparative Analysis of a Digital Game-

Based Approach and a Face-to-Face Approach
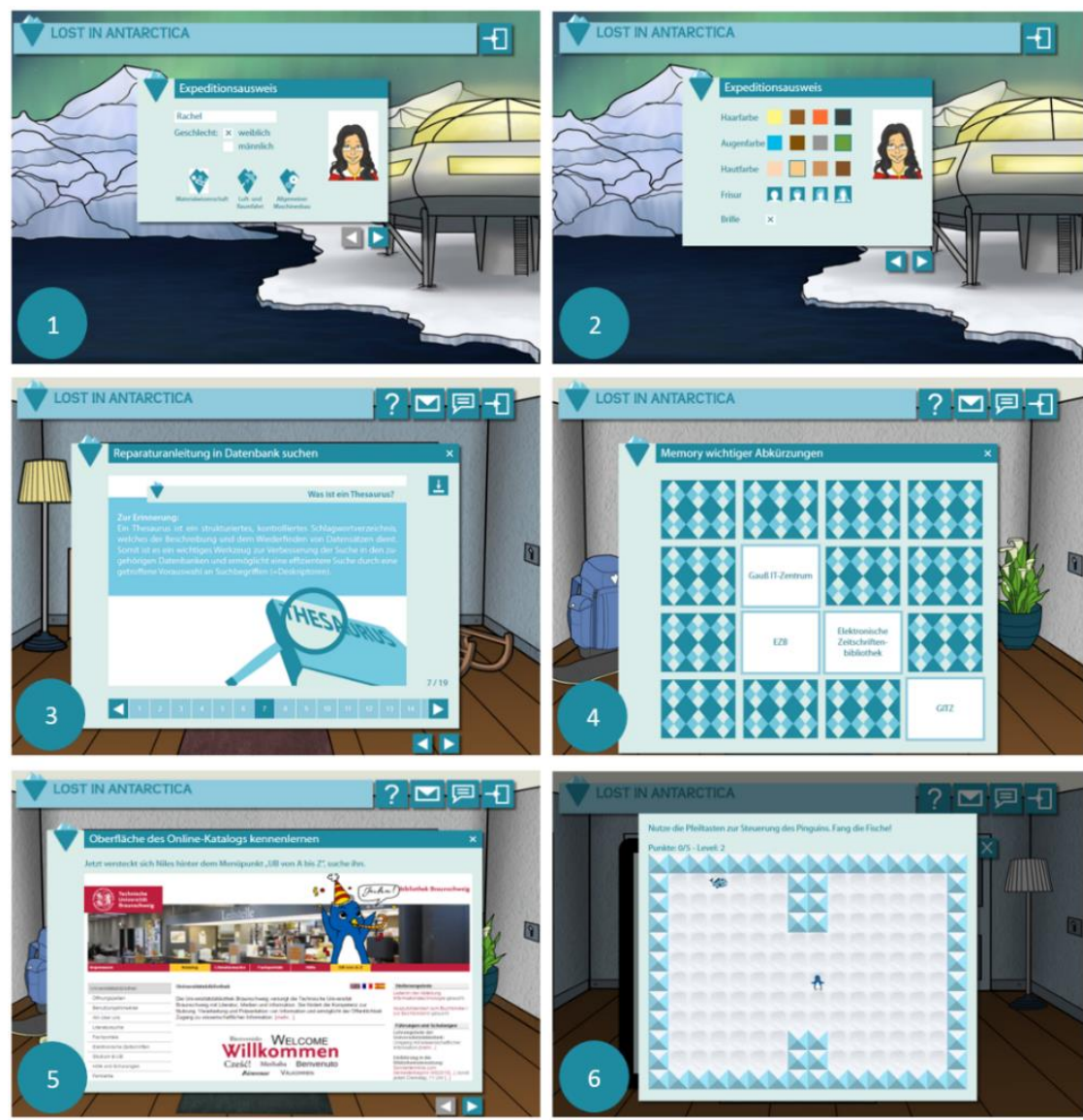

Figure 1: Screenshots of the Serious Game

In the beginning of the serious game, students can create an avatar (screen 1 and 2). Subsequently, students learn different aspects of information literacy in 12 levels that are embedded in an accompanying background story. Each level is structured identically. The students have to follow a checklist and thereby acquire knowledge or solve tasks. The transfer of knowledge takes place in form of videos or presentations (screen 3). The corresponding tasks vary from drag-and-drop, cloze texts, interactive system screenshots (screen 5) and multiple choice questions to connecting lines tasks, memory games (screen 4), free-text tasks and tasks to be solved in a team (e.g. case examples and votes). In each level, students can reach up to 300 points, but need only 200 points to progress within the serious game. Additional points can be exchanged on a market place through mini games (e.g. Pnake in the style of the popular game Snake) (screen 6). For the successful completion of a level, the student gets a component to repair the airplane (Eckardt \& Robra-Bissantz 2016). 


\section{$3 \quad$ Research Aims}

The following study compares the learning success of a digital GBL environment with a F2F learning environment.

Learning success is closely linked to motivation and fun (Mager 1972). The integration of game elements aims to promote motivation (Glover 2013). For this reason, the usage of the serious game "Lost in Antarctica" could enhance the learner's engagement. Accordingly, psychological results that come with the integration of game elements in the learning context are examined. This affects motivation, engagement and fun. In addition, the impact of satisfaction on learning success is also considered.

The following hypotheses are investigated as part of the comparative study: In comparison to traditional F2F learning,

- the learning success of a digital game-based learning application is higher.

- learner's attitude, motivation and fun are higher in a digital game-based learning application.

- learners are more satisfied with the learning process of a digital game-based learning application.

\section{$4 \quad$ Research Design}

The designed study is based on the four-level model of Kirkpatrick (1967). The model separates between reaction, learning, behavioral and result levels (Kirkpatrick 1967; Kirkpatrick \& Kirkpatrick 2006). The reaction level describes the emotional reactions to the course and measures customer satisfaction (Kirkpatrick \& Kirkpatrick 2006). Therefore, the student's satisfaction with the respective learning method is measured. The study differentiates between satisfaction with the content and the form of the course. The learning level from Kirkpatrick's model focuses on the learning objectives. Examples include the acquirement of new knowledge or skills, as well as attitude changes throughout this level (Kirkpatrick \& Kirkpatrick 2006). For this reason, knowledge gains and changes in attitude are questioned in this study. The behavioral level refers to applying the course content and consequently measuring changes in behavior (Kirkpatrick \& Kirkpatrick 2006). The result level measures the consequences of the behavioral changes with objective performance criteria (e.g. costs). In this study, the focus is set on learning success. It can be measured with a combination of knowledge questions and questions for self-assessment. Satisfaction, fun and motivation are only evaluated through self-assessment. A six point Likert scale is used for the self-assessment questions. Therefore, the participants have to make a decision regarding their opinion in a positive or a negative way. The trend towards the middle is avoided (Matell \& Jacoby 1971). The knowledge questions represent an objective measuring method. The knowledge is thereby checked by testing the achievement of certain learning goals through knowledge questions. 
L. Eckardt \& S. Robra-Bissantz: Learning Success: A Comparative Analysis of a Digital Game-

Based Approach and a Face-to-Face Approach

The comparative study is of quantitative nature and was conducted during the summer semester 2016.

\subsection{Participants}

A sample of 44 students were invited to participate in the study. The participants are Master's students of various disciplines, who deepen their knowledge on economy with an information management course. The students consisted of 38 males and 6 females, with the mean age being 25 , and they shared approximately the same level of knowledge. All participants had already written a Bachelor's thesis and therefore had learnt some aspects regarding information literacy.

\subsection{Learning Materials}

The students learned aspects of internet search in this study. Due to changes caused by media change and digitalization, students have more opportunities concerning when and how they gather information. The usage and access to information offered through the internet is more advantageous than the usage of library resources. Consequently, students often consider the availability of a resource to be of greater importance than its quality (Felker 2014). For this reason, students had to learn different aspects of internet search within the game-based or F2F approach. For example, they learnt how to rate the quality of websites or to optimize the search in a web search engine. Furthermore, they got to know the advantages and disadvantages of an internet search and to learn how to check their research for relevance. In both courses, the students learnt exactly the same but with a different learning method.

\subsection{Procedure}

The participants were randomly assigned into a control group and an experimental group at the beginning of the study. Figure 1 shows the research procedure, which is divided into three phases.

Phase 1: Pre-Test. A paper-based pre-test was performed to assess students' prior knowledge. For this purpose, questions were asked to measure their subjective and objective knowledge. Furthermore, their motivation, fun and satisfaction were assessed by other questions. Both groups completed the test immediately before learning with the respective method.

Phase 2: Face-to-Face or Game-Based Learning. Both experimental and control group students had a 90-minute learning session. The experimental group conducted the serious game in a computer lab. In this way, the students were able to decide the rate and scope to perform the serious game. Additionally, the repetition of tasks was possible. In comparison, the control group participated in a F2F learning environment. A librarian, being an expert in this field, held the presentation on information literacy. The F2F learning was a combination of lecture and tutorial. 
Phase 3: Post-Test. After the learning experiment, the students were required to fill out a second paper-based questionnaire for gathering information about their knowledge gain and their perceptions of the learning method.

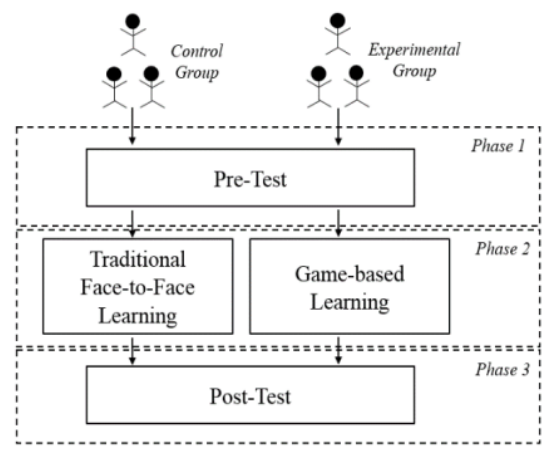

Figure 2: Study Design

\section{$5 \quad$ Research Findings}

Table 1 shows the results of the study. Thereby, the correctness of knowledge questions is expressed in percentage. For the other questions a six point Likert scale was used $(1=$ strongly disagree, ..., $6=$ strongly agree). The mean values (MV) and standard deviations (STD) are shown in Table 1. 
L. Eckardt \& S. Robra-Bissantz: Learning Success: A Comparative Analysis of a Digital GameBased Approach and a Face-to-Face Approach

Table 1: Results of the Pre- and Post-Test

\begin{tabular}{|c|c|c|c|c|c|c|c|c|}
\hline \multirow{2}{*}{ Questions } & \multicolumn{4}{|c|}{$\begin{array}{c}\text { Experimental Group } \\
\text { (Serious Game) }\end{array}$} & \multicolumn{4}{|c|}{$\begin{array}{c}\text { Control Group } \\
\text { (Face-to-Face) }\end{array}$} \\
\hline & \multicolumn{2}{|c|}{ Pre } & \multicolumn{2}{|c|}{ Post } & \multicolumn{2}{|c|}{ Pre } & \multicolumn{2}{|c|}{ Post } \\
\hline \multicolumn{9}{|l|}{ Knowledge Questions } \\
\hline $\begin{array}{l}\text { Advantages and } \\
\text { disadvantages of an internet } \\
\text { search }\end{array}$ & \multicolumn{2}{|c|}{$37.33 \%$} & \multicolumn{2}{|c|}{$62.66 \%$} & \multicolumn{2}{|c|}{$36.83 \%$} & \multicolumn{2}{|c|}{$47.33 \%$} \\
\hline $\begin{array}{l}\text { Meaning of: "inurl:[search } \\
\text { term]" (pre) and }\end{array}$ & \multicolumn{2}{|c|}{$12 \%$} & \multicolumn{2}{|c|}{$28 \%$} & \multicolumn{2}{|c|}{$5 \%$} & \multicolumn{2}{|c|}{$16 \%$} \\
\hline & MV & STD & MV & STD & MV & STD & MV & STD \\
\hline \multicolumn{9}{|l|}{ Knowledge } \\
\hline $\begin{array}{l}\text { My knowledge about } \\
\text { internet search... } \\
\ldots \text { is low (pre) } \\
\ldots \text { was previously low } \\
\text { (post) }\end{array}$ & 3.0 & 1.08 & 3.83 & 1.0 & 3.16 & 1.12 & 3.68 & 1.56 \\
\hline $\begin{array}{l}\text { I learned many new things. } \\
\text { (post) }\end{array}$ & - & - & 4.80 & 0.86 & - & - & 4.63 & 1.25 \\
\hline $\begin{array}{l}\text { The application / exercise } \\
\text { helped me to understand the } \\
\text { learning contents better. } \\
\text { (post) }\end{array}$ & - & - & 4.68 & 0.9 & - & - & 4.58 & 1.26 \\
\hline
\end{tabular}

\begin{tabular}{|c|c|c|c|c|c|c|c|c|}
\hline $\begin{array}{l}\text { I felt active participation as a } \\
\text { support for the knowledge } \\
\text { gain. (post) }\end{array}$ & - & - & $\begin{array}{c}4.7 \\
4\end{array}$ & 0.75 & - & - & 5.0 & 0.57 \\
\hline $\begin{array}{l}\text { I learned more in this course } \\
\text { than in others. (post) }\end{array}$ & - & - & $\begin{array}{c}4.3 \\
9\end{array}$ & 0.94 & - & - & 4.0 & 1.49 \\
\hline \multicolumn{9}{|l|}{ Attitude } \\
\hline $\begin{array}{l}\text { I am positively inclined } \\
\text { towards face-to-face / game- } \\
\text { based learning. (pre) }\end{array}$ & $\begin{array}{c}4.5 \\
8\end{array}$ & 1.0 & - & - & $\begin{array}{c}4.3 \\
2\end{array}$ & $\begin{array}{c}1.1 \\
5\end{array}$ & - & - \\
\hline $\begin{array}{l}\text { My attitude towards face-to- } \\
\text { face / game-based learning } \\
\text { has changed positively. (post) }\end{array}$ & - & - & $\begin{array}{c}4.5 \\
0\end{array}$ & 1.0 & - & - & $\begin{array}{c}3.6 \\
8\end{array}$ & 1.41 \\
\hline \multicolumn{9}{|l|}{ Motivation } \\
\hline $\begin{array}{l}\text { I am motivated to participate } \\
\text { actively. }\end{array}$ & 4.8 & $\begin{array}{c}0.8 \\
9\end{array}$ & - & - & $\begin{array}{c}4.3 \\
7\end{array}$ & $\begin{array}{c}0.8 \\
3\end{array}$ & - & - \\
\hline $\begin{array}{l}\text { I am ready to learn something } \\
\text { new. }\end{array}$ & 5.2 & $\begin{array}{c}0.7 \\
8\end{array}$ & - & - & $\begin{array}{c}4.7 \\
4\end{array}$ & $\begin{array}{c}0.9 \\
9\end{array}$ & - & - \\
\hline
\end{tabular}




\begin{tabular}{|c|c|c|c|c|c|c|c|c|}
\hline $\begin{array}{l}\text { The new teaching approach } \\
\text { motivated me to work more } \\
\text { actively than usual. }\end{array}$ & - & - & 3.72 & 0.67 & - & - & - & - \\
\hline $\begin{array}{l}\text { I could easily follow the } \\
\text { course without getting tired. }\end{array}$ & - & - & 4.88 & 0.88 & - & - & $\begin{array}{c}4.4 \\
7 \\
\end{array}$ & 1.27 \\
\hline \multicolumn{9}{|l|}{ Fun } \\
\hline $\begin{array}{l}\text { A face-to-face /game-based } \\
\text { learning would have been } \\
\text { more fun. (inverse scale) }\end{array}$ & - & - & 4.96 & 1.29 & - & - & $\begin{array}{c}3.8 \\
9\end{array}$ & 1.15 \\
\hline $\begin{array}{l}\text { I took an active part because } \\
\text { collecting points was fun. }\end{array}$ & - & - & 4.6 & 1.0 & - & - & - & - \\
\hline I enjoyed the course. & - & - & 5.08 & 0.7 & - & - & $\begin{array}{c}4.3 \\
7\end{array}$ & 1.21 \\
\hline \multicolumn{9}{|c|}{ Satisfaction / General Questions } \\
\hline $\begin{array}{l}\text { I am open towards new } \\
\text { learning methods. }\end{array}$ & $\begin{array}{c}4.7 \\
6 \\
\end{array}$ & $\begin{array}{c}1.2 \\
6 \\
\end{array}$ & 5.3 & 0.63 & $\begin{array}{c}4.4 \\
2 \\
\end{array}$ & $\begin{array}{c}1.5 \\
7\end{array}$ & $\begin{array}{c}4.6 \\
3 \\
\end{array}$ & 1.11 \\
\hline I am satisfied with the course. & - & - & 5.04 & 0.79 & - & - & $\begin{array}{c}4.6 \\
3 \\
\end{array}$ & 1.34 \\
\hline $\begin{array}{l}\text { I would like to participate } \\
\text { again in such a kind of } \\
\text { course. }\end{array}$ & - & - & 4.78 & 0.73 & - & - & $\begin{array}{c}4.2 \\
1\end{array}$ & 1.35 \\
\hline
\end{tabular}

Both groups increased their knowledge. However, the knowledge gain of the GBL group is greater. The knowledge about internet search of both groups is approximately the same. Nevertheless, the post-survey shows that the students knew less about this topic than they initially thought. That underlines one challenge of information literacy instruction. Students assumed that they already had the abilities (Gross \& Latham 2007). F2F, as well as GBL, were perceived positively. Even after the course, the attitude towards the different learning methods had not changed much. However, the attitude towards F2F learning had deteriorated slightly. In both groups, the students learned new things, could understand the content better and felt active participation to be an advantage. In comparison to other courses, the students learned more. Motivation was present in both learning environments, but the GBL group reported to be more motivated. Overall, fun was evaluated positively. However, the serious game was more fun because collecting points promotes an active cooperation. The GBL group evaluated the question of whether a F2F lecture would have been more fun in average with "somewhat disagree". In comparison, the F2F group thought that the serious game would have been more fun. The students were satisfied with both learning methods and, compared to the pre-test, became even more open to new learning methods. Overall, it is also clear that the GBL group was somewhat more.

A t-Test was performed to determine if the two samples significantly differ regarding factors. Table 2 shows the t-Test results for both independent samples, the serious game 
L. Eckardt \& S. Robra-Bissantz: Learning Success: A Comparative Analysis of a Digital Game-

Based Approach and a Face-to-Face Approach

group and the F2F group. A Shapiro-Wilks test was carried out to check the distribution of the individual samples. This showed that a normal distribution is present. The Levene test resulted in variance homogeneity for knowledge (pre and post), attitude (pre and post), motivation (pre and post) and fun. The satisfaction dimension (pre and post) showed variance heterogeneity. Therefore, a t-Test with Welch correction was used.

Table 2: Results of the t-Test for two independent samples

\begin{tabular}{|c|c|c|c|c|c|c|}
\hline \multirow{2}{*}{ Factor } & \multicolumn{2}{|c|}{$\begin{array}{c}\text { Experimental Group } \\
\text { (Serious Game) }\end{array}$} & \multicolumn{2}{c|}{$\begin{array}{c}\text { Control Group } \\
\text { (Face-to-Face) }\end{array}$} & \multicolumn{2}{c|}{ t-Test } \\
\cline { 2 - 7 } & MV & STD & MV & STD & T & p \\
\hline Knowledge (pre) & 3.0 & 1.08 & 3.16 & 1.12 & 0.234 & 0.816 \\
\hline Knowledge (post) & 4.46 & 0.59 & 4.37 & 0.94 & -0.349 & 0.729 \\
\hline Attitude (pre) & 4.60 & 0.86 & 4.32 & 1.15 & -0.933 & 0.356 \\
\hline Attitude (post) & 4.50 & 1.02 & 3.68 & 1.41 & -2.194 & 0.034 \\
\hline Motivation (pre) & 5.00 & 0.57 & 4.55 & 0.77 & -2.188 & 0.034 \\
\hline Motivation (post) & 4.88 & 0.88 & 4.47 & 1.17 & -1.314 & 0.196 \\
\hline Fun & 4.54 & 0.75 & 3.63 & 0.92 & -3.580 & 0.001 \\
\hline Satisfaction (pre) & 4.76 & 1.26 & 4.42 & 1.57 & -0.827 & 0.415 \\
\hline Satisfaction (post) & 5.04 & 0.52 & 4.49 & 0.96 & -2.237 & 0.034 \\
\hline
\end{tabular}

Previous knowledge and knowledge after learning with the serious game or in the F2F lecture showed no significant changes. This means that the groups did not subjectively assess their previous knowledge differently and consequently shows approximatly the same level of knowledge. Even after learning, knowledge does not significantly differ, which means that both learning methods perform equally well for learning and none is better regarding subjective knowledge gain. Consequently, the learning method should maybe be selected based on the learning content. The attitude of both student groups did not significantly differ before the experiment. After the experiment, attitude changed. The group that learned with the serious game still had a positive attitude towards this learning method whereas the control group's attitude decreased regarding F2F learning. This difference is significant. Effect size is calculated for determing the relevance of this result. Determing the effect size follows Cohen (1992). The effect size of attitude (post) is $\mathrm{r}=0.324$ and corresponds to a medium value. Before learning, motivation of the experimental group is significantly better because they are allowed to learn with the serious game. The effect size is $\mathrm{r}=0.319$ and corresponds to a medium value. After learning, both groups stated that they could easily follow the course without getting tired. However, the difference is not significant. Both groups differ regarding fun. The gamebased learning group evaluated fun more positive than the F2F group. This result is significant with an effect size of $\mathrm{r}=0.484$, which corresponds to a medium and strong value. Before learning, satisfaction was not differently assessed by both groups. This 
means that both groups are equally open towards new learning methods. Nevertheless, the serious game group evaluated satisfaction significantly better than the F2F group after the experiment. The experimental group was more satisfied with the course and would more like participate again in such a kind of course. The effect size is $r=0.40$ and corresponds to a medium value.

In summary, the study showed that the serious game achieved significant better results in the categories attitude, motivation, fun and satisfaction compared to F2F learning. Only the knowledge gain was not significantly better evaluated by the serious game group but also showed better medium values. The hypotheses were partly supported and consequently, the serious game is a good possibility to learn.

\section{Conclusion and Future Research}

Previous literature points out that learning methods cannot be easily compared. Many studies comparing learning methods only show tendencies but no significant results (Tergan 2003). For this reason, this study is also a first step towards the measurement of the learning success of such an application. Knowledge gain, attitude, motivation, fun and satisfaction were evaluated more positively in the GBL environment than in the F2F learning but only the knowledge gain did not show significant results.

However, further studies are necessary to measure learning success extensively and to make more detailed statements. For this reason, the serious game used in this work replaces a course for information literacy instruction in the next step completely. It is evaluated at various intervals. Thereby, the learning success is to be considered in more detail in several dimensions. For example, the existing knowledge is asked at the beginning of the serious game and the knowledge gain is evaluated in the middle and at the end of the GBL. This procedure offers the possibility to recognize changes in subjective and objective knowledge. Therefore, motivation, fun and satisfaction are measured with the same procedure. Additionally, system quality, learning strategies and subjective knowledge are recognized because they influence leaning success as well (Kerres 2001). An objective assessment is made via the database of the serious game. Information such as gained points, number of repetitions and points measuring the improvement or deterioration of students are recorded to enable better insights into learning success of serious games.

\section{References}

American Library Association. (1989). Presidential Committee on Information Literacy: Final Report. Retrieved 12. Feb. 2018, from http://ala.org/acrl/publications/whitepapers/presidential.

Branston, C. (2006). From Game Studies to Bibliographic Gaming: Libraries tap into the Video Game Culture. Bulletin of the American Society for Information Science and Technology. 32(4). pp. 24-26. DOI: 10.1002/bult.2006.1720320410.

Cohen, J. (1992). A Power Primer. Psychological bulletin. 112(1). pp. 155-159. DOI: 
$31^{\text {ST }}$ Bled eConference: Digital Transformation: MeEting the Challenges

June 17 - 20, 2018, BLED, SLOVENIA, CONFERENCE PROCEEDINGS

L. Eckardt \& S. Robra-Bissantz: Learning Success: A Comparative Analysis of a Digital Game-

Based Approach and a Face-to-Face Approach

http://dx.doi.org/10.1037/0033-2909.112.1.155

Deterding, S., Khaled, N., Nacke, L. \& Dixon, D. (2011). Gamification: Toward a Definition. In CHI 2011 Workshop Proceedings, pp. 12-15. Vancouver, Canada.

Deterding, S., Dixon, D., Khaled, R. \& Nacke, L. (2011). From Game Design Elements to Gamefulness: Defining Gamification. In Proceedings of the 15th International Academic MindTrek Conference: Envisioning Future Media Environments. pp. 9-15. Tempere, Finland.

Eckardt, L. \& Robra-Bissantz, S. (2016). Lost in Antarctica: Designing an Information Literacy Game to Support Motivation and Learning Success. In Proceedings of the International Conference of Design Science Research in Information Systems. pp. 202-206. St. Johns, Newfoundland.

Felker, K. (2004). Gamification in Libraries: The State of the Art. Educational References \& User Services Quarterly. 52(2). pp. 19-23.

Glover, I. (2013). Play as You Learn: Gamification as a Technique for Motivating Learners. In Proceedings of the World Conference on Educational Media and Technology. pp. 1999-2008. Chesapeake, Virginia.

Gross, M. \& Latham, D. (2007). Attaining Information Literacy: An Investigation of the Relationship between Skill Level, Self-estimates of Skill, and Library Anxiety. Library \& Information Science Research. 19(3). pp. 332-353. DOI: 10.1016/j.lisr.2007.04.012

Jong, M., Shang, J., Lee, F., Lee, J. \& Law, H. (2006). Learning Online: A Comparative Study of a Situated Game-based Approach and a Traditional Web-based Approach. In Proceedings of the International Conference on Technologies for E-Learning and Digital Entertainment. pp. 541-551. Berlin, Heidelberg: Springer.

Kapp, M. (2012). The Gamification of Learning and Instruction: Game-based Methods and Strategies for Training and Education. San Francisco: John Wiley \& Sons.

Kerres, M. (2001). Multimediale und telemediale Lernumgebungen: Konzeption und Entwicklung. Oldenbourg: Oldenbourg Verlag München Wien.

Kirkpatrick, D.L. (1976). Evaluation of Training. In R. L. Craig and L. R. Bittel (Eds.), Training and Development Handbook: A Guide to Human Ressource Development (pp. 35-56). San Francisco: Berret-Koehler Publishers.

Kirkpatrick, D.L. \& Kirkpatrick, J.D. (2006). Evaluating Training Programs: The Four Levels. San Francisco: Berret-Koehler Publishers.

Krause, M., Mohalle, M., Pohl, H. \& Williams, J. (2015). A Playful Game Changer: Fostering Student Retention in Online Education with Social Gamification. In Proceedings of the 2nd ACM Conference on Learning@Scale. pp. 95-102. Vancouver, Canada.

LaRose, R., Gregg, J. \& Eastin, M. (1998). Audiographic Telecourses for the Web: An Experiment. Journal of Computer-Mediated Communication. 4(2). DOI: 10.1111/j.14682885.2004.tb000302.x

Mager, R. (1972). Motivation und Lernerfolg: Wie Lehrer ihren Unterricht verbessern können. Weinheim: Beltz Verlag.

Markey, K., Swanson, F., Jenkins, A., Jennings, B. J., St. Jean, B., Rosenberg, V., Yao, X. \& Frost, R. L. (2008). The Effectiveness of a Web-based Board Game for Teaching Undergraduate Students Information Literacy Concepts and Skills. D-Lib Magazine. 14(9/10). DOI: 10.1045/september2008-markey.

Matell, M. \& Jacoby, J. (1971). Is there an Optimal Number of Alternatives for Likert Scale Items? Study I: Reliability and Validity. Educational and Psychological Measurement. 31(3). pp. 657674. DOI: $10.1177 / 001316447103100307$.

Sittler, R.L., Sherman, C., Keppel, D. P., Schaeffer, C. E., Hackley, D. C. \& Grosik, L. A. (2011). A Planet in Peril: Plagiarism: Using Digital Games to Teach Information Literacy Skills. In T. R. McDevitt (Eds.), Let the Games Begin! Engaging Students with Field-testes Interactive Information Literacy Instruction (pp. 134-137). New York: Neal-Schumann Publishers. 
L. Eckardt \& S. Robra-Bissantz: Learning Success: A Comparative Analysis of a Digital Game-

Based Approach and a Face-to-Face Approach

Tergan, S.-O. (2003). Realistische Qualitätsevaluation von E-Learning. In D. M. Meister, S.-O.

Tergan \& P. Zentel (Eds.), Evaluation von E-Learning (pp. 131-154). Münster: Waxmann Verlag. 
344 3 $31^{\text {ST }}$ Bled eConference: Digital TRANSFormation: MEeting the ChallengeS June 17 - 20, 2018, Bled, SLOVEnia, ConfERENCE PROCEEDINGS 


\title{
Blockchain-based Smart Contracts in Waste Management: A Silver Bullet?
}

\author{
Guido Ongena, KoEn SMit, JARno BoKSEBELD, Gerben \\ ADAMS, YORIN ROELOFS \& PASCAL RAVESTEIJN
}

\begin{abstract}
Blockchain technology may have the potential to fundamentally change society and we might currently witness the dawn of a cryptographically secured trust-free transactions economy. One relatively unexplored application domain is waste management. Incorrect waste management practices may lead to illegal pollution or enable fraudulent transactions. Using a design science approach, we formulate problem areas and evaluate the applicableness of using a blockchain solution to mitigate the problems identified. Our results indicate that it is important that the organization and its infrastructure is prepared for the use of blockchain. There are several conditional challenges that must be overcome to realize blockchain technology's full potential. Further research is needed in order to grasp a full understanding about the situations in which blockchain technology is beneficial or not.
\end{abstract}

Keywords: • Blockchain $\bullet$ Smart contracts • Waste management •

CORRESPONDENCE ADDRESS: Guido Ongena, Ph.D., Senior Lecturer/Researcher, HU University of Applied Sciences Utrecht, The Netherlands, e-mail: guido.ongena@hu.nl. Koen Smit, Lecturer/Researcher, HU University of Applied Sciences Utrecht, The Netherlands, e-mail: koen.smit@hu.nl. Jarno Boksebeld, student, HU University of Applied Sciences Utrecht, The Netherlands, e-mail: jarno.boksebeld@hu.nl. Gerben Adams, student, HU University of Applied Sciences Utrecht, The Netherlands, e-mail: gerben.adams@hu.nl. Yorin Roelofs, student, HU University of Applied Sciences Utrecht, The Netherlands, e-mail: yorin.roelofs@hu.nl. Pascal Ravesteijn, professior, HU University of Applied Sciences Utrecht, The Netherlands, e-mail: pascal.ravesteijn@hu.nl. 
The design of bitcoin was first described in a self-published paper by Nakamoto in 2008 (Nakamoto, 2008), after which an open-source project was registered on SourceForge. Propelled by its capricious quotation, the bitcoin received tremendous media attention recently. It is difficult, if not impossible, to open a popular publication today, and not run into a reference to bitcoin, cryptocurrency or some combination thereof. The bitcoin was the first attempt to solve the double-spending problem in the context of digital currency by means of blockchain technology.

Blockchain technology, often referred to as distributed ledgers, is the underlying technology that stores the same information at different nodes and the information will only be added when the nodes have reached consensus. New transactions can be added, but previous information cannot be removed enabling all nodes to track the history. This reduces the dependency on a central actor and the risk of manipulation or system failure as all nodes have all the information available (Ølnes, Ubacht, \& Janssen, 2017). Beyond cryptocurrencies like bitcoin, blockchain technologies may have the potential to fundamentally change society and we might witness right now the dawn of cryptographically secured trust-free transactions economy (Beck, Czepluch, Lollike, \& Malone, 2016). It is this potential disruptiveness that the venture capitalist Marc Andreessen (2014) even coined as the most important invention since the advent of the Internet.

The potential beneficiaries triggered many organizations to experiment with this technology. In 2016 alone, 26.000 new projects were started with this technology as a basis (Trujillo, Fromhart, \& Srinivas, 2017). Recent literature, for example, describes implementations for the insurance market (Hans, Zuber, Rizk, \& Steinmetz, 2017), crowdlending platform (Schweizer, Schlatt, Urbach, \& Fridgen, 2017), and digital crime prevention (Smith \& Dhillon, 2017). These instantiations are primarily situated in the private domain. It is however stipulated that blockchain technology is also a tool to increase efficiency and economic growth (Chapron, 2017). There is thus a need to address and learn from governmental initiatives to seek the blockchain's potential in this context (Ølnes, 2016). The aim of this study is to contribute to a discussion about blockchain in a governmental setting by exploring the potential use of blockchain and to provide a nuanced view of its use in the field of waste management in a Dutch municipality. This also fills the gap of the need to inquire the use of blockchain in the domain of waste management as Saberi, Kouhizadeh, \& Sarkis (2018) stipulate. Or to paraphrase the authors: "move beyond the hype to make this technology a productive tool for society".

Waste has always been generated due to human activities. Waste hasn't been a major issue as the human population was relatively small and nomadic. It, however, became a serious problem with urbanisation and the growth of large conurbations. Poor management of waste led to contamination of water, soil and atmosphere and to a major impact on public health (Giusti, 2009). Concerns about lack of controls, inadequate legislation, negative impact on the environment and human health were triggered due to 
several serious and highly publicised pollution incidents, for example, see the work of Triassi, et al. (2015). These incorrect waste management practices forced many national and federal governments to introduce new regulatory frameworks to deal with hazardous and unsustainable waste management operations. According to the United Nations, waste management entail activities including (a) collection, transport, treatment and disposal of waste, (b) control, monitoring and regulation of the production, collection, transport, treatment and disposal of waste and (c) prevention of waste production through in-process modifications, reuse and recycling (United Nations, 1997). The latter will not be taken into account in this study. In this study, we evaluate the applicability of blockchain technology in the domain of waste management in the area of Utrecht, the Netherlands. To do so, we address the following research question: How can blockchain technology be utilized by municipal bodies to process transactional waste management data?

\section{Blockchain: distributed ledgers}

Blockchain is an ongoing growing list of registrations of transactions that are divided into blocks. Every block refers back to the last block which shapes a chain, hence the name blockchain. Iansiti \& Lakhani, (2017) describes it as: "an open, distributed ledger that can record transactions between two parties efficiently and in a verifiable and permanent way". The main idea is that the information that is contained in a block is verifiable and permanent as it's impossible to change or mutate.

Blockchain offers new possibilities for controlling and sending information in, for example, a supply chain. However, when trust and robustness are no issues for an information system then blockchain is not always favorable to a traditional database (Greenspan, 2016). There are several differences between the traditional way and new methods developed on blockchain technology. Table 1 summarizes the advantages and disadvantages of blockchain technology versus traditional database systems. 
G. Ongena, K. Smit, J. Boksebeld, G. Adams, Y. Roelofs \& P. Ravesteijn: Blockchain-based Smart

Contracts in Waste Management: A Silver Bullet?

Table 1: Blockchain vs. traditional database system

\begin{tabular}{|c|c|}
\hline 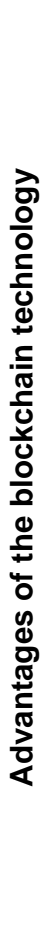 & $\begin{array}{l}\text { - Blockchain can prove the authority and validity of its own transaction instead of } \\
\text { using a central administrator that has to validate and take responsibility. } \\
\text { Transactions through a Blockchain can, therefore, be fully automated independently } \\
\text { and verifiably executed (Swan, 2015). } \\
\text { - Blockchain, just like any other (database) system, has to be run on physical } \\
\text { hardware. However, unlike other systems, there isn't any owner since it's physically } \\
\text { impossible for a Blockchain to run on } 1 \text { node. In this case, there isn't any single } \\
\text { entity that has the power to change or mutate any information that's stored in the } \\
\text { Blockchain. This means that a blockchain is less sensitive to corruption or fraud. By } \\
\text { effect, this means that the parties involved in the Blockchain can all trust the } \\
\text { information stored in such a way. } \\
\text { Information stored in a Blockchain is transparent for all parties involved. There's } \\
\text { always a way to check the history of all the transactions in a Blockchain. This also } \\
\text { means that audits for a Blockchain system are easier and always reliable } \\
\text { (Underwood, 2016; Atzori, 2015; Swan, 2015). } \\
\text { The data isn't stored in a single location. So there is not one person responsible for } \\
\text { the security surrounding the data. That means that there isn't any need for a security } \\
\text { specialist that has to take responsibility for the database and govern and proof the } \\
\text { integrity of the data (Ølnes, 2016; Underwood, 2016; Gervais, et al., 2016) . } \\
\text { Because of the inherent technology of Blockchain, there is a very low risk of system } \\
\text { failures. Blockchain has a much higher robustness compared to tradition database } \\
\text { system because it's run on multiple systems in multiple locations. If one node fails } \\
\text { or breaks down the other nodes will take over instantly. There is no extra } \\
\text { configuration or actions required because each node has a copy of the whole } \\
\text { Blockchain. This also means there is no expensive backup system required. (Ølnes, } \\
\text { Ubacht, \& Janssen, 2017) }\end{array}$ \\
\hline
\end{tabular}




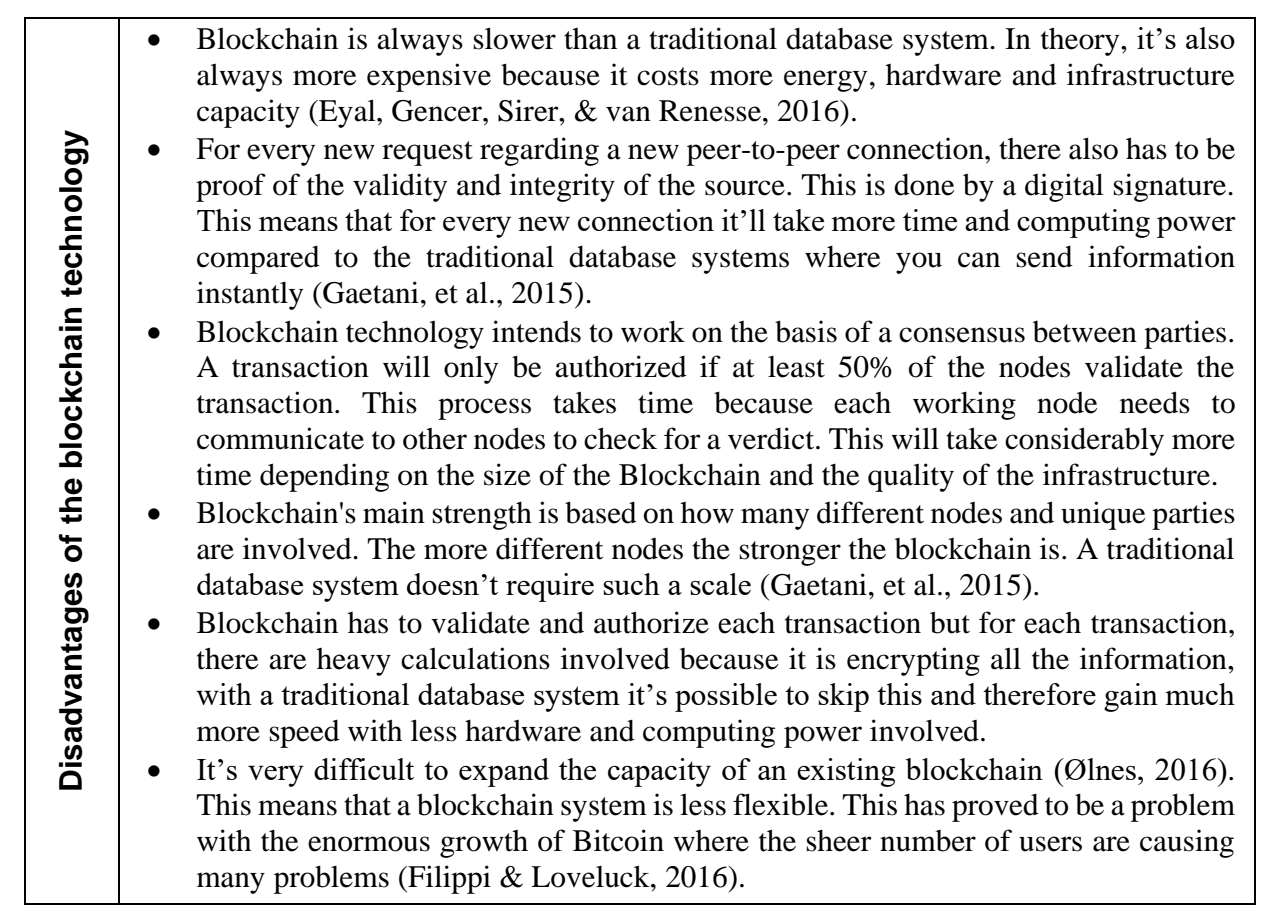

\section{Problem Identification and Motivation}

Our study can be best characterized as design science research (Hevner, March, Park, \& Ram, 2004) as a potential new artefact, represented by a blockchain solution, is the focal point of the study. It, however, must be noted that there is no actual demonstrator build during this research as this is research in progress. In line with common design science approaches, our research starts with the identification and description of a practical relevant problem (Peffers, Tuunanen, Rotherberger, \& Chatterjee, 2007). To acquire deeper knowledge about the process of waste management, interviews were held with both the local authorities as well as the waste station.

Four key stakeholders are identified. The disposer, a mediator (usually the municipality - in this case, Utrecht), logistics and the processor (waste station). Naturally, the process is triggered by a request from the disposer that notifies the municipality through a socalled guidance letter. This letter is used by the driver to check its weight. Then the waste is weighed at the waste station after which the waste is deposited. Thereafter, a weighing note is sent, together with an invoice, to the mediator. This simplified process is illustrated in Figure 1 by BPMN (OMG, 2011). 
G. Ongena, K. Smit, J. Boksebeld, G. Adams, Y. Roelofs \& P. Ravesteijn: Blockchain-based Smart Contracts in Waste Management: A Silver Bullet?

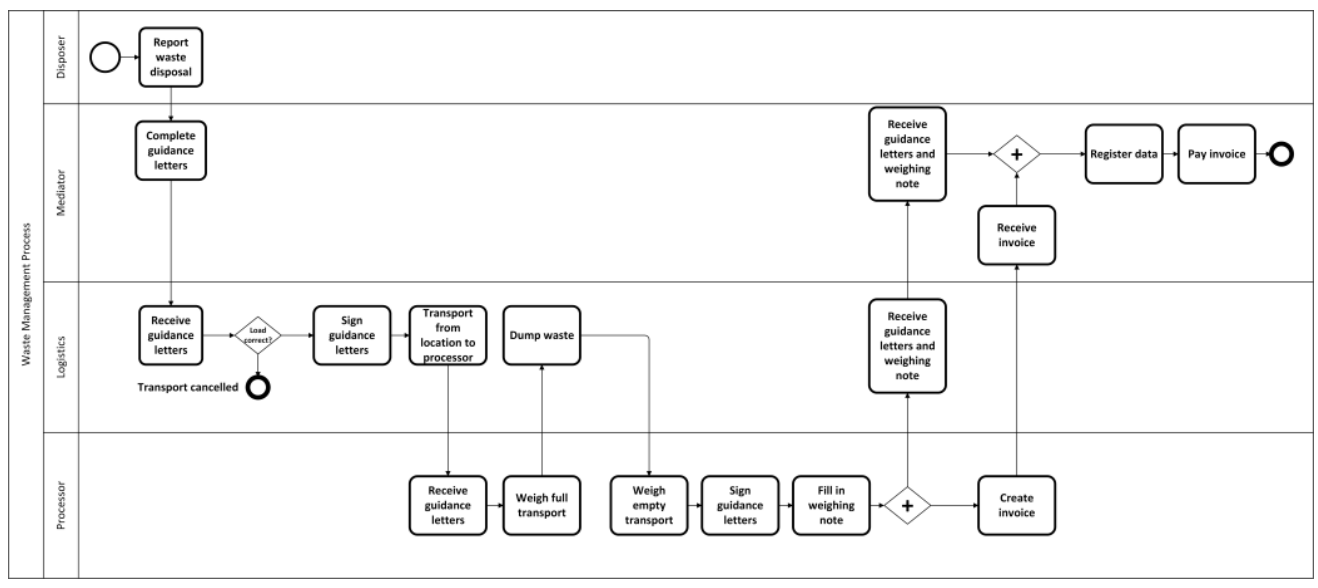

Figure 1: The process of waste management

Sharing of information in this process is digitally supported by an ERP-system. Data is manually entered into the system. This results, for instance, in the guidance letter. The process is governed by several stakeholders. NIWO is also a key stakeholder. The NIWO is the licence provider for road transport in the Netherlands. A national governmental body (ILT) that monitors the licenses of waste processors. Authorities on provincial level who provides licenses to waste processors. Hence, several (non-)governmental bodies are installed to monitor the process of waste management.

Based on the interviews, five main problem areas were identified. Table 2 provides an overview of these deficits and provides a short description of how this can be exemplified in the process of waste management. 
G. Ongena, K. Smit, J. Boksebeld, G. Adams, Y. Roelofs \& P. Ravesteijn: Blockchain-based Smart Contracts in Waste Management: A Silver Bullet?

Table 2: Deficits in the current process

\begin{tabular}{|c|c|}
\hline Problem area & Description \\
\hline Fraud and manipulation & $\begin{array}{l}\text { Payments per kilograms are made when getting rid of } \\
\text { waste. However, the local authorities cannot check the } \\
\text { number of kilograms as they don't possess a weighbridge. } \\
\text { In the past, some flows of waste that generate a lot of money } \\
\text { were fraudulent. This was done by sharing incorrect } \\
\text { information that couldn't be checked by means of a } \\
\text { weighbridge. }\end{array}$ \\
\hline $\begin{array}{l}\text { Wrong or loss of } \\
\text { information }\end{array}$ & $\begin{array}{l}\text { Guidance letters and are physical papers that pass by all the } \\
\text { activities of the current process. In the process, these papers } \\
\text { sometimes get lost. It so happens that the papers literally fly } \\
\text { out of the window during transport or the wrong letters are } \\
\text { given on departure. }\end{array}$ \\
\hline Manual processes & $\begin{array}{l}\text { When implementing the ERP system, it was intended that } \\
\text { data such as the weighing tickets would be automated. This } \\
\text { wasn't done. As a result, the employees of the municipality } \\
\text { must enter the data manually in the ERP system. }\end{array}$ \\
\hline $\begin{array}{l}\text { Lack of knowledge } \\
\text { about technology }\end{array}$ & $\begin{array}{l}\text { Knowledge about, and the ability to work with, technology } \\
\text { is rather limited. As a result, the ERP system does not come } \\
\text { to fruition. }\end{array}$ \\
\hline Lack of control & $\begin{array}{l}\text { Periodic governmental inspection at the waste division } \\
\text { station takes a lot of time. Since the resources are limited, } \\
\text { data is not fully monitored }\end{array}$ \\
\hline
\end{tabular}

\section{Field of Application: A Current Use Case}

To strengthen our possible design, we draw on prior experiences. The Human Environment and Transport Inspectorate (ILT) initiated a pilot a few years ago. The aim of this pilot was to develop an improved process for the cross-border transport of waste by means of blockchain technology (Donata, 2016). The reason for choosing blockchain technology is that at the moment several parties have separate closed accounts and there is not a plausible party that could (or would like to) arrange the administration process of all parties involved. In other words, there is no trusted third party within the process. As is shown in Table 2 this can cause problems in areas such as 'lack of control' and 'fraud and manipulation'.

The working prototype of ILT has proven that blockchain works as the technology can perform the tasks it has been given. It is, therefore, possible to implement a blockchain in 
a supply chain such as waste processing. However, the pilot shows that it is difficult to get everyone involved with the project. Some parties were very enthusiastic and proactive, while others were totally uninterested. This is partly due to a lack of knowledge about blockchain, or more generally a low IT maturity of the organisation influenced this attitude as well. This 'lack of knowledge about technology' has also been identified in Table 2 above. The branch of waste depositing is rather conventional and thus offline communication still characterizes the process of sharing of information between parties. This corresponds with two other possible problem areas that we have identified: "manual processes' and 'wrong or loss of information'.

Hitherto, the pilot is still running. The project leader indicated that it hopes to achieve the following benefits with the blockchain solution:

- The ILT establishes a key position as they control accessibility to information;

- They can then better map the waste flows and take action if needed;

- Faster handling and fewer administrative burdens so that bank warranties can be released earlier.

\section{Discussion, and Implications for Theory and Practice}

The working prototype of ILT has proven that blockchain works as a technology. It is, therefore, possible to implement blockchain technology in a supply chain such as waste processing. However, this study not only aimed to strive for the confirmation that a blockchain solution is applicable; it strives for an evaluation whether a blockchain solution is beneficial compared to the current situation, as proposed by Gregor and Hevner (2013). Thus, reflecting on the problem areas in the process of waste management (as depicted in figure 1) and the characteristics of the blockchain technology and whether the latter is beneficial to the deficit. The results and corresponding explanations are illustrated in Table 3. 
Table 3: Can blockchain overcome deficits?

\begin{tabular}{|c|c|}
\hline Problem area & Blockchain solution \\
\hline Fraud and manipulation & $\begin{array}{l}\text { With blockchain technology, it is important that the data entered } \\
\text { are correct, since it is not possible to change it afterwards (Xiaoqi, } \\
\text { Jiang, Chen, Luo, \& \& Wen, in press). The waste separation } \\
\text { station does not have the correct (automated) solutions to ensure } \\
\text { that these source data are correct. They are too dependent on } \\
\text { another party, which is not confidential enough to use as source } \\
\text { data. Blockchain technology is not going to solve this problem } \\
\text { and, in fact, a solution has to be found before blockchain can be } \\
\text { implemented. }\end{array}$ \\
\hline $\begin{array}{l}\text { Wrong or loss of } \\
\text { information }\end{array}$ & $\begin{array}{l}\text { Once something is entered in a blockchain, it is immediately safe. } \\
\text { Since the guidance letters and weighing vouchers are digitally } \\
\text { entered with a blockchain solution, they cannot be physically lost. } \\
\text { A blockchain implementation is the right solution to overcome } \\
\text { this problem. }\end{array}$ \\
\hline Manual processes & $\begin{array}{l}\text { Blockchain technology itself does not directly offer the solution } \\
\text { for automating data processing. However, it offers multiple } \\
\text { options with the help of other IT solutions. }\end{array}$ \\
\hline $\begin{array}{l}\text { Lack of knowledge } \\
\text { about technology }\end{array}$ & $\begin{array}{l}\text { Blockchain technology is not going to introduce a change in the } \\
\text { current maturity of knowledge and expertise in IT. }\end{array}$ \\
\hline Lack of control & $\begin{array}{l}\text { If organizations save the data using Blockchain and organizations } \\
\text { ensure that this is done in the right way, it is possible to use the } \\
\text { Blockchain technology as a "trust factor". The data contained in it } \\
\text { cannot be changed and if it is entered correctly you can guarantee } \\
\text { that the information is reliable (Crosby, Pattanayak, Verma, \& } \\
\text { Kalyanaraman, 2016). This offers a solution for inspection } \\
\text { services such as ILT, because everything is digital. }\end{array}$ \\
\hline
\end{tabular}

Overseeing the problem areas, one should take into account that almost all of these problems are not solved by blockchain technology. For instance, Control mechanisms must be installed to ensure correct data. Or sufficient infrastructure must be in place to implement a blockchain solution between different parties. In this, the municipality can have a key role as they can impose the use upon stakeholders. In other words, they can guide the development, execution, maintenance and adaptation of blockchain architectures and applications (Ølnes, Ubacht, \& Janssen, 2017).

There are several limitations that have to be pointed out. First, since blockchain is a relatively new technology, there is still a general lack of knowledge on its benefits and limitations. Therefore, the amount of people with deeper insights into the blockchain phenomenon is limited and restricted to a small group of innovators. Second, the study didn't fully complete the cycle of design science research. Building a demonstrator and evaluate this with the stakeholder would leverage our knowledge (and theirs) about the potential benefits or limitations of blockchain technology in this context. Thirdly, the 
logistical component of waste management is not fully considered in this research. In the Netherlands, there are only a few parties concerned with waste transport and these are often innovative. In this branch, they can, therefore, act as an accelerator for blockchain technology.

Despite these limitations, this research contributes a valuable discussion about the use of blockchain technology as its applications are still in its infancy. Further research is needed in order to grasp a full understanding about situations in which blockchain technology is beneficial or not. A multiple case study of current blockchain initiatives would support this understanding.

\section{Acknowledgements}

The authors wish to thank the municipality of Utrecht and the project leaders of the Blockchain Lab at the HU University of Applied Science Utrecht for their valuable contributions.

\section{References}

Andreessen, M. (2014, January 21). Why Bitcoin Matters. Retrieved from New York Times: http://dealbook.nytimes.com/2014/01/21/why-bitcoin-matters/

Atzori, M. (2015). Blockchain technology and decentralized governance: Is the state still necessary? Retrieved from http://dx.doi.org/10.2139/ssrn.2709713

Beck, R., Czepluch, J., Lollike, N., \& Malone, S. (2016). Blockchain - the Gateway to Trust-Free Cryptographic Transactions. Twenty-Fourth European Conference on Information Systems (ECIS). Istanbul, Turkey.

Chapron, G. (2017). The environment needs cryptogovernance. Nature, 545(7655).

Crosby, M., Pattanayak, P., Verma, S., \& Kalyanaraman, V. (2016). Blockchain Technology: Beyond Bitcoin. Apply Innovation Review(2), 6-10.

Donata, E. (2016). Pilot: Transport van afvalstoffen. In M. Pomp, \& K. Hartog, Resultaten Blockchainpilots juni - november 2016.

Eyal, I., Gencer, A., Sirer, E., \& van Renesse, R. (2016). Bitcoin-NG: A Scalable Blockchain Protocol. Proceedings of the 13th USENIX Symposium on Networked Systems Design and Implementation (NSDI '16) (pp. 45-59). Santa Clara, CA, USA: USENIX Association.

Filippi, P. D., \& Loveluck, B. (2016). The Invisible Politics of Bitcoin: Governance Crisis of a Decentralized Infrastructure. Internet Policy Review, 5(3).

Gaetani, E., Aniello, L., Baldoni, R., Lombardi, F., Margheri, A., \& Sassone, V. (2015). Blockchain-based Database to Ensure Data Integrity in Cloud Computing Environments. Proceedings of the First Italian Conference on Cybersecurity (ITASEC17), (pp. 146-155). Venice, Italy.

Gervais, A., Karame, G. O., Wüst, K., Glykantzis, V., Ritzdorf, H., \& Capkun, S. (2016). On the security and performance of proof of work blockchains. Proceedings of the 2016 ACM SIGSAC conference on computer and communications security (pp. 3-16). Vienna, Austria: ACM.

Giusti, L. (2009). A review of waste management practices and their impact on human health. Waste Management, 29, 2227-2239.

Greenspan, G. (2016, March 17). Blockchains vs centralized databases. Retrieved from https://www.multichain.com/blog/2016/03/blockchains-vs-centralized-databases

Gregor, S., \& Hevner, A. (2013). Positioning and presenting design science research for maximum impact. MIS Quarterly, 37(2), 337-355. 
Hans, R., Zuber, H., Rizk, A., \& Steinmetz, R. (2017). Blockchain and Smart Contracts: Disruptive Technologies for the Insurance Market. Twenty-third Americas Conference on Information Systems (AMCIS), (pp. 1-10). Boston.

Hevner, A. R., March, S. T., Park, J., \& Ram, S. (2004). Design Science in Information Systems Research. MIS Quarterly, 28(1), 75-105.

Iansiti, M., \& Lakhani, K. R. (2017). The Truth About Blockchain. Harvard Business Review(January-February), 118-127.

Nakamoto, S. (2008). Bitcoin: A Peer-to-Peer Electronic Cash System. Retrieved from https://bitcoin.org/bitcoin.pdf

Peffers, K., Tuunanen, T., Rotherberger, M., \& Chatterjee, S. (2007). A design science research methodology for information systems research. Journal of Management Information Systems, 24(3), 45-77.

Peters, G. W., \& Panayi, E. (2016, November 19). Understanding Modern Banking Ledgers Through Blockchain Technologies: Future of Transaction Processing and Smart Contracts on the Internet of Money Banking Beyond Banks and Money. In P. Tasca, T. Aste, L. Pelizzon, \& N. Perony, Banking Beyond Banks and Money (pp. 239-278). Switzerland: Springer International Publishing.

Saberi, S., Kouhizadeh, M., \& Sarkis, J. (2018). Blockchain technology_ A panacea or pariah for resources conservation and recycling? Resources, Conservation \& Recycling, 130, 80-81.

Schweizer, A., Schlatt, V., Urbach, N., \& Fridgen, G. (2017). haining Social Businesses Blockchain as the Basic Technology of a Crowdlending Platform. Thirty Eighth International Conference on Information Systems (ICIS), (pp. 1-21). South Korea.

Smith, K., \& Dhillon, G. (2017). Blockchain for Digital Crime Prevention: The Case of Health Informatics. Twenty-third Americas Conference on Information Systems, (pp. 1-10). Boston.

Swan, M. (2015). Blockchain: Blueprint for a new economy. Sebastopol: O'Reilly Media, Inc.

Triassi, M., Alfano, R., Illario, M., Nardone, A., Caporale, O., \& Montuori, P. (2015). Environmental pollution from illegal waste disposal and health effects: A review on the "Triangle of Death". International journal of environmental research and public, 12(2), 12161236.

Trujillo, J. L., Fromhart, S., \& Srinivas, V. (2017, November 06). Evolution of Blockchain Technology: Insights from the GitHub platform. Deloitte Insights.

Underwood, S. (2016). Blockchain beyond bitcoin. Communications of the ACM, 59(11), 15-17.

United Nations. (1997). Glossary of Environment Statistics. Retrieved from https://unstats.un.org/unsd/publication/SeriesF/SeriesF_67E.pdf

Xiaoqi, L., Jiang, P., Chen, T., Luo, X., \& \& Wen, Q. (in press). A survey on the security of blockchain systems. Future Generation Computer Systems.

Ølnes, S. (2016). Beyond Bitcoin Enabling Smart Government Using Blockchain Technology. In H. Scholl (Ed.), EGOVIS 2016. Lecture Notes in Computer Science. 9820, pp. 253-264. Cham: Springer.

Ølnes, S., Ubacht, J., \& Janssen, M. (2017). Blockchain in government: Benefits and implications of distributed ledger technology for information sharing. Government information Quarterly, 34(3), 355-364. 
356 | $31^{\text {ST }}$ Bled eConference: Digital Transformation: MeEting the Challenges June 17 - 20, 2018, BlED, SLOVEnIA, CONFERENCE PROCEEDINGS 


\title{
Boosting Innovation for the Development of Smart-Service Factories of the Future: The Cases of the Federal State of Vorarlberg and its Neighbouring Regions
}

\author{
FLORIAN MAURER \& ALBRECHT FRITZSCHE
}

\begin{abstract}
Factory of the Future is an initiative of the European Commission. It is highly narrative and describes the transformation of "ordinary" manufacturing operations and structures to fully-integrated cyber-physical manufacturing systems. Basing on case study research performed in the greater area of Vorarlberg, this article aims to explore how Small and Medium Enterprises (SMEs) in the field of manufacturing can evolve to smart-service Factories of the Future. It takes a mixed-methods approach with quantitative research (questionnaire) and qualitative case study interviews and provides findings about three main topics in service system engineering: "transformation of an operational need into a description of system performance parameters", "integration of related technical parameters and assurance of compatibility of all physical, functional and program interfaces" and "integration of reliability, maintainability, safety, survivability, human and other such factors". As it turns out, increased servitization measures, service management, service performance and service quality by development of service-oriented architectures (SOA) are key to evolve to a smart-service Factory of the Future.
\end{abstract}

Keywords: - Service Science - smart-service systems $~$ Factory of the Future $\cdot$ Industry $4.0 \cdot$ digital transformation •

CORRESPONDENCE ADDRESS: Florian Maurer, MA, PhD candidate/research assistant, FriedrichAlexander University Erlangen-Nuremburg/Vorarlberg University of Applied Sciences, Wirtschaftsinformatik 1 - Innovation and Value Creation/Product- and Process Engineering, Lange Gasse 20, 90403 Nuremburg, Germany/Hochschulstraße 1, 6850 Dornbirn, Austria, e-mail: florian.maurer@fau.de/florian.maurer@fhv.at. Albrecht Fritzsche, Dr. Dr., Post-Doc, FriedrichAlexander University Erlangen-Nuremburg, Wirtschaftsinformatik 1 - Innovation and Value Creation, Lange Gasse 20, 90403 Nuremburg, Germany, e-mail: albrecht.fritzsche@ fau.de

DOI https://doi.org/10.18690/978-961-286-170-4.24

ISBN 978-961-286-170-4

(C) 2018 University of Maribor Press

Available at: http://press.um.si. 
"Factory of the Future" (FoF) is an initiative of the European Commission. It was launched in 2008 with the aim to develop a sustainable and competitive EU manufacturing industry. In its first iteration, the initiative included the development of high added value manufacturing technologies that are also clean, highly performing, environmentally friendly and social sustainable (e.g. European Commission, European Commission (2013)). Since then, FoF has remained as narrative but, due to ongoing digital transformation of the manufacturing industry, it nowadays describes the manufacturing facilities as digital, fully integrated plants evolving to smart-service cyberphysical systems (e.g. Küpper et al. (2016), Project team in the IEC Market Strategy Board (MSB) (2015), v. Heynitz et al. (2016)). Especially in the German speaking countries (but also in neighbouring countries and beyond), FoF is highly associated with Industry 4.0 (I4.0) approach. Both concepts connect technology, information and human resources on equal ground to establish more performant and efficient but also more intelligent and self-managing smart-service systems. Smart-service systems are the subject of service (systems) innovation (Maglio, 2014).

(Smart) service systems are the basic abstraction of the academic discipline of Service Science (e.g. Maglio et al. (2009), Vargo \& Akaka (2009), etc.). It is a relatively new academic discipline Böhmann et al. (2014) with roots in marketing research (Vargo \& Lusch (2004), Vargo \& Lusch (2008)), but also systems engineering with International Business Machines (IBM) as an important protagonist. Anecdotal reference refers to a phone conversation between Jim C. Spohrer and Henry Chesbrough whereas last-named recommended - similar to the 1940s and 50s, where IBM was pioneer in development of computer science - to start Service Science (Intelligent Business Machines (IBM), 2012). Paul Horn, senior VP for research at IBM, approved this idea (Horn, 2005). Service Science was also selected as one of the top 20 ideas in 2005 by the Harvard Business Review (Chesbrough, 2005). Since its emergence, the Service Science community has quickly grown and made significant progress in research - including the study of smartservice systems which are systems in which autonomous technical operation contributes to continuous re-engineering and improvement (e.g., productivity, quality, compliance, sustainability, etc.) and co-evolution in all value creation processes (Demirkan, Spohrer, \& Badinelli, 2016).

The aim of this paper is to explore how "ordinary" manufacturing operations and structures can evolve to smart-service Factories of the Future. It intends to identify critical success factors for the development of smart-service Factories of the Future as well as to provide access points for organizational transformation and integration of identified critical success factors. The overall motivation and identified research gap is derived from the BIFOCAlps project scope (BIFOCAlps consoritium \& Interreg Alpine Space, 2018): due to globalization, many enterprises - especially small and medium enterprises (SMEs) in manufacturing sector are not as competitive as wished in global markets, resulting in increased levels of unemployment, abandoned facilities and remaining plants that need new products and new processes (BIFOCAlps consoritium \& Interreg Alpine Space, 
F. Maurer \& A. Fritzsche: Boosting Innovation for the Development of Smart-Service Factories of the Future: The Cases of the Federal State of Vorarlberg and its Neighbouring Regions

2018). BIFOCAlps is the supporting research project of this article at hand and aims to foster adoption of good practices in the manufacturing value chain, enhance knowledge transfer among its key stakeholders and raise awareness for impacts of the FoF paradigm in the manufacturing sector.

This paper presents the results of 13 case studies on best practices in the manufacturing service sector out of the greater region of Vorarlberg. Applied methodology is case study research (Yin, 2014) that is guided by the research question "How can Small and Medium Enterprises in the field of manufacturing evolve to a smart-service Factory of the Future?". To answer this question, the paper looks in particular the ability of companies to perceive digital transformation challenges for industry companies and find a suitable path towards digital transformation, their investment in digital technologies and the knowledge transfer and partnerships with other companies.

This paper at hand is organized in five sections. The following section (section two) gives a quick overview about the body of knowledge (Service Science). Furthermore, the section introduces the selected analytical framework. This framework is applied to present the case study finding (c.f. section 5). Section three explains the research methodology as well as the scope of research. It also describes the chosen data sources. Section four presents the case studies (from a cross-case perspective). Section five summarizes the case study findings and provides a conclusion and an outlook for successful implementation of a smart-service Factory of the Future.

\section{Body of Knowledge: Service Science \& smart-service Factory of the Future}

This scholarly article at hand contributes to the academic discipline of Service Science (e.g. Spohrer \& Maglio (2008), Stoshikj et al. (2016)) on the theoretical side as well as to digital transformation, Factory of the Future and Internet of Thing on the practical/operational side.

The goal of Service Science is, according to Wieland et al. (2012) (in reference to Spohrer \& Maglio (2008)), "to apply scientific understanding to advance our ability to design, improve, and scale service systems for business and societal purposes". Service Science combines human understanding, according to [5], "with business and technological understanding to categorize and explain service systems, including how they interact and evolve to cocreate value". This discipline "deals with the interaction within and between service systems" (Stoshikj et al., 2016). Spohrer (2008) defines a service system as "the basic unit of analysis, as a dynamic value co-creation configuration of resources, including people, organizations, shared information (language, laws, measures, methods), and technology, all connected internally and externally to other service systems by value propositions". These are "not only data and physical components, but also layers of knowledge, communication channels and networked actors" (Böhmann et al., 2014).

However, service systems are socio-technical artefacts (Alter, 2013, 2015) and the basic abstraction of Service Science (Maglio et al., 2009). Service systems are considered to be 
"everywhere" (Wieland et al., 2012) and are part of larger service ecosystems. Smartservice systems, according to Polese, base on intensive application and use of Information and Communication Technologies (ICT) for a wise and interacting management of service systems' assets, goals as well as being capable for self-reconfiguration (Barile \& Polese, 2010). Polese exemplifies intelligent utility network and metering, intelligent transportation, consumer driven supply chains and manufacturing productivity as smartservice systems. However, smarter service systems serve its clients better and develop enhanced opportunities for win-win situations that again result in increased value cocreation for both service providers and clients (Spohrer \& Maglio, 2009). Smart-services in the field of manufacturing, as (Boukhris, Fritzsche, \& Möslein, 2017) highlight, are advanced services and - as they cite from (Baines \& Lightfoot, 2013) - allow to "provide remote insight into the condition and use of a product, and advanced warning of impending failures".

To boost innovation in manufacturing operations and structures with the general aim to become a smart-service Factory of the Future, efforts and activities into service system engineering are indispensable. (Tien \& Berg, 2003) as well as (Buede \& Miller, 2016) provide list of common definitions of service system engineering (SSE). Focusing on the framework of the U.S. Department of Defense (1969), SSE is about the (1) transformation of an operational need into a description of system performance parameters and system configuration, the (2) integration of related technical parameters and assurance of compatibility of all physical, functional and program interfaces and the (3) integration of reliability, maintainability, safety, survivability, human and other such factors into the total engineering effort. In this article at hand, this approach serves as analytical framework to analyse the case studies and to synthegrate and summarize the findings.

Digital transformation is about the integration of digital technology into all areas of business and operations but also about replacement of outdated processes and legacy technologies (The Enterprisers Project - a community of CIOs discussing the future of business and IT, 2018). Factory of the Future and Industry 4.0, as discussed in Maurer \& Schumacher (2018), "is an emerging paradigm for businesses and industries (e.g. Project team in the IEC Market Strategy Board (MSB) (2015), Küpper et al. (2016), v. Heynitz et al. (2016)). It proposes improvements on three dimensions namely the plant structure, plant digitalization and plant processes Küpper et al. (2016) and aims is to merge the physical with the virtual world of manufacturing. Objective of these no longer reversible paradigms is to digitalize manufacturing processes as well as its services including, for example, product planning, product development, factory and production planning, production and logistics".

\section{$3 \quad$ Research Methodology and description of Data Sources}

Applied research methodology in this article at hand is case study research. Case study research is very common in the social research sciences (Yin, 2014). It is a qualitative research method that gives researches liberty to combine heterogeneous data and data collection methods such as interviews, questionnaires, organizational documents, service 
level agreements, etc. Based on Yin (2014), figure 1 highlights applied research process. It consists of a questionnaire (quantitative research, left hand side of figure 1), disseminated to a diverse group of business professionals, and case study interviews (qualitative research, right hand side of figure 1), performed with 13 representatives ${ }^{27}$ in the field of manufacturing. The quantitative research opened the door for the empirical field of digital transformation in organizations, FoF and I4.0 as well as - basing on the evaluation of the quantitative research results - was the origin to develop meaningful and more detailed questions for the empiric research. This article at hand focusses on the combined findings emerging from the last step in this process: the cross-case report.

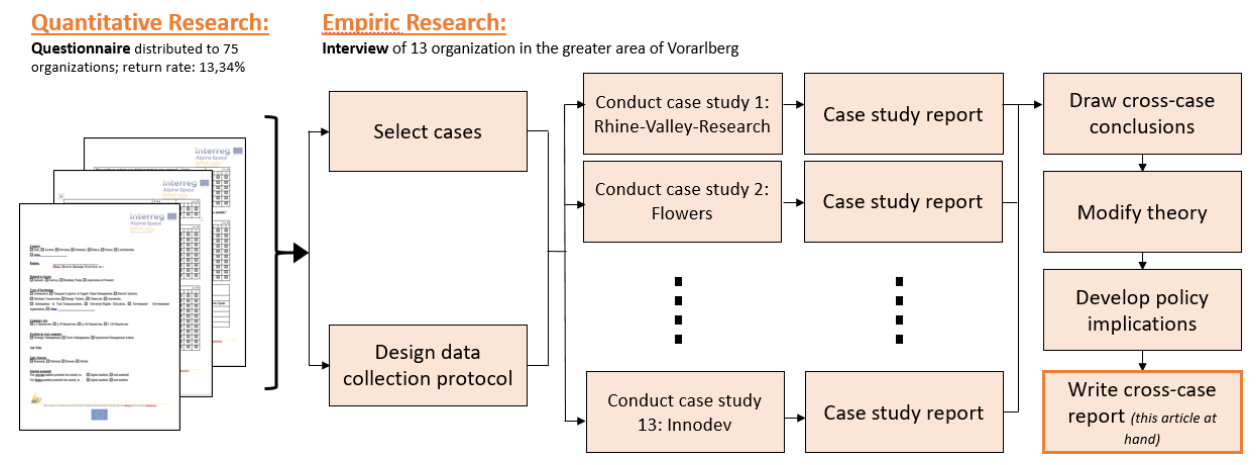

Figure 1: Applied research methodology (adopted from Yin (Yin, 2014))

The questionnaires were disseminated in Spring 2017 to 75 organizations in the manufacturing sector and related sectors (e.g. transport logistics and supply chain management) in the Alpine Space (Alpine Space, 2018). The questionnaire consists of closed questions related to the ongoing digital transformation towards smart-service Factories of the Future. The response options in this questionnaire were predefined on a Likert scale ranging from 6 (high importance) to 1 (low importance).

In continuation, all respondents of the questionnaire out of the region of Vorarlberg (7) plus six freely chosen organizations in the greater region of Vorarlberg were integrated into semi-structured case study interviews. In total, 11 organizations were selected from the Federal State of Vorarlberg (Austria), 1 organization form the canton of St. Gallen (Switzerland) and 1 organization from the region of Stuttgart (Baden-Württemberg, Germany). The return rate of the questionnaire is low $(13,34 \% ; 10$ (absolute)) and is not representative. Nevertheless, the questionnaire provides a good overview about managers' perspectives and expectations toward the ongoing digital transformation in the manufacturing industry.

\footnotetext{
${ }^{27} 7$ representatives are from small and medium enterprises (SME's), 2 from large companies, 2 from technical competence/research centers (related to Industry 4.0), 1 from an innovation agency and 1 Professor/Lecturer in the field of Manufacturing/Engineering
} 
The greater region of Vorarlberg is selected for several reasons: Vorarlberg is the second strongest economic region in Austria (behind the capitol of Vienna) and - accompanied to this economic strength - Vorarlberg and its neighbouring regions are one of the most powerful economic regions worldwide. The economic strengths of this region are widely based on innovation and innovative organizations as well as the region's economic power is mainly provided by SMEs that are not only providers of information for this case study research but also co-beneficiaries of this research. Further co-beneficiaries are managers and employees of related institutions to SMEs (e.g. chambers of commerce, business support organizations) as well as scholars and scientist in the field of I4.0 and FoF.

The interviews were conducted in summer and autumn 2017. They lasted in average $1,5 \mathrm{~h}$ and were conducted either via face to face or via telephone. In the course of the interview, the interviewees first experienced a succinct introduction in the field of research, the motivation and research question and further background about the research project (BIFOCAlps). The interviewees were then asked to comment on three thematic blocks: "ability in perceiving digital transformation challenges for industry companies/ability in perceiving and facing the path towards digital transformation", "investment in digital technologies" and "knowledge transfer and partnerships with industry companies". All interviews were summarized in single case study reports that provide the basis for this article at hand.

\subsection{Description of Data Sources}

In the analysis of the descriptive data from the questionnaire, it turned out that the majority of the respondents evaluate Industry $4.0(89 \%)$ and the Factory of the Future $(56 \%)$ as an important concept for their organizations ${ }^{28}$. For example, on a Likert scale ranging from 6 (high importance) to 1 (low importance), $33 \%$ (I4.0) and $22 \%$ (FoF) of the respondents evaluated that I4.0 and FoF have highest importance (scale 6) for their organization. Figure 2 highlights the result of the opening question of the questionnaire.

\footnotetext{
${ }^{28}$ One abstention out of 10 questionnaires
} 


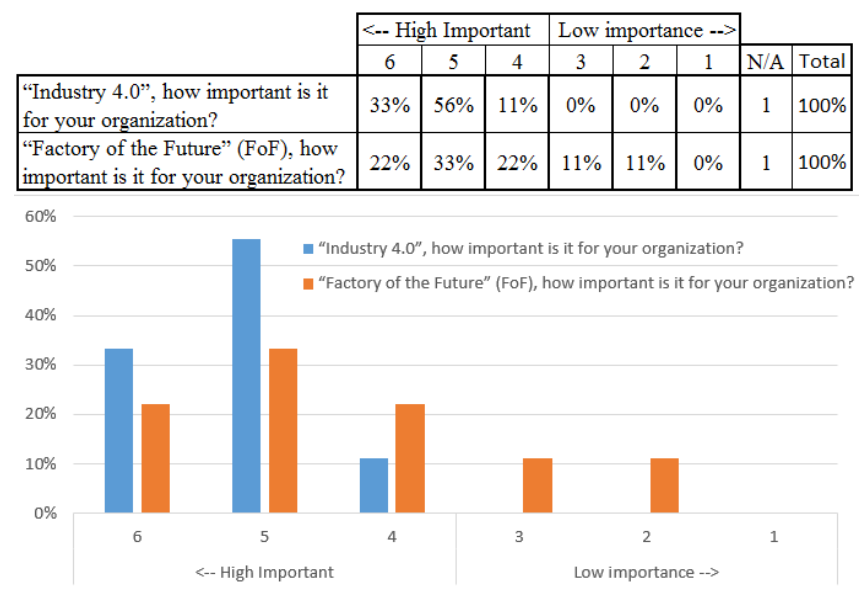

Figure 2: Importance of Industry 4.0 and Factory of the Future paradigm

Related to the question, what a megatrend for $\mathrm{I} 4.0$ and $\mathrm{FoF}$ is, questionnaire participants answered that "Shorter Product-Life-Cycles", "Dynamic Technology and Innovation" and "Mass Customization" are of extraordinary importance. Further megatrends are, for example, "Globalization and future markets", "Global Knowledge Society", "Scarcity of Resources", "Challenge of Climate Change", "Sharing Global Responsibility" and "Changing demographics". Figure 3 shows the megatrends and their importance for the respondents of the questionnaire.

\begin{tabular}{|l|c|c|c|c|c|c|c|c|}
\cline { 2 - 9 } \multicolumn{1}{c|}{} & \multicolumn{2}{c|}{$<-$ High Important } & \multicolumn{2}{l|}{ Low importance --> } & \multicolumn{3}{c|}{} \\
\cline { 2 - 10 } \multicolumn{1}{c|}{} & 6 & 5 & 4 & 3 & 2 & 1 & N/A & Total \\
\hline Shorter Product-Life-Cycles & $67 \%$ & & $11 \%$ & $11 \%$ & $11 \%$ & & 1 & $100 \%$ \\
\hline Dynamic Technology and Innovation & $50 \%$ & $50 \%$ & & & & & 0 & $100 \%$ \\
\hline Mass Customization & $50 \%$ & $20 \%$ & & $30 \%$ & & & 0 & $100 \%$ \\
\hline Globalization and future markets & $30 \%$ & $50 \%$ & $20 \%$ & & & & 0 & $100 \%$ \\
\hline Global Knowledge Society & $20 \%$ & $50 \%$ & $30 \%$ & & & & 0 & $100 \%$ \\
\hline Scarcity of Resources & $10 \%$ & $30 \%$ & $30 \%$ & $20 \%$ & $10 \%$ & & 0 & $100 \%$ \\
\hline Challenge of Climate Change & $10 \%$ & $10 \%$ & $30 \%$ & $50 \%$ & & & 0 & $100 \%$ \\
\hline Sharing Global Responsibility & & $20 \%$ & $30 \%$ & $40 \%$ & $10 \%$ & & 0 & $100 \%$ \\
\hline Changing demographics & & $11 \%$ & $22 \%$ & $33 \%$ & $33 \%$ & & 1 & $100 \%$ \\
\hline
\end{tabular}

Figure 3: I4.0 and FoF megatrends

As figure 4 indicates, three respondents of the questionnaire expect to change their business models because of emerging I4.0 and FoF paradigm. Two respondents started to perform projects to change business models and three already transformed their business models because of the ongoing digital transformation. Only one respondent answered that business models do not need to get changed. 


\begin{tabular}{|c|c|c|c|c|c|c|}
\hline Replies & Yes & No & Current project & Already done & N/A & Total \\
\hline 10 & 3 & 1 & 2 & 3 & 1 & 10 \\
\hline & $30 \%$ & $10 \%$ & $20 \%$ & $30 \%$ & $10 \%$ & $100 \%$ \\
\hline
\end{tabular}

Figure 4: Business model change and adaption

Figure 5 highlights the respondents' statements toward I4.0 and FoF paradigm. For example, four of the respondents of the questionnaire rate that I4.0 and FoF require to change business models with the highest rank (6). Additional four respondents rate this statement with the second highest rank (5) und 2 with the third highest rank (4). Computed with its eigenvalue ( 4 (respondents) $* 6$ (eigenvalue) $+4 * 5+2 * 4=52$ ), it turns out that I4.0 and FoF require change in business models is the most correct statement. Following statements with high truth value are: I4.0 and FoF require change in organizational strategy and I4.0 and FoF require increased collaboration with customers and business partners.

\begin{tabular}{|c|c|c|c|c|c|c|c|c|}
\hline \multirow[b]{2}{*}{ Which statement is correct? Industry $4.0 \ldots$} & \multicolumn{3}{|c|}{$<-$ High } & \multicolumn{3}{|c|}{ Low --> } & \multirow[b]{2}{*}{ N/A } & \multirow[b]{2}{*}{ Total } \\
\hline & 6 & 5 & 4 & 3 & 2 & 1 & & \\
\hline ... requires changes in business models & (4) 24 & (4) 20 & (2) 8 & & & & & 52 \\
\hline ... requires changes in organizational strategy & (3) 18 & (5) 25 & (2) 8 & & & & & 51 \\
\hline ... requires increased collaboration with customers & (2) 12 & (5) 25 & (3) 12 & & & & & 49 \\
\hline ... requires increased collaboration with business partners & (1) 6 & (6) 30 & $(2) 8$ & (1) 3 & & & & 47 \\
\hline ... create chances & (3) 18 & (3) 15 & $(2) 8$ & & (2) 4 & & & 45 \\
\hline$\ldots$ create challenges & (2) 12 & (3) 15 & (4) 16 & & (1) 2 & & & 45 \\
\hline ... make markets more disruptive & (2) 12 & (1) 5 & (6) 24 & (1) 3 & & & & 44 \\
\hline ... produce global competition & & (6) 30 & (4) 8 & (1) 3 & (1) 2 & & & 43 \\
\hline ... make markets more dynamic & (1) 6 & (2) 10 & (3) 12 & (3) 9 & (1) 2 & & & 39 \\
\hline ... requires increased collaboration with politics \& government & (1) 6 & (2) 10 & (4) 16 & & (1) 2 & (1) 1 & 1 & 35 \\
\hline
\end{tabular}

Figure 5: Trigger for I4.0 and FoF

\section{The cases of the Federal State of Vorarlberg and its neighbouring regions}

This section presents the results of the conducted single case study research from a crosscase perspective. It involves 13 single case studies from the manufacturing industry and related fields. 7 managers/representatives are from small and medium enterprises (SMEs) related to various fields of $\mathrm{FoF}$ and I4.0 (e.g. IoT managers, $\mathrm{CIO}$ of a packaging material company, data scientists), 2 from large companies (CIO and his deputy, data scientist), 2 from technical competence/research centres (related to Industry 4.0; managers on tactical business level), 1 from an innovation agency (responsible for funds related to innovation projects) and 1 Professor/Lecturer in the field of Manufacturing/Engineering.

The organization of this section is related to the thematic blocks addressed during the interviews. Sub-section one presents the "ability in perceiving digital transformation 
challenges for industry companies/ability in perceiving and facing the path towards digital transformation". Sub-section two presents the "investment in digital technologies" and sub-section three presents "knowledge transfer and partnerships with industry companies".

The opening question is answered positively by all case study partners. They associate the Industry 4.0 (I4.0) paradigm and the Factory of the Future (FoF) approach predominantly with new market opportunities. From a technological perspective, they associate I4.0 and FoF with increased digitalization, big data/analytics, machine to machine, communications/artificial intelligence, augmented reality, supplier-producercustomer network/adaptive automation and Internet of Things (IoT).

\subsection{Ability in perceiving digital transformation challenges for industry companies / ability in perceiving and facing the path towards digital transformation}

As the interviewee of Rhine-Valley-Research ${ }^{29}$ (RVR) highlights, SMEs are basically innovative and have always invested into efficiency increasing technologies. But today, as the interviewees highlight, SMEs are confronted with several challenges. A major issue to become a smart-service FoF is the readiness of ICT infrastructure of particular organization as well as its hardware and software. But this again is challenging, as the case of Flowers ${ }^{29}$ and Innodev $^{29}$ highlight, because technology changes very fast. Furthermore, cyber-attacks threaten not only parts but also the fully connected resources of a smart-service FoF as a whole. A virus, for example, can cause major disruptions in the smart-service FoF leading to its complete breakdown.

As the single cases turned out, SMEs are far behind current developments and solutions. For example, while large companies already started to simulate the smart-service FoF and test promising technologies as customer service platforms, robots, augmented/virtual reality, digital twins, batch size "one", 3D printing, autonomous driving, artificial intelligence, etc., SMEs are stuck in the further development of its organizational enterprise resource planning (ERP) systems. They are highly challenged by the development of interfaces and the integration of its Manufacturing Execution Planning Systems as well as its suppliers and customers into the manufacturing processes (observed by the interviewee of InnoAgent ${ }^{29}$ and case of PaperPack ${ }^{29}$ (current project: EDI and GS1 integration)).

Building a smart-service FoF, as examined in the single case studies, highly depends on the organizational capability to achieve an integration of organizational Manufacturing Execution Planning Systems. These systems are connected with organizational resources (e.g. human, technology (as sensors, data processing, data storage, data visualization, etc.) and processes, which again provide ubiquitous data and information for advanced

\footnotetext{
${ }^{29}$ due to the provision of company secrets in this case study at hand, the case study partner names are editorially modified and anonymized
} 
technologies. Focusing on these data and information, the interviewee of Flowers ${ }^{29}$ but also InnoDev ${ }^{29}$ expect that (in close future) all systems (human, technology) communicate with each other. This enables increased interaction with service system stakeholders and advanced technologies such as predictive maintenance, tracking/transparent production/manufacturing, remote control, extended software frameworks, machine learning, artificial intelligence, etc. The organizations are able to optimize the manufacturing facilities, its resource equipment and manufacturing processes.

\subsection{Investment in digital technologies}

According to the interviewee from PaperPack29, financial expenses are the biggest hurdle for SMEs to digital transformation. As the interviewee said: "From a technical perspective, it is definitely possible to automatize PaperPack's ${ }^{29}$ production and manufacturing facilities, but due to financial limitation it is impossible".

As the cases show, investments into the digital transformation towards a smart-service FoF are predominantly about human and technical resources. Digital transformation is performed in internal projects and include organizational employees and external consults. But also, as the interviewee of Craddle ${ }^{29}$ reports, SMEs start to cooperate with others and develop spin-off organizations. Flowers ${ }^{29}$ and SpeedSped ${ }^{29}$, both large companies maintain own department for research, development and innovation.

Investments into technological-organizational evolution towards a smart-service FoF are, for example, ERP interfaces, high speed internet solutions to increase speed and reaction times, placement systems, robotics, sensors and wireless communication interfaces - but also 3D printing (of metal products).

Considered from a human resource perspective, all case study partners invest into training and education of its employees. Efforts and activities comprise the organization of workshops, seminars, education and training events. These events are also in cooperation with higher education and training organizations. SpeedSped ${ }^{29}$ and InnoDev ${ }^{29}$ maintain an own college for employee training and education.

\subsection{Knowledge transfer and partnerships with accelerated organizations}

Although the case study partners rate their organizational digital maturity as high, emerging topics of I4.0 and FoF are continuously on their agendas. For example, PaperPack ${ }^{29}$ - but also remaining case study partners - perform continuous meetings about the chances and challenges of these emerging trends. The discussions involve strategic and operational businesses and incorporate managing directors, managers and employees equally. PaperPack ${ }^{29}$ additionally performs experiments that provide data and information to build up of scenarios. 
As the cases show, (formal and informal) cooperation are the essence to cope the challenges and take advantage of chances and opportunities of the digital transformation towards smart-service Factories of the Future. Case study interviewees reported organizational cooperation in vertical (same or similar organizations in particular field of business, e.g. competitors) and horizontal (accelerated organizations in particular field of business, e.g. suppliers, governmental organizations, chambers, etc. but also customers) partnerships and networks. These partnerships also cover excursions into friendly organization to evaluate, for example, software implementations, features and updates of ERP systems (e.g. SAP Hana). As the case study interview of CraddleInno ${ }^{29}$ reported, SMEs also start to organize themselves in spin-offs.

SpeedSped ${ }^{29}$ again, is part of the umbrella organization Logistics Alliance Germany. This is a vertical network and includes transport logistic and supply chain management providers with the aim to drive and support innovation engineering in particular organization. Flowers put premium on the maintenance of its network to industry leaders and trend setters as, for example, Microsoft, IBM and SAP. CraddleInno ${ }^{29}$ again maintain a proper customer relationship management (CRM) that allows to immediately react to customer needs and requirements.

As observed, the majority of the case study partners cooperate with universities, universities of applied sciences and research centres. Together, they perform student projects but also industry projects. Additional, SpeedSped ${ }^{29}$, Rhine-Valley-Research ${ }^{29}$ and InnoAgent ${ }^{29}$ cooperate in regional, national and/or international projects funded by governments (e.g. Interreg, EU-H2020, etc.). While InnoDev ${ }^{29}$ maintains a university for training and education of external people (they organize lectures related to the field I4.0, digital transformation, FoF, etc.), SpeedSped ${ }^{29}$ maintains a collage for the training and education of internal employees. Among others, in this collage, employees get prepared for the emerging challenges and trends of smart-service FoF. In cooperation with the University of Liechtenstein, Rhine-Valley-Research ${ }^{29}$ provides a certificate program for Industry 4.0 Management.

Only SpeedSped ${ }^{29}$ and Flowers ${ }^{29}$ maintain departments for research, development and innovation. SpeedSped ${ }^{29}$ uses this department for internal development and innovation and to collaboratively perform external research projects with universities and research centres. However, Flowers ${ }^{29}$ is more conservative and uses their R\&D department only internally: achievements are corporate secrets and are restricted to internal use only.

\section{5}

\section{Findings}

The majority of interviewees of this case study at hand shows a positive attitude towards the digital transformation of their business activities and associates the ongoing digital transformation towards a smart-service Factory of the Future as chance to create new market opportunities and provide organizational growth and prosperity. Based on the used analytical framework (c.f. section 2), the following sub-sections present the findings and conclusion of conducted case study research. 


\subsection{Transformation of an operational need into a description of system performance parameters}

The interviewees put major emphasis on technological fitness and readiness. They actively transform their ICT infrastructures and build up service-oriented architectures (SOA). SOA architectures aim to improve service management and to increase service orientation.

The cases highlight an essential advantage of large companies: they already transformed their physical and digital infrastructures. As the interviewee of Innodev highlight, a client developed new business models and evolved from a pure manufacturer of cable cars to an operator of cable car services. They now operate city cable cars and - basing on the operational needs - provide additional services (e.g. appropriate music during the passenger transport). They also take advantage by analyse the service client data and information. They now are able to transform operational service client needs into system performance parameters and are able to a broad range of new, service enhancing methods and technologies.

As it turned out, SMEs focus on service-related transformation and started to open their ERP systems for increased customer interaction and value co-creation mechanisms. SMEs actively expand their structures to include the customer into the manufacturing processes with the aim to increase manufacturing transparency and to get and put additional data and information into its service ecosystems. SMEs have realized that efficient and effective service provision systems are of major importance. A physical deviation accompanied with missing information can interrupt production and manufacturing processes - increased communication in these supply chain processes but also in production and manufacturing processes is key.

However, as the single case of PaperPack highlights, many current production and manufacturing processes will continue to be manual in future too. For example, the interviewee does not agree that a robot can replace the change, for example of a 10 tons paper roll at a packaging machine. For that, the robots are not sensitive enough. In addition, the investments would be too high and not affordable for SMEs. Additional, the return on investment is to less: what brings a fully automated packaging machine when the remaining ones are not converted to I4.0 principles?, as the interviewee asked during the interview.

Evolving to a smart-service Factory of the Future is project-, human- and finance based. As the cases show, in the evolution is driven by projects, with clear start and end dates, and requires appropriate human resources, investments and finance. The projects focus on a specific goal and technology that should successfully implemented within the project duration. 

of the Future: The Cases of the Federal State of Vorarlberg and its Neighbouring Regions

\subsection{Integration of related technical parameters and assurance of compatibility of all physical, functional and program interfaces}

Smart-servcie FoFs are about the interconnectivity of socio-technical systems - including technology, information and human resources - to enable innovative forms of manufacturing, productions and value constellations as well as to achieve holistic communication. Interconnectivity of socio-technical systems enables real-time data analysis and - in further consequence - big data analysis that again are the basis for decision making, artificial intelligence, driverless vehicles, etc. As the cases show, especially the SMEs lack behind the state-of-the-art in development of smart-service FoF. Reasons are, for example, limited resources to adapt and implement digital trends and challenges. As already highlighted, they are stuck in the design, development and implementation of ERP interfaces to increase communication and interactions.

Also, as the cases highlight, smart-service FoF are about advanced use of "Internet of Things" technologies that are, for example, sensors, data storage, data processing to realize track and tracing, predictive maintenance, etc. The case of InnoAgent - the innovation agency of the Federal State of Vorarlberg - underlines this finding. The interviewee reported, that frequently asked questions relate to Manufacturing Execution Planning Systems, automation of production and manufacturing processes, integration of suppliers and customers into these processes, innovative and efficient intra-logistics, digital twins and flexible production towards batch size "one".

\subsection{Integration of reliability, maintainability, safety, survivability, human and other such factors}

Smart-service FoF are about the digital integration of service clients and stakeholders into manufacturing processes. These stakeholders support providers to improve value constellations, increase service performance and service quality. In this sense, stakeholders are not only beneficiaries of services they are also its co-creators (Donofrio, Sanchez, \& Spohrer, 2008). Service stakeholders are seen as essential sources for renewal, change and innovation of products and services, incl. organizational processes and activities.

The cases indicate that it is highly beneficial for SMEs to maintain pro-active networks and partnerships to discuss, share and gain information about emerging challenges and solutions. These networks have a formal, but also an informal part and range from loose contacts to strong linkages to partner organizations. Some SMEs, as the case from CraddleInno highlights, already started to establish spin-off organizations: they cooperate in vertical and horizontal value co-creation networks to work on emerging trends and hot topics in digital transformation. They outsource the risk of failure and decrease the loss of venture capital.

Active and participative employees, especially service and data scientists, become a unique/key resource of an organization. They act as interface between real and digital 
processes. But also "normal" employees are of importance: well-educated and trained are the back-bone of organizations. However, during the interviews, all case study partners emphasize the lack of appropriate human resources and call for "T-shaped people" (Spohrer, Piciocchi, \& Bassano, 2012): people that are able to shape their knowledge and apply functional/disciplinary skills to implement the shift towards increased organizational servitization.

However, to increase sustainability factors, SMEs need to adopt and extend its organizational strategy. This includes the realignment of the vision and mission statements and goals towards the ongoing digital transformation. This also capture the realignment and adaption of organizational business models towards increased cocreation mechanisms in production and manufacturing processes.

\section{Discussion, recommendations and conclusion}

This article at hand presents a case study using quantitative (questionnaire) and an qualitative methods (interview, single case studies conducted with 13 heterogeneous organizations in and related to the field of manufacturing). It presents a cross-case analysis of three main themes that are "ability in perceiving digital transformation challenges", "investment into digital technologies" and "knowledge transfer and partnerships with accelerated organizations" to respond to the overall research question how "ordinary" organizations in the field of manufacturing can evolve to a smart-service Factory of the Future. As it turned out, Industry 4.0 and Factory of the Future paradigms are highly important to organizations and appears on their daily agendas. Related to I4.0 and $\mathrm{FoF}$ are the needs to change and adapt organizational business models, adjustment of organizational strategy and increased collaboration with customers (but also related service stakeholders).

In this research, the need to transform social and technological infrastructures towards service-oriented architectures is recognized. SOAs allow increased service orientation and management in organization. For example, shifting from proprietary to open ERP systems allows interconnections with its service clients. That again fosters increased interaction and information exchange and thus increased servitization. But also, open ERP system are a basis for the integration of data and the implementation of Internet of Things technologies, which are valuable to drive process and service innovation (e.g. predictive maintenance, supplier-customer interaction, robots, autonomous driving). However, as the case studies also show, a fully automated factory is not realistic - at least in the close future. There are processes (e.g. packaging machine) that cannot be digitalized yet and/or supported appropriately by technology.

Evolving towards a smart-service Factory of the Future relates to investments into human resources and technology. As it turned out, large companies have better initial positions: they have resource-based advantages and thus more leeway to overcome the challenges of digital transformation. SMEs have to pro-actively initiate and orchestrate organizational transformation and to integrate processes and activities. They are 
F. Maurer \& A. Fritzsche: Boosting Innovation for the Development of Smart-Service Factories of the Future: The Cases of the Federal State of Vorarlberg and its Neighbouring Regions

requested to systematically design, development and pilot of service systems (Böhmann et al., 2014) and capitalize organizational capabilities. However, all case study partners highlight the importance of well-educated and trained employees. It is a call for "Tshaped people" (Spohrer et al., 2012): people that are able to shape their knowledge and apply functional/disciplinary skills to implement the shift towards increased service, service orientation and management, service-orientated architectures and thus increased servitization.

\section{Acknowledgement}

This case study research is co-financed by the Interreg Alpine Space (2018) project BIFOCAlps. BIFOCAlps is an Industry4.0 and Factory of the Future related project with the aim to boost innovation in factory of the future value chain in the Alps. Find more information under http://www.alpine-space.eu/projects/bifocalps/en/home

\section{References}

Alpine Space. (2018). What is the Alpine Space programme? Retrieved March 15, 2018, from http://www.alpine-space.eu/about/the-programme/what-is-the-alpine-space-programme-

Alter, S. (2013). Work System Theory: Overview of Core Concepts, Extensions, and Challenges for the Future. Journal of the Association for Information Systems, 14(2). Retrieved from http://aisel.aisnet.org/jais/vol14/iss2/1

Alter, S. (2015). Work System Theory as a Platform: Response to a Research Perspective Article by Niederman and March. Journal of the Association for Information Systems, 16(6). Retrieved from http://aisel.aisnet.org/jais/vol16/iss6/1

Baines, T., \& Lightfoot, H. W. (2013). Servitization of the manufacturing firm: Exploring the operations practices and technologies that deliver advanced services. International Journal of Operations \& Production Management, 34(1), 2-35. https://doi.org/10.1108/IJOPM-02-20120086

Barile, S., \& Polese, F. (2010). Smart Service Systems and Viable Service Systems: Applying Systems Theory to Service Science. Service Science, 2(1-2), 21-40. https://doi.org/10.1287/serv.2.1_2.21

BIFOCAlps consoritium, \& Interreg Alpine Space. (2018, October 5). BIFOCAlps project Boosting Innovation in Factory of the Future value Chain in the Alps [Project homepage]. Retrieved May 11, 2018, from http://www.alpine-space.eu/projects/bifocalps/en/home

Böhmann, T., Leimeister, J. M., \& Möslein, K. (2014). Service Systems Engineering - A Field for Future Information Systems Research. Business \& Information Systems Engineering, 6(2), 7379. https://doi.org/DOI 10.1007/s12599-014-0314-8

Boukhris, A., Fritzsche, A., \& Möslein, K. (2017). Smart service development: a systematic literature review. In Proceedings 12th Research Colloquium on „Innovation \& Value Creation" (I+VC 2017). Hamburg University of Technology.

Buede, D. M., \& Miller, W. D. (2016). The Engineering Design of Systems: Models and Methods (3 edition). Hoboken, New Jersey: Wiley. Retrieved from http://www.pishvaee.com/wpcontent/uploads/downloads/2013/09/Buede-D-System-Eng.pdf

Chesbrough, H. W. (2005). Toward a New Science of Services. Harvard Business Review, 83, 16$17,43-44$.

Demirkan, H., Spohrer, J. C., \& Badinelli, R. (2016). Introducing to the Smart Service Systems: Analytics, Cognition and Innovation Minitrack. Presented at the Hawaii International 
$31^{\text {ST }}$ Bled eConference: Digital Transformation: MeEting the Challenges

JUNE 17 - 20, 2018, BLED, SLOVENIA, CONFERENCE PROCEEDINGS

F. Maurer \& A. Fritzsche: Boosting Innovation for the Development of Smart-Service Factories of the Future: The Cases of the Federal State of Vorarlberg and its Neighbouring Regions

Conference on System Sciences, Hawaii. Retrieved from https://www.computer.org/csdl/proceedings/hicss/2016/5670/00/5670b652.pdf

Donofrio, N., Sanchez, C., \& Spohrer, J. (2008). Collaborative Innovation and Service Systems: Implications for Institutions and Disciplines. In D. Grasso (Ed.), Holistic Engineering. Retrieved from http://www.ceri.msu.edu/wp-content/uploads/2010/07/Holistic-EngineeringBook-Chapter-20081015.pdf

European Commission. (2013). Factories of the Future: Multi-Annual Roadmap for the contractual PPP under Horizon 2020 (ISBN: 978-92-79-31238-0 // doi: 10.2777/29815). Luxembourg: Publications Office of the European Union. Retrieved from http://www.effra.eu/attachments/article/129/Factories\%20of\%20the\%20Future\%202020\%20 Roadmap.pdf

European Commission. (n.d.). Factories of the Future (FoF) - Research \& Innovation - Key Enabling Technologies - European Commission. Retrieved October 4, 2017, from http://ec.europa.eu/research/industrial_technologies/factories-of-the-future_en.html

Horn, P. (2005). The New Discipline of Service Science. BusinessWeek Online. Retrieved from https://is.muni.cz/el/1433/jaro2009/PV203/um/teorie/PaulHorn05.pdf?lang=en

Intelligent Business Machines (IBM). (2012). The Invention of Service Science (CTB14). Retrieved from http://www-03.ibm.com/ibm/history/ibm100/us/en/icons/servicescience/

Küpper, D., Kuhlmann, K., Köcher, S., Dauner, T., \& Burggräf, P. (2016). The Factory of the Future. The Boston Consulting Group \& RWTH Aachen University. Retrieved from http://imgstg.bcg.com/BCG-Factory-of-the-Future-Dec-2016_tcm9-150980.pdf

Maglio, P. P. (2014). Smart Service Systems. Service Science, Vol. 6(No. 1), i-ii.

Maglio, P. P., \& Spohrer, J. (2013). A service science perspective on business model innovation. Industrial Marketing Management, 42, 665-670.

Maglio, P. P., Vargo, S. L., Caswell, N., \& Spohrer, J. (2009). The service system is the basic abstraction of service science. Information Systems and E-Business Management, 7(4), 395406. https://doi.org/10.1007/s10257-008-0105-1

Maurer, F., \& Schumacher, J. (2018). Organizational Robustness and Resilience as Catalyst to Boost Innovation in Smart Service Factories of the Future. Presented at the International Conference on Engineering, Technology and Innovation (ICE/IEEE), Stuttgart: Paper accepet for presentation during the ICE/IEEE conference; paper not published yet - presentation on 18th June 2018. Retrieved from http://www.ice-conference.org/Call-for-Paper-(1).aspx

Project team in the IEC Market Strategy Board (MSB). (2015). Factory of the Future. International Electronic Commission (IEC). Retrieved from http://www.iec.ch/whitepaper/pdf/iecWPfuturefactory-LR-en.pdf

Spohrer, J. (2008). Services Sciences, Management, and Engineering (SSME) and Its Relation to Academic Disciplines. In Services Science (pp. 11-40). Springer, Berlin, Heidelberg. https://doi.org/10.1007/978-3-540-74489-4_2

Spohrer, J., \& Maglio, P. P. (2008). The Emergence of Service Science: Toward Systematic Service Innovations to Accelerate Co-Creation of Value. Production and Operations Management, 17(3), 238-246. https://doi.org/10.3401

Spohrer, J., \& Maglio, P. P. (2009). Service Science: Toward a Smarter Planet. In G. Salvendy \& W. Karwowski (Eds.), Introduction to Service Engineering (pp. 1-30). John Wiley \& Sons, Inc. https://doi.org/10.1002/9780470569627.ch1

Spohrer, J., Piciocchi, P., \& Bassano, C. (2012). Three Frameworks for Service Research: Exploring Multilevel Governance in Nested, Networked Systems. Service Science, 4(2), 147160. https://doi.org/10.1287/serv.1120.0012

Stoshikj, M., Kryvinska, N., \& Strauss, C. (2016). Service Systems and Service Innovation: Two Pillars of Service Science. Procedia Computer Science, 83, 212-220. https://doi.org/10.1016/j.procs.2016.04.118 
F. Maurer \& A. Fritzsche: Boosting Innovation for the Development of Smart-Service Factories of the Future: The Cases of the Federal State of Vorarlberg and its Neighbouring Regions

The Enterprisers Project - a community of CIOs discussing the future of business and IT. (2018, October 5). The Enterprisers Project: What is digital transformation? Retrieved May 11, 2018, from https://enterprisersproject.com/what-is-digital-transformation

Tien, J. M., \& Berg, D. (2003). A Case for Service Systems Engineering. Journal of Systems Science and Systems Engineering, Vol 12(No. 1), 13-38.

U.S. Department of Defense. (1969, July 17). MIL-STD-499 SYSTEM ENGINEERING MANAGEMENT. U.S. Department of Defense. Retrieved from http://everyspec.com/MILSTD/MIL-STD-0300-0499/MIL-STD-499_10376/

v. Heynitz, H., Bremicker, M., Amadori, D. M., \& Reschke, K. (2016). The Factory of the Future: Industry 4.0 - The challenges of tomorrow. KPMG AG Wirtschaftsprüfungsgesellschaft. Retrieved from https://assets.kpmg.com/content/dam/kpmg/es/pdf/2017/06/the-factory-of-thefuture.pdf

Vargo, S. L., \& Akaka, M. A. (2009). Service-Dominant Logic as a Foundation for Service Science: Clarifications. Service Science, 1(1), 32-41. https://doi.org/10.1287/serv.1.1.32

Vargo, S. L., \& Lusch, R. F. (2004). Evolving to a New Dominant Logic for Marketing. Journal of Marketing, Vol. 68(January 2004), 1-17.

Vargo, S. L., \& Lusch, R. F. (2008). Service-dominant logic: continuing the evolution. Journal of the Academy of Marketing Science, 36(1), 1-10. https://doi.org/10.1007/s11747-007-0069-6

Wieland, H., Polese, F., Vargo, S. L., \& Lusch, R. F. (2012). Toward a Service (Eco)Systems Perspective on Value Creation. International Journal of Service Science, Management, Engineering, and Technology, 3, 12-25. https://doi.org/10.4018/jssmet.2012070102

Yin, R. K. (2014). Case study research: design and methods (5th edition). Thousand Oaks, Calif.: SAGE Publications, Inc. 
$374 \quad 31^{\text {ST }}$ Bled eConference: Digital TRANSFormation: MEeting the ChallengeS June 17 - 20, 2018, Bled, SLOVEnia, ConfERENCE PROCEEDINGS 


\title{
Business Customer eXperience Alignment Framework: Improving Customer Satisfaction
}

\author{
FElix GRAs, PASCAL RAVESTEIJN, MARLIES VAN \\ STEENBERGEN \& ROLAND BIJVANK
}

\begin{abstract}
Globalization and technological innovation has led to an increasing competition between telecommunication service providers and has eroded traditional product- and service-based differentiation. One way to gain a competitive advantage is to create distinctiveness by improving customer experience in such a manner that it leads to higher customer satisfaction and loyalty. One of the drivers to improve the customer experience is the service interface. To improve this service interface, organizations must get insight into their customer interaction process. The amount of data about customers and the service provider processes is increasing and becoming more readily available for analysis. Process mining is a technique to provide insight into these processes. In this paper, a framework is presented to improve the customer satisfaction by alignment of the business service delivery process and the customer experience by applying process mining.
\end{abstract}

Keywords: • Customer satisfaction - Customer journey • Interaction process $\bullet$ Service quality $\bullet$ Process mining $\bullet$ Telecommunication industry $\bullet$

CORRESPONDENCE ADDRESS: ing. Felix Gras MSc, KPN, The Netherlands, e-mail: felix.gras@kpn.com Dr. ing. Pascal Ravesteijn, Dr. ir. Marlies van Steenbergen Drs. Roland Bijvank, HU University of Applied Sciences, Utrecht, The Netherlands, e-mail: pascal.ravesteijn@hu.nl; marlies.vansteenbergen@hu.nl; roland.bijvank@hu.nl

DOI https://doi.org/10.18690/978-961-286-170-4.25

ISBN 978-961-286-170-4

(C) 2018 University of Maribor Press

Available at: http://press.um.si. 
F. Gras, P. Ravesteijn, M. van Steenbergen \& R. Bijvank: Business Customer eXperience Alignment Framework: Improving Customer Satisfaction

In a saturated telecommunication market where the offer of services is huge, the options for the customer are overwhelming, and government regulations force providers to make services more transparent and more comparable, the risk of a commodity trap is lurking. Services are more and more alike, and customers make their decisions based on price. This can start a negative price cycle which leads to a 'commodity trap' (Lanen, 2008). According to Fornell (1992), one of the strategies in the telco industry to avoid a commodity trap is to improve the customer satisfaction as this has a strong positive effect on the customer loyalty intentions. Overall satisfaction has a positive effect on customer usage of telco services (Bolton \& Lemon, 1999) and has a positive effect on retention (Gustafsson, Johnson, \& Roos, 2005). Customer experience drives customer satisfaction (Pine \& Gilmore, 1998) and service providers must innovate on customer experience instead of only on services. Customer experience is based on the interactions between the customer and the service provider, and the gain in value for the customer and the provider is created through these interactions (Addis \& Holbrook, 2001). In regards to customer experience, there is a distinction between direct or indirect contact between customer and service provider (Meyer \& Schwager, 2007) and it is strictly personal (Gentile, Spiller, \& Noci, 2007). It is not only the touchpoints that matter when the customer interacts with the company, but it is the full journey of service delivery, service interruption or complaint handling that counts (Rawson, Duncan, \& Jones, 2013). To improve the customer satisfaction, service providers must understand and get insight into this direct, personal and end-to-end interaction process that drives the customer satisfaction. Service providers can use new technologies and processes in making a personalized customer journey with contextual interaction based on where the customer is, in her or his journey. Hereby customers will stay because they benefit from the journey itself (Edelman \& Singer, 2015). However, the interaction process between customer and service provider has increased in complexity due to the ability to interact via different channels and the influence the customer has in the service delivery process. More refined process analysis techniques are needed to improve the customer interaction process. Through process automation and digitization on the customer side, there is an enormous growth of data about both operational processes and customer actions. Process mining techniques allow service providers to extract knowledge from information systems that store processrelated data (Van Der Aalst, 2016). These techniques provide ways to discover, monitor and improve processes. The combination of event data and business process models gives new opportunities for process-centric analytics (Van Der Aalst, 2011).

\section{Research question and paper structure}

In the IT research field, scholars have identified IT/business alignment as an important principle for the success of IT deployment and implementation. Compared to this, the research in this paper is driven by the need to improve the alignment between the business processes and the customer experience through getting insight into the interaction process by applying process mining. The objective of this study is to improve the customer experience of service delivery by using the available data in information systems of an 
organization. For this a business customer experience alignment framework (BCXframework) is developed to manage process mining analyses. The contribution of this paper is both practical and academic. For service providers, it gives a guideline for the alignment process between the business processes and the customer experience by applying process mining. The academic contribution is a new framework which integrates the service quality model (SERVQUAL) with the process mining model and the customer journey (mapping). Also, concepts out of the marketing research field (SERVQUAL model and customer journey mapping), and the data science research field (process mining) are connected.

The remainder of this paper is organized as follows. In the next section the research method used, design science research, is explained. Section 3 describes the theoretical background of the research. In section 4 the framework is presented and in section 5 it is applied to the case of a service delivery process in the Telecommunications industry. The paper ends with conclusions and suggestions for further research.

\section{$3 \quad$ Research method}

As part of the research a framework is developed. Therefore, a design science research method is followed based on Peffers's research methodology for information systems research (Peffers, Tuunanen, Rothenberger, \& Chatterjee, 2007). The steps defined by Peffers et al., are implemented as follows:

1. Problem identification and motivation. The problem motivating our research is how to avoid the commodity trap that results from services becoming increasingly similar and thus only competing on price.

2. Define the objectives for a solution. The objective of the framework is to support process mining analyses (using available data) in order to improve the service delivery process in such a way that it increases customer satisfaction.

3. Design and development. Based on extant literature we operationalized the concepts that are relevant to improving service delivery and related them to each other in a framework: customer satisfaction, service quality, customer journey, and process mining analysis.

4. Demonstration. We demonstrate the use of the framework by applying it to the service delivery process of a large Dutch telecommunication service provider. The telecommunication industry and especially the Dutch telecommunication industry is a saturated and highly competitive market (Albrecht, 2017), showing characteristics of high costs of attracting new customers and the commodity trap of price.

5. Evaluation. Though a first application of the framework showed its usefulness, real evaluation of the framework still has to be done.

6. Communication. Communication is done by presenting the results and publishing a research report and this paper. 
F. Gras, P. Ravesteijn, M. van Steenbergen \& R. Bijvank: Business Customer eXperience

Alignment Framework: Improving Customer Satisfaction

The key concepts of the BCX framework are customer satisfaction, service quality, customer journey and process mining.

Customer satisfaction is frequently measured by the Net Promoter Score (NPS); the willingness to promote a company by a customer is a strong indicator of loyalty (Reichheld, 2003). However, NPS is not the only indicator companies need to monitor and manage to realize success (Grisaffe, 2007). Therefore, the Net Promoter Score has evolved into the Net Promoter System (Reichheld \& Markey, 2011). One of the basics of the system is the feedback that is given by the customer on individual events such as particular transactions or specific parts of the customer's experience. This granularity allows the company to improve specific parts of the customer journey or delivery aspects. NPS provides feedback on brand level or on transaction level e.g. delivery. These are 'the remember experience' or event measurements. NPS also provides feedback on interaction with the company (e.g. with employees). These are the in-the-moment experience or contact measurements. In the case study, the NPS event measurement service delivery is used.

Service quality is a major determinant of satisfaction and has a positive relationship with satisfaction in both the short and the long run (Oliver, 1993). A recent study confirms that this relationship also exists in the e-commerce industry (Ribbink, Van Riel, Liljander, \& Streukens, 2004). Service quality and customer satisfaction are two independent but closely related constructs from a customer's point of view. When service quality increases this leads to an increased customer satisfaction (Sureshchandar, Rajendran, \& Anantharaman, 2002). The service quality which the customer perceives is influenced by the technical aspect ("what" service is provided), the functional aspect ("how" the service is provided) and the image of the organization or brand (Grönroos, 1984). Originally the well-known SERVQUAL model distinguishes ten service quality determinants which later were captured in five generic service quality determinants: reliability, assurance, tangibles, empathy, and responsiveness (Parasuraman et al., 1991). Customers use these determinants as criteria in judging the service quality, reliability is the most critical determinant (Zeithaml, Parasuraman, \& Berry, 1990). In research about satisfiers and dissatisfiers of perceived service quality by Johnston (1995), one of the conclusions was that responsiveness is a key component in providing satisfaction and that lack of it is a major source of dissatisfaction. Reliability is predominantly a source of dissatisfaction not of satisfaction (Johnston, 1995). To measure the performance of service, the SERVQUAL model uses the gap between the customer's expectation and customer's perceived experience of the service performance (Parasuraman, Zeithaml, \& Berry, 1985). The SERVQUAL model enables to identify systematically service quality gaps between variables that influence the quality of service delivery from a customer point of view. Five quality gaps are identified: 1) incorrect perception, 2) incorrect specification, 3) incorrect delivery, 4) incorrect communication and 5) incorrect experience. The first four gaps refer to the organizational aspects of quality while gap 5 refers to the customer aspect of quality. In further research, the service quality model was elaborated in an 
extended service quality model in which gap 5 was identified as a function of the first 4 gaps with a positive relation between the size of gap 5: customer based measure and the size of gap 1-4: service provider based measure (Parasuraman, Berry, \& Zeithaml, 1991). In the framework, the service quality is presented as a function of the differences between expectations and performance along the five quality determinants.

Customer journey nowadays encompasses a myriad of touchpoints in multiple channels and media (Lemon \& Verhoef, 2016). Norton \& Pine (2013) define customer journey as "the sequence of events - whether designed or not - that customers go through to learn about, purchase and interact with company offerings - including commodities, goods, services or experiences". The aim of customer journey design is "... to deliver value to the customer, profitability to the company and differentiation from the competition" (Norton \& Pine, 2013, p.12).

There are various techniques to analyse customer journeys related to different fields and needs. Some techniques require manual labour by in-depth interviews, while other techniques require big-data and automated algorithms. Techniques for analysing customer journeys are often used to analyse and improve services from a customer point of view (Dunn \& Davis, 2003; Lee \& Karahasanović, 2013; Robertson, 2015; SchmidtSubramanian, 2014). Several methods have been developed to analyse the interaction process between the customer and the service provider. The most common methods are the Brand Touch Wheel (Dunn \& Davis, 2003), the customer journey canvas (Stickdorn \& Schneider, 2010) and the customer journey map (Schmidt-Subramanian, 2014).

Customer journey mapping originated from the widely used service blueprint technique which applies a process map to show the service delivery process from a customer perspective (Shostack, 1987). From a customer point of view, all touchpoints from beginning to the end of the service delivery are described. A touchpoint is defined as "an instance or a potential point of communication or interaction between a customer and a service provider" (Halvorsrud, Lee, Haugstveit, \& Følstad, 2014). The customer journey can depict the negative and positive touchpoints with the customer. This will give an emotion-curve through all customer interaction steps and enables improvement of the services. In this study, the service blueprint is used as a starting point and extended with the timeline of the customer journey map. The service blueprint consists of the following five components: customer actions, onstage/visible contact employee actions, backstage/invisible contact employee actions, support processes and physical evidence (Bitner, Ostrom, \& Morgan, 2008). Service blueprint can be further extended by creating customer groups based on personas (Cooper, Reimann, \& Cronin, 2007).

Process mining is a technique to extract knowledge from event logs that are derived from information systems (Van Der Aalst, et al., 2011). The advantage of mining processes from event logs is that there is no room for subjectivity because the process model is based on the process executions recorded in the event log. Process mining aims to bridge the gap between data-centric analysis techniques and model-based process analysis techniques. There are three basic process mining techniques: process discovery, conformance checking and process enhancement (Van Der Aalst, 2012). For analysis of 
the interaction process in the case study as part of this research, process discovery techniques will be used (De Weerdt, De Backer, Vanthienen, \& Baesens, 2012). There are three key methodologies to support organizations with their execution of process mining projects: 1) the Process Diagnostic Method (PDM) (Bozkaya, Gabriels, \& Van Der Werf, 2009), 2) the L* life-cycle model (Van Der Aalst, 2016) and the Process Mining Project Methodology $\left(\mathrm{PM}^{2}\right)$ (Van Eck, Lu, Leemans, \& Van Der Aalst, 2015). While PDM aims to quickly retrieve insights from event logs in the absence of domain knowledge, the L* life cycle methodology proposes a more profound step-wise approach to discover a control flow model which can be extended with insights from other process mining perspectives. A limitation of the $\mathrm{L}^{*}$ life-cycle model is that it is primarily designed for the analysis of structured processes and aims at discovering a single integrated process model. The $\mathrm{PM}^{2}$ methodology emphasizes the iterative character of process data analysis and states that both process models and analytical models can be generated from event data. Furthermore, it is suitable for the analysis of both structured and unstructured processes. Therefore, the $\mathrm{PM}^{2}$ methodology is most suitable to be used in this study as part of the framework for analysing the interaction process. $\mathrm{PM}^{2}$ is based on six stages: planning, extraction, data processing, mining and analysis, evaluation and process improvement. Stage 1 and 2 are needed for initialization of the project; stage 3, 4 and 5 are performed in one or more analysis iterations with specific research questions; if the findings are satisfactory they can be used in stage 6 for process improvement.

\section{$5 \quad$ Business Customer eXperience alignment framework}

The BCX alignment framework is developed based on the concepts of service quality, customer journey and process mining and gives guidelines for how to align business processes to touchpoints in a customer journey in order to improve the customer experience (Figure 1). The framework combines the perspectives of 1) getting the right question: examine the expectations of the customer, 2) getting the right data: extracting relevant data about the customer interaction process and 3) getting the right analysis: gaining insight into the perceived service during the interaction process. These perspectives, and with the use of process mining project methodology, guides the alignment of business processes and customer journey's in order to gain more customer satisfaction and loyalty. For the right question, the service quality determinants of the SERVQUAL model are used, to get insight in the satisfiers and dissatisfiers of the customer experience. For the right data, the five components of customer journey mapping are used, to get the right process and customer data. For the right analysis, process mining techniques are applied by performing the Process Mining Project Methodology $\left(\mathrm{PM}^{2)}\right)$. 
F. Gras, P. Ravesteijn, M. van Steenbergen \& R. Bijvank: Business Customer eXperience

Alignment Framework: Improving Customer Satisfaction

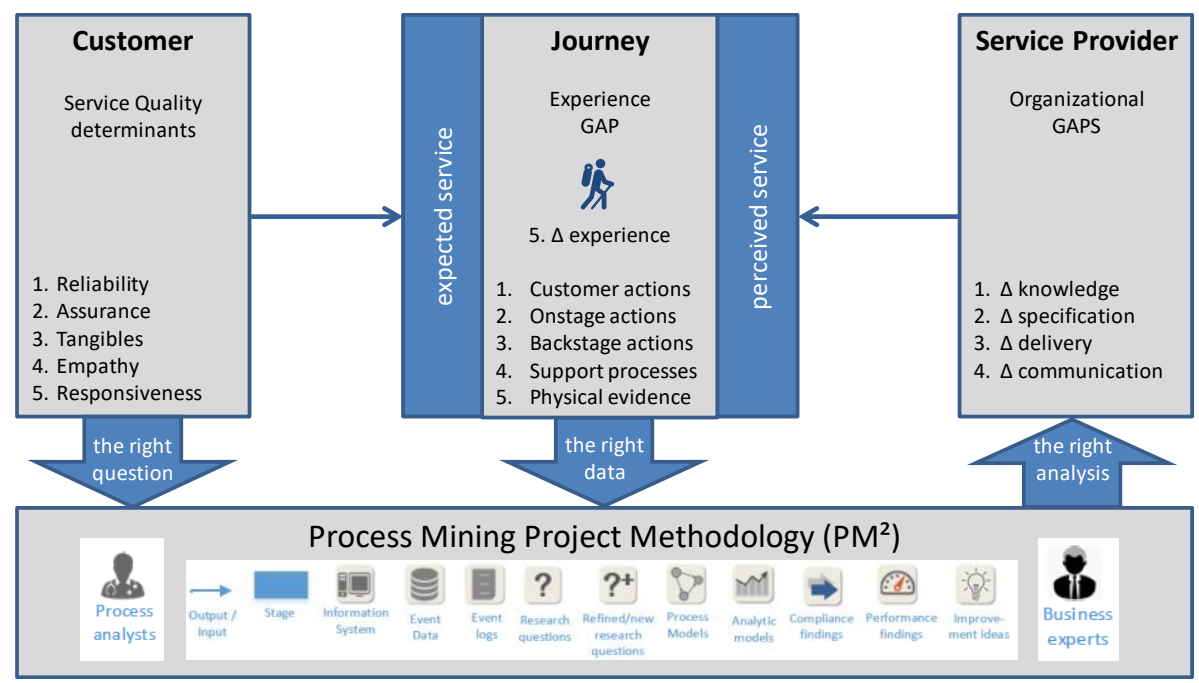

Figure 7: The Business Customer eXperience alignment framework

Figure 2 shows the integrated model of the three concepts on which the BCX-framework is developed. According to the SERVQUAL model, the integrated model is based on the gap analysis between the customer expected and perceived service (gap 5). Including with the customer world, this is the customer view of the model. The size of the gap can be analysed with the customer journey data and depends on the nature of the organizational gaps which is the organizational view of the model. 
$31^{\text {ST }}$ Bled eConference: Digital Transformation: MeEting the Challenges

June 17 - 20, 2018, BLED, SLOVENIA, CONFERENCE PROCEEDINGS

F. Gras, P. Ravesteijn, M. van Steenbergen \& R. Bijvank: Business Customer eXperience Alignment Framework: Improving Customer Satisfaction

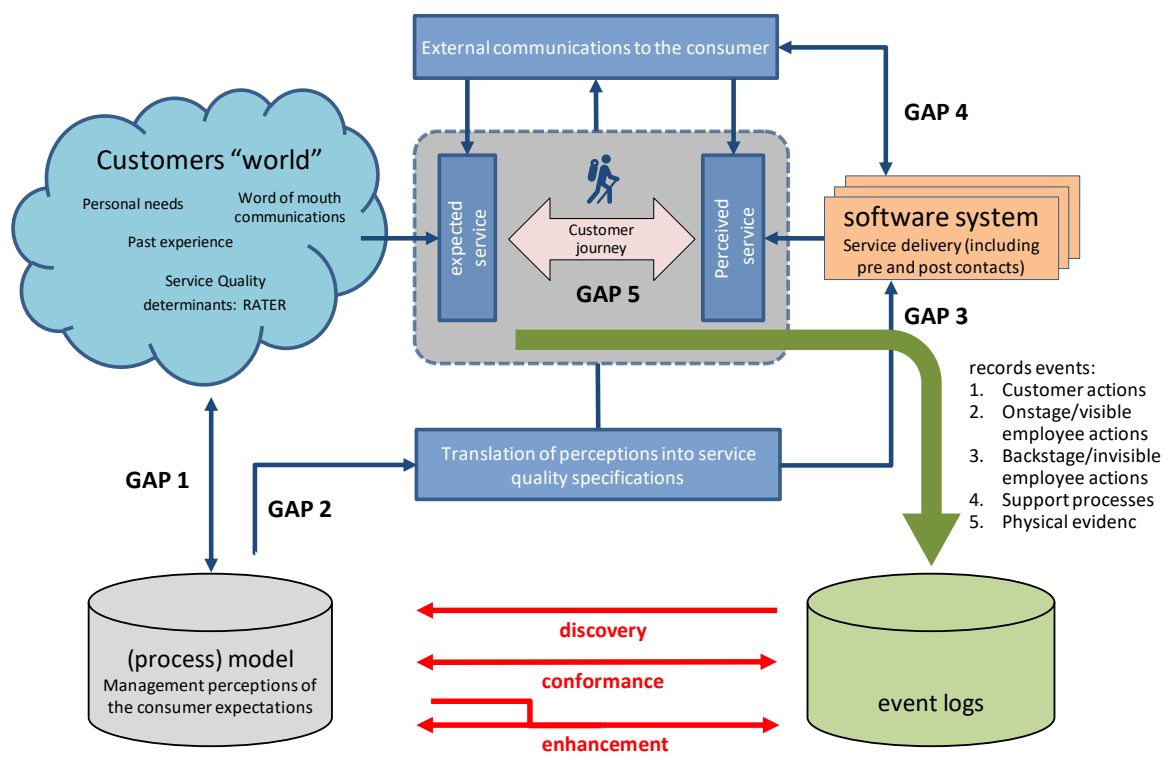

Figure 8: Integrated model

\section{Demonstration: application in a Telecommunication service provider}

To test the applicability of the BCX framework, it was applied at a large Dutch telecommunication service provider with a market share of approximately $40 \%$ for fixed services. In the case study, the delivery process of internet services (internet, voice, and TV) via a fixed network is analysed. The service provider aims to be a customer-centric provider and strives to improve the NPS by getting more insight into the customer interaction process. The BCX framework was operationalized in three ways. First, existing customer satisfaction surveys were used to get insight into the service quality determinants (the right question) as well as the expected and perceived service. To this end, customer satisfaction survey results are related to the SERVQUAL determinants. Second, the required data sources are determined, based on the five service blue print components. Third, process mining techniques were applied with the $\mathrm{PM}^{2}$ approach, and the open source ProM 6.7 toolkit.

7606 customer satisfaction surveys for the service delivery were collected in a period from 01-01-2016 till 28-03-2017. After data cleaning 5302 surveys appeared useful for further research. Not all cases could be matched with the customer interaction data, which decreased the total number of cases to 4065 . Besides the NPS question, the customer satisfaction survey contained 12 questions: 6 customer journey event questions and 6 service delivery aspect questions with a 5-point Likert scale. To examine the relation between these 12 questions and the NPS recommendation score, a correlation analysis was performed with the Pearson's R method (Bryman \& Bell, 2015). Table 1 shows the 
outcomes of the comparison between those survey questions related to the 5 determinants of the SERVQUAL model (column 1 and 3). The number in parenthesis indicates the ranking of the correlation between the 12 survey questions and the NPS score (column 2).

Table 5: Relationship between service delivery aspects and SQ determinants

\begin{tabular}{|l|l|l|}
\hline Survey questions & $\begin{array}{l}\text { Correlation (Pearson's } \\
\text { R) }\end{array}$ & SQ determinant \\
\hline Service provider follow up promises & $.622^{* *}(2)$ & Reliability \\
\hline Progress information & $.599^{* *}(3)$ & Responsiveness \\
\hline Service provider took responsibility & $.649^{* *}(1)$ & Assurance \\
\hline Call centre is easy to reach & $.501^{* *}(11)$ & Empathy \\
\hline $\begin{array}{l}\text { Information clear and } \\
\text { undoratnndabln }\end{array}$ & $.579^{* *}(4)$ & Tangibles \\
\hline
\end{tabular}

Out of the 12 survey questions, the questions with the highest correlation with the NPS score where service delivery aspects questions. This confirms that the service quality determinants are indeed important for customer satisfaction of the telecom industry. Besides the correlation analysis, a regression analysis was performed using the Enter and Stepwise regression method for priority analysis. The result is depicted in Figure 3, where the relation between the satisfaction level, based on the Likert score (x-axis), and the degree of importance with the NPS recommendation score (y-axis) of all 12 survey questions is shown.

The higher the degree of importance with NPS and the lower the satisfaction level, the higher the priority for improvement. A remark must be made about the items 'period between request and delivery' and 'pace from order to delivery'. Both have a low degree of importance and are not significant. However, they are highly correlated $\left(.800^{* *}\right)$. This means that in regression analysis these two items interfere with each other, which leads to a lower score. 
F. Gras, P. Ravesteijn, M. van Steenbergen \& R. Bijvank: Business Customer eXperience Alignment Framework: Improving Customer Satisfaction

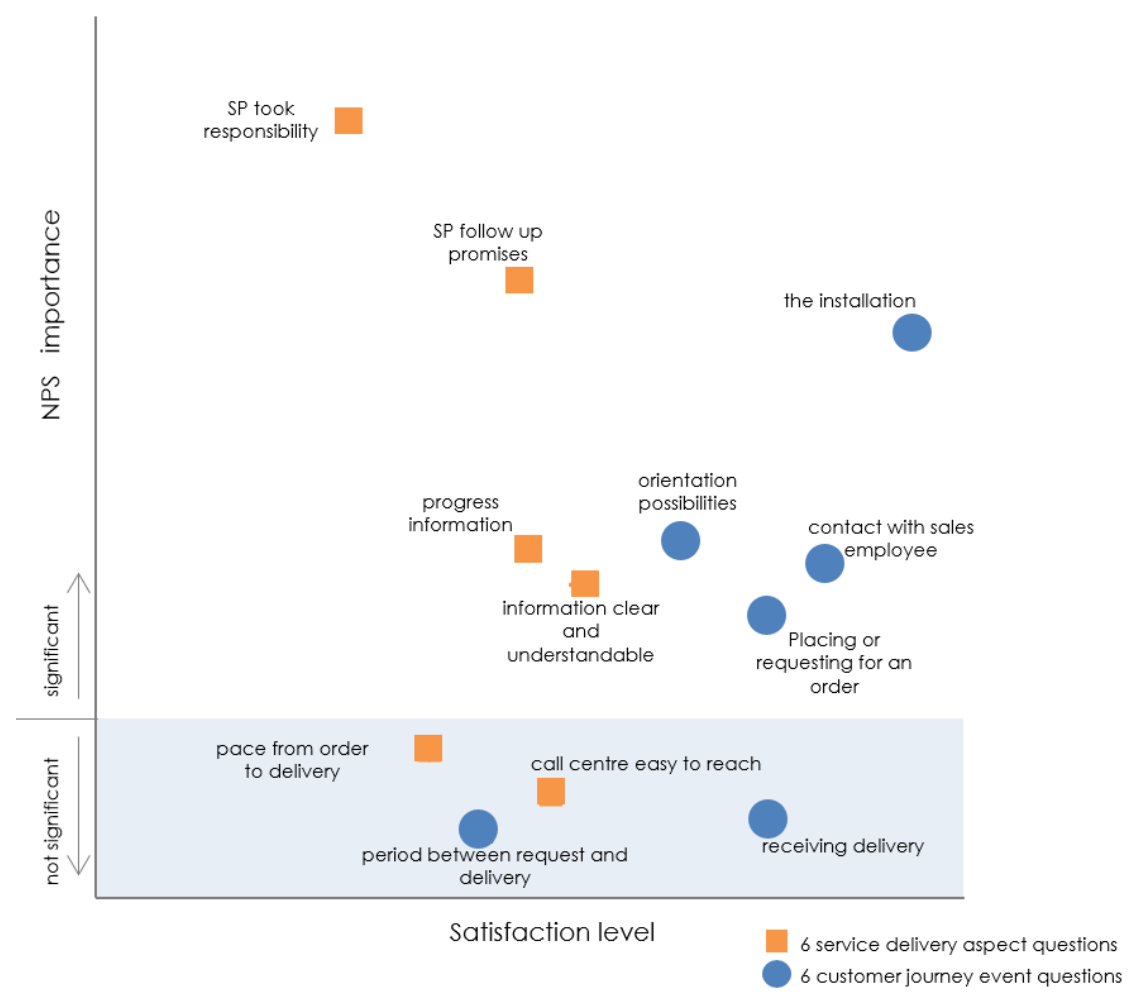

Figure 9: Priority analysis

Figure 3 shows that 'service provider took responsibility' is a candidate for improvement through a low satisfaction level and a high degree of importance with NPS. Therefore, this topic was further analysed by investigating the degree of interaction between the service provider and the customer.

For the case study, the interaction data was collected from twelve different systems. The basis was formed by the customer satisfaction survey data and enriched with data for the customer journey, i.e. order process, shop \& web-site visits, call centre, engineer, marketing communications and customer profile information. The customer journey was made more specific, by adding the attributes of customer profile, e.g. singles or families, and the customer situation, e.g. new or moving internet line. A query was developed for creating the event log for process mining. Basic process mining techniques such as filtering, process discovery and log visualizer were used. For the above mentioned topic 'service provider took responsibility', the event log contained 1373 cases with 1020 variants, and 39.676 events and divided into 584 detractors cases, with a NPS score of 16 and 789 promoter cases with a NPS score of 9-10. Several explorative analysis iterations 
have been performed, each iteration leading to more detailed questions that were investigated in additional iterations.

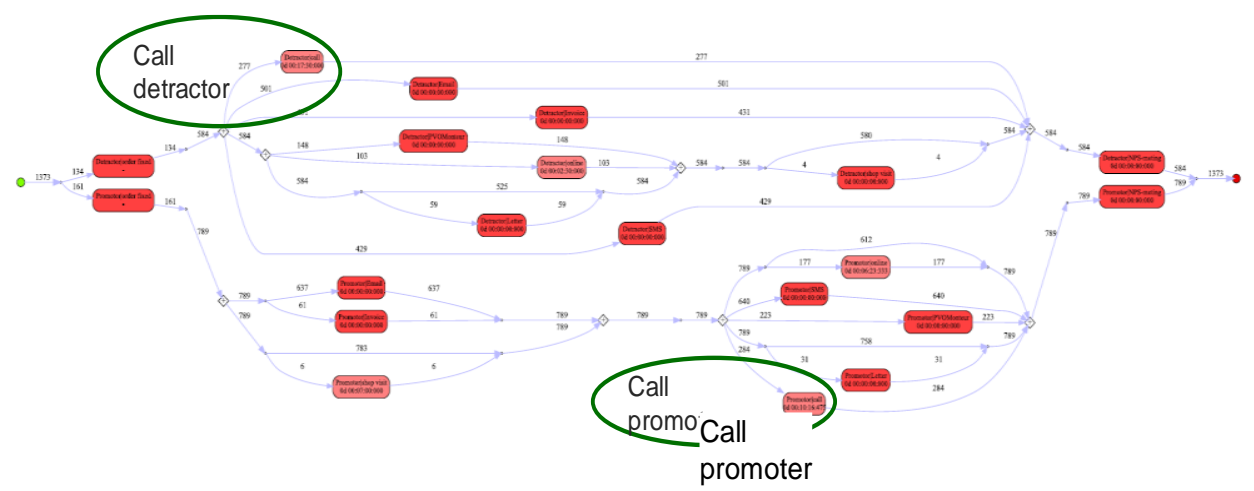

\section{$\mathrm{F}$}

Figure 10: Interaction process model

or illustration purposes, Figure 4 shows the process model created with the ProM Plug-in Inductive Visual Miner. The aim of this analysis was to investigate whether a difference exists in interaction process and the degree of interactions between detractors and promoters.

Table 6: Detail call information detractors and promoters

\begin{tabular}{|l|l|c|c|c|c|}
\hline \multirow{2}{*}{\begin{tabular}{l}
\multirow{2}{*}{ event } \\
\cline { 3 - 6 }
\end{tabular}} & sub-event & $\begin{array}{c}\text { Detractor }(584) \\
\text { number of } \\
\text { events }\end{array}$ & $\begin{array}{c}\text { Average } \\
\text { service time }\end{array}$ & $\begin{array}{c}\text { number of } \\
\text { events }\end{array}$ & $\begin{array}{c}\text { Average } \\
\text { service time }\end{array}$ \\
\hline call & Change & 78 & $00: 10: 05$ & 56 & $00: 07: 42$ \\
\hline call & Churn & 16 & $00: 12: 00$ & 18 & $00: 03: 15$ \\
\hline call & Complaint & 328 & $00: 14: 20$ & 200 & $00: 14: 41$ \\
\hline call & Orientation & 52 & $00: 05: 09$ & 52 & $00: 06: 30$ \\
\hline call & Sales & 86 & $00: 11: 11$ & 78 & $00: 10: 09$ \\
\hline call & Question & 1044 & $00: 13: 12$ & 752 & $00: 12: 13$ \\
\hline
\end{tabular}

Moreover, as can be noticed in Figure 4, the phone calls of detractors take place at the beginning of the delivery process, while the calls of promoters take place after installation. Furthermore, the analysis showed that detractors place more calls than promoters, i.e. 1604 calls and 1156 calls as shown in Table 2). In this case study, process mining gave more insight into the interaction process and the moment of when the events occur in the journey.

\section{$7 \quad$ Conclusions and further research}

The objective of this research was to improve the service delivery process in such a way that it increases the customer experience and makes optimal use of available data. To this 
F. Gras, P. Ravesteijn, M. van Steenbergen \& R. Bijvank: Business Customer eXperience

Alignment Framework: Improving Customer Satisfaction

end, a Business Customer eXperience alignment framework was developed, by combining the concepts of service quality, customer journey and process mining techniques. To test the usability of the framework it was applied in a case study to a telecommunication service provider. The case study shows that the introduction of customer journey data analysis, using process mining techniques, leads to an iterative cycle of analysis and refined question formulation. This cycle stimulates the generation of new questions leading to deeper insights.

Based on this study we conclude that the use of process mining provides many possibilities to explore and analyse processes. Process mining techniques are an add-on to existing analysis techniques and can be used to gain more insight into processes by creating various views on the customer journey with data.

To improve the framework directions of further research are provided by the three perspectives: getting the right question, getting the right data and getting the right analysis. For getting the right question, future work could focus on the exploration of the satisfiers and dissatisfiers of the customer journey related to the SERVQUAL determinants and extend the NPS measurement of the service delivery with the NPS contact measurement of the interaction moment, e.g. call or engineer visit. For getting the right data, future work could focus on extending the customer journey of delivery with data of the orientation phase prior the delivery and add journeys that are running at the same time, e.g. a delivery journey and a malfunction of another service of the customer. For getting the right analysis, future work could focus on developing process mining techniques that support analysis of processes with high variance and multiple journeys in parallel.

\section{References}

Addis, M., \& Holbrook, M. B. (2001). On the conceptual link between mass customization and experiential consumption: An explosion of subjectivity. Journal of Consumer Behaviour, 1(1), $50-66$.

Albrecht, K. (2017). Dutch broadband 2016-Q4. (PDF). Houten, The Netherlands: Telecompaper.

Bryman, A., \& Bell, E. (2015). Business research methods. (p. 351-353) Oxford University Press, USA.

Bitner, M. J., Ostrom, A. L., \& Morgan, F. N. (2008). Service blueprinting: A practical technique for service innovation. California Management Review, 50(3), 66-94.

Bolton, R. N., \& Lemon, K. N. (1999). A dynamic model of customers' usage of services: Usage as an antecedent and consequence of satisfaction. Journal of Marketing Research, 171-186.

Bozkaya, M., Gabriels, J., \& Van Der Werf, J. M. (2009, February). Process diagnostics: a method based on process mining. In Information, Process, and Knowledge Management, 2009. eKNOW'09. International Conference on (pp. 22-27). IEEE.

Bryman, A., \& Bell, E. (2015). Business research methods Oxford University Press, USA.

Cooper, A., Reimann, R., Cronin, D., \& Noessel, C. (2014). About face: the essentials of interaction design. John Wiley \& Sons.

De Weerdt, J., De Backer, M., Vanthienen, J., \& Baesens, B. (2012). A multi-dimensional quality assessment of state-of-the-art process discovery algorithms using real-life event logs. Information Systems, 37(7), 654-676. 
Dunn, M., \& Davis, S. M. (2003). Building brands from the inside. Marketing Management, 12(3), 32-37.

Edelman, D. C., \& Singer, M. (2015). Competing on customer journeys. Harvard Business Review, 88-100.

Fornell, C. (1992). A national customer satisfaction barometer: The Swedish experience. The Journal of Marketing, 6-21.

Gentile, C., Spiller, N., \& Noci, G. (2007). How to sustain the customer experience: An overview of experience components that co-create value with the customer. European Management Journal, 25(5), 395-410.

Grisaffe, D. B. (2007). Questions about the ultimate question: Conceptual considerations in evaluating Reichheld's net promoter score (NPS). Journal of Consumer Satisfaction, Dissatisfaction, and Complaining Behavior, 20, 36.

Grönroos, C. (1984). A service quality model and its marketing implications. European Journal of Marketing, 18(4), 36-44.

Gustafsson, A., Johnson, M. D., \& Roos, I. (2005). The effects of customer satisfaction, relationship commitment dimensions, and triggers on customer retention. Journal of Marketing, 69(4), 210218.

Halvorsrud, R., Lee, E., Haugstveit, I. M., \& Følstad, A. (2014, June). Components of a visual language for service design. In ServDes. 2014 Service Future; Proceedings of the fourth Service Design and Service Innovation Conference; Lancaster University; United Kingdom; 9-11 April 2014 (No. 099, pp. 291-300). Linköping University Electronic Press.

Johnston, R. (1995). The determinants of service quality: Satisfiers and dissatisfiers. International Journal of Service Industry Management, 6(5), 53-71.

Lanen, R. v. (2008). In Verburgh L., Tamminga T.(Eds.), Distinguish yourself! increase your margin with added value. Utrecht: Berenschot Groep B.V.

Lee, E., \& Karahasanović, A. (2013). Can business management benefit from service journey modeling language. Paper presented at the Proceedings of ICSEA 2013 Eighth International Conference on Software Engineering Advances, 579-582.

Lemon, K. N., \& Verhoef, P. C. (2016). Understanding customer experience throughout the customer journey. Journal of Marketing, 80(6), 69-96.

Meyer, C., \& Schwager, A. (2007). Customer experience. Harvard Business Review. 1-11.

Norton, D. W., \& Pine, B. J. (2013). Using the customer journey to road test and refine the business model. Strategy \& Leadership, 41(2), 12-17.

Oliver, R. L. (1993). A conceptual model of service quality and service satisfaction: Compatible goals, different concepts. Advances in Services Marketing and Management, 2(4), 65-85.

Parasuraman, A., Berry, L. L., \& Zeithaml, V. A. (1991). Perceived service quality as a customerbased performance measure: An empirical examination of organizational barriers using an extended service quality model. Human Resource Management, 30(3), 335-364.

Parasuraman, A., Zeithaml, V. A., \& Berry, L. L. (1985). A conceptual model of service quality and its implications for future research. The Journal of Marketing. 41-50.

Peffers, K., Tuunanen, T., Rothenberger, M. A., \& Chatterjee, S. (2007). A design science research methodology for information systems research. Journal of Management Information Systems, 24(3), 45-77.

Pine, B. J., \& Gilmore, J. H. (1998). Welcome to the experience economy. Harvard Business Review, 76, 97-105.

Rawson, A., Duncan, E., \& Jones, C. (2013). The truth about customer experience. Harvard Business Review, 91(9), 90-98.

Reichheld, F. F. (2003). The one number you need to grow. Harvard Business Review, 81(12), 4655. 
F. Gras, P. Ravesteijn, M. van Steenbergen \& R. Bijvank: Business Customer eXperience Alignment Framework: Improving Customer Satisfaction

Reichheld, F. F., \& Markey, R. (2011). The ultimate question 2.0: How net promoter companies thrive in a customer-driven world Harvard Business Press.

Ribbink, D., Van Riel, A. C., Liljander, V., \& Streukens, S. (2004). Comfort your online customer: Quality, trust and loyalty on the internet. Managing Service Quality: An International Journal, 14(6), 446-456.

Robertson, B. (2015). Connecting process to customer: Take the customer journey. (No. G00290973). Stamford, USA: Gartner.

Schmidt-Subramanian, M. (2014). How journey maps improve CX measurement efforts. (No. 119113). Forrester Research, Inc.

Shostack, G. L. (1987). Service positioning through structural change. The Journal of Marketing, 34-43.

Stickdorn, M., Schneider, J., Andrews, K., \& Lawrence, A. (2011). This is service design thinking: Basics, tools, cases (Vol. 1). Hoboken, NJ: Wiley.

Sureshchandar, G., Rajendran, C., \& Anantharaman, R. (2002). The relationship between service quality and customer satisfaction-a factor specific approach. Journal of Services Marketing, 16(4), 363-379.

Van Der Aalst, W., Adriansyah, A., De Medeiros, A. K. A., Arcieri, F., Baier, T., Blickle, T., ... \& Burattin, A. (2011, August). Process mining manifesto. In International Conference on Business Process Management (pp. 169-194). Springer, Berlin, Heidelberg.

Van Der Aalst, W. (2012). Process mining: Overview and opportunities. ACM Transactions on Management Information Systems (TMIS), 3(2), 7.

Van Der Aalst, W. M. (2016). Process mining: data science in action. Springer.

Van Eck, M. L., Lu, X., Leemans, S. J., \& Van Der Aalst, W. M. (2015, June). PM²: A Process Mining Project Methodology. In International Conference on Advanced Information Systems Engineering (pp. 297-313). Springer, Cham.

Zeithaml, V. A., Parasuraman, A., \& Berry, L. L. (1990). Delivering quality service: Balancing customer perceptions and expectations Simon and Schuster. 


\title{
Adaptation of enterprise architecture efforts to an agile environment
}

\author{
RoBin DUIJS, PASCAL RAVESTEIJN \& MARLIES VAN \\ STEENBERGEN
}

\begin{abstract}
Agile ways of working have become mainstream, with many organisations practising a form of agile. Agile maturity among those organisations differs. In a research conducted by VersionOne Inc. (2016), $82 \%$ of the participating organisations stated to be at or below the level of 'still maturing'. Existing agile and architecture methods have begun to incorporate some aspects of each other, with agile methods including architecting, such as the Scaled Agile Framework (SAFe), and architecture frameworks such as TOGAF (the Open Group Architecture Framework), adding agile elements (Poort, 2014). This study addresses the question how to shape the architecture function to effectively achieve compliance with architecture regulations, of solutions realised in an agile environment. To answer this question a multiple-case study was done, studying three different organisations. The findings are translated into seven propositions.
\end{abstract}

Keywords: • Agile $\bullet$ Enterprise Architecture $\bullet$ Agile maturity $\bullet$ SCRUM $\bullet$

CorResPOndence AdDress: Robin Duijs, MSc., HU University of Applied Sciences, Padualaan 99, Utrecht, The Netherlands, e-mail: rduijs@ sligro.nl Pascal Ravesteijn, Ph.D., Professor Process Innovation and Information Systems, HU University of Applied Sciences, Padualaan 99, Utrecht, The Netherlands, e-mail: pascal.ravesteijn@hu.nl. Marlies van Steenbergen, Ph.D., Professor Digital Smart Services, HU University of Applied Sciences, Padualaan 99, Utrecht, The Netherlands, e-mail: marlies.vansteenbergen@hu.nl 
R. Duijs, P. Ravesteijn \& M. van Steenbergen: Adaptation of enterprise architecture efforts to an agile environment

Agile methods are based on the agile manifesto (Beck et. al., 2001). One of the twelve agile principles states that good architectures, requirements, and designs tend to be constructed by self-organizing teams. According to the report 'the state of agile 2015' by VersionOne, Inc. (2015), nearly $70 \%$ of respondents use agile methods such as Scrum or Scrum/XP hybrid. According to Wilson and Altman (2013) the role of the architect does not exist in Scrum because of bad experiences with 'ivory tower' architects and resistance to 'big design up front'.

Petersen and Wohlin (2009) also mention that agile approaches are lacking in architectural design. More recently Yang et al. (2016) confirmed that the role of architecture in agile development is often overlooked. This leads to agile teams struggling due to the lack of good architecture and architects distrusting agile projects (Wilson \& Altman, 2013).

According to The Open Group Architecture Framework (TOGAF, 2009) ensuring the compliance of individual projects with the enterprise architecture is an essential aspect of architecture governance. TOGAF offers compliance review process descriptions, checklists and guidelines. There have also been several studies on architecture compliance checking approaches. Knodel \& Popescu (2006) define architecture compliance as a measure that compares the implemented architecture in the source code to the planned architecture and determines to which degree these differ. However, architecture frameworks such as TOGAF are not tuned to agile teams. TOGAF (2009) describes the use of its framework in an iterative process, but ever since the latest release of TOGAF 9 on the 4th of February 2009 a lot has changed in the world of IT and agile.

Agile methods implement a different way of working. An important difference between traditional and agile development, when it comes to architecture, is transparency. Transparency on everything done and decided as well as the reasoning behind everything. This is related to the greater autonomy of agile teams in comparison to traditional development teams. Whereas traditional teams might accept the task they are given, agile teams would like to be involved and as such demand to know why certain decisions are made.

Scrum, one of the leading agile methods, states "Scrum is founded on empirical process control theory, or empiricism. [...] Three pillars uphold every implementation of empirical process control: transparency, inspection, and adaptation." (Schwaber \& Sutherland 2017, p.4). One of the Scrum values is on 'Openness', stating "the Scrum Team and its stakeholders agree to be open about all the work and the challenges with performing the work" (Schwaber \& Sutherland 2017, p.5). Because of this, transparency is a key property architecture should possess.

Apart from transparency a major difference is the influence a Product Owner has on the product. Architects tend to feel less powerful in an agile environment because PO's 
overrule architecture for the sake of business value. This leads to architects stressing the importance of architecture and focussing on cost and risk aspects.

According to Poort (2014), the debate seems to be starting to settle down: today some agile methods include architecting, such as the Scaled Agile Framework (SAFe), and some architecting frameworks, such as TOGAF, are adding agile elements. Still, organisations are struggling how to adapt their architecture function to an organisation that is becoming more agile. There still is little support when it comes to architecture guidelines for agile development that match the organisation's maturity. Based on this the following research question is formulated:

In what way can enterprise architecture efforts be shaped (i.e. form and function) to effectively achieve compliance with architecture regulations of solutions realised in an agile environment?

To answer this question a multiple-case study is conducted in three organisations that are currently applying agile development.

The remainder of this paper is organized as follows. In section 2 the research method is described, followed by the findings in section 3. A discussion on the findings is provided in section 4. Finally, in section 5, conclusions are drawn and implications, limitations and suggestions for further research are described.

\section{$2 \quad$ Research method}

The goal of this study is to generate new theory on how to effectively apply architecture in an agile environment. According to Zikmund et. al. (2009), a theory consists of a coherent set of general propositions that offer an explanation of some phenomenon, by describing the way other things correspond to this phenomenon. A proposition explains the logical linkage among certain concepts by asserting a universal connection between concepts (Zikmund et. al., 2009).

In this study, an explorative multiple-case study paired with semi-structured interviews is used. Case study research is used, because the topic of this study requires inquiry into the way how certain processes are structured and why this is so. Multiple cases are necessary because of the interest in similar and contrasting results. Yin (2014) calls this a "replication logic". Eisenhardts (1989) process of theory building from case study research is used to structure the research process. According to Eisenhardt the theory building process should be free from prejudice as much as possible. To achieve this the researcher needs to retain theoretical flexibility. This flexibility limits the possibility of bias which could influence the findings. At the outset of the process, the study begins as close as possible to no theory under consideration and no hypothesis to test. However, as specifying constructs helps shape the design of the study, a preliminary conceptual model is created, based on the commonly distinguished aspects of any function, process, product and people. 
R. Duijs, P. Ravesteijn \& M. van Steenbergen: Adaptation of enterprise architecture efforts to an agile environment

Three cases were selected from different industries and investigated using semi-structured interviews and subsequently template-coding the transcriptions of the interviews. Withincase analysis was followed by cross-case analysis, leading to the formulation of propositions. The propositions were further validated by comparing them with extant literature. Because this theory building process is intimately tied to evidence, it is very likely that the resultant theory will be consistent with empirical observation (Eisenhardt, 1989). Overall, tying the emergent theory to existing literature enhances the internal validity, generalisability and theoretical level of theory building from case study research (Eisenhardt, 1989). The external validity is supported by choosing organisations from different industries. As can be seen in table 1, the first case is a university, the second a power company, and the third an IT service provider.

Table 1: Case study characteristics

\begin{tabular}{|l|l|l|}
\hline Label & Company & Architecture - Agile project type \\
\hline C1 & University & $\begin{array}{l}\text { Has some agile projects but also uses traditional } \\
\text { development methods; an architect advises the project } \\
\text { team on architectural concerns in both types of } \\
\text { projects. }\end{array}$ \\
\hline C2 & Power company & $\begin{array}{l}\text { All projects are agile, using some of the practices as } \\
\text { described by SAFe. External architect manages } \\
\text { multiple teams and coordinates architecture concerns } \\
\text { within a certain predefined domain. The domain } \\
\text { architect also keeps contact with tech leads from } \\
\text { various teams and the enterprise architects of the } \\
\text { company. }\end{array}$ \\
\hline C3 & IT Service Provider & $\begin{array}{l}\text { Provides services to government. Agile projects have a } \\
\text { project architect which is responsible for the project } \\
\text { architecture. The project architect is, however, no part } \\
\text { of the architecture function of the organisation. The } \\
\text { architects in the architecture function must review and } \\
\text { reach an accord on the architecture vision of the } \\
\text { project. }\end{array}$ \\
\hline
\end{tabular}

When examining the cases, multiple variations are seen. All cases have overarching EA teams influencing agile teams in an indirect manner. All cases show architecture involvement in agile teams. C2's agile development team actually contained a full-time delegate architect (under direct supervision of a domain architect). The other cases show either part-time architecture involvement or direct architecture influence through a project architect. Despite the variations the traditional architecture work is still done by people in (delegated) architecture roles. 
Each case is analysed individually (within-case analysis) and subsequently compared to the other cases (cross-case analysis). Next, based on all three cases, propositions are created. For guidance during the case study interviews, an interview guide is constructed. This guide is based on the preliminary conceptual model depicted in Figure 1.

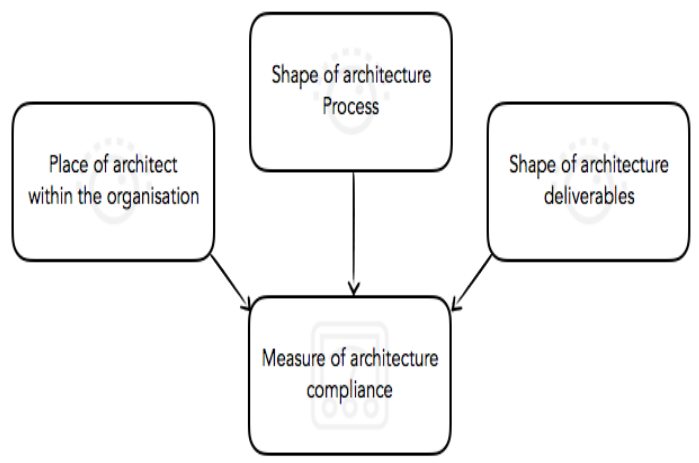

Figure 11: Preliminary Research Constructs

The goal of the interviews is to gain insight into the preliminary constructs and how they influence one another. In each organisation an agile team member as well as an architect is interviewed. Thus, both perspectives are included. All interviews are recorded, and data collected from the interviews (which are transcribed) are coded with a priori codes for within-case data analysis. The a priori codes are based on existing knowledge and theory regarding architecture frameworks and principals. During coding or analysis, additional codes emerged and were added to the existing codes. The codes used are involvement of architect, architecture design, architecture principles, architecture deviations, architecture decisions, architecture role, and standards. The last two codes emerged from the interviews. The codes were used to sort the statements from all interviewees and compare them both within the cases and across the cases.

Based on the findings from the within-case analysis and cross-case analysis certain constructs appeared. These refined the initial research model constructs as shown in figure 1. In the process of generating propositions based on these constructs, additional literature was used to establish the propositions as feasible findings or disprove them.

\section{$3 \quad$ Results}

The case study reveals that the preliminary research constructs need refinement (see Figure 2).

\section{Acceptance of architecture}

First, it appears that compliance with architecture regulations is not the main objective in an agile environment, but that acceptance of architecture by agile teams is more 
R. Duijs, P. Ravesteijn \& M. van Steenbergen: Adaptation of enterprise architecture efforts to an agile environment

important. In an agile environment the focus is on creating the architecture in collaboration with the agile team under supervision/direction of the architect while making decisions, taking into account the current situation and the existing constraints at this moment in time. Therefore, the dependent variable in the preliminary conceptual model is refined to 'acceptance of architecture', which is defined as the measure to which architecture is a part of the way of working, i.e. agile teams are receptive to architecture.

The independent variables, too, are refined by the case study, as described below.

\section{Transparency and documentation of reasoning}

A main topic which came forth from the cases is transparency on reasoning. The cases show that architecture principles should be applied in a transparent manner. The reasoning behind architecture decisions must be described clearly and transparently and communicated to all stakeholders. This is supported by literature. In their 'Understanding/Acceptance Principle', Slovic and Tversky (1974) describe that understanding results in acceptance. The more someone understands and comprehends something the more that person will accept it. By documenting reasoning of architecture decisions, the understanding can be increased, leading to greater acceptance. And being transparent on the procedure of how a decision was made also leads to greater acceptance (Skitka \& Mullen, 2002). This leads to the independent variable 'transparency and documentation of reasoning', which is defined as a clear understanding for all stakeholders on how decisions were made and making the reasoning behind decisions available for reference.

\section{Direct and active involvement of architects}

All cases show a need from the team perspective that an architect should be involved from the start and during the entire project. Architects should work together with the team, share knowledge and create architecture documents. The architecture perspective shows this same finding in only $\mathrm{C}$. The other cases vouch for fit for purpose or impact-based involvement, where the last of those two is paired with architecture by proxy. However, this is indicated to be ineffective because of disagreements or differences of opinion between the proxy and the architect. The idea that an architect only makes the design up front and then goes on to the next challenge is not valid in an agile environment. The teams themselves demand more from an architect. Grant (1996) describes 4 mechanisms for integrating knowledge (Rules and directives, Sequencing, Routines \& Group problem solving and decision making). Traditionally, in enterprise architecture, a rules and directives mechanism is applied. This provides "low cost communication between specialists and a large number of persons" (Grant, 1996). The use of agile knowledge sharing, means moving away from rules and directives to group problem solving and decision making. Group problem solving is to be used when dealing with high "task complexity and task uncertainty". This demands "high-interaction, non-standardized coordination mechanisms" (Grant, 1996). So, the architect working together with, and maintaining a collaborative relationship with the agile team(s) and product owners is important when working with agile teams. This leads to the independent variable 'direct and active involvement of architects', which is defined as the architect working together 
with and maintaining a collaborative relationship with the agile team(s) and product owners.

\section{Fit for purpose architecture}

All cases point out two things about architecture design. First, it should match the target audience, tailoring the information in the design to the stakeholders and containing the essential information relevant to them. Second, the design should be shared in a way that stakeholders are used to. Because of different ways of working within organisations, the architecture function cannot have a one size fits all approach. Organisations in transition to a more agile way of working will have waterfall development happening alongside agile development. Architecture tailored for its intended use, i.e. fit for purpose, making it suited to a certain audience will increase its acceptance. Fit for purpose is hard to define, since it suggests the possibility of multiple shapes and sizes. Van Steenbergen (2011) states that approaching Enterprise Architecture (EA) from a client perspective, i.e. expressing EA models in a format that is aligned with the way of thinking of the stakeholders, is a good technique to stimulate acceptance of the architecture. Hence, the independent variable 'fit for purpose architecture', which is defined as architecture processes and products tailored to the specific needs of the initiative on hand.

\section{Focus on technical debt and quality}

The agile team members of C2 and C3 agree that the architect should have a holistic view of the organisation. The architect must however also be able to go into the technical details if needed, also focussing more on quality aspects. This view is shared by the architects of $\mathrm{C} 1$ and $\mathrm{C} 2$. The cases show that in an agile environment, the focus of the architecture function is moving to quality aspects of products and to diminishing technical debt levels. According to Ernst et. al. (2015) the dominant source of technical debt is bad architectural decisions. Bad architecture choices stood out from others at 296 of the top three responses $(54 \%)$ in this study. In terms of the mean rank, the top three were 'Bad architecture choices', 'Overly complex code', and 'Lack of code documentation' (Ernst et. al., 2015). If architecture is the main cause of technical debt, it deserves the architect's attention. However, whether the technical debt caused by architects has anything to do with agile teams taking the role of architects remains to be studied. The independent variable 'focus on technical debt and quality' is defined as keeping track of, and actively managing technical debt levels and the ISO quality aspects to a level accepted by the organisation.

\section{Being flexible when applying rules and principles}

In agile environments, the enforcing of principles and rules does not work as it might have done before. The role of architect shifts towards a solution-oriented, supporting expert who is willing to work towards a feasible solution at this moment in time and accepting imperfections for the sake of business value. The architect is challenged to find the right balance between granting teams enough freedom and protecting the IT landscape from unnecessary complexity. Some agile team members claimed that because of a too benevolent approach, the IT landscape suffered. The independent variable 'being flexible when applying rules and principles' is defined as being flexible when it comes to applying 
architecture principles and willingness to work towards a feasible solution at this moment in time and accepting imperfections for the sake of business value.

\section{Using patterns and standards}

Case $\mathrm{C} 1$ points out that standards are an effective way for agile teams to work with architecture and it relieves architecture workload. C3 supports this by stating that because standards and patterns add predefined solutions they aid in the creation of architectures, thereby lowering the workload. Also, at C3, teams create standards and patterns in collaboration with architects. This, in turn, helps them to work effectively. There is a clear trend noticeable across the cases in this research with regard to the use of standards and patterns in relation to agile development. Cases $\mathrm{C} 1$ and $\mathrm{C} 3$ show that standards and patterns help them work effectively with agile teams: "If we see a gap in a certain solution, we consult the solution architect and together we search for a solution which eventually becomes a new pattern." Having standards and patterns helps achieve synergy across teams and initiatives. Existing literature shows that patterns represent implicit knowledge, which if documented, can be reused by others with the intent of managing the cognitive load while architecting complex systems (Cloutier \& Verma, 2006). While developing open source software, improved communications between team members of the architecture and design teams was a measured and quantified result of using patterns (Hashler \& Koch, 2004). Hence, the independent variable 'using patterns and standards', which is defined as the application of predefined best-practice solutions and industry standards or self-defined best-practice solutions and organisation standards.

\section{Architecture awareness of the product owner}

The final finding from the cases is that when working agile, the product owner (PO) decides the priority of the backlog and with it the work being done on the product. Because the product owner is mostly interested in adding new or improved functionality, architecture and overall quality is put on the back burner. This proves to be unwise since degradation of software ultimately leads to the product being unusable or inhibited to change. When awareness is lacking, the persuasion of the architect is more of a necessity. The 'Understanding/Acceptance Principle' (Slovic \& Tversky, 1974) can also be applied to the awareness of the PO. If the PO understands what architecture is, what the risks and opportunities are and why it has added value for the PO, then the perceptibility of the PO towards architecture should increase. This leads to the final independent variable, 'architecture awareness of the product owner', defined as the measure of insight a product owner has into the implications of (not) working with enterprise architecture.

With the insights from the case studies the preliminary conceptual model depicted in figure 1 is revised. The final model has gained additional, more detailed constructs and relations (figure 2 ). 


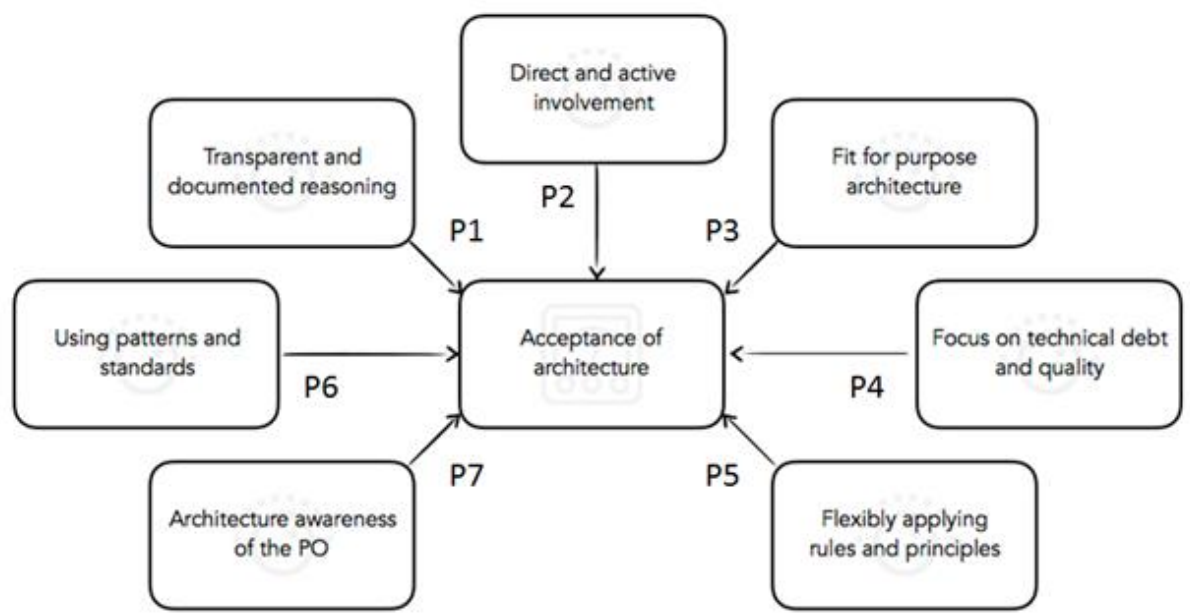

Figure 2: Revised research model

The relations between the variables in the model are expressed with the following seven propositions:

1. Transparency and documentation of reasoning has a positive impact on acceptance of architecture

2. Direct and active involvement of architects has a positive impact on acceptance of architecture

3. Fit for purpose architecture has a positive impact on acceptance of architecture

4. Focus on technical debt and quality has a positive impact on acceptance of architecture

5. Being flexible when applying rules and principles has a positive impact on acceptance of architecture

6. Using patterns and standards has a positive impact on acceptance of architecture

7. Architecture awareness of the PO has a positive impact on acceptance of architecture

Two of the propositions are more like prerequisites whereas the rest of them are activities to perform in a certain way. One of the prerequisites is being flexible when applying rules and principles and avoid forcing them on teams by having a regulatory mentality. The second prerequisite is the increased awareness of the PO. PO's overruling architecture is an enduring challenge and requires the architects' attention. All interaction with the PO should be aimed at increasing awareness and making them understand their responsibility.

From the case study a number of differences between agile and traditional waterfall development emerge. A main insight from the case study, is that compliance should not be the goal when dealing with an agile environment. The goal should be to reach a 
R. Duijs, P. Ravesteijn \& M. van Steenbergen: Adaptation of enterprise architecture efforts to an agile environment

measure of acceptance by agile teams where architecture is perceived as an essential ingredient for creating a solution.

Architecture deliverables in an agile environment differ from traditional deliverables in the sense that they are, more than before, aimed at the intended use. Use of standards and patterns by agile teams is also a reason why architecture deliverables have shrunk in size. Everything already described in standards and patterns is left out in architecture deliverables and most new issues and topics are translated into new standards or patterns. This almost makes the architecture a set of standards to apply and patterns to use in the scope of a project or change initiative.

Architecture regulations are not enforced like they are in a traditional environment. Deviations tend to happen in a more collaborative fashion. This means the architect is involved in the process and can influence the deviation and the gravity of the deviation. Because of this collaborative deviation process, deviations can be managed more easily. Deviation is made explicit and can immediately be addressed as technical debt. Because the PO understands the effect of the technical debt (or the architect stresses the importance) choices are made to either fix the technical debt or continue to live with it. Either way the responsibility lies with the PO.

\section{Conclusion}

The main contribution of this study is the final conceptual model and seven propositions relating architecture efforts to acceptance of architecture by agile teams. The propositions are a first step towards a theory of effective architecture function in an agile development environment. The exploratory nature of this study implies that the propositions and model need to be validated through scientific testing.

Findings from this study add to the understanding of the reasons why architecture and agile development struggle to cooperate. By speaking to team members and architects and analysing the cases a truthful image has been documented and propositions have been generated. These valuable insights provide a foundation to expand upon.

Apart from the scientific contribution this study also has a practical contribution. The findings of the study can be used by practitioners to further develop their architecture and agile development function. The propositions can be translated into the following activities and instructions for architects:

- Architecture functions can start documenting all decisions for everyone to see

- Architects can start attending agile team meetings and working with them on a daily basis

- Architecture deliverables can be adapted to the interests of stakeholders

- The law enforcing attitude can be exchanged for a more collaborative one, discussing the needs for deviation instead of enforcing principles 
- Architects can start documenting standards and guidelines in collaboration with the various agile teams to create a catalogue of standards that all teams need to use

By taking the steps described above, the gap between agile teams and architecture functions may close, even if it is just a little and at a slow and steady pace.

This study has some limitations. First, the case selection process was not as thorough and strict as research methods prescribe. Due to discouraging and disappointing reactions by prospective cases, some convenience sampling was applied. Also, Eisenhardt (1989) states that there is no ideal number of cases, but a number between 4 and 10 usually works well to generate complex theory. In that regard, this study lacks one case. However, all three cases are vastly different. This diversity means the current findings are not biased to one industry sector. The generated propositions are likely to be applicable to other similar organisations. Analysis, elaboration and triangulation with existing literature confirmed their relevance. Further testing of the propositions must be done to formalise them.

By using interviews as one of the research techniques there is a risk of subjects being biased. Subjects express lots of opinions and perceptions which could be misleading or false. During this study, no measures were taken to verify whether allegations were truthful. This could lead to results being less reliable (Bryman \& Bell, 2011).

The number of people interviewed was limited due to scoping of activities and time limitations.

The two people from each case were however selected to represent their colleagues' perspectives as well. So, the architecture perspective should represent the entire architecture function of that case. The same holds true for the agile team perspective.

The study leaves some interesting venues for further research. First and foremost, the propositions generated by this study need to be tested. Formalising and validating the propositions can be done by focussing on single propositions and testing them using additional cases. Another option is to do a quantitative study using a survey.

As another option for further research, additional cases of different levels of maturity can be studied. This might lead to a maturity model and recommendations for organisations at a certain maturity level. To achieve this, case selection should include criteria which clearly distinguish the difference in maturity.

The culture of an organisation is something which could have an impact on how agile an architecture teams operate. Culture is not an aspect which is analysed in this study. It is however very interesting to investigate what impact an organisations culture has on the propositions generated in this study and how cultural aspects influence collaboration between architecture functions and agile teams. 
R. Duijs, P. Ravesteijn \& M. van Steenbergen: Adaptation of enterprise architecture efforts to an agile environment

\section{References}

Beck, K. \& Beedle, M. \& van Bennekum, A. \& Cockburn, A. \& Cunningham, W. \& Fowler, M. \& Grenning, J. \& Highsmith, J. \& Hunt, A. \& Jeffries, R. \& Kern, J. \& Marick, B. \& C. Martin, R. \& Mellor, S. \& Schwaber, K. \& Sutherland, J. \& Thomas, D. (2001). Agile Manifesto. Retrieved on Wednesday 14th march 2018 from http://agilemanifesto.org/

Eisenhardt, K.M. (1989). Building theories from case study research. Academy of management review, 14(4), pp.532-550. DOI: 10.5465/AMR.1989.4308385

Ernst, N.A., Bellomo, S., Ozkaya, I., Nord, R.L. and Gorton, I. (2015) Measure it? manage it? ignore it? software practitioners and technical debt. In Proceedings of the 2015 10th Joint Meeting on Foundations of Software Engineering, pp. 50-60. ACM. DOI: $10.1145 / 2786805.2786848$

Galbraith, J.R. (1977). Organization design. Reading, MA: Addison Wesley Publishing Company.

Grant, R.M. (1996). Toward a knowledge based theory of the firm. Strategic management journal, 17(S2), pp.109-122. DOI: 10.1002/smj.4250171110

Hashler, Koch, S (Editor) (2004). Free/open source software development. Hershey PA: Idea Group Publishing.

Kelley, K., Clark, B., Brown, V., \& Sitzia, J. (2003). Good practice in the conduct and reporting of survey research. International Journal for Quality in health care, 15(3), 261-266. DOI: 10.1093/intqhe/mzg031

Knodel, J., \& Popescu, D. (2007). A comparison of static architecture compliance checking approaches. In Software Architecture, 2007. WICSA'07. The Working IEEE/IFIP Conference on (pp. 12-12). IEEE. DOI: 10.1109/WICSA.2007.1

Petersen, K. and Wohlin, C. (2009). A comparison of issues and advantages in agile and incremental development between state of the art and an industrial case. Journal of systems and software, 82(9), pp.1479-1490. DOI: 10.1016/j.jss.2009.03.036

Poort, E.R. (2014). Driving agile architecting with cost and risk. IEEE Software, 31(5), pp.20-23. DOI: $10.1109 / \mathrm{MS} .2014 .111$

Schwaber, K. \& Sutherland, J. (2017). The Scrum Guide; The Definitive Guide to Scrum: The Rules of the Game. Retrieved on Wednesday 14th march 2018 from https://www.scrumguides.org/docs/scrumguide/v2017/2017-Scrum-Guide-US.pdf

Skitka, L.J. and Mullen, E. (2002). Understanding judgments of fairness in a real-world political context: A test of the value protection model of justice reasoning. Personality and Social Psychology Bulletin, 28(10), pp.1419-1429. DOI: 10.1177/014616702236873

Slovic, P. and Tversky, A. (1974). Who accepts Savage's axiom?. Systems Research and Behavioral Science, 19(6), pp.368-373. DOI: 10.1002/bs.3830190603

Steenbergen, M. van (2011). Maturity and effectiveness of enterprise architecture. Doctoral dissertation, Utrecht University.

Van Haren Publishing (2011). TOGAF Version 9.1. http://pubs.opengroup.org/architecture/togaf9doc/arch/

VersionOne, Inc. (2015). 9th annual state of agile survey. Retrieved on Wednesday 14th march 2018 from https://explore.versionone.com/state-of-agile/9th-annual-state-of-agile-report-2

Wilson, N. \& Altman, R. (2013). Agile Teams Need Application Architects. Retrieved on Wednesday 14th march 2018.

Yang, C., Liang, P. and Avgeriou, P. (2016). A systematic mapping study on the combination of software architecture and agile development. Journal of Systems and Software, 111, pp.157184. DOI: $10.1016 /$ j.jss.2015.09.028

Yin. R.K. (2014). Case Study Research Design and Methods (5th ed.). Thousand Oaks, CA: Sage.

Zikmund, W.G., Babin, B.J., Carr, J.C. and Griffin, M. (2009). Business research methods. Mason, OH South-Western, Cengage Learning. 


\title{
Willingness to Use Smartphone Application Assistant to Support Migraine Treatment
}

\section{HANNA-LEENA HutTUNEN \& RAIJA HALONEN}

\begin{abstract}
Migraine is one of the most neurologically challenging diseases. Migraines are divided into two main forms: aura and without aura. The purpose of this study was to investigate the willingness of migraine patients to use sensors and intelligent migraine diary to be used as support for their own care. There were 565 responses to the questionnaire. Out of those responded, 12 migraine patients were selected for a qualitative interview. The research utilised mixed method that revealed that almost all of the respondents were willing to use sensors to be used as well as an electronic migraine diary for self-care.
\end{abstract}

Keywords: • Migraines $\bullet$ Wearable sensors $\bullet$ Migraine diary $\bullet$ eMobile • Health care information system • Bled eConference •

CORRESPONDENCE AdDRESS: Hanna-Leena Huttunen, Ph.D. Candidate, University of Oulu, Faculty of Information Technology and Electrical Engineering, P.O. Box 3000, 90014 University of Oulu, Finland, e-mail: hanna-leena.huttunen@oulu.fi. Raija Halonen, Ph.D., Adjunct Professor, University of Oulu, Faculty of Information Technology and Electrical Engineering, P.O. Box 3000, 90014 University of Oulu, Finland, e-mail: raija.halonen@oulu.fi. 
H. Huttunen \& R. Halonen: Willingness to Use Smartphone Application Assistant to Support

Migraine Treatment

\section{$1 \quad$ Introduction}

The purpose of the study was to find out the willingness of migraine patients to use the smartphone application assisted by care of migraine. The study was focuses on the willingness of migraine patients to use sensors to act as support for their own care, from which information is automatically transmitted to the electronic migraine diary and from there to a healthcare professionals' information system.

Migraine is one of the health-related neurological diseases and affects 10 to $15 \%$ of the world population every year and need medical treatments 7 - 17 time per year (Pagán et al., 2015; Linde, 2012). Migraine with two main forms, with aura and without aura. In migraine with aura, the pain is preceded by visual disturbances, numbness, muscle weakness and difficulty in speech. Migraine without aura usually begins without the aura symptoms. (Burstein et al., 2014.)

Mobile phones have become an increasingly important tool for healthcare, and eMobile applications have been used for patient care by collecting real-time data e.g. on blood glucose, hypertension, and medications requirements. Mobile application can be used to determine if the treatment is necessary or effective in treating the patient. Health professionals recommend keeping a migraine diary regularly. The patient can use a smartphone application, and enter trigger of headache, pre-symptoms, headache duration, headache time, and medication (Hundert et al., 2014; Nappi et al., 2006.)

The purpose of the wearable sensors is to collect information from the user and to provide feedback to the user in real time. Self-measurement technology means that an individual measures something about biological, physical, behavioural or environmental information. Self-measurement is a rising global trend that has been utilised for activity wristbands, smartphones, rings, mobile phones and mobile applications for several years. (Pantelopoulos \& Bourbakis, 2010.)

This research was about willingness of patients suffering from migraine to use ICT-based solutions that support migraine treatments. The study also wanted to find out the willingness of users to use an electronic migraine diary to support their own care. This study research used mixed methods (see Bryman, 2006; Venkatesh et al., 2013. The study includedquestionnaires with 562 responses and interviews with 12 persons.

The results of this study showed that migraine patients are able to determine the seven biosignals that a wearable sensor should measure to detect a migraine attack. The results offer important information to build a device that will help migraine patients to detect symptoms and assist them in monitoring their own care. Additionally, migraine patients provided researchers with valuable information on the emergence of migraine attacks to develop future devices for migraine diary. 


\section{$2 \quad$ Related Work}

This chapter presents earlier knowledge related to migraine, ICT in healthcare and applications in healthcare in separate sub-chapters.

\subsection{Migraine}

Migraine is one of the most challenging neurological and expensive diseases. In Europe, costs have been calculated to be EUR 111 trillion one year (Lymberis \& De Rossi, 2004.) There are not enough powerful tools on the market to treat migraine patients. Migraine patients feel that the treating physician is far from their illness. Intelligent systems can be used to provide the physician with proper information about the exante symptoms of a migraine patient, aura symptoms, headache, and postural symptoms. Information available of a patient can increase the sense of continuity and trust in access to care and proper care is increased (Burstein et al, 2004; Huttunen et al, 2017; Pryse-Phillips, 2002)

Primary health care physicians rarely see their patients during a migraine attack, and doctors have to make a diagnosis based on patients' description of symptoms. Patients' diagnosis are made during a call or in a reception, this takes usually 5-8 minutes. Although very effective treatments are available and the degree of care is good, patients feel that consultations are inadequate. Symptoms and their intensity are difficult to describe later during a short visit. Patients are willing to convey information to the doctor and nursing staff about the various stages of a migraine attack. With real-time data transfer, information is most readily available to nursing staff. (Pryse-Phillips, 2002.)

Working ability of working-age people is decreasing fast in Europe and the United States. Information and Communication Technology (ICT) enables advanced health care. By introducing sophisticated systems for health care and patient home care, it makes real-time care possible. Measuring symptoms of migraine can prevent symptoms from worsening, promote well-being and disease management, and people stay longer in work-life. (Chan et al, 2009; Huttunen et. al, 2017.)

\subsection{ICT in Healthcare}

The market for self-measuring technologies is growing rapidly in the world, and growth is expected to continue in the future. There are many different types of devices available on the market, and the interest in supporting devices for promoting own health has attracted a lot of attention to the next generation of portable devices (Fritz, et al, 2014, Yang et al, 2016). Wearable devices are designed to measure, for example, pulse, daily rest, quality of sleep, activity, stress and mood. Feedback allows the user to understand and modify their activities and behaviour and thereby promote their own health (Crawford et al., 2015.) The models of wearable devices may differ from, for example, the measurement method, the presentation of the measurement results or the structure, but there are key similarities between the devices 
H. Huttunen \& R. Halonen: Willingness to Use Smartphone Application Assistant to Support Migraine Treatment

(Fritz et al., 2014). The structure of defective devices is generally small and light and can be attached to, for example, a wrist or incorporated into shoes, clothing or sporting equipment.

In a study of willingness of migraine patients to use sensors to act as support for their own care most respondents recognised migraine symptoms and were willing to use sensor technology to support their own care. Migraine patients considered it important that the device measures blood pressure, sleep quality, stress levels, pulse and pain strength. (Huttunen et al, 2017.) The sensor should be located on the wrist in order to read the incoming migraine attack and send it to the migraine diary (see Figure 1). Patients can use sensor technology to measure and monitor their own health better. Studies show that monitoring of one's own care produces better results than using traditional therapy without assisted technology. Nurses can track patients well-being with sensors real-time and regardless of location, and treatments can be started timely (Chan, et al, 2009; Ko et al, 2010; Choe et al, 2014.)
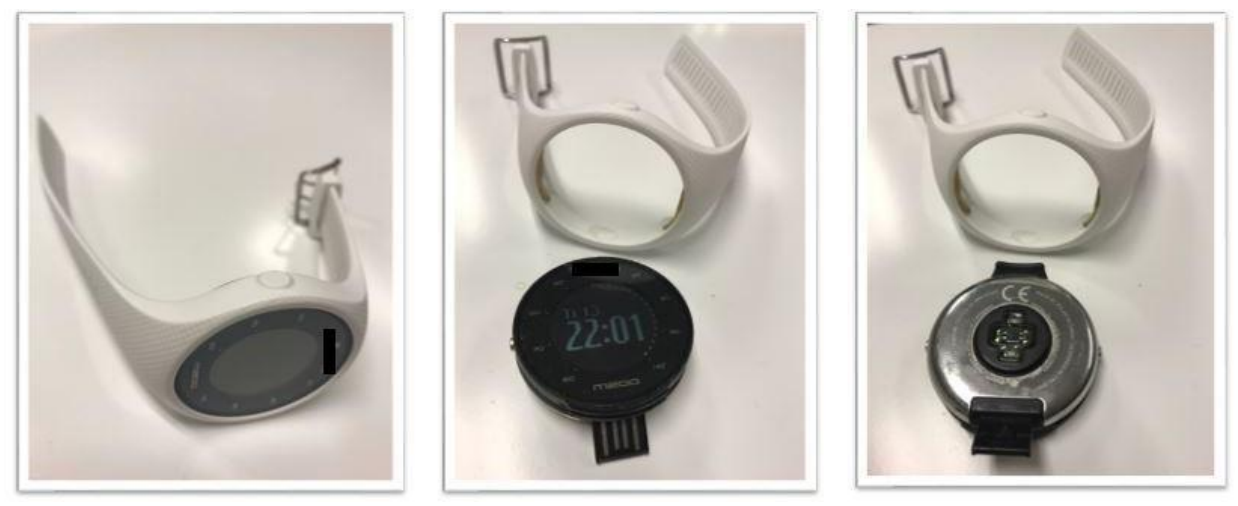

Figure 1: Wearable sensors to support healthcare

By collecting data in real-time, it can be stated whether treatment is necessary or whether the treatment is effective. Earlier studies have been verified by measuring human biosignals with Basis B1, Basis Peak and Empatica E4. Studies have shown that the quality and amount of sleep have a major impact on the emergence of migraine and a migraine attack occurs in most of the patients during the night (Huttunen et al., 2017.)

\subsection{Application in Healthcare}

Mobile phones have become an increasingly important tool in healthcare and eMobile applications have been used to promote physical activity and healthy diets, asthma, cardiovascular symptoms, cessation of smoking, and other numerous health problems. The phone application can manage appointments, provide support and utilize as a social environment among others with the same illness, providing peer support to others. In addition, patients can themselves use phone applications to monitoring their own health 
and sending information about own well-being to application (Klasnja \& Pratt, 2012). If healthcare technology is successfully integrated in patient life, it recognizes illnesses and helps healthcare professionals to identify the proper care (Ballegaard et al, 2008).

Healthcare professionals recommend keeping a migraine journal regularly (see figure 2), which includes the date, the triggering factor, the pre-symptoms, the headache strength, the duration of headache and the duration of the medication (Hundert et al., 2014; Nappi et al., 2006). Health care professionals have asked migraine patients to use the paper version for which the information must be entered manually. There may be a number of diaries, they are heavy to fill, they can be lost, these lead to a reliability problem. The increase in the use of electronic diaries has become more common as a follow-up to one's own care (Hundert, et al., 2014, Nappi et al, 2006.)

Using a diary in a mobile phone has several advantages. Mobile e-journals allow users to carry the application and add additional information on the application. Automated data input from sensors to the application makes data entry more efficient (Huttunen et al, 2017). This application allows the healthcare professional to see automatically generated reports of the data entered. Based on the reports, the users understand their illness more and can predict future migraine attacks. eMobile applications help healthcare professionals by providing real-time access to information, treatment quality and availability are improved. E-diaries have been shown to be more reliable than paper-based diaries (Jamison et al., 2001; Stinson et al, 2013.)
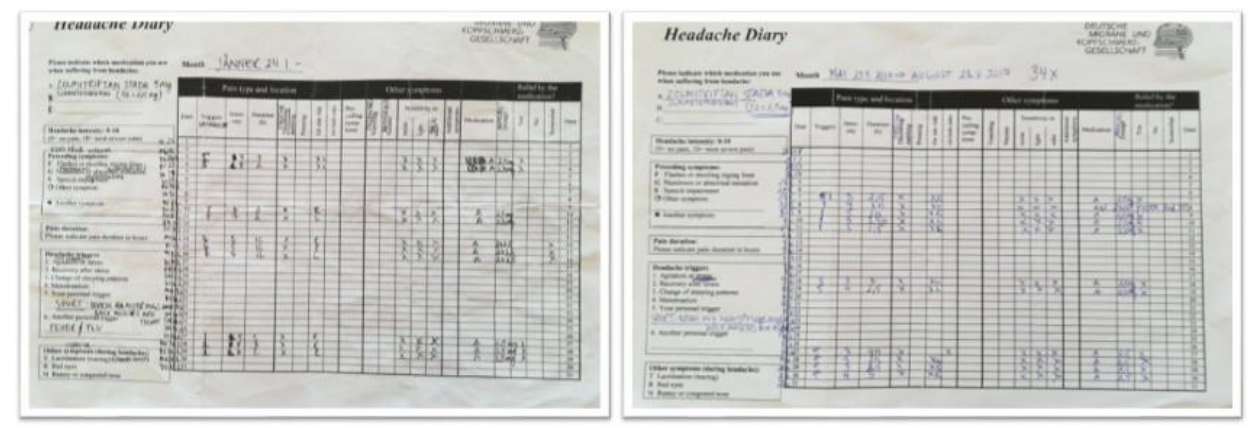

Figure 2: Migraine patient's migraine diary

Figure 2 shows one of the interviewee's migraine diary in which he has marked e.g. needed medicines for migraine, pain intensity and pain location, and if pain intensity decreased after taking the drug, whether there were any prior symptoms, headaches duration, which has triggered headaches and other symptoms. 
H. Huttunen \& R. Halonen: Willingness to Use Smartphone Application Assistant to Support Migraine Treatment

\section{$4 \quad$ Research Approach}

The current study applied mixed method approach that in its early phases was mostly applied by scientists representing behavioural and social sciences, and nursing science (Tashakkori \& Teddlie, 1998, Bryman, 2006), however currently ever more used by scientists representing information system scientists as well (Venkatesh et al., 2013). Figure 3 illustrates the approach and nature of the research material in the study.

The survey was answered through a questionnaire and a qualitative interview. The questionnaire was answered by 562 people with a migraine diagnosis and the questionnaire was analysed using the SPSS 3.0 tool and qualitative interview was made 12 people. Based on the answers to the questionnaire, the interview questions were defined, which were used as helping questions in the interview. Qualitative interviews were recorded and answers were written into text. Similarities were searched from responses and they were classified as background information and device issues. The results of this study show that migraine patients are able to determine the seven biosignals that a wearable sensors should measure for the detection of a migraine attack. In this study, we can define a device that helps migraine patients to detect symptoms and help them track their own treatment. Additionally, migraine patients provided researchers with valuable information on the occurrence of migraine attacks to develop future devices for migraine treatment.

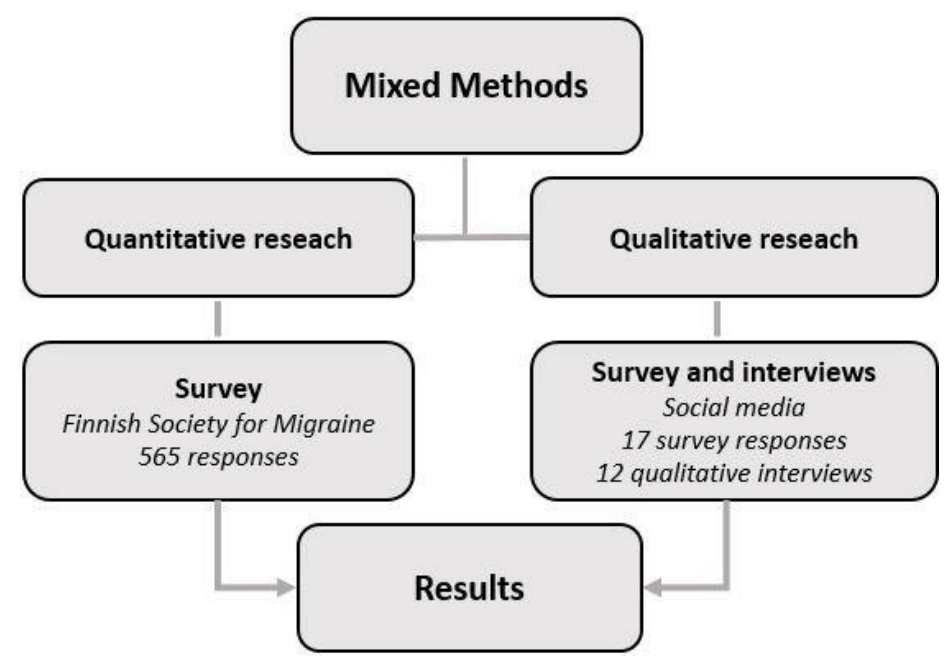

Figure 3: Mixed methods

The target group of the study was a random group of migraine sufferers. Collection of the data was carried out in three phases. In the first phase, people were asked to participate in research through social media. Migraine diagnosis was a criterion for participating in the study. Twenty- two people with migraine came forward and a migraine questionnaire form 
in October 2016 in cooperation with the Finnish Migrant Association were sent to them. There were 16 responses to the questionnaire, which resulted in a qualitative interview for 12 participants. An e-mail survey and a qualitative interview were conducted in the fall of 2017. We excluded five people from the interview because they did not live in the area. The questions for the interview were compiled on the basis of a literature review and evaluated the suitability and comprehensiveness of the content. Based on the evaluation of the content, the interview questions were modified to increase the suitability and comprehensiveness. After question quality check, invitation letter was sent to interviews. The questionnaire includes background information, questions related to device detecting migraine symptoms, and migraine diary questions about issues that are compatible with healthcare information.

The analysis of the questionnaire was divided into two phases. In the first phase, a migraine questionnaire was categorised into two main categories, background information and device issues. The questions of the interview were divided into three main categories, background information, intelligent devices and migraine sensitive sensors. The results of the survey were analysed with SPSS 3.0 tool and cross-table was made. The interview material was read several times to get a full picture and responds were recorded and tabulated. Similarities were sought from the material, it was organized into categories and named in accordance with the content. The categories were summarised and combined according to the survey and the interview. Text and percentages were used to describe the material. The background information was classified according to age, sex, hobby, profession, migraine type, pre-symptoms, medication, count of migraine attacks, trigger of migraine attacks, time when migraine attacks occur and if relatives suffer from migraine. The data were analysed for typical symptoms associated with migraine and were classified according to the pre-symptoms and the main symptoms.

Questions about the device were classified according to the users' interest, what kind of smart technology users are used to use, whether users have wearable devices at home, where users use wearable devices, what kind of experiences users have with wearable devices, what motivates users to wear wearable device, what problems users have encountered when using wearable devices and are wearable devices contributed to users health. Questions related to wearable device detecting migraine pre-symptoms were divided according to the pre- symptoms of migraine, whether users would use a device that identifies the symptoms of a migraine attack, what would users like the device to measure, whether users want the device to report directly to the migraine diary, what users feel about the migraine's pre-symptoms device and how users feel if device report directly to health care information system.

\section{$5 \quad$ Results}

The quantitative research material was collected in November 2016 using an online survey via Webropol. In total 565 completed questionnaires were returned. Further, additional material was collected by e-mail from 22 persons in November 2017, with 16 completed replies received. In the third stage, a qualitative interview was carried out for 12 persons. 


\subsection{Background Questions}

The second phase of the survey was answered by 15 women and one man. 12 women were selected to qualitative interview age ranging between 9 and 58 years. All respondents were active with physical exercise and had experience using computer at work.

Researchers wanted to know what is migraine patient typical migraine attack type. The interviewees described their typical migraine attacks:

"Behind the right eye starts a strange feeling, which gradually spreads and intensifies to ache. This is accompanied by sensitivity to odour and light, nausea (no vomiting), intermittent numbness of the head, weakening of thought activity. Duration usually $72 h$, usually starting in the morning."

/ Elsa 41 years

"Migraine usually strikes at night (sometimes even in the afternoon). It is accompanied by intense heartburn and more severe pain on the shoulder than in the head. Eyes require covering and preferably a little pressure, heartburn vertical position. In addition, sweat and feeling cold simultaneously and fresh air must be obtained in order not to vomit." / May 39 years

"The seizure always starts with visual disturbances, and after that comes an aura stage that lasts max. half an hour. The ache phase lasts longer. And many days after the actual seizure there is a bad feeling; dizziness and is unrealistic feeling. Focusing is also poor for many days after the seizure."

$/$ Mireille 50 years

"It starts almost always at night, early hours. It is one-sidedand generally pulsating. Sometimes squeezing. Often the pain is at the front of the forehead section and / or behind the eye. It takes 1.5 to 4 hours if I take the acute medication in time. Usually goes away with one tablet, sometimes I have to take two. During the seizure my eyes are sensitive to the light, the smells are nauseating and sometimes I vomit."

/ Tina 42 years

"First comes stomach pain, fatigue and paleness. After that hard headache. If the medicine is not taken at the right time, I will start to vomit."

Sarah 9 years 
"The aura begins as a point in the field of vision, expands within 5 to 10 min to a significant disturb in field of vision, either with or with our saw edge pattern. In a quarter of on hour, the eyesight may have gone almost completely. After the aura ache + vomiting (sometimes). Significant light and acoustic sensitivity during the seizure and weak feeling."

/ Anna 29

"With aura begins with a visual disturbance of approximately 30 minutes, after which there is not always a headache. Visual disturbances may occur every few days and usually on the third time becomes a hard headache. With the aura begins with a hard one sided headache."

/ Ursula 29 years

\subsection{Device Questions}

The questions about the devices aimed at exploring which kind of intelligent technology was used by migraine patients in everyday life and what were the reasons to acquire intelligent solutions.

Eleven respondents had smartphones but one of the respondents did not know it was an intelligent device. Four persons used a tablet and computer every day. Four of them used a smartphone every day to gather information on sports performance and energy consumption. Most persons informed they had acquired a smartphone for monitoring their health status.

The interview aimed for answers to the questions of which of the seven (7) most important biosignals the smart watch should measure to predict a migraine attack (see Table 1). Nearly all responded 'yes' when asked if they wanted to let the device to send automatically information about pre-identified migraine attack to the migraine diary. In total, 565 agreed and nine disagreed to press 'YES button' and can information be synced directly to the health care information system.

Table 1: Seven most important biosignals in the smart watch

\begin{tabular}{|l|r|l|}
\hline What would you like the device to measure? & N & $\%$ \\
\hline Blood pressure & 400 & 70,8 \\
\hline Pulse & 370 & 65,4 \\
\hline Stress level & 393 & 69,5 \\
\hline Quality of sleep & 409 & 72,4 \\
\hline Sleep rhythm & 254 & 44,9 \\
\hline Blood sugar & 246 & 46,7 \\
\hline Energy consumption (kcal) & 115 & 20,3 \\
\hline
\end{tabular}


Table 1 shows that the vast majority of respondents wanted the device to measure sleep quality $(72,4 \%)$, pulse $(65.4 \%)$, blood pressure $(70,8 \%)$, stress level $(69.5 \%)$, sleep rhythm $(44,9 \%)$ and energy consumption $(20,3 \%)$. These seven features were raised important for the device to measure to predict the incoming migraine attack.

All 16 respondents who responded to the questionnaire were willing to take the migraine report to the migraine diary. In the interviews, the same question was repeated and all 12 were willing to pass the information to the migraine diary. One of the respondents said she had fill the migraine diary manually and find it very laborious. The "reset" button would help migraine patients to be able to monitor the number and frequency of migraine attacks. Data collection helps migraine patients to avoid the oncoming migraine scene when they learn to identify with the migraine diary, when and how the scenes arise. From the responses, it emerged that the device should be fast and easy to use in order to maintain interest in the device.

Migraine diaries of one of the interviewed where he has marked date, the medicines needed for migraine, pain and place of the pain, other symptoms, affect of medicine, headache scale 0 to 10 , where there any pre-symptoms, headache duration, which has triggered headaches and other symptoms. Migraine attack has occurred during sports, when the muscles have been tense and when respondent have been ill. The respondents considered it important that the migraine diary is available in a mobile application that can be consulted by a physician / nurse if necessary. The respondents considered that if they press the acknowledge button, the information goes to the health care information system and is available to the nursing staff and can be visited when needed. $87.5 \%$ of the respondents considered it important that the device should be available from a health centre, occupational health care, neurologist or other healthcare provider. $12,5 \%$ of the respondents were willing to buy the device by them self.

\section{Discussion}

This study strengthens earlier studies that migraine is a genetic-regulated illness and it is inherited from generation to generation. Migraine is most common in the 25-44 age group and because of hormonal changes, women suffer from migraine more than men (Huttunen et al., 2017, Koskimäki et al., 2017). In this study respondents have been diagnosed with migraine and most of them were aged 30-49. Respondents close relatives had also been diagnosed with migraine, especially women. Respondents had migraine with aura and without aura and one of the respondents had no information on the type of migraine. All respondents at work did work with computer. Each respondent had some degree of exercise as a hobby. Scientists (Huttunen et al., 2017) find that measuring human biosignals on the wrist is useful in predicting the emergence of diseases. The seven most important biosignals were sleep quality, pulse, blood pressure, blood sugar, stress levels, sleep rhythm and energy consumption. Biosignals provide useful information on physiological changes that improve the availability of treatment. Smartphone applications have become more important tools for measuring your health (Klasnja \& Pratt, 2012). The migraine application allows patients to take advantage of their own health promotion. The 
data stays in the application and goes on the pocket included. There are various mobile devices on the market, whose applications enable healthcare development, as they can be combined with a variety of sensors to evaluate data collected (Huttunen et al., 2017). The study shows that migraine patients are willing to support their self care with mobile application, which will automatically record the migraine diary information. The "reset" button would help migraine patients be able to monitor the number and frequency of migraine attacks. Data gathering allows migraine patients to avoid a migraine attack by reacting faster. Feedback allows the user to understand and modify their activities, behaviours and thus promote their own health. (Crawford et al., 2015). The use of mobile application is nowadays easy and the use of migraine diary as a mobile application would facilitate the daily life of migraine patients. Mobile applications can be used to monitor migraine more effectively and also facilitate patients with medical visits when the diary passes comfortably and provides feedback graphically.

\section{$7 \quad$ Conclusion}

As a conclusion, one can state that the preliminary results are promising and they reveal the willingness of the migraine patients to use electronic migraine diaries to support their care. Information from these electronic diaries can be transferred to the healthcare providers' information systems. In addition, life quality of people suffering from migraine will be promoted in future with such an electronic migraine diary that can be available at all times and all places. When meeting their medical physicians, the patients can show up-to-date information of their migraine.

The study also suggests that a device that measures symptoms together with the electronic migraine diary can motivate and encourage the patients to adjust their living habits, and support self-care at home (see Figure 4). With the information monitored by the biosensors the patients can consider their medication timetable. When migraine is well treated and technology is properly applied, capability to work and physical, non-physical and social well-being can be supported. 
H. Huttunen \& R. Halonen: Willingness to Use Smartphone Application Assistant to Support Migraine Treatment

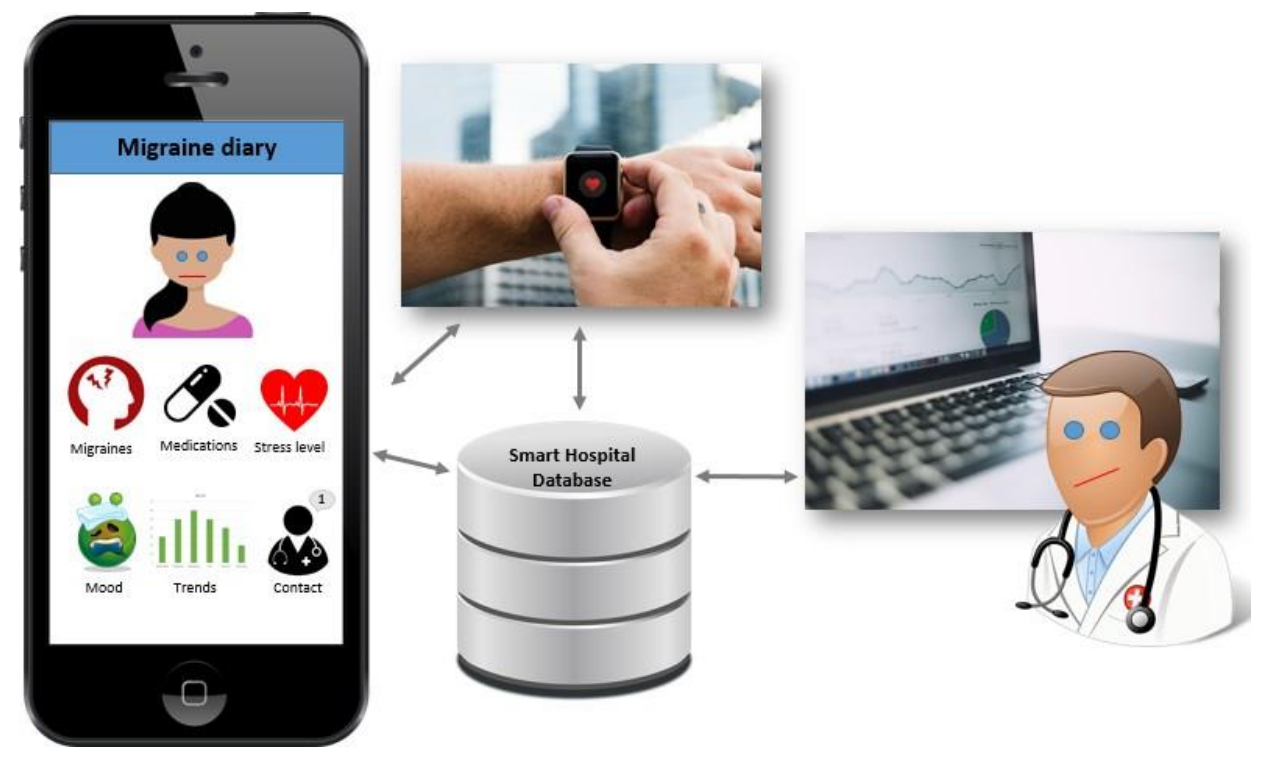

Figure 4: Technology helps migraine patients

So far there are only few earlier studies about using electronic migraine diaries, and due to the versatility of the studies it is challenging to define the influence of the electronic application on the care of migraine. More studies are needed to evaluate benefits and costs of electronic migraine diaries for supporting symptoms and care of migraine.

In the future health promotion services will become electronic when technology develops at a speed. Technology can help migraine patient in everyday life when pre-symptoms of migraine are easier to identify and treatment can be started faster. Technology helps migraine patients to stay at work for longer, to have less sick leave and to know their own health care themselves. The sensors used for self-measurement are small and can be used with wearable devices and mobile technology (Choe et al., 2014). Earlier research shows (Huttunen et al., 2017) that migraine patients want to use a smartwatch or intelligent bracelet that can measure the pre- symptoms of a migraine attack. With this study, we can conclude that migraine patients considered it important that the device measures the quality of sleep, pulse, blood pressure, blood sugar stress levels, sleep rhythm and energy consumption. Biosignals enable users to respond more quickly to taking the medicine and reduce the duration of the migraine attack. The study also wanted to find out whether users were willing to use a device that automatically transports data to migraine diary. Of the respondents, all 12 were willing to use a device that reads and syncs the information about migraine attack to migraine diary by confirm button. 
As a conclusion, self-measurement is rising worldwide, and migraine patients are willing to use smart devices to support their own care. Measuring the symptoms of patients with migraine can promote well-being and illness management.

\section{Acknowledgments}

The authors thank all the volunteers who participated in the research.

\section{References}

Ballegaard, S. A., Hansen, T. R., \& Kyng, M. (2008, April). Healthcare in everyday life: designing healthcare services for daily life. In Proceedings of the SIGCHI Conference on Human Factors in Computing Systems (pp. 1807-1816). ACM.

Bryman, A. (2006). Integrating quantitative and qualitative research: how is it done? Qualitative Research 6(1), 97-113. DOI: 10.1177/1468794106058877

Burstein, R., Collins, B., \& Jakubowski, M. (2004). Defeating migraine pain with triptans: a race against the development of cutaneous allodynia. Annals of Neurology, 55(1), 19-26.

Chan, M., Campo, E., Estève, D. \& Fourniols, J. Y. (2009). Smart homes-current features and future perspectives. Maturitas, 64(2), 90-97.

Choe, E. K., Lee, N. B., Lee, B., Pratt, W., \& Kientz, J. A. (2014, April). Understanding quantifiedselfers' practices in collecting and exploring personal data. In Proceedings of the 32nd annual ACM conference on Human factors in Computing Systems (pp. 1143-1152). ACM.

Crawford, K., Lingel, J., \& Karppi, T. (2015). Our metrics, ourselves: A hundred years of selftracking from the weight scale to the wrist wearable device. European Journal of Cultural Studies, 18(4- 5), 479-496.

Fritz, T., Huang, E. M., Murphy, G. C., \& Zimmermann, T. (2014, April). Persuasive technology in the real world: a study of long-term use of activity sensing devices for fitness. In Proceedings of the SIGCHI Conference on Human Factors in Computing Systems (pp. 487-496). ACM.

Hundert, A. S., Huguet, A., McGrath, P. J., Stinson, J. N., \& Wheaton, M. (2014). Commercially available mobile phone headache diary apps: a systematic review. JMIR mHealth and uHealth, 2(3).

Huttunen, H. L., Halonen, R., \& Koskimäki, H. (2017). Wishes For Wearables From Patients With Migraine. In Proceesings of The 11th Mediterranean Conference on Information Systems (MCIS), Genoa, Italy, 2017

Jamison, R. N., Raymond, S. A., Levine, J. G., Slawsby, E. A., Nedeljkovic, S. S., \& Katz, N. P. (2001).

Electronic diaries for monitoring chronic pain: 1-year validation study. Pain, 91(3), 277-285.

Klasnja, P., \& Pratt, W. (2012). Healthcare in the pocket: mapping the space of mobile-phone health interventions. Journal of Biomedical Informatics, 45(1), 184-198.

Ko, J., Lu, C., Srivastava, M. B., Stankovic, J. A., Terzis, A., \& Welsh, M. (2010). Wireless sensor networks for healthcare. Proceedings of the IEEE, 98(11), 1947-1960.)

Koskimäki, H., Mönttinen, H., Siirtola, P., Huttunen, H. L., Halonen, R., \& Röning, J. (2017, September). Early detection of migraine attacks based on wearable sensors: experiences of data collection using Empatica E4. In Proceedings of the 2017 ACM International Joint Conference on Pervasive and Ubiquitous Computing and Proceedings of the 2017 ACM International Symposium on Wearable Computers (pp. 506-511). ACM.

Linde, M., Gustavsson, A., Stovner, L. J., Steiner, T. J., Barré, J., Katsarava, Z., ... \& Ruiz De La Torre, E. (2012). The cost of headache disorders in Europe: the Eurolight project. European Journal of Neurology, 19(5), 703-711. 
414 31 $31^{\text {ST }}$ Bled ECONFERENCE: Digital Transformation: MEETing THE Challenges June 17 - 20, 2018, Bled, SLOVEnia, CONFERENCE PROCEEDINGS

H. Huttunen \& R. Halonen: Willingness to Use Smartphone Application Assistant to Support Migraine Treatment

Nappi, G., Jensen, R., Nappi, R. E., Sances, G., Torelli, P., \& Olesen, J. (2006). Diaries and calendars for migraine. A review. Cephalalgia, 26(8), 905-916.

Pagán J., Orbe, D., Irene M., Gago, A., Sobrado, M., Risco-Martin, J. L.,... \& Ayala, J. L. (2015). Robust and accurate modeling approaches for migraine per-patient prediction data from ambulatory. Sensors, 15(7), 15419-15442.

Pantelopoulos, A., \& Bourbakis, N. G. (2010). A survey on wearable sensor-based systems for health monitoring and prognosis. IEEE Transactions on Systems, Man, and Cybernetics, Part C (Applications and Reviews), 40(1), 1-12.

Patten, S. B., Williams, J. V., Lavorato, D. H., Modgill, G., Jetté, N. \& Eliasziw, M. (2008). Major depression as a risk factor for chronic disease incidence: Longitudinal analyses in a general population cohort. General Hospital Psychiatry, 30(5), 407-413.

Pryse-Phillips, W. (2002). Evaluating migraine disability: the headache impact test instrument in context. Canadian Journal of Neurological Sciences, 29(S2), S11-S15.

Stinson, J. N., Huguet, A., McGrath, P., Rosenbloom, B., Soobiah, C., White, M., \& Coburn, G. (2013). A qualitative review of the psychometric properties and feasibility of electronic headache diaries for children and adults: where we are and where we need to go. Pain Research and Management, 18(3), 142-152.

Tashakkori, A., \& Teddlie, C. (1998). Mixed methodology: Combining qualitative and quantitative approaches (Vol. 46). Sage.

Venkatesh, V., Brown, S. A., \& Bala, H. (2013). Bridging the qualitative-quantitative divide: Guidelines for conducting mixed methods research in information systems. MIS Quarterly, 37(1), 21-54.

Yang, H., Yu, J., Zo, H. \& Choi, M. (2016). User acceptance of wearable devices: An extended perspective of perceived value. Telematics and Informatics, 33(2), 256-269. 


\title{
ICT supporting healthcare for elderly in China: A systematic mapping study
}

\author{
ZIHAO LIU \& RAIJA HALONEN
}

\begin{abstract}
Ageing population is a global issue. The numbers of elderly people with health problems are increasing globally. This raises the demand for better quality and efficient healthcare services for elderly. Modern information and communication technology (ICT) offers numerous means to support people's lives, and also create the convenience to receive and deliver quality and efficient healthcare services. ICT has become natural part of healthcare, and is entrusted with an important role to support healthcare for elderly in the world context. China, like other countries, also faces fast ageing population. How to better support Chinese elderlies' lives and deliver quality and efficient healthcare becomes a great challenge. Through a systematic mapping study this study analysed how the means of ICT in healthcare for elderly in China are discussed in prior literature. The results showed that the existing studies addressing this issue are extremely scarce and relatively recent. The research field in China is still quite young and immature, and more studies focused on the Chinese context in this research field are urgently needed.
\end{abstract}

Keywords: • Information Communication Technology • ICT • Elderly • Healthcare $\bullet$ China $\bullet$ Systematic mapping study $\bullet$ Bled eConference •

CORRESPONDENCE ADDRESS: Zihao Liu, MSc, University of Oulu, ITEE, P.O.Box 4500, 90014 Oulu, Finland, e-mail: zihao.liu@student.oulu.fi. Raija Halonen, Ph.D., Adjunct Professor, University of Oulu, ITEE, P.O.Box 4500, 90014 Oulu, Finland, e-mail: raija.halonen@oulu.fi.

DOI https://doi.org/10.18690/978-961-286-170-4.28

ISBN 978-961-286-170-4

(C) 2018 University of Maribor Press

Available at: http://press.um.si. 
The numbers of elderly people with health problems are increasing globally. This raises the demand for better quality and efficient healthcare services for elderly. Elderly usually suffer from health problems such as weaker functionality, and less ability to deal with complicated situations (Mihovska et al., 2014). Nowadays, the majority of elderly receive care predominantly from their family members (Levine et al., 2010). The informal care givers often face intense caring tasks like constant presence with the elderly while quality of healthcare delivered to elderly declines (Hoffmann \& Rodrigues, 2010).

China differs from others; it is a developing country with huge population and underdeveloped healthcare system $(\mathrm{Wu}, 2016)$. There is an increasing need to improve healthcare for elderly especially in the context of China. The purpose of this study was to analyse how the information and communication technology (ICT) supports elderly healthcare in China is discussed in literature. The topic was seen significant due to the identified issues related to ageing in the world and especially in China (see e.g. Du \& Wang, 2016).

In recent years, ICT has been extending to all area of life. ICT solutions such as telehealth services, medical sensors, and healthcare applications, are widely used and have become natural part of healthcare (Vimarlund \& Olve, 2005). ICT is entrusted with the important role of revolutionise traditional approaches in healthcare. Future proposals have concentrated on empowering ICT's capabilities to support people' lives, and improve the quality and efficiency of healthcare. (eHealth, 2011.)

According to National Bureau of Statistics of China (NBSPRC), the number of Chinese citizens aged 60 or over has exceeded 241 million by the end of 2017, representing $17.3 \%$ of the total population. Moreover, the Chinese government predict the number of elderly in China will continue to grow until 2050, and the proportion of the Chinese elderly population will finally reach $30 \%$ (NBSPRC, 2018). How to better support elderlies' lives and deliver quality and efficient healthcare becomes a great challenge.

To catch the purpose of the current study, a research question was posed: What is known about ICT and Chinese elderly healthcare? The research question was answered with the help of a systematic mapping study (see Kitchenham \& Charters, 2007). The rigorous mapping study revealed urgent need to carry out more research. In literature, ICT supported elderly healthcare has been widely studied in the world context. However, even if a vast population is ageing and facing ageing-related problems, only insufficient scientific research is done to provide tools for elderly and relevant stakeholders providing healthcare and wellbeing.

The remainder of the paper is as follows. Section 2 gives the overview of background information, followed by research approach. Section 4 presents results, and the paper ends with discussion and conclusions. 


\section{$2 \quad$ Background}

The issues related to ageing population confirm the necessity of paying greater attention to elderly healthcare. When studying ICT support healthcare for elderly especially in China, it is important to understand what the current situation is. These topics are presented next.

\subsection{Issues Related to Ageing Population}

Ageing population is a global issue and raises a remarkable problem for the communities that settle elderly, and especially for health and social care providers (Howdon \& Rice, 2018). In general, costs related to health and long-term care are expected to increase in the OECD countries 3.3 and 7.7 percentage of GPD between years 2010 and 2016, respectively, and in the BRICS countries the increase is expected 2.8 and 7.3 percentage, respectively (de la Maisonneuve \& Martins, 2015).

Ashby and Beech (2016) pointed out several issues related to ageing e.g. limited financial status leading to choose between healthy food and keeping warm; increased risk of falls of the elderly; hidden reason behind falls and injuries; outdated medication; and social isolation. Furthermore, getting passive and inactive in daily life is identified a notable issue among elderly, and getting people activated requires resources but brings profits to the life of the elderly and decreases costs of healthcare (Muramatsu et al., 2017).

\subsection{ICT Support Elderly Healthcare in World Context}

Modern ICT offer numerous means to support people's lives, manage their health, and also create the convenience to receive and deliver quality and efficient healthcare services (Afifi \& Al-Hussein, 2014).

E-health systems such as electronic health and medical records system, telemedicine and telehealth systems, and also web or mobile health applications, provide the platform to centralize and manage health data and facilitate the process to transfer it between elderly patients and healthcare professionals (eHealth, 2011).

The concept of Ambient Assistive Living (AAL) drives the new trend to embed ICT in the living environments to support and assist the daily lives, especially for elderly and disable people (Nalin et al., 2016). ICT devices integrating microelectronics, sensor manufacturing and data analysis techniques, are widely used to monitor the health situation and support daily lives (Patel et al., 2015).

Utilising Internet-of-Things (IoT) is needed to provide integration between healthcare systems for ageing population. IoT offers possibilities to cover larger spatial and temporal coverage of healthcare services to meet the needs of the ageing population. Moreover, IoT-enabled healthcare services will be more efficient and available for users everywhere. (Pang et al., 2015.) 
Countries around the world are paying greater attention on the development of carerelated ICT systems and devices. According to the statistic, European countries have the advanced E-health industry that develops the chain of digital health systems, and its size has reached around 20 billion euros (eHealth, 2011). Japan with its rapid pace of the ageing population has huge investments in AAL market and estimated reach around 5 billion US dollars by 2024 (ResearchAndMarkets, 2018).

\subsection{ICT Support Elderly Healthcare in the Context of China}

Chinese government has marked the importance to the construction of ICT techniques in healthcare industry (Zhao et al., 2009). Some influential companies also tried to make innovation in this field. Alibaba invested in building 'future hospital' as an E-health innovation. Patients and healthcare professionals can reach each other and use hospital functions, like clinic and medical services, via an 'online hospital' platform. (Wu, 2016.) Tencent has ready integrated fitness tracking function into WeChat, which is the most popular social media application in China (Pai, 2015).

Though the trend of using ICT to support healthcare appears positive in China, empowering ICT's capabilities to support elderly healthcare still suffer the challenges. Some studies indicated that many Chinese elderly resist to new ICT solutions due to technology anxiety (Guo et al., 2013). Based on their study in Hong Kong, Ma et al. (2016) reported that especially older adults who had higher education are more willing to use ICT enabled applications than the others, but one third of the 109 informants had never used ICT for their healthcare issues. Prior studies have investigated to what extent the Chinese elderly can adopt ICT. The results show that perceived usefulness and ease of use are determining factors to influence the receptivity towards ICT products for older citizens. Therefore, new ICT solution need to pay attention on the technology and service quality as well as provide good illustrations and training and removing their biased evaluations on new technology. (Guo et al., 2013.)

\section{$3 \quad$ Methodology}

Systematic mapping study is increasingly applied to in new research areas, in where few relevant and high-class primary studies are available but need to have a board overview. Researchers are able to prepare a synopsis for further studies. (Kitchenham \& Charters, 2007.) This study intended to examine how the concerns of this study were addressed in the earlier studies, and to give backgrounds for practical studies. It was conducted by following the guidelines proposed by Kitchenham and Charters (2007), in order to have the rigorous protocol to scan studies, extract and classify data, and analyse and report the study results. 


\subsection{Research Questions and Protocol}

The following assisting research questions were formulated to acquire an overview of the connection between ICT and Chinese elderly healthcare in the existing research:

- What are the publication trends of the research topic?

- What specific research areas are most explored?

- What are the focuses of the research?

In regards to the search keywords, the starting point for conducting the mapping study was the understanding of how ICT was applied to assist the elderly's healthcare in the context of China. Therefore, the key search terms were formed based on the combination of different research fields: ICT, elderly, healthcare and China. It originally contained four parts: 'elderly' or 'older people', 'health' or 'healthcare', 'China' or 'Chinese' and the key word of 'information and communication technology' or 'ICT'.

Pilot searches in the bibliographic databases were conducted to test the defined set of keywords, with the purpose to maximise the results and acquire more the relevant papers for this study. The piloting results reflected that very few studies were conducted relating to the focus of this study. In order to extend the search, alternative terms and concepts addressing the same problems were considered, and singular/plural forms and verbal forms of key terms were also taken into account. Two terms similar to elderly, "aged" and "senior", were included.

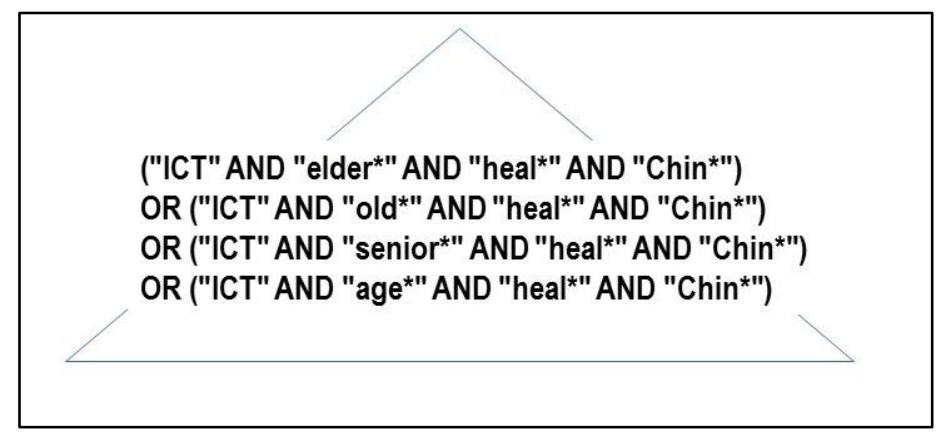

Figure 1: The search string

The final search string (Fig. 1) was applied in different bibliographic databases to get the understanding of the availability of relevant papers. It was adjusted to fit the syntax of each database and to search in the titles, abstracts and keywords. Information specialists of the Oulu University Library were consulted in the selection of databases, and eight digital databases were selected as literature sources. 


\subsection{Study Selection and Data Extraction}

After applying the search string in the chosen databases, the results were uploaded to Refworks. By removing duplicate papers, the remaining papers were screened for inclusion and exclusion in three rounds (Table 1). The first round was done using metadata, to screen papers based on publication quality and availability (Table 2). In the second round, the remaining papers were reviewed based on their titles, keywords, and abstracts to deduct the irrelevant papers that were clearly outside of the research domain of this mapping study.

Table 1: Criteria for primary study selection

\begin{tabular}{|l|l|l|l|}
\hline Round & Inclusion Criteria: & Exclusion Criteria: & Total\# \\
\hline 1. & $\begin{array}{l}\text { Metadata: A conference paper } \\
\text { OR a journal paper OR a book } \\
\text { chapter }\end{array}$ & Not written in English & 182 \\
\hline 2. & $\begin{array}{l}\text { Title, keywords and abstract: } \\
\text { setting is ICT AND elderly/older } \\
\text { people AND support/better living }\end{array}$ & $\begin{array}{l}\text { Clearly outside the scope of ICT OR } \\
\text { elderly OR health OR not focused on } \\
\text { the Chinese context }\end{array}$ & 43 \\
\hline 3. & $\begin{array}{l}\text { Light reading: criteria from round } \\
2 \text { exists in the paper }\end{array}$ & $\begin{array}{l}\text { The content cannot answer the } \\
\text { research questions }\end{array}$ & 12 \\
\hline
\end{tabular}

Table 2: Hits after the first round

\begin{tabular}{|l|l|}
\hline Database & Total\# \\
\hline Scopus & 30 \\
\hline Web of Science & 4 \\
\hline ACM digital library & 8 \\
\hline ScienceDirect & 4 \\
\hline Academic Search Premier (EBSCO) & 52 \\
\hline IEEE Xplore & 4 \\
\hline ProQuest Social Sciences Premium Collection & 52 \\
\hline Wiley Online Library & 28 \\
\hline & 182 \\
\hline
\end{tabular}

Each paper was marked as either "relevant", "irrelevant", "cannot decide". All papers marked as "relevant" and "cannot decide" were left for the next round. The final round was conducted through light reading of the paper. This resulted in 12 papers chosen as the primary studies (Table 3 ). 
The data extraction from the primary studies was performed using a standardised Excel template to obtain relevant metadata, classification data and descriptive data. The extracted data were: title of the paper, year of publication, publication venue, authors, acknowledgments, contribution, and concerns addressed in the research.

\section{$4 \quad$ Results}

In this section, the results of systematic mapping study are summarised to answer the research questions. The publication trends were identified. The primary studies were categorised to examine research areas of ICT and elderly healthcare in relation to the Chinese context. In addition, the contents from the paper were analysed to highlight the research focus.

\subsection{Identified Publication Trends}

The identified trend associated with publication year and author. In the context of China, all of the papers were published in the latest ten years and most of them were recent (11 out of 12 papers), having been published after the year of 2011. The earliest identified publication was from 2007 while the newest one was published in 2017.

Table 3: Publication situation in the Chinese context

\begin{tabular}{|l|l|l|}
\hline Authors & Publication year & Total\# \\
\hline Hong Kong & $2011,2012,2017$ & 3 \\
\hline Collaborative author & 2013,2015 & 2 \\
\hline Chinese (Mainland China) & $2007,2012,2014,2015$ & 7 \\
\hline
\end{tabular}

The primary studies were classified according to the analysis of the authors and acknowledgements: 3 of them were published by Hong Kong (HK) researchers, 2 were collaborated by Chinese and American authors and the remaining 7 were contributed only by the researchers from Mainland China (Table 3). Among the seven Chinese contributed papers, the Chinese government supported six of them. The publication time of those government supported papers were 2007 (1 paper), 2012 (2 papers), 2014 (2 papers) and 2015 (1 paper). One can see that in China (except Special Administrative Region), the publication trend in this field mainly depends on the Chinese government, either policy support or academic funding.

\subsection{Identified Research Areas}

The research area in this field included 5 research disciplines (Table 4). The overall identified research areas were based on publication venue. Meanwhile, the research areas were discussed from the perspective of timeline and region respectively. 
Table 4: Identified Research Area

\begin{tabular}{|l|l|l|}
\hline Research Forum Focus & Total\# & Primary Studies \\
\hline Nursing or Care management & 2 & P04, P12 \\
\hline Medical Science & 3 & P03, P01, P06 \\
\hline Computer Science & 2 & P11, P10 \\
\hline Engineering or Mechatronics & 4 & P02, P09, P07, P08 \\
\hline Consumer Science & 1 & P05 \\
\hline
\end{tabular}

One third of them were published in various Engineering and Mechanics forums. A quarter of the papers were published within medical science area. Two papers were related to nursing and care management field. Another two belong to the computer science studies and the remaining one was published about consumer studies. If the perspective is changed and topics looked from a more general aspect, half of them were in healthcare related forums and the rest were published in computer engineering related area.

From the timeline aspect, the topic was first emerged in care management area. Table 5 displays the identified research area based on publication year.

Table 5: Identified Research Area based on Timeline

\begin{tabular}{|l|l|l|}
\hline Year & Research Forum Focus & Primary Studies \\
\hline 2007 & Care management & P12 \\
\hline 2011 & Mechatronics & P02 \\
\hline 2012 & Medical Science, Engineering, Mechatronics & P01, P08, P09 \\
\hline 2013 & Medical Science & P6 \\
\hline 2014 & Medical Science, Computer Science & P03, P10, P11 \\
\hline 2015 & Consumer Science, Mechatronics, & P05, P07 \\
\hline 2017 & Nursing & P04 \\
\hline
\end{tabular}

During year 2011 to 2015 , the studies were mainly focused on the area of medical science, mechanic engineering and computer science. The last study was concentrated on nursing and care management area again. Table 5 also indicates healthcare and medical areas have been continuously studied. Technology area was emerged and received great attention after 2010. 
Table 6: Identified Research Area based on Region

\begin{tabular}{|l|l|l|}
\hline Region & Research Forum Focus & Primary Studies \\
\hline Hong Kong & Nursing, medical, Mechatronics & P01, P02, P04 \\
\hline $\begin{array}{l}\text { Mainland } \\
\text { China }\end{array}$ & $\begin{array}{l}\text { Care Management, Engineering, } \\
\text { Computer Science, Medical, } \\
\text { Mechatronics }\end{array}$ & $\begin{array}{l}\text { P03, P07, P08, P09, } \\
\text { P20, P11, P12 }\end{array}$ \\
\hline Overseas & Medical, Consumer Science & P05, P06 \\
\hline
\end{tabular}

An interesting phenomenon is that the studies in mainland China and Overseas covered not only medical related research fields but also other various research areas such as engineering and consumer science. On the contrary, most of the papers in HK region were focused on elderly healthcare research area (Table 6).

\subsection{Identified Research Focuses}

The main research focuses emerged from primary studies are non-physical well-being with ICT, physical healthcare with ICT, and also attitude towards ICT. Those ICTs range from "old fashion" Internet technology to the cutting-edge virtual reality technology. The details of identified research focuses are discussed next. Table 7 shows the identified research focuses.

Table 7: The research focuses

\begin{tabular}{|l|l|l|}
\hline Categories & Related ICTs & Primary Studies \\
\hline Psychological & Internet, Computer, Smart device & P12, P05, P04 \\
\hline Physical & $\begin{array}{l}\text { Telehealth, Robotics, Virtual reality, Smart } \\
\text { device application }\end{array}$ & $\begin{array}{l}\text { P01, P02, P06, P07, } \\
\text { P08, P09, P10 }\end{array}$ \\
\hline Reflections & $\begin{array}{l}\text { Computer, Internet, Social media, Smart } \\
\text { device }\end{array}$ & P03, P11 \\
\hline
\end{tabular}

\section{ICT and psychological well-being}

Simultaneous discussion about ICT and elderly's non-physical felling in the Chinese context emerged at 2007. The first identified paper (P12) focused on analysing the connection among ICT (Internet), elderly and well-being. It investigated how the Internet affects elderly's life and what are their opinions after frequently using network technology. The second identified paper (P05) was written 8 years later at 2015. The focused region was mainland China context. Rather than the first paper collecting the feedbacks after using ICTs, it was from a different angle to study the elderly's well-being through exploring how they use Internet in their daily lives. The remaining one was published in 2017 (P04). The focused region was HK. The paper was mainly about the 
positive influences of general ICT (computers, smartphones and tablets) on elderly's psychological well-being and the related associated elements, for instance, different age groups among the elderly.

\section{ICT and physical healthcare}

Seven papers concentrated on applying ICT to enhance elderly's physical health. Three of them examined telehealth solution. In recent decade, HK initiates many telehealth deployments elderly healthcare field (P02). It introduced three ongoing telehealth solutions in HK, which were electronic health record (eHR), mobile nurse patient folder and remote patient monitoring. eHR focused on patients' medical data record, and supported interoperable medical data exchange between public and private healthcare institutes. Mobile nurse patient folder let the nurses to retrieve and update the health data at real time when they visit patients' homes. It aimed to assist the nurses to help their patients timely and effectively. Remote patient monitoring connected medical professionals and patients without home visiting. It helped the patients to manage their health at home to reduce the nurses' burden and save their own costs. Similarly, P09 predicted the future situation of telemedicine technology demand among the elderly in mainland China and examined ICTs' effectiveness. It demonstrated healthcare information demand is the key demands of Chinese elderly in the future and Internet is the main frequently used ICT solution. P08 was focused on enhancing the current encryption technique to build a better remote continuous healthcare monitoring system. It proposed a new cryptography to protect the patients' vital medical data.

Two identified papers (P07, P01) were concentrated on body function rehabilitation, including P07 summarising the current state of the art studies on the area of robot-assisted lower limb rehabilitation and P01 introducing interactive virtual reality Wii technology as supporting the whole body rehabilitation in a geriatric day hospital in HK. Another two papers (P06, P10) examined the use of portable instruments, such as wearable sensors and smartphones, to enhance elderly healthcare in China. P06 focused on improving the design quality of mobile application for the elderly who has chronic diabetic disease. It investigated user-centred design, specifically ageing population profiles and personas. P10 systematically analysed recent health sensing technologies for health data detection and classified them by their application functions.

\section{Attitude towards ICT}

The final research focus was studying the feedbacks of ageing population regarding to ICT. Two papers (P11, P03) concentrated on investigating Chinese elderly's perceptions of ICT. P011 explored the reason of using ICT (Computer and Internet, social media application) in their daily lives. P03 studied the elderly's attitude towards to the adoption of mobile health service in China.

\section{$5 \quad$ Discussion and Conclusion}

In this study, the chosen research method was followed rigorously, and 12 primary studies discussing ICT's capabilities to support elderly healthcare in the Chinese context were identified. The results showed that prior studies addressing this issue are extremely scarce 
and relatively recent. At the time of the study, this research domain was still quite young and immature, and it seems there is a huge academic vacancy in the current the Chinese context. Consequently, it offers huge potentials for innovative research opportunities.

Because the ageing problem will become more serious in the upcoming decades in China (NBSPRC, 2018), more studies in this research domain are in urgent need in the future. As the support from Chinese government has big influence on the academic study in this field and Chinese government emphasised on implementing ICT in healthcare industry (Zhao et al., 2009), one can predict that increasing number of studies will be conducted and more academic paper will be published in the near future. The researchers in HK region were likely more interested in this topic. The reason could be considered as HK was an early developed region with no stringent family planning policy and it faced more serious ageing situation than mainland China (LifeNews, 2013).

The identified primary studies were almost equally either from the healthcare field or the technology field. However, the numbers of technical papers were increasing after 2010. Ericsson (2016) predicted cloud technology, self-managing devices, IoT, Virtual and augmented reality, robotics will be the near future technology trend. The emerging ICTs will play a significant role in healthcare industry (eHealth, 2011). One can predict that the future research will concentrate on computer science and mechanic engineering area.

Three research focuses emerged from primary studies were: psychological well-being, physical healthcare, and attitude towards ICT. How the Internet technology affects elderly's well-being has been seen as the main research direction for psychological wellbeing studies in the early times, while more recent researchers tend to focus more on the smart ICT equipment like smartphone and wearable device. It seems that the research focused in non-physical field is transforming based on the development trend of ICT. Physical healthcare studies focus on applying different ICTs to address the realistic problems for elderly. Telehealth seems to be the most popular solution to solve various geographic healthcare challenges. The novel technology like robotics and virtual reality were applied to solve elderly's body rehabilitation challenges. Meanwhile, smart phone applications and wearable devices were used for elderly to manage their own health and lives. Those are seen as the mature techniques, because the prior studies concentrated on improving the design quality instead of exploring the feasibility and some systematic analyses and classifications were existed. The attitude studies focus on Chinese elderly's perception regarding the adoption of ICTs such as computer, Internet, social media and smartphone in healthcare industry. The research on the perception for emerging ICTs still leave blank.

The current literature study revealed "old fashion" ICT like Internet, computer and smartphone, only few of them emphasised on emerging technologies while there are studies elsewhere made on both aspect of "old" technologies and novel concept. E.g. Nalin et al. (2016) introduced the concept of AAL and smart homes. Pang et al. (2015) pointed out the efficiency of IoT concept in the future. 
To conclude, this study was searching for existing researches that concentrated on the capability of ICT to support the elderly healthcare in China. Although this crossdisciplinary research field was quite young in China and limited the identified primary studies, the study still provides a comprehensive overview of the research field. It also discovered the research trend and its inducement. Meanwhile, the study classified the previous research focuses. It showed the previous priority research areas in China and found what research areas have being ignored, thus provided a significant starting point for the potential research. Overall, this study laid the foundation of synthesising existing knowledge from different research areas for ICT and elderly healthcare in the Chinese context.

The current study proposes more rigorous studies of the topic in the Chinese context to spread the knowledge. More research directions can follow the technology development trend and study how to apply each innovative ICT in this area, for instance, virtual reality or augmented reality technology, real-time healthcare supporting system and artificial intelligence (robotic solution) without forgetting elderly's attitude, caregiver's experience and feedbacks towards those emerging ICTs.

\section{References}

Afifi, M., \& Al-Hussein, M. (2014). Benchmark study for technological options available for older adults to reduce family and caregiver burden. Gerontechnology, 13(2), 164. doi: 10.4017/gt.2014.13.02.161.00

Ashby, S., \& Beech, R. (2016). Addressing the healthcare needs of an ageing population: the need for an integrated solution. International Journal of Collaborative Research on Internal Medicine \& Public Health, 8(4), 316-320.

de la Maisonneuve, C., \& Martins, J. O. (2015). The future of health and long-term care spending. OECD Journal: Economic Studies, 2014(1), 61-96.

Du, P., \& Wang, Y. (2016). Population ageing and the development of social care service systems for older persons in China. Ageing in Developing Countries, 1(1), 40-52.

eHealth. (2011). European Commission Information Society and Media. Policy and research ICT for a healthier EU. Retrieved 22.02.2018, from http://ec.europa.eu/information_society/doc/factsheets/009-ehealth-en.pdf

Ericsson. (2016). 5 trends shaping innovation in ICT. Retrieved 22.02.2018, from https://www.ericsson.com/en/ericsson-technology-review/archive/2016/technology-trends2016

Guo, X., Sun, Y., Wang, N., Peng, Z., \& Yan, Z. (2013). The dark side of elderly acceptance of preventive mobile health services in China. Electronic Markets, 23(1), 49-61. doi:10.1007/s12525-012-0112-4

Hoffmann, F., \& Rodrigues, R. (2010). Informal carers: who takes care of them?. Policy Brief 4/2010. Vienna: European Centre.

Howdon, D., \& Rice, N. (2018). Health care expenditures, age, proximity to death and morbidity: Implications for an ageing population. Journal of Health Economics, 57, 60-74.

Kitchenham, B., \& Charters, S. (2007). Guidelines for performing systematic literature reviews in software engineering (Technical Report EBSE-2007-01). Keele University, UK: Kitchenham, Barbara;Charters, Stuart;. Retrieved 22.02.2018 from https://www.elsevier.com/_data/promis_misc/525444systematicreviewsguide.pdf 
Levine, C., Halper, D., Peist, A., \& Gould, D. A. (2010). Bridging troubled waters: family caregivers, transitions, and long-term care. Health affairs, 29(1), 116-124.

LifeNews. (22.10.2013). Facing Aging Population Crisis, Hong Kong Considers "More Children Policy". Retrieved 22.02.2018, from http://www.lifenews.com/2013/10/22/facing-agingpopulation-crisis-hong-kong-considers-more-children-policy/

Ma, Q., Chan, A. H. S., Teh, P. L., \& Poon, S. N. (2016, July). Over 60 and ICT: Exploring factors that affect older adults' ICTs usage. In International Conference on Human Aspects of IT for the Aged Population (pp. 196-208). Springer, Cham.

Mihovska, A., Kyriazakos, S. A., \& Prasad, R. (2014). eWALL for active long living: Assistive ICT services for chronically ill and elderly citizens. Systems, Man and Cybernetics (SMC), 2014 IEEE International Conference on (pp. 2204-2209). IEEE. doi: 10.1109/smc.2014.6974251

Muramatsu, N., Yin, L., Berbaum, M. L., Marquez, D., Jurivich, D. A., Zanoni, J. P., ... \& Cruz Madrid, K. Y. (2017). From passive care to active care: promoting seniors'health with home care aides. Innovation in Aging, 1(suppl_1), 531.

Nalin, M., Baroni, I., \& Mazzara, M. (2016). A holistic infrastructure to support elderlies' independent living. In Maria Manuela Cruz-Cunha, Isabel Maria Miranda, Ricardo Martinho \& Rui Rijo (Eds.), Encyclopedia of E-health and telemedicine (pp. 591-605). Hershey, PA, USA: IGI Global. doi:10.4018/978-1-4666-9978-6.ch046

NBSPRC, National Bureau of Statistics of China. (28.02.2018). Statistical Communiqué of the People's Republic of China on the 2017 National Economic and Social Development. Retrieved from 01.03.2018, http://www.stats.gov.cn/english/PressRelease/201802/t20180228_1585666.html

Pai, A. (10.02.2015). Messaging app WeChat adds WeChat Sports for fitness tracking. Retrieved 22.02.2018, from http://www.mobihealthnews.com/40474/messaging-app-wechat-addswechat-sports-for-fitness-tracking

Pang, Z., Zheng, L., Tian, J., Kao-Walter, S., Dubrova, E., \& Chen, Q. (2015). Design of a terminal solution for integration of in-home health care devices and services towards the Internet-of-Things. Enterprise Information Systems, 9(1), 86-116.

Patel, M. S., Asch, D. A., \& Volpp, K. G. (2015). Wearable devices as facilitators, not drivers, of health behavior change. Jama, 313(5), 459-460.

ResearchAndMarkets. (12.01.2018). The Japanese Smart Home Market is Expected to Be US\$ 5 Billion by 2024, Growing With Double Digit CAGR. Retrieved 22.02.2018, from https://www.prnewswire.com/news-releases/the-japanese-smart-home-market-is-expected-tobe-us-5-billion-by-2024-growing-with-double-digit-cagr-300581910.html

Vimarlund, V., \& Olve, N. (2005). Economic analyses for ICT in elderly healthcare: Questions and challenges. Health Informatics Journal, 11(4), 309-321

$\mathrm{Wu}$, C. (26.08.2016). China e-health overview. Retrieved 22.02.2018, from http://www.sapidaily.com/china-e-health-overview/

Zhao, J., Zhang, Z., Guo, H., Li, Y., Xue, W., \& Chen, Y. (2009). E-health in China, our practice and exploration. In Proceedings of the 31st Annual International Conference of the IEEE Engineering in Medicine and Biology Science, Minneapolis, MN, 4888 (Vol. 489). 
Appendix A: List of Primary Studies

\begin{tabular}{|c|c|c|c|}
\hline & Authors & Title & DOI \\
\hline P01 & $\begin{array}{l}\text { Chan et } \\
\text { al. }\end{array}$ & $\begin{array}{l}\text { Interactive virtual reality Wii in } \\
\text { geriatric day hospital: a study to } \\
\text { assess its feasibility, } \\
\text { acceptability and efficacy }\end{array}$ & 10.1111/j.1447-0594.2012.00848.x \\
\hline P02 & Chao & $\begin{array}{l}\text { Telehealth initiative in Hong } \\
\text { Kong. In Technologies Beyond } \\
2020 \text { (TTM) }\end{array}$ & 10.1109/TTM.2011.6005176 \\
\hline P03 & $\begin{array}{l}\text { Deng et } \\
\text { al. }\end{array}$ & $\begin{array}{l}\text { Comparison of the middle-aged } \\
\text { and older users' adoption of } \\
\text { mobile health services in China. }\end{array}$ & 10.1016/j.ijmedinf.2013.12.002 \\
\hline P04 & $\begin{array}{l}\text { Fang et } \\
\text { al. }\end{array}$ & $\begin{array}{l}\text { Information and communicative } \\
\text { technology use enhances } \\
\text { psychological well-being of older } \\
\text { adults: the roles of age, social } \\
\text { connectedness, and frailty status }\end{array}$ & $10.1080 / 13607863.2017 .1358354$ \\
\hline P05 & $\begin{array}{l}\text { Fowler } \\
\text { et al. }\end{array}$ & $\begin{array}{l}\text { Analyzing Chinese older } \\
\text { people's quality of life through } \\
\text { their use of the internet }\end{array}$ & 10.1111/ijcs.12194 \\
\hline P06 & $\begin{array}{l}\text { LeRouge } \\
\text { et al. }\end{array}$ & $\begin{array}{l}\text { User profiles and personas in } \\
\text { the design and development of } \\
\text { consumer health technologies }\end{array}$ & 10.1016/j.jjmedinf.2011.03.006 \\
\hline P07 & $\begin{array}{l}\text { Meng et } \\
\text { al. }\end{array}$ & $\begin{array}{l}\text { Recent development of } \\
\text { mechanisms and control } \\
\text { strategies for robot-assisted } \\
\text { lower limb rehabilitation }\end{array}$ & 10.1016/j.mechatronics.2015.04.005 \\
\hline P08 & $\begin{array}{l}\text { Pan et } \\
\text { al. }\end{array}$ & $\begin{array}{l}\text { Security mechanism for a } \\
\text { wireless-sensor-network-based } \\
\text { healthcare monitoring system }\end{array}$ & 10.1049/iet-com.2011.0097 \\
\hline P09 & Shi et al. & $\begin{array}{l}\text { Telemedicine Information } \\
\text { Demands of Chinese Elderly } \\
\text { People in the Future: } \\
\text { Examination of Effectiveness in } \\
\text { Applications }\end{array}$ & 10.4028/www.scientific.net/AMM.235.373 \\
\hline P10 & $\begin{array}{l}\text { Song et } \\
\text { al. }\end{array}$ & $\begin{array}{l}\text { Health sensing by wearable } \\
\text { sensors and mobile phones: A } \\
\text { survey }\end{array}$ & 10.1109/HealthCom.2014.7001885 \\
\hline P11 & $\begin{array}{l}\text { Sun et } \\
\text { al. }\end{array}$ & $\begin{array}{l}\text { Being senior and ICT: a study of } \\
\text { seniors using ICT in China }\end{array}$ & $10.1145 / 2556288.2557248$ \\
\hline P12 & Xie & $\begin{array}{l}\text { Older Chinese, the Internet, and } \\
\text { well-being }\end{array}$ & $10.1891 / 152109807780494122$ \\
\hline
\end{tabular}




\title{
A case for participatory practices in the digital transformation of insurance
}

\author{
Michael PERSSON, CASANDRA GRUNDSTROM \& KARIN \\ VÄYRYNEN
}

\begin{abstract}
Digital transformation, or digitalization, is a near-ubiquitous concept in the contemporary insurance business ecosystem, and describes the work towards change that is carried out in insurance organizations towards novel, digitally empowered practices, services, and management structures. Large-scale studies have identified key factors for successful digital transformation as, among others, customer experience, digital development, and changing business processes. This case study investigates a customer-owned Finnish insurance company that currently resides in the nascent stages of such a transformation. Through a set of 13 interviews with 10 service developers and managers, we set out to understand and evaluate their current digital development practices, based from the perspectives of participatory design, towards informing marketing research. Our findings indicate that while there exists a general understanding of the value of user involvement in the design process, participatory design practices see limited implementation, and there is an apparent disparity between the customer-centric organizational culture and the development practices that it should inform. We suggest work to be put towards the creation of models for evaluating digital transformation, and towards aligning the management of the digital transformation process with a participatory mindset.
\end{abstract}

Keywords: - Digital transformation - Participatory design $・$ Customer experience $\cdot$ Bled eConference •

CoRRespondence AdDREss: Michael Persson, M.Sc., Researcher, University of Oulu, Information Processing Science, Tietotalo, Linnanmaan campus, Finland, e-mail: michael.persson@oulu.fi. Casandra Grundstrom, M.Sc., Researcher, University of Oulu, Information Processing Science, Tietotalo, Linnanmaan campus, Finland, e-mail: casandra.grundstrom@oulu.fi. Karin Väyrynen, Ph.D., Post-doctoral researcher, University of Oulu, Information Processing Science, Tietotalo, Linnanmaan campus, Finland, e-mail: karin.vayrynen@oulu.fi. 
Information systems research has long held that information and communication technology (ICT) enables the potential for innovation in service-based sectors such as insurance (Barrett, Davidson \& Vargo, 2015). With ever-increasing amounts of personal and public data, the ability of healthcare providers and service companies to make informed decisions is improving rapidly (Raghupathi \& Raghupathi, 2014). This shift challenges the traditional, reactive business model of insurance service provision, enabling insurance companies to develop new technology-driven business models and services. Rushing to harvest these opportunities, the contemporary insurance industry has undertaken a near-pervasive journey towards a digital transformation, or digitalization, of their offerings; the enactment of novel digital strategies to meet the challenges of an increasingly complex and technology-saturated context.

Over the last decade, large-scale business studies have been conducted to outline the particulars of digital transformation in the insurance industry. EY (2017: p.3) defines digital transformation as: “... capitalizing on the power of technology to revisit business models, acquire customers to new channels and create essential user experiences." Forrester Consulting (2015: p.1) found that the customer experience is at the heart of the digital transformation, and that “... digital development and customer experience improvement are two key priorities for businesses". However, the digitalization of the insurance industry is lagging behind compared to other fields, and should seek inspiration from technology-based companies (Eling \& Lehmann, 2017; Kettunen \& Lantti, 2017). Strategizing for the creation of customer experience is pervasive in the industry, but despite its recognition by practitioners, it has a limited body of work in marketing research academia (Verhoef et al., 2009), and research on the mindsets and capabilities required for an organization to successfully manage the customer experience is scarce (Lemon \& Verhoef, 2016). Exploring this gap in academic research of marketing practice affords the opportunity for this paper to contribute to the understanding of the customer experience from the human-computer interaction field, which posits that participatory design practices are required in order to properly understand the customer experience (Sanders, 2002). As such, this paper sets out to examine the intersection of participatory theory and marketing research in the context of understanding the creation of customer experience.

How, then, are the customers participating in the creation of the services that is intended to encapsulate their experiences? To address this, we asked the following research question: "To which degree are participatory practices utilized in early-stage digital transformation of insurance?"

Through a case study of a Finnish insurance company, this paper intends to investigate the practices that constitute their digital development, with the purpose of painting a picture of the degree to which participatory practices and mindsets are leveraged in the early-stage digital transformation work in the Finnish insurance context. The remainder of the paper is structured as follows: First, we discuss the theoretical background, 
followed by a description of the research methodology, the results, and discussion of our findings. We conclude the paper with managerial implications, research limitations, and suggestions for future research.

\section{Theoretical Background}

In this section, we define the key topics explored in this paper, and describe their relationships. The topics are structured into related groups and outlined in the following way: Digital transformation and organizational culture, customer experience and user experience, and finally, participatory design. These themes are considered to represent the overarching context of the paper (Digital transformation and organizational culture), a desired outcome of digital transformation, and determinant of success (Improving the customer experience and user experience), and finally the human-computer interaction theory informing the practices through which the aforementioned outcome is likely to be realized (Participatory design).

\subsection{Digital Transformation and Organizational Culture}

In this paper, we borrow the definition of digital transformation from the recent summary of the state of the art of digital transformation in the insurance industry by Eling and Lehmann (2017: p.5) as: “... the integration of the analogue and digital worlds with new technologies that enhance customer interaction, data availability and business processes". Kettunen \& Lantti (2017: pp.14) argue that with increased digitalization, companies invariably drift towards software development, and concludes that "truly transformational changes require revisiting and challenging the fundamental business assumptions and organizational culture". Organizational culture has been defined in many ways, but in the context of this paper we align with Barney (1986: p.657); “... organizational culture typically is defined as a complex set of values, beliefs, assumptions, and symbols that define the way in which a firm conducts its business. [...] culture has pervasive effects on a firm because a firm's culture not only defines who its relevant employees, customers, suppliers, and competitors are, but it also defines how a firm will interact with these key actors". As such it follows, that in facilitating for digital transformation, it is necessary to foster an understanding of the organization through examining the constituent parts of its cultural context. For this paper, we consider organizational culture to be of critical importance towards the contextualization of the digital transformation of the organization.

\subsection{Customer Experience and User Experience}

Customer experience is a holistic representation of a customer's journey (or, set of interactions) through the service provision of a company, outlining, among other things, moments of contact, or touch points (Gentile, Spiller, \& Noci, 2007; LaSalle and Britton, 2003). Customer experience is summarized by Lemon and Verhoef (2016: p.71) who concludes that it is “... a multidimensional construct focusing on a customer's cognitive, emotional, behavioral, sensorial, and social responses to a firm's offerings during the 
customer's entire purchase journey". Further, they posit that customer experience theory is firmly entrenched within marketing research, and holds that "A customer-centric focus is an important facilitator within firms to create stronger customer experiences" (p.84). In the context of digitalization, the ubiquity of the internet is empowering customers to put higher demands on their experience: "Always-online consumers have unprecedented power and choice. If they fail to have a rewarding customer experience in their digital interaction with a brand, they can readily take their business elsewhere." (Collin et al., 2015: p.94). Using methods derived from human-computer interaction practice to understand the customer experience has prior been explored in marketing research, for example, by leveraging the creation of personas (Herskovitz \& Crystal, 2010), a practice more commonly found within user experience. There is a large definition overlap between customer experience and user experience, and the terms are used almost interchangeably depending on the context (Sward \& McArthur, 2007). User experience concerns itself with facilitating the experience of a user as they interact with systems (Benyon, Turner, $\&$ Turner, 2005). Weighing in on the nature of user experience, Benyon et al. holds that experience has to be understood as a whole, and cannot be designed as much as facilitated: "Designers can design for experience, but it is individuals and groups who have the experience." (2005: p.99), implicitly stating that the holistic experience of others exist in their personal context, and as such the understanding of their experience is dependent on them being able and willing to extrapolate on it. This paper considers the outcome of good customer/user experience to be a primary driver of success in digital transformation, and the while the distinction between them is important, it is secondary to understanding the practices that outline the creation of a positive customer/user experience outcome.

\subsection{Participatory Design}

Towards understanding user inclusion in development practices from the humancomputer interaction perspective, we consider Sanders and Stappers (2008) framework of the participatory landscape, later iterated on by Pallot, Trousse, Senach, and Scapin in their social innovation context schema (2011). This schema (Figure 1) explores the contemporary landscape of design practice, where along the x-axis of users, the far left pertains to user-centered design with "Users as observed subjects" and the far right to participatory design with "Users as Value Creation". 


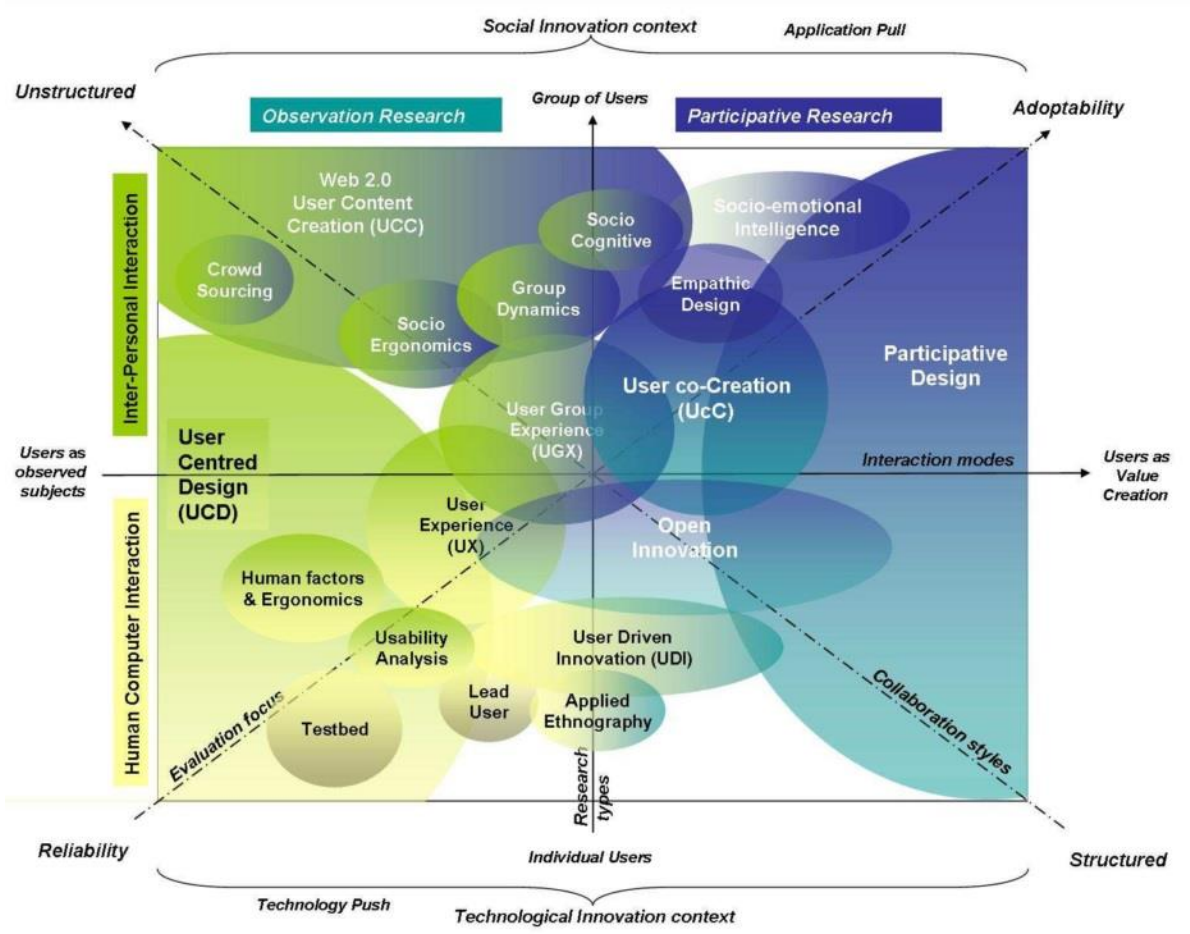

Figure 1: Domain Landscape of the Living Lab Research Map (Pallot et. al, 2011)

Participatory design is as such considered to encompass the areas where research is not so much performed on the users, as is the case of user-centered design, but rather with the users. Spinuzzi (2005) outlines three criteria for participatory design work with the users: Quality of life for workers (i.e. focusing on an outcome that empowers the user), collaborative development (i.e. granting the user agency within the development), and an iterative process (i.e. a cyclical reexamination of the design work being undertaken). Steen, Manschon, and De Koning (2011) have identified three types of benefits in the utilization of participatory practice - benefits for the service design project itself (such as improving the creative process and organization of the project), benefits for the service's customers and/or users (such as a better service experience and higher satisfaction), and benefits for the organization (such as improving creativity and normalizing the focus on customers and users). In this paper, we consider the implementation of participatory practices and mindsets to be suitable towards improving customer experience and organizational culture, and by extension, the digital transformation of the organization. 


\subsection{Case Description}

The subject of this qualitative case study is a Finnish insurance company (from here on out referred to as Alpha). Alpha is one of the biggest actors in the Finnish insurance ecosystem. With the increased digitalization of society and the predictive capabilities of data, the traditional models of insurance provision are growing increasingly inadequate. In the light of this outlined obsolescence, Alpha has set out to modernize its service offerings through a large-scale digital transformation. This transformation is described by their intention to create holistic, life-long relationships with their customers; a one stop package for all of their security needs. In a recent official newsletter, there is an explicit statement from Alpha regarding the context of the case study; establishing the fact that they understand the importance of practices that involve the customers, and that they are currently working on improving the customer experience and digital development of their services. Combined, these factors point towards the suitability for Alpha as a case through which to examine the research question of this paper. The case study presented in this paper investigates the underlying conditions of this transformation by exploring the organizational culture and the service development practices through the lens of contemporary service design - in other words, examining the degree to which Alpha is utilizing participatory practices to inform their digital transformation.

\subsection{Data Collection and Analysis}

We conducted this study as an empirical qualitative case study (Yin, 2013) to construct an understanding of the degree of participatory practices currently employed by Alpha. Data was gathered in the form of semi-structured interviews within the insurance company. The data gathering process of this case study was conducted in the form of semi-structured interviews within the insurance company, primarily selecting for professionals in various executive roles in service development, and structured to elicit descriptions of their work, their attitudes and knowledge towards customer participation in service development, and the policies that influence their professional context. The interviews were carried out across two periods, spaced nine months apart. Some of the interviewees in the first round of interviews was interviewed again for the second round, offering a limited longitudinal perspective. This case study consists of thirteen interviews in total. We interviewed the Analytics/Sales lead, the Chief Digital Officer, the Unit Director (Health and Wellbeing Strategy), and the Digital Health Development Project Manager twice to give us a longitudinal perspective on certain topics. In addition, we interviewed a Business Unit Director, three Development Managers, a Digital Health Director, and a Communications Manager. The interviews lasted between 50 and 90 minutes, with the average interview lasting roughly 80 minutes.

The analysis of the data was initiated in the interview process as a combination of notetaking and asking follow-up questions based on interviewee responses. After the conclusion of the data collection, all the interviews were transcribed in full (non-verbatim, 
$31^{\text {ST }}$ Bled eConference: Digital Transformation: MeEting the Challenges

to allow for clarification of language barrier idiosyncrasies). A number of the transcriptions were then fully coded and catalogued into themes using nVivo, four of which were selected for their relevance to the research question: Service development practices, Participatory practices, Customer experience, and Organizational culture. These themes were subsequently used as the basis of text query searches (Bazeley \& Jackson, 2013) through the rest of the transcribed material. An initial text query that were used to parse the transcriptions for responses pertaining to participatory practices could look like this: ["participat*" OR "co-creat*" OR "co-desig*"], but the queries evolved over time as we discovered new terms and mannerisms used to cogitate about participation in the body of the data.

\section{$4 \quad$ Results}

In this section, we present case findings related to the pertinent fields outlined in the theoretical background. Through investigating the practices and attitudes of the service design professionals, we intend to find descriptions of how services are developed, how customers are being involved in aforementioned development, how customer experience is defined and cogitated about within the company, and comments relating to the organizational culture.

\subsection{Service Development Practices}

Interspersed throughout the interview data, primarily from the development managers, we find mentions of user-centered design practices. The points of customer interaction are noted to exist primarily at the start of the process (as user research in the early stages of development) and at the end of the process (in pilot studies): "In some cases, we have customers involved in the early phases, also, but mainly, I would say, the customer is involved only at the end of the project.", and some notions that "... we don't ask [the customers] enough what they want, we don't test enough [...] [we've] built services [for which we] have no proof that [they are] working, and I don't like that. " Development work is divided amongst both in-house and external practitioners. During the time of the interviews, a customer portal that had previously been in use had closed, disrupting their standard channel of customer outreach.

\subsection{Participatory Practices}

The service designers report explicit knowledge surrounding participatory design, some even having experience of such practices from earlier workplaces and from academia, as well as being able to identify the participatory practices of their competitors. Several service designers were also of the opinion that there is not enough customer participation in the context of Alpha, but some have a positive outlook on the improvements being done in the area: "I think it's is [improving]. I have heard that there is some people who [nowadays] meet with customers, and [are organizing workshops], and things like that. But I think that we should do that much more. And in my project, we haven't done it enough." and "I believe that if we want to create good experiences, good services, we 
need to involve the customers in such a way that we are not merely asking them what we should do, but creating the services together, like actually co-creating them, co-designing them." There are notions that the skill of the practitioners may be insufficient: “... people here, the way I see it, don't really have the skill set-they don't really know how to involve the customers." but we also find opposite notions, implying that customer involvement is already integral to contemporary practice: “... I would say it's an essential operation mode for us - involving our clients, exposing them to how we operate and what we plan, and then taking their feedback into account."

\subsection{Customer Experience}

The customer experience theme presented itself in a majority of the interviews, from different perspectives, ranging from descriptions of the current experience of being an insurance customer, to the analysis of the definition of customer experience. The chief digital officer considered the role of the customer in the following way; "... how we use the client is to [continuously] monitor [their value and customer experience]. [...] we want to have the best customer experience, and then we can see [whether] this is the right way, and we try to understand where the customer experience came from, and [put] more focus on things that maximize the value and the customer experience." Another notion underlines the importance of customer experience in delivering the ultimate outcome of the digital transformation, that is, their vision of a pervasive personal security: “... we will actually recreate the customer experience when it comes to [Alpha] and their clients, and obviously, that's where we believe that it will be one of the key success factors in growing our business, in the local market." Some interviewees noted on the ambiguity in the definition of what customer experience means; "Someone would say that it's good customer experience that the billing is functioning properly, and for others it means that you feel good in communication with us. And [for yet] another it means that good customer experiences is that customer can choose different things and it will influence the solution. So the definition is not ready yet." and "... many people understand, nowadays, differently - What is the good customer experience, and what customer involvement means... ... it is very challenging to achieve one common metric so that everyone understands it in the same way." In regards to how the idea of customer experience is utilized in Alpha, it largely appears to be done as an evaluation rather than used as a tool to inform the design. One of the service designers claims that the company does not yet have a systematic, holistic approach to the analysis of customer experience, and that "it would be a good idea to understand the customer experience [through the use of] the application", underlining that even as the customer experience is understood to be a tool for evaluation rather than a design consideration, it's not widely used in either way.

\subsection{Organizational Culture}

The chief digital officer compares the organization to an "armada of ships", painting a metaphor for the cooperative, regional structure of the company, each led separately, but following a central direction, and lending an air of agility to the organization. There are 
$31^{\text {ST }}$ Bled eConference: Digital Transformation: MeEting the Challenges

differing notions of how the organizational culture of Alpha is affecting its development practices. A shift towards agile service development is believed to affect the organization, with some resistance: “... we are moving very strictly [towards] Sapphire methodology, which is agile, so we are changing our culture based on that. But still, there is sometimes too much bureaucracy [regarding those] methodologies..." and "... the top management has to give responsibility to the lower [levels] and rely on the experts. And this is the biggest cultural movement which should be taken." There are also notions about the upper management of the company as being detached from the practices: "... whatever gets the job done, [the senior management is] fine with that. They are not really interested in practices as long as [those practices] deliver results." As Alpha is in the process of entering into a service eco-system with third-party developers and healthcare providers, they have to act on disruptions to business as usual, and reconsider their customer experience in the new context: "Health is something where we foresee changes, [and we hope to be able to grab onto the] opportunity and build businesses around it, and then of course, build our customer experiences around it [...] [this represents] a disruption, when it comes to our current and existing business models". The place of the customer in the hierarchy of the organization was a recurrent theme throughout the case study, and the notions are mixed. Most interviewees hold that the customer is either at the top, or should be at the top: "... to me personally, the customer is in the top. And I hope [everyone in the company] says the same." and "I would like to say that the customer is rather high in our hierarchy, that we really do try to think of things from the customer's point of view [...] But I'm not sure if that's the case considering [the company] as a whole." represents the two overall types of responses in this category.

\section{$5 \quad$ Discussion}

In this section, we discuss the findings of the case study as outlined above.

While we find notions of participatory practices interspersed in the interview responses, the amount of user research that is carried out in the service development appears to be present at degree (according to the opinions of the service developers), as well as more closely related to user-centric practices than to participatory design practice; in that they observe and interact with largely passive users from an expert perspective (Pallot et al., 2011), and commonly only used at the beginning and the end of the design process. Regardless of this lack of participatory practices in the service development context, several of the interviewees placed the users central to the business and at the top of the company hierarchy. Despite talk of customer-centricity and customer experience, most service developers largely conceded to the issue of poor customer inclusion practices (often mentioned in conjunction with answering about the customers' purported place in the company hierarchy), and expressed skepticism about the notion that Alpha could truly be considered to possess a customer-centric organizational culture. Having an apparently customer-centric culture, it would seem, does not necessarily translate into customercentric development practices, something that could be exacerbated by a fuzzy definition of customer experience. 
Digital transformation literature posit that organizations stand to benefit from a move towards the structure of software development companies, as they become more invested in the technology-driven development practices that inform their service offerings (Kettunen \& Lantti, 2017). This movement is reflected in the shift of development methodology of Alpha, in their efforts to become more agile. As the management may hold the conviction that the company is customer-centric as a core value, despite the high variance in the understanding of customer experience, it may be difficult to align the organizational culture with participatory shortcomings in digital development practice, a notion that appears to be further exacerbated by a purported indifference towards practice in the higher echelons of the company. The apparent mismatch between customer-centric policy and customer-centric practice could represent a core issue in digital transformation work.

Despite the similarities between the objectives of customer experience and user experience, the cross-pollination between human-computer interaction and marketing research does not appear advanced. In the context of digital transformation, this might prove to be shortsighted, as combining both perspectives could offer new insights towards technology-based development and marketing practices in which the user-customer is more intrinsically invested in the formation of their own experiences. Acquisition and retention of digital talent needs to be prioritized throughout the organization, and a participatory mindset, or at least an understanding of company development practices, should be introduced to the upper management towards aligning organizational culture with organizational practice (Hansen, Kraemmergaard, \& Mathiassen, 2011). Further studies of the interaction between conductors of early-stage digital transformation and their customers, particularly through a participative lens, could inform new practice models through which to co-create customer experience and facilitate for digital transformation.

\section{Conclusion}

In this paper, we report on the results of a case study conducted in a large insurance provider in Finland. We studied to which degree participatory practices are employed by Alpha, an insurance provider in the early stages of a digital transformation initiative. We found that, despite internal knowledge of participatory practices among service developers, such practices only saw limited implementation in service development. We argue that a fuzzy definition of customer experience as well as a disparity between policy and practice can be held as preliminary reasons for the absence of customer inclusion.

This study has several limitations. The case study was limited to one company, and extending the study to other insurance providers would have allowed for a comparison of whether our findings would be generalizable to the greater context of the insurance sector, and/or whether they represent a trend in insurance provision business in Finland in general. In addition, interview studies can only extrapolate on the opinions and attitudes of individual people based on the topics of the discussion, and as such can only give a fairly one-dimensional and decontextualized interpretation of the organizational culture. 
Future studies of conductors of digital transformation involving their customers in development and customer experience creation could inform new models of practice through which to successfully facilitate the digital transformation. Investigation of the intersection of marketing research and participatory design is of particular interest to align the marketing research field in the practices that inform digital transformation.

\section{References}

Barney, J. B. (1986). Organizational Culture: Can It Be a Source of Sustained Competitive Advantage? The Academy of Management Review, 11(3), 656. https://doi.org/10.2307/258317

Barrett, M., Davidson, E., \& Vargo, S. L. (2015). Service Innovation in the Digital Age : Key Contributions and Future Directions. MIS Quarterly, 39(1), 135-154. https://doi.org/10.1016/S0090-2616(98)90006-7

Bazeley, P., \& Jackson, K. (Eds.). (2013). Qualitative data analysis with NVivo. Sage Publications Limited.

Benyon, D., Turner, P., \& Turner, S. (2005). Designing interactive systems: People, activities, contexts, technologies. Pearson Education.

Collin, J., Hiekkanen, K., Korhonen, J. J., Halén, M., Itälä, T., \& Helenius, M. (2015). Leadership in Transition: The Impact of Digitalization on Finnish Organizations. Science And Technology.

Forrester Consulting (2015). Digital Transformation in the Age of the Customer [White paper]. Retrieved March 16, 2018, from Accenture:https://www.accenture.com/_acnmedia/Accenture/ConversionAssets/DotCom/Documents/Global/PDF/Digital_2/Accenture-Digital-Transformation-In-TheAge-Of-The-Customer.pdf

Eling, M., \& Lehmann, M. (2017). The Impact of Digitalization on the Insurance Value Chain and the Insurability of Risks. Geneva Papers on Risk and Insurance: Issues and Practice, 138. https://doi.org/10.1057/s41288-017-0073-0

EY (2017). Digital Transformation in Insurance: Driving immediate value and enabling future innovation [White paper]. Retrieved March $16^{\text {th }}, 2018$, from EY: http://www.ey.com/Publication/vwLUAssets/ey-digital-transformation-ininsurance/\$FILE/ey-digital-transformation-in-insurance.pdf

Gentile, C., Spiller, N., \& Noci, G. (2007). How to Sustain the Customer Experience: An Overview of Experience Components that Co-create Value With the Customer. European Management Journal, 25(5), 395-410. https://doi.org/10.1016/j.emj.2007.08.005

Hansen, A. M., Kraemmergaard, P., \& Mathiassen, L. (2011). Rapid Adaptation in Digital Transformation: A Participatory Process for Engaging IS and Business Leaders. MIS Quarterly Executive, 10(4)

Herskovitz, S., \& Crystal, M. (2010). The essential brand persona: storytelling and branding. Journal of Business Strategy, 31(3), 21-28. https://doi.org/10.1108/02756661011036673

Kettunen, P., \& Laanti, M. (2017). Future software organizations - agile goals and roles. European Journal of Futures Research, 5(1), 16. https://doi.org/10.1007/s40309-017-0123-7 LaSalle, D., \& Britton, T. A. (2003). Priceless. Turning ordinary products into extraordinary experience, Harvard Business School Press, Boston, Massachusetts.

Lemon, K. N., \& Verhoef, P. C. (2016). Understanding Customer Experience Throughout the Customer Journey. Journal of Marketing, 80(6), 69-96. https://doi.org/10.1509/jm.15.0420

Pallot, M., Trousse, B., Senach, B., \& Scapin, D. (2011). Living Lab Research Landscape : From User Centred Design and User Experience towards User Cocre ation. 
Raghupathi, W., \& Raghupathi, V. (2014). Big data analytics in healthcare: promise and potential. Health Information Science and Systems, 2(1), 3. https://doi.org/10.1186/2047-2501-2-3

Sanders, E. B. E. (2002). From user-centered to participatory design approaches. Design and the Social Sciences Making Connections, 1-8. https://doi.org/10.1201/9780203301302.ch1

Sanders, E. B.-N., \& Stappers, P. J. (2008). Co-creation and the new landscapes of design. CoDesign, 4(1), 5-18. https://doi.org/10.1080/15710880701875068

Spinuzzi, C. (2005). The Methodology of Participatory Design. Technical Communication, 52(2), 163-174. https://doi.org/10.1016/j.infsof.2008.09.005

Steen, M., Manschot, M., \& De Koning, N. (2011). Benefits of co-design in service design projects. International Journal of Design, 5(2).

Sward, D., \& Macarthur, G. (2007). Making user experience a business strategy. In E. Law et al. (eds.), Proceedings of the Workshop on Towards a UX Manifesto (Vol. 3, pp. 35-40).

Verhoef, P. C., Lemon, K. N., Parasuraman, A., Roggeveen, A., Tsiros, M., \& Schlesinger, L. A. (2009). Customer Experience Creation: Determinants, Dynamics and Management Strategies. Journal of Retailing, 85(1), 31-41. https://doi.org/10.1016/j.jretai.2008.11.001

Yin, R.K. (2013). Case Study Research. (5 $5^{\text {th }}$ edition) Thousand Oaks, SAGE Publications Ltd. 


\title{
How a flexible collaboration infrastructure impacts healthcare information exchange
}

\author{
ROGIER VAN DE WETERING \& JOHAN VERSENDAAL
}

\begin{abstract}
Exchanging health information and data is considered to be critical for modern hospital operations. Research shows that exchanging, e.g., laboratory results, clinical summaries, and medication lists, across the boundaries of hospitals, will improve the efficiency, quality, costeffectiveness, and even safety of healthcare practices. However, views and strategies differ on how hospitals can facilitate or enable this exchange process, given the high dynamics of technology and IT developments. We explore a hypothesized relationship between a flexible collaboration infrastructure and health information and data exchange. This study builds on the resource-based view of the firm and subsequently tests two hypotheses using PLS-SEM analysis on a sample of 983 European hospitals. We find that there is a significant positive relationship between flexible collaboration infrastructures and health information and data exchange. Hospitals' security measures to protect the confidentiality, integrity, and availability of the data conditions this relationship.
\end{abstract}

Keywords: • Flexible collaboration infrastructure $\bullet$ IT flexibility $\bullet$ Health information and data exchange (HIDE) - PLS-MGA • Data security • Electronic Medical record (EMR) •

CoRRESPONDENCE AdDREss: Rogier van de Wetering, Ph.D., Associate Professor, Open University, Faculty of Management, Science and Technology, Valkenburgerweg 177, Heerlen, the Netherlands, e-mail: rogier.vandewetering@ou.nl. Johan Versendaal, Ph.D., Professor, Open University and HU University of Applied Sciences, Utrecht, the Netherlands, e-mail: johan.versendaal@ou.nl. 
R. van de Wetering \& J. Versendaal: How a flexible collaboration infrastructure impacts healthcare information exchange

Organizations currently explore and exploit new digital strategies and innovative technologies to survive in competitive and turbulent markets (Lyytinen, Yoo, \& Boland Jr, 2016; Mithas, Tafti, \& Mitchell, 2013). This trend also holds for the healthcare sector and hospitals in particular (Blumenthal, 2010; Hendrikx, Pippel, Van de Wetering, \& Batenburg, 2013; Kohli \& Tan, 2016). To this end, hospitals are in need of having realtime healthcare information and (patient) data (Hersh et al., 2015; Vest, Campion, Kaushal, \& Investigators, 2013). Driven, also, by various mandatory requirements, we see a trend toward rapid digitization of large amounts of patient data. This digitization is often complemented with the capability of compiling and electronically exchanging interoperable data with other providers within the ecosystem (Walker, Pan, Johnston, \& Adler-Milstein, 2005).

Health information and data exchange (HIDE) enables hospitals to share clinical information, e.g., laboratory results, physician documentation, and medication lists across the organizations' boundaries (Vest et al., 2013). HIDE can boost efficiency, reduce health care costs, and improve outcomes for patients (Hersh et al., 2015). Therefore, many hospitals are considering the adoption and use HIDE as a source of value (Patel, Abramson, Edwards, Malhotra, \& Kaushal, 2011; Walker et al., 2005). The recent attention to patient privacy (strengthened by the European General Data Regulation and Protection, GDPR, regulations) and systems security complement this these observations. Up until now, in practice, views differ on how hospitals can facilitate and enable HIDE in a safe and privacy-minded context, using specific IT configurations. Let alone, how the hospital, within the broader hospital ecosystem can leverage and deploy this strategic competence to enhance quality and services benefits. Typical collaboration systems and infrastructures do not adequately support organizations and business networks to exchange, use and leverage resources (Begole, Rosson, \& Shaffer, 1999; Byrd \& Turner, 2000). Flexible infrastructure configurations are considered a critical component to adapt and reconfigure IT architectures strategically and operationally, also in healthcare (Bhatt \& Grover, 2005; Kung, Wang, \& Kung, 2016). HIDE, however, is still in the early adoption phase (Patel et al., 2011). Gartner classified HIDE as a real-time health system technology that is currently beyond the peak of inflated expectations and is now sliding through (Runyon \& Pessin, 2017). Therefore, Gartner analysts observed inconsistent results from this technology and implementations often fail to deliver (Runyon \& Pessin, 2017). Thus, the full potential of HIDE in practice currently remains mostly unrealized even as mature IS/IT can provide patients with instantaneous information from anywhere and anyone (Carvalho, Rocha, van de Wetering, \& Abreu, 2017; Patel et al., 2011).

This study builds on both the shortcomings and foundations of previous HIDE investigations. We mainly focus on the question whether, and if so, to what extent a hospital's flexible collaboration infrastructure (as of now: FCI) influences HIDE. We derive the notion of FCI in this study from various relevant IT capabilities, i.e., IT flexibility and collaborative studies and perspectives (Broadbent, Weill, \& Neo, 1999; Camarinha-Matos, Afsarmanesh, Galeano, \& Molina, 2009; Duncan, 1995; Österle, 
Fleisch, \& Alt, 2012; Weill \& Vitale, 2002). Therefore, we consider hospitals' FCI as an integrated set of reliable IT assets and networking functionalities that support existing applications and anticipate and enable new possibilities with a nexus of relationships that can be forged within the hospital ecosystem. In practice, naturally, the exchange of health data should be accompanied by fitting security measures and procedures that contribute to confidentiality, integrity, availability, and timeliness of health information and patient's data (Benharref \& Serhani, 2014; Fedorowicz \& Ray, 2004; Sahama, Simpson, \& Lane, 2013).

We draw upon the resource-based view of the firms (RBV) (Barney, 1991) as our theory base. This theory provides a solid foundation to think about how IT contributes to organizational benefits and value creation (Wade \& Hulland, 2004). Given the above, we drive this research by the following questions: 'What is the impact of a hospital's FCI on HIDE?' and 'What is the conditioning effect of deployed hospital's security measures on this particular relationship?'

We have structured this paper as follows. First, we review theoretical aspects relevant to this study, propose our research model and develop hypotheses. The methods and results section then follows these sections. We end with main findings, discussions, inherent limitations of this study and we outline future research opportunities.

\section{Research model and hypotheses}

\subsection{The resource-based view of the firm}

The RBV is an acknowledged theory within the management domain as well as within the IS community. The RBV explains how organizations achieve a competitive advantage as a result of the resources they own or have under their control (Barney, 1991). Scholars apply this resource-based theory as a foundation in the IS context through the notion of single IT resources, sets of IT resources and IT capabilities (Bhatt \& Grover, 2005; Wade \& Hulland, 2004). The central premise of the RBV within the context of IT is that only investing in IT is insufficient to enhance competitive performance (Caldeira \& Ward, 2003; Wade \& Hulland, 2004). We follow this so-called 'resource-based' line of reasoning and argue that an IT infrastructure-that is both flexible and supports collaboration functionality - is deemed appropriate to target IT resources to efficiently exchange health information and data within and between hospitals.

\subsection{Flexible collaboration infrastructure}

Past literature proposed that IT infrastructure flexibility is a new competitive weapon that determines the value of that infrastructure to organizations (Byrd \& Turner, 2000). IT flexibility supports organizations to get sustained organizational advantage and even accommodates frequent business change, albeit to some extent (Mikalef, Pateli, \& van de Wetering, 2016; Tafti, Mithas, \& Krishnan, 2013; R. Van de Wetering, Mikalef, \& Pateli, 2017). Although flexible IT infrastructures can efficaciously alter the way hospitals 
exchange information, it is conceivable-following the RBV theoretic lens-that this aspect without the presence of complementary networking and collaboration assets, resources and capabilities is not sufficient to enable the process of HIDE. Collaborating organizations have become the 'new normal' in current dynamic markets to innovate, change and collaborate (Grefen, 2013). Within the literature on collaborative networks, information sharing is hardly addressed and mostly taken for granted, while these types of collaborations typically require fine-grained harmonization between resources (Grefen et al., 2009). IT-enabled collaborative capabilities form a foundation for an organization's ability to improve boundary spanning capabilities (Dewett \& Jones, 2001; Gnyawali \& Park, 2011) and thus also the exchange of data resources. Synthesizing from the above, we see the value and contribution of FCI in facilitating cross-enterprise HIDE. Following (Broadbent et al., 1999; Byrd \& Turner, 2000; Camarinha-Matos et al., 2009; Duncan, 1995; Österle et al., 2012; Termeer \& Bruinsma, 2016; Rogier van de Wetering, Mikalef, \& Helms, 2017; Weill \& Vitale, 2002) we represent FCI through two core dimensions, i.e., 1) IT flexibility and 2) collaborative networking assets. We expect that the process of exchanging health information mainly depends on a) the ability to flexibly anticipate on changes in circumstances and context, and b) the ability of interaction and collaboration with other providers, like other hospitals, external general practitioners, external specialists, and health care providers, even in other countries. Hospitals are becoming more aware that HIDE and other types of IT-enabled innovations promote patient, clinical as well as add social and organizational value by extending organizational boundaries and collaborating with multiple entities. Hence, we define:

\section{Hypothesis 1: FCIs within hospitals positively influences HIDE.}

\subsection{Security and privacy}

Conditions under which IT infrastructure capabilities and FCIs in particular add value have been a subject of much debate. Despite the enormous potential gains, there could be obstacles that impair the diffusion of IT, its adoption, usage and its performance contributions. Among those barriers are the perceived threats to the security and privacy of patients' health information and data (Sahama et al., 2013). Therefore, many countries around the world now working on legislative regulation of HIDE (in Europe: GDPR). In the meantime, adequate security measures and procedures within hospitals could contribute to confidentiality, integrity, availability, and timeliness of health information and patient's data (Benharref \& Serhani, 2014; Fedorowicz \& Ray, 2004; Sahama et al., 2013). However, much ambiguity remains concerning the influence of security measures on HIDE. Securing sensitive health data is an enormous challenge. It is in this process that we foresee that hospitals that heavily invest in security and privacy measures will be better equipped to facilitate HIDE. Hence, we propose:

Hypothesis 2. The degree to which hospitals deploy security measures-to protect patient data stored and transmitted by the hospital's IT system - influences the strength of the relationship between the FCI and HIDE. 
Figure 1 summarizes our research model and the associated hypotheses.

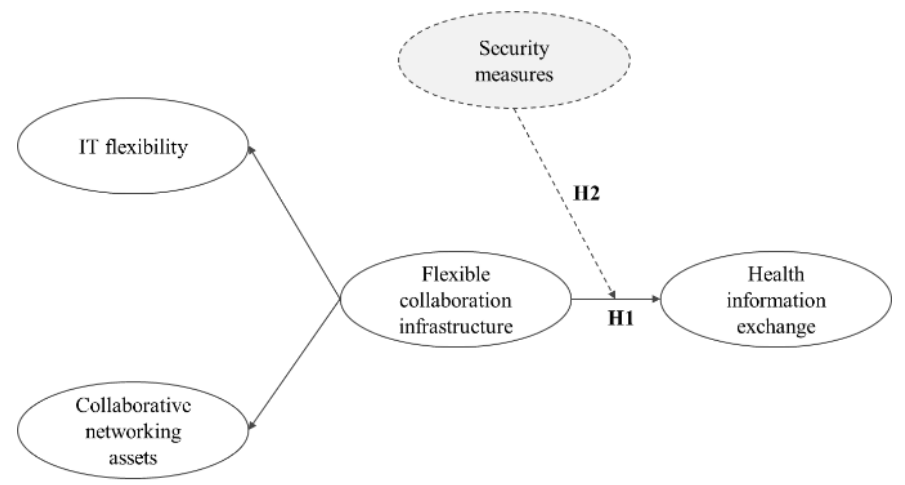

Figure 1: Research model and hypotheses

\section{$3 \quad$ Research methods}

\subsection{Design and sample}

To address our research questions, we need a substantial cross-sectional data sample containing considerable variation in technical, organizational and data (and information) capability measurements. Therefore, we used a unique, comprehensive cross-sectional dataset-from the European Hospital Survey: Benchmarking deployment of e-Health services (2012-2013) — to test our hypotheses. This dataset contains about 1,800 hospitals across 30 countries within Europe. In this survey, data were obtained from representative sample of European acute hospitals to benchmark their level of eHealth and medical IT deployment and take-up of ICT and eHealth applications. Therefore, the survey categories and questions and cover a wide range of aspects from IT infrastructure, IT applications, exchange of health data and information, and security and privacy issues. Initial pilots contributed to the quality of the survey. The final questionnaire was in most cases completed by chief information officers (CIOs), IT managers (directors) and Chief operating officer (COO) / Operations Manager.

We performed Harman's single factor test using SPSS v24 on the included constructs in our study to control for common method bias (CMB). We found that one factor could not attribute the majority of variance (Podsakoff, MacKenzie, Lee, \& Podsakoff, 2003). Therefore, our data and results are not affected by CMB.

Within our current scope, we only focused on the hospitals within our sample that use Electronic Medical Records (EMRs) for HIDE either through i) a hospital-wide EMR (shared by all clinical service departments), or ii) multiple local/departmental EMR systems which share information with a central EMR. EMRs integrate a wide variety of modules and IT components within the hospital enterprise to integrally and centrally 
R. van de Wetering \& J. Versendaal: How a flexible collaboration infrastructure impacts healthcare information exchange

collect, store and distribute patient health information (DesRoches et al., 2013). Thus, based on the concepts within our research model and to govern the data quality (due to missing values), we conservatively removed 768 cases. We included 983 hospitals in the final analyses.

\subsection{Measurement}

Each of the included operationalized latent constructs in our study are inspired based on past empirical and validated work, as initially presented in section 2.1. IT flexibility, can be broadly considered as the degree of decomposition of an organization's IT portfolio into loosely coupled subsystems that communicate through standardized interfaces (Byrd \& Turner, 2000; Mikalef et al., 2016). Accordingly, we operationalized this quality through I) the degree of standardization - referring to established standards/policies on how applications connect and interoperate with each other (Weill \& Ross, 2005) - and II) the degree to which applications are integrated. Standardization and thus also the standards the hospitals' systems support or comply with (e.g., HL7, IHE integration profiles, DICOM) and system integration are vital for HIDE to achieve its goal.

We adopt two critical indicators for hospital's collaborative networking assets, i.e., i) hospitals' reach of a computer system (from personal computers that are not part of a hospital-wide system toward systems are part of regional or national networks as reach refers to locations) (Broadbent et al., 1999; Dewett \& Jones, 2001; Termeer \& Bruinsma, 2016) and ii) the degree to which also patients - as an important stakeholder in this context — have online access to their records (Kruse, Bolton, \& Freriks, 2015). Finally, we operationalized HIDE as a latent construct containing the following measures 12 measurements ${ }^{36}$. All items were measured on or rescaled to a Likert scale from 1 to 5 (not in place - fully implemented), apart from our moderating variable security measures. We operationalized ${ }^{37}$ security measures using a binary scale based on theoretically appealing cutpoints (Baron \& Kenny, 1986; Sauer \& Dick, 1993). Therefore, group $1(\mathrm{~N}=482)$ represents low-security measures (cumulative scores 1 and 2) and group $2(\mathrm{~N}=501)$ represents high-security measures (cumulative scores 3 to 6). Together, they form representative groups of equal size.

This study incorporates the control variable 'hospital type.'

\footnotetext{
36 1) patient interaction, 2) make appointments at other care providers, 3) send/receive referral and discharge letters, 4) transfer prescriptions to pharmacists, 5) exchange medical patient data, 6) receive laboratory reports and 7) share them with other healthcare professionals, 8) exchange patient medication lists with healthcare professionals / providers, 9) exchange radiology reports, 10) exchange medical patient data, 11) certify sick leaves and 12) certify disabilities.

${ }^{37}$ This question contained multiple possible answers: (i) encryption of stored data, (ii) Encryption of transmitted data, (iii) workstations with access through health professional cards, (iv) workstations with access through fingerprint information, (v) workstations with access through a password, (vi) data entry certified with digital signature
} 
R. van de Wetering \& J. Versendaal: How a flexible collaboration infrastructure impacts healthcare information exchange 
R. van de Wetering \& J. Versendaal: How a flexible collaboration infrastructure impacts healthcare information exchange

We use PLS (Partial least squares)-SEM to assess our research model (Hair Jr, Hult, Ringle, \& Sarstedt, 2016). PLS-SEM is a mature variance-based approach that has undergone severe methodological and theoretical examinations and has been the target of constructive scientific debates (Jörg Henseler, Hubona, \& Ray, 2016). Hence, we estimate our model's parameters using SmartPLS version 3.2.7. (Ringle, Wende, \& Becker, 2015). We propose a reflective measurement model (Mode A) for both the first and second-order constructs through which the manifest variables are affected by the latent variables. For this study, we used 500 replications within the bootstrapping procedure to obtain stable results and to interpret the structural model. As for sample size requirements, the included data exceeds all minimum requirements.

\subsection{Outer model assessment}

We assessed the reliability of the outer model for the construct and item level. Reliability at the construct level was performed by examining the composite reliability (CR) scores and established that their values were above the threshold of 0.70 (Nunnally \& Bernstein). Furthermore, we assessed the obtained construct-to-item loadings. Hence, following (Fornell \& Bookstein, 1982) we removed all manifest indicators with a loading less than $0.6^{38}$ from our model. In total, we removed six indicators (i.e., no. 1, 2, 4, 10, 11, and 12) from the HIDE construct. Next, to reliability assessments, researchers should evaluate their measurement models by their convergent and discriminant validity (Campbell \& Fiske, 1959; Fornell \& Larcker, 1981; Hair Jr et al., 2016). We analyzed the average variance extracted (AVE), i.e., the average variance of measures accounted by the latent construct to assess convergent validity. The lowest AVE value is 0.550, and that still exceeds the lower limit of 0.50 (Fornell \& Larcker, 1981).

Discriminant validity concerns the extent to which constructs are genuinely distinct from other constructs by empirical standards (Hair Jr et al., 2016). We assessed discriminant validity through different, but related tests. First, we checked for cross-loadings on other constructs (Farrell, 2010). Second, we investigated if the square root of the AVEs of all constructs is larger than the cross-correlation (Chin, 1998). All correlations among all constructs were below the threshold (0.70) (Fornell \& Larcker, 1981). Third, and finally, we employed the heterotrait-monotrait (HTMT) ratio of correlations approach by Henseler, Ringle, \& Sarstedt (Jörg Henseler, Ringle, \& Sarstedt, 2015) that showed acceptable outcomes.

Based on these outcomes, we established adequate convergent and discriminant validity. Table 1 shows the primary outcomes of the reliability, convergent and discriminant validity assessments of our model.

\footnotetext{
${ }^{38}$ An even more liberal threshold is a loading value of 0.4 for exploratory studies, see (Hulland, 1999).
} 
Table 1: Assessment of reliability, convergent and discriminant validity of reflective constructs

\begin{tabular}{|l|c|c|c|}
\hline & 1 & 2 & 3 \\
\hline 1. Collaborative networking assets & $\mathbf{0 . 7 5 1}$ & & \\
\hline 2. IT flexibility & 0.277 & $\mathbf{0 . 7 8 1}$ & \\
\hline 3. Health information exchange & 0.272 & 0.396 & $\mathbf{0 . 7 4 2}$ \\
\hline \hline AVE & 0.564 & 0.610 & 0.550 \\
\hline Composite reliability & 0.721 & 0.757 & 0.879 \\
\hline
\end{tabular}

\subsection{Hypotheses testing and uncovering heterogeneity issues}

We estimated and validated the inner model, i.e., structural model and the relationship among its constructs to analyze the hypotheses. Outcomes reveal that FCI is significantly related to $\operatorname{HIDE}(\beta=.433 ; t=16.795 ; p<.0001)$. Moreover, the coefficient of determination $\left(R^{2}\right)$ explains $18.3 \%$ of the variance for HIDE $\left(R^{2}=.181\right)$ with the control variable 'hospital type' showing a non-significant effect on $\operatorname{HIDE}(\beta=-.040, t=1.342, p$ $=.180)$. These outcomes confirm our first hypothesis that hospitals' FCI positively influences HIDE.

To test, if security measures have conditioning (i.e., moderating) impact on the relation between FCI and HIE; we performed a non-parametric multi-group analysis (PLS-MGA) (J Henseler, Ringle, \& Sinkovics, 2009). Henceforth, we divided our sample into two separate groups (Hair Jr et al., 2016): group $1(N=482)$ with a low level of security measures and group $2(N=501)$ with a high degree of deployed security measures within the hospital. This subgroup approach is a widely used in regression-based approaches to test effects of categorical moderating variables (Baron \& Kenny, 1986). We estimated the model for these two groups separately following Henseler et al. (2009). Group differences are significant (at the $5 \%$ probability of error level) within this procedure if the obtained $p$-value is $\leq 0.05$ or $\geq 0.95$ for the focal path, regression coefficients. Hence, analyses show a statistically significant difference $(p=.971)$ between group one and two. For group one (low-level of security) we see a significantly lower impact on HIDE by FCI ( $\beta$ $=.346, t=8.460, p<.001)$. The model run for this particular group explains $11.7 \%$ of the variance for HIE. Group two (high-level of security), on the other hand, shows a significantly stronger effect, i.e., $(\beta=.451, t=13.067, p<.001)$. More so, the model's inner model for group two has an $R^{2}=.195$. These obtained outcomes confirm our second hypothesis.

Next, we controlled for possible unobserved heterogeneity within these two subgroups by employing the finite mixture (FIMIX) PLS procedures (Sarstedt \& Ringle, 2010). Therefore, we segmented the subgroups into two to five segments (s2 - s5) and ran separate analyses. Segmentation results do confirm that there indeed are factors that are currently not included in our analysis which might explain differences in coefficients of determination (up to $R^{2}=.335$ for the high-security group; a maximum $R^{2}=.135$ for the low-security group) across various hospital groups. Such a comprehensive FIMIX 
analysis is beyond our current scope. Finally, to evaluate the overall predictive relevance of our model, we performed Stone-Geisser's test using the blindfolding procedure in SmartPLS version 3.2.7. (Ringle et al., 2015). All case $Q^{2}$ values for the single endogenous construct (for both communality and redundancy measures) were above the threshold value of zero, thereby indicating predictive relevance.

\section{$5 \quad$ Discussion, conclusions, and limitations}

From literature, we know that HIDE is a promising technology-driven approach to improve resource utilization, and quality of healthcare delivery (Vest et al., 2013). Outcomes of our analyses empirically support our claim and hypothesis that hospitals can enable HIDE through the use of FCIs. Furthermore, as substantiated by PLS-MGA analyses, hospitals' FCIs can be exploited even more to facilitate the process of information sharing through the deployment of a range of security measures. With these outcomes, we make two substantial contributions to the literature. First, we contribute to the current knowledge base on HIDE by demonstrating the enabling effect of an FCI. Our results confirm past and recent claims made about the enabling role of flexible infrastructure configurations (Bhatt \& Grover, 2005; Byrd \& Turner, 2000; Kung et al., 2016). However, our study now shows that crucial role in the context of HIDE. Second, we extend recent conceptual literature (Benharref \& Serhani, 2014; Sahama et al., 2013) by showing - using empirical data of 983 European hospitals - the conditioning role of deployed security measures in the process of exchanging health data.

These current insights should be interpreted with caution as Governmental agencies in various countries may regulate HIDE and thus also hospitals' range of possibilities and opportunities to develop and deploy HIDE. Notwithstanding, from a practical relevance perspective, we believe that these results can help decision-makers in the process of efficiently allocating resources, and make purposeful IT investments to facilitate HIDE within the hospital enterprise.

Some limitations constrain this study that future research should seek to address. Our FIMIX results indicate that various homogeneous sub-groups can explain higher levels of $R^{2}$ for HIDE. Future research could focus on a configurational approach (Meyer, Tsui, $\&$ Hinings, 1993) through which researchers can compare groups and (sub)segments in detail. A good starting point would be looking at, e.g., the degree of IT investments, organization size, and other potentially related digital capabilities (such as the capability to process information or telehealth). Hence, research could then refine our work so that we can advance our understanding of HIDE even further. 


$$
\begin{array}{r}
31^{\text {ST }} \text { BLED ECONFERENCE: Digital TRANSFORMATION: MEETING THE CHALLENGES } \\
\text { JUNE } 17 \text { - 20, 2018, BLED, SLOVENIA, CONFERENCE PROCEEDINGS } \\
\text { R. van de Wetering \& J. Versendaal: How a flexible collaboration infrastructure impacts } \\
\text { healthcare information exchange }
\end{array}
$$

\section{References}

Barney, J. (1991). Firm resources and sustained competitive advantage. Journal of management, 17(1), 99-120.

Baron, R. M., \& Kenny, D. A. (1986). The moderator-mediator variable distinction in social psychological research: Conceptual, strategic, and statistical considerations. Journal of personality and social psychology, 51(6), 1173.

Begole, J., Rosson, M. B., \& Shaffer, C. A. (1999). Flexible collaboration transparency: supporting worker independence in replicated application-sharing systems. ACM Transactions on Computer-Human Interaction (TOCHI), 6(2), 95-132.

Benharref, A., \& Serhani, M. A. (2014). Novel cloud and SOA-based framework for E-Health monitoring using wireless biosensors. IEEE journal of biomedical and health informatics, 18(1), 46-55.

Bhatt, G. D., \& Grover, V. (2005). Types of information technology capabilities and their role in competitive advantage: An empirical study. Journal of Management Information Systems, 22(2), 253-277.

Blumenthal, D. (2010). Launching hitech. New England Journal of Medicine, 362(5), 382-385.

Broadbent, M., Weill, P., \& Neo, B.-S. (1999). Strategic context and patterns of IT infrastructure capability. The Journal of Strategic Information Systems, 8(2), 157-187.

Byrd, T. A., \& Turner, D. E. (2000). Measuring the flexibility of information technology infrastructure: Exploratory analysis of a construct. Journal of Management Information Systems, 17(1), 167-208.

Caldeira, M. M., \& Ward, J. M. (2003). Using resource-based theory to interpret the successful adoption and use of information systems and technology in manufacturing small and mediumsized enterprises. European Journal of Information Systems, 12(2), 127-141.

Camarinha-Matos, L. M., Afsarmanesh, H., Galeano, N., \& Molina, A. (2009). Collaborative networked organizations-Concepts and practice in manufacturing enterprises. Computers \& Industrial Engineering, 57(1), 46-60.

Campbell, D. T., \& Fiske, D. W. (1959). Convergent and discriminant validation by the multitraitmultimethod matrix. Psychological bulletin, 56(2), 81.

Carvalho, J. V., Rocha, Á., van de Wetering, R., \& Abreu, A. (2017). A Maturity model for hospital information systems. Journal of Business Research.

Chin, W. (1998). Issues and opinion on structural equation modeling. Management Information Systems Quarterly, 22(1), 7-16.

DesRoches, C. M., Charles, D., Furukawa, M. F., Joshi, M. S., Kralovec, P., Mostashari, F., . . . Jha, A. K. (2013). Adoption of electronic health records grows rapidly, but fewer than half of US hospitals had at least a basic system in 2012. Health affairs, 10.1377/hlthaff. 2013.0308.

Dewett, T., \& Jones, G. R. (2001). The role of information technology in the organization: a review, model, and assessment. Journal of management, 27(3), 313-346.

Duncan, N. B. (1995). Capturing flexibility of information technology infrastructure: A study of resource characteristics and their measure. Journal of Management Information Systems, 3757.

Farrell, A. M. (2010). Insufficient discriminant validity: A comment on Bove, Pervan, Beatty, and Shiu (2009). Journal of Business Research, 63(3), 324-327.

Fedorowicz, J., \& Ray, A. W. (2004). Impact of HIPAA on the integrity of healthcare information. International Journal of Healthcare Technology and Management, 6(2), 142-157.

Fornell, C., \& Bookstein, F. (1982). Two structural equation models: LISREL and PLS applied to consumer exit-voice theory. Journal of Marketing Research, 19(4), 440-452.

Fornell, C., \& Larcker, D. (1981). Evaluating structural equation models with unobservable variables and measurement error. Journal of Marketing Research, 18(1), 39-50. 
R. van de Wetering \& J. Versendaal: How a flexible collaboration infrastructure impacts healthcare information exchange

Gnyawali, D. R., \& Park, B.-J. R. (2011). Co-opetition between giants: Collaboration with competitors for technological innovation. Research Policy, 40(5), 650-663.

Grefen, P. (2013). Networked business process management. International Journal of IT/Business Alignment and Governance (IJITBAG), 4(2), 54-82.

Hair Jr, J. F., Hult, G. T. M., Ringle, C., \& Sarstedt, M. (2016). A primer on partial least squares structural equation modeling (PLS-SEM): Sage Publications.

Hendrikx, H., Pippel, S., Van de Wetering, R., \& Batenburg, R. (2013). Expectations and attitudes in eHealth: A survey among patients of Dutch private healthcare organizations. International Journal of Healthcare Management, 6(4), 263-268.

Henseler, J., Hubona, G., \& Ray, P. A. (2016). Using PLS path modeling in new technology research: updated guidelines. Industrial Management \& Data Systems, 116(1), 2-20.

Henseler, J., Ringle, C., \& Sinkovics, R. (2009). The use of partial least squares path modeling in international marketing. Advances in International Marketing, 20(2009), 277-319.

Henseler, J., Ringle, C. M., \& Sarstedt, M. (2015). A new criterion for assessing discriminant validity in variance-based structural equation modeling. Journal of the academy of marketing science, 43(1), 115-135.

Hersh, W. R., Totten, A. M., Eden, K. B., Devine, B., Gorman, P., Kassakian, S. Z., . . McDonagh, M. S. (2015). Outcomes from health information exchange: systematic review and future research needs. JMIR medical informatics, 3(4).

Hulland, J. (1999). Use of partial least squares (PLS) in strategic management research: a review of four recent studies. Strategic Management Journal, 20(2), 195-204.

Kohli, R., \& Tan, S. S.-L. (2016). Electronic health records: how can IS researchers contribute to transforming healthcare? MIS Quarterly, 40(3), 553-573.

Kruse, C. S., Bolton, K., \& Freriks, G. (2015). The effect of patient portals on quality outcomes and its implications to meaningful use: a systematic review. Journal of medical Internet research, $17(2)$.

Kung, L., Wang, Y., \& Kung, H.-J. (2016). Exploring Configurations for Business Value from Event-Driven Architecture in Healthcare.

Lyytinen, K., Yoo, Y., \& Boland Jr, R. J. (2016). Digital product innovation within four classes of innovation networks. Information Systems Journal, 26(1), 47-75.

Meyer, A. D., Tsui, A. S., \& Hinings, C. R. (1993). Configurational approaches to organizational analysis. Academy of Management Journal, 36(6), 1175-1195.

Mikalef, P., Pateli, A., \& van de Wetering, R. (2016). IT flexibility and competitive performance: The mediating role of IT-enabled dynamic capabilities. Paper presented at the 24th European Conference on Information Systems (ECIS).

Mithas, S., Tafti, A., \& Mitchell, W. (2013). How a Firm's Competitive Environment and Digital Strategic Posture Influence Digital Business Strategy. MIS Quarterly, 37(2).

Nunnally, J., \& Bernstein, I. Psychometric theory. 1994. New York, NY: McGraw-Hill.

Österle, H., Fleisch, E., \& Alt, R. (2012). Business networking: Shaping enterprise relationships on the Internet: Springer Science \& Business Media.

Patel, V., Abramson, E. L., Edwards, A., Malhotra, S., \& Kaushal, R. (2011). Physicians’ potential use and preferences related to health information exchange. International journal of Medical Informatics, 80(3), 171-180.

Podsakoff, P. M., MacKenzie, S. B., Lee, J.-Y., \& Podsakoff, N. P. (2003). Common method biases in behavioral research: A critical review of the literature and recommended remedies. Journal of Applied Psychology, 88(5), 879.

Ringle, C. M., Wende, S., \& Becker, J.-M. (2015). SmartPLS 3. Boenningstedt: SmartPLS GmbH, http://www.smartpls. com.

Runyon, B., \& Pessin, G. (2017). Hype Cycle for Real-Time Health System Technologies. Gartner, July 2017. 
Sahama, T., Simpson, L., \& Lane, B. (2013). Security and Privacy in eHealth: Is it possible? Paper presented at the e-Health Networking, Applications \& Services (Healthcom), 2013 IEEE 15th International Conference on.

Sarstedt, M., \& Ringle, C. (2010). Treating unobserved heterogeneity in PLS path modeling: a comparison of FIMIX-PLS with different data analysis strategies. Journal of Applied Statistics, 37(8), 1299-1318.

Sauer, P. L., \& Dick, A. (1993). Using moderator variables in structural equation models. ACR North American Advances.

Tafti, A., Mithas, S., \& Krishnan, M. S. (2013). The effect of information technology-enabled flexibility on formation and market value of alliances. Management science, 59(1), 207-225.

Termeer, C. J., \& Bruinsma, A. (2016). ICT-enabled boundary spanning arrangements in collaborative sustainability governance. Current Opinion in Environmental Sustainability, 18, 91-98.

Van de Wetering, R., Mikalef, P., \& Helms, R. (2017). Driving organizational sustainabilityoriented innovation capabilities: a complex adaptive systems perspective. Current Opinion in Environmental Sustainability, 28, 71-79.

Van de Wetering, R., Mikalef, P., \& Pateli, A. (2017). A strategic alignment model for IT flexibility and dynamic capabilities: toward an assessment tool. In Proceedings of the 25th European Conference on Information Systems (ECIS), Guimarães, Portugal, June 5-10, 2017 (pp. 14681485).

Vest, J. R., Campion, T. R., Kaushal, R., \& Investigators, H. (2013). Challenges, alternatives, and paths to sustainability for health information exchange efforts. Journal of Medical Systems, 37(6), 9987.

Wade, M., \& Hulland, J. (2004). Review: The resource-based view and information systems research: Review, extension, and suggestions for future research. MIS Quarterly, 28(1), 107142.

Walker, J., Pan, E., Johnston, D., \& Adler-Milstein, J. (2005). The value of health care information exchange and interoperability. Health affairs, 24, W5.

Weill, P., \& Ross, J. (2005). A matrixed approach to designing IT governance. MIT Sloan Management Review, 46(2), 26.

Weill, P., \& Vitale, M. (2002). What IT infrastructure capabilities are needed to implement ebusiness models? MIS Quarterly, 1(1), 17. 
454 | $31^{\text {ST }}$ Bled eConference: Digital Transformation: MeEting the ChallengeS June 17 - 20, 2018, Bled, SLOVEnia, ConfERENCE PROCEEDINGS 


\title{
Uncovering the digital " $x$ " phenomena in the IS field: A text analysis approach
}

\author{
JOAQUIN RODRIGUEZ \& GABRIELE PICCOLI
}

\begin{abstract}
As digital computers permeate an increasing number of activities, the term digital is associated with more processes, entities, and objects (e.g., digital economy, digital natives). This trend reflects in Information Systems research, with "digital" appearing before existing research concepts (e.g., digital infrastructure), often substituting for "IT". In this study, we contribute to the delineation between digital " $x$ " and IT " $x$ " research by investigating the degree of usage of the terms and uncovering the most widespread digital " $x$ " constructs. Using text analysis techniques, we can analyze a broad set of journals and a long time period. Early results, based on 17 years of MIS Quarterly publications, confirm the increasing use of the term digital. Conversely, digitize and digitalize, the two main forms of the term digital, are rarely used and do not show any significant increase in usage over time. While preliminary and not concluding, our results confirm the increasing popularity of the term digital. However, a limited number of digital " $\mathrm{x}$ " terms appear to connote novel constructs and the bulk of the research does not address the socio-technical process of digitalization that is central to the IS discipline. We discuss the implications of our early results and provide a research agenda.
\end{abstract}

Keywords: • Digital "x" • Digitalization • Digitization • IT “x” •

CORRESPONDENCE ADDRESS: Joaquin Rodriguez, Louisiana State University, Business Education Complex, Baton Rouge, LA 70803, USA, e-mail: jrod122@1su.edu. Gabriele Piccoli, Louisiana State University, Business Education Complex, Baton Rouge, LA 70803, USA, e-mail: gpiccoli@cct.lsu.edu 
As the computer mediation of activities continues unabated, the term "digital" is associated with an increasing number of processes, entities and objects. Digital economy, digital natives, and digital media are small sample of the terms that are now common use in academic research, the media, and everyday conversations. In Information Systems research the digital " $x$ " concept is now pervasive. The main examples are digital innovation (Yoo et al., 2010), digital business strategy (Bharadwaj et al., 2013), and digital options (Sambamurthy et al., 2003) - concepts that have gained widespread use. A panel at the International Conference of Information Systems (ICIS) 2017 noted that digital "x" concepts often mirror well-established IT "x" ones, such as IT innovation or IT strategy, raising the question of whether we are putting "old wines in new bottles" or producing novel contributions (Baiyere et al., 2017).

The question is critical for the field, because academic research is founded on agreed upon constructs that lay the conceptual foundation of a field of inquiry (Kuhn, 1970). Knowledge needs this foundation to advance, and new concepts are needed when new phenomenal emerge. Conversely, just relabeling constructs to follow fads leads to a proliferation in terminology that threatens knowledge accumulation and transfer between and within disciplines.

In this work we contribute to the discussion of whether digital " $\mathrm{x}$ " is a fruitful re-framing of established IT " $x$ " concepts. Specifically, we first provide a set of definitions of key constructs for digital " $\mathrm{x}$ " terminology. Second, we propose a methodology that leverages text analysis techniques to assess the degree of usage of new terms and the identification of the digital "x" concepts.

\section{Core Definitions}

In this section, we ground the definition of the term "digital" and we introduce its most common forms.

\subsection{Digital}

The term digital, as opposed to analog, indicates the discrete representation of signals or data using a sequence of finite number of values. We become familiar with digital computation as kids, when we learn to count using our fingers. It was computing pioneer George Stibitz, doing research on computational machines during World War II, who popularized the term "digital" to describe systems or devices based on discrete representation of signals and/or data (Williams, 1984).

Although digital can be used to describe any system or device that uses a discrete representation, it was conceived and became widely adopted in relation to general purpose computing devices following the Von Neumann architecture (Von Neumann, 1945). While computers are human-made "devices that can be instructed to carry out arbitrary 


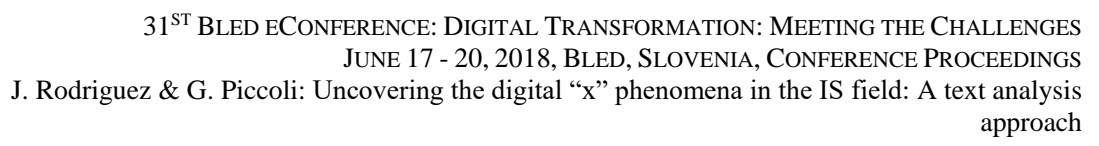

457

sequences of arithmetic or logical operations automatically" ("Computer," 2018), it was the invention of the transistor and integrated circuits that ushered in the digital electronic computer. Subject to "Moore's Law" (Moore, 1965), these devices experienced exponential growth in computation power, thus becoming pervasive. As digital electronic computers permeated all aspects of the economy over the last five decades, we observe two phenomena. First, the term digital becomes associated with objects (e.g., digital media) and phenomena (e.g., digital marketing) in which digital computers play an increasingly central role. Second, the term digital is associated with the outcomes derived from the use of electronic computers. Digital transformation, digital revolution, or digital innovation is common terminology to refer to the consequences of embedding digital computers in activities and processes.

\subsection{Digitize and digitalize}

When investigating the adoption of the term digital we need to consider its two main forms, digitize and digitalize. In mainstream parlance the two terms are used interchangeably ("Digitization," 2018). Conversely, they should have different connotations. Digitizing is the technical "process of converting analog signals into a digital form, and ultimately into binary digits." (Tilson et al., 2010, p. 749) The conversion of a paper book into an e-book is an example of digitization. Digitalization is a "sociotechnical process of applying digitizing techniques to broader social and institutional contexts that render digital technologies infrastructural." (Tilson et al., 2010, p. 749) For example, the Amazon Kindle radically changed the acquisition process of books for millions of people through the employment of digitizing techniques, which ultimately rendered the platform infrastructural. The Kindle platform does not only digitize the book content but also serves as an infrastructure for the creation of new services such as the possibility to loan books from public libraries directly to Kindle devices.

Although it is possible that researchers use the terms interchangeably as advocated by their general meanings, it is crucial to study their usage separately for two reasons. First, it helps determine if the literature prefers one or the other - assuming they are used interchangeably. Second, establishing different connotations of the terms presupposes that they are not already widely adopted. It would be daunting to reverse this trend if they are used interchangeably.

\section{$3 \quad$ Methodology}

We adopt text analysis techniques to determine the extent of use of the terms digital, digitize and digitalize, and the identification of the digital "x" concepts as used in IS literature. Although the use of text analysis techniques does not yet enable the categorization of advanced conceptualizations (Orlikowski and Iacono, 2001), they have proved valuable to synthesize large amounts of text and to uncover trends in research areas and topics (Blei and Lafferty, 2006; Sidorova et al., 2008). 
J. Rodriguez \& G. Piccoli: Uncovering the digital " $x$ " phenomena in the IS field: A text analysis approach

We analyze the full text of articles published in the IS basket of eight journals ${ }^{40}$ from 2000 to 2018 using R (R Core Team, 2017). The timeframe considered is constrained by the availability of native Pdfs enabling the extraction of text without optical character recognition (OCR). While pragmatic, this choice is also appropriate because it covers a long enough range of years to capture the emergence of the terms and concepts we are interested in.

In the remainder of this document we report results for 17 years of MIS Quarterly papers (from 2000 to 2017) for a total of 861 papers. We included in our analysis all types of manuscript categories, including editors' comments, and special issues ${ }^{41}$.

First, we downloaded the Pdf files for each paper from the AIS electronic library adopting a file naming convention that allows identifying the year and journal of publication. Pdf files are then parsed and read into R data structures using the "pdftools" library (Ooms, 2017). We preprocess the articles by removing any text from the references section on, thus excluding exhibits and appendices. We then tokenize the text and remove stopwords using the library "tidytext." (Silge and Robinson, 2016). The tokenization process separates hyphenated words in its single word components, therefore creating multiple tokens. The tokenization and stopword removal process reduced the number of tokens from 866,846 to 486,806 with 31,097 unique tokens. Terms are stemmed, using the SnowballC library (Bouchet-Valat, 2014), when analyzing the digital " $\mathrm{x}$ " bigrams. Stemming enable the consolidation of plurals and singular forms, as well as any forms that belong to the same root. The stemming process was not applied to the terms digital, digitization, and digitalization because they would stem to the same root. Finally, the data is converted into a tidy format (Wickham and others, 2014) that becomes available for analysis $^{42}$.

\section{$4 \quad$ Early results}

\subsection{How prevalent is digital, digitize, and digitalize}

As expected, the usage of the term digital significantly increases over time. We measure usage as the percentage of the total keyword frequency over the total word count of the articles in a given year. Therefore, usage conveys a measure of relative importance of the analyzed word over the total length of the articles. Furthermore, the measure accounts for differences in paper lengths and the number of papers published in each year. From 2000 to 2012 the usage remains relatively low, however 2013 represents an inflection point and we observe a significant increase afterward (Figure 12). The spike in 2013 is

\footnotetext{
${ }^{40}$ Basket of eight IS journals (https://aisnet.org/general/custom.asp?page=SeniorScholarBasket).

${ }^{41}$ Results from multiple journals will be available for presentation at the conference.

${ }^{42}$ At this stage of our research, we parse the Pdfs entirely. Therefore, keywords, titles, and abstracts are combined with the rest of the document body. As Pdfs do not contain document structure information, identifying different sections of the document require ad-hoc solutions that might not be consistent across all articles over the considered years.
} 
determined by the MIS Quarterly special issue on Digital Business Strategy, however, the prevalence of the term remains higher in the following years than those before 2012. The term "digitize" registers a slight increase over the years; however, its use remains quite limited. Digitalize, on the other hand, is rarely used and we see no sign of significant increase in usage. When compared to the term IT, we observe how IT and digital have opposite trends, with the usage of IT decreasing over time, whereas digital is on the rise. This result, if confirmed across the basket of eight journals, could signal a substitution effect from "IT" to "digital."

\subsection{Digital " $x$ " concepts}

Our analysis confirms that the number of unique digital "x" concepts that appears every year in MIS Quarterly is on the rise (Figure 13). From 2000 to 2007 the number of digital "x" concepts used in the papers was 7.75 on average. Afterwards, the number of concepts increased significantly, reaching its peak in 2013 with more than 120 digital "x" concepts in use, for a total of 1,253 occurrences over 23 different papers. From 2013 to 2017, the number of concepts used is on average 100 .

The frequency of the digital "x" terms follows a strong positive skew distribution. $64 \%$ of the digital " $\mathrm{x}$ " concepts appear only in one paper during the analyzed period, such as digital opportunity or digital leash. Nearly $29.8 \%$ of the concepts were present in more than two and less than ten papers. Concepts present in more than ten papers where only $6.2 \%$ of the total.

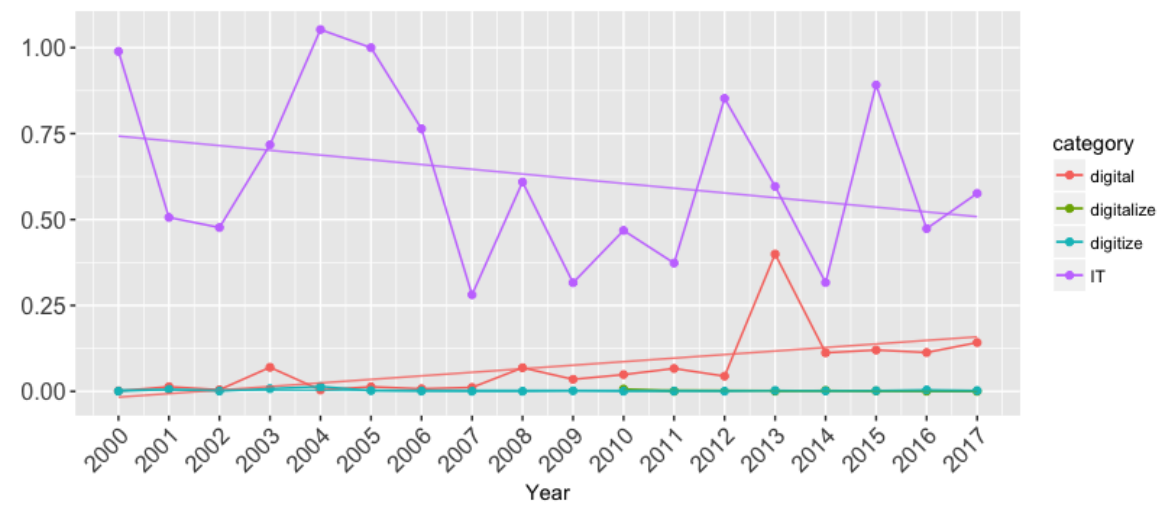

Figure 12: Yearly average usage of the keywords

This corroborates the hypothesis that researchers favor the use of digital " $\mathrm{x}$ " terms when they want to refer to the consequences of using digital computers (e.g., digital crime) or to those domains or contexts in which digital computers are employed (e.g., digital dashboard). As a consequence, only a small percentage of the digital "x" terms introduced are intended as new IS constructs. We define a construct as a "concept with added meaning, deliberately and consciously invented or adopted for a special scientific 
purpose" (Kerlinger, 1973). In the remaining cases "digital" is used as an adjective to characterize the digital nature of objects or process (e.g., digital game).

We identify 15 digital " $x$ " concepts present in at least ten papers which we interpret as IS constructs (Table 1). Therefore, in Table 1 we do not include terms, such as digital economy or digital age, as they are not IS constructs. Analyzing the terms associated to digital we can identify some common areas. Digital innovation, business strategy, options, capabilities, processes, and assets are concepts more likely to relate to the implications of the employment of digital computers to organizations. In contrast, we can reasonably associate digital infrastructure, platform, network, and market to the research of inter-organizational relationship and markets. We can speculate that digital services and artifacts are related to the investigation of novel forms of services or artifacts.

\section{$5 \quad$ Discussion}

This research is inspired by the timely and important call to delineate the differences between the streams of research of IT "x" and digital "x" (Baiyere et al., 2017). We are not yet in position to provide definite answers, however, some interesting insights emerge from our early analysis. First, our early results confirm the increasing popularity of the term digital. However, we observe a minimal increase of the term digitization and negligible use of digitalization. The scarce popularity of terms digitization and digitalization might indicate that work in the MIS Quarterly discipline has not yet focused on process as a focal issue in the analysis. Rather the work in this space started with a focus on the consequences of digitization (e.g., digital options).

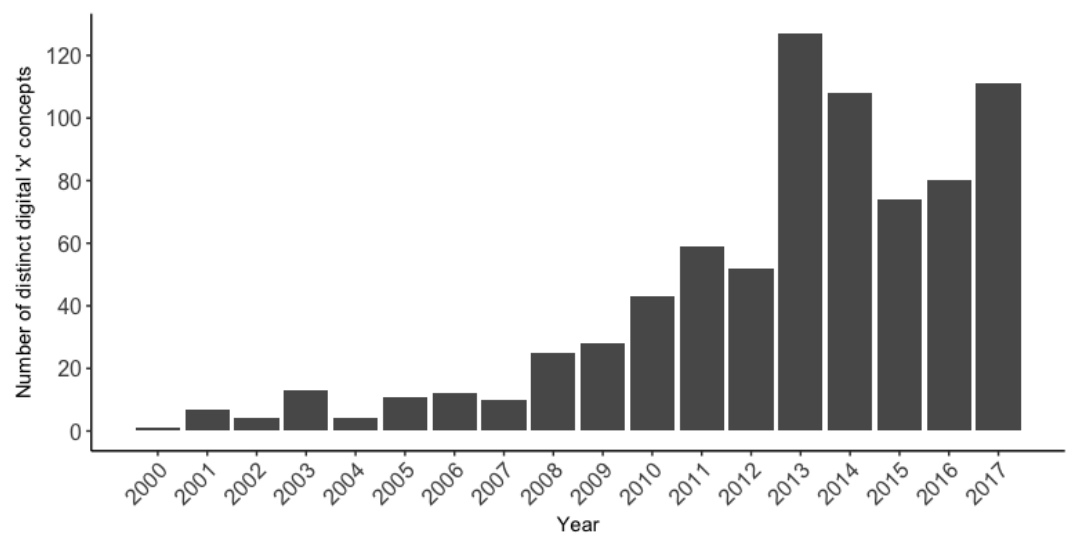

Figure 13: Yearly number of distinct digital " $x$ " concepts 
Table 1: Number of papers where the digital " $x$ " concept is present

\begin{tabular}{|c|c|c|c|c|c|c|c|c|c|c|c|c|c|c|c|}
\hline 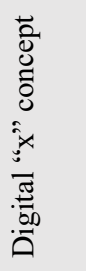 & 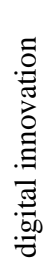 & 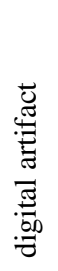 & 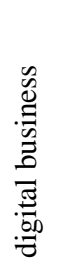 & 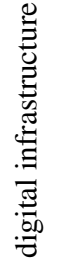 & 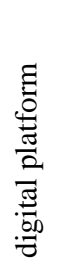 & 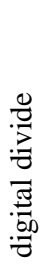 & 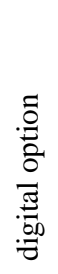 & 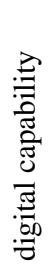 & 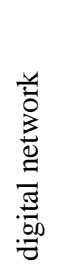 & 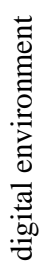 & 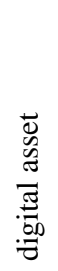 & 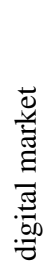 & 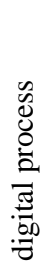 & 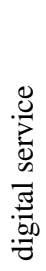 & 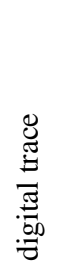 \\
\hline $\begin{array}{l}\text { N. of } \\
\text { paper } \\
\text { s }\end{array}$ & 24 & 22 & 22 & 21 & 20 & 18 & 18 & 15 & 14 & 12 & 11 & 11 & 11 & 11 & 11 \\
\hline
\end{tabular}

Secondly, although we agree that the study of digitization as a technical process is not relevant to the IS discipline, it is more concerning that there is limited interest in the sociotechnical process of digitalization. This result is consistent with previous research that shows how IS research tends to study the IT-artifact as an exogenous black box (Akhlaghpour et al., 2013; Orlikowski and Iacono, 2001). However, the results may also reflect the delay typically associated with publication in top journals and broadening our analysis to conferences may help balance the results.

Third, we provide some initial evidence showing that many digital " $x$ " terms (almost two thirds) are sparsely used (e.g., digital agreement). These terms are contextual to the analysis. Only a limited number of digital "x" terms appear to connote novel constructs. We identify the 15 most recurrent digital " $x$ " constructs published in the MIS Quarterly since the year 2000. Our results indicate that, while the number of digital " $x$ " concepts used in IS research is significant and growing, the percentage of those concepts that are prominent in the literature is limited.

Fourth, there are several digital " $x$ " concepts that may not have an IT " $x$ " counterpart (e.g., digital divide, digital trace, digital immigrant). Therefore, we might speculate that these concepts represent new phenomena that the literature did not address before - new wine if you will.

Finally, we showcase a systematic and scalable text analysis approach for literature analysis.

\section{$5 \quad$ Future research}

In future research, we will broaden the number of analyzed journals and the timespan considered. A more comprehensive analysis will determine whether the trend we observe in our preliminary results is consistent across journals. Moreover, a cross-journal analysis, and the inclusion of conferences, will uncover time-lag effects and differences across journals. Adopting a longitudinal perspective in the analysis of core digital " $x$ " constructs will establish whether once introduced they become increasingly used or they tend to 
$31^{\text {ST }}$ BLED ECONFERENCE: Digital Transformation: MeEting the Challenges

JunE 17 - 20, 2018, BLED, SLOVENIA, CONFERENCE PROCEEDINGS

J. Rodriguez \& G. Piccoli: Uncovering the digital " $x$ " phenomena in the IS field: A text analysis approach

vanish. More importantly, our research agenda aspires to conduct a literature review of the most prevalent digital " $\mathrm{x}$ " concepts and to compare them to established IT " $\mathrm{x}$ " construct, to address the question of whether digital " $\mathrm{x}$ " is mere substitution for IT " $\mathrm{x}$ " or truly "new wine."

\section{References}

Akhlaghpour, S., Wu, J., Lapointe, L., Pinsonneault, A., 2013. The ongoing quest for the IT artifact: Looking back, moving forward. Journal of Information Technology 28, 150-166.

Baiyere, A., Grover, V., Gupta, A., Woerner, S., Lyytinen, K.J., 2017. Digital“ x”-A new tune for IS research or old wine in new bottles? Thirty eighth International Conference on Information Systems, Seoul 2017.

Bharadwaj, A., Sawy, E., A, O., Pavlou, P.A., Venkatraman, N.V., 2013. Digital Business Strategy: Toward a Next Generation of Insights (SSRN Scholarly Paper No. ID 2742300). Social Science Research Network, Rochester, NY.

Blei, D.M., Lafferty, J.D., 2006. Dynamic topic models, in: Proceedings of the 23rd International Conference on Machine Learning. ACM, pp. 113-120.

Bouchet-Valat, M., 2014. SnowballC: Snowball stemmers based on the C libstemmer UTF-8 library.

Computer, 2018. The free encyclopedia. (2004, July 22). FL: Wikimedia Foundation, Inc. Retrieved March 14, 2018 from https://en.wikipedia.org/wiki/Computer.

Digitization, 2018. The free encyclopedia. (2004, July 22). FL: Wikimedia Foundation, Inc. Retrieved March 14, 2018 from https://en.wikipedia.org/wiki/Digitization.

Kerlinger, F.N., 1973. Foundations of behavioral research. New York, Holt, Rinehart and Winston [1973].

Kuhn, T.S., 1970. (1970). The structure of scientific revolutions . Chicago: University of Chicago Press.

Moore, G.E., 1965. Cramming more components onto integrated circuits, Electronics Magazine.

Ooms, J., 2017. pdftools: Text Extraction, Rendering and Converting of PDF Documents.

Orlikowski, W.J., Iacono, C.S., 2001. Research commentary: Desperately seeking the "IT" in IT research - A call to theorizing the IT artifact. Information Systems Research 12, 121-134.

R Core Team, 2017. R: A Language and Environment for Statistical Computing. R Foundation for Statistical Computing, Vienna, Austria.

Sambamurthy, V., Bharadwaj, A., Grover, V., 2003. Shaping agility through digital options: Reconceptualizing the role of Information Technology in contemporary firms. MIS Quarterly 27, 237-263.

Sidorova, A., Evangelopoulos, N., Valacich, J.S., Ramakrishnan, T., 2008. Uncovering the intellectual core of the information systems discipline. Mis Quarterly 467-482.

Silge, J., Robinson, D., 2016. tidytext: Text Mining and Analysis Using Tidy Data Principles in R. JOSS 1. https://doi.org/10.21105/joss.00037

Tilson, D., Lyytinen, K., Sørensen, C., 2010. Research Commentary-Digital Infrastructures: The Missing IS Research Agenda. Information Systems Research 21, 748-759. https://doi.org/10.1287/isre.1100.0318

Von Neumann, J., 1945. First draft of a report on the EDVAC.

Wickham, H., others, 2014. Tidy data. Journal of Statistical Software 59, 1-23.

Williams, B.O., 1984. Computing with electricity, 1935-1945. University of Kansas.

Yoo, Y., Henfridsson, O., Lyytinen, K., 2010. Research Commentary-The New Organizing Logic of Digital Innovation: An Agenda for Information Systems Research. Information Systems Research 21, 724-735. https://doi.org/10.1287/isre.1100.0322 


\title{
Can Sport and Wellness Technology be My Personal Trainer? - Teenagers and Digital Coaching
}

\author{
EEVA KeTTUNEN \& TUOMAS KARI
}

\begin{abstract}
The attention towards digital coaching solutions has increased among users of sport and wellness technologies, the related industry, the healthcare and wellness sector, and among scholars. However, as the commercial digital coaching solutions are rather novel, the number of studies about their influence or the usage experiences is still rather limited. Another topic that is lacking research is the relationship of teenagers and sport and wellness technology. Since using the internet and technological devices on a daily basis has become the norm for teenagers, it is worth paying attention to how technology could be developed in order to better motivate them towards a healthier lifestyle. The purpose of this study was to find out the perceptions of teenagers regarding sport and wellness technology and especially of digital coaching. According to the findings, teenagers perceive digital coaching positively. They prefer instructional guidance and advice especially related to physical activity and nutrition.
\end{abstract}

Keywords: - Digital coaching - Teenagers • Adolescence • Sport technology $\bullet$ Wellness technology $\bullet$ Digital wellness $\bullet$

CORRESPONDENCE AdDRESS: Eeva Kettunen, M.Sc, Ph.D. student, University of Jyvaskyla, Faculty of Information Technology, P.O. Box 3540014 Jyvaskylan yliopisto, Finland, e-mail: eeva.k.kettunen@jyu.fi. Tuomas Kari, D.Sc., Postdoctoral researcher, University of Jyvaskyla, Faculty of Information Technology, P.O. Box 3540014 Jyvaskylan yliopisto, Finland, e-mail: tuomas.t.kari@jyu.fi. 
$31^{\text {ST }}$ Bled ECONFEREnCE: Digital Transformation: MeEting the Challenges

June 17 - 20, 2018, BLED, SLOVENIA, CONFERENCE PROCEEDINGS

E. Kettunen \& T. Kari: Can Sport and Wellness Technology be My Personal Trainer? - Teenagers and Digital Coaching

The physical activity levels of teenagers and children over 10 years of age is decreasing and sedentary behaviour is becoming more common (Brodersen et al., 2007; World Health Organization (WHO), 2018). According to WHO already over $80 \%$ of the world's adolescence population is not physically active enough. Therefore, engagement with physical activity and health related issues is important especially for this age range. During adolescence, health related habits such as physical activity, nutrition and sleep related behavioural patterns are being established. These learned patterns are usually maintained throughout a person's entire life (Kumar, Robinson and Till, 2015). Promoting healthy behaviours during the teenage years has therefore a great impact on the overall quality of people's lives right through to adulthood. Promoting physical activity and enabling exercise participation can foster personal improvement and competence. This will help teenagers to achieve personal control over their intentions regarding physical activity, which is important to encourage long-term healthy behaviours (Hagger, Chatzisarantis \& Biddle, 2001).

Since many teenagers are constantly online and use various technological devices and applications daily, it is reasonable that technology could also be used in promoting health and physical activity. Unfortunately, there is a gap in the research about how teenagers use internet, mobile applications and wearable technology for health related purposes (Wartella et al., 2016). Technology can be a useful tool when promoting a healthier and more physically active lifestyle to teenagers. However, many sport and wellness technology products such as wearable fitness devices are mainly designed for adults. They tend to engage people who are already relatively active and interested in improving their lifestyle or their sport performance (Carrino et al., 2014). In order to use sport and wellness technology in health behaviour change campaigns directed to teenagers, it is important to understand what is relevant for this target group.

According to Wartella et al. (2016) one of the most often downloaded health applications among teenagers are fitness applications. Teenagers who were more active and had lower body mass index (BMI) tended to use these applications more often than less active teenagers. However, the study also highlighted that despite teenagers often downloading mobile health applications, they much more seldom actually use them. This indicates that these applications are not able to hold the attention after initial use and therefore further research is needed related to this target group's preferences and needs. Understanding the preferences of teenagers related to this area is important in creating products and applications that could sustain their engagement long term and thus positively affect their health.

Sport and wellness technology products designed for teenagers are still missing from the market. Some technology wearables have been created especially for the teenage population but these devices have been focused on connectivity or game related elements (Carrion et al., 2015). Providing a fashionable look for health, sport and wellness technology products could attract the teenage population. The importance of fashionable 
and trendy appearances was highlighted in a study by Toscos et al. (2006) where they focused on the use of pedometers integrated with teenage girls' fashion garments and accessories.

According to the study of Carrion et al. (2015), for teenagers the most attractive features of wearable sport and wellness technology devices were calorie consumption, step counters and sleeping time. These features were related to physical activity and were therefore already familiar to the target group, and were also highly associated with individual achievement and goal setting. The teenagers also associated the need of wearable devices with a serious goal and a strong purpose for achieving it. Therefore, they felt these devices were mainly targeted to sports people, older people or people with health conditions. The most important issues affecting teenagers' choice about potential use of sport and wellness wearables is the combination of utility and appearance. These aspects include, for example, the overall appeal, good design, small size, comfort, customizability, entertainment value, a tactile screen and informative elements. The design seems to play an important role affecting overall first impressions. However, whereas with teenage boys the importance of design seems to be replaced with usability and wearability factors, design becomes even more dominant for teenage girls as they start using the device more (Carrion et al. 2015). When talking about sport and wellness related mobile applications it is important to notice that both girls and boys seem to have similar wants and needs regarding mobile technology (Rees \& Noyes, 2007). Therefore, the preferences and expectations of sport and wellness applications may not vary significantly between genders.

Despite the lack of studies regarding teenagers and sport and wellness technology, there have been several studies that have focused on sport and wellness technology in general. These studies have found, for example, that the feedback these technologies provide can improve awareness of personal physical activity and motivate towards increasing it (e.g., Chan, Ryan \& Tudor-Locke, 2004; Faghri et al., 2008; Kang et al., 2009; Kari et al., 2016b; Kari et al., 2017a; Wang et al., 2016). While the tracking of wellness related data with suitable technologies may lead to better awareness of everyday activities, it may however, not be sufficient to maintain the use of those technologies (Miyamoto et al., 2016), which can also influence maintaining wellness routines (Warraich, 2016). Therefore, providing use guidance and achievable goals for using these technologies would likely increase the adherence of using them. Subsequently, this helps users to create and maintain wellness related routines such as regular physical activity, good nutrition and adequate sleep and recovery.

A common problem with sports and wellness technologies is that they mostly provide feedback through numbers and graphs instead of providing actual guidance and instructions for the related wellness task. Previous research indicates that wellness technology users want relevant, clear, and easy-to-understand information from their devices and software concerning their activities. Further, they feel the need to receive feedback and instructions on how they should go about their physical activity and other wellness related actions. This would likely lead to the technology use being more goal- 
oriented (e.g., Kari et al. 2016a; Kari et al. 2017b), which is generally beneficial (Locke \& Latham, 2002; Shilts, Horowitz, \& Townsend, 2004). Therefore, by providing the users with concrete and manageable steps, for example, in the form of a personalized exercise plans, the technologies could add to the possibility of making both their use and the behaviour of the users more goal-oriented and motivated. One prospective solution to cover this is digital coaching. The demand for digital coaching to address goal-driven and personalized support of fitness goal achievement has also been recognized by Schmidt et al. (2015).

Digital coaching refers to a service on a technological device that not only gives feedback but also offers advice, suggestions and future steps for a user to follow in the pursuit of their wellness and fitness goals. As described by Schmidt et al. (2015) a digital coach can identify the weaknesses and strengths of the user and generate a training plan based on the received user information. Whereas traditional sport and wellness technology products aim at improving the user's self-awareness based on their own fitness data, a digital coach takes it one step further by creating a personalized training plan for the user to follow. The acceptance of using a digital coach in an exercise setting as well as its motivational potential was also highlighted in the study of Kranz et al. (2013).

The attention towards digital coaching solutions has been increasing among various stakeholders. Nevertheless, as commercial digital coaching solutions are rather novel, the number of studies about their influence or the usage experiences is still quite limited. The purpose of this study is to address this research gap by finding out how teenagers think about digital coaching in a sport and wellness technology setting. The paper also addresses teenagers' perceptions about sport and wellness technology in general in order to serve as background information leading to discussion about digital coaching. As a qualitative study, the aim is to understand how digital coaching would be accepted within this target group, what kind of features teenagers' ideal digital coach would include, what kind of information the digital coach should offer and in what form the message should be delivered. By investigating these questions, we aim to assess whether digital coaching could be useful for this target group in order to motivate and help them in the pursuit of a healthier and more physically active lifestyle. Moreover, the purpose of this research is also to serve as a catalyst to further research regarding digital coaching.

\section{Theoretical Background}

The theoretical framework for this study comes from the social cognitive theory of Alfred Bandura (1986). This theory has often been used as a framework in studies regarding physical activity and motivation. According to social cognitive theory, the reactions, actions, and social behavior of an individual are influenced by actions they have seen by observing other people. The theory emphasizes the role of observational learning and social experience in personality development. In his theory, Bandura also introduced the concept of self-efficacy, which refers to the person's beliefs in their capabilities of performing a specific task. Whereas people with low levels of self-efficacy might avoid doing a task they perceive difficult, people with higher levels of self-efficacy are more 
likely to see difficult tasks as challenges and therefore perform better (Bandura, 1986). Self-efficacy is also related to motivation. If a task is perceived too easy or too difficult compared to their perceived own skills, the level of motivation to continue can decrease. However, moderately challenging and difficult tasks can produce satisfaction through the experience of achievement (Bandura, 1998)

Another well-known theory that is often connected to exercise motivation is the Selfdetermination theory by Ryan \& Deci (2000). According to the theory the three important components affecting motivation are the needs of competence, relatedness and autonomy. The need for competence refers to a person's need to effectively interact within the surrounding environment and being able to complete given tasks. The need for relatedness refers to a person's need to be connected with other people, while the need for autonomy refers to the need of being able to self-regulate the personal behavior. All these needs together or individually can facilitate intrinsic motivation, which is the motivation behind behaviors that are driven by internal rewards. In the context of physical activity, a high level of intrinsic motivation has been often connected with the formation of exercise habits in pursuit of a more physically active lifestyle.

The term proxy agency is also derived from Bandura's social cognitive theory. The theory of proxy agency is based on the idea that people play an important and active role in their self-development, self-renewal and adaption by using mechanisms called agencies. In this context an "agency" means acts which are done on purpose. According to Bandura there are three types of agencies: personal, collective and proxy. In the case of personal agency, the person itself acts as an agency. In the case of a collective agency an agent means a group or community. The third agency, proxy agency, refers to a situation where a third party acts as an agent on someone's behalf (Beauchamp \& Eys, 2007, Bandura, 1982). When talking about physical activity, for example, a fitness group or a team can act as a collective agent whereas a proxy agent could be a personal trainer, coach or in the case of teenagers, a teacher or parent.

Bandura has outlined three reasons people use proxy agency. First, people might feel they do not have the knowledge or the needed skills to reach their desired outcome. Second, people might perceive that a third person will be more capable of facilitating the journey toward the desired outcome. Third, even though people would have all the needed knowledge and skills to pursue their goal, they may want to give control over to another person because they do not want have the responsibility of direct control (Bandura, 1997). In a physical activity and exercise setting the use of a proxy agent, such as a personal trainer, can help a person to manage task and environment demands as well as offer extra help in controlling and regulating exercise behavior. It can also help in developing new skills as well as give support in lifestyle management (Beauchamp \& Eys, 2007). Having a proxy agent can also provide social support, which may increase positive outcomes and increasing the likelihood of focus, enjoyment and full involvement (Jowett \& Lavallee, 2007). In physical activity settings the role of a proxy agent is often performed by a trainer or a coach who is able to affect their trainee's self-efficacy in different ways. These ways include for example vicarious experiences, which refers to experiences received through 
observing other people. Another way a proxy agent can affect self-efficacy is verbal persuasion, which means providing comments, instructions and feedback.

In this study, the role of proxy agency theory is examined from a digital coach point of view. Therefore, the proxy agent in this study refers to a sport and wellness technology device or application combined with digital coaching features. As in the case of a human proxy agent, a sport and wellness technology device is also able to affect the feeling of competence by providing instructions, feedback and verbal persuasion as well as collecting and showing data regarding performance accomplishments. By providing a tool for social comparison and social sharing, a digital coach is also able to affect the feeling of relatedness. According to Shields and Brawley (2006), a long-term use of a proxy agent might lower the user's self-regulatory skills, which are important regarding the independent management of physical activity and sport participation. Using a digital coach as a proxy agent, compared to using a personal trainer or a coach as a proxy agent, requires the user to have a certain amount of self-regulatory skills and independence. Therefore, using a digital coach encourages the user to practice independence while still in the proxy context and that way affects also the feeling of autonomy.

\section{$3 \quad$ Methodology}

This study followed a qualitative approach. The study included 34 teenage participants of whom 18 were girls and 16 were boys. The age group was between 13 to 15 years old. The participants were recruited from two local junior high schools. The recruitment was made with the help of the schoolteachers as well as the local sports club. The invitation was sent to approximately 500 students. All the students who expressed their interest were selected to the study. Since participants were under-aged, all the participants were asked to bring a signed approval from their parents in order to approve their participation.

The data was collected in November and December 2017. The data collection was done in two phases. In the first phase, the participants filled a questionnaire regarding their current physical activity, motives for exercising and their experiences regarding the use of sport and wellness technologies. After this, all participants were given a free sport and wellness application, which they were asked to use for the next five weeks. The application was given to the participants in order to guarantee they would all have at least some experience with sport and wellness technology before the interviews and before the second round of questionnaires took place. With the help of this experience, the participants gained insights of the topic. With the help of this recent usage experience, the ideas and opinions regarding sport and wellness technology and digital coaching would be more clear in their minds. The application did not include digital coaching features. The second phase of data collection took place after the five-week use period. This time all the participants filled a questionnaire regarding their experiences with the sport and wellness application and their opinions about sport and wellness technology in general, followed by questions regarding digital coaching. All 34 participants filled the questionnaires and 18 of them also volunteered for an interview. The purpose of the interviews was to get more detailed answers and information regarding the topics covered 
in the questionnaires. The interviews were recorded and notes were taken during the interviews. The interviews lasted on average 20 minutes. The data used in the study was based on the questionnaires as well as the interview notes.

The analysis method used in the study was thematic analysis. It is a method for "identifying, analyzing and reporting patterns (themes) within data" (Braun and Clarke, 2006, p. 79) and also describes the data set in rich detail. It is the most widely used analysis method in qualitative research (Guest, MacQueen and Namey, 2012). When performing the data analysis the guidelines by Braun and Clarke (2006) were followed, but as they suggested the guidelines were adjusted to fit the research purpose of this current study. The data analysis started with familiarizing oneself with the data and dividing the data into three themes: background information and exercise habits, experiences and preferences regarding sport and wellness technology, and finally, perceptions and preferences regarding digital coaching in a sport and exercise setting. After this, all themes were individually studied in order to find differences and similarities between the participants. Finally, the report was produced aiming to highlight all the aspects that the participants considered important regarding the themes.

\section{$4 \quad$ Results}

\subsection{Background of the Participants}

The participants' physical activity background varied. Seven participants reported being physically active less than seven hours per week, 14 students reported to be active 7-10 hours per week and the remaining 13 students were physically active more than ten hours on a weekly basis. The reported physical activity time included active time in commuting to school, physical education classes as well as physical activity done in spare time. The physical activity recommendation for teenagers (ages 12-18) is 1-1,5 hours per day which equals 7-10 hours per week (Husu et al., 2011). Despite the fact that $79 \%$ of the participants reported being physically active enough to meet this recommendation, $56 \%$ of the participants felt they have to increase their physical activity levels.

The biggest reason that motivated the participants to be physically active was the good feeling that is associated with physical activity: "exercising makes me feel good and it is fun". This intrinsic type of motivation was reported to be the main reason for exercising for $65 \%$ of the participants. The next most important motivation for exercising was gaining and maintaining better physical condition. Other sources of exercise motivation were related to appearance and weight loss, being able to spend time with friends and being able to challenge oneself. Only two participants reported to be physically active because they wanted to make sure they would stay healthy in their future life.

\subsection{Sport and Wellness Technology}

Before the study, most of the participants (88\%) already had some previous experience with sport and wellness technology. However, in some cases the experience did not 
include longer-term usage but was limited to a few times. Most of the participants had used either step counters or exercise and health applications that were usually already included on their mobile phones. Some participants had used wearable fitness trackers, sport watches or heart rate belts. The biggest reasons for using sport and wellness technology was reported to be the desire to see actual data regarding exercising. For some participants this meant tracking their step count, keeping an exercise diary or comparing their fitness to previous results. Some of the participants said the main reason to use sport and wellness technology is because it is entertaining and makes exercising fun.

Participants were also asked whether sport and wellness technology have had any influence on their exercise motivation. 38\% of the participants stated no, whereas $53 \%$ of them stated the technology had increased their motivation to exercise. The most common features relating to increased motivation were goal setting, gamification and being able to see your results. Also, social pressure seemed to increase motivation for some participants. Despite the positive effects, participants felt that sport and wellness technology can also have a negative effect for exercising. The biggest negative effect was focusing too much on data and results instead of the actual performance. This might make exercising too competitive and performance oriented and also be an interruption during the actual exercise. Other negative effects were the need to carry the phone along or that having exercise data enables social comparison, which may lead feelings of inferiority. In general, the participants seemed to have relatively high trust for the information provided by sport and wellness technology. They also had high trust for themselves when it came to learning to use new exercise related technological devices and applications. Whereas the high trust for technology was almost equal between boys and girls, the level of self-efficacy regarding using new devices and applications was slightly higher among boys.

\subsection{Digital Coaching}

Participants had mixed perceptions when asked whether they could see themselves using a sport and wellness technology device or application as their personal trainer. $41 \%$ of the participants answered yes, whereas 35\% of them answered no. The remaining $24 \%$ had mixed feelings. The main benefit for having a digital device or application as their personal trainer was the easiness and the low cost. This coach would be present all the time and therefore be better able to motivate and provide support. Some participants even thought that technology would be able to provide more information and more personalized information than an actual human being and therefore be more useful. The negative aspects of using sport and wellness technology as a personal trainer were related to the lack of human aspect. According to some participants, a device or an application is not able to give enough personalized information, which lowers the level of reliability. Some participants felt it would be easier to cheat the digital coach or just ignore it. Some of them also said that unlike humans, a digital coach is not able to analyse their exercise movements or correct them and cannot ensure that the training is being done in a safe way. 
$31^{\text {ST }}$ Bled eConference: Digital TRAnSformation: MeEting the Challenges June 17 - 20, 2018, BLed, Slovenia, Conference ProceEdings E. Kettunen \& T. Kari: Can Sport and Wellness Technology be My Personal Trainer? - Teenagers and Digital Coaching

The participants were also asked to imagine a technological device or application that they could see themselves using as their personal trainer. The most occurring imagined product was a mobile phone application. This was seen as the easiest option since it is something that they always carry along. The second most popular option was a watch or an activity tracker, which were perceived easy to use and wear especially during exercise. The use of a heart rate monitor was often also connected to the application or watch usage. Some participants wanted wireless headphones to enable real time audio feedback whereas some participants imagined their personal trainer as a robot that could analyse and even assist them during their gym training. In order to be motivating, the participants in general perceived that the digital personal trainer needs to be supportive as well as easy and fun to use. It would have to give reminders when it is time to exercise but also not be too pushy. Gamification elements were also seen as motivational. Other issues seen as motivational for the participants were related to appearance. The device or applications needs to be colourful, trendy and small enough. However, as only $15 \%$ of the received answers were related to appearance, it can be seen as a less important factor than features related to usability and gamification. Some participants also highlighted some technical issues such as accuracy, reliability and low battery consumption, which are also important regarding the level of trust and usability.

Participants were also asked to describe what kinds of features their ideal digital coach would have. The most common feature the participants reported was the personalized guidance and suggestions related to exercising. The participants wanted support regarding how much they should exercise and what would be the best forms of exercising to a person at their age. Most also wanted a personalized training program that would also provide them different options of what to do and how to do it. They also wanted real time feedback on whether they are doing the exercise correctly and if they are at the right pace or intensity: "If I run too fast the device should tell me to slow down". Receiving a personalized exercise plan and suggestions about different exercise possibilities and instruction on how to do them was perceived as a very important part of exercise guidance.

Other important but slightly less reported features regarding exercising was the ability to set goals and track performance. Some of the participants also wanted the digital coach to remind them when it is time to exercise. After exercise guidance the next biggest feature participants wanted was related to eating and nutrition. Half of the participants wanted to receive information about the right type and amount of foods to eat, including calorie consumption: "I want to know what is the right type of diet for a person my age". Another important feature regarding nutrition was that some of the participants wished the digital coach would remind them when it is time to eat or drink water. Few participants also wanted to receive more information about nutritional values of different foods and what factors they should pay attention to considering their growth period. Other less often mentioned features were related to gamification, sleep tracking, recovery, music or blood pressure. A few of the participants wished their digital coach would be able to remind them also about other issues not directly related to eating or exercising: "If I go outside in the evening, it would be nice to get a reminder when it is so dark that I should wear a 
reflector". Participants were also asked whether they would want the digital coach to give them information regarding mental health. 39\% of them said yes, however, they were not able to describe in more detail what kind of issues this information should cover.

The participants were also asked about how they would like to communicate with their digital coach and especially how they would like to receive feedback and instructions. The most desired way of receiving feedback and instructions was text. Other popular options were numbers, emojis and actual voice feedback, all three of which were perceived as equally attractive. Other, less often mentioned feedback methods were pictures and videos. Participants were also asked what kind of messages they would want to receive as feedback. The participants were given three example messages, out of which one was supportive: "Good job, that's the way to go!", one was informational: "You ran $5,4 \mathrm{~km}$ in 42 minutes. This was 2 minutes faster than the last time!" and one was instructional: "Today you were training in a high heart rate zone. In order to recover from this training, tomorrow do a lighter exercise or have a rest day!". The most preferred feedback was instructional which was chosen by $44 \%$ of the participants. The second most preferred feedback was informational (35\%), while the supportive feedback (21\%) was the least preferred.

\section{Conclusion}

The purpose of this study was to explore teenagers' experiences and preferences regarding sport and wellness technology as well as find out their perceptions regarding digital coaching.

The results of this study indicate that sport and wellness technology as well as digital coaching is generally perceived as interesting by teenagers and has potential to positively affect teenagers' health behavior. This finding goes together with the findings of Wartella et al. (2016) who stated that providing teenagers with digital tools to further and better understand their health, can allow greater autonomy for their health and encourage them to pursue a healthy lifestyle.

According to the findings, the level of trust and level of self-efficacy for using sport and wellness technology is relatively high within most teenagers. The biggest reason for using sport and wellness technology was the desire to see their own exercise data. As highlighted by Hagger et al. (2001), exercise data can help teenagers to get personal control over their exercising. When looking at this from a theoretical point of view, providing teenagers an interesting and easy to use tool for monitoring their exercise performance can increase the level of autonomy over their own physical activity. And, by providing an opportunity for monitoring their results and development, a digital coach can increase perceived competence. As highlighted earlier, these two elements, together with the feeling of relatedness are key factors in developing long-term motivation for physical activity. 
The teenagers in general seemed to have an open and positive attitude towards digital coaching and saw it as motivating, which also follows the results of Kranz et al. (2013). The most important reasons for having a digital coach were related to giving advice and instructions related to exercise as well as nutrition. In terms of the proxy agency theory, the teenagers reported they wanted to have a digital coach because they desired guidance and were interested in receiving more information on following a healthy lifestyle. They are aware and willing to admit they do not know everything. Therefore, the biggest motivational reason for using a digital coach is to increase their level of knowledge and skills. This is also supported by the finding that the most preferred way of feedback was instructional feedback. Many participants also saw that a digital coach could work as a reminder tool, such as informing them when to exercise. From this perspective the one motivation for using a digital coach was also to shift the responsibility from self to an external actor. Teenagers are also used to having guidance in many aspects of their lives and therefore it might feel natural for them to have extra guidance in their physical activity.

The biggest reasons why teenagers would prefer a sport and wellness technology device as their personal trainer over an actual person was related to lower costs and convenience. A digital coach is available to give advice whenever and wherever needed. However, the lack of human aspect was also seen as the biggest negative reason for having a digital coach, particularly because it would not be able to analyze exercise technique. According to these findings, the reasons and perceptions for using a digital coach vary between people. What attracts one person was not necessarily important to others. In previous research regarding teenagers and sport and wellness technology the importance of design and outlook was highlighted. However, this study found teenagers perceived the informational and usability factors as far more important. Also, the importance of social factors as a part of digital coaching was not considered particularly important by the teenagers.

The findings of this study suggest that sport and wellness technology and especially digital coaching features can be a motivating tool for physical activity and health. Digital coaching is able to bring elements to sport and wellness technology that are viewed as essential and attracts this target group. Therefore, those working on teenager health promotion interventions should consider utilizing digital coaching, as it can be an important tool. They can make interventions even more personalized and engage teenagers for physical activity for longer term by increasing their level of motivation. If teenagers are introduced to sport and wellness technology and encouraged to pursue a healthy lifestyle, it is more likely they will continue being physically active as adults and be more interested in integrating technology to their exercising. Therefore, in order to get more loyal customers, sport and wellness technology companies should focus on creating products that interest teenagers and market them in a way that catches their attention. 
There are some limitations to the study. First, since the data is based on self-assessment questionnaires, the level of reporting in the questionnaires varied between participants. Second, regarding wellness and exercise behaviour related studies, there has been known to be challenges in research participants intentionally reporting their behaviour more positively compared to reality and thus biasing the responses. This is due to social desirability as well as deliberate misrepresentations (Sirard and Pate, 2001). However, in this study even though participants were asked to use sport and wellness technology applications for a five-week period, they were reminded that it does not matter how much they have used the application or how they used it. Instead, the application served only as a way for them to get familiar with the topic in order to being able to better express their perceptions about sport and wellness technology as well as digital coaching. This study is among the first ones to study the topic of teenagers and digital coaching, and more research in this field should be done. Future studies could focus on the effect digital coaching related sport and wellness technology would have on teenagers' physical activity levels or on their motivation regarding physical activity. Overall, the topic of teenagers and sport and wellness technology as well as digital coaching continues to be an important topic of research.

\section{References}

Bandura, A. (1982) Self-efficacy mechanism in human agency. American Psychologist. 37, 122147.

Bandura, A. (1986). Social Foundations of Thought and Action: A Social Cognitive Theory. Englewood Cliffs, NJ: Prentice-Hall

Bandura, A. (1997). Self-efficacy: The exercise of control. New York, NY: Freeman.

Bandura, A. (1998). Health promotion from the perspective of social cognitive theory. Psychology and Health 13 (4), 623-649.

Beauchamp, M. R. \& Eys, M. A. (2007). Group dynamics in exercise and sport psychology Contemporary themes. New York, NY: Routledge.

Braun, V., \& Clarke, V. (2006). Using thematic analysis in psychology. Qualitative Research in Psychology, 3(2), 77-101.

Brodersen, N., Steptoe, A., Boniface, D. \& Wardle, J. (2007). Trends in physical activity and sedentary behaviour in adolescence: ethnic and socioeconomic differences. British Journal of Sports Medicine, 41(3), 140-144.

Carrino, S., Caon, M., Khaled, O. A., Andreoni, G., \& Mugellini, E. (2014). PEGASO: Towards a Life Companion. In Digital Human Modeling. Applications in Health, Safety, Ergonomics and Risk Ma8.

Carrion, C., Caon, M., Carrino, S., Arroyo Moliner, L., Lang, A., Atkinson, S., Mazzola, M., Perego, P., Standoli, C., Castell, C., Espallargues, M. (2015) Wearable lifestyle tracking devices: Are they useful for teenagers?, In the 15th ACM International Joint Conference on Pervasive and Ubiquitous Computing, 7-11.9.2015, Osaka, Japan.

Chan, C. B., Ryan, D. A., \& Tudor-Locke, C. (2004). Health benefits of a pedometer-based physical activity intervention in sedentary workers. Preventive Medicine, 39(6), 1215-1222. 
Faghri, P. D., Omokaro, C., Parker, C., Nichols, E., Gustavesen, S., \& Blozie, E. (2008). Etechnology and pedometer walking program to increase physical activity at work. The Journal of Primary Prevention, 29(1), 73-91.

Guest, G., MacQueen, K. M., \& Namey, E. E. (2012). Applied thematic analysis. Los Angeles, CA: SAGE.

Hagger, M., Chatzisarantis, N. \& Biddle, S. (2001) The influence of self-efficacy and past behaviour on the physical activity intentions of young people, Journal of Sports Sciences, 19(9), 711-725.

Husu, P., Paronen, O., Suni, J. \& Vasankari, T. (2011) Suomalaisten fyysinen aktiivisuus ja kunto 2010 [The physical activity levels of Finns, 2010]. Opetus ja Kulttuuriministeriön Julkaisuja [The publications of the Ministry of Teaching and Culture], 2011:15.

Jowett, S. \& Lavallee, D. (2007). Social psychology in sport. Champaign, IL: Human Kinetics.

Kang, M., Marshall, S. J., Barreira, T. V., \& Lee, J. O. (2009). Effect of pedometer-based physical activity interventions: a meta-analysis. Research Quarterly for Exercise and sport, 80(3), 648655.

Kari, T., Kettunen, E., Moilanen, P., \& Frank, L. (2017a). Wellness Technology Use in Everyday Life: A Diary Study. In The 30th Bled eConference "Digital Transformation - From Connecting Things to Transforming Our Lives" Research Volume, 18.-21.6.2017 (pp. 279-294). Bled, Slovenia: University of Maribor.

Kari, T., Koivunen, S., Frank, L., Makkonen, M., \& Moilanen, P. (2016a). Critical Experiences During the Implementation of a Self-Tracking Technology. In The 20th Pacific Asia Conference on Information Systems (PACIS), 27.6.-1.7.2016 (16 pages). Chiayi, Taiwan: AIS.

Kari, T., Koivunen, S., Frank, L., Makkonen, M., \& Moilanen, P. (2017b). The expected and perceived well-being effects of short-term self-tracking technology use. International Journal of Networking and Virtual Organisations, 17(4), 354-370.

Kari, T., Piippo, J., Frank, L., Makkonen, M., \& Moilanen, P. (2016b). To gamify or not to gamify?: gamification in exercise applications and its role in impacting exercise motivation. In The 29th Bled eConference "Digital economy" Research Volume, 19.-22.6.2016 (pp. 393-405). Bled, Slovenia: University of Maribor.

Kranz, M., Möller, A., Hammerla, N., Diewald, S., Roalter, L., Ploetz, T. \& Olivier, P. (2012). The mobile fitness coach: Towards individualized skill assessment using personalized mobile devices. Pervasive and Mobile Computing, 9, 203-215.

Kumar, B., Robinson, R., \& Till, S. (2015). Physical activity and health in adolescence. Clinical Medicine, 15(3), 267-272.

Locke, E. A., \& Latham, G. P. (2002). Building a practically useful theory of goal setting and task motivation: A 35-year odyssey. American Psychologist, 57(9), 705-717.

Miyamoto, S. W., Henderson, S., Young, H. M., Pande, A., \& Han, J. J. (2016). Tracking health data is not enough: a qualitative exploration of the role of healthcare partnerships and mhealth technology to promote physical activity and to sustain behavior change. JMIR mHealth and uHealth, 4(1), e5.

Ryan, R. M. and E. L. Deci, (2000). Intrinsic and extrinsic motivations: Classic definitions and new directions. Contemporary Educational Psychology 25 (1), 54-67.

Shilts, M. K., Horowitz, M., \& Townsend, M. S. (2004). Goal setting as a strategy for dietary and physical activity behavior change: a review of the literature. American Journal of Health Promotion, 19(2), 81-93.

Schmidt, B., Benchea, S., Eichin, R., \& Meurisch, C. (2015). Fitness tracker or digital personal coach: how to personalize training. In The 2015 ACM International Joint Conference on Pervasive and Ubiquitous Computing and ACM International Symposium on Wearable Computers, 7.-11.9.2017 (pp. 1063-1067). Osaka, Japan: ACM. 
E. Kettunen \& T. Kari: Can Sport and Wellness Technology be My Personal Trainer? - Teenagers and Digital Coaching

Sirard, J. \& Pate, R. (2001) Physical activity assessment in children and adolescents. Sports Medicine, 31(6), 439-454.

Toscos, T., Faber, A., An, S., \& Gandhi, M. P. (2006, April). Chick clique: persuasive technology to motivate teenage girls to exercise. In CHI'06 extended abstracts on Human factors in computing systems (pp. 1873-1878). ACM.nagement (pp. 325-331). Springer International Publishing.

Wang, J. B., Cataldo, J. K., Ayala, G. X., Natarajan, L., Cadmus-Bertram, L. A., White, M. M., ... \& Pierce, J. P. (2016). Mobile and wearable device features that matter in promoting physical activity. Journal of Mobile Technology in Medicine, 5(2), 2-11.

Warraich, M. U. (2016). Wellness Routines with Wearable Activity Trackers: A Systematic Review. In The 10th Mediterranean Conference on Information Systems (MCIS), 4.-6.9.2016 (13 pages). Paphos, Cyprus: AIS.

Wartella, E., Rideout, V., Montague, H., Beaudoin-Ryan, L. \& Lauricella, A. (2016) Teens, Health and Technology: A National Survey. Media and Communication, 4(3), 13-23.

World Health Organization (2018). Physical Activity Fact Sheet. Retrieved 16.3.2018 from http://www.who.int/mediacentre/factsheets/fs385/en/ 


\title{
Designing business model tooling for business model exploration: An experimental design for evaluation
}

\author{
AleXia Athanasopoulou \& MARK DE REUVER
}

\begin{abstract}
Disruptive technologies drive enterprises to rethink how to create and capture value by revising their business models (BM). Even in cases that the need for BM innovation is clear, how entrepreneurs can do it and what they need to be changed it is not always obvious. That leads to the need for BM exploration. BM tooling can support this process, however, existing $\mathrm{BM}$ tools are not widely focused on the BM exploration. In previous steps of our research, we designed and developed a digital tooling for BM exploration. This RiP paper presents the experimental design we plan to use to evaluate the effects of the tooling on the BM exploration. Initial results and future steps are discussed. We expect to contribute to the $\mathrm{BM}$ literature by understanding what features of BM tooling contribute to BM exploration.
\end{abstract}

Keywords: • Business model experimentation • Business Model tooling • Experimental design • Business Models •

CORRESPONDENCE AdDRESS: Alexia Athanasopoulou, MEng, MSc, PhD Researcher, Delft University of Technology, Technology Policy and Management, Jaffalaan 5, 2628BX, Delft, The Netherlands, e-mail: a.athanasopoulou@tudelft.nl. Mark De Reuver, Ph.D., Associate Professor, Delft University of Technology, Technology Policy and Management, Jaffalaan 5, 2628BX, Delft, The Netherlands, e-mail: g.a.deReuver@tudelft.nl. 
Digital technologies are radically changing businesses (Bharadwaj, et al. 2013), and that forces enterprises to reinvent and reconsider, their existing Business Model (BM) (Sonsa et al. 2010; De Reuver, Bouwman and Maclnnes, 2009).

One potential solution to support enterprises with radical changes is to do BM exploration. With BM exploration, enterprises can discover new BM opportunities (De Reuver et al., 2016). During BM exploration enterprises are able to create BM alternatives and changes, (Cavalcante, Kesting and Ulhoi, 2011), conceptualize these changes (Sonsa et al. 2010) and assess what could happen under a range of different decision choices (Bisbe and Malagueño, 2012).

Within information systems (IS) research, BM is an emerging topic (e.g., Cosenz and Noto, 2017; Roelens and Poels, 2015; Fritscher and Pigneur, 2014; Kyriazis and Varvarigou, 2013; El Sawy and Pereira, 2013; Bouwman, De Vos, and Haaker, 2008). Special focus is paid on the BM tooling (e.g., De Reuver et al. 2016). However, the potential benefits of BM tooling are still overlooked (Eppler Hoffmann and Bresciani, 2011). Existing tooling is still not formally supporting the exploration of alternative BMs in a structured way. In previous steps of our research, we developed a prototype for a BM tooling based on identified design principles.

In this research in progress (RiP) paper we present the outline of our experimental design for evaluating the developed prototype. In an experimental setting, we will evaluate what features of BM tooling can contribute to the BM exploration. In this RiP some preliminary results regarding the hypothesis are presented.

We aim to contribute to the literature by investigating what functions of the developed prototype contribute to the BM exploration. This research will allow us to provide design guidelines for the development of BM exploration artefacts.

The RiP is structured as follows. Section 2 provides a background on BMs. Section 3 shortly describes the prototype. Section 4 discusses the research approach. Section 5 presents the experimental design, while section 6 presents preliminary results. In section 7 we conclude.

\section{$2 \quad$ Background}

BMs can be seen as '[...] a conceptual tool containing a set of objects, concepts and their relationships with the objective to express [...] what value is provided to customers, how this is done and with which financial consequences' (Osterwalder Pigneur and Tucci 22 p. 3). Magretta, points out that 'a good BM remains essential to every successful organization [...] (2002, p. 3). However, BMs need to get revised over time in response to internal or external drivers (De Reuver, Bouwman and Maclnnes, 2009). 
Digital technologies are a major external driver as they disrupt the business environment. A technology is defined as disruptive when causes turmoil in an existing market or creates a new market, requires major or minor revisions on the business model, leads to performance problems, and/or eventually leads to the need for new offerings (Bower and Christensen, 1995).

The existing studies on BM are mainly focused on the business design and (e.g. Osterwalder and Pigneur, 2010), evaluation (e.g. Ballon 2007; Bouwman, Haaker and De Vos, 2008). De Reuver, Bouwman and Haaker went a step forward and focused on how an enterprise can move from an old to a new BM (2013). In practice, tooling is available in different formats and for different purposes (e.g. Osterwalder and Pigneur, 2010; Foresight cards, 2012; Leanstack, 2017; SWOT app; Haaker, 2017). However, BM for systematic BM exploration tooling is lacking, especially in relation to disruptive technology innovations. As Sosna et al. argue most BMs have not 'gone straight from the drawing board into the implementation [...] in reality new BMs rarely work the first time around, since decision makers face difficulties in both exploratory and implementation stages' (2010, p. 384). In previous stages of our research we designed and developed a software-based BM tooling that aims to support enterprises during the business mode exploration process. Section 3 shortly presents the prototype we previously developed.

\section{Description of the prototype}

We created a working prototype of a software-based tool (using Microsoft Exel) based on specific design principles (Athanasopoulou, Haaker and De Reuver, 2018a, forthcomming), and a step by step approach to allow us to test each of the hypotheses independently: (1) description of components of the existing BM; (2) identification of new opportunities and potential changes towards a revised BM, and (3) the assessment, based on specific critical factors (Bouwman et al., 2008) of the changes defined in the previous step, see figure 1 for a screanshot of the first step. 
A. Athanasopoulou \& M. de Reuver: Designing business model tooling for business model exploration: An experimental design for evaluation

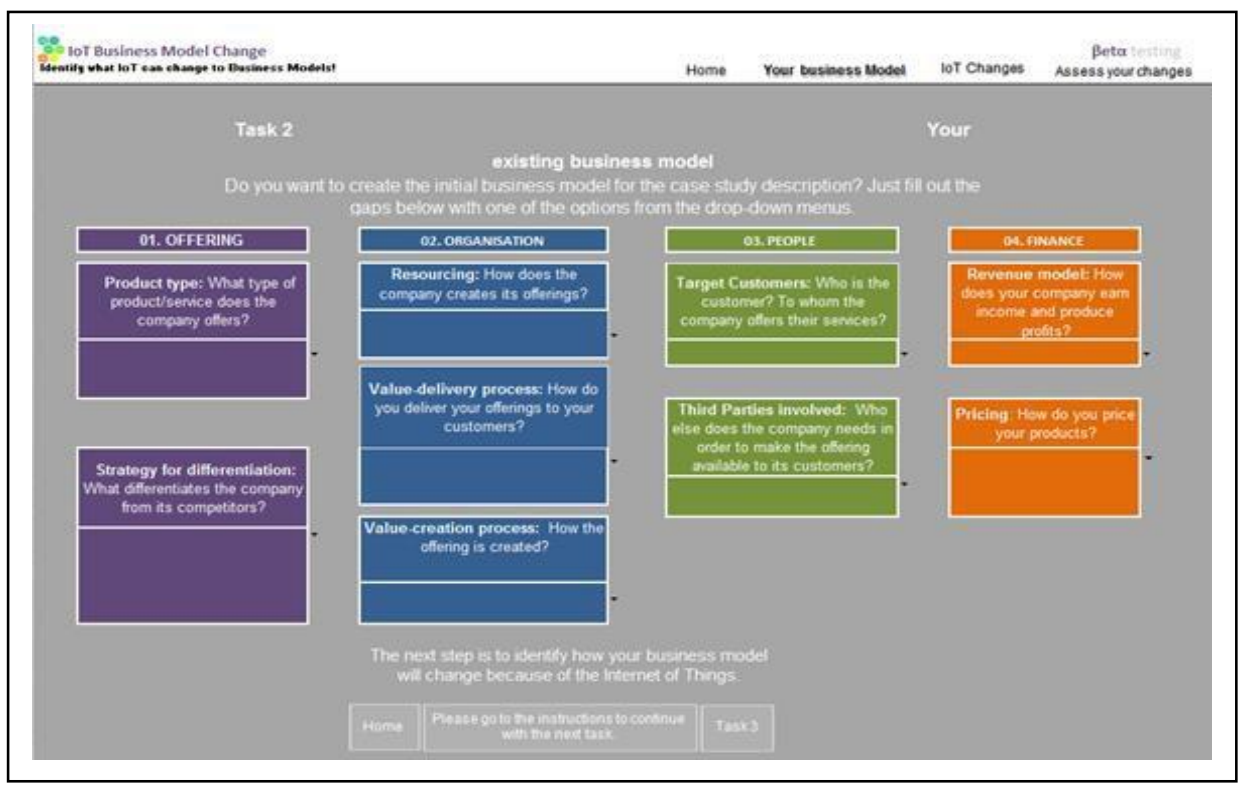

Figure 1: Screenshot of the first step of the developed prototype

4

\section{Research Model}

The main interest of our research is to evaluate what features a BM tooling can have to support entrepreneurs to facilitate BM exploration process. While a BM tooling can be designed based on various features for different purposes we focus on the three main design principles we identified on a previous phase of our research (Athanasopoulou et al., forthcomming), and the prototype is based on. In this RiP we present the research model (figure 2), and the hypotheses for the evaluation of the prototype. The developed hypotheses are derived from the design principles we identified previously, and informed the three steps of the prototype (section 3). The three design principles serve as hypotheses that we will test in an experimental setting. 


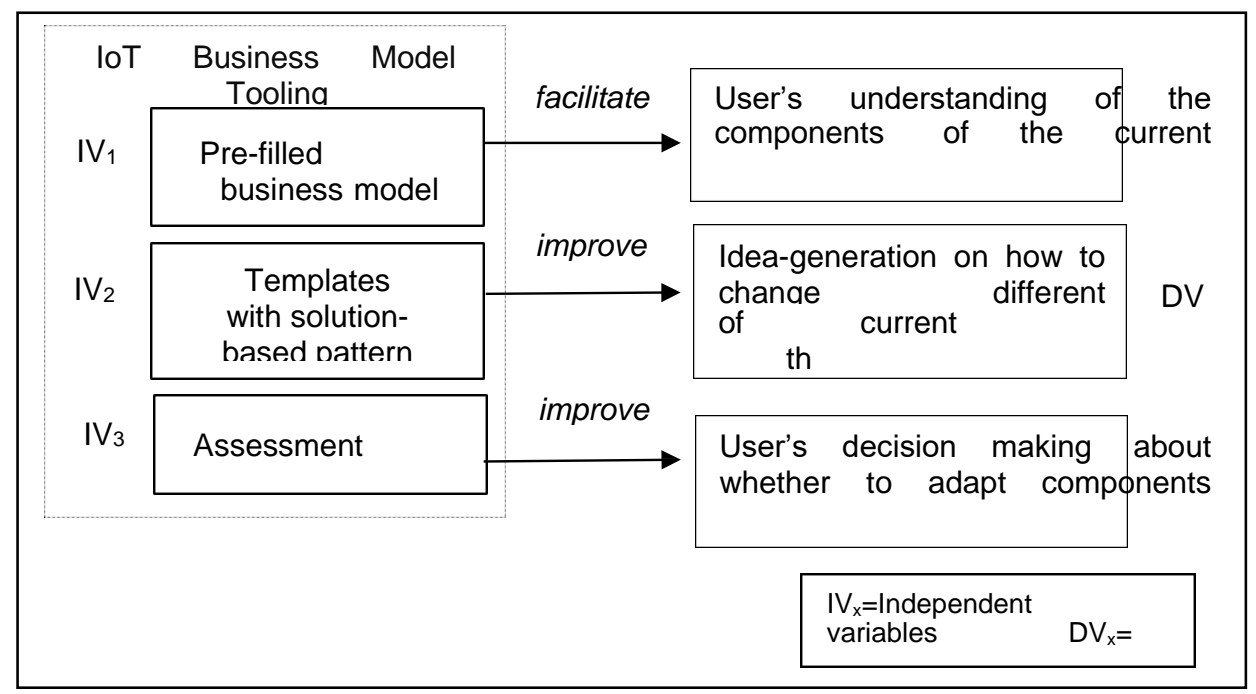

Figure 2: Research model

Therefore, we formulate the following hypotheses:

$\boldsymbol{H}_{\boldsymbol{I}}$ : Pre-filled BM templates, facilitate the users' understanding of the components of the current BM.

$\boldsymbol{H}_{2}$ : Templates with solution-based patterns, improve idea-generation on how to change different components of the current BM.

$\boldsymbol{H}_{3}$ : Assessment features, improve users' decision making about whether to adapt components in the BM.

\section{$5 \quad$ Methodology}

To analyse our hypothesis we plan to conduct an experiment. Our experimental design can be described as a typical pre- and post-testing experiment with treatment and control condition (Cook and Cambell, 1979). For that experiment we will use two conditions: (a) a treatment condition, that is prototype designed for this study, (b) a control condition where subjects use an online version of the widely known and used framework BM Canvas created by Osterwalder and Pigneur (2010). Randomly assigned to one of the two conditions, the experiment will start with the subjects filling out a pre-test questionnaire. Then they will follow specific scenario-based tasks with the use of the BM tool. The experiment will end with the participants feeling out the post-test questionnaire, see Figure 3. 
A. Athanasopoulou \& M. de Reuver: Designing business model tooling for business model exploration: An experimental design for evaluation

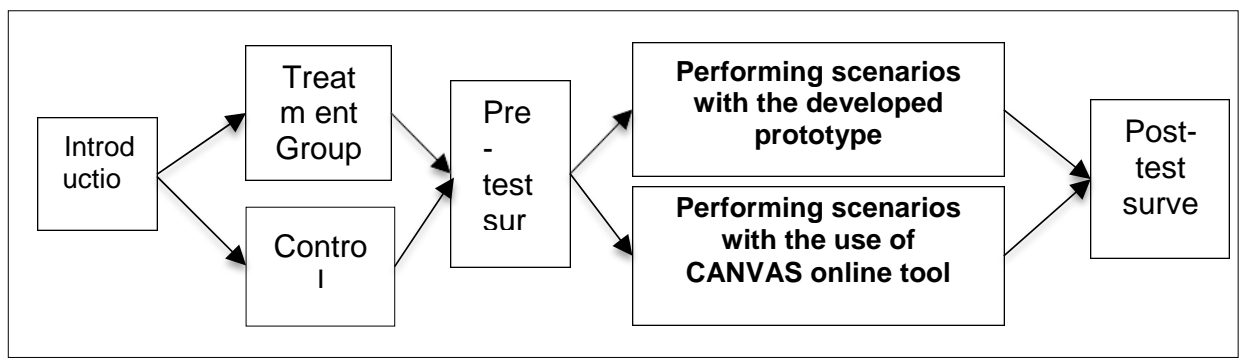

Figure 3: Experimental design overview

\subsection{Procedure during the experiment}

The subjects will be invited to a computer lab, and randomly assigned in one of the two conditions. The subjects form groups of three, so the experiment represents more accurate the business environment. The newly formed groups are asked to collaborate and discuss the available scenario in the computer in front of them (see figure 4 for an explanation). An external facilitator will be present at the class through the process and observe that the participants are continuing with the workshop and the scenarios. The subjects will have specific time (120 minutes) to complete the scenarios and fill out the questionnaires. While that is not totally realistic, it will allow us to collect completed questioners from all the subjects.

\subsection{Subjects}

The subjects will be master level students with an entrepreneurship interest who are partially experienced with the concepts of BMs, and service design. We aim to subjects that are both experienced, and inexperienced with a working environment, creating their own business, or not. That allows us testing the artefact with different potential users. To increase validity we aim to include practitioners (i.e. entrepreneurs) as subjects to the experiments. 


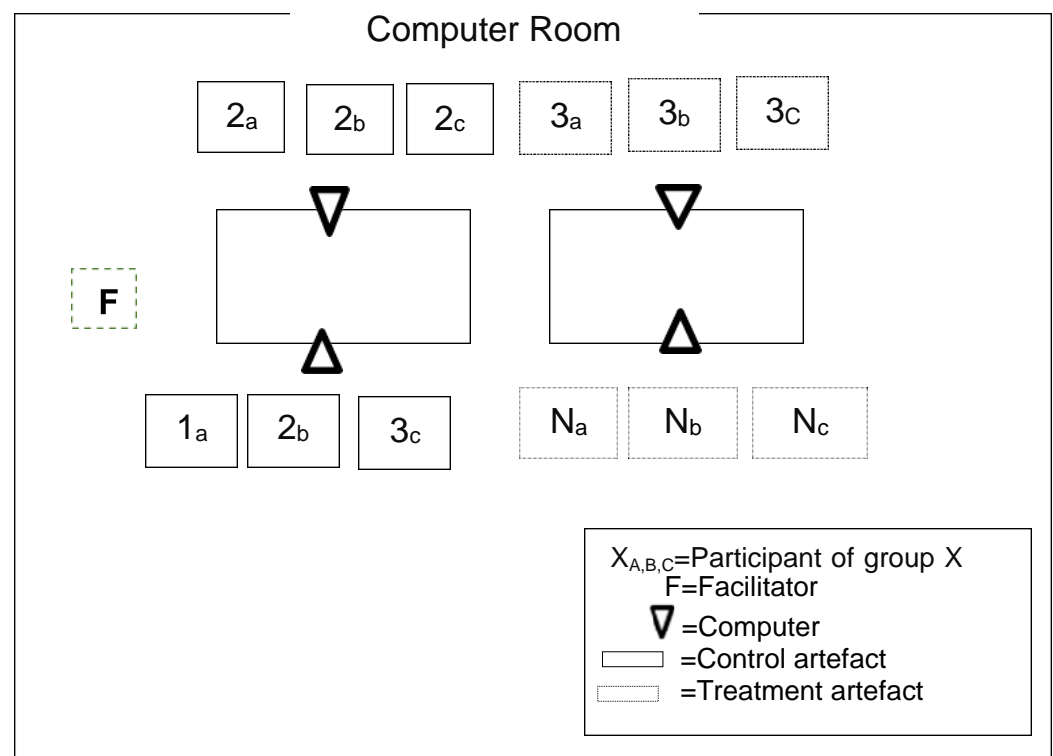

Figure 4: Experiment room layout

\subsection{Questionnaire}

Following the approach by Cook and Cambell (1979), the participants are asked to, individually, fill out a pre- and a post-test questionnaire. The subjects will fill out the questionnaires on hardcopies. Pre- and post-tests are used as measurements instruments just before and just after the use of the tool. Additionally, the pre-test includes some demographics (that will help us to decide if the data are appropriate for analysis), while post- test includes questions for evaluation of the session (for validity reasons). The preand post- questionnaires include questions (based on the hypotheses) regarding the understanding of BM components (e.g. BM tooling helped me to improve my understanding regarding BMs; I am aware of what I do not understand regarding BMs components), idea-generation and BMs (e.g. I am able to generate a sufficient number of ideas on how I can change an existing BM; I am able to generate qualitative ideas on how BMs components can be changed), and decision making and BMs (e.g. BM tooling helped me to make decisions regarding what I should change; When it comes to a decision regarding a BM change I prefer to do nothing).

\subsection{Scenario}

To ensure that the participants utilise the prototype apropriatly, we created a scenario with specific tasks that the subjects have to follow. In the scenario we created we will ask the subjects to work in groups to illustrate a realy life setting where they are managers of a car leasing company. The subjects follow the tasks to create the existing the BM of the 
case leasing company (based on given description), to brainstorm how ths BM can change in the case of a technology disruption (i.e., Internet of Things), and to asses these chances.

\section{$6 \quad$ Preliminary results}

While this research is still in progress some initial results are available (Athanasopoulou, Haaker and De Reuver, 2018b, forthcoming). We did that by partially following the experimental design described above. For these workshops the participants only used the developed prototype and not the controlled condition. We collected data from three workshops from November 2017 to January 2018. The subjects of these workshops were Master level students with entrepreneurship interest. The setting of the experiment is artificial and controlled, as it does not represent absolute a business environment. Computer rooms were arranged within the university (see figure 5 for an example of the setting). These workshops had a two-fold purpose: (a) for us to evaluate our experimental design, and second to collect initial data regarding the effects of the tooling to the BM exploration. The participants were invited to participate to the experiment (with a voucher as a reward). The researchers welcome the participants and shortly explained the purpose of the workshop. A concern form was also available. For ethical reasons the researchers left the room and a facilitator stayed in the room. The room was reserved for 120 minutes. The participants followed the instructions for the scenario. We collected preliminary results regarding the experimental design and the effect of the developed tooling regarding BM tooling (Athanasopoulou. Haaker and De Reuver, 2018b, forthcoming). We should mention that not all the subjects $(\mathrm{N}=23)$ fully filled-out the questionnaires. However, the results were significant to give us some initial results partially confirming the hypotheses. We shortly present the initial results regarding the hypotheses.

In the workshops, we collected quantitative data to evaluate the impact of the prototype on BM exploration. We did so by asking the participants to fill out the same questionnaire before and after the use of the prototype. The questionnaires were divided in three sections, each containing statements related to one of the three design principles.Then, we ran paired t- tests to measure differences before and after using the prototype. Out of the 17 pairs of statements (e.g. same question in the pre- and post- questionaire), five were significantly $(\mathrm{p}<.05)$, see Table 1. 
A. Athanasopoulou \& M. de Reuver: Designing business model tooling for business model exploration: An experimental design for evaluation

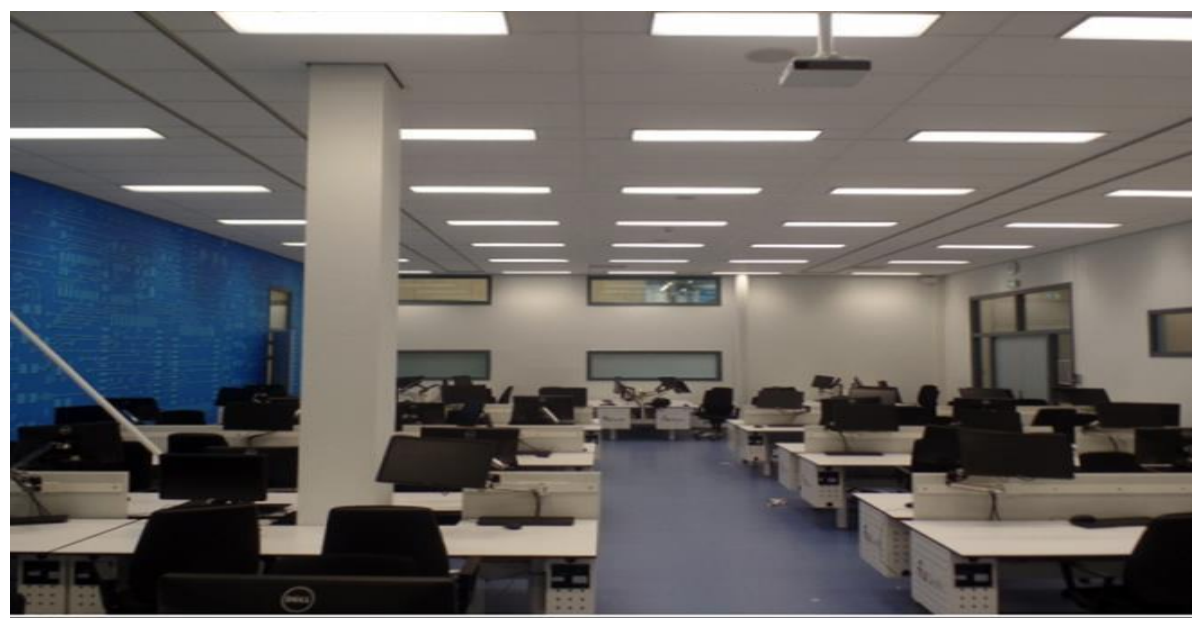

Figure 5: Experimental setting (http://educationrooms.tudelft.nl/zaleninfo.php?zid=31)

From these results we are not able to confirm or reject the hypotheses (something that we plan to do in the future), but we can see that the prototype, at least parcialy, contributes to the BM exploration. More specific, two pair related to the first Hypothesis, show that partcipants after the use of the tool had a better understanding of the BM componets and were able to apply their acquired knowlwdge to different settings. Regarding hypothesis 2 , the use of the tool supported the idean generation and participants are able to do estimations about unexpecxted ideas. Finaly, regarding the third hypothesis, we were not able to confirme it, but the results showed that after the use of the tool the participants shown more eager to make decitions than staying neutral. 
A. Athanasopoulou \& M. de Reuver: Designing business model tooling for business model exploration: An experimental design for evaluation

Table 1: Initial results $(\mathrm{N}=23)$.

\begin{tabular}{|c|c|c|c|c|}
\hline Hypotheses & Statements & $\begin{array}{c}\text { Mean } \\
\text { Difference } \\
\left(\mathrm{M}_{\text {post }}-\mathrm{M}_{\text {pri }}\right)\end{array}$ & $\begin{array}{c}\text { Standard } \\
\text { deviation of } \\
\text { Mean } \\
\text { Difference } \\
\left(S_{\text {post }}-S_{\text {pri }}\right)\end{array}$ & T- test \\
\hline \multirow{2}{*}{$\begin{array}{l}H_{1}: \quad \text { Pre-filled } \\
\quad \text { BM templates, } \\
\text { facilitates users' } \\
\text { the } \\
\text { understanding of the } \\
\text { components of the } \\
\text { current BM. }\end{array}$} & $\begin{array}{l}\text { Pair } 2 \text { I I have a } \\
\text { solid interpretation of } \\
\text { what the BM } \\
\text { components are. }\end{array}$ & $\begin{array}{l}\text { Pair }_{2}\left(M_{\text {post }}\right. \\
\left.M_{\text {pri }}\right)=1.00\end{array}$ & $\begin{array}{l}\text { Pair }_{2}\left(S_{\text {post }}\right. \\
\left.S D_{\text {pri }}\right)=-1.70\end{array}$ & $\begin{array}{l}t(16)=2.43 \\
p<.05\end{array}$ \\
\hline & $\begin{array}{l}\text { Pairs: I am able to } \\
\text { apply my } \\
\text { knowledge on BM } \\
\text { on a new } \\
\text { context/case/indu } \\
\text { stry. }\end{array}$ & $\begin{array}{l}\text { Pair }_{3}\left(M_{\text {post }}\right. \\
\text { Mpri })=0.65\end{array}$ & $\begin{array}{l}\mathrm{Pair}_{3}\left(\mathrm{SD}_{\text {post }}\right. \\
\left.\mathrm{SD}_{\text {pri }}\right)=1.17\end{array}$ & $\begin{array}{l}t(16)=- \\
2.281, p<.05\end{array}$ \\
\hline \multirow{3}{*}{$\begin{array}{l}\mathrm{H}_{2} \text { : Templates with } \\
\text { solution-based } \\
\text { patterns, improves } \\
\text { idea-generation } \\
\mathrm{n} \text { to change } \\
\text { how different components } \\
\text { of the current BM. }\end{array}$} & \begin{tabular}{|l|r|} 
Pair 10: & am able \\
to & generate \\
qualitative & ideas \\
on how & BMs \\
& \\
components & \\
con
\end{tabular} & $\begin{array}{l}\text { Pair } 10\left(M_{\text {post }}\right. \\
\text { Mpri) }=.69\end{array}$ & $\begin{array}{l}\text { Pair } 10\left(S_{\text {post }}\right. \\
\left.S D_{\text {pri }}\right)=1,30\end{array}$ & $\begin{array}{l}(\mathrm{t} 15)=2,11 \\
p<.05\end{array}$ \\
\hline & be changed. & & & \\
\hline & $\begin{array}{l}\text { Pair11: I am able to } \\
\text { estimate how } \\
\text { inexperienced my } \\
\text { generated ideas } \\
\text { are. }\end{array}$ & $\begin{array}{l}\text { Pair }_{11}\left(M_{\text {post }}\right. \\
\left.M_{\text {pri }}\right)=1.00\end{array}$ & $\begin{array}{l}\text { Pair }_{11}\left(S_{\text {post }}\right. \\
\left.S D_{\text {pri }}\right)=-1,63\end{array}$ & $\begin{array}{l}(\mathrm{t} 15)=-2.45, \\
p<.05\end{array}$ \\
\hline 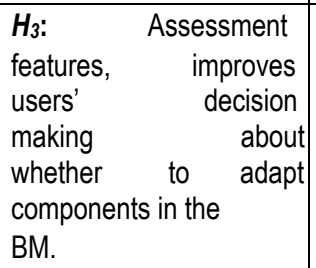 & $\begin{array}{l}\text { Pair16: When it } \\
\text { comes to a } \\
\text { decision } \\
\text { regarding a BM } \\
\text { change I prefer to } \\
\text { keep everything } \\
\text { as it is. }\end{array}$ & $\begin{array}{l}\text { Pair }_{16}\left(M_{\text {post }}\right. \\
\left.M_{\text {pri }}\right)=-.62\end{array}$ & $\begin{array}{l}\text { Pair }_{16}\left(S_{\text {post }^{-}}\right. \\
\left.\mathrm{SD}_{\text {pri }}\right)=.96\end{array}$ & $\begin{array}{l}(\mathrm{t} 15)=2.61, \\
p<.05\end{array}$ \\
\hline
\end{tabular}




\section{A. Athanasopoulou \& M. de Reuver: Designing business model tooling for business model exploration: An experimental design for evaluation}

\section{$7 \quad$ Conclusion, Next Steps and Expected Contributions}

In this RiP paper we present an experimental design for the evaluation of a new BM tooling. We presented the experimental design and preliminary data. The hypotheses are relatively confirmed (five statements out 17 were significand different).

A main limitation of these results is the number of the participants. In the near future we plan to repeat the experiments. Another issue is that the subjects might not be familiar with the BM concept and how a business operates. We could overcome this limitation by including at the experiments entrepreneurs. However, our results can present that our developed prototype has a positive effect on the subjects experience with the BM exploration. This RiP contributes to the field by providing initial insights on what type of functionalities of a $\mathrm{BM}$ contribute to the $\mathrm{BM}$ exploration process.

The next steps of our research are to improve the prototype, repeat the experiments, and to make final conclusions. Once our research is completed we aim to contribute to the $\mathrm{BM}$ innovation theory by focusing on the $\mathrm{BM}$ exploration phase and investigating the effect of BM tooling in this phase. We will contribute to the practice with the development of a theory based, and easy to use BM tool for the BM exploration.

\section{Acknowledgments}

This work is part of ENviSION project. ENviSION has received funding from the European Union's Horizon 2020 research and innovation program under grant agreement 645791.

\section{References}

Athanasopoulou, A., Haaker, T., and De Reuver, M. (2018a) Tooling fot Internet of Thing Business Model Exploration: A Design Science Research Approach. In ECIS 2018, Portsmouth, UK (forthcomming).

Athanasopoulou, A., Haaker, T., and De Reuver, M. (2018b) Designing digital tooling for business model exploration. for the Internet-of-Things. In DESRIST 2018, Chennai, India (forthcomming).

Athanasopoulou, A., De Reuver, M., Kosman, R, and Roelfsema, M. (2018). Understanding business model innovation in practice: Recommendations for future business model tooling by an action research. In procentings of $R \& D$ conference, Milan, Italy (forthcomming).

Ballon, P. (2007). Business modelling revisited: the configuration of control and value. Info, 9(5), 6-19.

doi.org/10.1108/14636690710816417.

Bharadwaj, A., El Sawy, O. A., Pavlou and P. A., Venkatraman V.N. (2013). Digital business strategy: towards a next generation of insights. MIS Quarterly 37(2), 471-482.

Bisbe, J. and R. Malagueño (2012). How Control Systems Influence Product Innovation Processes: Examining the Role of Entrepreneurial Orientation. Accounting and Business Research 44 (0), 1-46. 
Bower, J. L. and Christensen, C. M. (1995). Disruptive Technologies: Catching the Wave, https://hbr.org/1995/01/disruptive-technologies-catching-the-wave, last accessed 2018/02/06.

Bouwman, H., De Vos, H. and Haaker, T. (2008). Mobile service innovation and business models.

Springer-Verlag Berlin Heidelberg. doi.org/10.1007/978-3-540-79238-3.

Cavalcante, S., Kesting, P. and J. Ulhøi (2011). Business model dynamics and innovation: (re)establishing the missing linkages. Management Decision, 49(8), 1327-1342. doi.org/10.1108/00251741111163142.

Cook, T.D. and Campbell, D.T. (1979). Quasi-experimentation: Design and analysis issues for field settings. Chicago: Rand McNally.

Cosenz, F. and G. Noto (2017). A dynamic business modelling approach to design and experiment new business venture strategies. Long Range Planning In press. doi.org/10.1016/j.lrp.2017.07.001.

De Reuver, M., Athanasopoulou, A., Roelfsema, M, Riedi, A (2016). A. Designing an ICT tooling platform to support SME business model innovation : Results of a first design cycle. In: Proceedings of BLED 2016. 7, pp. 556-570.

De Reuver, M., Bouwman, H. and T. Haaker (2013). Business Model Roadmapping: a Practical Approach To Come From an Existing To a Desired Business Model. International Journal of Innovation Management 17 (1). 1340006. doi.org/10.1142/S1363919613400069.

De Reuver, M., Bouwman and Maclnnes, H. I. (2009). Business model dynamics: a case survey. Journal of Theoretical and Applied Electronic Commerce Research 4 (1), 1-11 doi.org/10.4067/S0718-18762009000100002.

El Sawy, O. and F. Pereira (2013). Business Modelling in the Dynamic Digital Space - An Ecosystem Approach. Springer Briefs Series in Digital Spaces 68. doi.org/10.1007/978-3-642-31765-1.

Eppler, M. J., Hoffmann and Bresciani, F., S. (2011). New Business Models Through Collaborative Idea Generation. International Journal of Innovation Management 15 (6), 1323-1341 doi.org/10.1142/S1363919611003751.

Foresight cards URL: Available at https://foresightcards.com/workshops/businessmodels/ (visited on $25 / 11 / 2017$ ).

Fritscher, B. and Y. Pigneur (2014). Computer Aided Business Model Design: Analysis of Key Features Adopted by Users. In: "Proceedings of the 47th Hawaii International Conference on System Sciences". 3929-3938. doi.org/10.1109/HICSS.2014.487.

Haaker, T., Bouwman, H., Janssen, W. and M. De Reuver (2017). Business model stress testing: A practical approach to test the robustness of a business model. Futures, 89 (Supplement C), 14-25. doi.org/10.1016/j.futures.2017.04.003.

Kyriazis, D. and T. Varvarigou (2013). Smart, autonomous and reliable Internet of Things. In Procedia Computer Science 21, 442-448. doi.org/10.1016/j.procs.2013.09.059 doi.org/10.1.1.83.7452.

Linder, J. and Cantrell, S. (2000). Changing Business Models: Surveying the Landscape. Accenture Institute for Strategic Change, 1-15 doi.org/10.4018/9781-59904-939-7.

Magretta, J. (2002) Why business models matter https://hbr.org/2002/05/whybusiness-models-matter, (last accessed 2018/02/06).

Osterwalder, A. and Pigneur, Y. (2010). Business Model Generation: A Handbook for Visionaries, Game Changers, and Challengers. A handbook for visionaries, game changers, and challengers.

John Wiley end Sons Ltd. doi.org/10.1523/jneurosci.0307-10.2010. 
A. Athanasopoulou \& M. de Reuver: Designing business model tooling for business model exploration: An experimental design for evaluation

Osterwalder, A., Pigneur, Y. and C.L. Tucci (2005). Clarifying business models: origins, present, and future of the concept. Communications of the Association for Information Systems 15 (1), 1-43.

Roelens, B. and G. Poels (2015). The Development and Experimental Evaluation of a Focused Business Model Representation. Business \& Information Systems Engineering 57 (1), 6171. doi.org/10.1007/s12599-014-0363-z.

Sosna, M., Trevinyo-Rodríguez, R. N. and Velamuri, S.R. (2010). Business Model Innovation through Trial-and-Error Learning: The Nature house Case. Long Range Planning, 43 (2), 383-407 http://doi.org/https://doi.org/10.1016/j.lrp.2010.02.003. 
490 31 $31^{\text {ST }}$ Bled eConference: Digital Transformation: MeEting the Challenges JunE 17 - 20, 2018, BLED, SLOVEnIA, CONFERENCE PROCEEDINGS 


\title{
Identifying the Sales Patterns of Online Stores with Time Series Clustering
}

\section{MARKUS MAKKONEN \& LAURI FRANK}

\begin{abstract}
During the past decades, electronic commerce, especially in the business-to-consumer (B2C) context, has emerged as a popular research topic in information systems (IS). However, this research has traditionally been dominated by the consumer focus instead of the business focus of online stores. In this explorative study, we aim to address this gap in prior research by identifying the most typical sales patterns of online stores operating in the B2C context. By segmenting the monthly sales time series of 399 online stores with time series clustering, we are able to identify four approximately equally sized segments, of which two are characterised by a clear upward or downward trend in the sales and two are characterised by strong seasonal sales variation. We also investigate the potential segment differences in terms of several key business and technical parameters as well as discuss more broadly the applicability of time series clustering to IS.
\end{abstract}

Keywords: - Electronic Commerce - Business-to-Consumer (B2C) • Online Stores $\bullet$ Sales Patterns • Time Series Clustering $\bullet$ Segmentation •

CORRESPONDENCE AdDRESS: Markus Makkonen, Project Researcher, University of Jyvaskyla, Faculty of Information Technology, PO Box 35, 40014 University of Jyvaskyla, Finland, e-mail: markus.v.makkonen@jyu.fi. Lauri Frank, Ph.D., Research Professor, University of Jyvaskyla, Faculty of Information Technology, PO Box 35, 40014 University of Jyvaskyla, Finland, e-mail: lauri.frank@jyu.fi. 
During the past decades, electronic commerce, especially in the business-to-consumer (B2C) context, has emerged as a popular research topic in information systems (IS). However, the prior studies on the topic have traditionally been dominated by the consumer focus, such as the factors affecting online consumer behaviour (e.g., Perea y Monsuwé, Dellaert \& de Ruyter, 2004; Chang, Cheung \& Lai, 2005; Cheung, Chan \& Limayem, 2005) and the segmentations of online consumers, based either on self-reported survey data (e.g., Brown, Pope \& Voges, 2003; Swinyard \& Smith, 2003; Kau, Tang \& Ghose, 2003; Bhatnagar \& Ghose, 2004a, 2004b; Rohm \& Swaminathan, 2004; Brengman et al., 2005; Allred, Smith \& Swinyard, 2006; Barnes et al., 2007; Soopramanien \& Robertson, 2007) or on click-stream data about the actual visits in online stores (e.g., Moe, 2003; Su \& Chen, 2015). In contrast, the business focus of online stores has traditionally gained far less attention. For example, whereas various segmentations exist for online consumers based on their purchase behaviour, no such segmentations have been developed for online stores based on their sales patterns.

In this explorative study, we aim to address this gap in prior research by identifying the most typical sales patterns of online stores operating in the $\mathrm{B} 2 \mathrm{C}$ context. With a sales pattern, we refer to the temporal variation in the aggregate sales of an online store across all its sold items. Based on our review of prior literature, we find this study to be the first of its kind. Of course, sales patterns (or sales variation) as such have been investigated in several prior studies (e.g., Geurts, 1988). However, these studies have traditionally aimed at forecasting the future sales of an individual item or store instead of investigating the past sales of a wider sample of stores and identifying typicalities in them. Or those studies that done this, have done it only in the context of traditional offline retailing (e.g., Carman \& Figueroa, 1986). We see that this kind of an investigation and identification can be highly valuable in both theoretical and practical respects. First, it helps us to better understand the characteristics of online markets and, for example, to anticipate the upcoming seasonal sales peaks, which can be considered important especially for logistic and payment service providers in terms of proper resource allocation. Second, if we are able to find causal explanations for the emergence of specific sales patterns, or at least associate them with specific business and technical parameters of the stores, we may be able to offer the stores competitive advantage by suggesting what kind of strategies help them to move away from sales patterns that are likely to be perceived as mostly negative (e.g., decreasing sales and strong seasonal sales variation) and towards sales patterns that are likely to be perceived as more positive (e.g., increasing and more stable sales).

We conduct the study in two phases by analysing the data collected from 399 online stores operating mainly in the Finnish market. In the first phase, we segment the stores based on their monthly sales time series from January 2016 to December 2017 by using time series clustering. In the second phase, we investigate the potential segment differences in terms of several key business and technical parameters. 
The paper proceeds as follows. After this introductory section, Section 2 briefly discusses the basics of time series clustering, which has remained a rarely used data analytics method in IS. After this, we will describe the methodology and results of the study in Sections 3 and 4. The results will be discussed in more detail in Section 5, which also discusses more broadly the applicability of time series clustering to IS. Finally, Section 6 describes the main limitations of the study and proposes some potential paths of future research.

\section{Time Series Clustering}

As mentioned above, time series clustering has remained a rarely used data analytics method in IS. However, it has been commonly used in other disciplines and domains, such as finance and signal processing. Literature reviews on time series clustering are provided, for example, by Liao (2005), Fu (2011), as well as Aghabozorgi, Shirkhorshidi, and Wah (2015).

Clustering, in general, refers a statistical technique in which objects are grouped together so that they have maximum similarity (or minimum dissimilarity) with the objects in the same group, but minimum similarity (or maximum dissimilarity) with the objects in the other groups. Time series clustering, in turn, refers to a specific case of clustering in which the grouped objects are time series consisting of multiple data points in a chronological order (Liao, 2005; Aghabozorgi, Shirkhorshidi \& Wah, 2015). Time series clustering can be divided into three main types (Aghabozorgi, Shirkhorshidi \& Wah, 2015): (1) whole time series clustering, (2) subsequence time series clustering, and (3) time point clustering. Of these, whole time series clustering refers to the clustering of a set of separate time series by considering the similarity or dissimilarity of the time series as a whole, whereas subsequence time series clustering and time point clustering refer to the clustering of a set of sub-sequences or time points from a single time series. In this paper, we will concentrate only on whole time series clustering.

The typical process of whole time series clustering can be divided into four main phases (Aghabozorgi, Shirkhorshidi \& Wah, 2015): (1) the selection of a representation method, (2) the selection of a distance measure, (3) the selection of a clustering algorithm, and (4) the evaluation of the clustering solution. First, the dimensionality of the raw time series is typically reduced by using a representation method, which can be divided into data adaptive, data non-adaptive, model based, and data dictated approaches (Aghabozorgi, Shirkhorshidi \& Wah, 2015). The purpose of this phase is to reduce both the memory and computation requirements of the following phases as well as to filter out outliers and noise.

Second, the similarity or dissimilarity of the time series is calculated by using the selected distance measure. Its selection depends on the characteristics of the time series, the selected representation method, and the overall objective of the clustering, which may be to find similar time series in terms of time, shape, or change (Aghabozorgi, Shirkhorshidi $\&$ Wah, 2015). The distance measures can be divided into shape-based, comparison- 
based, feature-based, and model-based measures, of which the shape-based measures, especially the Euclidean distance and the dynamic time warping (DTW) distance, are currently the most commonly used ones (Aghabozorgi, Shirkhorshidi \& Wah, 2015). The Euclidean distance is suitable for finding similar time series in terms of time, meaning that the potential patterns in the time series must occur synchronously. For example, if there are sales peaks in the sales time series of two online stores, the sales time series are considered similar only if the sales peaks occur at the same time. In contrast, the DTW distance is suitable for finding similar time series in terms of shape, meaning that the potential patterns in the time series may occur asynchronously. For example, in the aforementioned case of two online stores, it would not be necessary for the sales peaks to occur at the same time in order for the sales time series to be considered similar.

Third, after the distances between the clustered objects have been calculated, the selected clustering algorithm can be applied. On a general level, there are six main clustering methods (Aghabozorgi, Shirkhorshidi \& Wah, 2015): (1) hierarchical clustering, (2) partitioning clustering, (3) model-based clustering, (4) grid-based clustering, (5) densitybased clustering, and (6) multi-step clustering. Of these, hierarchical and partitioning clustering are currently the most commonly used ones (Xu \& Wunsch, 2005). On a more specific level, each clustering method is realised by one or more clustering algorithms. For example, hierarchical clustering can be conducted by using either an agglomerative or divisive algorithm. In the agglomerative algorithm, each object first forms its own cluster, which are then merged together in a bottom-up fashion. In contrast, in the divisive algorithm, all the objects first form one large cluster, which is then split into smaller clusters in a top-down fashion. The weakness of both these algorithms is that after conducting a merge or split, the resulting clusters cannot be anymore adjusted. In turn, partitioning clustering first forms $\mathrm{k}$ number of clusters (the value of $\mathrm{k}$ is pre-assigned before conducting the clustering) and then groups the objects into them so that each cluster finally contains at least one object. The grouping is based on minimising the distance of the objects from the cluster centre. The two most common algorithms for partitioning clustering are k-means and k-medoids, which differ in their definition of the cluster centre. In k-means, the cluster centre is the cluster centroid (i.e., the average of all the clustered objects), whereas in k-medoids, the cluster centre is the cluster medoid (i.e., a prototype object near the cluster centre). Because of this difference, k-medoids is typically more robust against outliers than k-means. The most common realisation of kmedoids is the partitioning around medoids (PAM) algorithm (Kaufman \& Rousseeuw, 1990).

Fourth, the goodness of the resulting clustering solution is evaluated statistically by using either external or internal indices as well as by considering its interpretability in terms of both theory and practice. External indices compare the resulting clustering solution to an ideal clustering solution, which is typically crafted by human experts. In contrast, internal indices evaluate the goodness of the resulting clustering solution based only on the information inherent in the clustered data and the clustering objectives. One of the most commonly used internal indices is the silhouette width (Rousseeuw, 1987), which evaluates both tightness or cohesion (i.e., how similar an object is to the objects in its own 
cluster) and separation (how different an object is from the objects in the other clusters). The silhouette width varies from -1 to 1 , in which negative values indicate a bad fit to a cluster and positive values indicate a good fit to a cluster. In addition to individual objects, the silhouette width can also be used to evaluate the goodness of individual clusters by calculating their average silhouette widths as well as the goodness of the whole clustering solution by calculating the overall average silhouette width.

\section{$3 \quad$ Methodology}

The data for this study was collected from 399 online stores, and it covers both their monthly sales time series from January 2016 to December 2017 as well as their key business and technical parameters at the end of January 2018. The data collection was conducted in co-operation with a Finnish electronic commerce platform provider, which uses a platform-as-a-service (PaaS) model to provide its customers an electronic commerce platform for operating the stores. The participating stores operated mainly in the Finnish market but in several product and service segments, such as clothing, jewellery and accessories, health and beauty, home and garden, sport and hobby, food and beverage, electronics, as well as automotive. All the stores had to fulfil three criteria in order to take part in the study. First, each store had to be first opened before January 2015. Second, each store had to be still open at the end of January 2018. Third, each store had to have at least one sales transaction per month. The first two criteria were intended to ensure that all the stores had been open for the whole two-year period from which the sales data was collected and that no store had opened just before or closed just after the period. In other words, all the stores had more or less an equal status in terms of being relatively mature stores, which had been in business for some time before and were not about to go out of business immediately after the two-year period. The third criterion was intended to ensure that there was an adequate amount of data to be analysed from each store.

In the sales time series, the sales were measured as both sales volume (the number of sales transactions) and sales value (the value of sales transactions). Of these, this study concentrates only on the sales measured as sales volume, but the implications of measuring the sales as sales value are addressed in the limitations. The median monthly sales of the stores ranged from a minimum of three transactions or $108 €$ to a maximum of 9,545 transactions or $927,476 €$, with the median monthly sales of the whole sample being 34 transactions or $2,935 €$. The key business and technical parameters of the stores covered their number of items, item variations, item categories, item images, campaigns, campaign items, banners, payment methods, shipping methods, customers, e-mail subscribers, and SMS subscribers. Of these, customers refer to the registered customers of the store, while the e-mail and SMS subscribers refer to the subscribers of the store newsletters via either electronic mail or short message service (SMS).

The time series clustering was conducted by using the TSclust version 1.2.4 and cluster version 2.0.6 packages of R (Montero \& Vilar, 2014). When conducting the time series clustering, no representation method was used, but the sales time series were standardised 
so that the sales of each store were measured as standard deviations from its mean sales. This way the differences in the average sales of the stores did not affect the clustering. As a distance metric, we used DTW because we were interested in similarities in terms of shape rather than similarities in terms of time. In turn, as a clustering algorithm, we used PAM. The statistical evaluation of the clustering solutions was based on the silhouette widths, which evaluate both tightness or cohesion and separation. Because not all the assumptions for parametric testing (e.g., normality and homoscedasticity) were met by the data, the statistical significance of the potential cluster differences were investigated by using the non-parametric Kruskal-Wallis (1952) tests and Dunn's $(1961,1964)$ tests with the Bonferroni correction for multiple testing. These were both conducted by using the dunn.test version 1.3.5 package of $\mathrm{R}$.

\section{$4 \quad$ Results}

The results are reported in the following two sub-sections, of which the first focuses on finding the proper clustering solution and the second focuses on the potential cluster differences.

\subsection{Clustering Solution}

As mentioned above, the statistical evaluation of the clustering solutions and the selection of the suitable number of clusters $(\mathrm{k})$ was based on the silhouette widths. The overall average silhouette widths of the clustering solutions with different values of $\mathrm{k}$ are reported in the silhouette plots presented in Figure 1. As can be seen, the overall average silhouette widths of the clustering solutions dropped sharply when the value of $\mathrm{k}$ exceeded four, suggesting that either a two-cluster, a three-cluster, or a four-cluster solution would be the most suitable one in strictly statistical terms. Of these, after considering also the interpretability of each solution, we decided to select the four-cluster solution because it was seen to give the best insight into the typical sales patterns of online stores in terms of not only the general trend in the sales but also the more specific seasonal sales variation. The silhouette plot of this four-cluster solution, which also reports both the size and the average silhouette width of each cluster, is presented in Figure 2. As can be seen, the sizes of all the four clusters were approximately equal. However, both the average silhouette widths of the clusters and the overall average silhouette width of the whole clustering solution remained relatively low, and all the clusters contained also objects with a negative silhouette width. This suggests that not all the clustered objects really fitted any of the four clusters. This cannot be seen as particularly surprising when considering that we were clustering real-life data in which the sales time series of individual stores were likely to vary considerably. 
M. Makkonen \& L. Frank: Identifying the Sales Pattern of Online Stores with Time Series

Clustering

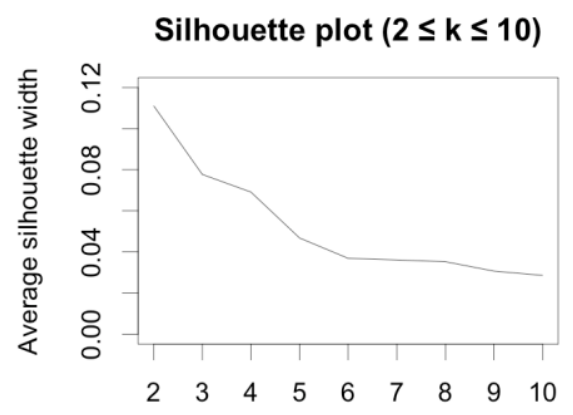

Number of clusters $(k)$

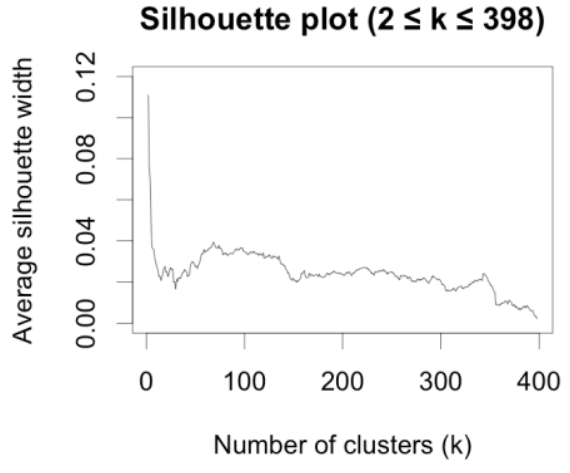

Silhouette plot $(2 \leq k \leq 398)$

Figure 1: Overall average silhouette widths of the clustering solutions

\section{Silhouette plot $(k=4)$}

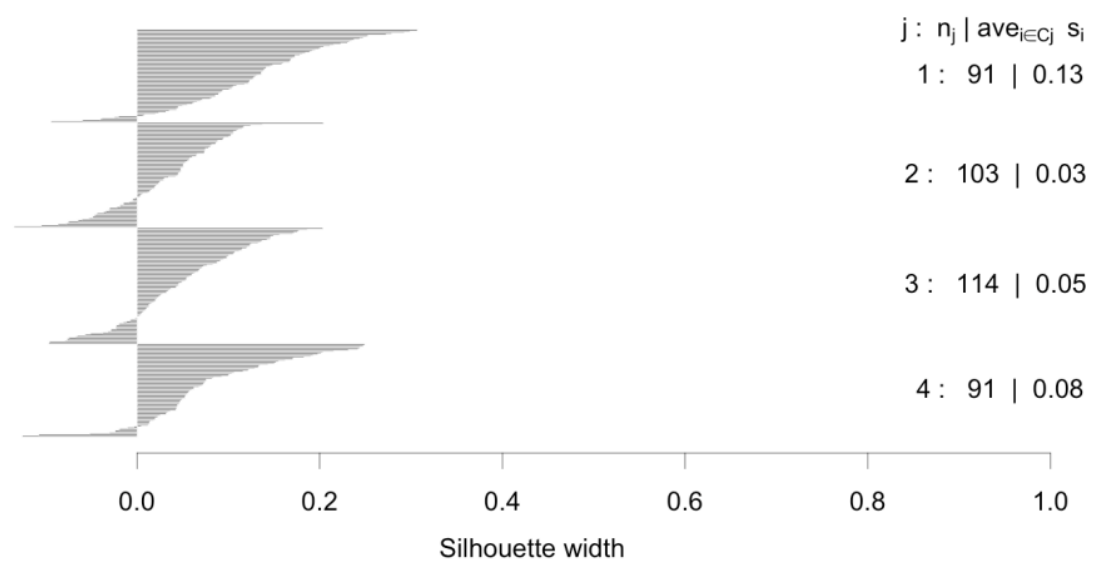

Average silhouette width : 0.07

Figure 2: Silhouette widths and cluster sizes of the four-cluster solution 
$31^{\text {ST }}$ Bled eConference: Digital Transformation: MeEting the Challenges June 17 - 20, 2018, BLED, SLOVENIA, CONFERENCE PROCEEDINGS

M. Makkonen \& L. Frank: Identifying the Sales Patterns of Online Stores with Time Series Clustering
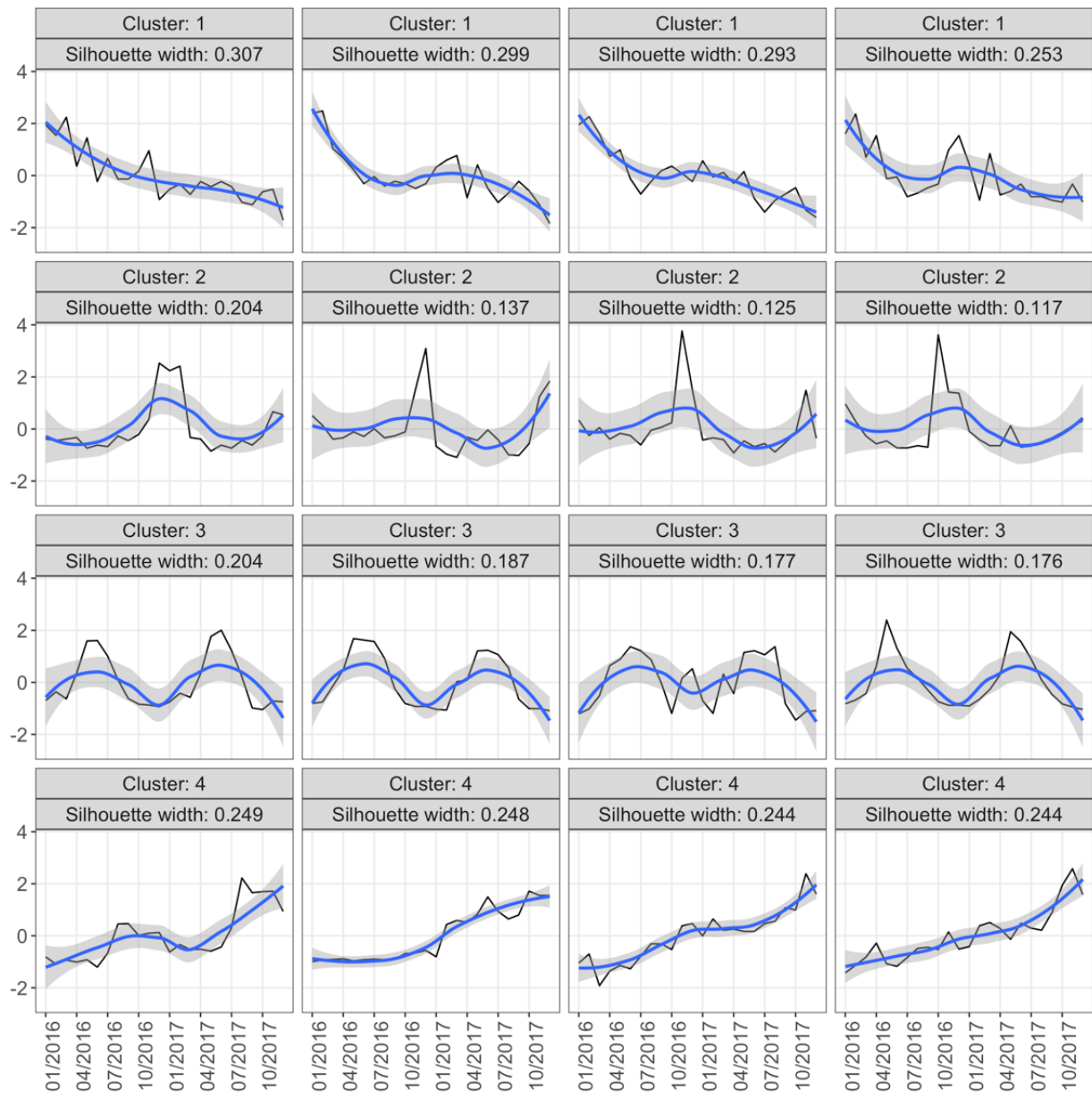

Figure 3: Time series selected as the cluster medoid and with the highest silhouette widths

Figure 3 illustrates the four-cluster solution by presenting the for each cluster the sales time series selected as the cluster medoid and three additional sales time series with the highest silhouette widths. These represent the most typical sales patterns of each cluster. In the case of the first cluster, the cluster medoid is the fourth sales time series with the lowest silhouette width, whereas in the case of the other three clusters, the cluster medoid is the first sales time series with the highest silhouette width. The black curve represents the standardised monthly sales. In order to smooth local variations, also a blue LOESS curve and its $95 \%$ confidence interval are presented (Cleveland, 1979; Cleveland \& Devlin, 1988). As can be seen, there are considerable differences between the four clusters. The typical sales time series in the first cluster have a clear downward trend, whereas the typical sales time series in the fourth cluster have a clear upward trend. In contrast, the typical sales time series in the remaining two clusters are characterised by strong seasonal variation. In the case of the second cluster, there seems to be a sharp sales 
peak timed at around Christmas, whereas in the case of the third cluster, the sales peaks seem to be less sharp and timed at the summer months. However, most importantly, in both these latter cases, the sales time series lack a clear upward or downward trend.

\subsection{Cluster Differences}

Table 1 reports the medians of 14 store parameters for the whole sample and for each of the four clusters as well as the differences between the sample median and the cluster medians in percentages. The store parameters include the monthly sales measured as both sales volume $(\mathrm{N})$ and sales value $(€)$ as well as the 12 key business and technical parameters. Respectively, Table 2 reports the results of the Kruskal-Wallis tests and the Dunn's tests that were used to investigate the statistical significance of the differences in the cluster medians.

Table 1: Sample and cluster medians of the store parameters

\begin{tabular}{|l|r|r|r|r|r|r|r|r|r|}
\hline \multirow{2}{*}{ Store parameter } & \multicolumn{1}{|c|}{ All } & \multicolumn{2}{|c|}{ Cluster 1 } & \multicolumn{2}{c|}{ Cluster 2 } & \multicolumn{2}{c|}{ Cluster 3 } & \multicolumn{2}{c|}{ Cluster 4 } \\
\cline { 2 - 9 } & Median & Median & Difference & Median & Difference & Median & Difference & Median & Difference \\
\hline $\begin{array}{l}\text { Monthly sales } \\
\text { M) }\end{array}$ & 34 & 27 & $-21 \%$ & 30 & $-12 \%$ & 31 & $-9 \%$ & 68 & $+100 \%$ \\
\hline Monthly sales $(€)$ & 2,935 & 2,008 & $-32 \%$ & 1,937 & $-34 \%$ & 3,537 & $+21 \%$ & 6,230 & $+112 \%$ \\
\hline Items & 329 & 225 & $-32 \%$ & 241 & $-27 \%$ & 425 & $+29 \%$ & 770 & $+134 \%$ \\
\hline Item variations & 167 & 109 & $-35 \%$ & 152 & $-9 \%$ & 141 & $-16 \%$ & 214 & $+28 \%$ \\
\hline Item categories & 43 & 33 & $-23 \%$ & 32 & $-26 \%$ & 47 & $+9 \%$ & 61 & $+42 \%$ \\
\hline Item images & 679 & 539 & $-21 \%$ & 629 & $-7 \%$ & 614 & $-10 \%$ & 1,629 & $+140 \%$ \\
\hline Campaigns & 6 & 5 & $-17 \%$ & 5 & $-17 \%$ & 5 & $-17 \%$ & 8 & $+33 \%$ \\
\hline Campaign items & 101 & 62 & $-39 \%$ & 94 & $-7 \%$ & 94 & $-7 \%$ & 187 & $+85 \%$ \\
\hline Banners & 10 & 7 & $-30 \%$ & 10 & $0 \%$ & 8 & $-20 \%$ & 23 & $+130 \%$ \\
\hline Payment methods & 3 & 2 & $-33 \%$ & 3 & $0 \%$ & 3 & $0 \%$ & 3 & $0 \%$ \\
\hline $\begin{array}{l}\text { Shipping } \\
\text { methods }\end{array}$ & 5 & 4 & $-20 \%$ & 6 & $+20 \%$ & 5 & $0 \%$ & 6 & $+20 \%$ \\
\hline Customers & 494 & 485 & $-2 \%$ & 383 & $-22 \%$ & 429 & $-13 \%$ & 710 & $+44 \%$ \\
\hline $\begin{array}{l}\text { E-mail } \\
\text { subscribers }\end{array}$ & 412 & 436 & $+6 \%$ & 358 & $-13 \%$ & 355 & $-14 \%$ & 646 & $+57 \%$ \\
\hline SMS subscribers & 207 & 206 & $0 \%$ & 180 & $-13 \%$ & 189 & $-9 \%$ & 275 & $+33 \%$ \\
\hline
\end{tabular}


M. Makkonen \& L. Frank: Identifying the Sales Patterns of Online Stores with Time Series Clustering

Table 2: Results of the Kruskal-Wallis tests and the Dunn's tests $(* * *=\mathbf{p}<0.001, * *=\mathbf{p}<0.01, *=\mathbf{p}<0.05$, n.s. $=$ statistically not significant $)$

\begin{tabular}{|l|c|c|c|c|c|c|c|c|c|}
\hline \multirow{2}{*}{ Store parameter } & \multicolumn{2}{|c|}{ Kruskal-Wallis test } & \multicolumn{6}{|c|}{ Dunn's tests } \\
\cline { 2 - 12 } & $\mathbf{H}$ & $\mathbf{d f}$ & $\mathbf{p}$ & $\mathbf{1}$ vs. 2 & $\mathbf{1}$ vs. 3 & $\mathbf{1}$ vs. 4 & $\mathbf{2}$ vs. 3 & $\mathbf{2}$ vs. 4 & $\mathbf{3}$ vs. 4 \\
\hline Monthly sales (N) & 493.009 & 3 & $* * *$ & n.s. & n.s. & $* * *$ & n.s. & $* * *$ & $* * *$ \\
\hline Monthly sales (€) & 656.341 & 3 & $* * *$ & n.s. & $* * *$ & $* * *$ & $* * *$ & $* * *$ & $* * *$ \\
\hline Items & 18.921 & 3 & $* * *$ & n.s. & n.s. & $* * *$ & n.s. & $* *$ & n.s. \\
\hline Item variations & 3.749 & 3 & n.s. & n.s. & n.s. & n.s. & n.s. & n.s. & n.s. \\
\hline Item categories & 15.740 & 3 & $* * *$ & n.s. & n.s. & $* *$ & n.s. & $* *$ & n.s. \\
\hline Item images & 18.145 & 3 & $* * *$ & n.s. & n.s. & $* * *$ & n.s. & $*$ & $*$ \\
\hline Campaigns & 7.839 & 3 & $*$ & n.s. & n.s. & n.s. & n.s. & n.s. & n.s. \\
\hline Campaign items & 9.828 & 3 & $*$ & n.s. & n.s. & $*$ & n.s. & n.s. & n.s. \\
\hline Banners & 24.578 & 3 & $* * *$ & n.s. & n.s. & $* * *$ & n.s. & $* *$ & $* *$ \\
\hline Payment methods & 7.226 & 3 & n.s. & n.s. & n.s. & n.s. & n.s. & n.s. & n.s. \\
\hline Shipping methods & 13.509 & 3 & $* * *$ & $* *$ & n.s. & $* *$ & n.s. & n.s. & n.s. \\
\hline Customers & 9.031 & 3 & $*$ & n.s. & n.s. & n.s. & n.s. & n.s. & $*$ \\
\hline E-mail subscribers & 9.843 & 3 & $*$ & n.s. & n.s. & n.s. & n.s. & n.s. & $*$ \\
\hline SMS subscribers & 5.755 & 3 & n.s. & n.s. & n.s. & n.s. & n.s. & n.s. & n.s. \\
\hline
\end{tabular}

As can be seen, statistically significant differences between the clusters were found in terms of all the store parameters except for the number of item variations, payment methods, and SMS subscribers. Most of the differences concerned the fourth cluster, which was found to have higher monthly sales measured as both sales volume and sales value as well as a higher number of item images and banners in comparison to all the other clusters. The fourth cluster was also found to have a higher number of items and item categories in comparison to the first and second cluster, a higher number of campaign items and shipping methods in comparison to the first cluster, and a higher number of customers and e-mail subscribers in comparison to the third cluster. In addition, a few differences were found between the other three clusters, of which the second cluster was found to have a higher number of shipping methods in comparison to the first cluster, whereas the third cluster was found to have higher monthly sales measured as sales value in comparison to the first and second cluster.

\section{$5 \quad$ Discussion and Conclusions}

In this explorative study, we aimed at identifying the most typical sales patterns of online stores operating in the B2C context. By segmenting the monthly sales time series of 399 online stores with time series clustering, we were able to identify four approximately equally sized segments, each with its characteristic sales pattern. Two of the segments were characterised by a clear upward or downward trend in the sales, whereas the other two segments were characterised by strong seasonal sales variation. In one of the segments, the seasonal sales peaks lasted for about three or four months and were timed at the summer months, whereas in the other segment, they only lasted for about one or two months and were timed at around Christmas. However, most importantly, the two latter segments lacked a similar clear upward or downward trend in the sales that was found in the two former segments, meaning that the sales of the stores stayed about the same each year. Therefore, if the stores are aiming at increasing their sales in the long- 
term, it seems that they are likely to benefit from strategies that decrease their short-term sales variation. The explanation for this finding is most likely linked to the differences between the segments in terms of risk perceptions and investment propensity, which are traditionally expected to be inversely related (Caballero, 1991). The stores with low seasonal sales variation obviously operate in a more certain business environment, which can be expected to have a positive effect on their investment propensity and result in increased sales if the return on investment is positive (or decreased sales if the return on investment is negative). In contrast, the stores with high seasonal sales variation obviously operate in a more uncertain business environment, which can be expected to have a negative effect on their investment propensity and hinder their growth. For example, whereas the stores with steady sales have the chance to both identify the potential changes in their economic environment and assess their return on investment throughout the year, the stores with seasonal sales can typically do this only during the on-peak months. During the off-peak months, they can often only speculate with the future while waiting and preparing for the next sales peak.

In addition, we investigated the potential differences between the online stores in each segment in terms of several store parameters. Here, especially the fourth segment was found to differ considerably from the other three segments. For example, the stores in the fourth segment were found to have higher monthly sales measured as both sales volume and sales value. Of course, this cannot be seen as particularly surprising when considering the clear upward trend in their sales. In addition, the stores in the fourth segment were found to be forerunners in terms of several other key business and technical parameters. These latter differences can be considered from two perspectives.

On one hand, the differences between the stores in the fourth segment as well as the stores in the second and third segment can be seen as providing insights on the business and technical parameters that are most closely associated with the reduction of seasonal sales variation. For example, the stores in the fourth segment were found to have a higher number of items and item categories in their selection, especially in comparison to the stores in the second segment. This can be expected to offer them more opportunities for diversification in terms of having in their selection also items with less seasonal sales patterns or at least items with different kinds of seasonal sales patterns. The outcomes of this diversification are likely to be seen also in the fact that the stores in the fourth segment were found to have more banners and item images on their site as well as more registered customers and e-mail subscribers, especially in comparison to the stores in the third segment. After all, a more diverse item selection is likely to attract more customers to register to the store and subscribe to its newsletters. Respectively, a more diverse item selection not only offers the store more opportunities but also requires it to have more item images on its site and use more banner advertisement in order to gain attention for the individual items in its vast selection.

On the other hand, the differences between the stores in the fourth segment and the stores in the first segment can be seen as providing insights on the business and technical parameters that are most closely associated with having an upward rather than a 
downward trend in the sales. Many of these differences concerned the same parameters that were already discussed above. For example, the stores in the fourth segment were found to have more items and item categories in their selection as well as more item images and banners on their site also in comparison to the stores in the first segment. This would seem to suggest that these parameters are closely associated with not only reducing seasonal sales variation but also promoting the overall sales of the stores. This suggestion is supported by several prior studies. For example, the width and depth of the item selection have been found important especially from the perspective of capitalising the so-called "long tail" phenomenon (Anderson, 2006), which states that in many online stores, a considerable share of the sales comes not only from a few top items sold in high quantities but also from numerous niche items sold in low quantities individually, but in high quantities collectively. In turn, item images have been found important particularly in terms of promoting the flow of online shopping, the perceived usefulness of the stores, and the return intention to the stores through improved perceived diagnosticity (Jiang \& Benbasat, 2004, 2007), whereas banner advertising has been found to positively affect purchase probabilities especially in the case of current customers (Manchanda et al., 2006). In addition, differences were found in the number of campaign items and shipping methods, which were also found to be higher in the stores belonging to the fourth segment in comparison to the stores belonging to the first segment. These can be seen to highlight especially the importance of active marketing as well as offering consumers a wide range of alternatives in terms of delivering the purchased items. Interestingly, the range of alternatives in terms of paying for the purchased items seemed not to be as important.

In addition to the aforementioned theoretical and practical insights concerning electronic commerce and online stores in particular, this study also contributes to IS research in general by providing an illustrative case example of a data analytics method for investigating the temporal dimension of various IS phenomena, which has often been overlooked in prior IS studies. For example, although time unarguably plays an important part in phenomena like technology acceptance and use, most prior studies, such as the numerous applications and extensions of the technology acceptance model (TAM) by Davis (1989) and the unified theory of acceptance and use of technology (UTAUT) by Venkatesh et al. (2003), have examined them only by using cross-sectional data collected at a single time point instead of longitudinal data collected at multiple time points. By analysing this kind of temporal data with time series clustering or other corresponding data analytics methods, more rigorous, relevant, and richer arguments can typically be made on the causalities concerning the phenomenon in question. For example, instead of treating IS usage as a simple dichotomous construct by dividing individuals into users and non-users, also the more complex differences in their temporal usage patterns can be considered. Therefore, backed by our positive experiences from this study, we strongly encourage their usage in future IS studies. 


\section{Limitations and Future Research}

We consider this study to have three main limitations. First, the analysed sales time series covered only a two-year period and were collected only from online stores operating mainly in the Finnish market. Therefore, it is impossible to say anything about the sales patters that exceed this two-year period or how generalisable the sales patterns found in this study are to other markets. Even the external validity of our sample to the Finnish market remains difficult to assess because although the 399 online stores included both very small and very large stores in the Finnish scale, there does not exist any reference statistics on the total number of online stores operating in the Finnish market or on their distributions in terms of sales volume and sales value. Second, we were not able to obtain from the partnering electronic commerce platform provider longitudinal data on the key business and technical parameters from the two-year period but only cross-sectional data from January 2018. Therefore, we can only make associative rather than causal claims on the relationships between the store parameters and the store sales. Third, we were also not able to obtain from the partnering electronic commerce platform provider data on whether all the stores had been open for the whole two-year period or whether some of them had been temporarily closed, for example, due to maintenance. This data could have obviously been used as a valuable control variable in our study. However, although such temporary suspensions were possible, we do not believe that any of them were particularly long-lasting because all the stores participating in the study had to have at least one sales transaction per month.

Finally, it should be noted that in addition to clustering the sales time series in which the sales were measured as sales volume, we also replicated the clustering with the sales time series in which the sales were measured as sales value. This resulted in a three-cluster solution, in which the first three clusters were more or less identical to the ones of the aforementioned four-cluster solution, but the fourth cluster with the clear upward sales trend was missing. This would seem to suggest that even though some stores were able to grow their sales in terms of sales volume, this did not necessarily result in a similar growth in sales in terms of sales value, potentially due to the price erosion associated with the growing sales volumes. Whether such price erosion actually exists and how severe a problem it is for online stores, would be an interesting and important topic of future studies.

Another potential path of future research would be to concentrate more precisely on the causal explanations for the sales patterns found in this study through a more thorough control of the store parameters. These parameters do not have to be strictly quantitative, as they were in this study, but they can also be more qualitative, such as assessments of the usability and aesthetics of the stores as well as information on the primary product or service segment in which the stores operate and their level of diversification. In addition, instead of investigating the sales patterns within one common time period, one could also investigate them within a certain time period since the opening of each store (e.g., the sales of the first year). 


\section{References}

Aghabozorgi, S., Shirkhorshidi, A. S., \& Wah, T. Y. (2015). Time-series clustering - A decade review. Information Systems, 53, 16-38. doi: 10.1016/j.is.2015.04.007

Allred, C. R., Smith, S. M., \& Swinyard, W. R. (2006). E-shopping lovers and fearful conservatives: a market segmentation analysis. International Journal of Retail \& Distribution Management, 34(4/5), 308-333. doi: 10.1108/09590550610660251

Anderson, C. (2006). The Long Tail: Why the Future of Business is Selling Less of More. New York, NY: Hyperion.

Barnes, S. J., Bauer, H. H., Neumann, M. M., \& Huber, F. (2007). Segmenting cyberspace: a customer typology for the internet. European Journal of Marketing, 41(1/2), 71-93. doi: $10.1108 /$ 03090560710718120

Bhatnagar, A., \& Ghose, S. (2004a). A latent class segmentation analysis of e-shoppers. Journal of Business Research, 57(7), 758-767. doi: 10.1016/S0148-2963(02)00357-0

Bhatnagar, A., \& Ghose, S. (2004b). Segmenting consumers based on the benefits and risks of Internet shopping. Journal of Business Research, 57(12), 1352-1360. doi: 10.1016/S01482963(03) 00067-5

Brengman, M., Geuens, M., Weijters, B., Smith, S. M., \& Swinyard, W. R. (2005). Segmenting Internet shoppers based on their Web-usage-related lifestyle: a cross-cultural validation. Journal of Business Research, 58(1), 79-88. doi: 10.1016/S0148-2963(02)00476-9

Brown, M., Pope, N., \& Voges, K. (2003). Buying or browsing? An exploration of shopping orientations and online purchase intention. European Journal of Marketing, 37(11/12), 16661684. doi: 10.1108/03090560310495401

Caballero, R. J. (1991). On the Sign of the Investment-Uncertainty Relationship. American Economic Review, 81(1), 279-288.

Carman, H. F., \& Figueroa, E. E. (1986). An Analysis of Factors Associated with Weekly Food Store Sales Variation. Agribusiness, 2(3), 375-390. doi: 10.1002/15206297(198623)2:3<375::AID-AGR2720020308>3.0.CO;2-I

Chang, M. K., Cheung, W., \& Lai, V. S. (2005). Literature derived reference models for the adoption of online shopping. Information \& Management, 42(4), 543-559. doi: 10.1016/j.im.2004.02.006

Cheung, C. M. K., Chan, G. W. W., \& Limayem, M. (2005). A Critical Review of Online Consumer Behavior: Empirical Research. Journal of Electronic Commerce in Organizations, 3(4), 1-19. doi: 10.4018/jeco.2005100101

Cleveland, W. S. (1979). Robust Locally Weighted Regression and Smoothing Scatterplots. Journal of the American Statistical Association, 74(368), 829-836. doi: 10.2307/2286407

Cleveland, W. S., \& Devlin, S. J. (1988). Locally Weighted Regression: An Approach to Regression Analysis by Local Fitting. Journal of the American Statistical Association, 83(403), 596-610. doi: $10.2307 / 2289282$

Davis, F. D. (1989). Perceived Usefulness, Perceived Ease of Use, and User Acceptance of Information Technology. MIS Quarterly, 13(3), 319-340. doi: 10.2307/249008

Dunn, O. J. (1961). Multiple Comparisons Among Means. Journal of the American Statistical Association, 56(293), 52-64. doi: 10.2307/2282330

Dunn, O. J. (1964). Multiple Comparisons Using Rank Sums. Technometrics, 6(3), 241-252. doi: $10.2307 / 1266041$

Fu, T.-c. (2011). A review on time series data mining. Engineering Applications of Artificial Intelligence, 24(1), 164-181. doi: 10.1016/j.engappai.2010.09.007 
Geurts, M. D. (1988). The Impact of Misrepresentative Data Patterns on Sales Forecasting Accuracy. Journal of the Academy of Marketing Science, 16(3-4), 88-94. doi: 10.1007/BF02723364

Jiang, Z., \& Benbasat, I. (2004). Virtual Product Experience: Effects of Visual and Functional Control of Products on Perceived Diagnosticity and Flow in Electronic Shopping. Journal of Management Information Systems, 21(3), 111-147. doi: 10.1080/07421222.2004.11045817

Jiang, Z., \& Benbasat, I. (2007). Investigating the Influence of the Functional Mechanisms of Online Product Presentations. Information Systems Research, 18(4), 454-470. doi: 10.1287/isre. 1070 .

0124

Kau, A. K., Tang, Y. E., \& Ghose, S. (2003). Typology of online shoppers. Journal of Consumer Marketing, 20(2), 139-156. doi: 10.1108/07363760310464604

Kaufman, L., \& Rousseeuw, P. J. (1990). Finding Groups in Data: An Introduction to Cluster Analysis. Hoboken, NJ: Wiley.

Kruskal, W. H., \& Wallis, W. A. (1952). Use of Ranks in One-Criterion Variance Analysis. Journal of the American Statistical Association, 47(260), 583-621. doi: 10.2307/2280779

Liao, T. W. (2005). Clustering of time series data - a survey. Pattern Recognition, 38(11), 18571874. doi: 10.1016/j.patcog.2005.01.025

Manchanda, P., Dubé, J.-P., Goh, K. Y., \& Chintagunta, P. K. (2006). The Effect of Banner Advertising on Internet Purchasing. Journal of Marketing Research, 43(1), 98-108. doi: 10.1509/jmkr.43.1.

98

Moe, W. W. (2003). Buying, Searching, or Browsing: Differentiating Between Online Shoppers Using In-Store Navigational Clickstream. Journal of Consumer Psychology, 13(1-2), 29-39. doi: 10.1207/S15327663JCP13-1\&2_03

Montero, P., \& Vilar, J. A. (2014). TSclust: An R Package for Time Series Clustering. Journal of Statistical Software, 62(1), 1-43. doi: 10.18637/jss.v062.i01

Perea y Monsuwé, T., Dellaert, B. G. C., \& de Ruyter, K. (2004). What drives consumers to shop online? A literature review. International Journal of Service Industry Management, 15(1), 102121. doi: $10.1108 / 09564230410523358$

Rohm, A. J., \& Swaminathan, V. (2004). A typology of online shoppers based on shopping motivations. Journal of Business Research, 57(7), 748-757. doi: 10.1016/S01482963(02)00351-X

Rousseeuw, P. J. (1987). Silhouettes: a graphical aid to the interpretation and validation of cluster analysis. Journal of Computational and Applied Mathematics, 20, 53-65. doi: 10.1016/03770427(87)90125-7

Soopramanien, D. G. R., \& Robertson, A. (2007). Adoption and usage of online shopping: An empirical analysis of the characteristics of "buyers", "browsers" and "non-internet shoppers". Journal of Retailing and Consumer Services, 14(1), 73-82. doi: 10.1016/j.jretconser.2006.04.002

$\mathrm{Su}, \mathrm{Q}$., \& Chen, L. (2015). A method for discovering clusters of e-commerce interest patterns using click-stream data. Electronic Commerce Research and Applications, 14(1), 1-13. doi: 10.1016/j.elerap.

2014.10.002

Swinyard, W. R., \& Smith, S. M. (2003). Why People (Don't) Shop Online: A Lifestyle Study of the Internet Consumer. Psychology \& Marketing, 20(7), 567-597. doi: 10.1002/mar.10087

Venkatesh, V., Morris, M. G., Davis, G. B., \& Davis, F. D. (2003). User Acceptance of Information Technology: Toward a Unified View. MIS Quarterly, 27(3), 425-478. doi: 10.2307/30036540

$\mathrm{Xu}, \mathrm{R} .$, \& Wunsch, D. (2005). Survey of Clustering Algorithms. IEEE Transactions on Neural Networks, 16(3), 645-678. doi: 10.1109/TNN.2005.845141 
506 3 $31^{\text {ST }}$ Bled eConference: Digital Transformation: MeEting the Challenges JunE 17 - 20, 2018, BLED, SLOVEnIA, CONFERENCE PROCEEDINGS 


\title{
The Role of Competition in the Adoption of Mobile Payment among Merchants
}

\author{
FRANCESCO PISANI \& JÜRGEN MOORMANN
}

\begin{abstract}
Mobile payment has been predicted to become the "new normal" in the payments industry. However, such predictions have hardly been realized in the Euro area, since most payments at the point of sale (POS) are still conducted in cash. Mobile payment represents a specific case of multi-sided markets, where the functioning of the whole market relies on the interaction between several players - in this case at least two, i.e. merchants and consumers - on a common platform. As such, every innovation that is brought to this market has to be adopted by both sides in order to be widely diffused. For the successful dissemination of mobile payment, however, it is important that merchants are among the early adopters, as merchants are the ones who directly cover the costs of the system. Nevertheless, despite its importance, extant research on mobile payment has often neglected the role of merchants. Our research in progress is set to investigate the main features of competition that will eventually stimulate merchants' adoption of mobile payment at the POS. Empirical evidence will be provided via a survey targeting merchants with at least one physical POS. The results are expected to contribute to the literature on mobile payment, as well as that on the diffusion of innovations and multisided markets.
\end{abstract}

Keywords: • Competition • Innovations • Merchants • Mobile Payment • Multi-sided Markets •

Correspondence AdDress: Francesco Pisani, Ph.D. candidate, Frankfurt School of Finance \& Management, ProcessLab, Adickesallee 32-24, 60322 Frankfurt, Germany, f.pisani@fs.de. Jürgen Moormann, Prof. Dr., Concardis Professor for Bank and Process Management and Co-head of ProcessLab, Frankfurt School of Finance \& Management, Adickesallee 32-24, 60322 Frankfurt, Germany,j.moormann@fs.de 
F. Pisani \& J. Moormann: The Role of Competition in the Adoption of Mobile Payment among Merchants

The "use of a mobile device to initiate, authorize or confirm a financial transaction" (Au \& Kauffman, 2008, p. 141) was introduced in the late 1990s (Dahlberg et al., 2015) and since then it has accompanied the evolution of mobile phones. Mobile payment is expected to take on a central role in the payments industry. Nevertheless, the majority of payments at point of sale (POS) in the Euro area are still made in cash (Esselink \& Hernández, 2017).

This low adoption of mobile payment is certainly not due to a lack of technological opportunities. In effect, a range of new technologies that seem suitable for facilitating this service already exists, especially considering innovations to be used at the POS, such as Near Field Communication and Quick Response codes. The low level of mobile payment adoption is, therefore, rather the result of other historical factors, such as (1) the absence of promising business models (Au \& Kauffman, 2008; Ondrus et al., 2009; Pousttchi et al., 2009), (2) the main stakeholders' inability to cooperate (Oczan \& Santos, 2015; Pousttchi et al., 2009), and (3) the failure to generate network externalities among the participants (Apanasevic, 2013; Au \& Kauffmann, 2008; Diniz et al., 2011; Lao \& Liu, 2011; Pousttchi, 2007).

Like other multi-sided markets, such as credit card payments, the use of mobile payment relies on direct interaction between distinct agents (in particular, merchants and consumers) on a platform. For the successful diffusion of mobile payment, however, it is not only necessary to generate network externalities among the parties involved; it is also important that merchants are among the early adopters, as they appear to be the most important group for the whole adoption process (Dahlberg et al. 2008; Ondrus \& Lyytinen, 2011; Ondrus \& Pigneur, 2007; van der Heijden, 2002). Merchants are thought to be the ones who will decide the future of the system, since in the payments industry merchants are usually the party who directly cover the costs of the system, which are eventually passed on to consumers.

Nevertheless, despite the importance of mobile payment, past research on the topic has often neglected the role of merchants, and knowledge about the merchants' adoption process is currently lacking (Dahlberg et al., 2015). Similarly, research on diffusion of innovations, as well as on multi-sided markets, has not provided dedicated insights about the aspects of competition that might play a role in the adoption of a new technology. The environmental context (Tornatzky \& Fleischer, 1990), and in particular external pressure (Iacovou et al., 1995), has already been identified as a key factor stimulating the adoption of innovations. Nevertheless, environmental aspects represent only a minor factor influencing decision makers, as indicated in classical theories on the diffusion of innovations. In fact, further key factors need dedicated attention, especially when considering the role that the adoption of innovations can play in the creation of network externalities and the diffusion of innovations in multi-sided markets. Hence, our research in progress aims to contribute to this literature by analyzing the role that competition among merchants plays in the dissemination of mobile payment at the POS. Our research 
project explicitly tries to answer the question: What are the key aspects of competition that motivate the adoption of mobile payment among merchants?

Empirical evidence will be provided via a survey conducted among merchants with at least one physical POS. We plan to focus on Germany because around $80 \%$ of the total number of transactions made by consumers are still conducted in cash in this country (Esselink \& Hernández, 2017), making it a suitable setting to answer the research question at the center of this project. Because mobile payment still represents an innovation for most merchants in this country, our study analyzes a payment system before it has gained widespread diffusion. This represents a valuable case through which to investigate the potential motivations to adopt mobile payment. Our research aims to add evidence to the stream of literature related to the diffusion of innovations and to multi-sided markets, in which the development of network externalities among participants is a necessary milestone for successful adoption. In particular, the results will contribute to understanding of key aspects of mobile payment diffusion.

\section{Theoretical Background}

Since its inception, mobile payment has been perceived as an innovation capable of providing new customer experiences. Advantages such as enhanced purchasing processes, as well as better benefits for consumers, have often been proposed as key within this argument. As such, mobile payment has attracted the interest of many companies and become the object of large investments. For instance, large groups such as Otto Group and Deutsche Telekom have founded their own ventures in an attempt to expand into this market. However, contrary to expectations, mobile payment has yet to really take off in Germany.

Mobile payment can be identified as a particular example of a multi-sided market. A multi-sided market brings together agents from distinct groups via a common platform (Gazé \& Vaubourg, 2011) where the exchange of products and services takes place. Consequently, the success of a multi-sided platform depends on direct interaction between the agents.

The concept of network externalities (or consumption externalities, as per the original terminology) has been used to identify the increase in benefit that an agent derives from other agents joining the network (Katz \& Shapiro, 1985). Network externalities can be distinguished into direct and indirect, depending on whether the increased number of new joiners that bring additional value come from the same group as the agent, or from a complementary group (Katz \& Shapiro, 1985). Consequently, fertilization of the interdependence between merchants and consumers is important for reaching a critical mass of mobile payment adopters (Ondrus et al., 2015) at which a typical multi-sided market becomes self-sustained and the propensity toward establishing a specific standard is increased (Clements, 2004; Mahler \& Rogers, 1999). 
Conversely, a lack of participants may undermine the market existence. In the past, the low number of merchants adopting mobile payment technology resulted in a lack of customers willing to use it, and vice versa (van der Heijden, 2002). The subsequent slowdown effect generated a circumstance defined as a wait-and-see status (Goldenberg et al., 2010), in which potential users wait for the early adopters who will eventually develop more demand for the product or service. This status can ultimately lead to an increasing number of users abandoning the system if they wait too long for others to join, and eventually the network disappears (Evans, 2009; Ondrus et al., 2015).

To overcome this standstill, a typical strategy adopted to further the dissemination of a new platform is to subsidize the product or service for one of the agent groups, and thus build a solid base that will make it attractive for the other side to join as well. This kind of strategy has been used by Diners Club, for instance, which gave its cardholders a card for free and let merchants indirectly bear the cost of it. Eventually, the large number of consumers adopting this card incentivized merchants to accept it in order to increase their customers' satisfaction. However, previous trials of mobile payment that followed a similar approach were ineffective, suggesting that there might be other reasons stimulating mobile payment adoption.

Generally, theories about the diffusion and adoption of innovations can be divided between those centered on consumers and those embracing a firm perspective. A model clearly focusing on the diffusion of innovations at firm level is the Technology Organization Environment (TOE) framework (Tornatzky \& Fleischer, 1990). The TOE identifies the technological context, the organizational context, and the environmental context as those aspects of a firm that play a relevant role for the adoption of innovations (Tornatzky \& Fleischer, 1990). The model has been enhanced over time, and further aspects have been introduced to the framework. For instance, Iacovou et al. (1995) added organizational readiness, external pressure toward adoption, and perceived benefits as the main factors influencing the adoption of innovations among small firms. In particular, external pressure includes pressure from trading partners and competitors.

Nevertheless, the influence that the behavior of competitors has on a decision maker represents only a minor factor in the above-mentioned theories concerning the diffusion of innovations. This study provides an important opportunity to generate further knowledge on the topic. Moreover, given the peculiarities of mobile payment as a multisided market, the setting of this study adds a distinct perspective. Since the first publications focusing on multi-sided markets or platforms, literature on this topic has advanced. However, there are still aspects, such as competition, that need to be explored. Furthermore, with the increasing role of the "platform economy" and the dominance of platforms including Airbnb, Uber, etc. this research aims to address a topic that has highly important implications.

The classical literature (on micro economics) has tended to propose competition as the main factor forcing companies to reduce their surplus and eventually pass it on to consumers. Furthermore, a blind observer might even believe that competition is the force 
shaping companies' behavior. Nevertheless, the role of competition can be less intuitive than expected (Dufwenberg \& Gneezy, 2000). For instance, whether competition will provide incentives for managers to perform better is still a matter of debate in the literature (Karuna, 2007). Likewise, it remains unclear whether competition stimulates investments (Yang et al., 2015). Yet, as for other kinds of innovation (Iacovou et al., 1995), we hypothesize that external pressure exercised by competitors will stimulate decision makers to embrace mobile payment. We then try to expand this concept in order to better define which aspects of competition might be important for the adoption of mobile payment.

\section{$3 \quad$ Methodology}

Via a thorough analysis of previous studies focusing on competition, we identified the most relevant theories that could be applied in our setting. We then developed a specific questionnaire that we tested via interviews and an initial online survey among a small sample of merchants. The main aspects of competition addressed in the questionnaire were intensity of competition, competitors' orientation, competitors' innovation propensity, spatial proximity, and organizational proximity to competitors. While intensity of competition is used as an independent variable impacting the adoption of mobile payment, the other factors are used as moderators of this relationship. This implies, in addition to the central hypothesis that a more competitive environment will stimulate the adoption of mobile payment, that competitors' propensity to innovate, being acquainted with competitors' moves, having shops in similar locations, and perceiving competitors as similar organizations to one another will positively moderate this impact. In addition, the costs of introducing mobile payment are included as a further moderating variable, since costs often represent a critical motive in investment decisions. The questionnaire ended with questions on the merchants' background information. Answers to the questions were based on a seven-point Likert scale ranging from strongly disagree to strongly agree. The model used for this research is illustrated in Figure 1.

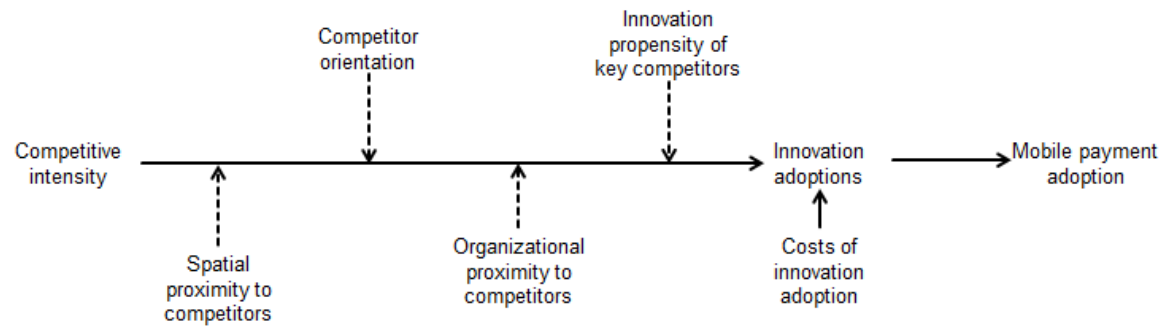

Figure 14: Model used for developing the questionnaire

To test the suitability of the questionnaire, first, interviews were conducted with merchants having a physical POS in Germany. Second, a test was conducted among 26 merchants responding to the questionnaire via an online tool. The results of both were used to refine the questionnaire and eliminate any misunderstandings of the text. In the 
F. Pisani \& J. Moormann: The Role of Competition in the Adoption of Mobile Payment among Merchants

next step of our project, the survey will be mailed to a representative number of merchants with a physical POS in Germany.

\section{$4 \quad$ Conclusions}

Mobile payment has long been predicted to revolutionize the payments industry. Nevertheless, in Germany and in most other European countries, the majority of payments at the POS are still conducted in cash. Mobile payment represents a specific example of a platform for a multi-sided market in which merchants and consumers are expected to interact. Importantly, however, the success of a platform depends on the network externalities that can be created among and between the different sides. Since merchants have been identified as the main agents determining the diffusion of mobile payment, this research aims to contribute to the literature on mobile payment through an analysis of specific aspects of competition that are hypothesized to impact the adoption of mobile payment among merchants. Figure 2 describes the status of this project and the course of action that will be taken until completion.

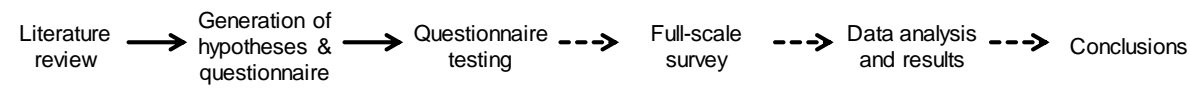

Figure 15: Steps of the research project

\section{References}

Apanasevic, T. (2013). Factors Influencing the Slow Rate of Penetration of NFC Mobile Payment in Western Europe. International Conference on Mobile Business (ICMB) (p. 8).

Clements, M. T. (2004). Direct and indirect network effects: are they equivalent?. International Journal of Industrial Organization, 22(5), 633-645. DOI: 10.1016/j.ijindorg.2004.01.003

Dahlberg, T., Mallat, N., Ondrus, J., \& Zmijewska, A. (2008). Past, present and future of mobile payments research: A literature review. Electronic Commerce Research and Applications, 7(2), $165-181$.

Dahlberg, T., Guo, J., \& Ondrus, J. (2015). A critical review of mobile payment research. Electronic Commerce Research and Applications, 14(5), 265-284.

Diniz, E. H., Porto de Albuquerque, J., \& Cernev, A. K. (2011). Mobile Money and Payment: a literature review based on academic and practitioner-oriented publications (2001-2011). Proceedings of SIG GlobDev Fourth Annual Workshop, Shanghai, China.

Dufwenberg, M., \& Gneezy, U. (2000). Price competition and market concentration: an experimental study. International Journal of Industrial Organization, 18(1), 7-22. DOI: 10.1016/S0167-7187(99)00031-4

Esselink, H., \& Hernández, L. (2017). The use of cash by households in the euro area. European Central Bank (ECB), Occasional Paper No. 201.

Evans, D. S. (2009). How catalysts ignite: the economics of platform-based start-ups. Platforms, Markets and Innovation, Cheltenham, UK, and Northampton, MA: Edward Elgar, 99-128.

Gazé, P., \& Vaubourg, A. G. (2011). Electronic platforms and two-sided markets: A side-switching analysis. The Journal of High Technology Management Research, 22(2), 158-165. DOI: 10.1016/j.hitech.2011.09.007 
F. Pisani \& J. Moormann: The Role of Competition in the Adoption of Mobile Payment among Merchants

Goldenberg, J., Libai, B., \& Muller, E. (2010). The chilling effects of network externalities. International Journal of Research in Marketing, 27(1), 4-15. DOI: 10.1016/j.ijresmar.2009.06.006

Iacovou, C. L., Benbasat, I., \& Dexter, A. S. (1995). Electronic data interchange and small organizations: Adoption and impact of technology. MIS Quarterly, 19(4), 465-485. DOI: $10.2307 / 249629$

Karuna, C. (2007). Industry product market competition and managerial incentives. Journal of Accounting and Economics, 43(2-3), 275-297. DOI: 10.1016/j.jacceco.2007.02.004

Katz, M. L., \& Shapiro, C. (1985). Network externalities, competition, and compatibility. The American Economic Review, 75(3), 424-440.

Lao, G., \& Liu, H. (2011). Study of mobile payment business model based on third-party mobile payment service provider. International Conference on Management and Service Science (MASS 2011) (pp. 1-4).

Mahler, A., \& Rogers, E. M. (1999). The diffusion of interactive communication innovations and the critical mass: the adoption of telecommunications services by German banks. Telecommunications Policy, 23(10-11), 719-740.

Ozcan, P., \& Santos, F. M. (2015). The market that never was: Turf wars and failed alliances in mobile payments. Strategic Management Journal, 36(10), 1486-1512. DOI: 10.1002/smj.2292

Ondrus, J., \& Lyytinen, K. (2011). Mobile payments market: Towards another clash of the Titans?. Tenth International Conference on Mobile Business (ICMB 2011) (pp. 166-172).

Ondrus, J., \& Pigneur, Y. (2007). An assessment of NFC for future mobile payment systems. International Conference on the Management of Mobile Business (ICMB 2007) (pp. 43-43).

Ondrus, J., Lyytinen, K., \& Pigneur, Y. (2009). Why mobile payments fail? Towards a dynamic and multi-perspective explanation. In 42nd Hawaii International Conference on System Sciences (HICSS 2009) (pp. 1-10).

Pousttchi, K., Schiessler, M., \& Wiedemann, D. G. (2009). Proposing a comprehensive framework for analysis and engineering of mobile payment business models. Information Systems and eBusiness Management, 7(3), 363-393.

Pousttchi, K., \& Wiedemann, D. G. (2007). Success factors in mobile viral marketing: A multi-case study approach. International Conference on the Management of Mobile Business (ICMB 2007) (pp. 34-34).

Tornatzky, L. G., Fleischer, M., \& Chakrabarti, A. K. (1990). Processes of technological innovation. Lanham, MD: Lexington books.

Van der Heijden, H. (2002). Factors affecting the successful introduction of mobile payment systems. Proceedings of the 15th Bled eCommerce Conference.

Yang, Y., Lu, Q. S., Tang, G., \& Pei, J. (2015). The Impact of Market Competition on Search Advertising. Journal of Interactive Marketing, 30, 46-55. DOI: 10.1016/j.intmar.2015.01.002 
514 31 $31^{\text {ST }}$ Bled eConference: Digital TRANSFormation: MeEting the Challenges June 17 - 20, 2018, Bled, SLOVEnia, ConfERENCE PROCEEDINGS 


\title{
Co-creation Model to Design Wearables for Emotional Wellness of Elderly
}

\author{
MuHAMmad USMAN WARRAICH, IRUM RAUF \& ANNA SELL
}

\begin{abstract}
Ways to influence emotions have always been an area of interest within the scientific community. The objective of this research is to find the role of technology in order to improve emotional wellness for the elderly population. We conducted a qualitative and quantitative study with the help of interviews and a survey. A sample of 24 respondents is selected randomly from the elderly population. The results showed a strong correlation between emotional, psychological and social wellness dimensions and elders comfort with the use of technology. Based on our study, we present a co-creation model to design wearables for monitoring and improving emotional wellness for elderly. There is a need for focused efforts to develop digital interventions for emotional wellness for elderly. It is important to include elders as co-designers to form effective solutions for elderly through a co-creation process.
\end{abstract}

Keywords: - Emotional wellness - Co-creation model • Elderly • Wearables • Personalized threshold $\bullet$ Unobstructive •

CORRESPONDENCE AdDRESS: Muhammad Usman Warraich, M.Sc., Doctoral Student, Åbo Akademi University, Faculty of Social Sciences, Business and Economics, Department of information Systems,ASA, 20500 Turku, Finland, e-mail: mwarraic@abo.fi. Irum Rauf, Ph.D., PostDoc Researcher, Åbo Akademi University, Faculty of Natural Sciences, , Agora 20500 Turku, Finland, e-mail: irauf@abo.fi. Anna Sell, Ph.D., Senior lecturer, Åbo Akademi University, Faculty of Social Sciences, Business and Economics, Department of information Systems, ASA, 20500Turku, Finland, e-mail: anna.sell@abo.fi. 
The emotional wellness of individuals emphasizes the importance of a positive outlook towards life circumstances, the capability to cope with stress and ability to maintain fulfilling relationships with others (Foster and Keller, 2007). With age, several factors contribute towards the emotional wellness of an individual, for example, loneliness, isolation etc. In addition, deteriorating health conditions may add extra stress to older adults (Garzo et al., 2010). WHO defines the mental health of individuals as an equally contributing part of the overall wellness of an individual and considers emotional wellness as one of the most important and overlooked parts of overall health (WHO,2010). In recent years, we have seen a significant increase in efforts by individuals and healthcare sectors to promote digital solutions to increase overall wellness. The digital intervention to improve the emotional wellness of older adults is still an underexplored area (Warraich and Rauf,2017). Research shows that emotional self-regulation helps to improve the quality of life in patients with different medical problems, like diabetes, immune functions, etc. (McCraty et al., 2010).

The need to provide digital interventions for emotional wellness is further highlighted as the segment which needs mental and emotional support is becoming large worldwide. According to Techcrunch (Techcrunch, 2017), in the year 2015, market sizes (USD) for meditation was 1 billion, yoga was 27 billion, addiction treatment was 35 billion, selfhelp was 10 billion and budget related to depression, stress and anxiety drugs was 22 billion. The annual cost of stress in the US alone is estimated to be 300 billion (Techcrunch, 2017). Regardless of this, 27\% of the population living in EU countries have mental health issues. Out of this number, $74 \%$ of the patients are not getting any treatment or care services (Schoenberg, et al., 2014). The increase in stress across countries, cultures, and ages is creating high impact on healthcare cost. This, when combined with the aging problem which is growing worldwide (Sell et al., 2017), motivates the need for focused and efficient approaches to developing a digital solution for the elderly. In addition, when it comes to emotional wellness of older adults, their emotional health propagates to their caregivers (friends and families) creating negative feelings in individuals. Thus, the emotional wellness of elders provides an important measure of the wellness of a society.

Many software applications and digital devices currently exist that track activities, sleep quality, breathing patterns and other attributes of individuals to assist in improving the wellness of an individual e.g. Fitbit, Jawbon, Apple watch etc. Most of these digital interventions do not consider the needs of elderly which are entirely different from another age group.

In this paper, we study the emotional wellness of elders to identify factors that can contribute to the development of digital interventions for the elderly. We adopt the strategy for value co-creation by identifying the factors that contribute to emotional wellness of elders. We carry out with questionnaires and interviews and subsequently match with the outcome functionality offered by wearables. The process of value co- 
$31^{\text {ST }}$ Bled eConference: Digital Transformation: MeEting the Challenges June 17 - 20, 2018, Bled, Slovenia, ConfEREnCE ProceEdings

creation emphasizes joint target sets for the entire process that give benefits to both the service providers and consumers of the service (Vargo et al. 2008). In doing so, we involve the target of our wellness services, i.e. the elder population as co-designers of the service. Co-designer is one of the co-creation approaches in which the users of the service are involved in the design of the service (Voorberg et al., 2015).

The paper is organized as follows: Section 2 explains motivation. Section 3 and section 4 explains research questions and research methodology respectively. The results of this research, on the basis of the research questions that we have formulated, are in section 5 . In section 6, we discuss what we learned from the review and section 7 presents a cocreation model. Section 8 concludes the paper and discusses our future work.

\section{Wearables and Emotional wellness}

\subsection{Technology}

Plenty of areas are emerging on the Internet. One of them is the Internet of the Future context which is known as Web Squared (Web 2.0) (O'Reilly and Battelle, 2009). The aim of web squared is to integrate web and sensing technologies together, to enrich the content. This is obtained with the help of information of user collected from the sensors (microphone, cameras, GPS, etc.) deployed in the user terminals. Web Squared can be one of the applications running on IoT (Internet of Things). IoT is connecting physical world of things with the virtual world of the Internet with the help of RFID, sensors, wireless communication devices and the software and the hardware platforms (Attridge et al., 2013). Wearables are increasingly being used as technological interventions to connect human world to virtual world through the use of sensors. Wearables refer to small electronic devices that are used as accessories that enable processing of personalized information (Sazonov et al., 2014). Technology interventions can improve user's wellness. They are very helpful in cost reduction for social services, medical care and furthermore, important technological remedies with different applications and devices are verified for decrease in mortality and increase in the quality of life (Schwartz and Andrasik, 2017). We are now living in a time where people can get their personal, realtime insights about stress, increase in heart rate, breathing and even headaches. Technical devices are acting like a coach (Tracker, 2017). According to WSJ, technology and innovations can make life better, though at the same time aging population and the right use of technology to make it more productive poses many challenges (WSJ, 2017).

\subsection{Human emotions and technology}

There are many wearables in the market and it is not easy to select the best wearable. Best activity tracker is based on the user needs. The wearable technology market is drastically increasing. In the year 2012, wearable technology revenue was approximately 8.5 billion dollars with 96 million devices (Techcrunch, 2017). By the year 2019, the revenue is expected to be 32 billion dollars with more than 230 million devices. Wellness wearables are attracting both individuals and organizations. All wearable supporting technologies 
are playing an important role in the growth of these wearables. Applications where users can view the status of their activities and give them targets are a great support for wearable. Different physiological signs (e.g., facial muscle tension, blood volume pressure, skin conductance which measures electro-dermal activity, etc.) can be collected using wearables and sensors (Picard et al., 2001). This data can be interpreted as emotional data and analysed further by experts or intelligent applications to provide recommendations to users to improve their emotional wellness. The work presented by (Farooq et al., 2011) and (Korda and Itani, 2013) also show how physical health relates to mental health and emotional states. Sanches et al. (2010) presented stress management applications based on wearable biosensors. Their work suggests that instead of taking an expert role in interpreting bodily data, users should be mirrored back the short-term stress reactions to help them manage their stress better as every individual has a different stress coping ability.

There exists a considerable amount of research articles that address emotional wellness with wearables; however, most of them discussed this provision for the general audience e.g. (Sanches et al., 2010). Researchers discuss the provision of emotional wellness to individuals, however, when it comes to validation of the works, authors mostly validate their work on young adults or population in general e.g., (Gruebler and Suzuki 2014), (Majoe et al. 2007), Tajadura et al. 2015). Providing one-size-fits-all solutions, however, may not yield the best possible results nor can they fully exploit the potential that wearables have to offer. The complexities of human emotions have been explored by technologists for decades. The concept of using technology to monitor things like stress and happiness is not new. Many consumer technology products are developed with advanced biometric sensors so that they can seamlessly synthesize complex information taken from our bodies, minds and digital habits. Currently, some devices which are mainly designed to measure emotions are:

Spire Stone: Spire stone is a small molten rock which can be attached to a waistband and women can use with the bra strap. It uses your breathing patterns to determine if you are feeling calm, focused or tense (Spire, 2018).

Muse: It is a brain-sensing headband and it tells how to overcome distraction and provide real-time information (Muse, 2018).

Feel: A bracelet which uses body temperature, heart rate, and skin conductance to track emotion and provide information about better wellness (Feel,2018).

Bellabeat Leaf Urban: A bracelet, necklace or clip for women that measures stress, breathing patterns, sleep quality and tracks menstrual and ovulation cycles (Bell,2018).

Pip: It monitors changes in skin pores to track stress levels and then recommends strategies to reduce stress through activities in its companion applications (Thepip, 2018). Emotional wellness is subjective in nature and different individuals may have different reactions and coping abilities to untoward incidents in life. This is the reason, we can find many studies in the literature that provide targeted approaches that cater to different target groups, e.g., those that provide emotional wellness using wearables at work(Hänsel et al., 2016), in sports, e.g., (Jones et al., 2016) and for young adults e.g., (Fahim et al. 2014). However, there is an obvious research gap in research for wearables that address emotional wellness for the elderly (Warraich and Rauf 2017). 
There are many health and wellness services in general that elderly population may use. However, we need to identify the need, as we know elderly people cannot perform physical activities as young people can do. People of this age have memory problems (dementia), lack of social interaction, mental wellness issues etc. These issues can be addressed and resolved by engaging them in physical, social and intellectual activities.

\subsection{Needs and solutions}

As more and more players arise in this space of emotional technology, the challenge is to discover novel ways to address the needs of digital devices that integrate well with user routines and behaviours.

Wellness service providers are providing customer solutions in order to monitor user's daily activities, sleep patterns and suggesting and guiding users accordingly. It is needed that these wellness activities should become a part of the users daily routine, i.e., healthy eating, healthy workout, and daily scheduling, socialization so that they remain active and healthy even in their later stages of life. Engaging in healthy behaviours, scheduled daily routines, and physical activities are part of wellness services that can slow functional decline in human behaviour and improve quality of life. Wellness services can assist in quitting different habits like smoking, drinking etc.

\section{$3 \quad$ Research Questions}

Based on our study of the literature, we identified the following objective and research questions for our study. Our primary objective is to identify factors that can contribute towards the emotional wellness of elderly with the help of digital technology. With this objective, we formulate the following research questions:

- What kinds of emotions are typical for the elderly?

- Does emotional wellness have any relations to psychological and social wellness?

- Can we use digital technology to improve emotional wellness?

- What could be a co-creation model for wellness wearables?

\section{$4 \quad$ Research Methodology}

In order to find answers to these research questions, we follow a two-step approach to study the factors that affect emotional wellness of elderly. In the first step, we conduct survey with a group of elders to get some understanding of their emotional, psychological and social wellness. In the second, step, we conduct interviews with the same participants to get a better understanding of their emotional wellness. The first step qualifies towards the quantitative study and the second step provides the qualitative study of the research problem. The details of the study are given below. 


\subsection{Participants}

The participants of the study are elders from an elder meet-up place in Turku, Finland. In total 24 respondents participated in the study. All the respondent were volunteers and their permission was taken for this research study. We visited that place four times in order to complete the survey and interviews. Of 24 respondents, 14 were female and 10 were male. The average age was 68 years and the range was from 50 to 81 . All the participants were familiar with the use of computers.

\subsection{Survey}

The survey was carried out with a questionnaire to collect data on the perceived understanding of elders on emotional, psychological and social wellness, followed by the questions on the use of technology. Emotional wellness recognizes the positive sense of self-regard, psychological wellness addresses one's perception that he/she will experience positive outcomes to the events and circumstances of life and the social wellness is defined as the perception of having support available from family or friends in times of need and the perception of being a valued support provider (PWS).

The questionnaire had 20 questions: the wellness dimensions questions were 18 in total with 6 questions in each dimension and 2 questions were for the use of technology. The questions are scored from 1, "Strongly disagree" to 6, "Strongly agree" (Matell et al., 1972). The wellness dimension questions were from the Perceived Wellness Survey (PWS) presented by Adams et al. (1997). The PWS survey has been widely used in the literature e.g. (Carter, 2004) (Bezner and Hunter, 2001).

\subsection{Interviews}

The questionnaire was followed by individual interviews of the participants. The semi structured interviews (design research) were conducted with open-ended questions and the interviewer made notes on the answers and their general behaviour towards the study, i.e. how willing they were to share their personal information. The interview questions are formulated to study participant's interest towards various interventions of wellness and self-awareness.

\subsection{Threats to Validity}

The survey and the interviews were conducted with utmost care to get clear insights into the factors influencing emotional wellness and the elder's attitudes towards technology; however, there may be certain things that may effect the validity of the results.

The participants of the study are all from socially and financially independent segments of the society. These participants were selected to see the behaviour, habits and mental state of individuals from a 'happy' society. The selection of the participants may affect 
the results; however, utmost care has been taken to involve participants from both genders and covering a relatively-wide range for elderly, in order to better reflect the society.

In addition, small sample sizes reduce the power of tests and increases the margin of error. The can make the results meaningless. However, we try to address this by reducing the diversity of the study participants.

\section{$5 \quad$ Results}

\section{$5.1 \quad$ Survey Results}

The survey results show a strong correlation between emotional and psychological wellness, (0.6), emotional and social wellness (0.55) and psychological and emotional wellness (0.65). This means that all these factors collectively affect an individual's outlook towards life.

We further analysed the results of questions individually for each dimension. Collectively, on average the answers of participants for each dimension were above 4 . This means that the participants generally perceived themselves to be emotionally, socially and psychologically well. We further divided our participant's data into two categories Gender-wise, and Age-wise, $<70$ and $>=70$. The results of the questions are shown in Figure 1.

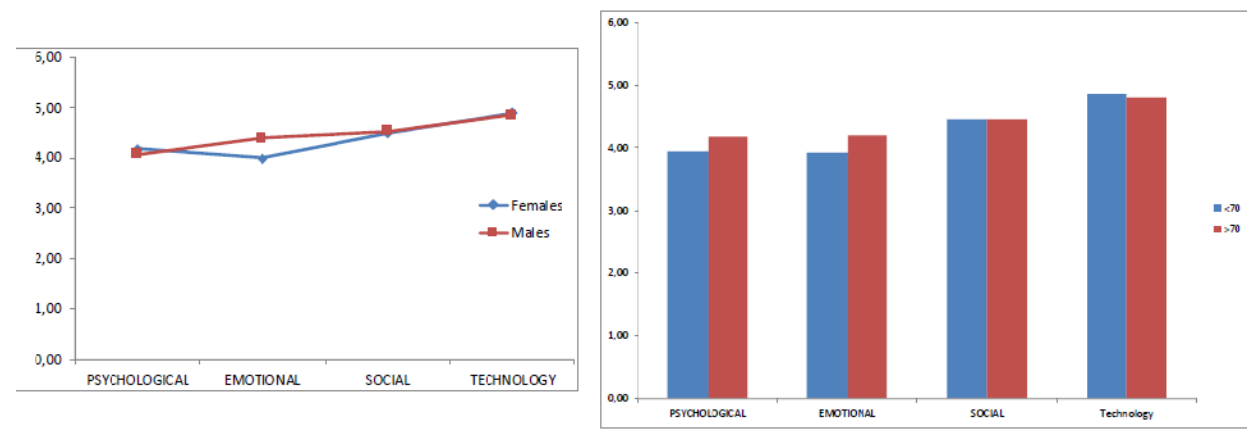

Figure 1: Results of survey-(Left) Gender-wise (Right) Age-wise

\section{Gender-wise}

We compared the average answers for each dimension gender-wise. While both the genders scored almost the same on psychological $(\mathrm{F}=4.1, \mathrm{M}=4.2)$ and social $(\mathrm{F}=4.53$, $\mathrm{M}=4.50)$ wellness, the female participants scored relatively less than male on emotional wellness $(\mathrm{F}=3.8, \mathrm{M}=4.4)$. The question that scored the least for the female was: I will always be secure with who I am. Females also generally scored less in all the other questions of emotional wellness, compared to male participants. The male group scored highest on the question, "In general, I feel confident about my abilities", whereas this question scored second lowest in the female. 


\section{Age-wise}

The age-wise categorization was done as $<70$ and $>=70$. This categorization was done to reflect a difference between data of elderly in both early and later stages of aging. The elderly group that is also known as the young-elderly age group (Carlsson and Walden, 2015) (Warraich, 2016) is generally found to be the healthier portion of the elderly population that has not declined in their cognitive and functional abilities. The distribution of data, with 70 as the middle line, also resulted in an equal number of participants in both categories. The average answers on each dimension were scored as: Psychological: < 70: 3.95, >= 70: 4.18, Emotional: <70: 3.9, >= 70: 4.21, Social: <70: $4.45,>=70: 4.45$.

Thus both categories, generally scored equal in all the dimensions, indicating a healthy society with a good social care system.

\subsection{Results of Digital Use}

According to Duh et al. elderly can benefit from engaging with technology. They need more attention to get familiar with the use of technology. Ijsselsteijn et al. (2007) suggested a digital interface game design in which they hade addressed the functional limitations with age. They also explained the requirements to design digital interface for elderly, which can be enjoyable and easy to use. In this work, to study the role of technology for the elders, the following two questions were asked: "Do you think that the use of technology distracts you?" and "Do you think technology/social media is the only reason that you are in touch with your friends?". These questions were asked to see whether technology has positive or negative effects on this age-group and to study their use of technology.

The results showed that technology does not have a negative effect on this age group. In the current era of digital revolution, technology is said to play a critical role for the lost of focus and distraction in the younger generation. However, since the elderly age-group has lived their lives before the digital-boom age, the use of technology does not have an adverse effect on them and they can use it more intelligibly. This is an important finding since all the elder that were part of the group were educated and computer literate giving them enough hands-on on today's technology. Despite this, the elders did not feel that technology distracts them.

In addition, although the role of social media in people's life is increasing, the elders did not consider that it to play any major role in staying close to their friends. 


\subsection{Interview Results}

The interviews were carried out with open-questions and asked the interviewees about the activities that made them feel better, their willingness to seek emotional support when necessary and the means of such support and also their attitudes towards adopting new healthy habits.

The analysis of interview answers showed a wide range of activities that elders participated in to feel better. These activities generally included physical activities like exercising and walking, mental activities like listening to music, yoga, painting etc. Most of all elders participated in social activities that included meeting friends and doing volunteer work. People at this age also visit church or other religious places in order to improve their spiritual wellness. Figure 2 shows a 'word cloud' of the activities mentioned by the participants of the study. A word cloud emphasizes the words based on the frequency and their occurrences. Figure 2 shows that socializing with friends dominated all the activities that elders participated in to get emotional support.

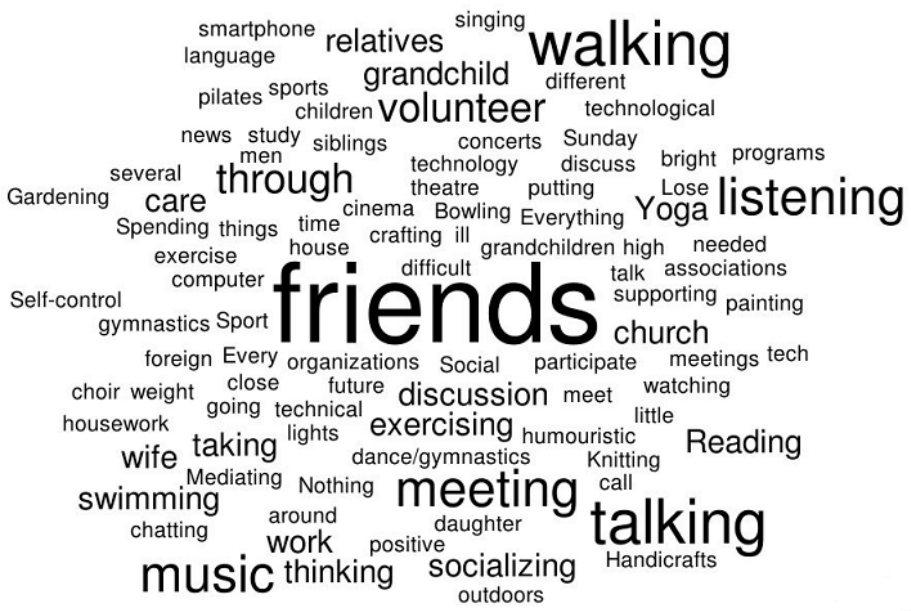

Figure 2: Word cloud of the activities that elder's engage

We observed that for emotional support, elders generally talked with their friends, or family members, in most cases grandchildren or they participated in religious or meditation activities. The majority of the participants also showed interest in identifying and adopting new healthy habits. The general observation by the interviewer also showed that elders were talking about technology, smartphones, social media and computers. They were technology friendly and wanted to learn and experience new services and were also willing to change habits if they are healthy for them. 
In this section, we attempt to answer the research questions in the light of study result.

\subsection{Emotions Experienced by Elders}

Elders belong to the age group of society who are generally not active contributors to society and are going through the aging process. This can lead to emotionally unwell elders which can lead to physical and social problems. However, our study indicates that if the elders are offered means to stay active, their emotional wellness can be more stable than that of the middle-aged and young adults. This is further supported by (Warraich and Rauf, 2017) in which elders were found to be more emotionally and psychologically well than other age groups. This can be linked to the fact that with age, people's expectations towards life become less and they learn to be satisfied with what they have compared to younger adults who are expecting more from life and get disappointed on getting results (Etxeberria et al., 2017). This is also evident from our survey results in which the question "In the past, I have expected the best." scored the lowest among all questions showing disappointment.

\subsection{Emotional vs. Social vs. Psychological Wellness}

The three dimensions studied show strong correlation with the limitations of small samples. We looked at each individual data in detail to find out values that did not correlate well with each other, i.e., scoring high in one dimension and not in the other. We found that those participants that did not mention involvement in any activity did not seek emotional support or did not show any interest in improving current habits, scored considerably lower in all or more than one of the wellness dimensions studied, compared to more active participants.

\subsection{Role of Digital Technology for Emotional Wellness}

The use of digital technology, in the lives of elders is very selective and they are not very aware of the functionality and use of technology. The limited use of technology is evident from the survey results. The elders in the study are willing to change their habits to improve their overall health. Thus, we see that the limited use of technology but a willingness to change one's behavior for better physical and mental health provides good opportunities for digital intervention to improve emotional wellness.

\section{$7 \quad$ Reflections on Sample}

The participants of our study are taken from a meet-up place for elderly that is allocated by the city of Turku in Finland. Finland is among the world's best places for the wellness of elderly (Kang et al., 2008). The elders in Finland have more access to social benefits including services like meet-up benefits, financial support, etc. For this reason, we believe that our study with elders generally showed positive results for emotional, psychological 
and social wellness. From the reflections of the participants, we identified attributes that can contribute to developing a co-creation model for wearables for the elderly.

\section{Co-Creation Model}

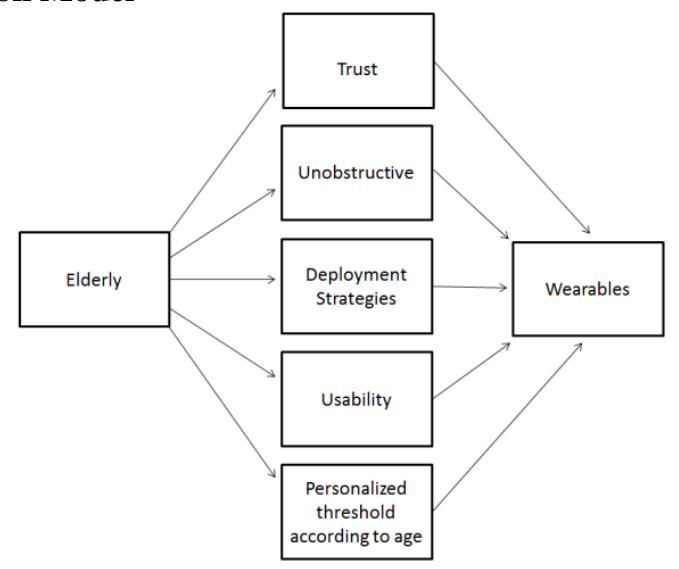

Figure 3: Co-creation Model for Wearables for Elderly

The value co-creation provides opportunities for digital services that benefit both the service provider and consumer of the service, emphasizing joint target sets for the entire process (Vargo et al. 2008), (payne et al. 2008). Based on our studies and reviewed literature, we propose a co-creation model for wearables for elderly. Below, we discuss the factors identified:

Unobstructive: Our user studies show that elders are comfortable with technology, however, since they are from the pre-digital boom era, they do not rely much on technology and they do not find it distracting. This implies that a technology intervention that could be obstructive in their daily life and could distract them continuously may not be adopted or welcomed by the elderly. Wearables can be designed to be unobstructive as a passive recorder of individual's activities and to notify or interact with the user when important.

Social Needs: The word cloud in Figure 2 shows 'friends' as the main intervention that elders use to feel better, followed by 'talking' and 'walking'. This shows that elders put a lot of emphasis on their social needs; interacting with friends and talking about their problems to friends and family. Thus, the wearables should be designed in such a way that they fulfill the social needs of adults without being distracting, uncomfortable and obstructive.

Deployment Strategies: Adoption of wearables is significantly affected by the deployment strategies used to encourage users towards their use. Preusse et al. (2017) suggests deployment strategies for wearable activity trackers like creating tutorial videos that facilitate the learning of new/ difficult features, allowing trial-of-use periods etc. These deployment strategies should be customized towards elders. At a certain age, elderly people may develop bad eyesight, arthritis and stability problems among others. 
The elderly person may not be able to hold a mouse, click a mouse or press a button. Their performance on a computer is generally slower. Similarly, the design of wearables and their use can be complex or simple. Elders should be encouraged to participate in technology-related interventions. They can embrace different information technology applications if given appropriate and customized training. The interventions should be designed with hardware and software features that address potential functional limitations and inexperience of elders with wearables as digital interventions.

Usability: Most interfaces proposed so far for smart watches offer limited accessibility to older adults: screens are small and the information is often shown with small characters; small buttons are used to navigate in the interface. Differences between younger and older people should be taken into consideration during application development (Hough and Kobylanski, 2009). Designing an interface that takes into account common impairments of older adults is important to increase the desirability of the whole product. Choosing the best modalities to interact with the wearables could reduce errors and thus frustration during the utilization. In order to figure out user need and design applications according to his/her desires, it is important to know what is needed by analyzing user behavior. Joe et al. (2016) described older adult's behavior towards multifunctional technology and expectations and preferences that can maximize the usability of the technologies. It has been concluded that participants are positive toward a multifunctional wellness tool and users are willing to use it if they can have reliable health-related information on the device. Changes in behavior and lifestyle is a long-term process endeavor that permeates daily life (Consolvo et al., 2009). If designers have not done it properly then it will result in abandoned technology. Technology has high potential to support and motivate healthy living (Grimes et al., 2010).

Trust: An important point observed during our interview sessions was that elders were generally restrictive to talk about their emotional wellness. The developed digital intervention should be able to keep users motivated in the management of their wellness while also developing user trust in its use. Changes in behavior, routines and habits can be changed with time but an important aspect which needs to be addressed is trust.

Personalized thresholds: Existing digital interventions mostly generalize the treatment and recommendations or ask too many questions to personalize the experience that affects their usability. However, emotional wellness of an individual depends on various factors that may differ from one individual to another. Different aspects of one's personality, environmental factors, and behavior traits may affect the well-being of an individual and all the features collectively affect the emotional wellness (Foster and Keller, 2007). Wearable activity trackers, as technical interventions, have great potential to influence wellness of individuals in everyday life as they provide means to collect, quantify, analyze and monitor different attributes of the wearer and her environment. Thus, they can help to provide personalized wellness services to wearers. It is important that the analysis of the personal data of individuals is done on the thresholds suitable for elders since physical threshold values may vary with age. 


\section{Conclusion and Future Work}

The elder population is increasing worldwide. It is important to address the emotional wellness of elders, which is an under-researched area since emotional wellness has propagating effects on other dimensions for wellness. In addition, low emotional wellness of elders cause negative feeling on their caregivers as well. Elders are generally considered to be challenging and it becomes difficult to change their habits and addictions with age. Loneliness is playing an important role in worsening the overall condition of elders. In this paper, we study different dimensions of wellness related to the mental health of elders and also their attitudes to digital technology. Our study indicates positive results and based on that we identify contributing factors that affect the emotional wellness of individuals. We present a co-creation model for wearables that contribute to emotional wellness of elderly.

The participants of the study are from Finland that is considered one of the best places in the world for the wellness of elderly; therefore, it is not possible to generalize the conclusions for older people across all of Europe. However, based on the lessons learnt from the study, different factors can be identified to develop digital interventions for emotional wellness of elderly. Further study designs can expand and include participants from different cultures in order to reach deeper conclusions.

\section{References}

Adams, T., Bezner, J., \& Steinhardt, M. (1997). The conceptualization and measurement of perceived wellness: Integrating balance across and within dimensions. American Journal of health promotion, 11(3), 208-218.

Attridge, M., Herlihy, P. A., \& Maiden, R. P. (Eds.). (2013). The integration of employee assistance, work/life, and wellness services. Routledge.

Bell(2018). https://www.wareable.com/health-and-wellbeing/bellabeat-leaf-urban- review, 2017 retrieved February 6, 2018

Bezner, J. R. and Hunter, D. L. (2001). Wellness perception in persons with traumatic brain injury and its relation to functional independence. Archives of physical medicine and rehabilitation, 82(6):787-792.

Carlsson, C., \& Walden, P. (2015, June). Digital Wellness for Young Elderly: Research Methodology and Technology Adaptation. In Bled eConference (p. 1).

Carter, C. S. (2004). Effects of formal dance training and education on student performance, perceived wellness, and self-concept in high school students (Doctoral dissertation, University of Florida).

Consolvo, S., McDonald, D. W., \& Landay, J. A. (2009, April). Theory-driven design strategies for technologies that support behavior change in everyday life. In Proceedings of the SIGCHI conference on human factors in computing systems (pp. 405-414). ACM.

Dennis Majoe, Irena Kulka, and Jurg Gutknecht. Qi energy flow visualisation using wearable computing. In Pervasive Computing and Applications, 2007. ICPCA 2007. 2nd International Conference on, pages 285-290. IEEE, 2007.

Design research, .http://designresearchtechniques.com/casestudies/semi-structured-interviews/ retrieved February 15, 2018 
M. U. Warraich, I. Rauf \& A. Sell: Co-creation Model to Design Wearables for Emotional Wellness of Elderly

Duh, Henry Been-Lirn, et al. "Senior-friendly technologies: Interaction design for senior users." CHI'10 Extended Abstracts on Human Factors in Computing Systems. ACM, 2010.

Etxeberria, I.,Etxebarria,I.,Urdaneta,E.(2017). "Profiles in emotional aging: does age matter?." Aging \& mental health : 1-9.

Fahim, M.,Idris, M.,Ali, R.,Nugent, C.,Kang, B.,Huh, EN.,Lee, S.(2014).. Athena: a personalized platform to promote an active lifestyle and wellbeing based on physical, mental and social health primitives. Sensors, 14(5):9313-9329.

Farooq, U., Jang, D. G., Jang, J. K., \& Park, S. H. (2011, August). Mental health promotion system. In Engineering in Medicine and Biology Society, EMBC, 2011 Annual International Conference of the IEEE (pp. 5283-5286). IEEE.

Feel(2018), https://www.wareable.com/wearable-tech/feel-wristband-specs-price- release-datedetails-2148, 2017. retrieved January 17, 2018.

Foster, L. T., Keller, C. P., \& Boomer, J. (2007). Defining wellness and its determinants. British Columbia atlas.

Garzo, A., Montalbán, I., León, E., \& Schlatter, S. (2010). Sentient: an approach to ambient assisted emotional regulation.

Grimes, A., Kantroo, V., \& Grinter, R. E. (2010, September). Let's play!: mobile health games for adults. In Proceedings of the 12th ACM international conference on Ubiquitous computing (pp. 241-250). ACM.

Gruebler, A., \& Suzuki, K. (2014). Design of a wearable device for reading positive expressions from facial emg signals. IEEE Transactions on affective computing, 5(3), 227-237.

Hänsel, K. (2016, September). Wearable and ambient sensing for well-being and emotional awareness in the smart workplace. In Proceedings of the 2016 ACM International Joint Conference on Pervasive and Ubiquitous Computing: Adjunct (pp. 411-416). ACM.

Hough, M., \& Kobylanski, A. (2009). Increasing elder consumer interactions with information technology. Journal of Consumer Marketing, 26(1), 39-48.

Ijsselsteijn,W.,Nap, HH.,Kort,Y de.,Poels,K.(2007). "Digital game design for elderly users." Proceedings of the 2007 conference on Future Play. ACM.

Joe, J., Chaudhuri, S., Chung, J., Thompson, H., \& Demiris, G. (2016). Older adults' attitudes and preferences regarding a multifunctional wellness tool: a pilot study. Informatics for Health and Social Care, 41(2), 143-158.

Jones, L., Marshall,P., Denison, J.(2016). Health and well-being implications surrounding the use of wearable gps devices in professional rugby league: A fou- cauldian disciplinary analysis of the normalised use of a common surveillance aid. Performance Enhancement \& Health, $5(2): 38-46$.

Kang, M., Russ, R. R., \& Ryu, J. S. (2008). Wellness for older adults in daily life. Division of Agricultural Sciences and Natural Resources, Oklahoma State University.

Korda,H. and Itani,Z.(2013). Harnessing social media for health promotion and behavior change. Health promotion practice, 14(1):15-23.

Matell, M. S., \& Jacoby, J. (1972). Is there an optimal number of alternatives for Likert-scale items? Effects of testing time and scale properties. Journal of Applied Psychology, 56(6), 506.

Muse(2018), http://www.choosemuse.com/, 2017 retrieved February 21,2018

O'Reilly, T., \& Battelle, J. (2009). Web squared: Web 2.0 five years on. " O'Reilly Media, Inc.".

Oreilly(2009), https://conferences.oreilly.com/web2summit/web2009/public/schedule/detail/10194 Retrieved March 15,2018.

Payne, A. F., Storbacka, K., \& Frow, P. (2008). Managing the co-creation of value. Journal of the academy of marketing science, 36(1), 83-96.

Pip(2018), https://thepip.com/en-eu/, 2017. Retrieved February 7, 2018. 
Petr Slov'ak, Ran Gilad-Bachrach, Mia Doces, and Geraldine Fitzpatrick. Intervening for wellbeing: Developing social-emotional competencies with technology.

PWS, http://www.perceivedwellness.com/, retrieved February 15, 2018

McCraty, R., Atkinson, M., \& Lipsenthal, L. (2000). Emotional selfregulation program enhances psychological health and quality of life in patients with diabetes. Boulder Creek, CA: HeartMath Research Center, Institute of HeartMath, Publication No. 00-006.

Picard, R. W., Vyzas, E., \& Healey, J. (2001). Toward machine emotional intelligence: Analysis of affective physiological state. IEEE transactions on pattern analysis and machine intelligence, 23(10), 1175-1191.

Preusse, K. C., Mitzner, T. L., Fausset, C. B., \& Rogers, W. A. (2017). Older adults acceptance of activity trackers. Journal of Applied Gerontology, 36(2):127-155.

Sanches, P., Höök, K., Vaara, E., Weymann, C., Bylund, M., Ferreira, P., ... \& Sjölinder, M. (2010, August). Mind the body!: designing a mobile stress management application encouraging personal reflection. In Proceedings of the 8th ACM conference on designing interactive systems (pp. 47-56). ACM.

Sazonov, E., \& Neuman, M. R. (Eds.). (2014). Wearable Sensors: Fundamentals, implementation and applications. Elsevier.

Schoenberg. Pla and David, S,(2014) "Biofeedback for psychiatric disorders: a systematic review." Applied psychophysiology and biofeedback 39.2 : 109-135. range). Place of publication: Publisher.

Schwartz, M. S., \& Andrasik, F. (Eds.). (2017). Biofeedback: A practitioner's guide. Guilford Publications.

Sell, A., Walden, C., \& Walden, P. (2017, January). My wellness as a mobile app. identifying wellness types among the young elderly. In Proceedings of the 50th Hawaii International Conference on System Sciences.

Spire, https://spire.io/, 2017. . Retrieved February 7, 2018.

Tajadura-Jiménez, A., Basia, M., Deroy, O., Fairhurst, M., Marquardt, N., \& Bianchi-Berthouze, N. (2015, April). As light as your footsteps: altering walking sounds to change perceived body weight, emotional state and gait. In Proceedings of the 33rd Annual ACM Conference on Human Factors in Computing Systems (pp. 2943-2952). ACM.

Techcrunch (2017), https://techcrunch.com/2016/10/17/science-and-technology- will-makemental-and-emotional-wellbeing-scalable-accessible-and-cheap/, 2017. Retrieved December 142017

Tracker(2017).Worldwide Quarterly Wearable Device Tracker. https://www.idc.com/tracker/. retrieved December 2, 2017

Vargo, S. L., Maglio, P. P., \& Akaka, M. A. (2008). On value and value co-creation: A service systems and service logic perspective. European management journal, 26(3), 145-152.

Voorberg, W. H., Bekkers, V. J., \& Tummers, L. G. (2015). A systematic review of co-creation and co-production: Embarking on the social innovation journey. Public Management Review, 17(9), 1333-1357..

Warraich, M. U. (2016). Wellness Routines with Wearable Activity Trackers: A Systematic Review. In MCIS (p. 35).

Warraich, M. U., \& Rauf, I.(2017) STUDYING EMOTIONAL WELLNESS WITH WEARABLES FOR YOUNG ELDERLY-AN INSIGHT.

WHO (2010). "World Health Organization". World health statistics.

WSJ(2017). https://www.wsj.com/articles/finland-is-flourishing- after-100-years-ofindependence-1512333515, 2017 /. retrieved December 14, 2017 
M. U. Warraich, I. Rauf \& A. Sell: Co-creation Model to Design Wearables for Emotional Wellness of Elderly

\section{Appendix}

Age:

\section{Wellness Questionnaire}

Gender:

\section{Location (City/Country):}

This survey is part of an ongoing research and the results published from it will be anonymous. Please fill carefully and thoughtfully consider each statement, then select the one response option with which you agree the most.

$$
\begin{array}{lc}
\text { Very } & \text { Very } \\
\text { Strongly } & \text { Strongly } \\
\text { Disagree } & \text { Agree }
\end{array}
$$

\begin{tabular}{|c|c|c|c|c|c|c|c|}
\hline 1. & I am always optimistic about my future. & 1 & 2 & 3 & 4 & 5 & \\
\hline 2. & I rarely count on good things happening to me. & 1 & 2 & 3 & 4 & & \\
\hline 3. & I always look on the bright side of things. & 1 & 2 & 3 & 4 & 5 & \\
\hline 4. & In the past, I have expected the best. & 1 & 2 & 3 & 4 & 5 & 6 \\
\hline 5. & In the past, I hardly ever expected things to go my way. & 1 & 2 & 3 & 4 & 5 & \\
\hline 6. & Things will not work out the way I want them to in the future. & 1 & 2 & 3 & 4 & 5 & 0 \\
\hline 7. & There have been times when I felt inferior to most of the people & 1 & 2 & 3 & 4 & 5 & \\
\hline 8. & In general, I feel confident about my abilities. & 1 & 2 & 3 & 4 & 5 & \\
\hline 9. & I sometimes think I am a worthless individual. & 1 & 2 & 3 & 4 & 5 & 6 \\
\hline 10. & I am & 1 & 2 & 3 & 4 & 5 & \\
\hline 11. & I will always be sec & 1 & 2 & 3 & 4 & 5 & \\
\hline 12. & In the past, I have felt sure of myself among stran & 1 & 2 & 3 & 4 & 5 & 6 \\
\hline 13. & Members of my family come to me for support. & 1 & 2 & 3 & 4 & 5 & 6 \\
\hline 14. & $\begin{array}{l}\text { Sometimes I wonder if my family will really be there for me when I am } \\
\text { in need }\end{array}$ & 1 & 2 & 3 & 4 & 5 & 6 \\
\hline 15. & My friends know they can always confide in me and ask me for advice. & 1 & 2 & 3 & 4 & 5 & 0 \\
\hline 16. & My family has been available to support me in the past. & 1 & 2 & 3 & 4 & 5 & 6 \\
\hline 17. & $\begin{array}{l}\text { In the past, I have not always had friends with whom I cor } \\
\text { joys and sorrows. }\end{array}$ & 1 & 2 & 3 & & 5 & 6 \\
\hline 18. & My friends will be there for me when I need help. & 1 & 2 & 3 & 4 & 5 & 0 \\
\hline 19. & Do yo & 1 & 2 & 3 & 4 & 5 & 6 \\
\hline & Do you think technology/social media is the only reason that & 1 & 2 & & & & 6 \\
\hline
\end{tabular}

\section{Interview Questions}

1: What activities do you do that makes you feel better?

2: Do you seek emotional support when necessary and how?

3: Do you want to choose your own healthy habit if yes then what? 


\title{
Determining the Required Capacity of Business Information Management: Towards a Concise Instrument
}

\author{
Frank Van Outvorst, Mart Meijnen, Pascal Timens, SJoerd \\ WALENBERGH, BENNY DE WAAL
}

\begin{abstract}
Many organizations are striving for a structural and professional approach toward business information management (BIM). With help of BiSL they can shape the BIM responsibilities and processes, but they struggle with the required capacity for the BIM activities necessary for their particular situation. Therefore, research was started to develop an instrument to determine the required capacity of the BIM activities in an organization. In this paper the construction of the instrument will be described. A limited set of factors may be of importance to identify the required capacity of BIM activities that is needed: complexity of business processes, complexity of IS/IT, dynamics of the organization and its environment and the size of the organization are examples of relevant factors. However, factors that appear relevant may prove useless in practice due to the fact that organizations have no data on these indicators available. Furthermore, the relationships between the present and desired quality of information and information services are part of the instrument. The instrument was tested in practice to determine the usefulness. The results show that the instrument has the potential to determine the required capacity of BIM.
\end{abstract}

Keywords: • Business Information Management • IS/IT management • Business IT alignment • BiSL Framework • Required capacity •

CORRESPONDENCE ADDRESS: Frank Van Outvorst, The Lifecycle Company / ASL BiSL Foundation, Netherlands, e-mail: frankvanoutvorst@hotmail.com. Mart Meijnen, HU University of Applied Sciences Utrecht, Utrecht, Netherlands, e-mail: mart.meijnen@ student.hu.nl. Pascal Timens, HU University of Applied Sciences Utrecht, Utrecht, Netherlands e-mail: pascal.timens@student.hu.nl. Sjoerd Walenberg, HU University of Applied Sciences Utrecht, Utrecht, Netherlands, e-mail: sjoerd.walenbergh@student.hu.nl. Benny M.E. De Waal, HU University of Applied Sciences Utrecht, Utrecht, Netherlands, e-mail: benny.dewaal@hu.nl.

DOI https://doi.org/10.18690/978-961-286-170-4.37

ISBN 978-961-286-170-4

(C) 2018 University of Maribor Press

Available at: http://press.um.si. 
Information systems and information technology (IS/IT) have a still increasing impact on organizations. IS/IT is becoming a crucial factor to more and more organizations by penetrating into the core of organizational performance (Markus and Loebbecke, 2013). Usage of IS/IT is still growing, as are the expenditures on IS/IT. Management of IS/IT is considered pivotal in ensuring successful use of IS/IT in organizations (Pult, 2013). From a business point of view management of IS/IT is responsible for a wide range of activities, from system initiation through design and implementation to direction of deployment and use (Booth and Philips, 2005). This comprises the care for the entire lifecycle of IS/IT. To provide guidance for this crucial responsibility, in 2005 the Business information Services Library (BiSL) was published (Van der Pols, Donatz, Van Outvorst, 2012). BiSL describes a framework for business information management and has developed to an industry standard for business information management in the Netherlands. BiSL was developed for different purposes, such as an instrument for professionalization, establishing a common vocabulary for the field of business information management, and to create a connection between information strategy/governance and operational business information administration. Many organizations are striving for a structural and professional approach toward business information management (BIM). With help of BiSL they can shape the BIM responsibilities and processes, but they struggle with the question of the required capacity of the BIM department in order to deploy all activities necessary for their particular situation. This issue leads to the following questions in this research:

- Which activities must be taken into account to determine the capacity of the BIM department?

- Which factors are relevant with data available to determine the capacity of the BIM department?

- How can service quality of the BIM department be measured?

In the next section we discuss how the instrument to determine the required capacity of BIM is constructed and some results to validate the instrument.

\section{Theoretical Background}

\subsection{Required Capacity Factors of Business Information Management}

In the domain of Business Information Management several studies have been carried out to determine the required capacity for the BIM department. These studies are discussed and summarized by Van Outvorst, De Vries and De Waal (cf. Van Outvorst, De Vries and De Waal, 2016), Based on these studies and theories, a set of 20 factors were classified in three main categories: 1) complexity of the user organization, 2) complexity of the BIM department, and 3) complexity of the information systems landscape (Van Outvorst, De Vries and De Waal, 2016). Their research showed that the three categories were useful and usable to determine the required capacity of BIM. However, there were also some points of attention. In practice it turns out that not every factor within one of 
the three categories leads to sufficient data. Organizations do collect a lot of data in this area, but not all data were found suitable for the purpose to determine the required capacity. Therefore, further research was necessary to define the ultimate set of factors on each of the three categories.

To determine these factors expert interviews were conducted with three professionals in the field of BIM. Two of these experts were found by mediation of the ASL BiSL Foundation which is a Dutch society that aims to improve professionalism in the field of business information management. A third expert was found within the working organization of the Utrecht University of Applied Science. So one expert was employed in an educational organization, one in a government organization, and one in a financial institution. All persons had more than ten years of experience in the field and work for a large organization. During the three interviews the 20 factors were assessed on relevance and availability of data. For the interviews a semi structured questionnaire was used to ensure that in all interviews all 20 thought-to-be relevant factors were addressed in a similar way. Besides focus on the 20 factors the interviews also gave room to the experts to bring in additional factors and other relevant issues. All interviews were tape-recorded and fully transcribed (Patton, 2002). After the expert interviews, the findings were classified by two junior and two senior researchers, by using the following schema: $0=$ not mentioned properly, $1=$ not relevant, $2=$ moderately relevant, and $3=$ highly relevant. After the factors of each experts were classified, the average score was calculated. A factor with a score of 2.3 or more was rated as relevant. In the same way, from the selected factors the availability of data was classified. The classification schema was in this case: $0=$ not mentioned properly, $1=$ not available, $2=$ moderately available, and $3=$ highly available. Factors with a score of 2.0 were rated as sufficient availability of data. 
Table 1: Relevance and data availability of factors

\begin{tabular}{|l|c|c|}
\hline \multicolumn{1}{|c|}{ Factor } & Relevant & Data Available \\
\hline Number of applications & 2,7 & 2,7 \\
Number of business domains & 1,3 & \\
Number of projects & 1,3 & \\
Annual budget for changes & 1,7 & \\
Number of end users & 2,7 & 3,0 \\
Functional stability of applications & 3,0 & 2,0 \\
Technical stability of applications & 2,3 & 2,0 \\
Number of (sub) processes & 3,0 & 2,3 \\
Size and Impact of business domain & 1,7 & \\
Stability of business domains & 2,0 & \\
Number of stakeholders & 3,0 & 2,0 \\
Maturity of BIM responsibility & 2,0 & \\
Size of projects & 2,3 & 2,3 \\
Success rate of projects & 1,5 & \\
Maturity of project management & 2,3 & 1,7 \\
Maturity of user organization & 3,0 & 1,7 \\
Organization of the BIM responsibility & 1,7 & \\
Information intensity in primary process & 2,7 & 1,0 \\
Ratio customization or standard application & 2,5 & 1,3 \\
Annual budget of IT & 1,7 & \\
\hline
\end{tabular}

The results of the expert interviews are presented in Table 1. As shown, 11 factors were assessed by the experts as relevant. From seven of these factors, the experts indicated that hereof data is available. After discussion between the researchers it was also decided to add the factor ratio customization and standard application. The reason was that from the available data about the number of applications this ratio can be calculated.

\subsection{Required Capacity Model of Business Information Management}

Besides the factors to determine the required capacity of BIM, Van Outvorst et al. (2016) mentioned also to consider the desired information quality and service quality of the BIM department. The capacity of BIM workers can be different if the service quality is high or low (Van der Pols, 2009). In the construction of the instrument to determine the required capacity, we need to know how information- and service quality is appreciated. 
The conceptual model of the proposed instrument is depicted in Figure 1. As can be seen, a restricted set of factors will lead to the required capacity of BIM workers for a specified set of BIM activities. This relationship is intervened by the factor of information quality and service quality. In the next section we describe how the instrument is constructed and how the first validating research is conducted.

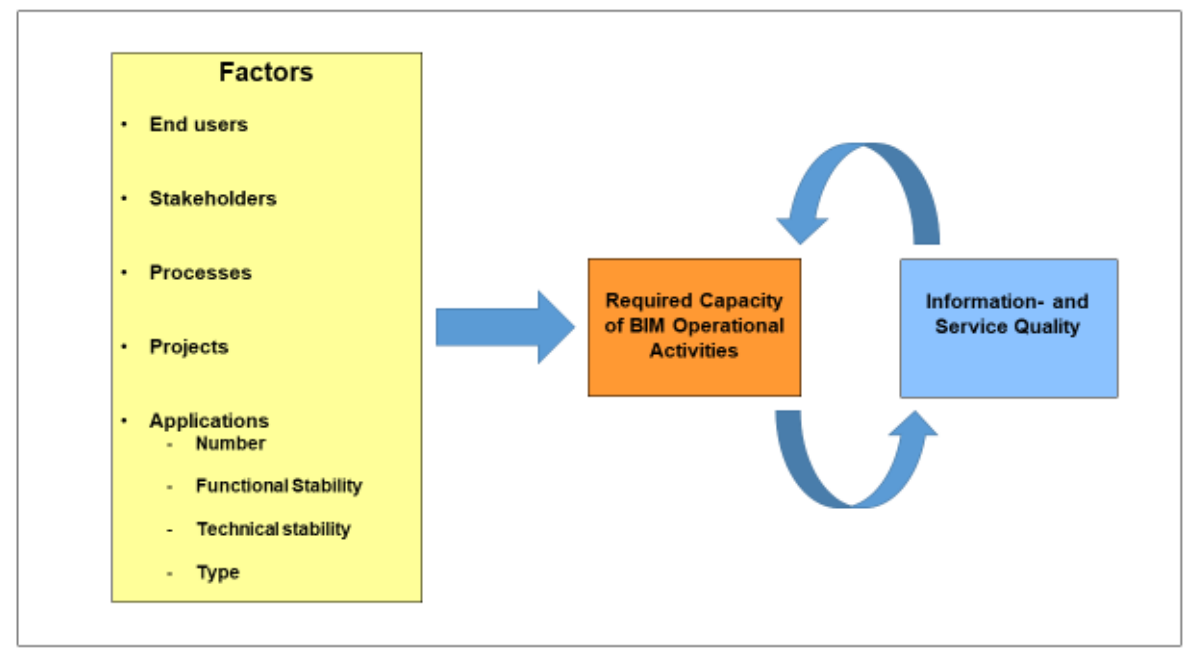

Figure 1: Conceptual model

\section{$3 \quad$ Research method}

\subsection{Instrument construction}

To construct the proposed instrument a literature review was conducted to precisely define the selected factors and to find a way to measure information- and service quality. Full-text articles were searched in a combination of 28 databases, including Academic Search Premier, Business Source Elite, Cochrane Database of Systematic Reviews, Communication \& Mass Media Complete, Directory of Open Access Journals, EBSCOhost, ScienceDirect, and Web of Science, with topic-related keywords for articles published between 2010 and 2016. Keywords used for the search were a combination of Dutch and translated equivalents in English.

Articles were selected to use in this study after perusal of abstracts. Thereafter, the snowball method was used to find more relevant publications.

Table 2 shows the keywords and the corresponding search results. 
F. Van Outvorst, M. Meijnen, P. Timens, S. Walenbergh, B. De Waal: Determining the Required Capacity of Business Information Management: Towards a Concise Instrument

Table 2: Search results literature study

\begin{tabular}{|l|l|l|}
\hline Keyword & Number of hits & Used hits \\
\hline $\begin{array}{l}\text { Users of information system / users } \\
\text { BiSL }\end{array}$ & 5.325 & 3 \\
\hline Stakeholders & 515.000 & 3 \\
\hline Sub process & 37.000 & 2 \\
\hline Number of applications & 12.400 & 1 \\
\hline Type of application & 10.700 & 2 \\
\hline Functional change & 36.000 & 2 \\
\hline Technical change wijziging & 17.200 & 1 \\
\hline Size of projects & 437.000 .000 & 3 \\
\hline Quality of IS/IT & 5.800 .000 & 4 \\
\hline
\end{tabular}

As a result of the literature review, the definitions of the selected factors are presented in Table 3. 
Table 3: Definitions of factors

\begin{tabular}{|c|c|}
\hline Factor & Definition \\
\hline End user & $\begin{array}{l}\text { An end user is a person in the organization who is authorized } \\
\text { to produce or use information form an information system. } \\
\text { (Bon, 2011) } \\
\text { End users can be divided into active and inactive users. } \\
\text { Active users use applications daily, inactive users limited } \\
\text { and irregular (Bon, 2011; Zijlstra, 2011). }\end{array}$ \\
\hline Stakeholders & $\begin{array}{l}\text { People or groups that influence the design of information } \\
\text { systems and benefit of it (McGrath and Whitty, 2015). }\end{array}$ \\
\hline Processes & $\begin{array}{l}\text { A process is chain of activities and is initiated by a clear } \\
\text { trigger and ends with a result (Camunda, 2015; Oliver Kopp, } \\
2010 \text { ). }\end{array}$ \\
\hline Size of projects & $\begin{array}{l}\text { A project is a set of unique, versatile and related activities } \\
\text { with a goal that should be achieved within a certain time, } \\
\text { within cost constraints and according to specifications } \\
\text { (Rikowski, 2015). The size is determined by costs, risks } \\
\text { impact, strategic priority, duration and dependency. }\end{array}$ \\
\hline Applications & $\begin{array}{l}\text { An application is a software program that offers direct } \\
\text { support to business functions, processes and / or procedures } \\
\text { (Clarke, 2002). }\end{array}$ \\
\hline Type of application & $\begin{array}{l}\text { Type of application is divided in three categories: (1) } \\
\text { mission critical (business interest is high), (2) business } \\
\text { critical (impact on the business) and (3) nice to have (not } \\
\text { necessary for the core business) (McCabe, 2007). }\end{array}$ \\
\hline $\begin{array}{l}\text { Functional stability of } \\
\text { applications }\end{array}$ & $\begin{array}{l}\text { Functional stability is defined as the number of functional } \\
\text { alterations within the current applications in the business } \\
\text { (Van Faassen, 2010; McCabe, 2007). }\end{array}$ \\
\hline $\begin{array}{l}\text { Technical stability of } \\
\text { applications }\end{array}$ & $\begin{array}{l}\text { Technical stability is defined as the percentage uptime, } \\
\text { determined by two factors: Reliability and Manageability. } \\
\text { Reliability is the frequency with which a network and/or its } \\
\text { components are expected or unexpectedly unavailable. } \\
\text { Manageability is the average time it takes from shutdown of } \\
\text { a system to complete workability after planned maintenance } \\
\text { or failure (McCabe, 2007). }\end{array}$ \\
\hline
\end{tabular}

To define the activities of BIM in the conceptual model, the BiSL Framework is used. This framework exists of three layers: the strategic layer, the managing layer and the operational layer (Van der Pols, Donatz and Van Outvorst, 2012). The strategic level is concerned with the long term plans for information systems and specifies how control over / governance of information will be organized in organizations. This is mainly the role of the business information manager and CIO (chief information officer). The managing level deals with profits, costs, planning, contracts with IT service providers and quality of information and quality of IS/IT services. Roles at this level are system owner, 
quality manager and budget holder. The operational level is concerned with (supporting) the daily use of information systems and the definition and implementation of changes in information systems. For the construction of the instrument the operational layer is most relevant, because the main body of the BIM activities take place in this layer (Van Outvorst and De Waal, 2015).

To measure information- and service quality several studies were conducted (cf. De Waal, Breman and Batenburg, 2012). A leading study in this area is the DeLone and McLean's (D\&M) model of IS success (DeLone and McLean, 2016). In this model, IS success is dependent of six interdependent constructs: (1) quality of information (e.g. completeness, ease of understanding, relevance); (2) system quality (e.g. usability, availability, reliability); (3) service quality (e.g. the empathy and responsiveness of the IT department); (4) use (intended or actual); (5) user satisfaction; and (6) net benefits. The authors assume that the quality constructs will directly affect IS/IT use and user satisfaction. For the purpose of this study (and the construction of the instrument) it is not possible to measure the quality construct directly in organizations. Therefore, in the instrument the information- and service quality is measured indirectly by asking the perceived value.

\subsection{Data collection}

To test the instrument, a survey was conducted. The aim was to collect data on the selected factors and the current capacity of BIM employees. The survey was conducted using a web-based tool that held 22 questions. An invitation with a link to the tool was sent to the corporate mail address of IT professionals in the Netherlands. They were approached through an IT branch network, a network of IT master students and a network of an IT service provider. Roughly 500 people were approached. Only the invitations that were sent through the network of the IT service provider were adressed to specific persons. After a week a reminder was sent. The data was collected in December 2017 - January 2018. Unfortunately, only nine organizations responded. These organizations were active in the field of consultancy, culture and sport, public services and education.

Questions in the survey were on name and industry of organization and present number of BIM workers (in FTe), numbers of users (daily and incidental) and stakeholders, budget for IT projects, number of people involved with IT projects, risks, impact, priorities, duration, dependencies and number of IT projects, number of processes (divided into categories mission critical, business critical and nice to have), number of functional and technical changes and period of down time of information systems over a certain period, appraisal of the quality of information systems and the desired appraisal.

\section{$4 \quad$ Results}

In this section the results of the survey will be discussed, despite the low response rate. In Figure 2 the present BIM capacity is compared to the complexity of IT projects. The complexity is calculated by multiplying the value of project size with the number of 
F. Van Outvorst, M. Meijnen, P. Timens, S. Walenbergh, B. De Waal: Determining the Required Capacity of Business Information Management: Towards a Concise Instrument

projects. The value of project size was composed from the scores on costs, risks impact, strategic priority, duration and dependency. When these two factors are compared to each other, we see that whenever the project size becomes higher, the capacity of BIM slowly rises.

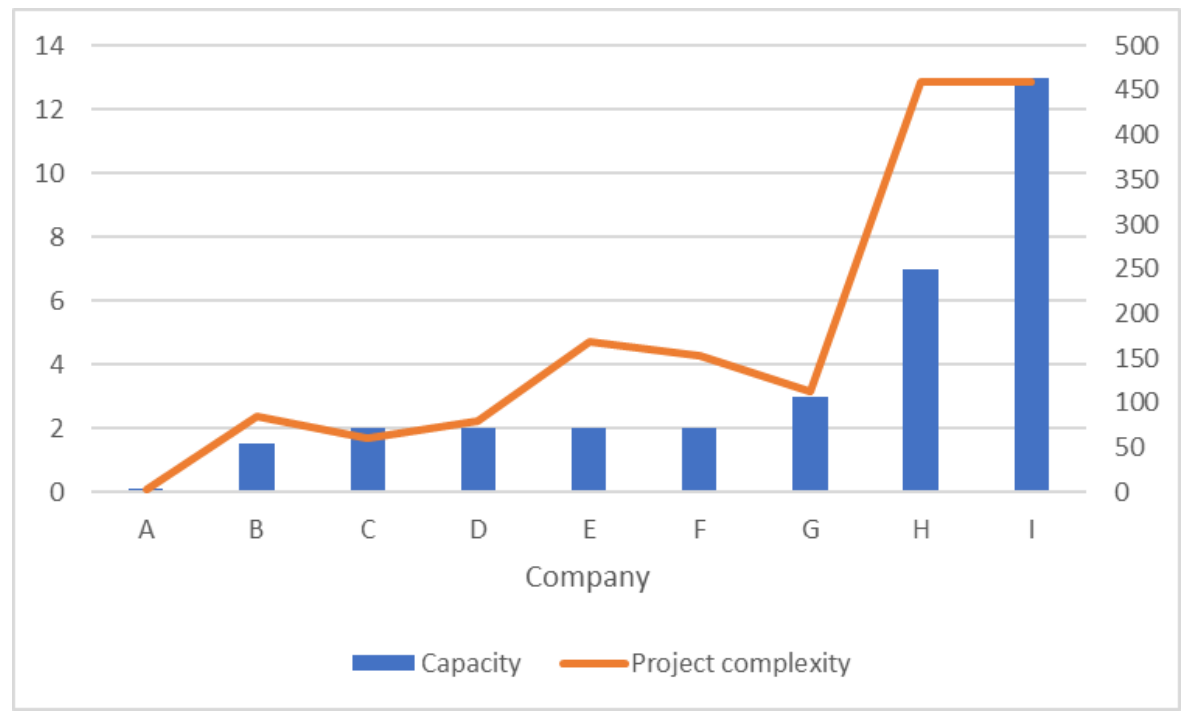

Figure 2: BIM capacity and Project complexity

In Figure 3 the data of the number of the different applications and the BIM capacity is shown.

As can be seen, almost all organizations distinguish between different types of application. In organization I the number of applications is low, compared to the BIM capacity. On the other hand, in organization B the number of applications is high compared to the BIM capacity. However, the applications in this organization are mainly 'nice to have'. Overall 
F. Van Outvorst, M. Meijnen, P. Timens, S. Walenbergh, B. De Waal: Determining the Required

Capacity of Business Information Management: Towards a Concise Instrument

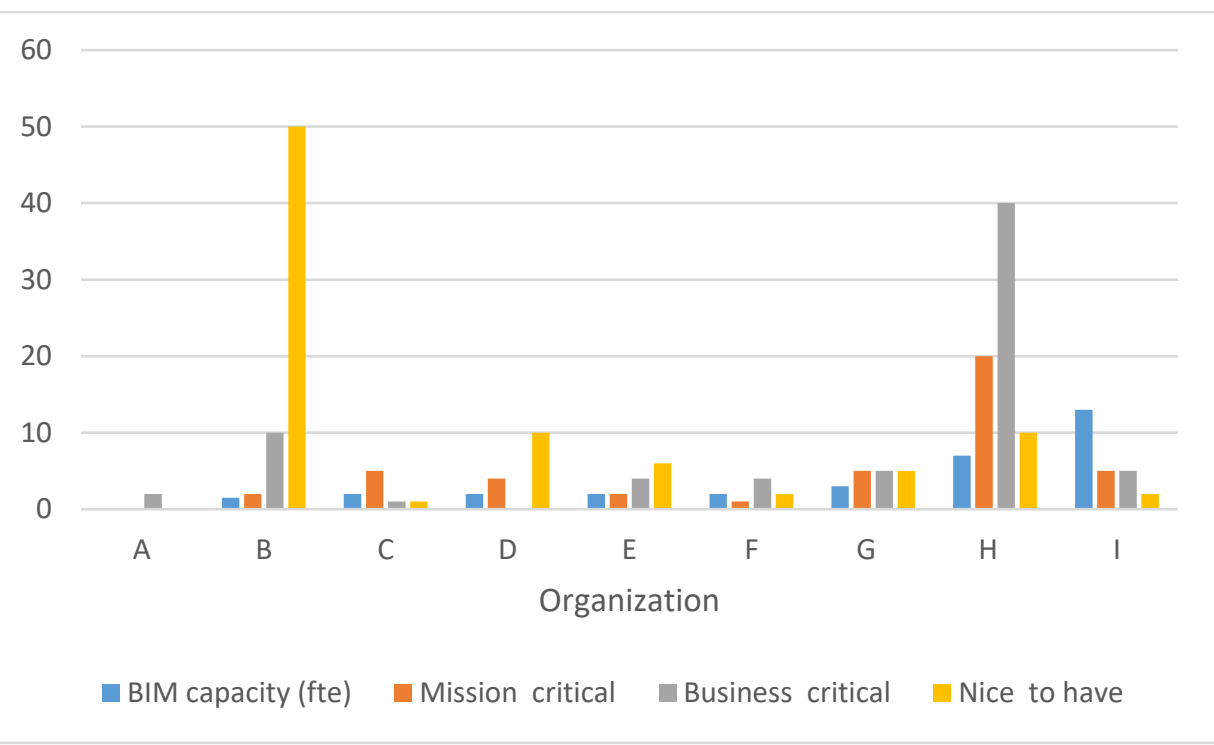

Figure 16: BIM capacity and Applications

The data on the other factors were too diverse to compare and therefore offer no possibility for further analysis.

\section{$5 \quad$ Conclusion and Discussion}

In this study an instrument is demonstrated to determine the required capacity of the operational activities of BIM in an organizations. From earlier work we took the idea of a 20 factor 3 dimensional model and had this model assessed by three experts. This assessment revealed that not all 20 factors might be equally relevant. Furthermore this assessment showed that not on all factors accurate data would be available. Based on the expert review, eight relevant factors were selected.

To define and operationalize these factors a literature study was conducted. This resulted in a preliminary instrument that was tested by several organisations. Although only nine organisations responded, some conclusions can be drawn.

One of the most important findings of the survey responses was that a relation between project complexity and BIM capacity is visible. The higher the overall score of project complexity, the more Business Information Administrators are active in a company. A second finding of this study was that there was some relation between BIM capacity and the number and type of applications. The study shows some evidence that 'nice to have' applications need little BIM capacity. 
Although the response was low, this is not an indication that there is no interest in a predictive model for the capacity of BIM. On the contrary it was quite easy to get cooperation from the platform organizations through which the survey was launched and from professionals for the expert reviews. We learned the obvious lesson that careful planning and design of research is necessary in order to get reliable data.

Even in the case of a low response the suggestion of certain relations between factors and BIM capacity comes forward. From these results we can conclude that the instrument has potential to determine the required capacity of the operational activities of BIM. Further validation and development of this model seems appropriate. In the further development of the instrument at least the factor of quality of information and service needs to be addressed. Minimal attention was paid to this factor in the survey as described in this paper. Further research and operationalization of this factor is needed.

All in all further research is needed. This research needs to be accompanied by sponsorship of more organizations in order to gather the relevant data.

\section{References}

Bon, J. van. (2011). ITIL Pocketguide. In J. v. Bon, ITIL® 2011 Editie - POCKETGUIDE (p. 36). Amersfoort: van Haren.

Booth, M.E. and Philips, G. (2005). Information systems management: Role of planning, alignment and leadership. Behaviour \& Information Technology, 24(5), 391-404.

Camunda. (2015). Camunda BPM Manual. Retrieved Camunda: https://docs.camunda.org/ manual/7.4/reference/bpmn20/subprocesses/embedded-subprocess/

Clarke, B. (2002). Best Practices for Application Management. TSO.

Fjodor van Faassen, A. S.-B. (2010). BiSL meetbaar gemaakt. ASL BiSL Foundation. Nederland.

DeLone, W.H. and E. R. McLean E.R. (2016). Information Systems Success Measurement. Foundations and Trends R in Information Systems, 2(1), 1-116.

De Waal, B.M.E., Breman, P. and Batenburg R. (2012). Do employees accept the information systems that management buys? A BPM implementation case study. In Proceedings of the $8^{\text {th }}$ European Conference on Management, Leadership and Governance ECMLG 2012, 8-9 November, Pafos, Cyprus.

Markus, M.L. and Loebbecke, C. (2013). Commoditized digital processes and business community platforms: New opportunities and challenges for digital business strategies. MIS Quarterly, 37(2), 649-653.

McCabe, J. D. (2007). Network Analysis, Architecture, and Design. Burlington: Elsevier Inc.

McGrath, S. K., \& Whitty, S. J. (2015). Stakeholder Defined. Retrieved usq.edu.au: https://eprints.usq.edu.au/33158/1/Mcgrath_Whitty_AV.pdf

Oliver Kopp, H. E. (2010). The Subprocess Spectrum. Stuttgart: Institute of Architecture of Application Systems, University of Stuttgart, Germany.

Van der Pols, R., Donatz, R., and Van Outvorst, F. (2012). BiSL ${ }^{\circledR}$ - Een Framework voor business informatie-management - 2de herziene druk. Van Haren Publishing, Zaltbommel.

Patton, M.Q. (2002). Qualitative research and evaluation methods. Sage Publications, Thousand Oaks.

Pult, S. A. (2013). Evaluating the interdependencies between managing business change, IT sourcing and IT Governance. In Proceedings of the International Conference on Management, Leadership and Governance (pp. 387-395). Bangkok, Thailand. 
F. Van Outvorst, M. Meijnen, P. Timens, S. Walenbergh, B. De Waal: Determining the Required

Capacity of Business Information Management: Towards a Concise Instrument

Rikowski, R. (2015). Project Management for Information Professionals. Chandos Publishing.

Van der Pols, R. (2009). Business informatiemanagement en BiSL in de praktijk. Van Haren Publishing, Zaltbommel.

Van Outvorst, F., De Vries, E. and De Waal, B.M.E. (2016). Sourcing of Business Information Management. In D. Vasilenko and N. Khazieva (Eds.) Proceedings of the 4th International Conference on Management ICMLG 2016, 14-15 April, St. Petersburg, Russia, 361-369.

Van Outvorst, F. and De Waal, B.M.E, (2015). The profession of Business Information Management. In Proceedings of the $11^{\text {th }}$ European Conference on Management, Leadership and Governance ECMLG 2015, 12-13 November, Lisbon, Portugal.

Zijlstra, W. (2011). Functioneel Beheer van ICT-gebruik en gebruikers. Retrieved from zbc.nl: https://zbc.nu/ict/functioneel-beheer-bisl/functioneel-beheer-van-ict-gebruik-en-gebruikers 


\title{
Business Model Innovation in European SMEs - Descriptive analysis of quantitative survey and case survey data
}

\section{MARIKKA HEIKKILÄ \& HARRY BOUWMAN}

\begin{abstract}
In this paper we analyse Business Model Innovation (BMI) in European micro, small and medium sized enterprises (SME). We present descriptive findings from our quantitative survey and qualitative case survey on how SMEs are innovating their Business Models. Our survey indicates that $37 \%$ of European SMEs innovate their Business Model. We found some differences in BMI depending on the age and industry sectors. We also describe the changes the SMEs make in differing Business Model components when they are improving their Business Model.
\end{abstract}

Keywords: • Business Model Innovation • SME • industry sector • age • $\mathrm{BM}$ components •

CORRESPONDENCE ADDRESS: Marikka Heikkilä, Ph.D., Senior research fellow, University of Turku, School of Economics, Finland, e-mail: marikka.heikkila@utu.fi Harry Bouwman, Ph.D., prof, Åbo Akademi University, Finland \& Delft University of Technology, the Netherlands, e-mail: W.A.G.A.Bouwman@tudelft.nl 
Research on Business Models (BMs) really made a breakthrough with the emergence of Information Technology and the broad acceptance of the Internet. Since then different academic disciplines like strategic management, innovation management and Information Systems have adopted the BM concept as an important object to study (Bouwman et al., 2012). The early days of BM research is characterized by studies searching for a clear, broadly accepted common definition of $\mathrm{BM}$; by development of typologies and ontologies, all with their own BM components; and design projects with a focus on how to design a BM. Until today there are still debates on the demarcation of BM versus strategy, on the relation of a BM with a business architecture or enterprise architecture, or on what a BM design implies (DaSilva \& Trkman, 2014). One issue nowadays agreed upon is the definition of a BM: BM is defined as the logic to creation, capturing and delivering value for customers and business.

By mid 2010, BMs were already seen by the academics as an approach to the abstract representation of a company's business (Al-Debei et al., 2008). Wirtz et al. (2016) analysis of BM literature from the period of 1965-2013 shows that the previous heterogeneous understanding of authors from various scientific disciplines was gradually uniting into a converging BM understanding - the BM concept was comprehensively defined in the literature, as well as the components of a BM were identified. Wirtz et al. (2016) concluded that the main future research areas are design, innovation and change of BMs.

Research on BM Innovation (BMI) has emerged and quickly evolved during the last years. BMI is described as an activity or process in which core elements of a firm and its business logic are deliberately altered (Bonakdar, 2015; Bucherer et al., 2012; Hartmann et al., 2013; Lindgardt et al., 2009; Pohle and Chapman; 2006). Empirical research mainly focused on cases, and then mainly discussing large corporations or well-known start-ups. The number of studies based on samples of companies are limited. The latter studies are often focused on theory testing and basic descriptive understanding on BM Innovation, especially in SMEs, is often lacking.

The research question in this paper is to study the extent to which BM Innovation is actually an issue for micro, small and medium -sized companies (SMEs), in which industries and what kind of SMEs BM Innovation is a relevant phenomenon (size, ownership, etc.). Therefore, we provide basic descriptive data on quantitative and qualitative research as executed over the last three years among SMEs within Europe.

The paper is structured as follows: section 2 is a literature review, section 3 is about our Research Methodology for collecting the data. This is followed with result section where we provide descriptive results based on data. Finally discussion and conclusions ends the paper. 
$31^{\text {ST }}$ Bled eConference: Digital Transformation: MeEting the Challenges

\section{$2 \quad$ Literature review}

Even though SMEs are the driving force behind the economy and de facto employ the most people (EASME, 2015), few studies have thus far focused specifically on innovation of BM at SMEs. Scopus search for SME and "Business Model Innovation" results in only 16 articles: Guo et al. (2017) survey on Chinese SMEs shows that BMI serves as a key construct through which SMEs can take advantage from the business opportunities they have recognized and improve their performance. Still, it is still relatively unclear how SMEs actually innovate their BMs (Barjak et al., 2014; Foss and Saebi, 2017). In general, BMI is seen to be derived from the strategic activities of a SME (Cortimiglia et al., 2016), and managers are expected to maintain consistency between their strategic goals and the core components of the BM (Demil and Lecocq, 2010). Arbussa et al. (2017) show that strategic sensitivity is less natural and therefore more critical to SMEs, while resourcefulness enables SMEs to overcome limitations of size. An empirical study by Cortimiglia et al. (2016) involving small, medium-sized and large firms found that when $\mathrm{BMI}$ is used alongside a formal strategic approach, most companies tend to focus first on the design or improvement of their key activities and resources (i.e. the value creation dimension of BM), after which they innovate the other BM components. However, previous studies indicate that most SMEs do not have a formal strategy process, do not implement a structured process when engaged in a BMI process (Lindgren, 2012), and typically experience BMI as a highly emergent and often unintended process (Laudien and Daxböck, 2017). A multicase study involving SMEs innovating their BMs (Heikkilä et al., 2018) evidence that strategic goals (start new business, seek growth or seek profitability) lead SMEs to alternative innovation path in terms of BM components affected: Growth seekers start from the right-hand side of a BM Canvas, while profitability seekers start from the back end, the left side of a Canvas; and new businesses adopt a cyclical approach considering BM components in turn, while at the same time redesigning and testing the $\mathrm{BM}$.

There are some studies on SMEs in specific geographical or industry sectors: Survey results by Anwar (2018) on manufacturing SMEs operating in Pakistan indicates that BMI has a significant positive impact on competitive advantage and performance. A multicase study in the Dutch food and beverage industry shows that SMEs wishing to develop a BM for sustainability must make sustainability the key principle upon which the SME is founded (Long et al., 2018). A sample of 68 German SMEs from three industries (automotive suppliers, mechanical and plant engineering, as well as electrical engineering and ICT) show that internal motivation and external pressure towards implementation has an impact on which BM elements are innovated (Müller et al., 2018). An in-depth qualitative study on four plastic-producing SMEs analyses application of social media in B-to-B (Brink, 2017), study on four Slovenian SMEs, coming from different sectors, show very limited usage of ICT for BMI, except in SME from ICT industry. In addition, observations have confirmed that there is little or no awareness in SMEs on how to systematically approach BMI (Marolt et al, 2016; Pucihar et al., 2016). Lastly, a survey on European food industry shows that medium sized firms engaged in collaboration with 
competitors and suppliers are more likely to innovate their BM compared to micro and small firms (Minarelli et al., 2014).

From the above literature analysis, we can conclude that at least some SMEs are engaged in BMI. But we are still missing the big picture - therefore in this paper we want to find out how common is BMI within SMEs? are there any differences between e.g. industry sectors? And which BM components do SMEs change?

\section{Research Methodology}

We used a mixed method approach, by focusing on large scale survey data as well as multiple case studies. Although both approaches have different epistemological roots, i.e. theory development and theory testing, in this paper we take a pragmatic and descriptive approach. We first discuss the quantitative data collection, and then the qualitative case study survey. All data was collected in 2015-2018.

\subsection{Quantitative research}

To collect statistically representative data we made use of a longitudinal research design to collect data on European SMEs. We will discuss the questionnaire, the sample approach, and the way we selected the companies which we considered being engaged in BM Innovation.

The questionnaire contains several concepts related to BM and BMI. The questionnaire starts with a generic selection question, asking if the SME under study has changed its BM in the last 24 months. Next, four specific selection questions were posed giving examples of BMI related to (a) value proposition and market; (b) ecosystem; (c) information technology, that is related to BMI, such as use of social media and/or big data; and (d) pricing and related financial issues. These questions were included to make sure SMEs were actually involved in BMI (Langerak et al., 2004; Lee and O'Connor, 2003). Next, the key respondent from each SME had to prove that he/she was knowledgeable about BMI practices in their company (Atuahene-Gima, 2005).

The questionnaire was iterated and pretested. The questionnaire was developed in English and then translated into 11 languages. In order to detect potential problems (e.g., ambiguous expressions) and cultural issues, back-translation of the questionnaire into English was done to prevent any bias. Minor changes were made between the years in which data was collected, in 2016, 2017 and 2018. A final check on translations and consistency was done by the research agency that collected the data using native speakers and computer-assisted telephone inquiry. The countries included in this research are spread over Europe and contain, for all European regions (North, West, Central, South, and East), a large country with a large number of SMEs and a small country were selected. Quota for micro, small, and medium enterprises was established as $33 \%,-33 \%$, and $-33 \%$, respectively. There is no quota defined for industry sectors. Agriculture, public administration, and nonmarket activities in households are excluded. Companies were 


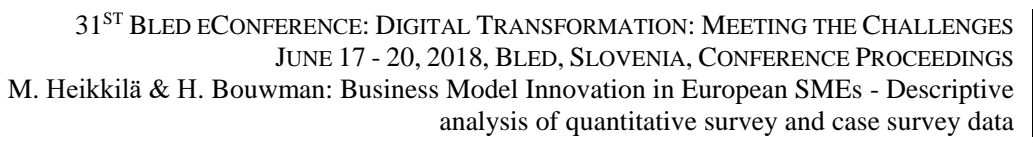

547

randomly selected from the Dun and Bradstreet database and key respondents (owner or BMI manager) were interviewed. Normal non-response rates were achieved.

The research agency also took into account the incidence rate that provides the hit rate, that is, the number companies that responded to the four selection questions discussed above, before continuing the survey with those SME that were classified as doing BMI. Results obtained showed similarity patterns between countries. As a further test, respondents' suitability (Atuahene-Gima, 2005) to answer the questionnaire and their degree of knowledge $(1=$ very limited knowledge, $7=$ very substantial knowledge $)$ regarding the product/service on offer, business process, and new product/service development was assessed, which indicates adequate knowledge levels.

\subsection{Qualitative research}

We also conducted 123 qualitative SME case studies. To study BMI in SMEs, we defined the following case selection criteria:

- SME which is/has been innovating its BM. Sometimes this innovation is very explicit, sometimes there are minor changes in the BM.

- SIZE: Micro enterprise, Small or Medium-Sized Enterprise (using definition by EU, 2003/361/EC).

- LOCATION: Representation of geographical regions, i.e. North, East, West, South and Central Europe.

- FAMILY: family businesses from each region and firm size.

- FEMALE: some SMEs with females in crucial managerial positions fom each region and firm size.

For qualitative study we first wrote a case study protocol, which was used by all researchers of the project. The protocol contains instructions for interviews, a fixed case report format and guidelines for the use of triangulation techniques, both in data collection and data analyses. In qualitative research the data informants were primarily the owners, core managers or people responsible for BM Innovation or business development. The interviews lasted on average lasted about an hour. Following standard procedures in case study research, we further triangulated our primary data source with secondary documents and website information to cross -validate factual information about the cases. The reliability of our data analysis was improved by involving all the original researchers in reviewing our analysis and by researchers who had not been engaged in the specific case. The case reports were also send to the case organizations for validation and for informed consent. The data, around 600 documents (interview recordings, transcripts, the case reports, etc.), are stored in a structured and secure database.

In this report, we analyse the qualitative case data using Case survey approach. Case survey provides a quantitative overview of the set of cases based on simple quantifications (Larsson, 1993). Case surveys combine advantages of survey research and qualitative case studies, as they enable quantitative analyses, while at the same time capitalizing on the richness of case material (Larsson 1993). Yin and Heald (1975) argue that case 
surveys are particularly suited when there is a heterogeneous collection of case studies and researchers are interested in their common characteristics. It should be noted that, in a case survey, the aim is not to generalize in a statistical sense, but to show the width of the phenomenon as illustrated by the diversity of the cases.

\section{$4 \quad$ Results}

First, we discuss some generic findings for the quantitative research and next we present some data on the case survey, before we discuss some generic findings based on both.

\subsection{Quantitative data}

The most important insight we gained is related to the salience of BM Innovation for SMEs. Based on spontaneous responses of the respondents 38\% (2016), $36 \%$ (2017) and $37 \%$ (2018) of SMEs are innovating their BM. If we use the selection questions we see that the respondents answer as follows.

Table 1: Selection questions and number of companies that indicate that they are actively involved in BMI

\begin{tabular}{|c|c|c|c|}
\hline & 2016 & 2017 & 2018 \\
\hline $\begin{array}{l}\text { S2. A company no longer wants to sell products but earn money by } \\
\text { renting them out, or make money by bundling the product with } \\
\text { services. Did your company make this type of change during the } \\
\text { last } 24 \text { months? }\end{array}$ & $24 \%$ & $20 \%$ & $16 \%$ \\
\hline $\begin{array}{l}\text { S2b. A company enters a new market or starts working with new } \\
\text { type of partners. Did your company make this change during the } \\
\text { last } 24 \text { months? }\end{array}$ & $69 \%$ & & \\
\hline $\begin{array}{l}\text { 2b1. Or a company offers a new product or service, or focuses on a } \\
\text { new group of customers. Did your company make this change } \\
\text { during the last } 24 \text { months? }\end{array}$ & & $65 \%$ & $62 \%$ \\
\hline $\begin{array}{l}\text { 2b2. Or a company starts working with new type of partners, } \\
\text { suppliers or advisors. Did your company make this change during } \\
\text { the last } 24 \text { months? }\end{array}$ & & $67 \%$ & $67 \%$ \\
\hline $\begin{array}{l}\text { S2c. Changing the pricing strategy, that goes beyond the regular } \\
\text { price adaptations. Did your company make this change during the } \\
\text { last } 24 \text { months? }\end{array}$ & $50 \%$ & $42 \%$ & $39 \%$ \\
\hline $\begin{array}{l}\text { S2d. Incorporation of IT for business purposes for example using } \\
\text { social media or big data IN SALES CHANNELS or IN } \\
\text { MARKETING. Did your company make this change during the last } \\
24 \text { months? }\end{array}$ & $58 \%$ & $58 \%$ & $65 \%$ \\
\hline
\end{tabular}


Based on this set of indicators we decided if the SME was going to be included in the dataset. For the three years we included the following numbers of SMEs in our final dataset that was analysed in more detail; in $2016 \mathrm{~N}=586$; in $2017 \mathrm{~N}=560$; and in 2018 $\mathrm{N}=451$. The lower number of observations for 2018 can be explained by the fact that we didn't include Sweden for 2018, seen serious problems with response rate in Sweden (see figure 2), the huge effort needed to collect the data, specifically in finding sufficient midsized companies.

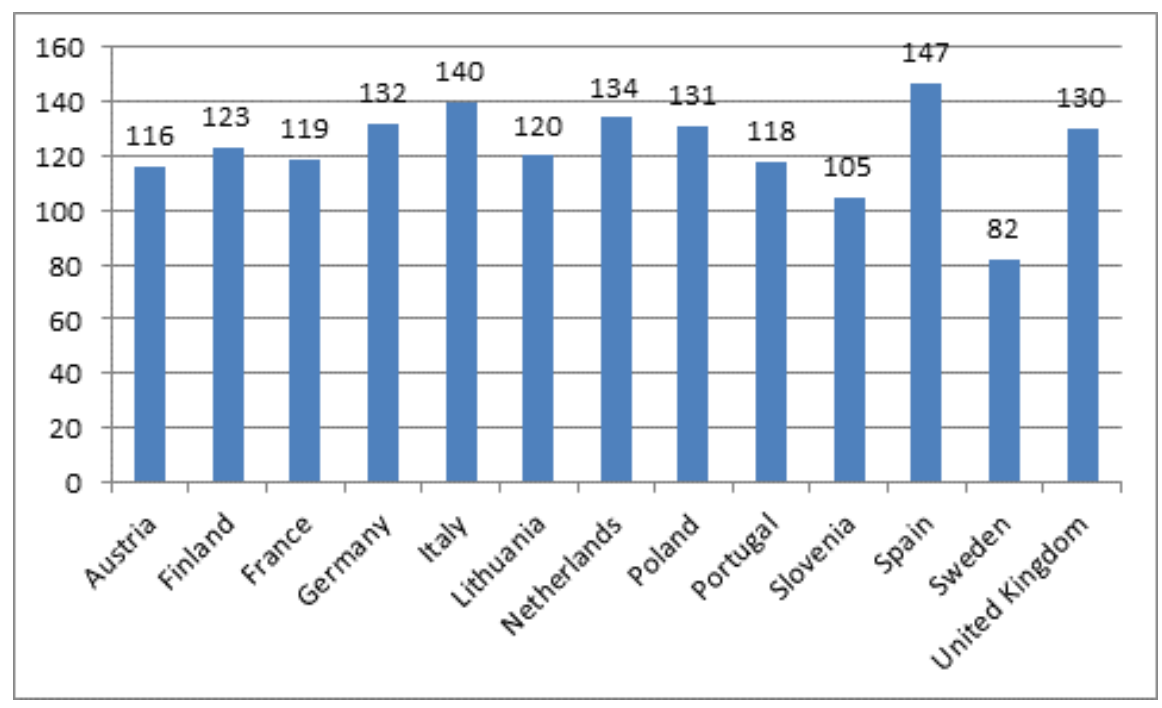

Figure 2: Number of companies per country of the three years

The oldest SME in our sample is established in 1700. On average the SME are established in 1984 , the median score is 1993 , while the most companies (modus) are established in 2003. Of the companies $15 \%$ are established in the last ten years, potential qualifying as a start-up as defined by the EU. Age distribution for survey data is provided in table 2 .

Table 2: Age distribution survey data

\begin{tabular}{lrc} 
& Frequency & Percent \\
\hline Before 1950 & 186 & 12 \\
$1951-1990$ & 484 & 31 \\
$1991-2000$ & 371 & 24 \\
$2001-2010$ & 390 & 25 \\
$>2010$ & 141 & 9 \\
\hline Total & & $\mathbf{1 0 0}$
\end{tabular}


Next to confirm the distribution per year per size as strived for, we see some deviations. Micro companies are a bit overrepresented, while mid-sized companies are slightly less than we wanted. Of the SMEs engaged in BMI $57 \%$ is a family business, $45 \%$ is manged by a family member, $51 \%$ of the SME is (co-)owned by females, however only $17 \%$ of the SME have a female CEO or core manager.

Table 3: SMEs that are involved in BMI per year

\begin{tabular}{lcccc}
\hline Size & $\mathbf{2 0 1 6}$ & $\mathbf{2 0 1 7}$ & $\mathbf{2 0 1 8}$ & $\mathbf{N}$ \\
\hline Micro: $0-10$ & 210 & 203 & 160 & 573 \\
& $(36 \%)$ & $(36 \%)$ & $(36 \%)$ & $(36 \%)$ \\
Small: $11-50$ & 194 & 182 & 155 & 531 \\
& $(33 \%)$ & $(33 \%)$ & $(34 \%)$ & $(33 \%)$ \\
Mid-size: $51-$ & 182 & 175 & 136 & 493 \\
249 & $(31 \%)$ & $(31 \%)$ & $(30 \%)$ & $(31 \%)$ \\
\hline & $\mathbf{5 8 6}$ & $\mathbf{5 6 0}$ & $\mathbf{4 5 1}$ & $\mathbf{1 5 9 7}$ \\
& $(\mathbf{1 0 0 \%})$ & $(\mathbf{1 0 0 \%})$ & $\mathbf{( 1 0 0 \% )}$ & $\mathbf{( 1 0 0 \% )}$ \\
\hline
\end{tabular}

With regard to distribution over industry sector we see that BM Innovation can be found in Other service activities, manufacturing, wholesale and retail and construction (see table 4).

Table 4: BMI as found per industry sector

Industry

Manufacturing

Electricity, gas, steam and air conditioning supply

Water supply; sewerage, waste \& recycling

Construction

Distributive trades

Transportation and storage

Accommodation and food services

Information and communication

Financial and insurance activities

Real estate activities

Professional, scientific and technical activities

Administrative and support service activities

Education

Human health and social work activities

Arts, entertainment and recreation

Other service activities

Total

\begin{tabular}{rr} 
Frequency & \multicolumn{1}{c}{$\%$} \\
\hline 249 & 15,6 \\
36 & 2,3 \\
17 & 1,1 \\
169 & 10,6 \\
231 & 14,5 \\
49 & 3,1 \\
116 & 7,3 \\
67 & 4,2 \\
54 & 3,4 \\
33 & 2,1 \\
45 & 2,8 \\
36 & 2,3 \\
65 & 4,1 \\
81 & 5,1 \\
38 & 2,4 \\
308 & 19,3 \\
$\mathbf{1 5 9 4}$ & $\mathbf{1 0 0 \%}$
\end{tabular}


Typical is that BM innovation is taking place in the service industries, followed by distributive trades (whole sale and retail). Strikingly most of the SMEs don't make use of a formal method. Only 19\% use a formal method, 7\% use Canvas, 3\% use Lean CANVAS, and $9 \%$ another method. SWOT is the most mentioned alternative method. Other BM specific tools, like roadmaps (De Reuver et al, 2013), stress- testing (Haaker et al, 2017) or other ontologies than CANVAS, like STOF, VISOR or others, are not mentioned.

The BM changes are related to all elements of a BM. Although changes in product or service definition are often leading, the increasing role of ICT is important (enables 90\%), as well as variable and fixed costs are affected $(87 \%, 89 \%)$, and do lead to changes in pricing mechanisms $(69 \%)$, new revenue streams $(81 \%)$ and profitability $(91 \%)$.

\section{business model canvas name Envisionreseach project}

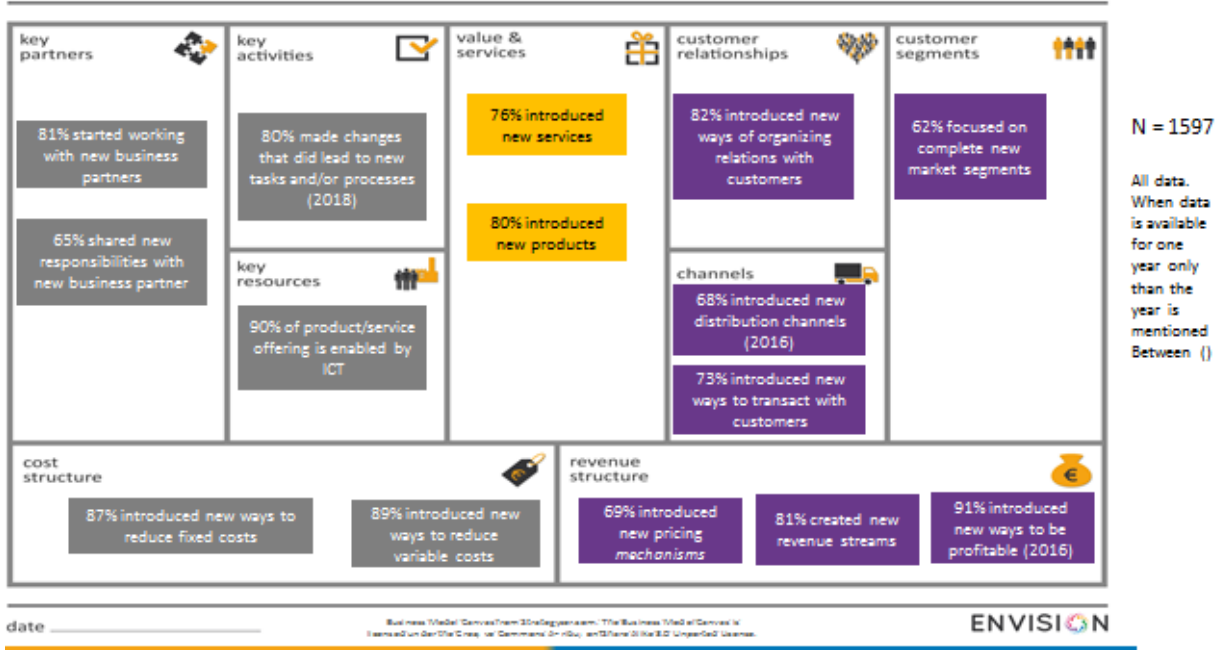

Figure 3: Components affected by BMI

In order to mirror these findings we will present the results of the case survey.

\subsection{Qualitative data}

In this section, we present an overview of the 123 case studies, based on a case survey approach (Larsson, 1993). 


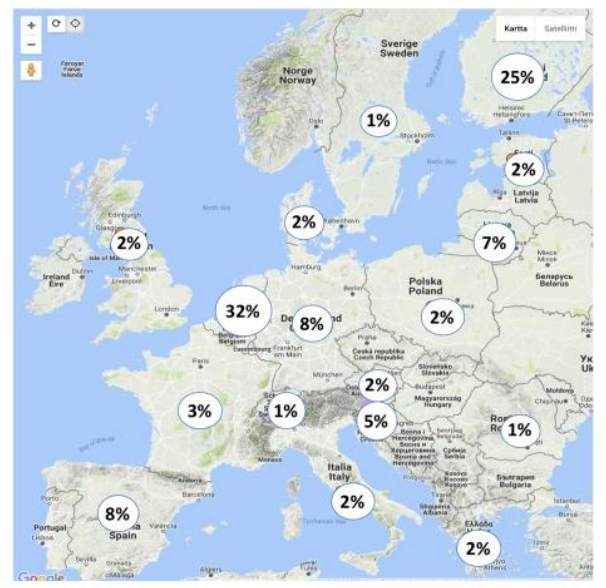

Figure 4: Geographical of spread of cases.

The case companies come from 17 European countries. From the map we see that the distribution over European regions is not even. The most cases are based in West Europe (35\%), next North (26\%), East (15\%), South (12\%) and Central Europe (12\%).

On average the companies are about 20 years old, but this can be attributed to some very old companies in the case sample. One SME is established in 1696, and other in 1887. Eight are established before 1950 (Table 5). However, the most companies in our case sample are established in 2010 or 2014 (modus), while the median score is 2009. Of the SME's in the case study sample $54 \%$ are younger than ten years. Ten years is considered to make the difference between a start-up, and scale-up. Although often additional criteria are used like growth rate and entrepreneurial culture. In three cases the research was on a start-up that in the end was not established or still in a very early conception phase, therefore the $\mathrm{N}=120$.

Table 5: Case companies' age distribution

\begin{tabular}{lcc} 
& Frequency & Percent \\
\hline Before 1950 & 9 & 8 \\
$1951-1990$ & 14 & 12 \\
$1991-2000$ & 14 & 12 \\
$2001-2010$ & 36 & 30 \\
$>2010$ & 47 & 39 \\
\hline Total & $\mathbf{1 2 0}$ & $\mathbf{1 0 0}$
\end{tabular}

Some case organizations (eight, 6\%) are active in agriculture or forestry (NACE2 A0103), mainly with a focus on horticulture or support of the agriculture companies. $15 \%$ of case SMEs are active in manufacturing (C 10-33), 11\% in retail and wholesale (G 45-47), five cases are from the transport sector, three from travel, and five from the hospitality 


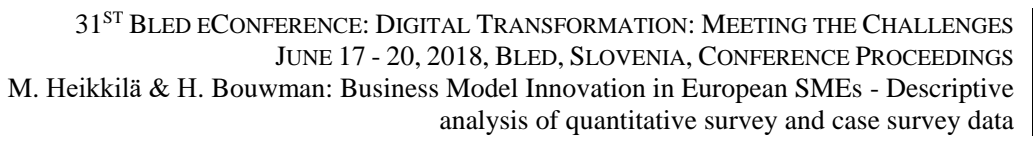

industry (together 11\%; H 49-53, I 55-56 \& N 77-82), 30\% of the cases are from the ICT domain (telecom and It, J63 58-), 12\% are active in the service industry (M 69-75), and 7 cases are related to education, social work or arts (5\%, P 85, Q 86-88 and R 90-93).

About $38 \%$ of the companies are micro-enterprises (less than 10 employees), 35\% are small and $26 \%$ are mid-sized. One firm is large, but we included this SME because it was a very fast-growing SME, also labelled as a gazelle, that received quite an impressive support from Venture Capitalist. Of the case SMEs 30\% were family businesses and in $43 \%$ women were either owner or involved in management.

The distribution over Europe is presented in table 6. Most family businesses in our sample are from the Southern parts of Europe, while female led enterprises can be found in Norther, Eastern and Southern Europe in our sample. Be aware that this is no way a random or other type of sample on basis of which generalisations can be made. We only sketch the back ground of the cases based on a selective approach as used to engage SMEs.

Table 6: Case companies' geographical distribution in Europe

\begin{tabular}{lllllllllll} 
& \multicolumn{2}{l}{ Micro } & \multicolumn{2}{l}{ Small } & \multicolumn{2}{c}{ Mid-sized } & \multicolumn{2}{l}{ Family } & \multicolumn{2}{l}{ Female } \\
\hline Central & 9 & $19 \%$ & 3 & $7 \%$ & 2 & $6 \%$ & 3 & $8 \%$ & 5 & $10 \%$ \\
East & 5 & $11 \%$ & 10 & $24 \%$ & 3 & $9 \%$ & 6 & $17 \%$ & 11 & $22 \%$ \\
North & 14 & $30 \%$ & 9 & $21 \%$ & 9 & $27 \%$ & 14 & $34 \%$ & 16 & $31 \%$ \\
South & 5 & $11 \%$ & 7 & $17 \%$ & 4 & $12 \%$ & 10 & $28 \%$ & 11 & $22 \%$ \\
West & 14 & $29 \%$ & 13 & $31 \%$ & 15 & $46 \%$ & 3 & $8 \%$ & 8 & $16 \%$ \\
\hline Total & 47 & $100 \%$ & 42 & $100 \%$ & 32 & $100 \%$ & 36 & $100 \%$ & 51 & $100 \%$
\end{tabular}

The relation between region and family business in the sample is significant $\left(\mathrm{chi}^{2}=24\right.$, $467, \mathrm{df}=4, \mathrm{p}<.001$ ). Most family businesses as studied are from Southern Europe: 2 out of 3 is a family business. In Northern parts this is almost in balance (17 non-family versus 14 family businesses) while in other parts of Europe Family businesses are less prominent. Specifically, in the Western and central parts of Europe Family business are less present in our case selection.

Also, the relation between presence of women in management or as owner and region is significant for our sample $\left(\mathrm{chi}^{2}=17,186, \mathrm{df}=4, \mathrm{p}<.01\right)$. In East and South, the ratio is 2 out of 3 SMEs a woman is involved in ownership or management. In the North, the ratio is in balance, while in Central Europe the balance is 1 out of 2, and in West Europe it is 1 out of 3 . So be aware that this a select sample and no way representative for real data. The companies make use of BM ontologies to describe their BM (79\%), however a considerable share of SMEs discuss BM but don't have their BM formally described (to our knowledge). If an ontology is used then BM Canvas is by far the most popular (56\%), followed by the STOF approach (28\%), VISOR (10\%) and CSOFT (6\%). The intervention of the researchers may play a role. Based on our experience we have the 
impression that if a BM was already analysed by SMEs themselves then this is the case for start-ups and SMEs where stakeholders are higher educated. In almost all cases this was done by making use of BM Canvas. In five cases, multiple ontologies were used for instance combining BM Canvas with STOF, or VISOR with STOF.

The objective of the SMEs is to become profitable, create growth, or to start a new business. Every case SME has its almost unique formulation what they want to achieve. Seldom, this is formulated in short direct statements. Examples are for instance

- "Design BM for my new invention"

- "Create metrics for my BM" and

- "Enter to the UK market"

But there are also very detailed descriptions, like

- "I want to shift from free service to paid services (commission from each sale is charged). The strategic objective is to become a world leader (be the first of the world) and to be a leading company in each country. The company has chosen the principle of "divide and rule" and has been developing its activities in Europe and the USA first. The further development of the principle will depend on marketing research that is performed in a given area before entering a new market. The company's target is to grow continentally". Or

- "To diversify customer portfolio in order to mitigate risk of losing one or a few key customers (government entities). Improve operations through real and meaningful integration of units and operations (culture, procedure, flow of subject matter experts between projects, i.e. improved project and program management)."

In the analytical cases stress-testing as a tool was used by 29 SMEs, metrics in 18 cases, VIP by 16 SMEs and roadmaps by 14 . When we focus on combinations of ontologies with tools, the cases reveal that BM Canvas is combined with a broad range of tools like stress-test (12 times), roadmap ( 2 times), BM Canvas with metrics (10 times), and other tools like partner analysis, viability radar, roadmap, SWOT and VIP. CSOFT is almost always combined with metrics, as this is also one of the core foci of the CSOFT ontology. STOF is also quite often ( 8 times) combined with stress test and roadmaps.

Table 7 shows the cases categorized according to the SMEs' strategic goals (start new business, growth and profitability). of the studied SMEs, 35 (30\%) aimed primarily at improving profitability, while growth was the strategic target in 46 cases (37\%), and 41 SMEs (34\%) considered themselves as starting up a new business. One of the case SMEs was excluded, because it did not want to change at all. The table shows that most Southern European SMEs want to improve profitability, while many Northern European SMEs are interested in starting new businesses. Family businesses and companies with females in crucial managerial positions are less interested in starting new businesses.

Businesses usually start small - in our case selection, they are either micro-sized or small companies - while the other two strategy groups, profitability and growth, consist of 
M. Heikkilä \& H. Bouwman: Business Model Innovation in European SMEs - Descriptive analysis of quantitative survey and case survey data

micro-sized, small and medium -sized companies in equal shares. As expected, the profitability-seekers are on average the oldest group, while the youngest group consists of those who are starting a new business. This would appear to be in line with literature relating firm maturity to strategic goals. 
M. Heikkilä \& H. Bouwman: Business Model Innovation in European SMEs - Descriptive analysis of quantitative survey and case survey data

Table 7: Strategic objectives that drive BMI of SMEs

\begin{tabular}{|c|c|c|c|c|c|}
\hline $\begin{array}{l}\text { Descriptive } \\
\text { data }\end{array}$ & & $\begin{array}{l}\text { I want } \\
\text { to start } \\
\text { new } \\
\text { business }\end{array}$ & $\begin{array}{l}\text { I want } \\
\text { to grow }\end{array}$ & $\begin{array}{l}\text { I want to } \\
\text { be more } \\
\text { profitable }\end{array}$ & Total \\
\hline \multirow{5}{*}{$\begin{array}{l}\text { Geographical } \\
\text { Location in } \\
\text { Europe }\end{array}$} & South & 3 & 4 & 8 & 15 \\
\hline & West & 16 & 18 & 10 & 44 \\
\hline & North & 13 & 12 & 6 & 31 \\
\hline & East & 3 & 8 & 7 & 18 \\
\hline & Central & 6 & 4 & 4 & 14 \\
\hline \multirow[t]{3}{*}{ SME size } & Micro < 10 employees & 27 & 10 & 9 & 46 \\
\hline & Small <50 employees & 11 & 18 & 12 & 41 \\
\hline & Medium <250 employees & 3 & 19 & 14 & 35 \\
\hline \multirow[t]{13}{*}{ Industry } & $\begin{array}{l}\text { Agriculture, fishing, } \\
\text { forestry and mining }\end{array}$ & 3 & 4 & 2 & 9 \\
\hline & Manufacturing & 4 & 8 & 7 & 19 \\
\hline & $\begin{array}{l}\text { Electricity \& } \\
\text { Construction }\end{array}$ & 1 & 0 & 1 & 2 \\
\hline & Trade & 2 & 6 & 5 & 13 \\
\hline & Transport & 1 & 2 & 2 & 5 \\
\hline & Accommodation, food & 0 & 2 & 3 & 5 \\
\hline & $\begin{array}{l}\text { Information and } \\
\text { communication }\end{array}$ & 19 & 15 & 8 & 42 \\
\hline & $\begin{array}{l}\text { Professional, scientific } \\
\text { and technical activities }\end{array}$ & 3 & 6 & 5 & 14 \\
\hline & $\begin{array}{l}\text { Administrative and } \\
\text { support service activities }\end{array}$ & 2 & 0 & 2 & 4 \\
\hline & Education & 0 & 1 & 0 & 1 \\
\hline & $\begin{array}{l}\text { Human health and social } \\
\text { work activities }\end{array}$ & 5 & 0 & 0 & 5 \\
\hline & $\begin{array}{l}\text { Arts, entertainment and } \\
\text { recreation }\end{array}$ & 0 & 2 & 0 & 2 \\
\hline & Other Services & 1 & 0 & 0 & 1 \\
\hline Family & Family SME & 5 & 15 & 16 & 36 \\
\hline Female & in mgmt. position & 11 & 21 & 17 & 49 \\
\hline \multirow[t]{2}{*}{ SME Age } & Mean & $\begin{array}{l}4,2 \\
\text { years }\end{array}$ & 22,4 & 19,6 & 32,3 \\
\hline & Std. Dev & 3,5 & 29,3 & 36,6 & 55 \\
\hline \multirow{2}{*}{\multicolumn{2}{|c|}{ Total }} & 41 & 46 & 35 & 122 \\
\hline & & $34 \%$ & $37 \%$ & $30 \%$ & $100 \%$ \\
\hline
\end{tabular}


To illustrate the differences in the BMI foci of the three strategic goal groups, Figure 5 lists which BM components the SMEs want to change. In average each SME mentioned 2,3 specific focuses they wanted to concentrate in their BM innovation. The Figure shows how many percent of SMEs in each group focuses on improving the specific BM components.

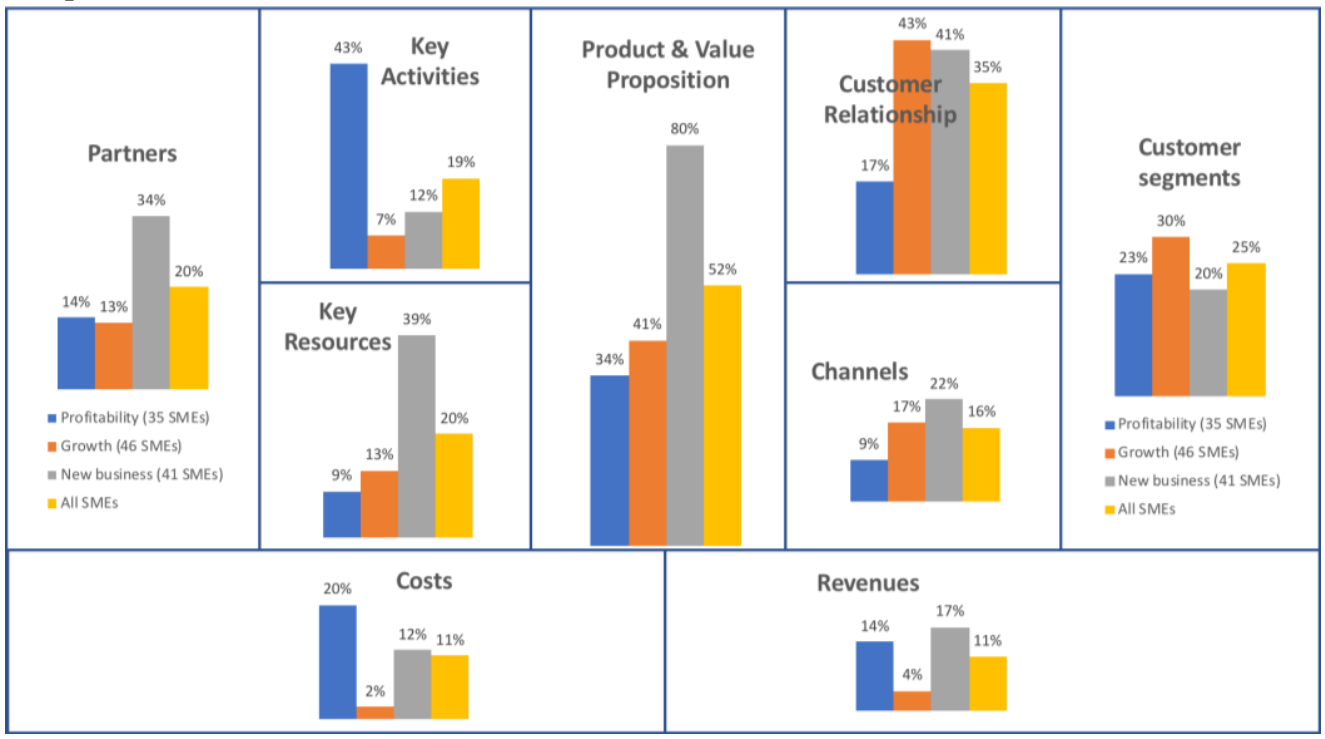

Figure 5: Centre of attention of BMI for the three SME groups

Looking at figure 5, we see that half of the SMEs want to improve their value proposition, followed by the customer relationship component. Surprisingly, the costs and revenues components come in last.

Moreover, the figure reveals clear differences between the groups. Profitability-seekers want to improve the excellence and efficiency of their key activities component. They typically also want to change their value proposition component. By contrast, Growthoriented companies focus their main BMI effort on providing better value to their customers. They focus on both customer relationships and value proposition. And last, most Business start-ups pay great attention to the value proposition, followed by customer relationship. It is also noteworthy that they often mentioned that they 'want to develop viable Business Model', indicating that they want to improve the BM as a whole, not just individual components.

\section{$5 \quad$ Discussion and Conclusions}

The objective of this paper was to present descriptive findings on BM Innovation based on (1) a survey data from a longitudinal study and (2) set of 123 cases of European SMEs, which are analysed in this paper using case survey method. This paper doesn't try to 
develop or test theory. We used cases for theory development in other papers (Heikkilä et al, 2018) or tested research models making use of advanced statistics (Bouwman et al, 2018). We felt that a more descriptive paper would put discussion on BM Innovation in perspective.

First, we find it important to emphasize that many SMEs engage in BM Innovation while not being aware that they do so; Our survey indicates that $37 \%$ of European SMEs are innovating their BM. Two thirds of them start working with new type of partners, suppliers or advisors. More than $60 \%$ of them offer a new product or service, or focuses on a new group of customers. We see also a rising percentage of SMEs incorporating IT for business purposes.

Second, contrary to general belief that only start-up companies and recently established SMEs engage in BMI, we found that also older SMEs are innovating their BMs. However, still $15 \%$ of SMEs involved in BMI are less than 10 years old.

Third, comparing our survey results to EU statistics on the number of SMEs in different industries (Eurostat, 2011), we find that the share of Manufacturing SMEs innovating their BM is considerable higher than expected. Further research is needed to uncover the reasons for this, but one potential explanation for this can be that the industry 4.0 and similar programmes are driving manufacturing SMEs to innovate their BM (see e.g. Müller et al., 2018). Other finding is the lack of BMI within professional and scientific services, which becomes evident from the quantitative survey. However, in our BMI case studies this industry is well represented, which suggest that also SMEs in this industry are actively innovating their BMI. Similarly, more research is needed about BMI within ICT sector. The quantitative survey indicates that ICT companies would rank rather well measured in percentage of SMEs doing BMI within the industry. In our case survey ICT companies were also over represented.

Fourth, BM Innovation affect almost all components of a BM. To what degree is not yet evident. According to the case survey, in average the SMEs are focusing in their changes on two BM components at the time. This suggests that they are changing the BM gradually, tackling the most urgent changes first. The focus differs depending on the strategic aim of the SME: Profitability seeking SMEs tend to put their BMI effort in streamlining their activities and they also pay, compared to other two SME groups, most attention to costs. Growth oriented SMEs emphasise the customer need by focusing on customer segments and relations. The new businesses mainly focus on value proposition and then designing the other BM components in a rather iterative and dynamic way.

This paper provides rather basic analysis of the research data. The collected data provides a lot of opportunities to do fine grained, more expanatory analyses combining quantitative and qualitative research. 


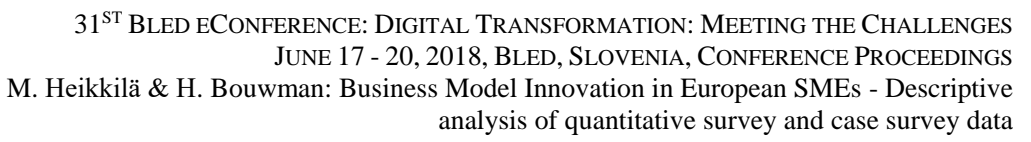

\section{Acknowledgments}

The work leading to these results has received funding from the European Community's Horizon 2020 Program (2014-2020) under grant agreement 645791. The content herein reflects only the authors' view. The European Commission is not responsible for any use that may be made of the information it contains.

\section{References}

Al-Debei, M.M., \& Avison, D. (2010). Developing a unified framework of the business model concept. European Journal of Information Systems. 19(3), 359.

Anwar, M. (2018). Business Model Innovation and SME Performance - Does competitive advantage mediate?. International Journal of Innovation Management. online ready.

Arbussa, A, Bikfalvi, A. \& Marquès, P. (2017). Strategic agility-driven business model renewal: the case of an SME. Management Decision. 55(2), pp. 271-293.

Atuahene-Gima, K. (2005). Resolving the capability-rigidity paradox in new product innovation. Journal of Marketing. 69(4), pp. 61-83.

Barjak F, Niedermann A, \& Perret P. (2014). The Need for Innovations in Business Models. Final Policy Brief (Deliverable 5) to the European Commission. DG Research \& Innovation.

Bonakdar, A. (2015). Business Model Innovation. PhD diss., University of St. Gallen.

Bouwman H., De Reuver M., Solaimani S., Daas D., Haaker T., Janssen W., Iske P. \& Walenkamp B. (2012). Business Models, Tooling and Research Agenda. In Clark R, Pucihar A, Gricar J (Eds) The first 25 years of the Bled Conference, Kraj: Moderna organizacija.

Bouwman, H., Nikou, S., Molina, F., \& M. de Reuver (2018). The Impact of Digitalization on Business Models. Journal of Digital Policy, Regulation and Governance. INFO, 20(2). pp.

Brink, T. (2017). B2B SME management of antecedents to the application of social media. Industrial Marketing Management. 64, pp. 57-65.

Bucherer, E., Eisert, U., \& Gassmann, O. (2012). Towards Systematic Business Model Innovation: Lessons from Product Innovation Management. Creativity and Innovation Management. 21(2), pp. 183-198.

Cortimiglia, M. N., Ghezzi, A., \& Frank, A. G. (2016). Business model innovation and strategy making nexus: evidence from a cross-industry mixed-methods study. R\&D Management. 46(3), pp. 414-432.

DaSilva C.M. \& Trkman, P.(2014). Business Model: What It Is and What It Is Not. Long Range Planning. 47(6), pp. 379-389.

Demil, B., \& Lecocq, X. (2010). Business model evolution: in search of dynamic consistency. Long range planning. 43(2), pp. 227-246.

De Reuver, M., H. Bouwman \& T. Haaker (2013). Business model roadmapping: A practical approach to come from an existing to a desired business model. International Journal of Innovation Management. 17(1), pp. 1-18.

EASME (2015). Horizon 2020's SME Instrument. Retrieved from http://ec.europa.eu/easme/en/horizons-2020-sme-instrument.

Eurostat (2011). Key figures on European business with a special feature on SMEs. Luxembourg: Publications Office of the European Union,

Foss, N. J., \& Saebi T., (2017). Fifteen Years of Research on Business Model Innovation: How Far Have We Come, and Where Should We Go?. Journal of Management. 43(1), pp. 200-227.

Guo, H., Tang, J., Su, Z., \& Katz, J.A. (2017). Opportunity recognition and SME performance: the mediating effect of business model innovation. R and D Management. 47(3), pp. 431-442

Haaker, T., Bouwman, H. Janssen, W. \& de Reuver, M. (2017). Business model stress testing: a practical approach to test the robustness of a business model, Futures. 89, pp. 14-25 
$31^{\text {ST }}$ Bled eConference: Digital Transformation: MeEting the Challenges JunE 17 - 20, 2018, BLED, SLOVENIA, CONFERENCE PROCEEDINGS M. Heikkilä \& H. Bouwman: Business Model Innovation in European SMEs - Descriptive analysis of quantitative survey and case survey data

Hartmann, M., Oriani, R., \& Bateman, H. (2013). The Performance Effect of Business Model Innovation: An Empirical Analysis of Pension Funds. In 35th DRUID Celebration Conference (pp. 17-19).

Heikkilä, M., Bouwman, H., \& Heikkilä, J. (2018). From strategic goals to business model innovation paths: an exploratory study. Journal of Small Business and Enterprise Development. 25(1), pp. 107-128.

Langerak, F., Hultink, E.J. \& Robben, H.S.J. (2004). The role of predevelopment activities in the relationship between market orientation and performance. R\&D Management. 34(3), pp. 295309.

Larsson, R. (1993). Case survey methodology: Quantitative analysis of patterns across case studies. Academy of Management Review. 39(6), pp. 1515-46.

Laudien, S. M., \& Daxböck, B. (2017). Business model innovation processes of average market players: A qualitative-empirical analysis. R\&D Management. 47(3),

Lee, Y. \& O'Connor, G.C. (2003). The impact of communication strategy on launching new products: the moderating role of product innovativeness. Journal of Product Innovation Management. 20(1), pp. 4-21

Lindgren, P. (2012). Business model innovation leadership: How do SME's strategically lead business model innovation?, International Journal of Business and Management, 7(14), 53.

Lindgardt, Z., Reeves, M., Stalk, G., \& Deimler, M. S. (2009). Business Model Innovation. When the Game Gets Tough, Change the Game. The Boston Consulting Group, Boston, MA.

Long, T.B., Looijen, A. \& Blok, V. (2018). Critical success factors for the transition to business models for sustainability in the food and beverage industry in the Netherlands. Journal of Cleaner Production. 175, pp. 82-95

Marolt, M., Lenart, G., Maletič, D., Borštnar, M.K. \& Pucihar, A. (2016). Business model innovation: Insights from a multiple case study of Slovenian SMEs. Organizacija. 49(3), pp. 161-17.

Miles, M.B., \& A. M. Huberman (1994). Qualitative Data Analysis. An expanded sourcebook. Thousand Oaks: Sage, 2nd edition.

Minarelli, F., Raggi, M., \& Viaggi, D. (2014). Innovation in European food SMEs: Determinants and links between types. Bio-based and Applied Economics, 4(1), pp. 33-53.

Müller, J.M., Buliga, O., \& Voigt, K.-I. (2018). Fortune favours the prepared: How SMEs approach business model innovations in Industry 4.0. Technological Forecasting and Social Change. in press.

Pohle, G., \& Chapman, M. (2006). IBM's global CEO report 2006: business model innovation matters. Strategy \& Leadership, 34(5), pp. 34-40.

Pucihar, A., Lenart, G., Marolt, M., Borštnar, M.K., \& Maletič, D. (2016). Role of ICT in business model innovation in SMEs - Case of Slovenia. IDIMT 2016, 24th Interdisciplinary Information Management Talks, pp. 231-241.

Strauss, A., \& J. Corbin (1998). Basics of Qualitative Research. Grounded Theory, Procedures and Techniques. Newbury Park: Sage.

Yin, R.K. \& Heald, K.A. (1975). Using the Case Survey Method to Analyze Policy Studies. Administrative Science Quarterly. 20(3), pp. 371-81

Wirtz, B.W., Pistoia, A., Ullrich, S. \& Göttel, V. (2016). Business Models: Origin, Development and Future Research Perspectives. Long Range Planning. 49(1), pp. 36-54. 


\title{
Means to Survive Disruption: Business Model Innovation and Strategic Continuity Management?
}

\author{
JukKa HeIKKILÄ, MARIKKA HEIKKILÄ, MARKo NIEMIMAA \& JONNA \\ JÄRVELÄINEN
}

\begin{abstract}
Advances in Information Technology provide opportunities for totally new business. However, we are facing not only growing number of new ventures, but increasing restructuring of existing businesses. This can be perceived e.g. in shortening life-cycles of the companies. The restructuration and birth of new companies means changing or even disrupting existing businesses. Therefore, companies, regardless of their maturity, should be prepared to evaluate these threats and opportunities actively.

Against this backdrop, we suggest to combine business modelling with systematic Business Continuity Management. We discuss the two approaches and their usefulness under different circumstances and illustrate their use when implementable, rapid reaction to changes is required, such as in industry restrucutration, or business merging and reorganization. We coin this combination as Strategic Busiess Continuity Management.
\end{abstract}

Keywords: - Business Model Innovation - Business Continuity Management • Disruptions $\bullet$ Growth • Disruption •

CORRESPONDENCE ADDRESS: Jukka Heikkilä, University of Turku, School of Economics, Finland, e-mail: jups@utu.fi; Marikka Heikkilä, University of Turku, School of Economics, Finland, email: marikka.heikkila@utu.fi; Marko Niemimaa, University of Jyväskylä, Department of Computer Science and Information Systems, Finland, e-mail:marko.i.niemimaa@jyu.fi; Jonna Järveläinen, University of Turku, School of Economics, Finland, e-mail: jonna.jarvelainen@utu.fi

DOI https://doi.org/10.18690/978-961-286-170-4.39

ISBN 978-961-286-170-4

(C) 2018 University of Maribor Press

Available at: http://press.um.si. 
We have recently witnessed numerous occasions where the technological progress has enabled new companies to innovate business models (BMs) that have severely threatened incumbents' business continuity (BC) (Eggers \& Park, 2017). These disruptions have established business models obsolete by shaking the industry boundaries. While the newcomers are bringing their business models to the markets, also the incumbents are under severe pressure to renew their own business models, or gradually fade into nonexistence. This means that business modelling is of importance not only for start-ups, which build their business model from scratch and adapting their model based on feedback from the markets, but also for more established companies facing needs to restructure their businesses, balancing with introduction of new business models and of securing the continuity of their existing revenue streams.

In this paper our main question is whether we could make companies more adaptive by business modelling, and especially, by BC management? We focus specifically on the continuity of business models due to their central role for companies' business strategies and for ensuring the continuity of revenue streams (e.g. Amit \& Zott, 2001; Bouwman, et al., 2008; Chesbrough \& Rosenbloom, 2002; Chesbrough, 2010). With BC Management we refer to a company's ability to withstand and restore from intra- and extraorganizational contingencies. And BM we define as the logic to creation, capturing and delivering value for customers and business (Teece 2010: 172).

We integrate these two separate streams of literature - BC management and BM - to conceptually elaborate an approach coined as Strategic Business Continuity Management (SBCM) consisting two parts: (1) value preservation, as suggested by BC; and (2) value creation, a distinction also considered relevant in BM-literature (Demil \& Lecoq, 2019), as suggested by BMI and Stress Testing.

This paper is structured as follows: we start with description of literature on company survival, Business models and Business continuity management. Then we present the SBCM approach and provide some illustrative cases. Discussion and Conclusions, and future research sections end this paper.

\section{Combining Business Continuity Management and Business Modelling for survival and performance}

In this chapter we first describe the statistics regarding survival of the companies and the drivers for the business model innovation. We continue with the literature on Business Continuity and thereafter Business Model and Business Model Innovation research. 


\subsection{Survival of the companies and drivers for changing the Business Model}

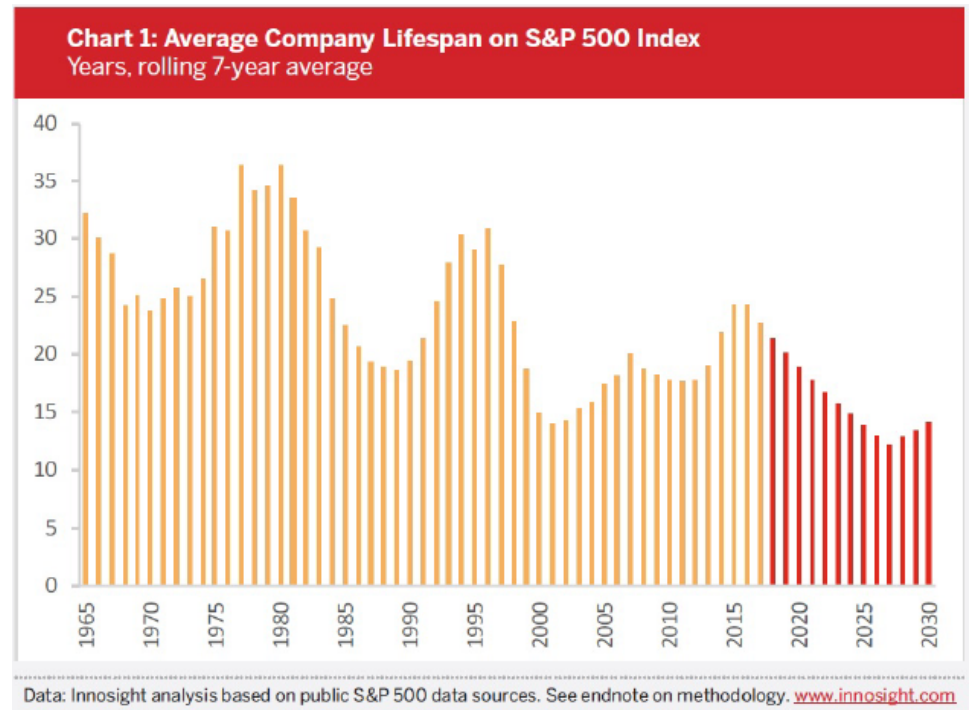

Figure 17 Shortening Corporate Lifespan (Anthony et al., 2018)

Increased use of Information and communication technology and big companies shortening life-span has happened simultaneously: The average lifespan of a company listed in the S\&P 500 index of leading US companies has decreased by more than 50 years in the last century, expected to go towards 15 years after 2020 (Figure 1). The majority of corporations is closer to the average of constant 10-years half-life (half-time means that $50 \%$ of companies are discontinued during their first ten years), because there are relatively speaking less long-living outliers (Daepp et al., 2015). This means that we can expect more than two-thirds of the S\&P 500 to consist of companies that we have not heard of after 2025. Similar phenomenon can be seen within Small and Medium-sized enterprises (SMEs); typically, less than half of the new European SMEs survive for the first five-year period (Eurostat, 2015).

The mortality of organizations does not, however, mean that the business is destroyed. On the contrary, the business ideas, intellectual property, and whole parts of the organizations may get traded and continue life after restructuration. The evidence emphasises the importance of company after-life: only in $8 \%$ of the publicly traded firms in North-America the closing of the company is due to liquidation or bankruptcy (Daepp et al., 2015). More often, the reasons are mergers and acquisitions, reverse acquisitions and takeovers, which mean continued business survival. However, the news is that reviving existing business have been only marginally more effective than incubating from the beginning (Laakso, 2012; Xi et al., 2017).

What are then the drivers of these incontingencies, disruptions and business modelling? In empirical studies it has been found that the major reasons to dynamic business 
modelling stem from technological development and especially from the market developments - in few cases regulatory drivers play a role (only $18 \%$ of all cases studied by de Reuver et al., 2009). It has also been found that the changes of the virtuous, or vicious cycles may also arise from the business model itself, especially on its higher-order unintended direct and indirect side-effects on a company's business drivers (Demil \& Lecoq, 2010). On the other hand, restructuring and financial market mechanisms allow successful companies to buffer against extrinsic age-dependent sources of mortality by either raising capital or acquiring skill-sets of competitors (Xi et al., 2017) to meet the threats, a strategy discussed in one of the seminal papers on long term role of business models (Demil \& Lecoq, 2010). So even though SMEs are not up to cope with latest advances in technology - the main disruptor - in the long run, SMEs are adaptive in the short term and targets for restructuring.

To summarize, the survival rate of big corporations and SMEs are surprisingly similar and their survival rate over time does not seem to depend on initial conditions. But, of the vanished companies, the majority continue as part of an incumbent, many as spin-offs or otherwise in new ownership. Therefore, we find it useful to reconsider the role of business modelling practices against the backdrop of continuity management. It is thus imperative for companies - whether market leaders or challengers - to not contemplate but to be proactive with their business models (Demil \& Lecoq, 2011; Heikkilä et al., 2016). They need to stay alert and periodically evaluate the viability of their business models against environmental contingencies, but also to keep their changes implementable internally.

\subsection{Business Models and Business Model Innovation}

BMs are studied especially in the fields of information systems science, organization science and management strategy (Zott et al., 2011; DaSilva \& Trkman, 2014; Wirtz et al., 2016). Recently, term Business Model Innovation has emerged to describe an activity or process in which core elements of a firm and its business logic are deliberately altered (Bonakdar, 2015; Bucherer et al., 2012; Hartmann et al., 2013; Heikkilä et al., 2018; Lindgardt et al., 2009; Pohle and Chapman; 2006). The logic through which organization transforms its products and services into value is one of the most significant strategiclevel decisions (Foss \& Lindenberg, 2013; Zott et al., 2011). The BMs are typically succeeding strategy (Casadesus-Masanell \& Ricart, 2010) with a shorter temporal perspective (DaSilva and Trkman, 2014), and - from the perspective of BC Management - leading to improved, positive realization of the strategy.

BM Innovation is a transformational approach to create new solutions for business (Demil \& Lecoq, 2010). The aim is to specifically innovate new aspects of the business with BM techniques on continuous cyclical basis (Casadesus-Masanell \& Ricart, 2010, 2011; Demil \& Lecoq, 2010) even with trial and error (Sosna et al., 2010). Thus, this may server as the means to circumvent the foreseen threats to value creation capacity ex-ante at least in theory. 
$31^{\text {ST }}$ Bled eConference: Digital Transformation: MeEting the Challenges

A crucial component of BMI is stress testing. It is a kind of sensitivity analysis targeted towards identifying stress factors that may put elements of business model at risk. Stress testing consists of following stages (Haaker et al., 2017): 1) Describe BM, 2) identify and select stress factors, 3) map BM to stress factors, 4) create heat map, 5) analyze results, and 6) formulate improvements and actions (Haaker et al., 2017). From the point of view of this paper, the implementation of the changes are formulated, but not implemented. Furthermore, the value of Business Continuity Management is to have planned ahead and rehearsed optional courses of actions, whereas after completing stress testing, you are starting the preparations for change.

\subsection{Business Continuity and Business Continuity Management}

The early literature on Business continuity were about disaster recovery (Herbane, 2010). In practice, this meant that companies prepared detailed procedures that would support their recovery efforts should an IT system fail (Post \& Diltz, 1986). Later on, Business continuity approach was broadened to business processes (Smith \& Sherwood, 1995; Trček, 2003; Cerullo \& Cerullo, 2004) where focus was on designing considerate redundancy in critical business processes and on the resources needed to run those processes to increase the resilience against contingencies (Butler \& Gray, 2006). In this paper we follow the recent Business Continuity stream, BC Management, aims at holistic and socio-technical approach to proactively manage preparations and response to incidents (Herbane, 2010). It seeks to prepare organizations to all kinds of contingencies, although in any contemporary setting technological incidents are the priority. BC Management is seen as strategic as it "readies an organisation to preserve value derived from competitive advantage" (Herbane, et al., 2004, p. 439). This kind of value preserving thinking feels rather intuitive since, after all, unanticipated contingencies "threaten the strategic goals of organisations" (Richardson, 1994, p.63). Thus, operational disruptions do not only create immediate loss but, when prolonged, hamper reaching the set strategic goals. BC is thus seen as an essential part of the realization of the strategy that is implemented in practice through various resources (e.g., employees, servers, facilities) and processes (e.g., order handling, sales, IT service production). BC seeks to ensure these resources and processes are resilient such that they are able to continue even in the wake of adverse events, and restore promptly when disrupted. The resilience is inherently socio-technical in nature (Herbane, 2010; Järveläinen, 2012) and built both on diverse technologically redundant solutions (Bajgoric, 2006; 2010) and social and organisational arrangements (Niemimaa, 2017), such as high-availability servers, redundant network connectivity, deputy arrangements and so forth.

Scholars and practitioners have brought forth several business continuity methods to assist organizations to improve their BC (e.g., British Standard Institute, 2006; International Organization for Standardization, 2012; Botha \& von Solms, 2004; Gibb \& Buchanan, 2006; Lindström et al., 2010). Generally, the preparations span across several methodological steps that involve 1) initiating a business continuity project; 2 ) identifying risks and their business impact; 3 ) designing continuity plan, processes, and procedures necessary for establishing a management system; 4) implementing the designed 
measures; 5) testing their effectiveness and exercising for incidents; and 6) continuous maintenance and update of measures through the established processes and procedures (Pitt \& Goyal, 2004; Stucke et al., 2010; Niemimaa, 2017), see Figure 2, right hand side. The generic frameworks are complemented with methodologies and approaches that focus on specific issues, such as achieving business continuity standard compliance (Freestone \& Lee, 2008), integration with risk management (Nosworthy, 2000), managing supply chains (Benyoucef \& Forzley, 2007), outsourcing (De Luzuriaga, 2009), and building a resilient IT infrastructure (Bajgoric, 2006).

There is a serious downside of $\mathrm{BC}$ Management in its original value preserving role, because strategy and its business model realization do not usually consider resilience. In the best case, $\mathrm{BC}$ can spotlight the potential contingencies of the present business model (Niemimaa, 2015) but fails to notice contingencies that may render the whole strategy obsolete. In the turbulent economy, business modellers have been better aware of the need to adapt to existing and upcoming contingencies or uncertainties strategically (DaSilva \& Trkman, 2014; Haaker et al., 2017). A business model related approach for resilience is a form of sensitivity analysis called stress-testing (Bouwman, et al., 2017; Haaker et al., 2017), in which business model elements are tested against future uncertainties using scenario analysis.

BC Management uses sometimes scenarios, too (Herbane, Elliott, \& Swartz, 2004; Tammineedi, 2010), but strategic issues have received only cursory treatment in BC literature (Herbane et al., 2004), and even then, the focus has been largely on finding compelling arguments to win senior management support (e.g., De Koning, 1995; Lindström \& Hägerfors, 2009; Seow, 2009).

We can summarise that multidisciplinary groups of BC Management scholars and practitioners have sought to provide companies with necessary tools and knowledge to help them proactively and holistically prepare for all kinds of contingencies. Consequently, they suggest combining BC Management with organizational strategic initiatives (e.g., Herbane et al., 2004; Niemimaa, 2015b), since strategic initiatives tend to be better resourced and win management buy-in more easily than separate operational initiatives $^{51}$.

As the above discussion suggests, through its history, $\mathrm{BC}$ has focused on either restoring or ensuring the continuity of operations. In other words, BC has essentially focused on value preservation (Herbane et al., 2004). We argue that due to the tendency to focus on the value preservation, the literature has overlooked an important source of contingencies which threaten the actual business logic through which the organization creates value to its customer. More specifically, these relate to environmental or internal contingencies that threaten the organization's business model. Accounting for these contingencies, requires a shift in BC approaches from operational value preservation to strategic value creation. Otherwise, BC Management should be able to deal with some of the most

${ }^{51}$ Both sufficient resources and management buy-in are broadly recognized as critical success factors for BC (e.g., Lindström \& Hägerfors, 2009; Seow, 2009) 
significant business continuity risks - risks that have potential to render business models ineffective, or when under restructuration to maintain an organization's value creation capability (see the competitive cycles in Casadesus-Masanell \& Ricart, 2011). This means that BC Management has to provide both the means to recover quickly, and to maintain performance during the disturbances.

\section{BM Stress testing}

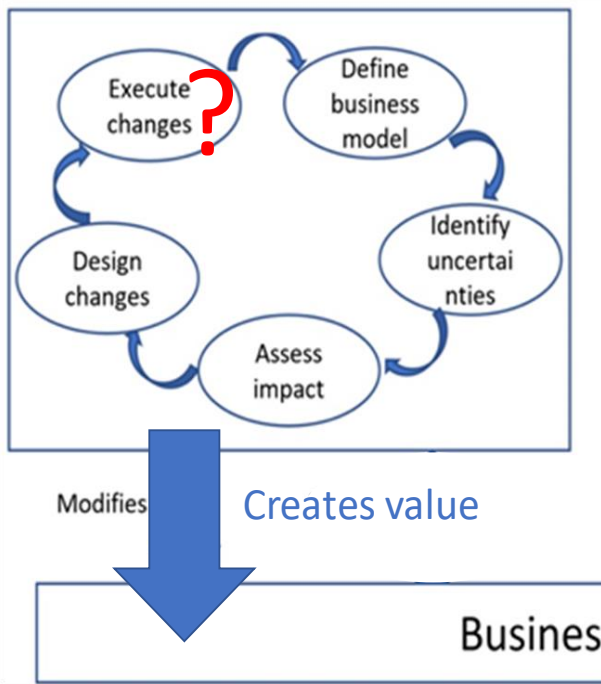

\section{Business Continuity Management}

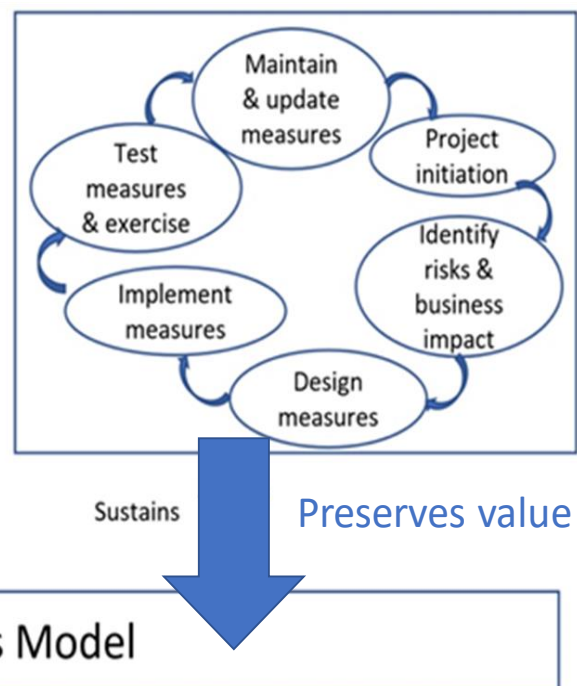

Figure 2. Strategic Business Continuity Management Framework

This way BC Management relates to BM innovation. This leads us to consider the potential combinations of BC Management and BM Innovation together. which we coin as Strategic Business Continuity Management.

\section{Strategic Business Continuity Management}

Reflecting the identified shortcomings in literature, we propose an extension to existing approaches so that $\mathrm{BC}$ management would truly become a) holistic; and b) strategic. Figure 2 provides an abstract depiction of the approach we propose.

Our extension proposes BM and Stress Testing as inter-related concepts to BC Management. In Figure 2, the right-hand side is the traditional, value preservation, approach of BC Management, explained above. The left side depicts the value of Business Model Stress testing by keeping the business model updated against disturbances by revising the business model elements. The proposed BM Management approach combines the both above to implement the changes faster, by helping to identify early the candidates of threats and response to them in advance. 
The steps we propose in Figure 2 should feel rather intuitive to any BC Management expert - in the content rather than in the structure. By proposing an approach that makes use of transformational business model innovation and stress testing in BC Management context, the BM becomes itself as a potential disturbance for company's business continuity. It directs our attention better on the potential elements under transformation the benefit from the approach is that it mediates the strategy and transformational business model to BC Management.

This is crucial under the circumstances of moving or disrupting markets. We typically are able to see and describe those threats we already have concepts for (Weick \& Putnam, 2006), and thus it is no wonder that these considerations have not easily emerged from the traditional BC Management methods. Next, we'll elaborate the combination of Stress testing with Business Continuity Management with steps of Stress Testing (the steps adapted from Haaker et al., 2017):

\section{Define Business Model}

- As suggested, if the organization has not already explicitly articulated its business logic, it should be done at this step. Articulating the static businessmodel-in-practice can be a thorny quest. Though this can be done by building on any of the available (formal) business model methods and languages (Haaker et al., 2017), it is equally useful to freely describe the components of business model in common language with the help of an BM innovation expert.

Identify Uncertainties

- Identifying uncertainties for BC focuses primarily around issues that threaten operations and define feasible optional arrangements, e.g., how can we set up alternative customer service processes promptly, and what is the (absolute) minimum level of service we have to deliver and how long does it suffice (i.e. business requirements for recovery. Combined with business model stress testing methods such as using ready-made scenarios with SWOT analysis (Haaker et al., 2017) and/or on brainstorming with likely scenarios, such as merging with or acquiring a new company in this paper. Even though qualitative risk analysis methods are well-documented and often well-known for organizational planner, Stress Testing provides a feasible alternative for SBCM. Instead of enumerating and estimating all possible external uncertainties in the first place, the focus is on the level of business model, i.e., what risks does the uncertainty pose to the components of the business model (or to the transformational business model). Only thereafter the impacts on organizational resources and processes will be evaluated in the BC Management sense.

\section{Assess Impact}

- Assessing the impact of the identified uncertainties can be done during the business modelling using e.g., Stress Testing systematically the impact of the legislative change across the business model component parts (e.g., does it impact our customer base, how does it change the value proposition, do we need changes to technologies that deliver the product/service). Thereafter this can be juxtaposed with the company's current business model and what modification it 
will bring to BCM. This could be represented in tabulated form, as it allows the planners to start comprehending the potential impact of the business model's transformation that they deem to have most potential for disrupting their current business. All identified impacts should be documented to be considered in the next phase.

Design changes

- After documenting the potential impact, practical measures for the change can be crafted. important point is to develop measures upon likely disruptions rather than estimate the feasibility of the strategic changes at this point. The power of $\mathrm{BC}$ Management is in the pro-actively planned measures against changes and maintaining performance during disruption and recovery, so the temporal effects should be articulated precisely - what are the signals of a disruption taking place, and when the continuity measures should start. The challenge here is to be generic enough and not going into too much details; but the measures must be specific enough to be practical. A feasible option is to define the changes in such a way that BC Management addresses the BM modification with the help of such adverbs as "redundant", "resilient", "backup", and "alternative" that remind of the high-availability requirements for "sustaining", "corrective", "revising" and "redirecting" outcomes. These adverbs give an idea of the BC Management methods that account the risks and cushion the business impacts.

Execute changes

- BC Management plays a major role in maintaining the way the company operates and makes revenue under changes, and prepares for rapid response to changes, by sustaining the existing situation, or by getting prepared to alternative operations. Some advocate "trial-and-error" discovery approach to BM innovation (McGrath, 2010), or consider it a vital part of the BM evolution (Sosna et al., 2010), but in SBCM thinking the response should be also implementable, and this is where BMs and Stress Testing fall short. The decision on which changes to execute and which "fights to fight" on the markets is largely a decision for the senior management, but the espoused strategy, current resources and operations are an important constraint to the extent of change. For the actual execution of the plans, standard project management methods and quality function deployment are useful in designating resources and responsibilities and feasible measures in practice. This provides the senior management grounds to prioritize feasible alternatives under the prevailing internal and external circumstances.

\section{Evidence from the practice: need for SBCM}

During the years 2014-2018, we conducted 123 case studies studying innovation of BMs in European SMEs. Out of these cases, 29 were Action Design Research Cases (ADR) carried out in close collaboration with companies.

A tool for Business Model Stress Testing combining future scenario planning with BM thinking was developed in four of these ADR studies. The companies considered Stress 
Test as a structured, mature and generically applicable tool. Stress Testing appears to bring forth relevant and critical issues of BM components, and to lead towards agile and iterative BM innovation. In addition, five cases tested the Stress test without the help of us researchers. These cases show that if entrepreneurs use the Stress Test tool, they use the tool according to their own convenience and tweak the steps and the content of scenarios to what is convenient and what does make sense to them. Stress test helped them to focus and to see where changes in their BM are required.

Thereafter, Stress testing tool was tested in twelve more case companies. These cases show that users had difficulties in deciding the abstraction level of the scenarios, but on the other hand the usage of the tool was becoming more creative, implying that the tool is utilised by users in ways, which were not originally intended by the developers. The overall conclusions from these cases was that the BM Stress Test increases awareness of BM's viability.

Looking carefully in some of the other case studies, we notice further complications that justify combining BC Management and BM Stress Testing for Strategic Business Continuity Management. First, the case of a company, which provides solutions for improving in-door air and atmosphere with plants: It utilized BM tools and thinking for transforming and innovating its product-based business towards services. After 8 years of operation, it focuses heavily on financial calculations and follow carefully its success in monetary terms. Business model is nowadays utilized only implicitly, but the emphasis is clearly on the value preservation of the present business model. As the time passes and low-end disruption competition emerges they should move to the transforming side of the SBCM model, while simultaneously maintaining their profit-making capacity against profit reducing competition.

Another case is the Sport Prescription case, where the entrepreneur proposed an innovative business model, requiring close collaboration with several incumbent companies. He was not willing to anticipate the uncertainties of the networked mode of operations, but instead wanted to handle them one by one when he faces them. This led him to stick to his original BM and consequently, denial of alternative, transformational business models. In this case there was no Business Continuity Planning - not to mention BC Management - and the business models could not be implemented. As a consequence, there was now plan B, nor any systematic way to tackle the inevitable options for merging, trade-sales, or solvency. The business idea is still owned by the founder, but it does not generate any revenue.

The case of Pain Meter involved a serial entrepreneur, who understood from the very beginning the difficulties of introducing a new instrument for clinical follow-up. In retrospect, a kind of BCM started from the exit-plan, but it soon emerged towards SBCM, when the founder and partners were considering alternative plans to implement alternative transformational business models. The focus was on the partner network and securing for funding to run proofs-of-concepts with subcontracted prototypes to create 
further value and additional options for investors, whenever they are willing to move. The company is soon to be traded for integrated with a medical company.

A case of a mature company in maritime sector brings up an interesting aspect regarding selection of potential future scenarios - bury one's head in the sand -phenomenon. When the company decided against which uncertainty they stress test their current BM, they did not want to take into account the trend of autonomous shipping. This was because the owner simply did not believe that ships could be autonomous and refused to even consider such option.

With these anecdotal evidence, we wanted to highlight the importance to have optional, concrete plans that ensure/preserve profitability, or create additional value while being under the pressure to perform against the evitable, disruption or restructuring.

\section{$5 \quad$ Discussion and Conclusions}

In this article, we have proposed an extension to the $\mathrm{BC}$ approaches that aim to increase the scope of $\mathrm{BC}$ and its organizational significance in the landscape of accelerating restructuring of industries and merging and fusioning companies. These extensions match with the aims of other scholars that have argued for holistic and strategic BC (Herbane et al., 2004; Gerber \& von Solms, 2005; Zuccato, 2007) by combining it with BM Innovation. The discussions have, however, largely focused on the former arguing how value preservation can be viewed as strategic (Richardson, 1994; Herbane et al., 2004). Here we broaden the scope to range of threats to the value creation, while under the inevitable disruptive and restructuring pressure.

The benefits of $\mathrm{BC}$ in general stem from the preparedness to circumstances measures of fast recovery from contingent situations, whereas its handicap is the loose connection with strategy. In this article, we illustrate, how to combine it with static business models and transformational BM innovation to realize the ideas of Demil and Lecoq (2010) and iterative approach suggested by Casedesus-Masanell and Ricart (2011). BMs serve as proxies for the strategy and provide the necessary granularity and vehicle for communication with actual implementation and strategic direction (Heikkilä, 2010).

We see the contingencies of disruption and restructuring particularly contemporary and current markets as the technological progress has enabled organizations to innovate new, radical business models that can render obsolete in an instant any incumbent's value creation logic (Eggers \& Park, 2017). The rapid technological change combined with new innovative business models provide both possibilities and serious threat to organisations, and the role of BC Management is increasing in maintaining the profitability and survival during the change. The question of "why some incumbents do well and adapt, while others struggle?", under these technology-driven changes has become a key question of our time (Eggers \& Park, 2017). When viewed from the perspective of BC, the new BMs represent (abrupt) contingencies in the environment that appear as risks threatening the business continuity of a company, and that, consequently, require organizations to make 
preparations. To respond to these changes, SBCM serves as a promising tool for business continuity threats.

The proposed two-part approach of Strategic Business Continuity Management (SBCM) differentiates between $\mathrm{BC}$ activities that focus on value preservation and those that focus on value creation, but are simultaneously linked to each other through business models. While value preservation focuses on sustaining (by BCM) those processes and resources that implement a particular existing business model, the value creation part focuses on exploring threats to business model innovation (by Stress Testing) that can directly contribute to how the organization can implement the additional value creating changes faster. When this combination becomes a part of the company's strategic, value creating activities, we expect that it can secure more resources and gain management buy-in more easily that are needed for effective value preservation but that are often recognized as significant challenges (Lindström et al., 2009; Seow, 2009). That is, we'd like to stress that the importance of the value preservation part has not diminished neither have we sought to reduce its importance. When the implementation of the new BM through technologies, resources and processes is designed, the value preservation part of SBCM should be used to ensure that they meet the organization's BC targets (such as maximum time to recovery) and communicating about the strategic intent and the feasible possibilities of innovative changes.

The latter is especially important in the context of business modelling, as indicated by Sosna et al. (2010) in their analysis of trial-and-error during business evolution: "We have seen that the 'who' was as important as the 'how' in Naturehouse's business model development process. The level of resilience and commitment to change of the OM [operational management] and top-management team were absolutely critical to the success of the business model experiments. In this context, the role of centralized decision power can be seen as a two-edged sword: if a leader with significant (or complete) decision power is committed to business model experimentation, the chances for success are significantly increased. But if they are obstructive to business model re-designs or innovations, it will be nearly impossible for other managers to run any experiments, set up learning processes, or implement a new business model effectively." (Sosna et al., 2010).

Last, we have merely started to explore this area emerging at the intersection of $\mathrm{BC}$ and $\mathrm{BM}$ and call for more contribution between the scholars and practitioners working in these areas. Indeed, this paper is an outcome of a fruitful collaboration between scholars from both "camps". We argue that such interdisciplinary efforts are needed to prepare organizations and respond for the significant technology-driven reconfigurations that take place both at organizational and societal level.

\subsection{Future Research}

In this research, we have opened a new discussion between Business Continuity Management and BM (especially Stress Testing). The approach we provide focuses on 
high-level, abstract phases, by supplementing Stress Testing with the features of BCM and taking Stress Testing output to the benefit of Business Continuity. This we provide a Strategic Business Continuity Management framework that covers both value preservation and value creation in Business Modelling, especially for the situations like re-structuration of industries and merging of companies, which we expect to increase along the progress of digitalization.

While the phases of SBCM are already readily applicable (see figure 2.) for business benefits, more research needs to be taken to provide more effective tools for different circumstances. Identifying uncertainties and contingent circumstances is a crucial part of the whole approach as it largely determines the content of the subsequent phases. But, how well do our existing business continuity methods perform when dealing with environmental contingencies pertaining to BMs? For BC to be truly proactive (Butler \& Gray, 2006) companies need to (optimally) recognize uncertainties already before they actually unfold, so this could be mainly in retrospect. However, the relevant approach, would be to develop methods to surface potentially disruptive BMs to effectively help companies to prepare before the BMs transform from potentially disruptive to disruptive.

\section{Acknowledgments}

The work leading to these results has received funding from the European Community's Horizon 2020 Program (2014-2020) under grant agreement 645791. The content herein reflects only the authors' view. The European Commission is not responsible for any use that may be made of the information it contains.

\section{References}

Amit, R., \& Zott, C. (2001). Value creation in e-business. Strategic Management Journal 22(6-7), pp. 493-520.

Anthony, S.D., Viguerie, S. P., Schwartz, E. I., \& Landeghem, J. V. (2018). 2018 Corporate Longevity Forecast: Creative Destruction is Accelerating. S\&P 500 lifespans continue to shrink, requiring new strategies for navigating disruption. Executive Briefing // February 2018, Innosight.

Bajgoric, N. (2006). Information technologies for business continuity: an implementation framework. Information Management \& Computer Security. 14(5), pp. 450-466.

Bajgoric, N. (2010). Server operating environment for business continuance: framework for selection. International Journal of Business Continuity and Risk Management. 1(4), pp. 317338.

Benyoucef, M. \& Forzley, S. (2007). Business continuity planning and supply chain management. Supply Chain Forum. 8(2), pp. 14-22.

Bonakdar, A. (2015). Business Model Innovation. PhD diss., University of St. Gallen.

Botha, J. \& von Solms, R. (2004). A cyclic approach to business continuity planning. Information Management \& Computer Security. 12(4), pp. 328-337.

Bouwman, H., Faber, E., Haaker, T., Kijl, B., \& Reuver, M. D. (2008). Conceptualizing the STOF Model. In Mobile Service Innovation and Business Models. Springer, Berlin, Heidelberg, pp. $31-70$ 
Bouwman, H., Heikkilä, J., Heikkilä, M., Leopold, C., \& Haaker, T. (2017). Achieving agility using business model stress testing. Electronic Markets, 1-14.

British Standards Institute (2006). Societal security — Business continuity management systems - Requirements - Part 1: Code of Practice.

Bucherer, E., Eisert, U., \& Gassmann, O. (2012). Towards Systematic Business Model Innovation: Lessons from Product Innovation Management. Creativity and Innovation Management. 21(2), pp. 183-198.

Butler, B. S. \& Gray, P. H. (2006). Reliability, Mindfulness, and Information Systems. MIS Quarterly. 30(2), pp. 211-224.

Casadesus-Masanell, R., \& Ricart, J. E. (2010). From Strategy to Business Models and onto Tactics. Long Range Planning. 43(2), pp. 195-215.

Casadesus-Masanell, R., \& Ricart, J. E. (2011). How to Design a Winning Business Model. Harvard Business Review, Jan-Feb (Internet version).

Cerullo, V. \& Cerullo, M. J. (2004). Business Continuity Planning: A Comprehensive Approach. Information Systems Management. 21(3), pp. 70-78.

Chesbrough, H. (2010). Business model innovation: opportunities and barriers. Long range planning. 43(2), pp. 354-363.

Chesbrough, H., \& Rosenbloom, R. S. (2002). The role of the business model in capturing value from innovation: evidence from Xerox Corporation's technology spin-off companies. Industrial and Corporate Change. 11(3), pp. 529-555.

Daepp, M. I. G., Hamilton, M. I. J., West, G. B., Bettencourt L. M. A. (2015). The Mortality of Companies. Journal of the Royal Society Interface, https://doi.org/10.1098/rsif.2015.0120

DaSilva C.M. \& Trkman, P.(2014). Business Model: What It Is and What It Is Not. Long Range Planning. 47(6), pp. 379-389.

De Koning, W. F. (1995). A methodology for the design of security plans. Computers \& Security. 14(7), pp. 633-643.

De Luzuriaga, J. (2009). Ensuring business continuity for business process outsourcing companies. Journal of Business Continuity \& Emergency Planning. 3(4), pp. 312-316.

Demil, B., \& Lecocq, X. (2010). Business model evolution: in search of dynamic consistency. Long range planning. 43(2), pp. 227-246.

De Reuver, M., H. Bouwman \& T. Haaker (2013). Business model roadmapping: A practical approach to come from an existing to a desired business model. International Journal of Innovation Management. 17(1), pp. 1-18.

Eggers, J. \& Park, K. (2017). Incumbent Adaptation to Technological Change: The Past, Present, and Future of Research on Heterogeneous Incumbent Response. Academy of Management Annals, 11(2), pp. 1-83.

Eurostat (2015). Business demography statistics, retrieved 25.3.2018 from http://ec.europa.eu/eurostat/statisticsexplained/index.php/Business_demography_statistics\#Death_rate.

Foss, N. J., \& Lindenberg, S. (2013). Microfoundations for strategy: A goal-framing perspective on the drivers of value creation. The Academy of Management Perspectives. 27(2), pp. 85-102.

Foss, N. J., \& Saebi T. (2017). Fifteen Years of Research on Business Model Innovation: How Far Have We Come, and Where Should We Go?. Journal of Management. 43(1), pp. 200-227.

Freestone, M. \& Lee, M. (2008). Planning for and surviving a BCM audit. Journal of Business Continuity \& Emergency Planning. 2(2), pp. 138-151.

Gerber, M. \& von Solms, R. (2005). Management of risk in the information age. Computers \& Security. 24(1), pp. $16-30$.

Gibb, F. \& Buchanan, S. (2006). A framework for business continuity management. International Journal of Information Management. 26(2), pp. 128 - 141. 
Haaker, T., Bouwman, H. Janssen, W. \& de Reuver, M. (2017). Business model stress testing: a practical approach to test the robustness of a business model, Futures. 89, pp. 14-25

Hartmann, M., Oriani, R., \& Bateman, H. (2013). The Performance Effect of Business Model Innovation: An Empirical Analysis of Pension Funds. In 35th DRUID Celebration Conference (pp. 17-19).

Heikkilä, M. (2010). Coordination of Complex Operations Over Organizational Boundaries. Jyväskylä Studies in Computing 111, Dissertation, 265 pages.

Heikkilä, M., Bouwman, H., Heikkilä, J., Haaker, T., Lopez-Nicolas, C., Riedl, A., (2016). Business Model Innovation Paths and Tools. 29th Bled eConference: Digital Economy, June 19-22, 2016, Bled, Slovenia

Heikkilä, M., Bouwman, H., \& Heikkilä, J. (2018). From strategic goals to business model innovation paths: an exploratory study. Journal of Small Business and Enterprise Development. 25(1), pp. 107-128.

Herbane, B. (2010). The evolution of business continuity management: A historical review of practices and drivers. Business History. 52(6), pp. 978 - 1002.

Herbane, B., Elliott, D. \& Swartz, E. M. (2004). Business Continuity Management: time for a strategic role? Long Range Planning. 37(5), pp. 435-457.

International Organization for Standardization (2012). ISO 22301, Societal security - Business continuity management systems - Requirements.

Järveläinen, J. (2012). Information security and business continuity management in interorganizational IT relationships. Information Management \& Computer Security. 20(5), pp. 332-349.

Kim, W. C. \& Mauborgne, R. (2004). Blue Ocean Strategy. Harvard Business Review. (Oct:), pp. $1-10$.

Laakso T., (2012). Yrityssaneerausohjelman onnistuminen : käyttäytymistaloustieteellinen näkökulma (Success of restructuring programs). Aalto University publication series Doctoral Dissertation, 163/2012, ISSN: 1799-4934, 180 pages (in Finnish).

Lindgardt, Z., Reeves, M., Stalk, G., \& Deimler, M. S. (2009). Business Model Innovation. When the Game Gets Tough, Change the Game. The Boston Consulting Group, Boston, MA.

Lindström, J. \& Hägerfors, A. (2009). A model for explaining strategic IT- and information security to senior management. International Journal of Public Information Systems. 2009:1, pp. 17-29.

Lindström, J., Samuelsson, S. \& Hägerfors, A. (2010). Business continuity planning methodology. Disaster Prevention and Management. 19(2), pp. 243-255.

Niemimaa, M. (2015a). Interdisciplinary Review of Business Continuity from an Information Systems Perspective: Toward an Integrative Framework. Communications of the Association for Information Systems. 37(4), pp. 69-102.

Niemimaa, M. (2015b). Extending 'Toolbox' of Business Continuity Approaches: Towards Practicing Continuity. in Americas Conference on Information Systems. Puerto Rico, US: Association for Information Systems, pp. 1-11

Niemimaa, M. (2017). Information systems continuity process: Conceptual foundations for the study of the "social". Computers \& Security. 65:March, pp. 1-13.

Niemimaa, M. \& Järveläinen, J. (2013). IT Service Continuity: Achieving Embeddedness Through Planning. In Eight International Conference on Availability, Reliability and Security (ARES), pp. 1-19

Nosworthy, J. D. (2000). A practical risk analysis approach: managing BCM risk. Computers \& security. 19(7), pp. 596-614.

Osterwalder, A., \& Pigneur, Y. (2010). Business Model Generation: A Handbook for Visionaries, Game Changers, and Challengers. John Wiley \& Sons.

Pitt, M. \& Goyal, S. (2004). Business continuity planning as a facilities management tool. Facilities. 22(3/4), pp. 87-99. 
Pohle, G. and Chapman, M. (2006). IBM's global CEO report 2006: business model innovation matters. Strategy \& Leadership. 34(5), pp. 34-40.

Post, G. V. \& Diltz, J. D. (1986). A Stochastic Dominance Approach to Risk Analysis of Computer Systems. MIS Quarterly. 10(4), pp. pp. 363-375.

de Reuver, M., Bouwman, H., McInnes, I. (2009). Business Model Dynamics: a case survey. Journal of Theoretical and Applied Electronic Commerce Research. 4(1) On-line version ISSN 0718-1876, http://dx.doi.org/10.4067/S0718-18762009000100002

Richardson, B. (1994). Crisis Management and Management Strategy - Time to "Loop the Loop"?. Disaster Prevention and Management: An International Journal. 3(3), pp. 59-80.

Seow, K. (2009). Gaining senior executive commitment to business continuity: Motivators and reinforcers. Journal of Business Continuity \& Emergency Planning. 3(3), pp. 201-208.

Smith, M. \& Sherwood, J. (1995). Business Continuity Planning. Computers \& Security. 14(1), pp. 14-23.

Sosna, M., Trevinyo-Rodríguez, R. N., \& Velamuri, S. R. (2010). Long Range Planning. 43(2-3), April-June 2010, pp. 383-407.

Statistics Finland (2018). New and terminated companies. ISSN=1797-0660. 3rd quarter 2017, $\begin{array}{lllll}\text { appendix } & 1 . & \text { Start-ups. } & \text { Helsinki: } & \text { Tilastokeskus }\end{array}$ http://www.stat.fi/til/aly/2017/03/aly $201703 \quad 2018-01-25$ tau 001 fi.html. (in Finnish),

Stucke, C., Straub, D. W. \& Sainsbury, R. (2008). Business Continuity Planning and the Protection of Informational Assets. in Information Security: Policy, Processes and Practices, D. W. Straub, S. Goodman \& R. L. Baskerville (eds.), Armonk, NY: M.E. Sharpe, pp. 152-171.

Tammineedi, R. L. (2010). Business Continuity Management: A Standards-Based Approach. Information Security Journal: A Global Perspective. 19(1), pp. 36-50.

Teece, D. J. (2010). Business models, business strategy and innovation. Long range planning. 43(2), pp. 172-194.

Trček, D. (2003). An integral framework for information systems security management. Computers \& Security. 22(4), pp. 337-360.

Von Solms, R. \& Van Niekerk, J. (2013). From information security to cyber security. computers \& security. 38:2013, pp. 97-102.

Weick, K. E. \& Putnam, T. (2006). Organizing for mindfulness: Eastern wisdom and Western knowledge. Journal of management inquiry. 15(3), pp. 275-287.

Wirtz, B. W., Pistoia, A., Ullrich, S., \& Göttel, V. (2016). Business Models: Origin, Development and Future Research Perspectives. Long Range Planning. 49(1), 36-54.

Xi, G., Block, J. H., Lasch, F., Robert, F. \& Thurik, R. (2017). How Does Firm Survival Differ between Business Takeovers and New Venture Start-Ups?. IZA Institute of Labor Economics Discussion Paper No. 11155. Available at SSRN: https://ssrn.com/abstract=3081387

Zott, C., Amit, R., \& Massa, L. (2011). The Business Model: Recent Developments and Future Research. Journal of Management. 37(4), 1019-1042.

Zuccato, A. (2007). Holistic security management framework applied in electronic commerce. Computers \& Security. 26(3), pp. 256-265. 


\title{
SMEs Perspective on Business Model Innovation
}

\section{Marjeta Marolt, Gregor Lenart, MirJana KlJajiĆ BorŠtnaR, DOROTEJA VIDMAR \& ANDREJA PUCIHAR}

\begin{abstract}
This paper extends previous studies on business model innovation (BMI) by analysing the drivers and outcomes of BMI in micro, small and medium-sized enterprises. The paper develops a research model, which analyses these relations using partial least square squares modeling on a data set of 71 Slovenian SMEs. Results suggest that innovation and environment positively influence the level of BMI in the enterprises, while in our case the contrary is found for technology. In addition, the results show that the level of BMI contributes positively to BMI outcomes and further to overall business performance. The results of the research can be useful for Slovenian SMEs that innovate or intent to innovate their business model(s).
\end{abstract}

Keywords: • Business Model Innovation • Drivers • Outcomes • SMEs •

CORRESPONDENCE ADDRESS: Marjeta Marolt, University of Maribor, Faculty of organizational sciences, Kidričeva cesta 55a, 4000 Kranj, Slovenia, e-mail: marjeta.marolt@fov.uni-mb.si. Gregor Lenart, University of Maribor, Faculty of organizational sciences, Kidričeva cesta 55a, 4000 Kranj, Slovenia, gregor.lenart@fov.uni-mb.si. Mirjana Kljajić Borštnar, University of Maribor, Faculty of organizational sciences, Kidričeva cesta 55a, 4000 Kranj, Slovenia, mirjana.kljajic@fov.uni-mb.si. Doroteja Vidmar, University of Maribor, Faculty of organizational sciences, Kidričeva cesta 55a, 4000 Kranj, Slovenia, doroteja.vidmar@fov.uni-mb.si. Andreja Pucihar, University of Maribor, Faculty of organizational sciences, Kidričeva cesta 55a, 4000 Kranj, Slovenia, andreja.pucihar@fov.uni-mb.si. 
In recent years BMI is increasingly gaining attention in academic literature as well as in practice (Haaker, Bouwman, Janssen, \& de Reuver, 2017). Research on BMI has mainly focused on large enterprises, only several studies (Barjak, Es-Sadki, \& Arundel, 2015; Bouwman, Nikou, Molina-Castillo, \& de Reuver, 2018; Heikkilä, Bouwman, \& Heikkilä, 2018) have focused on SMEs. However, as SMEs represent key players of the European economy, more attention is needed in the understanding of their practices, innovativeness, and competitiveness in the global marketplace (OECD, 2017). However, even though SMEs seems to improve business performance by innovating their business model (BM), a little is known about SMEs business model innovation practices (Hartmann, Oriani, \& Bateman, 2013). Furthermore, the research methods applied in studies related to BMI in SMEs are predominantly case studies (Laudien \& Daxböck, 2017), which do not allow generalization of results.

Past research has mainly focused on defining a business model (Teece, 2010; Christoph Zott \& Amit, 2008) and studying the antecedents and barriers to BMI (Amit \& Zott, 2001; Hartmann et al., 2013). There has been less attention on the impact of BMI on performance (Desyllas \& Sako, 2013; Christoph Zott \& Amit, 2007). According to Hartmann et al. (2013) past work has also looked at internal and external factors of the business model innovation success.

Based on the past work this study is trying to derive drivers and outcomes of business model innovation. Therefore, in this paper, we strive to answer the following research questions: What factors play a role in BMI? What is the performance outcome of BMI? We build upon the BM literature to guide our theoretical development and to formulate relevant hypotheses. To test our model and hypotheses, we used qualitative data collected in the H2020 Envision project. A data set of 71 Slovenian SMEs engaged in BMI was used. Data were collected in 2017. A PLS-PM statistical approach was used to test hypotheses.

This remaining of the paper is organised as follows. Firstly, we present literature that guided research model development, secondly, we formulated hypotheses. Thirdly, the research methodology is discussed, followed by the presentation of research results. Finally, the findings are discussed and conclusions are made.

\section{Theoretical Background and Hypotheses Development}

\section{BM and the level of BMI}

BM generally refers to a representation of firm's logic to create, distribute and capture value for its stakeholders (Bouwman, Zhengiia, Duin, \& Limonard, 2008; Chesbrough \& Rosenbloom, 2002). While BM has been investigated by many researchers from various disciplines there is a wide variety of definitions (DaSilva \& Trkman, 2014). In this paper, we define BM as a description of how an enterprise or network of enterprises intends to create and capture value for both, (networked) enterprises and the customers (Bouwman, 


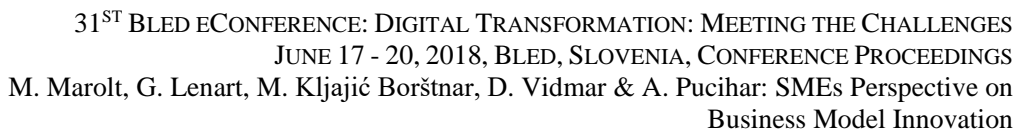

Vos, \& Haaker, 2008). The definition of BMI according to Zott \& Amit (2010) is the activity-based perspective of BM, resulting in a changes in an enterprises BM that is new to the world or just new to the enterprises under analysis.

BMI includes changes in BM components which are the building blocks of a BM. Several researchers (e.g. Lambert \& Davidson, 2013; C. Zott, Amit, \& Massa, 2011) provided an overview of BM components. Furthermore, some researchers provided BM ontologies, for example, BM Canvas (Osterwalder \& Pigneur, 2010), STOF (Bouwman, Faber, Haaker, Kijl, \& De Reuver, 2008), and VISOR (El Sawy \& Pereira, 2013). The practitioner-oriented BM canvas (Osterwalder \& Pigneur, 2010) consist of nine building blocks, including value proposition, key partners, key resources, key activities, customer relationship, communication and distribution channels, customer segmentation, revenue streams, and cost structure. These components have been used by several researchers. For instance, Haaker et al. (2017) have used all these nine components of BM as well, while Hartmann, Zaki, Feldmann, \& Neely (2016) have used only six components (key resources, key activities, value proposition, customer segment, revenue model, and cost structure). This study follows an approach by Osterwalder, Pigneur, \& Tucci (2005) suggesting BMI as a development or even a modification of BM components.

BMI components are measured differently by several authors. For instance, Santos, Spector, \& Van Der Heyden (2009) considered changes in the architecture of BM as an indicator of BMI. Furthermore, Huang, Lai, Kao, \& Chen (2012) used a list of randomly selected components of BM. According to Foss \& Saebi (2017), BMI literature provides two diverse perspectives of BMI, including changes in the architecture of BM and changes in one or more components in BM. Therefore, they suggested two-dimensions of BMI: scope and novelty. The scope dimension is characterized by architectural and modular changes of BM while novelty dimension describes BM changes as novel to an enterprise or an industry. Another valuable conceptualisation is provided by Clauss (2017) who developed a validated scale for BMI. In our study, we perceived 4 levels of BMI: BM new to the industry, BM never implemented by competitors before, BM not found in dominant BM in industry, BM not invented by other enterprises.

It can be concluded that there is no consensus regarding definitions and conceptualisations of BM and BMI. Moreover, there is a lack of understanding of what drives BMI and how BMI impacts on performance outcomes.

\section{Drivers of the level of BMI}

There have been many previous discussions and studies on drivers, influencing BMI activities and practices. Drivers of the level of BMI can be internal as well as external (Andreini \& Bettinelli, n.d.; Foss \& Saebi, 2017b). In this study, we perceive environment and technology as external drivers and innovation as an internal driver, influencing SMEs level of BMI.

The environment consists of competitive intensity (Jaworski \& Kohli, 1993) and market turbulence (Jaworski \& Kohli, 1993) and is one of the external drivers that influence the 
BMI. However, in one of the recent studies (Bouwman et al., 2018) the correlation between competitive intensity and BM experimentation was not supported. Even though there are mixed results related to the impact of environment on the level of BMI, we aim to re-evaluate its impact and thus we hypothesise that:

H1: Environment has a positive effect on the level of BMI.

According to Johnson \& Christensen, C. M. Kagermann (2008) and Bouwman et al. (2018) technology turbulence has a direct impact on BM experimentation. The technology innovation has been identified as an important determinant of effective business in many previous studies. Therefore, we hypothesise that:

H2: Technology has a positive effect on the level of BMI.

Innovation in this study is seen as a driver and is defined as enterprises ability or capacity to introduce new processes or new product/service in the enterprise (Hult, Hurley, \& Knight, 2004). The innovation can drive the SMEs experimentations in BMI. For instance, Bouwman et al. (2018) have shown a positive relationship between innovation activity and BM experimentation. Hence, we hypothesise that:

H3: Innovation has a direct effect on the level of BMI.

\section{Outcomes of BMI}

Level of BMI refers to the level of novelty of BMI for the enterprise or the industry. According to Heikkilä et al. (2018) in the context of SMEs BMI is related to BMI outcomes. Therefore, we hypothesize that:

H4: Level of BMI has a positive effect on BMI outcomes.

The relationship between BMI and business performance has been confirmed by several previous studies (e.g. Cucculelli \& Bettinelli, 2015; Christoph Zott \& Amit, 2007). For example, studies have shown that different types of BM changes can lead to improved business performance (Giesen, Berman, Bell, \& Blitz, 2007). Hence, we hypothesise that:

H5: BMI outcomes have a positive effect on performance.

Figure 1 presents a research model proposed in this study. It consists of above-defined concepts and correlations. 


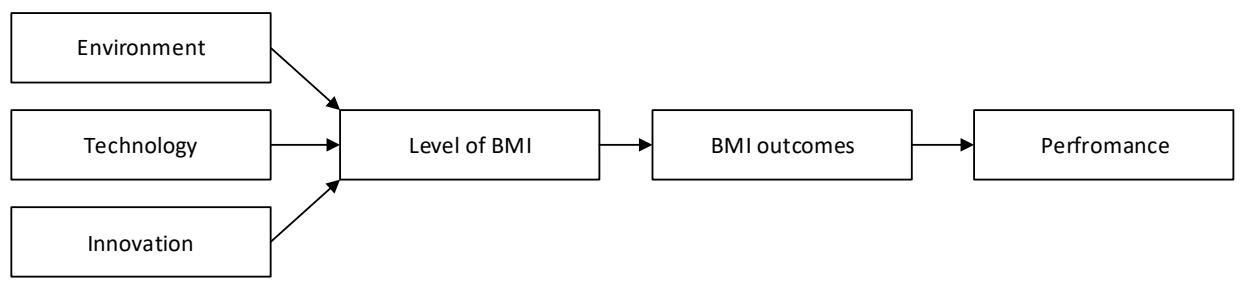

Figure 18: Research model

\section{Sample and data collection}

The empirical data for this paper were collected in H2020 Envision project using a questionnaire. The questionnaire consists of several questions regarding BM and BMI, including BMI drivers, type of innovations, changes of BM, methods, and tools used for BM, BMI outcomes. Data were collected through a professional research agency based in the Netherlands. There were 11 countries (the Netherlands, France, Finland, Austria, Italy, Lithuania, Poland, Portugal, Slovenia, Spain, Sweden) included into the research. The SMEs (using definition by 2003/361/EC (2003) were randomly selected from Dun and Bradstreet database that collects data on enterprises on a regular basis from chambers of commerce and other organizations. Respondents in each enterprise were collected in 2017 from owners or managers who are involved in BMI, innovation or business development. A seven-point Likert scale $(1=$ totally disagree, $7=$ totally agree $)$ was used to measure the level of agreement with a given statement.

In this paper, only the data from SMEs in Slovenia that are engaged in BMI were used. 71 useable responses were utilized for the statistical analysis. For the descriptive statistics, we used SPSS, while the hypotheses were tested with R. The PLS-PM method was applied to find and identify the relationship among constructs.

\section{Measurement model}

In order to set up the empirical analysis, we defined relevant constructs for the regression. Items to measure constructs were selected from previously validated measures and are presented in Table 1. A seven-point Liker scale was used in this study.

Independent constructs. To capture the Environment and Technology constructs Jaworski \& Kohli (1993) items were adopted and used in this study. For the Innovation construct, five items were adopted from previous studies (Hult et al., 2004; Subramanian, 1996).

Dependent constructs. To measure a Level of BMI the four items considering the novelty of BMI were adopted from Christoph Zott \& Amit (2008). Ross, Weill, \& Robertson (2006) items were used to measure BMI outcomes construct. This construct consists of four items that reflect changes in BM that potentially cause the business performance. For 
the performance construct, six items were adopted from previous studies (Cucculelli \& Bettinelli, 2015; Venkatraman \& Ramanujam, 1986).

Table 7: Constructs and items used in this study

\begin{tabular}{|c|c|c|}
\hline Construct & Items & Sources \\
\hline \multirow[t]{3}{*}{ Environment } & 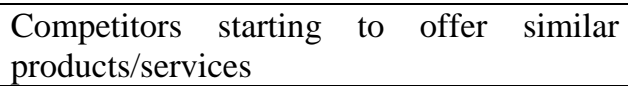 & \multirow[t]{3}{*}{$\begin{array}{l}\text { (Jaworski \& Kohli, } \\
\text { 1993) }\end{array}$} \\
\hline & Competitor's reaction to our initiatives & \\
\hline & Frequently changing customer preferences & \\
\hline \multirow[t]{2}{*}{ Technology } & Rapid changing technology & \multirow{2}{*}{$\begin{array}{l}\text { (Jaworski \& Kohli, } \\
\text { 1993) }\end{array}$} \\
\hline & Increasing technology development & \\
\hline \multirow[t]{5}{*}{ Innovation } & $\begin{array}{l}\text { Corporate culture focused on constant } \\
\text { innovation }\end{array}$ & \multirow[t]{5}{*}{$\begin{array}{l}\text { (Hult et al., 2004; } \\
\text { Subramanian, 1996) }\end{array}$} \\
\hline & Aim to create multiple innovations annually & \\
\hline & $\begin{array}{l}\text { Introduce innovations completely new to } \\
\text { the markets }\end{array}$ & \\
\hline & $\begin{array}{l}\text { Creating more than one innovation at the } \\
\text { same time is common practice }\end{array}$ & \\
\hline & $\begin{array}{l}\text { Our enterprise is one of the first to introduce } \\
\text { innovations }\end{array}$ & \\
\hline \multirow{4}{*}{$\begin{array}{l}\text { Level of BMI } \\
\text { innovation }\end{array}$} & BM new to the industry & \multirow{4}{*}{$\begin{array}{l}\text { (Christoph Zott \& } \\
\text { Amit, 2008) }\end{array}$} \\
\hline & $\begin{array}{l}\text { BM never implemented by competitors } \\
\text { before }\end{array}$ & \\
\hline & BM not found in dominant BM in industry & \\
\hline & BM not invented by other enterprises & \\
\hline \multirow[t]{4}{*}{ BMI outcomes } & Changes in BP standardization & \multirow[t]{4}{*}{ (Ross et al., 2006) } \\
\hline & Changes in BP integration & \\
\hline & Changes in ICT applications & \\
\hline & Changes in ICT infrastructure & \\
\hline \multirow[t]{6}{*}{ Performance } & Sales growth & \multirow{6}{*}{$\begin{array}{l}\text { (Cucculelli \& } \\
\text { Bettinelli, 2015; } \\
\text { Venkatraman \& } \\
\text { Ramanujam, 1986) }\end{array}$} \\
\hline & Profit growth & \\
\hline & Market share & \\
\hline & Market penetration rate & \\
\hline & Market value & \\
\hline & Net income & \\
\hline
\end{tabular}




\section{$4 \quad$ Results}

\section{Descriptive statistics}

Out of 71 respondents, 37.1 percent represented micro enterprises, 38.5 percent small enterprises, and 24.4 percent medium-sized enterprises. Among the respondents, only 25 percent claimed that they have innovated their business model in last two years. Figure 2 shows what changes in the business model they have made in last year. According to data, the focus was on collaboration with new business partners, development of new products/services, the introduction of new distribution channels, the introduction of new ways to reduce fixed and variable costs and the introduction of new ways to be profitable.

Our enterprise last year introduced new...

Our enterprise last year introduced new...

Our enterprise last year introduced new...

Our enterprise last year introduced new...

Our enterprise last year created new...

Our enterprise last year introduced new...

Our enterprise last year shared new...

Our enterprise last year started to..

Our enterprise last year introduced new...

Our enterprise last yearintroduced new...

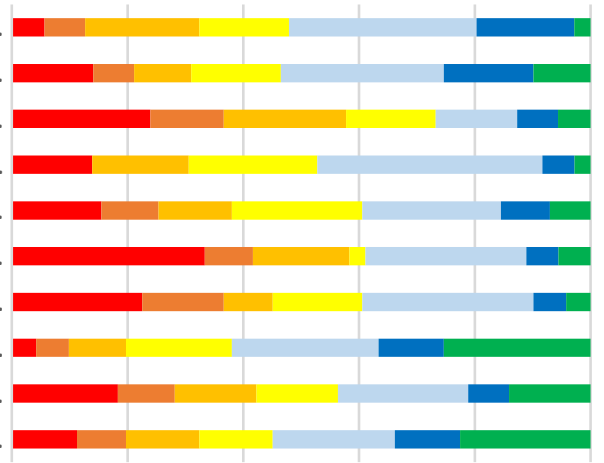

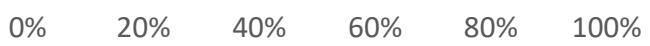

1 Totally disagree $\quad 2 \quad \square 3 \quad 4 \quad \square 5 \quad \square 6 \quad \square 7$ Totally agree

Figure 19: Area of business model innovation in last year

The changes in business model mainly lead to changes in internal controls to monitor processes, business processes standardization, ICT applications, ICT infrastructure, and business/organisational structure (Figure 3). 
M. Marolt, G. Lenart, M. Kljajić Borštnar, D. Vidmar \& A. Pucihar: SMEs Perspective on Business Model Innovation

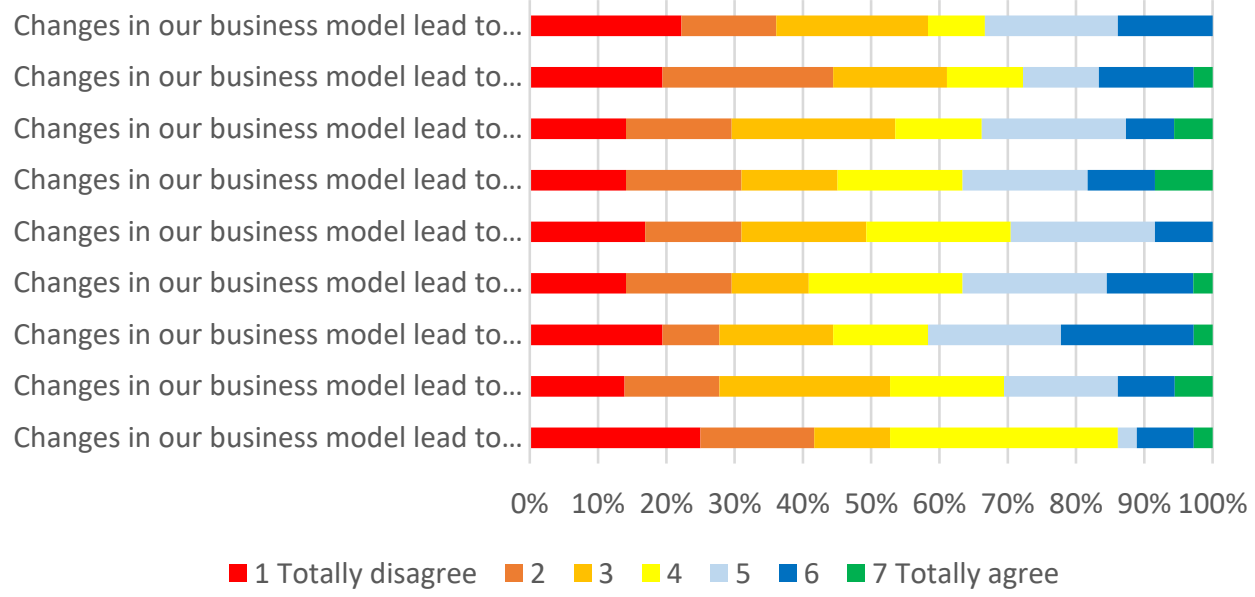

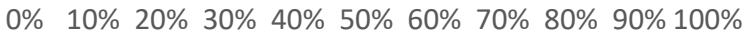

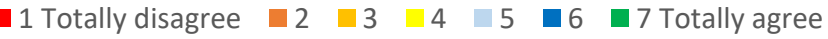

\section{Figure 20: Impact of business model changes}

As regards to the drivers, the following drivers prevail: offering products/services at low prices, minimize costs, to scale up their business, customer needs different to traditional customer needs, price competition.

\section{Validity and reliability}

We used R software to analyse data. Using Dillon-Goldstein's rho (DG. Rho), average variance extracted (AVE) and composite reliability (CR) the convergent and discriminant validity and internal consistency were examined. Table 2 illustrates the items loadings (the items that have loadings less than a threshold value of 0.60 were dropped), DG. Rho, AVE, and CR for the model components. All displayed acceptable validity and reliability of the used measurements. 
Table 8: Measurement items and internal validity

\begin{tabular}{|c|c|c|c|c|c|}
\hline Construct & Items & Factor loadings & DG. Rho & AVE & CR \\
\hline \multirow{3}{*}{ Environment } & Q12_4 & 0.78 & \multirow{3}{*}{0.78} & \multirow{3}{*}{0.54} & \multirow{3}{*}{0.78} \\
\hline & Q12_5 & 0.71 & & & \\
\hline & Q12_6 & 0.71 & & & \\
\hline \multirow{2}{*}{ Technology } & Q12_7 & 0.94 & \multirow{2}{*}{0.95} & \multirow{2}{*}{0.9} & \multirow{2}{*}{0.95} \\
\hline & Q12_8 & 0.95 & & & \\
\hline \multirow{5}{*}{ Innovation } & Q13_2 & 0.75 & \multirow{5}{*}{0.86} & \multirow{5}{*}{0.55} & \multirow{5}{*}{0.86} \\
\hline & Q13_7 & 0.67 & & & \\
\hline & Q13_8 & 0.81 & & & \\
\hline & Q13_9 & 0.67 & & & \\
\hline & Q13_10 & 0.78 & & & \\
\hline \multirow{4}{*}{ Level of BMI } & Q6_1 & 0.84 & \multirow{4}{*}{0.87} & \multirow{4}{*}{0.62} & \multirow{4}{*}{0.87} \\
\hline & Q6_2 & 0.80 & & & \\
\hline & Q6_3 & 0.71 & & & \\
\hline & Q6_8 & 0.81 & & & \\
\hline \multirow{4}{*}{ BMI outcomes } & Q9_4 & 0.84 & \multirow{4}{*}{0.91} & \multirow{4}{*}{0.71} & \multirow{4}{*}{0.91} \\
\hline & Q9_5 & 0.90 & & & \\
\hline & Q9_6 & 0.85 & & & \\
\hline & Q9_7 & 0.78 & & & \\
\hline \multirow{6}{*}{ Performance } & Q14_1 & 0.88 & \multirow{6}{*}{0.95} & \multirow{6}{*}{0.74} & \multirow{6}{*}{0.94} \\
\hline & Q14_2 & 0.92 & & & \\
\hline & Q14_3 & 0.87 & & & \\
\hline & Q14_5 & 0.80 & & & \\
\hline & Q14_6 & 0.85 & & & \\
\hline & Q14_7 & 0.85 & & & \\
\hline
\end{tabular}

Dillon-Goldstein's rho values were all above the threshold of 0.70 . The AVE values ranged from 0.54 to 0.95 , which is above the recommended threshold of 0.50 . Therefore, we can conclude that there is the internal consistency of the items. After the internal consistency was tested, we examined discriminant validity. Table 3 shows that values for established discriminant validity are larger than other correlation values among the latent variables (Fornell \& Larcker, 1981). Based on this we can determine that discriminant validity is not an issue. 
M. Marolt, G. Lenart, M. Kljajić Borštnar, D. Vidmar \& A. Pucihar: SMEs Perspective on Business Model Innovation

Table 9: Discriminant validity of measurement model

\begin{tabular}{|l|c|c|c|c|c|c|}
\hline & ENV & TECH & INNOV & LBMI & BMIO & PERF \\
\hline Environment & $\mathbf{0 . 7 4}$ & & & & & \\
\hline Technology & 0.63 & $\mathbf{0 . 9 5}$ & & & & \\
\hline Innovativeness & 0.38 & 0.40 & $\mathbf{0 . 7 4}$ & & & \\
\hline Level of BMI & 0.46 & 0.40 & 0.54 & $\mathbf{0 . 7 9}$ & & \\
\hline BMI outcomes & 0.40 & 0.54 & 0.49 & 0.56 & $\mathbf{0 . 8 4}$ & \\
\hline Performance & 0.33 & 0.32 & 0.29 & 0.38 & 0.29 & $\mathbf{0 . 8 6}$ \\
\hline
\end{tabular}

\section{Structural model analysis and hypotheses testing}

The conceptual research model has been examined using PLS-PM technique. We obtained Goodness-of-Fit index value of about 0.41 , which is considered as the slightly large effect size of $\mathrm{R}^{2}$, thus, indicating an adequate global validation of the overall PLS model.

The results are presented in Figure 4 and show that four out of five hypotheses were supported. Environment and innovation are positively associated with the level of BMI ( $\beta=0.26, p<0.05$ and $\beta=0.41, p<0.01$ respectively), while technology in our case is not associated with the level of BMI. Moreover, the level of BMI was found to positively and significantly contribute to BMI outcomes $(\beta=0.56, p<0.01)$. Similarly, BMI outcomes are positively associated with performance $(\beta=0.29, \mathrm{p}<0.05)$.

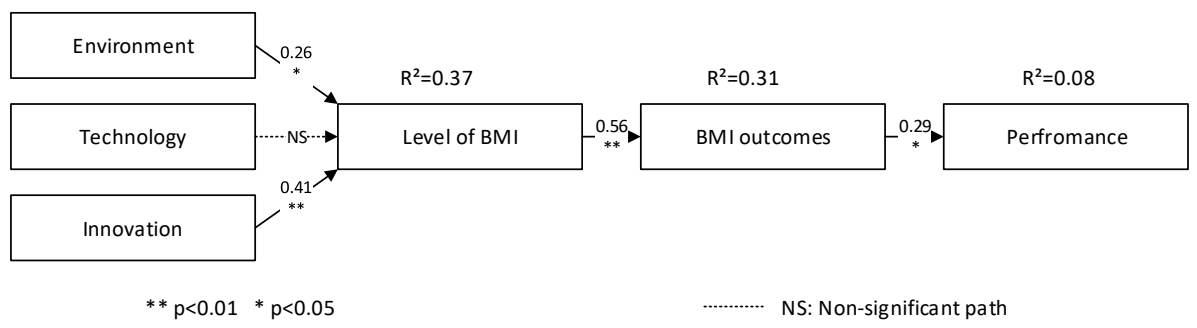

Figure 21: Empirical results

\section{Discussion}

The empirical results revealed that environment as external factor and innovation as an internal factor have an effect on the level of BMI. Therefore, this research results support theoretical foundations that combination of internal and external drivers stimulates BMI. Furthermore, a non-significant relation was found for the relation between technology and the level of BMI. This finding counters existing research (e.g. Bouwman et al., 2018) which found that technology is positively associated with BMI. A possible explanation is that this study has focused on the tangible technology, while the intangible technology assets (e.g. specialized IT personnel) may be more crucial than tangible. Therefore, the 


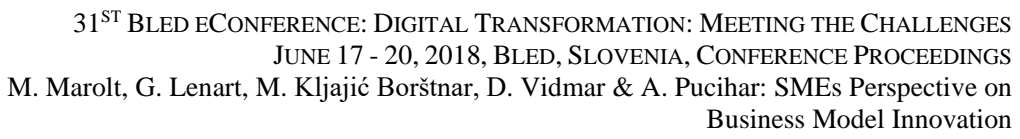

results of this study support the idea that technology per se does not play a key role in the BMI.

The level of BMI construct is presented by the level of novelty of BMI for the enterprise or the industry. The results suggest a positive relationship between the level of BMI and $\mathrm{BMI}$ outcomes. This finding supports previous research suggesting that BMI is related to BMI outcomes (Heikkilä et al., 2018). Therefore, the characteristics of the level of BMI make it suitable to enhance efficient BMI, which, in turn, leads to higher BMI outcomes. The BMI outcomes are necessary changes in BM. As hypothesized in this study the BMI outcomes have a positive impact on enterprise overall business performance. The results are consistent with the study conducted by Giesen, Berman, Bell, \& Blitz (2007) that provides insights on how different types of BM changes can lead to improved business performance. Our study has confirmed that the cogent changes in BM lead to the improved overall business performance of the SMEs.

\section{Practical implications}

Our study confirmed that environment (competitors' behaviour and changing customer preferences) and level of enterprise innovativeness (dynamic of innovation) have a positive impact on the level of BMI (the level of BMI novelty). Level of BMI mainly resulted in changes in business processes and ICT (outcomes), which have a positive impact on overall performance.

These results confirm that in the digital economy, business model innovation is one of the key activities, that has to be continuously undertaken in every enterprise, either to survive or to achieve growth (Hanelt, Hildebrandt, \& Polier, 2015). However, systematic approach with proper methods and tools is a key to successful BMI.

Our observations and awareness of challenges that many SMEs face with (e.g. limited number of employees, knowledge, and skills) have confirmed the limited use of BM methods (e.g. Canvas) and tools (e.g. spreadsheets like Excel) for BMI. Consequently, SMEs managers/owners do not have a complete overview on how they create, capture and deliver value for enterprises and the customers. This may lead to inefficient decisionmaking, overall inefficiency, and lower competitiveness. Therefore, if SMEs want to successfully innovate their BM they need to use available BM methods and tools more systematically and comprehensively. Systematic and cogent changes in the individual elements of BM are not only made to satisfy customers but also to differentiate from competition and achieve competitive advantages.

Furthermore, it seems that more innovative SMEs are more prone to innovate their BMs and are able to change them in a way that are different from BM of their competitors. The environmental pressure is another driver that motivates SMEs to innovate their BM differently than their competition. Surprisingly, information technology was not recognized by SMEs to have an influence on the level of BMI novelty. Information technology is often identified as an enabler and supporter in realization of enterprises strategy and goals. While there is a variety of information technologies and solutions 
targeting SMEs needs available on the market it is often quite challenging for SMEs to recognize their needs and adopt the most appropriate ones. According to a recent report from OECD, the lack of investments as well as also lack of personnel, knowledge, and skills hinder the adoption of digital technologies in SMEs (OECD, 2017). Therefore, the government should support SMEs in a form of tax relief and alternative funding ways. Furthermore, SMEs should put more emphasis on continuous learning and ICT skills development.

As regards to BMI outcomes and performance, the findings indicate that the level of BMI novelty impact the changes in the way SMEs are doing business and consequently help them to be more successful on the market. Therefore, if SMEs want to achieve competitive advantage they should try to make changes in BM that will differentiate them from competitors.

\section{Conclusions}

This paper aimed to explore the external and internal drivers and outcomes of BMI. Among 71 Slovenian SMEs that have participated in the study, only 25 percent have innovated their BM in the last two years; however, all of them had experiences with BMI. Interestingly, the majority of SMEs who have experimented with BMI did not dedicate specific funds or established team for this purpose. Furthermore, the majority of SMEs claimed that they are not using specific methods and tools for BMI. Nevertheless, they are using computer-based tools, especially spreadsheets.

Overall, the results of hypotheses testing suggest that internal as well as external drivers have a positive impact on SMEs level of BMI. Noteworthy, the technology was not recognized as a BMI driver. Furthermore, the level of BMI has a positive impact on BMI outcomes. Moreover, the BMI outcomes positively associate with overall performance outcomes.

Even though this study has focused on several BMI issues, there are several limitations which highlight opportunities for further research. First, the research findings are based on one geographical region. The comparison of these finding with other European countries could provide insights regarding differences in BMI. Second, the responses were provided only by the owners or managers who are involved in BMI. Therefore, further research could include different roles (not only owners/managers but also other employees who are involved in BMI) in the enterprise, which may reflect in different perceptions of BMI. Third, this study offers only partial insights on a vast area of BM and BMI research. Therefore, the future studies should give more emphasis on different drivers, more detailed BMI practices as well as BMI outcomes. 


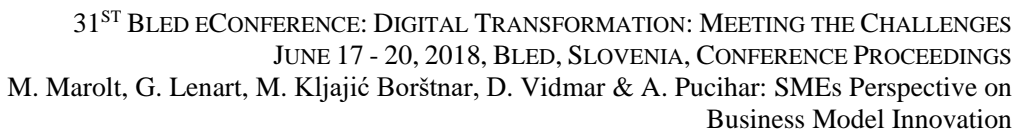

\section{Acknowledgement}

The work leading to these results has received funding from European Community's Horizon 2020 Program (2014-2020) under grant agreement 645791. The content herein reflects only the authors' view. The European Commission is not responsible for any use that may be made of the information it contains.

\section{References}

2003/361/EC, E. (2003). Commission recommendation 2003/361/EC of 6 May 2003 concerning the definition of micro, small and medium-sized enterprises. Official Journal of the European Union, 124(36), 36-41.

Amit, R., \& Zott, C. (2001). Value creation in E-business. Strategic Management Journal, 22(67), 493-520. https://doi.org/10.1002/smj.187

Andreini, D., \& Bettinelli, C. (n.d.). Business Model Innovation: From Systematic Literature Review to Future Research Directions.

Barjak, F., Es-Sadki, N., \& Arundel, A. (2015). The effectiveness of policies for formal knowledge transfer from European universities and public research institutes to firms. Research Evaluation, 24(1), 4-18. https://doi.org/10.1093/reseval/rvu024

Bouwman, H., Faber, E., Haaker, T., Kijl, B., \& De Reuver, M. (2008). Conceptualizing the STOF Model. In H. Bouwman, H. de Vos, \& T. Haaker (Eds.), Mobile Service Innovation and Business Models (pp. 31-70). Springer Publishing Company, Incorporated. Retrieved from http://dl.acm.org/citation.cfm?id=1951590

Bouwman, H., Nikou, S., Molina-Castillo, F. J., \& de Reuver, M. (2018). The impact of digitalization on business models. Digital Policy, Regulation and Governance, 20(2), 105-124. https://doi.org/10.1108/DPRG-07-2017-0039

Bouwman, H., Vos, H. de., \& Haaker, T. (2008). Mobile service innovation and business models. Springer.

Bouwman, H., Zhengjia, M., Duin, P. Van Der, \& Limonard, S. (2008). A business model for IPTV $\begin{array}{lllll}\text { service: a dynamic } & \text { framework. }\end{array}$ https://doi.org/10.1108/14636690810874377

Chesbrough, H., \& Rosenbloom, R. S. (2002). The role of the business model in capturing value from innovation: evidence from Xerox Corporation's technology spin-off companies. Industrial and Corporate Change, 11(3), 529-555. https://doi.org/10.1093/icc/11.3.529

Clauss, T. (2017). Measuring business model innovation: conceptualization, scale development, and proof of performance. $R \& D$ Management, 47(3), 385-403. https://doi.org/10.1111/radm.12186

Cucculelli, M., \& Bettinelli, C. (2015). Business models, intangibles and firm performance: evidence on corporate entrepreneurship from Italian manufacturing SMEs. Small Business Economics, 45(2), 329-350. https://doi.org/10.1007/s11187-015-9631-7

DaSilva, C. M., \& Trkman, P. (2014). Business Model: What It Is and What It Is Not. Long Range Planning, 47(6), 379-389. https://doi.org/10.1016/J.LRP.2013.08.004

Desyllas, P., \& Sako, M. (2013). Profiting from business model innovation: Evidence from PayAs-You-Drive auto insurance. Research Policy, 42(1), 101-116. https://doi.org/10.1016/J.RESPOL.2012.05.008

El Sawy, O. A., \& Pereira, F. (2013). Business Modelling in the Dynamic Digital Space. Berlin, Heidelberg: Springer Berlin Heidelberg. https://doi.org/10.1007/978-3-642-31765-1

Fornell, C., \& Larcker, D. F. (1981). Evaluating Structural Equation Models with Unobservable Variables and Measurement Error. Journal of Marketing Research, 18(1), 39. https://doi.org/10.2307/3151312 
Foss, N. J., \& Saebi, T. (2017a). Fifteen Years of Research on Business Model Innovation. Journal of Management, 43(1), 200-227. https://doi.org/10.1177/0149206316675927

Foss, N. J., \& Saebi, T. (2017b). Fifteen Years of Research on Business Model Innovation. Journal of Management, 43(1), 200-227. https://doi.org/10.1177/0149206316675927

Giesen, E., Berman, S. J., Bell, R., \& Blitz, A. (2007). Three ways to successfully innovate your business model. Strategy \& Leadership, 35(6), 27-33. https://doi.org/10.1108/10878570710833732

Haaker, T., Bouwman, H., Janssen, W., \& de Reuver, M. (2017). Business model stress testing: A practical approach to test the robustness of a business model. Futures, 89, 14-25. https://doi.org/10.1016/J.FUTURES.2017.04.003

Hanelt, A., Hildebrandt, B., \& Polier, J. (2015). Uncovering the Role of Is in Business Model Innovation - a Taxonomy-Driven Aproach To Structure the Field. Twenty-Third European Conference on Information Systems (ECIS), (2010), 1-18.

Hartmann, M., Oriani, R., \& Bateman, H. (2013). The Performance Effect of Business Model Innovation: An Empirical Analysis of Pension Funds. In 35th DRUID Celebration Conference (pp. 17-19).

Hartmann, M., Zaki, M., Feldmann, N., \& Neely, A. (2016). Capturing value from big data - a taxonomy of data-driven business models used by start-up firms. International Journal of Operations \& Production Management, 36(10), 1382-1406. https://doi.org/10.1108/IJOPM02-2014-0098

Heikkilä, M., Bouwman, H., \& Heikkilä, J. (2018). From strategic goals to business model innovation paths: an exploratory study. Journal of Small Business and Enterprise Development, 25(1), 107-128. https://doi.org/10.1108/JSBED-03-2017-0097

Huang, H.-C., Lai, M.-C., Kao, M.-C., \& Chen, Y.-C. (2012). Target Costing, Business Model Innovation, and Firm Performance: An Empirical Analysis of Chinese Firms. Canadian Journal of Administrative Sciences / Revue Canadienne Des Sciences de l'Administration, 29(4), 322335. https://doi.org/10.1002/cjas.1229

Hult, G. T. M., Hurley, R. F., \& Knight, G. A. (2004). Innovativeness: Its antecedents and impact on business performance. Industrial Marketing Management, 33(5), 429-438. https://doi.org/10.1016/J.INDMARMAN.2003.08.015

Jaworski, B. J., \& Kohli, A. K. (1993). Market orientation: antecedents and consequences. The Journal of Marketing, 57(3), 53-70.

Johnson, M. W., \& Christensen, C. M. Kagermann, H. (2008). Reinventing Your Business Model. Harvard Business Review, 86(12), 50-68.

Lambert, S. C., \& Davidson, R. A. (2013). Applications of the business model in studies of enterprise success, innovation and classification: An analysis of empirical research from 1996 to 2010. European Management Journal, 31(6), 668-681. https://doi.org/10.1016/j.emj.2012.07.007

Laudien, S. M., \& Daxböck, B. (2017). Business model innovation processes of average market players: a qualitative-empirical analysis. $R \& D$ Management, 47(3), 420-430. https://doi.org/10.1111/radm.12208

OECD. (2017). Enhancing the contributions of SMEs in a global and digitalised economy. Paris. Retrieved from https://www.oecd.org/mcm/documents/C-MIN-2017-8-EN.pdf

Osterwalder, A., \& Pigneur, Y. (2010). Business Model Generation: A Handbook for Visionaries, Game Changers, and Challengers. Wiley.

Osterwalder, A., Pigneur, Y., \& Tucci, C. L. (2005). Clarifying Business Models: Origins, Present, and Future of the Concept. Communications of the Association for Information Systems.

Ross, J. W., Weill, P., \& Robertson, D. (2006). Enterprise architecture as strategy: creating a foundation for business execution. Harvard Business School Press.

Santos, J., Spector, B., \& Van Der Heyden, L. (2009). Toward a Theory of Business Model 
Innovation within Incumbent Firms. Retrieved from http://org.business.utah.edu/opsconf/pages/vanderHeyden_Paper.pdf

Subramanian, A. (1996). Innovativeness: Redefining the concept. Journal of Engineering and Technology Management, 13(3-4), 223-243. https://doi.org/10.1016/S0923-4748(96)01007-7

Teece, D. J. (2010). Business Models, Business Strategy and Innovation. Long Range Planning, 43(2-3), 172-194. https://doi.org/10.1016/j.lrp.2009.07.003

Venkatraman, N., \& Ramanujam, V. (1986). Measurement of Business Performance in Strategy Research: A Comparison of Approaches. Academy of Management Review, 11(4), 801-814. https://doi.org/10.5465/AMR.1986.4283976

Zott, C., \& Amit, R. (2007). Business Model Design and the Performance of Entrepreneurial Firms. Organization Science, 18(2), 181-199. https://doi.org/10.1287/orsc.1060.0232

Zott, C., \& Amit, R. (2008). The fit between product market strategy and business model: implications for firm perfromance. Strategic Management Journal Strat. Mgmt. J, 29, 1-26. https://doi.org/10.1002/smj.642

Zott, C., \& Amit, R. (2010). Business Model Design: An Activity System Perspective. Long Range Planning, 43(2-3), 216-226. https://doi.org/10.1016/J.LRP.2009.07.004

Zott, C., Amit, R., \& Massa, L. (2011). The Business Model: Recent Developments and Future Research. Journal of Management, 37(4), 1019-1042. https://doi.org/10.1177/0149206311406265 
592 31 $31^{\text {ST }}$ Bled eConference: Digital TRANSFormation: MeEting the Challenges JunE 17 - 20, 2018, BLED, SLOVEnIA, CONFERENCE PROCEEDINGS 


\title{
Comparative Study of Sharing Economy Business Models in Accommodation Sector
}

\author{
RIMANTAS GATAUTIS $\dagger$, EgLĖ VAIČIUKYNAITĖ \& ElENA VITKAUSKAITĖ
}

\begin{abstract}
Recently, the sharing economy continued growing and creating new business models (BMs) and in turn, generating new challenges for traditional business models. As existing studies usually compare sharing economy business models versus more traditional ones in the accommodation sector, this study aims to explore differences of accommodation sector shared economy business models. This study used a comparative analysis following a framework of Business Model Canvas by Osterwalder and Pigneur (2010). The data on two shared economy business models (global Airbnb and local Trumpam.lt) was collected from secondary sources. The findings indicate that the analysed BM of Airbnb ensures their success in comparison with local company's BM. The main differences involve many components of BM such as segments, value propositions, customer relationships, communication channels, key activities, partners, revenue streams, and costs. This study offers a starting point for accommodation sector researchers to contribute to the shared economy business models. Future research may include interviews with sharing economy company's founders and provide a more detailed case analysis.
\end{abstract}

Keywords: • Accomodation sector $・$ Airbnb $\bullet$ Business Model $\bullet$ Business Model Canvas $\bullet$ Comparative study $\bullet$ Sharing Economy $\bullet$ Trumpam.lt •

CORRESPONDENCE ADDRESS: Rimantas Gatautis $\dagger$,Kaunas University of Technology, Lithuania. Eglè Vaičiukynaitė, Kaunas University of Technology, Lithuania, egle.vaiciukynaite@ktu.lt. Elena Vitkauskaitè, Kaunas University of Technology, Lithuania, elena.vitkauskaite@ktu.lt.. 
The rapid development of information communication technologies (ICT) has empowered users to create their content, share information, collaborate, and make transactions through digital platforms (Wang and Nicolau, 2017). Sharing economy has emerged recently as a response to the environment, socio-cultural and globalization concerns (Bratianu, 2018; Cohen and Kietzmann, 2014). The sharing economy describes organizations that connect users/renters and owners/providers through diverse types of digital platforms, such as consumer-to-consumer (C2C) (e.g., Airbnb) or business-toconsumer (B2C) platforms (e.g., Zipcar) (Parente et al., 2017).

Nowadays sharing economy is in the process of transforming the diverse range of sectors including accommodation, mobility, and logistics, labour,and service, food, and dining, financial services, goods and equipment (Akbar and Tracogna, 2018; Mody et al., 2017; Plenter et al., 2017). As a result, the new type of business models (BM) known as sharing economy has emerged (Wang and Nicolau, 2017). The pioneer of the sharing economy is Airbnb that connects owners of diverse types of accommodations with customers looking for a place for stay (Gyódi, 2017). Moreover, previous studies paid more attention to new types of BM such as social BM and data-driven BM (DDBMs) (Hartmann et al., 2016; Rantala et al., 2018; Spiess-Knafl et al., 2015). Thus, the recent study by Li (2018) has provided a detailed analysis of the new BMs and traditional BMs of the creative industry. However, the BM of sharing economy remains poorly explored in the literature.

Only a few studies to the date focused on accommodation sector, despite the growing number of studies in sharing economy BM in many other sectors, such as financial (e.g., Lending Club) and transportation services (e.g., Uber) (Lee and Shin, 2018; Cohen and Kietzmann, 2014; Yang et al., 2017). However, Tussyadiah and Sigala (2018) argued that the accommodation sector is one the most important sectors in the travel and tourism industry.Few studies used a comparative analysis and showed similarities, and differences between sharing economy BM (Airbnb) versus traditional BM (Booking.com or a Hotel chain; see Gyódi, 2017; Parente et al., 2017). Nonetheless, no studies analysed various sharing economy BMs in accommodation sector, to the best of authors' knowledge. Therefore, this context presupposes the research question: what are peculiarities of shared economy business models in accommodation sector? To tackle the research question, this study aims to explore differences of accommodation sector shared economy business models.

Following Laudien and Daxböck (2017), the study uses a qualitative research design because it enables to gain rich data and more in-depth understanding of sharing economy BMs. More specifically, this study has applied a comparative analysis of two cases: a global one (Airbnb), and a local one (Trumpam.lt).

The main contributions of this study are twofold. First, this study will contribute to the theoretical discussion about sharing economy BMs. Second, to the best of authors knowledge, this is the first attempt to compare sharing economy BMs in the 


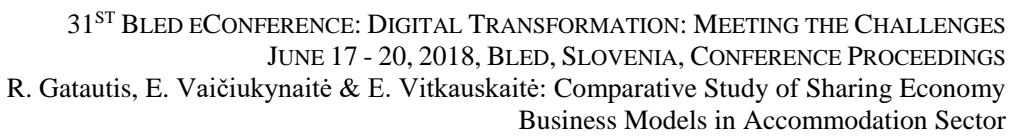

accommodation sector. Further, this paper contributes to research on travel and tourism industry and accommodation sector more specifically.

\section{Literature Review on Sharing Economy Business Models, and Accommodation Sector}

Recently, the notion of "sharing economy" has received attention from researchers and practitioners. Sharing economy (or crowd-based capitalism) has occurred at scale around 2010 (Sundararajan, 2016). Botsman and Rogers (2010) note that sharing (or Collaborating Consumption) is not a niche trend or even the response to the 2008 global financial crisis but its growing movement with millions of people participating from the entire World. Despite the popularity of the term, academic literature identifies some common misconceptions which are related to its novelty (Frenken and Schor, 2017). Historically, the term "sharing" does not present anything new (Sundararajan, 2016). Indeed, long time ago people tended to share their food, room with their community members.

The new phenomenon of sharing economy is associated with the term "strangers sharing" (Frenken, and Schor, 2017). This new phenomenonis mainly driven by ICT and is enabledthrough social networks. For instance, community (peers) are connected through ICTs and can share their resources such as goods and services on digital platforms (Bernardi, 2018). However, this digital community empowered by technologies is extended far beyond the traditional community members such as family, relatives and close friends. Indeed, sharing economy companies are specialised in the virtual environment, use data-driven platforms targeted to reduce users' search and information costs and increase their opportunities to monitor transactions or evaluate risks (Parente et al., 2017). For instance, users do have a capacity to read reviews and ratings. Therefore, these changes create new opportunities for companies that can launch new BMs in sharing economy while are disrupting traditional BMs.

Scientific debates on the concepts of business models began several decades ago. Despite the attention, the understanding of BM still has diverse interpretations in literature. Most often, researchers have focused on one or several facets of the entire BM definition. For instance, Baden-Fuller and Haefliger (2013) have noted BM as a system and provided a typology with four dimensions; namely, customer identification, customer engagement, value delivery, and monetization. Also, several authors propose a unified BM framework, synthesising the existing literature (Morris et al., 2005; Al-Debei and Avison, 2010). More specifically, Al-Debei and Avison (2010) reviewed 22 concepts of BM from 19982008 and offered a comprehensive concept of BM. Following the concept, BM entails fourmajor facets (i.e., the four value dimensions of BMs; modelling principles, BM reach, and $\mathrm{BM}$ functions) and covers 13 classes. In essence, BM has been defined as " $a$ presentation of how a business creates and delivers value, both for the customer and the company" (Johnson, 2010; p. 22; Osterwalder and Pigneur, 2010). Similarly, BM is defined by De Reuver et al. (2013) and Haaker et al. (2017). The study uses the definition 
of BM by Osterwalder and Pigneur (2010; 14 p.): "A business model describes the rationale of how an organization creates, delivers, and captures value."

Traditional BMs and sharing economy BMs are diverse, and the latter BMs contain several key elements. For instance, Richardson (2015) provided three elements of the sharing economy such as digital 'platform', peer-to-peer and access-based. Moreover, Piscicelli et al (2018) noted that the success of sharing-based BMs assumes beyond traditional metrics such as financial profitability (i.e., revenue) and involve metrics such as the platform's market penetration, the type and level of user engagement, and the social and environmental impact.

Regarding accommodation sector, the sharing economy plays a vital role in different industries, but an impact on hotel industry is undeniable. The most prominent example is Airbnb (Ert et al., 2016). Airbnb is a digital platform (P2P) that enables individuals (hosts) rent their living space to other individuals (guests) who seek short-term accommodation (Ert et al., 2016). Recently, the Airbnb is growing exponentially and its impact remarkable. For instance, Airbnb's supply is the highest in Austin (US) and the impact on hotel industry is approx. 8\%-10\% range (Zervas at al., 2017). Moreover, the impact is highest for the lower-priced hotels (Zervas at al., 2017). In other words, the Airbnb is changing the traditional hotel market. Indeed, due to the development and use of ICT in many industries, traditional BMs are disrupted, and new BMs occur such as social BM, data-driven BM (DDBMs) (Hartmann et al., 2016; Rantala et al., 2018; Spiess-Knafl et al., 2015) or even sharing economy BMs.Moreover, previous studies have mainly noted that the shared accommodation market is different from the traditional accommodation market because it offers different hospitality experiences (i.e., "authentic experience") and thus, denotes new market (Sigala, 2018). Indeed, the traditional market includes tourist renting rooms from formal business (i.e., hotels) while Airbnb provides an online marketplace that enables a large-scale rental of spaces from one person to another ("peerto-peer" accommodation) (Guttentag, 2015).

\section{$3 \quad$ Methodology}

The objective of this paper is to explore differences of accommodation sector shared economy business models. The qualitative research design was chosen following Laudien and Daxböck (2017). The study uses a qualitative research design because it enables to gain rich data and more in-depth understanding of sharing economy BMs. Moreover, a qualitative research design was employed widely in the recent studies of BMs or combined with the quantitative survey (Cortimiglia et al., 2016; Heikkilä et al., 2017; Li, 2018). However, this study has applied a comparative analysis.

As a basis for the comparative analysis of business models, this study uses a Business Model Canvas (Osterwalder and Pigneur, 2010). It is the most popular approach widely accepted by practitioners and academics. Besides, earlier studies have applied a business model logic but used only six elements (Hartmann et al., 2016). The nine elements of business model empower to compare both companies and provide a more detailed 
analysis of their features. The Business Model Canvas includes following building blocks: value proposition, customer segments, channels, customer relations, key activities, key resources, key partners, revenue streams, and cost structure.

The cases for comparison were selected based on following criteria: 1) they have to be operating in accommodation sector, 2) have to meet the three main features of sharing economy companies as defined by Parente et al. (2017; p. 54): "a) the business focuses on unlocking the value of unused or underutilized assets; $b$ ) consumers pay for temporary access instead of ownership using an internet-based platform; c) it relies on $C 2 C$ interactions and network effects for growth". In addition to these criteria, authors sought to compare a business operating globally versus one operating locally. For global case Airbnb was chosen as to facilitate comparability of the findings to other existing research on accommodation sector shared economy business models (Gyódi, 2017; Parente et al., 2017). To choose a local case a Lithuanian market was chosen because of the convenience of understanding sources in local language.

To collect the data for the comparison of the selected cases authors have searched titles, keywords and abstracts for "sharing economy" (lit. "dalinimos iekonomika"), brand names of selected cases and "business model" through Emerald Insight, and (Scholar) Google. Researchers reviewed secondary sources one by one and narrowed the list of references based on its relevance to the main focus of the study and to ones that were more recent and up-to-date. For each case, selected sources were analyses and used until the sufficient information for the description of nine components of both BMs was reached. Therefore, this study uses a broad set of information sources and is sufficient to define BMs (Hartmann et al., 2016).

\section{$4 \quad$ Results}

In Lithuania, two local cases were identified that fit the two core criteria: Trumpam.lt and dayrent.lt. Further analysis revealed that dayrent.lt is one of the sub-brands of Trumpam.lt. Therefore Trumpam.lt case was chosen for further analysis.

Data collection for the cases resulted in twelve sources in total for Airnbn, and three references for Trumpam.lt were retrieved. 
R. Gatautis, E. Vaičiukynaite \& E. Vitkauskaitè: Comparative Study of Sharing Economy Business Models in Accommodation Sector

Table 1: An overview of secondary sources selected

\begin{tabular}{|l|l|l|}
\hline Secondary sources & \multicolumn{1}{|c|}{ Airbnb } & \multicolumn{1}{c|}{ Trumpam.lt } \\
\hline Research publications & Akbar and Tracogna & - \\
& (2018); Bernardi (2018); & \\
& Guttentag and Smith & \\
& (2017); Parente et al. & \\
& (2017); Zervas at al.(2017) & \\
\hline Online articles, blogs & Gerdeman (2018); Martin & Galdikaitè (2018), \\
& (2017); Zadarackas & Rudzevičiūtè, (2014) \\
& $(2016) ;$ Butler (2018); & \\
& Jardine (2018); Kurdabar & \\
(2017) & Trumpam (2018a) \\
\hline Company's web sites & Airbnb (2018a) & Trumpam (2018b) \\
\hline $\begin{array}{l}\text { Company's social } \\
\text { media }\end{array}$ & Airbnb (2018b, 2018c, & \\
\hline
\end{tabular}

Airbnb is a provider of travel accommodation and has served thirty million consumers without owning even a single room but the reservation system (Akbar and Tracogna, 2018; Parente et al., 2017). Airbnb has hosts share their living space in 191 countries and 81,000 cities list home (Airbnb, 2018). Thus, Airbnb offers a vast variety of atypical places to stay, including treehouses, a seashell house, and even castles (Cheng and Foley, 2018). For instance, Airbnb has nearly 1,400 treehouses and 3,000 castles (Airbnb, 2018). Recently, Airbnb has launched its offerings to an additional 1,000 cities (Gerdeman, 2018). Parente et al. (2017) compared it to traditional hotels and highlighted that Airbnb has their reservation system but do not have properties. On the other hand, the hotel has their property but relies heavily on search engines for reservations. Hence, Airbnb presents a substitute to the hotel industry (Stone, 2017) and is the major player in the market.

Trumpam.lt is a Lithuanian company which owns an online platform that enables users to lease or rent a short-term room, flat and/or apartment in Lithuania. The company covers a wide range of cities and resorts in Lithuania. Trumpam.lt also provides a great variety of accommodation choices. For instance, from a night at studio flat for 22 EUR to a night in an apartment for 204 EUR in Old Town of the capital city Vilnius.

Table 2 summarises the comparison of the sharing economy business models of Airbnb and Trumpam.lt based on Business Model Canvas. 
R. Gatautis, E. Vaičiukynaitė \& E. Vitkauskaitė: Comparative Study of Sharing Economy Business Models in Accommodation Sector

Table 2: A comparative analysis of business models of Airbnb and Trumpam.lt.

\begin{tabular}{|c|c|c|}
\hline $\begin{array}{l}\text { Business Model } \\
\text { building block }\end{array}$ & Airbnb & Trumpam.lt \\
\hline $\begin{array}{l}\text { Customer } \\
\text { segments }\end{array}$ & $\begin{array}{l}\text { - Global travellers (luxury } \\
\text { (celebrities) })^{1} \text { (millennials) } \\
\text { travellers, business travellers, } \\
\text { family travellers, solo (group) } \\
\text { travellers who enjoy contact with } \\
\text { local, price-sensitive travellers } \\
\text { - Global hosts (e.g., room, house, } \\
\text { apartment, castles) }\end{array}$ & $\begin{array}{l}\text { - Travellers (business travellers, } \\
\text { family travellers, solo (group) } \\
\text { travellers). Mainly, local and } \\
\text { neighbour (e.g., Russia, Poland) } \\
\text { travellers and price-sensitive } \\
\text { travellers } \\
\text { - Local hosts (e.g., room, house, } \\
\text { apartment, castles) } \\
\text { - Small or medium-sized } \\
\text { businesses that need their brand } \\
\text { awareness or online presence } \\
\text { (advertising) }\end{array}$ \\
\hline Value propositions & $\begin{array}{l}\text { Global travellers: A safe } \\
\text { overnight stay with less money in } \\
\text { any place in the World. } \\
\text { Benefits of value: } \\
\text { - Easy and fast way to get } \\
\text { accommodation place (e.g., room, } \\
\text { house, apartment) in any place in } \\
\text { the World; } \\
\text { - An opportunity to meet locals } \\
\text { and know more about the local } \\
\text { culture (e.g., food, the authentic } \\
\text { experience }{ }^{7} \text { ); } \\
\text { - An opportunity to get a unique } \\
\text { place. } \\
\text { Global hosts: An opportunity to } \\
\text { earn extra income by sharing } \\
\text { room, home, apartment and reach } \\
\text { travellers from different } \\
\text { countries. } \\
\text { Benefits of value: } \\
\text { - Airbnb provides home } \\
\text { protection Insurance for every } \\
\text { host and full of control of house } \\
\text { prices, rules; } \\
\text { - Airbnb enables functionality } \\
\text { that empowers them to enhance } \\
\text { traveller experience. }\end{array}$ & $\begin{array}{l}\text { Travellers: Several hours or an } \\
\text { overnight stay with less money } \\
\text { (without commissions) in unique } \\
\text { flats, apartments in Lithuania } \\
\text { Benefits of value: } \\
\text { - A convenient way to get } \\
\text { accommodation in Lithuania } \\
\text { (e.g., room, house, apartment). } \\
\text { Local hosts: An opportunity to } \\
\text { earn extra income by sharing } \\
\text { room, home, apartment } \\
\text { Benefits of value: } \\
\text { - Trumpam.lt offers an } \\
\text { opportunity to list host' space on } \\
\text { the online platform with limited } \\
\text { functionality; } \\
\text { - Low prices. } \\
\text { Smaller business: Advertising } \\
\text { services on the website } \\
\text { Trumpam.lt } \\
\text { Benefits of value: } \\
\text { - To promote products/ services } \\
\text { on the websiteTrumpam.lt and } \\
\text { reach brand's awareness }\end{array}$ \\
\hline Channels & $\begin{array}{l}\text { - Collaboration with celebrities } \\
\text { (endorsed marketing) }\end{array}$ & $\begin{array}{l}\text { - No special collaborations with } \\
\text { famous people; }\end{array}$ \\
\hline
\end{tabular}


R. Gatautis, E. Vaičiukynaitė \& E. Vitkauskaitė: Comparative Study of Sharing Economy Business Models in Accommodation Sector

\begin{tabular}{|c|c|c|}
\hline & $\begin{array}{l}\text { - Online media channels (e.g. } 15 \\
\text { min })^{2,3,4} \text {; } \\
\text { - Social media channels (e.g. } \\
\text { Facebook, Twitter, Instagram) } \\
\text { - Online platform. }\end{array}$ & $\begin{array}{l}\text { - Online platform; } \\
\text { - Dayrent.lt (sub-brand) provides } \\
\text { rent services for } 3 \text { hours and } \\
\text { promotes Trumpam.lt); } \\
\text { - Social media channel (e.g., } \\
\text { Facebook). }\end{array}$ \\
\hline $\begin{array}{l}\text { Customer } \\
\text { relationships }\end{array}$ & $\begin{array}{l}\text { - 24/7 customer support; } \\
\text { - Social media presence on } \\
\text { Facebook, Twitter, Instagram }\end{array}$ & $\begin{array}{l}\text { - Limited customer support by } \\
\text { email (i.e., specific form); } \\
\text { - Social media presence on } \\
\text { Facebook. }\end{array}$ \\
\hline Key resources & $\begin{array}{l}\text { - Airbnb brand; } \\
\text { - Platform; } \\
\text { - Information about hosts and } \\
\text { travellers (global network); } \\
\text { - Human capital (e.g., marketing } \\
\text { professionals, IT specialists, } \\
\text { Airbnb community members). }\end{array}$ & $\begin{array}{l}\text { - Trumpam.lt brand; } \\
\text { - Platform; } \\
\text { - Information on (local) hosts and } \\
\text { travellers; } \\
\text { - Human capital (e.g., owners and } \\
\text { marketing specialist). }\end{array}$ \\
\hline Key activities & $\begin{array}{l}\text { - Updating the platform; } \\
\text { - Maintenance of social media } \\
\text { presence (e.g., Instagram, } \\
\text { Facebook, Twitter); } \\
\text { - Collaboration with celebrities, } \\
\text { local bloggers } \\
\text {; } \\
\text { - Public relations management. }\end{array}$ & $\begin{array}{l}\text { - Updating the platform; } \\
\text { - Selling of advertising space on } \\
\text { the website; } \\
\text { - Maintenance of social media } \\
\text { presence (Facebook) and } \\
\text { dayrent.lt. }\end{array}$ \\
\hline Key activities & $\begin{array}{l}\text { - Updating the platform; } \\
\text { - Maintenance of social media } \\
\text { presence (e.g., Instagram, } \\
\text { Facebook, Twitter); } \\
\text { - Collaboration with celebrities, } \\
\text { local bloggers'; } \\
\text { - Public relations management. }\end{array}$ & $\begin{array}{l}\text { - Updating the platform; } \\
\text { - Selling of advertising space on } \\
\text { the website; } \\
\text { - Maintenance of social media } \\
\text { presence (Facebook) and } \\
\text { dayrent.lt. }\end{array}$ \\
\hline Partners & $\begin{array}{l}\text { - Communication partners (e.g., } \\
\text { Endorsed marketing); } \\
\text { - Online payment service (e.g., } \\
\text { PayPal, MasterCard), }\end{array}$ & - Online payments providers \\
\hline
\end{tabular}




\begin{tabular}{|c|c|c|}
\hline & $\begin{array}{l}\text { infrastructure providers (e.g., } \\
\text { website maintenance) } \\
\text { - Home protection insurance } \\
\text { partners }\end{array}$ & \\
\hline Revenue stream & $\begin{array}{l}\text { - A fee is applied both to hosts } \\
\text { and travellers (hosts pay } 3 \% \\
\text { administration fee, and travellers } \\
\text { pay approx. } 6 \% \text { to } 12 \% \text { fee) }\end{array}$ & $\begin{array}{l}\text { - A fee is applied only for hosts } \\
\text { (hosts pay for } 2,6 \text { or } 12 \text { months, } \\
\text { e.g., } 2 \text { months - 1,5 EUR) } \\
\text { - Advertising services (companies } \\
\text { buy advertising services on } \\
\text { company's website) }\end{array}$ \\
\hline Costs & $\begin{array}{l}\text { - Online platform maintenance; } \\
\text { - Human resources (e.g., Airbnb } \\
\text { community members, social } \\
\text { media specialists, 24/7 support } \\
\text { customer supporters); } \\
\text { - Host insurance; } \\
\text { - Celebrities sponsorship. }\end{array}$ & $\begin{array}{l}\text { - Online platform maintenance } \\
\text { - Human resources (e.g., selling } \\
\text { of advertising space, Facebook } \\
\text { administrator, advertising on } \\
\text { Facebook). }\end{array}$ \\
\hline
\end{tabular}

Notes: ${ }^{1}$ For instance, John Legend, Ariana Grande, Britney Spears, and Lady (Butler, 2018; Martin, 2017)1 ${ }^{2}$ Based on an article by Jardine (2018); ${ }^{3}$ Zadarackas (2016); ${ }^{4}$ Galdikaite (2018); ${ }^{5}$ Kurdabar (2017); ${ }^{6}$ Bernardi (2018); ${ }^{7}$ Guttentag and Smith (2017).

The findings of the analysis indicate that both companies' customer segments share similar characteristics such as young people who enjoy meeting locals and are pricesensitive. Meanwhile, hosts are motivated to earn extra money for renting services. Thus, Trumpam.lt has a segment who is interested in advertising services on their website. More importantly, the company does not provide the information about advertising services and prices.

Regarding value propositions for hosts, both companies enable hosts to earn some extra income for their renting services. More specifically, Trumpam.lt enables a smaller fee for hosts in compare to Airbnb (see Table 2) and does not include the unique functionality on their platform (e.g., the label of the new room, notifications about an experience of reviewers and their rating results). Additionally, Airbnb offers some extra benefits for hosts such as insurance.

Travellers can get a vast range of different solutions for renting services in different towns in Lithuania. For instance, Trumpam.lt can offer more than 214 places for renting in Palanga city while Airbnb offers more than 225 places. Airbnb enables to select the type of trip and arrange the searching by using a specific filter (functionality). Thus, travellers pay less for the Trumpam.lt but they do not trust the hosts less because some hosts do not include images. 
Airbnb uses more social communication channels such as Twitter, Facebook, and Instagram for both brand awareness and communication with customers, while Trumpam.lt uses the only Facebook channel for relations with customers. More specifically, Airbnb communicates with both segments hosts and travellers. Furthermore, Airbnb has the community members that do provide their opinions about Airbnb company or successful traveller's stories. On the contrary, the Trumpam.lt does pay more attention only fortravellers on Facebook and avoid to communicate the value for local hosts. Trumpam.lt does not have any more presence on online media, except several attempts to give their brand awareness in the very early stage of their start-up (Rudzevičiūtè, 2014).

Regarding key resources and cost structure, Airbnb does have more human resources than Trumpam.lt. Moreover, the Airbnb brand is more known than Trumpam.lt. Besides, Airbnb guarantees the insurance for all hosts and 24/7 customer support.

Revenue structure is different for both companies. Trumpam.lt platform gets the fee only from hosts while Airbnb gets fees from both parties (hosts and travellers). For instance, hosts pay 3\% of an administration fee, and travellers pay approx. 6 to $12 \%$ fee.

Finally, both platforms of Airbnb and Trumpam.lt have several differences which are associated with specific functionality on platform or features. For instance, Trumpam.lt does not include the feedback of previous travellers (e.g., rating functionality). Moreover, hosts have to provide their image on Airbnb while hosts of Trumpam.lt do not have the image. These mentioned features of platforms are important for P2P platforms and particularly for millennials (Bernardi, 2018; Ert et al., 2016). More specifically, the most recent study confirms that hosts with images are more trustworthy (Ert et al., 2016).

\section{$5 \quad$ Conclusions}

The study has explored differences of existing sharing economy business models in the context of accommodation sector. More specifically, the study investigated BM of Airbnb and compared it to the BM of Trumpam.lt. Findings indicated that both BMs have similarities such as primary customer segments (mainly millennials, price-sensitive travellers), communication channels (e.g., Facebook). Despite similarities, the most prominent differences lie with the customer segments (Trumpam.lt has a new segment of small and medium-sized companies which are interested in the advertising services), value propositions for hosts, communication channels, partners (Airbnb has more partners for their presence in ((local) global market), revenue streams, and different cost structure. Moreover, Trumpam.lt platform does not include some features (e.g., images or other relevant information of hosts) on their website as do provide Airbnb that ensures to meet millennials needs and wants.

There are several limitations to the study presented. First of all, analysing and comparing of only two cases is not enough to identify generalisable peculiarities of sharing economy business models in the accommodation sector. Analysis of more cases is needed, covering a wider variety of sharing economy businesses from accommodation sector. The second 
limitation is related to the fact that this study only used secondary sources to analyse the cases. This limitation was caused by limited availability of representatives of both companies during the time the study was conducted. In-depth analysis of the cases would enable a richer comparison of the cases and result in more significant contribution. Authors perceive current study as one of the first steps towards better understanding of sharing economy accommodation sector business models. Future research may include interviews with sharing economy company's founders and provide a more detailed case analysis.

\section{Acknowledgments}

We thank late professor Rimantas Gatautis who encouraged us to pursue this study. We deeply appreciate his inspiration and guidance for the research idea which will be developed as professor R. Gatautis expected.

\section{References}

Airbnb (2018a). Fast facts. Available at: https://press.atairbnb.com/fast-facts/[accessed 22 March 2018]

Airbnb (n.d.) (2018b). InFacebook. Available at: https://www.facebook.com/airbnb[accessed 14 May 2018]

Airbnb (n.d.) (2018c). In Twitter. Available at: https://twitter.com/airbnb[accessed 14 May 2018]

Airbnb (n.d.)(2018d). In Instagram. Available at: https://www.instagram.com/airbnb/[accessed 14 May 2018]

Akbar, Y. H., \&Tracogna, A. (2018). The sharing economy and the future of the hotel industry: Transaction cost theory and platform economics. International Journal of Hospitality Management, 71, 91-101.

Al-Debei, M. M., \&Avison, D. (2010). Developing a unified framework of the business model concept. European Journal of Information Systems, 19(3), 359-376.

Baden-Fuller, C., \&Haefliger, S. (2013). Business models and technological innovation. Long range planning, 46(6), 419-426.

Bernardi, M. (2018). Millennials, sharing economy and tourism: the case of Seoul. Journal of Tourism Futures, doi: 10.1108/JTF-12-2017-0055.

Botsman, R., \&Rogers, R.(2010), What's Mine Is Yours: The Rise of Collaborative Consumption. The United States of America, US: Harper Collins Publishers.

Bratianu C. (2018) The Crazy New World of the Sharing Economy. In: Vătămănescu EM., Pînzaru F. (eds) Knowledge Management in the Sharing Economy. Knowledge Management and Organizational Learning, vol 6. Springer: Cham.

Butler, A. (2018). Here are the Airbnbs that celebrities rented in 2017. Available at: https://www.lonelyplanet.com/news/2018/01/10/celebrity-airbnb-rentals/ [accessed 22 March 2018]

Cheng, M., \& Foley, C. (2018). The sharing economy and digital discrimination: The case of Airbnb. International Journal of Hospitality Management, 70, 95-98.

Cohen, B., \& Kietzmann, J. (2014). Ride on! Mobility business models for the sharing economy. Organization \& Environment, 27(3), 279-296.

Cortimiglia, M. N., Ghezzi, A., \& Frank, A. G. (2016). Business model innovation and strategy making nexus: evidence from a cross industry mixed methods study.R\&D Management,46(3), 414-432. 
R. Gatautis, E. Vaičiukynaitė \& E. Vitkauskaitė: Comparative Study of Sharing Economy Business Models in Accommodation Sector

Dayrent.lt (2018). Apie mus. Available at: https://www.dayrent.lt/LT/page/apie-mus/ [accessed 14 May 2018]

De Reuver, M., Bouwman, H., Haaker, T. (2013). Business model roadmapping: A practical approach to come from an existing to a desired business model. International Journal of Innovation Management, 17(01), [18 p.].

Ert, E., Fleischer, A., \& Magen, N. (2016). Trust and reputation in the sharing economy: The role of personal photos in Airbnb.Tourism Management,55, 62-73.

Frenken, K., \& Schor, J. (2017). Putting the sharing economy into perspective.Environmental Innovation and Societal Transitions,23, 3-10.

Galdikaitè, S. (2018). Kaip užsidirbti iš trumpalaikès nuomos - trijų vilniečių patirtys. Available at: https://bustas.lrytas.lt/nekilnojamasis-turtas/2018/03/20/news/kaip-neblogai-uzsidirbti-istrumpalaikes-nuomos-vilnieciu-patirtys-5206697/ [accessed 22 March 2018]

Gerdeman, D. (2018).The Airbnb Effect: Cheaper Rooms For Travelers, Less Revenue For Hotels. Available at: https://www.forbes.com/sites/hbsworkingknowledge/2018/02/27/the-airbnbeffect-cheaper-rooms-for-travelers-less-revenue-for-hotels/\#58d52683d672 [accessed 22 March 2018]

Guttentag, D. (2015). Airbnb: disruptive innovation and the rise of an informal tourism accommodation sector. Current issues in Tourism, 18(12), 1192-1217.

Guttentag, D. A., \& Smith, S. L. (2017). Assessing Airbnb as a disruptive innovation relative to hotels: Substitution and comparative performance expectations. International Journal of Hospitality Management, 64, 1-10.

Gyódi, K. (2017). Airbnb \& Booking.com: Sharing Economy Competing Against Traditional Firms? Available at: http://www.delab.uw.edu.pl/wpcontent/uploads/2017/09/WP_3_2017_K.Gyodi_.pdf [accessed 27 January 2018]

Haaker, T., Bouwman, H., Janssen, W., \& de Reuver, M. (2017). Business model stress testing: A practical approach to test the robustness of a business model. Futures, 89, 14-25.

Hartmann, P. M., Zaki, M., Feldmann, N., \& Neely, A. (2016). Capturing value from big data-a taxonomy of data-driven business models used by start-up firms. International Journal of Operations \& Production Management, 36 (10), 1382-1406.

Heikkilä, M., Bouwman, H., \& Heikkilä, J. (2017). From strategic goals to business model innovation paths: an exploratory study.Journal of Small Business and Enterprise Development. 25(1), 107-128.

Jardine, A. (2018). Airbnb turns its "expletive-filled' destinations Ad into a video. Available at: http://creativity-online.com/work/airbnb-expletivefilled-interest/53792 [accessed 22 March 2018]

Johnson, M. W. (2010). Seizing the white space: Business model innovation for growth and renewal, MA: Harvard Business Press, Boston.

Kurdabar (2017). "Airbnb" - kastai? Kokie privalumaiir trūkumai. Available at: https://kurdabar.lt/2017/01/09/airbnb-kas-tai-kokie-privalumai-ir-trukumai/ [accessed 22 March 2018]

Laudien, S. M., \& Daxböck, B. (2017). Business model innovation processes of average market players: a qualitative-empirical analysis.R\&D Management,47(3), 420-430.

Lee, I., \& Shin, Y. J. (2018). Fintech: Ecosystem, business models, investment decisions, and challenges.Business Horizons,61(1), 35-46.

Li, F. (2018). The digital transformation of business models in the creative industries: A holistic framework and emerging trends. Technovation. (In Press), doi: 10.1016/j.technovation.2017.12.004.

Martin, E. (2017). Look inside the $\$ 10,000$-a-night Airbnb mansion where Lady Gaga stayed. Available at: https://www.cnbc.com/2017/11/13/10000-a-night-airbnb-mansion-where-ladygaga-stayed-during-coachella.html [accessed 22 March 2018] 
Mody, M. A., Suess, C., \& Lehto, X. (2017). The accommodation experiencescape: A comparative assessment of hotels and Airbnb.International Journal of Contemporary Hospitality Management,29(9), 2377-2404.

Morris, M., Schindehutte, M., \& Allen, J. (2005). The entrepreneur's business model: toward a unified perspective. Journal of business research, 58(6), 726-735.

Osterwalder, A., \& Pigneur, Y. (2010). Business model generation: a handbook for visionaries, game changers, and challengers. John Wiley \& Sons.

Parente, R. C., Geleilate, J. M. G., \& Rong, K. (2017). The Sharing Economy Globalization Phenomenon: A Research Agenda.Journal of International Management. 24 (1), 52-64.

Piscicelli, L., Ludden, G. D., \& Cooper, T. (2018). What makes a sustainable business model successful? An empirical comparison of two peer-to-peer goods-sharing platforms. Journal of Cleaner Production, 172, 4580-4591.

Plenter, F., Fielt, E., Hoffen, M., Chasin, F., \& Rosemann, M. (2017). Repainting the business model canvas for peer-to-peer sharing and collaborative consumption. In Proceedings of the 25th European Conference on Information Systems (ECIS), Guimarães, Portugal, June 5-10, 2017 (p. 2234-2249). ISBN 978-989-20-7655-3

Rantala, T., Ukko, J., Saunila, M., \& Havukainen, J. (2018). The effect of sustainability in the adoption of technological, service, and business model innovations. Journal of Cleaner Production, 172, 46-55.

Richardson, L. (2015). Performing the sharing economy. Geoforum, 67, 121-129.

Rudzevičiūtè, M (2014). Netikèta 1 MLN. Litų investicijaportalui - naujoversloetapo pradžia. Available at: http://www.bznstart.lt/verslas/sekmes-istorijos/1708/Netiketa-1-mln-lituinvesticija-portalui-naujo-verslo-etapo-pradzia[accessed 22 March 2018]

Sigala, M. (2018). Market Formation in the Sharing Economy: Findings and Implications from the Sub-economies of Airbnb. In Social Dynamics in a Systems Perspective (pp. 159-174). Springer, Cham.

Spiess-Knafl, W., Mast, C., \& Jansen, S. A. (2015). On the nature of social business model innovation. Social Business, 5(2), 113-130.

Stone, M (2017). How The Hotel Industry Can Catch Up To Airbnb Available at: https://www.forbes.com/sites/delltechnologies/2017/12/01/how-the-hotel-industry-can-catchup-to-airbnb/\#4d1a6f8b5d97 [accessed 27 January 2018]

Sundararajan, A. (2016). The sharing economy: The end of employment and the rise of crowdbased capitalism. Mit Press.

Trumpam (2018a). Apie mus. Available at: https://www.trumpam.lt [accessed 22 March 2018]

Trumpam.lt (n.d.) (2018b). InFacebook. Available at: https://www.facebook.com/Trumpam/ [accessed 14 May 2018]

Tussyadiah, I. P., \& Sigala, M. (2018). Shareable tourism: tourism marketing in the sharing economy. Journal of Travel \& Tourism Marketing, 35 (1), 1-4.

Wang, D., \& Nicolau, J. L. (2017). Price determinants of sharing economy based accommodation rental: A study of listings from 33 cities on Airbnb.com.International Journal of Hospitality Management,62, 120-131.

Yang, Yang S., Song, Y., Chen, S., \& Xia, X. (2017). Why are customers loyal in sharing-economy services? A relational benefits perspective.Journal of Services Marketing,31(1), 48-62.

Zadarackas, L. (2016). „Airbnb“ bendruomenès atstovas Lietuvoje: kas gi norès apsistoti Panevėžyje. Available at:https://www.15min.lt/verslas/naujiena/kvadratinismetras/bustas/airbnb-bendruomenes-atstovas-lietuvoje-kas-gi-nores-apsistoti-panevezyje-665590093 [accessed 22 March 2018]

Zervas, G., Proserpio, D., \& Byers, J. W. (2017). The rise of the sharing economy: Estimating the impact of Airbnb on the hotel industry.Journal of Marketing Research,54(5), 687-705. 
606 3 $31^{\text {ST }}$ Bled eConference: Digital Transformation: MeEting the ChallengeS JunE 17 - 20, 2018, BLED, SLOVENIA, CONFERENCE PROCEEDINGS

R. Gatautis, E. Vaičiukynaite \& E. Vitkauskaitė: Comparative Study of Sharing Economy Business Models in Accommodation Sector

Zott, C., \& Amit, R. (2008). The fit between product market strategy and business model: implications for firm performance. Strategic management journal, 29(1), 1-26. 


\title{
What do we Know about Personality Traits, Technology Use, Intention, Reputation and Brand Credibility? Cross Cultural Issues in the Aviation Industry's User-Generated Content (UGC)
}

\author{
UKAMAKA ONYENUCHEYA
}

\begin{abstract}
User-generated content (UGC) encourages participatory forms of interaction that allow users to create and add both correct and incorrect or false content which generates rumours. The purpose of this study is as follows: firstly, to investigate how people with different personality traits use UGC in contributing to conversations related to the aviation industry. Secondly, to introduce additional factors that may affect users' attitudes and intentions towards participating in conversations involving UGC. In addition, this study seeks to measure how personality traits and behaviour affect corporate reputations and also to measure the effect of brand credibility on the attractiveness of different personality traits. The study will apply Eysenck's Big Five Personality Traits Model, the Technology Acceptance Model (TAM), Dreyfus and Dreyfus' Skill Acquisition Model, the Corporate Character Scale, and Erdem and Swait's Model. Further, the study proposes to analyse the quantitative data using a structural equation modelling (SEM) technique in Mplus while NVivo is expected to support the analysis of the qualitative data. Comparisons, combinations and evaluations will be made using the results generated to better understand the purpose of the study.
\end{abstract}

Keywords: • Personality traits $\bullet$ Criticality $\bullet$ Credibility $\bullet$ Novice skill $\bullet$ Proficiency skill $\bullet$ Competency skill $\bullet$ Expert skill $\bullet$ Brand Credibility $\bullet$ Reputation • User-generated content $\bullet$ Social media $\bullet$ Social networking sites $\bullet$ Rumour $\bullet$ Web $2.0 \bullet$ Electronic word-of-mouth •

CORRESPONDENCE AdDRess: Ukamaka Onyenucheya, Ph.D.Candidate, University of Plymouth, Faculty of Business School, Plymouth, United Kingdom, email:ukamaka.onyenucheya@plymouth.ac.uk 
U. Onyenucheya: What do we Know about Personality Traits, Technology Use, Intention, Reputation and Brand Credibility? Cross Cultural Issues in the Aviation Industry's User-Generated Content (UGC)

\section{Introduction}

The use of electronic technology, especially the Internet, is increasing rapidly. Billions of people around the world now have access to the Internet. The rise of the Internet has resulted in the success of social media - a group of Internet-based applications created using Web 2.0 which allow the creation and exchange of user-generated content (UGC) (Kaplan \& Haenlein, 2010). The content created by users while participating on consumer review sites, social networking sites, blogs and media-sharing sites is commonly known as UGC or consumer-generated media (CGM), but it is also regarded as electronic wordof-mouth (Ayeh, Norman \& Law, 2013b). There are strong psychological, social and utilitarian factors driving this participation in online social networks (Cheung, Chiu \& Lee, 2011; Ukpabi, Onyenucheya \& Karjaluoto, 2017; Kang, Tang \& Fiore, 2014). For example, when travelling, people can use user-generated platforms like TripAdvisor, Fodor, Qunar, virtual tourist, and lonely planet (Ukpabi et al., 2017; Horster \& Gottschalk, 2012; Luo, Remus \& Sheldon, 2007) to evaluate and exchange information about the performance of travel companies (Horster \& Gottschalk, 2012). Such sites also provide users with the opportunity to introduce themselves, and to communicate and maintain connections with others (Lilleker \& Jackson, 2013). Likewise, customers have turned to UGC when making their travel-buying decisions (Blackshaw \& Nazzaro, 2006).

Clearly, the statistics indicate that there has been a rapid increase in the use of the Internet as well as in the uptake of UGC. A study conducted by the International Telecommunication Union (2014; 2015), reports that 3 billion users ( $40 \%$ of the world's population) had access to the Internet by the end of 2014. This grew to 3.2 billion people by the end of 2015. In 2016, the number of Internet users worldwide reached 3,675,824,813 (Internet World Statistics, 2016). As of June 2017, Internet World Stats reported that 3,885,565,619 people around the world were using the Internet-a 51\% worldwide penetration rate. In 2014, TripAdvisor featured 150 million reviews and opinions (ETB Travel News, 2014). In 2015, this reached more than 200 million (MarineRoig \& Clavé, 2015) and it now carries 570 million reviews and opinions (TripAdvisor, 2018). Given such figures, UGC is recognised as a valuable source of information, capable of circulating reviews and opinions much faster than traditional journalism can confirm them.

However, these participatory forms of interaction mean that the content uploaded by users may be incorrect or false, which can start false rumours spreading which, in turn, can negatively affect a company's reputation and brand credibility on the UGC platform. Corporations are thus under increasing pressure to monitor the accuracy of information about them on UGC websites (Twentyman, 2015; America CGTN live, 2017; Naidoo, 2017). The aviation sector, in particular, is concerned about the impact of inaccurate information. Reports suggest that the aviation industry is in crisis (da Silva Rocha \& Pinto, 2006), due to quick spread of false rumour by people. Thus, the industry pays particular attention to the scope social media has to help circulate the truth as well as misleading information. For example, Emirates Airline-one of the best airlines 
according to TripAdvisor (Smith 2016) — suffered as a result of a rumour on twitter. On August $3^{\text {rd }}, 2016$, Emirates Airlines flight EK521 took off from Trivandrum International Airport in India at 10.19 am and was scheduled to arrive at Dubai International Airport at $12.50 \mathrm{pm}$. The flight took off with no problem. However, while landing in Dubai as scheduled at about 12:45 pm local time, there was an emergency. A tweet by the airline reporting this was shared more than 2,675 times. News broke at $1 \mathrm{pm}$ Dubai local time that a plane had crash-landed and there was widespread panic on social media. Photos showing thick plumes of black smoke rising from a burning plane circulated on social media. At 2 pm, Emirates confirmed that the 282 passengers and 18 crew on board the plane were safe, in a tweet which read: "We can confirm that there are no fatalities among our passengers and crew. All passengers and crew are accounted for and safe. \#EK521" (Ral, 2016). However, while companies can face problems from social media, those companies that avoid using social media during a crisis also come in for criticism from the public and news media across the world (Austin and Jin, 2017).

\section{Problem Definition}

There are three problems that need to be addressed in this study: first, despite the increasing popularity of UGC platforms in e-tourism and e-marketing (Buhalis \& Law, 2008; Hernández-Méndez \& Muñoz- Leiva, 2015), only a handful of studies have been conducted into UGC and personality traits in tourism (e.g. Yoo \& Gretzel, 2011). However, no existing research has been identified that sought to understand how people with different personality traits use UGC to contribute to conversations related to UGC in the aviation industry. Personality is defined as "the characteristics or blends of characteristics that make a person unique" (Weinberg \& Gould, 2014, p. 27). Previous studies have argued that populations of Internet users are not all the same but, rather, are comprised of different personality types (Kraut et al., 1998; Amichai-Hamburger \& BenArtzi, 2003) who adopt the emerging information and communication technology (ICT) in different ways. Consequently, this study seeks to understand how people with different personality traits use UGC to contribute to conversations regarding aviation in tourism.

Secondly, although factors that influence the use of Google applications in e-learning (Cheung \& Vogel, 2013) and sports (Scherer \& Hatlevik, 2017) have been investigated, another issue concerns the limited research done into the study of individual acceptance and the use of technology-related applications in tourism in general. Ayeh, Au \& Law (2013b), for example, looked at the cognitive factors affecting online travel consumers' intentions towards using CGM. A study by Ayeh et al. (2013b) focused on factors such as trustworthiness, enjoyment and similarity of interests. However, in the aviation industry, there is a general lack of studies looking at factors affecting user intentions. However, Legris et al. (2003) argued that it is very likely that factors which influence the acceptance of a new technology vary with the technology, its target users, and its content. That is why Wang et al. (2003) extended the Technology Acceptance Model (TAM) and introduced perceived credibility as a new TAM factor to reflect users' security and privacy concerns in the acceptance of Internet banking, and examined the effect of 
computer self-efficacy on the intention to use Internet banking. However, in tourism in general, understanding of the impact of credibility on the TAM is still lacking. It is also difficult to understand why a critical evaluation of people with different personalities has been omitted. Criticality is another factor that can be traced to other studies outside tourism research or mostly outside UGC content research. This study refers to De Cremer (2002) as a guide to understanding the criticality effect on a user's contribution to UGC. Other factors to investigate in this study include novice skill, proficient skill, competent skill and expert skill, all of which relate to skill acquisition. Dreyfus \& Dreyfus (1986) has been neglected in the understanding of UGC in tourism. Thus, this study will introduce a number of additional factors that may impact users' attitudes and intentions towards participating in conversations in UGC in the context of aviation. By doing so, the original TAM model is extended to include additional constructs such as credibility, criticality, novice skill, proficient skill, competent skill and expert skill.

The third issue identified is that within the tourism industry, researchers have conducted studies in the field of UGC and reputation (for example, Dijkmans, Kerkhof \& Beukeboom, 2015; Ntalianis, Kavoura, Tomaras \& Drigas, 2015; Phillips, Zigan, Silva \& Schegg, 2015). However, it is important to recognise that it is not difficult to conflate reputation and brand; many companies do so. They are different, and conflating them may have cost implications (Ettenson \& Knowles, 2008). Within the consumer service markets, a company's reputation is likely to play a key role in the buying process that is different to the product-specific influence of the brand's image (Berry, 2000). Berry (2000) further advised that there are extensive marketing investments in building brand image and in building a company's reputation. However, other scholars have different perspectives and state that brand and reputation are similar. As recognised by Langley (2016, p.1): "The word "brand" has continued to evolve and encompasses identity. It affects the personality of a product, company or service.' Langley (2016) further commented that, in practice, the term 'brand' is interchangeable with the term 'reputation'. Brand is preferred by marketers and reputation is preferred by those in public relations. Building on the argument that reputation and brand are not the same, no research has been identified in tourism that relates to the impact of personality trait behaviour on reputation and personality attractiveness to brand credibility. Hence, based on this gap, this study seeks to measure the effect of personality trait behaviour on corporate reputation as well as to measure the effect of brand credibility on different personality trait attractiveness. One of the problems companies are facing today on UGC websites is that of false reports and rumours, which impact on their brand and reputation online. Rumours can affect a company's reputation and brand credibility online, and rumour has been understood to have a negative impact on reputation (Dentith, 2013). Hence, based on this gap, this study sets out to measure the effect of personality trait behaviour on corporate reputation. On the other hand, the credibility of a brand is built on consumers' past experiences with it, either directly or indirectly (Kim, Morris \& Swait, 2008). Despite its obvious importance, brand credibility, and its effect on consumer response, has received little research in services literature, including literature on tourism 
in general and aviation in particular (Jeng, 2016). Therefore, this study will seek to measure the effect of brand credibility on different personality trait attractiveness.

\subsection{Conceptual Development}

The study aims to fulfil the following three broad aims: to investigate how people with different personality traits use UGC; to investigate the factors affecting attitudes and intentions towards UGC; and to investigate the impact that these behavioural traits could have on reputation and measure the impact of brand credibility on different personality trait attractiveness. The study addresses these aims by adopting: 1) Eysenck's Big Five Personality Traits Model (Eysenck et al., 1985); 2) the Technology Acceptance Model (TAM) (Davis, 1989); 3) Dreyfus \& Dreyfus' Skill Acquisition Model (Dreyfus \& Dreyfus, 1986); 4) criticality (De Cremer \& Dijk, 2002); 5) the Corporate Character Scale (Davies et al., 2004); and 6) Erdem and Swait's model (2004). Table 1 below outlines the relevance of these models. 
U. Onyenucheya: What do we Know about Personality Traits, Technology Use, Intention, Reputation and Brand Credibility? Cross Cultural Issues in the Aviation Industry's User-Generated Content (UGC)

Table 1: Different Models Acquired (adapted from various sources)

\begin{tabular}{|c|c|}
\hline $\begin{array}{c}\text { Model/Theo } \\
\text { r y }\end{array}$ & $\begin{array}{l}\text { Relev } \\
\text { ance }\end{array}$ \\
\hline $\begin{array}{l}\text { Eysenck's } \\
\text { Big Five } \\
\text { Personality } \\
\text { Model } \\
\text { (Eysenck et } \\
\text { al., 1985) }\end{array}$ & $\begin{array}{l}\text { The purpose of this theory is to understand how the Big Five personality traits } \\
\text { (surgency, emotional stability, agreeableness, openness and conscientiousness) } \\
\text { relate to UGC. }\end{array}$ \\
\hline $\begin{array}{l}\text { Technolog } \\
\text { y } \\
\text { Acceptanc } \\
\text { e Model } \\
\text { (TAM) } \\
\text { (Davis, } \\
\text { 1986) }\end{array}$ & $\begin{array}{l}\text { TAM is important in this study because consumers' adoption is a critical success } \\
\text { factor for the operation of ICT in tourism. Understanding the theories and } \\
\text { framework models is important for both academics and practitioners to keep } \\
\text { abreast of the field (Ukpabi \& Karjaluoto, 2017). } \\
\\
\text { In this study, TAM will help to understand factors affecting users' intentions and } \\
\text { attitudes towards contributing to UGC. This study strongly believes in TAM as a } \\
\text { theoretical framework for examining the effect of credibility, criticality, novice } \\
\text { skill, proficient skill, competent skill and expert skill to user acceptance of UGC } \\
\text { in tourism. Researchers of task- technology fit suggest that perception of a } \\
\text { technology varies in accordance with the type of task (Goodhue et al., 1995). } \\
\text { Hence, TAM is considered one of the best frameworks for understanding } \\
\text { technology- related adoption that can be extended and adapted to various features } \\
\text { of many diverse situations (Belanche et al., 2012). }\end{array}$ \\
\hline $\begin{array}{l}\text { Dreyfu } \\
\text { s \& } \\
\text { Dreyfu } \\
\text { s } \\
(1986)\end{array}$ & $\begin{array}{l}\text { Acquiring novice, competency, proficiency and expert factors from Dreyfus and } \\
\text { Dreyfus'(1986) five skill levels. This study will examine the effect of novice, } \\
\text { proficiency, competence and expert skill factors on intentions and attitudes } \\
\text { towards contributing to UGC. By doing this, new variables are being introduced } \\
\text { into TAM. }\end{array}$ \\
\hline $\begin{array}{l}\text { Criticality } \\
\text { (De Cremer } \\
\text { \& Dijk, } \\
\text { 2002) }\end{array}$ & $\begin{array}{l}\text { This study will examine the criticality (critical evaluation) factor on UGC } \\
\text { contribution following De Cremer \& Dijk's (2002) approach to understanding the } \\
\text { impact of criticality on contributions in UGC conversations and adding a new } \\
\text { factor to TAM. }\end{array}$ \\
\hline $\begin{array}{l}\text { Corporate } \\
\text { character }\end{array}$ & $\begin{array}{l}\text { This model will help to measure how customers and businesses of the airlines } \\
\text { selected perceive their online reputation and how this affects the personality trait } \\
\text { behaviour on UGC. }\end{array}$ \\
\hline
\end{tabular}


U. Onyenucheya: What do we Know about Personality Traits, Technology Use, Intention, Reputation and Brand Credibility? Cross Cultural Issues in the Aviation Industry's User-

Generated Content (UGC)

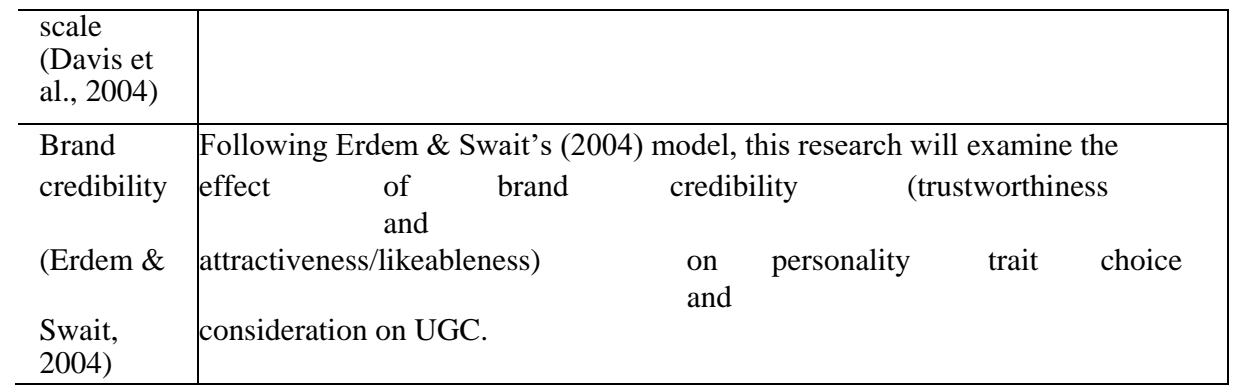

\section{$3 \quad$ Potential Methodology}

This study will involve two main approaches to data collection: secondary and primary data collection. Secondary sources of information will be collected from books, academic journal articles and user- generated platforms, specifically, TripAdvisor and twitter in order to gain a general view of conversations and rumours about the chosen airlines. Following the results from the UGC search, primary data will be gathered through qualitative and quantitative approaches, known as 'mixed method' (Creswell, 2013). According to Creswell (2002), the mixed method is exploratory in nature. The exploratory design comprises first collecting qualitative data to explore a phenomenon, and then gathering quantitative data to explain connections found in the qualitative data (Teddlie \& Tashakkori, 2003). Thus, the mixed method is considered appropriate in this study to achieve the proposed aims. The initial phase involves three stages: the first involves semistructured face-to-face interview with managers of the selected airlines to gain insight into their understanding of rumours about the company that circulate on UGC platforms and to understand their perceptions of the personalities of the users who participate. The second stage involves face-to-face interviews with airline customers. Questions will revolve around the topic of technology use, i.e. UGC (unstructured interview) and their feelings regarding their personality (structured interview), as well as their perceptions of the chosen airlines' reputation and brand credibility. The third stage involves focus group discussions with the airlines' customers. All interviews will be audio and video recorded with consent. Following the interview phase, the next phase will involve a structured survey questionnaire to test personality trait usage of UGC, users' perceptions of the impact of their personality on reputation and brand credibility and the factors influencing the adoption and intention to contribute to UGC conversations. This will help to test hypotheses and improve the conceptual framework towards best practice.

\subsection{Selection of Participants and Data Collection}

This study will gather data through several interviews, focus groups and questionnaires. The study aims to investigate: how people with different personality traits use UGC; the factors affecting attitudes and intentions towards UGC; and the impact that these trait behaviour could have on reputation and brand credibility in the aviation industry. Airline customers who contribute to discussions on UGC are considered best suited as they are 
thought to be able to offer a more in-depth response in view of their use of technology, their feelings and other factors that affect their use of technology, as well as their intentions and attitudes. Nevertheless, it is crucial to note that the initial interview will also be conducted with airlines managers to gain insight into how they see their airlines' reputation and brand credibility as well as to know if the selected airlines understand the problems they are facing from rumours circulating on UGC platforms. Airlines based in two different cultures are selected. The reason for selecting the two different cultures is that cross-cultural studies can reveal crucial evidence of the importance of differences between biological and cultural factors in personality traits (Costa, 2001). Only a few studies have been conducted regarding personality traits across cultures.

\subsection{Method and Data Analysis}

The study proposes to use structural equitation modelling using Mplus software in analysing the data collected through the quantitative survey, while NVivo would be used to support the qualitative analysis of data gathered through face-to-face interviews and focus groups. Finally, comparisons, combinations and evaluations will be made using the results generated to better understand the impact of personality traits on UGC, and the factors influencing attitudes and intentions towards the use of technology, as well as the effect of personality traits on reputation and brand credibility in UGC within the context of airlines in the tourism industry.

\section{$4 \quad$ Preliminary/Expected Result}

At present, the study is at the methodology stage. This study expects to contribute to the research field of personality traits and the use of UGC, the factors that affect intentions and attitudes in contributing to the use of ITC (in this case, UGC). The impact of personality traits on reputation and brand credibility will be recognised. It is further expected that academics and practitioners in tourism will both be able to adopt the recommendations as a basis for understanding personality traits, UGC reputation and brand credibility.

\section{$5 \quad$ Future Development}

In terms of data analysis, the author has been trained in how to use structural equation modelling for quantitative data analysis. However, the study plans to expeditiously develop more advanced skills and expertise to improve the methodological aspect and data analysis. Skills include training to explore the most innovative methods of gathering conversations on UGC platforms. Kaisler et al. (2013) noted that digital data gathering is more relaxed and more accurate than the manual method. Moreover, the researcher is currently receiving training in NVivo qualitative data analysis software. However, the analysis method is continuous and dynamic as the researcher continues to enhance the ideas and thoughts. Once the methodology section is finalised, the plan is to conduct a meeting in collaboration with the airlines chosen. The aim is to gain insight into their 
perspective of UGC and service user behaviour in order to inform the design of the survey questionnaires and interviews. Upon completing this initial meeting with managers, the researcher then plans to go through the research design to validate the information relevant to addressing the research questions and hypotheses. According to De Vans (2001, p. 9), research design 'deals with a logical problem and not a logistical problem'. De Vans argued that before a builder can develop a work plan or order materials they must first establish the type of building required, its uses and the needs of the occupants. The work plan flows from this. Similarly, in social research, the issues of sampling, the method of data collection (e.g. questionnaire, observation, document analysis), and the design of questions are all subsidiary to the question: 'What evidence do I need to collect?' Too often, researchers begin interviewing far too early, before they have thought critically about what information is required to answer the research question (De Vans, 2001). Without attending to these critical issues of design at the beginning, the overall research problem will not be addressed adequately, and any conclusions drawn will run the risk of being weak and unconvincing, and the overall validity of the study will be undermined. In order to avoid the type of mistake highlighted by De Vans, this study will carefully attend to the research design before collecting data.

\section{Acknowledgement}

The author wish to acknowledge Prof Sheela Agarwal and Dr Nigel Jackson for their valuable advice in this on- going PhD. Special thanks are due to the Chair and Co-Chairs of the Bled eConference Doctoral Consortium 2018 for their useful comments on this paper.

\section{References}

America CGTN news (2017, January7). Can social media platforms put an end to fake news? Retrieved 17 December 2017, from: https://america.cgtn.com/2017/01/06/can-social-mediaplatforms-put-an-end-to-fake-news.

Amichai-Hamburger, Y. \& Ben-Artzi, E. (2003). Loneliness and Internet use. Computers in Human Behavior, 19(1), pp. 71-80

Austin, L.L., \& Jin, Y. (Eds.) (2017). Social Media and Crisis Communication.

London: Routledge.

Ayeh, J.K., Au, N. \& Law, R. (2013b). Predicting the intention to use consumer-generated media for travel planning. Tourism Management, 35, pp. 132-143.

Belanche, D., Casaló, L.V. \& Flavián, C. (2012). Integrating trust and personal values into the Technology Acceptance Model: The case of e-government services adoption. Cuadernos de Economía y Dirección de la Empresa, 15(4), pp. 192-204.

Berry, L.L. (2000) Cultivating service brand equity. Journal of the academy of Marketing Science, $28(1), \mathrm{pp}$.

$128-137$.

Blackshaw, P. \& Nazzaro, M. (2006).Consumer-generated media (CGM) 101: Word-of-mouth in the age of the web-fortified consumer. New York: Nielsen BuzzMetrics, 3.

Buhalis, D. \& Law, R. (2008). Progress in information technology and tourism management: 20 years on and 10 years after the Internet-The state of eTourism research. Tourism Management, 29(4), pp. 609-623. 
U. Onyenucheya: What do we Know about Personality Traits, Technology Use, Intention, Reputation and Brand Credibility? Cross Cultural Issues in the Aviation Industry's User-Generated Content (UGC)

Cheung, R. \& Vogel, D. (2013). Predicting user acceptance of collaborative technologies: An extension of the technology acceptance model for e-learning. Computers \& Education, 63, pp. $160-175$.

Cheung, C. M., Chiu, P. Y. \& Lee, M. K. (2011). Online social networks: Why do students use facebook? Computers in Human Behavior, 27(4), pp. 1337-1343.

Costa, P.T. \& McCrae, R.R. (1992). Reply to Eysenck. Personality and Individual Differences, 13(8), pp. 861-865.

Creswell, J.W. (2013). Research design: Qualitative, quantitative, and mixed methods approaches.

Sage publications.

Creswell, J.W. \& Maietta, R.C. (2002). Qualitative research. Handbook of Research Design and Social Measurement, 6(1), pp. 143-184.

da Silva Rocha, A.B. \& Pinto, A.C.F. (2006). The Air Transport Industry Crisis in Brazil and in the USA and Companies' Additional Value Due to Real Options Analysis. Latin American Business Review, 6(3), pp. 85-111.

Davis, F.D. (1989). Perceived usefulness, perceived ease of use, and user acceptance of information technologies, MIS Quarterly 13 (3), pp. 319-340.

Davis, F.D. (1986). A technology acceptance model for empirically testing new end-user information system: Theory and results. Doctoral dissertation, Sloan School of Management, Massachusetts Institute of Technology.

Davies, G., Chun, R., da Silva, R.V. \& Roper, S. (2004). A corporate character scale to assess employee and customer views of organization reputation. Corporate Reputation Review, 7(2), pp. 125-146.

De Cremer, D. and van Dijk, E. (2002). Perceived criticality and contributions in public good dilemmas: A matter of feeling responsible to all? Group Processes \& Intergroup Relations, 5(4), pp. 319-332.

De Vaus, D. A. \& de Vaus, D. (2001). Research design in social research. London: Sage.

Dentith, M. (2013). Have you heard? The rumour as reliable. In G. Dalziel (ed.) Routledge, pp. 4661. Retrieved 15 February 2018, from https://philpapers.org/rec/DENHYH.

Dijkmans, C., Kerkhof, P. \& Beukeboom, C.J. (2015). A stage to engage: Social media use and corporate reputation. Tourism Management, 47, pp. 58-67.

Dreyfus, H.L. \& Dreyfus, S.E. (1986). Mind over machine: The power of human intuition and expertise in the era of computer. New York: The Free Press.

Erdem, T. \& Swait, J. (2004). Brand credibility, brand consideration, and choice. Journal of consumer research, 31(1), pp. 191-198.

ETB Travel News (2014). TripAdvisor now offers 150 million reviews and opinions. Retrieved 12 February 2018, from http://europe.etbtravelnews.global/191109/tripadvisor-now-offers-150million-reviews-opinions/.

Ettenson, R. and Knowles, J. (2008). Don't confuse reputation with brand. Management Review (Peer Review) Journal 49(2), pp. 19-21.

Eysenck, S.B., Eysenck, H.J. \& Barrett, P. (1985). A revised version of the psychoticism scale. Personality and individual differences, 6(1), pp. 21-29.

Goodhue, D.L. \& Thompson, R.L. (1995). Task-technology fit and individual performance. MIS quarterly, pp. 213-236.

Hernández-Méndez, J. \& Muñoz-Leiva, F. (2015). What type of online advertising is most effective for eTourism 2.0? An eye tracking study based on the characteristics of tourists. Computers in Human Behaviour, 50, pp. 618-625.

Horster, E. \& Gottschalk, C. (2012). Computer-assisted webnography: A new approach to online reputation management in tourism. Journal of Vacation Marketing, 18(3), pp. 229-238. 
Internet world stats. (2017). Internet users in the world by regions. Retrieved 01 January 2018, from http://www.internetworldstats.com/stats.htm.

International Telecommunication Union (2015). ICT Fact and Figures 2015. Retrieved 03 December 2017, from https://www.itu.int/en/ITUD/Statistics/Documents/facts/ICTFactsFigures2015.pdf.

International Telecommunication Union. (2014). Measuring the Information Society Report, 2014. Geneva, Switzerland. Retrieved 17 December 2017, from https://www.itu.int/en/ITUD/Statistics/Documents/publications/mis2014/MIS2014_without_Annex_4.pdf.

Kaplan, A.M. \& Haenlein, M. (2010). Users of the world, unite! The challenges and opportunities of Social Media. Business Horizons, 53(1), pp. 59-68.

Kang, J., Tang, L. \& Fiore, A.M. (2014). Enhancing consumer-brand relationships on restaurant Facebook fan pages: Maximizing consumer benefits and increasing active participation. International Journal of Hospitality Management, 36, pp. 145-155.

Kaisler, S., Armour, F., Espinosa, J. A. \& Money, W. (2013, January). Big data: Issues and challenges moving forward. In System sciences (HICSS), $201346^{\text {th }}$ Hawaii International Conference on system sciences (pp. 995-1004). IEEE.

Kim, J., Morris, J.D. \& Swait, J. (2008). Antecedents of true brand loyalty. Journal of Advertising, 37(2), pp. 99-117.

Kraut, R., Patterson, M., Lundmark, V., Kiesler, S., Mukophadhyay, T. \& Scherlis, W. (1998). Internet paradox: A social technology that reduces social involvement and psychological wellbeing. American Psychologist, 53(9), p. 1017

Langley, Q. (2016). Brandjack: How Your Reputation is at Risk from Brand Pirates and what to Do about it. Basingstoke, UK: Palgrave Macmillan

Legris, P., Ingham, J. \& Collerette, P. (2003). Why do people use information technology? A critical review of the technology acceptance model. Information \& Management, 40(3), pp. 191-204.

Lilleker, D. \& Jackson, N. (2013). Political campaigning, elections and the Internet: Comparing the US, UK, France and Germany (Vol. 4). Routledge.

Luo, M.M., Remus, W. \& Sheldon, P.J. (2007). Technology acceptance of the Lonely Planet website: An exploratory study. Information Technology \& Tourism, 9(2), pp. 67-78.

Marine-Roig, E. \& Clavé, S.A. (2015). Tourism analytics with massive user-generated content: A case study of Barcelona. Journal of Destination Marketing \& Management,4(3), pp. 162-172.

Naidoo, A. (2017). The heat: The impact of fake news. America CGTN News. Retrieved 12 January 2018, from https://america.cgtn.com/2017/01/02/the-heat-fake-news.

Ntalianis, K., Kavoura, A., Tomaras, P. \& Drigas, A. (2015). Non-Gatekeeping on Social Media: A Reputation Monitoring Approach and its Application in Tourism Services. Journal of Tourism and Services, 6(10).

Phillips, P., Zigan, K., Silva, M.M.S. \& Schegg, R. (2015). The interactive effects of online reviews on the determinants of Swiss hotel performance: A neural network analysis. Tourism Management, 50, pp. 130-141.

Ral, S. (2016, August, 3). EK521: How the story unfolded on social media. Khaleejtimes. Retrieved 10 February 2018, from https://www.khaleejtimes.com/emirates-flight-ek521-how-the-storyunfolded-on-social-media.

Scherer, R., \& Hatlevik, O. E. (2017). "Sore eyes and distracted" or "excited and confident"? - The role of perceived negative consequences of using ICT for perceived usefulness and selfefficacy. Computers \& Education, 115, pp. 188-200.

Smith, O. (2016, July 26). The world's best (and worst) airlines according to TripAdvisor. The Telegraph. Retrieved 20 January 2018, from http://www.telegraph.co.uk/travel/news/best-andworst-airlines-tripadvisor-rankings/ 
U. Onyenucheya: What do we Know about Personality Traits, Technology Use, Intention, Reputation and Brand Credibility? Cross Cultural Issues in the Aviation Industry's User-Generated Content (UGC)

Teddlie, C. \& Tashakkori, A. (2003). Major issues and controversies in the use of mixed method in the social and behavioural sciences. In A. Tashakkori and Teddlie (Eds.) London: Sage Publications.

TripAdvisor. (2018). Press release. Retrieved 30 January 2018, from https://tripadvisor.mediaroom.com/.

Twentyman, J. (2015, July 14). Beware online words that can lead to a libel charge. Financial Times. Retrieved 12 December 2018, from https://www.ft.com/content/374299f0-295a-11e5acfb-cbd2e1c81cca.

Ukpabi, D. C., Onyenucheya, U.D. \& Karjaluoto, H. (2017). Do Online Travel Communities Matter? A Literature Review. In BLED econference 2017 Proceedings, pp. 604-616. United State of America: AIS electronic library (AISel). http://aisel.aisnet.org/bled2017/9.

Ukpabi, D.C. \& Karjaluoto, H. (2017). Consumers' acceptance of information and communications technology in tourism: A review.Telematics and Informatics, 34(5), pp. 618-644.

Wang, H. Y. (2016). Predicting customers' intentions to check in on Facebook while patronizing hospitality firms. Service Business, 10(1), pp. 201-22.

Wang, Y.S., Wang, Y.M., Lin, H.H. \& Tang, T.I. (2003). Determinants of user acceptance of Internet banking: an empirical study. International Journal of Service Industry Management, 14(5), pp. 501-519.

Weinberg, R.S. \& Gould, D. (2014). Foundations of Sport and Exercise Psychology, 6E (6 $\left.{ }^{\text {th }} \mathrm{ed}\right)$. United State of America: Human Kinetics

Yoo, K.H. \& Gretzel, U. (2011). Influence of personality on travel-related consumer-generated media creation. Computers in Human Behavior, 27(2), pp. 609-621. 


\title{
A model for smart technology adaptation in the case of urban infrastructure development with the purpose of improving the quality of citizens' well-being
}

\author{
VASJA ROBLEK
}

\begin{abstract}
This dissertation conceptually contributes to the development and meaning of the scientific theories that represent fundamental principles for understanding the complexity of European smart cities. The goal of the qualitative research is to develop theoretical grounds about the phenomena of the European middle and large smart city models and their influence on citizen's well-being. The research is focused on the concept of social wellbeing of citizens based on economic, social, environmental, and technological factors.
\end{abstract}

Keywords: • Smart City • Urbanisation $・$ Smart technologies $\bullet$ Qualitative research •

CORRESPONDENCE AdDRESS: Vasja Roblek, MSc., PhD Student, Faculty of Organizational studies, Ulica talcev 3, 8000 Novo mesto, Slovenia, e-mail: vasja.roblek@gmail.com. 
The roots of smart cities can be found in ancient Greece, with Plato's philosophies of the Republic (circa 380 BC). Throughout history, cities have been economic, social, and cultural centres bringing about developmental changes. In the first half of the 20th century, the first and second industrial revolutions transformed Europe from a mostly rural and agricultural community into an industrial urban society. By 1950, more than one half of the European population lived in urban areas (UN, 2014).

The development of ICT in the second half of the 20th century accelerated the transformation of the industrial economy into a technological developmental-oriented economy (Brynjolfsson \& McAfee, 2014).

In the same period, urban development influenced further migration to cities. According to the United Nations (2014), more than half of the world's population lives in cities and, in the coming decades, this proportion will continue to increase. It is expected it that will exceed $65 \%$ in 2050. Currently, the proportion of urban population is the highest in North America (close to 82\%), and the smallest in Africa (40\%). In Slovenia, around 50\% of people live in urban areas, while in Europe the figure is $73 \%$.

Urbanisation, technological innovations, the rapid adoption of change in public and private sector organisations, climate change, and the diversity of natural resources demand a different model of the city.

The fundamentals for smart cities can be found in the 1850s when the transatlantic telegraph was invented. This was a movement that changed the urban planning of cities. It represented a major shift in how urban development could be perceived. City planners had a new form of communication that helped them to overcome geographical boundaries (Abbott, 2008).

The next breakpoint was in the 1960s when the second order cybernetic approach occurred. At that time, sociocybernetics, which encouraged the integration processes of the individual with society, was developed. This is a more subjective approach, which includes more than a one- way knowledge transfer (Bailey, 2006; Staehle, 1991).

From this era, it is necessary to highlight two cases that are critical for understanding the term 'smart city theories'. They also aid in understanding the phenomenon of people networking and inter-communicating in the human environment.

Between 1959 and 1989, Soviet scientists were attempting to network their nation. Their attempts failed, and the project was abandoned with the end of the Soviet Union. At this time, ARPANET was invented in the USA in 1969; it was the predecessor of the Internet (Peters, 2016).

The research focus of the second-order cybernetic was on the problems of the instability, flexibility, learning change, evolution, and autonomy. 


$$
\begin{array}{r}
31^{\text {ST }} \text { BLED ECONFERENCE: DIGITAL TRANSFORMATION: MEETING THE CHALLENGES } \\
\text { JUNE } 17 \text { - 20, 2018, BLED, SLOVENIA, CONFERENCE PROCEEDINGS } \\
\text { V. Roblek: A model for smart technology adaptation in the case of urban infrastructure } \\
\text { development with the purpose of improving the quality of citizens' well-being }
\end{array}
$$

In the 1980s in the USA, the Sociocybernetics movement theorised the concept of smart growth by the New Urbanism movement; they were discussing the concept of the technology-based intelligent city (Hollands, 2008; Vanolo, 2014).

In recent years, discourse has emerged about urban development strategies that include the technological solutions of companies that have become key stakeholders in cities' smart urban strategies. Specifically, IBM, Cisco, and Siemens are highly important players in cooperation with municipalities in providing new solutions for smart city initiatives (Niaros, Kostakis \& Drechsler, 2017). They offer municipalities some proposals for creating smart models of urban management with the goal of solving the problems of sustainability in urban environments, which are expected to be resolved in the long run (e.g. the city strategies are prepared until 2050) (Soderstrom, Pasche \& Klauser, 2014).

In the 21st century, different concepts and theories about smart cities in Europe exist (e.g. sustainable cities). The smart cities practice and theory remain in a formation phase (Angelidou 2015; McNeill, 2016; Violi, 2017; Yigitcanlar, 2015). The literature is divided into two main categories. There are studies focused on the technological side, especially on energy efficient carbon emission. The second group is analysing the importance of the ICT infrastructure, e- government, mobile applications (public transport), e-health, and e-drive mobility. These articles aim at increasing competitiveness, administrative efficiency, and social inclusion (e.g. applications and portals for senior citizens). The fundamental problem is that politicians and companies have used smart cities more for their own self-promotion than for solutions that take into account the needs of citizens. It is regarding the processes of the smart urbanisation for further development of cities and citizens' wellbeing. The critical literature after 2011 examines the phenomenon from different viewpoints: socio-economic, ecologic, political, science and technology studies, governmental studies and ideological critiques (Morozov \& Bria, 2018).

From the municipal strategies, it can be determined that infrastructure has played a vital role in enabling urbanisation and facilitating growth and development. The smart city is understood as a complex mechanism, where we begin to realise the often-unintended human, environmental, social and economic consequences of a technological- and engineering-led approach. The latest thinking and smart urban projects are aimed at the comprehension of the smart and/or sustainable infrastructure as a networker between the places and people in order to create a more sustainable, healthy, and resilient future for citizens (e.g. project of the Vienna suburb of Aspern). They need to address the global socio-economic factors, processes of the innovation of new technology, constant adaptation in public and private sector organisations, and the diversity of qualified resources. The development of Internet of Things, Internet of Services, artificial technologies, blockchain technologies, new sustainable materials, new economic models (sharing economy, cycling economy), smart processes (e-mobility, e-health, e- 
governance), etc. leads to the continuous development and semantic features of the smart city (Han \& Hawken, 2018; Roblek, Erenda \& Meško, 2018; Santonen et al. 2017).

It is expected that the smart urban regions will have more industrial competences and that universities' spin-offs and starts-ups will be important for their development. This will help to compensate for the negative effects of smart technologies (e.g. reducing the number of employees) by investing in smart technology social innovation projects that will also improve the well-being and the development of society.

This paper is structured as follows: it starts with the theoretical background of smart urbanisation and the concept of smart city, as given by different authors. In the second section, the research problem is defined. The third section presents the methodology. Finally, the main research results are presented and discussed, and conclusions, including limitations and directions for future researchers, are given.

\section{$2 \quad$ Problem definition}

This dissertation conceptually contributes to the development and meaning of the scientific theories that represent fundamental principles for understanding the complexity of European smart cities.

The research is prepared primarily in the context of social systems theory, which is useful in understanding the social process of governance. Luhmann's social system theory (Luhmann, 1995), using the complexity theoretical approach, explains the external context of impacts of smart urbanisation factors, with an emphasis on the (UN, 2014):

- $\quad$ spatial distribution of cities in the EU (limited space and resources),

- considerable differences in the size and spatial distribution of urban developments across the EU Member States,

- the fact that in most EU Member States the capital city tends to outperform other cities and regions,

- European policymakers are seeking ways to make urban areas more sustainable by encouraging smart city initiatives,

- urban areas are often responsible for environmental damage (climate change, urban heat), large and compact cities can potentially deliver sizeable savings in terms of resource efficiency,

- young generations tend to live in the suburbs of some of the largest cities in the EU,

- employment rates for women tend to be higher in cities than in rural areas,

- capital cities are often faced with considerable housing challenges,

- foreign-born populations in the EU tend to congregate in relatively few, large cities,

- 34 million people living in EU cities are at risk of poverty or social exclusion (population growth, migration),

- people living alone in cities had higher levels of life satisfaction than those living alone in more remote areas, 
$31^{\text {ST }}$ Bled eConference: Digital Transformation: MeEting the Challenges June 17 - 20, 2018, Bled, Slovenia, ConfEREnCE ProceEdings

V. Roblek: A model for smart technology adaptation in the case of urban infrastructure development with the purpose of improving the quality of citizens' well-being

- $\quad$ slow economic growth, difficult framework conditions.

Complexity theory aids in understanding the urban transformation predicated on cuttingedge technology and, on their basis, prepares strategies for providing smart sustainable cities (Batty et al., 2012; Grandin, Haarstad, Kjærås \& Bouzarovski, 2018; Grimaldi \& Fernandez, 2017). The urban actors in smart city initiatives and stakeholders have a crucial role in establishing environments for innovation activities in the smart cities, which includes developing technological parks (Bibri, 2018; Kumar, 2017; Raten, 2017). Such holistic models include the promotion of sustainable development and applying the term 'sustainable' beyond its environmental dimensions (Rauter, Jonker \& Baumgartner, 2017; Starik \& Kashiro, 2013). The information and communication technologies (ICT) that are based on the IoT and IoS represent a new wave of computing for urban sustainability as a structure of science and technology (S\&T) within the concept of a smart sustainable city (Bibri \& Krogstie, 2016).

The valid urban sustainable structural reforms include economic and environmental perspectives and strategies of long-term planning to ensure continuity in policy through urbanisation, as well as socio-political and cultural aspects of development (Bibri \& Bardici, 2015; Dent, 2017; Gibson et al., 2013).

The research is focused on an overview of launching successful and unsuccessful conceptualisations of networked urbanism, innovation concepts (education, economy, research, governance, technology, and innovation), resources (energy, mobility, infrastructure, and buildings) and quality of living (social inclusion, participation, healthcare and environment). (Anthopoulos, Janssen \& Weerakkody, 2016; Bibri \& Krogstie, 2016; Letaifa, 2015; Morosov \& Bria, 2018; Paulin, 2016; Peters, 2016).

According to the literature review, we have developed the research question (RQ1): What are the premises that define the development of the EU smart and sustainable city?

The research focuses on the complexity of the emerging 'smart' city paradigm, which has become common in the previous twenty-five years (Söderström, Paasche \& Klauser, 2014). The goal of the conceptual research is to develop theoretical grounds about the phenomena of the European middle and large smart city models and their influence on their citizens' well- being. The research is focused on the concept of the social wellbeing of citizens based on economic, social, environmental, and technological factors (Berkman et al., 2014). Municipalities have to offer small and middle companies attractive locations and prepare funding programmes for R\&D (Lawton, 2017). The companies' drive innovations are based on the fact that increasing productivity achieved through the use of smart technologies can help to provide jobs and increase consumer demand with additional income (compensatory effect) (Willard, 2012). This means that essential measures will also be needed to transform and adapt the field of education and employee development (Weber, 2015). 
V. Roblek: A model for smart technology adaptation in the case of urban infrastructure development with the purpose of improving the quality of citizens' well-being

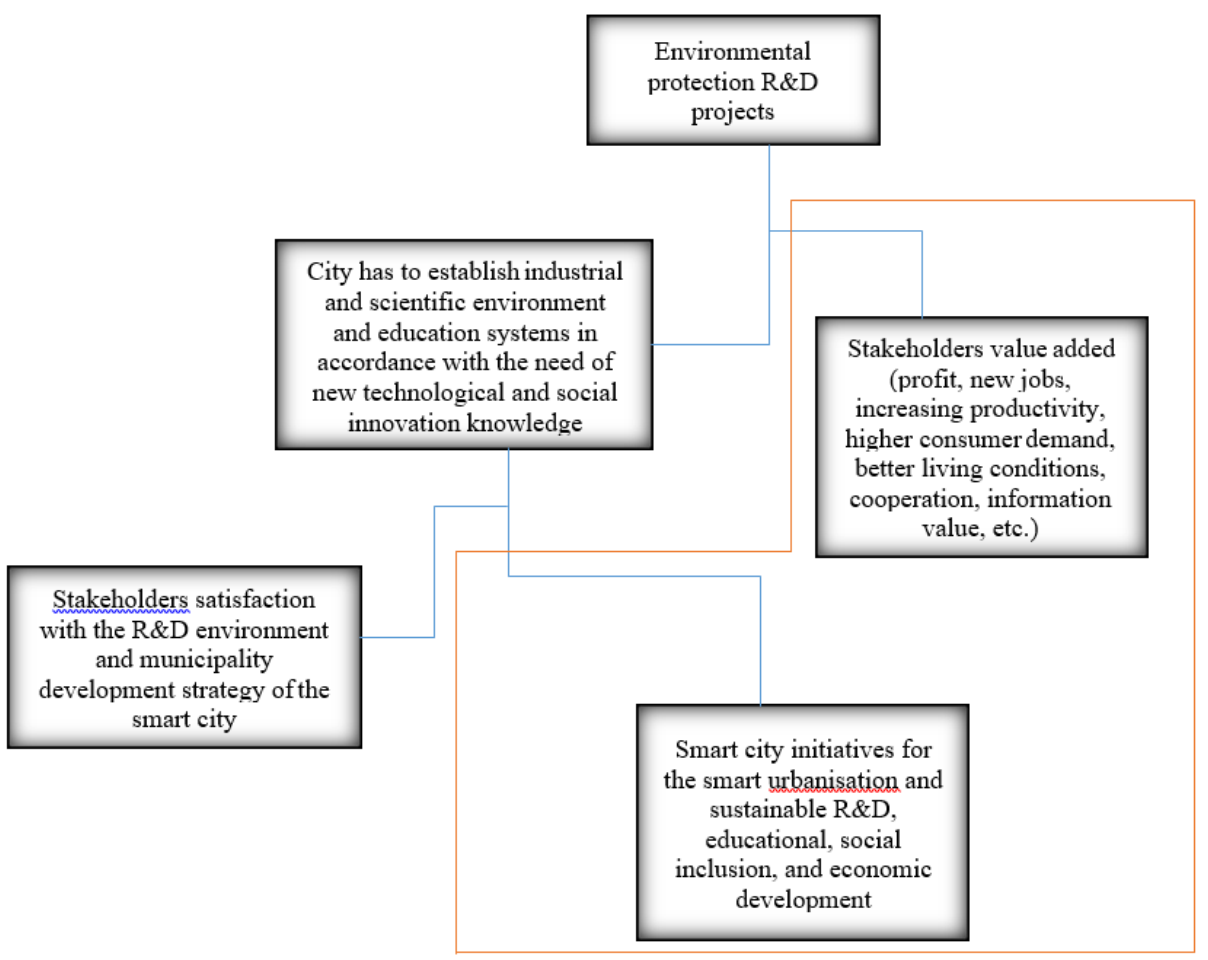

Figure 1: A visualisation of an objective hierarchy for establishing the well- being factors of the citizens

According to Figure 1, the research especially considers the factors and trends for increasing the liability, environmental quality, quality of life and sustainability in European middle-sized and large smart cities (Edelenbos et al. 2018; Caragliu, Del Bo, \& Nijkamp, 2011; Garau \& Pavan, 2018).

We aim to answer the following research question (RQ2): How do the processes of the urban digital (technological) transformation influence the well-being of the citizens of smart cities? 
V. Roblek: A model for smart technology adaptation in the case of urban infrastructure development with the purpose of improving the quality of citizens' well-being

We conducted an inductive qualitative study. The purpose of using such a methodology is to enable the interpretation of certain behaviours, events, the functioning of various entities (e.g. stakeholders), the social environment, and the interaction of mutual relations. We focus on social processes rather than on social structure (Dimovski et al., 2008). Bryman and Bell (2003) remind us that certain data are also quantitatively obtained, but the analysis itself is qualitative. This is a quantification of qualitative data.

From Figure 2, it can be seen that qualitative research follows the sequence of the problem - planning, data capture - analysis - evaluation of results. The process ends with the theory based on the data. It should be emphasised that in the framework of qualitative theory we do not abandon the theorisation, and we do not allow it to be merely a methodological mechanical determination of isolated facts (Roblek, 2009).

The study was designed according to the general method of case studies (Easterby-Smith et al., 2005). A study on the impact of ST in the future life processes contained elements of exploratory and descriptive case studies. According to Dimovski et al. (2008) and Yin (2003), a combination of both grounded theory and case study are appropriate for the design study model, which enables using the research results in practice. Narrative analysis and interpretation of the collected data have been carried out for interviews (Roblek, 2009). An inductive content analysis was used to analyse secondary documents in areas in which only limited knowledge exists (Neuendorf, 2016). This research is based on the primary and secondary data collected from multiple sources, which allows triangulation (Crowe et al., 2011; Jack \& Raturi, 2006; Straus, 1987).

In the inductive approach, the theory has to be developed after the data are collected. The expected cause and effect relations among the variable in the model are not known prior to the data analysis (Saunders et al., 2009).

\subsection{Data collection}

Data collection followed theoretical sampling and the half-structured interviews with the specialists involved in projects using smart technologies in the EU. We will develop the theory and identify themes by studying research papers, interview results, municipalities' strategic documents, smart initiative reports, stakeholder's strategies, study cases and reports, European Union documents, as well as web pages of the smart city initiatives and municipalities.

\subsection{Data processing and research findings}

According to the study of the half-structured interviews, secondary research documents, professional papers, web pages, recording materials and other printed and verbal material, the goal is to develop a theory and identify themes. Inductive content analysis relies on inductive reasoning. Themes emerge from the raw data through repeated examination and 
comparison. The most important feature of the analysis was to create a category on the basis of which the acquired data were structured. It is essential that each category allows classification of the obtained data, given the importance of the meaning of the open codes. The definition of this was done on the basis of the units of analysis that were obtained from reviewing the text material. The open coding process often requires repeated reading of the material, after which the researcher transcribes the notes and headings onto a coding sheet. The next step involves grouping the data, reducing the number of categories by combining similar headings into broader categories. Through this process, researchers generate knowledge and increase understanding of the material. The documents will be analysed with the Atlas.ti software.

Triangulation was used for improving the validity and reliability of the research study. Charmaz (2011) suggested triangulating and evaluating collected data for possible biases before inclusion in the analysis. 

June 17 - 20, 2018, BLED, SLOVENIA, CONFERENCE PROCEEDINGS

V. Roblek: A model for smart technology adaptation in the case of urban infrastructure development with the purpose of improving the quality of citizens' well-being

Preparation phase

The research problem defining:

What are the premises that define the development of the EU smart and sustainable city? How do the processes of the urban digital (technological) transformation influence the smart citizens' well-being?

Selecting the unit of analysis
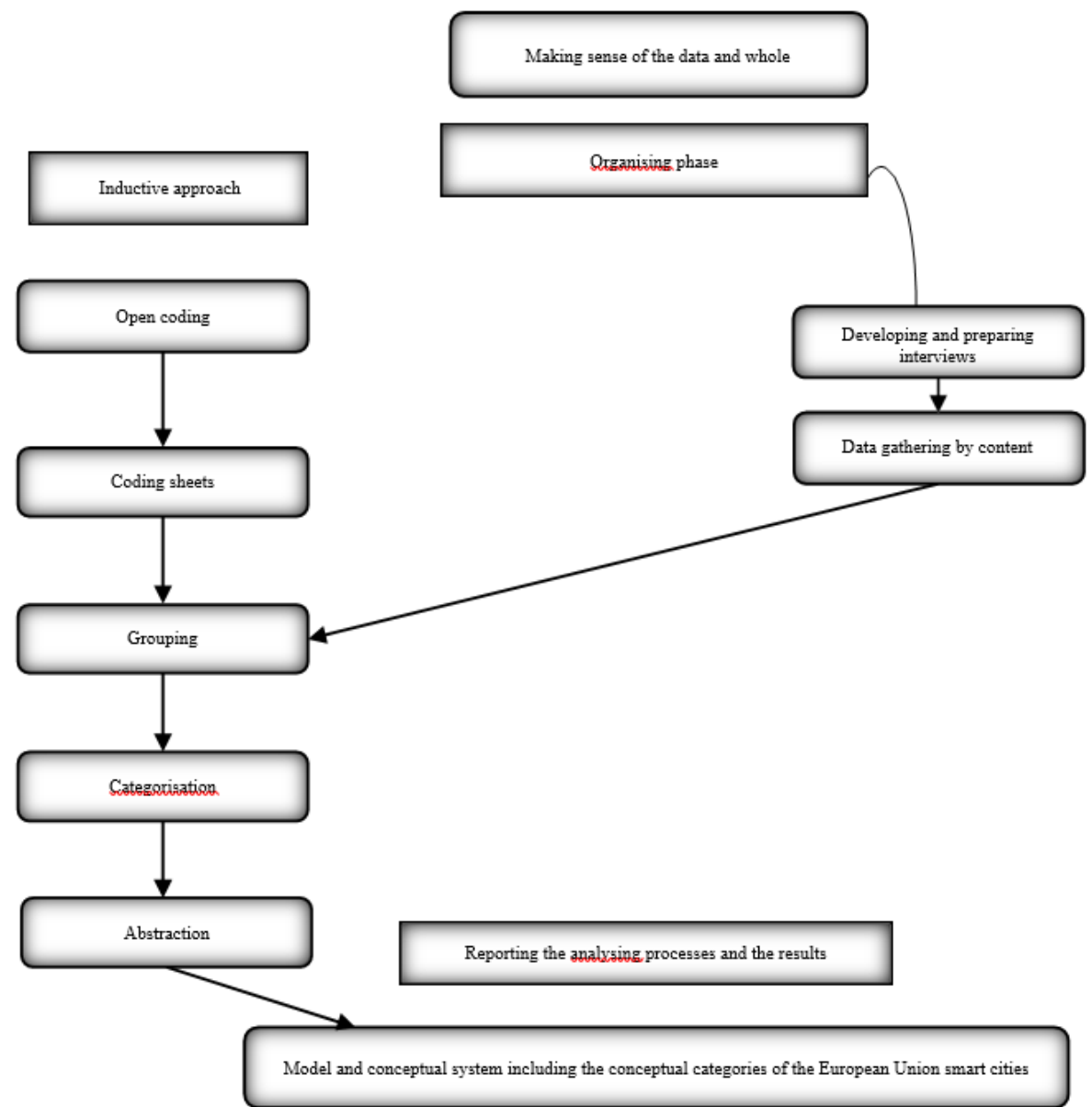

Figure 2: Preparation, organising, and resulting phases in the content analysis processes (Source: adaptation according Elo \& Kyngas, 2008).

\section{Preliminary/Expected results}


The new economic and political development models, such as the circular economy, the sharing economy, and Industry 4.0, will play an important role in ensuring a higher quality of living conditions, especially in cities with a high population density. In such an environment, citizens' quality of life depends on the size of their living spaces.

Urbanization is important because urban residents have higher incomes than their rural counterparts, and they are better educated. This urbanisation can result in greater consumer market gains (Zhang, 2016).

The urbanisation factor is critical for the development of new models that include sharing and circular economies, which are based on phenomena such as green cities, smart cities, etc. In the next ten years (by 2030), 70\% of households in the world will be urban (Lavesson, 2017). Municipalities are faced with the modernisation of the city. In their development plans, they must include the integration of the innovative (smart) technologies. According to their stakeholders and citizens, a city's management has to identify the factors that influenced the municipalities decisions' to approach to the implementation of those technologies. The future development and capabilities of the smart cities system and its adaptation to the citizens' needs depend on these factors. The results of the literature review show that organisations that collaborate with other stakeholders in urban smart sustainability projects have the potential to create and sustain competitive advantage and simultaneously add value to society, thus enhancing its wellbeing. In Table 1 an analysis of stakeholders is provided, in which we attempt to review some of the most relevant social, institutional and political factors that have significant roles in smart urban development (Bernardino \& Santos, 2017; Bonaccorsi, 2017; Borowik, 2014; Joshua, 2017; Lawton, 2017). 
Table 1: Smart cities development supporter's analysis

\begin{tabular}{|c|c|c|c|c|c|}
\hline Supporte rs & Inte re sts & $\begin{array}{l}\text { De sire d } \\
\text { situation/obje } \\
\text { ctive s }\end{array}$ & $\begin{array}{l}\text { Ex isting or e } \\
\text { xpe cting } \\
\text { situation/gap }\end{array}$ & Ca use s & $\begin{array}{l}\text { Possibilitie s to } \\
\text { influe nce /course } \\
\text { s of solution }\end{array}$ \\
\hline $\begin{array}{c}\text { Regional } \\
\text { development } \\
\text { agency }\end{array}$ & \begin{tabular}{|l|} 
More \\
technological \\
firms in \\
region
\end{tabular} & $\begin{array}{r}\text { Economic and s } \\
\text { ocial regional } \\
\text { development }\end{array}$ & \begin{tabular}{|l|} 
Nork trategic frame \\
works for \\
smart \\
technological \\
environment
\end{tabular} & $\begin{array}{l}\text { Not enough } \\
\text { technological } \\
\text { firms }\end{array}$ & $\begin{array}{l}\text { Inve s tment in non- } \\
\text { profit univers ity } \\
\text { R\&D as s } \\
\text { ociation's }\end{array}$ \\
\hline $\begin{array}{l}\text { SC local } \\
\text { initiative's }\end{array}$ & $\begin{array}{l}\text { De veloping s } \\
\text { mart city } \\
\text { projects }\end{array}$ & \begin{tabular}{|c|} 
Inte lligent and s \\
ys tem- oriented s \\
olutions to optimize \\
energy s \\
ys tems \\
Moda I s \\
plit \\
Social and \\
organizational \\
innova tions \\
through \\
inc orporation of s \\
takeholde rs \\
\end{tabular} & $\begin{array}{l}\text { De mo phas es } \\
\text { of s ome } \\
\text { technologies } \\
\text { like s mart } \\
\text { lighting, s mart } \\
\text { mobility and } \\
\text { energy s a vings }\end{array}$ & $\begin{array}{l}\text { Not } \\
\text { enough } \\
\text { inve s } \\
\text { tors and } \\
\text { knowledge } \\
\text { in the re } \\
\text { gion }\end{array}$ & $\begin{array}{l}\text { Building new s mart } \\
\text { urban s uburbs } \\
\text { and parts of the } \\
\text { cities }\end{array}$ \\
\hline $\begin{array}{l}\text { City } \\
\text { municipalities }\end{array}$ & \begin{tabular}{l}
\multicolumn{1}{c|}{ Strategic } \\
pos itioning on \\
the smart city \\
map
\end{tabular} & $\begin{array}{l}\text { Economic and s } \\
\text { ocial } \\
\text { development } \\
\text { Smart } \\
\text { urbanization }\end{array}$ & $\begin{array}{l}\quad \text { Le gis lation, } \\
\text { Guarantee for the } \\
\text { efficiency and s } \\
\text { us tainability of } \\
\text { local } \\
\text { services }\end{array}$ & \begin{tabular}{|l}
\multicolumn{1}{c|}{ Outdated } \\
infra s \\
$\quad$ tructure, \\
citizens \\
interes ts , \\
specifics of \\
European \\
cities , \\
inve s tors
\end{tabular} & $\begin{array}{l}\text { Inve s tment in } \\
\text { projects for s mart } \\
\text { urbanization, } \\
\text { preparing city } \\
\text { projects and } \\
\text { networking all } \\
\text { stakeholders }\end{array}$ \\
\hline Citiz en's & $\begin{array}{l}\text { Pers } \\
\text { onalized and } \\
\text { e fficient } \\
\text { local } \\
\text { services, } \\
\text { low energy } \\
\text { cos ts, } \\
\text { City welfare, } \\
\text { quality of life }\end{array}$ & $\begin{array}{l}\text { Jobs, high } \\
\text { income, s ocial } \\
\text { and } \\
\text { environmental } \\
\text { sustainability, } \\
\text { efficient urban } \\
\text { services for all } \\
\text { generations }\end{array}$ & $\begin{array}{l}\text { Citizens ' } \\
\text { preferences for } \\
\text { urban s ervices : } \\
\text { demographics } \\
\text { factors, options to } \\
\text { facilitate acces s } \\
\text { to public s mart s } \\
\text { ervices and infras } \\
\text { tructure }\end{array}$ & $\begin{array}{l}\text { Critical } \\
\text { mas s of } \\
\text { re gular us } \\
\text { e rs } \\
\text { knowledge } \\
\text { of } \\
\text { citizens ' pre } \\
\text { ferences and } \\
\text { needs }\end{array}$ & $\begin{array}{l}\text { Emphas ize of the us } \\
\text { e of s mart urban s } \\
\text { ervices, providing } \\
\text { citizens with the } \\
\text { choice and detailed } \\
\text { urban informa tion, } \\
\text { Facilitate } \\
\text { citizens infras } \\
\text { tructure } \\
\text { interactions }\end{array}$ \\
\hline
\end{tabular}

Based on the analysis of the literature and sources of cities and technological companies, it can be concluded that an outbreak of technologies that will truly enable the development of smart cities will occur in the near future (Anthopoulos, 2017). The current technology is mostly inthe development and testing phase. It is necessary to be aware that, in particular, the technologies related to IoT will have consequences on the behaviour of the citizens. 
Smart urbanisation provides not only added value to firms in the form of social capital as an internal adhesive for the creation of the organisational culture or an external relationship agent, but also affect the development of the products and services, raising the quality, focusing on the societal needs, and increasing employability and the growth of incomes (e.g. lower energy costs) of society and companies (Anthopoulos, Fitsilis \& Ziozias, 2016).

\section{$5 \quad$ Future development}

In addition to municipalities' urban development strategies, it also is necessary to consider the current and future needs and demands of the citizens regarding the functionality of the city's infrastructure and smart technologies role within it, in a context of the implementation of smart technology. It is necessary to determine under what conditions citizens are prepared to use the system frequently. Within this, the question of system security and citizens' trust in it must be focussed on, because there is no economic justification to develop and implement a system that citizens refuse to use.

The limitation of the research is that it is focused only on a review of secondary documents. Geographically, it is limited to the smart cities in the EU. It should also be noted that access to sensitive information on the development and implementation of technologies was limited. These limitations offer further opportunities for exploration and comparisons between cities from different continents (other geographical features, other cultures and different socio- economic development). Future research must determine citizens' preferences for using smart systems. The research must also include demographics, sociological and environmental psychology perspectives. If we wish to understand how to move the system closed to citizens and other stakeholders, we must analyse not only their demands but also their attitudes, city attachment levels and demographic characteristics of their usage behaviour.

\section{References}

Abbott, C. (2008). How cities won the West: Four centuries of urban change in western North America. New Mexico: UNM Press.

Angelidou, M. (2015). Smart cities: A conjuncture of four forces. Cities. 47, 95-106.

DOI10.1016/j.cities.2015.05.004.

Anthopoulos, L. (2017). Smart utopia VS smart reality: Learning by experience from 10 smart city cases. Cities. 63, 128-148. DOI 10.1016/j.cities.2016.10.005.

Anthopoulos, L., Fitsilis, P. \& Ziozias, C. (2016). What is the Source of Smart City Value?: A Business Model Analysis. International Journal of Electronic Government Research (IJEGR). 12(2), 56- 76. DOI10.4018/IJEGR.2016040104.

Anthopoulos, L., Janssen, M. \& Weerakkody, V. (2016). A Unified Smart City Model (USCM) for smart city conceptualization and benchmarking. International Journal of Electronic Government Research (IJEGR), 12(2), 77-93. DOI 10.4018/IJEGR.2016040105.

Bailey, K.D. (2006). Sociocybernetics and social entropy theory. Kybernetes. 35(3/4), 375-384. DOI 10.1108/03684920610653683. 

development with the purpose of improving the quality of citizens' well-being

Bernardino, S. \& Santos, F.J. (2017). Building Smarter Cities through Social Entrepreneurship. In Carvahlo, L.C. (Ed.), Handbook of Research on Entrepreneurial Development and Innovation Within Smart Cities (327 - 362). Hershey: IGI Global. DOI: 10.4018/978-1-5225-19782.ch015

Bibri, S. E. (2018). Transitioning from Smart Cities to Smarter Cities: The Future Potential of ICT of Pervasive Computing for Advancing Environmental Sustainability. In Bibri, S.E. (Ed.), Smart Sustainable Cities of the Future (pp. 535-599). Cham: Springer. DOI 10.1007/978-3319-73981-6_10.

Bibri, E.S. \& Krogstie, J. (2016). On the social shaping dimensions of smart sustainable cities: A study in science, technology and society. Sustainable Cities and Society. 29, $219-246$. DOI 10.1140/epjst/e2012-01703-3.

Bibri, S. E. \& Bardici, V. M. (2015). The Sustainability of Eco-City Model: Green and Energy Efficiency Technology-Related Framing and Selectivity Issues in Eco-City Projects in Stockholm. World Academy of Science, Engineering and Technology, International Journal of Architectural and Environmental Engineering. 2(5), 156-167.

Bonaccorsi, A. (2017). Addressing the disenchantment: universities and regional development in peripheral regions. Journal of Economic Policy Reform 20, 4 (2017), 293-320. DOI 10.1080/17487870.2016.1212711.

Borowik, I.M. (2014). Knowledge exchange mechanisms and innovation policy in post-industrial regions: Approaches of the Basque country and the west midlands. Journal of the Knowledge Economy. 5,1 (2014), 37-69. DOI 10.1007/s13132-012-0134-3.

Bryman, A. \& Bell, E. (2003). Business research methods. New York: Oxford University Press.

Brynjolfsson, E. \& McAfee, A. (2012). Race against the machine: How the digital revolution is accelerating innovation, driving productivity, and irreversibly transforming employment and the economy. New York: W. W. Norton.

Caragliu, A., Del Bo, C. \& Nijkamp, P. (2011). Smart cities in Europe. Journal of urban technology. 18(2), 65-82.

Crowe, S., Cresswell, K., Robertson, A., Huby, G., Avery, A. \& Sheikh, A. (2011). The case study approach. BMC medical research methodology. 11(1), 100. DOI 10.1186/1471-2288-11-100.

Dent, C. M. (2017). East Asia's new developmentalism: state capacity, climate change and lowcarbon development. Third World Quarterly, 1-20. DOI 10.1080/01436597.2017.1388740.

Dimovski, V., Škerlavaj, M., Penger, S., Ghauri, N.P. \& Gronhaug, K. (2008). Business research. Essex: Pearson.

Edelenbos, J., Hirzalla, F., van Zoonen, L., van Dalen, J., Bouma, G., Slob, A. \& Woestenburg, A. (2018). Governing the complexity of smart data cities: Setting a research agenda. In Bolivar, R. \& Pedro, M. (Eds.), Smart Technologies for Smart Governments (pp. 35-54). Cham: Springer. DOI 10.1007/978-3-319-58577-2.

Garau, C. \& Pavan, V. M. (2018). Evaluating Urban Quality: Indicators and Assessment Tools for Smart Sustainable Cities. Sustainability. 10(3), 1 - 18. DOI 10.3390/su10030575.

Gibson, B., Hassan, S. \& Tansey, J. (2013). Sustainability assessment: criteria and processes. London, Routledge.

Grandin, J., Haarstad, H., Kjærås, K. \& Bouzarovski, S. (2018). The politics of rapid urban transformation. Current Opinion in Environmental Sustainability. 31. 16-22. DOI 10.1016/j.cosust.2017.12.002.

Grimaldi, D. \& Fernandez, V. (2017). The alignment of University curricula with the building of a Smart City: A case study from Barcelona. Technological Forecasting and Social Change. 123, 298-306. DOI 10.1016/j.techfore.2016.03.011.

Han, H. \& Hawken, S. (2018). Introduction: Innovation and identity in next generation smart cities. City, Culture and Society. In Press. DOI 10.1016/j.ccs.2017.12.003 
Jack, E. P. \& Raturi, A. S. (2006). Lessons learned from methodological triangulation in management research. Management Research News. 29(6), 345-357. DOI 10.1108/01409170610683833.

Joshua, J. (2017). Economic Policies of Economic Growth and Development. In Joshua, J. (Ed.), China's Economic Growth: Towards Sustainable Economic Development and Social Justice (pp. 45 - 80). London: DOI: Palgrave Macmillan. DOI 10.1057/978-1-137-59403-7_3.

Kumar, T. V. (2017). Smart Economy in Smart Cities. In Kumar,V. (Ed.), International Collaborative Research 'Smart Economy in Smart Cities' and Conclusions of Cities Case Studies (pp. 3-76). Singapore: Springer. DOI 10.1007/978-981-10-1610-3.

Lawton. P. (2017). Uneven development, suburban futures and the urban region: The case of an Irish 'sustainable new town'. European Urban and Regional Studies. In Press. DOI: $10.1177 / 0969776417694679$

Lavesson, N. (2017). When and how does commuting to cities influence rural employment growth?. Journal of Regional Science. 57 (4), 631-654. DOI 10.1111/jors.12324.

Letaifa, S. B. (2015). How to strategize smart cities: Revealing the SMART model. Journal of Business Research, 68(7), 1414-1419. DOI 10.1016/j.jbusres.2015.01.024.

Luhmann, N. (1995). Social systems. Stanford: Stanford University Press.

McNeill, D. (2016). IBM and the visual formation of smart cities. Smart Urbanism. In Marvin, S., Ayala-Luque, A. \& McFarlane, C. (Eds.), Utopian Vision or False Dawn (pp. 34-51). Abingdon: Routledge.

Morozov, E. \& Bria, F. (2018). Rethinking the smart city. New York: Rosa Luxemburg Stiftung.

Neuendorf, K. A. (2016). The content analysis guidebook. London: Sage.

Niaros, V., Kostakis, V., \& Drechsler, W. (2017). Making (in) the smart city: The emergence of makerspaces. Telematics and Informatics. 34(7), 1143-1152. DOI 10.1016/j.tele.2017.05.004.

Paulin, A. (2016). Informating Smart Cities Governance? Let Us First Understand the Atoms!. Journal of the Knowledge Economy. 7(2), 329-343. DOI 10.1007/s13132-016-0368-6.

Peters, B. (2016). How not to network a nation: the uneasy history of the Soviet internet. Cambridge: The MIT Press.

Ratten, V. (2017). Entrepreneurship, Innovation and Smart Cities. London: Taylor \& Francis.

Rauter, R., Jonker, J. \& Baumgartner, R. J. (2017). Going one's own way: drivers in developing business models for sustainability. Journal of Cleaner Production, 140, 144-154. DOI 10.1016/j.jclepro.2015.04.104.

Roblek, V. (2009). Primer izpeljave analize besedila v kvalitativni raziskavi. Management. 4(1), 53 $-69$.

Roblek, V., Erenda, I. \& Meško, M. (2018). The Challenges of Sustainable Business Development in the Post-Industrial Society in the First Half of the 21st Century. In Leon, D.R. (Ed.), Managerial Strategies for Business Sustainability During Turbulent Times (pp. 1-22). Hershley: IGI Global. DOI 10.4018/978-1-5225-2716-9.

Santonen, T., Creazzo, L., Griffon, A., Bódi, Z. \& Aversano, P. (2017). Cities as Living Labs: Increasing the impact of investment in the circular economy for sustainable cities. Brussels: European Commission.

Starik, M. \& Kanashiro, P. (2013). Toward a theory of sustainability management: Uncovering and integrating the nearly obvious. Organization \& Environment. 26(1), 7-30. DOI $10.1177 / 1086026612474958$.

Söderström, O., Paasche, T. \& Klauser, F. (2014). Smart cities as corporate storytelling. City. 18(3), 307-320. DOI 10.1080/13604813.2014.906716.

Staehle, W.H. (1991). Management. Verlag F. Vahler, Munchen.

Strauss, A. L. (1987). Qualitative analysis for social scientists. Cambridge: Cambridge University Press. United Nations. (2014). World urbanisation prospects. New York: United Nations. Available at: https://esa.un.org/unpd/wup/ 
V. Roblek: A model for smart technology adaptation in the case of urban infrastructure development with the purpose of improving the quality of citizens' well-being

Violi, P. (2014). Smart City between Mythology, Power Control and Participation. In New semiotics: between tradion and innovation, 16-20 September, 1125-1131. Sofia: New Bulgarian University.

Weber, E. (2015). Industrie 4.0-Wirkungen auf Wirtschaft und Arbeitsmarkt (Industry 4.0 Impact on the economy and labor market). Wirtschaftsdienst, 95 (2015), 722-723.

Willard, B. (2012). The new sustainability advantage: seven business case benefits of a triple bottom line. Toronto: New Society Publishers.

Yigitcanlar, T. (2015). Smart cities: an effective urban development and management model?. Australian Planner. 52(1), 27-34. DOI 10.1080/07293682.2015.1019752.

Yin, R.K. (2003). Case study research: design and methods. Thousand Oaks, CA: Sage.

Zhang, X. Q. (2016). The trends, promises and challenges of urbanisation in the world. Habitat International. 54, 241-252. DOI 10.1016/j.habitatint.2015.11.028. 
634 3 $31^{\text {ST }}$ Bled eConference: Digital TRANSFormation: MEeting the ChallengeS June 17 - 20, 2018, Bled, SLOVEnia, ConfERENCE PROCEEDINGS 


\title{
Managing Complexity of Digital Transformation with Enterprise Architecture
}

\section{FABIAN GAMPFER}

\begin{abstract}
Digital transformation presents opportunities for organizations in almost any industry. At the same time, especially large enterprises struggle with managing the associated complexity. Enterprise Architecture (EA) can be leveraged to structure and align transformation and consequently manage this complexity. Hence, EA has the potential to play a major role in the current times of digital transformation by enabling organizations to effectively manage and transform their architectures. However, to do so the discipline EA itself needs to evolve and adapt to changing conditions. This research investigates based on a Complex Adaptive Systems (CAS) perspective, how EA can be practiced effectively to support digital transformation.
\end{abstract}

Keywords: • Enterprise Architecture • Digital Transformation • Complex Adaptive Systems • Complexity Theory •

CORRESPONDENCE ADDRESS: Fabian Gampfer, MSc., Research Fellow, FOM University of Applied Sciences, Institute of IT Management and Digitization, Toulouser Allee 53, 40211 Düsseldorf, Germany, e-mail: fabian.gampfer@gmail.com. 
In today's economy constant change has become the new normal. Since 1960, the average lifespan of companies on Standard \& Poor's 500 has decreased from more than 60 to less than 20 year (Satell, 2014), which severs as one vivid indicator for a business world with increasing dynamics. A major driver for this development is technical progress which itself is accelerating. Moore's law is a prominent observation of this acceleration, which outlines that the number of transistors in a dense integrated circuit doubles approximately every two years and hence is exponentially growing (Moore, 1965).

Digital transformation is one of the latest effects driven by technical progress which disrupts existing business models in various industries (Iansiti \& Lakhani, 2014; Porter \& Heppelmann, 2015). Examples range from the financial industry, where young, digital first companies take away significant market share from long-year existing competitors with their online offerings, up to the transportation sector, where digital platforms enable entirely new business models such as car-sharing (Bughin \& Zeebroeck, 2017).

The increasing dynamics in both technology and economy impose significant challenges for enterprises since there is a constant need to adapt to changing conditions while at the same time ensuring internal alignment. Since the late nineteen eighties, the concept of Enterprise Architecture (EA) has evolved as a discipline and as a method to cope with these challenges and facilitate the management of information systems in alignment with corresponding business elements within complex organizations (Lapalme et al., 2016; Zachman, 1987). Today, a variety of practices and frameworks are available that help to manage existing architectures of enterprises and support the transition from a given to a future state (Buckl \& Schweda, 2011; Matthes, 2011; Schekkerman, 2004). EA has been and still is a constantly evolving discipline which is shaped by social progress and technological advance as well as learning outcomes (Romero \& Vernadat, 2016)

The ISO/IEC/IEEE 42010 standard, defines architecture as: "The fundamental organization of a system, embodied in its components, their relationships to each other and the environment, and the principles governing its design and evolution." (ISO/IEC, 2011). This definition can be applied to EA by viewing an enterprise as a "system". The result is a commonly used definition for EA, which is for example embraced in the TOGAF framework, one of the most popular EA frameworks (Matthes, 2011; The Open Group, 2013). This research also embraces the ISO/IEC/IEEE 42010 definition and considers EA as a discipline which manages the architecture of an enterprise resulting in the following definition:

"Enterprise Architectures is a discipline which manages the fundamental organization of an enterprise, embodied in its components, their relationships to each other and the environment, and the principles governing its design and evolution."

Based on the definition of EA above this research investigates how the discipline and its methods can be applied in current times of increasing dynamics. 


$$
\begin{array}{r}
31^{\text {ST }} \text { BLED ECONFERENCE: Digital TRANSFORMATION: MEETING THE CHALLENGES } \\
\text { JUNE } 17 \text { - 20, 2018, BLED, SLOVENIA, CONFERENCE PROCEEDINGS } \\
\text { F. Gampfer: Managing Complexity of Digital Transformation with Enterprise Architecture }
\end{array}
$$

\section{Problem Definition}

We live in times of increasing dynamics. The effects of digital transformation enable new companies to be founded and grow swiftly. At the same time, existing organizations have to adapt more quickly than ever to changing conditions in order to remain successful (Bughin \& Zeebroeck, 2017).

Information technology takes a special role within digitization since it is a core enabler for this transformation. Lately, various approaches have emerged in information technology, which help to cope with the more rapidly changing business world. Some examples are: Agile software development - The implementation of IT projects in short iterations with the goal to release a first version of the product as soon as possible (Beck et al., 2001); DevOps - A practice to bring software developers and IT operations personnel closer to each other in order to enable a more rapid and more frequent release of software (Debois, 2009); Cloud Computing: The delivery of IT as a service over the internet on a pay per use basis which increases flexibility (Armbrust et al., 2010).

One key objective of Enterprise Architecture is to keep the different facets of an organization aligned which includes business interests and the underlying information systems. Therefore, in a more flexible and more rapidly changing IT world also the approaches to Enterprise Architecture must be revised.

The presented approaches from IT are reasonable attempts to cope with the increasing dynamics of the business world. However, to produce sustainable results not only shortterm flexibility needs to be pursued, but also long-term strategic alignment. EA has the potential to play a major role in these new realities of increasing dynamics by enabling organizations to effectively manage and transform their architectures. However, to do so the discipline EA itself needs to evolve and adapt to the changing conditions. This challenge has been recognized by both scholars (Korhonen, Lapalme, McDavid, \& Gill, 2016; Lapalme et al., 2016) and practitioners (Matthijssen, 2016; O'Neill, Macgregor, \& Livadas, 2017). At the same time, the discipline EA is still relatively immature (Lapalme, 2012). Consequently, immaturity can be also observed for the implementation of EA in many organizations. (Steenbergen, 2011; Winter, Legner, \& Fischbach, 2014). The presented observations lead to the conclusion that the discipline EA will likely need to undergo changes in the upcoming years to be effective in the future, which presents the foundational problem for the research presented in this work.

Individual authors have recently come up with first suggestions on how EA could be practiced in increasingly dynamic environments (Hinkelmann et al., 2016; Korhonen \& Halen, 2017; Korhonen et al., 2016; Lapalme et al., 2016). However, exiting approaches have not yet been considered based on Complex Adaptive Systems (CAS) perspective which presents a suitable theoretical framework to assess the existing initial ideas. To address this gap, this research takes an integrative view and aims to validate, consolidate and enhance existing approaches based on a CAS perspective. 
This research aims to address one main research question (MRQ), which is:

"How can Enterprise Architecture evolve to be effective in times of increasing dynamics?"

The underlying observation is that economic and technology dynamics are overall increasing which requires a different than the current way of working in EA to be effective. To find a solution to the MRQ, first the influence of increasing dynamics on the discipline EA needs to be formally understood and described. Afterwards, different approaches can be identified and assessed which ensure effectiveness of EA given these changing conditions. To address the main research question, this work applies a structured approach, which is also commonly applied in EA to develop and implement architectures (The Open Group, 2013). However, in case of this research it is applied not to an enterprise or a part of it, but to the discipline of EA. The structured approach considers two parts:

1. The current state of Enterprise Architecture as a discipline and especially the challenges imposed by increasing dynamics

2. The future state of Enterprise Architecture considering different approaches on how the discipline can evolve to better cope with increasing dynamics
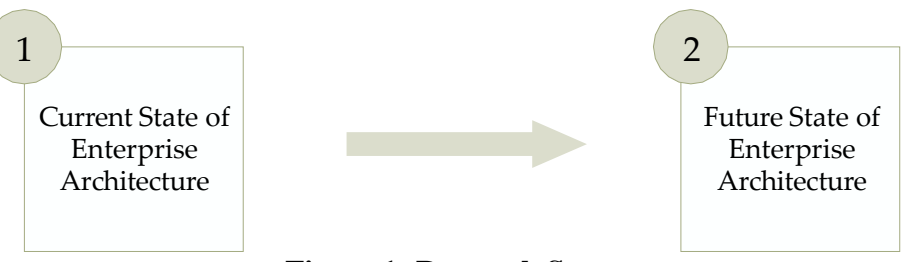

Figure 1: Research Structure

This research applies a CAS perspective. CAS is grounded in complexity theory which presents a framework for understanding based on concepts such as non-linear systems and network theory. It can be applied in various areas, including social sciences (Byrne \& Callaghan, 2013). For EA, complexity theory can be applied to understand, measure and optimize the complexity of architectures (Fu, Luo, Luo, \& Liu, 2016; Schütz, Widjaja, \& Kaiser, 2013). Moreover, in particular CAS can be applied at the methodological level of EA. CAS has been described to be a suitable theoretical lens to analyse the emergence of order in complex socio-technical systems as a result of individual actions (Anderson, 1999; Schilling, Beese, Haki, Aier, \& Winter, 2017). Therefore, the CAS perspective is chosen within this research to assess the current state of EA as well as evaluate approaches for the future state.

\section{$4 \quad$ Preliminary/Expected results}

The key result of the current state analysis within this research is a model which descibes the influence of increasing dyanmics on EA effectivesness. The current working version 
of this model is depicted in Figure 2. It combines the general theoretical framework for EA practices and benefits by Foorthuis et al. (Foorthuis, van Steenbergen, Brinkkemper, \& Bruls, 2016) with the ideas presented by Schilling et al. (Schilling et al., 2017) around dynamic complexity.

Changes in both business and technology result in dynamic complexity for EA. The faster things are chaning, the higher is the dynamic compelxity which needs to be handled. EA approaches create benefits for organizations and projects by delivering an EA which is correctly used. This means that an EA is defined and actually used in the organisation. The correct use of EA is influenced by multiple contextual factors. The reserach model of this work considres both dynamic organizational complexity and dynamic technoligical complexity as contextual factors which influence the correct use of EA.

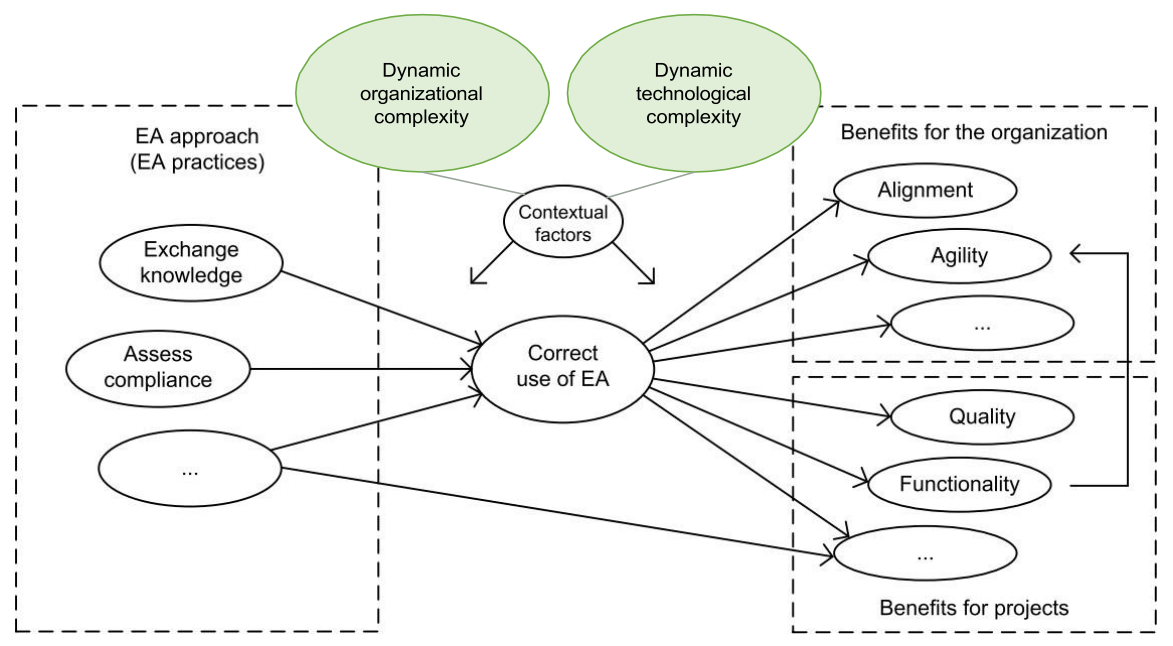

Figure 2: Working version of the research model applied, based on (Foorthuis et al., 2016)

\section{$5 \quad$ Future development}

The next step within this research is to collect and consolidate approaches which improve the effectiveness of EA in environments with high dynamic complexity. This step will be supported by a series of expert interviews. Afterwards the identified approaches are assessed based on the given reserach model with the goal to define a reference architecture for the EA capability in environments with high levels of dynamic complexity. The resulting reference architecture will present guidance to EA practitioniers on how EA can be applied for current digital transformation initiatives. 


\section{References}

Anderson, P. (1999). Complexity Theory and Organization Science. Organizational Science, 10(3), 216- 232. http://doi.org/10.2307/2640328

Armbrust, M., Stoica, I., Zaharia, M., Fox, A., Griffith, R., Joseph, A. D., ... Rabkin, A. (2010). A view of cloud computing. Communications of the ACM, 53(4), 50. http://doi.org/10.1145/1721654.1721672

Beck, K., Beedle, M., Van Bennekum, A., Cockburn, A., Cunningham, W., Fowler, M., ... others. (2001).

The agile manifesto. Retrieved from http://agilemanifesto.org/

Buckl, S., \& Schweda, C. M. (2011). State of the Art in Enterprise Architecture Management. Retrieved from https://wwwmatthes.in.tum.de/pages/qmobnr2wocn2/BS11-On-the-State-ofthe-Art-in- Enterprise-Architecture-Management...

Bughin, J., \& Zeebroeck, N. Van. (2017). The Best Response to Digital Disruption The Best Response to Digital Disruption. MIT Sloan Management Review, 58(4), 80-86.

Byrne, D., \& Callaghan, G. (2013). Complexity Theory and the Social Sciences: The State of the Art. Taylor \& Francis.

Debois, P. (2009). DevOps Days Ghent. RetrievedNovember 3, 2017, from http://www.devopsdays.org/events/2009-ghent/

Foorthuis, R., van Steenbergen, M., Brinkkemper, S., \& Bruls, W. A. G. (2016). A theory building study of enterprise architecture practices and benefits. Information Systems Frontiers, 18(3), 541-564. http://doi.org/10.1007/s10796-014-9542-1

Fu, J., Luo, A., Luo, X., \& Liu, J. (2016). Charting the landscape of enterprise architecture complexity cybernetics: A systematic literature analysis. Proceedings of the World Congress on Intelligent Control and Automation (WCICA), 2016-Septe(71571189), 1393-1397.

http://doi.org/10.1109/WCICA.2016.7578415

Hinkelmann, K., Gerber, A., Karagiannis, D., Thoenssen, B., van der Merwe, A., \& Woitsch, R. (2016). A new paradigm for the continuous alignment of business and IT: Combining enterprise architecture modelling and enterprise ontology. Computers in Industry, 79, 77-86.

http://doi.org/10.1016/j.compind.2015.07.009

Iansiti, M., \& Lakhani, K. (2014). Digital Ubiquity: How Connections, Sensors, and Data Are Revolutionizing Business. Harvard Business Review, 92(11), 91-99.

ISO/IEC. (2011). Systems and software engineering-architecture description.

Korhonen, J. J., \& Halen, M. (2017). Enterprise Architecture for Digital Transformation. 2017 IEEE 19th Conference on Business Informatics (CBI), 349-358. http://doi.org/10.1109/CBI.2017.45

Korhonen, J. J., Lapalme, J., McDavid, D., \& Gill, A. Q. (2016). Adaptive Enterprise Architecture for the Future: Towards a Reconceptualization of EA. Proceedings - CBI 2016: 18th IEEE Conference on Business Informatics, 1, 272-281. http://doi.org/10.1109/CBI.2016.38

Lapalme, J. (2012). Three Schools of Thought on Enterprise Architecture. IT Professional, 14(6), 37-43. http://doi.org/10.1109/MITP.2011.109

Lapalme, J., Gerber, A., Van Der Merwe, A., Zachman, J., Vries, M. De, \& Hinkelmann, K. (2016). Exploring the future of enterprise architecture: A Zachman perspective. Computers in Industry, 79, 103-113. http://doi.org/10.1016/j.compind.2015.06.010

Matthes, D. (2011). Enterprise Architecture Frameworks Kompendium. Vasa. Berlin, Heidelberg: Springer Berlin Heidelberg. http://doi.org/10.1007/978-3-642-12955-1

Matthijssen, P. (2016). Successful Business Transformation in the Adaptive Enterprise. The Open Group.

Retrieved from https://publications.opengroup.org/d169

Moore, G. E. (1965). Cramming more components onto integrated circuits. Electronics, 38(8). http://doi.org/10.1109/N-SSC.2006.4785860 
O’Neill, T., Macgregor, S., \& Livadas, D. (2017). What Will the Future of Enterprise Architecture and Innovation Look Like? The Open Group. Retrieved from https://publications.opengroup.org/webinars/d208

Porter, M. E., \& Heppelmann, J. E. (2015). How Smart, Connected Products Are Transforming Companies. Harvard Business Review, 93(10), 96-114. Retrieved from https://hbr.org/2015/10/how-smart-connected-products-are-transforming-companies

Romero, D., \& Vernadat, F. (2016). Enterprise information systems state of the art: Past, present and future trends. Computers in Industry, 79, 3-13. http://doi.org/10.1016/j.compind.2016.03.001

Satell, G. (2014). Managing For Disruption. Retrieved October 26, 2017, from http://www.creativitypost.com/business/managing_for_disruption

Schekkerman, J. (2004). How to Survive in the Jungle of Enterprise Architecture Frameworks: Creating Or Choosing an Enterprise Architecture Framework. Trafford.

Schilling, R. D., Beese, J., Haki, K. M., Aier, S., \& Winter, R. (2017). Revisiting the Impact of Information Systems Architecture Complexity: A Complex Adaptive Systems Perspective. In Thirty Eighth International Conference on Information Systems (pp. 1-18).

Schütz, A., Widjaja, T., \& Kaiser, J. (2013). Complexity in enterprise architectures: conceptualization and introduction of a measure from a system theoretic perspective. 21st European Conference on Information Systems, 12.

Steenbergen, M. (2011). Maturity and Effectiveness of Enterprise Architecture. Utrecht University. Retrieved from http://igitur-archive.library.uu.nl/dissertations/2011-0609200519/UUindex.html

The Open Group. (2013). TOGAF Version 9.1.

Winter, R., Legner, C., \& Fischbach, K. (2014). Introduction to the special issue on enterprise architecture management. Information Systems and E-Business Management, 12(1), 1-4. http://doi.org/10.1007/s10257-013-0221-4

Zachman, J. A. (1987). A Framework for Information Systems Architecture. IBM Systmes Journal, 26(3), 454-470. http://doi.org/10.1147/sj.263.0276 
642 31 $31^{\text {ST }}$ Bled eConference: Digital TRANSFormation: MEeting the ChallengeS JunE 17 - 20, 2018, BLED, SLOVENIA, CONFERENCE PROCEEDINGS 


\title{
Energy security as an indicator of the efficiency of strategic energy management in the European Union
}

\author{
BOJANA VASIĆ
}

\begin{abstract}
The main problem of this research is, in general, Energy policy in EU. Current energy profile of EU and the prospects for the future are highly unfavourable and uncertain. During last two decades, energy policy in the EU have proved to be inefficient. European Commission adopted numerous legal and accompanying documents both at European and national level(s), but it is evident that energy policy does not provide the results expected by decision makers and satisfactory for EU citizens. The main results of this research can be summarize as follows: a) EU, in general, is not successful in achieving its goals related to energy policy; b) Reasons for such a performance are very complex and of different nature; c) The significant causes for short-term and long-term energy instability are identified in area of energy management, whose part is strategic control; d) Research shows that absence of unique methodology for measurement of energy strategy efficiency is important obstacle for current and future planning; e) This study suggests use of energy security as an indicator for measurement because its application on research sample (EU 28 member states, 2005-2015) proves its reliability, accuracy and applicability. Research also, points to main limitation for use of energy security indicator in strategic control.
\end{abstract}

Keywords: • Energy policy $\bullet$ Energy security $\bullet$ Strategic control $\bullet$ EU $\bullet$

CorResPondence AdDress: Bojana Vasić, PhD student, University of Maribor, Faculty of organizational sciences, Kidričeva cesta 55a, 4000 Kranj, Slovenia, bvasic01@gmail.com. 
B. Vasić: Energy security as an indicator of the efficiency of strategic energy management in the European Union

\section{Scope of the reseach}

The main problem of the research is the critical analysis of strategic energy management in the EU at all stages, with particular emphasis on strategic control, as a phase of the management process, which assesses the effectiveness of the implementation of the anticipated measures and decisions about necessary changes. Energy policy and strategic energy management in the EU have proved to be inefficient. Over the past twenty years, numerous strategies have been adopted in the field of energy policy, a number of measures have been proposed to improve energy security, but the results are not as expected. Regardless to the numerous directives and regulations in this area, all EU countries face the problem of the ability to provide enough energy for all their needs, from a reliable source and at an affordable price. The complex geopolitical changes and the specificity of the relations between the EU and the Russian Federation only further complicate the already high dependence of the EU on energy imports. In such a situation, some Member States are in a particularly unfavourable position. The EU's energy policy and strategic directions for further development of the energy sector (related to environmental regulations) are, in addition to the migrant crisis, the biggest subject of dispute between the European Commission and individual Member States. Common EU policies and interests of individual Member States are very often in conflict, which in turn leads to the deepening of energy security problems in the EU, and may have wider implications.

The EU has defined energy security as one of the priority goals of long-term development, but on the other hand, neither the defined ways of achieving the stated objective are clearly defined nor accepted. One of the major causes of the problems that exist in the assessment of strategic energy management is the lack of a single approach to the concept of energy security itself, as well as the lack of a single consensus on the methodology for assessing (quantifying) energy security. All of this creates major problems in the energy management process because parameters for defining the success of its implementation are not clearly defined. In this situation, without adequate analytic, high data and clearly based data processing methods, there is a growing potential for making wrong decisions that are always far reaching in the sphere of energy security and have a major impact on national security as a whole.

All of this creates major problems, both in the further direction of the EU's common energy policy and in the design of the energy management process at Member State level.

\section{Subject of the research}

Subject of this research is conceptualization and application of energy security as indicator for measurement of achieved energy security policy results. 


\section{$3 \quad$ Novelty of the research}

Main contribution of this research lays in three key novelties:

\subsection{Research will suggest new - improved definition of energy security}

Besides the fact that successful energy policy is one of the key priorities of all countries, there is still no single accepted definition of energy security. There are a number of definitions which can be divided into those focused on the security of supply (short-term energy security) and definitions which take account of a broader concept of energy security (long-term energy security). Wizner (2012) analyzed 36 definitions of energy security and he himself defined energy security as "the continuity of energy supplies relative to demand". A broader concept of energy security assumes that energy security is a complex issue based on multidisciplinary approach including economics, engineering, political and natural science (Mansson, Johansson and Nilsson 2015). Every discipline analyzes energy security from its point of view, so this could lead to conflict of assumptions. In addition, the very method of defining energy security is associated with a number of challenges because one cannot expect that all-important factors are relevant to all countries equally, whereby their importance changes over time (Vivoda 2010). Therefore, it can be said that energy security is a dynamic category because the approach varies depending on the analyzed timeframe. Depending on the analyzed timeframe, the difference arises in the perception of the perspective (Cherp and Jewell 2011) and in the national priorities in general, and in particular for energy security (Johansson 2013).

\section{2 Research will suggest new methodology for measurement of energy security}

Due to a number definitions and different approaches to energy security, development of a methodology for its calculation is connected with a number of difficulties. This can certainly result from the previously mentioned limiting factors, but high-priority positioning of energy security on the agenda of all countries certainly deserves continuous efforts in finding a reference methodology to assess all aspects and to include the factors of importance. The existing methodologies are quite different from each another primarily depending on the dimension of energy security they analyze, on whether they evaluate energy security on macro (country, region) or micro level, on whether they are related to the security of supply or they include demand as well, and depending on the factors they include, etc. It is therefore necessary to develop new methodologies that will be more comprehensive and that will include as many factors that affect energy security.

Each of the observed factors can have direct and indirect impact on energy security. An aggravating circumstance is the fact that many factors of importance to energy security are not quantitatively measurable. For example, geopolitical conditions, political instability and armed conflicts certainly affect the price and transport of energy, and hence energy security. Regardless of the great importance, it is difficult to quantitatively measure the countries' political stability. It should also be taken into account that energy 
B. Vasić: Energy security as an indicator of the efficiency of strategic energy management in the European Union

security is a dynamic category that follows global changes. Therefore, it is necessary to monitor the global changes but also the changes in the value of a defined indicator of energy security. Only monitoring of energy security over a longer period can certain changes to be established and certain conclusions to be made accordingly.

A whole range of economic, political, social and environmental factors (Kruyt 2009) affects energy security. There are many different approaches in literature for calculating energy security indices (Jansen, Arkel and Boots 2004; Martchamadol and Kumar 2013). The difference is most commonly made between the indices that recognize the security of supply and ignore the security of demand. Most of the indices recognize only some factors of energy security, such as economic and environmental factors (Bollen, Hers and Van der Zwaan 2010; Criqui and Mima 2012), while political and social factors are less common.

Political and/or social aspects are often excluded because, inter alia, they are not quantitatively measurable. Political risks are notoriously hard to quantify because there are limited sample size values or case studies regarding when an individual nation. Geopolitical risk covers all kinds of risks that investors, for example, would take because of the political changes or instability in a country. Political instability affecting investment returns could stem from a change in government, legislative bodies, other foreign policy makers, or military control (Filipović and Petrović 2015). The outcome of a political risk could drag down investment returns or even go so far as to eliminate the ability to withdraw capital from an investment.

\subsection{Research will test applicability and validity of energy security as indicator for measurement of energy policy effectiveness}

Most of the existing indices are created for the purpose of country rankings. However, non-homogeneity among countries has the effect of inadequate comparison and thus loses its meaning in country ranking. In addition, if indices are analyzed per se and as isolated cases, then they make no sense and have no practical value. Decision-making and the creation of measures to improve energy security is meaningful only based on the analysis of parameters that gain importance over time and on monitoring of their mutual impact on energy security. Based on a critical analysis of the methods, a new Energy Security Index (ESI) was proposed and applied in a sample of EU-28 member states, with clearly outlined recommendations for decision-making in the future.

\section{$4 \quad$ The main objective(s) of the research}

On basis of research problem, it can be defined one primary and five secondary objectives of the research. 


\section{Primary objective}

Whether is the energy security as complex, composite and aggregated indicator applicable for the assessment of effectiveness of EU energy policy.

\section{Secondary objective 1:}

Energy profile of EU. Production and consumption of energy products in the EU by source (oil, natural gas, coal, renewable energy, nuclear energy). Energy infrastructure in the EU.

\section{Secondary objective 2:}

The EU's energy policy and strategic directions for further development of the energy sector. Critical analysis.

\section{Secondary objective 3:}

Researching modern approaches to energy security. Short-term and long-term energy security.

\section{Secondary objective 4:}

Researching contemporary approaches to strategic energy management, with the aim of achieving energy security. Strategic Energy Management. Strategic management phases. Control as a phase of strategic management. Techniques for qualitative and quantitative control of the predicted goals (in this case energy security), which is a very valid indicator of the efficiency of the implementation of strategic energy management.

\section{Secondary objective 5:}

Research of the achieved level of energy security. Defining the approach to quantifying energy security. Critical analysis of the quantification approach. Input and output parameters. Database. Data mining. Selection of data. Number of observations. Methods for data processing. Interpretation of individual results and trend analysis.

\section{$5 \quad$ Methodology of the research}

Research strategy can be defined as survey. Yet, since research will include data processing and results for $\mathrm{EU}$ member states and $\mathrm{EU}$ as a whole, it can be, to some extent, seen as case study.

For the research of this kind, two main group of methods will be used:

\section{Method of literature survey}

First stage of research includes survey of existing literature sources and reliable and official data bases. 
B. Vasić: Energy security as an indicator of the efficiency of strategic energy management in the European Union

Data collection will be done by using following sources:

- official EU database (Eurostat),

- International Energy Agency database,

- World Bank database and

- relevant scientific literature.

Having in mind difficulties connected with collection of reliable data, it is necessary to use three mentioned data sources (for comparison).

\section{Methods of data processing}

Research predicts use of three techniques for explanatory data analysis. All processing methods will be applied on the data collected from 4 data collection indicated sources (mentioned above).

Conceptualization and determination of energy security will be conducted by Aggregation of Composite Indicators, which allows use of indicators of different nature (Handbook on constructing composite indicators: methodology and user guide, EU JRC Ispra, Italy, 2008).

The method of Principal Component Analysis (PCA) will be used to define a new Energy Security Index. This method assigns weights to each variable that was included in index formation, thus resulting in one index that best represents the values of several given variables. Before applying PCA, the mean normalization and feature scaling were carried out in order for all the data to have comparable range of values. In particular, the PCA allows identification of the principal directions in which the data vary, by transforming a set of correlated variables into a set of uncorrelated 'components' (Principal Component Analysis Handbook, Clanrye International, 2015). The first principal component is selected as the linear index of all the variables that captures the largest amount of information common to all of the variables, which may subsequently be used as the index (EC, 2013). The first principal component involves a linear combination of variables whose weights represent the degree of correlation between a given variable and the formed index, on the basis of which it can be concluded that the variables have a key role in explaining the index.

Taking into account the fact that EU member states have their specificities, KruskalWallis test will be used. The Kruskal-Wallis analysis of variance (KW ANOVA) is a nonparametric version of standard one-way ANOVA, in which the data are replaced by their ranks, and the test evaluates the median rank values (Kruskal Wallis H Test: Definition, Examples \& Assumptions, chapter in: Statistics Handbook, 3rd Edition, CreateSpace Independent Publishing Platform, 2016). 
B. Vasić: Energy security as an indicator of the efficiency of strategic energy management in the European Union

\section{Expected research results}

The basic scientific result of the research is a critical analysis of the existing ones and a proposal for a new methodology for assessing energy security (as an indicator of the efficiency of the strategic energy management process), which differs from the previous ones because it is based on the specifics of individual countries, that is, they respect their development priorities and geopolitical interests.

The research will also contribute in the field of data science. Namely, certain data used for assessing energy security (and whose relevance is questionable) are still used by the decision maker, which leads to wrong conclusions and, consequently, to making wrong decisions in the further implementation of the strategic energy management process.

In addition, a scientific contribution will be given in the field of trend analysis and forecasting, since the analysis of the acceptability and accuracy of certain statistical and econometric methods for the quantification of energy security will be conducted, which will be done by trend analysis and forecasting.

\section{References (Initial list)}

Badea, A.C., Rocco, S. (2016) Composite indicators for security of energy supply using ordered weighted averaging. Reliability Engineering \& System Safety 96(6): 651 - 62.

Bambawale M.J., Sovacool B.K. (2011) China's energy security: the perspective of energy users. Applied Energy 88(5): 1949-1956.

Bollen, J., Hers, S., Van der Zwaan, B. (2008) An integrated assessment of climate change policy, air pollution, and energy security policy. Energy policy 38(8): 4021-30.

Chontanavat, J., Hunt, L.C., Pierse, R. (2008) Does energy consumption cause economic growth? : Evidence from a systematic study of over 100 countries. Journal of Policy Modeling 30(2): 209-220.

Cherp, A., Jewell, J. (2011) The three perspectives on energy security: intellectual history, disciplinary roots and the potential for integration. Current Opinion in Environmental Sustainability 3(4): 202-212.

Criqui, P., Mima, S. (2012) European climate - energy security nexus: a model based scenario analysis. Energy policy 41: 827-42.

European Commission. (2013) Annex 5: Principal components analysis and wellbeing index in Studies for carrying out the Common Fisheries Policy: Lot 3 Socio-economic dimensions in EU fisheries. Available

at: http://ec.europa.eu/fisheries/documentation/studies/socio_economic_dimension/

European Commission. (2010) Energy 2020 - A strategy for competitive, sustainable and secure energy. European Commission, Brussels, Belgium.

European Commission. (2014) Member states energy dependence: an indicator based assessment. DG for Economic and Financial Affairs, Brussels, Belgium.

European Commission (2014) European Energy Security Strategy, Brussels, Belgium.

European Commission (2014) In-depth study of European Energy Security, Brussels, Belgium.

Filipovic, S. Petrovic, P. (2015) Positioning of economy in global economic surrounding. Belgrade, Serbia: Economics Institute, p. 98. 
B. Vasić: Energy security as an indicator of the efficiency of strategic energy management in the European Union

Filipović, S., Verbič, M., Radovanović, M. (2015) Determinants of energy intensity in the European Union: A panel data analysis. Energy 92(3): 547-555.

Greene, D.L. (2010) Measuring energy security: can the United States achieve oil independence? Energy policy 38: 1614-21.

Johansson, B. (2013) A broadened typology on energy and security. Energy 53, 199-205.

Kruyt, B., van Vuuren D.P., de Vries H.J.M., Groenberg, H. (2009) Indicators for energy security. Energy Policy 37(6): 2166-81.

Le Coq, C., Paltseva, E. (2009) Measuring the security of external energy supply in the European Union. Energy Policy 37(11): 4474-4481.

Lee C.F., Lee J.C., Lee A.C. (2013) Statistics for Business and Financial Economics. Springer.

Mansson, A., Johansson B., Nilsson, L.J. (2015) Assessing energy security: An overview of commonly used methodologies. Energy 73: 1-14.

Martchamadol, J. Kumar, S. (2013) An aggregated energy security performance indicator. Applied Energy 103: 653-70.

Narula, K., Reddy, S. (2016) A SES (sustainable energy security) index for developing countries. Energy 94: 326-343.

Radovanović, M., Filipovic, S. (2015) New approach to Energy Intensity in the EU - Total energy and carbon cost approach. Energy and Environment 26(1): 601-616.

Radovanović, M, Filipovic, S, Pavlovic, D. (2016) Energy security measurement - A sustainable approach. Renewable and Sustainable Energy Reviews, in press.

Sovacool B.K. (2011) Evaluating energy security in the Asia-Pacific: towards a more comprehensive approach. Energy Policy 39: 7472-7479.

Sovacool B.K. (2012) The methodological challenges of creating a comprehensive energy security index. Energy Policy 48: 835-40.

Sovacool B.K., Mukherjee, I. (2011) Conceptualizing and measuring energy security: a synthesis approach. Energy 36: 5343-55.

Soytas, U., Sari, R. (2006) Energy consumption and income in G-7 countries. Journal of Policy Modeling 28(7): 691-718.

Tol, R.S.J., Pacala, S.W., Socolow, R.H. (2009) Understanding Long-Term Energy Use and Carbon Dioxide Emissions in the USA. Journal of Policy Modelling 31(3): 425-445.

Union list of projects of common interest (2013) Official Journal of the European Union, No. 347.

Vivoda, V. (2009) Diversification of oil import sources and energy security: a key strategy or an exclusive objective? Energy policy 37: 4615-23.

Vivoda, V. (2010) Evaluating energy security in the Asia-Pacific region: A novel methodological approach. Energy Policy 38(9): 5258-5263.

Wizner, C. (2012) Conceptualizing energy security. Energy Policy 46: 36-48.

You, J. (2013) China's challenge for decarbonized growth: Forecasts from energy demand models. Journal of Policy Modeling 35(4): 652-668.

Zhang, Z.X. (2009) An Economic Model-based Analysis of Climate and Energy Policy. Journal of Policy Modeling 31(3): 359-361. 


\title{
Obtaining and Evaluating Digital Competences of Slovenian General Gymnasium Students
}

\author{
SREČKO ZAKRAJŠEK
}

\begin{abstract}
With our research, carried out according to the Design Science Research methodology, we want to establish the possible educational models in which students would obtain appropriate digital competences, which would consequently modernise lessons and make them more interesting and effective. Based on the results of previous research, we intend to continue with the development of the first artefact of our research - an organisational-information model (or several alternative models). We will prepare five selected educational model. As the second artefact of our research, we will prepare a multi-criteria model using the DEX method and evaluate five proposed educational models with the DEXi program.
\end{abstract}

Keywords: • Paper about research • Digitalization• Digital competence • Gymnasium • Students •

CORRESPONDENCE ADDRESS: Srečko Zakrajšek, Researcher, Institut and Academy for Multimedia, Leskoškova 12, Ljubljana, Slovenia, Researcher, e-mail: sreco.zakrajsek@iam.si. 
S. Zakrajšek: Obtaining and Evaluating Digital Competences of Slovenian General Gymnasium Students

\section{$1 \quad$ Introduction}

The current Slovenian gymnasium education system is obsolete and, in regard to both the programme and the examination of learning outcomes, does not allow for modern education that would ensure the acquisition and verification of students' digital competences. Many EU institutions and authors advise that the education system is the key to obtaining digital competences (Schleicher, 2016, Vermeulen, 2017).

At the EU level, recommendations and general guidelines for obtaining digital competences in educational systems (DigComp 2.1, 2017) have been adopted, and these were also accepted by Slovenia. In 2016, the Ministry of Education and Science of the Republic of Slovenia confirmed their orientation towards digital society by joining the Digital Coalition of Slovenia (Digital Coalition, 2016).

In its guidelines, the EU does not prescribe solutions, but leaves the decision to its members. For now, only the frameworks for envisaged digital competences for secondary school pupils are adopted, while detailed competences should be prepared after 2020. In general, the EU gives Member States guidelines and incentives, and carries out research to conduct comparisons between individual EU members and the developed world (Panagiotis, 2015).

Each country has to find solutions that will enable systematic acquisition of digital competences of students in Slovenian general gymnasium and modernise teaching.

With our research, carried out according to the Design Science Research methodology, we want to establish the possible educational models in which students would obtain appropriate digital competences, which would consequently modernise lessons and make them more interesting and effective.

Based on the guidelines, recommendations and solutions in different countries, we have identified various practical implementations (ECDL, Digital Competences, 2017), but they are still not comprehensive and satisfactory (Calvani, 2012, Hatlevik, 2014, Sancho, 2016). We have also analysed the situation in the Slovenian educational system (Aberšek, 2015, Zakrajšek, 2016), identified and defined eight basic education models and, among them, selected five models that could facilitate the acquisition, verification and assessment of students' digital competences in the Slovenian gymnasium. All options are based on the minimum requirement for the state to decide and advise schools or require them to follow EU and Slovenian guidelines in the field of digital competence acquisition in general gymnasium.

The selected educational models will require different interventions into goals, programmes and educational processes, therefore it is essential to be aware and know the impacts and requirements of a particular educational model in a specific environment and to assess its feasibility. 
With further research, we will prepare a model for evaluating and assessing educational models and, with it, evaluate the proposed educational models. The results will be reviewed by the scientific and professional public.

\section{Problem Definition}

The digital competences of Slovenian students in general gymnasium are not adequate. Direct research on this topic was not performed because the criteria for gymnasiums are not yet known, but we can indirectly make conclusions based on some studies among students of the first years of faculties, from monitoring media literacy among Slovenian students, and from the report of the National Education Institute Slovenia (Posodobitev, 2014).

Key problems and challenges in obtaining digital competences of Slovenian students in general gymnasium are:

- $\quad$ students of Slovenian general gymnasium do not obtain adequate digital competences according to EU standards,

- the current educational model of Slovenian general gymnasium is not suitable for students obtaining digital competences,

- the goals and curricula of the Slovenian gymnasium do not specify the acquisition of digital competences,

- students' digital competences are not reviewed in Slovenian gymnasium,

- the EU sets only frameworks and recommendations for digital competences, and concrete solutions will have to be prepared by each individual country.

Based on the above findings, we can assert a thesis that the digital competences of students attending Slovenian general gymnasium can be increased by appropriately placing digital competences into the compulsory curriculum (outcomes) of the gymnasium programme. On the basis of this thesis, we can now ask the following research questions:

- What factors influence the acquisition of digital competences of students in the Slovenian general gymnasium?

- Can an appropriate educational model be developed to achieve an increase in digital competences of students in the Slovenian general gymnasium?

The study aims to present the basic possibilities of educational models of Slovenian general gymnasiums, which include obtaining, verification and evaluation of digital competences of students, and then explore the depth of the selected models. The proposed solutions must also be evaluated in regard to their feasibility, impacts and requirements in the Slovenian educational environment. 
S. Zakrajšek: Obtaining and Evaluating Digital Competences of Slovenian General Gymnasium Students

We will use the Design Science Research (Peffers, 2007) method, as shown in Figure 1, in order to develop two artefacts, namely an organisational-information model (or several alternative models) of education, which could enable the acquisition of digital competences of students in Slovenian general gymnasium, and the DEX multi- criteria model with the DEXi program, with which we will evaluate the organisationalinformation model (or several alternative models).

We will obtain data through examinations and analyses of documents, interviews, surveys and the Delphi method, and analyse them using the appropriate statistical methods, decision analysis, qualitative analysis for interviews, etc.

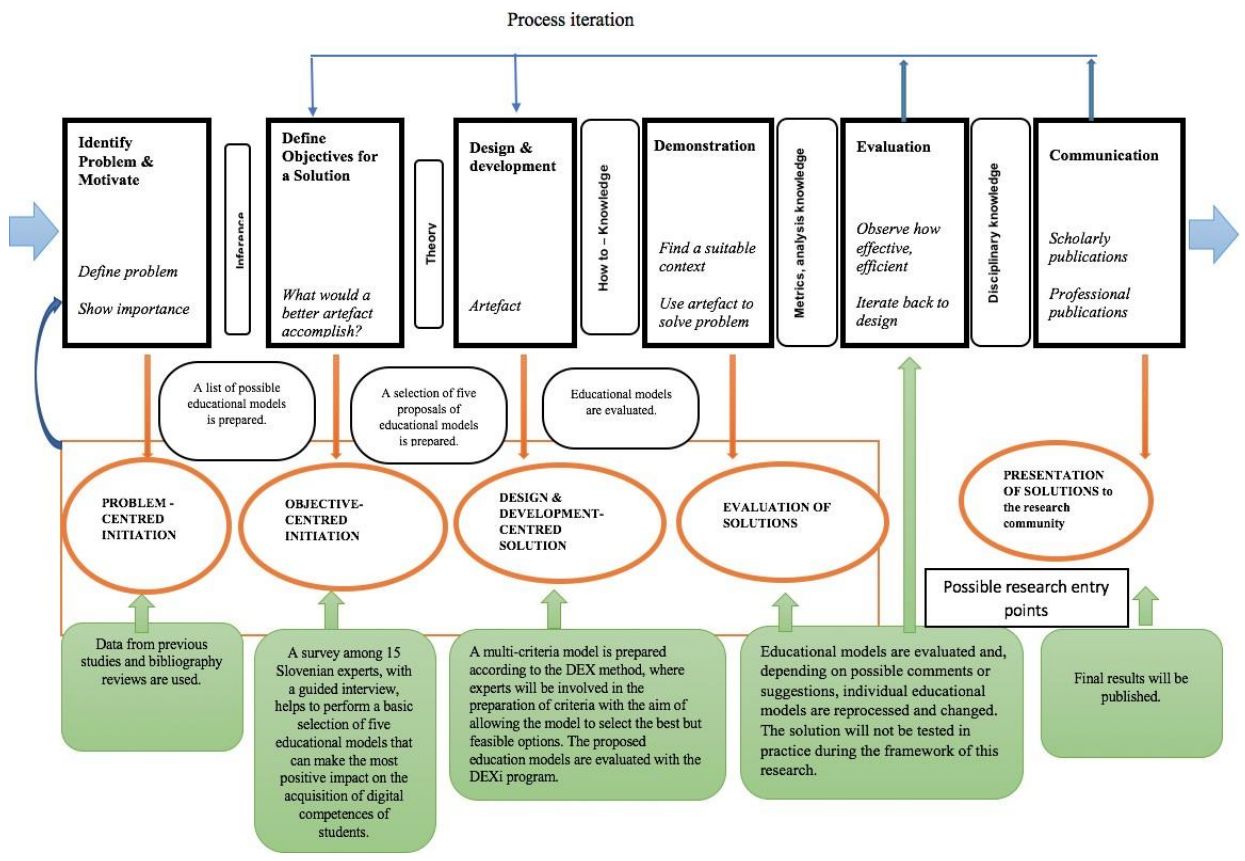

Figure 1: Predicted course of the research

In the first phase, we carried out a review (literature, resources) of the options that are used or planned for use in secondary schools in the EU and in Slovenia for the acquisition of digital competences of students. On this basis, we prepared eight options. From the proposed options, we chose five most suitable options based on information acquired through interviewing Slovenian experts, ICT directors and teachers. This way, we assessed the possibilities that the most suitable opportunities are those that can best guarantee digital competences of students in Slovenia. 
In the next phase, we will prepare a multi-criteria model using the DEX method, which will evaluate the five proposed education models. When choosing the criteria for a multicriteria model, we will include EU experts working in this field in order to determine the requirements, impacts and feasibility of each educational model in the Slovenian educational system.

\section{$4 \quad$ Preliminary/Expected Results}

With many years of pedagogical and research work in the Slovenian general gymnasium (Zakrajšek, 2016) and preliminary research (study of sources, interviews and surveys with Slovenian digital education experts, principals and teachers), we identified the basic possibilities that can influence the improvement of digital competences of students in Slovenian general gymnasium. The basic starting points of educational models for obtaining and confirming digital competences of Slovenian general gymnasium graduates, including descriptions, are shown in Table 1. As a prerequisite for changes, the general gymnasium curriculum should include the goal of students obtaining adequate digital competences before graduation. 
S. Zakrajšek: Obtaining and Evaluating Digital Competences of Slovenian General Gymnasium Students

Table 1: Options (alternatives) of platform educational models for obtaining and confirming digital competences of Slovenian general gymnasium graduates

\begin{tabular}{|c|c|}
\hline No. & Description of proposed options \\
\hline 1 & $\begin{array}{l}\text { The gymnasium curriculum and the Matura exam remain unchanged.* As gymnasium have a } \\
\text { very different attitude towards obtaining students' digital competences, depending on the } \\
\text { motivation of } \\
\text { the management and some teachers, the acquisition of students' digital competences is left to the } \\
\text { natural development of the general gymnasium and each individual school. }\end{array}$ \\
\hline 2 & $\begin{array}{l}\text { Gymnasiums receive guidelines and professional and technical assistance in the introduction of } \\
\text { modern technologies and the acquisition, verification and assessment of students' digital } \\
\text { competences. The organisation of acquisition and verification of digital competences is in the } \\
\text { domain of gymnasiums. There is no systematic external examination of students' competences. The } \\
\text { Matura exam remains unchanged. }\end{array}$ \\
\hline 3 & $\begin{array}{l}\text { The gymnasium curriculum and the Matura exam remain unchanged.* In gymnasiums, a course } \\
\text { of preparation for the acquisition of one of the EU-certificates (ECDL, Europass ...) is } \\
\text { prepared, which is followed by the external verification and evaluation of digital competences of } \\
\text { students by } \\
\text { one of the authorised organizations. }\end{array}$ \\
\hline 4 & $\begin{array}{l}\text { The gymnasium curriculum and the Matura exam remain unchanged.* Gymnasiums } \\
\text { introduce various authentic projects at the regional or country level, which include the } \\
\text { obtaining, } \\
\text { verification and evaluation of digital competences. Part of digital competences is } \\
\text { externally examined and evaluated. }\end{array}$ \\
\hline 5 & $\begin{array}{l}\text { The existing gymnasium curriculum introduces a special subject - digital competences, which is } \\
\text { carried out in the } 2^{\text {nd }} \text { year as a subject (instead of the current subject Informatics) and in the } 1^{\text {st }} \text {, } \\
3^{\text {rd }} \\
\text { and } 4^{\text {th }} \text { year within the framework of activities (or as a subject). The Matura exam } \\
\text { remains unchanged. }\end{array}$ \\
\hline 6 & $\begin{array}{l}\text { The gymnasium curriculum remains unchanged,* but the acquisition of digital competences is } \\
\text { introduced in only two elective subjects of the Matura exam. The existing Matura exam is changed } \\
\text { by examining and evaluating digital competences with the use of modern technologies in } \\
\text { two elective subjects. }\end{array}$ \\
\hline 7 & $\begin{array}{l}\text { The gymnasium curriculum remains mostly unchanged, }{ }^{*} \text { but acquisition of digital competences is } \\
\text { introduced to a certain extent in all Matura subjects. The existing Matura exam is changed by } \\
\text { examining and evaluating digital competences in all Matura subjects by using modern } \\
\text { technologies, so that only part of the Matura examination is carried out using modern } \\
\text { technologies, or that digital } \\
\text { competencies are checked within the subject and taken into account in the final assessment of the } \\
\text { subject. Digital competences only form one part of the total assessment of the subject. }\end{array}$ \\
\hline 8 & $\begin{array}{l}\text { The gymnasium curriculum is changed by introducing the acquisition of digital competences to all } \\
\text { subjects. The Matura exam is completely changed and enables external evaluation and assessment } \\
\text { of digital competences in full and in all subjects forming the Matura exam. }\end{array}$ \\
\hline
\end{tabular}

* The gymnasium curriculum determines 70-hours of informatics in the second year of study, where all students receive some digital competences (mainly ICT), depending on the programme implemented in individual gymnasiums. 
In order to evaluate and classify the proposed possibilities for acquiring digital competences of Slovenian general gymnasium students, we have prepared starting points for the evaluation of the options proposed in Table 1. The evaluation criteria are prepared in order to classify the top option as the one with the highest probability of students acquiring the appropriate digital competences, and the bottom option as the option where the probability that students would acquire appropriate digital competences is the lowest.

Table 2 shows nine groups or areas with the greatest impacts on learning, work and competences of students, which will help to evaluate the possibilities, acquisition, verification and evaluation of students' digital competences.

Table 2: Groups or areas that will influence the learning and work process of students in order for Slovenian general gymnasium students to obtain digital competences.

\begin{tabular}{|l|l|}
\hline A & Increasing digital competences \\
\hline B & Increasing subject knowledge, skills and competences \\
\hline C & Modern communication \\
\hline C & Regular acquaintance with novelties \\
\hline D & Using different portals and databases \\
\hline E & Working with different experts \\
\hline F & Project integration, networking \\
\hline G & Increasing opportunities for learning and work \\
\hline H & $\begin{array}{l}\text { Increasing schooling opportunities for students with special needs and those who are } \\
\text { temporarily absent, etc. }\end{array}$ \\
\hline
\end{tabular}

In order to evaluate various options shown in Table 1 for the areas in Table 2.

At the first level of this scale, we can estimate that the selected option does not affect or there is no progress with regard to the current state (grade 0), while the last level denotes the optimal effect (grade 3). The second and third grades (1 and 2) represent an intermediate state. Grades are selected so that they can evaluate all options, from the baseline, which exemplifies the existing status (grade 0 ) to the most complex one (grade $3)$.

We have evaluated the proposed options with preliminary research that we have conducted with a guided interview among 15 Slovenian experts, principals and ICT teachers in Slovenian general gymnasiums. Estimates are shown in Table 3. 
S. Zakrajšek: Obtaining and Evaluating Digital Competences of Slovenian General Gymnasium Students

Table 3: Evaluation of the proposed options (from Table 1) to increase digital competences of gymnasium students

\begin{tabular}{|c|c|c|c|c|c|c|c|c|c|}
\hline & Option & 1 & 2 & 3 & 4 & 5 & 6 & 7 & 8 \\
\hline $\mathrm{No}$ & Area of evaluation & $\begin{array}{l}\text { unchange } \\
\text { d }\end{array}$ & $\begin{array}{l}\text { Only } \\
\text { guideline } \\
\mathrm{s}\end{array}$ & $\begin{array}{l}\text { Only } \\
\text { certificat }\end{array}$ & $\begin{array}{l}\text { Authenti } \\
\text { c project }\end{array}$ & $\begin{array}{l}\text { Specia } \\
\text { subjec } \\
t\end{array}$ & $\begin{array}{l}\text { At } \\
\text { wo } \\
\text { electiv } \\
\text { e } \\
\text { subject } \\
\text { s }\end{array}$ & $\begin{array}{l}\text { In part } \\
\text { of all } \\
\text { subject } \\
\text { s }\end{array}$ & $\begin{array}{l}\text { Fully in all } \\
\text { Matur } \\
\text { a } \\
\text { subjec } \\
\text { ts }\end{array}$ \\
\hline 1 & $\begin{array}{l}\text { Increasing } \\
\text { digital } \\
\text { competences }\end{array}$ & 1 & 1 & 3 & 2 & 2 & 3 & 3 & 3 \\
\hline 2 & $\begin{array}{l}\text { Increasing subject } \\
\text { knowledge, } \\
\text { skills and } \\
\text { competences }\end{array}$ & 0 & 0 & 0 & 1 & 0 & 1 & 2 & 3 \\
\hline 3 & $\begin{array}{l}\text { Modern } \\
\text { communication }\end{array}$ & 1 & 1 & 2 & 2 & 2 & 3 & 3 & 3 \\
\hline 4 & $\begin{array}{l}\text { Regular } \\
\text { acquaintance } \\
\text { with } \\
\text { novelties }\end{array}$ & 1 & 1 & 1 & 0 & 1 & 2 & 3 & 3 \\
\hline 5 & $\begin{array}{l}\text { Using } \\
\text { different } \\
\text { portals and } \\
\text { databases }\end{array}$ & 1 & 1 & 1 & 1 & 2 & 3 & 3 & 3 \\
\hline 6 & $\begin{array}{l}\text { Working with } \\
\text { different experts }\end{array}$ & 0 & 1 & 1 & 1 & 1 & 2 & 2 & 2 \\
\hline 7 & $\begin{array}{l}\text { Project } \\
\text { involvemen } \\
\text { t, } \\
\text { networking }\end{array}$ & 0 & 1 & 0 & 2 & 1 & 2 & 2 & 3 \\
\hline 8 & $\begin{array}{l}\text { Improving } \\
\text { opportunities } \\
\text { for } \\
\text { learning and work }\end{array}$ & 0 & 1 & 2 & 2 & 2 & 2 & 2 & 3 \\
\hline 9 & $\begin{array}{l}\text { Increasing } \\
\text { schooling } \\
\text { options for } \\
\text { students with } \\
\text { special needs } \\
\text { and those who } \\
\text { are temporarily } \\
\text { absent, etc. }\end{array}$ & 0 & 0 & 0 & 0 & 0 & 2 & 3 & 3 \\
\hline & TOTAL & 4 & 7 & 10 & 11 & 11 & 20 & 23 & 26 \\
\hline
\end{tabular}


As seen in Table 3, the best rated options for obtaining students' digital competences are options 8, 7 and 6, where acquisition of digital competences for certain subjects is introduced and evaluated at the Matura exam. It is uniform that, from the point of view of students' acquisition of digital competences, the best option is 8 , where full acquisition, verification and evaluation of competences in all subjects is introduced.

Options 4 and 5, which ensure students' acquisition of digital competences with authentic projects or a specific subject, are assessed the same, but the grade is significantly lower than in the first three options.

Options 1 and 2, to keep the situation unchanged, or to only provide guidelines to schools, were assessed as deficient by the respondents, and option 3 with the introduction of certification was somewhat better but assessed with a lower grade than options 4 and 5 , as current certification systems do not provide adequate digital competences.

The results are expected, as the respondents believe that with the current goals, curriculum and implementation of the curriculum in Slovenian general gymnasium, no significant increase in digital competences is anticipated.

At the same time, the respondents pointed out that immediate introduction of the theoretically most appropriate and complete solution, i.e. Number 8, would probably not be successful and that different models should be studied and methods of gradual introduction of digital competence acquisition into Slovenian general grammar school should be sought.

\section{$5 \quad$ Future development}

Based on the results of previous research, we intend to continue with the development of the first artefact of our research - an organisational-information model (or several alternative models) of education in our research according to the methodology of Design Science Research. We will prepare five selected educational model proposals based on the results shown in Table 3 .

As the second artefact of our research, we will prepare a multi-criteria model using the DEX method and evaluate five proposed educational models with the DEXi program.

In the elaboration of structures and the preparation of criteria for a multi-criteria model, we will also include experts from the EU who theoretically and practically deal with areas of the acquisition of digital competences of secondary school students, in order to determine the requirements, impacts and feasibility of each educational model into the Slovenian educational system.

During the evaluation of individual educational models, we will have to take into account the following current findings regarding the proposed bases of educational models. 
Option 8 (obtaining, measuring and evaluating digital competences in all subjects) is best from the point of view of obtaining, verifying and evaluating students' digital competences, since it represents a comprehensive approach and enables the greatest desired effect and modernisation of Slovenian general gymnasium, but requires a complete change of educational processes in the gymnasium and related large-scale interventions.

Option 7 offers the second-best results, but provides lower competences in individual subjects, reduces the possibility of involving students in projects, and presents some problems in the Matura exam, as some students would be taught completely in a modern way, and others only in one segment, and this would also result in differences in the methods of work, subject matters and evaluations of the effects of education. The advantage of this option is that not all subjects need to be completely converted into a modern form, and some teachers can continue to teach with the help of modern teaching experts.

Option 6 still provides good effects, as students with two elective subjects (which they like best or will be upgrading into their study) would acquire adequate digital competences, while problems arise in the educational process, as subjects and teachers are divided into classical and modern, with all the consequences that arise from this division. It is perhaps not bad that this system offers partially classic teaching in gymnasiums, which is probably more acceptable for some teachers and students.

In options 4 and 5, the acquisition of digital competences is ensured only in a particular segment and with some teachers, which does not guarantee a modernisation of gymnasium, but, at the same time, does not require significant changes in the educational process.

From the description of certain effects of individual educational models on the organisation and work of the gymnasium it is evident that each new element in education causes different effects, requirements and changes in goals, programs, concepts, personnel and organisation, as it requires different educational processes. Among the key factors of the selected changes are the measures that influence the work of principals and teachers, as well as the legislation and programme funding.

With the multi-criteria model, we will evaluate individual educational models according to the chosen criteria and adequately complement and optimise them. We will familiarise the scientific and professional public with the results of the research.

The research does not provide for the implementation of the results in educational practice. 


\section{References}

\section{Books}

Aberšek, B., Flogie, A., Šverc, M. (2015). Sodobno kognitivno izobraževanje in transdisciplinarni modeli učenja: pedagoška strategija. Faculty of Natural Sciences and Mathematics, University of Maribor.

Schleicher, A. (OECD). (2016). Teaching Excellence through Professional Learning and Policy Reform: Lessons from around the World, International Summit on the Teaching Profession. Paris.

Zakrajšek, S. (2016). Kako do sodobne slovenske gimnazije? $1^{\text {st }}$ edition. Ljubljana: Vega: distribution Biteks. 358 pages, illustrated. ISBN 978-961-6991-01-8. [COBISS.SI-ID 283741184]

\section{eBooks}

Cornell

University.

(2018).

From

http://www.cornell.edu/search/?q=elf\%20assessment+site:https://www.cte.cornell.edu March 2018).

DEXi: A Program for Multi-Attribute Decision Making, Version 5.02. From http://kt.ijs.si/MarkoBohanec/dexi.html (15 March 2018).

Poročilo o digitalnem napredku v Evropi (EDPR) za leto 2017, Profil države Slovenija. (2017). From https://ec.europa.eu/slovenia/news/DESI_index_sl (10 December 2017).

Posodobitev kurikularnega procesa na OŠ in GIM, Končno poročilo o uvajanju poskusa, 2014, »Preverjanje nekaterih elementov gimnazijskega programa s poskusom«, šolsko leto 2013/2014. National Education Institute Slovenia. From http://155.gvs.arnes.si/blog3/wp-content/uploads/PKP-poskus-gimn-zbornikprispevkov.pdf (15 March 2018).

Vermeulen, E. P. M. (2017). Education Disrupted (Finally)! How New Technology is Transforming Teaching \& Learning.

From https://hackernoon.com/education-disrupted-finally-cecc1ba64506 (25 December 2017).

\section{Government publications}

DigComp 2.1: The Digital Competence Framework for Citizens with eight proficiency levels and examples of use. From http://publications.jrc.ec.europa.eu/repository/bitstream/JRC106281/webdigcomp2.1pdf_(online).pdf (15 March 2018).

Digital Coalition. From http://www.digitalna.si/digitalna-koalicija.html (27 December 2017).

Digital Competences. (2017). From https://europass.cedefop.europa.eu/sl/resources/digitalcompetences (25 June 2017).

$\begin{array}{lllll}\text { ECDL } & \text { (European } & \text { Computer Diving } & \text { From }\end{array}$ http://www.ecdl.si/files/ucni_nacrt_ecdl_5.pdf (27 December 2017).

\section{Journal Articles}

Calvani, A., Fini, A., Ranieri, M., Picci, P. (2012). Are young generations in secondary school digitally competent? A study on Italian teenagers. Computers \& Education, 58(2), 797-807.

Hatlevik, O. E., Guðmundsdottir, G. B., Loi, M. (2014). Digital diversity among upper secondary students: A multilevel analysis of the relationship between cultural capital, self-efficacy, strategic use of information and digital competence. Computers \& Education, 81 (2015), 345-353. 
S. Zakrajšek: Obtaining and Evaluating Digital Competences of Slovenian General Gymnasium Students

Kampylis, P., Punie, Y., Devine, J. (2015). Promoting Effective Digital-Age Learning: A European Framework for Digitally- Competent Educational Organisations. Joint Research Centre, European Union.

Peffers, K., Tuunanen, T., Rothenberger, M. A., Chatterjee, S. (2007). A Design Science Research Methodology for Information Systems Research. Journal of Management Information Systems, 24(3), 45-78.

Sancho Gil, J. M., Padilla Petry, P. (2016). Promoting digital competence in secondary education: are schools there? Insights from a case study. New Approaches in Educational Research, 5(1), 57-63. ISSN: 2254-7399, DOI: 10.7821/naer.2016.1.157. 


\title{
Technology Enabled Sustainable Business Model Innovation
}

\author{
DOROTEJA VIDMAR
}

\begin{abstract}
Business models, sustainable innovation and digital technologies all started gaining momentum in the late 1980's to early 1990's. Throughout their time they were mostly studied separately, although they are increasingly interconnected in practice, harnessing each other's effects on business practices. We argue that interdisciplinary approach is needed in order to reconcile those fields and reach deeper understanding of what is happening when the need to adapt enterprise's business model for sustainability and towards the digital, manifest in changed or completely new business models.
\end{abstract}

Keywords: • technology • sustainability • business models • digital transformation $\bullet$ sustainable business model innovation •

CorRespondence AdDRess: Vidmar Doroteja, PhD student, University of Maribor, Faculty of organizational sciences, Kidričeva cesta 55a, 4000 Kranj, Slovenia, e-mail: doroteja.vidmar@fov.uni-mb.si. 
Sustainability, defined as meeting the needs in the present, without compromising the ability to meet the needs in the future (World Commission on Environment and Development, 1987), as well as benefits for everyone involved, social and environmental in addition to economic value (Baldassarre, Calabretta, Bocken, \& Jaskiewicz, 2017; Dao, Langella, \& Carbo, 2011; Evans et al., 2017), started gaining momentum after the Brundtland report (World Commission on Environment and Development, 1987). Since then, the interest of public and academia has been growing steadily.

At approximately the same time enterprises faced pressure to first include various digital technologies in their business practices and then to adapt to business environment completely changed by digital technologies (the process of adaptation, that is now referred to as digital transformation). Something else happened during the process of digitalization and the rise of the internet; the awareness of society regarding sustainability grew and new technologies opened many new options for sustainable innovation.

The process of digital transformation is caused by fast evolving digital technologies ( $\mathrm{S}$. Berman \& Marshall, 2014; Kane, 2017b; Rayna \& Striukova, 2016). Rogers (2016) noted that "in constant digital change, no business can thrive for long just delivering the same value proposition to customers", talking about technology impacting one particular element of business model - value proposition.

Many digital transformation initiatives are focused on impacting customer relationships with re-envisioning customer experience, business processes and models (Capgemini Consulting \& MIT Sloan Management, 2011), all part of the continuous creation of new value for the customer.

It is evident, that sustainable innovation in some enterprises (e.g. SpaceX, Aura Light, Sun Contract) is positively supported by digital technologies, more precisely from advanced use of digital technologies, which is a clear indicator of digital maturity (Kane, Palmer, Phillips, Kiron, \& Buckley, 2017).

\subsection{Business models}

According to Magretta (2002) business models are stories that explain how enterprises work. It is a holistic perspective how business is conducted (Amit \& Zott, 2010; Schneider \& Spieth, 2013). Every enterprise has a business model, even though some do not consciously formulate or express it (Chesbrough, 2007). It's two main functions according to Chesbrough (2007) are value creation and value capture. Some authors focus rather on value creation (Teece, 2010; Zott \& Amit, 2010), some even omitting the value capture from business models all together (Zott \& Amit, 2010), arguing that business model and revenue models are conceptually distinct.

There is some confusion in terminology, as business model, strategy, business concept, revenue model, economic model are often used interchangeably. Also, business model 
has been referred to as architecture, design, pattern, plan, method, assumption and statement (Morris, Schindehutte, \& Allen, 2005). To our understanding, all of these expressions relate to the »how « aspect of doing business.

Authors that write about business models usually focus either on model aspect of business models or on how the enterprise does business (Osterwalder et al., 2005). In the case of the latter, enterprise is usually seen as »black box«, where only some elements are analysed and the others disregarded (Boons \& Lüdeke-Freund, 2013).

For the purpose of our study we will build on definitions of several authors:

»Business model articulates the logic of how a business creates and delivers value to customers « Teece (2010). It defines the value proposition, value chain, market segment and value capture mechanisms, describes the position of the enterprise and it's competitive strategy « (Chesbrough, 2007). »A business model is a concise representation of how an interrelated set of decision variables in the areas of venture strategy, architecture, and economics are addressed to create sustainable competitive advantage in defined markets"' (Morris et al., 2005). It is geared toward total value creation for all parties involved (Zott \& Amit, 2010) and is constantly under external pressures (e.g. competitors, society, technology, customers and policy) (Osterwalder et al., 2005). It has been referred to as the relation between strategy, organization and systems.

\subsection{Sustainability}

»Focusing on developing sustainability capabilities will not only serve the environment and people, but also help enterprises generate value that could enhance profitability and gain sustainable competitive advantage « (Dao et al., 2011).

The most widely adopted definition of sustainability is of the World Commission on Environment and Development (1987), which states that »Sustainable development seeks to meet the needs and aspirations of the present without compromising the ability to meet those of the future $\ll$. Along with this vague and hard to apply definition, in recent years, Elkington's triple bottom line perspective on sustainability became the most widely adopted.

Triple bottom line, a term coined by Elkington (1994), means that in order to be sustainable, every business practice needs to fulfil three distinct conditions: as well as economic profit, it needs to create environmental and social value. Additionally, all three values need to be in balance (Dao et al., 2011; Evans et al., 2017). Sometimes these three conditions are also named profit, people and planet (Dao et al., 2011).

Triple bottom line framework is pictured in figure 1, presenting sustainable value as the intersection between environmental value, social value and economic value. The triple bottom line implies that the value of the transaction is no longer shared only between the enterprise and the customer, but between all stakeholders (employees, local community, environment, ...) (Dao et al., 2011). 


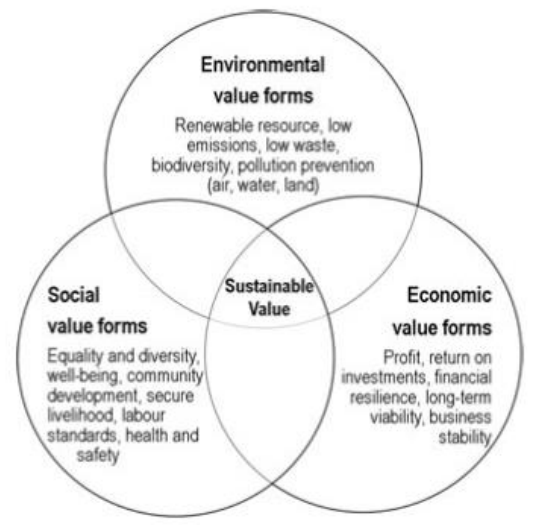

Figure 1: Sustainable value (Evans et al., 2017)

According to Baldassarre, Calabretta, Bocken, \& Jaskiewicz (2017) the sustainable business model innovation approach aims at achieving sustainability objectives by generating economic value.

Transition towards sustainability is closely connected to being able to innovate, design and build business models that function in the context of sustainability (França, Broman, Robert, Basile, \& Trygg, 2017). This implies that sustainable innovation would do best implemented into strategy, but in reality innovations for sustainability of business models tend to be non-systematic and based on ad-hoc actions (Evans et al., 2017).

According to (Keskin, Diehl, \& Molenaar, 2013), human resources are the ones driving innovation for sustainability of products and services in design phase, while the degree of market orientation drives the approach to market.

After the World Commission on Environment and Development report (1987) various approaches to realising sustainable consumption arose. While the first approaches (e.g. Ecodesign and Design for Sustainability) focused on optimization of existing products, services and processes, more advanced ones (e.g. Product-Service Systems and System Innovation for Sustainability) focus rather on innovation of new products and services (Keskin et al., 2013).

According to Evans et al. (2017) the nature of product-service systems (PSS), which provide functionalities as opposed to products (e.g. use of car instead of car ownership), makes enterprises more accountable for the issues during and after the product use phase, since the enterprises are the owners of these products through their whole life cycle. Shifting perception of value, PSS offers insights on what is considered a promising sustainable business model (SBM).

While some authors view sustainability only as achieving long-term survival of an enterprise (Bakoğlu, Bige, \& Y1ldırım, 2016), we argue that the long-term survival of the enterprise does not suffice the broad 1987 Brundtland commission definition of 
sustainability. We believe that the use of term sustainability in this case holds an alternate meaning, which won't be covered in this thesis.

The funnel metaphor explains the urgency of action towards sustainability (represented in the figure 2). As we as a society move toward the narrowing of the funnel, we face harsher constraints and less freedom. Also, the longer we delay the decision to take action, the less likely is the positive outcome (França et al., 2017).

The narrowing walls of the funnel represent loss of ecological and social systems (França et al., 2017), declining availability of resources, restorative capacity of environment, purity of resources and social fairness and equity (Dyer, 2004). Other demands are increasing, such as competitiveness, market pressure, global demands and population (Dyer, 2004).

As the enterprises continue planning their unsustainable practices, they are hitting the walls of the funnel, which are getting narrower. This shows in many different forms, including; increased costs for resources and waste management, projects quickly becoming obsolete, stricter legislation, loss of market share, consumer and shareholder activism, deteriorating reputation, etc. (Dyer, 2004).

For some enterprises, economic consequences of unsustainable practices can still be postponed, (e.g. by lobbying against tax increase). In long term those enterprises risk higher costs, lost innovation opportunities, new markets that are lost to enterprises that become a part of solution first, etc. (França et al., 2017). Only after building sustainable practices, the narrowing of the funnel could stop, and the restoration phase could begin (Dyer, 2004).

\section{The Funnel}

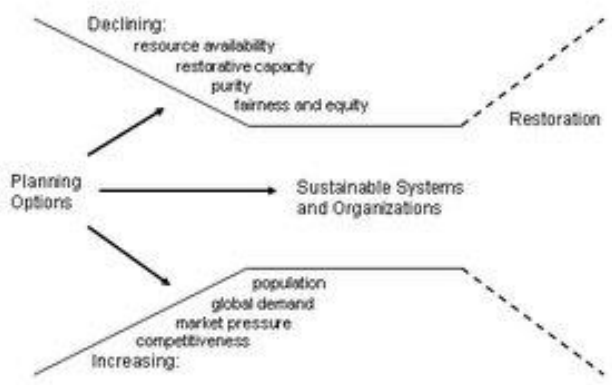

Figure 2: Representation of the funnel-metaphor (Dyer, 2004) 


\subsection{On technology and digital transformation}

The shortening of product lives means that technology itself can no longer bring satisfactory income. Innovation nowadays must include (along with technology and R\&D) business models (Chesbrough, 2007). Chesbrough (2010) stated that technology itself has no objective value, until it is commercialized through a business model.

When a new technology has no obvious business model (meaning that business model is not implied in the way said technology should be used), managers must find (or invent) it in order to be able to capture value from it (Chesbrough, 2010). This implies that sometimes technology (as a product) demands business model innovation for successful market launch. And after it is put on the market through a business model, this might disrupt the market itself, causing chain reaction.

Dao et al. (2011) explain the role of IT in sustainability; technologies enable standardization, monitoring, capturing and utilization of data, that help evaluate economic, environmental and social impact. They improve information flows, employee training in environmental matters, monitor internal and external performance... They conclude that close collaborations and information exchange within and across enterprises enabled by information systems are critical for enterprises to develop sustainability capabilities.

Digital transformation is currently an important trend in industry and society, but it is also a process, which has been undergoing since the adoption of digital technologies, allowing stakeholders to incorporate different forms of innovation into their enterprises (Gray \& Rumpe, 2017).

Kane (2017) claims that the most common understanding — that digital transformation is about the implementation and use of cutting-edge technologies - is likely the most misguided. Using technology in organizations to do business in new and different ways is better, but incomplete. He argues that digital transformation means adapting business processes and practices to help the organization compete effectively in an increasingly digital world.

Digital transformation is a business transformation (Ross, 2017). This implies that digital transformation is about how your business responds to digital trends (Kane, 2017b) and that technologies are only a part of the story, while other issues (strategy, talent management, organizational structure, and leadership) are just as important, if not more important, than technology for digital transformation (Kane, 2017a). Digitally mature organizations focus their strategies on both technology and core business capabilities (Kane et al., 2017).

Prior to the rise of digital transformation trend, Casadesus-Masanell and Ricart (2011) wrote about the economic slowdown in the developed world, which is forcing enterprises to change their business models or to create new ones. In addition, the rise of new technology-based and low-cost rivals is threatening traditional enterprises, affecting 
industries, and redistributing profits - in other words, forcing enterprises to adapt to changed business environment.

Similar observations were also made by other authors; Ross (2017) claims that trying to succeed in a digital economy without adaptation, might be the riskiest alternative.

Similar effect of digital maturity was observed by Sebastian et al. (2017), who claimed that with new technology-enabled capabilities, enterprises introduce fundamental business changes. Talking about production companies, Lee, Lee, \& Chou (2017) wrote that within the next several years, the advanced implementation of Industry 4.0 will become a qualifier to compete and will also likely to be seen by investors as a qualifier for funding.

Successful digital transformation comes from transforming your organization to take advantage of the possibilities that new technologies provide, rather than implementing new technologies (Capgemini Consulting \& MIT Sloan Management, 2011).

Naming it digital business transformation, Prentice (2017) described it as an effort to create new, connected, platform, and industry revenue. This definition once again connects new technologies (connected and platform), and business models - new forms of value proposition and value capture models.

An important finding, that also upholds our observations about digital transformation impacting strategy was made by Rogers (2016), who argues that digital transformation is fundamentally not about technology but about strategy. Although it may require upgrading organization's IT architecture, the more important upgrade is to strategic thinking.

Digital business transformation is a type of digital journey that has the ambition of pursuing net-new revenue streams, product/services and business models and creates a new paradigm that makes the old business model obsolete (LeHong \& Waller, 2017).

Regarding digital transformation as a journey (Capgemini Consulting \& MIT Sloan Management, 2011; Ross, 2017), implies what was also observed by Kane (2017), that transformation is maybe not the best word for describing it. He suggests using the phrase digital maturity, as maturity is a gradual process that unfolds across the organization over time. Even though different companies may be at different stages of digital maturity, there are always ways that they can continue to grow and adapt in order to become more digitally mature, and the process is never complete.

This is further supported by Gray \& Rumpe (2017), who claim that transformation describes a general process that starts with some initial situation that moves toward a changed, and supposedly better situation. May be that in this case the word transformation is not the best word choice because the underlying transformation may never meet a stable end, but rather undergo a continual set of evolutionary optimizations. 
Digital transformation is directly related to the changing digital economy with individuals, businesses, and society becoming interconnected in real-time, supported by technology (SAP IDC, 2017).

Based on their research and industry experience, Berman (2012) notes that there are three basic approaches to [digital] transformation: focusing on customer value proposition, transformation of the business model, or the combination of both. The path of digital transformation will vary by industry, but those enterprises that have a cohesive plan for integrating the digital and physical components of operations can successfully transform their business models (Berman, 2012).

Unfortunately, Kane (2018) recognizes that companies are not doing enough to respond to digital disruptors. He believes that leaders have very optimistic view of digital disruption. According to his research, $75 \%$ of them perceive digital as an opportunity and only $25 \%$ as a threat. He suggests that it might also be, that they expect digital to positively affect the fortune of their enterprise, but not the competitor's.

According to Gotay (2013) technology can also be seen as a culprit for ecological unsustainability - technology needs resources for development and consumes a lot of energy.

First attempts at information technology sustainability were the so called »green initiatives «. Enterprises mainly focused their efforts to reduction of energy consumption, which also reduced costs (Dao et al., 2011). But since contributions of information technology to the sustainability go beyond reducing IT's energy consumption through green initiatives, research on the sustainability value of information technology needs to go beyond "green", aimed at reducing IT's energy consumption to the contribution of IT in a broader sustainability framework. Investments in IT resources for sustainability must be aligned with other business resources (Dao et al., 2011).

Emerging E2E (everyone to everyone) economy requires reinvention of markets, strategy and value; successful organizations will rethink all aspects of their business (Berman \& Marshall, 2014).

Organizations should invest in individual-centricity while recognizing it is just a step toward the digital reinvention in the future (Berman \& Marshall, 2014).

As (Ihlström Eriksson, Akesson, \& Lund, 2016) explain, when network effects are positive, users will turn to fewer, or eventually even only one platform.

Through our literature review, we noticed that digital transformation and sustainable innovation share some common constructs regarding their influence on business models. In this time, when competition on the market is already harsh, both sustainability and technological pressure are significant and require businesses to adapt. Both share some common constructs, such as strategy, coopetition, platforms, customer-centricity, E2E 
economy, new models of ownership, innovativeness, open innovation, necessity and urgency, technologies...

In future work, we want to use these constructs to be able to clearly establish in what ways digital maturity and sustainable innovativeness are connected and affect business models. These insights could help us further develop our proposed model.

\section{$2 \quad$ Problem definition}

We argue that digital technologies are equally a disruptor of existing business models and an enabler of sustainable business models. Digital technologies and the need to reach digital maturity, defined as an ability to adapt to changes in business caused by effects of digital technologies (Kane, Palmer, Phillips, Kiron, \& Buckley, 2017), together with need for sustainability in business practices in order to preserve resources, are both pressures and opportunities for existing business practices.

Our main interest is focused on how to ensure sustainable business model innovation (SBMI) in the times of harsh competition, pressure from the environment, markets and technological disruptions, when there is already the need to quickly adapt to changed market demands, especially in relation to and with the help of digital technologies.

Based on the literature review in the area of sustainable innovation, business models, sustainable business models, digital transformation and digital maturity, it is evident, that sustainable innovation, defined as the ability to innovate (products, services and business models) in terms of sustainability (Boons \& Lüdeke-Freund, 2013; Evans et al., 2017; França et al., 2017) and digital transformation (S. J. Berman, 2012; Casadesus-Masanell \& Ricart, 2011; Sebastian et al., 2017) both strongly affect business models.

The process of digital transformation is driven by the market demands, which are also driven by capabilities of digital technologies (Rayna \& Striukova, 2016).

Sustainable innovation is needed, since planet is no longer able to restore itself and resources at the rate of demands posed by the growing human population and it's economy (Dyer, 2004).

Business models are constantly under pressure of external factors, such as competitors, society, technology, customers and policy (Osterwalder et al., 2005).

In their own way, both processes, digital transformation and sustainable innovation, are necessary for the enterprise to survive. The process of digital transformation is urgent, because the enterprises that don't transform and reach digital maturity, soon wouldn't be able to successfully compete on the market (Lee et al., 2017; Rogers, 2016; Ross, 2017; Sebastian et al., 2017). 
The process of sustainable business model innovation can in some cases still be put off to a later time, but later that it is started, less options are available (for the whole planet) and the outcome is less likely to be positive (França et al., 2017).

By reviewing literature, we have determined that, even though those threats are very much intertwined, they are in most cases studied separately. Some scholars before us noticed this discrepancy and suggested inter-disciplinary studies to be conducted.

Both processes, sustainable innovation and digital transformation as the drivers for sustainable business model innovation, are the most effective if they are incorporated in enterprise as a strategy, expanding from top to bottom.

In our thesis we want to propose and validate a model, 1st version, based on our understanding of problem, included below in figure 3. It represents incorporation of digital maturity and sustainability innovation in business models.

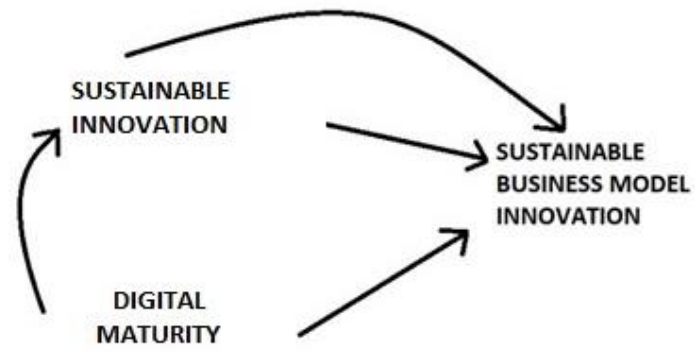

Figure 3: Sustainable business model innovation -V1.

We propose that sustainable innovation and digital maturity both affect business models and enable sustainable business model innovation (SBMI). We also argue, that digital maturity affects sustainable innovation, as one of its enablers and drivers.

We want to stress that business models need to be continuously evaluated in relation to the pressures they are facing, and then adapted and innovated in order for organization to remain competitive (Chesbrough, 2010). Also, when adapting or innovating business model, sustainability plays a larger role than ever before, combining economic, environmental and also societal value. We will be looking at what enables sustainable innovation in enterprises and how that interferes with the process of reaching digital maturity.

Possible hypotheses based on this model:

H1: Digital maturity drives sustainable innovation.

H2: Digital maturity drives sustainable business model innovation.

H3: Sustainable innovation drives sustainable business model innovation. 
In future, research on IT and sustainability needs to combine IT resources and strategies integrated with other business resources and strategies, aligned with the situational context in order to develop sustainable capabilities for specific sustainability objectives. Additional research should expand existing insights by examining how bundling of IT resources with other specific resources differs in enabling enterprises address specific sustainability issues (Dao et al., 2011). From these recommendations we draw that case studies and interviews, both of which are qualitative in nature, should be conducted to gain deeper, more situational insight.

França, Broman, Robert, Basile, \& Trygg (2017) who conducted a qualitative case study in an enterprise shifting their business model from product-based towards sustainable service-based model, argue that »presented approach and others like it will benefit from more case studies for testing and feedback for further improvement and validation« For our research approach, we will be using a survey. In preparation, we will combine qualitative and quantitative methods.

- Initially, we will conduct literature review on the fields of business models, sustainability, sustainable innovation, business model innovation, sustainable business model innovation, digitalization, digital transformation, disruptive technologies, digital maturity and other related terms. Also we will review models and questionnaires for classification and assessment of business models, sustainability, digitalization, digital and digital maturity and other related terms based on snowball sampling procedure.

- We will analyse existing literature and questionnaires to establish underlying theories, models and constructs to be able to construct conceptual model.

- We will propose conceptual model and initial hypotheses.

- Based on conceptual model and with the help of questionnaires used in studies conducted by European Commission, Republic of Slovenia Statistical office, MIT and Deloitte, Envision and others we will write first version of questionnaire.

- To test our questionnaire, we will conduct interviews in enterprises, who already have experience with sustainable innovation in combination with economic, ecological and technological pressures.

- Based on data conducted in interviews, we will write multiple case studies. Case-studies will be cross-analysed, to determine whether we gathered the information we need and whether we need to further adapt our questionnaire and model.

- Based on existing knowledge (revised literature and insight from our gathered data), we will try to develop additional hypotheses.

- After adapted questionnaire is completed, small sample of Slovenian enterprises will be selected for test-survey, which will enable us to revise questionnaire and analyse conducted data again. In this step we could also look at the response rate of questionnaires gathered by e-mail and by mail to determine which way should be used for contacting possible participants in the final round of survey. 
- After final adaptation of the questionnaire and determining whether to send our questionnaires via mail or e-mail, we will conduct survey on selected sample of Slovenian enterprises.

- Gathered data will be analysed and compared to pre-set predictive statements or hypotheses. We will assess sustainable business model innovation, its drivers (emphasis on digital maturity and sustainable innovativeness) and the interplay between them in Slovenian companies. Based on results we will try to provide insight on pressures and opportunities that enterprises are experiencing at the time of the research. In what ways striving for sustainability affects business models and other accompanying factors enablers and pressures that enterprises are facing.

- Based on our findings, conceptual model and hypotheses will be evaluated and our findings presented and elaborated upon.

- Additionally, we will try to find connections between different factors.

- If possible, recommendations will then be proposed for enterprises and policy makers on introducing sustainability practices in business models.

Our findings will be compared to existing data from other countries, which will help us make comparisons and possibly generalize our findings.

\section{$4 \quad$ Preliminary/Expected results}

Nowadays, enterprises are facing many different threats that are affecting the way they are doing business and shaping contemporary business models. These threats affect business models together, not separately. It is sometimes hard to determine, what effect is caused by which of them, since they are interconnected and depending on each other. On this account, we will combine sustainability innovation (defined by the triple bottom line framework) with contemporary threats (ecological sustainability, determined by the funnel metaphor; economical sustainability determined by value creation, technological disruptions, resources and in lesser degree social sustainability, mostly focusing on pressures that people in enterprises are facing - stress, poverty...). We want to find interconnections between these threats and business model innovation. We also want to show if there is any correlation between technological disruption and sustainable innovation.

By using interviews and survey, we will provide deeper understanding on which threat factors enterprises are facing. We will try to determine how these threats are interconnected and how they affect business models.

Better insight is needed, as most studies done by now were focused on only one of these factors. There is a need to recognize and close these gaps in order to understand the interplay of business models, sustainability, technology, social and environmental threats. We aim to establish and use our own model and questionnaire based on preceding models and questionnaires, which will then be validated through our research. 
Our research should in conclusion help us better understand, what are the factors that affect business model innovation, leading up to creation of sustainable business models. This should enable us to determine in what way enterprises should approach sustainable business model innovation in a way that all three parts of triple bottom line are in equilibrium. This is an added value for enterprises.

Added value of thesis for academia will most probably be in a form of a validated model, questionnaire and revision of interconnections between business models, triple bottom line, funnel metaphor, ecological, social and economical sustainability and technological threats.

\section{$5 \quad$ Future development}

Since research acknowledged broad impacts of IT resources on different aspects of organizational performance and competitiveness, the impacts of information technologies should be studied in relation to enabling enterprise development of sustainability capabilities (Dao et al., 2011).

Sustainability research should take interdisciplinary approach and contributions of IT towards sustainability should be studied beyond »green« IT initiatives (Dao et al., 2011). Also, future research needs to examine how IT integrated with separate business functions (e.g. marketing, accounting, ...) can be used to promote and enable performance of enterprise in terms of sustainability (Dao et al., 2011).

This claim is additionally supported by Evans et al. (2017), who argue that the study of sustainable business models is rapidly evolving, but little research has been made regarding their successful adoption. They also argue in favour of using a simulation model in order to reveal opportunities for business model innovation and de-risk experimentation.

As far as digital transformation is concerned, it is current research topic of interest. It is highly relevant for enterprises, but as was previously noted by Henriette, Feki, \& Boughzala (2015), little research (mostly in the form of case-studies) has been done around this topic.

Since the article by Henriette, Feki, \& Boughzala (2015) was published, there was a rise of reports on digital transformation by statistical offices and consultant firms [(European Commission, 2015a); (European Commission, 2015b); (European Commission, 2016); (European Commission, 2017); (Probst et al., 2017); (SAP IDC, 2016); (SAP IDC, 2017); (Kane, Palmer, Phillips, Kiron, \& Buckley, 2016); (Kane et al., 2017); (Chakravorti \& Chaturvedi, 2017)]. Each of these organizations uses their own definition of digital transformation or digital maturity. Accordingly, models for measuring digital transformation are widely different, some of them rely on strategic component of digital transformation, but we could not find any, referencing constructs of sustainability. 
Previous research in this area (especially inter-disciplinary and from the IS perspective) is limited and is focused primarily on reducing energy consumption of IT infrastructure. There are only few of interdisciplinary studies integrating IT with sustainability (Dao et al., 2011), but from them the connection between IT (including also digital transformation), is clearly present. In the past years, with the rise of the information technologies new options opened up for sustainable innovation, which implies that revision of this topic should be done.

From that we conclude, that additional interdisciplinary research on IT, or even digital transformation and sustainable innovation, regarding their effects on business models, should be conducted.

\section{References}

Amit, R., \& Zott, C. (2010). BUSINESS MODEL INNOVATION: CREATING VALUE IN TIMES OF CHANGE. IESE Business School - University of Navarra (Vol. WP-810). Retrieved from http://ssrn.com/abstract=1701660

Bakoğlu, R., Bige, O., \& Yıldırım, A. (2016). The Role of Sustainability in Long Term Survival of Family Business: Henokiens Revisited. Procedia -Social and Behavioral Sciences, 235, 788796. https://doi.org/10.1016/j.sbspro.2016.11.081

Baldassarre, B., Calabretta, G., Bocken, N. M. P., \& Jaskiewicz, T. (2017). Bridging sustainable business model innovation and user-driven innovation: A process for sustainable value proposition design. Journal of Cleaner Production, 147, 175-186. https://doi.org/10.1016/J.JCLEPRO.2017.01.081

Berman, S. J. (2012). Digital transformation: opportunities to create new business models. Strategy \& Leadership, 40(2), 16-24. Retrieved from https://doi.org/10.1108/10878571211209314

Berman, S., \& Marshall, A. (2014). The next digital transformation: from an individual-centered to an everyone-to-everyone economy. Strategy \& Leadership, 42(5), 9-17. Retrieved from http://www.emeraldinsight.com/doi/pdfplus/10.1108/SL-07-2014-0048

Boons, F., \& Lüdeke-Freund, F. (2013). Business models for sustainable innovation: state-of-theart and steps towards a research agenda. Journal of Cleaner Production, 45, 9-19. https://doi.org/10.1016/J.JCLEPRO.2012.07.007

Capgemini Consulting, \& MIT Sloan Management. (2011). DIGITAL TRANSFORMATION: A ROADMAP FOR BILLION-DOLLAR ORGANIZATIONS. Retrieved from https://www.capgemini.com/wp-content/uploads/2017/07/Digital_Transformation_A_RoadMap_for_Billion-Dollar_Organizations.pdf

Casadesus-Masanell, R., \& Ricart, J. E. (2011). How to Design A Winning Business Model. Harvard Business Review. Retrieved from http://www.bmg-businessconsulting.com/wpcontent/uploads/2012/09/How-to-Redesign-A-Winning-Business-Model.pdf

Chakravorti, B., \& Chaturvedi, R. S. (2017). DIGITAL PLANET 2017 HOW COMPETITIVENESS AND TRUST IN DIGITAL ECONOMIES VARY ACROSS THE WORLD. Retrieved from https://sites.tufts.edu/digitalplanet/files/2017/05/Digital_Planet_2017_FINAL.pdf

Chesbrough, H. (2007). Business model innovation: it's not just about technology anymore. Strategy \& Leadership, 35(6), 12-17. https://doi.org/10.1108/10878570710833714

Chesbrough, H. (2010). Business model innovation: Opportunities and barriers. Long Range Planning, 43, 354-363. https://doi.org/10.1016/j.lrp.2009.07.010

Dao, V., Langella, I., \& Carbo, J. (2011). From green to sustainability: Information Technology and an integrated sustainability framework. Journal of Strategic Information Systems, 20, 6379. https://doi.org/10.1016/j.jsis.2011.01.002 


$$
\begin{array}{r}
31^{\text {ST }} \text { BLED ECONFERENCE: Digital Transformation: MEETING THE CHALlenges } \\
\text { JunE } 17 \text { - 20, 2018, BLED, SLOVEnIA, CONFERENCE PROCEEDINGS } \\
\text { D. Vidmar: Technology Enabled Sustainable Business Model Innovation }
\end{array}
$$

Dyer, G. (2004). Strategies for Sustainability: The Funnel. Retrieved March 7, 2018, from http://strategiesforsustainability.blogspot.si/2006/04/funnel.html

Elkington, J. (1994). Towards the Sustainable Corporation: Win-Win-Win Business Strategies for Sustainable Development. California Management Review, 36(2), 90-100. Retrieved from http://journals.sagepub.com/doi/abs/10.2307/41165746

European Commission. (2015a). Digital Transformation of European Industry and Enterprises.

European Commission. (2015b). Monitoring the Digital Economy \& Society 2016 - 2021. European Commission DG Communications Networks, Content \& Technology, 52. https://doi.org/10.12968/jowc.2015.24.Sup5.S4

European Commission. (2016). Big data and B2B digital platforms : the next frontier for Europe, $s$ industry and enterprises Recommendations of the Strategic Policy Forum on Digital Entrepreneurship Forthcoming toolkit.

European Commission. (2017). COMMISSION STAFF WORKING DOCUMENT Europe's Digital Progress Report 2017.

Evans, S., Vladimirova, D., Holgado, M., Van Fossen, K., Yang, M., Silva, E. A., \& Barlow, C. Y. (2017). Business Model Innovation for Sustainability: Towards a Unified Perspective for Creation of Sustainable Business Models. Business Strategy and the Environment, 26(5), 597608. https://doi.org/10.1002/bse.1939

França, C. L., Broman, G., Robert, K.-H., Basile, G., \& Trygg, L. (2017). An approach to business model innovation and design for strategic sustainable development. Journal of Cleaner Production, 140, 155-166. https://doi.org/10.1016/j.jclepro.2016.06.124

Gotay, J. A. (2013). A classical Delphi study to identify the barriers of pursuing Green Information and Communication Technologies. University of Phoenix. Retrieved from https://searchproquest-

com.ezproxy.lib.ukm.si/pqdtglobal/docview/1499837440/8DAFE88ED67E4FD6PQ/32?acco untid=28931

Gray, J., \& Rumpe, B. (2017). Models for the digital transformation. Software \& Systems Modeling, 16, 307-308. https://doi.org/10.1007/s10270-017-0596-7

Henriette, E., Feki, M., \& Boughzala, I. (2015). The Shape of Digital Transformation: A Systematic Literature Review. In MCIS 2015 Proceedings. Retrieved from http://aisel.aisnet.org/mcis2015

Ihlström Eriksson, C., Akesson, M., \& Lund, J. (2016). Designing Ubiquitous Media Services: Exploring the Two-Sided Market of Newspapers. Journal of Theoretical and Applied Electronic Commerce Research, 11(3), 1-19. https://doi.org/10.4067/S071818762016000300002

Kane, G. C. (2017a). Digital Maturity, Not Digital Transformation. Retrieved December 12, 2017, from https://sloanreview.mit.edu/article/digital-maturity-not-digital-transformation/

Kane, G. C. (2017b). "Digital Transformation" Is a Misnomer. Retrieved January 4, 2018, from https://sloanreview.mit.edu/article/digital-transformation-is-a-misnomer/

Kane, G. C. (2018). Why Companies Don't Respond to Digital Disruption. Retrieved January 12, 2018, from https://sloanreview.mit.edu/article/why-companies-dont-respond-to-digitaldisruption/

Kane, G. C., Palmer, D., Phillips, A. N., Kiron, D., \& Buckley, N. (2016). Aligning the organization for its digital future. MIT SMR, 2-5.

Kane, G. C., Palmer, D., Phillips, A. N., Kiron, D., \& Buckley, N. (2017). Achieving Digital Maturity. MIT Sloan Management Review.

Keskin, D., Diehl, J. C., \& Molenaar, N. (2013). Innovation process of new ventures driven by sustainability. Journal of Cleaner Production, 45, 50-60. https://doi.org/10.1016/J.JCLEPRO.2012.05.012

Lee, M.-X., Lee, Y.-C., \& Chou, C. J. (2017). Essential Implications of the Digital Transformation in Industry 4.0. Journal of Scientific \& Industrial Research, 76(August), 465-467.

LeHong, H., \& Waller, G. P. (2017). Digital Business Ambition: Transform or Optimize? Gartner, 
(June).

Retrieved

from https://www.gartner.com/document/3753470?ref=TrackRecommendedEmail\&refval=150903 0006827

Magretta, J. (2002). Why Business Models Matter. Harvard Business Review. Retrieved from http://repository.binus.ac.id/2009-2/content/A0154/A015481231.pdf

Morris, M., Schindehutte, M., \& Allen, J. (2005). The entrepreneur's business model: Toward a unified perspective. Journal of Business Research, 58(6), 726-735. https://doi.org/10.1016/j.jbusres.2003.11.001

Osterwalder, A., Pigneur, Y., \& Tucci, C. L. (2005). Clarifying Business Models: Origins, Present, and Future of the Concept. Communications of the Association for Information Systems, 16(16), 1-25. Retrieved from http://aisel.aisnet.org/cais

Prentice, B. (2017). Digital Business Transformation Strategy Needs a Change of Perspective. Retrieved November 23, from https://www.gartner.com/document/3798771?ref=TrackRecommendedEmail\&refval=151128 0007220

Probst, L., Pedersen, B., Lonkeu, O.-K., Martinez-Diaz, C., Novelle Araujo, L., PwC, ... CARSA. (2017). Digital Transformation Scoreboard 2017: Evidence of positive outcomes and current opportunities for EU businesses. Retrieved from https://ec.europa.eu/growth/toolsdatabases/dem/

Rayna, T., \& Striukova, L. (2016). From rapid prototyping to home fabrication: How 3D printing is changing business model innovation. Technological Forecasting and Social Change, 102, 214-224. https://doi.org/10.1016/j.techfore.2015.07.023

Rogers, D. L. (2016). The Digital Transformation Playbook. https://doi.org/10.7312/roge 17544

Ross, J. (2017). Don't Confuse Digital With Digitization.

SAP IDC. (2016). Thriving in the Digital Age. https://doi.org/10.1016/B978-0-08-100251-3.000147

SAP IDC. (2017). The Next Steps in Digital Transformation. 2017. Retrieved from http://news.sap.com/wp-content/blogs.dir/1/files/SAP_IDC_infobrief_SMB_DX_102016.pdf

Schneider, S., \& Spieth, P. (2013). Business Model Innovation: Towards an Integrated Future Research Agenda. International Journal of Innovation Management, 17(1), 1340001. https://doi.org/10.1142/S136391961340001X

Sebastian, I. M., Mocker, M., Ross, J. W., Moloney, K. G., Beath, C., \& Fonstad, N. O. (2017). How Big Old Companies Navigate Digital Transformation. MIS Quarterly Executive, 16(3), 197-213. Retrieved from http://misqe.org/ojs2/index.php/misqe/article/viewFile/783/468

Teece, D. J. (2010). Business Models, Business Strategy and Innovation. Long Range Planning, 43, 172-194. https://doi.org/10.1016/j.lrp.2009.07.003

World Commission on Environment and Development. (1987). Report of the World Commission on Environment and Development: Our Common Future. Retrieved from http://www.undocuments.net/our-common-future.pdf

Zott, C., \& Amit, R. (2010). Business model design: An activity system perspective. Long Range Planning, 43(2-3), 216-226. https://doi.org/10.1016/j.lrp.2009.07.004 


\title{
Literature Review on Root Cause Analysis
}

\author{
JAKA TOMAN
}

\begin{abstract}
The purpose of this paper is to review publications on root cause analysis topic. This review was made in the scope of our $\mathrm{PhD}$ thesis where we address unknown reason for scrap on a semi-automatic assembly production line with help of root cause analysis techniques in combination with dark data and machine learning. Consequently, our review has greater focus on manufacturing, scrap and data mining. Clarifying the definition of root cause analysis, classifying all relevant articles and developing future research directions were objective in this paper. Root cause analysis has long history, therefore large amount of publications can be found. In this research, 1118 relevant articles regarding root cause analysis were found. Publications on this topic started in 1981 and were constantly growing ever since. Increase in number of publication is seen every year, highlighting the growing interest in root cause analysis. Review of root cause analysis definitions is provided. Articles were classified by year, research area and context in which root cause analysis is used. The review of articles provides better understanding of root cause analysis and overview on publications to date.
\end{abstract}

Keywords: • Root Cause Analysis • Literature review •

CorRespondence AdDress: Jaka Toman, PhD Student, University of Maribor, Faculty of Organisational Sciences, Kidričeva cesta 55a, 4000 Kranj, Slovenia, e-mail: jaka.toman@gmail.com. 
Historically, Root Cause Analysis (RCA) has been used to identify the core and most basic factors that contribute to an incident of any kind (Klaus, 2003). Looking at a larger context, RCA is a part of a problem-solving process. And furthermore, problem solving is an integral part of continuous improvement. RCA is therefore one of the core building blocks in an organization's continuous improvement efforts (Andersen \& Fagerhaug, 2006). Effective RCA is arguably one of the most valuable management tools in any organization (Latino, Latino, Latino, \& Latino, 2006).

We are conducting this literature review in the scope of our $\mathrm{PhD}$ thesis. Our suggested research derives from a specific problem of unknown reason for scrap on a semiautomatic assembly production line in Iskra Mehanizmi. Our goal is to identify previously unknown reason for scrap with help of RCA techniques in combination with dark data and machine learning.

Last literature reviews we found was made by Livingston, Jackson and Priestly (2001). The purpose of this article is to review the works published on RCA topic. Research objectives of this paper are to:

- clarify the definition of RCA,

- classify and summarize all relevant articles and

- develop future research directions.

This article is organized as follows. After the introduction, definition of RCA is provided. Next section introduces the research methodology and presents the results. This section provides classification by year of publication, research area and context in which RCA is used. These results are then discussed. We defined shortcomings and potential further research possibilities.

\section{$2 \quad$ What is Root Cause Analysis?}

RCA is a collective term used to describe a wide range of approaches, tools, and techniques for uncovering causes of problems (Andersen \& Fagerhaug, 2006). Consequently the definition of a root cause and root cause analysis varies between authors and root causes methodologies, with different levels of causation being adopted by different systems (Livingston, Jackson, \& Priestley, 2001). Some of the approaches are focused more on identifying the true root causes than others and some are more general problem-solving techniques. Others simply offer support for the core activity of root cause analysis. Some tools are characterized by a structured approach, while others are more creative in nature (Andersen \& Fagerhaug, 2006).

Reid and Smyth-Renshaw (2012) provided examples of RCA use in various contexts: manufacturing improvements, software projects, crime reports and client incidents.

Despite this versatility we can find one basic definition that prevails in literature and will be used also in our paper. Paradise and Butch (1988) defined a root cause as the most 
basic cause that can reasonably be identified and that management has control to fix. Root cause analysis is the task of identifying root causes. This definition contains three key elements. Root causes must be so basic that one can fix them. On the other hand, given that fixing them is the whole point, it is not reasonable to further split root causes into more basic causes (Klaus, 2003).

More definitions of RCA of other authors are provided in Table 1.

Table 10: RCA definitions

\begin{tabular}{|c|c|}
\hline Authors, Date & Definition \\
\hline $\begin{array}{l}\text { (Andersen \& Fagerhaug, } \\
\text { 2006) }\end{array}$ & $\begin{array}{l}\text { Root cause analysis is a structured investigation that aims to } \\
\text { identify the true cause of a problem and the actions necessary to } \\
\text { eliminate it. }\end{array}$ \\
\hline (Livingston et al., 2001) & $\begin{array}{l}\text { Root causes analysis is a tool designed to help incident } \\
\text { investigators describe what happened during a particular incident, } \\
\text { to determine how it happened and to understand why it happened. }\end{array}$ \\
\hline (Paradies \& Busch, 1988) & $\begin{array}{l}\text { Root cause is the most basic cause that can reasonably be } \\
\text { identified and that management has control to fix. Root cause } \\
\text { analysis is the task of identifying root causes. }\end{array}$ \\
\hline $\begin{array}{l}\text { (Wilson, Dell, } \\
\text { Anderson, 1996) }\end{array}$ & $\begin{array}{l}\text { Root cause analysis is a method of problem solving used for } \\
\text { identifying the root causes of faults or problems. }\end{array}$ \\
\hline $\begin{array}{l}\text { (Lehtinen, Mäntylä, \& } \\
\text { Vanhanen, 2011) }\end{array}$ & $\begin{array}{l}\text { Root cause analysis is a systematic process of detecting a target } \\
\text { problem, detecting and organizing its causes, and recognizing its } \\
\text { root causes }\end{array}$ \\
\hline $\begin{array}{l}\text { (Golinska \& Romano, } \\
\text { 2012) }\end{array}$ & $\begin{array}{l}\text { Root cause analysis is a technique which involves brainstorming, } \\
\text { intended to identify potential causes of problems in the first place, } \\
\text { then collecting data and analysing it in an organized fashion, } \\
\text { narrowing down the area of interest to several root causes. }\end{array}$ \\
\hline (Jenicek, 2011) & $\begin{array}{l}\text { Root cause analysis tries to identify a kind of necessary cause, a } \\
\text { kind of triggering element leading to a chain of events as an } \\
\text { accumulation of error eventually causing an accident or any other } \\
\text { undesirable event. }\end{array}$ \\
\hline (Stavert-Dobson, 2016) & $\begin{array}{l}\text { Root cause analysis attempts to identify the factors which } \\
\text { contribute to an incident and then work back to determine the } \\
\text { underlying causes with a view to addressing them. }\end{array}$ \\
\hline
\end{tabular}

Through history different RCA methodologies developed. Some of more known are Ford's 8D method, Six Sigma (Gamal Aboelmaged, 2010) and A3 thinking (Sobek \& Smalley, 2008). The majority of root causes analysis methodologies reviewed were essentially checklists of potential root cause factors to stimulate thought (Livingston et al., 2001). 
Supporting these methodologies, various tools and techniques were developed. Some of more known tools and techniques are Pareto Chart, Six Sigma, Five Why's and Fishbone diagram. Due to vast amount of tools, Andersen and Fagerhaug (2006) suggested grouping them according to their purpose:

- Problem understanding

- Problem cause brainstorming

- Problem cause data collection

- Problem cause data analysis

- Root cause identification

- Root cause elimination

- Solution implementation

These tools contribute in their own way to the RCA. Some are best applied sequentially while others can be applied at many different points in the analysis. In general, these tools are simple and easy to use. But with growing complexity of organizational environments, new tools have emerged, based on data mining software, leveraging computer capabilities and vast amount of available data. An extensive literature review of data mining in quality improvement field has been made by Köksal, Batmaz and Testik (2011). Due to this trends in root cause analysis, this aspect will be reviewed in greater detail.

\section{$3 \quad$ Research methodology}

A comprehensive literature review of journal articles dealing with »Root Cause Analysis« topic was conducted. This review was based on a similar approach used by Wamba et al. (2015) for big data, Lim et al. (2013) for RFiD and Ngai \& Wat (2002) for review of ecommerce related topics. Two key characteristics relevant for our paper are: conduction of literature review and classification of relevant journal articles.

A comprehensive search using the descriptor "Root Cause Analysis" was conducted within following databases: Web of Science, Scopus, Emerald and ProQuest. Included journals in this databases are also defined by Vankatesh (2013) to assess IS research ratings.

We started our review on April $2^{\text {nd }}, 2018$ and ended on April $30^{\text {th }}, 2018$. Search was made within topics, titles, abstracts and full texts. The review resulted in 1803 results. We excluded irrelevant articles considering titles and category. From research perspective, mainly articles with Medicine research area were excluded. Exclusion of this articles ended in 1118 results. All the results were then exported to Mendeley, a reference management software package, for further analysis. Export included articles references, abstracts and full texts in pdf format. These articles were then a subject of further, more detailed review.

Each article was then reviewed to assess relevance to our research objectives and identify duplicated ones. Due to our filed of interest, articles were then categorized according to their topic. We have recognized 208 articles of RCA in manufacturing and production. 164 articles are addressing RCA regarding scrap, yield and defects management. 
We found 55 articles using machine learning and data mining techniques in RCA. There are 24 articles addressing RCA, manufacturing or production, scrap, yield or defects and machine learning or data mining topics all in one.

\section{$4 \quad$ Results}

In following sections, we will present results of reviewed articles per previously defined classification framework.

\subsection{Distribution of articles by the year of publication}

Figure 1 shows a distribution of RCA relevant articles over the years. Separately are show articles that address RCA topic relating to manufacturing; scrap, yield, defects and with data mining and machine learning topics. From first publications in year 1981 we can notice steady increase of publicized articles. In year $201712 \%$ of all articles were published. From 2013 to 2017, in average 115 articles per year were published. $52 \%$ of all articles were published in this last 5 years. This continuous increase of numbers of publications is showing an increase of interest about RCA topic.

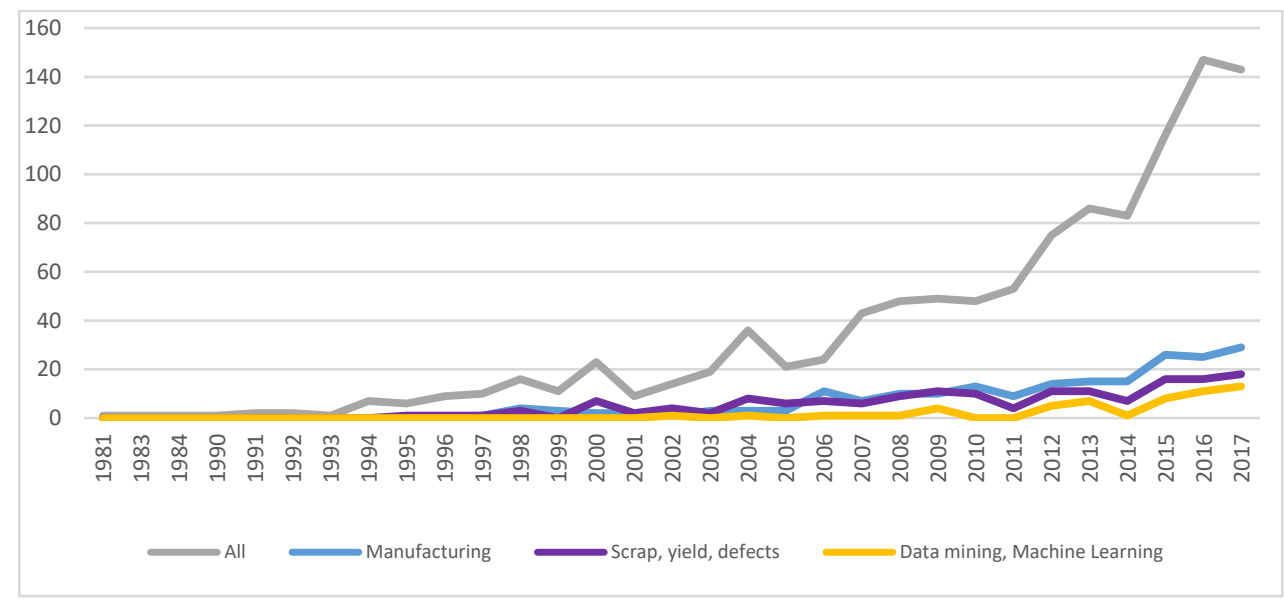

Figure 22: Distribution of articles by the year of publication

\subsection{Distribution of articles by research area}

Table 2 show the distribution of articles by top 10 research areas. As mentioned before, Medical associated research areas were excluded from analysis. One article can belong to multiple research areas. The highest number of articles is in Engineering area, 66,28\% of articles. Following by Computer Science with 360 articles, or 32,2\% of all articles. 107 seven articles belong to Material Sciences area. In Telecommunications area are 101 article and Operations Research Management Science 77 articles. Energy Fuels, 
Automation Control System and Physics each represent 4,74\% of articles. Articles from research area Business Economics were 48 and 33 from Optics. Other articles belong to other research areas.

Table 11: Distribution of articles by research area

\begin{tabular}{|c|c|c|}
\hline Research Area & $\begin{array}{l}\text { No. of articles } \\
(\%)\end{array}$ & References (top ten most cited) \\
\hline Engineering & $\begin{array}{c}741 \\
(66,27 \%)\end{array}$ & $\begin{array}{l}\text { (M. Y. Chen, Kiciman, Fratkin, Fox, \& Brewer, 2002), } \\
\text { (Bartelmus \& Zimroz, 2009), (Mena, Adenso-Diaz, \& Yurt, } \\
\text { 2011), (Bonnett, 2000), (Breitbart et al., 2004), (Weidl, } \\
\text { Madsen, \& Israelson, 2005), (Friedman, Hansen, Nair, \& } \\
\text { James, 1997), (Goh, Brown, \& Spickett, 2010), (Marais, } \\
\text { Saleh, \& Leveson, 2006), (Muchaidze et al., 2008) }\end{array}$ \\
\hline Computer Science & $\begin{array}{c}360 \\
(32,20 \%)\end{array}$ & $\begin{array}{l}\text { (M. Y. Chen et al., 2002), (Kobayashi, Otomo, Fukuda, \& } \\
\text { Esaki, 2018), (Breitbart et al., 2004), (Weidl et al., 2005), } \\
\text { (Khatib, Gomez-Andrades, Serrano, \& Barco, 2018), (Al- } \\
\text { Mamory \& Zhang, 2009), (Jabrouni, Kamsu-Foguem, } \\
\text { Geneste, \& Vaysse, 2011), (Brauckhoff, Dimitropoulos, } \\
\text { Wagner, \& Salamatian, 2009), (Alaeddini \& Dogan, 2011), } \\
\text { (Lehtinen, Itkonen, \& Lassenius, 2017) }\end{array}$ \\
\hline Materials Sciences & $\begin{array}{c}107 \\
(9,57 \%)\end{array}$ & $\begin{array}{l}\text { (Rehm et al., 2011), (Poursaeidi, Babaei, Arhani, \& Arablu, } \\
\text { 2012), (Nad, Buzik, Letal, \& Losak, 2017), (Murugan \& } \\
\text { Ramasamy, 2015), (Sawatdee \& Chutima, 2017), (Harjac, } \\
\text { Atrens, \& Moss, 2008), (Guerin, 2014), (Luka, Grosser, } \\
\text { Hagendorf, Ramspeck, \& Turek, 2016), (Han, Lee, \& Park, } \\
\text { 2016), (Nakayashiki et al., 2016) }\end{array}$ \\
\hline Telecommunications & $\begin{array}{c}101 \\
(9,03 \%)\end{array}$ & $\begin{array}{l}\text { (Breitbart et al., 2004), (Khatib et al., 2018), (Muchaidze et } \\
\text { al., 2008), (Al-Mamory \& Zhang, 2009), (Khatib, Barco, \& } \\
\text { Serrano, 2017), (Khatib, Barco, Munoz, \& Serrano, 2017), } \\
\text { (Solmaz et al., 2017), (Molnar, Sonkoly, \& Trinh, 2009), } \\
\text { (Gomez-Andrades, Barco, Munoz, \& Serrano, 2017), }\end{array}$ \\
\hline $\begin{array}{l}\text { Operations Research } \\
\text { Management Science }\end{array}$ & $\begin{array}{c}77 \\
(6,89 \%)\end{array}$ & $\begin{array}{l}\text { (Goh et al., 2010), (Marais et al., 2006), (Chien, Chen, Wu, } \\
\& \text { Hu, 2007), (Alaeddini \& Dogan, 2011), (Le Coze, 2008), } \\
\text { (S. J. Hu \& Roan, 1996), (Kumar \& Schmitz, 2011), (Carlson } \\
\text { \& Soderberg, 2003), (Kum \& Sahin, 2015), (Ferjencik, } \\
\text { 2011) }\end{array}$ \\
\hline Energy Fuels & $\begin{array}{c}53 \\
(4,74 \%)\end{array}$ & $\begin{array}{l}\text { (Eti, Gaji, \& Probert, 2006), (Gil, Martinez, \& de la Rubia, } \\
\text { 2017), (Broekaert, Demuynck, De Cuyper, De Paepe, \& } \\
\text { Verhelst, 2016), (Luka et al., 2016), (Krishna, Ormel, \& } \\
\text { Hansen, 2016), (Nakayashiki et al., 2016), (Gonzalez- } \\
\text { Salazar, Venturini, Poganietz, Finkenrath, \& Spina, 2016), } \\
\text { (Song-Manguelle et al., 2013), (Skrimpas et al., 2015), } \\
\text { (Hudson, Vasilyev, Schmidt, \& Horner, 2010) }\end{array}$ \\
\hline $\begin{array}{l}\text { Automation } \\
\text { Systems }\end{array}$ & $\begin{array}{c}53 \\
(4,74 \%)\end{array}$ & $\begin{array}{l}\text { (Jabrouni et al., 2011), (Atashgar \& Noorossana, 2011), (He, } \\
\text { Wang, He, \& Xie, 2016), (Rato, Blue, Pinaton, \& Reis, } \\
\text { 2017), (Noorossana, Atashgar, \& Saghaei, 2011), (Mohan, } \\
\text { Saygin, \& Sarangapani, 2008), (Sterritt, 2004), (Halterman } \\
\text { \& Scrapper, 2017), (Zhang, Li, Cabassud, \& Dahhou, 2017), } \\
\text { (J. Hu, Zhang, Cai, \& Wang, 2015) }\end{array}$ \\
\hline
\end{tabular}


53
Physics
$(4,74 \%)$

Business Economics

Optics
(Friedman et al., 1997), (X. Wang et al., 2010), (Rehm et al., 2011), (J. Wang, Wu, Liu, \& Xing, 2017), (Guldi, 2004), (Egger, Griitzner, Burmer, \& Dudkiewicz, 2007), (Gil et al., 2017), (Chertkov, Disyuk, Pimenov, \& Aksenova, 2017), (Luka et al., 2016), (Chuang \& Lee, 2004)

(Isack, Mutingi, Kandjeke, Vashishth, \& Chakraborty, 2018), (Mahendrawathi, Zayin, \& Pamungkas, 2017), 48 (Samopa, Astuti, \& Lestari, 2017), (Wieczerniak, Cyplik, \& (4,29\%) Milczarek, 2017), (Richter, Aymelek, \& Mattfeld, 2017), (Usman \& Rendy, 2017), (Aligula, Kok, \& Sim, 2017), (Sawalha, 2017), (Claxton \& Campbell-Allen, 2017), (Markopoulos \& Vanharanta, 2017)

(X. Wang et al., 2010), (Giollo, Lam, Gkorou, Liu, \& van Haren, 2017), (Schulz, Egodage, Tabbone, Ehrlich, \& Garetto, 2017), (Xie, Venkatachalam, Lee, Chen, \& Zafar, 2017), (Horvath, Krkos, \& Dubravec, 2017), (Tchikoulaeva, Holfeld, Arend, \& Foca, 2008), (Mora et al., 2016), (Gutjahr et al., 2016), (McCroskey, Abell, \& Chidester, 2000),

Total $1118 \quad$ *note that one article can belong to multiple research areas

\subsection{Distribution of articles by context of use}

In articles RCA is used in different contexts. We have identified three areas relevant for our problem of unknown scrap reason on production line and potential of finding root cause with help of data mining and machine learning. First area is manufacturing and production. Second area is scrap, yield or defects. Third area is data mining and machine learning. Table 3 presents articles considering this classification. There are 208 articles where RCA is used in context of manufacturing or production. Addressing scrap, yield or defects are found in 164 articles. Data mining or machine learning was used 55 times in combination with RCA. We identified 6 articles addressing all three areas at once. These articles are addressing the combination of areas most relevant for our problem. 
Table 12: Distribution of articles by context of RCA use

\begin{tabular}{|c|c|c|}
\hline $\begin{array}{l}\text { Context of } \\
\text { use }\end{array}$ & $\begin{array}{c}\text { No. of articles } \\
(\%)\end{array}$ & References (top ten most cited) \\
\hline $\begin{array}{l}\text { Manufacturing, } \\
\text { Production }\end{array}$ & $\begin{array}{c}208 \\
(64,60 \%)\end{array}$ & $\begin{array}{l}\text { (Chao, Iravani, \& Savaskan, 2009), (Mena et al., 2011), } \\
\text { (Friedman et al., 1997), (Chien et al., 2007), (Kumar \& Schmitz, } \\
\text { 2011), (Jayswal, Li, Zanwar, Lou, \& Huang, 2011), (Carlson \& } \\
\text { Soderberg, 2003), (Kurdve, Shahbazi, Wendin, Bengtsson, \& } \\
\text { Wiktorsson, 2015), (Iacocca \& Allgeier, 2007), (He et al., 2016) }\end{array}$ \\
\hline $\begin{array}{l}\text { Scrap, Yield, } \\
\text { Defects }\end{array}$ & $\begin{array}{c}164 \\
(50,93 \%)\end{array}$ & $\begin{array}{l}\text { (Leszak, Perry, \& Stoll, 2002), (Friedman et al., 1997), } \\
\text { (Nakayashiki et al., 2016), (Hwang \& Kuo, 2007), (Rehm et al., } \\
\text { 2011), (Iacocca \& Allgeier, 2007), (Bjornson, Wang, \& } \\
\text { Arisholm, 2009), (Meyer et al., 2013), (Guldi, 2004), (Kitamura } \\
\text { et al., 2005) }\end{array}$ \\
\hline $\begin{array}{l}\text { Data Mining, } \\
\text { Machine } \\
\text { Learning }\end{array}$ & $\begin{array}{c}55 \\
(17,08 \%)\end{array}$ & $\begin{array}{l}\text { (M. Y. Chen et al., 2002), (Brauckhoff, Dimitropoulos, Wagner, } \\
\text { \& Salamatian, 2012), (Malik, Hemmati, \& Hassan, 2013), } \\
\text { (Brauckhoff et al., 2012), (Suriadi, Ouyang, van der Aalst, \& ter } \\
\text { Hofstede, 2013), (Jung, Jeong, \& Lu, 2006), (Khatib, Barco, } \\
\text { Gomez-Andrades, Munoz, \& Serrano, 2015), (Rashid, Place, \& } \\
\text { Braithwaite, 2013), (Sauvanaud, Lazri, Kaaniche, \& Kanoun, } \\
\text { 2016), (Costa, Cachulo, \& Cortez, 2009) }\end{array}$ \\
\hline $\begin{array}{l}\text { All above in } \\
\text { one }\end{array}$ & $\begin{array}{c}6 \\
(1,86 \%)\end{array}$ & $\begin{array}{l}\text { (Ye, Zhang, Chakrabarty, \& Gu, 2015), (Kitcharoen, } \\
\text { Kamolsantisuk, Angsomboon, \& Achalakul, 2013), (Ye, Zhang, } \\
\text { Chakrabarty, \& Gu, 2013), (Sand, Kunz, Hubbert, \& Franke, } \\
\text { 2016), (Sand, Bogus, Kunz, \& Franke, 2016), (Sabet, Moniri, \& } \\
\text { Mohebbi, 2017) }\end{array}$ \\
\hline Total & 322 & *note that one article can belong to multiple topics \\
\hline
\end{tabular}

A comprehensive review of literature on root cause analysis was made in our article. We started our review by clarifying the definition of RCA. Then we presented our research methodology, composed with conduction of literature review and classification of relevant journal articles. In the process of our literature search, we found 1118 articles relevant articles, referring to RCA. We have also found that a literature review on this topic made by Livingston, Jackson and Priestly (2001). We have classified articles in three ways: year of publication, research area and context of use.

First classification we made was distribution of articles by the year of publication. RCA was developed was developed by Sakichi Toyoda for the Toyota Industries Corporation in 1953 (Serrat, 2009). Scientific articles addressing this subject begin in 1981 (Armor, Parkes, \& Leaver, 1981). We have shown the distribution for all the articles together and for RCA related articles addressing manufacturing, production, scrap, yield, defects and data mining, machine learning. Our review shows a constant growth and interest in this 
topic since more than $50 \%$ of published articles are dating in past 5 years. This growth is also seen in subcategories of manufacturing, scrap and data mining.

We continued our review from the perspective of research areas articles belong to. It is important to emphasize one article can belong to multiple research areas. Our review showed that majority of articles $(83 \%)$ are in the field of engineering and computer science. With that we must consider that $37 \%$ of all articles found were excluded from our review as irrelevant. The majority of them were in the medicine research area.

Our last classification was made regarding the context RCA is used in articles. We have chosen this classification due to our objectives in $\mathrm{PhD}$ thesis. In that thesis our objective is to identify previously unknown reason for scrap with help of RCA techniques in combination with dark data and machine learning.

For that reason, three contexts of use were reviewed in greater detail. We have identified 322 different articles addressing manufacturing or production topic, scrap, yield or defects topic and data mining and machine learning topic.

Brundage, Kulvantunyou, Ademujimi and Rakshith (2017) introduced a framework for a knowledge-based diagnosis as part of smart manufacturing system. By synthesizing different approaches from engineering and the medical community, this framework enables more accurate communication, discovery, and reuse of manufacturing diagnosis, corrective and preventative action plans. In automotive manufacturing Pradhan, Singh, Kachru and Narasimhamurty developed Bayesian Network based approach for RCA (Pradhan, Singh, Kachru, \& Narasimhamurthy, 2007). The objective of their model is to initiate quality improvements in the manufacturing shop floor and process-engineering departments.

When talking about using data mining in manufacturing an important contribution was made by Köksal, Batmaz and Testik (2011). They have conducted a review of data mining applications for quality improvements in manufacturing. Chen, Tseng and Wang (2005) introduced a manufacturing defect detection method using association rule mining technique. Their model searches correlations between combinations of machines and the defective products.

Similarly, Krupa and Myres (2017) conducted a review of data mining in context of RCA. Their review included numerous real-life cases over eight years, confirming that failing to address root causes increases the potential that other related incidents would occur.

Our review showed a growing interest in root cause analysis. Accordingly, the number of publications of RCA in manufacturing, scrap and data mining is growing. Despite a long history RCA and numerous applications of data mining in manufacturing we do not find any case study regarding RCA in context of unknown reason for scrap on production line, solving it with help of data mining and machine learning. Therefore, we recognize a potential for case study on this topic. 


\section{References}

Al-Mamory, S. O., \& Zhang, H. (2009). Intrusion detection alarms reduction using root cause analysis and clustering. COMPUTER COMMUNICATIONS, 32(2), 419-430. https://doi.org/10.1016/j.comcom.2008.11.012

Alaeddini, A., \& Dogan, I. (2011). Using Bayesian networks for root cause analysis in statistical process control. EXPERT SYSTEMS WITH APPLICATIONS, 38(9), 11230-11243. https://doi.org/10.1016/j.eswa.2011.02.171

Aligula, G. K., Kok, C. K., \& Sim, H. K. (2017). Driving quality in product development in a Malaysian optoelectronic firm. INTERNATIONAL JOURNAL OF LEAN SIX SIGMA, 8(4), 482-498. https://doi.org/10.1108/IJLSS-06-2016-0026

Andersen, B., \& Fagerhaug, T. (2006). Root cause analysis: simplified tools and techniques (2nd ed.). Retrieved from https://www.amazon.com/Root-Cause-Analysis-SimplifiedTechniques/dp/0873896920

Armor, A. F., Parkes, J. B., \& Leaver, D. E. (1981). ROOT CAUSE ANALYSIS OF FOSSIL POWER-PLANT EQUIPMENT FAILURES - THE EPRI PROGRAM. IEEE TRANSACTIONS ON POWER APPARATUS AND SYSTEMS, 100(6), 2752-2758. https://doi.org/10.1109/TPAS.1981.316388

Atashgar, K., \& Noorossana, R. (2011). An integrating approach to root cause analysis of a bivariate mean vector with a linear trend disturbance. INTERNATIONAL JOURNAL OF ADVANCED MANUFACTURING TECHNOLOGY, 52(1-4), 407-420. https://doi.org/10.1007/s00170-0102728-x

Bartelmus, W., \& Zimroz, R. (2009). Vibration condition monitoring of planetary gearbox under varying external load. MECHANICAL SYSTEMS AND SIGNAL PROCESSING, 23(1, SI), 246257. https://doi.org/10.1016/j.ymssp.2008.03.016

Bjornson, F. O., Wang, A. I., \& Arisholm, E. (2009). Improving the effectiveness of root cause analysis in post mortem analysis: A controlled experiment. INFORMATION AND SOFTWARE TECHNOLOGY, 51(1), 150-161. https://doi.org/10.1016/j.infsof.2008.02.003

Bonnett, A. H. (2000). Root cause AC motor failure analysis with a focus on shaft failures. IEEE Transactions on Industry Applications, 36(5), 1435-1448. https://doi.org/10.1109/28.871294

Brauckhoff, D., Dimitropoulos, X., Wagner, A., \& Salamatian, K. (2009). Anomaly Extraction in Backbone Networks using Association Rules. In IMC'09: PROCEEDINGS OF THE 2009 ACM SIGCOMM INTERNET MEASUREMENT CONFERENCE (pp. 28-34).

Brauckhoff, D., Dimitropoulos, X., Wagner, A., \& Salamatian, K. (2012). Anomaly Extraction in Backbone Networks Using Association Rules. IEEE-ACM TRANSACTIONS ON NETWORKING, 20(6), 1788-1799. https://doi.org/10.1109/TNET.2012.2187306

Breitbart, Y., Garofalakis, M., Jai, B., Martin, C., Rastogi, R., \& Silberschatz, A. (2004). Topology discovery in heterogeneous IP networks: The NetInventory system. IEEE-ACM $\begin{array}{llll}\text { TRANSACTIONS ON NETWORKING, } & \text { 12(3), }\end{array}$ https://doi.org/10.1109/TNET.2004.828963

Broekaert, S., Demuynck, J., De Cuyper, T., De Paepe, M., \& Verhelst, S. (2016). Heat transfer in premixed spark ignition engines part I: Identification of the factors influencing heat transfer. ENERGY, 116(1), 380-391. https://doi.org/10.1016/j.energy.2016.08.065

Brundage, M. P., Kulvatunyou, B., Ademujimi, T., \& Rakshith, B. (2017). Smart Manufacturing Through a Framework for a Knowledge-Based Diagnosis System. In Volume 3: Manufacturing Equipment and Systems (p. V003T04A012). ASME. https://doi.org/10.1115/MSEC2017-2937

Carlson, J. S., \& Soderberg, R. (2003). Assembly root cause analysis: A way to reduce dimensional variation in assembled products. INTERNATIONAL JOURNAL OF FLEXIBLE MANUFACTURING SYSTEMS, 15(2), 113-150. https://doi.org/10.1023/A:1024453207632

Chao, G. H., Iravani, S. M. R., \& Savaskan, R. C. (2009). Quality Improvement Incentives and Product Recall Cost Sharing Contracts. Management Science, 55(7), 1122-1138. 
https://doi.org/10.1287/mnsc. 1090.1008

Chen, M. Y., Kiciman, E., Fratkin, E., Fox, A., \& Brewer, E. (2002). Pinpoint: problem determination in large, dynamic Internet services. In Proceedings International Conference on Dependable Systems and Networks (pp. 595-604). IEEE Comput. Soc. https://doi.org/10.1109/DSN.2002.1029005

Chen, W.-C., Tseng, S.-S., \& Wang, C.-Y. (2005). A novel manufacturing defect detection method using association rule mining techniques. https://doi.org/10.1016/j.eswa.2005.06.004

Chertkov, Y. B., Disyuk, V. V, Pimenov, E. Y., \& Aksenova, N. V. (2017). Equalization of energy density in boiling water reactors (as exemplified by WB-50). Development and testing of WB50 computational model on the basis of MCU-RR code. In Smirnov, A and Bahdanovich, R and Proshkina, E (Ed.), INTERNATIONAL CONFERENCE FOR YOUNG SCIENTISTS, SPECIALISTS, AND POSTGRADUATES ON NUCLEAR REACTOR PHYSICS 2016 (ICNRP2016) (Vol. 781). https://doi.org/10.1088/1742-6596/781/1/012024

Chien, C.-F., Chen, H.-K., Wu, J.-Z., \& Hu, C.-H. (2007). Constructing the OGE for promoting tool group productivity in semiconductor manufacturing. INTERNATIONAL JOURNAL OF PRODUCTION RESEARCH, 45(3), 509-524. https://doi.org/10.1080/00207540600792515

Chuang, J. H., \& Lee, J. C. (2004). Conductive atomic force microscopy application on leaky contact analysis and characterization. IEEE TRANSACTIONS ON DEVICE AND MATERIALS RELIABILITY, 4(1), 50-53. https://doi.org/10.1109/TDMR.2004.825556

Claxton, K., \& Campbell-Allen, N. M. (2017). Failure modes effects analysis (FMEA) for review of a diagnostic genetic laboratory process. INTERNATIONAL JOURNAL OF QUALITY \& RELIABILITY MANAGEMENT, 34(2, SI), 265-277. https://doi.org/10.1108/IJQRM-05-20150073

Costa, R., Cachulo, N., \& Cortez, P. (2009). An Intelligent Alarm Management System for LargeScale Telecommunication Companies. In Lopes, LS and Lau, N and Mariano, P and Rocha, LM (Ed.), PROGRESS IN ARTIFICIAL INTELLIGENCE, PROCEEDINGS (Vol. 5816, p. $386+)$.

Egger, P., Griitzner, M., Burmer, C., \& Dudkiewicz, F. (2007). Application of time resolved emission techniques within the failure analysis flow. MICROELECTRONICS RELIABILITY, 47(9-11, SI), 1545-1549. https://doi.org/10.1016/j.microrel.2007.07.067

Eti, M. C., Gaji, S. O. T., \& Probert, S. D. (2006). Development and implementation of preventivemaintenance practices in Nigerian industries. APPLIED ENERGY, 83(10), 1163-1179. https://doi.org/10.1016/j.apenergy.2006.01.001

Ferjencik, M. (2011). An integrated approach to the analysis of incident causes. SAFETY SCIENCE, 49(6), 886-905. https://doi.org/10.1016/j.ssci.2011.02.005

Friedman, D. J., Hansen, M. H., Nair, V. N., \& James, D. A. (1997). Model-free estimation of defect clustering in integrated circuit fabrication. IEEE TRANSACTIONS ON SEMICONDUCTOR MANUFACTURING, 10(3), 344-359. https://doi.org/10.1109/66.618208

Gamal Aboelmaged, M. (2010). Six Sigma quality: a structured review and implications for future research. International Journal of Quality \& Reliability Management, 27(3), 268-317. https://doi.org/10.1108/02656711011023294

Gil, E., Martinez, M., \& de la Rubia, O. (2017). Operation and Maintenance Results from ISFOC CPV Plants. In Siefer, G and Hinzer, K and ReyStolle, I (Ed.), 13TH INTERNATIONAL CONFERENCE ON CONCENTRATOR PHOTOVOLTAIC SYSTEMS (CPV-13) (Vol. 1881). https://doi.org/10.1063/1.5001405

Giollo, M., Lam, A., Gkorou, D., Liu, X. L., \& van Haren, R. (2017). Machine Learning for Fab Automated Diagnostics. In Behringer, UFW and Finders, J (Ed.), 33RD EUROPEAN MASK AND LITHOGRAPHY CONFERENCE (Vol. 10446). https://doi.org/10.1117/12.2280257

Goh, Y. M., Brown, H., \& Spickett, J. (2010). Applying systems thinking concepts in the analysis of major incidents and safety culture. SAFETY SCIENCE, 48(3), 302-309. https://doi.org/10.1016/j.ssci.2009.11.006 
Golinska, P., \& Romano, C. A. (Eds.). (2012). Environmental Issues in Supply Chain Management. Berlin, Heidelberg: Springer Berlin Heidelberg. https://doi.org/10.1007/978-3-642-23562-7

Gomez-Andrades, A., Barco, R., Munoz, P., \& Serrano, I. (2017). Data Analytics for Diagnosing the RF Condition in Self-Organizing Networks. IEEE TRANSACTIONS ON MOBILE COMPUTING, 16(6), 1587-1600. https://doi.org/10.1109/TMC.2016.2601919

Gonzalez-Salazar, M. A., Venturini, M., Poganietz, W.-R., Finkenrath, M., \& Spina, P. R. (2016). Methodology for improving the reliability of biomass energy potential estimation. BIOMASS \& BIOENERGY, 88, 43-58. https://doi.org/10.1016/j.biombioe.2016.03.026

Guerin, T. (2014). Root causes of fluid spills from earthmoving plant and equipment: Implications for reducing environmental and safety impacts. ENGINEERING FAILURE ANALYSIS, 45, 128-141. https://doi.org/10.1016/j.engfailanal.2014.06.011

Guldi, R. L. (2004). In-Line Defect Reduction From a Historical Perspective and Its Implications for Future Integrated Circuit Manufacturing. IEEE Transactions on Semiconductor Manufacturing, 17(4), 629-640. https://doi.org/10.1109/TSM.2004.835717

Gutjahr, K., Park, D., Zhou, Y., Cho, W., Ahn, K. C., Snow, P., ... Adel, M. (2016). Root Cause Analysis of Overlay metrology excursions with Scatterometry overlay technology (SCOL). In Sanchez, MI and Ukraintsev, VA (Ed.), METROLOGY, INSPECTION, AND PROCESS $\begin{array}{llll}\text { CONTROL FOR MICROLITHOGRAPHY XXX (Vol. 9778). } & \end{array}$ https://doi.org/10.1117/12.2219668

Halterman, R., \& Scrapper, C. (2017). A Systematic Approach to Autonomous Unmanned System Experimentation. In Karlsen, RE and Gage, DW and Shoemaker, CM and Nguyen, HG (Ed.), $\begin{array}{lllll}\text { UNMANNED SYSTEMS TECHNOLOGY XIX } & \text { (Vol. }\end{array}$ https://doi.org/10.1117/12.2266798

Han, H. S., Lee, K. H., \& Park, S. H. (2016). Parametric study to identify the cause of high torsional vibration of the propulsion shaft in the ship. ENGINEERING FAILURE ANALYSIS, 59, 334346. https://doi.org/10.1016/j.engfailanal.2015.10.018

Harjac, S. J., Atrens, A., \& Moss, C. J. (2008). Six Sigma review of root causes of corrosion incidents in hot potassium carbonate acid gas removal plant. ENGINEERING FAILURE ANALYSIS, 15(5), 480-496. https://doi.org/10.1016/j.engfailanal.2007.05.003

He, Y.-H., Wang, L.-B., He, Z.-Z., \& Xie, M. (2016). A fuzzy TOPSIS and Rough Set based approach for mechanism analysis of product infant failure. ENGINEERING APPLICATIONS OF ARTIFICIAL INTELLIGENCE, $25-37$. https://doi.org/10.1016/j.engappai.2015.06.002

Horvath, T., Krkos, R., \& Dubravec, L. (2017). Deep data analysis in gigabit passive optical networks. OPTICA APPLICATA, 47(1), 157-170. https://doi.org/10.5277/oa170114

Hu, J., Zhang, L., Cai, Z., \& Wang, Y. (2015). An intelligent fault diagnosis system for process plant using a functional HAZOP and DBN integrated methodology. ENGINEERING APPLICATIONS OF ARTIFICIAL INTELLIGENCE, 45, 119-135. https://doi.org/10.1016/j.engappai.2015.06.010

Hu, S. J., \& Roan, C. (1996). Change patterns of time series-based control charts. JOURNAL OF QUALITY TECHNOLOGY, 28(3), 302-312.

Hudson, J., Vasilyev, L., Schmidt, J., \& Horner, G. (2010). ECONOMIC IMPACTS AND APPROACHES TO ADDRESS HOT-SPOT DEFECTS IN PHOTOVOLTAIC DEVICES. In $35 T H$ IEEE PHOTOVOLTAIC SPECIALISTS CONFERENCE (pp. 1706-1709). https://doi.org/10.1109/PVSC.2010.5616102

Hwang, J. Y., \& Kuo, W. (2007). Model-based clustering for integrated circuit yield enhancement. EUROPEAN JOURNAL OF OPERATIONAL RESEARCH, 178(1), 143-153. https://doi.org/10.1016/j.ejor.2005.11.032

Iacocca, R. G., \& Allgeier, M. (2007). Corrosive attack of glass by a pharmaceutical compound. JOURNAL OF MATERIALS SCIENCE, 42(3), 801-811. https://doi.org/10.1007/s10853-006$0156-\mathrm{y}$ 


$$
\begin{array}{r}
31^{\text {ST }} \text { BLED ECONFERENCE: Digital TRANSFORMATION: MEETING THE CHALlenges } \\
\text { June } 17 \text { - 20, 2018, BLED, SLOVEnIA, CONFERENCE PROCEEDINGS } \\
\text { J. Toman: Literature Review on Root Cause Analysis }
\end{array}
$$

Isack, H. D., Mutingi, M., Kandjeke, H., Vashishth, A., \& Chakraborty, A. (2018). Exploring the adoption of Lean principles in medical laboratory industry Empirical evidences from Namibia. INTERNATIONAL JOURNAL OF LEAN SIX SIGMA, 9(1), 133-155. https://doi.org/10.1108/IJLSS-02-2017-0017

Jabrouni, H., Kamsu-Foguem, B., Geneste, L., \& Vaysse, C. (2011). Continuous improvement through knowledge-guided analysis in experience feedback. ENGINEERING APPLICATIONS OF ARTIFICIAL INTELLIGENCE, 24(8, SI), 1419-1431. https://doi.org/10.1016/j.engappai.2011.02.015

Jayswal, A., Li, X., Zanwar, A., Lou, H. H., \& Huang, Y. (2011). A sustainability root cause analysis methodology and its application. COMPUTERS \& CHEMICAL ENGINEERING, 35(12), 2786-2798. https://doi.org/10.1016/j.compchemeng.2011.05.004

Jenicek, M. (2011). Medical error and harm : understanding, prevention, and control. Productivity Press/CRC Press.

Jung, U., Jeong, M. K., \& Lu, J.-C. (2006). A vertical-energy-thresholding procedure for data reduction with multiple complex curves. IEEE TRANSACTIONS ON SYSTEMS MAN AND $\begin{array}{lll}\text { CYBERNETICS PART B-CYBERNETICS, 36(5), } & 1128-1138 .\end{array}$ https://doi.org/10.1109/TSMCB.2006.874681

Khatib, E. J., Barco, R., Gomez-Andrades, A., Munoz, P., \& Serrano, I. (2015). Data mining for fuzzy diagnosis systems in LTE networks. EXPERT SYSTEMS WITH APPLICATIONS, 42(21), 7549-7559. https://doi.org/10.1016/j.eswa.2015.05.031

Khatib, E. J., Barco, R., Munoz, P., \& Serrano, I. (2017). Knowledge Acquisition for Fault Management in LTE Networks. WIRELESS PERSONAL COMMUNICATIONS, 95(3), 28952914. https://doi.org/10.1007/s11277-017-3969-x

Khatib, E. J., Barco, R., \& Serrano, I. (2017). Degradation Detection Algorithm for LTE Root Cause Analysis. WIRELESS PERSONAL COMMUNICATIONS, 97(3), 4563-4572. https://doi.org/10.1007/s11277-017-4738-6

Khatib, E. J., Gomez-Andrades, A., Serrano, I., \& Barco, R. (2018). Modelling LTE Solved Troubleshooting Cases. JOURNAL OF NETWORK AND SYSTEMS MANAGEMENT, 26(1), 23-50. https://doi.org/10.1007/s10922-017-9406-3

Kitamura, T., Kubota, K., Hasebe, T., Sakai, F., Nakazawa, S., Vohra, N., ... Inoue, M. (2005). Introduction of a die-to-database verification tool for the entire printed geometry of a die Geometry verification system NGR2100 for DFM. In Komuro, M (Ed.), PHOTOMASK AND NEXT-GENERATION LITHOGRAPHY MASK TECHNOLOGY XII, PTS 1 AND 2 (Vol. 5853, pp. 988-999). https://doi.org/10.1117/12.620389

Kitcharoen, N., Kamolsantisuk, S., Angsomboon, R., \& Achalakul, T. (2013). RapidMiner Framework for Manufacturing Data Analysis on the Cloud. In Puangpronpitag, $\mathrm{S}$ and Khummanee, S and Suwanasa, A (Ed.), 2013 10TH INTERNATIONAL JOINT CONFERENCE ON COMPUTER SCIENCE AND SOFTWARE ENGINEERING (JCSSE) (pp. 149-154).

Klaus, J. (2003). Using Root Cause Analysis to Handle Intrusion Detection Alarms. Universit" at Dortmund am Fachbereich Informatik. Retrieved from https://d-nb.info/969432127/34

Kobayashi, S., Otomo, K., Fukuda, K., \& Esaki, H. (2018). Mining Causality of Network Events in Log Data. IEEE TRANSACTIONS ON NETWORK AND SERVICE MANAGEMENT, 15(1), 53-67. https://doi.org/10.1109/TNSM.2017.2778096

Köksal, G., Batmaz, I., \& Testik, M. C. (2011). A review of data mining applications for quality improvement in manufacturing industry. https://doi.org/10.1016/j.eswa.2011.04.063

Krishna, V. B., Ormel, F., \& Hansen, K. S. (2016). Alternative approach for establishing the Nacelle $\begin{array}{llll}\text { Transfer } \quad \text { Function. } & \text { WOND } & \text { 307-318. }\end{array}$ https://doi.org/10.1177/0309524X16647847

Krupa, P., \& Myers, J. (2017). Data Mining Root Cause Analysis Findings. In 2017 ANNUAL RELIABILITY AND MAINTAINABILITY SYMPOSIUM.

Kum, S., \& Sahin, B. (2015). A root cause analysis for Arctic Marine accidents from 1993 to 2011. 
SAFETY SCIENCE, 74, 206-220. https://doi.org/10.1016/j.ssci.2014.12.010

Kumar, S., \& Schmitz, S. (2011). Managing recalls in a consumer product supply chain - root cause analysis and measures to mitigate risks. INTERNATIONAL JOURNAL OF PRODUCTION RESEARCH, 49(1), 235-253. https://doi.org/10.1080/00207543.2010.508952

Kurdve, M., Shahbazi, S., Wendin, M., Bengtsson, C., \& Wiktorsson, M. (2015). Waste flow mapping to improve sustainability of waste management: a case study approach. JOURNAL OF CLEANER PRODUCTION, 98, 304-315. https://doi.org/10.1016/j.jclepro.2014.06.076

Le Coze, J. (2008). Disasters and organisations: From lessons learnt to theorising. SAFETY SCIENCE, 46(1), 132-149. https://doi.org/10.1016/j.ssci.2006.12.001

Lehtinen, T. O. A., Itkonen, J., \& Lassenius, C. (2017). Recurring opinions or productive improvements-what agile teams actually discuss in retrospectives. EMPIRICAL SOFTWARE ENGINEERING, 22(5), 2409-2452. https://doi.org/10.1007/s10664-016-9464-2

Lehtinen, T. O. A., Mäntylä, M. V., \& Vanhanen, J. (2011). Development and evaluation of a lightweight root cause analysis method (ARCA method) - Field studies at four software companies. Information and Software Technology, 53(10), 1045-1061. https://doi.org/10.1016/J.INFSOF.2011.05.005

Leszak, M., Perry, D. E., \& Stoll, D. (2002). Classification and evaluation of defects in a project retrospective. Journal of Systems and Software, 61(3), 173-187. https://doi.org/10.1016/S01641212(01)00146-7

Lim, M. K., Bahr, W., \& Leung, S. C. H. (2013). RFID in the warehouse: A literature analysis (1995-2010) of its applications, benefits, challenges and future trends. International Journal of Production Economics, 145(1), 409-430. https://doi.org/10.1016/j.ijpe.2013.05.006

Livingston, A. D., Jackson, G., \& Priestley, K. (2001). Safety Executive Root causes analysis: Literature review Root causes analysis: Literature review. Retrieved from http://www.hse.gov.uk/research/crr_pdf/2001/crr01325.pdf

Luka, T., Grosser, S., Hagendorf, C., Ramspeck, K., \& Turek, M. (2016). Intra-grain versus grain boundary degradation due to illumination and annealing behavior of multi-crystalline solar cells. SOLAR ENERGY MATERIALS AND SOLAR CELLS, 158(1, SI), 43-49. https://doi.org/10.1016/j.solmat.2016.05.061

Mahendrawathi, E. R., Zayin, S. O., \& Pamungkas, F. J. (2017). ERP Post Implementation Review with Process Mining: A Case of Procurement Process. In Lwin, KT (Ed.), 4TH INFORMATION SYSTEMS INTERNATIONAL CONFERENCE (ISICO 2017) (Vol. 124, pp. 216-223). https://doi.org/10.1016/j.procs.2017.12.149

Malik, H., Hemmati, H., \& Hassan, A. E. (2013). Automatic Detection of Performance Deviations in the Load Testing of Large Scale Systems. In Notkin, D and Cheng, BHC and Pohl, K (Ed.), PROCEEDINGS OF THE 35TH INTERNATIONAL CONFERENCE ON SOFTWARE ENGINEERING (ICSE 2013) (pp. 1012-1021).

Marais, K., Saleh, J. H., \& Leveson, N. G. (2006). Archetypes for organizational safety. SAFETY SCIENCE, 44(7), 565-582. https://doi.org/10.1016/j.ssci.2005.12.004

Markopoulos, E., \& Vanharanta, H. (2017). Delphic Maxims Based Applied Philosophy for Business and Governance Management. In Kantola, JI and Barath, T and Nazir, S and Andre, T (Ed.), ADVANCES IN HUMAN FACTORS, BUSINESS MANAGEMENT, TRAINING AND EDUCATION (Vol. 498, pp. 33-45). https://doi.org/10.1007/978-3-319-42070-7_4

McCroskey, D. M., Abell, G. C., \& Chidester, M. H. (2000). A study of Aeroglaze Z306 black paint for cryogenic telescope use - Outgassing and water vapor regain. In Chen, PTC and Uy, OM (Ed.), OPTICAL SYSTEMS CONTAMINATION AND DEGRADATION II: EFFECTS, MEASUREMENTS, AND CONTROL (Vol. 4096, pp. 119-128). https://doi.org/10.1117/12.400824

Mena, C., Adenso-Diaz, B., \& Yurt, O. (2011). The causes of food waste in the supplier-retailer interface: Evidences from the UK and Spain. RESOURCES CONSERVATION AND RECYCLING, 55(6, SI), 648-658. https://doi.org/10.1016/j.resconrec.2010.09.006 


\section{$31^{\text {ST }}$ Bled ECONFEREnCE: Digital Transformation: MeEting the Challenges June 17 - 20, 2018, BLED, Slovenia, CONFERENCE ProceEdings J. Toman: Literature Review on Root Cause Analysis}

Meyer, S., Richter, S., Timmel, S., Glaeser, M., Werner, M., Swatek, S., \& Hagendorf, C. (2013). Snail trails: root cause analysis and test procedures. In Brendel, $\mathrm{R}$ and Aberle, A and Cuevas, A and Glunz, S and Hahn, G and Poortmans, J and Sinton, R and Weeber, A (Ed.), PROCEEDINGS OF THE 3RD INTERNATIONAL CONFERENCE ON CRYSTALLINE SILICON PHOTOVOLTAICS (SILICONPV 2013) (Vol. 38, pp. 498-505). https://doi.org/10.1016/j.egypro.2013.07.309

Mohan, D., Saygin, C., \& Sarangapani, J. (2008). Real-time detection of grip length deviation during pull-type fastening: a Mahalanobis-Taguchi System (MTS)-based approach. INTERNATIONAL JOURNAL OF ADVANCED MANUFACTURING TECHNOLOGY, 39(910), 995-1008. https://doi.org/10.1007/s00170-007-1280-9

Molnar, S., Sonkoly, B., \& Trinh, T. A. (2009). A comprehensive TCP fairness analysis in high speed networks. COMPUTER COMMUNICATIONS, 32(13-14), 1460-1484. https://doi.org/10.1016/j.comcom.2009.05.003

Mora, A., Biermann, M., Bombrun, A., Boyadjian, J., Chassat, F., Corberand, P., ... Thoral, P. (2016). Gaia: focus, straylight and basic angle. In MacEwen, HA and Fazio, GG and Lystrup, M (Ed.), SPACE TELESCOPES AND INSTRUMENTATION 2016: OPTICAL, INFRARED, AND MILLIMETER WAVE (Vol. 9904). https://doi.org/10.1117/12.2230763

Muchaidze, G., Koo, J., Cai, Q., Li, T., Han, L., Martwick, A., ... Pommerenke, D. (2008). Susceptibility Scanning as a Failure Analysis Tool for System-Level Electrostatic Discharge (ESD) Problems. IEEE TRANSACTIONS ON ELECTROMAGNETIC COMPATIBILITY, 50(2), 268-276. https://doi.org/10.1109/TEMC.2008.921059

Murugan, R., \& Ramasamy, R. (2015). Failure analysis of power transformer for effective maintenance planning in electric utilities. ENGINEERING FAILURE ANALYSIS, 55, 182-192. https://doi.org/10.1016/j.engfailanal.2015.06.002

Nad, M., Buzik, J., Letal, T., \& Losak, P. (2017). ROOT-CAUSE ANALYSIS OF SUPERHEATER-TUBE FAILURE. MATERIALI IN TEHNOLOGIJE, 51(3), 503-507. https://doi.org/10.17222/mit.2016.204

Nakayashiki, K., Hofstetter, J., Morishige, A. E., Li, T.-T. A., Needleman, D. B., Jensen, M. A., \& Buonassisi, T. (2016). Engineering Solutions and Root-Cause Analysis for Light-Induced Degradation in p-Type Multicrystalline Silicon PERC Modules. IEEE JOURNAL OF PHOTOVOLTAICS, 6(4), 860-868. https://doi.org/10.1109/JPHOTOV.2016.2556981

Ngai, E. W. T., \& Wat, F. K. T. (2002). A literature review and classification of electronic commerce research. Information \& Management, 39(5), 415-429. https://doi.org/10.1016/S0378-7206(01)00107-0

Noorossana, R., Atashgar, K., \& Saghaei, A. (2011). An integrated supervised learning solution for monitoring process mean vector. INTERNATIONAL JOURNAL OF ADVANCED MANUFACTURING TECHNOLOGY, 56(5-8), 755-765. https://doi.org/10.1007/s00170-0113188-7

Paradies, M., \& Busch, D. (1988). Root Cause Analysis at Savannah River. In Proceedings of the IEEE Conference on Human Factors and Power Plants (pp. 479-483).

Poursaeidi, E., Babaei, A., Arhani, M. R. M., \& Arablu, M. (2012). Effects of natural frequencies on the failure of R1 compressor blades. ENGINEERING FAILURE ANALYSIS, 25, 304-315. https://doi.org/10.1016/j.engfailanal.2012.05.013

Pradhan, S., Singh, R., Kachru, K., \& Narasimhamurthy, S. (2007). A Bayesian Network Based Approach for Root-Cause-Analysis in Manufacturing Process. In 2007 International Conference on Computational Intelligence and Security (CIS 2007) (pp. 10-14). IEEE. https://doi.org/10.1109/CIS.2007.214

Rashid, H. S. J., Place, C. S., \& Braithwaite, G. R. (2013). Investigating the investigations: a retrospective study in the aviation maintenance error causation. COGNITION TECHNOLOGY \& WORK, 15(2), 171-188. https://doi.org/10.1007/s10111-011-0210-7

Rato, T. J., Blue, J., Pinaton, J., \& Reis, M. S. (2017). Translation-Invariant Multiscale Energy- 
Based PCA for Monitoring Batch Processes in Semiconductor Manufacturing. IEEE TRANSACTIONS ON AUTOMATION SCIENCE AND ENGINEERING, 14(2), 894-904. https://doi.org/10.1109/TASE.2016.2545744

Rehm, R., Walther, M., Rutz, F., Schmitz, J., Woerl, A., Masur, J.-M., ... Ziegler, J. (2011). DualColor InAs/GaSb Superlattice Focal-Plane Array Technology. JOURNAL OF ELECTRONIC MATERIALS, 40(8), 1738-1743. https://doi.org/10.1007/s11664-011-1674-1

Reid, I., \& Smyth-Renshaw, J. (2012). Exploring the Fundamentals of Root Cause Analysis: Are We Asking the Right Questions in Defining the Problem? QUALITY AND RELIABILITY ENGINEERING INTERNATIONAL, 28(5, SI), 535-545. https://doi.org/10.1002/qre.1435

Richter, F., Aymelek, T., \& Mattfeld, D. C. (2017). Automatic Root Cause Analysis by Integrating Heterogeneous Data Sources. In Doerner, KF and Ljubic, I and Pflug, G and Tragler, G (Ed.), OPERATIONS RESEARCH PROCEEDINGS 2015 (pp. 469-474). https://doi.org/10.1007/9783-319-42902-1_63

Sabet, S. A. A. M., Moniri, A., \& Mohebbi, F. (2017). Root-Cause and Defect Analysis based on a Fuzzy Data Mining Algorithm. INTERNATIONAL JOURNAL OF ADVANCED COMPUTER SCIENCE AND APPLICATIONS, 8(9), 21-28.

Samopa, F., Astuti, H. M., \& Lestari, M. A. (2017). The Development of Work Instruction as a Solution to Handle IT Critical Incidents in Units within an Organization. In Lwin, KT (Ed.), 4TH INFORMATION SYSTEMS INTERNATIONAL CONFERENCE (ISICO 2017) (Vol. 124, pp. 593-600). https://doi.org/10.1016/j.procs.2017.12.194

Sand, C., Bogus, K., Kunz, S., \& Franke, J. (2016). Holistic production analysis for actuator manufacturing using data mining. In PROCEEDINGS OF 2016 6TH INTERNATIONAL ELECTRIC DRIVES PRODUCTION CONFERENCE (EDPC) (pp. 281-285).

Sand, C., Kunz, S., Hubbert, H., \& Franke, J. (2016). Towards an inline quick reaction system for actuator manufacturing using data mining. In PROCEEDINGS OF $2016 \quad 6 T H$ INTERNATIONAL ELECTRIC DRIVES PRODUCTION CONFERENCE (EDPC) (pp. 74-79).

Sauvanaud, C., Lazri, K., Kaaniche, M., \& Kanoun, K. (2016). Anomaly Detection and Root Cause Localization in Virtual Network Functions. In 2016 IEEE 27TH INTERNATIONAL SYMPOSIUM ON SOFTWARE RELIABILITY ENGINEERING (ISSRE) (pp. 196-206). https://doi.org/10.1109/ISSRE.2016.32

Sawalha, I. H. (2017). A context-centred, root cause analysis of contemporary terrorism. DISASTER PREVENTION AND MANAGEMENT, 26(2), 183-202. https://doi.org/10.1108/DPM-07-20160140

Sawatdee, T., \& Chutima, P. (2017). DESIGN PROCESS IMPROVEMENT FOR ELECTRIC CAR HARNESS. In Gaol, FL and Webb, J and Ding, J (Ed.), 5TH INTERNATIONAL CONFERENCE ON MANUFACTURING, OPTIMIZATION, INDUSTRIAL AND MATERIAL ENGINEERING (Vol. 215). https://doi.org/10.1088/1757-899X/215/1/012011

Schulz, K., Egodage, K., Tabbone, G., Ehrlich, C., \& Garetto, A. (2017). SEM AutoAnalysis: enhancing photomask and NIL defect disposition and review. In Behringer, UFW and Finders, J (Ed.), 33RD EUROPEAN MASK AND LITHOGRAPHY CONFERENCE (Vol. 10446). https://doi.org/10.1117/12.2280828

Serrat, O. (2009). The Five Whys Technique. Retrieved from https://digitalcommons.ilr.cornell.edu/cgi/viewcontent.cgi?article=1200\&context=intl

Skrimpas, G. A., Sweeney, C. W., Marhadi, K. S., Jensen, B. B., Mijatovic, N., \& Holboll, J. (2015). Employment of Kernel Methods on Wind Turbine Power Performance Assessment. IEEE TRANSACTIONS ON SUSTAINABLE ENERGY, 6(3), 698-706. https://doi.org/10.1109/TSTE.2015.2405971

Sobek, D. K., \& Smalley, A. (2008). Understanding A3 thinking : a critical component of Toyota's PDCA management system.

Solmaz, S. E., Gedik, B., Ferhatosmanoglu, H., Sozuer, S., Zeydan, E., \& Etemoglu, C. O. (2017). ALACA: A platform for dynamic alarm collection and alert notification in network 


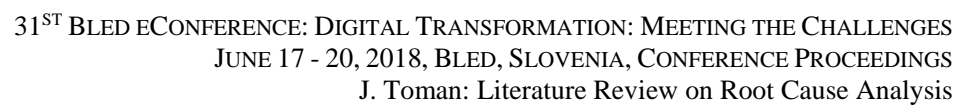

management systems. INTERNATIONAL JOURNAL OF NETWORK MANAGEMENT, 27(4, SI). https://doi.org/10.1002/nem.1980

Song-Manguelle, J., Ekemb, G., Schroeder, S., Geyer, T., Nyobe-Yome, J.-M., \& Wamkeue, R. (2013). Analytical Expression of Pulsating Torque Harmonics due to PWM Drives. In 2013 IEEE ENERGY CONVERSION CONGRESS AND EXPOSITION (ECCE) (pp. 2813-2820).

Stavert-Dobson, A. (2016). Health information systems : managing clinical risk.

Sterritt, R. (2004). Autonomic networks: engineering the self-healing property. ENGINEERING

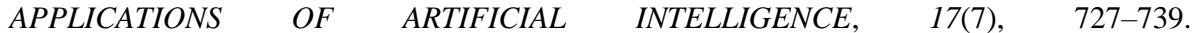
https://doi.org/10.1016/j.engappai.2004.08.028

Suriadi, S., Ouyang, C., van der Aalst, W. M. P., \& ter Hofstede, A. H. M. (2013). Root Cause Analysis with Enriched Process Logs. In LaRosa, $\mathrm{M}$ and Soffer, $\mathrm{P}$ (Ed.), BUSINESS PROCESS MANAGEMENT WORKSHOPS (BPM) (Vol. 132, pp. 174-186).

Tchikoulaeva, A., Holfeld, A., Arend, M., \& Foca, E. (2008). ACLV degradation: root cause analysis and effective monitoring strategy. In T. Horiuchi (Ed.) (Vol. 7028, p. 702816). International Society for Optics and Photonics. https://doi.org/10.1117/12.793047

Usman, I., \& Rendy, O. (2017). Toward Lean Construction through Critical Chain Project Management and Root Cause Analysis in a Construction Project. In Shieh, C and Tichy, T and Dass, BK and Auliandri, A (Ed.), PROCEEDINGS OF THE 2017 INTERNATIONAL CONFERENCE ON ORGANIZATIONAL INNOVATION (ICOI 2017) (Vol. 131, pp. 153-158).

Venkatesh, V., Brown, S. a, \& Bala, H. (2013). Bridging the qualitative-quantitative divide: Guidelines for conducting mixed methods research in information systems. MIS Quarterly, 37(1), 21-54. https://doi.org/10.1186/s12874-015-0070-6

Wamba, S. F., Akter, S., Edwards, A., Chopin, G., \& Gnanzou, D. (2015). How "big data" can make big impact: Findings from a systematic review and a longitudinal case study. Intern. Journal of Production Economics, 165, 234-246. https://doi.org/10.1016/j.ijpe.2014.12.031

Wang, J., Wu, Y., Liu, S., \& Xing, R. (2017). A new sensitivity model with blank space for layout optimization. JOURNAL OF SEMICONDUCTORS, 38(6). https://doi.org/10.1088/16744926/38/6/065003

Wang, X., Crump, P., Wenzel, H., Liero, A., Hoffmann, T., Pietrzak, A., ... Traenkle, G. (2010). Root-Cause Analysis of Peak Power Saturation in Pulse-Pumped $1100 \mathrm{~nm}$ Broad Area Single Emitter Diode Lasers. IEEE JOURNAL OF QUANTUM ELECTRONICS, 46(5), 658-665. https://doi.org/10.1109/JQE.2010.2047381

Weidl, G., Madsen, A. L., \& Israelson, S. (2005). Applications of object-oriented Bayesian networks for condition monitoring, root cause analysis and decision support on operation of complex continuous processes. COMPUTERS \& CHEMICAL ENGINEERING, 29(9), 19962009. https://doi.org/10.1016/j.compchemeng.2005.05.005

Wieczerniak, S., Cyplik, P., \& Milczarek, J. (2017). ROOT CAUSE ANALYSIS METHODS AS A TOOL OF EFFECTIVE CHANGE. In Dujak, D (Ed.), BUSINESS LOGISTICS IN MODERN MANAGEMENT (pp. 611-627).

Wilson, P. F., Dell, L. D., \& Anderson, G. F. (1996). Root Cause Analysis: A Tool for Total Quality Management. Journal For Healthcare Quality, 18(1), 40. https://doi.org/10.1111/j.19451474.1996.tb00823.x

Xie, Q., Venkatachalam, P., Lee, J., Chen, Z., \& Zafar, K. (2017). Precise Design-Based Defect Characterization and Root Cause Analysis. In Sanchez, MI and Ukraintsev, VA (Ed.), METROLOGY, INSPECTION, AND PROCESS CONTROL FOR MICROLITHOGRAPHY XXXI (Vol. 10145). https://doi.org/10.1117/12.2270408

Ye, F., Zhang, Z., Chakrabarty, K., \& Gu, X. (2013). Information-Theoretic Syndrome and RootCause Analysis for Guiding Board-Level Fault Diagnosis. In 2013 18TH IEEE EUROPEAN TEST SYMPOSIUM (ETS 2013).

Ye, F., Zhang, Z., Chakrabarty, K., \& Gu, X. (2015). Information-Theoretic Syndrome Evaluation, Statistical Root-Cause Analysis, and Correlation-Based Feature Selection for Guiding Board- 
696 3 $31^{\text {ST }}$ Bled eConference: Digital Transformation: MEeting the Challenges June 17 - 20, 2018, BLED, SLOVENIA, CONFERENCE PROCEEDINGS

J. Toman: Literature Review on Root Cause Analysis

Level Fault Diagnosis. IEEE TRANSACTIONS ON COMPUTER-AIDED DESIGN OF INTEGRATED CIRCUITS AND SYSTEMS, 34(6), 1014-1026. https://doi.org/10.1109/TCAD.2015.2399438

Zhang, M., Li, Z., Cabassud, M., \& Dahhou, B. (2017). Root cause analysis of actuator fault based on invertibility of interconnected system. INTERNATIONAL JOURNAL OF MODELLING IDENTIFICATION AND CONTROL, 27(4), 256-270. https://doi.org/10.1504/IJMIC.2017.084723 


\title{
Designing an Adaptive and Sustainable ITG model for SMEs
}

\author{
ALEŠ LEVSTEK
}

\begin{abstract}
In this paper, we wanted to set direction for our further research on IT Governance (ITG) area. Despite extensive research in ITG area, considerable work is needed to further understand ITG and its mechanisms. Despite the efforts to develop methods for governing IT, the adoption rate is rather disappointing. Especially this applies to Small and Medium Enterprises (SMEs), which are significantly different from large enterprises and extra care should be taken by researchers and practitioners designing artefacts for them. The use of IT has the potential to be the major driver of economic wealth in the 21 st century. Following this, IT is a key factor for success of survival and prosperity as well as an opportunity to differentiate and to achieve competitive advantage. In order to ensure this, we need an effective and successful ITG model, which follows and adapts to business needs. This is the goal of our further work. We want to combine the best practices and findings of previous research and design an Adaptive and Sustainable ITG model, which will be designed and implemented through case study into six insurance SMEs in SE Europe. The previous research in the ITG models was predominantly focused on level of management and the operational level. Unfortunately, in previous research, we did not find the role and influence of supervisory level, for example supervisory board or advisory board. In our research, we will also extend ITG model on supervisory level, which is crucial for supervision and has an impact on strategic level represented by management board. These conclusions are our directions for further work, which will address the impact of stakeholders on ITG within the insurance group companies in SE Europe.
\end{abstract}

Keywords: • IT Governance • IT Governance models • IT Governance mechanisms • IT Corporate Governance • Enterprise IT Governance • IT Governance in SMEs •

CORRESPONDENCE AdDRESS: Aleš Levstek, University of Maribor, Faculty of Organizational Sciences, Kidričeva cesta 55a, SI-4000 Kranj, Slovenia, e-mail: levsteka@gmail.com 
Over the past decades, the role of Information Technology (IT) has changed significantly, from office and process automation to value aggregation and innovation through its use. This means that the IT role is no longer primarily technical and reactive, but has become proactive and focused on the core activities of organizations (Van Grembergen \& De Haes, 2016; Walsham, 2001; Weill, Woerner, \& Ross, 2016).

Therefore, the use of IT has the potential to be the major driver of economic wealth in the $21^{\text {st }}$ century. IT not only has the potential to support existing business strategies, but also to shape new strategies. Following this, IT becomes a success factor for survival and prosperity as well as an opportunity to differentiate and to achieve a competitive advantage (Van Grembergen \& De Haes, 2016).

To ensure that IT is aligned with the objectives of the organizations, and sustains and extends the organization's strategy, we need effective ITG (Rusu \& Gianluigi, 2017). ITG ensures that IT goals are met and IT risks are mitigated. Therefore, IT delivers value to enterprise sustainability and growth. ITG drives strategic alignment between IT and the business and must judiciously measure performance.

In short, effective governance addresses three questions: What decision must be made? Who should make this decision? How will we make and monitor this decision? (Weill \& Ross, 2004).

Previous research has shown positive effects of successful ITG implementations. For example, efficient ITG assures IT benefits (Kan, 2003) and helps to decrease IT Risks (Ridley, Young, \& Carroll, 2004) which leads to control for IT function (Van Grembergen, De Haes, \& Guldentops, 2004). With well-organized ITG, organizations may increase their returns on IT investment by as much as $40 \%$ (Weill \& Ross, 2004) and make $20 \%$ more profit than their competitors (Huo, Liu, Yuan, \& Wu, 2010).

Rapid technological developments affect our lives and change the way how enterprises conduct their business. Furthermore, digitalization is one of the key drivers of economy and has a strong influence on societal developments (Pucihar, Lenart, Marolt, Maletič, \& Borštnar, 2016). All these changes require the need for continuous and sustainable ITG practices.

While ITG has been the subject of considerable debate amongst researchers and practitioners, it remains a poorly understood phenomenon that is continuously evolving with increasing complexity. Since IT has recognisably become crucial for enterprises, the most important decisions regarding IT have moved from the IT department to the management boards and senior management executives calling for a specific focus on enterprise governance of IT (De Haes, Van Grembergen, \& Debreceny, 2013). This situation has reinforced the role of ITG as an integral part of the corporate governance. 
Despite extensive research in focus areas, considerable work is needed to improve further understanding of ITG in the context of digital society. Rapid technological developments, disruptive changes in Information and Communications Technology (ICT) and emerging of new, often digital business models call for new, Adaptive and Sustainable ITG practices and measurement models.

\section{Problem definition}

Despite more than 30 years of research, there are still some unfilled gaps, mainly due to the lack of a consistent and well-established body of knowledge in ITG area (Lunardi, Gastaud Macada, Becker, \& Van Grembergen, 2017).

Although there is an extensive research in wider ITG area, considerable work is still needed to further understand ITG and to develop a successful holistic measure of ITG. To enable ITG to become an accepted part of enterprise strategic and operational governance processes, it is important that researchers develop more practical methods for organizations to use in establishing and assessing ITG (Hovelja, Rožanec, \& Rupnik, 2010; Osterwalder et al., 2010).

However, implementing ITG is not an easy task, since its definition and role is not clear and to determine the right ITG mechanisms remains a complex challenge.

In the past, unsuccessful attempts have been made to implement ITG mechanisms. We would like to understand the reason behind unsuccessful attempts, and would further like to develop an ITG model that would work in practice.

ITG problems that we aim to address in our research can be divided into the following:

- ITG in SMEs is still immature and despite the efforts to develop methods for governing IT in SMEs the adoption rate is rather disappointing.

- Available generic ITG models do not work the same on enterprises of different industry, size, maturity etc. This means that different enterprises may need a combination of different structures, processes and rational mechanisms. In general, these models are developed for large enterprises and then adjusted for SMEs in such way that their scope is narrowed.

- Existing ITG models are predominantly focused on the management and operational level. Management level, represented by management board, has been highlighted in the previous research as a key element of the success in a case of ITG deployment or operating. Unfortunately, in previous research, it is not possible to find the role and influence of supervisory authorities that have a direct impact on a management board.

\section{Explanation of the problem definition}

Available generic ITG models do not work the same on enterprises of different industry, size, maturity etc. An ITG model that is successful in one company is not achieving its goals in another company from the same industry. In general, these models are developed 
for large enterprises and then adjusted for the SMEs segment in such way that their scope is narrowed (Rusu \& Gianluigi, 2017).

It is believed by many researchers that SMEs cannot be seen through the lens of a large firm. Theories explaining ITG in large enterprises and leading to methodologies used by practitioners can therefore not be extrapolated to SMEs, because we are dealing with a completely different economic, cultural and managerial environment (Devos, Van Landeghem, \& Deschoolmeester, 2009).

It should also be recognized that what strategically works for one company does not necessarily work for another (Patel, 2002), even if they work in the same industry sector. This means that different organizations may need a combination of different structures, processes and relational mechanisms (Van Grembergen et al., 2004).

Previous research conclude that the world of SMEs is significantly different from that of large enterprises and extra care should be taken by researchers and practitioners designing artefacts for SMEs (Devos et al., 2009).

Why are SMEs so important? SMEs are the backbone of the EU economy. The 22.6 million SMEs in the EU-28 in 2013 represented $99.8 \%$ of enterprises in the non-financial business economy, and are regarded as a key driver for economic growth, innovation, employment and social integration (Eurostat, 2017).

For SMEs, their definition differs from country to country, which means that it is difficult to equate SMEs in the US with SMEs in SE Europe. This also makes it difficult to use the results of previous researches in the area of SMEs.

Research also showed that SMEs do not excel in knowledge retention and obtaining a sustainable competitive advantage. There is a slower adoption of IT in SMEs than in large enterprises. Existing mechanisms of ITG built on a strong belief that IT creates values for the business do not work as such in SMEs, where decision-making is mostly focused on one person. SMEs also cannot learn and benefit from past experience, because there are not enough information systems (IS) projects conducted (Rusu \& Gianluigi, 2017).

While research on devising standards and frameworks has been going on at a fairly fast and hectic pace, little enthusiasm has been shown by enterprises in adopting them (Othman, 2016). Winniford, Conger and Erickson-Harris (2009), in their survey on US companies, found that less than half of the companies had implemented any type of IT service management standard or framework. A survey by Debreceny and Gray (2013) found that, in general, there was very little usage of these standards and frameworks. Although some enterprises in developing countries are aware of the importance of adopting relevant standards and frameworks, there seems to be a lack of commitment and motivation to adopt them. A data from recent research in SE Europe has shown, that only $16 \%$ of the enterprises implemented one of the best practices and only $3 \%$ of them implemented CobIT (Kolar \& Groznik, 2017). 
Despite the efforts to develop methods for ITG in SMEs, for example the CobIT QuickStart model, the adoption rate is rather disappointing. Interestingly, while many enterprises in developing countries continue to make large investment in IT (Hall, Futela, \& Gupta, 2017), it seems that they fail to realize that their IT investment also require proper governance.

If the first part of the dissertation problem derives from the use and implementation of ITG, the second part of the problem is related to the ITG concept itself.

In general, governance is a concept that can be used in many contexts and is by now a well-known term in business. It is focused on the role of a board of directors in representing and protecting the interests of shareholders (Fama \& Jensen, 1983; Kooper, Maes, \& Lindgreen, 2011), and addresses the proper management of organizations (Spafford, 2003).

Significant literature in governance area reveal that government processes can be lined up in three groups: corporate governance, enterprise governance, and IT governance.

Corporate Governance - is the system by which organizations are directed and controlled (Van Grembergen \& De Haes, 2008). A responsibility is delegated by stakeholders and the public, defined by legislators and regulators and shared by boards, in some measure, with managers (Webb, Pollard, \& Ridley, 2006).

Some countries use a formal two-tier structure, where the supervisory function of the board is performed by a separate entity known as a supervisory board or audit and supervisory board, which has no executive functions. Other countries use a one-tier structure in which the board of directors has a broader role. Still other countries have moved or are moving to a mixed approach that discourages or prohibits executives from serving on the board of directors or limits their number and/or requires the board and board committees to be chaired only by non-executive or independent board members (Basel Committee, 2015).

Enterprise Governance - is a set of responsibilities and practices exercised by the board and executive managers, with the goal of providing strategic direction, ensuring that plans and objectives are achieved, assessing that risks are proactively managed, and assuring that the enterprise's resources are used responsibly (Van Grembergen \& De Haes, 2008).

IT Governance (ITG) - despite the visibility and importance of the ITG term since 1990's, literature has demonstrated a lack of a clear shared understanding of the term ITG. None of the definitions reflects all of the elements of the framework, possibly indicating that authors do develop definitions to support their particular focus. A commonly agreed definition of ITG does not exist (Othman, 2016).

We identified several ITG definitions in many articles and books, with minor differences. For the purpose of our further work we will use the definition provided by Steven De 
Haes and Van Grembergen (2015), because it seems to be the most comprehensive definition.

"Enterprise governance of IT is an integral part of corporate governance, exercised by the Board, overseeing the definition and implementation of processes, structures and relational mechanism in the organization that enable both business and IT people to execute their responsibilities in support of business/IT alignment and the creation of business value from IT enabled business investment" (De Haes \& Van Grembergen, 2015). The definition of ITG is presented in Figure 23.

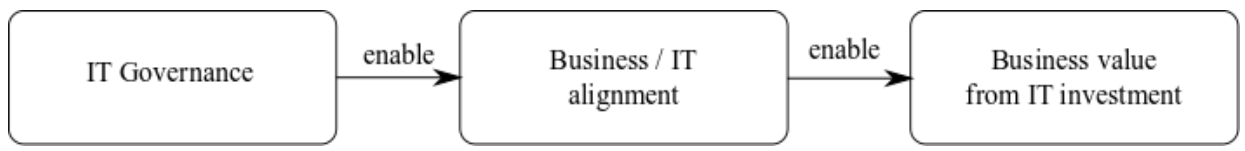

Figure 1: IT Governance definition (De Haes \& Van Grembergen, 2015)

While governance developments have primarily been driven by the need for the transparency of enterprise risks and the protection of shareholder value, the pervasive use of technology has created a critical dependency on IT that calls for a specific focus on ITG. Boards and executive management need to extend governance to IT and provide the leadership, organizational structures and processes that ensure that the enterprise's IT sustains and extends the enterprise's strategies and objectives (Turel, Liu, \& Bart, 2017).

ITG responsibility in organizations is typically subdivided into three layers: strategic, management and operational layer. It is clear that ITG is a part of each of these layers in the organization: at strategic level, where the board is involved; at management level within the executive level and senior management level; and finally at the operational level with operational IT and business management (De Haes \& Van Grembergen, 2015).

The previous research in the ITG area was predominantly focused on the level of management and the operational level. Strategic layer, which is represented by management board, has been highlighted in the previous research as a key element of the success in the case of ITG deployment or operating (Ilmudeen \& Babur, 2016). Unfortunately, in previous research, it was not possible to find the role and influence of supervisory authorities that have a direct impact on management board.

In our research, we will extend ITG model also on supervisory level shown on Figure 2, which is crucial for supervision and has an impact on strategic level, which is represented by management board. 

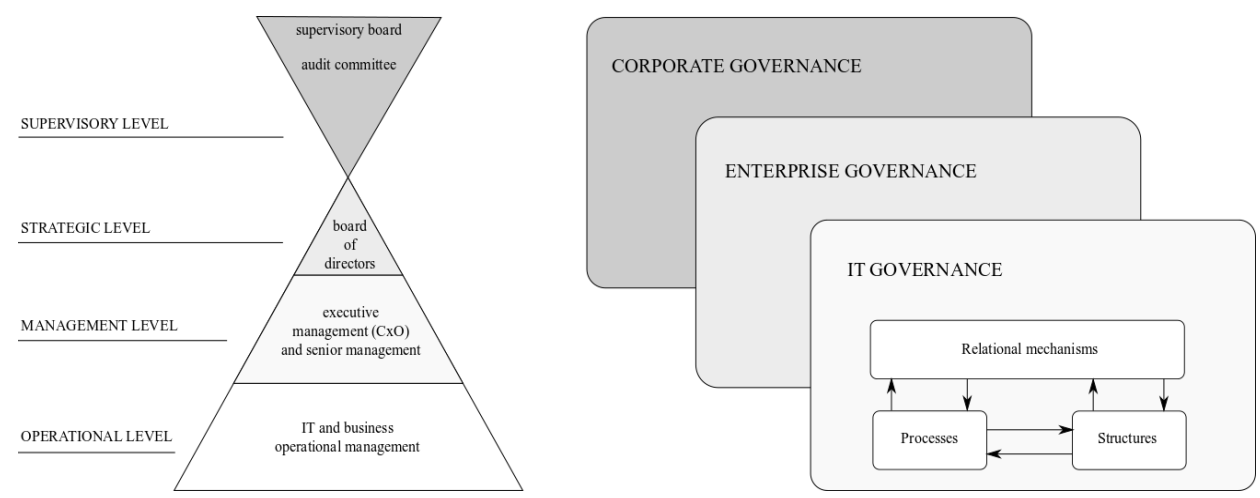

Figure 2: Enterprise levels included in the proposed model

This implies that all these levels of corporate governance need to be involved in the ITG processes and all participants have to understand their individual roles and responsibilities within the framework. Based on this, we can conclude that ITG is the sum of corporate ITG and enterprise ITG, which is shown in Figure 3.

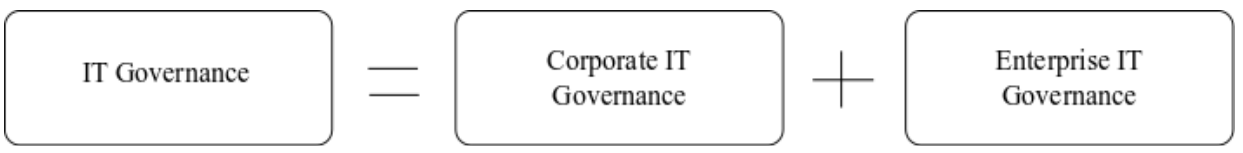

Figure 3: ITG as a sum of corporate and enterprise ITG levels

\section{$3 \quad$ Methodology}

In order to address the research problems we will use a qualitative approach based on a case study of six insurance companies in SE Europe.

We will also use a dominant IS theories and models, such as DeLone and McLean's Success Model, Technology Acceptance model, Organization Innovativeness Theory, Diffusion of Innovations Theory, Institutional Theory, User Resistance Theory and others, which helped us to understand why enterprises adopt and the factors that enable adaptation.

The first part of the dissertation will consist of a detailed literature review (LR). Literature regarding corporate governance, ITG and small business will be studied and analysed. The aim of the LR is to determine existing experience about implementing ITG mechanisms, barriers of implementing ITG models and contingency factors that are prerequired for development of Adaptive and Sustainable ITG model.

A review of prior, relevant literature is an essential feature of any academic project. An effective review creates a foundation for advance knowledge and makes theory development easier, closes areas where there is a substantive research, and uncovers areas 
where research is needed (Webster \& Watson, 2002). A LR is "the use of ideas in the literature to justify the particular approach to the topic, the selection of methods, and demonstration that this research contributes something new" (Hart, 1998; Nakano \& Muniz Jr., 2018).

In the second part a model called Adaptive and Sustainable ITG model will be developed. The model will be based on the (a) results of previous scientist and practitioners research (ITG mechanisms, ITG contingency factors, ITG barriers), (b) previous experience of implementing ITG mechanisms into enterprises that are the subject of research and (c) CobIT QuickStart ITG model.

To design the Adaptive and Sustainable ITG model it is suggested to use Design Science Research (DSR).

Toward the end of the 1990s, DSR began growing in popularity for use in scholarly investigations in IS. This methodology is a system of principles, practices and procedures required to carry out a study. To address problems at the intersection of IT and organizations, IS can draw advantage from DSR methodology by often using theories from diverse disciplines, such as social science, engineering, computer science, economics, and philosophy (Gregor \& Hevner, 2013).

DSR methodology is conducted in two complementary phases: build and evaluate. In contrast to behaviour research, design-oriented research builds a "to-be" conception and then seeks to build the system according to the defined model taking into account the restrictions and limitations. Design science addresses research through the building and evaluation of artefacts designed to meet the identified business needs, instead of analysing existing IS in order to identify causal relations (Osterle et al., 2011).

The aim of the third part of dissertation is a qualitative study of implementing developed Adaptive and Sustainable ITG model in six insurance enterprises. The proposed qualitative research is multiple case study with semi-structured interviews.

Case research, also called case study, is a method of intensively studying a phenomenon over time within its natural setting in one or a few sites. Multiple methods of data collection, such as interviews, observations, pre-recorded documents, and secondary data, may be employed and inferences about the phenomenon of interest tend to be rich, detailed, and contextualized. Case research can be employed in a positivist manner for the purpose of theory testing or in an interpretive manner for theory building. This method is more popular in business research than in other social science disciplines (Hevner, March, Park, \& Ram, 2004).

Interview is a managed verbal exchange (Ritchie, J. Lewis, 2003). We know several types of interviews, for example (Bryman, 2012):

- Unstructured Interviews: when the researcher has a clear plan, but minimum control over how the interviewees answers. 
- Semi-structured Interviews: when the researcher uses a guide with questions and topics that must be covered.

- Structured Interviews: when the researcher has fixed questions and they are asked in a specific order.

In our dissertation, we will use a semi-structured interview. We are planning to conduct interviews at all levels of research:

Supervisory level - we will interview president of supervisory board or president of audit committee. In case of one-tier corporate governance, the interview will be conducted with president of management board.

Board level - we will interview board member who is responsible for IT. In case of onetier system, the interview will be conducted with executive director responsible for IT.

Executive level - we will interview $\mathrm{CIO}$ and executive director who is responsible for business development.

Operational level - we will interview all key business users.

Finally, the effectiveness of the model will be evaluated by analysing, interpreting and reporting the overall results (semi-structured interviews and literature review).

\section{$4 \quad$ Preliminary/Expected results}

In general, the expected results of the dissertation can be summarized in the following points:

\section{Present a broader area of ITG with a literature review}

This chapter gives an overview and explanation of ITG concept. It further defines the role and significance of the ITG and its position within corporate governance

2. Present the narrower area of ITG, which covers the area of SMEs with a literature review

This chapter present the ITG in SMEs with all specifics and issues.

\section{Development of an Adaptive and Sustainable ITG model for SMEs}

The aim of this chapter is to develop an Adaptive and Sustainable ITG model for SMEs based on CobIT Quick Start Model and findings from previous research. The chapter deals with potential theories, which are used for IS research and then use them for developing the model.

However, implementing ITG is not an easy task, since its definition and role is not clear and finding the right ITG mechanisms remains a complex challenge. Despite the efforts 
to develop methods for governing IT in SMEs, for example Cobit QuickStart model, the adoption rate is rather disappointing.

The aim of this chapter is to develop and design Adaptive and Sustainable ITG model that aims to assist enterprises and practitioners by providing more guidance on how ITG can be successfully implemented.

Therefore, we will perform an exploratory research by formalizing the ITG mechanisms, contingency factors, key impact factors for ITG, barriers to the adoptions of ITG and analysing several ITG case studies which is shown on Figure 4.

\section{CobIT Quickstart}

CobIT is the most well-known framework for ITG. Control Objectives for Information and related Technology $($ COBIT $®)$ is a comprehensive set of resources that contains all the information that enterprises need to adopt an IT governance and control framework. Implementation is based on a number of factors, including the size of the organisation. CobIT Quickstart provides a selection from the components of the complete CobIT framework. Quickstart can be used as a baseline and a set of 'smart things to do' for many small- and medium-sized enterprises (SMEs) and other entities where IT is not strategic or absolutely critical for survival. Quickstart can also be a starting point for larger enterprises in their first move towards an appropriate level of control and governance of IT (ITGI, 2007).

\section{ITG Mechanisms}

Several authors believed that organizations should implement ITG over the use IT mechanisms (De Haes \& Van Grembergen, 2009; Weill \& Ross, 2004). ITG can be deployed using a mixture of various structures, processes and relational mechanisms (De Haes \& Van Grembergen, 2004), that encourage behaviours consistent with the organization's mission, strategy, values, norms, and culture (Weill, 2004).

Researchers suggest that enterprises develop ITG frameworks in three levels: designing structures, processes, and communication protocols or approaches (Van Grembergen et al., 2004; Weill \& Ross, 2004).

\section{ITG Contingency Factors}

ITG implementation is influenced by external and internal factors (Gu, Ling Xue, \& Ray, 2008). Beyond that, understanding how and why an enterprise has adopted a specific ITG arrangement is important. Summarizing there is no single "best" ITG arrangements, because IT needs to respond to the unique environments within which it exist (Lunardi, Becker, \& Gastaud Maçada, 2009) and therefore, a guide that assists the organizations with similar characteristics to implement ITG lacks in the field. 


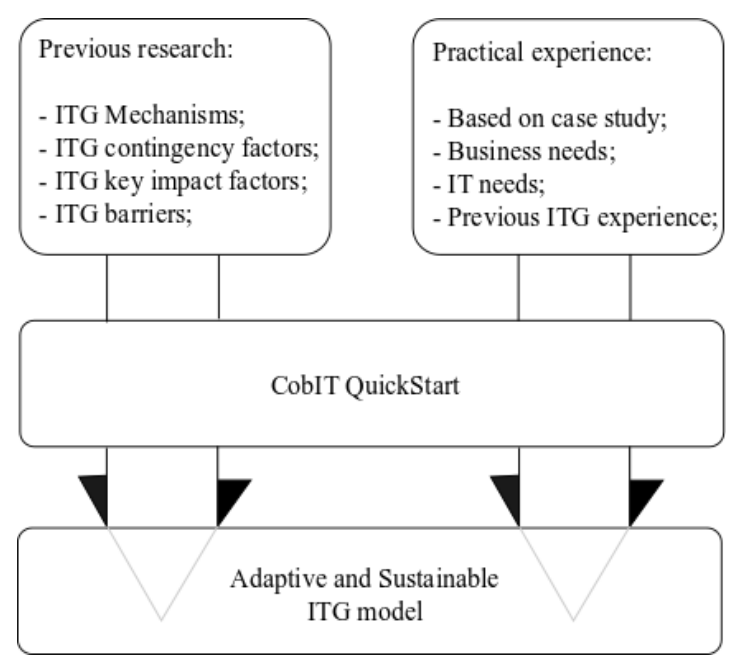

Figure 4: Adaptive and Sustainable ITG model

4. Qualitative study of implementing an adoptive and sustainable ITG model for SMEs

The research methodology is a case study conducted on six enterprises of insurance group in SE Europe.

5. Data analysis and results of the qualitative research of the implementation and use of Adaptive and Sustainable ITG model

The aim of this chapter is data analysis before and after the implementation of the Adaptive and Sustainable ITG model.

We can summarize expected results or benefits into two categories:

Academic benefits:

- To contribute to the current knowledge of the development and adoption of formal ITG models and practices;

- To provide a proper conceptualization of what formal ITG practice is, which further leads to the potential use of existing theories to support the study of the adoption of developed ITG model;

- To develop an Adaptive and Sustainable ITG model;

- To investigate the impact of implementation and use of developed ITG model.

\section{Practical benefits}

- To help enterprises to adjust and adopt Adaptive and Sustainable ITG model that fits their needs and maturity and support their business strategy. 


\section{$5 \quad$ Future development}

IT is an integral part of most organizations and will certainly become even more fundamental in the future. Therefore, ITG must be an essential part of corporate governance and develop along with it. While there is no single right way for organizations to approach improvements in ITG, it is necessary to continue with research and answer all those questions regarding ITG mechanisms and processes such as which mechanisms influence ITG and how they are interconnected.

The ITG research will continue to develop frameworks, which are crucial for adoption within a developing organization and aligning with the market.

We encourage researchers to conduct more case studies and leverage information about ITG mechanisms, in order to elicit some possible ITG patterns for different enterprise environments.

\section{References}

Basel Committee. (2015). Corporate governance principles for banks. Basel Committee on Banking Supervision. Retrieved from http://www.bis.org/bcbs/publ/d328.htm

Bryman, A. (2012). Social Research Methods. Oxford University Press.

De Haes, S., \& Van Grembergen, W. (2004). IT Governance and its Mechanisms. Information Systems Control ..., 1, 1-14. https://doi.org/citeulike-article-id:9755150

De Haes, S., \& Van Grembergen, W. (2009). An Exploratory Study into IT Governance Implementations and its Impact on Business/IT Alignment. Information Systems Management, 26(2), 123-137. https://doi.org/10.1080/10580530902794786

De Haes, S., \& Van Grembergen, W. (2015). Enterprise governance of information technology: achieving strategic alignment and value, featuring COBIT 5 (2nd ed.). Springer. https://doi.org/10.1007/978-3-319-14547-1

De Haes, S., Van Grembergen, W., \& Debreceny, R. S. (2013). COBIT 5 and Enterprise Governance of Information Technology: Building Blocks and Research Opportunities. Journal of Information Systems, 27(1), 307-324. https://doi.org/10.2308/isys-50422

Debreceny, R. S., \& Gray, G. L. (2013). IT Governance and Process Maturity: A Multinational Field Study. Journal of Information Systems, 27(1), 157-188. https://doi.org/10.2308/isys50418

Devos, J., Van Landeghem, H., \& Deschoolmeester, D. (2009). IT Governance in SMEs: Trust or Control? Information Systems - Creativity and Innovation in Small and Medium-Sized Enterprises, 301(Riemenschneider 2003), 135-149. https://doi.org/10.1007/978-3-642-02388$0 \_10$

Eurostat. (2017). Key figures on Europe 2016. European Commission (2016th ed.). Luxemburg: European Union. https://doi.org/10.2785/81608

Fama, E. F., \& Jensen, M. C. (1983). Separation of Ownership and Control. Journal of Law and Economics, 26(2), 301-325. https://doi.org/10.1086/467037

Gregor, S., \& Hevner, A. R. (2013). Positioning and presenting Design Science research for maximum impact. MIS Quarterly, 37(2), 337-355. https://doi.org/10.2753/MIS07421222240302

Gu, B., Ling Xue, \& Ray, G. (2008). IT Governance and IT Investment Performance : An Empirical Analysis IT Governance and IT Investment Performance: An Empirical. ICIS 2008 


$$
31^{\text {ST }} \text { Bled eConference: Digital Transformation: MeEting the Challenges }
$$

June 17 - 20, 2018, BLED, SLOVENIA, CONFERENCE PROCEEDINGS A. Levstek: Designing an Adaptive and Sustainable ITG model for SMEs

\section{Proceedings, (July).}

Hall, L., Futela, S., \& Gupta, D. (2017). IT Key Metrics Data 2017: Key Industry Measures. Gartner Research Report, (December).

Hart, C. (1998). Doing a literature review: Releasing the social science research imagination. SAGE Publications Ltd. https://doi.org/10.1080/01422419908228843

Hevner, A. R., March, S. T., Park, J., \& Ram, S. (2004). Design Science in Information Systems research. Design Science in IS Research MIS Quarterly, 28(1), 75-105. Retrieved from https://pdfs.semanticscholar.org/fa72/91f2073cb6fdbdd7c2213bf6d776d0ab411c.pdf

Hovelja, T., Rožanec, A., \& Rupnik, R. (2010). Measuring the Success of the Strategic Information Systems Planning. Management, 15(2), 25-47.

Huo, L., Liu, B., Yuan, R., \& Wu, J. (2010). An IT governance framework of ERP system implementation. In 1st International Conference on Computing Control and Industrial Engineering, CCIE 2010 (Vol. 2, pp. 431-434). https://doi.org/10.1109/CCIE.2010.226

Ilmudeen, A., \& Babur, H. M. (2016). A Review of Information Technology Governance, Business Strategy and Information Technology Strategy International Journal of Advanced Research in A Review of Information Technology Governance, Business Strategy and Information Technology Strategy. International Journal of Advanced Research in Computer Science and Software Engineering, Volume 6(June).

ITGI. (2007). COBIT Quickstart $2^{\circ}$ Edition. IT Governance Institute.

Kan, A. R. (2003). Managing a multi-billion dollar IT budget. In International Conference on Software Maintenance, 2003. ICSM 2003. Proceedings. (p. 2). IEEE Comput. Soc. https://doi.org/10.1109/ICSM.2003.1235400

Kolar, A., \& Groznik, A. (2017). Standards , Best Practices and Codes of Ethics Impact on It Service Quality - the Case of Slovenian It Departments. Economic and Business Review, 19(1), 51-72. https://doi.org/10.15458/85451.39

Kooper, M. N., Maes, R., \& Lindgreen, E. E. O. R. (2011). On the governance of information: Introducing a new concept of governance to support the management of information. International Journal of Information Management, 31(3), 195-200. https://doi.org/10.1016/j.ijinfomgt.2010.05.009

Lunardi, G. L., Becker, J. L., \& Gastaud Maçada, A. C. (2009). The Financial Impact of IT Governance Mechanisms' Adoption: An Empirical Analysis with Brazilian Firms. In System Sciences, 2009. Retrieved from http://ieeexplore.ieee.org/abstract/document/4755734/

Lunardi, G. L., Gastaud Macada, A. C., Becker, J. L., \& Van Grembergen, W. (2017). Antecedents of IT Governance Effectiveness: An Empirical Examination in Brazilian Firms. Journal of Information Systems, 31(1), 41-57. https://doi.org/10.2308/isys-51626

Nakano, D., \& Muniz Jr., J. (2018). Writing the literature review for empirical papers. Production, 28. https://doi.org/10.1590/0103-6513.20170086

Osterle, H., Becker, J., Frank, U., Hess, T., Karagiannis, D., Krcmar, H., ... Sinz, E. J. (2011). Memorandum on design-oriented information systems research. European Journal of Information Systems. https://doi.org/10.1057/ejis.2010.55

Osterwalder, A., Pigneur, Y., Smith, A., Clark, T., van der Pijl, P., Alex, O., ... Yves, P. (2010). Business model generation: A handbook for visionaries, game Changers, and challengers (portable version). New York: John Wiley \& Sons.

Othman, M. F. I. (2016). Barriers To The Adoption of Formal IT Governance Practice: A Malaysian Case. Queensland University of Technology.

Patel, N. V. (2002). Global ebusiness IT governance: Radical re-directions. In Proceedings of the Annual Hawaii International Conference on System Sciences (Vol. 2002-Janua, pp. 31633172). https://doi.org/10.1109/HICSS.2002.994355

Pucihar, A., Lenart, G., Marolt, M., Maletič, D., \& Borštnar, M. K. (2016). Role of Ict in Business Model Innovation in Smes - Case of Slovenia. Organizacija, 49, 161-171.

Ridley, G., Young, J., \& Carroll, P. (2004). COBIT and its utilization: a framework from the 
literature. 37th Annual Hawaii International Conference on System Sciences, 2004. Proceedings of The, OO(C), 1-8. https://doi.org/10.1109/HICSS.2004.1265566

Ritchie, J. Lewis, J. (2003). The Foundations of Qualitative Research. Qualitative research practice: A guide for social science students and researchers. London: SAGE Publications. https://doi.org/10.4135/9781452230108

Rusu, L., \& Gianluigi, V. (2017). Information Technology Governance in Public Organizations. Integrated Series in Information Systems.

Spafford, G. (2003). The benefits of standard IT governance frameworks. IT Management. April, 11-12. Retrieved from http://www.datamation.com/netsys/article.php/2195051/The-Benefitsof-Standard-IT-Governance-Frameworks.htm

Turel, O., Liu, P., \& Bart, C. (2017). Board-Level Information Technology Governance Effects on Organizational Performance: The Roles of Strategic Alignment and Authoritarian Governance Style. Information Systems Management, 34(2), 117-136. https://doi.org/10.1080/10580530.2017.1288523

Van Grembergen, W., \& De Haes, S. (2008). Implementing Information Technology Governance. (W. Van Grembergen, Ed.), IGI Publishing. New York: IGI Publisher. https://doi.org/10.4018/978-1-59904-924-3

Van Grembergen, W., \& De Haes, S. (2016, January). Introduction to the IT governance and its mechanisms minitrack. Proceedings of the Annual Hawaii International Conference on System Sciences, 2016-March, 4890. https://doi.org/10.1109/HICSS.2016.606

Van Grembergen, W., De Haes, S., \& Guldentops, E. (2004). Structures, Processes and Relational Mechanisms for IT Governance. IGI Global, 1-36. https://doi.org/10.4018/978-1-59140-1407.ch001

Walsham, G. (2001). Making a world of difference : IT in a global context. J. Wiley.

Webb, P., Pollard, C., \& Ridley, G. (2006). Attempting to define IT governance: Wisdom or folly? Proceedings of the Annual Hawaii International Conference on System Sciences, 8(February 2006). https://doi.org/10.1109/HICSS.2006.68

Webster, J., \& Watson, R. T. (2002). Analyzing the Past to Prepare for the Future: Writing a Literature Review. MIS Quarterly, 26(2), xiii-xxiii. https://doi.org/10.1.1.104.6570

Weill, P. (2004). Don't just lead, govern: How top-performing firms govern IT. MIS Quarterly Executive, 8(1), 1-21. https://doi.org/10.2139/ssrn.664612

Weill, P., \& Ross, J. W. (2004). How Top Performers Manage IT Decisions Rights for Superior Results. IT Governance, (Harvard Business School Press Boston, Massachusetts), 1-10. https://doi.org/10.2139/ssrn.664612

Weill, P., Woerner, S. L., \& Ross, J. W. (2016). TOP-Performing CIOs in the Digital era. CISR Research Briefing, $X V(5), 1-4$.

Winniford, M. A., Conger, S., \& Erickson-Harris, L. (2009). Confusion in the ranks: IT service management practice and terminology. Information Systems Management, 26(2), 153-163. https://doi.org/10.1080/10580530902797532 


\section{Sponsors, Co-organizers and Supporters}

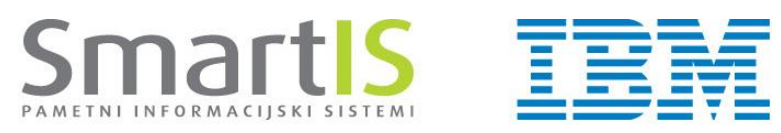

\section{Pošta Slovenije}

Gospodarska zbornica Slovenije

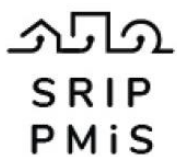

PMiS

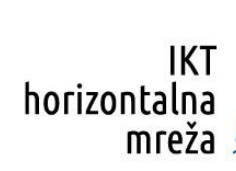

